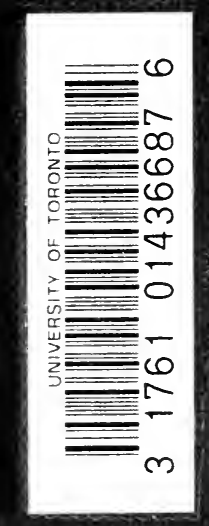



Digitized by the Internet Archive in 2007 with funding from Microsoft Corporation 



\section{A TEXT-BOOK \\ OF \\ EUROPEAN ARCHAEOLOGY}


CAMBRIDGE UNIVERSITY PRESS

C. F. CLAY, MANAGER

LONDON : FETTER LANE, E.C. 4

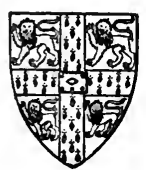

NEW YORK : THE MACMILLAN CO. BOMBAY

MALCUTTA $\}$ MACMILLAN AND CO., LTD. TORONTO : THE MACMILLAN CO. OF CANADA, LTD.

TOKYO : MARUZEN-KABUSHIKI-KAISHA

ALL RIGHTS RESERVED 
$A n \cdot A$

M1145t

\section{A TEXT-BOOK \\ $\mathrm{OF}$}

\section{EUROPEAN ARCHAEOLOGY}

BY

R. A. S. MACALISTER, Litt.D., F.S.A.

PROFESSOR OF CELTIC ARCHAEOLOGY, UNIVERSITY COLLFGE, DUBLIN

VOLUME I

THE PALAEOLITHIC PERIOD

CAMBRIDGE

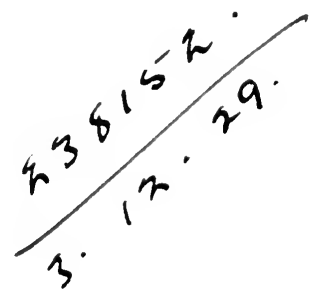

AT THE UNIVERSITY PRESS

I 92 I 



\section{PREFACE}

THE primary purpose of the work before the reader is to provide a text-book for the students in the classes in Archaeology in University College, Dublin : and it is based upon the lectures in this subject given there from year to year. It is hoped that it will be of use to others who desire to study the subject.

The book has grown considerably - far beyond the size originally planned-in the course of preparation: yet so wide is the field to be covered that it could probably have been made at least twice as large as it actually is. To exhaust the subject, even in the present limited state of knowledge, would be impossible: the author of a synthetic treatise must perforce make selections from the mass of materials at his disposal, and probably no two students would agree as to the selections that should be made. The writer can but plead that on this difficult question he has used his judgment to the best of his ability. One omission he greatly regrets: a description of the wonderful cavesanctuary called after its fortunate discoverers La Caverne des Trois Frères. Down to the moment of publication no printed account of this discovery had come into his hands (except a short notice in Abbé Mainage's work, mentioned below), and he feared to infringe the privilege of priority if he made any use of the descriptions with which he had been privately favoured.

$\mathrm{He}$ also regrets that when writing of the human remains found at Solutré, he overlooked the work of Broca and of Hamy (published in B.S.A.P. 1873) as well as the remarks of Broca (A.F.A.S. 1873, summarised in Matériaux pour l'histoire de l'homme, vol. viII [1873], p. 342); also Cartailhac's important review, in the same journal, of Arcelin's collection of all the materials relating to these disputed relics (Matériaux, XIII [1878], p. 527). Those who have wandered most in the maze of archaeological and anthropological literature will be the readiest to forgive these oversights.

The definition of the word "henotheism" adopted in this work is that which has become current in treatises on Comparative Religion, though it differs in some degree from the significance attached to it by Max Müller, who introduced its use (see his Physical Religion, p. I8I, especially the footnote). 
Since the printing of this volume began, three works have appeared, which may be recommended to the student desirous of carrying his reading in various directions beyond the limits imposed by the size and scope of the present work: Prof. Marcellin Boule's masterly treatise entitled Les hommes fossiles; M. l'Abbé Mainage's work Les religions de la préhistoire; and Mr Carveth Read's Origin of Man and his Superstitions, published by the Cambridge University Press.

The second volume of the present work, dealing with the Neolithic and Early Bronze Ages, is well advanced: and it is hoped to follow it with volumes on the Late Bronze and Early Iron Age, and on the Late Iron Age.

It is the author's pleasant duty to thank his friends, Mr E. C. R. Armstrong, keeper of the Irish Antiquities in the National Museum, Dublin, for reading through the first draught of this volume, and also a set of proof-sheets, and making many useful criticisms; and Dr R. F. Scharff, for reading through and criticising the chapter on Palaeontology. He has also to acknowledge his obligations to the Cambridge University Press, for undertaking the publication of the work, and for the skill with which they have carried it through: and to the following, for generous permission to use illustrations-in some cases for the loan of the original blocks:

Messrs Edward Stanford, for illustrations borrowed from W. G. Smith's Man, the Primeval Savage.

M. l'Abbé Breuil, for the numerous illustrations to which his name is attached.

M. le Prof. Marcellin Boule, for illustrations from the sumptuous publications of the Institut de Paléontologie humaine.

La Société linnéenne de Bordeaux (fig. 12).

Messrs J. B. Ballière et Fils, Paris, for illustrations from Girod and Massénat, Laugerie Basse.

Messrs Masson et Cie, for numerous illustrations from their wonderful journal, L'Anthropologie-possession or access to a set of which is absolutely indispensable for work in this field.

The Royal Society, and Sir E. Ray Lankester (figs. 37, 38).

The Smithsonian Institution, for illustrations from its Reports.

The Geological Society of London, and Dr A. Smith Woodward, for illustrations from the Society's Fournal.

M. A. de Mortillet, for illustrations signed by him.

La Société Préhistorique française, for illustrations from its publications.

M. Alfred Costes, publisher, Paris, for illustrations from G. and A. de Mortillet, Musée préhistorique.

Prof. Pigorini (fig. 57).

L'École d'Anthropologie de Paris, for illustrations from its publications.

L'Académie de Bruxelles, for illustrations from its publications.

L'Association française pour l'Avancement des Sciences (fig. 75).

La Société d'Anthropologie de Paris (fig. 82).

Dr Henri Martin, for illustrations from his works. 
The Royal Anthropological Institute, for illustrations from its fournal.

The Trustees of the British Museum (fig. I 10).

Dr C. G. Seligman (fig. I 19).

The Suffolk Institute of Archaeology (fig. 14I, No. 3).

Messrs Macmillan, for figures from Boyd Dawkins, Early Man in Britain.

El Museo Nacional de Ciencas Naturales, Madrid, for figures from Obermaier's El Hombre Fósil.

The Society of Antiquaries of Scotland, for figures from its Fournal.

Dr Sophus Müller, for figures from Affaldsdynger fra Stenalderen i Danmark and Aarb申ger for nordisk Oldkyndighed.

Svenska Sällskapet för Antropologi och Geografi (fig. I81).

Norges geologiske Unders $\not$ gelse (fig. 182).

Kungl. vittenhets historie och antikvitats Akademien (fig. I83).

R.A.S.M.

University College, Dublin.

Fune, $192 \mathrm{I}$. 



\section{CONTENTS}

CHAP.

PAGE

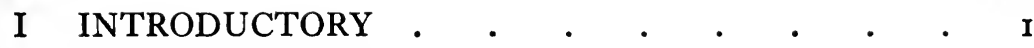

II GEOLOGICAL PROLEGOMENA • • • • • 23

III PALAEONTOLOGICAL PROLEGOMENA • • $\quad 5^{8}$

IV ANTHROPOLOGICAL PROLEGOMENA . • . 93

V THE BEGINNINGS OF HUMAN LIFE IN EUROPE I45

VI THE LOWER PALAEOLITHIC STAGES • · . 207

VII THE MIDDLE PALAEOLITHIC STAGE . . . $\quad 284$

VIII THE UPPER PALAEOLITHIC STAGES • • • • 347

IX THE PSYCHOLOGY OF UPPER PALAEOLITHIC MAN 438

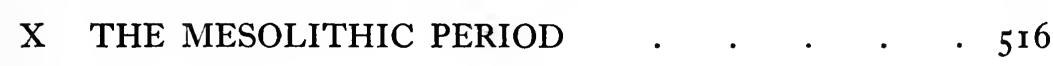

XI THE PALAEOLITHIC PERIOD AS A WHOLE • • $57 \mathrm{I}$

INDEX $\quad \cdot \quad \cdot \quad \cdot \quad \cdot \quad \cdot \quad \cdot \quad \cdot \quad \cdot \quad \cdot \quad \cdot \quad \cdot 597$ 



\section{LIST OF ILLUSTRATIONS}

FIG.

I Map of the European glacial centres . . . . . . . $\quad$. 28

2 Diagram of Alpine detritus deposits . . . . . . 30

3 Map of Europe showing land-bridges $\quad . \quad$. $\quad . \quad$. $\quad$. 39

4 Diagram illustrating formation of a raised beach . . . $4 \mathrm{I}$

5 Maps of Scandinavia at different phases of land-oscillation . $\quad$. 42

6 Flint implement showing double patination . . . ${ }^{5}$

7 Monkey (?): cave of Hornos de la Peña . . . . . 63

8 Engraving on stone of a wolf from the cave of Gourdan . . 65

9 Head of a fox carved on a bâton de commandement from Placard 66

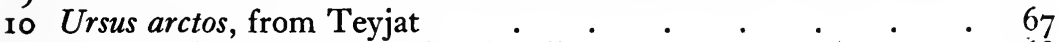

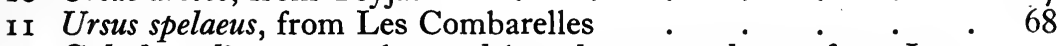

12 Gulo borealis, engraved on a bâton de commandement from Lau-

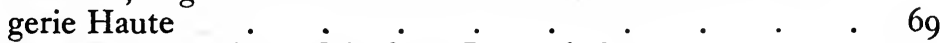

I3 Lutra vulgaris pursuing a fish, from Laugerie Basse . . $\quad$. 70

14 Felis spelaea, from Les Combarelles . . . . . 70

I5 Felis catus, engraving from Saint-Michel d'Arudy . . . . 7 I

I6 Supposed figure of a hare, from Laugerie Basse. . . . . 7 I

I7 Sus scrofa, painted on the wall of the cave of Altamira . . $\quad 73$

I8 Cervus elaphus, male and female, with fishes; on a reindeer-horn

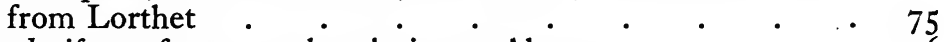

I9 Alces latifrons, from a rock-painting at Alpera . . . . 76

20 Rangifer tarandus, from an engraving on reindeer-horn found at

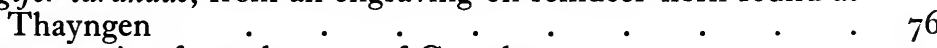

2 I Saiga tartarica, from the cave of Gourdan $\quad$. $\quad$. $\quad$. $\quad$ - 77

22 Rupicapra tragus, from the Cave of Gourdan . . . . 77

23 Capra ibex, engraved on a javelin-propulsor from Le Mas d'Azil 78

24 Ovibos moschatus, on a javelin-propulsor from Bruniquel . $\quad 79$

25 Bos primigenius, engraving in the cave of Les Combarelles $\quad 79$

26 Bison priscus, painted on the wall of the Cave of Altamira . 80

27 Equus caballus, engraved on a bâton de commandement from $\mathrm{La}$ Madeleine

28 Supposed figure of Equus hemionus engraved on a plate of limestone from Schweizersbild . . . . . . 8I

29 Painting of Rhinoceros tichorhinus from the Cave of Font-deGaume . . . . . . . . .82

30 Elephant, probably Elephas antiquus, from the Cave of Pindal . $\quad 83$

$3 \mathrm{r}$ Elephas primigenius, engraved on the wall of the Cave of Font-deGaume . . . $\quad . \quad \ldots \quad . \quad . \quad . \quad . \quad .84$

32 Capercailzie, from Le Mas d'Azil, as restored by Breuil . $\quad .85$

33 Swan engraved on stone from Lourde, duck on stone from Gourdan, and duck on reindeer-horn from Lourde . .

34 Accipitrine bird engraved on a bâton de commandement from Raymonden

35 Diagram to illustrate the relation between racial and individual characteristics. . . . . . . IOI

36 The types of Kentian eoliths . . . . . . . . . . . . $\quad$ r55

37 Ideal form of a rostro-carinate implement $\quad . \quad$. $\quad . \quad$ I 59

38 A rostro-carinate implement . . . . . . . . . $\quad$. 159 
F1G.

39 Eoliths from Le Puy Courny . . . . . . . $\quad$ 162

40 The Trinil femur compared with a modern specimen . . $\quad$ I79

4I The Trinil skull compared with a modern specimen . . I8I

42 Mesvinian eoliths . . . . . . . . . . . 190

43 Flint fragments from a garden walk . . . . . . . I9I

44 The Mauer sands . . . . . . . . . . . $\quad$. 193

45 The Mauer jaw . . . . . . . . . . $\quad$ r 95

46 Extant fragments of the Piltdown skull . . . . . . . 198

47 Bone implement found with the Piltdown skull . . . 20 r

48 Pre-Chellean flint implements from Saint-Acheul . . 226-7

49 Poignard, arrow-heads, and supposed primitive coup-de-poing, from Binche and Strépy . . . . . . . 228

50 Varieties of coups-de-poing . . . . . . . . 23I

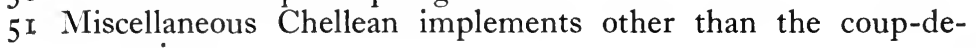
poing

52 Chellean ornaments made of pebbles and shells

52 Chtrast betweents made of pebbles and shells $\cdot 236$

53 Chellean and Acheulean coups-de-poing

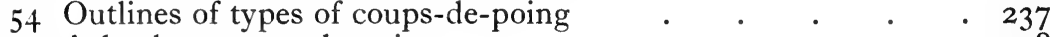

55 Acheulean coups-de-poing . . . . . . . . . $\quad 238$

56 La Micoque coup-de-poing and Levallois scraper . . . $\quad 239$

57 Acheulean coup-de-poing from Venosa . . . . . . 243

58 Coups-de-poing from Casal do Monte . . . . . . 248

59 Sketch-map of the Somme valley . . . . . . 251

60 Section of the Chellean station of La Celle-sous-Moret . . 254

6I Specimens of the Ilm valley implements . : . . . . 258

62 Sketch-map of the valley of the Thames . . . . . . 263

63 Section of brick-earth pit at Caddington . . . . . $\quad 267$.

64 Restored implement, and the nodule from which it was fashioned 269

65 Pre-Chellean (?) implements from the Limpsfield gravels . . 272

66 Sketch-map of the valley of the Ouse . . . . . $\quad 274$

67 Sketch-map of the valley of the Solent river . . . . 277

68 The Neandertal skull . . . . . . . . 286-7

69 The Gibraltar skull . . . . . . . . . 290

7o Human jaw and perforated bone from Trou de La Naulette $\quad 292$

7 I Coup-de-poing found with the Le Moustier skeleton . . 296

72 The Le Moustier skull . . . . . . . $\quad$. 297

73 The skull of La Chapelle-aux-Saints . . . . . 300

74 Section of the strata at La Quina . . . . . . 302

75 The La Quina skull . . . . . . . . 303

76 Nodule showing the completion of the external chipping of a tool before dislodging the flake . . . . . 317

77 Side-scraper with the bulb of percussion chipped . . . 3 II

78 Mousterian points . . . . . . . . . . 3I9

79 Side-scrapers . . . . . . . . . . . $322-3$

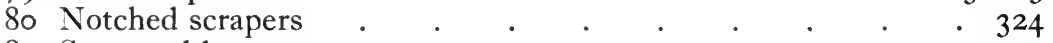

$8 \mathrm{I}$ Saws and borers . . . . . . . . . . $\quad .325$

82 The beaked scraper $\quad . \quad$. $\quad . \quad . \quad . \quad . \quad . \quad 326$

83 Mousterian flake knives . . . . . . . . . . $\quad$. 327

84 Engraver-chisels and chisels . . . . . . . . . . . 328

85 Various worked bones from La Quina . . . . . 330

86 'The so-called reindeer-bone whistle . . . . . . . 33 I

87 Mousterian implements from der Sirgenstein . . . . 338 
88 Skull of the woman of Cro-Magnon

89 Collar on the boy's skeleton from the Barma Grande, and eggshaped ornaments from the interment . . . . 357

90 Châtelperron knives

91 End-scrapers.

92 Engravers

93 Aurignacian bone implements

94 The carinate scraper

95 Notched flakes

96 The evolution of the curved engraver from the carinate scraper

97 Forms of the lateral engraver

98 Gravette points

99 Evolution of the tang

Solutrean javelin-heads

Solutrean scrapers and borers

A

Aurignacian types from late Magdalenian deposits

Io6 Harpoons

I07 Supposed fishing instruments

Io8 Bâtons de commandement

I09 Javelin propulsor

I IO Needles and instruments for their manufacture

I I I Supposed poignard from Laugerie Basse .

II 2 Sculpture of two reindeer, wrongly supposed to have been two dagger-handles; from Bruniquel

I 3 Human skull made into a cup .

II 4 Wooden figure of a beetle, Arcy-sur-Cure

II Figure of a bird in reindeer-horn from Andernach

II6 Pendants from the Kesslerloch Cave

I17 Ivory objects from the Wiérzchow cave.

I 19 Bâton de commandement from Gough's Cave, Cheddar

I20 Ornamental objects from Magdalenian sites in Russia 
I 38 Representation of a walking animal, and of a crane (?) with waving neck

I39

Dying bison and cast stone

I 40 Charging horses, Chaffaud

I4I English examples of Magdalenian art

I 42 Engraved vegetable forms

44 Supposed "writing" on a rod of ivory from

44 "Supription" "fro cho de Gentillo

I 45 "Inscription" from Rochebertier compared with an Australian message-stick

I46 Supposed "tally" or "hunting-record" .

I 47 Bone pendant, Saint-Marcel

I 48 Clay figures of bisons from Tuc d'Audoubert

I 49 Bone tube for paint

I 50 Stone and throwing-stick (?), Niaux

I 5 I Arrows (?), Niaux.

I 52 Tectiform devices

I 53 Scutiform and naviform devices

I 54 Stags, Roca del Moro

I 55 Man killing stags, Cogul

I 56 The Cogul dance

I 57 The wall-painting at Alpera

I 58 Bison, Marsoulas

I 59 Charging bison, Altamira

I 60 Figure of a woman from Předmost .

I6I Ornamental teeth pendants from Lacave .

I62 Bull-roarer pendants

I63 Horse-head from Saint-Michel d'Arudy with a supposed representation of harness . . . . . . . . 519

r64 Azilian harpoons . . . . . . . . . . . $\quad .526$

I65 Azilian painted pebbles compared with stylised human figures 529-30

I 66 Stylistic figures of horse-heads from Magdalenian caves . $\quad 532$

I67 Objects from the Azilian cave at Oban . . . . . 534

I68 Pygmy flints . . . . . . . . . . . . . 536

I69 Harpoon with flint teeth . . . . . . . . . $\quad$. 536

r70 One of the Ofnet skull-burials $\quad . \quad$. $\quad . \quad$. $\quad 540$

I 7 I Ornamented reindeer-horn objects from Belgian caves . $\quad 545^{-6}$

172 Campignian picks .. .5 .550$

I 73 Campignian chisels (the kitchen-midden axe) . . . $\quad$. $55^{\mathrm{I}}$

I74 Campignian pottery $. \quad . \quad$. $\quad . \quad$. . . 553

I75 Section of a Danish shell-heap . . . . . . 555

I 76 Hearth found in the shell-heap of Erteb $\phi$ lle . . . . . $\quad .556$

I 77 Objects from the Danish shell-heaps . . . . $55^{8-9}$

178 Stone objects from Maglemose . . . . . . . $\quad$. 562

I79 Bone and horn objects from Maglemose . . . . . $\quad$. 563

I80 Objects from Viby . . . . . . . . . $\quad .564$

I8 I Flint and pottery from Järavallen . . . . . . $\quad . \quad 566-7$

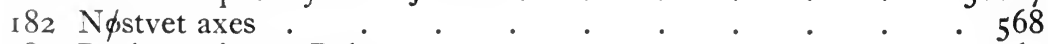

I83 Rock-carving at Böla $\quad . \quad$. $\quad . \quad 5 \quad$. $\quad . \quad 569$

I84 Upper Palaeolithic and Bushman animal figures compared $\quad 578$ 


\section{LIST OF ABBREVIATIONS}

\section{OF THE NAMES OF BOOKS AND PERIODICALS FREQUENTLY QUOTED.}

Evans, Stone

The Ancient Stone Implements, Weapons, and Ornaments $o$ Great Britain. By Sir John Evans, K.C.B. Second edition, London, I897.

Mortillet, Prehist. $\quad$ La Préhistoire; origine et antiquité de l'homme. Par G. et A. de Mortillet. (First appeared under the title Le Préhistorique, 1900.)

Reinach, Alluvions Antiquités nationales; description raisonnée du Musée de SaintGermain-en-Laye. I. Epoque des Alluvions et des Cavernes. Par Salomon Reinach. Paris, I889.

A.f.A. Archiv für Anthropologie (Brunswick).

A.F.A.S. Association française pour l'avancement des sciences, Comptesrendus (Paris).

B.S.A.B.

Bulletin de la société d'anthropologie de Bruxelles.

B.S.A.P. Bulletin de la société d'anthropologie de Paris.

B.S.P.F. Bulletin de la société préhistorique française (Paris).

C.A.P.A. Congrès d'anthropologie et d'archéologie préhistorique, Comptesrendus (Paris).

Corr.

Correspondenzblatt der deutschen Gesellschaft für Anthropologie, Ethnologie und Urgeschichte (printed as supplement to A.f.A.).

C.P.F. Congrès préhistorique de France, Comptes-rendus (Paris).

F.A.I. Fournal of the Royal Anthropological Institute.

L'Anthr. L'Anthropologie (Paris).

M.A.G.W.

Mittheilungen der Anthropologischen Gesellschaft in Wien (Vienna).

R.E.A.

Revue de l'école d'anthropologie de Paris.

Q.F.G.S.L.

Quarterly Journal of the Geological Society of London.

V.B.A.G.

Verhandlungen der Berliner Gesellschaft für Anthropologie Ethnologie und Urgeschichte (printed in Z.f.E.).

Z.f.E.

Zeitschrift für Ethnologie (Berlin).

Other Journals, less frequently quoted, have their titles given in sufficient fullness to be recognised at once. 



\section{CHAPTER I}

\section{INTRODUCTORY}

\section{Definition of "Archaeology"}

ARCHAEOLOGY is a branch of the science of Anthropology-the study of Man, his body, his mind, his ways, and his works. It is chiefly concerned with the remains of bodily structure and of handiworks, bequeathed to us by the men of past generations. But the Archaeologist must also pay heed to such objects as modern utensils, survivals of primitive types persisting in remote or uncivilised regions; for the analogies which these present will not infrequently explain relics of antiquity otherwise incomprehensible. He must likewise take into account matters so intangible as legends, traditions, customs, and beliefs, all of which have a bearing more or less direct upon his work.

For many reasons the Archaeology of Europe is more interesting, and more instructive, than that of any other division of the globe. True, there are no intelligible written records in Europe so ancient as those which reward the excavator in Egypt or in Mesopotamia. But, thanks to the activity of a countless number of investigators, whose labours have reaped a harvest bewildering in its richness, the amount of material for archaeological study available in Europe is fuller and more varied than that in any other region: and the problems which European Archaeology presents are on the whole nearer to their solution than those awaiting us in Asia, Africa, or America. Even if the student be attracted to labour in one of these other fields, a preliminary study of European Archaeology is necessary, in order to secure a grounding in archaeological "method."

\section{Archaeology and History}

The work of the archaeologist differs from that of the historian, in that the latter bases his researches mainly upon written documents relating to, and as nearly as possible contemporary with, the events which concern him; while the former gleans what facts he can, about the peoples of antiquity and their mode of life, from a great variety of objects, or fragments of objects-implements, potsherds, and the like. It is a common mistake to suppose that the purpose of archaeological research is to confirm the truth of written history, sacred or profane. Only in a few exceptional cases can it undertake to do so, as when it brings inscriptions or other written records to light: 
although these, in so far as they are historical, are materials for the study of the historian rather than of the archaeologist.

The discovery at Rome of a royal palace of the seventh century B.c. would not prove the truth of the opening chapters of Livy's History: but it would enable us to place the stories there contained, assuming their historical truth, in their proper cultural setting. The most that such a discovery could enable us to do, from the point of view of historical criticism in the restricted sense, would be to expose anachronisms in the written narratives, indicating that they had suffered distortion in the course of transmission. This simple example will illustrate the true function of the archaeologist in his relation to the historian-to supply the background, to dress the stage on which the historian directs the action of his characters. The archaeologist and the historian work in partnership, each supplementing, but not to any considerable extent overlapping, the researches of the other.

\section{Archaeology and "Pre-history"}

This, however, is but one side, and that the least important, of the work of the archaeologist. His labour is only begun when he has provided the historian with his scenery and stage properties. After the archaeologist has traced out the history and development of the arts in mediaeval Europe, in ancient Rome, Greece, Syria, Egypt, Mesopotamia, India, and other countries which have preserved written records of their past, he parts company with his colleague, and sets forth upon a journey which he must pursue alone, over the uncharted wilderness of "pre-history." The civilisations of Etruria and of Crete are still his exclusive domain, until the historian shall have asserted at least a partial claim to them by solving the riddle of their respective writings. But the historian can never take from the archaeologist the endless problems which beset every step of the way as the latter penetrates into the remoter past-problems such as the origin of the different schools of art, whose later phases the two fellow-workers may study side by side; the cause, and the antiquity, of the complex mingling of races, to which the bones found even in the most ancient sepulchres bear witness; the beginnings of the various manifestations of human industry; and, last and greatest problem of all, the beginning of Man himself.

\section{A Sketch of the History of Archaeological Research}

(i) Popular Notions

It is now known that there have been men on the earth for many tens of thousands of years. But this fact has only recently, comparatively speaking, been discovered. Man had totally lost the 
tradition of his own vast antiquity. Relics of prehistoric ages, as they came to light from time to time, were explained in many fantastic ways-not merely by the unlettered, but by those who professed the science of their time.

A single example of such popular interpretations will suffice. Axe-heads of stone, which we now know to have been the tools of people living at an epoch so remote that the use of metals was as yet undiscovered by them, have been almost universally supposed by the unlearned to be "thunderbolts." Though it may appear strange to us, such an explanation is not unnatural, in the absence of better knowledge. Thunder is often explained by simple folk as a sound produced by a god, either speaking or else smiting with a hammer. As stone implements sometimes take the form of large heavy hammer-heads, the association of ideas might easily suggest some connexion between such objects and the thunder. Whether this be the true explanation or not, the fact remains that in all, or almost all, of the countries of Europe, as well as in Asia and in aboriginal America, this explanation of stone implements is to be found, enshrined in the popular lore. It appears in a Chinese encyclopaedia, as well as in Suetonius' Life of Galba ${ }^{1}$. Traditions such as this, which are very tough and difficult to dislodge, though doubtless first developed under paganism, pass easily into Christian beliefs.

From the mystical origin thus postulated for such objects a certain mystical character would naturally be deduced. Hence we find them used as charms against thunder and lightning, on the homoeopathic principle of the old cure for hydrophobia, "a hair of the dog that bit you." Sir John Evans quotes some lines from the metrical treatise on Gems, written by the twelfth-century bishop of Rennes, Marbodaeus Gallus, entitled De lapidibus preciosis enchiridion. This effusion, which is for the greater part founded on Pliny, was printed at Paris in I 53I. We may give here a translation of the lines in question, as they are a good synopsis of the classical and mediaeval notions current about some of the objects with which we shall be concerned in the present volume ${ }^{2}$.

1 See Evans, Stone, chap. iii. where a wealth of references will be found. See also Reinach, Alluvions, p. 78 , note 2, for further references. Consult, further E. Cartailhac, L'âge de la pierre dans les souvenirs et les superstitions populaires (Paris, I877); M. Baudouin and L. Bonnemère, "Les haches polies dans l'histoire jusqu'au xixe siècle" (B.S.A.P. ser.v.vol.v. [1904], pp.496-548); Chr. Blinkenberg, The Thunderweapon in Religion and Folklore; a Study in Comparative Archaeology (Cambridge, I9I I); and, especially, Paul Cogels, "Céraunies et pierres de foudre" (Bull. de l'Acad. Royale d'Archéologie de Belgique, Antwerp, 1907), a very thorough monograph.

2 The original Latin will be found in Evans; Stone, p. 64, with the exception of the last four lines, which Evans omits. 
When with the rage of wind the troubled air is seething; when the aether flashes fire, and dreadful thunders roll; then, from the clouds a little stone falls, broken from the sky.

For this the Greeks devised a name, derived from thunder; for, 'twas said, this stone was found in every place where fell a thunderbolt.

Keraunios in Greek is thus its name, from thunder, in their speech keraunos called.

Who bears this stone, him lightning never hurts, nor strikes the house whereinto it is borne.

It guards a ship on river or on sea, from stroke of thunderbolt or whirlpool plunge.

In battle, whoso wears it wins the day; and pleasant sleep and pleasant dreams it brings. Two kinds there are, each with its several hue; Carmania $^{1}$ so 'tis said, produces one, like crystal, with a blue and reddish tinge; and Spain the other, with a bronze-like blaze.

In like manner, in Ireland and elsewhere, small stone arrow-heads are or were regarded as being the arrows of the fairies; and cattle which fell sick, and were supposed to have been "elf-shot," were given to drink decoctions in which one or more of these weapons had been boiled ${ }^{2}$.

\section{(ii) "Learned" Opinions}

Down to the seventeenth century even the learned had no suspicion of the real nature of prehistoric stone implements. Another of Sir John Evans' quotations is from the voluminous Aldrovandi of Bologna, who expressed the opinion that they were due to "an admixture of a certain" exhalation of thunder and lightning with metallic matter, chiefly in dark clouds, which is coagulated by the circumfused moisture and conglutinated into a mass, and subsequently indurated by heat $!^{3}$ " There were, indeed, a few enlightened men, born before their time, such as Mercati ${ }^{4}$ in the sixteenth century, who held saner views; but it was not till the beginning of the eighteenth century that the artificial nature of stone implements was demonstrated and fully accepted. About that time travellers had been penetrating to remote corners of the world, where savages were to be seen who still made use of stone implements; and they had

1 "Germania" in the Paris edition; but see Pliny, Hist. Nat. xxxvi1, 134.

${ }^{2}$ A description of the curing of an "elf-shot" cow by means of a gruel containing flint arrow-heads will be found in Ulster Fournal of Archaeology, new series, vol. Iv. [1 898 ], p. 1о. See also Evans, Stone, pp. 364 ff., Stevens, Flint Chips, p. 87.

3 Evans, Stone, p. 64.

${ }^{4}$ See his Ceraunia cuneata, reprinted in Matériaux pour l'hist. de l'homme, vol. XI. [1875], p. 49 . 
brought back with them specimens of those primitive tools. The analogies between such handiworks of modern savages and their ancient prototypes were too striking to be overlooked. Thus was the true nature of the "thunderbolts" at last revealed, by the process of comparison, which lies at the foundation of all scientific research in archaeology ${ }^{1}$.

We might equally well have used other illustrations of popular aberrations. For instance, we might have referred to beliefs about giants of ancient days, based, at least partly, on the discovery of the fossil bones of large extinct animals. But it is not our intention here to write a formal history of Archaeology, a subject that would fill a large volume. We cannot spare the space for any further enumeration of pre-scientific fantasies, entertaining though such a catalogue would be.

\section{(iii) Archaeology during the Eighteenth Century}

Throughout the eighteenth century, although some advance in a scientific direction had thus been made at its beginning, archaeology was little better than a sort of learned trifling with "old things." Sir Walter Scott, in The Antiquary, has drawn for us a picture, in no degree exaggerated, of the dogmatism and the pretensions that took the place of serious study of antiquities. It is not to be denied that there were men, of the type of the Rev. James Douglas ${ }^{2}$, gifted with insight and with duly controlled ingenuity, who were working at the subject on scientific principles. But such men were the rare exceptions; and naturally they were not exempt from the limitations of their time. In fairness we must remember that down to, and even after, the end of the eighteenth century, it was a cardinal article of belief, based on the authority of Holy Writ, that the world had been created some 6000 years previously, and that its first inhabitants had been drowned by a universal, all-destroying deluge about 1600 years later. These dates being assumed to have been fixed by a supernatural Revelation, everything had to be squeezed into the narrow limits of time which they allowed. Similar preconceptions prevented progress in other directions. Thus, if anyone had been led by his

1 The chief honour of this achievement rests with Nicholas Mahudel, "Sur les prétendues pierres de foudre" (read in 1734, published in Histoire de l'Académie des Inscriptions, vol. XII. [1740], p. I63), and Bernard de Jussieu, "De l'origine et des usages de la pierre de foudre" (Histoire de l'Académie royale des Sciences, année 1723 [Paris, 1725]; p. 6 of the Mémoires). Others before them, however, had had an inkling of the truth. The two papers here cited have been reprinted in Matériaux pour l'histoire de l'homme, vol. x. pp. 97, 145. For an interesting series of comparisons between prehistoric objects and the handiworks of modern savages see Arthur Haberlandt, "Prähistorisch-ethnographische Parallele" (A.f.A. xL. [1913], p. 1).

2 Author of Nenia Britannica, 1793. 
researches to the conception of a long-enduring Age of Stone at the beginning of human existence, during which metals were unknown, he would have been obliged to find some means of reconciling his ideas with the knowledge of metals possessed by Tubal-Cain, wh appears on the scene in the Book of Genesis only a page or two after Adam.

It was clear from scriptural and from classical references that there had been great civilisations in Egypt and Babylonia in ancient times. Indeed, travellers had brought home accounts of the astonishing monuments still to be seen in the centres of those civilisations. But there was not a man alive who could interpret the writings which covered the monuments, and which enshrined their history. The languages and the letters were utterly unknown. It was reserved for the first half of the nineteenth century to find the key to these mysteries, and to learn from them that the world, so far from having come into existence a short 6000 years ago, was then already peopled by flourishing nations, highly organised, and able to keep their records in writing. It was reserved for the closing years of the nineteenth century to reveal the astonishing fact that in the island of Crete there had centred yet another civilisation, almost equally ancient and equally great, the memory of which had been all but lost, and the vague legends of which had been swept aside with disdain, as though they were but the dreams of myth-makers.

In a word, there was not a single object of antiquity-even of classical antiquity, the branch of the science the best understood and the most carefully cultivated-with which the most learned antiquary of the eighteenth century was fully competent to deal. This was not his fault; the requisite knowledge was nowhere available. It must be added, that the necessity of methodical and accurate description even of what lay under the very eyes of the describer does not seem to have been realised. When we read old accounts of such monuments as, for example, Stonehenge, we are amazed to see to what an extent ill-regulated theories and speculations can pervert the plain evidence of the senses ${ }^{1}$; and we become painfully conscious that very little reliance can be placed upon old descriptions of structures which have disappeared. There seems to be a sort of fatality in the way in which such descriptions, often our only record of valuable remains

1 This is not confined to the old observers who at the moment are under discussion : everyone who has attempted archaeological observation has had to contend with the same curious psychical difficulty. Let an archaeologist once become obsessed with the idea that a defaced inscription must be read in a particular way, or that an abraded figure must have been vested in some particular costume, and he is lost: his eyes will follow the dictates of his mind. In such cases it is often an expedient of real value to submit the point in dispute to the judgment of an intelligent and observant child, who, having no theories, will be unbiassed. 
of antiquity, perversely avoid enlightening us regarding points on which modern science most particularly requires information!

\section{(iv) Progress of Discovery in the Nineteenth Century}

When the nineteenth century was well begun, while some investigators were solving the riddle of the ancient scripts, and were thus opening out regions of history once undreamt-of, others were developing the newly-born science of Geology, from which we have learnt the vast antiquity of the earth itself, and the long process of development through which it has passed. Scrutiny of the rocks, and of the fossils contained in them, revealed the secret of a succession of long ages, during which the plants and the animals of the various countries had been very different from those now to be seen.

At first this succession was explained on the catastrophal hypothesis, which assumed that there had been a series of creations of life, each of them in its turn wiped out by gigantic cosmic calamities. As such a theory evidently excluded the possibility of the existence of Man as a contemporary of extinguished animals, it enabled would-be harmonists to reconcile systems of chronology derived from Biblical data with the ever-accumulating evidence for the fact of bygone ages in the world's history. But discoveries made early in the nineteenth century gradually closed this easy road. Already in 1797 John Frere had announced the discovery of worked flints in brick earth at Hoxne, Suffolk, which from their situation he referred "to very remote times indeed ${ }^{1}$." Even earlier than this, the finding in Gray's Inn Lane, London, of an axe-head of flint, associated with an elephant's tooth ${ }^{2}$, had presented all the evidence necessary for establishing the remote antiquity of Man, if there had been anyone at the time able to interpret it aright. On the Continent of Europe these neglected discoveries were followed up by Ami Boué in Lower Austria $^{3}$, and by P. C. Schmerling in the caves of Belgium. The

1 John Frere, "Account of Flint Weapons discovered at Hoxne in Suffolk" (Archaeologia, xIII. [1800], p. 204).

2 So in the British Museum Guide, Stone Age, p. I ; but a description contained in a letter written by Mr John Bagford, and published in Hearne's edition of Leland's De Rebus Britaniicis Collectanea, vol_. I. pp. Iviii ff. (Oxford, I71 5), seems to shew that an entire skeleton was found. Bagford rejects the idea that the elephant had lain there since the universal deluge, preferring to believe that it had been imported with many others by the Romans, in the time of the emperor Claudius. This is a fair example of eighteenth century speculation.

" "Ossemens humains présumés fossiles" ("Revue bibliographique" appended to Annales des sciences naturelles, xvirI. [1829], p. 150); "La race humaine, a-t-elle précédé la formation des terrains d'alluvion, ou est-elle même contemporaine de l'époque tertiaire et secondaire?" (Bulletin de la soc. géologique de France, I. [1830], p. 106); "Erläuterungen über die von mir im Löss des Rheinthales im Jahre I 823 aufgefundenen Menschenknochen" (Sitzungsberichte der mathem.-naturwissensch. Klasse der Kaiserl. Akademie der Wissenschaften, viII. [1852], p. 88). 
latter found at Engis ${ }^{3}$ the bones of tropical animals, such as the cave bear and the hyaena, long extinct and forgotten in that part of the world, associated with human bones and with artificially-made flint implements. Even then it was for a while still possible to save the theory, which these discoveries assailed, of the recent origin of Man. For it could be said that the owners of the human bones had entered the cave long after the animals had disappeared. But unfortunately for any such interpretation, a cave was afterwards excavated in the south of France, which was found to contain bones upon which some ancient human occupant had scratched pictures of mammoths and of other extinct beasts-pictures so life-like that there was no alternative to admitting that they had been drawn by a person familiar with the living creatures, and therefore contemporary with them ${ }^{2}$.

\section{(v) Boucher de Perthes}

In the year 1847 the head of the custom-house of the town of Abbeville, by name Jacques Boucher de Crèvecour de Perthes, leaped into fame by the publication of a book, afterwards completed in three volumes ${ }^{3}$, containing pictures and descriptions of thousands of flint objects of various kinds, which he had discovered at Abbeville and at other places in the valley of the Somme. He indicated reasons for believing that great geological changes, implying an enormous lapse of time, must have affected the river-beds of the part of France concerned, since the epoch when the flints had been deposited where he had found them.

Considering the beliefs then current as to the antiquity of Man, it is not surprising that this thesis had to run the gauntlet of violent opposition: and it must be admitted that by certain errors of judgment Boucher laid himself open to justifiable hostile attack. Some of his statements shewed that he lacked the power of selfcriticism; and even at the time of publication it could be seen that some of the objects which he illustrated were forgeries, palmed off upon him by his workmen. But in spite of these handicaps, Boucher's chief contention was sound, and it has stood permanently, while his human weaknesses have been forgiven, if not forgotten. An international committee of expert geologists visited his excavations while

1 P. C. Schmerling, Recherches sur les ossements fossiles découverts dans les cavernes de la province de Liège (Liège, I 833), vol. I. p. 30 .

2 Particulars of this and similar discoveries will be found below, in Chap. Ix.

${ }^{3}$ Antiquités celtiques et antédiluviennes, par M. Boucher de Perthes (Paris, I 847-1 860). Abbeville contained an energetic Société d'émulation, several members of which engaged to a greater or less extent in the researches which brought renown to Boucher. See E. Prarond, "Sur la date des premières recherches préhistoriques à Abbeville" (C.A.P.A., Stockholm, 1874, vol. II. p. 851). 
his results were still a matter of controversy. Some of them came prejudiced against him and his theories; but they retired converted and convinced. The battle for the claim of mankind to a high antiquity was won.

\section{(vi) The Principle of the "Three Ages"}

Shortly before this, the clear-sighted archaeologists of Denmark had been developing important and far-reaching principles of classification. Hesiod in ancient Greece ${ }^{1}$, Lucretius, guided by his Greek teachers, in ancient Rome ${ }^{2}$, to mention the two most prominent names only, had as in a flash of prophetic instinct anticipated the scientific principle of the "Three Ages"-the truth that civilisation has advanced through a succession of epochs, distinguished respectively by the use of stone, bronze, and iron as the chief material of which tools and weapons were made. Though the germ of this theory was thus lying in the pages of the authors cited, at the disposal of all scholars, it bore no fruit till the nineteenth century was well started on its course. So late as I806, Rasmus Nyerup, the founder of the National Museum at Copenhagen, and the most eminent archaeologist of his time in Denmark, was obliged to confess that "everything which has come down to us from heathendom is wrapped in a thick fog; it belongs to a space of time which we cannot measure. We know that it is older than Christendom, but whether by a couple of years, or by a couple of centuries, or even by more than a millennium, we can do no more than guess ${ }^{3}$." But when these words were written, a youth was growing up who was destined to dissipate the fog of which Rasmus Nyerup thus complained. His name was Christian Jürgensen Thomsen. The son of a merchant, destined for his father's occupation, he had not received a specially literary education; but he had a keen natural interest in art and archaeology, and he thus attracted the attention of Nyerup, whom he succeeded in the administration of the Museum in 1816 . His educational deficiencies were not altogether disadvantageous. He might have begun his career weighed down with a number of preconceptions, taught in the schools of the time without any suspicion that they were fundamentally erroneous. These he would have had to unlearn. Instead, he came to his duties with no such prejudices, and he brought an alert and open mind to bear on the problems of classification which presented themselves daily, in dealing with the

1 Works and Days, line 150.

2 De rerum natura, v. 1282.

3 "Oversyn over Fædernelandets Mindesmærker fra Oldtiden," cit. ap. Sophus Müller, Nordische Altertumskunde (Strassburg, 1897), I. 218. 
collections in the museum and with new acquisitions. Thus he discovered for himself the long-lost truth, which the ancient poets had seen "as in a glass, darkly."

It often happens that an epoch-making discovery is in some mysterious way "in the air," and affects receptive minds independently of one another. There seems to be no reason to doubt that Friedrich Lisch, in arranging the private museum of the Grand Duke of Mecklenburg-Schwerin (1836), hit upon the same principle of classification, without previous knowledge of the work of Thomsen. Other claimants to priority have been put forward, both in Denmark and in Germany. Indeed, some anticipation of the principle may be found in the writings of Eckard, a professor of History in Brunswick (obiit 1730 ), and of Mahudel in 1734 . But the time was then not yet ripe; those pioneers failed, like their ancient classical predecessors, to find a following. Thomsen and Lisch were the first to make a practical application of the principle to the classification and the chronology of prehistoric antiquities.

But the honour of demonstrating the truth of what, even with these two, was nothing more than a working hypothesis, belongs to Thomsen's eminent pupil, Jan Jakob Asmussen Worsaae. His investigations into the grouping of objects deposited in the ancient tombs of his country, especially of later graves intruded on earlier sepulchres, proved it, we may almost say, mathematically. It is not too much to call Worsaae the father of scientific Archaeology. Additional and corroborative evidence was forthcoming from the Danish peat-mosses, as investigated by Worsaae and by his colleagues and contemporaries Nilsson, Steenstrup, and Forchhammer. These accumulations display a well-marked stratification, the layers being distinguished by the species of the principal trees whose remains were buried in the peat. There was at the bottom a layer containing the Scotch fir, a tree no longer found in Denmark: above that was a layer containing oak: over that again, a layer containing another species of oak, with alder and birch: over which grew the beech, this being still the commonest tree in the country. In, and underneath, the lowest stratum were found stone implements; these persisted into the oak strata, but bronze implements, absent from the fir stratum, were there found along with them; while iron implements were for the greater part associated with the beech-trees ${ }^{1}$.

${ }^{1}$ See Sir Charles Lyell, The Geological Evidences of the Antiquity of Man, with Remarks on Theories of the Origin of Species by Variation (second edition, London, $1863)$, pp. $8 \mathrm{ff}$. For a fuller account of the history of the establishment of the principle of the Three Ages, see Sophus Müller, op. laud. I. 217; Moritz Hoernes, "Geschichte und Kritik des Systems der drei prähistorischen Culturperioden" (M.A.G.W. xxıI. [1893], p. (7I)); H. Mötefindt, "Das Dreiperioden System, ein 
The system thus formulated met at first with some criticism; but the progress of discovery gradually silenced its opponents, and the controversies are now of historical interest only. The clue, found thus for Northern Europe, was followed up in other regions, by Worsaae himself and by his fellow-labourers. The facts proved to be true for Denmark were before long proved also for the Lakedwellings of Switzerland, which began to attract attention shortly after the middle of the nineteenth century. In short, in every place where Archaeology has been studied, in the Old and in the New Worlds, and in the islands of the Southern Seas, it has been shewn that civilisation has passed through the same stages, unless interrupted by special circumstances-as when an iron-using community teaches its arts to a more backward tribe, previously unacquainted with any form of metal.

This is the corner-stone of modern Archaeology, and it must be clearly understood. There was a time, at the beginning of human existence, when all tools and implements were made of stone, chipped and sometimes polished into the shape required. To this epoch is given the name Stone Age, or Age of Stone. As we advance in the course of time, we find that the art of fusing and casting copper was somewhere evolved; followed by the discovery of how to harden it by mixing it with tin, thus making Bronze, and so inaugurating the Bronze Age. Finally the Iron Age begins with the invention of means of obtaining and of working that metal. Strictly speaking, the Iron Age is still in progress: but in European Archaeology it is convenient to restrict the term to the interval of time between the introduction of iron and the spread of the domination of the Roman Empire over the greater part of the Continent.

We must be careful not to misunderstand or to misuse this clue to chronology. In the first place, it is not to be supposed that the history of the entire human race can be divided into these three periods-that, in other words, they successively dominated the whole world at once. Each region has to be considered independently, in determining the antiquity of its remains ${ }^{1}$. The Bronze Age of one country may be contemporary with the Stone Age of another less advanced, and with the Iron Age of a third which has surpassed it in cultural development. Indeed, we may find two cultures, of

Jubiläumsbeitrag zur Geschichte der prähistorischen Forschung" (Mannus, II. [1910], p. 294); Hoernes, Natur- und Urgeschichte des Menschen (Vienna, 1909), vol. I. part ii. chap I, may also be consulted.

1 It would avoid an undeniable ambiguity if we were to speak of the Stages rather than of the Ages of civilisation; but the latter term has become so well established that nothing but confusion would result from disturbing it. In this book we reserve the word "stage" for another purpose. 
different "Ages," co-existing at one and the same time in a single country-as when the first iron-using Celtic-speaking invaders dominated the bronze-using aborigines in Ireland; or, to take a more modern and more familiar illustration, as when the iron-using colonists shared Tasmania with its stone-using native population. In the second place, it is not to be inferred that the advent of bronze caused an immediate cessation in the use of stone; or that the introduction of iron at once put a stop to the manufacture of bronze implements. As we shall see in the course of our study, there was a notable overlap at each period of transition; and it is a mistake, though one not infrequently made, for museums to segregate their collections too rigidly into a "Stone Room," a "Bronze Room," and an "Iron Room." It is also a fatal error to assume that an ancient deposit necessarily belongs to the Stone Age because metal happens to be absent from it. The absence of metal may be a pure accident. And contrariwise, the presence of a stray scrap of bronze is not a rigid proof of anything more than that the Bronze Age had begun in some centre accessible from the site of the deposit; it does not necessarily prove that the people who prepared the deposit were themselves acquainted with metallurgical arts. Mutatis mutandis, the same principle applies to the transition between the Bronze and the Iron Ages. The dating of a deposit depends, not on one circumstance or group of circumstances only, but on a large number of small indications, which only long practice can enable an investigator to detect and to apply.

\section{(vii) The Divisions of the Stone Age}

As the study of the remains of prehistoric times advanced, it became more and more evident that the Stone Age in Europe must have been of a duration immensely longer than that of the other two Ages put together; and that there were profound cultural differences between the different stages of its progress. It thus became necessary to subdivide it, for purposes of classification, into subordinate periods. The first division made was into two, the Palaeolithic or "Old Stone" and the Neolithic or "New Stone" periods". For the intervening period of transition the convenient term Mesolithic is sometimes used, and will be adopted in this book. In the Palaeolithic period Man was a hunter, making his tools of chipped stone, and unacquainted with the manufacture of pottery ${ }^{2}$, and with the arts of spinning and weaving. In the Neolithic period Man was an agriculturist, some-

1 These names were invented by Sir John Lubbock (Lord Avebury) in 1865 .

2 Certain alleged discoveries of Palaeolithic pottery will be considered in the proper place. 
times polishing his stone tools, and he had learnt the arts just mentioned. In more recent years attempts have been made to push the history of humanity yet further back, in time, and to prefix to the Palaeolithic an Eolithic or "Stone-dawn" period, during which the first rude tentative efforts at flint-fashioning were made. In a later chapter we shall consider the claim of the Eolithic period to be a genuine stage in human development.

The Palaeolithic period is further subdivided; but the enumeration of its divisions may be postponed to the chapters in the present volume which contain a detailed description of the remains of Palaeolithic Man in Europe.

The foundations of scientific Archaeology may be said to have been completed by the sixties of the nineteenth century. This coincides with the gradual dying down of the storm of controversy that had been aroused by the publication of the evolutionary hypothesis. The early struggles of the science for recognition were over, thanks to the labours of the pioneers, some of whom have been named in the foregoing pages: and all the work which the later decades have witnessed has been based upon the principles which they established. The seventies inaugurated the era of archaeological excavation, the story of which begins with Schliemann's work in the Troad ${ }^{1}$, and continues through a series of innumerable similar undertakings. An amount of material has been accumulated, in almost every centre of ancient human occupation, calculated to terrify the stoutest heart! There is probably not a town of moderate size in Europe (except; perhaps, in Turkey) which does not boast of an antiquarian society of some kind, publishing a periodical journal: and it is with a feeling of despair that one contemplates these rows of accumulating volumes - unduly filled with chaff, yet all containing grains of real value. Some scheme of co-ordination, of synthesis, and of indexing will have to be evolved, if the science of Archaeology is not to be smothered under the dead weight of its own products.

We need not here enumerate discoverers and discoveries. Those which are of importance for our present purpose will be referred to as occasion arises. A detailed account of the progress of archaeological research would occupy more space than the scheme of this volume could afford. The outline contained in the preceding pages sufficiently sets forth the chief landmarks in the advance of the science, and the principal steps whereby the traditions about

1 This is, perhaps, not strictly accurate; archaeological excavation begins with the first ancient Egyptian tomb-robber, and is continued through a succession of barrow-diggers, who, like Alexander the Coppersmith, have wrought much evil. But Schliemann's excavations are among the first on an extensive scale, with a scientific purpose in view, and bearing on European Archaeology. 
thunderbolts and the like, and the guesses of pre-scientific days, have been made to give place to ordered and reasonable explanations of objects of antiquity 1 .

\section{The Methods of Archaeological Research: the Requisites}

Too often, in England at least, is Archaeology looked upon as a mere pastime. Collecting antiquities is not Archaeology; and delightful excursions to old churches or castles are nothing better than picnics. Archaeology, properly pursued, is a science, which demands an exceptionally wide range of study on the part of its followers. At least half-a-dozen European languages, surveying, photography, draughtsmanship, geology, anatomy, pathology, zoology, botany, mineralogy, chemistry, technology-for all of these branches of knowledge occasion will be sure to arise as the Archaeologist pursues his researches. It need hardly be said that he cannot be a master of the tenth part of so wide a range of subjects; but he ought to have some understanding of their general principles, applying for details, as circumstances may arise, to those who are specially engaged in their pursuit. He ought further to endeavour to acquire what may fairly be called a detective instinct, to enable him to divine the most probable causes that have led to observed effects-taking care to develop concurrently a critical judgment, such as will keep in check a natural but fatal tendency to be too clever in framing ingenious deductions.

The methods of archaeological research vary in detail according to circumstances. It is obvious that the study of historic antiquities must differ to some extent from that of anhistoric or of prehistoric

1 The reader may be referred to A. Michaelis, A Century of Archaeological Discovery (English trans., London, 1908), which, though almost exclusively concerned with remains of the Classical and pre-Classical civilisations of the Mediterranean, does not altogether ignore work done in the fields of Northern Europe. An interesting "Esquisse d'une histoire de l'archéologie gauloise," by M. Salomon Reinach, will be found in Revue celtique, xIx. [1898], pp. 101, 292. A summary of the earlier literature, convenient but not altogether free from inaccuracies, is contained in the relevant chapters of Andrew D. White's Warfare of Science and Theology (London and New York, 1896). In chaps. x. xI. of Lord Avebury's Prehistoric Times (seventh edition, London, 1913) is a useful account of the most important discoveries made in the caves and the river-drifts, whereby our present knowledge of early man in Europe has been attained. R. Munro's Palaeolithic Man and Terramara Settlements in Europe (Edinburgh, 1912) is to a large extent written on the basis of a record of successive discoveries. An excellent historical introduction is prefixed to each section of Hoernes' Natur- und Urgeschichte des Menschen, quoted in a previous footnote. The opening pages of R. R. Schmidt's Die diluviale Vorzeit Deutschlands (Stuttgart, 1912) contain a summary of the course of research, especially in Central Europe. 
antiquities ${ }^{1}$. But the underlying principles remain the same, affecting the obtaining, the treatment, and the final disposal of the material on which the work is based.

\section{(i) The Obtaining of the Material}

Objects of antiquity for scientific study are usually obtained by the process of excavation. There are other ways of collecting them: for instance, they may be purchased from dealers. But this latter method of acquiring antiquities for such a purpose is eminently unsatisfactory. The objects are often obtained by the dealers through an evasion of the laws by which most civilised communities very properly seek to safeguard their ancient monuments. To shield plunderers; and to cover the sources of supply, the purchaser may be told any story of the provenance of an object of antiquity but the right one. Thus the history of the object is not merely lost, it is falsified, and its scientific value is ipso facto reduced to insignificance. Properly conducted excavations alone will yield satisfactory new material for study. But it is a fatal popular error to suppose that excavation is carried out for the purpose of finding things. It is not a mere paradox to say that some of the most successful and instructive excavations that have ever been made have been singularly deficient in actual "loot"; while too many excavations, in which the harvest was enviably rich, have been made worse than useless by the unscientific way in which they have been conducted. Excavation should be carried out for the purpose of finding facts. The successive periods in the history of an ancient site are as a rule clearly marked in the stratification of the soil which covers it. This stratification must be studied with the most anxious care as the work proceeds, and the antiquities found in each layer must be sedulously kept apart. Hideous damage has been done in some of the caves, whose contents we are to study in the present volume, by people hunting for specimens to sell to collectors, without regard to the stratification. Such proceedings are a grave crime against science, for the mere process of excavation inevitably destroys evidence that can never again be

1 Historic antiquities are those whose elucidation is assisted by inscriptions or other literary documents. Anhistoric antiquities do not happen to be so explained, though they may actually belong to a time covered by written record. Prehistoric antiquities antedate the period of written record. As writing was introduced into some countries earlier than into others, each region has to be considered apart, as in the case of the chronology of the Three Ages, in thus classifying its ancient monuments. Objects seven thousand years old from Babylonia may be historic; objects not more than a hundred years old from New Guinea may be prehistoric. When a form of writing is used which is to us unintelligible (as the Hittite or the Cretan scripts) it may be treated as non-existent, for the purpose of this classification. 
recovered if not recorded from stage to stage during the progress of the work.

The excavation, once begun, should be thorough; and therefore, like the man in the parable who would build a tower, no one should embark on an excavation unless he has counted the very considerable cost which it involves, and has assured himself that the funds at his disposal are sufficient to cover the examination of the whole site. There are two reasons for this. In the first place, there is a chance that unexplored parts might contain evidence essential to the comprehension of discoveries made in the excavated portions. In the second place, the unexcavated portions of a productive site offer an irresistible temptation to dealers' agents and other parasites of Archaeology. This is the drawback to the otherwise meritorious practice followed by some excavators, of leaving a section of the site intact, as a record of its stratification. It is impossible to guard the abandoned portion from plunderers; and if the stratification be well "documented" by photographs and, if possible, by the independent evidence of more than one excavator, it should not be necessary thus to leave a proof of good faith.

The camera must be in constant use during the course of the work. Many more photographs should be taken than will be needed in the final report. It is generally advisable to take a number of photographs from various points of view, near and far, before digging out buried objects, in order to record the stratification. However copious the notes taken on the spot may be, a surprising number of questions will often arise when the "finds" come to be described, which cannot be answered without such records. On the other hand, the camera must not be the exclusive means of illustration. Quite apart from plans and sections, which naturally have to be drawn by hand, there are many objects of which a careful measured diagram will give a more accurate and intelligible idea than even the best photograph. Some otherwise good German work is vitiated by excessive reliance upon the camera for illustrative purposes.

As a negative result is not less important than a positive, a note recording the excavation should always be published, no matter how unproductive it may have been.

It is not always realised that to note the depth at which an object was found buried in the ground is not the same as to record its stratification. The strata are not always horizontal, nor are they necessarily of a uniform thickness. Thus, we frequently find descriptions of objects found in peat-mosses or turf-bogs, in which we are told that they were sunk so many feet beneath the surface of the ground. In such a case the actual depth is a matter of comparatively 
small importance. The vital fact, which is too often withheld, is the species of tree with which the object was associated in the bog. On this point may depend the question of its antiquity; we have already seen the important results that followed from just such observations in Denmark. In other words, stratification should be described relatively, but not necessarily absolutely.

There are two other matters which it ought not to be necessary to mention, and yet even a moderate experience of archaeological publications shews that they are sometimes forgotten. The first is, that there should be no squeamishness about describing and illustrating wall-paintings and sculptures containing details such as are usually withheld from "the young person." These details are often of scientific importance, and archaeological work is carried out for the purposes of men of science, and not for the delectation of that troublesome entity ${ }^{1}$. On the other hand, it is equally unscientific to emphasise unduly anything which modern taste condemns as gross; and it must be remarked that this has sometimes been done needlessly under the cloak of Anthropology or Archaeology. For example, dignity is sacrificed, and nothing is gained, by labelling Palaeolithic statuettes with such nicknames as La Vénus impudique. The second point is, that there should be no false sentimentality, miscalled "reverence," about the proper and minute examination of human bones. The present writer has actually read reports of excavations in which the diggers confessed to this weakness, thereby proving their incompetence for the work which they had undertaken.

\section{(ii) The Treatment of the Material}

We now turn to the treatment of the material collected-not the chemical treatment, to ensure its preservation (though this is also important), but the processes by which historical and other deductions may be drawn from it. Naturally these vary with the nature of the site and its contents, so that we cannot set forth hard and fast rules; we can but give a few general principles.

Comparison and classification are the cardinal processes on which archaeological reasoning is based. But it must never be forgotten that they are means to an end, not an end in themselves. Classification, especially, is often overdone. "There is no use in making long lists of varieties of flint chips, for instance, unless there is good reason to believe that some principle of history, chronology, or ethnology

1 Some English archaeological writings display this defect, while certain others have the contrary and equally objectionable fault of reading the expression of phallic and similar ideas into ancient remains and monuments here, there and everywhere. 
is likely to result from them. The present writer must confess that to him many of the elaborately minute classifications of flint implements which he has come across seem to be based on nuances not more important than the trivial peculiarities of perforations, etc., which give certain postage-stamps an enhanced value in the eyes of their collectors. Indeed, injudicious classification may be actually misleading, and so may be worse than useless; and when a practical application of it is made to break up a series of tomb-groups, in order to have trophies of triangular arrow-heads in one case, leaf-shaped in another, and so on, it becomes mere savagery.

Archaeological science is to a large extent a matter of deduction, based on minute and accurate observations. In drawing his conclusions the student must exercise his common sense. There are plenty of specious arguments which can be brought forward in favour of any insane theory, as the history of such crazes as Anglo-Israelism shews. A properly trained critical judgment is the only safeguard against such aberrations. It may be laid down as a good working rule, that the more ingenious and complicated a theory is, the more certain it is to be wrong. It is, indeed, often impossible, with the data at our disposal, to come to a definite conclusion at all. A quadratic equation has two solutions, and if we be obliged to choose between them, we must take into account considerations external to the mathematical statement of the problem; in like manner an archaeological difficulty can often be solved in more ways than one, and if the conditions brought to our notice should be insufficient to determine which solution is to be adopted, we must be content to await further light from later discoveries.

We cannot expect to know everything. There are countless matters to which no clue could possibly survive. A too-confiding tourist in Jerusalem once told me that his guide had pointed out to him the very spot where Abraham had tethered his ass when going up the hill to sacrifice Isaac. It had not occurred to him that no record of such an event could in any conceivable way have survived to mark the site. When the actual historical circumstances under which a deposit of antiquities was originally laid down have passed from living memory or record, it is absolutely impossible to reconstruct them in at least 99 per cent. of the cases.

Again, many of the materials used by man are perishable. It is only in very exceptional circumstances that we can find direct information about ancient tools of wood, or about garments or textiles. If the reader will at this point glance round the room in which he may be reading this page, and will ask himself how many of its contents are at all likely to be in existence in their present form in, 
let us say, 5000 A.D., he will very quickly realise how imperfect our materials for the study of the ways and the works of long-gone generations must necessarily be.

The solution of practically all the problems, which any archaeological discovery will present, depends ultimately on a determination of the date to which its component antiquities are to be assignedwhen possible the absolute date, in years or centuries B.C. or A.D.; in other cases the relative date, as compared with other discoveries made in the same place or region. Chronology is in every case the fundamental problem, and an erroneous solution will throw the most logically constructed theories regarding other aspects of the discovery out of gear. Some words about the processes by which dates are assigned will therefore not be amiss.

If the find be associated with an inscription, which can be dated on historical, linguistic, or palaeographical grounds, our task is easy, though not childishly so. For we must assure ourselves, in such a case, that the objects associated with the inscription are really contemporary with it. When the inscription is cut on a small portable object it may be considerably older than the deposit in which it finds a place. On the other hand it may be later than it appears to be; Egyptian scarabs, for example, often bear the name of a king long anterior to their own time, just as the postage-stamps of the United States of America always bear the effigy of a past President. In spite of these elements of difficulty, the dating of ancient deposits begins with the dating of those for whose age we have epigraphic evidence.

The dating of deposits not accompanied by inscriptions depends on more indirect reasoning. The first step towards the solution of the problem is to establish an evolutionary seriation of types of objects-weapons, implements, pottery, and so forth. Each group of objects passes through a definite line of development; and by the study of a large number of deposits-especially of the grave-goods placed in tombs - their several types can be arranged in chronological order. Thus we may have

$\begin{array}{lll}\text { Pottery } & \ldots & P_{1}, P_{2}, P_{3}, P_{4} \text {, etc. } \\ \text { Axe-heads } & \ldots & A_{1}, A_{2}, A_{3}, A_{4} \text {, etc. } \\ \text { Brooches } & \ldots & B_{1}, B_{2}, B_{3}, B_{4} \text {, etc. }\end{array}$

to mention but three of the classes of objects at random. After study of a sufficient number of associated groups it will be found that certain stages in these seriations are always associated together; thus, in deposits containing $P_{1}$, we may always find $A_{1}$ and $A_{2}$, but never any later 'stage of axe-head; and brooches may be entirely absent, $B_{1}$ not appearing until we reach $P_{3}$ in the pottery scale. These observations will enable us to construct a relative history of the 
development of civilisation in the region with which we are concerned. The discovery of a datable hoard will then give us a fixed point from which to reckon forwards and backwards, thus indicating an approximately accurate absolute chronology. Such a datable hoard would be one associated with an inscription; or, it may be, a stratum lying between two layers of ashes in a site, of the history of which we know enough to say that it was sacked or burnt on two occasions at recorded dates.

The same principle of association of types will enable us to reckon across from a country whose chronology is thus established to another whose archaeological history has not yet been worked out. Thus, we may find, let us say, a cache of objects in Crete, among which are one or two works of art of Egyptian origin, and of styles associated with the twelfth Egyptian dynasty. If then we find in Egypt a twelfth-dynasty tomb containing Cretan objects analogous to those in the Cretan hoard, we are justified in dating these as contemporary with the twelfth dynasty of Egypt. This will evidently give us the required fixed point to enable us to date the Cretan type-sequences.

The accuracy of the date required depends upon circumstances. If we be concerned with a mediaeval literary document, it may be necessary to fix its date exactly to the year-sometimes even to the month and day. With ancient Classical or Egyptian objects, an error of a decade or two is rarely very serious. When we penetrate into prehistoric times, we may deem ourselves fortunate if we can fix a date within a margin of error of a couple of centuries either way. And in the vast abysses of antiquity with which the present volume is concerned, an error of a thousand years is of comparatively small account.

In dealing with Palaeolithic remains, we have to rely upon a rather different order of observations for chronological deductions. The seriation of types of implement is here also of the first importance for the preliminary determination of relative chronology; but the fixation of absolute points of date in the series is a more difficult matter. For measuring the later periods we have, so to speak, a fast-moving human clock-the vicissitudes of empires, the accessions and deaths of kings, the battles, murders, and sudden deaths which make up the greater part of human history-events happening in rapid succession, and thus dividing the stream of time into a large number of short intervals. But for measuring the Palaeolithic period we have only the clock of nature, the slow movement of which is proverbial: the oscillations of climate, with the consequent modifications of animal and vegetable life; river-erosion; the gradual rise and fall of the land relative to the sea. All these processes, though their ultimate results may be of imposing magni- 
tude, require centuries of action before even a perceptible change is obtained, and therefore cannot enable us to measure small intervals of time.

\section{(iii) The final Disposal of the Material}

While there is no objection to the archaeological student having a few type specimens of antiquities by him, as an adjunct to his working library, the true archaeologist will resist all temptation to degenerate into a mere collector. The essentially commercial spirit of the collector, and that which should inspire the man of science, are so antagonistic, that it is in the last degree unusual for the two to co-exist in one personality. If the student can become a scientific collector, well and good; the cardinal test of the distinction lies in whether or not he recognises and acts on the principle that there is only one legitimate place for unique or otherwise important antiquities-namely in a public museum, where they are safeguarded so far as is humanly possible from loss or injury, and are at the disposal of all scholars. Were we living in Utopia, there would be a stringent law forbidding anyone to collect antiquities unless he undertook to keep a careful register of the circumstances of their discovery, and to bequeath them, with the register, to some public collection, which would be authorised to exchange duplicates with other museums, but not with private collectors. All important material would thus in time be secured for general study, and collectors would be obliged to make some return for the harm which the brotherhood, as a whole, has done to science: Thanks to the competition of owners of cabinets, prices have been raised to an absurd height, and valuable objects, which ought in the very nature of things to be public property, pass into the undeserving hands of the merely monied. The museums have meanwhile to struggle on against this unfair competition, with no resources but annual grants, which may have been adequate fifty years ago, but are merely ridiculous now. It is hardly necessary to add that in Utopia archaeological excavation would be absolutely interdicted, except under the control of scholars of established position.

Here is a sentence from a recent book on the joys of collecting, which will serve, if anything is needed, to corroborate the above remarks on the anti-scientific spirit of the collector. The writer of the book is speaking chiefly about pictures, but the passage is capable of a wider application:

" To own a picture is to be able to do what you please with it; to hang it where you please, to change it about, to look at the back of it, to show it to your friends, and to shut it up from people you don't like. A picture in a gallery belongs in any effectual fashion only to the director of the gallery for the time being. He has the fun [the 'fun'!] of it, and no one else." 
All this merely means that the collector wastes his time in doing, inefficiently, the work of a museum porter. It ignores the fact that if there be any serious reason why you should "look at the back," the director of the gallery is ready to give you every facility to do so. As for shutting it up "from people you don't like," who knows whether the man you don't happen to like may not be the one man in your generation competent to make a proper use of the object? The selfishness of an English nobleman, in the earlier years of the last century, who frohibited all access to the valuable collection of Irish manuscripts in his library-to himself perfectly uselessretarded Celtic studies for nearly fifty years. In gathering materials for a course of lectures, recently delivered, on Irish antiquities, the present writer read over and over again, in papers describing important objects, words such as these: "Needless to say, this object has passed into my possession." We can picture the smirk of satisfaction with which this noble sentiment was uttered at the original reading of the paper. But it was heart-breaking to reflect that the writer of the paper is now dead; that his collection was dispersed to the four winds in the auction-room; and that the object may now be anywhere-or nowhere!

I cannot but speak with feeling on these matters. I have stood in the midst of the necropolis of an important city of the ancient East, and have there seen every tomb empty and rifled, to enrich soulless Arab fellahin and greedy Levantine hucksters by providing "curios" for hordes of brainless tourists.

In any case, the yield of an excavation should always be deposited in a public museum, if only for the practical reason that a check is necessary on the most expert archaeologist in the world. However minutely he may examine an object, there is at least an even chance that someone else, with better eyes perhaps, or with a different range of previous experience, will find something which he has missed. It is a pity that Prof. Petrie's admirable scheme for a national repository of archaeological material still exists on paper only; if and when it takes a tangible shape, the difficulty of finding space for large quantities of such material will be overcome ${ }^{1}$.

${ }^{1}$ See W. M. Flinders Petrie, "A National Repository for Science and Art" (Fournal of the Society of Arts, I8 May 1900, p. 525); and the same writer's Methods and Aims in Archaeology (London, 1904). This book, though more especially relating to work in Egypt, may be recommended to the student of practical archaeology in any country. See also the admirable Manuel de recherches préhistoriques published by the Société préhistorique de France (Paris, 1906); and J*. P. Droop, Archaeological Excavation (Cambridge, 1915). Reference may also be made to L. Capitan, "La science préhistorique, ses méthodes" (R.E.A. vol. Ix. [1899], p.333). 


\section{CHAPTER II}

\section{GEOLOGICAL PROLEGOMENA}

\section{Purpose of this and the following Chapters}

IN this and the next two chapters the reader is put, once for all, in possession of certain general facts to which it will be necessary to make frequent reference in the course of our study. These facts relate, first, to the preparation of the earth as the theatre of the developments and of the events to be described in later pages; secondly, to the species of animals found, at successive stages of the history, living along with man in the regions with which we are concerned; and thirdly, to the principles of classification applicable to the individuals of the human species. By thus grouping into three preliminary chapters such of the details, falling under these heads, as are essential to our study, the interruption by explanatory digressions of the archaeological descriptions which follow later will be avoided. While an attempt will be made to give some idea of the relation of Man, the being whose works and ways we are to study, to the Universe around him, it must not be understood that these chapters of prolegomena are intended to be outline treatises on the sciences of Geology, Palaeontology, and Anthropology, such as would be found in an encyclopaedia. The selection of facts to be set forth is limited by the requirements of the work before us.

\section{A. The Formation of the Earth and its Geological History}

There was a time, countless aeons ago, when the matter now distributed among the bodies of the Solar System was an enormous mass of glowing vapour-or else an enormous cloud of meteorites; it is needless for us to attempt to decide here, even empirically, between these rival theories ${ }^{1}$. Whatever the original form of this matter may have been, Science has no answer to the question how it came into existence at the first. Obviously this question is merely evaded, not answered, by the simple and frequently-stated hypothesis that it was produced by the collision of two large solid bodies. Quite possibly this is true, but how did the large solid bodies come into existence? The matter, whatever its ultimate origin may

1 Any standard modern text-book, such as Chamberlin and Salisbury's Geology (London, 1905), will give the reader the arguments for and against each of these theories. 
have been, passed (by the action of statical, dynamical, and chemical laws, whose causation is equally hidden) through a number of transformations, and coalesced ultimately into a series of spheroidal bodies; these, gradually cooling, tended in time to become wholly, or at least partly solid. Naturally the smaller planets, among them the earth, would be the first to cool and harden; there is reason to believe that the process is as yet very far from completion in the case of the larger planets, while there is probably little or nothing solid about the central sun round which the planets are circling.

What may be the condition of the matter at the centre of the globe is nothing more than a subject for speculation and theory; for from the top of the highest mountain to the bottom of the deepest excavation a vertical height of at most ro miles of the crust is open for our direct inspection. Such a question as this, however, lies outside the scope of our present study: we must be content to say that whatever may be the state of the interior, a solid crust formed over the surface so soon as the cooling process was far enough advanced. To the rocks of which this primitive covering consisted is given the name Archaean Rocks; these are the oldest formations of which we can now find any trace.

During this formative period, the condition of the matter of which the earth is made must have been such that no life, in any form of which we can conceive, was capable of existence upon it. The name Azoic ("without life") is therefore used to denote this initial stage.

The solid crust of the earth does not now, and never did, possess the element of permanence. So soon as the Archaean rocks were formed, they became subject to various disintegrating agents-either chemical (as carbonic acid) or mechanical (as the eroding action of wind and water). Their materials, thus reduced, and more or less modified in chemical or mineralogical constitution, were carried by wind, or by water in one or other of its forms, and were deposited afresh in new rock-formations, differing widely in character from those to which they had originally belonged. This process has continued ceaselessly through the incalculable ages of geological time, and is still in progress. The rocks of the globe can in consequence be classified into a chronological series, in which is enshrined the record of the formation of the earth.

That mystery which we call "Life" probably made its appearance so soon as its existence on the earth became possible; and the petrified remains of once living creatures, vegetable and animal, embedded in these new rock-formations, form the chief basis of the classification referred to. By a study of the evolution of successive types of 
organic remains, the geological history of the earth has been divided into four periods. Three of these periods lie wholly in the past; each of them was of enormous length, and each was distinguished by forms of life different from those to which we are accustomed in the modern world. The fourth is still in progress, and has witnessed the gradual attainment of modern conditions.

These four periods are thus named, and have characteristics which may be very briefly stated as follows:

I. Primary or Palaeozoic Period. The earliest forms of life appeared in both the animal and the vegetable kingdoms; fishes were evolved; the fossilised forests which we call the coal-measures were laid down.

II. Secondary or Mesozoic Period. The earth was peopled for the greater part by colossal reptiles; birds as well as the most primitive mammals made their first appearance. During the Secondary Period the great limestone formations were deposited.

We need say nothing more here about the Primary and the Secondary Periods; they do not touch the life of Man except indirectly, in so far as many of the most valuable commodities of commerce, ancient and modern (coal, flint, amber, etc.), were then stored up.

III. Tertiary or First Cainozoic Period. During this period the mammals (animals which bring forth their young alive, and nourish them by suckling during the early stages of development) were the most prominent of the fauna.

All the above periods are subdivided by geologists into epochs, but in the case of the Primary and-Secondary we need not trouble ourselves with their names. We must enumerate the divisions of the Tertiary period, however, as we shall have occasion to refer to them on later pages. They are four in number, and are named with terms derived from Greek, as follows:

$\begin{array}{lll}\text { Eocene } & \ldots & \text { Dawn of the New. } \\ \text { Oligocene } & \ldots & \begin{array}{l}\text { Few of the New. } \\ \text { Miocene }\end{array} \\ \text { Pliocene } & \ldots & \text { A Minority of the New. } \\ \text { A Majority of the New. }\end{array}$

These names are designed to express the course of an evolution wherein forms of living creatures, now extinct, dropped out one by one, and new forms, gradually approximating to those of the modern age, made their appearance. This terminology was primarily based on a classification of the shells of molluscs found in Tertiary gravels, but the facts which it enshrines are equally true for the rest of the flora and fauna.

IV. Quaternary or Second Cainozoic Period. This period, which 
is still in progress, is divided into two epochs; their names continue the scheme of nomenclature used for the Tertiary divisions:

$\begin{array}{lll}\text { Pleistocene } & \ldots & \text { Most of the New. } \\ \text { Holocene } & \ldots & \text { All of the New. }\end{array}$

The Holocene is the modern world, beginning with the Neolithic archaeological period; the Palaeolithic, the first period of human life determined with certainty, lies in the Pleistocene.

\section{The Ice Age.}

When we reach the transition from the Tertiary to the Quaternary Period, we are confronted with a remarkable phase in the history of the earth and of its development, which is of capital importance in the early stages of human evolution. This is the Quaternary Ice Age. It is called "Quaternary" to distinguish it from previous phases of the same kind, for which there is geological evidence (in the Cambrian and the Permian, the first and last epochs of the Primary): an ice age, whatever its cause, appears to be a periodic phenomenon. But in these pages we shall omit the qualifying prefix, which is here unnecessary; previous ice ages, being long anterior to the appearance of Man, lie wholly outside our subject.

The exact relationship between the beginning of the Ice Age and the periods of geological history is not very clearly defined. Some geologists confine the Ice Age to the Quaternary Period, others make it begin at the end of the Tertiary. But inasmuch as there was a prolonged time of transition between each pair of adjacent periods, the dispute is little more than a question of terminology, and has no immediate importance for our present purpose.

As in the case of other geological phenomena to which we refer in the present chapter, we need not expend any space upon the much-debated problem of the cause of an Ice Age-a problem which seems to be still as far from a generally accepted solution as it ever was. Our business is with its effects, which profoundly influenced the early development of humanity in Europe. During the domination of the Ice Age, much of the area of Northern Europe was under conditions which we can best realise by studying modern Greenland, or the South Pole. At least, this is true for the plains of Northern Europe; Penck ${ }^{1}$ is careful to point out that the conditions of Alpine glaciation were rather different. Ice sheets covered the plains, and the valleys were filled with huge glaciers, compared with which those of modern Switzerland would be as a mountain rill beside a river estuary.

${ }^{1}$ Die Alpen im Eiszeitalter, vol. III. p. II4I. 
Traces of the work of the ice are to be found, by those who have eyes to see, in almost any place that came within its influence. Rocks are scored and scratched by stones which were embedded in the under surface of the ice-flow. Great boulders are torn from their native beds, and are deposited, often many miles away, in regions to which they are geologically foreign. Mountains are polished smooth and their tops are rounded. The whole surface of the lands affected is covered with one or more strata of boulder-clay ${ }^{1}$, containing many ice-scored pebbles. These are only a few of the most prominent indications of the passage of the ice; for others we refer the student to text-books of Geology.

At the beginning of the Ice Age the mountains were considerably higher than they are now. Since the time of which we are speakingsome 500,000 years ago, on a moderate estimate-they have been eroded by ice, rain, rivers, frost, and wind. As the climate became colder, with the advance of the Ice Age, the line of perpetual snow gradually crept down the mountain slopes. The ever-increasing snow-caps became the sources of glaciers or ice-rivers, which flowed into the valleys, growing and extending until, at last, the lands affected were covered with ice-sheets of great thickness, above whose surface rose the peaks of the highest mountains, like the nunataks of Greenland.

There were four important centres of glaciation in Europe-the Baltic Basin, whose glaciers affected to a greater or less extent the whole of Northern Europe eastward and westward, as well as the basin of the North Sea: the British Islands, whose glaciation was conterminous with the ice of the Baltic centre; the Alps; and the Pyrenees. There were, besides, a number of minor local centres of glaciation in the Continent. Traces of the work of ice are to be found in Spain, Portugal, Italy, Austria, the Balkan Peninsula, and the Caucasus (see the map of the European glacial centres, Fig. I).

\section{(i) The Alpine Ice-Centre}

From the nature and distribution of the deposits of glaciation, chiefly those to be seen in the Alpine region, it has been inferred that the Ice Age was not an undivided whole, but that the glacial periods were interrupted by interspersed genial intervals. The evidence on which this inference is based consists $(a)$ of the multiplicity of moraines, and $(b)$ the complexity of glacial river deposits. A third

1 Boulder-clay is a hard compact soil, resembling closely compressed dried mud, which is what it actually is; it consists of material ground off from the surfaces of the rocks and the mountains over which the glaciers passed, reduced to mud, and deposited along the courses of the ice-streams. 
group of facts, the superposition of successive beds of boulder-clay (from which the same conclusion has been drawn), can be otherwise

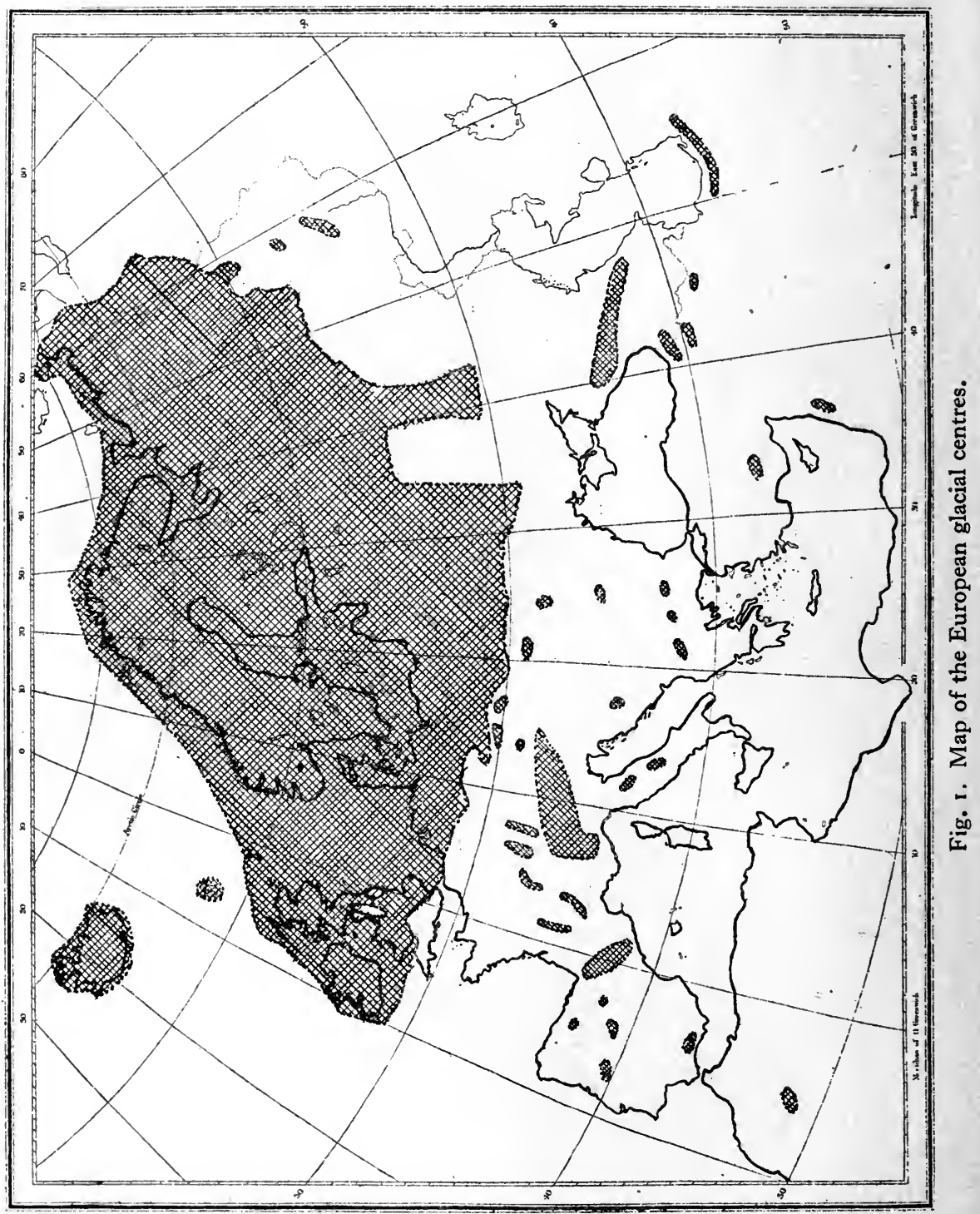

explained, and does not of inevitable necessity indicate a succession of different glacial maxima.

Moraines are the deposits of boulders and other detritus carried 
down from the mountains on the surface of the glacier streams, and left at the edge of the ice where it melts, and is no longer able to bear its burden. A ring of morainic accumulation therefore surrounds the centre from which the glaciers took their rise, and marks the limit of the extension of the ice. When there is a concentric series of several such rings, one of two possible explanations can be adopted: either that each ring marks a phase in the retreat, under improving conditions of climate, of a single glacier; or else that there was a succession of glacial systems, each of them being responsible for one of the rings of morainic deposit. In order to enable us to decide between these alternatives, other groups of phenomena must be considered, in each specific case.

When the ice melts, the water flows onward in the form of a river; and though it is no longer able to carry the larger detritus, borne by the ice and deposited in the moraines, it still continues to carry away much of the mud that the glacier has ground from the underlying rock surfaces. In the alluvium deposited along the lower courses of these glacial rivers we find the further evidence of periodicity which we require to confirm the testimony of the moraines. The alluvia of the glacial streams of the Alps have been the most systematically studied, having been made the subject of the classic researches of Penck and Brückner ${ }^{1}$. Here the oldest alluvium was spread over the surface of the plains surrounding the Alpine area. After the disappearance of the ice had reduced the water-supply of the rivers to a minimum, these cut their narrowed beds through the wide sheets of alluvium, which in their days of maximum extent they had themselves deposited over the plains. When another glaciation took place, and the rivers were in consequence once more augmented, a second layer of alluvium was deposited, filling the watercourses which had thus been cut. Traces of four repetitions of this process of alternation have been observed in connexion with the Alpine glaciers, indicating four successive glaciations. To the alluvium-beds corresponding to the four glaciations, and represented in the diagram (Fig. 2), Penck and Brückner have given the following names:

\section{Aelterer Deckenschotter (elder detritus-sheets) \\ fungerer Deckenschotter (younger detritus-sheets) \\ Hochterrassenschotter (upper terrace detritus) \\ Niederterrassenschotter (lower terrace detritus)}

The distinction of name expresses the distinction of character which these different beds of alluvium display. The first two are

1 Albrecht Penck and Eduard Brückner, Die Alpen im Eiszeitalter, three volumes (Leipzig, 1909). 
spread widely to a greater or less extent over the plain; the third and fourth are confined to the river-courses, and appear as terraces along their banks. Obviously the upper terrace would be the first to be formed; hence the upper terrace detritus represents a glaciation preceding that to which the lower terrace detritus owes its existence.

The nomenclature introduced by Penck and Brückner for the Alpine phenomena is simple and convenient, and it has accordingly been adapted by other writers-a little loosely, perhaps-to the iceage phases of regions outside the Alpine area. It should however be remembered that the terminology was originally intended to apply, mainly if not exclusively, to the Alps. To the four glacial periods of which they have thus found evidence, Penck and Brückner give the names Günz, Mindel, Riss, and Würm, after certain rivers in the Alpine area. The interglaciations are labelled with compound names, derived from the ice-advances preceding and following them: thus,

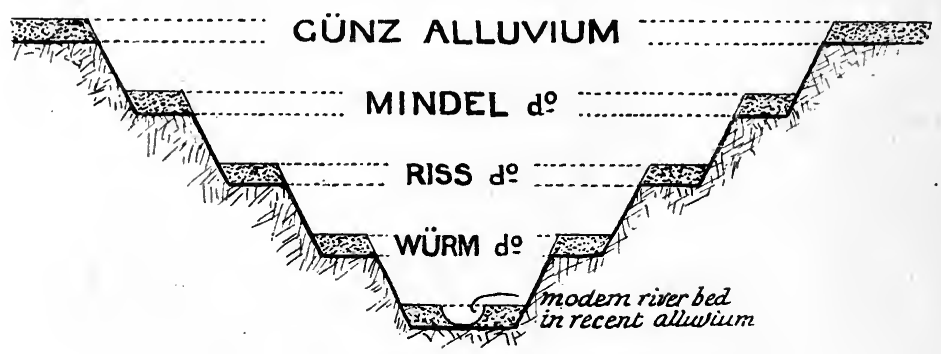

Fig. 2. Diagram of Alpine detritus deposits.

the Günz-Mindel interglaciation lies between the Günz and the Mindel glaciations, and similarly for the others. These names are chosen, partly because the deposits of those rivers afford typical examples of the detritus of the four phases respectively, and partly for the practical reason that the names are conveniently short, and fall into an alphabetical arrangement ${ }^{1}$. The use of these names to denote the phases of advance and recession in other centres of glaciation is in a measure a petitio principii. However probable it may appear that the succession of glacial and genial conditions in other European centres should correspond to those in the Alpine centre, this has not been fully demonstrated; and it is well to exercise caution in using a terminology which assumes too readily what has not been certainly proved.

1 This is not merely a "fortunate chance" as it has sometimes been expressed; it is a deliberate intention (see Penck and Brückner, op. laud. vol. I. p. I IO). The names are chosen with intervals between their initials in the alphabetic order, so as to give an opportunity of inserting additional names, should future discovery make this necessary, without disturbing the alphabetical arrangement. 
The Günz glaciation was probably the longest in duration, if we may judge from the apparent original size of the gravel-deposits, which are its principal monument. It has, however, left fewer actual traces of its passage than have its successors, for the simple reason that the ice of the later advances has ground most of its relics away. So far as the fragmentary condition of the Günz moraines permits us to judge, its glaciers seem to have been of about the same extent as those of the Würm glaciation.

The length of the Günz-Mindel interglaciation is estimated by Penck as approximately equal to thrice the length of the post-glacial period, or about 60,000 years ${ }^{1}$.

The Mindel glaciation was on the whole the most extensive of the four, as is shewn by the fact that its moraines lie outside those of the other glaciations-except in certain areas, where they are exceeded by the Riss moraines.

The Mindel-Riss interglaciation is regarded by Penck as having been by far the longest of the interglacial periods; he assigns to it a length equal to twelve times the length of the post-glacial age, or about 240,000 years.

The moraines of the Riss glaciation are more perfectly preserved than are those of its predecessors. They form, indeed, an almost complete ring round the region of the Alps, broken only at the south-east corner. Application of formulae expressing the relationship of the size of the glaciers to the height of the snow-line ${ }^{2}$ shews that the Riss snow-line was about 1300 mètres below the present level of perpetual snow.

The length of the Riss-Würm interglaciation is estimated at about equal to that of the Günz-Mindel, or about 60,000 years.

The Würm glaciation was not so severe as the Riss, as is shewn by the fact that almost everywhere its end moraines lie within the line of the Riss moraines, indicating a smaller extent of ice-surface; and by its higher snow-line, which was about roo mètres above that of the Riss.

The retreat of the Würm ice is marked by two oscillations

1 For the evidence upon which this and similar estimates of duration are based, see Penck and Brückner, op. laud. vol. Irr. p. I 53 ff. There is no series of phenomena common to glacial and genial phases, on the basis of which the relative length of the two groups of phases can be determined. Indeed it is scarcely, if at all, possible to measure the actual duration of the glacial periods.

2 The snow-line cuts across a glacier at between one-third and one-half of the vertical distance between its upper and its lower end, measured from below. Also, the mean height of the surface of a glacier is equal to the height of the snow-line (Penck and Brückner, op. laud. vol. I. pp. 170 ff., 234; on the latter page will be found a specimen calculation of mean height. See also W. B. Wright, The Quaternary Ice Age [London, 1914], p. 144). 
(Schwankungen) called respectively the Laufen oscillation and that of Achen.

The Laufen oscillation took place during the maximum of the Würm glaciation. It was marked by a retreat of the snow-line to about 200 mètres above the Würm level (i.e. about 1000 mètres below the present level), after which it sank again to the Würm maximum level ${ }^{1}$.

The Achen oscillation was another restoration of genial conditions, which took place while the Würm ice was diminishing in extent. The snow-level rose to 300 mètres above that of the Laufen oscillation, or some 700 mètres below the modern level. The Achen oscillation was of considerable length-Penck and Brückner assign to it several thousand years, though they decline to commit themselves to more definite figures ${ }^{2}$. The Achen oscillation derives its name from that of the Achensee.

Finally, Penck and Brückner recognise evidence of a series of smaller variations of climate, subsequent to the four main glaciations, and leading gradually to modern conditions. Indications of three advances of the ice have been detected, intervening between the Würm glaciation and the establishment of the existing climate. These advances are too insignificant, in comparison with the great glaciations, to be reckoned in the series; but they are too well-rnarked to be neglected, and, in the Archaeology of Europe, they are of the first importance. Penck and Brückner give them the convenient name stadia, and label them with names which fall into a separate alphabetic series, based on the Greek alphabet-Bühl, Gschnitz, and $D_{a u n^{3}}$. The snow-line during the maxima of these three stadia was respectively about $95^{\circ}, 600$, and 300 mètres below the present level. The end of the Daun stadium is dated roughly by Penck about 7000 B.C.; the Bühl stadium he would place about 20,000 B.C. Too much importance should not be attached to figures like these, but they are useful as giving a rough idea of the length of the spaces of time with which we have to deal.

Whatever may be the ultimate cause of the extraordinary series of phenomena which we have now briefly described, it is clear that these successive advances and retreats of the ice must have been

${ }^{1}$ Penck and Brückner, op. laud. vol. II. pp. 58I, 588.

2 Op.laud. vol. I. p. 342 . Elsewhere (vol. II. p. 533) they quote various estimates ranging from 5000 to $\mathrm{I} 6,000$ years.

3 'This series of names further differs from those of the glaciations in not being derived from river-names. Bühl is from Bühle, a dialect word for small hills covered with glacial deposit; Gschnitz from the Gschnitztal, a valley of the system of the geologically important river Inn; Daun is a syllable frequently occurring in the mountain nomenclature of the Stubaital, another of the valleys of the same system. 
accompanied by very considerable fluctuations of climate. It is not to be supposed that there was any abruptness in the variations; indeed, a transition phase is recognised, preceding and following each glaciation, during which the climate was gradually approximating to that of the phase next in order. These intermediate or transitional spaces of time are called Pre-Günz, Post-Günz, and so on.

The climate at the maximum of an interglaciation was rather more genial than under present conditions. Some of the species of flora, whose remains are embedded in the famous interglacial (RissWürm) deposit known as the Breccia of Hötting, near Innsbrück, could not have flourished at all under climatic conditions similar to those now prevalent in the same region. They testify to a mean temperature of at least $2^{\circ} \mathrm{C}$. higher than the present, implying a snow-line 400 mètres above the modern level ${ }^{1}$. Under such conditions vegetation must have flourished in the Alps far more richly than in recent times.

. The approach of glacial conditions must have been heralded by a very gradual increase in the severity and length of the winters, and a corresponding diminution in the length of the summers. It is not to be understood that the total annual temperature during the glaciations was less than during the interglaciations. The distribution of the heat was different, the warmth being concentrated in very short summers, which did not last long enough to melt all the accumulated ice of the correspondingly protracted winters. And as more and more moisture became locked up in the snow and ice, the air became drier and clearer, and in consequence less capable of preventing the loss by radiation of heat received from the sun.

\section{Steppes and Tundras. Löss}

These meteorological changes inevitably produced corresponding changes in the aspect of the countries directly or indirectly affected. The forest conditions of the interglacial periods gradually gave place to steppe conditions as the climate deteriorated. Steppes are grassy plains or plateaux, hot in summer but severely cold in winter. As a result of this inequality of temperature, they are visited by heavy wind-storms, laden with either dust or snow. The snow blizzards have a serious effect in diminishing the life of the steppes; the duststorms, by transporting material from one place and depositing it in another, have much influence in changing the configuration of the country. The hollows of the ancient European steppes were filled, and the open spaces covered, with beds of a wind-drift, to which is

1 Penck and Brückner, op. laud. vol. I. p. 389.

M.E.A.I. 
usually given the German name Löss. This deposit is of a yellowish colour, and is recognisable by the absence of stratification (which distinguishes it from alluvial formations), and by the presence of small land-shells. By the weight of superincumbent strata the material of the Löss may become consolidated into a mass which, however, has but little cohesion. During the phases of steppe conditions in the Ice Age the dried mud of the outwash from the preceding glaciations was taken up by the winds and blown over the plains and valleys, where it still remains, spread over a large part of the Continent. In the south of England, in France, in Central Europe, in Russia, and above all in China, the Löss is an important element in the stratification of the soil. It is probable that there was a bed of Löss associated with each interglaciation, as well as a post-glacial bed; but the recoverable relics of such deposits for the earlier phases are scanty and doubtful. The post-glacial beds of Austria have yielded rich and important archaeological material, as we shall see ${ }^{1}$.

As the climate deteriorated further, the steppe conditions gave place in their turn to those of tundras - the Russian name now generally given to the great plains, frozen hard in winter, marshy in summer, which are to be seen in Northern Siberia within the Arctic circle. During the periods of ice-maximum, tundra conditions must have prevailed over countries bordering on glaciated regions, even when they were not themselves invaded by glaciers or by ice-sheets.

The improvement in the climate following a glaciation would naturally be marked by a reversal of the stages described in the foregoing paragraph.

\section{(ii) The Pyrenean Ice-Centre}

The Pyrenean centre of glaciation, which has been chiefly studied by Obermaier ${ }^{2}$, presents close analogies with the Alpine centre. Naturally its phenomena are of less imposing magnitude, owing to the smaller size of the mountains, and their situation on a slightly warmer isothermal line. Obermaier's researches have established evidences of a succession of glacial and genial phases similar in number and character to, and presumably synchronous with, those of the Alpine system.

\footnotetext{
1 For further particulars about Löss, reference may be made to any text-book of Geology. Its nature, a question long in dispute, was settled by $F$. von Richthoven as a result of his studies in China. See his book, China: Ergebnisse eigener Reisen und darauf gegriondeter Studien (Berlin, 1877); also his letter, "On the Mode of Origin of the Loess" (Geological Magazine, New Series, Decade II, vol. Ix. [1882], p. 293).

2 Hugo Obermaier, "Beiträge zur Kenntniss des Quartärs in den Pyrenäen" (A.f.A. xxxil. [1906], p. 299 ; xxxi1I. [1907], p. 244).
} 


\section{(iii) The Northern Ice-Centres}

The Northern glaciation was, however, of a rather different character. No doubt it began in the same way as the Alpine and the Pyrenean glaciations-the increase of snow-caps on the higher mountains, giving birth to ice-streams which flowed down the valleys. But these glaciers, instead of melting when they reached the plains, continued to flow in the shape of ice, and coalesced with other glaciers proceeding from other sources. In consequence, the final aspect of the glaciation of the northern countries was different from that of the central mountainous regions. In the latter the ice was confined to the valleys, the higher ridges standing up as icesheds; in the former the whole surface of the country was covered with an unbroken sheet of ice, above which nothing was exposed except the highest mountain-tops.

The glaciers of the Scandinavian mountains, flowing down to the coast, invaded the North Sea on the one side, the Baltic on the other. At first they entered these seas in the form of icebergs; but as the latter increased in number and in size, with the advance of the glaciation, they first congested and then completely covered the seas. with an unbroken ice-sheet, which at its maximum must have been several thousand feet in thickness. The ice of the North Sea impinged on the coast of Britain, there coalescing with the ice of the British glaciers. The ice of the Baltic crossed into Russia, covering the whole northern half of that country, and ended at the Ural mountains, which were themselves the centre of a minor glacial system.

It has not yet been found possible to establish with complete certainty any correlation between the phases of the Alpine glacial system and corresponding phases in the Northern ice-sheet. It is natural that the farther north we go the less should be the difference between glacial and interglacial conditions: and it is still a matter of dispute whether there was one glacial period or several in the Northern ice-field; geologists who have devoted their attention to this question are divided into two camps, sometimes labelled with the ugly hybrids "monoglacialists" and "polyglacialists." Complicated systems of moraines are to be seen in North Germany, Denmark, and Scandinavia; but it is disputed whether these represent stages in a single ice-retreat, or limits of successive ice-advances. Superposed layers of boulder-clay, with strata of other material interpolated, are to be observed in many places; but it is questioned whether these are the records of two successive glaciations, or of the change in the direction of flow of a single glacier. There is, however, very strong 
evidence for at least one extensive interglacial ice-retreat; and Geikie, from a study especially of the glacial phenomena in the British Islands, has indicated no less than six glacial periods with associated interglaciations. The first four of Geikie's list may correspond with the four great glaciations of the Alpine region, and the remaining two to two of the subsequent stadia; but in the present uncertainty this is not to be lightly assumed as anything more than a working hypothesis. The names which Geikie gives to his glacial and interglacial phases are as follows:

$\begin{array}{lc}\text { Glaciations } & \text { Interglaciations } \\ \text { Scanian } & \ldots \ldots \\ \ldots \ldots & \text { Norfolkian } \\ \text { Saxonian } & \ldots . . \\ \text { Polonian } & \text { Tyrolian } \\ \ldots \ldots & \text { Dürntenian } \\ \text { Mecklenburgian } & \ldots \ldots \\ \ldots \ldots & \text { Lower Forestian } \\ \text { Lower Turbarian } & \ldots \ldots \\ \ldots \ldots & \text { Upper Forestian } \\ \text { Upper Turbarian }{ }^{1} & \ldots .\end{array}$

The Northern ice-sheet thus extended, during the maximum of glaciation, from the Ural Mountains to beyond the present west coast of Ireland, covering North Russia, Scandinavia, Denmark, Germany southward to about the 5oth parallel of latitude, Holland, Belgium, and the whole of the British Islands with the exception of the part of England south of the valleys of the Thames and the Severn. Less extensive areas were covered during different phasesa term which we use here without intending to imply the interpolation of genial interglaciations. The map, Fig. I, shews at a glance the limits of the Northern ice-sheet at its maximum extent.

In the following table the facts regarding the history of the earth, briefly summarised in the foregoing. paragraphs, are set forth for convenience of reference: the succession of periods runs from the bottom of the table upwards. In using this table it must never be forgotten that there was no discontinuity between the successive stages; each shaded imperceptibly into its successor, as one colour

${ }^{1}$ For the history of the Ice Age, from a multiglacial point of view, the works of James Geikie may be consulted (Prehistoric Europe, London, I88I; The Great Ire Age and its Relation to the Antiquity of Man, $3 \mathrm{rd}$ edition, London, 1894; The Antiquity of Man in Europe, Edinburgh, 1914). A very convenient summary of the known facts regarding the Ice Age, written from a uniglacial standpoint, but with a fair statement of the opposing arguments, will be found in W. B. Wright, op. laud. 
shades into another in a spectrum. It will also be remembered that some authorities would count the earlier phases of the Ice Age to the Pliocene.

\begin{tabular}{|c|c|c|}
\hline Periods & Epochs & Characteristics \\
\hline $\begin{array}{l}\text { QUaternaRY or CaINo- } \\
\text { zoIC (second section) }\end{array}$ & $\begin{array}{l}\text { Holocene } \\
\text { Pleistocene } \\
\text { (Ice Age) }\end{array}$ & $\begin{array}{l}\text { The modern world } \\
\text { Daun stadium } \\
\text { Gschnitz stadium } \\
\text { Bühl stadium } \\
\text { Achen oscillation } \\
\text { Würm maximum restored } \\
\text { Laufen oscillation } \\
\text { Würm glaciation } \\
\text { Riss-Würm interglaciation } \\
\text { Riss glaciation } \\
\text { Mindel-Riss interglaciation } \\
\text { Mindel glaciation } \\
\Xi \begin{array}{l}\text { Münz-Mindel interglaciation } \\
\text { Gün } \\
\text { Günz glaciation }\end{array}\end{array}$ \\
\hline $\begin{array}{l}\text { TERTIARY or CAINOZOIC } \\
\text { (first section) }\end{array}$ & $\begin{array}{l}\text { Pliocene } \\
\text { Miocene } \\
\text { Oligocene } \\
\text { Eocene }\end{array}$ & $\begin{array}{l}\text { Mammals, gradually approxi- } \\
\text { mating to modern forms }\end{array}$ \\
\hline $\begin{array}{l}\text { SECONDARY or MesozoIC } \\
\text { PrimaRy or PaLAEOZOIC } \\
\text { ARCHAEAN or AzOIC }\end{array}$ & $\begin{array}{l}\text { various } \\
\text { various }\end{array}$ & $\begin{array}{l}\text { Deposition of sedimentary rocks } \\
\text { and early forms of life } \\
\text { No life }\end{array}$ \\
\hline
\end{tabular}

\section{B. Geotechnics: Land Oscillation}

When we find a bed of rock containing marine fossils on a mountain top, there is only one admissible explanation of the fact; the site, notwithstanding its present elevation, must at the time of the deposition of the rock have been sunk beneath the surface of the sea. Even the briefest experience of geological observation will be sure to bring to a student's attention some evidence of a former distribution of land and water different from that represented in our familiar modern maps.

Such a variation of the relationship between land and water must be due either to a rise and fall of the sea, or to a fall and rise of the land. There is one way in which the surface of the ocean could have been affected-the reservation of large stores of the world's watersupply in the glaciers and ice-sheets of which we have just been speaking, and the return of these immense quantities of water to the seas after the melting of the ice. This was certainly one cause of the oscillations referred to here. But otherwise there is no imaginable 
way in which the water of the sea can be increased or diminished in bulk to any perceptible extent, and therefore, in accordance with an elementary hydrostatic principle, it must retain its level constantly, the main area of water being continuous over the whole globe. The observed variations of land and water distribution must therefore have been due principally to alternate upheavals and depressions of the land. True, a subsidence of the ocean-bed would cause a recession of the sea from land that maintained a fixed distance from the earth's centre; this is, however, only a special case of landoscillation. As in the previous case, we pass over the question of the cause of these oscillations, which is a purely geological problem, outside our scope.

Land-oscillations supply an explanation of a fact that would otherwise be inexplicable - the existence of plants, and of animals unable to fly or to swim far, the existence even of Man himself, on islands now separated from the parent continents by wide expanses of ocean. Clearly, as the land rises, the shallows are one by. one rescued from the ocean; and when, as is often the case, there is a line of shallow water between the island and the continent, this will give place to a land-bridge, to use the technical term, after a sufficient emergence.

In the accompanying map, Fig. 3 , there is given a reconstruction of Europe at its maximum elevation, shewing the land-bridges uniting what are now islands with the mainland; as well as those which, by spanning the Mediterranean Sea, united the south coast of Europe with the north coast of Africa, making communication between the two continents as easy as modern communication between Europe and Asia.

The following are the leading points to be noted in this map. The Mediterranean becomes a pair of inland lakes, due to the filling up of the shallow channels between opposite headlands on its northern and southern shores. The Atlantic is many miles further out than it is now, beyond the west coasts of Spain, France, and Ireland. The English channel is dry land, Britain and Ireland being embedded far inland in a peninsula running northwards, beyond and including Iceland. The greater part of the North Sea is a plain, over which run the continuations of the Rhine and the other German rivers, emptying into the Arctic Ocean at a latitude north of that of Shetland. The Rhine receives in its course the tribute of the Thames, the Ouse, the Forth, and the other rivers of eastern Britain. What are now islands of the British archipelago appear as mountain-tops; what are now deep-sea bottoms are inland lakes. There is such a lake between Britain and Ireland, receiving the West British and the 
East Irish rivers, and itself drained by an imposing river that flows southward and westward, into which flow as tributaries the Severn, the Suir, the Blackwater; while the Somme and the Seine, as well

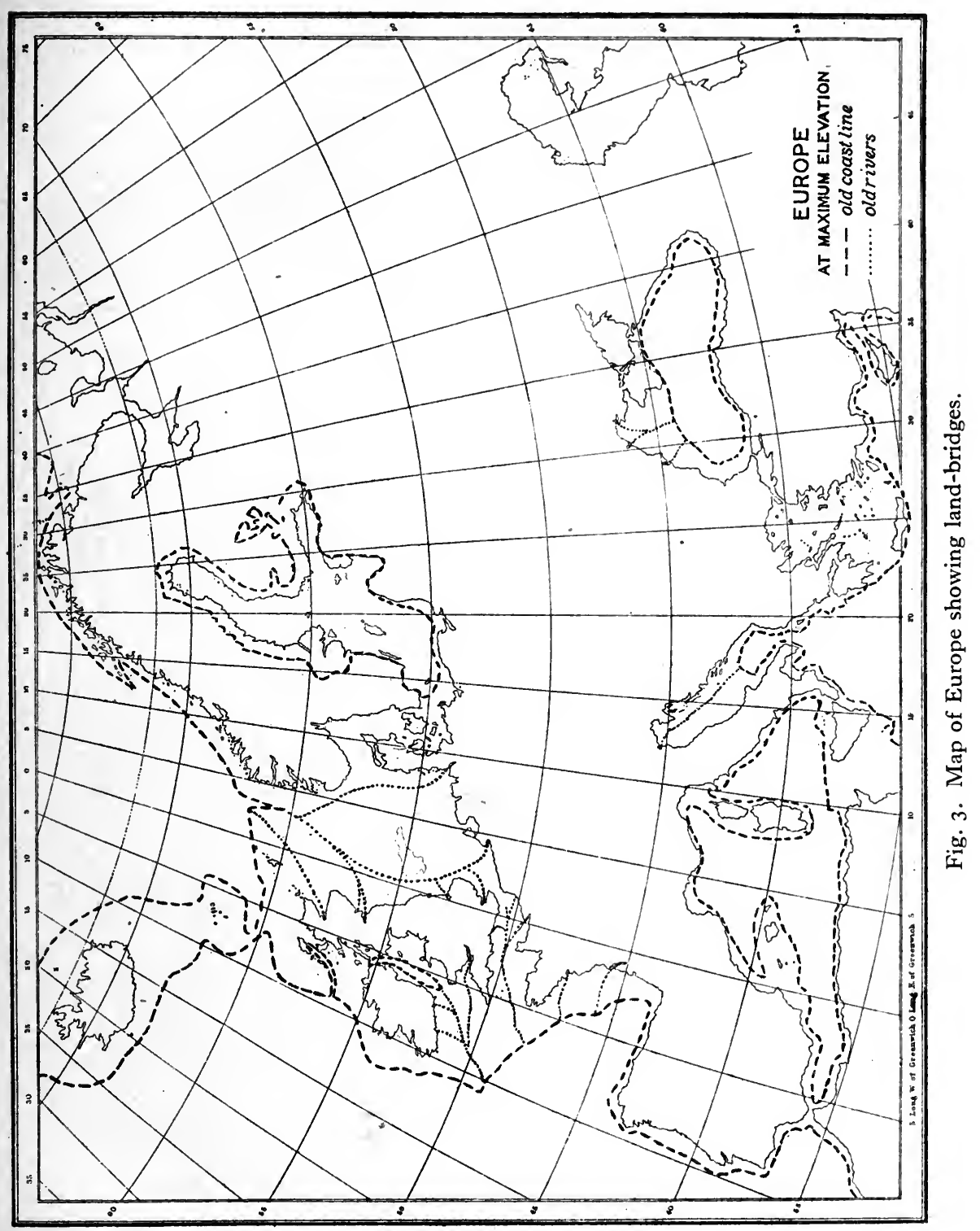

as the great English river of which the Solent is the only relic, are tributaries of another river draining the lands now covered by the English Channel. 
It is not to be understood, however, that this map necessarily represents the appearance of the Continent at any definite moment of geological time. It is rather a synthesis of all the many maps that would have to be drawn if we undertook to represent the whole complex history of the successive relations of land and water-a task which, it is hardly necessary to say, would be impossible. In other words, it is not to be supposed that the whole shelf of Europe rose vertically in a single mass, and then sank again, like the pillar of rock that rose from the crater of Mont Pelée after the eruption. It is more than probable that there were tilts, so that at any moment of time emergence in one region was to some extent compensated for by submergence in another. But to determine the relative chronology of emergence and submergence in different parts of the Continent is a task beyond our powers.

It is most likely that the interglaciations were periods of greater or less emergence. Especially was the genial phase which witnessed the first certain development of human industry, a time when we may presume an unbroken connexion between our Continent and Africa. But though elaborate maps have been constructed to represent the outline of Europe at different phases of the Ice Age, it is open to question whether a sufficient knowledge of this complex subject has been attained to justify their extreme definiteness ${ }^{1}$.

The evidence for land-oscillations in pre-glacial times, as has already been hinted, lies in the nature of the fossils embedded in the rocks of successive periods. The oscillations of post-glacial times are indicated by testimony of various kinds.

The gain of the sea is shewn by the fact that deep-sea dredging often brings to the surface the shells of molluscs belonging to species that cannot live except in shallow waters, or even between the tidemarks. In such cases, as there is no reason to assume a horizontal displacement of the deposits, we must postulate a vertical displacement, which has sunk the shells to a depth below that at which the mollusc could exist. Another indication of the encroachment of the sea is afforded by beds of submarine peat. Peat being a forest-growth (as explained on a later page), the presence of peat indicates the former existence of a forest on the site where it is found. As forests cannot grow under the sea, the place where submarine peat makes its appearance must have been at one time dry land. Sometimes the submerged remains of human industry indicate an encroachment of the sea on a region once occupied by man. A good example is at

'For such maps see Geikie's works, already cited. On the uncertainty attaching to solutions of these problems see W. B. Wright, op. laud. p. $363 \mathrm{f}$. 
Havre, where the remains of a settlement of the late Lower Palaeolithic exists, covered by the sea except at low tide ${ }^{1}$.

The gain of the land is best shewn by raised beaches. A raised beach. is a shelf of shore-accumulation, at a vertical height above sea-level unattainable by the highest modern tides. The presence of a raised beach is a proof that the sea once played on the land at the level where it is found, and that all the stretch between the raised beach and the actual beach has been gained from the sea by emergence. The diagram, Fig. 4, will make this clear.

The post-glacial oscillations of the land, which are of very considerable archaeological importance, have been studied with especial care in Northern Europe-chiefly in Scandinavia, to a less thorough degree in the British Islands. At the end of the period of domination

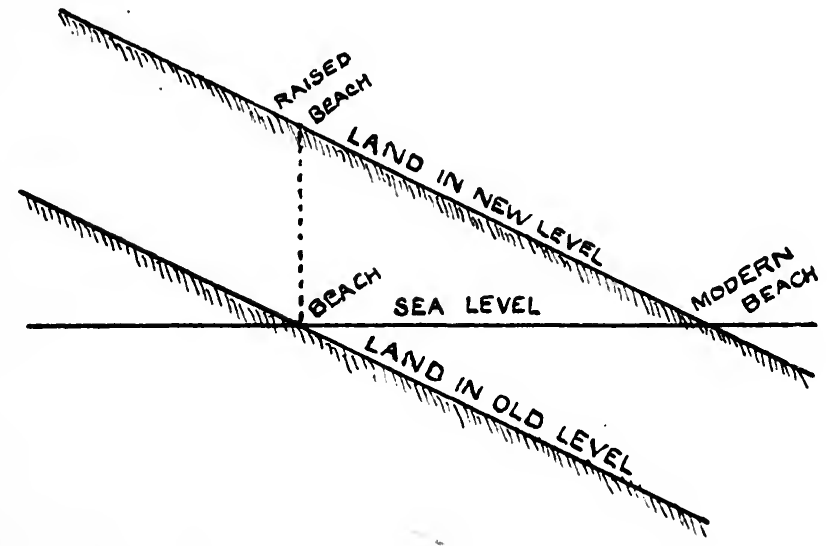

Fig. 4. Diagram illustrating formation of a raised beach.

of the great Northern ice-sheet the land was submerged to a considerable depth below its present level. This was a natural result of the enormous weight of ice which it was constrained to bear; but the melting of the ice did not witness an immediate recovery from the submergence. On the contrary, the sea at first gained on the land, presumably because the melting ice made such a vast addition to the free water in the ocean. When the ice ultimately retreated back to the Scandinavian valleys where it had first appeared, much of Denmark was under water, as also were Southern Sweden and Southern Norway. The isthmus which now connects Scandinavia with Russia, closing the north end of the Baltic Sea, was likewise

1 G. de Mortillet, "Station paléolithique sous-marine du Havre (Seine-Inférieure)" (B.S.A.P. ser. Iv. vol. v. [1894], p. 370). G. Romain, "La station paléolithique sous-marine dans la plage du Havre" (A.F.A.S. Havre [1914], p.6 6 1 ; also C.P.F. Beauvais [1909], p. 103, with a bibliography). 

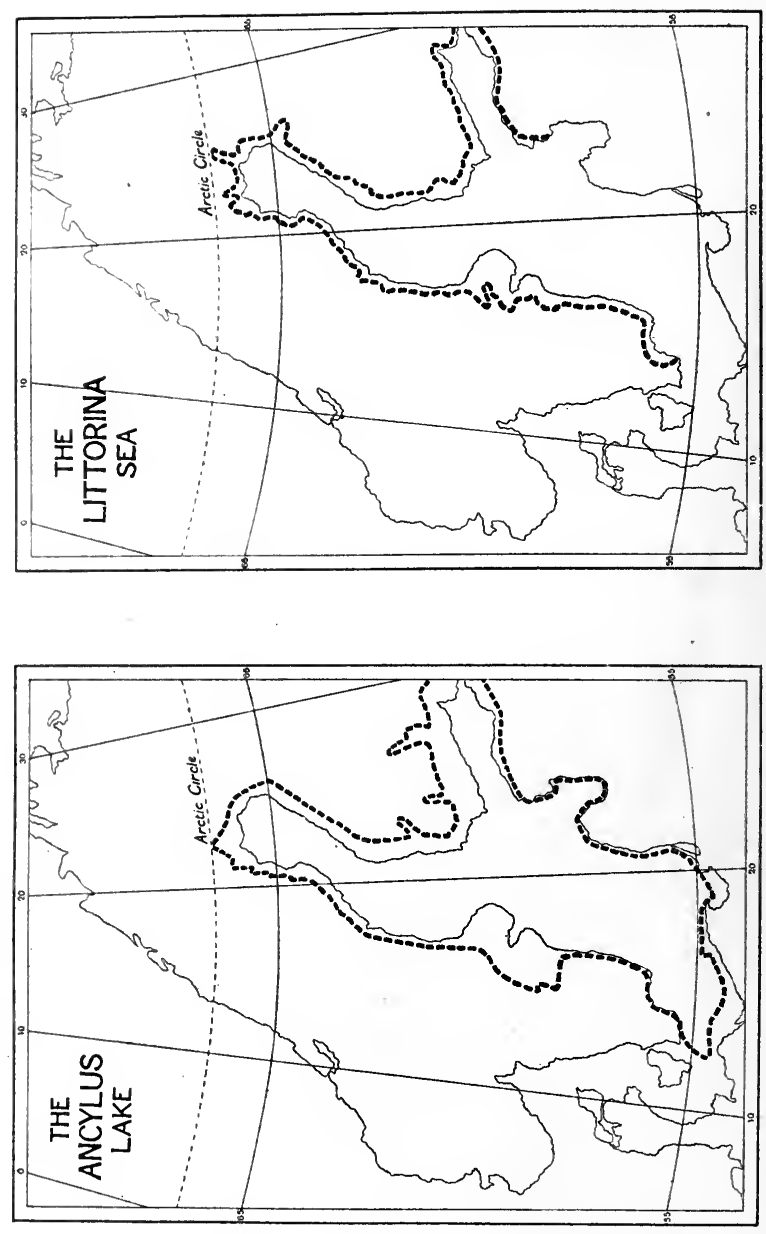

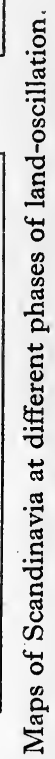

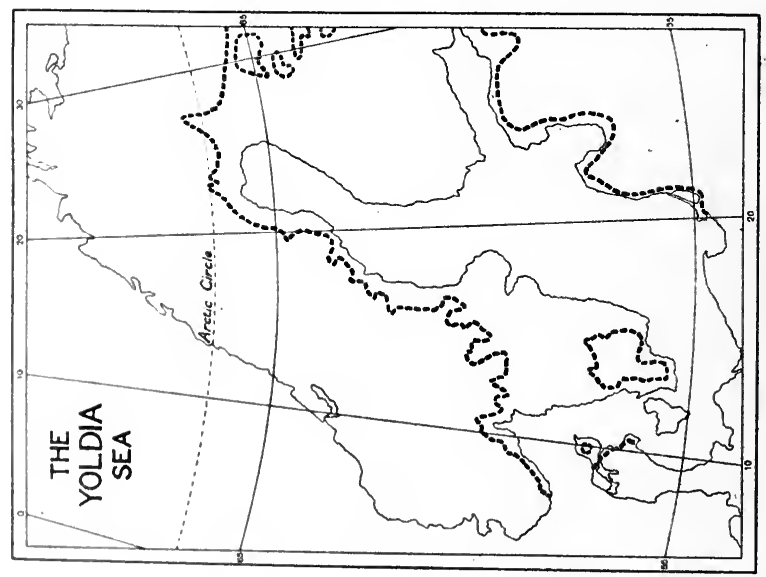


cut through by open water; Scandinavia, along with the Kola Peninsula, formed an island, with a sea to the south and east completely separating it from the mainland. This sea is called the Yoldia Sea, from the mollusc which is most characteristic of its deposits. The period of greatest submergence of the land, at the time of this sea, may be termed the Yoldia Minimum.

Following on the Yoldia Minimum, the land began once more to emerge. The record of this process has been read in the successive clays and gravels deposited along the shores of the Yoldia Sea at different stages of its retreat. Finally the land attained a maximum height considerably above its present level. What is now the Baltic Sea became completely closed at both ends, and was thus transformed into an inland sheet of fresh water. In the place of the Yoldia Sea there appeared the Ancylus Lake, likewise so-called from its chief mollusc. The time of greatest emergence in this oscillation may be called the Ancylus Maximum.

The movement of the land was once more reversed; having attained its maximum elevation it began to sink again. In this oscillation, however, the minimum was by no means so deeply sunk as in the first. The Baltic Sea became of much the same configuration as at present, but rather larger in extent and more salt; the name given to this stage of its history, once more derived from the name of its mollusc, is Littorina Sea. The greatest depression of this phase of land-movement may be called the Littorina Minimum. The Littorina period is also known as the Tapes period.

An intermediate stage between the Littorina Minimum and the present conditions is the Mya period. With each of these later phases of land-oscillation is associated a stage of human culture, as we shall see in the sequel.

With very considerable probability we may correlate these Baltic land-movements with the much less extensive land-movements testified to by the British system of raised beaches. Of these there are three of outstanding importance. The first, at about 100 feet above sea-level, and therefore usually spoken of as the roo-feet beach, runs along a great part of the coast of Scotland. This beach probably belongs to the Yoldia Minimum. Another raised beach, at the level of 50 feet, probably marks a stage in the elevation of the land on its way from the Yoldia Minimum to the Ancylus Maximum. The submarine forests of Norfolk and elsewhere may be reasonably regarded as British monuments of the latter stage.

Corresponding to the Littorina Minimum is a third raised beach, at about 25 to 35 feet above the present sea-level. The oldest remains of human occupation in Scotland and in Ireland have been found in 
association with this 25 -feet beach. It is not, like the 50 -feet beach, to be regarded as a stage in the elevation from the Yoldia Minimum; we are forbidden to do so by the relation between its deposits and the forest-peat. Where peat is found in association with the roo-feet and with the $5^{\circ}$-feet beach it overlies them, shewing that it is a later formation; but the contrary is the case when it is found along with the 25 -feet beach.

After the Littorina Minimum the land again rose to its present elevation, passing through the Mya stage on the way.

\section{River Erosion}

Some of the oldest remains of human industry known have been found in river-gravels; and it now becomes necessary to say a few words about the formation of those deposits.

Every river is constantly carrying down material from the upper part of its bed, and transferring it seawards. The swifter the river, other things being equal, the greater will be its carrying power; it is the common experience that when a river is in spate, owing to heavy rains or to melting mountain snows, it is turbid, although in ordinary times it may be quite clear; and frequently the sea is stained, for some distance outside the river mouth, by the mud carried down by the stream. Thus the river-bed is continually being deepened. The imposing cañons of Arizona are the most striking examples of fluviatile erosion to be seen in the world, but any mountain stream will illustrate it to some extent.

There is, however, a limit below which the erosion cannot be carried, depending upon the size and swiftness of the river, and its relation to the level of the sea. This limit is known as the base-level. When the river reaches its base-level, it begins to deposit the detritus, carried down from the upper reaches, on the bed of the lower stages of its course; the accumulation of silt gradually creeping backwards from the mouth. If an oscillation of the land should produce a depression of the region containing the river-bed, the accumulation of detritus will naturally be greatly increased, as a new base-level will be formed as many feet (other things being equal) above the old base-level as the land has sunk.

If on the other hand the land should rise, the base-level will be correspondingly lowered. The process of erosion will begin again. 'The river will now cut a channel through the deposits which it has already made. Since there is as a rule a greater body of water in the middle of the stream, the erosion will proceed faster in the middle; and there will be a tendency for lines of the old accumulation to be left in the form of terraces along the sides of the river valley. These 
terraces may be disturbed by later floods, such as would result from the melting of a glacier, but otherwise they will remain to mark a stage in the history of the river. The river will continue to wear its way down to the base-level of its new position, and the process of re-deposition will thereafter begin afresh. The process may be repeated with later oscillations; or if this does not take place, the accumulation of silt will continue till it reaches a stage at which further deposition would block the stream. A fresh channel will then be cut through the middle of the silt accumulated,. and this process will continue indefinitely, never coming to complete equilibrium.

The climate in Tertiary and early Quaternary times was on the whole moister than it is at the present time. The mountains were higher, not having been subjected to the full amount of attrition which they suffered in the Ice Age; and therefore the rivers fed by the rains and the snows on the much greater catchment-areas which they presented, were larger and more powerful than their modern representatives. Their wearing and carrying powers were alike greater. The rivers in the regions with which we are concerned in this volume carried and deposited gravel, detached from the rocky beds over which they or their tributaries flowed. The attenuated modern rivers which flow in the place of these mighty ancient torrents carry a burden little heavier than mud. In consequence we find an accumulation of alluvium or silt overlying the ancient gravels, especially on the lower terraces. Silt is also washed down the sides of the valley by rain, and therefore the whole series of gravel terraces are usually covered from view, and have to be revealed by excavation.

The river terraces of the Somme and of the Thames have proved of especial importance for the history of early man in Europe, and we shall have to pay attention to them on a later page. In the meanwhile it will suffice to say that the uppermost gravels are naturally the earliest to be deposited; and that the alluvium covering the gravels dates from the Neolithic period onward. The implements embedded in the deposits accord with this dating; but it is not amiss to remark, even at this early stage of our study, that there are three ways in which implements may become associated with river gravels. (r) They may be the relics of communities established on the river banks, living actually upon the ancient gravels. In such cases the implements will lie in a stratum upon the surface of the gravels, and the edges of the flakes and the ridges between flaked surfaces will be sharp, not having been subjected to water-rolling. (2) They may have been carried down by floods as part of the gravels containing them, from the site of the settlement of their owners. 
In such cases they will be found scattered irregularly through the gravels, and the edges and ridges will shew signs of attrition or water-rolling. (3) They may have been similarly carried by floods, but from more ancient gravels, not directly from the flint-workers' settlement. In such cases the attrition will be further advanced, and the implements will belong to types of more ancient facies than those which properly belong to the terrace in which they are found. It is however not always easy to distinguish between innate implemenits and derived implements, as deposits of class (2) and class (3) are respectively called.

\section{The Formation of Caves}

Some of the most important remains that we are to study in the present volume have been found in caves. These-are the earliest abodes of humanity which we are able to examine; it may be well, therefore, to say a word or two about their formation. Caves are excavated by the action of water, in rocks, such as limestone, the constituents of which are easily soluble. This water action is both chemical and mechanical-chemical, in dissolving the materials, and mechanical in eroding the rock-surface and in carrying away the matter dissolved or dislodged. The water may have been rain-water, percolating through the rock; a river, or the underflow of a glacier, finding a channel for itself in a rock-fissure; or the hammering waves of the sea.

Caves are of every possible variety of size, and have an infinite variety of plan. The latter depends on the constitution of the rock, on the presence or absence of planes of stratification, cleavage, or faulting - all of which offer vulnerable points of attack for the water -and on the exact nature and force of the excavating agent. Some caves are mere corridors, straight or tortuous; others are labyrinthine groups of chambers, sometimes of immense extent, united often by scarcely passable creep-passages. They may be in any number of levels-it is sometimes next to impossible to draw an intelligible plan of a cave, owing to the maze of lines produced by the vertical superposition of irregular chambers-and the passages may run at any slope from horizontality to verticality, thus often adding greatly to the dangers of exploration.

Let us imagine ourselves excavating the floor' of a cave where early man has established himself. There will as a rule be found to be a bed of stratified accumulation covering the rock-surface, each layer corresponding to a stage in the history of the cave. Naturally, any given cave may have had peculiarities in its history, producing a corresponding modification in the deposits; but the average cave 
will be found to yield material arranged in some such fashion as the following. Over the rock-surface there may be a bed of silt, washed in, perhaps, by the Tertiary water-course which excavated the cave. This silt will not be likely to contain anything noteworthy for our purpose-certainly no relic of man, though it may have a bone or two of some Tertiary mammal which will give us a welcome indication of date. Above the silt there may be a small bed of loam, washed into the cave from the surface of the earth above, by water dripping through cracks in the roof. Then there will come an accumulation of soil, mingled with bones-the bones of savage carnivora which found a home in the cave. Among them will be the bones of smaller animals dragged in and devoured by the bears and hyaenas, the marks of whose teeth will be clearly visible on the remains of their victims. On the wall of the cave may sometimes be noted the traces of the scratching of the claws of the cave bear. Next we begin to find Man disputing with the beasts for the possession of a shelter so desirable. His resourcefulness is pitted against their strength; mind conquers matter, and Man prevails. In the upper strata will be found his tools, his hearths, and his kitchen refuse, amid the piles of which disagreeable material he lives with as complete unconcern as does the modern savage. With luck we may light upon a skull or a skeleton, which will add something to our gradually growing knowledge of the physical constitution of the Palaeolithic people-the skeleton, perhaps, of someone buried by his surviving friends in the floor of his cave-dwelling, or else of some unfortunate who had been crushed in his sleep by a mass of rock falling from the roof. The beds of human accumulation may themselves be laid in a number of different strata, between which may be interpolated layers of loam, animal refuse, silt, stalagmite, or other sterile material (i.e. material containing no objects of antiquity). These successive strata will illustrate, by the number and variety of the implements which they contain, the gradual evolution of civilisation. Above the archaeological beds there may be an accumulation of material which has collected after the abandonment of the cave as a place of habitation-more loam, perhaps, and above all a layer of stalagmite, sealing up the whole accumulation. Stalagmite is the floor-accumulation corresponding to, and identical in composition with, the pendant festoons of stalactite hanging from the cave roof. Both are deposits of carbonate of lime, held in solution by water trickling through the cave roof, and gradually deposited as the water falls drop by drop. The growth of stalactite and stalagmite is as a rule very slow-in Kent's Hole near Torquay a visitor's graffito, dated I688, is now covered with a layer of stalagmite not thicker than a thin 
sheet of paper-and nothing testifies more eloquently to the great antiquity of the underlying remains than a thick bed of this material spread over them. But where the climate is damp, and the water finds free access to the cave, the accumulation of stalagmite proceeds much more rapidly. Thus, in the moist county of Galway, the artificial underground chambers that abound in the prehistoric forts and other dwellings which are there so common are thickly covered with stalagmite on their walls and floors, although they cannot be of very remote antiquity.

Attempts have been made to estimate the antiquity of buried remains by the thickness of the stalagmite covering them, but the results of such calculations are untrustworthy. We cannot assume a uniform rate of dissolution and precipitation, or of percolation; and small errors of measurement multiply into thousands of years, when we start from a thin sheet such as the Kent's Hole example just quoted. Moreover we are not entitled to suppose that the climate has been equally damp at all stages of the history of the growth of the stalagmite. Least of all can we rely upon estimates of the antiquity of stalagmite-covered remains in one cave, on the basis of calculations of the rate of the accumulation in another.

In the following pages we shall have frequent occasion to set forth the details of the stratification of actual examples of cavedeposits and other archaeological accumulations. In drawing up such tables a uniform system will be adopted. The strata will be lettered in order, $A$ denoting the lowest layer, which is almost invariably the oldest ${ }^{1}$; the remaining strata being lettered $B, C, D$, and so on. Their descriptions will be set forth on the printed page in the same order as they themselves occur on the site, the lowest being at the bottom. Thus the ideal cave accumulation, described in the foregoing pages, would be represented in the following form:

G. Stalagmite.

$F$. Loam.

E. Stratified beds of archaeological deposit (each stratum enumerated separately).

$D$. Beds of deposit with bones of animals.

C. Loam.

B. River-gravel.

A. Rock of cave floor.

1 In a few cases there has taken piace a re-sorting, or as the French archaeologists call it, a remaniement: a disturbance of the soil, due either to human or to natural agencies, which has upset the original stratification. 


\section{Peat}

Peat is a formation of considerable archaeological importance. We have already seen, in the preceding chapter, that the remains found in the successive layers of the Danish peat-mosses proved of great service in the investigations that resulted in the establishment of the principle of the "Three Ages." The tannin and the gallic acid which enter into the composition of peat give it a powerful antiseptic property, owing to which antiquities of wood and of other perishable materials are often preserved intact, when they have had the good fortune to become embedded in a deposit of this material. The formation of peat is due to the fall and decay of forest trees in marshy soil. Mosses grow on the fallen trunks, and in time these also decay and partially decompose with the trunks on which they found a lodgment. The peat is the residuum remaining from this decomposition. We have already called attention, in the preceding chapter, to the necessity of identifying the species of tree associated with antiquities buried in peat; many chronological problems depend on such observations for their solution.

\section{Geognosy}

Geognosy is that branch of geology which treats of the several elements of which the earth is composed. We are here concerned only with such of those elements as afforded material for the handiworks of early Man; and for the present need notice only such of these as were used during the Stone Age. Of the materials used by Man during that phase of civilisation, by far the most important is Flint.

\section{Flint}

Flint is a lustrous, translucent substance, consisting almost entirely of silica, found embedded in chalk cliffs. Its natural colour (as contrasted with its patina, of which we shall speak presently) ranges from almost perfect black to a light brown or whitish grey. It seems to have been formed, in the first instance, by organic agency-the silica having been abstracted by living organisms from the waters of the sea under which the chalk beds were laid down, and then redeposited in the form of nodules. These nodules range in size from minute particles up to lumps a yard or more in diameter, and they are of every possible variety of shape, or, rather, of shapelessness. They lie in the chalk bed in layers, which, though they often correspond to the bedding-planes of the chalk, are not infrequently tilted at an angle to them, shewing that their formation did not take place concurrently with the deposition of the chalk. While we may say 
generally that the silica of which the nodules consist was derived from diatoms, sponges, and other lowly forms of life, dissolved and very gradually re-formed in fissures in the chalk bed, it should be noticed that the details of the geological history of flint present some difficult problems, for a discussion of which we must refer the reader to a text-book of Geology, as it would here be out of place.

Flint is very hard-harder than steel-and it possesses in a higher degree than any other stone the property that when struck with a sharp blow it breaks with a conchoidal fracture, whose surface is of glass-like smoothness. When the points upon which to strike are selected with judgment, and the blows delivered with skill, a sharp cutting edge is produced, between two adjacent planes of fracture. In consequence, flint became the chief material for the manufacture of cutting tools before the discovery of methods of metal-working. It is an almost invariable rule that when flint is to be had at all, either in local deposits or brought in by importation from some accessible region, it is the chief material for stone tools. A remarkable exception to this rule is the station of La Vignette (Seine-et-Marne), where a number of tools of sandstone, of unusual form, were found, and scarcely any worked flint, although flint is abundant in the neighbourhood. The shapes of the tools were evidently dictated by the difficulty of working the sandstone ${ }^{1}$.

Heat, light, damp, or carbonic acid, acting on the surface of a flint, burn out its natural colouring matter to a greater or less extent, leaving the surface pitted with microscopic hollows. If the flint should continue to lie exposed to the air, it will assume a poreelainlike white skin, to which the name cacholong has been given. But if it should be buried, it will derive a new colour from the soil with which it happens to be in contact-reddish-yellow from the oxide of iron, black from manganese, and so on. The resulting tint of the stone will thus vary considerably, depending as it does on the chemical nature of the surrounding soil. This new colour, called the patina, will sometimes penetrate beneath the surface of the stone to a depth of as much as an eighth of an inch ${ }^{2}$.

The mere collector puts an absurd value upon highly patinated specimens, merely because they have a pleasing appearance-just as the same person gives ridiculously inflated sums of money, thus

1 L. Capitan, "La station de La Vignette" (R.E.A. vir. [1897], p. 208), where illustrations of the tools will be found. See also Emile Collin, Reynier, and Fouju, "La station de La Vignette" (B.S.A.P. ser. Iv. vol. viII. [1897], p. 420).

"See A. Rutot, "Sur l'origine de la patine des silex" (B.S.A.B. vol. v. [1886], p. 376); W. Allen Sturge, "The Patina of Flint Implements" (Proceedings Prehistoric Society of East Anglia, vol. I. [1912], p. 160). See also a discussion on patina by Prof. Sollas, F.A.I. vol. XLIII. [1913], p. 353 . 
encouraging the native tomb-robber in centres of ancient civilisation, for glass which has decomposed and has in consequence assumed pretty iridescent colours. But patina is sometimes of scientific value to the archaeologist. It may be a useful test of the genuineness of a doubtful specimen; or it may help to expose a case of the fraud of "salting"-for if flints from elsewhere be introduced into a site under examination, for the sake of mischief, or of filthy lucre, the patina of the interloper may betray the trick by the contrast between itself and that of the genuine local products. It is also the chief, if not the only certain indication of a re-worked flint. If a flint tool have lain long enough in a soil to acquire a patina; and then if it should happen to have been picked up by a stone-age man of a
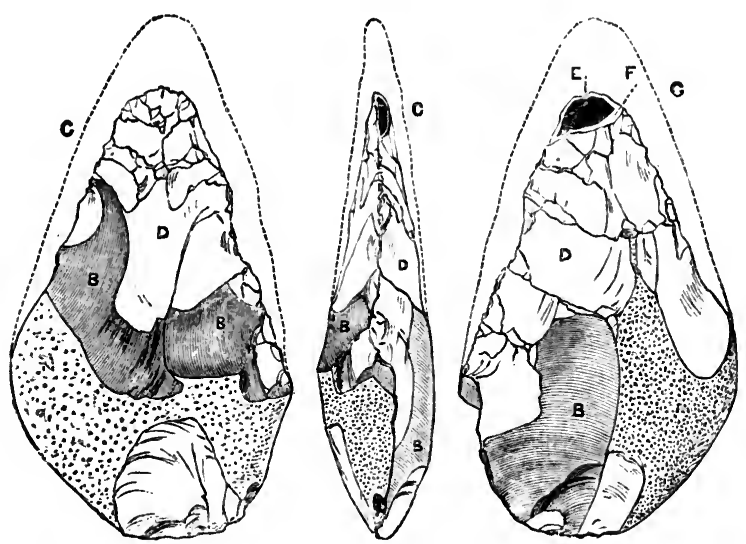

Fig. 6. Flint implement shewing double patination.

(The calcareous surface of the original nodule is represented by the dotted areas at the butt of the implement. The dotted outline, $C$, represents the probable shape of the implement before retouching. The dark flaked surfaces, lettered $B$, denote the original working; this has been stained brown by contact with the drift gravel where the flint lay embedded. The lighter-shaded flaking marked $D$ is later; and the extent to which it has been coloured is shown at the tip, where there is a recent fracture, $E$. The shaded part, $E$, shews the natural colour of the flint; the unshaded part $F$ indicated the depth of the secondary patination.) From W. G. Smith, Man, the Primeval Savage.

later generation and re-trimmed to serve his purposes; and then once more become lost and'buried-the chances are that the soil in which it will find its second resting-place will not be quite identical in composition with that in which it lay buried at the first. The second set of chips will therefore be patinated with a different colour from the first set. Fig. 6 represents a good example of this, from Kempston, Bedfordshire, now in the British Museum. 


\section{Chert}

Chert is a siliceous concretion similar to flint, but coarser, and less homogeneous in texture; it contains a certain proportion of calcareous impurities in its composition. It is as a rule of a brown or greyish-black colour. As flint is found in cretaceous limestone (chalk), so chert appears principally, though not exclusively, in carboniferous limestone. Chert is often used as a substitute for flint, when the latter material is not to be obtained; but it is not possible in this stone to attain the highest excellence of implements in true flint.

\section{Obsidian}

Obsidian is also a silicate, but is produced in a different way. It is a natural glass, resulting from the quick cooling of the lava-flow of a volcano. Obsidian therefore cannot be found except in the neighbourhood of volcanoes, active or extinct; and implements made of this material discovered elsewhere must necessarily have been artificially introduced. In such wanderings of stones, having a limited range of natural distribution, we may often read the fragmentary record of the wanderings of peoples, or at least of their commercial relations and of the routes of their trading caravans.

Obsidian implements resemble those of flint, from which they can be distinguished by the beautiful glossy (usually black) surface of the material. It does not alter its colour by patination; in appearance it resembles a fractured surface of the black glass of a winebottle.

\section{Fade}

Jade is a general term popularly applied to two distinct classes of mineral, properly called jadeite and nephrite respectively. These stones are capable of taking a high polish, and they were evidently much prized in Neolithic times; they supply the material for highly finished polished stone axe-heads, which were most probably used for ceremonial purposes. It is possible, moreover, that these stones were valued on account of supposed curative virtues with which they were credited; survivals of such beliefs are still to be met with, especially in China. Nephrite, which is chemically a calciummagnesium silicate, is coloured with various tints of green, ranging from yellow to grey. Jadeite is an aluminium-sodium silicate, containing chromium, the effect of which is to diversify its pale colour with bright green patches. Chloromelanite and Fibrolite are varieties of Jadeite, which were also used for ornamental axe-heads and other objects during the Neolithic period.

It was for long supposed that these stones were not native to 
Europe, and that their presence in the form of artificially-worked objects was (like the obsidian just mentioned) an indication of a far-extended trade during the Neolithic period. China is the chief modern source of supply, and it was even suggested that the Neolithic Europeans drew their jades from that distant country. However the discovery of native nephrite in Silesia and of jadeite in the Alps has rendered these inferences untenable, or at least unjustifiable.

\section{Other Stones}

Other stones have been used by stone-age man for the manufacture of implements. Basalt, syenite, granite, porphyry, hornblende, sandstone, and other varieties are all worked on occasion into implements, when flint is unobtainable. In fact, we may say generally, that any hard stone that presented itself to the artificer was pressed into his service.

\section{Amber}

Amber is a material of great importance for the history of European civilisation. It is a fossil resin, found chiefly in Lower Oligocene strata, but traceable also in Eocene as well as in later layers. Amber is principally collected on the southern coast of the Baltic Sea, especially the coasts of Eastern Prussia in the neighbourhood of Königsberg. It is also found on the east coast of England, principally at Cromer, washed up from submarine forest deposits in the North Sea; and in greater or less quantities in Holland, Denmark, Sweden, Russia, Germany, Switzerland, Italy, and Sicily. These different ambers differ to a certain extent from one another in chemical constitution, and it is not certain that any of the sources of supply other than the Baltic was worked in ancient times.

For two reasons amber was much prized in antiquity. Its beauty was one of these, but probably the less important. Its remarkable magneto-electric properties were observed from an early date, and this uncanny and inexplicable character invested it with a supernatural halo. It was therefore a material much in request for making amulets. A considerable importance has been attached to the amber-trade between the Mediterranean and the north as the route whereby the civilisations of southern Europe influenced the barbarous tribes of the interior of the Continent.

\section{fet}

Jet possesses the same properties as amber, though to a less marked degree. It is not so attractive aesthetically as amber, but was nevertheless much used for beads and other ornaments during the Neolithic and Bronze Ages. Jet is a fossilised coniferous wood, 
which has most probably been washed to sea by a river; after it had become impregnated with the salt water it sank, and became embedded in a deposit of fine mud which ultimately became compressed and hardened into a kind of shale. Yorkshire, especially Whitby, is an important source of this material, but it is also found in Spain, and elsewhere.

\section{Geography}

Before proceeding to the next division of our subject, we must note in a few words a point of considerable importance.

It is impossible to study the Archaeology of Europe as an undivided whole. The area is so great, that there are inevitably local peculiarities which break the uniformity of development; these depend on a complication of local conditions. It therefore becomes necessary to divide the area of the Continent into regions, in order that these may be separately studied. On the other hand, we cannot with profit study the Archaeology of one region alone. The civilisations of different regions have influenced each other to such an extent, that the antiquities of one region are almost unintelligible, until they are set in the light of another. We must not echo the words of a Belgian geologist, who said, in combating some conclusions reached by his French brethren, nous n'avons pas à nous occuper de ce qui se passe dans les pays voisins. Quite the contrary; indeed, we must consider not only les pays voisins, but those which are many hundreds of miles away. The enthusiasm which has been shewn during the past century for the study in Ireland of the native antiquities has not borne fruit of a proportionate scientific value, from a neglect of this principle.

But how are we to divide the Continent? Obviously the modern territorial divisions will not serve our purpose-they would, indeed, be almost worse than useless. In the first place, as the disastrous war through which we have recently passed is enough to shew, they are not permanent. In the second place, they cut across all natural archaeological boundaries. The only admissible scheme of division is one depending on natural barriers - seas, rivers, mountains, and isothermal lines, all of which influenced to a greater or less extent the movements of peoples.

Accordingly, for the purposes of this book, we divide the Continent unto four zones, each subdivided into regions. Three of the zones are latitudinal; the fourth-the greater part of Russia-is longitudinal. It would be natural for a person looking at a modern map to ask why Russia should be included at all. It seems rather to be an eastward extension of the mass of the continent of Asia, and to 
be more properly included in a study of the archaeology of that division of the globe. This would, however, be an error. At the beginnings of the colonisation of Europe, Russia was much more definitely European, and was cut off by a barrier from Asia. The three lakes, the Caspian Sea, the Sea of Aral, and Lake Balkash, are the comparatively insignificant relics of a once vast inland sea, which certainly extended as far north as Kazan, and not improbably communicated with the North Sea. This barrier, coupled with the ice of the North European glacial system, shut off access to Russia from Asia except through the passes of the Caucasus, while on the European side the communication was free and open.

\section{The Archaeological Regions of Europe}

The following is a list of the zones into which we divide the Continent, with their subordinate regions:

I. Mediterranean Zone. All south of lat. $46^{\circ} \mathrm{N}$.

I. Crete and the Aegean Sea.

2. The Balkan Peninsula.

3. Italy and Sicily.

4. The Islands between Italy and Spain, including Malta.

5. Southern France and Liguria.

6. The Iberian Peninsula.

II. Central Zone. From lat. $46^{\circ}$ N. to lat. $55^{\circ}$ N., excluding Britain.

7. From long. $6^{\circ} \mathrm{W}$. to long. $6^{\circ} \mathrm{E}$. West of the Rhine-France, Belgium, Holland.

8. From long. $6^{\circ} \mathrm{E}$. to long. $15^{\circ} \mathrm{E}$. East of the Rhine, northern half-the plain of Germany.

9. From long. $6^{\circ} \mathrm{E}$. to long $15^{\circ} \mathrm{E}$. East of the Rhine, southern half-the Alpine region.

ro. From long. $15^{\circ}$ E. to long. $30^{\circ}$ E.-Austria and Eastern Russia.

III. Northern Zone.

I I. South Britain.

I2. North Britain.

13. Ireland.

14. Denmark.

I5. Scandinavia.

I6. Iceland.

IV. Eastern Zone.

17. Russia notth of lat. $55^{\circ} \mathrm{N}$.

I8. Russia south of lat. $55^{\circ} \mathrm{N}$.

These regions are by no means of equal archaeological importance, and some of them, so far as the present volume is concerned, will not need to be mentioned again. The following details will give the reader a bird's-eye view of the extent of the Palaeolithic and the 
Mesolithic periods and their remains in Europe, so far as is at present known. For his convenience in reading these particulars we may anticipate the subject-matter of later chapters so far as to note that the Palaeolithic age is divided into three terms, called respectively the Lower, Middle, and Upper Palaeolithic; and that the first and third of these are further divided into stages; those of the Lower Palaeolithic are the Pre-Chellean, Chellean, and Acheulean; those of the Upper Palaeolithic are the Aurignacian, Solutrean and Magdalenian.

I. Crete and the Aegean. No Palaeolithic remains are known. They probably exist, but, perhaps owing to preoccupations induced by the paramount importance and interest of the later phases of civilisation in this region, they have not been successfully looked for.

2. The Balkan Peninsula. No Palaeolithic remains known. The, same remark applies to this region as to the last, so far as Greece is concerned. The rest of the Balkan region is archaeologically almost an untilled field, except in a few centres.

3. Italy and Sicily. Palaeolithic remains of all stages except Solutrean and Magdalenian are found in Italy. In Sicily Palaeolithic remains are scanty and doubtful. Some rude chips which have been figured ${ }^{1}$ can hardly be made to bear the strain of far-reaching deductions.

4. The Islands between Italy and Spain. Palaeolithic unknown or doubtful.

5. Southern France and Liguria. Auvergne, having been for the greater part covered with quaternary glaciers, is poor in Palaeolithic remains. The region is, however, on the whole of great importance; it borders on the famous sites of Dordogne, and it also includes the caves of Mentone.

6. The Iberian Peninsula. Spain is rapidly becoming one of the most important countries in the world for the student of Palaeolithic remains. Discoveries of the first rank have in recent years been made there in rapid succession. All stages of the Palaeolithic period are well represented.

7. Northern France, Belgium, and Holland. This region shares with Spain the front rank among countries important for Palaeolithic remains. All stages are well represented.

8. Northern Germany. Remains of Palaeolithic Man are not common in Northern Germany, doubtless owing to the obstacles which the glaciation of this region put in the way of colonisation.

9. The Alpine Region. The Lower Palaeolithic is completely absent in Switzerland, but Magdalenian settlements are not un-

${ }^{1}$ L'Anthr. virr. [I897], I3I. 
common, and some of them are of great importance. Lower and Middle Palaeolithic sites are likewise rare in Bavaria and Württemberg, though the latter province has yielded important Upper Palaeolithic remains.

10. Austria and Eastern Russia. The Löss of Austria has yielded much of great importance, especially for the earlier stages of the Upper Palaeolithic. Croatia, which just falls south of the limit of this region, but which must be reckoned to it, is of great importance because it contains the site of Krapina; as is Moravia, on account of the deposits at Prredmost. Hungary is on the whole poor in Palaeolithic remains, and the entire region has but little belonging to the Lower Palaeolithic.

II. South Britain. The Palaeolithic period well represented (except the Solutrean stage), especially in the southern counties, which were outside the domination of the ice.

12. North Britain. Uninhabitable until Mesolithic times. No Palaeolithic remains anywhere.

13. Ireland. Ditto.

14. Denmark. Ditto.

15. Scandinavia. Ditto.

I6. Iceland. Unknown till the ninth century A.D.; no traces of earlier occupations.

17. Northern Russia. No trace of Palaeolithic Man.

18. Southern Russia. No Lower Palaeolithic remains anywhere. Ukrania has yielded flint implements, as well as the governments of Podolia, Poltava, and Wironetz.

This apparent inequality of distribution is due to two causes. First, an actual inequality, caused by the covering of so much of the continent with ice during the Pleistocene period; and secondly, an inequality of study. Certain regions have been explored much more carefully than others; and the discoveries of the future may bring into prominence regions which are as yet insignificant.

In the chapters devoted to the different stages of the Palaeolithic Age, the outlines here sketched will be filled in with greater detail. 


\section{CHAPTER III}

\section{PALAEONTOLOGICAL PROLEGOMENA}

\section{Origin and Nature of Life}

We now pass from the history of the earth itself, and of what we may describe as its preparation as a stage for the enactment of the human drama, to a consideration of the living creatures with which it is peopled. The present chapter is concerned with Palaeontology, the science which relates to the living "beings" that were in existence of "old."

We all know what "Life" is-or, to speak more accurately, we all know by observation and experience something of its manifestations. It is a property shared by the most highly developed animal and by the most rudimentary vegetable. But no one has ever found it possible to formulate a satisfactory definition of "Life"; we cannot express its nature in words, except by contrast with death, or with the absence of life. We can say that Mount Everest is inanimate, a microbe animate; we can say that the man passing our window is alive, and that Queen Anne is dead. But we cannot tell what is the nature of the essential character on which these contrasts depend.

We have seen that Science has no answer to the question of the ultimate origin of the matter of which the earth and its related bodies are formed. The ultimate origin of Life is equally beyond the ken of Science. We know that the man whom we have just seen derived his life from his parents, they in their turn from theirs, and so back through millions and millions of years till we reach the delicate protoplasmal speck of animate jelly that theoretically heads the genealogy of every living creature. But how was that quickened? Such a question leaves us knocking at the mystic door of the Sanctum Sanctorum.

It has often been suggested that a meteor may have brought Life to the earth. This theory is in the first place extremely improbable, for if such an event happened once in the history of the world there is no apparent reason why it should not still continue to happen; and the incandescent condition of a meteor rushing through the atmosphere is not favourable to the said meteor's suitability as a vehicle of life, even if the life which it carried could have survived its previous flight through the cold of space. In the second place the theory is obviously a mere evasion of the real difficulty, like the 
collision theory of the origin of the matter of the Solar System. For from what secret reservoir did the supposed meteoric visitor derive the life which it brought to our earth? Where are we to look for a world in which the balance of natural conditions is so exactly identical with that in our earth, that living matter can be transferred suddenly from the one to the other, and yet can flourish in its new surroundings? And even if there were such a world, how did the life of that world come into being?

Passing over these insoluble problems of origin, we must content ourselves by saying that at some comparatively early stage in the history of the earth, Life made its appearance.

\section{Evolution in the Animal Kingdom}

A number of causes, such as the necessity of adaptation to varying conditions, led to the creatures, possessing this mysterious property of Life, developing forms which we can divide into classes, orders, families, genera, and species; these forms, in outward appearance and anatomical structure, underwent profound modifications as time went on. The history of such developments is recorded for us in the fossil remains of plants and animals embedded in the rocks-a record necessarily imperfect, as it is only in the most favourable circumstances that such remains could be preserved at all. But we are not called upon here to trace out the early evolution of forms of life at the different phases of geological history. Only in so far as the remains of animals are in one way or another associated with those of Men are they of importance to us in our present study.

\section{Importance of Palaeontology to the Archaeologist}

Such remains are of importance for two reasons. In the first place, the flesh of animals formed the chief sustenance of the ancient hunting communities in which the history of the human race begins, The life of Man was a constant struggle to obtain animal food. Animals therefore occupied much of his thoughts; he was continually engaged in devising ways and means of finding, hunting, and killing them: many of his earliest experiments in magic and religion were devices framed to stock his larder with flesh by what we should describe as supernatural means. No picture of his life can therefore be complete which does not take account of his relation to the animal world around him. In the second place, the remains of animals found in association with early Man afford a much needed chronometer. During the glacial period, when Man first became conspicuous among the inhabitants of Europe, there was a 
wide range of climatic oscillation. In the height of the glacial phases a large part of the Continent was covered with sheets of ice; in the intervening genial phases the mean temperature was as high as, or even higher than, it is in modern times. These differences of climate necessarily caused differences in the animal life. In the glacial phases, the lands affected cannot have supported any creatures not adaptable to arctic or sub-arctic conditions; and these, in their turn, could not have thriven well in the interglaciations, except in the colder regions of the north. During the genial phases, on the other hand, the Continent would be inhabited by animals accustomed to warmer climates, which would probably retreat during the glaciations. Some of the more delicate and less adaptable animals were killed outright during early stages of these trying variations of climate: others did not find a domicile in Europe at all until the Pleistocene epoch was well advanced. It is thus easy to see how these facts can be applied to the chronology of human remains. If the bones of associated animals belong to Arctic types, then the deposit is to be assigned to a glacial period; if they belong to animals adapted to steppe or to temperate conditions, they likewise tell of the nature of the climate at the time of the deposit. If the deposit should contain the bones of animals known to have disappeared early, it must be assigned to an equally early date; contrariwise, if the animals represented arrived late, it must be dated accordingly.

Thus a check is put at our disposal, whereby we can control chronological deductions based on other considerations. It is possible to classify the flints of the Palaeolithic age into groups of types, each characteristic of the successive stages into which the period is divided. But deposits cannot be dated with certainty, over all Europe, on the basis of the evolution of flint implements alone: if we attempt to do so, we inevitably make mistakes, which a study of the associated animal remains helps us to correct. Thus, the important station at Taubach near Weimar, to be more fully described in a later chapter, would be dated to the Middle Palaeolithic had we nothing but its flints; the animal bones shew that it must belong to the Lower Palaeolithic. A cave called by name of Saint Wolfgang, near Mörnsheim in Franconia, contained flints which might have been called Lower Palaeolithic, but the entirely modern fauna compels us to date the deposits in this case to Neolithic or even to later times ${ }^{1}$.

Our duty in this chapter is therefore to enumerate the various type-animals which thus help us to a fuller comprehension of the archaeological remains: and then to shew how they may be divided

1 M. Schlosser, "Ueber Höhlen bei Mörnsheim" (Corr. 1899, No. 2). 
into groups from which chronological deductions can be drawn. For this purpose the mammalia are by far the most important, although the lower orders of the animal kingdom, and vegetables, cannot wholly be neglected, as these have their contributions to make to the problems involved. For the present, however, we confine our attention to the mammalia.

\section{The Classification of Mammalia}

These, like all other groups of living creatures, are classified into a number of orders, which are divided successively into families, genera, and species: and they are usually named with two terms, the first indicating its genus, the second its species, the generic name being distinguished by a capital initial letter. This classification is based on a large variety of anatomical criteria, which we cannot attempt to describe here; they form the subject of special treatises. To the student familiar with Zoology such an attempt on our part would be superfluous; while the reader unacquainted with that science could not be given any adequate idea of the subject in the space at our disposal. Nor can we offer here a guide to the identification of the bones which may chance to come to light in the course of an excavation. This is a very delicate task, requiring a high degree of special knowledge not to be acquired from books alone: the intimate familiarity that cannot come except from iong and minute study of properly identified and labelled specimens is indispensable. The excavator who for any reason is unable to undergo such a training must take into partnership some one who has done so. We are therefore obliged to refer the reader to some one of the numerous text-books of Zoology and of Palaeontology (of which he will find at his disposal, in any library, a large number, of all degrees of difficulty or simplicity), for descriptions or illustrations of any animals named in the present chapter with which he may not be acquainted.

There is, however, one class of illustrations which will not be out of place. As we shall see in a later chapter, the men of the Upper Palaeolithic stages devoted much time and attention to the delineation of animals. Where, how, and why they did so are questions that we shall discuss in the proper place; for the moment all that we need say is that the representations are in many cases so lifelike that the species intended can be identified without the smallest difficulty.

In our present study, Palaeontology must be treated as ancillary to Anthropology; we are concerned with animals exclusively in their 
relation to human life. It thus becomes important for us to notice which animals more especially attracted the attention of the ancient artists. Accordingly we give a copy of one figure, selected from these ancient picture-galleries, of every animal of which the Palaeolithic artists took cognisance.

\section{Europe before the Ice Age}

'Throughout the Pliocene epoch the temperature in Europe had been warm and moist. 'The Continental shelf, at the end of the Pliocene, was raised to a sufficient height above its present level to join Britain with the mainland and to bridge the Mediterranean. Africa and Europe thus formed one continuous land, while Asia was to some extent cut off by the great Caspian-Aral Sea, mentioned in the preceding chapter. Forests flourished over the Continent, consisting of oak, beech, larch, poplar, and other trees still familiar in Europe, but mingled with others now known in America on'y, such as the sumach, tulip-tree, locust-tree, and liquidambar. A correspondingly rich and raried fauna peopled the land; the zoological history of the Pleistocene epoch is, indeed, the history of its gradual imporerishment.

An inland sea extended partly over the area of the present North Sea. encroaching on the modern land-area at Norfolk in England, and in the north of France and the Low Countries; and it is the stratified deposits of this sea which sound the alarm of the coming of the altered conditions of the Pleistocene era. In the lower strata of these cieposits many of the shells belong to species of molluscs now found only in warm southern seas. As we proceed upwards through the successive layers, we can see these "warm" species gradually dropping out, and their places taken by others better adapted to colder surroundings,

\section{A List of the Most Important Pleistocene Mammals}

In the following list are enumerated the most important of the mammalian fauna (exclusive of Man) found in Europe, in deposits dating from the end of the Pliocene to the end of the Pleistocene.

\section{Order I. Primates (apes, monkevs, lemurs)}

There had been several species of Primates in Europe during the Pliocene era, but almost all of them had disappeared before the dawn of the Pleistocene, and those which survived were greatly restricted in their territorial range. These were some species of Iacaque, closely allied to the apes still to be found in Gibraltar. 
The Macaque had existed in England in Pliocene times, but the latest species were restricted to the south of Europe-Macacus florentinus in Italy (Pliocene): $M$. tolosanus in Spain and the south of France, the ancestor of the still surviving macaque of Gibraltar.

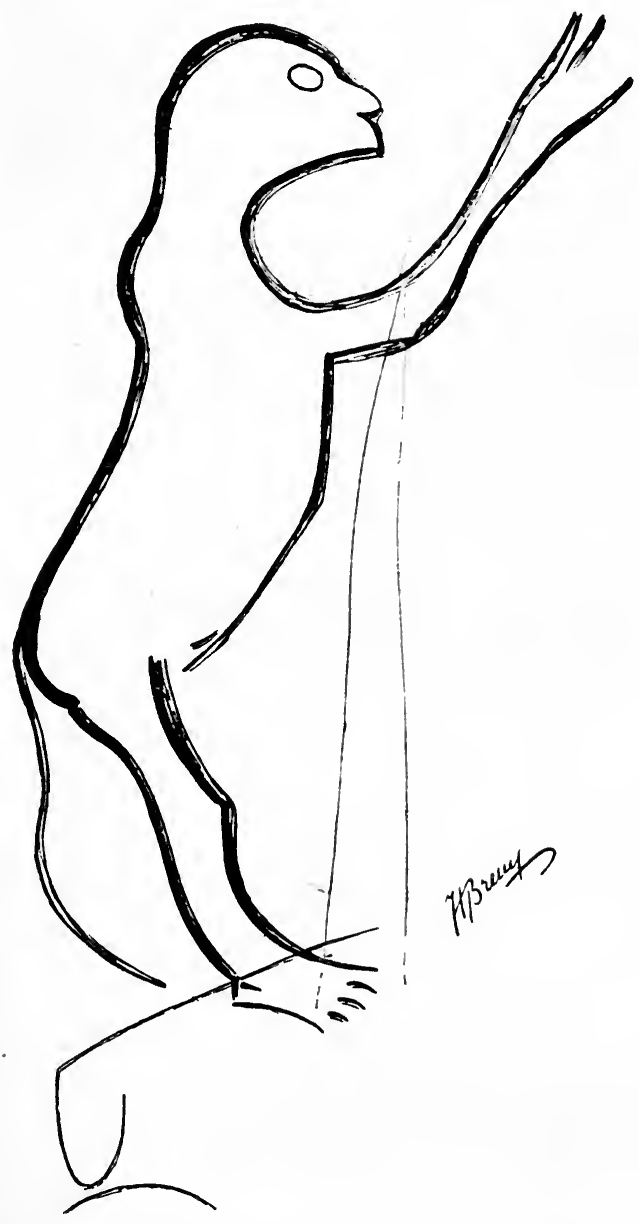

Fig. 7. Monkey (?): Cave of Hornos de la Peña.

(Drawing by M. l'Abbé Breuil: from Les cavernes de la région cantabrique.)

In any case, these animals do not appear to have touched in any way on human life. No ape bones have been found in any archaeological deposit; nor are there any certain representations of apes in the Upper Palaeolithic art. It has been supposed that some very rude figures, seemingly representing dancing man-like figures with 
animal snouts, were intended to pourtray apes ${ }^{1}$. But this explanation is more than doubtful; the snouts with which the creatures are fitted are not human, but no more are they simian; and the explanations that they represent men dancing an animal dance, with animal masks, or simply that they are crude delineations of men by artists more expert in representing animals, are both preferable. In any case the "ape" theory is too uncertain to permit us to figure these strange drawings on this page; one or two of them will be found in Chapter IX, in which the Upper Palaeolithic art is analysed. A tailed figure in the Spanish Cave of Hornos de la Peña (Fig. 7) is more likely to be intended for a monkey. It seems so far to be unique, but the creature represented has perhaps rather too long a tail for a Macaque.

\section{Order II. Cheiroptera (Bats)}

Various genera of bats have inhabited Europe continuously since Miocene times. It is seldom if ever that remains of these animals have been found in archaeological deposits; and it is therefore unnecessary to catalogue the species of this order in detail. No representations of bats have been identified in Palaeolithic art.

\section{Order III. Insectivora}

This order also contains a number of genera of no special archaeological importance, such as Erinaceus (hedgehog) and Myogale (the desman, an aquatic insectivorous animal with a long snout, found in Russia and the Pyrenees)-both of which have inhabited Europe since the Miocene era: Talpa (mole) and Sorex (shrew), which date back to the Oligocene: Crossopus (water-shrew), a Pleistocene importation: and Crocidura (musk-shrew), which begins in the Miocene. For reasons similar to those which apply to the Cheiroptera, we need not enter into fuller particulars about the animals of this order.

\section{Order IV. Carnivora}

This important order is divided into three sub-orders. The first of these, the Creodonta, were all extinct before our period began. The remaining two are called respectively Carnirora vera (the terrestrial carnivores), and Pinnipedia (with a fin-like film or web connecting the digits, adapting the limb for swimming).

The Carnivora rera are further divided into a number of families, of which the following call for our attention:

1 The suggestion was made by Edouard Piette (B.S.A.P. ser. v. vol. III. [1902], p. 771 ). He seems indeed to have toyed with the idea that the figures might represent an intermediate form between apes and man-a theory crudely impossible. 


\section{(a) Canidae}

I. Belonging to the close of the Pliocene, and probably extinct before the Pleistocene:

Canis megamastoides, the first of the Canis genus to make its way into Europe; a large species of wolf.

2. Surviving into the beginning of the Pleistocene, and found in early deposits of that epoch:

Canis falconeri from early deposits in Italy.

Canis etruscus, ditto.

Canis neschersensis, a primitive form of jackal, surviving to Middle Palaeolithic, but rare.

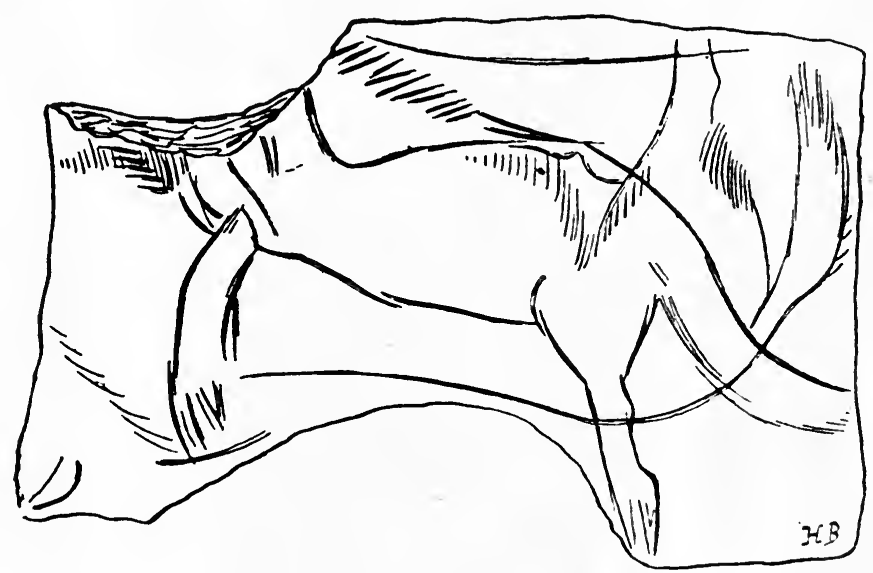

Fig. 8. Engraving on stone of a wolf from the Cave of Gourdan (Haute-Garonne).

(Drawing by M. l'Abbé Breuil: from La Caverne de Font-de-Gaume.)

\section{Pleistocene forms:}

Canis suessi, a kind of wolf.

Canis lupus, the common wolf (Fig. 8).

Canis vulpes, the fox (Fig. 9).

Canis lagopus, the Arctic fox, which, though now confined to the Polar regions, was spread over a great part of Europe during the Ice Age.

Cuon alpinus, the Alpine wolf, occasionally found in archaeological deposits.

Lycaon anglicus, the Cave hunting-dog. 


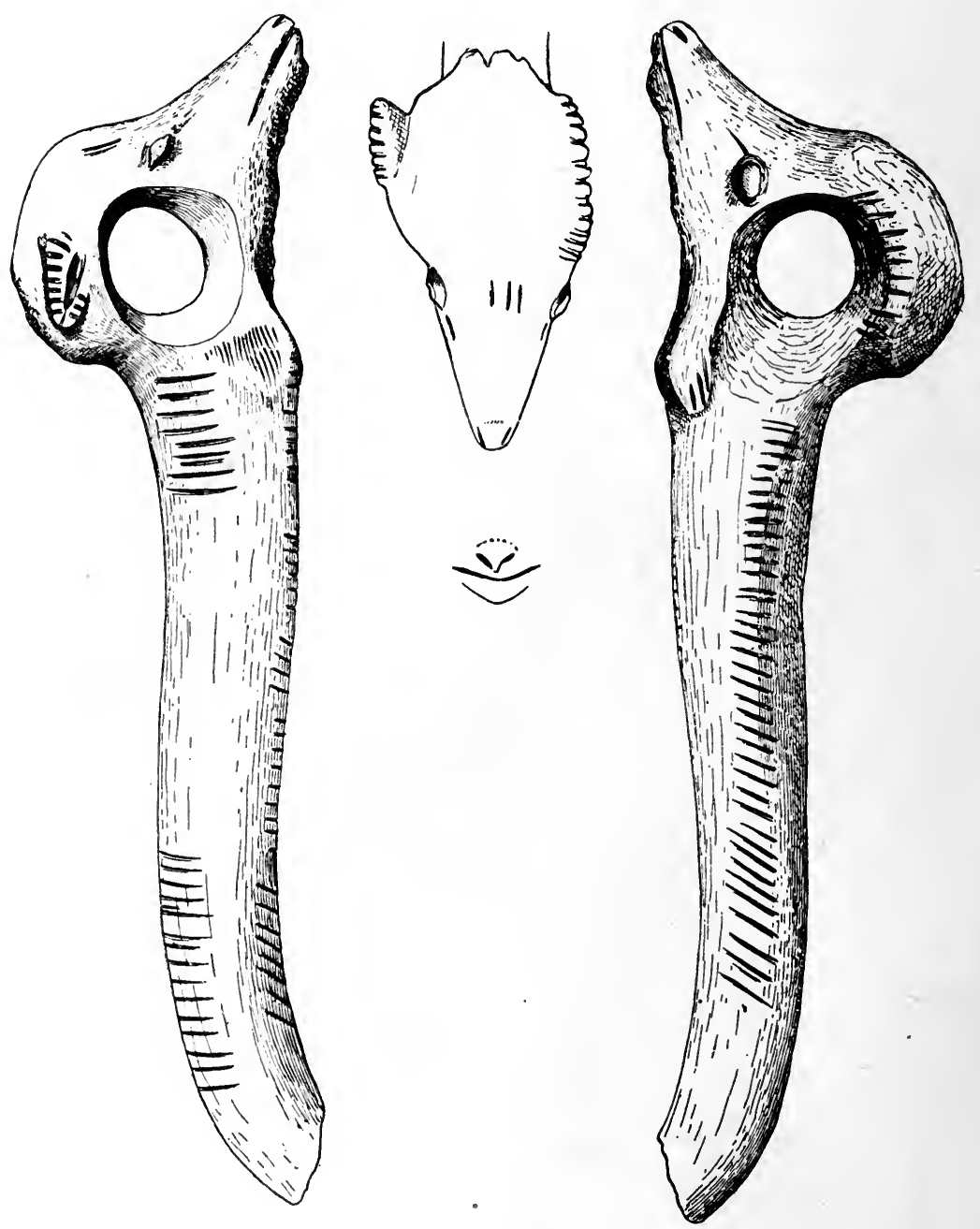

Fig. 9. Head of a fox carved on a bâton de commandement from Placard (Charente). (Drawing by M. l'Abbé Breuil: from La Caverne de Font-de-Gaume.) 


\section{(b) Ursidae}

Ursus arctos, the brown bear (Fig, 10).

Ursus spelaeus, the cave bear, a large species of bear (Fig. II). The contrast between the two figures of bears here shewn well represents the contrast in the shape of the heads of the two species.

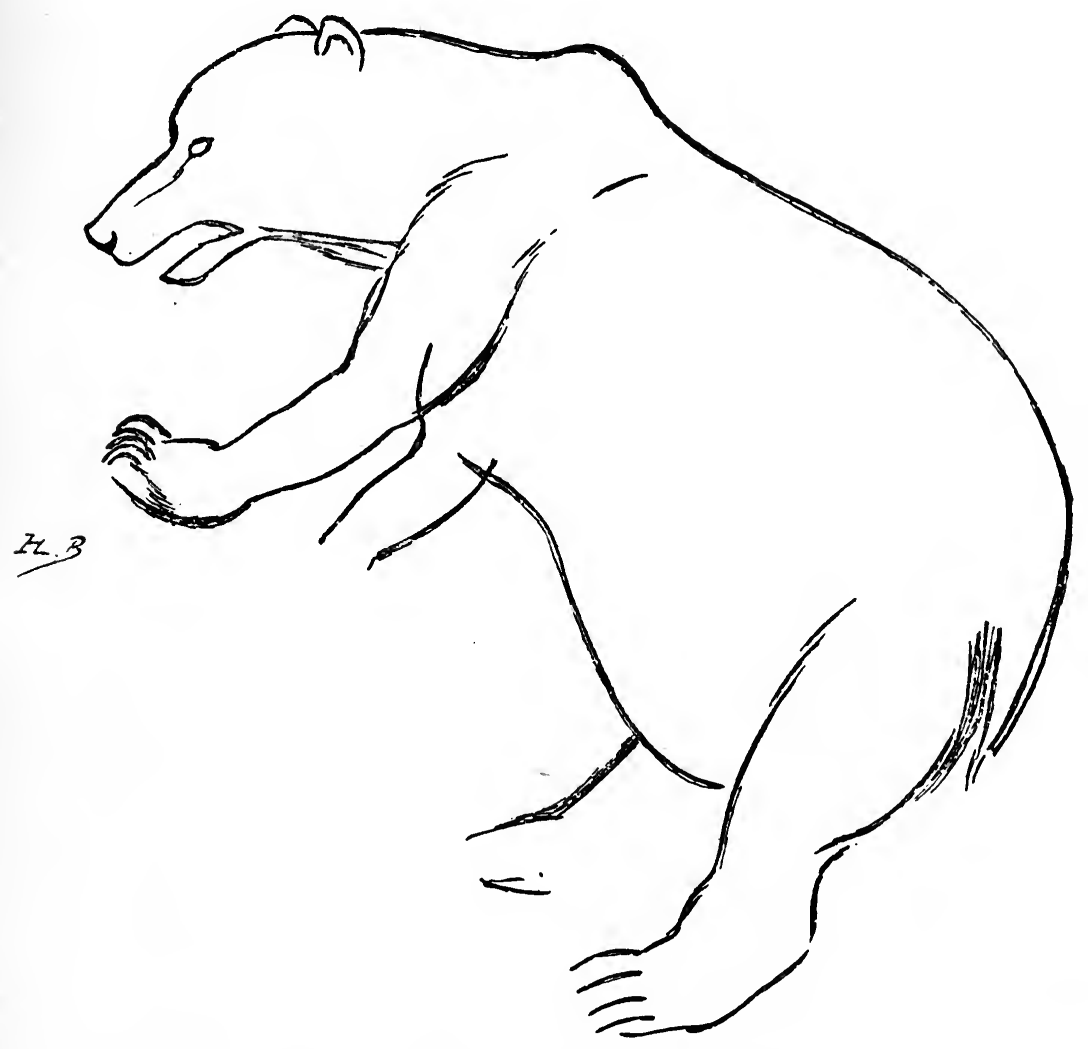

Fig. 10. Ursus arctos: Teyjat (Périgord).

(Drawing by M. l'Abbé Breuil: from the Report, C.A.P.A., Monaco.)

Marks of the claws of the cave bear are frequently found on the walls of caves which it has occupied.

We may also mention two earlier species, dating from Late Pliocene, and surviving for some time into Pleistocene:

Ursus etruscus (rare, and early extinct).

Ursus arvernensis. 


\section{(c) Mustelidae}

The following are the species likely to be found in archaeological deposits in Europe:

Mustela erminea, the ermine.

Mustela martes, the marten.

Mustela putorius, the pole-cat.

Gulo borealis, the wolverene (Fig. 12).

Meles taxus, the badger.

Lutra vulgaris, the otter (Fig. 13).

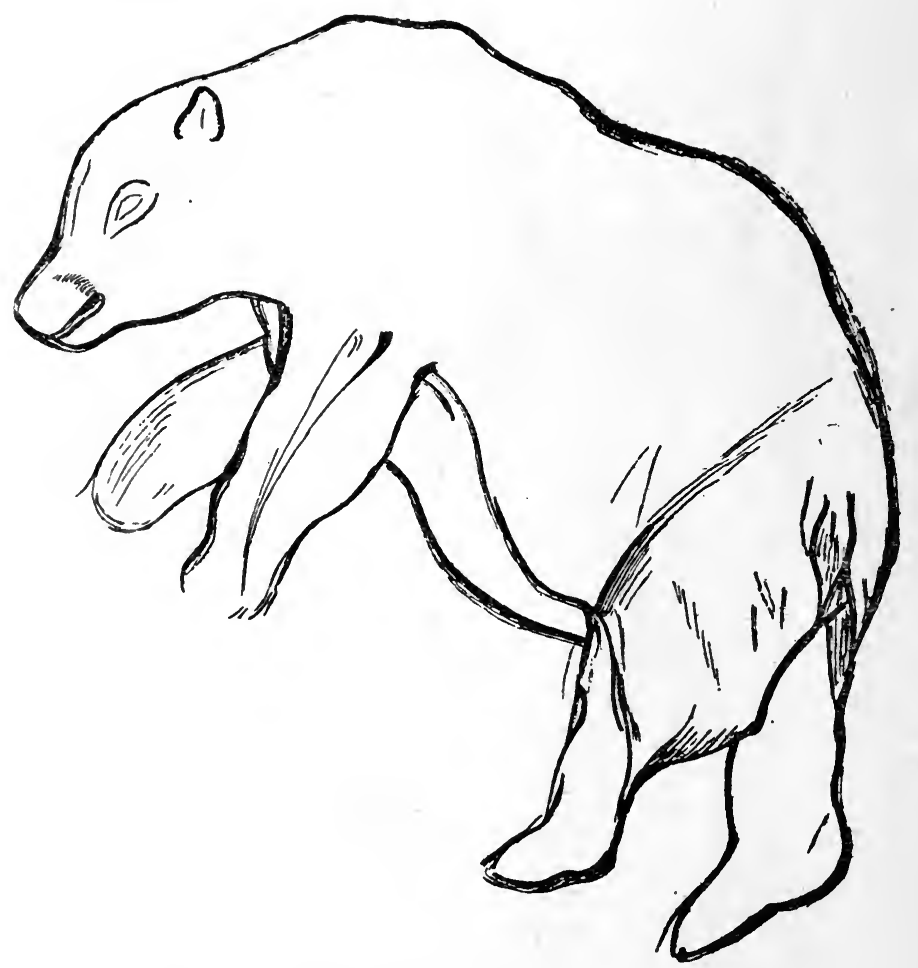

Fig. II. Ursus spelaeus: Les Combarelles (Périgord).

(Drawing by M. l'Abbé Breuil: from the Report, C.A.P.A., Monaco.)

\section{(d) Hyaenidae}

It is a remarkable fact that, although the hyaena must have been a very common animal in the Upper Palaeolithic times, no representation of it has been identified with any certainty in the 
Upper Palaeolithic art. The species of hyaena known in Pleistocene Europe are as follows:

Hyaena prisca [Pliocene].

Hyaena brunaea, the brown hyaena.

Hyaena spelaea, the cave hyaena (a variety of $H$. crocuta). Hyaena crocuta, the spotted hyaena.

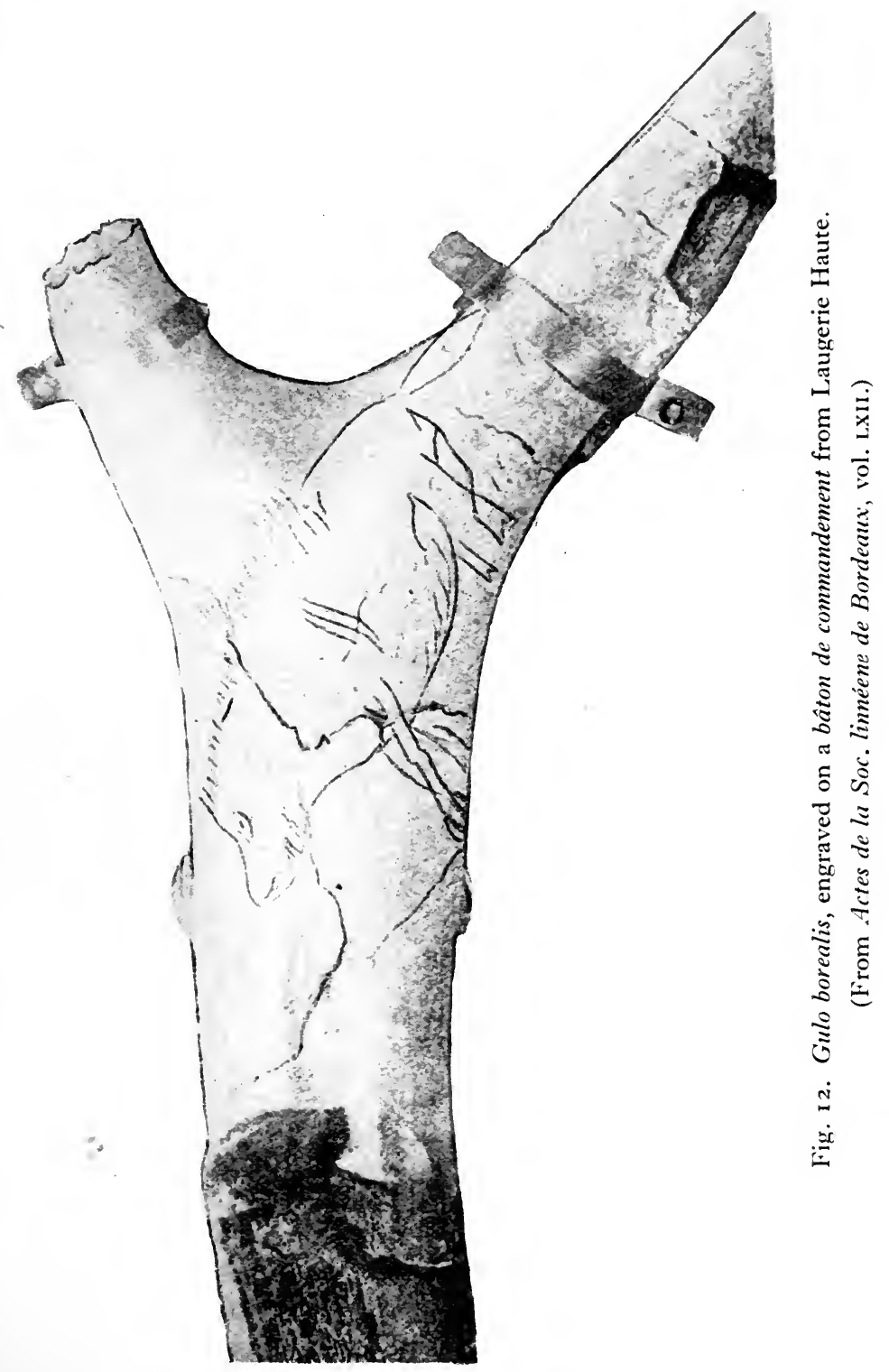




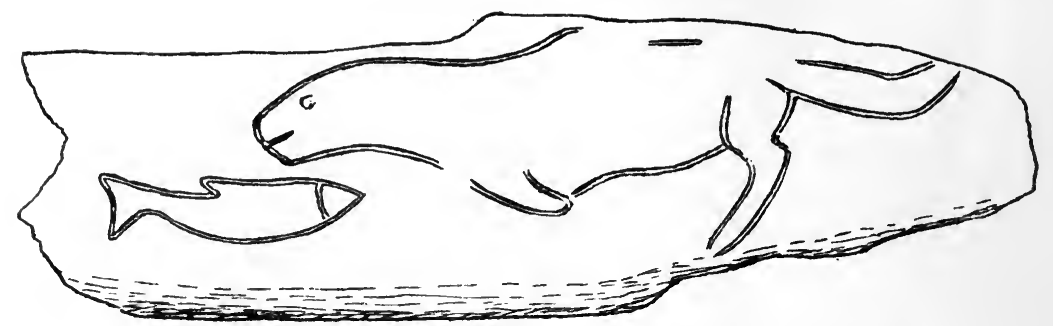

Fig. 13. Lutra vulgaris pursuing a fish, from Laugerie Basse.

(From La Caverne de Font-de-Gaume.)

\section{(e) Felidae}

Machaerodus latidens, the sabre-toothed tiger. This formidable animal, whose teeth were probably the strongest cutting teeth ever known, was distinguished especially by the enormous tusk-like upper canines, which are the reason for its name. M. latidens is the only species which may possibly have survived into the human period, but there had been several previous species of the same genus.

Felis spelaea, the cave lion (Fig. I4) - a variety of $F$. leo.

Felis leo, the lion.

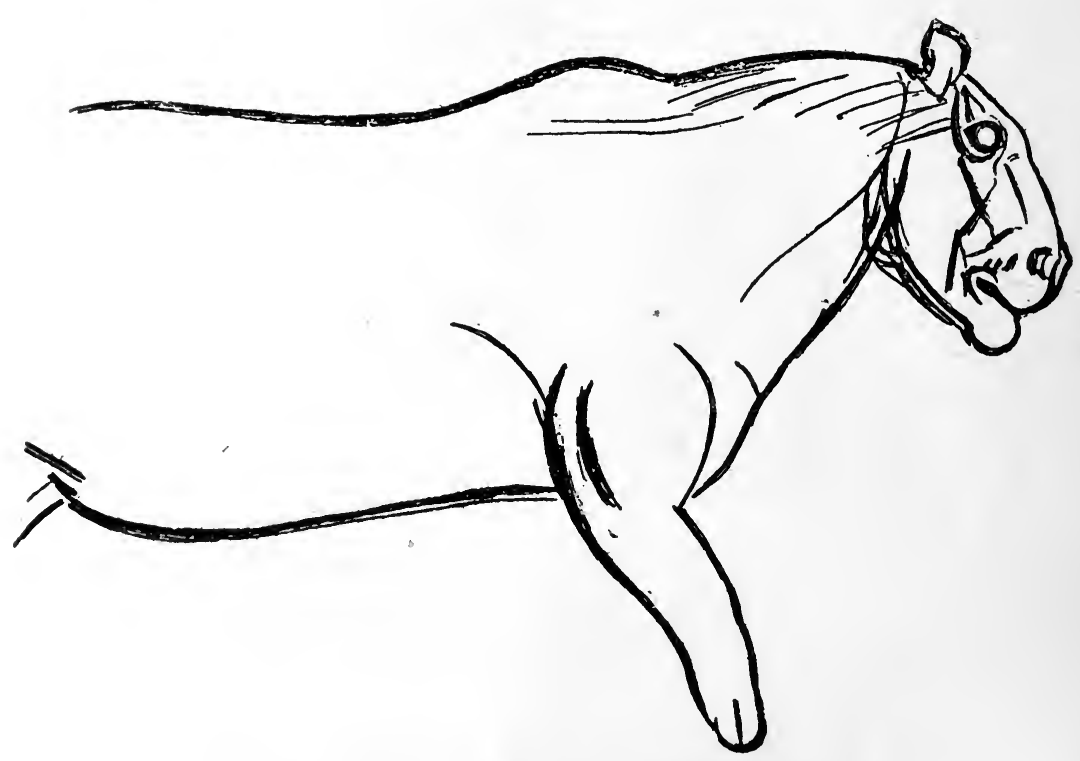

Fig. 14. Felis spelaea: Les Combarelles (Périgord).

(Drawn by M. l'Abbé Breuil: from La Caverne de Font-de-Gaume.) 
Felis catus, the wild cat (Fig. I5).

Felis manul, Pallas's cat.

Felis libyca, the African cat.

Felis serval, the serval.

Felis pardus, the leopard.

Felis lynx, the lynx.

The Pinnipedia need not be specified in detail, as this group of sea-living animals (seals and walruses) did not come very much
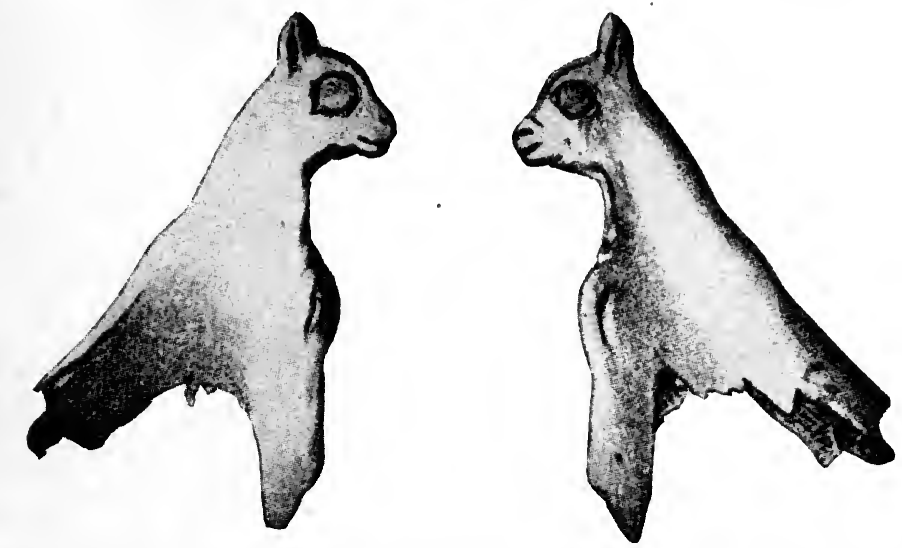

Fig. 15. Felis catus, engraving from Saint-Michel-d'Arudy (Basses-Pyrénées).

(Drawn by M. l'Abbé Breuil: from La Caverne de Font-de-Gaume.)

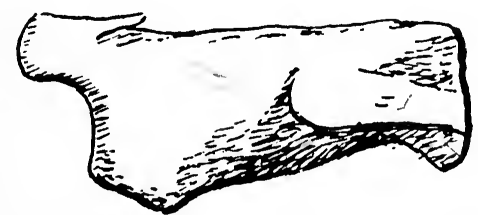

Fig. 16. Supposed figure of a hare, from Laugerie Basse.

(After Girod and Massénat, Laugerie Basse.)

into relation with man. That they were not wholly unobserved is shewn by the engraving Fig. I34 on a later page; but few if any bones of this group of animals have been identified in archaeological deposits.

\section{Order V. Rodentia}

This order contains a number of animals which though of small size are of very considerable chronological importance. They do not appear to have attracted the attention of the Upper Palaeolithic artists; a supposed figure of a hare, from Laugerie Basse (Fig, I6) is doubtful. 
Of the families of the Rodentia, one, the Hystricidae or porcupine-like animals, is for us unimportant, though one or two species of porcupine are found, especially in southern Europe, in Pleistocene deposits. Of the other families the chief species are as follows :

(a) Sciuridae

Sciurus vulgaris, common squirrel.

Spermophilus rufescens, the suslik, a small burrowing rodent, not unlike a guinea-pig.

Arctomys marmotta, the marmot.

Arctomys bobac, the bobac marmot.

\section{(b) Castoridae}

Castor fiber, the beaver.

Trogontherium cuvieri, the giant beaver.

\section{(c) Muridae}

We may pass over the universal mice and rats, and the comparatively unimportant Myoxidae (dormice), and proceed to enumerate the following:

Arvicola amphibus, the water vole.

Arvicola gregalis, the Siberian vole.

Arvicola agrestis, the common vole.

Arvicola ratticeps.

Arricola nivalis, the Arctic vole.

Myodes torquatus, the banded lemming.

Myodes obensis, the Obi lemming.

Myodes lemmus, the Norwegian lemming.

Cricetus frumentarius, the hamster.

\section{(d) Diprodidae}

Alactaga jaculus, the jerboa.

(e) Lagomyidae

Lagomys pusillus, the tailless hare.

\section{(f) Leporidae}

Lepus timidus, the common hare.

Lepus cuniculus, the rabbit.

Lepus variabilis, the variable hare. 


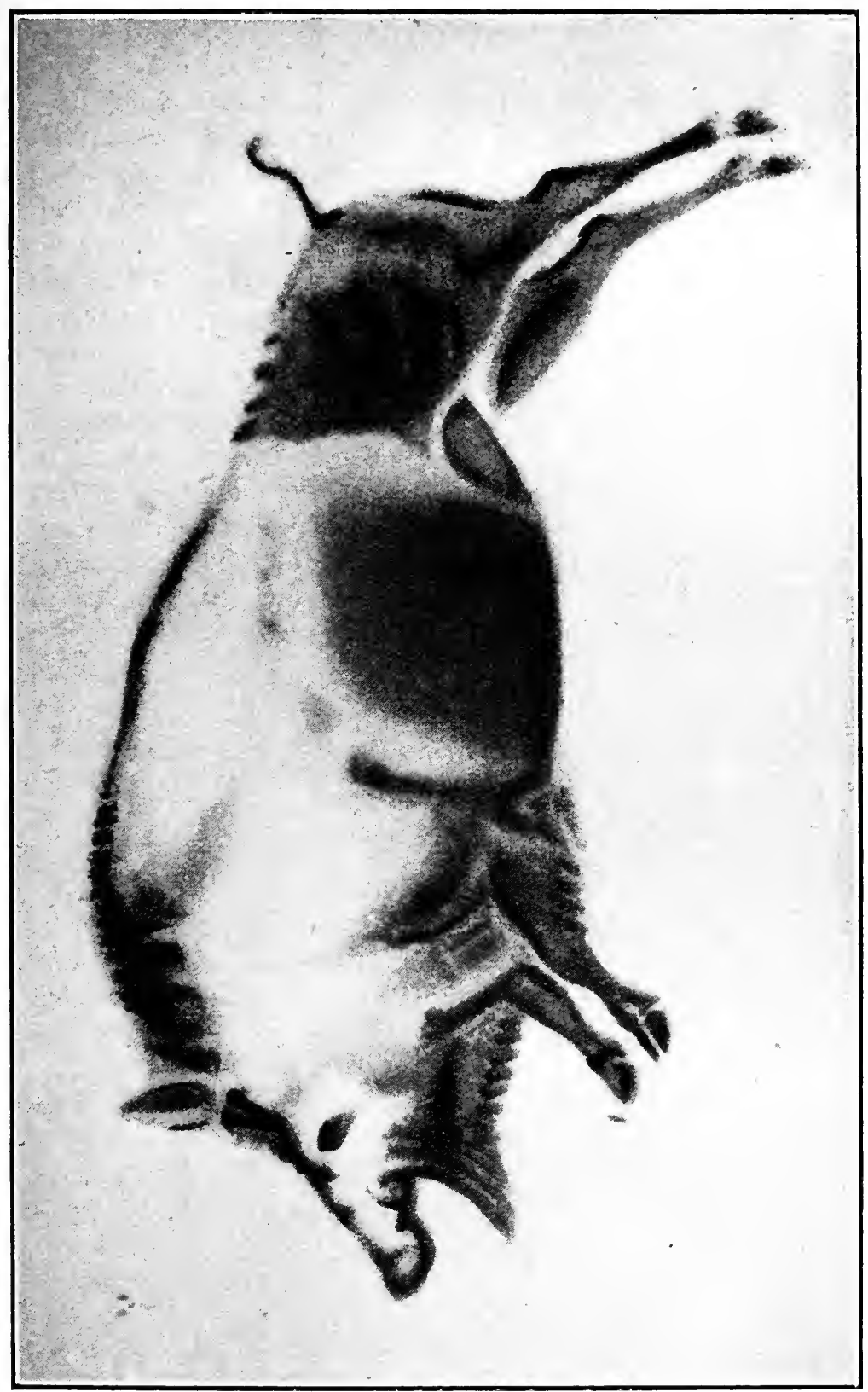

作 


\section{Order VI. Ungulata}

This order contains the great majority of the animals which have been pressed into the service of Man, in one capacity or another. During the Pleistocene era, however, they were still entirely wild; the arts of domestication had not yet been so much as thought of. All the animals enumerated below were chased by the hunter for their flesh or their hides. Most of the animals represented by the Upper Palaeolithic hunters belong to this group, and so many excellent drawings, paintings, and engravings of the different species have survived that it is difficult to make a choice for illustration.

The Ungulaia are divided into a number of groups, elevated, in some schemes of classification, to the rank of separate orders. In the present list it is unnecessary to enumerate these: we merely name the species which came under the notice of Palaeolithic man, or which in one way or another have a bearing on the interpretation of Palaeolithic remains. These, classified under the families to which they belong, are as follows:

\section{(a) Suidae}

Sus scrofa, the wild boar (Fig. 17).

\section{(b) Hippopotamidae}

Hippopotamus major, a variety of $H$. amphibius.

Hippopotamus amphibius, the still surviving hippopotamus.

Hippopotamus melitensis, $H$. minutus, $H$. pentlandi, three dwarf species found in certain of the Mediterranean islands (Sicily, Malta, Cyprus, etc.).

\section{(c) Cervidae}

Cervus sedgwicki [Pliocene].

Cervus maral, the Siberian deer.

Cervus giganteus, the Irish elk.

Cervus elaphus, the red deer (Fig. I8).

Cervus dama, the fallow deer.

Cervus capreolus, the roe deer.

Alces latifrons, the moose (Fig. I9).

Rangifer tarandus, the reindeer (Fig. 20). This animal ranged as far south as the Alps, and occasionally even further, during the height of the glacial extensions, as is shewn by remains found in 


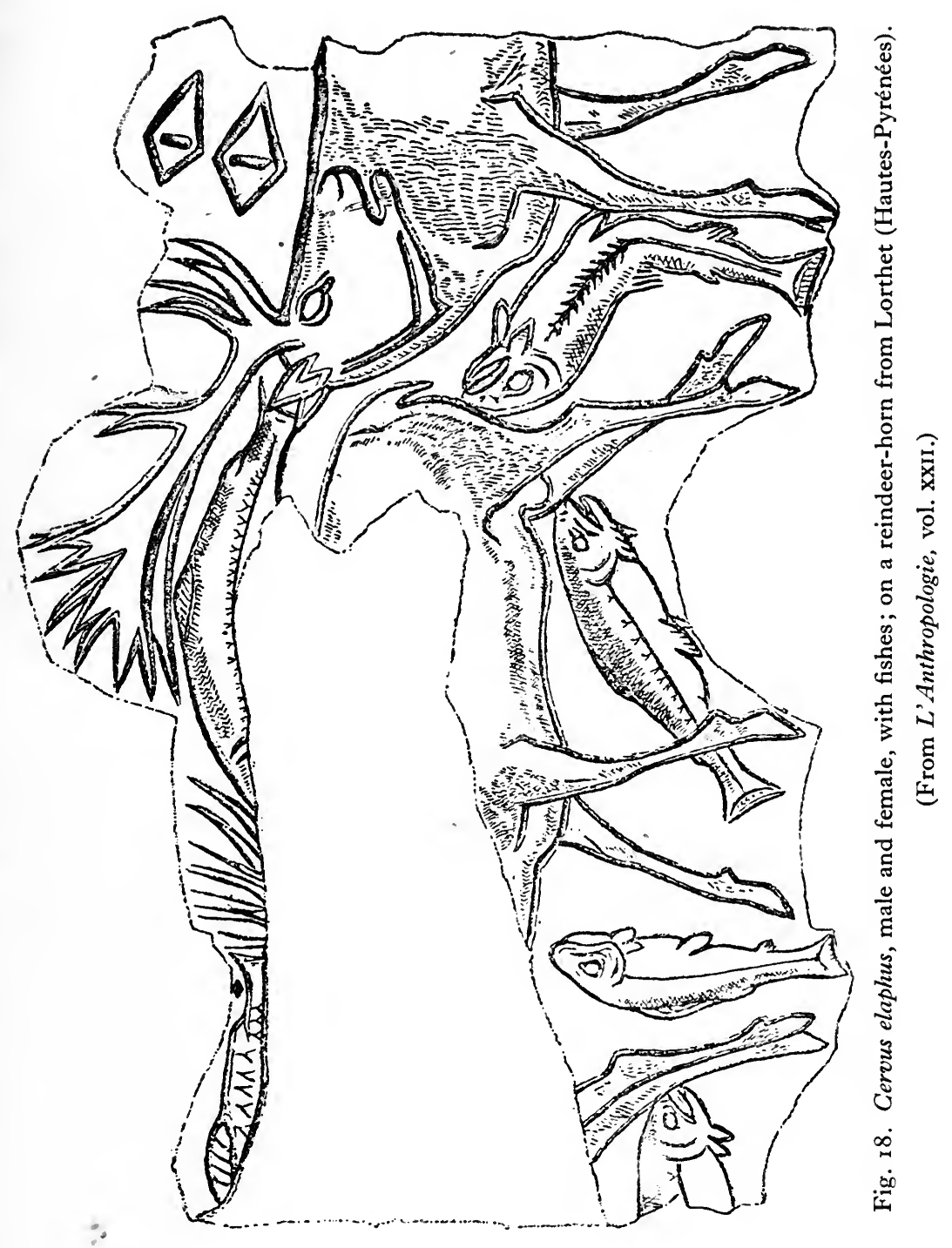




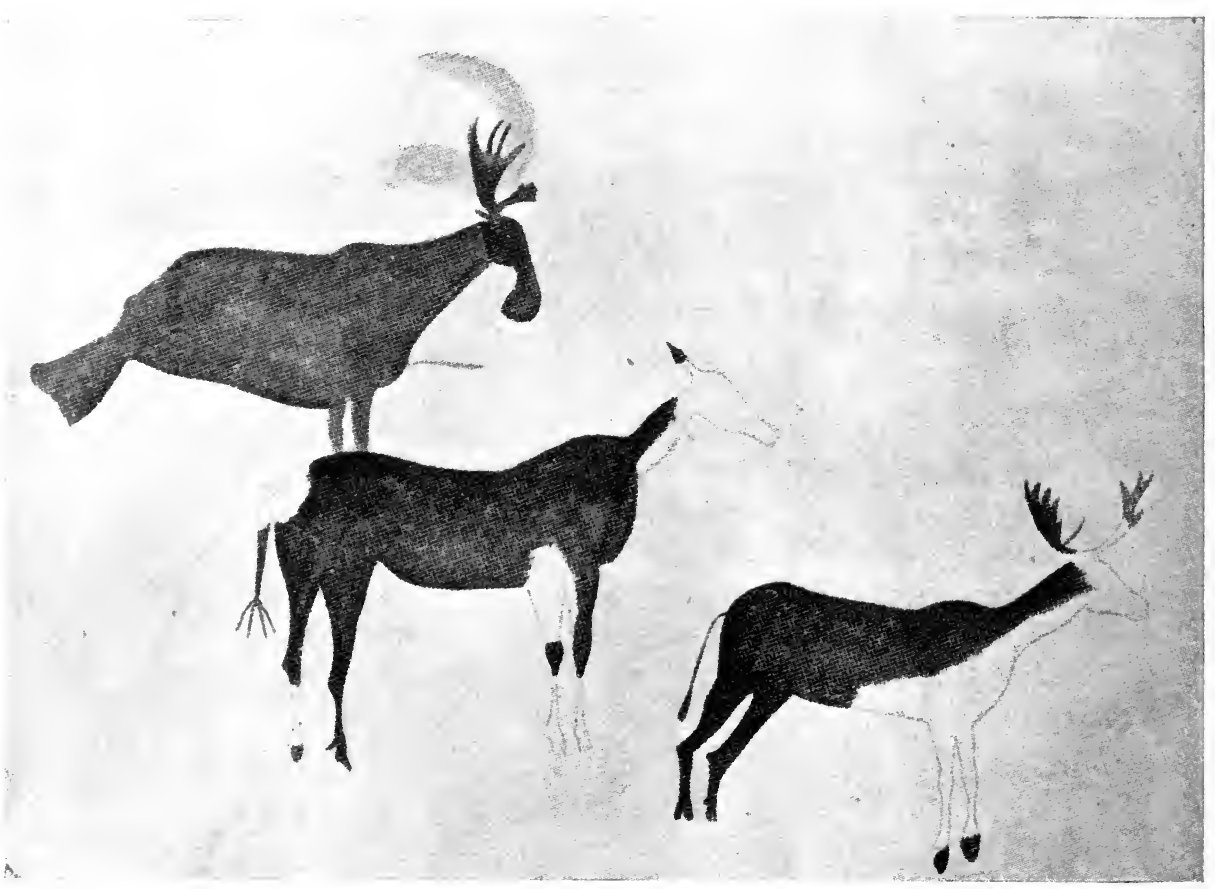

Fig. 19. Alces latifrons, from a rock-painting at Alpera, Spain. (Drawn by M. l'Abbé Breuil: from L'Anthropologie, vol. xxırI.)

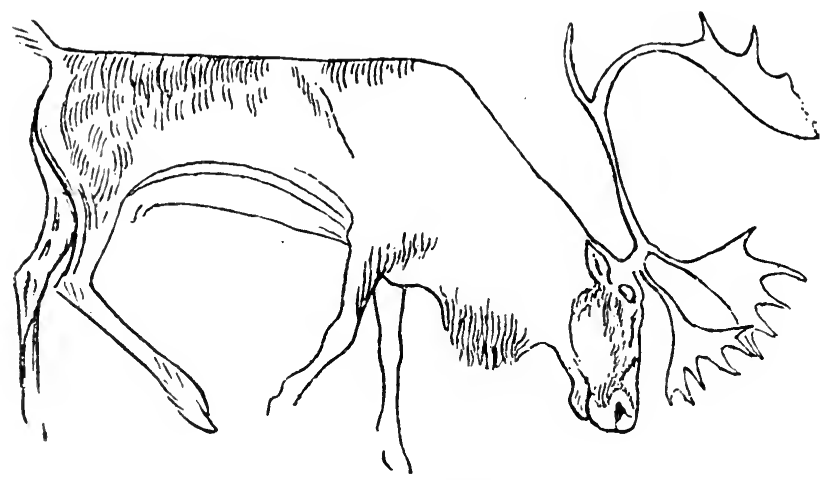

Fig. 20. Rangifer tarandus, from an engraving on reindeer-horn found at Thayngen, Switzerland.

(Drawn by M. l'Abbé Breuil: from La Caverne de Font-de-Gaume.) 
the Mentone Caves ${ }^{1}$, a horn found at Ober-Laibach in Carniola ${ }^{2}$, and also bones found in the north of Spain ${ }^{3}$.

\section{(d) Bovidae}

Saiga tatarica, the Saiga antelope (Fig. 2I).

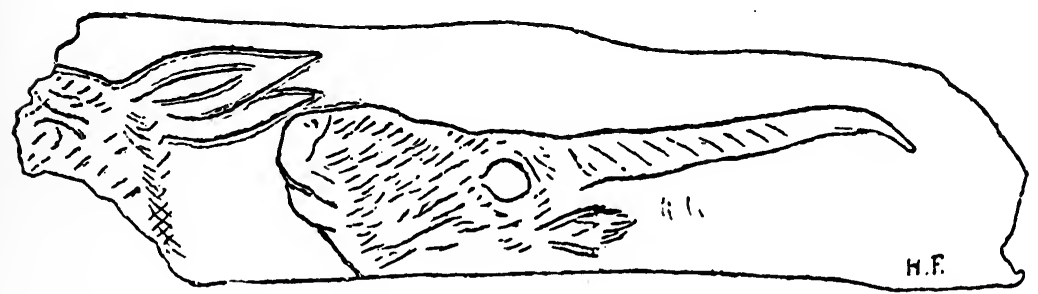

Fig. 21. Saiga tatarica, from the Cave of Gourdan (Haute-Garonne).

(From L'Anthropologie, vol. xv.)

Rupicapra tragus, the chamois (Fig. 22).

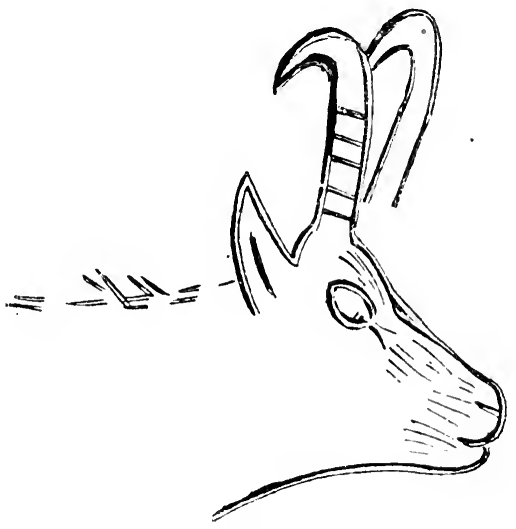

Fig. 22. Rupicapra tragus, from the Cave of Gourdan (Haute-Garonne).

(From L'Anthropologie, vol. xv.)

1 R.Verneau, "Les nouvelles trouvailles de M. Abbo dans la Barma-Grande près de Menton" (L'Anthr. x. [1899], 439 ff., esp. p. 449).

2 V. Hilber, "Ein Rengeweih aus Ober-Laibach in Krain" (M.A.G.W. xxxvi. [1906], p. 163).

3 Edouard Harlé, "Ossements de Renne en Espagne" (L'Anthr. XIx. [1908], p. 573). 
Capra ibex, the Alpine ibex (Fig. 23). Ovis argaloides, the Argali sheep.

Ovis antiqua

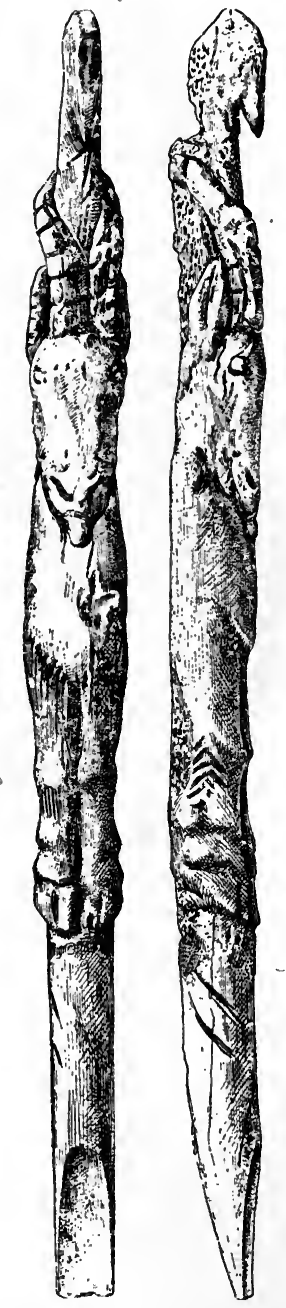

Fig. 23. Capra ibex, engraved on a javelin-propulsor from Le Mas d'Azil (Ariège).

(From L'Anthropologie, vol. xv.)

Ovibos moschatus, the musk-ox (Fig. 24).

Leptobos elatus, L. etruscus, primitive [Pliocene] forms of cattle. Bos primigenius, the urus (Fig. 25).

Bison bonasus, B. priscus, the bison (Fig. 26). 

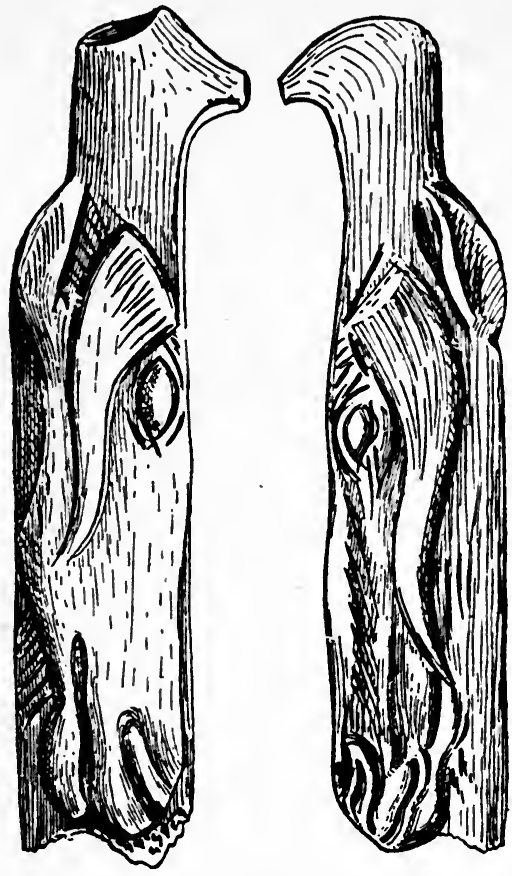

Fig. 24. Ovibos moschatus, on a javelin-propulsor from Bruniquel (Tarn-etGaronne).

(Drawn by M. l'Abbé Breuil: from La Caverne de Font-de-Gaume.)

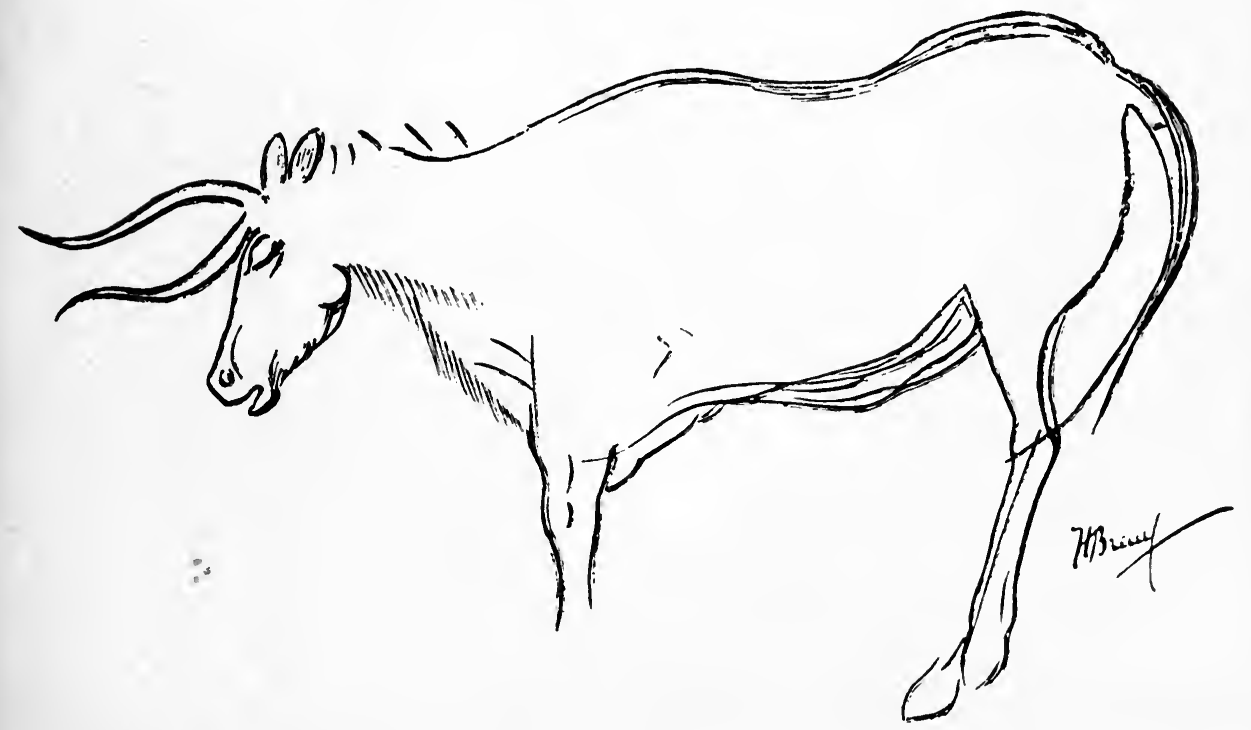

Fig. 25. Bos primigenius, engraving in the Cave of Les Combarelles (Périgord).

(Drawing by M. l'Abbé Breuil: from La Caverne de Font-de-Gaume.) 


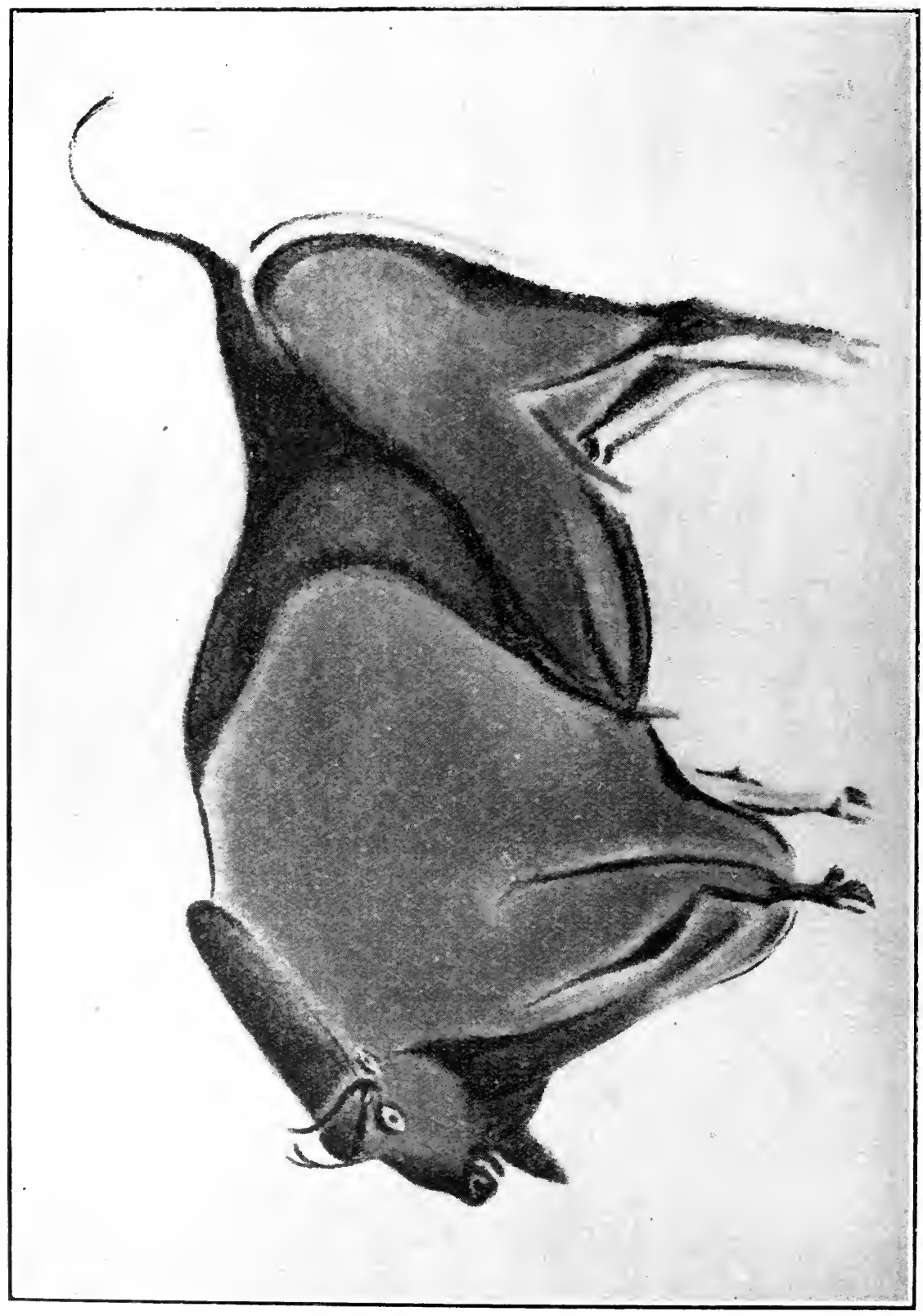

क 


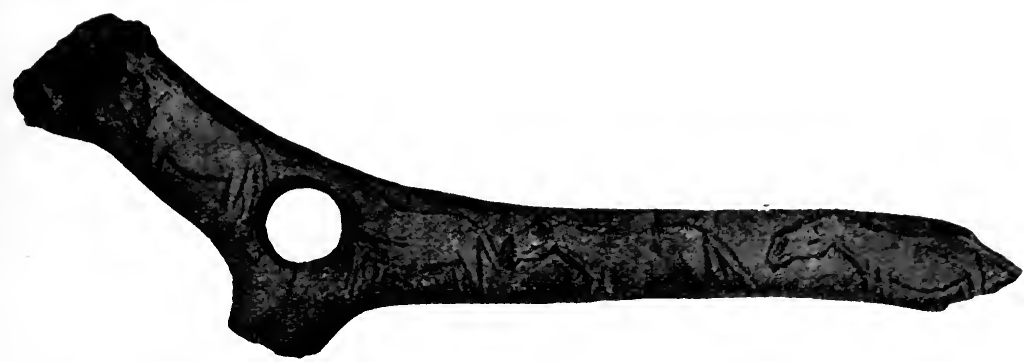

Fig. 27. Equus caballus, engraved on a bâton de commandement from La Madelaine (Dordogne).

(From Lartet and Christy, Reliquiae Aquitaniae.)

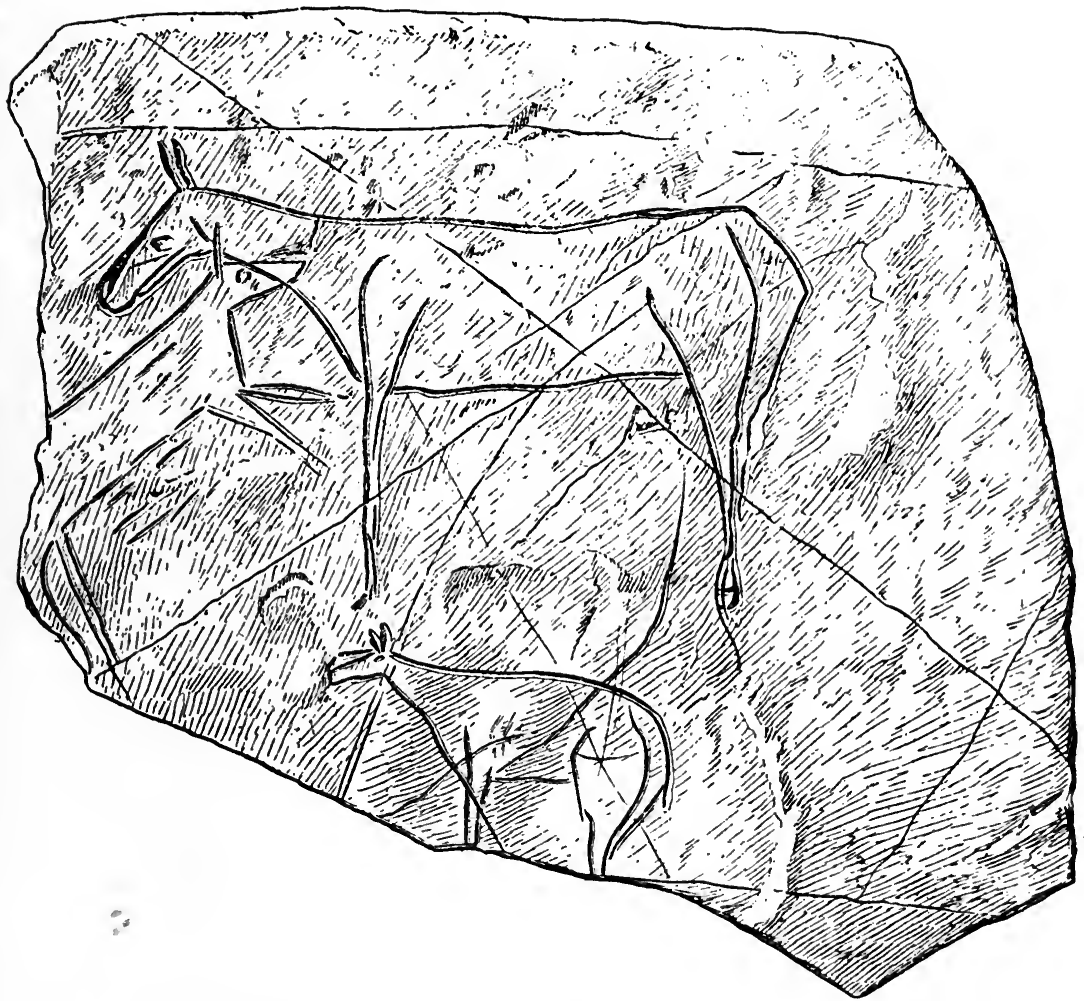

Fig. 28. Supposed figure of Equus hemionus engraved on a plate of limestone from das Schweitzersbild, Switzerland.

(From Revue de l'École d'anthropologie de Paris, vol. viII.)

M.E.A.I. 


$$
\text { t }
$$




\section{(e) Camelidae}

Camelus alutensis, the camel (found in quaternary gravels in Roumania ${ }^{1}$ ).

\section{(f) Equidae}

Equus stenonis, Steno's horse [Pliocene].

Equus caballus, the ordinary horse, in several varieties (Fig. 27). Equus przvalskii, Przvalski's horse (a variety of E. caballus).

Equus hemionus, the kiang or wild ass (Fig. 28).

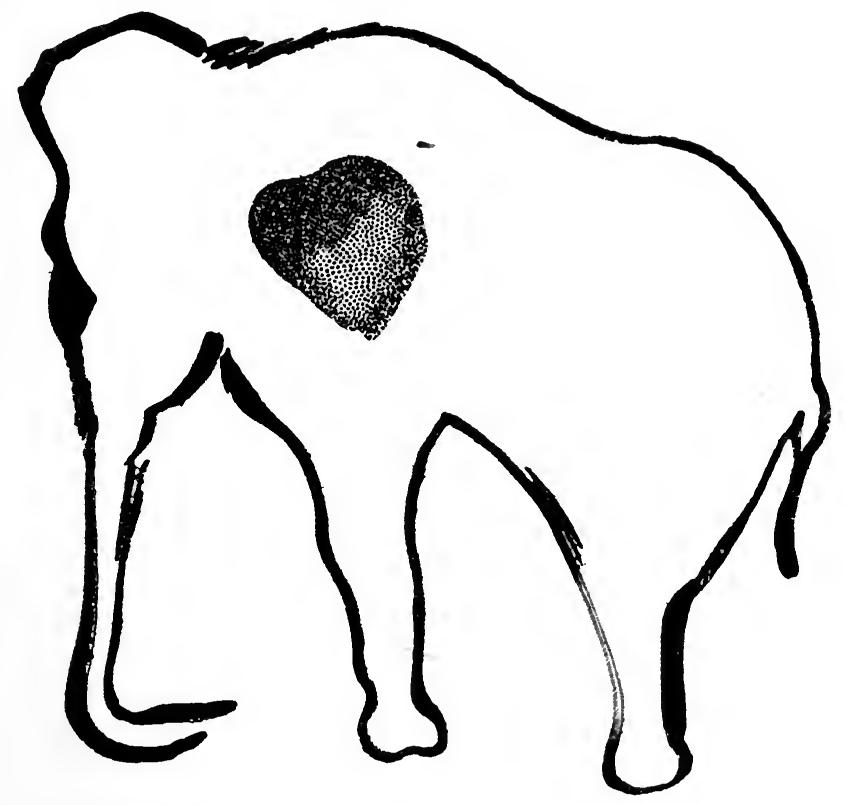

Fig. 30. Elephant, probably Elephas antiquus, from the Cave of Pindal, Spain.

(Drawn by M. l'Abbé Breuil: from Les Cavernes de la région cantabrique.)

\section{(g) Rhinocerotidae}

Rhinoceros mercki, Merck's rhinoceros.

Rhinoceros tichorhinus, the woolly rhinoceros (Fig. 29).

Rhinoceros etruscus.

Elasmotherium sibiricum.

1 G. Stefanescu, "Le Chameau fossile de Roumanie," in a Roumanian publication analysed L'Anthr. vir. [1896], p. 459. 


\section{(h) Elephantidae}

Elephas meridionalis, the southern elephant [Pliocene].

Elephas trogontherii.

Elephas antiquus (Fig. 30).

Elephas primigenius, the mammoth (Fig. $3 \mathrm{I}$ ).

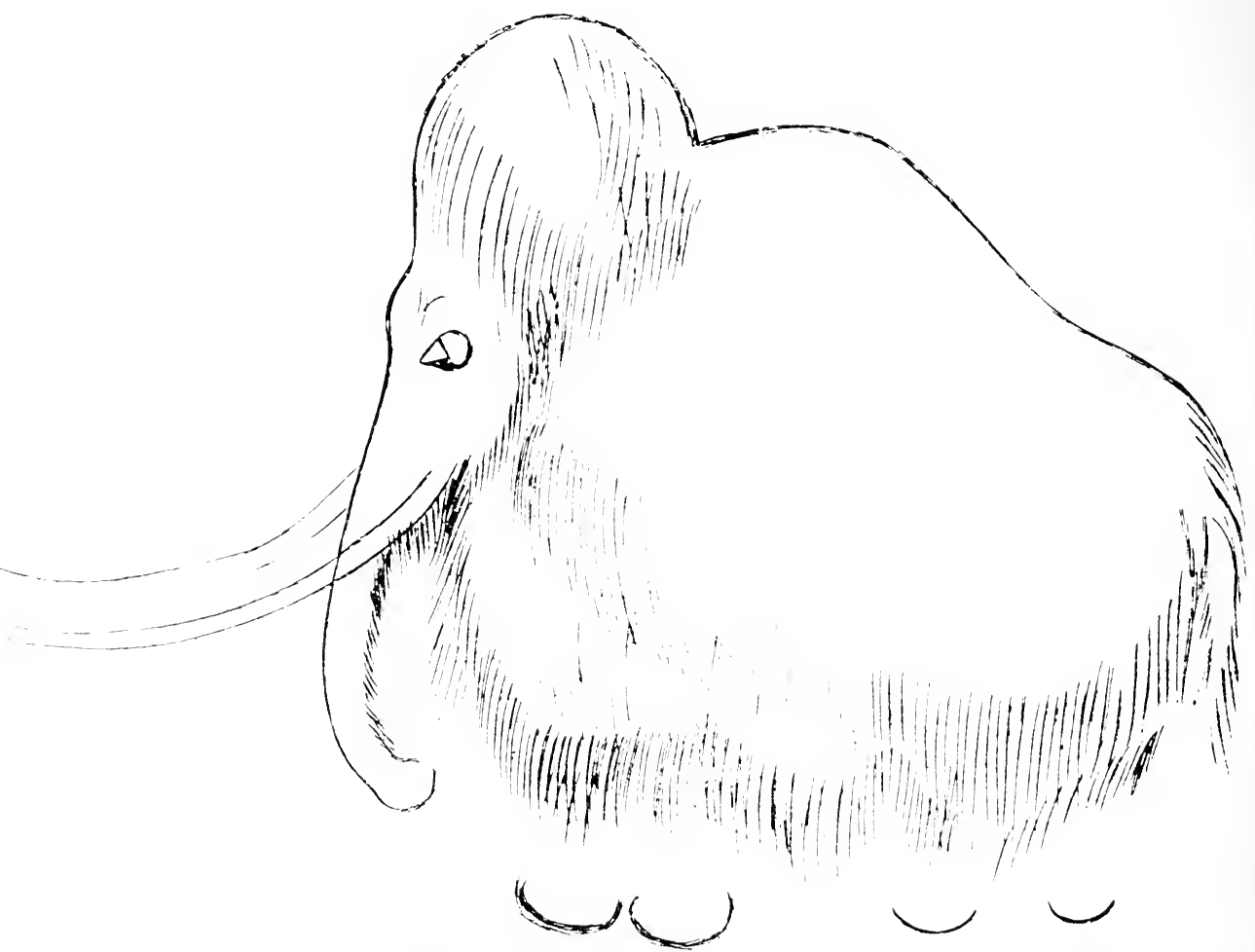

Fig. 31. Elephas primigenius, engraved on the wall of the Care of Font-de-Gaume (Dordogne).

(Drawn by M. l'Abbé Breuil: from La Carerne de Font-de-Gaume.)

\section{Birds}

The above list comprises all the Pleistocene mammalia with which the student of Palaeolithic man need concern himself. The bircls are of less importance'; the most important species found in archaeological deposits are the grouse (Lagopus albus), ptarmigan (L. mutus), capercailzie (Tetrao urogallus) and swan (Cygnus musicus).

1 For a list of these see Milne-Edwards, "Observations sur les Oiseaux dont les ossements ont été trouvés dans les cavernes du Sud-Ouest de France" (Matériaux pome l'hist. de thomme, x1. [1875], p. 473). This is an expansion of an article previously published in Lartet and Christy's Reliquige Aquitaniae, p. 226. 


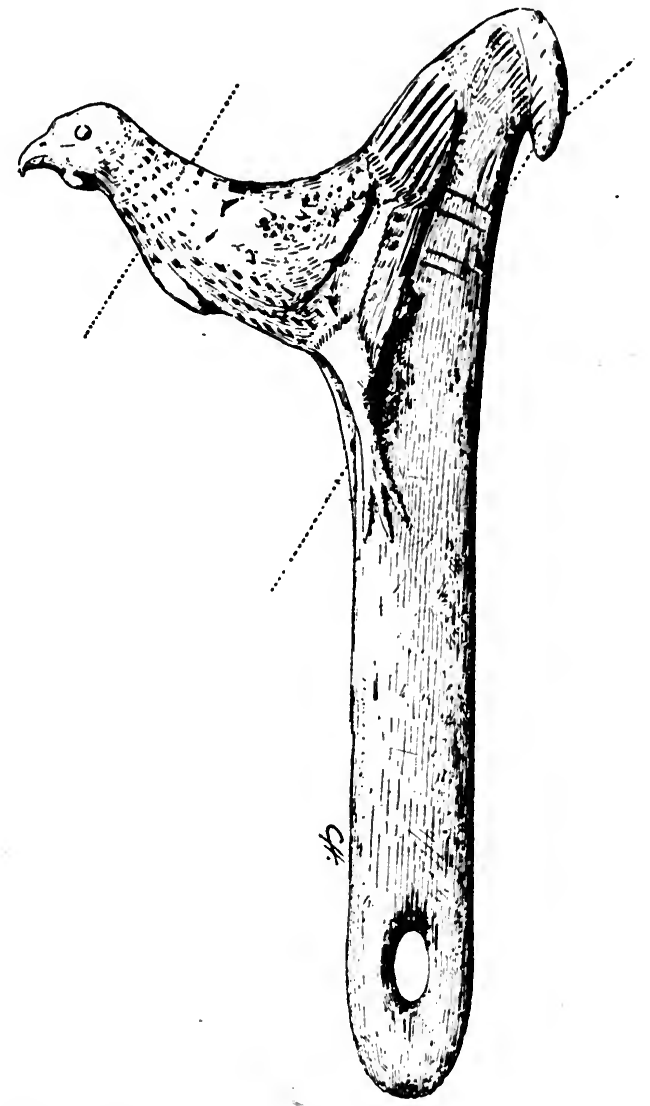

Fig. 32. Capercailzie, from Le Mas d'Azil, as restored by Breuil. (Drawn by M. l'Abbé Breuil: from Les Cavernes de la région cantabrique.)
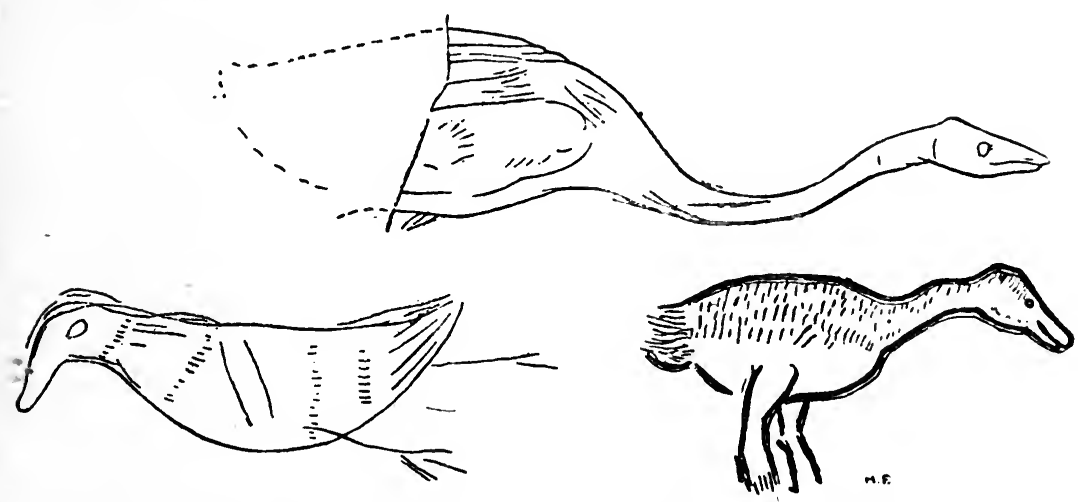

Fig. 33. Swan engraved on stone from Lourde, duck on stone from Gourdan, and duck on reindeer-horn from Lourde.

(Drawn by M. l'Abbé Breuil: from Les Cavernes de la région cantabrique.) 
There are only a few representations of birds extant in Upper Palaeolithic art; we may mention a representation of the capercailzie, on a fragment of a propulsor from Le Mas d'Azil. This was originally described as a "sphinx," but its true nature has been determined,
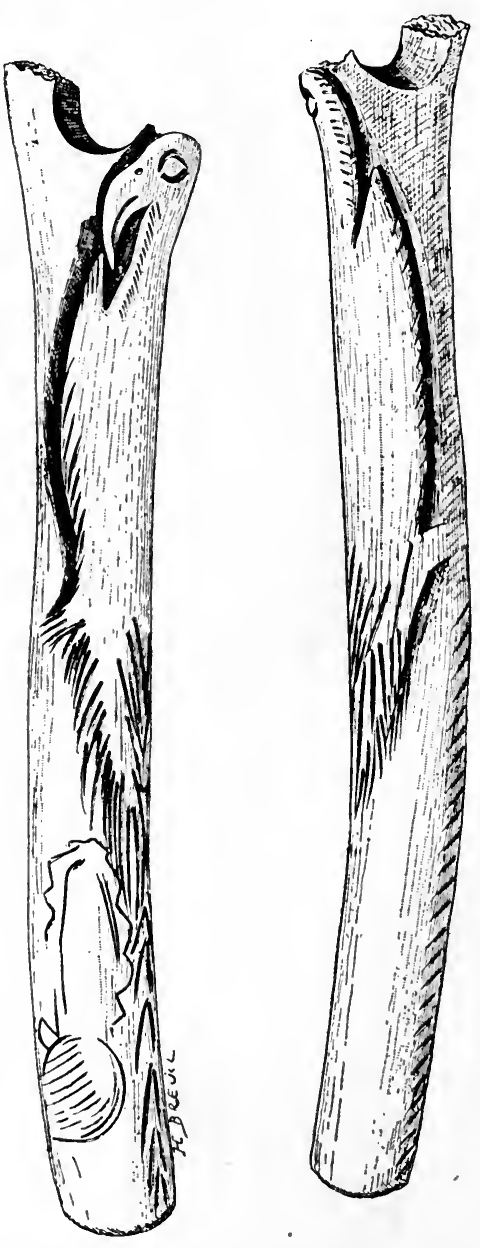

Fig. 34. Accipitrine bird, engraved on a bâton de commandement, from Raymonden (Dordogne).

(Drawn by M. l'Abbé Breuil: from Les Cavernes de la région cantabrique.)

and the object most ingeniously restored by M. l'Abbé Breuil (Fig. 32). We may also notice representations of a crane, from Bruniquel (Fig. 138, post), and of a swan and ducks from Lourde and from Gourdan (Fig. 33), and a bird with accipitrine hooked beak, which however it is impossible to identify more exactly. The last- 
named is engraved on a bâton de commandement from Raymonden (Dordogne).

Our next step must be to shew how the animals in the foregoing list may be grouped chronologically. It is a matter of common knowledge that certain animals, such as the reindeer and the polar bear, flourish in cold regions only; certain others, such as the ape, the lion, and the elephant, need a considerable degree of warmth; and others, such as the rat, appear to be indifferent to variations of temperature.

\section{The Climatic Classification of these Animals}

A classification of the more important animals in the foregoing list, with regard to the climate appropriate to each, would run as follows :

I. Animals definitely adapted to a warm climate:

The Primates

Felis leo, pardus

Hippopotamus amphibius
Rhinoceros mercki

Elephas (except E. primigenius)

Hyaena crocuta

II. Animals which prefer a genial climate, but may be found associated with a steppe fauna:

$\begin{array}{lll}\text { Canis lupus } & \text { Ursus arctos } & \text { Cervus dama } \\ \text { Canis vulpes } & \text { Sus scrofa } & \text { Equus caballus }\end{array}$

III. Animals of the steppes:

$\begin{array}{llll}\text { Spermophilus } & \text { Alactaga } & \text { Saiga } & \text { Elephas primigenius } \\ \text { Myodes obensis } & \text { Lagomys } & \text { Rhinoceros tichorhinus } & \text { Equus hemionus }\end{array}$

IV. Animals of the tundras:

$\begin{array}{llll}\text { Caris lagopus } & \text { Arctomys } & \text { Myodes lemmus } & \text { Ovibos } \\ \text { Gulo } & \text { Myodes torquatus } & \text { Rangifer tarandus } & \end{array}$

The above are the most valuable animals for a thermometric determination of the nature of an archaeological site.

\section{The Effect of the Ice Age on European Mammals}

If we take the animals of the world alive at any one moment of time, and study their geographical distribution relative to climate, we have only one element to take into account-that of space. But when we study, from this point of view, the animals of Europe during the Pleistocene epoch, we must in addition take into account the element of time. For with the glacial fluctuations, the climate of any one spot, especially in the centre and the north of the Continent, underwent very considerable changes. This adds in no small degree to the complexity of our task. We have to take each of the phases in the glacial epoch in turn, and consider separately, under each, 
the different zones into which in the last chapter we divided Europe. It may be questioned whether the materials which have so far accumulated from researches in ancient deposits are sufficient to enable us to compile complete lists of the fauna of these different regions and periods. The following is merely an outline.

\section{END OF THE PLIOCENE, JUST BEFORE THE BEGINNING OF THE ICE AGE}

Macacus tolosanus survives in the Southern Zone.

Of the Carnivora, Canis megamastoides is found in the Middle Zone; two other species, C. etruscus and C. falconeri, survive in the Southern. The bears are represented by Ursus arvernensis in the Middle, and $U$. etruscus in the Southern Zone. Two Pliocene hyaenas, $H$. perrieri and $H$. arvernensis, appear over all Europe. The true cats have scarcely yet appeared, their place being held by Machaerodus, of which there are several species over the whole Continent. There are, however, two Felidae, Felis arvernensis and $F$. issiodorensis, which have appeared in Italy.

The Rodents are represented by early species of Trogontherium, Castor, and Hystrix, in the Middle and Southern Zones.

The Ungulata whose remains belong to this period are: Sus giganteus in the south: Hippopotamus amphibius over all Europe (including England): Cervus sedgwickii and ctenoides in the south, douvilii and pardinensis in the middle, carnutorum in middle and north, etueriarium over all Europe. Capreolus cusanus in the middle. Leptobos strozii and etruscus in the south, elatus in the middle - the first cattle to arrive. There are also some gazelles in the middle and north, and some Palaeoreas (primitive eland) in middle and south. A tapir (Tapirus arvernensis) survives from the Pliocene epoch in the middle and south: and Rhinoceros etruscus is found over the whole Continent. The elephants are represented throughout the whole Continent by the gigantic Elephas meridionalis, which attained a height of over i 2 feet; Mastodon arvernensis, similarly throughout the Continent; and Mastodon borsoni, confined to the middle and south.

\section{THE FIRST GLACIATION}

We have insufficient material for the study of the effect which the first glaciation produced upon the mammalian fauna of Europe. Probably it was slight in comparison with that of the much more severe glaciations which followed. There was little difference between the fauna of the time immediately preceding this glaciation and of that which followed it; the profound modifications which the 
Pleistocene era witnesses in the animals of Europe had hardly yet begun. Probably the chief effect of the first advance of the ice was to thin out such of the Pliocene species as were unable to withstand or to adapt themselves to the more adverse conditions of climate, and to cause the survivors to withdraw from the middle of the Continent to more genial surroundings in the south, whence they came back after the return of favourable conditions.

There does not seem to have been any notable invasion of Arctic fauna during this first glaciation. Ovibos moschatus, which has been doubtfully identified in some early glacial beds in England, is perhaps the only pioneer of its kind.

The flora suffered severely, and all species of trees of modern American types now disappeared from Europe.

THE FIRST INTERGLACIATION

Macacus tolosanus still survives in the south.

The ordinary Canidae, Canis lupus and vulpes, probably also Cuon alpinus, are found throughout the Continent. Canis megamastoides has vanished, as have $C$. etruscus and $C$. falconeri. The bears are represented by Ursus ferox and $U$. spelaeus. which have almost completely taken the place of $U$. arvernensis and $U$. etruscus. The Pliocene hyaenas still, apparently, survive throughout Europe: and Machaerodus'still holds the place of the Felidae, though in diminished number and variety. The Rodents are unchanged.

Among the Ungulata, Hippopotamus amphibius survives throughout the Continent. Cervus sedgwicki survives from the Preglacial fauna, and in addition $C$. giganteus and $C$. elaphus have now come into the middle and north. Alces latifrons now makes its appearance: Capreolus survives. Palaeoreas and Tapirus have now left Europe. Leptobos remains, and the cattle are powerfully reinforced with Bison priscus and Bos primigenius. Ovibos moschatus is doubtful. Equus stenonis still represents the horses, and Rhinoceros etruscus the rhinoceros. Elephas meridionalis and its variety, E. trogontherii, are still the representative elephants; Mastodon has gone.

\section{THE SECOND GLACIATION}

The second glaciation was the turning-point in the development of the later aspects of European fauna. It was a time of deadly slaughter. Macacus (except in the Pyrenees, where $M$. tolosanus has "been found), the early hyaenas, Machaerodus, and Cervus sedgwicki are now practically cleared out of Europe. Elephas meridionalis also goes, except in Spain, where it seems to linger a little longer. There seems to have been no accession of Alpine or Arctic fauna to compensate for these losses. 


\section{THE SECOND INTERGLACIATION}

Macacus tolosanus, as has just been said, remains in the Pyrenees, and associated with it there have been reported survivals of $\mathrm{Ma}$ chaerodus. Otherwise these species have gone. Canis neschersensis occurs in Central Europe, in addition to the better known Canidae. Pliocene species of Ursus still linger, as well as of Hyaena; but Hyaena crocuta is the characteristic species. The Felidae are now well established; we have $F$. catus, spelaea, issiodorensis (a primitive lynx) and pardus. Among the Ungulata, we find Sus scrofa, Cervus elaphus, euryceros, capreolus, giganteus, intermedius, and, for the first time, dama; Alces latifrons, Bos primigenius and priscus; Equus stenonis, and, along with that small species, two larger varieties, E. masbachensis and E. süssenbornensis; Rhinoceros etruscus, with in addition mercki; Hippopotamus, diminished in numbers and in size; and Elephas trogontherii, with in addition E. antiquus, which is destined to supplant it altogether.

\section{THE THIRD GLACIATION}

The third glaciation witnessed an important zoological event in Europe-the first invasion of the centre of the Continent by Arctic fauna, adapted to the tundra conditions that then prevailed. Hippopotamus, Equus stenonis, and Rhinoceros etruscus were eclipsed, though the first and third of these made one more return in the third interglaciation. Several species of Cervus have now disappeared. In their place came Rangifer tarandus, apparently its first appearance in Europe-but not in such numbers as in the later glaciation-Rhinoceros tichorhinus and Elephas primigenius, animals better adapted than others of their kinds to withstand the cold of the steppes and tundras on account of their covering of hair. With them came Gulo borealis, Ovibos moschatus, Mustela erminea, and Canis lagopus. Especially noteworthy were the enormous numbers of small rodents-Myodes torquatus, Arctomys nivalis, A. bobac, Lepus variabilis; indeed, the bed of bones of these animals is often one of the most striking features in the stratification of a deposit whose period cuts across this and the following glaciations. For the rest, the chief animals of this period were Ursus spelaeus, Felis spelaeus, Hyaena spelaea, Rupicapra tragus, Capra ibex.

\section{THE THIRD INTERGLACIATION}

The Arctic fauna disappeared as it had come, when the Arctic conditions gave place to a return of the forest conditions. There was a closer approximation to modern forms than there ever had been before. The Canidae were of the ordinary forms, C. lupus and vulpes; 
Ursus arctos and spelaeus represented the bears. Mustela martes and Guloborealis or a variety thereof remained to represent the Mustelidae. The hyaena was the common H. striata. Felis catus, leo, pardus, and manul represented the cats. The small rodents had retired. The Ungulata were Sus scrofa, Cervus elaphus and capreolus, Alces latifrons, Bison priscus, Bos primigenius, Elephas antiquus, Rhinoceros mercki. Hippopotamus and Rhinoceros etruscus appeared for the last time.

As the fourth glaciation drew near, and the forests gave place to steppes, there were notable modifications in this fauna, at least in central Europe. The Felidae declined in numbers, the small rodents began to return-in archaeological deposits there are two wellmarked bands of their bones ${ }^{1}$ - and the Cervidae gave place to the horses, Equus caballus, przvalski, and hemionus. Rhinoceros tichorhinus supplants $R$. mercki, which finally disappears, and Elephas primigenius takes the place of $E$. antiquus which likewise finally disappears. Rangifer tarandus begins to return.

\section{THE FOURTH GLACIATION}

The fauna of the fourth glaciation resembled in general that of the third, but with a considerable increase in the proportion of Rangifer tarandus.

\section{THE POST-GLACIAL PERIOD}

Elephas primigenius lasted on at any rate until the Bühl-stadium in central Europe, and Cervus giganteus into the Gschnitz. Rangifer tarandus likewise lasted on in the mainland of Europe till the Gschnitz, when it finally retreated to the north. Bones of a small lion have been found between Palaeolithic and Neolithic deposits at SaintMartory (Haute-Garonne) ${ }^{2}$. Otherwise there is but little difference between the European fauna of the Neolithic period and that of the modern Continent.

\section{The Animals most useful for Chronological Purposes}

Summarising what has been said in the foregoing chapter, it will be seen that the most important groups of animals from the chronological point of view are the following:

I. The small arctic rodents, which delimit the later interglaciations.

1 The strata of rodents differ from one another in the preponderance of Myodes in the lower stratum, Lagomys in the upper.

2 Edouard Harlé, "Restes d'élan et de lion dans une station préhistorique de transition entre le Quaternaire et les temps actuels" (L'Anthr. v. [1894], p. 402). 
2. The elephants. The following table is a convenient statement of the chronology of this group of animals:
Elephas meridionalis alone
Pliocene ${ }^{1}$.
$E$. meridionalis with $E$. antiquus ...
E. antiquus alone
$E$. antiquus with $E$. primigenius ...
$E$. primigenius alone
Early Pleistocene.
Lower Palaeolithic.
Late Lower Palaeolithic.
... Middle Palaeolithic.

The three species are said to have been found together in the gravels of Tilloux and in the Cromer forest-bed, but confirmation is needed in both cases. Elephas antiquus alone is found at Chellessur-Marne and at Taubach; it does not happen to occur in the important station of Krapina, but Rhinoceros mercki, an animal always associated with $E$. antiquus, is found there. E. antiquus associated with E. primigenius is found in the late Lower Palaeolithic beds of Saint-Acheul. Fuller particulars about these sites are given below.

3. The reindeer.

4. The horse.

The animals which were most frequently depicted on the cave walls, and whose remains most frequently appear in the middens of ancient settlements, are naturally the various species of Ungulata; the Carnivora are seldom portrayed ${ }^{2}$.

1 On the question as to whether Man and Elephas meridionalis were contemporaries, see P.Favreau, "Neue Funde aus dem Diluvium von Neuhaldensleben" (Z.f.E. xxxvir. [1905], p. 275 ; see also F. Wiegers' comments, p. 91 5 of the same volume).

${ }_{2}^{2}$ Further particulars on the subject of this chapter can be obtained from any of the numerous text-books of Palaeontology, such as Nicholson's Manual (third edition, London, 1889), or Von Zittel's Textbook (trans. London, I9r3); R. F. Scharff, The History of the European Fauna. (London, 1899); H. F. Osborn, The Age of Mammals in Europe, Asia, and North America (New York, 1910); A. Nehring, Ueber Tundren und Steppen der Fetzt- und Vorzeit, mit besonderer Berïcksichtigung ihrer Fauna (Berlin, I890). 


\section{CHAPTER IV}

\section{ANTHROPOLOGICAL PROLEGOMENA}

\section{The Descent of Man}

IT is not our purpose in the present work to enter into the question of the physical descent of Man. The subject could not be studied here except in the most general way; and in spite of all the research of the past 50 years, too little is as yet known about it to make any such superficial discussion at all profitable. It could at best be little more than a record of more or less empirical speculation.

A man does not differ essentially, in his bodily structure, from the animals that most nearly resemble him-that is to say, the anthropoid apes. The body of Man has certainly been developed by evolutionary processes from the body of a much humbler ancestor. It has many anatomical details which cannot be explained except as vestigial relics of corresponding details in the bodily structure of its animal forebears. Man and the chimpanzee are shewn to be closely related by the fact that human blood, and the blood of the chimpanzee, respond sympathetically to certain chemical tests-in accordance with a remarkable law of physiological chemistry, which has proved, inter alia, to be a valuable guide to the determination of the nearness of relationship in different species of animals ${ }^{1}$. We are entitled to say this much. But when we endeavour to draw up a detailed genealogy of the Primates, with man and the different species of apes represented in their proper relative positions, we find ourselves involved in difficulties at every step.

Fach new species of fossil ape, as it has come to light, has been hailed in its turn as the long-sought forerunner of the human species. But invariably sober criticism has dispelled these premature enthusiasms. An attentive examination of the bodies of recent apes, and of the fossils of all known extinct species of apes, has resulted in placing them on side branches, not on the main human stem. Man has not developed out of any known species of ape, recent or extinct. The relationship is cousinly, not ancestral; the respective lines of descent do not unite until we reach an unknown common progenitor, far back in the beginning of the Oligocene epoch.

1 On this subject see G. H. F. Nuttall, Blood Immunity and Blood Relationship (Cambridge, 1904) esp. p. 444 . 
The reader will find a diagram of the complicated genealogical tree of the Primates, with its ramifications branching from a common point in the Oligocene era, in Hoernes' Natur- und Urgeschichte des Menschen, vol. I. p. I93. He will find another in Keith's Antiquity of Man, p. 509. He will find a third in Osborn's Men of the Old Stone Age, p. 54. He will find others in other books ${ }^{1}$; but these three will suffice. The works which we have named have been written by authors of established reputation, and are easily accessible. When he puts these three tables side by side, and compares them each with the others, he will find that they are at total variance in almost every respect; and he will most likely draw the obvious and only reasonable conclusion from this disconcerting fact--namely, that no one has as yet attained to any real knowledge as to the immediate ancestry of Man, or to his degree of relationship to his nearest kin in the animal world.

\section{Homosimius}

This has not deterred speculators from exercising their imaginations on the reconstruction of a creature, fitted out with the elegant Latin name Homosimius precursor, and destined, as they would have us believe, to become the progenitor of the human race. We do not propose here to make any further contribution of this kind, to what is sometimes, paradoxically but not unsuitably, called "The Romance of Science." We thankfully adopt in these pages the name Homosimius, on account of its convenience, as a quasi-algebraical symbol, whenever we may have occasion to refer to the creature which doubtless immediately preceded Man in the genealogical scale. But this creature is as yet an unknown theoretical abstraction, and we shall not presume to describe its life-history or its external form. There is no evidence on which to found any such description.

\section{The Test of Humanity}

For us the question of most interest at this point must be, What is the test whereby we can distinguish Homó from Homosimius? At what stage in the development does this product of evolution become entitled to be called a Man?

Physically there are four leading points of difference between the Man and the ape, and we may presume (though it is only a presumption) that in these points Homosimius would have held an intermediate position. These are:

I. The great size and weight of the brain in proportion to that of the body; and its superior development, whereby certain faculties,

1 E.g. in H. Klaatsch, "Die Aurignac-Rasse und ihre Stellung im Stammbaum der Menschheit" (Z.f.E. XLII. [1910], p. 567). 
such as that of speech, impossible or rudimentary in the ape, become possible in Man.

2. The flexibility of the hand, especially the human power of opposing the tip of the thumb to the tips of the four fingers.

3. The special adaptation of the foot for walking and for balancing, and for these functions only. In the ape the hand is a hand, and the foot is a foot-the term "Quadrumana" sometimes applied to apes and monkeys is not strictly accurate. But these members, in their simian form, mutually supplement each others' functions to a degree impossible in their more highly specialised human form. As the human thumb is more "opposable" than the simian thumb, so contrariwise the simian great toe is to some extent opposable, but the human great toe is not opposable at all.

4. The erect posture, the adoption of which proceeds parallel with the development of the brain-though which is cause and which effect is a disputed question ${ }^{1}$. None of the apes can walk upright for any length of time without supporting themselves by means of the fore-limb in one way or another. In Man the upright posture having been fully adopted, the fore-limb has been left free to develop the hand as a touching and grasping organ, while the extremity of the hind-limb renounces its prehensile powers in order to perfect its balancing and carrying functions.

These differentiations, however, will hardly suit our purpose. We may venture to say that it is not utterly inconceivable that Homosimius might in time have developed all of these characters, except, perhaps, the use of articulate speech, to their fullest extent, and yet have fallen short of Manhood-remaining nothing more than an animal of the order Primates. Such a creature could hardly substantiate a claim to be considered a Man in the fullest sense of the word.

Indeed, it is not in his bodily structure, but in his mental and psychical constitution that the lowest Man differs profoundly from the highest ape. Perhaps the difference can best be expressed by saying that Man is the first living being which revolts against a merely animal existence.

All other living creatures are content with the ordinary cycle of animal life. The life-history of the chimpanzee, or of an intelligent dog, differs little if at all, in its essential details, from that of the primitive creatures of remote geological epochs-a round of birth; of eating, sleeping, and reproduction of the species; and then of death, finally terminating the activities of the individual. So far

1 On this subject see R. Munro, Prehistoric Problems (London, 1897), chap. II. See also F. Wood-Jones, Arboreal Man (London, 1916), passim. 
back as we can trace Man, he is fighting against this monotonous routine. Indeed, the story to be told in these pages is essentially a record of the struggle.

For example, Man develops an aesthetic sense, and gathers possessions not necessary to the animal functions enumerated above. It may be possible to detect a rudimentary aesthetic sense in some animals: perhaps-though this is by no means certain, even if it be likely - the accumulation of useless odds and ends by the magpie may indicate something of this kind. But what animal would willingly undergo pain and inconvenience (as in the process of tatu, for instance) to gratify the aesthetic sense? The domestic cat is rarely proud of the ribbon with which its mistress decorates it, but does its best to get rid of it as a nuisance.

Again, Man develops a religious instinct, which is to a large extent, if not chiefly, interested in the problem of life after deatha revolt against the animal finality of the extinction of the individual. We cannot penetrate so far into the arcana of animal psychology as to tell whether they have any rudimentary conception of an elysium, but this is highly improbable. Many writers have attempted to describe man's religious instinct as a purely animal impulse, instancing in support of this view what they call the anthropolatry which a dog displays towards its master, even when the master is not kind ${ }^{1}$. The devotion of the dog in such circumstances is a wonderful, we might almost say a sacred thing; but after all it is nothing more recondite than a question of the source of food. Kind or not, the dog's master feeds him. There is little or no "anthropolatry" in the masterless curs of an Oriental city, which forage for themselves. The affection of the dog had been impressed upon him from without, by generations of domestication and feeding, and, on the whole, of good treatment. The theolatry of the Man, whichever of a multitudinous possibility of forms it may take, is essentially different. It is an instinct coming from within. The dog is devoted to a superior being who is visible; the Man worships a Power who is essentially invisible, though supposed to be occasionally discernible in various impressions on the senses (such as the noise of thunder). The dog's affection is concentrated on the source of his good; the man's religious feelings are centred in a Being often believed to be implacably hostile. Indeed, this conception of a "jealous" god is only another way of expressing the revolt against the limitations of the animal. Man is ambitious of higher things; he would pile Pelion on Ossa, he would build a

1 See, for instance, Ch. Letourneau, "L'évolution mythologique" (R.E.A. vol. I. [1891], p. 65 ff. esp. p. 68). 
Tower of Babel to scale the heavens; but the god is keeping him down.

The same revolt, once more, is expressed in the mystery in which almost from the beginning of human existence the functions and organs of reproduction are shrouded; it is the expression of a deeprooted desire to "de-animalise" the animal part of the nature of Man.

This essential instinct of mankind is the more extraordinary, inasmuch as in all external respects the man is nothing more than a highly developed animal. Even his brain is similar to that of the ape, and its parts correspond with those of the ape brain. Its details are however much more complex, and in proportion to the size of the body it is much larger. If a man and an orang-utan, both normally proportioned, and of equal weight, could be found, the weight of the man's brain would be about three and a half times that of the ape's.

We thus come to an apparent paradox, which suddenly breaks the ordered course of evolution. The more perfect the animal is made, the harder does it strive to cease to be an animal.

This endeavour to "de-animalise" the animal is the self-expression of the "soul" of Man-a term which we use here simply for convenience, without expressing any opinion, much less embarking on any discussion, of philosophical conceptions or theological dogma. But though we can trace this instinct back to a very early stage in human history, as will be seen in the pages of this book, we shall find it convenient, even essentiai, to discover a simpler test of humanity than the possession of a soul. Obviously no anount of research among the bones of long-dead men or animals could determine whether they had souls or not. Nor will the possession of articulate speech serve our purpose; for though from a study of jaw-bones and brain-cases we might be entitled to say whether their owners could speak if they tried, we could not say with certainty that they had actually discovered and exercised this latent gift.

\section{Man a Tool-fashioner}

Our quest for a criterion of humanity reaches its goal when we call to mind that Man, and Man alone, is a tool-fashioner.

Observe the expression, a tool-fashioner; not merely a tool-user. Apes will use stones for cracking hard nuts. Lower down in the scale of creation, sea-birds will drop molluscs from a height on to a rock, in order to get at the meat-using the whole world as a tool with which to break the shell. But no animal fashions a tool out of the raw materials with which nature supplies it. An ape may perhaps belabour an enemy with a stick; but it would not occur to 
him to trim the stick of set purpose, in order to make it more easily grasped, or to increase its efficiency as a club. The universality of this limitation is hardly disturbed by a few phenomenal instances of intelligence on the part of apes and other animals in captivity. In all such cases the initiative has doubtless been supplied, consciously or unconsciously, by the animal's keeper or owner.

That animals have constructive instincts and capacities cannot be denied, in the face of the fact that beavers and birds, and even bees, wasps, and ants, make dwellings for themselves. But they use no tools for the purpose other than those which they possess by nature. To put the distinction in another way, the constructive powers of animals are limited to the first degree-animals make things (nests, dams, etc.): the constructive powers of Man rise to the second degree -Man makes things by means of which to make other things. In describing Man as the tool-fashioning animal, it is to be understood that the meaning of the word "tool" is not to be confined to the instruments of a craftsman, but is to be extended to include everything in nature pressed into his service and modified artificially to suit his ends - the fuel of fire, the materials of clothing, and so forth. We thus arrive at the following important principle-If at any place, and in any geological level however ancient, we find artificial tools, designed not for their own sakes but for the purpose of fashioning other objects, then we must conclude that Men have been there, even if not a single human bone remains to us.

It is not to be supposed that by formulating this principle we make the study of the beginnings of Man in Europe a simple and straightforward matter. For, as we shall see in the following chapter, the essential question as to whether certain flint chips were or were not meant to be used as tools is one which has divided the whole body of "Pre-historians" into two hotly opposing camps. But having adopted "tool-fashioning" as a test of humanity, we exclude the view held by some writers, that these supposed primitive tools were the work of Homosimius. A tool-fashioning Homosimius is a contradiction in terms. If Homosimius was an animal, he did not fashion tools; if he fashioned tools, then he was a Man.

\section{The Classification of Human Communities}

Such, then, is the being whose early activities in Europe we are to examine. But before we come to close quarters with the first Europeans, we must prepare ourselves for the encounter by laying down the general principles on which we are to study them and their handiworks. Classification, within the limitations defined in 
our first chapter, is the foundation of all scientific work. To study primitive, or indeed any, Men, we must first classify them: and in order to do so, we must settle the bases upon which such classifications are to be set out.

There are several characters in terms of which human communities can be divided into groups. We can divide them physically; the most obvious form of such a classification, though at the same time one of the crudest, is by skin-colour, white, black, brown, red, or yellow. Then we can sort them out linguistically, according to the affinities of the languages which they speak. A religious classification is appropriate to some branches of anthropological research. Further we can draw up a cultural classification, depending on the stage of civilisation to which our tribes have attained, and on their mode of life and general standard of manners. Finally, we may often have occasion for a social classification, based on the organisation and constitution of the tribe as a community.

Of these different bases of classification, all but the first depend upon environment. The Ethiopian cannot change his skin; but he may chance to be born in surroundings where, as he grows up, he assimilates a language, social customs, cultural attainments, and a religion, totally different from those of his near but stay-at-home relations. Thus we must consider the racial or physical classification of mankind quite apart from the other bases of classification. The latter are not completely independent of one another. The religious beliefs and the social order often interact, as also do culture and language - for a language associated with a superior culture has always a tendency to swamp languages that have not such an advantage.

We may now proceed to the details of these bases of classification. We confine ourselves to describing them only in so far as they may be useful to us in our present study; to give a complete account of them would more than fill the entire book.

\section{i. Racial Classification}

\section{Definition}

All confusion of "Race" with the other bases of classification, especially Language, must be carefully avoided. Thus, to take a notorious case, we often hear such an expression as "The Celtic Race." This is quite meaningless; there is no such thing. There is a certain family of languages closely related to one another, called the Celtic languages, and those who by nature are speakers of those tongues may be called Celtic, or, better, Celtic-speaking. But within 
the narrow limits of those born to speak the Celtic languages are to be found almost every variety of racial type that we can identify over the whole of Europe; and contrariwise, there are groups of people of identical racial types who never so much as heard a Celtic language spoken.

The physical and temperamental peculiarities which define races of human beings are very numerous, and they are different in different parts of the world. Almost every one of the parts of the body, almost every mental idiosyncrasy, may, in one place or another, assume some degree of importance as a test for race-discrimination. But it is well to bear constantly in mind certain principles, which would appear to be sometimes forgotten by those who classify racially the scanty remains of men of the Palaeolithic period available for our examination. When we wish to determine the racial affinities of a population, the method adopted is to make as large a number as possible of observations on the characters of individuals in the population-their head-shapes, statures, pigmentation, and so forth. Having tabulated the measurements thus obtained, we draw averages from them, and conclude that the population belongs to this race or that, according as certain specific characters are found prevalent or evanescent. But it does not follow that any particular individual, whose name we may pick out from a census-roll of the community, will be found to have all, or even a large proportion, of the typical characteristics. "Race" is the expression of the average of a population-group, not the description of any one individual in that group. A race cannot define an individual, nor can an individual define a race.

This distinction, which is very important, can be understood by considering the accompanying diagram (Fig. 35). Suppose that the circle represents the whole of a community in which we wish to isolate the typical members. Let us say that the community proves to be, on the average, long-headed; then the short-headed people, represented by the area $A C B$, must be excluded for the purpose which we have set before us. Suppose the community to be fairhaired; then $C E D$, the dark-haired people, must be cut out. Suppose it to be tall: then we must remove the short people, represented by $E D F$. We have now whittled down the original circle to the comparatively small area marked $X$ in the diagram, and its proportion to the area of the circle will give us the proportion of really typical individuals which we shall find in the whole community. By applying further tests we may still further reduce the area $X$, and it is quite possible, and not a mere paradox, that by continuing the process we may make it vanish altogether. This would seem to be a reductio ad 
absurdum; but it is really a truth, which can be illustrated in a very simple way. We all know the typical figure called John Bull, and we have an instinctive feeling of his suitability to express ideally the people for whom he stands. But we may travel through England from end to end and hardly meet a single person in the least resembling that figure. The reason is, that John Bull is a sort of composite photograph, a collection of traits some of which most Englishmen have, though in every possible variety of selection and combination; but which very few Englishmen possess in their entirety. The caricatures drawn of a people by a foreign artist are always instructive from this point of view; they shew what features, mental or physical, strike the observer who views the people as a whole, from an external standpoint. The caricature is an expression of averages; and so are all scientific tables of racial criteria.

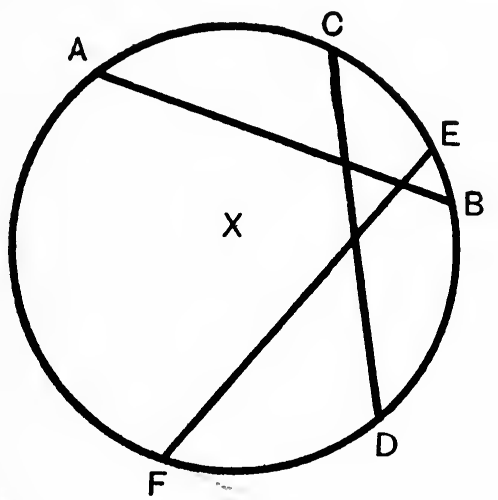

Fig. 35. Diagram to illustrate the relation between racial and individual characteristics.

The converse of the principles set forth in the foregoing paragraph is equally true. Suppose that we were to meet one single individual belonging to a certain country, and find him to be, let us say, fair-haired; we cannot infer that any appreciable proportion of his compatriots will have the same peculiarity. We may have hit upon an abnormal specimen. This applies with the same force to peculiarities in primitive bones-even with greater force. There are ways open to us of finding out whether our fair-haired friend is or is not a typical representative of his people. But when a single isolated prehistoric skeleton comes to light having a certain abnormality, we are absolutely in the dark as to whether this abnormality was or was not an individual peculiarity. In such a case it is in the last degree rash to so much as suggest that at some time in the future the abnormality will prove to be a racial test. Our duty ends with 
recording the fact of the peculiarity; we are not entitled to take a single step further.

It may be granted that there is no such thing as a causeless abnormality, though we may not be competent to determine the cause in every specific instance. In the example just supposed, should the fair-haired man prove to be unlike his fellows in this respect, we might reasonably conclude that he had inherited his unusuallycoloured hair from some ancestor-it may be, a remote ancestoralien to the race from which the majority of his community were drawn. An absolutely pure race does not, indeed, exist: symptoms of mixture are to be found, even in the solitary communities of the Oceanic Islands.

But here someone may say, that in such a case the man's complexion after all does define the race, not necessarily of himself, but of the hypothetical ancestor. To a certain small extent this is true; but the admission does not affect our principle. For in the first place it is not inevitably true that personal peculiarities are necessarily derived from inheritance. Some of them may be due to prenatal influences or accidents affecting the one individual only, and having no more bearing upon the question of his race than had Jacob's unprincipled experiments with the flocks of Laban ${ }^{1}$ upon the breed of the sheep. In the second place, race is not defined by one idiosyncrasy only, but by a combination of a large number, and few indeed are the individuals who possess the complete combination.

This fact is to a large extent due to the inextricable mixture which has taken place over the whole world, producing unions of characters that are eliminated by the process of averaging. It might have been supposed that when we found ourselves back at the furthest point to which we can trace humanity, an approximately pure race would have been discovered. The exact contrary is the case. Considerably less than 100 Palaeolithic skeletons or parts of skeletons are known, and these display greater mutual differences than would any assortment of a similar number of bones, thrown together at random from all parts of the modern world. Their mutual differences are indeed so great, that many of the most eminent authorities recognise not only distinct races, but distinct species and even distinct genera of mankind, differing from each other at least as much as a gorilla differs from a chimpanzee.

1 Genesis $\mathrm{xxx} .32 \mathrm{ff}$. 


\section{Race and Species}

It may be seriously questioned whether we have material enough at our disposal as yet-whether, indeed, we can hope ever to have material enough - to form the basis of theories so far-reaching. In saying that two skeletons belong to men of different species, what do we mean? Is it that their owners have descended by evolutionary processes from two distinct kinds of Homosimius, these in their turn having an equally divergent origin? But so long as even one species of Homosimius fails to report itself, what right have we to presume the existence of more than one? Again, is it that the two skeletons belonged to human groups that could not have interbred? But how can we say whether this was or was not possible? As knowledge stands at present, the use of the words "race" or "species" in this connexion can be little more than a question of arbitrary terminology, and raises questions which it is as yet impossible even to begin to answer.

Kazimierz Stolyhwo, in a notable article ${ }^{1}$, has shewn that out of 49 characters that have been supposed to prove the specific independence of the men of the Middle Palaeolithic, ordinary man approaches to these peculiarities in five, overlaps in 26 , and completely includes 18 within his own range of variation. He concludes that the line of demarcation that has been drawn by other investigators, such as Schwalbe and, later, Keith, is too absolute; and that the two groups, instead of representing two species, together constitute but one. To this line of argument there is a very obvious answer available, as it is only right to point out. Suppose the man of the MidPalaeolithic is defined by a number of physical characters, which all the skeletons or parts of skeletons possess; these we may denote algebraically thus

$$
A_{1}+A_{2}+A_{3}+A_{4}+A_{5}+A_{6}+\ldots
$$

And suppose that by contrast ordinary modern humanity differs to such an extent that its corresponding normal characters must be represented by different symbols, as

$$
B_{1}+B_{2}+B_{3}+B_{4}+B_{5}+B_{6}+\ldots
$$

If this be the case, we must allow the existence of two normals, which are not united into one by the accidental existence of individuals of mixed character, as

$$
\begin{aligned}
& B_{1}+A_{2}+B_{3}+B_{4}+B_{5}+\ldots \\
& B_{1}+B_{2}+A_{3}+A_{4}+B_{5}+\ldots
\end{aligned}
$$

1 "Homo primigenius, appartient-il à une espèce distincte de Homo sapiens?" (L'Anthr. xIX. [1908], p. 19I). 
and so forth. But this admission of two normals does not settle the question whether the normals are to be called species or widelydivergent races.

Let us for the moment make the impossible supposition that the whole of the complicated modern dog tribe had been part of the extinct Palaeolithic fauna, and that the only material for its study available were fragmentary skeletons of one mastiff, one bulldog, one Pomeranian, one Dachshund, and one toy terrier. The palaeontologist who had to reconstruct the relationship between these several animals would be in very much the same position as ourselves, when we try to find out something of the natural history of Palaeolithic Man from such of his osseous remains as have come down to us. Would not all of these dogs have been described, in the case supposed, as separate species? Zoologists, having ample material for studying the dog tribe, and being informed of the experiments in artificial breeding which have produced so many of its varieties, recognise at least most of them as specifically identical; and it may be questioned whether, if we had at our disposal as rich material for the study of Palaeolithic man, we should have so complicated a system of races and species as some of his investigators would seek to establish.

Indeed, the multiplication of generic and specific names in dealing with early man is of doubtful advantage. If we were to believe some writers, there were almost as many races, if not species, as there are skeletons: people talk of the "Krapina Race," the "Ipswich Race," and so on. Individual peculiarities are exaggerated into racial peculiarities, after the fashion of the tourist who noted in his diary, of a town where he had slept, "Everyone here has red hair" - that being a peculiarity of the night porter of the hotel, the only person whom he had seen in the place. When these skeletons are named with Latin names, after the model of the binomial nomenclature of species, the result is a positive source of error. We not infrequently see Homo krapinensis, Homo bréladensis and the like, which merely mean (or ought to mean) the particular skeletons or fragments found at the places indicated. This would be perfectly right and proper if the much-to-be-desired consummation were ever to take place-the restoration of Latin to its former place as the universal language of instruction and of scientific treatises. We should then say homo krapinensis quite naturally ${ }^{1}$ as in English we speak of "the man of Krapina," and our French colleagues of "l'homme de Krapina." But in an English setting Homo krapinensis, with or

${ }^{1}$ But not Homo krapinensis with a capital $H$. This necessarily implies a generic and specific nomenclature. 
without a capital $H$, is an affectation, and what is worse, a misleading affectation. The addition of a further specific name advertising the discoverer-in the formula Homo neandertalensis smithii-is in all circumstances to be deprecated.

In this book we express no opinion as to whether any group of Palaeolithic men did or did not form a separate species, and we give them no label that would imply any such specific classification. We do not believe that the evidence available is enough to bear any such conclusions, one way or the other.

With the exception of some slight fragments, no osseous remains of the men of the Lower Palaeolithic have as yet come to light. There are a number of bones of men of the Middle and Upper Palaeolithic terms so far known, and there are undoubtedly profound physical differences between these groups. It seems possible further to subdivide the people represented by the Upper Palaeolithic skeletons available into two, or perhaps three, separate racial groups. Beyond that we do not venture. We run the risk of exalting individual idiosyncrasies into racial characters if we attempt any further subdivision of the material at our disposal.

\section{Criteria of Race}

Of the numerous physical and temperamental peculiarities that define a race, the few most relevant to our present purpose may now be described.

Head-form. This is expressed by means of a number, obtained by measuring with a pair of callipers the length of the head from the glabella (the point of junction of the nose and brow) to the most prominent point of the occiput (the back of the head); the maximum transverse breadth, wherever it may happen to be; and then finding their proportion in terms of a percentage, by applying the formula breadth length

the seventies or the eighties; it is called the cephalic index, or cranial index ${ }^{1}$. Clearly when the index is high a broad skull is indicated, the breadth being large in proportion to the length; when the index is low, on the other hand, the skull will be long. Broad, medium, and long skulls are respectively termed Brachycephalic, Mesaticephalic (sometimes Mesocephalic), and Dolichocephalic.

1 It would be convenient to maintain a distinction between these terms, restricting cephalic index to measurements obtained upon the head of a living subject, and cranial index to those derived from a skull. In actual practice the terms are interchanged rather loosely. 
There are various schemes in use for classifying these figures. The simplest is what is called the trinary scheme, which is as follows:

$\begin{array}{lll}\text { Brachycephalic } & \ldots & \text { index above } 80 \\ \text { Mesaticephalic } & \ldots & \text { index between } 75 \text { and } 80 \\ \text { Dolichocephalic } & \ldots & \text { index below } 75\end{array}$

but the quinary scheme is more exact. This subdivides the first and third terms into two each. There is, however, a difference of opinion among authorities as to the terminology and limitations of each class; the method of Broca is as follows:

$\begin{array}{lll}\text { Brachycephalic } & \ldots & \text { index above } 83 \cdot 3 \\ \text { Hypobrachycephalic }^{1} & \ldots & \text { index between } 80 \text { and } 83 \cdot 3 \\ \text { Mesaticephalic } & \ldots & \text { index between } 77 \cdot 7 \text { and } 80 \\ \text { Hypodolichocephalic }^{1} & \ldots & \text { index between } 75 \text { and } 77 \cdot 7 \\ \text { Dolichocephalic } & \ldots & \text { index below } 75\end{array}$

while Deniker prefers an even more elaborate system, thus:

Ultrabrachycephalic (sic) ... index above 90

Hyperbrachycephalic $\ldots \quad$ index between 85 and 90

Brachycephalic $\quad \ldots \quad$ index between 83 and 85

Mesaticephalic $\quad \ldots \quad$ index between 80 and 83

Sub-dolichocephalic (sic)... index between $77 \cdot 7$ and 80

Dolichocephalic $\quad \ldots \quad$ index between 75 and $777^{\circ} 7$

Hyperdolichocephalic ... index below 75 .

It may be questioned whether such excessive elaboration (to say nothing of such inconvenient polysyllabism), is worth the trouble and confusion which it causes. The quinary scheme is quite minute enough to enable us to state the general relationship to other skulls of any skull which we may be describing; if we wish to define it more exactly, the figures themselves are more satisfactory than a multiplication of classificatory terms.

The most instructive way of setting out the results of the headmeasurements, or, indeed, of any other of the physical measurements with which we have to deal, is to reduce the observations upon population-groups to a series of curves, in which the horizontal coefficient of each point denotes the cephalic index, and the vertical coefficient the percentage of individuals possessing the index. Such curves express graphically to the eye facts which it requires a strong effort of the imagination to deduce from tables of figures. In a modern mixed population these curves are apt to be very complex, rising to a number of apices or maxima; we are probably to presume a different component element in the population for each maximum. The curves thus indicate clearly the degree of complexity in the composition of a population.

1 Some authorities give these words as Sub-brachycephalic, Sub-dolichocephalic; a microcosm of the Tower of Babel! 
Without measurement it is impossible to determine the cephalic index exactly ${ }^{1}$. But, as a rule, an observant traveller can form a rough general idea of the relative proportion of short and long headed people in a population by noticing the faces of the people as they pass. It is easy to distinguish a long narrow face from a short round face. The former kind is usually associated with a dolichocephalic, the latter with a brachycephalic skull. Heads in which this correlation does not exist-such as the broad-faced, long-headed Eskimo -are called dysharmonic.

The head of the living subject is slightly broader than the skull; but it would obviously be difficult to obtain a sufficient mass of data to determine the exact relationship between the cephalic and the cranial indexes, and in point of fact this relation is not certainly known.

It is still a matter of dispute how far head-shape is subject to modification by environment, natural selection, or other natural causes $^{2}$. If a population remain long subject to the same condition, the cephalic index remains constant. When we have an opportunity, as in Egypt, of studying the remains of many successive generations of a long unchanging population, fixed in one territory, we find that the average head-form remains constant from age to age. On the other hand, the frequently observed appearance of the Indian "hatchet-face" among the European immigrants into New Englandit is seen even in the national type of "Uncle Sam"- -seems to suggest that in some subtle and entirely unknown way a change of environment has a perceptible influence upon head-shape. The assimilation of type, in this case, can hardly be due to intermarriage. Observations upon Jews from different parts of the world point to the same conclusion; they tend to become assimilated to the dominant type of their surroundings.

Still, there is a sufficient degree of invariability in the cephalic or cranial index to render it the most useful instrument in the hand of the ethnologist. In order to shew the value of such observations, we may set forth in a few words some of the main results of investigations of head-shape in the population of the modern world. In Europe the head-form is mixed; the inhabitants of the north and the south of the Continent are on the whole dolichocephalic, but through

1 Some authorities have been daring enough to commit themselves to deductions as to the relationships of skulls deduced from measurements of photographs. No reliance can possibly be placed upon figures thus obtained, as the margin of possible error is enormous. It is hard enough to obtain satisfactory measurements from the skulls themselves!

${ }_{2}$ Natural, to exclude artificial modifications such as are practised by Chinuks, Natchez, and other tribes, who flatten or otherwise deform the heads of their infant children with tight bandages. 
the middle, along the ridge of the Alps, there runs a wedge of brachycephaly. The Africans are to a large extent dolichocephalic, while, on the other hand, the inhabitants of Asia, north of the Himalayas, are conspicuously brachycephalic. Already we seem to see, from this distribution of head-shape in the Old World, a historical event vaguely adumbrated: the irruption, from a brachycephalic "reservoir" in the East, of invaders, following the line of the Himalayas and the Alps, and cutting their way into the midst of the European continent, till then uniformly dolichocephalic, and probably peopled with communities of African origin. With one remarkable exception, no brachycephalic skulls have as yet come to light from Palaeolithic Europe, which fact suggests a date for this invasion, at the beginning of the Neolithic era.

In Oceania, the Fijians are among the longest-headed people known, and indeed dolichocephaly is the rule throughout the islands of the Southern Seas. In America the aboriginal inhabitants are on the whole dolichocephalic or mesaticephalic, though there are some brachycephalic tribes, especially in South America.

It is not amiss to say in passing that no deductions as to the mental powers of a race can be drawn from the average skull-shapea mistake to which the English-speaking student is especially liable, owing to the current use of the foolish slang expression "longheaded" to denote a certain form of intellectual superiority. Abnormal extremes either way are likely to be associated with mental abnormality; but the wide range of normal variation does not seem to be associated with a corresponding variation in mental powers.

Besides skull-proportions, skull-shape or outline is a character of racial importance. Skulls may not only be classified as long or broad, but they may also be classified according to the shape which they present when viewed from above-in norma verticali, to use the technical expression. This form of classification has been especially developed by the Italian anthropologist Sergi, who prefers it as a race-criterion to the cephalic index. He classes skulls under the following heads:

$\begin{array}{ll}\text { Beloid or sphenoid } & \text { broad at the back and narrow in front } \\ \text { Ellipsoid } & \text { of elliptical shape } \\ \text { Ooid } & \text { of egg shape } \\ \text { Pentagonoid } & \text { of pentagonal shape }\end{array}$

with a number of minor varieties.

Coloration. We have already seen that skin-colour is the most obvious way of distinguishing between different types of men; the most unobservant can tell a white man from a black man, and either from a red or a yellow man. The anthropologist needs to be more 
minute in his systematisation, and accordingly scales of colour, ranging in number from to to 34 , have been drawn up for classificatory purposes.

The ultimate cause of the difference of colour is probably some external stimulus, such as air, heat, light, or moisture; but the manner of its operation has not been satisfactorily ascertained. It is immediately due to a deposit of colouring matter in what are known as the pigmentation-cells, which lie in the skin beneath its outer transparent surface. These cells are present in all individuals, but the colouring matter is present in the darker coloured people in greater abundance. Once fixed, the colour is very persistent. It is well known that it requires many generations of intermarriage to eradicate the external evidences of a negro strain.

Whatever may be the reason, the colour divisions of humanity are almost conterminous with the continental divisions of the land. We may say, speaking generally, that Europe is the home of the white man, Asia of the yellow, Africa and Asia south of the Himalayas of the brown, America of the red, and Melanesia, with parts of Africa and a corner of Australia, of the black. The Ainus of Japan are the only exception to the rule that the white races are confined to Europe.

But this classification is too rough and ready for scientific purposes, for the reason that communities are brought together in each of these colour-groups differing in almost every other respect among themselves, and certainly belonging to different racial stocks. A more minute and trustworthy classification is afforded by hair and eye colour. The colour of the iris of the eye ranges from a pale washedout blue to deep brown; that of the hair from flaxen to black; and scales of colour have been prepared, by comparison with which people can be classified. In Modern Europe the line of the Alps, once more, forms a racial boundary in connexion with this element of distinction; it separated the fair (xanthochrous) northerners from the dark (melanochrous) southerners. Indeed, blue eyes are almost confined to the fair-complexioned people of northern Europe; elsewhere in the world they appear only as individual peculiarities.

For our present purpose, however, coloration is one of the least useful tests, for the simple and obvious reason that we cannot make observations upon coloration when we have nothing before us but dead skeletons. The Palaeolithic rock-paintings of Spain afford us no help in this particular, for they colour the figures conventionally. When in a later part of our study we reach the Iron Age, we shall then find that contemporary classical writers occasionally tell us something about the complexions of foreign peoples. But 
even such descriptions have to be taken with caution. These authors were not trained in modern scientific methods, and the anthropological value of such observations was naturally not understood in their time. Their descriptions are therefore not necessarily accurate, and are always influenced by the "personal equation" of the observer. Coming from the melanochrous populations of the south, they were apt to exaggerate the fairness of a xanthochrous northern community among which they may have found themselves; and returning home and writing up their observations from memory (which is what they probably did) they were most likely to exaggerate in this respect still further. In like manner the early travellers to South America brought home absurdly exaggerated reports about the stature of the Patagonians, who for a long time were supposed to be a race of giants $^{1}$, simply because they were tall in contrast to their European visitors.

Stature. The stature of normal individuals ranges, roughly speaking, from a little under 5 feet up to about 6 feet; authorities differ as to the exact limits of normality. The limits of variation of population-groups are rather narrower ( 5 feet to 5 feet 10 inches). This does not, however, take into account the dwarf or pygmy races, such as the Bushmen of South Africa or the Negritos of the East Indian Archipelago; if we reckon these with the rest of mankind, we bring the lower limit of normality down to about 4 feet 4 inches.

Stature, though doubtless a racial criterion, is subject to rapid modification by environment. Transfer a people stunted by a hard life in a poor country to a rich land, and they will rapidly improve in physical well-being; one manifestation of this will be an increase in stature. Reverse the process, and a contrary result will be obtained in the course of a few generations. The inhabitants of a low-lying fertile plain are as a rule taller than are those who dwell in barren and rugged mountain regions. Moreover, natural and matrimonial selection here come conspicuously into play. Tall people are, as a rule, stronger than short (within the limits of normality; giantism is either a cause or an index of weakness); and in a hard climate the weaker and more stunted are less likely to survive the rigours of life. Also, tall individuals are likely, on the whole, to select tall mates, with the result of maintaining tallness as a racial feature of the community.

Although every allowance must thus be made for environment, it can be shewn that the tall and the short peoples group themselves into definite zones, which do not always coincide with the zones of

${ }^{1}$ Compare the report which the spies brought back to Moses of the tall Canaanites, Numbers xiii. 32. 
fertility or other favourable conditions. Thus, the rugged and barren land of Scotland has a population which shews the highest average of stature in Europe. This is enough to prove that stature is fundamentally a racial character. In Europe the tall communities are found in the north, the short in the south; the people of the Alpine region are intermediate, and rather stouter in build than the southerners.

Hair-texture. The texture of the hair depends ultimately on the shape of the outline of a cross-section of a single hair. This may range from a circle to a flat ellipse. If the section be circular, each hair being cylindrical, the general appearance of the coiffure is straight - the kind alluded to in disrespectful argot as "rat's tail" hair. The Mongolians or the American Indians afford instances. If the section be flat and elliptical, so that each hair is ribbon-shaped, the tightly coiled "wool" of the negro is the result. Intermediate forms, according as they approximate to the round or to the flat shape, give the wavy variety of straight hair, common in Europe, or the frizzled variety of the coiled shape, such as is found among the Australians. Such intermediate forms are probably the result of a deep-seated and long-established blend. But, like colour, hair-shape is clearly of no service when we have nothing but skeletons to study. We can use it only as a basis of inference as to past movements and minglings of peoples, deduced from observations made upon their living descendants.

Eye-shape. Eye-shape, like head-shape, is expressed in terms of an index-the orbital index $\left(\frac{\text { breadth }}{\text { height }} \times 100\right)$. This enables us to divide the people of the world into megaseme (such as the Polynesians), mesoseme (Negroes, Europeans), and microseme (Australians). In the living subject the shape of the eye-opening is sometimes of racial importance, as for instance the oblique eye-opening of the Mongolian.

Nose-shape is similarly expressed by a nasal index (same formula as in previous indices, the length being measured from the root of the nose at the top to the lowest point of the nasal openings, and the breadth across the greatest width). This divides the people of the world into platyrrhine or flat-nosed (Australians, Negroes), mesorhine (Malays, Hindus, Mongolians), and leptorhine or prominent-nosed (American Indians, Europeans). In the living subject the shape of the soft parts of the nose is of racial importance; the nose may be straight, flat, convex, concave, with a large number of minor and intermediate varieties.

Face-shape, measured by a similar index (length from the glabella 
to the point of the chin, breadth across the zygomatic arches or cheek-bones), divides people into leptoprosopic or long and narrow faced, mesoprosopic or medium faced, and chamaeprosopic or short and broad faced. The correspondence which is usual between head proportions and face proportions has already been noted. Facial angle, expressing the degree of prognathism, that is, of outward projection of the lower part of the face (as in Negroes) is also an important measurement. There is some difference of opinion among anthropologists as to the most satisfactory way of calculating these indices.

The above are the principal racial criteria which concern us. There are others, which for our purpose are of minor importance, or which for one reason or another are inapplicable to the study of Early Man. For these we must refer the reader to special treatises ${ }^{1}$.

The causes of these race-variations in the human inhabitants of the world, ancient and modern, are to all intents and purposes utterly unknown. Environment has something to do with developing them, but it is not a master-key to every lock. For all we know, many of these differences may have their roots deep down in the pre-human stages of development.

We have already said something about the racial differences between the modern inhabitants of Europe, and for future reference may note that these, excluding a few isolated communities, are divisible into three race-groups, whose names and characters are as follows:

Scandinavian, Teutonic, or Nordic: dolichocephalic, xanthochrous, tall stature.

ALPINE: brachycephalic, melanochrous (or medium), medium stature and stout.

MEDITERRANEAN : dolichocephalic, melanochrous, medium stature and slight.

\section{ii. Linguistic Classification}

\section{Nature of Language}

Next, we can classify mankind according to the structure and affinities of languages. This classification cuts completely across the racial classification just described.

It may be thought superfluous to include here a section on linguistic classification, seeing that the languages of the Stone Age have gone beyond recall. Even if, as some scholars not unreasonably suppose, the very primitive tongue spoken by the Basques should be

1 Consult W. Z. Ripley, The Races of Europe (London, 1899); P. Topinard, Éléments d'anthropologie générale (Paris, I885); G. Sergi, The Mediterranean Race (London, I901); J. Deniker, The Races of Man (London, 1900). 
a survival from the Stone Age, it has been subject to evolutionary changes, like everything else that is human. A modern Basque would be as unintelligible to a stone-age man as he is to an average Englishman. We cannot therefore study Basque with the assurance that we are listening to anything resembling the speech of the cavedwellers. But when in a future volume we come to study the Iron Age, opportunity for linguistic classification will arise; and it is on the whole more convenient to marshal once for all the principles of study which we hope to adopt throughout.

The possession of language, and the power of extending its functions, like the art of tool-fashioning, distinguish all men from all beasts. Animals have a limited interjectional language to express their emotions; the bark of a dog welcoming his master, his yelp when hurt, his snarl against a doubtful stranger, the cry of a bird to its mate, the warning note of a hen to her chickens-all these are sounds meant to convey a sentiment from one being to another, which is the function of a language. But the language of animals is essentially unprogressive. A modern British cat or dog would understand an ancient Egyptian or Greek animal of like species, for the attempts made by ancient Egyptians or Greeks to express in writing the cries of these creatures would equally well represent the cries of their modern descendants. But the speech of man changes from generation to generation. It is progressive, and, in spite of the conservative influence of literature, is highly mutable.

We may define language as a convention established between a number of people, whereby definite sounds or combinations of sounds are associated with definite ideas or combinations of ideas. The connexion between the sound chosen and the sense to be conveyed is, as a rule, not traceable; we may call a certain animal a "cat," for example, without being able to explain why we use that particular combination of sounds for the purpose in preference to any other. Indeed, the choice of sound seems to be more or less arbitrary, except in the limited group of onomatopoeic words. This definition of language enables us to understand something of its probable origin. It must have been a gradual growth from the gibberings of Homosimius, and the development must have begun at a very early stage of the appearance of definitely human characteristics. If one of the almost human Homosimii had formed a habit of making a certain ejaculation whenever he saw a snake, and one of his fellows observed this fact and imitated him, then the two would have a language of one word, the very useful word whereby each warned the other of the presence of a dangerous reptile. To observe the habits of another, and to draw simple deductions therefrom, is quite 
within the power of an animal; a dog deduces that his master is going for a walk when he sees him putting his hat on. There would be no obstacle in the mental limitations of Homosimius, so far as we can imagine them, to his making so simple an observation as is suggested above, followed by an only less simple deduction and imitation. The exploration of the region of sound, the discovery of the capabilities of the homosimian throat for making different kinds of noises, the gradual accumulation of a series of association-groups between specific noises and specific ideas, would be nothing more than a matter of time and experiment.

\section{Groups of Languages}

Languages are primarily classified into isolating, polysynthetic, agglutinating, and inflexional. This classification is, however, almost if not quite as vaguely general as the classification of the speakers of language by their skin-colour, and that for a similar reasonit lumps together into broad groups languages which can have no sort of real connexion with one another.

In Isolating languages, of which Chinese is the leading representative, each word is a symbol denoting a group of ideas, and it may be treated without alteration of its form as any part of speech according to its position in the context. English, once a highly inflexional language, has shed nearly all of its word-modifications, and now approximates to the isolating stage, in which the boundarywalls between the parts of speech are breaking down. This for us in our present study has the convenient consequence, that instead of borrowing at second-hand and on trust incomprehensible examples of isolation from Chinese, we can find equally good and intelligible illustrations from current English. Consider these four expressions:
I. The ship-man
2. Man the ship
3. Ship the man
4. The man-ship

the first three of which are current, while the fourth, though improbable, would not be impossible in a suitable context, as the analogy of "the slave-ship" shews. Here "ship" is an adjective in the first, a noun substantive in the objective case in the second, a verb in the imperative mood in the third, and a substantive in the nominative case in the fourth. "Man" is a noun in the nominative case in the first, a verb in the second, a noun in the objective case in the third, and an adjective in the fourth. We need not here enter into further details about the isolating languages, such as the devices whereby the large number of different meanings attaching to the various roots in Chinese are distinguished. For such particulars reference must be made to special treatises. 
In the Polysynthetic languages, which form the group to which the tongues of the aborigines of America belong, the unit of language is not the word, but the sentence; indeed, the word has hardly any existence at all apart from the sentence. An English child, in learning his mother-tongue, passes through a polysynthetic stage; he acquires and understands sentences like "How do you do"-pronounced as one word, Howjedoo-before he learns to analyse them into their component elements. The Polysynthetic languages are marked by the enormous length of their verbal units, which are really inextricable compounds of words melted thus into one another; and the analogy of the child's acquisition of his own language suggests that they represent a very early stage in the development of speech, when ideas were expressed all at once, so to speak, without analysing them into the words which, put together in syntactic order, were associated with those ideas.

In Agglutinating languages, under which head there are a large number of entirely unrelated groups, the roots, which in the isolating languages form the whole sentence, and in the polysynthetic languages almost lose their individuality, are preserved intact, but are combined with a considerable number of prefixes and suffixes, in themselves meaningless, but exercising various forms of modification upon them. The degree of agglutination possible varies in different groups; it exceeds the possibilities of the inflexional languages in this direction, but falls short of the indefinite powers of composition displayed by the polysynthetic tongues.

We may take Turkish as a good example of a pure agglutinating language. The following instances will shew how such a language is constructed.

In Turkish, ghèm means "a ship." It can be combined thus with suffixes:
Ghēm-im, my ship.
Ghēm-imiz, our ship.
Ghēm-imiz-ler, our ships.
Ghēm-imiz-ler-den, from our ships.
Ghèm-iji, a ship-man or sailor.
Ghēm-iji-miz-ler-den, from our sailors.
Ghèm-iji-ja, in a sailor-like manner.

Again, in the same language, the root wür means "to strike." It can be compounded thus:

Wūr-mak, to strike (infinitive).

Wūr-ma-mak, not to strike.

Wür-ama-mak, not to be able to strike.

Wūr-al-mak, to be struck.

Wür-ash-mak, to strike mutually.

Wūr-dar-mak, to cause to strike. 
and should occasion arise there is nothing to prevent the accumulation of more than one of such qualifying suffixes into a single compound.

At first sight there appears to be little difference between Inflexional and agglutinating languages; and indeed, the boundary between these different groups is by no means hard and fast. Both agglutinating and inflexional languages depend for the modification of the meaning of their roots upon the affixing of syllables, meaningless in themselves, to the root. The difference lies in the limitation of the number of affixed syllables in the inflexional languages, and in the possibility which they possess of a modification of the root itself.

The most important inflexional family of languages is the IndoEuropean, to which the principal tongues of Europe and some of the chief Asiatic languages belong. It is divided into a number of groups, each characterised by phonetic and syntactic peculiarities, but all maintaining a close relationship of vocabulary and construction. The most important of these groups are the Indian, Iranian, Armenian, Celto-Italian, Albanian, Hellenic, Lettish, Slavonic, and Teutonic: in this family, the inflexions are for the greater part expressed by external suffixes. In the Semitic family, however, which does not affect the European populations, the roots consist of consonants, usually three in number, and the modifications of meaning are expressed not only by prefixes and suffixes, but also by duplications of the root consonants and by modification of the vowels with the aid of which the consonants are pronounced.

\section{Origin of Language}

The problem of the origin of language has exercised many minds and many pens, to little purpose; and so has the search for a common basis of comparison among the existing languages, from which something may be deduced as to the nature of the tongue that theoretically was the common parent of them all. The close kinship of the IndoEuropean languages, the still closer relationship of the Semitic tongues, makes it practically certain that each of these families is descended from a common ancestor. The Egyptian has certain points of resemblance with the Semitic group; this suggests that at some remote time the Egyptian group branched off from the main Semitic stem. But no success has crowned the numerous efforts that have been made to correlate the Indo-European group with the Semitic on the one hand, or with the agglutinating Finnish on the other.

It is not inconceivable that such apparently unrelated groups of 
languages are actually descended from a single ancestor. But proof of this must be considered as for ever beyond our reach: and there is no real necessity to suppose that there was ever a common parent speech at all-it is, indeed, highly improbable. It is not likely that a primitive man, or a Homosimius, in Java, and another in Sussex, would hit upon exactly the same expletive whenever he saw a snake. Each community would from the first establish its own group of conventions. Even if the tribes or communities all started from a common centre, where they first evolved their human or semi-human form, their languages would very quickly diverge. Every change of surroundings would bring new experiences, requiring new sounds to express them; and the accumulated body of these neologisms would very soon far exceed in bulk the common element which they had carried with them from the cradle of the species.

As intercourse between adjacent tribes developed, a lingua franca, composed of elements borrowed from their local jargons, would develop also, which in time might shape itself into a fully-organised language. Let us suppose that there were a number of communities, $A, B, C, D, \ldots$ living within a given area of territory. Three of these, which are adjacent, have intercourse, and develop a medium of speech which we may call $a$, composed of elements borrowed from each of their jargons. Three others, $C, D, E$, similarly develop a language $b$. $C$ is common to both of these groups, and if $a$ and $b$ should become the parents of families of languages, philologists may therefore discover common elements in the $a$-family and the $b$-family which will deceive them into supposing that these are derived from a single ancestor. Again, there may be three more groups, $B, F, G$, which form a language $c$. But perhaps the elements which $c$ borrows from the jargon of $B$ may be different from the elements which the language $a$ has borrowed from the same source. In that case the $c$-family will have no element common with the $a$-family, and yet it is actually as closely related to it as is the $b$-family, which does display such common elements.

This reconstruction of the beginnings of linguistic development, theoretical though it admittedly is, will shew the utter hopelessness of trying to arrive at a conception of the language of Homosimius, or even of Palaeolithic man, by reasoning back from existing tongues. Just as in studying geology we cannot penetrate more than a few miles into the crust of the earth, and our conceptions of the state of its interior can be nothing more than inferences based upon a balance of probabilities, so in studying language we have no materials to carry us back more than a few thousand years-a mere nothing in the history of mankind. 


\section{Fallacy of Linguistic Palacontology}

It will illustrate further the futility of the so-called science of linguistic palaeontology: ingenious and specious though the idea may be, to deduce some conception of the culture of the speakers of a parent language from the words common to the daughter tongues. If certain languages, $A, B, C$, descendants of a common ancestor, have words in common for a fox, or an oak-tree, or a ship, or whatnot; and if certain other languages, $D, E, F$, though belonging to the same group, have different words; it is inferred, by those who would follow this line of argument, that $A, B, C$, developed together in some place where foxes and oak-trees were to be found, and where men used ships; whereas these things did not come to the knowledge of the speakers of $D, E, F$, until after they had hived off from the parent stem.

But there are endless possibilities of cross-borrowing, for which we cannot sufficiently make allowance in such reasoning, and which vitiate all such conclusions. To give a single instance, the $A$ people and the $B$ people may have the same word for a fox, not because they grew up together in a common acquaintance with the animal, but because the $B$ people at some time raided the $A$ people and carried off their women wholesale; the women taught the word in their new life to their children, and so it became incorporated in the language of $B$. Such possibilities reduce to uncertainty all deductions as to common culture based upon common words.

\section{iii. Cultural Classification}

\section{Evolution of Culture}

The ascent of Man, from the level of the ape, even to the moderate degree of civilisation in which the end of the Palaeolithic era leaves him, was long and toilsome. The secrets of nature had to be won slowly, step by step.

The chain of this evolution was partly continuous, partly discontinuous. The assumption of the upright posture, the final differentiation of hand and foot, the slow development of language and the extension of its means of expression-all these must have advanced gradually, almost imperceptibly. Having thus slowly learned to walk and to talk, the human baby went to school, so to speak, and there, like the average English schoolboy of the twentieth century, he acquired a small modicum of useful information, and a vast amount of useless and inaccurate mental lumber. He learnt, on the one hand, that if you eat one kind of fruit you experience pleasant 
sensations, while if you eat another kind of fruit you go to sleep for such a long time that your wandering spirit loses its way and never comes back at all. Some of this information he had already acquired in his pre-human days; bold experimenters must have greatly extended it, and there were at this stage, as we cannot doubt, many victims of the fruit of the divine Tree of the Knowledge of Good and Evil. He also at this stage acquired a number of notions, perhaps to be counted among his less valuable lessons, such as that if a man drills a hole in his nose or his ear and puts a skewer of bone through it, he looks more attractive than he did before the process.

These were the gradual acquisitions; but from the beginning there must have been also sudden acquisitions. We speak of epochmaking discoveries, when some bold thinker succeeds in leaping the chasm that separates us from new and as yet unconquered worlds, and carries the banner of civilisation into regions of energy hitherto unexplored. Such epoch-making discoveries are not the monopoly of any time or place; they can be traced all through the history of civilisation.

The first discovery of this kind was doubtless that of means to produce fire artificially. No tribe of savages, however low in the scale, is ignorant of the use of fire, and hardly any is without means of kindling it $^{1}$. No ancient race has been discovered from whose remains are absent lumps of charcoal or other evidence of the use of fire. On the other hand, no species of animal, however intelligent, has any idea of how to light a fire, or how to replenish it when dying.

The maleficent properties of fire, as manifested in the lightning and the volcano, are at first sight more obvious than its useful and beneficial qualities. These latter, however, must early have been revealed by some means, and perhaps Lamb's Essay on Roast Pig, extravaganza though it be, is not so very far wrong as a reconstruction of the steps whereby they became known. We may suppose that, at first, mankind was dependent on natural sources of fire, such as we have just mentioned, and on keeping perpetually burning the flame which they kindled. Indeed, the difficulty of obtaining fire even in comparatively civilised times, before the invention of matches, made a perpetual hearth the least troublesome way of providing the household with this necessity, and so gave rise to all the fancies that religion has enshrined in the domestic altar. But accidents will happen; an unlucky rain-storm will quench the most carefully tended hearth; and the community dependent on the caprice of natural sources of fire will be in sorry case.

1 The Andamanese are among the rare exceptions: see E. H. Man, "On the Aboriginal Inhabitants of the Andaman Islands" (f.A.I. XII. [1883], p. 150). 
Somebody, somewhere, must have been the first man to light a fire. However he may have done it, the discovery cannot have been more than an accident, like so many other great discoveries. Sparks struck with a flint tool may have fallen upon and ignited a heap of dry leaves: heat generated by the rubbing of dry branches together in the wind may have suggested the production of fire by friction. It is impossible to say exactly how the accident may have happened, but we can safely say that the first man to light a fire was the first man to make an epoch-making discovery. We might indeed say in truth that it was he who made the epoch-making discovery, inasmuch as fire is at the basis of most of the other contributions to civilisation that succeeding ages have made. Without fire, for example, the next epoch-making discovery that followed-that of the fusibility of metals-would have been impossible.

\section{Bases of Cultural Classification}

On the general subject of Cultural classification there is little that need be said on the present page. The greater part of this book is virtually a study of the cultural classification of the inhabitants of Europe. We have already, in our first chapter, spoken of the division of the history of civilisation into the Stone, the Bronze, and the Iron Ages, with their subdivisions-the basis of all study of prehistoric Man. This we may call classification by the materials of culture. We can also from time to time make use of a second form of cultural classification which may be called classification by the instruments of culture, depending upon the kind of tools most prevalent in different centres or at different periods, and their form and the manner of their use.

There is a third variety of cultural classification of great importance, which we may call classification by mode of life. The earliest men with whom we come into contact are hunters and fishers, living entirely on the product of the chase, and on wild fruits. After a long time the discovery is made that certain species of useful animals are capable of domestication, thus inaugurating the pastoral life; and later still, it is found that the wild fruits can be artificially cultivated and improved, and the community thus becomes agricultural. In later chapters we shall indicate, as occasion arises, the changes which these discoveries made upon the life of Europe. For the present we content ourselves with the simple fact that communities may be culturally classified as hunters, pastors, and agriculturists, according to the means whereby the majority of their members obtain their livelihood. Another aspect of the same category 
is classification by habitation: we can sort communities into cavedwellers, nomadic tent-dwellers, or sedentary house-dwellers.

\section{iv. Social Classification}

\section{Organisation of Human Communities}

By Social classification is meant a classification on the basis of social or political organisation.

Mankind is essentially gregarious. In fact he must live in societies for mutual aid and protection, otherwise he will certainly perish. No man could live a Robinson Crusoe existence in a country infested by large and savage animals; nor could he satisfy all his own wants unaided, unless his lot happened to be cast on an unusually fortunaie island. Even there his death would mean the end of the human occupation of the island, until it was re-colonised. To hunt big game, with the very inadequate weapons at the disposal of Palaeolithic savages, requires the co-operation of a large number of persons. Such combinations must be organised upon some basis, otherwise they cannot stand. There must be rules and regulations, plans and schemes, whereby each man takes his proper place for the good of the community at large.

Again, the long helplessness which distinguishes the human infant from the young of all other animals has played a very considerable part in both the physical and the social evolution of humanity. It becomes absolutely necessary that a number of adults shall remain together in order to tend the wants of the children while these are unable to look after themselves. And as it is obviously natural that the near relations of the children should thus tend them, it follows that kinship is the readiest basis on which to found a scheme of social organisation.

\section{Kinship}

It being thus premised that a primitive community would most probably establish itself on some system of reckoning kinship, certain consequences will follow. In the beginning, the theory of kinship will be maintained by restrictions upon marriage, sanctioning union with certain persons and forbidding it with others. It used to be supposed that the earliest condition of social organisation was a complete promiscuity, in which marriages took place at random, each man pairing with any and every woman that took his fancy. Such a crude theory can no longer be maintained. No certain trace can anywhere be found of a state of society in which custom does not lay definite restrictions upon marriage. It may, indeed, be taken 
as a general principle that the lower we go in the scale of civilisation the more complex do the regulations affecting marriage become. Among the native Australians, for instance, the rules are of the greatest intricacy, and their study and comprehension are almost as difficult as an involved mathematical problem.

But in process of time, the theory of kin-solidarity, on which the community was originally based, can hardly remain intact when the idea of personal property, especially property in land, and the rights of inheritance, come into conflict with it. When this stage of evolution is reached, the kin-bond must give place to a political bond of one kind or another; otherwise the community will fall apart. This new organisation will afford scope for personal ambition, which was scarcely possible, when the interests of the individual were subordinate to those of the kin-group. Forms of government thus arise, in which the will of a single individual, or of a small number of individuals, is imposed upon the majority of the community.

As before, in these chapters of prolegomena, we must again remind the reader that no exhaustive treatment of this complicated subject can here be attempted. We can do no more than give a sufficient outline to enable the reader to form a clear conception of the nature of the communities with whose handiworks we are concerned. This sketch we can arrange for convenience under four divisions, following out the lines of development briefly set forth in the foregoing paragraphs, namely:

r. The definition of kinship, and the means of expressing it.

2. The regulations affecting marriage.

3. The evolution of the political unit from the tribal unit.

4. The evolution of forms of government.

\section{(i) Definition and Expression of Kinship}

In using such words as "relatives," "kindred," "family," and the like, we must be careful to avoid importing into them the restricted meanings attached to them by modern Europeans. In fact one of the greatest desiderata in the study of primitive sociology is a series of terms sufficiently definite, but at the same time sufficiently neutral to avoid misconceptions based on their current signification. We modern Europeans understand by "family" a community consisting of one man with his one wife and the children born of their union; and by "kindred" a number of people united by ties of consanguinity (blood relations) or of affinity (relations by marriage). But in dealing with the institutions of humanity as a whole, we cannot define the words so narrowly. Even in Europe the rite of adoption 
occasionally supplements the numbers of those connected together by blood or affinity. In ancient Wales a man could claim kinship with another by doing him certain specified services, such as rescuing him from a would-be murderer ${ }^{1}$; and in different parts of the world the performance of some ceremony, or the fulfilment of some duty, may constitute a claim to a kinship actually more binding than relative position in a genealogical tree.

Further, we in Europe graduate kinship, defined as we define it, into degrees of nearness or remoteness. Consanguineous kinship is of two kinds, linear and collateral. The first includes those in the direct line of ancestors or descendants-great-grandfather, grandfather, father, Ego, son, grandson, great-grandson, and so on, backwards and forwards. The second contains those not on the direct linebrothers and sisters of Ego or of his ancestors, and their descendants, his cousins and nephews. These are reckoned near or distant, according to the number of steps in the genealogy which separate them from the common ancestor who unites them to Ego. Thus, the brothers and sisters of Ego are children of the father of Ego, and separated by one step only from a common ancestor : his first cousins, descendants of Ego's grandfather, are separated by two steps from a common ancestor, and thus are a little more distant; his second cousins, descendants of Ego's great-grandfather, are separated by three steps, and so on. After a few further steps we reach a degree so remote that the relationship is no longer effective or recognised.

It is an example of the difficulties of this subject, induced by the too great definiteness of the technical terms which we are obliged to use, that even the words expressing the primary relationships have to be extended in meaning when we seek to find equivalents for terms in the languages of those who use other systems. Lewis $\mathrm{H}$. Morgan, whose elaborate work $^{2}$ forms the basis of studies in this subject, divided methods of expressing kinship into two groups, descriptive and classificatory.

In the descriptive system, which is that of the civilised peoples of the world, there are definite technical terms for a certain limited number of primary relationships (thus, in English, father, mother: uncle, aunt: brother, sister: cousin: son, daughter: nephew, niece), and remoter degrees are expressed by prefixes and suffixes, or by combinations of the primary terms, following out the steps of a pedigree. Such prefixes or suffixes, in English, are grand-, greatgrand- (with an indefinite multiplication of "greats" as necessity

1 Ancient Laws and Institutions of Wales (Public Record Commissioners), pp. $547-8$.

2 Lewis H. Morgan, "Systems of Consanguinity and Affinity of the Human Family," Smithsonian Contributions to Knowledge, vol. xvII. (Washington, i $87 \mathrm{I}$ ). 
requires); -in-law, step-, paternal, maternal, and the numerical adjectives defining the degree of cousinship: while, should occasion arise, $A$ may describe $B$ as his maternal grandfather's brother's daughter's son-in-law, and when we take the trouble to follow out these terms, we know exactly how the two stand with respect to one another. The very clumsiness of the expression shews that the descriptive method attaches a diminishing degree of importance to relationship as its remoteness increases.

In the classificatory system, however, the remoteness of actual blood-relationship does not diminish its importance. The power of expressing exact genealogical relationship is sacrificed in favour of the expression of a sense of kin-solidarity. The same or similar primary terms are used as in the descriptive system, but their sense is extended to cover, without modifying terms, the secondary relationships.

Thus, among the Iroquois Indians, there is no relationship recognised among linear kinship more remote than grandfather and grandson. Every ancestor before the grandfather is a grandfather and every descendant after the grandson is a grandson ${ }^{1}$. The brothers and sisters of the grandfather and grandmother are likewise called grandfathers and grandmothers. The brother of the father is also father, the sister of the mother is also mother. The terms aunt and uncle are restricted respectively to father's sister and mother's brother. All collaterals are cousin, without any modification of degree. As the father's brother is father, it follows that the brother's sons and daughters (Ego being a male) are sons and daughters, though his sister's sons and daughters are nephews and nieces. Contrariwise, should Ego be a female, her sister's children are counted as her children, and her brother's children are her nephews and nieces. The children of all nephews and nieces are grandchildren, just as much as the children of Ego's own children. All later generations are likewise grandchildren.

The terminology of this classification is not wholly satisfactory, and Morgan drew from its phenomena certain deductions unnecessary to detail here, which are now recognised as untenable?

1 For purposes of distinction we print the names of relationships used in their European sense in ordinary type, and those used in the Iroquois sense in italics. For the native words reference may be made to Morgan's work. It is of course not accurate to say that "grandfather" and so forth are the equivalents of such-and-such words in the native language. But they are the only words in English that can be used to represent the corresponding native words. There is no word in English that implies "a class of relationships including grandfather"; and no word in the native languages that means "grandfather excluding the relationships associated with it." The conceptions are mutually untranslatable.

${ }^{2}$ See strictures in J. F. McLennan, Studies in Ancient History (London, 1886), p. 249 ff.; also A. L. Kroeber, "Classificatory Systems of Relationship" (F.A.I. Xxxix. [1909], p. 77). 
Even in the systems which he called "descriptive" there is latent a considerable degree of the "classificatory" element. In English, "grandfather," "uncle," with the corresponding feminine terms, include two different relationships each, which have to be distinguished by prefixing the adjectives "paternal" and "maternal"; while the words "first cousin" include in their scope no less than 32 possible varieties of the relationship 1 . Our words "brother" and "sister" ignore the questions whether the persons alluded to are senior or junior to the speaker, and also ignore the sex of the speaker. These matters are indifferent to ourselves, but they are of fundamental importance in various schemes of savage society.

It is easy to see that the classificatory system greatly increases the number of persons who are united by a sense of kindred. Ego's cousin is the descendant of his grandfather; but if he call every ancestor in the direct line, removed from him by no matter how many genealogical steps, grandfather, it follows that he must call and consider as cousin many persons so remotely connected with him by blood that the relationship would hardly if at all be recognised in modern Europe. The advantage which this wide-spread net of kinship will give to his kin in its struggle for existence with other, rival, kins, is obvious; the greater the man-power the greater its chance of success in the battle of life. The classificatory system may be said to have its roots in two facts-primarily, the incapacity of the simple savage for sustained thought, such as would be necessary to follow out the steps of a complicated pedigree in order to determine the actual connexion of any two persons named in it; and secondarily, the necessity for uniting as many fighting men as possible under one banner.

\section{Totemism}

"Under one banner"- the phrase suggests the next question that arises. How is kinship expressed? Our method of doing so is by the family name. In many or most of the primitive communities of the world it is expressed by means of that strange heraldry called totemism.

A totem (a corruption of an Ojibway Indian word) is an object of some kind-usually an animal, sometimes a plant, occasionally

1 For (a) a man or woman may have first cousins who are

(b) senior or junior;

(c) male or female;

(d) on father's side or on mother's;

(e) children of parent's brother or of parent's sister; and as there are two alternatives in each of these possibilities, the total number of relationships is $2 \times 2 \times 2 \times 2 \times 2$, that is 32 . 
something inanimate ${ }^{1}$, such as a stone, or one of the heavenly bodies, with which a community of persons considers itself bound by a peculiarly sacred bond of kinship. A group of people will take, let us say, the emu (the species, not a single bird) as its totem. They will then call themselves emus, will imitate in their tribal ceremonies the motions of the emu so far as they can, will never kill an emu or eat its flesh except in very special and extraordinary circumstances, and will in all respects treat an emu in life and in death as they would treat a fellow-tribesman. It is not to be inferred, from what has just been said, that totemism was first invented or evolved in order to give expression to a sense of human kinship. Indeed, the ultimate origin of totemism is one of the darkest problems in anthropology, and its solution still remains elusive. But totemism is one of the most powerful expressions of the fact of kinship known to primitive society. If two men have the likeness, or what passes as the likeness, of a common totem marked in tatu on their bodies, or carved upon their houses or their weapons, they are united by a bond far closer than most of the degrees of cousinship that unite collaterally related Europeans.

Not the least remarkable and baffling of the numerous phenomena of totemism is its universality. Whether it developed at some very remote time in one centre and spread thence orer the whole world, or whether it came into existence independently in more centres than one, the fact remains that at least traces of it are found nearly everywhere. It is in full working order in Australia and Oceania, as well as among the aborigines of America. Even the high civilisation of Ancient Greece displays many relics of it, shewing that it formerly existed in full force among the savage ancestors of the Hellenic people. It may also be detected in the literature which enshrines the customs and the doings of the ancient Celtic peoples; and it is not impossible that it is traceable among the earlier peoples of Europe with which we are concerned in the present volume 2 .

Before passing from this part of the subject a possible source of error should be noticed; the frequent use of terms of relationship other than those actually subsisting between the speakers as a mere courtesy, without intending to convey any suggestion of kinship. The Arabs, for example, who are perfectly informed on genealogical subtleties, and who are reckoned in Morgan's classification among people using the "descriptive" method, will call unrelated men

1 But not necessarily conceived of as inanimate by those who use it as a totem.

2 For particulars as to totemism see [Sir] J. G. Frazer, Totemism and Exogamy, four vols. (London, 1910). See also Andrew Lang, Myth, Ritual and Religion, especially chap. iii. The literature of totemism is very extensive, but the solid results of the vast amount of work which it indicates are disproportionately small. 
"brother," in the sense of "co-religionist." I have even heard a father addressing his infant son by this word. Older men will be called "uncle" in the same way. Unwary observers, having their heads unduly filled with theories, may sometimes be misled by such innocent practices!

\section{(ii) Regulation of Marriage}

The regulation of marriage affords an important basis for the classification of human communities. They can primarily be grouped into monogamous and polygamous communities, according as they prohibit or sanction marriage with more than one spouse at one time. Polygamy is not essentially a savage institution; it is not even necessarily an animal institution, for it seems to be regarded as probable that certain of the higher apes are monogamous, though it is not obvious how this could be proved. When the community is to be classed as polygamous, it is not to be inferred that polygamy is the rule, or even frequent; nothing is implied more than that in certain circumstances it is permitted. Sometimes only those of specified ranks or castes are allowed to take more than one spouse; sometimes the permission is limited by practical considerations to the wealthy, or is granted only to those who have distinguished themselves in battle. The polygamy is of three kinds: group-marriage, polygyny, and polyandry. Group-marriage defines a limited number of specified persons who are entitled to have marital relations one with another; thus, Caesar tells us of the inhabitants of the interior of Britain, that fathers had the right of approach to their sons' wives, in which case parent and sons formed a group of the kind ${ }^{1}$. Elsewhere we find brothers forming such a group. In the other two forms there appears to be no such restriction. Polygyny is much commoner than polyandry, which is confined to places where for one reason or another the women are scarce.

Again, we may classify communities into exogamous and endogamous, according as they require a man to select his wife from without or within the tribe. But the definition must be used with caution. It is not to be supposed that the wives of an exogamous community are necessarily all foreign: the two principles are as a rule combined. The tribe is subdivided into a number of minor groups, distinguished, it may be, by differences of totem; and a man, while choosing his wife from within the tribe, must marry one of a group other than his own. A pure endogamy is rare, and, with but few exceptions, is found only at a higher stage of social development than that which we are at present considering. It is mostly confined to certain classes

${ }^{1}$ De Bello Gallico, v. 14 . 
or ranks (such as priests, kings, or nobility) in which for one reason or another it is considered important to keep the blood pure.

In the case of an exogamous marriage of the kind just described, the children of the marriage are as a rule counted to the division to which their mother belongs. The father, being of a different division, often has little share in their upbringing, the duty not infrequently devolving by preference on the children's maternal uncle, who naturally belongs to the same group as themselves. Frequently there are further complications. Thus, two groups, $A$ and $Z$, may be subdivided further into $A^{\prime}, A^{\prime \prime}$, and $Z^{\prime}, Z^{\prime \prime}$ respectively. Then there will be some such rule as this: a man of $A^{\prime}$ may not marry a woman outside $Z^{\prime \prime}$, and vice versa. If such a marriage takes place, the children will belong to $Z^{\prime}$-the same major group as their mother's, but the opposite minor group. This will evidently prevent, what would otherwise be a possibility, the marriage of father and daughter. It is not, however, to be understood that such complex regulations were specifically designed to prevent such unions. There is no reason to suppose that primitive Man, to say nothing of Homosimius, when he formulated such regulations, had any idea that unions of the kind were, on hygienic or other grounds, undesirable. We simply do not know how it was that early man came to develop such elaborate restrictions. We can, however, say that in so far as they prevented irregularities of the kind instanced, they were wholly to the advantage of the species. On the other hand, an instinct against marriage with relations by affinity may be at the basis of the frequent prohibition to have any intercourse with, or so much as look at them ${ }^{1}$.

A further basis of classification is afforded by consideration of the question of how a wife is to be obtained. When the kin of the bridegroom and the bride are friendly, this is usually by arrangement between the parents or other relatives, the contracting parties having little or no say in the matter. The marriage may be arranged directly, or through an intermediary; and the contract may be made in the early years or even before the birth of the parties to be united. Sometimes, though comparatively rarely, the contracting parties themselves make the match; in such a case the permission of certain relatives may or may not be necessary, and the initiative may come either from the man or, less frequently, from the woman. As a general rule a price is paid for the bride, which may sometimes be extremely heavy; it is often compounded for, either by labour (as Jacob laboured for the

1 The element of primitive hostility must also underlie regulations such as this. When the wife was captured from a hostile community, her relatives were $i p s o$ facto enemies, and to be treated as such. 
daughters of Laban $^{1}$ ) or by exchange, as when two men will agree to exchange sisters. Sometimes a woman is given freely to be married into another community in compensation for an injury, such as a murder; this is a frequent event in village life in Palestine.

When the kin of the contracting parties is hostile, more violent methods are adopted. The woman is captured, either as an individual by her future husband and his people, or as a unit in a number of captives taken in a raid. It would appear that reminiscences of marriage by capture may be traced in matrimonial rites, even when the woman is not actually carried away. In Palestine, where the practice of exchanging sisters is very common, there is often a fight-occasionally with serious consequences-at the spot where the two processions meet on the road between the two villages where the contracting parties live. This is perhaps a relic of the kind suggested.

Finally we may classify the community according to the relative position in the household of the husband and the wife. In the days of the primitive hunting community, when the father was obliged to be absent on the chase for days on end, the women staying at home with the children, the wives were naturally the repositories of the family traditions, and ruled the house. The husband was in a sense a foreigner, as he belonged to a different exogamous group from that to which his wife and children belonged. Indeed, the husband often lived in the wife's house and among the wife's people (matrilocal marriage) rather than the wife with the husband (patrilocal); or else the husband remained in his own home and the wife in hers, the husband visiting her at intervals (sadika marriage) as Samson visited his Timnathite wife ${ }^{2}$. Descent is reckoned in such cases through the mother (matrilinear succession) rather than through the father (patrilinear), and the mother rules the home (matriarchate). When the hunter gives place to the pastor, and he in his turn to the agriculturist, and in consequence the man stays at home, he begins to assert the authority which his superior strength gives him. Thus one of the first steps on the road to civilisation is marked by a change from matriarchate to patriarchate.

It is not to be supposed that the various communities of the world, ancient and modern, can be sorted out under these various heads as mechanically as we might deal a pack of cards. In a very large number of cases we have not sufficient data to enable us to assign a community to its proper group. In other cases we have to deal with intermediate stages, the number of which is very great. Mankind is naturally conservative, and old customs die hard; it is

\footnotetext{
1 Genesis xxix.
}

2 Judges xiv. xv. 
therefore not surprising to find ancient forms of organisation surviving, with or without modification, into a stage of civilisation higher than that in which it first evolved.

\section{(iii) Political Evolution}

The break-down of the kin-classification and the substitution of some form of political classification is a direct result of the development of the idea of personal property.

The earliest hunting communities were most probably complete communisms. $A$ with his fellows went out and killed an elephant. Then that elephant belonged to all the hunters, and they shared its flesh between them. But suppose now that $A$ made a particularly serviceable axe-head. He would probably for a time keep $B$ from using it, just as we may watch apes in the Zoological Gardens prevent their fellow-captives from sharing in something that a visitor has given them. But probably at first $A$ 's mentality would not be equal to the sustained strain of keeping watch over his possession; he would get tired of it, as an animal easily tires of a plaything, and thus the axe-head would become sooner or later the common property of the whole group.

As the mentality of the race improved, the makers of implements would naturally assert a more and more exclusive ownership over them; but till the end of the hunting period there were few things in which such ownership could be asserted, and the influence of personal property upon social organisation would be insignificant.

But when the discovery was made that animals could be domesticated, there must have been very considerable changes produced in organisation, both within the community and in its relation to other communities. A group of persons owns a flock of sheep: what are the limitations of the rights of each individual over those sheep; how many may he kill, and who is entitled to a share of the flesh of the slaughtered animals? These questions must have presented themselves immediately, and they had to be answered with no precedents to guide those who grappled with them. Again, $A$ and $B$ are two communities, each with cattle; what are their respective rights over pasturage and water-springs? Some conventions must have been agreed upon, doubtless after many quarrels and raids: and all such conventions must have influenced in one direction or another the internal organisation of the communities.

Still more must this have been the case when the pastoral life gave place to the agricultural. Groups of agriculturists must have lived in communities in the middle of the fields which they ploughed. How were the fields to be apportioned to the different ploughmen? 
Was each to remain on the one holding, or were the lands to be re-allotted every year? The unsatisfactoriness of the latter arrangement, though it is still prevalent in many places (such as Palestine), would in time become apparent to any progressive community. $A$ is not going to trouble to improve the land so that $B$ may reap the benefit next year; the land therefore deteriorates. Sooner or later, the principle of fixed holdings would become established. What then would happen after the death of the holder? Is his land to be divided up among a multitude of cousins? Such a question has only to be asked in order to find its answer. Elaborate subdivision of landed property would clearly be impossible; so soon as personal property became a recognised element in human affairs, the problems which inheritance presented must have led to a revision of the classificatory method of reckoning kinship.

With the introduction of agriculture, we find the village community definitely established as the normal unit of human society. In the days of the hunting communities, the hunter, or a community of hunters, might make their abode more or less permanently in a series of caves, or in huts along the banks of a river; but as their property was small and portable, they could without difficulty change their abode whenever scarcity of game or other causes made it desirable to do so. The shepherds were almost of necessity nomadic, as they were obliged to wander with their flocks to seek fresh pastures and water-springs. But the agriculturist was anchored to one spot by the nature of his calling. It would be natural for the farmers of adjacent plots of ground to dwell together, for mutual protection. So a village of houses would spring up, in the centre of each patch of land as it was reclaimed for cultivation.

These communities would still be organised on a basis of kinship, which, as Gomme has shewn ${ }^{1}$, is the theory underlying most or all primitive human associations of the kind. This kinship might be totemistic, or based on real or theoretical descent from a common ancestor, or both. But, as we have just seen, the exigencies of inheritance would very soon begin to collide with primitive ideas of kin-solidarity.

The alliance of adjacent communities of this kind, even though not technically kin to one another, would only be a matter of time. For one large domineering village, whose inhabitants had a practice of raiding the lands or the cattle of smaller and weaker communities, would very soon drive the latter into a protective league. Although the language of kinship might still be used, as when Ahab, in reconciling himself to the hostile king Ben-Hadad, called him his

${ }^{1}$ [Sir] G. L. Gomme, The Village Community (London, 1890), passim. 
"brother"1, yet so soon as such leagues began to be established, kinship, as a basis of human organisation in the wider sense, was doomed: the language of kinship in such a sense would more and more become regarded as a mere fiction. The innate bond of kinship sooner or later gives place to a more external but more permanent bond of political alliance. A good illustration of this form of organisation, giving birth to a political state, is afforded by the beginnings of Rome. At first the league of a small group of village communities, it gradually but very slowly fused into one people; the often hostile dichotomy of patrician and plebeian, which presumably had its roots in different elements of the original league, lasted for a long time in the history of the state; and evidently there was no sense of kindred between the two opposing parties-quite the contrary.

\section{(iv) Evolution of the Kingship}

But in order that such leagues should become operative, there must be some individual to take the initiative. It is clearly impossible for the whole body of kindreds to meet together and with one voice to determine that such-and-such steps must be taken for the good of the community. Even in earlier stages of the development, questions like those which we have already noticed in passing -individual rights over the community's cattle, the delimitation of the pasture-lands of adjacent tribes, and the like-must almost of necessity have required the guiding mind of some person or persons in authority to settle them, and to secure that the settlement should be accepted. In other words, from a very early stage in social evolution some form of government must have come into being. No community in which every man did what was right in his own eyes, irrespective of the effect which it might have on the life, the interests, or the convenience of his associates, could continue to exist for any length of time.

In a primitive community of early hunters there would in the first place be a number of old men, who by virtue of their longer lives and experience would almost mechanically become the consultants of the community in cases of doubt. In the old Welsh laws, for instance, to name but one example out of many, the pencenedl, the oldest man of sound mind and body in the kin-the "head of the kin," to translate his name literally-was recognised as a person of supreme importance in the community. He had seen all the events of recent history, and might be presumed to have in his memory a larger number of precedents to guide the actions of his fellows in

1 I Kings xx. 32 . 
difficult circumstances. Thus the authority of a council of elders would early be recognised. At first doubtless unofficial, it would quickly become a sort of permanent parliament, and as such we find it operative in the village communities of most primitive folk.

Again, a powerful and resourceful leader in war or in the chase would wield much personal influence over the people of his generation, and would often be taken as a guide-sometimes we may suppose with disastrous results -in matters that lay outside his own particular talents. This is not peculiar to savage man; even in civilised countries the victor of a decisive battle may sometimes be appointed by a grateful country to a political post for which he has little aptitude.

But the efficiency of a council of elders depends on the number and the mental capacity of the elders who happen to be available; and an epidemic or some such calamity may clear them out and leave the community without their guidance. A notable leader may render good service to his own generation, but he leaves no successor. For a centralised power to be really efficient it must be independent of the accident of the death of the individual. Such a permanent central power early came into existence, but at first it was a religious rather than a social or political authority.

Almost, if not quite, from the beginning of his human existence, mankind became conscious of the existence of mysterious powers operative in the world, higher than his own. The problem of how to control those powers was one with which he began early to grapple. In every community there were men of what we may fairly call genius, who professed to find solutions to this pressing problem. Actually more gifted, intellectually, than their fellows, they would excel them in one way or other in the arts of life, and would be generally supposed to be in some mysterious way in touch with the unseen. Such persons would very quickly acquire a sacrosanct inviolability; and, protected by this invisible but invulnerable armour, they would speedily acquire an absolute control over their tribe. Unless, indeed, a man had at his back the authority of the Unknown, it is difficult to see how he could have acquired an arbitrary power of commanding and enforcing the obedience of the wild hunters among whom his lot was cast.

Such a person would be maintained by the community. He would receive fees for his services in securing the capture of game and controlling the weather. Thus freed from the necessity of spending his days in the chase, he would have leisure to study the arcana of his own profession, and for his own sake he would find it expedient to do so. In a world where everything was still new, such a person would make many discoveries. Some of them would be mere 
fraudulent conjuring tricks; some of them would be mistakes and misapprehensions, due to faulty logic on his own part; but some of them would be really valuable secrets of nature. These discoveries would form the body of the trade secrets of his craft. In many cases he would need an assistant-an accomplice, if you will-and the necessity would force him to teach the secrets of some of his mysteries to another, who would in all probability be a nephew or a son. Thus a successor would be provided for him when he went the way of all the earth, and the hereditary principle would be established. The authority would thus become permanent, not terminable by death.

It was thus the medicine-man who dereloped into the king of later times. That the king was originally a religious, not a social or political functionary, has now, since the researches of recent years, become a commonplace of anthropology. Even yet, in Siam, India, Africa, and other regions, the king is something sacred, more than human, if not actually a god upon earth.

This institution of the religious leader was the first step to the specialisation of human life into the different professions and occupations. It was also the first step towards the development of the different forms of government which we find in the modern civilised world.

\section{v. Religious Classification}

\section{Difficulties of the Study of Primitize Religion}

Like language and social organisation, Religion passes through certain erolutionary phases, and communities may be classified according to the stage in the development to which they have attained. The study of this subject is, however, of very great difficulty, and that for two main reasons.

In the first place, about nothing are primitive peoples so reticent as they are about their religious customs and beliefs. Fear of ridicule, and a dread of revealing secrets not to be revealed, are both operative in making the primitive man either to hold his tongue altogether, or else to take refuge in any shift or evasion available, when awkward questions are propounded. Indeed, he may not know the true answer to his interrogator's enquiries. Many of the tribal religious secrets are concealed from uninitiate members of the tribe itself, and the chances are at least equal that a casual native may be one of those in outer darkness. For all these reasons a foreigner may be obliged to live on very close and intimate terms with a tribe for a long while, before he begins to suspect that they have any form of religion at all. In former times a number of tribes were described as being without religion; but in every case that has been scientifically in- 
vestigated the observation has been shewn to be imperfect or superficial. It is now believed that just as there is no race of people, however low in the scale of civilisation, without language or without social order, so there is no tribe or race, however low, without some form of religion. A completely religionless community does not exist, and probably never has existed.

The second difficulty is that of language. By this is not meant the difficulty of learning to utter the sounds, and to follow out the syntactic construction, of savage ${ }^{1}$ dialects, though this seems to be a feat beyond the powers of most Europeans. It is rather the significance to be attached to savage terminology. A missionary, translating the Scriptures, may find that such-and-such words can be used as the equivalent of "God," "heaven," "soul," and so forth. But they are not really equivalent to the European terms, and such a use of them is often in the last degree misleading. We have seen in the preceding section that the European and the Iroquois or the Melanesian have no common ground in interpreting even such apparently simple words as "father" and "son." It is impossible for Europeans to use such words as "gods," or "soul," to express conceptions in the native ${ }^{1}$ creeds, without unconsciously importing into them the senses which they themselves associate with these words. Even when there is a certain affinity between two religions-as for instance between Islām and Christianity - the apparently synonymous words must be used with the greatest caution. The conception of Allah in the Kur'ān, apart from elements directly borrowed, is totally different from the conception of the Divine Father in the New Testament. The more remote the religions are from one another, the more acute become the difficulties involved in this essential irreconcilability of terminology.

\section{Mana and Tabu}

At the basis of natural religion-the germ from which it has developed-lie, some modern scholars would have us believe, two complementary conceptions. For these, in the absence of European names, have been adapted the native (respectively Melanesian and Polynesian) names mana and tabu. Mana is a sort of impersonal supernatural power-something perhaps similar to what is expressed by the word "virtue," as used in Luke viii. 46 (Authorised version), "I perceive that virtue is gone out of me"-a sort of ether, pervading the universe, not the property of any definite supernatural being, but at the service of man. He may draw upon it to work his ends, as he draws on the atmosphere for purposes of respiration. An amulet,

1 Some apology should perhaps be made for the use of the unsatisfactory words "savage" and "native," here and elsewhere: but it is difficult to find a substitute. 
which is successful in averting some dreaded evil, does so by virtue of the mana inherent in it. The words of a spell which produces a desired result have mana. So has a javelin which strikes down an enemy.

Tabu is the converse of this. It is a mysterious power which is not to be meddled with. Certain meats must not be eaten, certain things must not be touched; vaguely defined, but real, punishment will follow a breach of the prohibition. If in some way a man has been fortunate, he has tapped the world's stores of mana; if on the other hand a misfortune has befallen him, he has consciously or unconsciously violated some tabu ${ }^{1}$.

From this twin conception of mana and tabu there flow, according to the very probable theory which we may provisionally adopt, two parallel streams of thought concerned with the relation of Man to the unseen world. These are Religion and Magic. The first of these is the essential antithesis of the other. The religious man recognises the existence of forces superior to himself, which he cannot control; religion is essentially an attitude of submission. The worker of magic, on the other hand, seeks to control the higher (personal or impersonal) powers of Nature; magic is thus essentially an attitude of revolt. This is not the place to enter into the much-discussed problem of the relation between religion and magic-whether religion developed out of a previously existing magic, or whether, as we prefer to believe, the two ran parallel courses, co-existing in one and the same community.

\section{Animism}

But a vague impersonal mana could not long stand alone in human thought. Man, especially savage man, thinks in the concrete; mana must sooner or later become impersonate in a world of spirits. We thus enter on the phase of religious evolution to which has been given the name Animism. By the theory of animism all things, not. only men, animals, and plants, but also things which the civilised man has learnt to call "inanimate," are invested with a sort of spiritual essence or "soul." The line of demarcation between the

1 It should be noticed that the word "tabu" is rather loosely used to cover two entirely different conceptions. It is sometimes used in the sense in which it is employed here, that of a prohibition. But strictly it also involves the sense of a reserved privilege. A thing is tabu when its use is permitted to certain persons (priests, chieftains, etc.) and forbidden to others. For the mere prohibition, without the sense of privilege, it would be better to use the old Irish term geis, which, like tabu, denotes a prohibition, but does not carry the sense of a reservation. Even this would not be quite accurate, however. A tabu in strictness says "No one but a chief may use this canoe." A geis says "Certain specified persons must not use this canoe." Not the least of the problems of this complicated subject is an accurate fixation of the terminology. 
living and the not-living is not always obvious to the child of nature. Is motion the test? But a stone which without visible external impulse rolls down a hillside conforms to such a test, and is therefore alive. Is growth the proof of life? Even a well-to-do County Meath farmer has spoken to the writer of the time when a certain large stone on his field "grew." The savage arrives at the conception of a soul, or sometimes of many souls, within his own body by various means. It is suggested by the motion of his shadow; by his miniature reflection in his friend's eye; or by his adventures in the land of dreams. Analogy with himself leads him to extend the possession of a soul or souls to all things.

\section{Fetichism}

As everything is thus associated with a soul, or with mana, it follows that by treasuring objects which may in themselves be insignificant-a bit of wood, a nail, a bone, a tooth, a lock of hair, a bundle of grass-we are really treasuring up their souls, and are keeping them at our disposal in order to obtain some benefit from their possession. To this religious phase the not very scientific term Fetichism has been applied. The value and nature of a fetich does not matter in the least. It is not always clear whether the fetich is regarded as being in itself an animated being, or as the medium through which a spirit works for the advantage of the owner; the latter is most probably the normal conception. The contemporaryand contemptible-cult of mascots is the purest fetichism. Search the most benighted corners of Africa through, and you will find no better example of this form of religion than was displayed by a young lady who, when a candidate in a musical examination some years ago, placed a stuffed black cat on the piano, saying that it was her mascot, and that unless it was there she would be sure to fail in the prescribed tests ${ }^{1}$.

The distinction between fetichism and idolatry is not always as carefully maintained as it should be. It lies in this, that a fetich is in itself the thing worshipped (if we may use the word, for convenience); it is in itself the receptacle of the spiritual essence to which the man pays homage: while an idol is only the tangible representative of an unseen power behind it, but not necessarily immanent within it.

1 The incident was reported at the time in Musical News, where I read it. I have not, however, kept a note of the reference, and it is hardly worth the trouble of a search. 


\section{Magic and Religion}

While the religious evolution is still in the stage of animism or fetichism, the line of demarcation between magic and religion is too indefinite to be exactly drawn. Perhaps the most satisfactory definition of the one as opposed to the other, in this phase of development, is that religious rites are those performed for the sake of securing something good, while magical rites are those performed for the sake of securing something evil ${ }^{1}$. A medicine-man, let us say, pours water on the ground, hoping thus to secure rain in a time of drought. This is a religious rite--to all intents and purposes, an acted prayer, for the benefit of the community: we may call it so even if there is only the most nebulous conception of a personal prayer-hearing being. The same or another man makes the image of an enemy and maltreats it, hoping that the enemy will suffer the like injuries. This also is an acted prayer; but inasmuch as it is for the injury of the person aimed at, it must be classed, on the principle stated, as magic. In a primitive community most public acts of the kind are by this definition religious - they are performed for the general good of the community. Even those acts that are intended to secure the defeat of an enemy in warfare are to be so classed, as they are for the good of the community which sanctions them. On the other hand, most private rites of the kind, at the same stage of evolution, are for evil purposes. They are as a rule for the advantage of the individual at the expense of another individual within the same community. They are therefore evil, and therefore to be classed as magical. The necessity of thus finding a purely ethical distinction is enough to shew that the line separating magic from religion is as yet very indefinite. They carry on the fundamental idea of good and evil inherent in the amorphous conceptions of mana and tabu; but in outward appearance they are essentially identical.

\section{Spirits}

The nature of the spirits conceived of as immanent in the falling stone and the fetich is not very easy to define. They are hardly figured as immaterial; and probably at least at an early stage in the development of the beliefs about them, they are so far identified with the object which they quicken as to be undistinguishable from it. A man worships the sun, the actual globe of glowing gas which we call the sun, and not any intangible being resident within it or responsible for its beneficence.

${ }^{1}$ Of course using these terms in their modern ethical sense. To blast an enemy by magic would seem to the magician thoroughly good and praiseworthy. 
But a differentiation between the material body and the immaterial spirit begins to be suggested, probably by the phenomena of dreams, and by the waking hallucinations to which men in the savage existence seem to be especially liable. A man wanders through strange places in his sleep, and even holds converse with the longvanished dead; while his friends can testify that his body has never left the place where the sleep fell upon him. It follows that something apart from his body must have been going through these experiences: there must be an invisible complement to the visible Ego, separable from it on occasion. Especially must this be the case at death. The body disappears, the ghost remains, to be a source of unknown perils to the surviving foes, of unimagined blessings (not, however, free from danger) to the surviving kindred. Such ghosts familiarise humanity with the conception of disembodied spirits, apart from those confined within his fetich, a waving tree, or a savage animal.

These disembodied spirits are a fruitful source of peril. They have powers for good or for evil-disease, misfortune, death itself, are all ascribed to their interference with the ordinary course of human life, acting either on their own responsibility or at the instigation of some controlling force. Were it not for wizardry a man would live in happiness for ever. The wizard, then, can control the spirits. They are not omnipotent. If a fetich fail to do its duty, as its owner conceives it, he throws it away, buries it, destroys it without compunction: and the malignity or beneficence of a spirit, of whatever nature, may be controlled or directed one way or another by the man who has the necessary skill in occult matters.

These principles are laid down from a study of contemporary savages; but it must never be forgotten that in such deductions there is a hidden source of possible error. In every elementary introduction to this study the reader has to be cautioned that the beliefs of modern savages are not necessarily fossils of the beliefs of Primitive Man. The savage has as long a pedigree behind him as the civilised man, the only difference being that evolution has moved more slowly-slightly more slowly-with the one than with the other. But it has moved, and many of the elements of modern savage beliefs may be of much later development than the times which we are endeavouring to reconstruct; while others, though to be traced back to those times, may be so worn down and effaced that they can hardly tell us anything about their original form. In many directions the study of primitive religion can be nothing more than a matter of conjecture, founded on as large a collection of facts as possible. 


\section{Gods}

It is the dread of the local spirits, even though these may not be omnipotent, which is the most potent controlling factor in the life of an ordinary savage: and it is highly probable that his Palaeolithic ancestors had the same dread. These spirits are not yet gods, however, and we must now consider very briefly this further development in religion.

There are several theories current to account for the development of a belief in a deity, and there may be an element of truth in all of them, for the one fact that is certainly known about this subject is that there is no universal open sesame to the solution of all its problems. The propitiation of ancestral spirits, conceived of as ghosts, may have had much to do with the development of tutelary kin-deities, extra-terrestrial, but still taking an interest in the affairs of their descendants.

Again, the savage, like the child, is inquisitive. The Universe offers countless questions which cry aloud for an answer. Any answer is better and more satisfactory than none; and we can picture the endless discussions round the camp-fires, on the hunting-field, or in the cave-dwellings during the long winter evenings, trying to find answers to such unanswerable questions as these-What are the stars? What is the earth? What is under lakes and seas? Whence come the rain, and the bubbling waters of the spring? Whence comes Man? Whither does he go? How did all these things which we see have a beginning, and how and why will they have an end? All such questions were disputed through countless generations by unknown philosophers, who gradually found solutions by analogy with their own experiences. A man makes his tools and his house; some "Superman" must have made the much greater Universe. Speculations on cosmogony, on the problems of the origin of visible nature, had a great influence in the development of the idea of a universal creating power, impersonate in an extra-terrestrial being, who might either be conceived of as a great man or as a mighty animal.

But there are also other elements in the making of a deity. Dr R. R. Marett ${ }^{1}$ has with much persuasiveness argued for the growth of such a belief out of the mysterious sound of the bullroarer. This is an instrument consisting of a lath of wood cut to a more or less rhomboidal form, and attached by one end to a cord. When it is whirled round at the end of the cord a weird buzzing noise is produced. This instrument is used in the mysteries of the

\footnotetext{
1 "Savage Supreme Beings and the Bull-roarer," in The Threshold of Religion
} (2nd edition, London, 1914), p. I45. 
Australians and the Aborigines of America, and its use has been traced in ancient Europe: like totemism, one of the most remarkable features about it is its universality. In Australia it is used to scare away non-initiates, especially women, from the tribal mysteries. They are never allowed to see it, or to know how the alarming noise which they hear is produced; but are told that it is the voice of a variously named god. When boys are initiated these are at last shewn the instrument, and instructed in its nature and use. This revelation, says Marett, basing his statement on the words of trustworthy firsthand observers, does not carry as a consequence that "the spirit of awe is utterly discomfited; the native mind struggles against the materialism, seeking to distinguish the inward grace from its external vehicle, though all uncertain whether to ascribe to this indwelling vitalizing force a personal or a quasi-impersonal nature."

Thus, and most probably by other routes as well, is the mind of the nature-folk led to a conception of extra-terrestrial gods. At the first stage, these beings are still in the background. They have created the world, but take no further interest in it-unless it be that they come down "to make the boys men" in the initiation ceremonies. They have otherwise but little concern in the affairs of Man, and the people in their turn are more or less neglectful of them. So far as the unseen world is concerned, the chief or only interest of the people as a whole is to propitiate the doubtful-tempered spirits who walk the earth around them.

But once the possibility of the existence of extra-terrestrial gods has become formulated, a seed has been sown capable of a wondrous growth: and it grows as human life and civilisation grow. Each new invention or discovery introduces mankind to a new and hitherto unknown group of supernatural beings; and these tend to increase in strength and superiority as man learns slowly to appreciate his own impotence in the face of the mighty forces of the universe. If he cross the sea-an act of astonishing boldness-he puts himself under the control of a set of powers different from those which regulated his actions in his home; if he settle in a new territory, one of his first cares must be to discover the "manner of the gods of the land"; to seek out means to propitiate the mysterious beings who were there before him.

Thus do departmental gods find their birth, and these develop into an organised polytheism; which the myth-makers will fit out with a Theogonia, to shew us how they were conceived of as coming into being, and how they were connected together.

Gods are departmental in two senses. In the first place, they are the gods of a particular tribe, hostile to the gods of hostile tribes 
Such a conception easily grows out of the kinship basis of early society, of which we have already spoken. The god may be conceived of as being kin with, if not actually the physical progenitor of, his worshippers. Or, where the sense of kin-solidarity is not so strong (as among the Romans, in contrast with the different Semitic tribes) the gods may be treated as gods of countries and territories rather than the gods of tribes and clans; as when a Roman soldier at Winchester dedicated an altar Matribus Italis, Germanis, Gallis, Britannis ${ }^{1}$.

In the second place, the gods may be departmental within the limits of one national pantheon; one god of the sky, another of the sun, a third of the earth, the sea, and so forth; and healing, ploughing, and other human pursuits and handicrafts may also contain tutelary deities within the sacred circle. Here, however, we have to be careful not to be misled by mere names. The many departmental gods of Greek mythology can be reduced to a much smaller number by elimination of all who are merely doublets or particular aspects of one universal divinity, such as Zeus.

The later developments of these beliefs hardly concern us here. But for the sake of completeness we may simply say that as human thought becomes refined and enlightened, a crude polytheism becomes reduced to a henotheism, in which the tribe worships its own one god when within its own territory. The other nations have gods also, which exist, but of which no account need be taken except when a man changes his abode. In that case he exchanges the jurisdiction of one god for that of another, as he changes in like manner the jurisdiction of the earthly sovereign under whose rule he lives. In the hands of the sublime prophets of Israel this theory developed into the pure monotheism, for which the world is indebted to that nation-the teaching that the "gods of the nations" are but idols, and that there is one universal God who is Lord of all the earth.

It may be suggested that to a certain extent a parallel can be traced between political and religious evolution; the worshipper projects into the unseen world the polity to which he is accustomed on earth. With the communism of the primitive tribe, in which the individual can hardly be said to have a separate existence, there goes a vaguely plural horde of spirits, not individually definable: of this stage the Matres just mentioned are survivals. As the human chief develops a personality, so a chief develops among these shadowy beings; the tribal god of a primitive Semitic horde, for example, is to all intents and purposes a magnified sheikh. And it

1 Corpus Inscriptionum Latinarum, viI. 5. 
is at least noteworthy that it was when the Assyrian monarchy was beginning to develop the novelty of a world-empire that the conception of a universal Divine Ruler first began to take shape.

While these profound changes are in progress, altering the whole attitude towards Divinity, magic remains at a stand-still. This is another, and a most important, point of difference between religion and magic. Religion develops. Men, notwithstanding an innate conservatism which has a powerful influence in stereotyping religious belief and practice, completely change, with advancing civilisation, their ideas of spirits and of gods, and their conception of their duty towards them and of the attitude of the supernatural beings to themselves. But magic remains just where it was at the first. The Highland witch may attend a service on Sunday in which the whole expression of religious thought and emotion is spiritualised, as a result of the accumulated experience of countless generations; yet on the Monday she may go out and place her corp criadhach in a running stream as her ancestors did in the Stone Age.

\section{Table of Human Classification}

For convenience of reference it may be useful to collect in tabular form the various bases of classification which we have now shewn to be applicable to humanity.

\begin{tabular}{|c|c|}
\hline \multicolumn{2}{|c|}{ Racial Classification } \\
\hline By Head-form & $\left.\begin{array}{l}\text { Brachycephalic } \\
\text { Mesaticephalic }\end{array}\right\}$ and intermediate forms \\
\hline By Coloration & $\left.\begin{array}{l}\text { Melanochrous } \\
\text { Xanthochrous }\end{array}\right\}$ and intermediate forms. \\
\hline $\begin{array}{l}\text { By Stature } \\
\text { By Hair-shape } \\
\text { By Eye-shape }\end{array}$ & $\begin{array}{l}\text { various, within the normal limits. } \\
\text { from round-section to flat-section. } \\
\text { Megaseme. } \\
\text { Mesoseme. }\end{array}$ \\
\hline By Nose-shape & $\begin{array}{l}\text { Platyrrhine. } \\
\text { Mesorhine. } \\
\text { Leptorhine. }\end{array}$ \\
\hline By Face-shape & $\begin{array}{l}\text { Chamaeprosopic. } \\
\text { Mesoprosopic. } \\
\text { Leptoprosopic. }\end{array}$ \\
\hline
\end{tabular}

\section{Linguistic Classification}

Isolating languages

Polysynthetic ,"

Agglutinating ," $\}$ each with numerous subordinate families. 


\begin{aligned} & \multicolumn{2}{c}{ Cultural Classification } \\ & By materials of culture Stone (Palaeolithic and Neolithic). \\ & Copper. \\ & Bronze. \\ & Iron. \end{aligned}

By instruments of culture Numerous departments, such as

Weapons: daggers, rapiers, swords, etc.

Cutting instruments: axes, chisels, etc.

Houses: wigwams, huts, caves, houses, etc.

By mode of life

(And so on.)

\begin{tabular}{|c|c|c|c|}
\hline \multicolumn{2}{|c|}{ By mode of life } & \multicolumn{2}{|c|}{$\begin{array}{l}\text { Hunters and Fishers. } \\
\text { Shepherds and Cattle-tende } \\
\text { Agriculturists (Sedentary). }\end{array}$} \\
\hline ganisation & \multicolumn{3}{|c|}{$\begin{array}{l}\text { Single kin-groups, with or without totemis } \\
\text { Kin-groups allied together. } \\
\text { Nomads settling as agriculturists; village c } \\
\text { Union of several village communities into er }\end{array}$} \\
\hline \multicolumn{4}{|c|}{$\begin{array}{l}\text { " } \quad \text { with unfriendly" tribes-bride wo } \\
\text { en contracting parties: }\end{array}$} \\
\hline \multicolumn{2}{|c|}{$\begin{array}{l}\text { Authority } \\
\text { Matriarchal } \\
\text { Patriarchal }\end{array}$} & $\begin{array}{l}\text { Place of home } \\
\text { Matrilocal } \\
\text { Patrilocal } \\
\text { Șadika }\end{array}$ & $\begin{array}{l}\text { Descent } \\
\text { Matrilinear } \\
\text { Patrilinear }\end{array}$ \\
\hline
\end{tabular}

Government Council of elders, developing into village parliament. Medicine-man, developing into king.

Religious Classification

Crude beginnings

Growth of belief in spirits
Mana (good), tabu (bad).

Animism.

Fetichism.

The powers controlled by religion for good purposes.

Ghosts

Dreams

Bull-roarer

" " " magic " bad "

Cosmogonic speculations

give rise to conception of extra-terrestrial gods.

The gods are $\left\{\begin{array}{l}\text { distant and inoperative. } \\ \text { near and operative. } \\ \text { members of a polytheistic pantheon. } \\ \text { units in a henotheistic belief. } \\ \text { the Unit in a monotheistic belief. }\end{array}\right.$

1 The ingenious theories of Mr J. J. Atkinson (in Lang and Atkinson's Social Origins and Primal Law, London, 1903) may quite possibly carry us yet further back in the history of social development: but it is here hardly necessary to enter into such speculative regions. 


\section{CHAPTER V}

\section{THE BEGINNINGS OF HUMAN LIFE IN EUROPE}

\section{The Problem of Tertiary Man}

Our preliminary studies are now over, and we begin the special work before us. At the very outset we find ourselves plunged into one of the most violently agitated of all the many storm-centres of scientific discussion. Did Man appear in Europe in any of the phases of the Tertiary period, and if so, what traces of himself has he left behind? Or are we without any evidence of his existence until we find it in Quaternary deposits?

This question of the existence or non-existence of Tertiary man is inextricably bound up with another, on the answer to which, indeed, its solution is to a large extent dependent. What are we to make of certain remarkable objects of flint, which have been assiduously collected from Tertiary deposits in various centres, and to which the name Eoliths has been given?

\section{The Industrial use of Flint}

In Chapter II (pp. 49-50) we gave a short account of the origin and the nature of flint, and of the reasons which gave it a pre-eminent industrial importance during the Stone Age. As an introduction to the study of the problem of Eoliths we must now say a few words about its use as a material for tools and weapons, and, especially, as to the way in which artificially made flint implements can be distinguished from fragments broken by mere chance natural causes.

We said on the page referred to that "When the points upon which to strike are selected with judgment, and the blows delivered with skill, a sharp cutting edge is produced, between two adjacent planes of fracture." The effectiveness of the edge can be, and very often is, improved by fine chipping along its line, thus turning it into a miniature saw. To such fine chipping is sometimes given the name retouching - a not very satisfactory term, for reasons that will presently appear.

Flint, like the cognate material glass, is very liable to be affected by external forces acting upon it in one way or another. Heat, or sudden alternations of heat and cold, produce effects in a lump of flint varying with the size of the nodule, the intensity of the agent, 
and other elements in the experiment. Sometimes small particles will be splintered off, covering the surface of the nodule with a number of little pits. Sometimes the surface will be fissured in all directions. If the heat be strong enough, and the nodule moist, the whole may be disintegrated by the expansion of steam and reduced almost to powder ${ }^{1}$.

If a sharp blow be struck upon a flint with a hammer of any hard material, having a spherical striking surface, the result produced will be different from these. Owing to the shape of the hammer, the blow impinges directly upon a spot of very limited dimensions on the surface of the nodule. Flint is elastic, and the particles on which the blow falls are compressed, and split away from those not so affected. Moreover, as each of them rests on a number of particles in the body of the nodule, and these in their turn on others, the compressing process is carried through for a certain depth into the nodule, expanding conically as it penetrates deeper. Thus a blow, delivered in the middle of a large nodule, will break away the surrounding surface and will leave a cone of flint the axis of which is the point on which the blow was delivered. But if the blow should be delivered near the edge of the nodule, the effect will be different. Owing to imperfect support, the part of the nodule outside the point of impact will be split off instantaneously, and the cone will not have time to form completely. Its beginning will appear as a lump or mass at the end of the flake which the blow has disengaged, just under the spot where the hammer fell. This lump is known as the bulb of percussion. It will be seen in the flint tool illustrated in Fig. 78 (nos. ii and iv), p. $3^{19^{2}}$.

\section{Tests of Artificiality of a Flint Implement}

The bulb of percussion is one of the tests of the artificiality of a stone implement. It is not the only test, and it is very far indeed from being the infallible test which some enthusiastic writers assert it to be. A well-known collector in Belfast once committed himself to the statement that he had turned over "thousands of tons" of flint flakes, broken by natural causes, and had failed to find a single one with this and other alleged marks of artificiality ${ }^{3}$. There is usually something wrong when a writer expresses himself so loosely;

1 For a study of this subject, based on numerous experiments, see M. le Dr Jousset de Bellesme, "De l'action du feu sur les silex" (B.S.P.F. v. [1908], p. 282).

2 See Evans, Stone, p. 274, where the formation of flint cones and of the bulb of percussion is more fully described, with an illustration. Reference to other authorities will there be found.

3 Fournal, Royal Historical and Archaeological Association of Ireland, ser IV. vol. v. [1882], p. II 5 . 
if I have not made a miscalculation, it would have taken this good man rather more than six years, working incessantly day and night, to turn over even a single thousand tons of flint chips; and with regard to his main assertion, I can only say that I have picked up flint fragments with excellent bulbs of percussion, while strolling casually over the gravel of a garden walk, where no question of artificial manufacture could possibly arise.

However, it may be conceded that if a flint object be found displaying this bulb; and, more especially, if the reverse impressions of similar bulbs appear in the places whence supplementary flakes have been dislodged, in order to bring the object to a definite shape: then we have at least presumptive evidence that the object is artificial, and we are encouraged to examine it further. If then it can be shewn (a) that it is of such a character that it would serve as a tool for some of the simple purposes of stone-age man-that, in other words, it shews evidence of design-and (b) that it conforms to some already well-established type of stone implement; then we are fairly safe in accepting our find as an artefact ${ }^{1}$.

The provision that the tool should conform to some type already known is prudent, though it should not be applied with a cast-iron absoluteness. It is always possible that a genuine flint implement of hitherto unknown type should come to light; but this becomes increasingly improbable as knowledge advances, and every novelty of the kind must be submitted to more and more searching criticism before it can be accepted. In all such special cases the student must learn to exercise his common sense.

There are, as we have already hinted, other criteria for distinguishing artificially manufactured ancient flint implements from naturally broken fragments on the one hand, and from the extremely excellent productions of forgers on the other. A very thorough account of these has been given us by G. and A. de Mortillet ${ }^{2}$. Among them are incrustations of lime or of lichen; dendrites (crystals, usually of manganese, that assume the form of minute fern-like fronds ramifying over the surface of the stone); traces of the wearing and rolling of water, and other external agencies, acting for a long time on the specimen; lustre; patina; and the like. Any or all of these are useful guides in special cases. But it is probable that the unconsciously exercised instinct, which is acquired by long practical experience in the handling of specimens, is better than any of these

1 A word more useful than beautiful, meaning an object artificially manufactured. It has the advantage of indefiniteness, enabling us to speak of such objects as waste chips of flint as human products, without giving them names (weapons, implements, flakes) that would imply intentional manufacture for some specific purpose.

${ }^{2}$ Préhist. part II. chapter ii. See also part I. chapter $\mathrm{x}$. 
indications. Even this instinct, however, is not infallible; it is more than likely that if a case containing 10,000 flints-naturally broken fragments, genuine ancient artefacts, and modern forgeries, all mixed up together-were submitted to a parliament of the most expert prehistorians in the world, there would be no complete agreement as to how the specimens were to be sorted out under each of the three categories named. That this is not an unfair statement of the facts of the case, the history of the "Eolith" controversy is sufficient to shew.

\section{Eoliths}

For there have been found in Tertiary deposits in France, England, Spain, Belgium, Germany, and elsewhere ${ }^{1}$, certain flint flakes to which the name "Eoliths" has been given. Eoliths are thus defined by Prof. Klaatsch" : "Primitive flint implements, consisting of splinters or fragments of flint nodules, whose natural form is but little altered by human handiwork. The aptitude to serve as instruments for cutting, boring, striking, sawing, etc., which they already possess by nature, is intensified by retouching." A stone, not artificially formed as a whole, possesses a sharp point or edge. This edge displays a little subsidiary chipping, which, perhaps, makes it a little sharper or more effective. Was that chipping the work of an intelligent being, or was it fortuitous? Some say that the evidence for intentional chipping is clear; others, not less expert, declare that they can see nothing whatever to justify the hypothesis of artificial workmanship. The dispute is simply a deadlock.

But the controversy is even more complicated than the foregoing statement would suggest; Eolithists (some such word is wanted for the sake of brevity) do not always keep within the definition which has just been quoted from Prof. Klaatsch. There is no agreement between them as to the nature and origin of the "retouch," upon which to a large extent their conclusions depend. In any case the word, as used by prehistorians, involves a misnomer, or at least an ambiguity. I should understand by the word "retouch," if I came upon it for the first time, a process by which I restored an edge that had become blunted by use, as I might grind a penknife that needed sharpening; but in English, as well as in French, German, and Italian (retouche, retuschieren, ritocco), the word is not infrequently used for the chipping by which an edge is made serviceable from the

1 Some eoliths reported at Narver $\phi \mathrm{d}$ in Norway proved to be merely ballast discharged from French ships some forty years before, and deposited for purposes of land reclamation; see Brøgger, "Strandliniens Beliggenhed under Stenalderen" (Norges geologiske Undersфgelse, No. $4 \mathrm{r}$, Kristiania, 1905), p. $8 \mathrm{ff}$.

2 Z.f.E. xxxv. [1903], p. I16. 
beginning ${ }^{1}$. By some writers it seems to be extended yet further beyond its legitimate meaning, and to be made to denote minute chipping that comes of itself when the flint edge is subjected to rough usage. Homosimius takes up a flint chip which lies to his hand, produced by nature, and he uses it to crack a hard nut. The impact of the flint on the nut knocks off a number of little scales from the edge of the flake, and behold, Homosimius has produced an eolith If the meaning of the distinction that some of the chief Eolithists draw between silex utilisés and silex taillés, both of them "retouched," but the former alone to be called "Eoliths," is not to be expressed by some such illustration as this, I confess my complete inability to understand it. The "retouching" is often so delicate as not to appear at all in the reproductions of photographs; for which reason the German Eolithists sometimes draw dotted lines outside such reproductions, in order to make us clearly understand where the retouching actually is. It is hard to believe that the handiwork of a primitive type of Man, to say nothing of a Homosimius, would be so minute; the delicate fingers of a watchmaker would almost be required to produce work so fine! We may therefore infer that eoliths are supposed to have been fashioned by some such automatic process as we have imagined. It must be admitted at the outset that an "industry," whose tools come into existence in any such manner, seems a truly indefinite, not to say nebulous, subject of study!

In another respect the Eolithists do not adhere to the plain sense inherent in the name given to this class of object. A neolith, coming from the "new stone" period, is later in date than a palaeolith belonging to the same region, and assigned to the "old stone" period. We ought to define an eolith, from the "dawn of stone," as older still; and in this sense the term is generally understood. But the interpretation put on the term is as inconsistent in this respect as is everything else about these objects. Rutot ${ }^{2}$ defines an eolith in effect as any rude stone, not shaped intentionally to a definite form, and yet capable of classification in an industrial series, which may be used for a variety of technical purposes at any stage in human history; but must not be associated with actual flint artefacts ${ }^{3}$. The

1 "Secondary chipping," a term frequently used in English books, though longer, is preferable, and will be generally employed in these pages to express this meaning.

2 "Qu'est-ce qu'un Eolithe?” C.P.F. Iv. (Chambéry, 1908), p. r61 ff. esp. p. 162 .

3 I give here the original French of this definition, to prevent any suspicion of misrepresenting the sense of the author. "Un Eolithe est, en dehors de toute idée chronologique, l'un des outils destinés à frapper, à couper, à racler, à gratter, et à percer, faisant partie d'un ensemble industriel dans lequel il n'existe aucun instrument taillé intentionnellement." The italics are mine. 
plain meaning of this is that if I go into my garden, and, noticing that a nail happens to be loose, pick up a stone which happens to lie conveniently to serve as a makeshift hammer, I thereby make it just as much an eolith as any chipped flake from oligocene or pliocene strata, so long as I do not at any time manufacture real flint implements. If I do, my eclith loses its character. Ed. Krause ${ }^{1}$ describes as eoliths certain stone fragments discovered in association with neolithic polished axe-heads, and apparently contemporary with them.

Eoliths, then, may come from deposits of all dates: but those about which there has been the greatest controversy are naturally those from Tertiary gravels, and supposed to afford proof of the existence of Tertiary Man. The discovery of bones in the strata yielding the flints would relieve the situation. But the postulated makers of the Eoliths have vanished as completely as did the Baker when he met with the Boojum. Undoubtedly the bones of men or of anthropoids are much more perishable than are those of larger animals; and the gravels of the Lower Palaeolithic Period, which contain undisputed artefacts, have yielded hardly any human bones. Still, it is unfortunate that there should be

\section{Not a button, or feather, or mark}

of the much longed-for Tertiary Man, at any of the now fairly numerous places where finds of eoliths have been reported. Considering that in some layers of gravel eoliths have been found literally in thousands, testifying, on the assumption of their artificial origin, to a very considerable and prolonged population, it would be only reasonable to expect that by now a tooth or a fragment of a femur might have come to light somewhere.

The "Eolithic problem," as it is sometimes not very logically called, was started on its wild career in 1867, when M. l'Abbé Bourgeois, then the director of the college of Pontlevoy (Loir-et-Cher) described before the International Congress of Anthropology and Prehistoric Archaeology certain flints found by himself at Thenay, in the neighbourhood of his home. These flints were embedded in Tertiary gravels, and were claimed to prove that a being, mentally so far advanced as to be a tool-fashioner, was living in that part of France in the Tertiary period ${ }^{2}$.

1 "Über Quartzit-Eolithe in Lössgebiet von Allrath in Rheinland" (Z.f.E. xLII. [19 10], p. 586).

${ }_{2}$ "Etude sur des silex travaillés trouvés dans les dépôts tertiaires de la commune de Thenay près Pontlevoy (Loir-et-Cher)" (C.A.P.A. Paris, 1867, p. 67). 
A controversy was immediately aroused, following the familiar pattern of the old dispute about the chameleon:

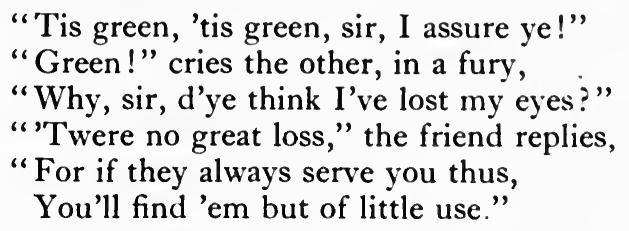

Those of the one party said that the Thenay flints were clearly artificial. Those of the other party said that they were not artificial, but were produced by natural means. As M. Salomon Reinach says, a literature on the subject of these flints came into being, huge out of all ratio to their importance ${ }^{1}$. Almost the whole of this literature may be boiled down to these simple assertions and counter-assertions. Controversy on the same lines has been aroused by each subsequent discovery of eoliths, so that a history of the dispute would be monotonous to write and inexpressibly dreary to read. Its course may be reduced to a series of almost mathematical formulae. $A$ produces certain flints, which he asserts are clearly the work of an intelligent being-whether Homo or Homosimius does not for the moment matter. $B$ produces other flints, which have been fractured by some natural or accidental means-those found by M. Marcellin Boule in the rubbish of a cement-mill at Mantes are the best-known ${ }^{2}$ and he claims that his eoliths are quite as good as $A$ 's. $C$, who is an Eolithist, says that while $A$ 's flints and $B$ 's may be superficially alike, there is so much essential difference between them that only one who did not really understand the subject could be deceived into mistaking one for the other. $D$, who is not an Eolithist, comes forward and dares to say that he cannot see any difference between the two series. $C$ then, of course, pours scorn on $D$; and $D$ in his turn treats $C$ to a little vitriol. And so the quarrel goes on interminably.

In the course of the dispute one of the Eolithists is sure to introduce a favourite argument-a long list of distinguished men who have expressed their belief in the artificial nature of these Tertiary chips. But this is a dangerous weapon, which cuts both ways. An equally long list of distinguished opponents could be drawn up; and the formidable catalogue of supporters is not altogether above criticism. Without mentioning names, it may be questioned whether eminence, even super-eminence, in one science necessarily entitles a scholar to express an authoritative opinion on a subject that does

1 Alluvions, p. 102, where a select bibliography will be found.

2 M. Boule, "L'origine des éolithes" (L'Anthr. xvi. [1905], p. 257). 
not fall within the scope of that science. A geologist, a chemist, even a physical anthropologist, is not necessarily any better qualified to express an opinion on the artificial nature of flint objects than a musician, a merchant, or even that commonplace abstraction the man in the street. If we respectfully erase the names of ornaments of such irrelevant branches of learning, and substitute those of scientific owners of private collections, like Sir John Evans, or of directors of public museums, such as Déchelette and Reinach, who have expressed themselves as incredulous, the list of supporters might be turned into an impressive argument in the opposite direction!

Someone else will repeat another well-worn argument. He will remind his readers that Boucher de Perthes had to fight long and hard against a world of cold scepticism before he could obtain recognition of his labours: and that therefore Eolithists must expect the same treatment, but may look forward to such an ultimate victory over their opponents as Boucher secured. This is consoling, but illogical. Doubtless, if Tertiary flints be once admitted, some enthusiast will discover Secondary artefacts, and will even look for Primary man and his handiworks; but most sane people will agree that we must stop somewhere in pushing back human origins into the depths of time. True, there are those, whose sanity is not in dispute, who would appear to think differently; for they would have us use the word "archaeolithic" for an advanced phase of eolithic culture, and speak of the earlier phases as "pre-archaeolithic"-a word which suggests something that happened "before the beginning!" This is certainly to write the history of humanity sub specie aeternitatis ${ }^{1}$. But suppose that as a matter of irrevocable history, Man did not appear in Europe before the Pleistocene era, then the final triumph of Boucher de Perthes in his struggles for recognition offers no encouragement to anyone who would seek to change the unchangeable facts of the past.

It would almost appear-as though Eolithists claim to possess a sort of "inner light" whereby they can distinguish true artefacts from naturally broken pebbles. [Incidently one may be allowed to express the wish that the inner light had inspired them to find some other name for their treasures, so saving us all from the trouble of distinguishing, in speech, between "an eolith" and "a neolith'?"]

${ }^{1}$ Rutot in the paper cited above (p. I67) quotes with approval the discovery by Prof. Klaatsch of a "pre-eolithic culture" in Australia, of all places. But why "pre-eolithic"? [It should in any case be pro-eolithic]. Why not maintain the meteorological metaphor, and call this assuredly very elementary culture "nyctolithic"? Perhaps nephelolithic would be yet more appropriate!

2 This is only one example of the strange love for symmetrical terminology, at the expense of clearness, which some scientific word-coiners display. The man who would have us call wind-borne deposits eluvium, as opposed to alluvium or water- 
This is not quite the same as the instinct to which we referred above, that comes from long handling of ancient tools; it is a sort of inspiration. Those from whom Nature has seen fit to withhold this gift cannot follow its mysterious workings, just as a man with no musical talent must watch in blind amazement the performance of a youthful prodigy. To shew that this is not an unjust criticism, I quote the following from a paper which will be found among the publications of an important French archaeological society- "In a word, one must learn to see eoliths. In process of time one acquires this gift, which has nothing miraculous about it, for it is the result of observation and of reasoning; it is thus at the disposal of everyone." So far the author seems to contradict what I have just said; but he proceeds thus: "Common workmen have often surprised me by their sure eye; it is because, not being 'savants,' they have no preconceived ideas. L'Abbé Bourgeois made the same remark." This, to me, seems to mean that if you study enough you will learn to see eoliths. But if you study flints as long as, say, Déchelette, and do not learn to see them, your evidence is of no value, for you have preconceptions; you are to be rated below simples ouvriers, who, though they have not had the advantage of the necessary study, can nevertheless detect eoliths by the light of nature. I trust sincerely that I do not misrepresent a fellow-worker, but I have tried my best to make a fair statement of the implications latent in the passage I have quoted, which to me look uncommonly like the gambler's old trick of " heads I win, tails you lose."

\section{List of the Chief Sites where Eoliths have been found}

We may now set before the reader a descriptive list, as concise as possible, of the chief discoveries of Tertiary eoliths in Europe that have been announced, from the time when L'Abbé Bourgeois laid on the table of the Prehistoric Congress the chips which he had collected in the gravels of Thenay. It will be best to arrange these in the chronological order, not of their discovery, but of their stratification; beginning with those found in Pliocene gravels and then working back to the earlier beds. When the whole material has thus been described, some of the arguments on both sides, other than mere assertion and counter-assertion, will be set forth.

There are three different "industries" of Pliocene eoliths-two in England, the "Kentian" and the "Icenian"; and one in France,

borne deposits, was almost as unkind as our French friends, when for the confusion of average foreign ears and tongues they evolved their au-dessous and audessus! Gabriel de Mortillet seems to have been the inventor of the term éolithique (Préhist. part I. chap. iv). The English adaptation eolithic is apparently due to Mr J. Allen Brown (F.A.I. xxII. [1893], p. 94). 
the "Prestian." Some authorities describe the Kentian and Prestian as Pleistocene, and others call Pliocene a number of industries that have been assigned by the chief Eolithists to the Pleistocene.

The Kentian eoliths derive their name from the Plateau of Kent. This is an area lying between Serenoaks in the south and Darenth in the north, and extending, roughly speaking, to about 16 miles west of the Medway at Snodland. It is an elevated surface of chalk, deeply fissured with river valleys. The uncut chalk plateau is covered with a red clay Tertiary drift; the valleys cutting through the plateau contain Quaternary drifts of various periods. The latter yield numerous flint implements of well recognised Pleistocene forms; the former yield a very few of these Pleistocene implements, and in much larger numbers the ruder forms with which we are here specially concerned.

Scientific attention was first called to the Kentian eoliths by Sir Joseph Prestwich, in 1889 and subsequent vears ${ }^{1}$. They had previously been objects of interest to local collectors, chiefly $\mathrm{Mr}$ Benjamin Harrison, of Ightham, who seems to have been the first to form the theory that they were the work of pro-Palaeolithic Man². The derelopment of the Eolith controversy on the Continent called further attention to them, and besides English authorities, the site was visited and examined by Rutot of Brussels ${ }^{3}$ and Klaatsch of Heidelberg ${ }^{4}$, both of whom expressed themselves satisfied that the chipped flints found there are genuine artefacts. On the other hand, Sir John Erans and Prof. Bord Dawkins expressed their doubts at the reading of Prestwich's paper before the Anthropological Institute, and Prof. Marcellin Boule and others of the leading Continental authorities are equally sceptical.

Sir Joseph Prestwich, in his paper read to the Anthropological Institute, made a catalogue of no less than $\mathrm{I} 7$ typical forms of Kentian

1 "On the occurrence of Palaeolithic flint implements in the neighbourhood of Ightham, Kent" (Q.F.G.S.L. XLv. [1889], p. 270); "On the age, formation, and successive drift stages of the Valley of the Darent; with remarks on the Palaeolithic implements of the district, and on the origin of its chalk escarpment" (Ibid. Xlvir. [1891], p. I 26); “On the primitive characters of the flint implements of the chalk Plateau of Kent, with teference to the question of their Glacial or pre-Glacial age" ( $\mathcal{F} .4 . I$. xxi. [1892], p. 246).

2 B. Harrison, "On certain rude implements from the North Downs" (F.A.I. xxi. [1892], p. 263). See also A. M. Bell, "Remarks on the flint implements from the chalk Plateau of Kent" (F.A.I. xxiII. [1894], p. 266); and J. Russell Larkby, "Notes on Prehistoric Man in West Kent" (Antiquary, XLI. [1905], pp. 95, 129).

3 A. Rutot, "Sur la distribution des industries paléolithiques dans les couches quaternaires de la Belgique" (C.A.P.A. Paris [1900], p. $106 \mathrm{ff}$; ; also published in L'Anthr. xi. [1900], p. 707, esp. p. 734 ff.).

${ }^{4} \mathrm{H}$. Klaatsch, "Bericht über einen anthropologischen Streifzug nach London und auf das Plateau von Süd-England" (Z.f.E. xxxv. [1903], p. 875, esp. pp. 919, 920). 
flints, divided into three groups. The first group contained those "in which the natural flint has been used with little modification, and in which the original shape of the stone has determined the ultimate form." In such a case, obviously, further classification would be not only superfluous but misleading; Prestwich, however, recognises three subsidiary types (small pebbles, split pebbles, and large stones). The second group contains those in which the natural form of the pebble is still used, but with more apparent design in adapting them for a specific purpose. The third group shews the whole surface of the flint worked over, as in true Palaeolithic implements. These are rare on the Plateau, though common in the valleys.

We would remind the reader of what was said in our first chapter as to the futility of minute classifications of rude objects such as these. That any sort of man who could have existed in the Tertiary epoch, had a tool-box of 17 different sorts of specialised instruments is simply beyond discussion; it is a reductio ad absurdum. For all practical and theoretical purposes it is sufficient to admit three types, in the various series of specimens that have been figured by Prestwich, Klaatsch, and others, and in the specimens which the present author has himself examined (Fig. 36). These are:

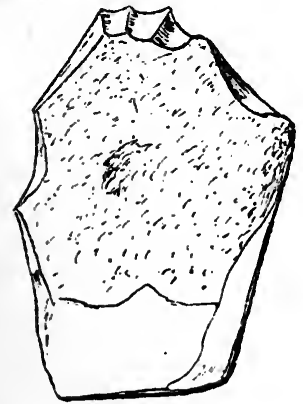

(i)

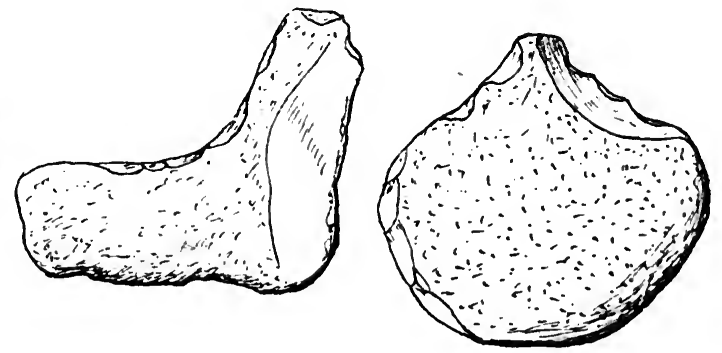

(ii)

(iii)

Fig. 36. The types of Kentian "eoliths."

(i) Nodules of flint which, while retaining their native form, are chipped more or less completely round the edges.

(ii) Nodules in which the chipped edge is a hollow between two projections-as it were in the angle of a rather flat letter Y.

(iii) Nodules in which the chipped edges lie on the two sides of a projecting point-something like the second kind turned inside-out.

It is evident that the fact that Kentian eoliths can thus be classified into series amounts to very little. Naturally chipped flints, to whatever causes the chipping may be due, would fall into an exactly similar scheme of classification, quite independently of the 
volition of an artificer. For a nodule if chipped at all, must be either wholly or partially chipped; that is, it must belong either to type (i), or else to types (ii) and (iii). If only partially chipped, the chipped edge must be a straight line, convex, or concave; and the chances are enormously on the side of one of the two latter alternatives, that is, of types (ii) and (iii). Therefore the fact that seriation is possible proves nothing as to the origin of the chipping.

Owing to the enthusiasm of local collectors, Kent is the bestknown centre for these objects. They have, however, been reported from other districts. Klaatsch, in the paper just cited, mentions similar objects from Beachy Head; and they have also been found in Berkshire ${ }^{1}$, Dorsetshire ${ }^{2}$, Essex ${ }^{3}$, Norfolk ${ }^{4}$, Suffolk ${ }^{5}$, Sussex ${ }^{6}$, Wiltshire ${ }^{7}$, Cheshire and North Wales ${ }^{8}$, Hampshire ${ }^{9}$, Surrey ${ }^{10}$, the North of Ireland ${ }^{11}$, and no doubt elsewhere. Those found in the Cromer Forest-bed were associated with the bones of Elephas meridionalis, as were also those from Dewlish. On the whole, all of these series of English eoliths resemble one another.

The Prestian group derives its name from Saint-Prest near Chartres (Eure-et-Loire). They were first discovered by L'Abbé Bourgeois, the finder of the Thenay flints. His attention had been called to the site by a discovery that made great noise at the time, belated echoes of which may still be heard occasionally, though few if any archaeologists of repute have now any faith in it as bearing in any way on the early history of mankind. This discovery consisted of certain bones of animals, covered with scratches, supposed when

1 O. A. Shrubsole, "On flint implements of a primitive type from old (preGlacial) Hill-gravels in Berkshire" (F.A.I. xxiv. [1895], p. 44).

2 C. J. Grist, "Some eoliths from Dewlish, and the question of origin" (F.A.I. XL. [1910], p. 192).

3 Eoliths from Grays, Essex, are reported in Essex Naturalist, xIII. [1903-5], p. 88 .

4 W. J. Lewis Abbott, "Worked fints from the Cromer Forest-bed" (Natural Science, x. [1897], p. 89).

5 E. S. G[rew] in Knowledge, April, 1907, p. 76; J. Reid Moir, "A series of pre-Palaeolithic implements from Darmsden, Suffolk" (Proceedings Prehist. Soc. E. Anglia, II. p. 210).

6 P. A. B. Martin in a letter published in American Anthropologist, N.S. vol. vir. in a paper by G. G. MacCurdy.

"H. P. Blackmore, cit. ap. Rev. R. A. Bullen, "Eolithic implements" (Fournal of Victoria Institute, xxxIII. [1901], p. 191 ff. esp. p. 211 ff.).

8 Joseph Lomas, cited in the same paper.

9 Rev. R. Ashington Bullen, "Eoliths from South and South-west England" (Geological Magazine, N.S. decade iv. vol. x. [1903], p. 102).

10 Ibid.

11 E. F. J. Bennett, "Eolithic implements at Belfast and Bloomsbury" (Geological Magazine, N.S. decade iv. vol. x. [1903], p. 127); W. J. Knowles, On Objects of the Plateau Kind from the Interglacial Gravels of Ireland (British Association, Belfast meeting [1902], p. 756). 
they were first found to have been the work of $\operatorname{man}^{1}$. We need say nothing here about these scratched bones, whether from Saint-Prest or elsewhere (for such objects were afterwards announced from other places as well). They are all to be explained as the result of natural causes-either the gnawing of other animals, or slight earth-movements, whereby embedded bones rub on one another or on the edges of adjacent stones.

Some apology may be necessary for even this slight mention of the Saint-Prest bones. Déchelette has entered a very reasonable protest $^{2}$ against the continual repetition of the details of exploded discoveries of this kind. Such an "obituary of ephemeral theories," he writes, "should not for ever cumber the threshold of prehistoric science." This is both just and true. But unfortunately these apparently ephemeral discoveries are singularly tenacious of life. They seem to be dead and done with, and are passing into the oblivion that they merit, when someone browsing in a library resurrects them and gives them fresh currency. In a book intended for students, it is therefore necessary to forestall such a possibility by this single word of warning. Even the ghosts of those tiresome persons, the man of Calaveras and the owner of the Moulin Quignon jaw, still "walk," in spite of the energetic exorcisms to which they have more than once been subjected.

L'Abbé Bourgeois had no doubt of the authenticity of the eoliths which he collected at Saint-Prest ${ }^{3}$; but Gabriel de Mortillet, who had a faith in eoliths in general, found them without any conclusive signs of human workmanship ${ }^{4}$. On the other hand, Rutot accepts them ${ }^{5}$, and Klaatsch found in the upper of two Pliocene layers quite a number of fragments of flint, regarding which he could have as little doubt of their evident manipulation-very rude, but unmistakable-as he could feel in the case of the specimens from the Kent Plateau which he saw in Rutot's collection ${ }^{6}$. He gives a photograph of five of these specimens; the sceptic might very fairly venture the criticism that, if Prof. Klaatsch considers that these are as clearly artefacts as are the Kentian fints, then the photograph weakens our

1 J. Desnoyers, "Note sur des indices matériels de la coexistence de l'homme avec l'Elephas meridionalis dans un terrain des environs de Chartres, plus ancien que les terrains de transport quaternaires des vallées de la Somme et de la Seine" (Comptes-rendus hebdomadaires des séances de l'Acad. des Sciences, vol. LVI. [1863], p. 1073).

2 Manuel d'archéologie, I. p. 19.

3 "Découverte d'instruments en silex dans le dépôt à Elephas meridionalis de Saint-Prest, aux environs de Chartres" (Comptes-rendus hebdomadaires des séances de l'Acad. des Sciences, vol. LxIv. [1867], p. 47).

${ }^{4}$ Préhist. part I. chap. iv.

5 A. Rutot, "Sur l'homme pré-quaternaire" (B.S.A.B. xix.).

6 Z.f.E. xxxv. [1903], p. 129. 
faith in the authenticity of the Kentian rather than strengthening our belief in that of the Prestian!

For the present, however, we are leaving criticism on one side, and merely enumerating the chief sources of eoliths. So far, the collectors of Pliocene eoliths have been content to give us flints with the minimum of chipping. But now we learn the astonishing fact that more or less contemporary with the Kentian "Pliocene Man," who was chipping his trumpery scrapers, there was living in the neighbourhood of the site of Ipswich a being who had attained to the art of making tools of a considerable degree of complexity. These are the so-called eagle-beak or rostro-carinate flints. Quite a luxuriant crop of literature has sprung into existence about these flints, during the few years that have elapsed since they were first published ${ }^{\mathbf{1}}$.

To this type of flint, or to the supposed industry which it represents, has been given the name Icenian-not a pedantically scientific term, as it is derived from the name of a Celtic tribe which inhabited the district some hundreds of thousands of years after the alleged time of the implements.

The ideal form to which the makers of rostro-carinate implements are supposed to have desired their handiworks to attain is shewn in Fig. 37; and an actual specimen in Fig. 38. The shape is thus described by Sir E. Ray Lankester: "It resembles a hammerhead with broad posterior region, narrowed anteriorly to a quasivertical cutting or chipping edge. Some hammers made for geologists have somewhat this shape, but in them the vertical anterior cutting edge is truly at right angles to the upper and lower parallel faces of the hammer. In the pre-Crag implements the anterior narrow edge - though tending to the vertical - is strongly curved and

1 Sir E. Ray Lankester, "On the discovery of a novel type of flint implement below the base of the Red Crag of Suffolk, proving the existence of skilled workers of flints in the Pliocene Age" (Philosophical Transactions, Royal Society, vol. ccrr. B, p. 283). See also J. Reid Moir (the first discoverer of these objects), "The flint implements of sub-Crag Man" (Proceedings Prehistoric Soc. of E. Anglia, vol. I. [1910], p. 17); Idem, "A defence of the 'Humanity' of the pre-River Valley implements of the Ipswich district" (ibid. vol. I. [1913], p. 368); W. G. Clarke, "Implements of sub-Crag Man in Norfolk" (ibid. vol. 1. [1912], p. 160); J. Reid Moir, "Pre-Palaeolithic Man" (Proceedings of the Suffolk Institute of Archaeology and Natural Hist. Xv. [1915], p. 9); the book by the same author under the same title; Sir E. Ray Lankester, "Description of the test specimen of the rostro-carinate industry found beneath the Norwich Crag" (Royal Anthrop. Instit. Occasional Papers, No. 4 [1914]; the illustrations reproduced in L'Anthr. xxvi. [1905], pp. 14, 15); J. Reid Moir, "On the further discoveries of flint implements of man beneath the base of the Red Crag of Suffolk" (Proceedings Prehist. Soc. East Anglia, II. [I9I 5], p. I), with pictures of all sorts of specialised implements of Pliocene times; Rev. H. G. O. Kendall, "Middle Glacial and pre-Crag implements in South Norfolk" (ibid. p. 3I); W. G. Clarke, "The Norfolk sub-Crag implements" (ibid. p. 213); J. Reid Moir, "The flaking and flake characteristics of a pre-Red-Crag rostro-carinate implement" (ibid. p. 524). 


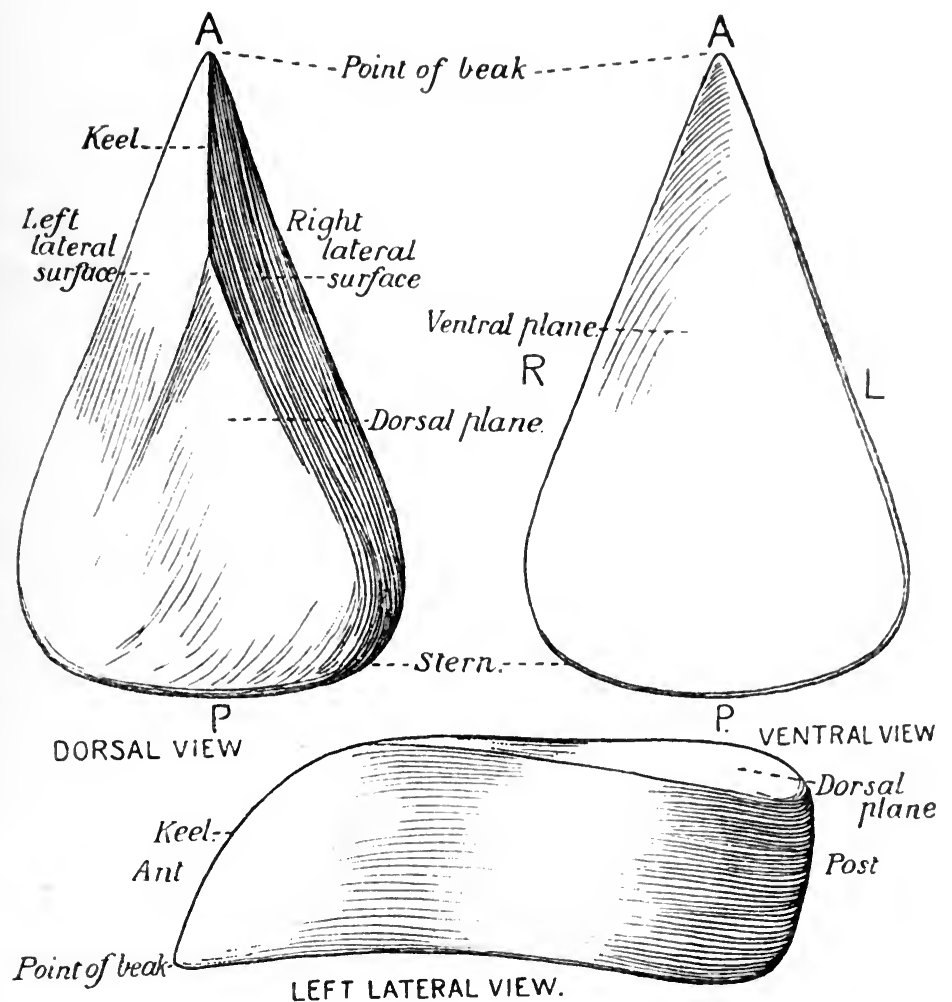

Fig. 37. Ideal form of a rostro-carinate implement.

(From Philosophical Transactions, Royal Society, vol. ccir. B.)

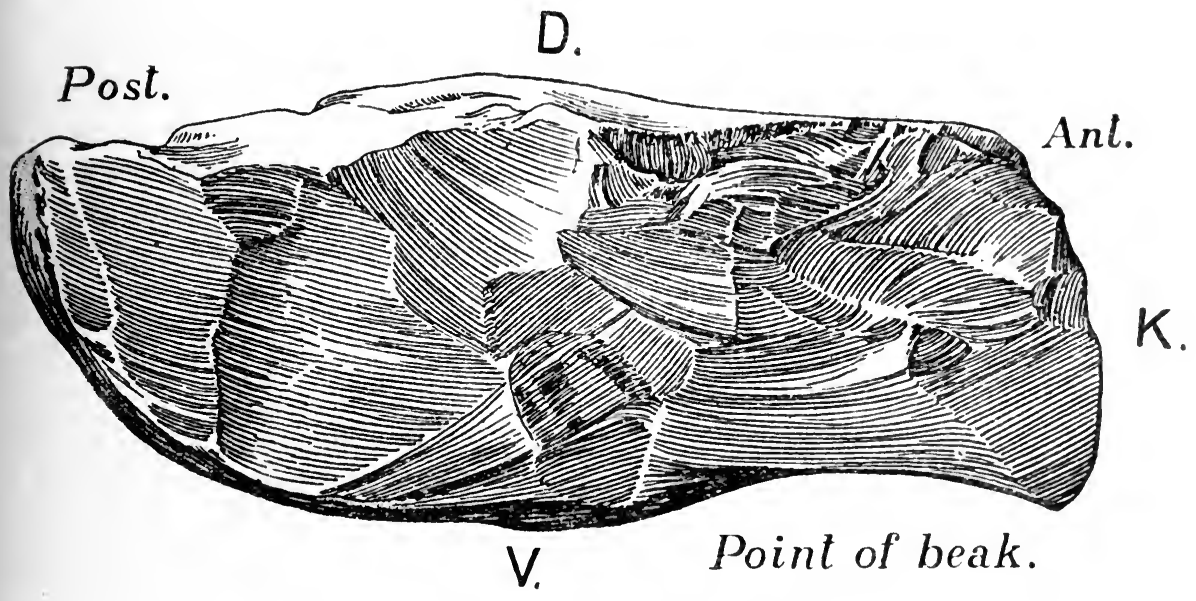

Fig. 38. A rostro-carinate implement.

(From Philosophical Transactions, Royal Society, vol. ccII. B.) 
gives the implement the form of the beak of an accipitrine bird. We distinguish (keeping the prow or beak to the front) an upper or dorsal plane, a lower or ventral plane, a right lateral and a left lateral surface, a posterior surface or stern ( $P$ in Fig. 37$)$, usually very irregular, heavy and roughly shaped as though for holding in the hand, and an anterior surface, narrowed to the form of a keel and ending in a beak (hence we call the implement 'rostro-carinate') as a consequence of the oblique direction and convergence of the lateral surfaces, which approach one another so as to leave only a narrow keel-like ridge between them. We usually see this keel or 'carina' reaching forward from the broad middle and posterior portions of the upper surface of the implement, as a very distinct and leading feature in its sculpture ${ }^{1}$."

These peculiar instruments were found in great numbers lying on the floor of the London Clay, and overlaid by three feet of the Crag, supposed to be Pliocene, that being covered with $\mathrm{I}_{5}$ feet of mid-Glacial gravels and this in its turn with seven feet of later gravels. If their claims to be artefacts be admitted, we can see no alternative to supposing that some being, capable of making tools of a distinctly complicated kind, lived on the land surface before the Pliocene deposits were laid down.

In a letter to Nature ${ }^{2}$ Sir E. Lankester protests against these tools being called and classed with "eoliths"; and in the letter to the Times, wherein the discovery was first announced ${ }^{3}, \mathrm{Mr}$ J. Reid Moir also contrasts them with eoliths, and hints at the possibility of assigning a yet more abysmal antiquity to the true eoliths, on account of their relative rudeness. It is, however, convenient to consider the two classes of objects together, as both alike are put forward as evidence for the existence in England of Tertiary man. Mr Moir, further, writing to Nature ${ }^{4}$, described the difficulty which he experienced in finding, by practical experiment, how the makers of these tools fashioned them" . He then goes on to say "I hope this description of the rostro-carinate flints will convince archaeologists that we are dealing with a very complex type of implement and that such a

1 Op. laud. p. 294.

23 I October I 9 I2, p. 249.

3 Published 17 October 19 I0 (page 8, column $b$ ).

4 2r November 1912, p. 334.

5 Sir E. Ray Lankester does not appear to be conscious of this difficulty, for he says (op. laud. p. 295): "In the most simply worked specimens... it is obvious that three blows have been enough to effectively fashion the 'eagle's beak' from a specially selected piece of flint of appropriate form.... A little trimming of the edges is all that remains for the tool-maker to do. But many of the implements are more elaborately worked by repeated flaking, so as to arrive more completely at the ideal shape." 
highly specialised tool cannot very well have been produced by unguided, haphazard natural forces."

But, surely, the more "highly specialised" a tool is, the more obvious must be the very limited range of purposes which it is intended to serve. A "universal flake" may serve as many ends as a schoolboy's pocket-knife. But a specialised tool is restricted in its scope by the very fact of its specialisation. Further, the needs of such men as we may suppose to have lived on the surface of the London Clay, before the Pliocene Crag was deposited, cannot have been very numerous. It would surely be possible to catalogue these with a little effort of the imagination, and then to pick out from the list the exact purpose for which rostro-carinate tools were made. But Sir E. Ray Lankester in the course of his paper more than once expresses his regret that he cannot imagine what end the tools served; though in his "Summary of Conclusions" he suggests that they were "not improbably used for dressing and smoothing the skins of animals." This hardly explains their peculiar form.

Similar objects have been found by Prof. Sollas at Selsey Bill ${ }^{1}$ in Sussex; he does not, however, claim for them a human origin, but regards them as being due to natural causes, also operative in the Suffolk deposits.

We now step back to the Miocene era, where we find two further groups awaiting us.

These are the flints found at Le Puy Courny, near Aurillac, as well as at one or two other sites in the department of Cantal-from which the Miocene flint industry has received the name Cantalian; and those found by C. Ribiero at Ota, or Otta, in Portugal ${ }^{2}$.

The Puy Courny flints are certainly more like genuine artefacts than most of the chips that have been labelled "eoliths." They were found in a stratum of whose geological date there can be no doubt. It overlies a marine deposit of Oligocene times, and is itself overlaid by a layer of volcanic débris about Io mètres thick-the record of some tremendous eruption or series of eruptions of the late Miocene. The flint-bearing stratum itself is alluvial sand, the deposit of an early Miocene river. Since the earliest investigations ${ }^{3}$, the site has

1 W. J. Sollas, "The formation of rostro-carinate flints" (British Association Report, Birmingham Meeting [1913], p. 788).

2 For the Cantalian flints see J. B. Rames, "Géologie du Puy Courny; éclats de silex tortoniens du bassin d'Aurillac (Cantal)" (Matériaux pour l'histoire de l'homme, xvirI. [1884], p. 385). For those of Ota see C. Ribiero, Descripção de alguns silex e quartzites lascádos encontrados nas camadas dos terrenos terciario e quaternario (Acad. Lisbon I871). Also C.A.P.A. Lisbon [1880], pp. 61, 92. J. F. N. Delgado, "Les silex tertiaires d'Otta" (C.A.P.A. Paris [1889], p. 529).

${ }^{3}$ For the bibliography of these see Reinach, Alluvions, p. 100.

M. E. A. I. 
been visited by Klaatsch ${ }^{1}$, who has convinced himself that the implements are artificial. Capitan, Rutot, and Verworn are also assured of this. Prof. Verworn, indeed, has such a high opinion of the civilisation of the Miocene flint-chippers of Cantal, based on the number and variety of the tools which he has identified, that he desires to take from them the reproach of being merely "eolithic," and would call them "archaeolithic ${ }^{2}$," a proposal to which we have already referred.

The general appearance of the Cantal flints resembles that of the Kentian series, though on the whole they are rather less unconvincing; a few specimens are shewn in Fig. 39. The Ota flints are of minor

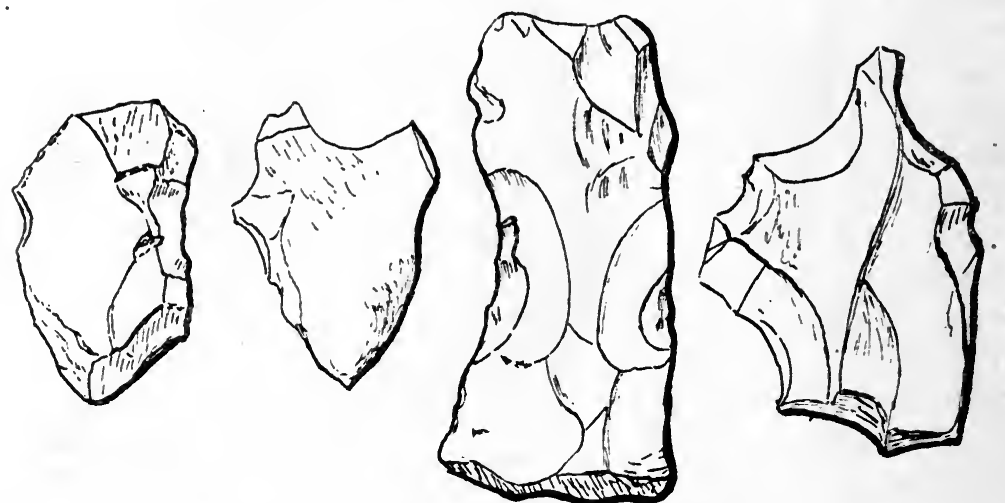

Fig. 39. Eoliths from Le Puy Courny.

importance, and they have in recent years dropped into the background, where we may be content to leave them. Prof. Verworn, though he evidently had a good will towards them, was not able to satisfy himself that there were any pro-Pleistocene remains to be found on the site. There are two flint-bearing strata ${ }^{3}$ here, a lower and an upper. The upper is Palaeolithic, and undoubted artefacts have been found within it. The flints from the lower, pro-Palaeolithic stratum, can in no case be identified as artefacts, in Prof. Verworn's judgment. The stratification in the case of the flints first published by Ribiero seems to have been very unsatisfactorily noted or recorded.

1 "Anthropologische und paläolithische Ergebnisse einer Studienreise durch Deutschland, Belgien, und Frankreich" (Z.f.E. xxxv. [1903], p. 92 ff. esp. pp. I 29, I 3 I) ; "Die tertiären Silexartefakte aus den Subvulkanischen Sanden des Cantal" (A.f.A. xxxi. [1905], p. 153 ff.).

2 Max Verworn, "Archäolithische und paläolithische Reisestudien in Frankreich und Portugal"' (Z.f.E. xxxviri. [igo6], p. 6I I). Per contra, M. L. Mayet does not accept the human origin of the Cantal flints: see "La question de l'homme tertiaire" (A.F.A.S. Lyon [1906], p. 603).

3 We follow here the description by Prof. Verworn, op. laud. esp. pp. 634-639. 
We next proceed to the Oligocene era, for even at that early period a flint-chipping being is supposed by some to have lived in Europe.

The Thenay flints, which, as we have already seen, were the first eoliths to be published, belong to this group ${ }^{1}$. The wildest ideas were at one time current with regard to the Thenay flints. Some of them displayed a cracked outer surface, which was supposed to be due to the action of fire-from which the deduction was made that they were the handiwork of an Oligocene Homosimius who had already discovered the properties of that essential aid to civilisation. Subsequent investigation of the cracks shewed that the idea of their being due to fire was not justified ${ }^{2}$ : that in fact alterations of the kind are not produced by fire in flints, and that atmospheric influences are sufficient to account for the peculiar condition of the specimens. Prof. Verworn made a special visit to the site of the discovery of these flints for the purpose of investigating the question of their origin on the spot. His conclusions were wholly negative, both as to their being the work of an intelligent being, and as to their shewing traces of the action of fire. This evidence is of special value, inasmuch as we have seen that he accepts the Cantal eoliths wholeheartedly: but of Thenay he says So führten unsere Studien in Thenay zu einem vollkommen negativen Ergebnis ${ }^{3}$.

At Boncelles, province of Lüttich, in the Ardennes, finds of supposed Oligocene eoliths have also been made, forming what is called the Fagnian industry, from the plateau of Hautes-Fagnes. They have been described by Rutot $^{4}$, and classified as hammers, anvils, scrapers, hollow scrapers, hammer stones, borers, double scrapers, double hollow scrapers, and engravers - not a bad record for whatever simple creature Oligocene Homosimius may be supposed to have been.

But the enthusiasm of Eolithists does not stop at the Oligocene. We are told of pre-eoliths (sic), defined as being naturally broken pebbles, of which the Eocene Homosimius might be supposed to have made use. If these are to be seriously included in the scheme

1 In books written before the separation of the Oligocene as an independent phase, or by writers who do not recognise its separate existence, the Thenay flints are described as Miocene.

2 Mahoudeau and Capitan, "La question de l'homme tertiaire à Thenay" (R.E.A.XI. [1901], p. I29): a very thorough investigation.

3 Op. laud. pp. 612-620; see also F. Houssay, "Collection topographique des pièces trouvées à Pont-Levoy-Thenay" (C.P.F. Tours [1910], p. 85).

${ }^{4}$ A. Rutot, "Un grave problème; une industrie humaine datant de l'époque oligocène" (Bull. Soc. Belge de Géologie, xxI. [1907]); Idem, "Une industrie éolithique antérieure à l'Oligocène supérieur ou Aquitanien" (C.P.F. Chambéry [1908], p. 90). 
of evolution, it appears, to the present writer at least, that any and every stone in the world may reasonably be collected as a potential archaeological specimen. And why should we stop at pre-eoliths? Why not proceed to describe proto-pre-eoliths, defined as being the stones to which the first sea-anemones attached themselves?

It is only fair to say, however, that most of the Eocene eoliths which have been described have been brought to notice as a reductio ad absurdum of the whole subject. M. l'Abbé Breuil has made an impressive use of them for this purpose in a paper cited below. Similarly M. A. Laville has treated as pseudo-eoliths a series from Duan (Eure-et-Loir) ${ }^{1}$. As the stem of the Primates appears to have begun to develop its branches in the Oligocene, an "Eocene Homosimius" is something of a contradiction in terms. But that is a minor matter in comparison with some of the other difficulties of the subject.

\section{Discussion of Eoliths}

Having now enumerated the principal discoveries of eoliths, we now turn to consider the subject as a whole. We decline to discuss Eocene eoliths seriously, except (as already suggested) to serve as a reductio ad absurdum of the whole subject. Oligocene eoliths are not much worthier of consideration. The Miocene eoliths have a greater measure of support from serious students, and would have to be considered carefully if we accept Pliocene eoliths; if Pliocene eoliths be rejected, the Miocene eoliths will automatically follow them to limbo. We therefore in reviewing the whole controversy need not, at first at least, take into account any objects found in pre-Pliocene deposits.

The question that these flints present to us is primarily, are they the work of a conscious agent, fashioning them for a definite purpose, or are they not? The answer to this question appears to be almost wholly subjective, not objective, and is therefore outside the region of scientific study, except, perhaps, for the psychologist. "There is," admits a German review-writer ${ }^{2}$, "no eolithognomic symptom: only by the combination of several such symptoms, such as never occurs in Nature, can these implements be recognised as artificial." It is irrelevant to comment on the "bull," and we may also pass over the beautiful word "eolithognomic." But who is to say that

1 A. Laville, "Les pseudo-éolithes du Senonien et de l'éocène inférieure" (Feuille des jeunes naturalistes, Paris, I January 1906, No. 423). Obermaier suggests that these Duan deposits may be Miocene: see his paper, "Zur Eolithenfrage" (A.f.A. xxxir. [1906], p. 77). See further, V. Commont, "A propos d'éolithes; silex présentant les apparences de la taille intentionnelle à la base de l'éocène" (Ann. soc. Géol. du Nord, xxxviII. [1909], p. 462).

2 Z.f.E. xxxviI. [1906], p. 237. 
among the myriad forms of Nature any given combination of these (alleged non-existent) symptoms will never occur?

The same subjectivity even affects the interpretation which the adherents of opposite schools put upon printed statements. A Commission nominated at Lisbon by the Prehistoric Congress sat upon and made a report regarding the Ota flints ${ }^{1}$. G. de Mortillet, who was an Eolithist, says of the findings of this Commission, "somme tout, l'opinion de la Commission a été des plus favorables"," while M. Salomon Reinach, who is not an Eolithist, coldly describes the same findings as "conclusions sceptiques ${ }^{3}$." It need not be said that there is no intention here to impute bad faith to any of those who have taken part in the dispute on one side or on the other; indeed, one of the most regrettable features of the controversy is the way in which some of the antagonists have been betrayed by the heat of conflict into making charges, unworthy of men of science, against their colleagues. That one archaeologist should accuse another, for instance, of doctoring his photographs, is intolerable ${ }^{4}$.

Thus it is clear that the "personal equation" in this matter is of such overwhelming dimensions that it completely deprives direct observations of the objects in dispute, on both sides, of all value. In other and perhaps less offensive words, there is no definable criterion which can enable everyone, in spite of his personal prepossessions, to distinguish between a rude artificially-chipped flint and one naturally broken.

This result makes it impossible to disprove the artificial nature of eoliths by comparison with "pseudo-eoliths" naturally or artificially produced. The eoliths from the cement-mill already referred to, or those such as M. l'Abbé Breuil has described from an Eocene stratum in the neighbourhood of Paris ${ }^{5}$, are just as much exposed to the subjectivity of their observers as are the true, or alleged true, eoliths. The Paris flints were submitted to a prominent eolithist without a note of provenance, and were pronounced by him to be true eoliths, indistinguishable from those found in late Tertiary or

1 C.A.P.A. Lisbon [1880], p. 92.

2 Préhist. part I. chap. $\mathrm{x}$.

3 Alluvions, p. IOI, note 2.

4 I abstain from giving references, but the charge has been made in the pages of an important German scientific publication. The author of the paper in which it occurs has been betrayed by passion into speaking impatiently of the Silexzertriummerungsprodukten aus den sogenannten Kreidemiuhlen; causing his readers to wonder what better name he has to propose for this industrial apparatus! When a writer stoops to call his opponents Halblaien, einseitige Beobachter, und Unberufene, the suspicion is aroused that he has some.inward qualms about the strength of his own cause.

5 "Sur la présence d'éolithes à la base de l'éocène parisien" (L'Anthr. XxI. [1910], p. 385). 
early Quaternary beds. This unfortunate guess might have been expected to discourage the cult, but the cult continues unmoved. Indeed, it must be remarked that eolithists are sometimes not altogether reasonable in the way in which they receive adverse evidence. There is an instructive discussion recorded in the Bulletin of the Société d'Anthropologie de Bruxelles ${ }^{1}$ bearing upon this. At the meeting of the society there reported, one of the members, M. Cels, exhibited certain chipped flints from an Eocene stratum near Mons. The members present could not agree as to whether they were intentionally chipped or not, and another member, M. Delvaux, as a geologist, pointed out the dilemma involved: either the flints were Eocene, and therefore long anterior to the appearance of any creature capable of chipping them; or they were artificial, in which case there must have been a later disturbance of the soil containing them. $\mathrm{He}$ also shewed that the strata in which the flints had been found were marine deposits, so that if the flints really belonged to the place where they were found, and were really artificial, their maker must have been some sort of merman! After a discussion, a Commission was appointed to examine the question on the spot, and to report at a later meeting. The findings of the Commission were to the effect that one of the groups of strata seemed to be disturbed, but the other was intact; therefore the flints were Eocene and marine, for both of which reasons it was impossible that they should have been artefacts. Even then, some of the members present, while accepting the geological evidence, pressed for another Commission to determine whether the flints had been artificially chipped or not!

In describing the Parisian Eocene pseudo-eoliths, M. l'Abbé Breuil (in his paper quoted above) records his opinion that these and all similarly fractured flints were produced by the pressure of the superjacent soil. It may also be added that slight earth-tremors, to us imperceptible, would be sufficient to produce the fractures and chips. But it is not possible to evade the question by imagining natural processes by which the flints might have been shaped, without human or homosimian intervention. River action, earth movements, the pressure of overlying soil, the trampling of animals' hoofs, have all been suggested in their turn as the causes to which eoliths are due. But we know very little about the conditions of such stones, buried for untold thousands of years in the heart of the earth; there may be other causes at work of which we are ignorant. Nor are we sufficiently informed as to the actual working of the agents specified, to be able to assert dogmatically that they would, in point of fact, produce the "tools" which we see before us. Certainly, on the other

1 Vol. vi. p. ${ }_{5} 6 \mathrm{ff}$. 
hand, the theory of a natural origin cannot be disproved by attempting to reproduce artificially the natural conditions, and by shewing that eoliths do not result from the experiment. For it is impossible to reproduce the natural conditions. It is not the same thing to shake a number of flints up in a sack, as it is to leave them to knock against one another in the bed of a stream, with its alternating droughts and spates, for myriads of years. It is not the same thing to put flint nodules in a copying-press, as it is to bury them in the earth under a slowly accumulating series of strata, and to leave them for countless millennia subject to all the minute but effective strains and stresses that play upon them in such a position. Not is it the same thing to take a stone in a pair of tongs and scrape it over a cement floor, as it is to embed it in the bottom of a glacier and grind it over a surface of rock. And as before, the subjectivity of the observer affects the judgment passed on the results of such experiments. Diametrically opposite verdicts have been given on the result of the copying-press experiment ${ }^{1}$.

Déchelette has acutely pointed out that in the flint-bearing strata at Le Puy Courny there were found large blocks, too heavy to have been used by any probable form of Man or of Homosimius, which displayed precisely the same kind of chipping as the small implements called eoliths ${ }^{2}$.

It has often been pointed out that there is not any appreciable difference in technique between the eoliths that come from Oligocene deposits and those from Pliocene and Pleistocene strata. The skill of the Pliocene Homosimius was not any greater than that of his Oligocene ancestor (admitting for the moment the existence of such a creature in Europe) a million or more years before him. It is hard to believe in such a complete stagnation of mentality as this implies, granted the postulate that the mentality had so far advanced as to make and use tools at all. The whole physical world, organic and

1 See J. Reid Moir, "The natural fracture of flint and its bearing upon rudimentary flint implements" (Proceedings Prehistoric Soc. of E. Anglia, vol. I. [1912], p. 171); F. N. Haward, "The chipping of flints by natural agencies" (ibid. p. 185); Idem, "The problem of eoliths" (ibid. vol. I. [1913], p. 347); S. Hazzledine Warren, "On the origin of 'eolithic' flints by natural causes, especially by the foundering of drifts" (F.A.I. xxxv. [1905], p. 337), and the discussion thereupon. Mr Warren claimed to produce eoliths by means of a copyingpress, and gives a plate of his results, which is certainly very impressive. $\mathrm{Mr} \mathrm{J}$. Russell Larkby, "The eolithic controversy" (Knowledge, March 19c6), rather grudgingly admits that Mr Warren's handiworks "certainly to some extcnt resembled eolithic implements," but adds (what is perfectly true) that the copyingpress process is essentially artificial, and does not reproduce natural processes. On the other hand, Mr Reid Moir repeated the copying-press experiment and did not get eoliths; see his letter, "The natural fracture of flint" (Nature, 26 December, I912, p. 46I). See also Mr Warren's criticisms in Man, vol. XIII. [1913], No. 20.

${ }^{2}$ Manuel d'archéologie, I. p. 28, where one of these blocks is figured. 
inorganic, was to a greater or less degree changed by evolutionary processes between the formation of Oligocene and of Pliocene eoliths: it is surely much easier to suppose that some mechanical cause common to both periods produced both groups, than that the human intellect, even in embryo, was alone impervious to evolutionary influences.

Assuming that the "retouching" of eoliths is artificially made, and not produced mechanically by the usage of the tool, it must be said that to make implements by delicate retouching is by no means an elementary process. It does not stand at the natural beginning of a development. It requires skill, lightness of touch, a number of special tools, and experience as to the best means of producing the effects desired. Consider for a moment the actual technique of flint-chipping, as it can be studied among people who still use flint tools, such as certain tribes of North American Indians ${ }^{1}$. The simplest way is to hold the flint nodule in the left hand and to strike it with a stone which does duty as a hammer, held in the right. A large flake is thus dislodged. If a smaller flake is to be removed, pressure, rather than a blow, is applied, the fabricating tool being pressed laterally against the edge of the flint. A yet more delicate chipping is produced with indirect percussion, in which the mallet strikes, not on the flint, but on a punch-a bar of stone, or when such can be procured, a nail-held against the flint operated upon. Sometimes this work will require two operators, one holding the flint and the punch, the other the mallet; but sometimes an expert man can work alone, holding the flint in his palm and grasping the punch between his first two fingers. For delicate touching a bone is used, gently drawn across the edge, thus dislodging minute flakes. A forceps is occasionally employed; this consists of two bones tied together with a thong, leaving a beak projecting, with which the operator breaks off flakes, as a glazier breaks off the fragments remaining in the frame of a broken window.

The analogy of modern savage processes is not overlooked by Eolithists. A committee appointed by the Berlin Anthropologische

1 This account is adapted from a series of illustrations in the Smithsonian Report for I 890, p. $547 \mathrm{ff}$. accompanying an abstract of a paper in the American Anthrnpologist, to which I have not obtained access. See also W. H. Holmes, "Stone implements of the Potomac-Chesapeake Tidewater Province" (Bureau of Ethnology, 15th Report, Washington, 1897); T. Wilson, "Arrow-points, spearheads and knives of prehistoric times" (Smithsonian Report, r897, p. 81 r); Geo. E. Sellers, "Observations on stone-chipping" (ibid. [1885], part I. p. 871); F. C. J. Spurrell, "On some Palaeolithic knapping tools and modes of using them"' (F.A.I. XIII. [1 884], p. I09); O. T. Mason, The Origins of Invention (London, 1 895), chap iv.; W. I. Lewis Abbott, "On the classification of the British Stone-Age industries, and some new and little-known well-marked horizons and cultures" (F.A.I. XLI. [I9II], p. 458), has many details about varieties of flint-flaking, though the cumbrous terminology adopted by the author makes the paper hard reading; Stevens, Flint Chips, p. 87. 
Gesellschaft to consider the authenticity of eoliths exhibited by Prof. Klaatsch, came to conclusions which appear in the Society's journal over the signature of Dr Eduard Krause ${ }^{1}$. This investigation was certainly made in a very business-like way, deserving of all praise. Dr Krause had put himself under the tuition of natives of Tierra del Fuego, and from them had received practical instruction in the art of flint-chipping. The conclusion is that the "retouching" resembles the actual work of Man, which may be admitted; and cannot be anything else, which is a non sequitur. We might as well say, in defiance of experience, that nature unaided by man cannot sculpture rocks and stones into a likeness of human faces and other pictorial forms. Dr Krause raises the question which we must presently consider, of what use were eoliths; and he comes to the conclusion that it is impossible to say, for, as Man was at the beginning of all the arts, he was only beginning to evolve the most suitable shapes for tools; but, he adds, a certain implement which he figures "was a hollow scraper for making arrow-shafts, etc." (op. laud. p. 551). Apparently Eolithic Man said to himself, "Go to, let us evolve a chisel," or some other tool. Perhaps he did; but that is not my conception of the nature of industrial evolution. In any case I really cannot bring myself to believe that he possessed " arrow-shafts, etc.," which needed to be fashioned in a neat cylindrical form, at the time when he is supposed to have come to this resolution.

What does common sense tell us would have been the normal course of evolution of the manufacture of stone implements? Surely (I) the use of an unworked stone with a naturally sharp point or edge; (2) the improvement of such a stone by coarse chipping - at first, indeed, merely smashing it with another stone, and making use of the raw edges of the fractures; (3) gradually learning how to shape tools, still by rough chipping with large coarse flakes; $(4)$ when a considerable amount of expertness and lightness of touch had been attained, sharpening or otherwise improving the tool by fine chipping along the edge. This is actually the course of development which we can observe, if we put the eoliths on one side. The first Palaeolithic tools that can be identified as artefacts lie in stage (3) of the above scheme; mere fractured stones can evidently not be recognised as artificial. But Eolithists would appear to wish us to accept the difficult credo that Man or Homosimius started in stage (4), and through it worked on to stage (2)!

We may freely admit that there must have been a long series of experiments before the coup-de-poing, the typical tool of the Lower

1 "Bericht über die Konferenz zur genaueren Prüfung der in der Sitzung vom 2 I März d. J. [1903] vorgelegten Feuerstein-Funde"' (Z.f.E. xxxv. [1903], p. 537). 
Palaeolithic period, was fully evolved ${ }^{1}$. But it is impossible to discover any test whereby we can certainly distinguish between the first tentative efforts at flint-chipping and natural products.

It should not be forgotten that it is just the edge or point of a flint flake which is the weakest part; and if such a flake be embedded in earth or gravel, and natural forces act upon it, it is this weak part which will suffer. That the "retouching" should lie on that part of the flint where it would be of the greatest industrial service to its hypothetical user, is only what we might expect; and it is needless to burden our powers of faith with an evolutionary hysteron proteron such as is involved by accepting these objects as genuine artefacts.

One of the strongest arguments in favour of eoliths as being artificial products, and not the result of natural causes, is the fact, which may be admitted, that the continuance of the agent which produces the eolith form also destroys $\mathrm{it}^{2}$. In an ingenious paper ${ }^{3}$, Rutot comments on some observations of his opponent Boule, who had found, on the sea-beach between Cromer and Sheringham, stones having all the appearance of eoliths, broken into shape by the action of the waves. Rutot does not attempt to deny that the Cromer flints actually resemble eoliths, though such a position is maintained by later writers in the following volume of the same journal. Into this side-issue, which again is a question of subjectivity, we need not enter. The point which Rutot makes is that in all such circumstances there are eoliths, or pseudo-eoliths, of the past, the present, and the future. In the case under consideration, the flints found by M. Boule were the eoliths of the present. All around were flints which, having once had a "quasi-eolithic" form, had been rolled and smoothed by the waves, and had lost that form-those were the eoliths of the past; while there were other stones which later storms would hammer into an eolithic shape, to be preserved for a short time and then lost again in like manner. Those were the eoliths of the future. In short, Rutot argues that pseudo-eoliths, produced by natural causes, are essentially ephemeral, but those which have once been fashioned and deposited in their proper strata are permanent.

This argument is extremely clever, but it is fallacious. For it assumes that it is impossible to admit that the temporary facies of

1 It is, however, possible to exaggerate the complexity of the coup-de-poing, and the degree of skill required for its manufacture. After all, it is only a nodule of flint sharpened at one end. Eolithists have a way of talking about it as though it were comparable in intricacy with a steam-engine.

2 M. Gillet, "Eolithes recueillis à Arpagon" (B.S.P.F. Iv. [1907], p. $283 \mathrm{ff}$. esp. p. 284); see also the description of the experiments and observations of MM. de Munck and Ghilain in A. Rutot, "La fin de la question des éolithes" (C.P.F. Autun [1907], p. 77 ff. esp. pp. 81-82).

3 "A propos des pseudo-éolithes de Cromer" (B.S.P.F. IV. [1907], p. 505). 
an object, naturally in a state of change, can in any circumstances be preserved permanently. This is, of course, contrary to experience, and is an especially strange assumption for a geologist to make, even unconsciously. There is nothing in nature more ephemeral than a footmark, or the dent left in mud by the fall of a raindrop; yet the footmarks of Mesozoic reptiles, and the traces of equally ancient rain-storms, have been preserved, and are to be seen in most of our prominent geological museums. If some combination of circumstances could stereotype these fleeting imprints and keep them unchanged for the millions of years that have passed since the day when they were made, may not some other combination of circumstances stereotype an "eolith of the present" at the moment of its formation, and keep it unchanged through the subsequent ages?

There is another fallacy latent in the frequent citation of the ancient Tasmanians as an "eolithic" people". The worst of the stone implements of the Tasmanians were certainly as rude as any eoliths; but they were not in flint, a material not at the disposal of the inhabitants of that island. No other stone fractures so easily and so conveniently as flint; if a people cannot get flint they cannot expect to attain to the perfection of more fortunate communities in the manufacture of stone implements. In the shore midden-heaps of the west of Ireland are found neolithic implements made of various intractable stones which are quite as rude as the rudest Tasmanian manufacture. On the other hand, the Tasmanians, even with their imperfect materials, were not wholly despicable as stone-implement makers. The comparisons which reduce them to the level of the hypothetical Eolithic people of Europe take no account of a large number of well-made knives, scrapers and other tools which they have left behind.

On the other hand there is an eolithophobe argument which has been put forward, but must in reason be dismissed as likewise fallacious, and so a weakness to the cause which it would support. This is the argument from association. Returning to Sir Joseph Prestwich's paper, already cited, on the implements from the Kent Plateau, we see that he distinguishes three groups of objects-two kinds of "eoliths," and a third kind, comparable with the Lower Palaeolithic tools in general, and with the Acheulean or latest phase of the Lower

1 See E. B. Tylor, "On the Tasmanians as representatives of Palaeolithic Man" (F.A.I. XxIII. [1894], p. 14I); H. Klaatsch, "Die Steinartefakte der Australier und Tasmanier verglichen mit denen der Urzeit Europas" (Z.f.E. XL. [1908], p. 407); Maurice Exteens, "Note sur les instruments de pierre des Tasmaniens éteints" (B.S.A.B. xxx. [1911]); Idem, "L'industrie des Tasmaniens éteints" (C.A.P.A. Geneva [1912], vol. II. p. 352), a paper emphatically opposed to the "eolithic" view of the Tasmanians; J. Paxton Moir, "On Stone Implements from Tasmania" (F.A.I. xxx. [1900], p. 257). 
Palaeolithic in particular. The last-named are sparse on the plateau itself, though common in the valleys. It might seem at first sight that we should here apply a canon of archaeological criticism which holds good in the vast majority of cases-that a deposit must be dated by the latest objects which it contains. If Acheulean implements are found on the Plateau, then the Plateau deposits are Acheulean. But this must be admitted as an exception to the rule. If in a garden in England we dig up (as is quite possible) at one cast of a spade a Roman coin and a bit of a jam-pot, we infer a resortment of the soil at a date later than that of the jam-pot. If we find Palaeolithic and Neolithic tools together on the same level, we must not bring down the date of the former implements to explain the phenomenon ${ }^{1}$. But the case of the Plateau flints is different. The Acheulean implements are found on the surface of the gravels only; the eoliths are found through their thickness. This clearly shews that the eoliths were formed, by whatever means, during the deposition of the gravels, whereas the Acheulean tools were casually dropped on the surface of the gravels, it may be many millennia afterwards.

In the following chapter we shall say a word or two about the formation of the Plateau gravels, and need only say here that the admission of the immensely older date of the eoliths does not in the least amount to an admission of their human origin. On the contrary, the fact, emphasised by Eolithists, that they are found scattered through the gravels, makes this explanation of their origin the more difficult. The gravels were presumably deposited by long-continued flood-streams, sweeping down from a higher level. If these floodstreams had been intermittent, with interspersed periods of drought, then there would have been definite strata, to which the eoliths would have been confined. Had this been the case, a human origin for the objects could hardly have been questioned. But they are scattered indiscriminately through the gravels; therefore either Eolithic man must have lived on the spot during the formation of the gravels, that is, in the floods; or he must have lived at the higher level from whence the gravels were derived. The latter is the only possible alternative. But then his handiwork must have been waterrolled and abraded, which would have effaced his delicate chips. By the time they reached the Plateau, they would have become, in the words of Eolithists themselves, "eoliths of the past," and would have been unrecognisable. The fact that they are "eoliths of the present" shews that the chipping is the result of the force which carried them

${ }^{1}$ See for an example P. de Givenchy, "Note sur une hache paléolithique trouvée à Antilly" (B.S.P.F. III. [1906], p. 376). 
to the Plateau-that is, of the water-rolling which formed the gravels.

Again, it is argued that there are places where flints would be subjected to natural causes just as much as in Cantal, in Kent, and elsewhere, and yet where eoliths are not to be found ${ }^{1}$. This means nothing more than that the possibility of natural causes has not yet been exhausted. We do not know how these natural causes work, and it is not very clear how we can acquire this desirable information; so that we do not know what elements are absent in places where eoliths are not to be found, to account for their non-appearance. On the other hand, one of the most serious and cogent objections to eoliths is the fact of their being confined to places where flints are abundant. Where there is flint there are, as a rule, eoliths; where there is no flint there are no eoliths. Homo or Homosimius cannot be supposed to have lived only in those parts of the Continent or of England where flint is to be found. He must have wandered elsewhere; and when he did so, what did he do for tools? The Tasmanians made shift to manufacture tools out of the stones which their island supplied; why did not the Eolithic Europeans do likewise, in places where flint is not to be found? Surely the only reasonable explanation is that eoliths are not artificial products, but are the result of some natural stress, acting in a way not certainly known, to whose "chipping" influence flint, owing to its texture and constitution, is susceptible in a marked degree.

And what is the use of eoliths? That is a point which as a rule Eolithists either resentfully denounce as "irrelevant," or else gracefully slide over, contenting themselves with generalities such as that "their makers were still in the infancy of all the arts," or that the tools were intended for scraping hides or (mirabile dictu) arrow-shafts. Another answer to this awkward question is of the $t u$ quoque order. There are implements belonging to the Neolithic and Bronze Ages to which no use can be assigned, yet this is not used as an argument against their human origin, which is indubitable ${ }^{2}$ That is so: but the cases are not parallel. A use can be satisfactorily assigned to most Neolithic and Bronze Age implements: those which cannot be explained are exceptional. No use can be assigned to the majority of eoliths, though these ex hypothesi came from a simpler phase of culture. It has been suggested that they may have been meant for the attrition of callosities from the foot; and it is surprising to find a theory on record that they were for removing vermin from

$1 \mathrm{Mr}$ C. J. Grist names a few such places in England in F.A.I. XL. [1910], p. 198.

2 This argument is used by the Rev. R. A. Bullen, "Eolithic implements" (Fournal Victoria Institute, xxxIII. [1901], p. I9I). He cites especially the wellknown balls with spiral ornament found in Scotland. 
the persons of their manufacturers ${ }^{1}$. If this was not meant for an attempt at a joke, of which I can find no evidence, it must be classed with the "boomerang" theories which are occasionally to be found in archaeology and other sciences, and which merely recoil and hurt their authors' own case. It is like the idea of a dabbler in Irish antiquities many years ago, who, believing that the Irish Round Towers were the cells of Buddhist monks [!], suggested that some oyster-shells which he found in one of them might have been the monks, who had become ostrified by long contemplation ${ }^{2}$. Or like an eminent contemporary English man of letters who, though posing as an uncompromising advocate of science, wrote some years ago a gruesome novel picturing the horrors of vivisection, much as they are . conceived of in the uninformed imaginations of the morbidly sentimental.

But let us hear something more definite and less frivolous. Prof. Verworn ${ }^{3}$, speaking of the Cantalian flints of Le Puy Courny, says: "It is certain that at the end of the Miocene epoch the valleys of Cantal were inhabited by beings already familiar with the art of flint chipping ${ }^{4}$, and of making implements by fine working of the edges.... I do not scruple to consider this being as already near to man, or to treat him as actually a man; the implements are all well suited for the modern human hand.... No bodily remains of the old inhabitants of Cantal have as yet been found. We know not whether in their bodily form they more resembled the men of modern times or the animal precursors of men, whether they already had an articulate speech, whether they were acquainted with fire, whether they possessed clothing or dwellings, whether they ate meat, etc. Many other questions rise to our lips, but investigation gives no answer. All that this mysterious being has left behind are his works in stone. Where man is dumb, stones will speak." In quoting this eloquent passage, Reinhardt ${ }^{5}$ adds a footnote of his own to the questions asked by its writer- "The answer to all these questions is quite certainly in the negative."

Now let us accept this as a fair statement of the views of Eolithists, and let us see whither it leads us. We are to imagine a being of uncertain form-apparently some would picture him as intermediate between a lemur and a man, but the point is immaterial. This

1 Matériaux pour l'histoire de l'homme, vol. xIx. p. 283.

2 From a letter printed in Petrie's Round Towers of Ireland, p. 85.

3 Umschau, August 1905. The original being inaccessible to me, I borrow the quotation from Reinhardt's Mensch zur Eiszeit, p. $4 \mathrm{I}$.

${ }_{4}^{4}$ It will not escape notice that the distinction between silex utilisés and silex taillés is here ignored.

${ }^{5}$ Ludwig Reinhardt, Der Mensch zur Eiszeit in Europa (Munich, 1908), p. 41. 
nightmare creature cannot speak, cannot light a fire, and constructs no dwelling-place. So much on the negative side. On the positive side, he chips flints. We ask in wonder, what for? If he wore no clothes, he needed no scraper to dress hides. If he built no dwellings, he needed no tools to fashion wood. If he had no fire, he needed no strike-a-light. What, then, did this Jabberwock do with his tools when he had made them? They are too small to have been used as weapons for slaughtering beasts for food, supposing him to have been a flesh-eater; they would have to be mounted as spears or as arrows to do any effective service, and he must be a truly enthusiastic Eolithist who would venture to claim that Tertiary Man had made an advance so extraordinary as to use such complicated weapons. For my part, I can conceive no purpose which eoliths would serve, within any probable limitations of Tertiary human or homosimian life, except to pelt enemies, animal or human, and to crack nuts. For the former purpose the majority of eoliths are too smallimagine an unfortunate Homosimius defending himself against a Machaerodus with an eolith!--and for the latter the chipping, in so far as it diminishes the size and weight of the stone, actually diminishes its usefulness. It is sometimes suggested that the chipping was made to render the stone more convenient for grasping. This suggestion cancels out the other theory, that it was for the purpose of making a cutting or scraping edge, but let that pass. Tertiary Man or Homosimius would not have taken the trouble, even if he had had the skill, thus to trim an inconvenient stone; he would have thrown it away and picked up another.

The words of M. Salomon Reinach, written in 1889 , are as true now as they were then: La presque totalité des silex allégués comme portant des marques de travail humain ne pourraient être d'aucun usage à aucun être intelligent ${ }^{1}$. Later, Prof. Sollas said much the same thing in other words: he speaks of "Eolithic scrapers that will not scrape, borers that will not bore, and planes that will not plane2."

\section{Conclusions}

In short, the conclusion to which we are led by this discussion is that No theories about Tertiary man, or precursors of man, in Europe, can be based on the objects called eoliths: because

I. They are found only in flint-bearing regions, which indicates that they are produced by natural causes of some kind to which flint responds more readily than other stones.

1 Alluvions, p. I0I. The writer is, of course, speaking of eoliths, not of flints in general.

2 Report of British Association for the Advancement of Science, Birmingham Meeting [1913], p. 790. 
2. There is no test whereby they can be distinguished, so clearly as to command universal acceptance, from naturally broken pebbles.

3. There is no probability that the requirements of Tertiary man, or precursors of man, were so complex as to call for the use of tools at all.

4. Even if they were, the flints called eoliths would not serve any such purposes.

5. There are many alleged eoliths for which no conceivable use of any sort can be suggested.

On these grounds we reject the Pliocene eoliths, and a fortiori those of earlier eras. It follows that if we deny the existence in Europe, during the Tertiary times, of a being capable of making and using even such feeble attempts at flint tools as the average eolith, we must still more strongly deny the existence of a manufacturer of the more complicated rostro-carinates.

There is an instructive incident to be found reported in the volumes of the Bulletin of the Société préhistorique de France for the years 1906-1907. At a meeting of that society, in the former year, a member exhibited a great collection of pebbles arranged in series-squares, triangles, lozenges, circles, etc. He had spent the leisure of 30 years in collecting them from gravel-pits round Paris; and he proposed to regard them as a sort of Palaeolithic money. At a later meeting of the society another member turned the powerful weapon of parody upon this unfortunate theory and its author. He exhibited a similar collection of stones, which he had gathered from a few casual heaps of road-metal in the space of two or three hours. This incident shews that it is possible to prove anything about types of stone implements, by selecting stones of the appropriate shape from a heap and rejecting the rest. This, we repeat, does not involve any charge or imputation of bad faith; self-deception is a perfectly innocent misfortune, to which archaeologists are peculiarly liable. M. Marcellin Boule, who has reviewed the whole subject in a trenchant article ${ }^{1}$, has personally examined the strata in the neighbourhood of Ipswich in which the rostro-carinate flints were found. He points out that these strata contained a vast mass of broken flints to which no archaeological value can be attached: and that the rostro-carinates are simply one series of such accidental fragments. He further shews that the stratum is a marine deposit, so that (like the Eocene flintchippers of Mons) the makers of the rostro-carinate tools must have been at least amphibious, if not actually mermen. And, as we have already seen, even those who are responsible for bringing forward these objects, while claiming that they are "highly specialised," are

1 "La paléontologie humaine en Angleterre" (L'Anthr. Xxvi. [1915], p. I). 
unable to suggest any probable use which would require so high a degree of specialisation. After this it would be unprofitable to pursue the subject further ${ }^{1}$.

\section{Pithecanthropus erectus}

We have already seen that no bones of the "Precursor" have come to light in Europe. We shall presently see that strong simian reminiscences may be traced in some of the early human remains that this continent has yielded. This is, however, a different thing; such bones are certainly human, not homosimian. The only group of remains that can fairly be classed with the theoretical "missing link" is the famous assortment of bones known collectively as Pithecanthropus erectus.

These bones were found at Trinil, a village on the river Bengawan, in the island of Java. The gravels in which they were embedded most probably belong to the beginning of the Pleistocene era, though some authorities would assign them to the end of the Pliocene. Practically every single point about these bones is a centre of dispute.

The remains consist of a left femur, a very small fragment of a lower jaw, three ${ }^{2}$ teeth, and the top of a skull. It is agreed that these bones are contemporaneous, whatever may be the exact period to which they belong; but there agreement ceases. It is in the first

1 The reader desirous of following up the subject of eoliths further will find material for his study in the following publications, in addition to those mentioned in previous footnotes.

EolithoPHILE: M. Verworn, "Die archäologische Cultur in den Hipparionschichten von Aurillac" (Abh.d.k. Gessell. d. Wissensch. zu Göttingen, Mathem.Phys. Klasse, N.F. vol. Iv. No. iv. [1905]); Idem, "Ein objektives Kriterium für die Beurteilung der Manufaktnatur geschlagener Feuersteine" (Z.f.E. XL. [1908], p. 548); A. Rutot, La préhistoire dans l'Europe centrale (Congrès d'archéol. 1 903 , 1904); Idem, "Défense des Eolithes (B.S.A.B. xx. [1902]); G. G. MacCurdy, "The Eolithic Problem" (American Anthropologist, N.S. vol. vir. [1905], p. 425). The last-named paper has an admirably thorough bibliography.

EOLIтHOPновE: H. Obermaier, "Zur Eolithenfrage" (A.f.A. xxxi1. [1906], p. 77); Idem, Der Mensch der Vorzeit, Berlin, I912; Idem, El hombre fósil, Madrid, 1916; Idem, "Das geologische Alter des Menschengeschlechts" (Mittheil. d. geolog. Gesellsch.in Wien, 1. [1908], p. 290); F. Wiegers, "Die natürliche Entstehung der norddeutschen Eolithe (sic)" (Z.f.E. xxxvilI. [1906], p. 395); L. Mayet, "La question de l'homme tertiaire" (L'Anthr. Xvir. [1906], p. 64I); F. Sarasin, "Ueber die Fehlerquellen in der Beurteilung der Eolithen" (Verhandl. $d$. naturforschend. Gesellsch. Basel, xxII. [1 III I], p. 24), describes fragments of broken glass found on the shore at Nice, exactly resembling eoliths, "retouches" and all; J. G. N. Clift, "A study in "Eoliths"” (British Archaeol. Association, N.S. xv. [1909], p. 1 29); Worthington G. Smith, "Eoliths" (Man, virr. [1908], No. 53). See also a controversy in Man, vol. v. [1905].

2 Only two of these teeth have been published by Dubois, the original discoverer. A fourth (which was primitive human, not homosimian) was found by the Selenka expedition, at a considerable distance from the lair of Pithecanthropus, and it was impossible to determine the chronological relationship between the two sites with any certainty. It is fully described by M. Blanckenhorn, "Vorlage eines fossilen Menschenzahns von der Selenka-Trinil-Expedition auf Java" (Z.f.E. xLII. [1910], p. 337). 
place not universally admitted that they belong to a single individual. They were scattered over so wide an area, in fact, that there was a horizontal distance of from 12 to 16 mètres between the femur and the skull, while the teeth were separated from the skull by distances of 1 to 2 metres respectively. If these bones all belonged to one individual, we must suppose that some external cause-a river spate, for example, or perhaps the operations of crocodiles-had separated them some time after the body had become deposited in the river that formed the gravels. On the other hand, it is on the whole more difficuit to accept the consequences of treating the bones as belonging to different individuals. For then we should have to suppose that two beings, the one a man-like ape, the other an ape-like man, had lived together and had happened to find their last resting-place side by side. Other suggestions have been made from time to time to account for the strange mingling of simian and human characters which the bones present. It has been supposed by some that the peculiarities of the bones were due to disease; but though the femur is not healthy, the suggestion is insufficient to account for all the facts. Another suggestion, that the creature to whom the bones belonged was the result of a Homo-Simian cross, apart from other objections, postulates the existence of fully-dereloped Homo at the time to which the gravels belong.

The femur differs in detail from an ordinary human thigh-bone, but not so markedly that it would not have been labelled humanabnormal, but still human-had it been found alone. According to Hrdlička, one of the latest writers on the subject", the "principal differences of the bone from a modern human femur consist in its less-marked antero-posterior curve [i.e. the curve in the length of the shaft when the bone is looked at sideways], in a more evenly cylindrical shaft, in the more mesial position of the smaller trochanter, in the inter-trochanteric line being less raised, and hence more simian in character, and in the popliteal space which, as a rule concave from side to side in present man, is convex in the Trinil specimen" (see Fig. 40, where the Trinil femur is compared with a modern specimen, and the parts mentioned in this description are indicated). According to many authorities, this thigh-bone indicates a being which had already assumed the erect attitude characteristic of man. Some writers, such as Duckworth ${ }^{2}$, indicate a doubt as to the legitimacy of this assertion, and eren claim that it is possible to deny the essentially human character of the bone, and to regard it as belonging

\footnotetext{
1 Aleš Hrdlička, "The most ancient skeletal remains of Man" (Smithsonian Report for 1913, p. 49 I ff. esp. p. 501).

2 Prehistoric Man (Cambridge, 1912), p. $\delta$.
} 
to some unknown species of ape; questioning whether the bone certainly indicated the assumption of the erect posture.

Application to the measurements of this bone of scales of proportion, established for normal human beings, would indicate that its owner was about $\mathrm{I} \cdot 4$ mètre in height and weighed about $6.9 \mathrm{~kg}$.; and it is regarded as probable that the individual to which it belonged was a female. We may perhaps be allowed to question

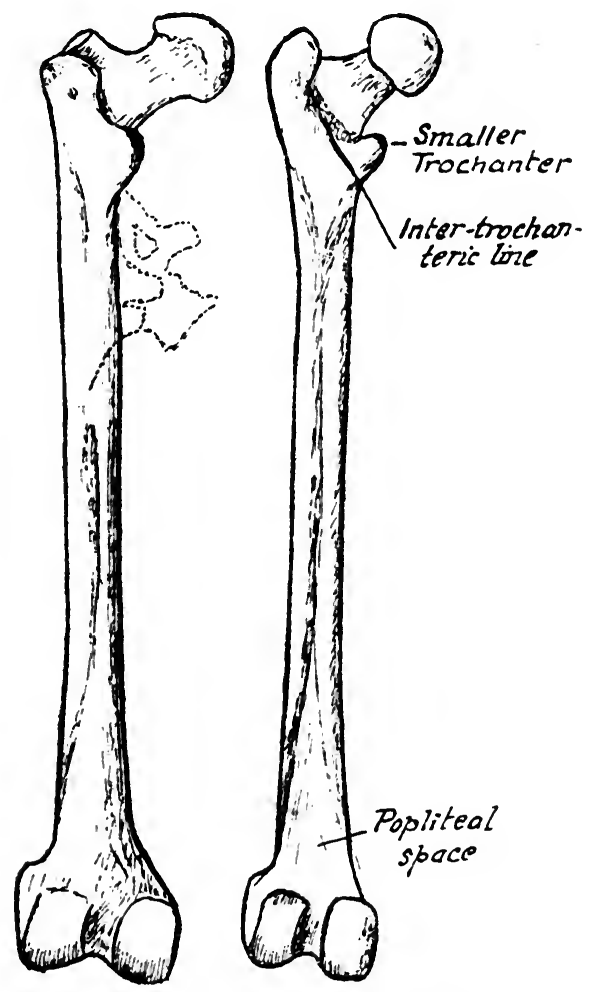

Fig. 40. The Trinil femur compared with a modern specimen.

whether scales of proportion determined for normal bones and normal human beings can be applied without leaving a large margin of error to a skeleton which is so fragmentary, and in which so much is abnormal: also whether the differentiation of sex can be so certain on this femur as it is in ordinary femora. In any case, even if the subject was certainly a female, the affectation of speaking of the Java Pithecanthropus as "she," in which some writers have indulged, picturesque though it may be, is hardly justifiable.

The femur is not a healthy specimen. There is a remarkable bony 
growth or exostosis on the side of the shaft, of which ${ }^{1}$ several explanations have been given: deriving it from a traumatic periostitis $\left(\right.$ Dubois $^{2}$ ) an abscess (Virchow ${ }^{3}$ ) a muscular affection called Myositis ossificans (Bland Sutton ${ }^{4}$ ) or a sympathetic growth induced by the repair process in another bone, not now forthcoming, which had been fractured (Duckworth ${ }^{5}$ ).

Notwithstanding its minor peculiarities, the femur, as we have said, would probably have been accepted without question as human if it had been found alone. The skull, however, if found alone, would assuredly have been labelled as that of a highly developed ape. Though on the whole it has an intermediate position, it is certainly more ape-like than human. "In most respects," says Hrdlička ${ }^{6}$, "this specimen differs more or less from the ordinary human skull of to-day, and approaches correspondingly the crania of the anthropoid apes." The horizontal outline of the skull resembles that of a man more than that of an ape; but the vertical outline, with its brutally low forehead and the great ridges over the eye-holes, is certainly more like that of an ape's skull.

If we represent the average height of the vault of the skull of a modern man above a certain fixed plane by the figure 100, the height in the anthropoid ape will be between $5^{\circ}$ and 60 , while that of Pithecanthropus is $74^{7}$. Here, therefore, Pithecanthropus is nearer to the ape. Again, the cranial capacity of the brain-case in normal man ranges from 1300 to 1500 cubic centimètres-the extreme range, including abnormal cases, being 930 to 2000 . In the higher apes this capacity ranges from 290 to 610; in Pithecanthropus it is estimated at about $85^{\circ}$. Thus, while Pithecanthropus was nearer in cranial capacity to some small-headed human idiots than to the highest apes, it still fell far short of the full attainment even of the lowest types of normal man ${ }^{9}$. The skull is dolichocephalic, the index being $72 \cdot 5$.

The development of the brain, the essential concomitant of the

1 The outline of this morbid growth has been indicated in dotted lines in Fig. 40, in order not to confuse the comparison of the normal details of the femur with those of a modern specimen.

2 Eugene Dubois, "Pithecanthropus erectus, a form from the ancestral stock of Mankind" (Smithsonian Annual Report, 1898, p. 445 ff. esp. p. 457).

3 Ibid.

4 In F.A.I. xxv. [1896], p. 248.

5 W. H. L. Duckworth, "Les fractures des os des ourang-outangs et la lésion fémorale du Pithecanthropus erectus" (L'Anthr. xIII. 204, also published in C.A.P.A. Paris, 1900, p. 459).

${ }^{6}$ Op. laud. p. $50 \mathrm{r}$.

7 A. Keith, Antiquity of Man (London, 1915), p. 264.

8 Owing to the imperfect condition of the skull the cranial capacity cannot be measured with complete accuracy.

9 Keith, op. laud. p. 267. 
advance in intellectuality of the human species, renders necessary a brain-case larger in size than that which served the purposes of the animal ancestor, and differing from it in shape. The human braincase is higher in the vault and broader in the sides than is that of the ape. It is a fact generally familiar that the various regions of the brain control one or other of the senses, faculties, or organs; if any one of these regions be injured, the corresponding sense or faculty

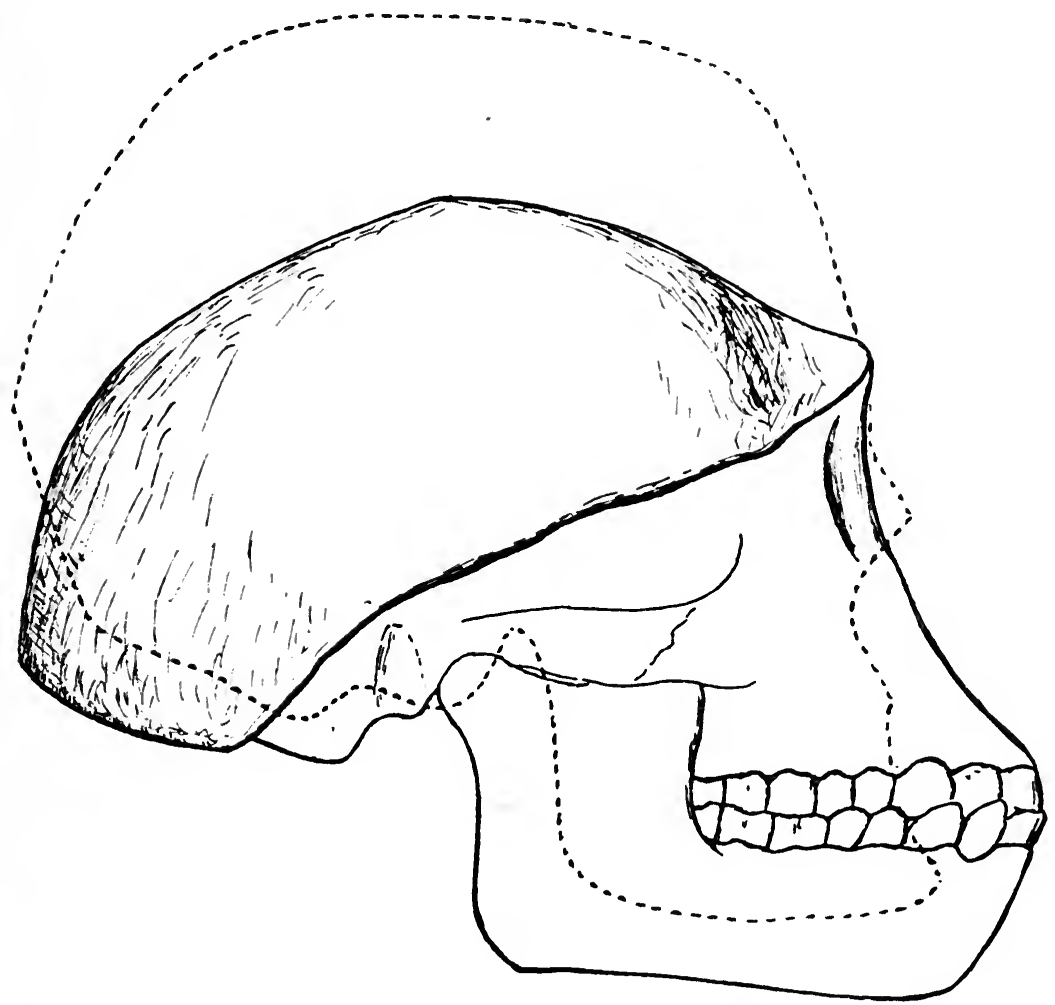

Fig. 4I. The Trinil skull compared with a modern specimen.

will be impaired or destroyed. It has been found possible to make an examination of the interior of the brain-case of Pithecanthropus, and thereby to form certain conclusions as to his mental attainments and limitations. The sense-areas--touch, taste, sight, etc.-appear to have been well developed, as they are in the anthropoid ape. The speech-area shews a decided advance on the corresponding part of the ape; if Pithecanthropus had not yet evolved the art of speech, he seems to have had at least a rudimentary latent capacity to do so. But the frontal part of the brain, where are situated the control- 
centres of attention, memory, and co-ordination of the other faculties, was still in a very early stage of evolution as compared with the corresponding parts of fully-developed man $^{1}$.

The teeth bear out the conclusion indicated by the skull. They are "not exactly like any known teeth, either human or simian"": and they are rather nearer to the teeth of the higher primates than to any known human molars. "On the whole," adds Hrdlička, "it seems evident that the teeth represent a higher primate form, and... are such that they may well have belonged to the same species or even the same individual as the skull-cap." The general conclusion drawn by anatomists seems to be, that the size of the teeth as compared with the other bones is larger than the human norm, and thus approximated to the simian norm; but taking each tooth by itself, the proportions of the several parts and measurements are more human than simian.

Before we leave Pithecanthropus a word of caution must be spoken. It is not to be understood that this creature is a step in the direct ancestry of the existing human race. Though it holds anatomically an intermediate place between the ape and Man, it does not necessarily hold the intermediate place. Rather is it to be considered as a collateral, which might have in time developed into some kind of man had circumstances allowed its branch to survivethe end of a side-line which early separated itself off from the direct line of human ancestry, and which never fully reached the goal of humanity. His place in evolution may be illustrated with a parallel borrowed from the development of civilisation. We know that as Man had developed from the common ancestor of the human and simian branches of the Primates, so the culture of civilised man has developed from the savagery of primitive ancestors. But contemporaneously with civilised man, we find savages who from one cause or another have been retarded in cultural development. Their culture has come to nothing in the scale of civilisation, just as the branch of Pithecanthropus came to nothing in the scale of human evolution.

One reason for thus explaining the phenomenon of Pithecanthropus is the slowness with which evolution works. The gravels where the bones were found are dated to the beginning of the Pleistocene era, according to the more probable theory. This would hardly allow sufficient time, before the appearance of the oldest fullydeveloped human fossils, for the evolution of Pithecanthropus into $\mathrm{Man}^{3}$.

1 Keith, op. laud. p. 268.

2 Tomes, Dental Anatomy, cit. ap. Hrdlička, op. laud. p. 500.

3 The literature of Pithecanthropus is enormous. A bibliography of the subject, up to the date of publication (1899), will be found in G. Schwalbe, "Studien über 


\section{Other Alleged Remains of Tertiary Man}

Such has been the contribution of Asia, so far, to the problem of Human Origins. Africa has yielded nothing as yet. The Tertiary and even the Pleistocene bones that have been reported from time to time from North and from South America have all been personally examined by Hrdlička, who reports his conclusion that there is not a single trace yet found in that continent of any human race older than the present aborigines ${ }^{1}$. We may confidently accept this result, based as it is on a minute and highly competent personal examination of the entire series. Even the "ancestor" labelled with the polysyllabic jargon Tetraprothomo argentinus, whose interesting personality was evolved from the atlas of a modern Indian and the femur of some fossil species of $\mathrm{cat}^{2}$, may be suffered to drop into the Tophet prepared of old for Kimmeridge coal-money, Atlantis, Anglo-Israel, the Hidden Mysteries of the Great Pyramid, and all the other waste products of "antiquarianism."

Oceania is likewise silent as yet. There is however one group of skeletons from Europe that we cannot pass over without mention in this connexion.

\section{The Castenedolo Skeletons}

This is the discovery made at Castenedolo in Lombardy. Here were found the bones of a man, a woman, and two children, embedded in a Pliocene stratum. They were unearthed by a competent geologist, Ragazzoni, in 1860 , and examined by a competent anatomist, Sergi. There is thus no element of irresponsibility, such as is conspicuous, for instance, in the story of the Calaveras skull ${ }^{3}$. The Castenedolo deposits, whatever we may think of them, have to be treated seriously.

But there must be something wrong somewhere. In the first place the skeletons are in all respects modern in their type. There is, says Keith" "not a single character we can identify as primitive."

Pithecanthropus erectus Dubois," published in the Zcitschrift für Morphologie und Anthropologie, vol. I. pp. 16-240; and a later bibliography appears in the same writer's Die Vorgeschichte des Menschen (Brunswick, 1904). An interesting popular study of the problems involved will be found in Munro's Prehistoric Problems (Edinburgh, 1897), chap. iv. For the report of the latest expedition to the site of the discovery see Frau Lenore Selenka and M. Blanckenhorn, Die PithecanthropusSchichten auf Ұava, geologische und paläontologische Ergebnisse der Trinil-Expedition, 1907-8, Leipzig, 191 I ; see also H. F. Osborn, Men of the Old Stone Age, p. 72.

1 "Skeletal remains suggesting or attributed to Early Man in North America,"

Smithsonian Bulletin of American Ethnology, No. 33 (Washington, 1907); "Early Man in South America," ibid. No. 52 (Washington, 1912); "Recent discoveries attributed to Early Man in America," ibid. No. 66 (Washington, 1918).

${ }^{2}$ Hrdlička, Early Man in South America, p. $346 \mathrm{ff}$.

3 It is apparently supposed to be necessary in works of this kind to recapitulate the facts about this absurd imposture, but really it is high time that the subject should be dropped finally.

4 Op. laud. p. 249. 
Now, if they really belonged to the stratum in which they were found, this would imply an extraordinarily long stand-still for evolution. It is much more likely that there is something amiss with the observations-quandoque bonus dormitat Homerus - than that people so highly advanced in physical and mental development should have been contemporary with any phase of mere Eolithic culture. At this distance of time it is scarcely possible to check any errors of observation that may have been made; a good illustration of the necessity for the scrupulous caution which we advocated in the first chapter of this volume. In the second place, the bones were buried at a depth of between three and four mètres in the ground-not too deep for a grave-and one of the skeletons was crouched up, with the knees drawn up under the chin, a well-known ancient attitude of burial. It is true that the smashed condition of the bones at first sight suggests violence rather than burial; but it is a common experience of excavators to find bones that have undoubtedly been buried reduced to fragments by the pressure of the overlying soil.

In a well-written popular work on the subject of primitive man, there is a picturesque verbal snap-shot of a family at this place (there called Castenedola) living beside "a shallow tranquil lagoon," the waters of which were "kept more or less fresh by small rivers" but which, notwithstanding such a discouraging circumstance, had "an extraordinary abundance of oysters and corals." One of the small rivers in spate, we are told, overwhelmed the family when they were gathering oysters "in shallow warm water." But examination of the bones and their setting, by Issel of Geneva ${ }^{1}$, revealed the fact that the strata were full of marine deposits, and that everything solid within them, except the human bones, shewed marine incrustations. Gabriel de Mortillet long ago commented on the singular perversity which so often led men of sense and learning to seek proofs of the existence of Tertiary man in marine deposits ${ }^{2}$; we have already seen one or two other examples of this curious phenomenon. But the Castenedolo human bones themselves did not present the marine traces that distinguished their surroundings; suggesting that they had been intruded at a date subsequent to the deposition of the stratum in which they were found. The site was re-examined by Prof. G. B. Cacciamali on behalf of the Ateneo of Brescia, in the hope of finding evidence that would upset this adverse verdict ${ }^{3}$. But

1 The publication was in an early volume of Revue d'Anthropologie, to which I have failed to obtain access.

${ }^{2}$ Préhist. part I. chap. vi.

3 G. B. Cacciamali, Geologia della collina di Castenedolo e connessavi questione dell' uomo plioceno (Brescia, 1897). Analysed in L'Anthr. vill. [1897], p. 459. See also Ferraz de Macedo, "L'homme tertiaire de Castenedolo" (C.A.P.A. Paris 
the most that he could say was that whereas certain of the skeletons were unquestionably buried at a later period, that did not exclude the possibility that others might have been contemporary with the Pliocene deposits.

It is not likely that any pre-quaternary ancestor of humanity, at least in Europe, was entitled to be called a "Man." The very inconsistencies of the reported discoveries are self-condemnatory. On the one hand we are asked to believe in eoliths; on the other hand we are introduced to highly advanced and intellectual people like those of Castenedolo. The two are incompatible. The quest for Tertiary Man is a game at which the player must play fair; he cannot win both ways. Let him become an Eolithist if he see fit, but let him then give up all expectation of finding a Tertiary man with a fully-developed mental equipment. Or let him seek a Tertiary Man; but he must then throw his eoliths and all the rest of his ballast overboard.

On the one hand, mistakes in observation are so very easily made; on the other, the acceptance of a Pliocene date for the Castenedolo skeletons would create so many insoluble problems; that we can hardly hesitate in choosing between the alternatives of adopting or rejecting their authenticity. And in any case it is a sound principle (which we shall have further occasions to apply) that it is better to reject altogether a specimen about which there is any doubt, than to erect an edifice of theory upon it. Such edifices have a way of being unstable, and (though this is a minor matter) the reputation of their architect often collapses along with them!

\section{The Dewlish Trap}

There are only two other alleged indications of Tertiary Man in Europe to which we need refer, before we leave this unprofitable subject. These are the Dewlish Elephant-trap, which still entraps unwary students of prehistoric times; and the Penzance hearths ${ }^{1}$.

[1889], p. 543), and the observations of MM. A. de Mortillet and Topinard in the subjoined discussion.

1 Scarcely worth so much as a mention, except as an example of Archaeology pour rire, is the human face depicted upon a scallop-shell (Pectunculus glycimeris), alleged to have been found in the Red Crag of Walton-on-the-Naze, Essex, and supposed to prove that Pliocene man not only existed, but was able to make portraits of himself and his friends. Not the least amusing part of the story are the circumstances of the discovery of this object, by a young man who was an enthusiastic atheist, and who rejoiced in adding one more to the "mistakes of Moses." But later, becoming converted, he wished to prove the honesty of his new convictions by destroying this anti-religious piece of evidence. He was prevented from doing so, however, by a well-known collector, who secured the prize. A mere glance at the object is enough to condemn it as a preposterous forgery. An admirable illustration 
The elephant-trap is a trench 100 feet long and 12 feet deep, cut through the chalk at Dewlish, Dorsetshire. It was found to contain bones of Elephas meridionalis, as well as eoliths; and it was inferred that it had been artificially made as a sort of corral to capture elephants, like the traps constructed by modern Africans for catching large animals. Quite apart from the extreme improbability that Pliocene men, if such men existed in Dorsetshire, could have executed a piece of engineering so gigantic (presumably with eoliths and their finger-nails!) this cutting was fully excavated in I9I4 by the Dorset Field Club, and proved to be entirely natural. It had at first been supposed to end downwards in a definite "floor"; but this excavation shewed that it divided downwards in a series of narrow pipes or fissures in the chalk ${ }^{1}$.

\section{The Penzance Hearths}

The Penzance hearths were found by Mr Clement Reid at the Prah sands, about seven miles east of Penzance. They formed a stratum of carbonised bone, wood, and other material, overlying the ancient raised beach, and covered by a rubble-drift of local rocks, some 32 feet thick, with three feet of soil above that again. A few lumps of vein-quartz, which might possibly have been rude implements, were embedded in the stratum. There is, however, a complete uncertainty as to the date of the deposit, and as to the human origin of these alleged implements, one of which is figured in Mr Reid's paper ${ }^{2}$ : and the possibility is at least worth considering that the fire of which the charcoal was evidence was not ignited by man, but by a lightning flash.

The conclusion to which we find ourselves led is that up to the date of writing, no success has crowned the search for Tertiary Man in Europe, or even for Tertiary precursors of Man. No bones of such a being have come to light; and while eoliths can be reasonably explained as natural products, they are inexplicable if they are to be regarded as artificial. There was doubtless a series of non-human creatures in the direct ancestral line of man, but nothing has as yet come to light to suggest that Europe will ever tell the story of human

of this precious work of art, accompanied by an unduly solemn report, will be found in the Proceedings of the Prehistoric Society of East Anglia, vol. 1. [1913], plate LXXIII. p. $323 \mathrm{ff}$.

${ }^{1}$ For a description of the cutting, with two excellent photographs, see Rev. O. Fisher, "On the Occurrence of Elephas meridionalis at Dewlish (Dorset): second communication; human agency suggested" (Q.F.G.S.L. LXI. [1905], p. 35). For the excavation see a note in Nature, 16 July 1914, p. 511 , and the report by $\mathrm{Mr}$ Colley March and others in Dorset Nat. Hist. and Antiquarian Field Club, xxxiII. [1912], p. ix and XXXv. [1915], p. 209.

2 Clement Reid and Eleanor M. Reid, "On a probable Palaeolithic floor at Prah Sands, Cornwall” (Q.F.G.S.L. Lx. [I904], p. 106). 
evolution. That drama may well have been played out on some other stage-it may have been Asia, which has already yielded Pithecanthropus; it may have been Africa, which is still almost unsearched; it may have been some continent now sunk beneath the depths of Ocean, of which we can never hope to know anything. But all the evidence, or, rather, the absence of evidence, points us to the conclusion that man entered Europe as an already fully developed human being, and that the formative stages were passed elsewhere. An argument $e$ silentio is notoriously weak, and even as I write these words a turn of a spade somewhere or other may be revealing the bones of a Homosimius. But we might have expected something more definite to have rewarded, long before this, the eager search of a hundred years, if such a creature really did exist in Europe.

If the evolution of humanity actually took place in Europe, we may say in the present stage of knowledge that it was not in preglacial times. It may well have been the rigour of the Ice Age that gave the external stimulus to the development of the mental powers of the coming Lord of Creation. As we still say of the troubles that help to mould the character of the individual, it was the hardships which he then endured that "made a Man of him."

\section{Early Quaternary Man: Eoliths}

We now proceed to examine the remains that have been supposed to tell of Man in Europe in the earlier phases of the Ice Age.

Quaternary eoliths are reported from France, Belgium, and northern Germany. Like the Tertiary eoliths these are classified into "industries," which carry on the Apostolical Succession that began with the Oligocene Fagnian. The series now proceeds thusReutelian, Mafflian and Mesvinian, the last-named being subdivided into earlier and later stages ${ }^{1}$. We use anglicised forms of these and similar adjectives here, as they seem to be more in keeping with their English setting, though the original French forms, reutélien, mafflien, mesvinien, are frequently used in English books (but with an incongruous capital initial).

It is not easy to find the eolithists in complete accord as to the nature of these different industries, or how to distinguish the one from the other. Reinhardt, for instance, tells us ${ }^{2}$ that the Reutelian implements were "chipped exclusively from flints weathered from the chalk cliffs; and that having regard to the as yet very slightly developed technique of flint chipping, only such nodules were chosen

1 On Mesvinian eoliths see A. Rutot, "Sur l'âge des silex taillées recueillis à Mesvin près Mons" (B.S.A.B. Iv. [1885], p. 134).

${ }^{2}$ Der Mensch zur Eiszeit, p. 113. 
as could be used with but little modification--perhaps nothing but the addition of an edge, leaving the rest of the nodule unaltered." Consider what this implies. Homosimius, in his various manifestations, has ex hypothesi been chipping Fagnian eoliths during the Oligocene period-say for I,200,000 years; this estimate will serve our purpose as well as any other. He has spent the Miocene era, say 900,000 years, more or less, in making Cantalian eoliths. He has benevolently occupied the enviably spacious leisure of the Pliocene, 500,000 years or thereabouts, in preparing specimens for collectors of Kentian eoliths, with an occasional ambitious "flutter" in rostrocarinates. And yet, after thus chipping flints for 2,600,000 years, he has only attained to the stage of making tools with the least possible chipping; his tẹchnique was still "only slightly developed." In that long stretch of time every plant and every animal on the world's surface had undergone profound physical modifications. The body of the horse, to mention but one familiar instance, has grown to its present perfection out of an ancestor about the size of a small fox. Everywhere the law of evolution manifests itself-except in this one solitary department of the human intellect. We may fully admit that the first steps in civilisation are the slowest. But a creature who had so far risen above the level of the mere animal as to chip flints at all, ought to have turned out better workmanship than a Reutelian eolith as defined in the above-quoted description after two or three million years of practice!

But if now we turn to a paper by Herr Eugen Bracht ${ }^{1}$ we find that he credits Reutelian man with no less than eight different sorts of tools. We turn back in our bewilderment to Reinhardt, and learn that the much later Mesvinian man had found out how to make only three different sorts of tools ${ }^{2}$. These were small rounded stones, split and hammered on one side; discs of rhomboidal form; and a sort of hollow scraper. So that Mesvinian man was still behind his Reutelian predecessor, and far behind the Fagnian Homosimius, which had quite a well-stocked tool-box of specialised instruments. Again, M. Delvaux, the inventor of the term Mesvinian, has yet another and different story to tell. In his paper Les silex mesviniens ${ }^{3}$ he says: "The specimens of the collection made by Neyrinckx...which we assign to the Mesvinian type shew as their principal character the absence of any clearly defined or attested form, and rather resemble unworked stones than the product of the work of a reasoning

1 “'Bericht über eine Reise nach den Fundstellen der 'Eolithen' in WestFlandern vom 29 Mai bis 9 Juni 1903" (Z.f.E. xxxv. [1903], p. 823).

${ }^{2}$ Op. laud. p. I 5.

${ }^{3}$ As quoted in R.E.A. vol. I. [1891], p. 196. 
being." Once more, Lieut. Bourlon, after a study of the great collection of eoliths of all periods and industries in the Museum of Natural History at Brussels, records in the pages of the Bulletin of the Société préhistorique de France ${ }^{1}$ his surprise at seeing that the eoliths were "identical with the flint chips of other epochs." The curator of the museum, M. Rutot, gave him an explanation of this fact; but the explanation, when set beside the other accounts, seems only to add to the general confusion. "There is no difference at all, either essential or of an inferior order, between eoliths and what are usually called chipped flints": and he said, further, that the only difference between the Eolithic and the Palaeolithic epochs is that in the former the tools are utilisés and in the latter intentionally taillés into forms deliberately planned. Of the Mesvinian flints, about one-third are made from natural fragments, twothirds are made from fragments intentionally broken from the nodule. In the earlier phases only accidental fragments were used. If I understand M. Rutot's theory aright, especially as set forth in his papers communicated to the Congrès préhistorique de France ${ }^{2}$, it is to the effect that in the Tertiary period Eolithic man had it all his own way; but in the Quaternary period Palaeolithic man entered Europe and lived side by side with his more primitive kinsman, who persisted unmoved in the Eolithic arts of his forefathers right down to the time of the Neolithic culture. Such a theory seems to me extremely improbable. Would Palaeolithic Man have tolerated the presence of Eolithic Man trespassing on his hunting-grounds? Would the fate of Eolithic Man at the hands of the Palaeolithic colonists have been any kinder than the fate of the so-called eolithic Tasmanians? To kill an Eolithic man, and most probably to eat him afterwards, would have been such an obvious duty in the eyes of the Palaeolithic interloper that I can hardly imagine his evading it.

And now Prof. Klaatsch comes on the scene, and tells us that "One can without difficulty classify the majority of Mesvinian implements into a number of categories, hammer-stones, scrapers, hollow scrapers, borers, knives, etc. Rutot has in his numerous works delineated the full variety of these instruments in sharp and characteristic line drawings, which are far better than the wash-illustrations of English authors ${ }^{3}$." So as not to fall under this condemnation, we borrow Prof. Klaatsch's own photograph of Mesvinian eoliths collected by himself (Fig. 42). Beside it we set a similar plate of

1 "Les éolithes quaternaires" (B.S.P.F. III. [1906], p. 370).

2 "La fin de la question des Éolithes" (C.P.F. Autun [1907], p. 77); "Une industrie éolithique contemporaine d'une industrie du Paléolithique supérieur" (ibid. Chambéry [1908], p. 150); “Qu'est-ce qu'un Eolithe?” (ibid. p. I6r).

${ }^{3} Z . f . E$. xxxv. [1903], p. 118. 

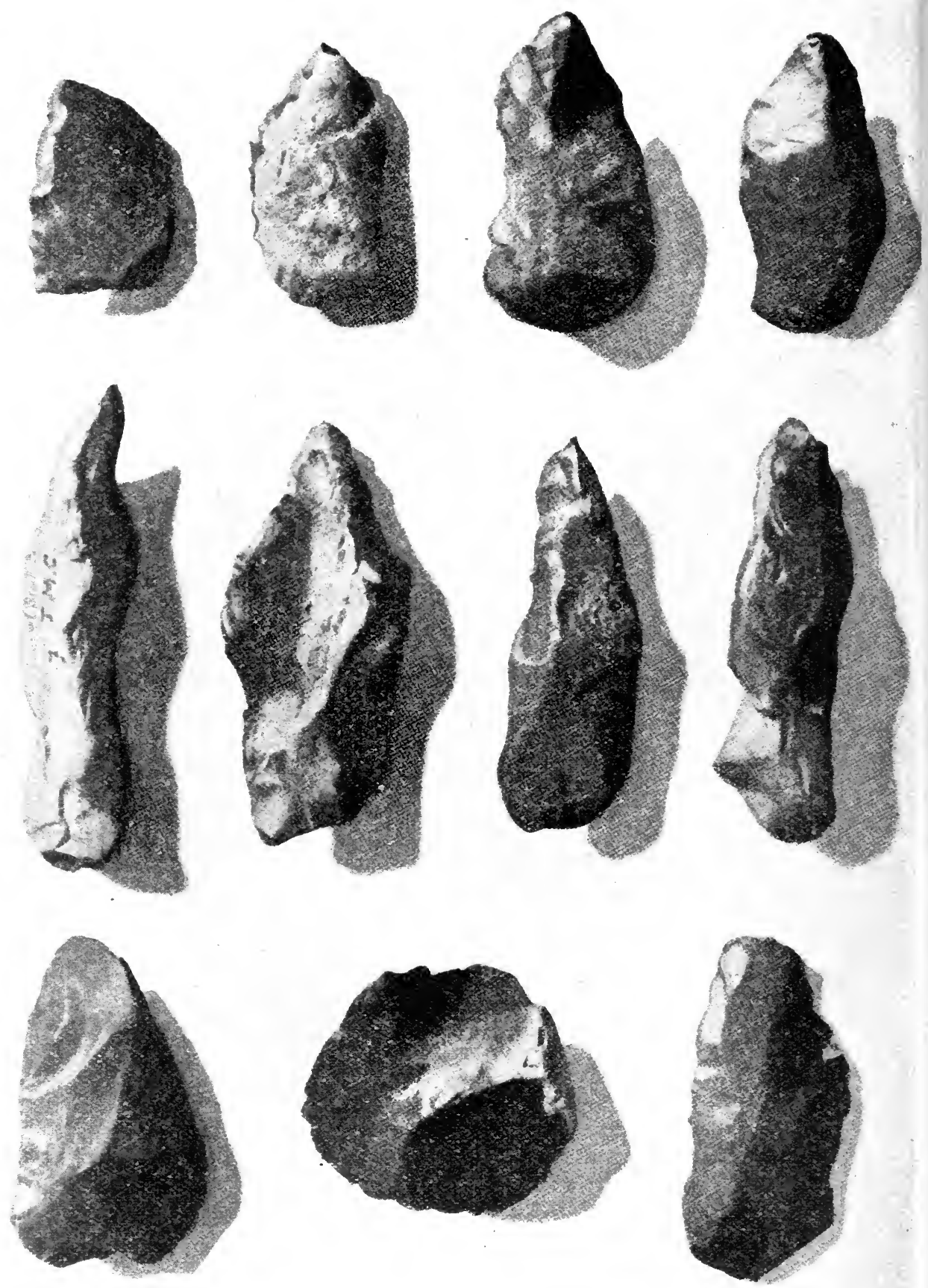

Fig. 42. Mesvinian eoliths (after Klaatsch). (From Zeitschrift fïr Ethnologie, vol. xxxv.) 
photographs of chips of flint collected at random from a garden walk. Doubtless someone will say that these, too, are implements: I prefer to regard them as the products of the garden roller. The reader is free to form his own conclusions (Fig. 43).

None of the European Eolithic men could compete in versatility with those of Egypt. Herr G. Schweinfurth has described and illus-

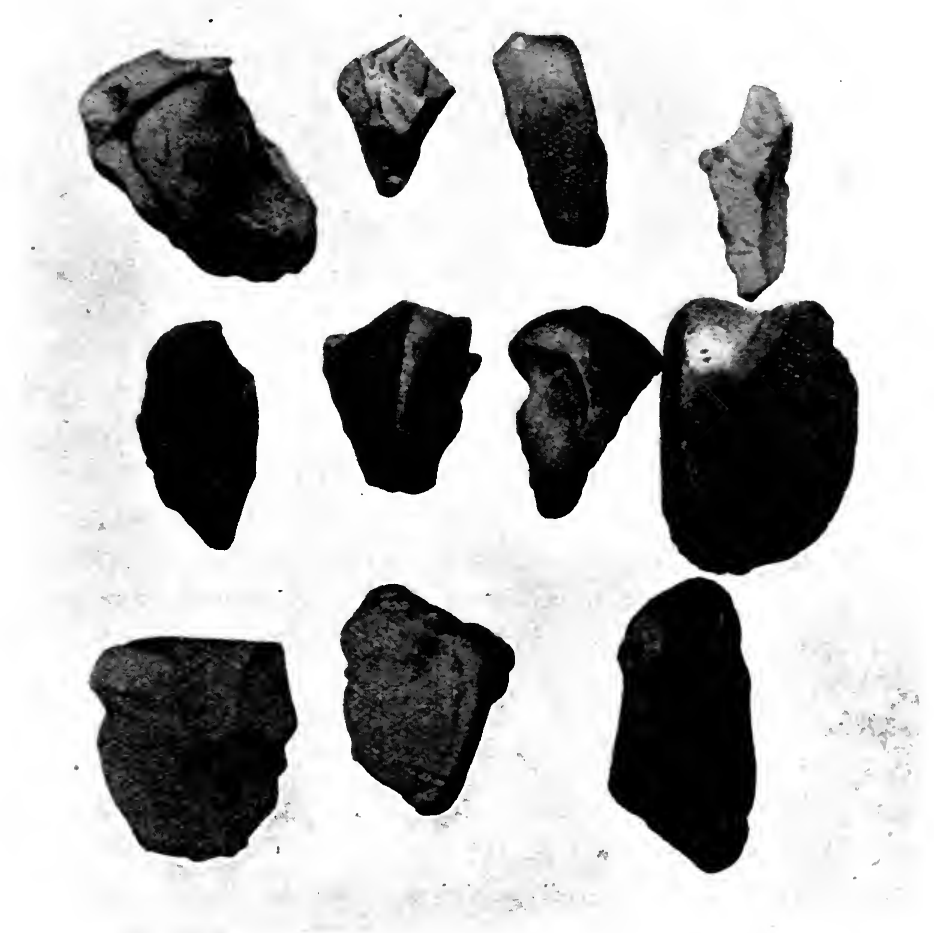

Fig. 43. Flint fragments from a garden walk.

trated no less than 58 different types of eoliths found by him at Thebes in Upper Egypt ${ }^{1}$ !

If Eolithists themselves are thus nebulous about eoliths, how can they expect these objects to be taken seriously? How can we argue about specimens that do not present a form which their describers can agree in defining? The eminently sane Déchelette declined to discuss these classifications of eoliths, on the ground that he had

1 G. Schweinfurth, "Uber steinzeitliche Forschungen in Oberägypten" (Z.f.E. Xxxvi. [1904], p. 766). 
been unable to convince himself of their actuality ${ }^{1}$, and we do well to follow his trustworthy guidance.

Of much greater importance, for the study of the beginning of human occupation of Europe in the Quaternary period, are the remains of two skeletons, representing beings which have been christened with the portentous names Homo heidelbergensis and Eoanthropus dawsoni respectively. These are in an even more imperfect state than the Java Pithecanthropus. Of the first nothing remains but the lower jaw. Of the second we have only a few fragments of the much broken skull.

\section{The Mauer faw}

The first of these specimens derives its name from the fact that it was found buried, at 24 mètres beneath the surface of the ground, in a sand-pit at the village of Mauer, some ten kilomètres S.E. of Heidelberg. The sands had been deposited by the washing of an ancient river-a bend, in fact, of the Neckar; they belong to the beginning of the Quaternary period ${ }^{2}$. This explains why only the lower jaw was found. The skeleton to which it had belonged had been washed apart higher up the river, and had been carried down, bone by bone. Doubtless the rest of it is scattered along the old river-bed, and could be found, at least partially, if we knew exactly where to look and how deep to dig. But chance is the great discoverer, and the sand-diggers chanced to light upon the spot where the jaw had found its resting-place.

Associated with the jaw were the remains of other creatures that had become submerged in the river. These bones belonged to animals which were presumably contemporary with the owner of the jaw. The list includes the following:

$\begin{array}{lll}\text { Canis neschersensis. } & \text { Castor fiber. } & \text { Bos priscus. } \\ \text { Ursus arvernensis. } & \text { Sus scrofa. } & \text { Equis }{ }^{3} \text {. } \\ \text { Ursus arctos. } & \text { Cervus latifrons. } & \text { Rhinoceros etruscus. } \\ \text { Felis leo. } & \text { Cervus elephas. } & \text { Elephas antiquus. } \\ \text { Felis catus. } & \text { Cervus capreolus. } & \end{array}$

From a chronological point of view, the most important animal in this list would at first sight appear to be Rhinoceros etruscus, which would indicate a Pliocene date for the gravels. But this evidence is discounted first, by the fragmentary condition of the rhinoceros remains; for single bones and fragments of bones are by no means

1 Manuel d'archéologie, I. 29.

2 A. Sauer, "Exkursion in die Mauer Sande" (Bericht über die $4^{2}$ Versammlung des oberrheinischen geologischen Vereins zu Heidelberg, 1909, p. 25).

${ }_{3}$ The horse was rather larger than Equus stenonis. 
certain guides to the dating of gravels in which they are found. A skeleton, or even a number of bones retaining their proper relative anatomical position, shews that the flesh was still upon the bones

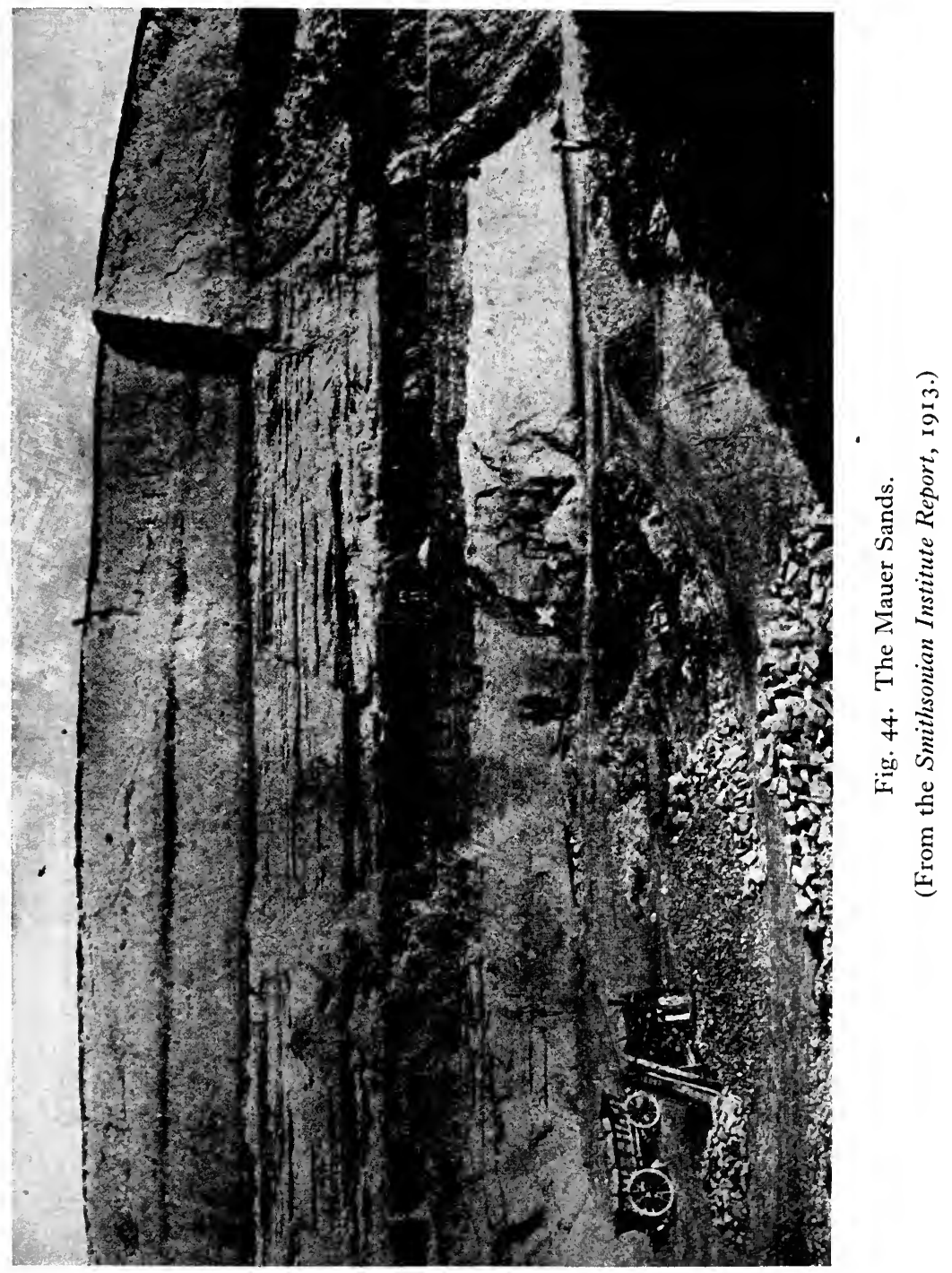

when they were deposited, and indicates that they are contemporary with the gravel; but single bones may have been washed down from anywhere higher up the river. Secondly, the elephant is the Pleisto- 
cene $E$. antiquus, not the Pliocene $E$. meridionalis. The gravels are therefore Pleistocene.

The following is the stratification of the sand-pit where the bone was found (Fig. 44):

$G$. White surface soil.

$F$. Brown loam.

$E$. Recent Löss, $5 \cdot 74$ mètres thick.

$D$. More ancient Löss, $5 \cdot 18$ mètres thick.

C. Sand, partly calcareous partly siliceous, alternating with beds of pebbles and marly deposits.

$B$. Clay. $B$ and $C$ together are 15.62 mètres thick, $C$ being about $\mathrm{I}_{3} \frac{2}{3}$ times the thickness of $B$.

$A$. Sand,

and the bone lay in stratum $A$, the lowest of the series.

The Mauer jaw-bone might be loosely described as an ape's jaw-bone fitted with human teeth. Had the teeth been absent, the jaw might well have been considered as that of a large and highly developed ape, though there are certain points of anatomical detail, such as the nature and disposition of the muscular attachments, in which its character is human rather than simian. Its chief general features are

I. Its massiveness and great strength, in which it surpasses all other human jaws recorded.

2. The total absence of chin, in which, again, it surpasses all other human jaws.

3. The great breadth of the ascending ramus, i.e. the part at the back of the jaw which stands upright when the bone is placed in its natural position.

4. The shallowness of the sigmoid notch between the two processes at the top of the ascending ramus.

All these are simian characteristics (see Fig. 45). But when we examine the teeth, which fortunately are preserved, there seems to be no reason to doubt that the owner was essentially a human being. They are entirely human, and differ altogether from the teeth of an ape. They are larger than the teeth of the average European, but are surpassed in size by individuals from the lower races, such as the Australians. On the other hand, they are singularly small in proportion to the colossal jaw-bone in which they are set, and the canine teeth are less tusk-like than the corresponding teeth often are in a modern man. The pulp-cavity of some of the teeth is exposed by a fracture; from these, and from radiographs of the rest, it appears that the cavity is unusually large in proportion to the size of the 

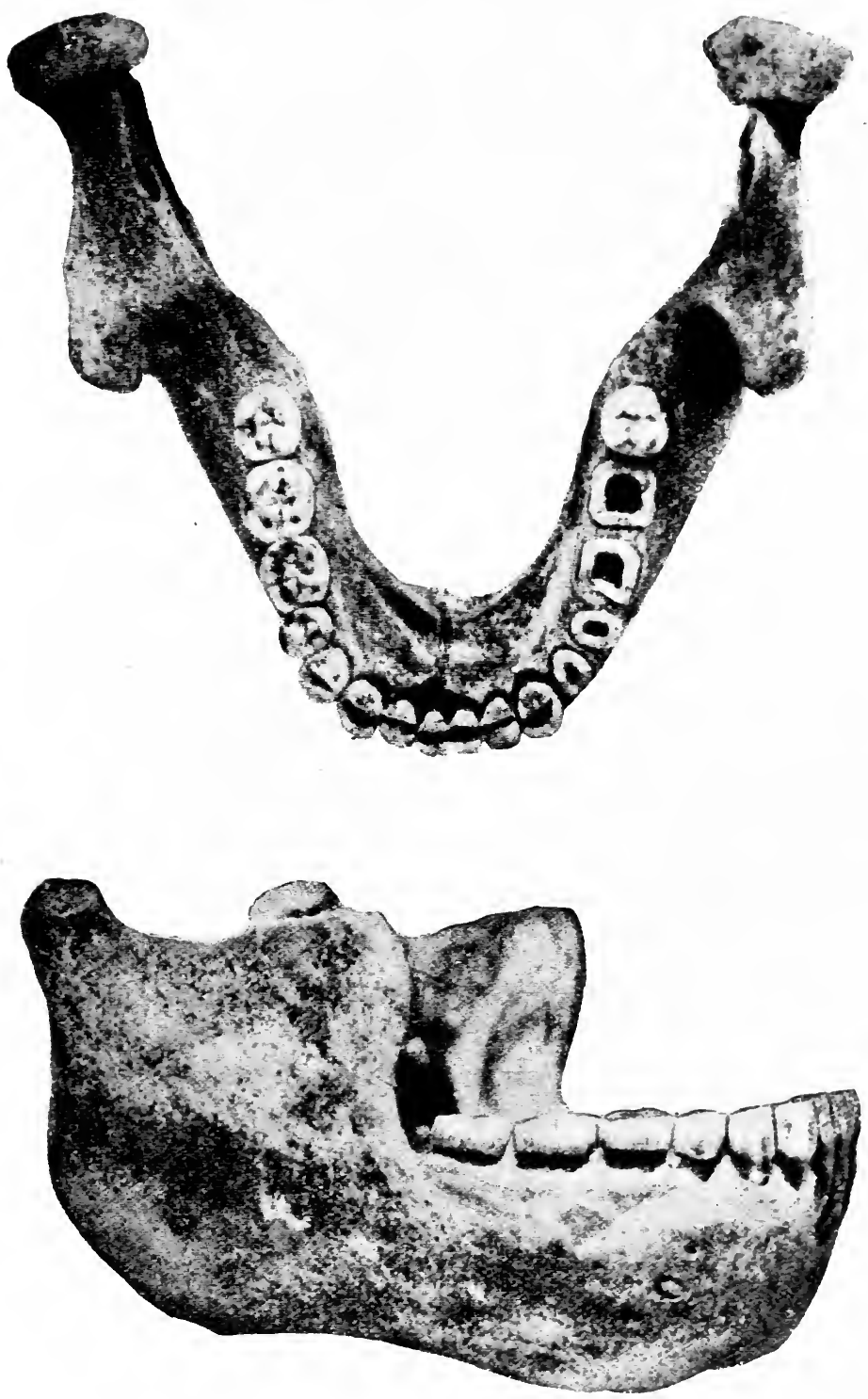

Fig. 45. The Mauer Jaw.

(From the Smithsonian Institute Report, I913.) 
teeth, with walls correspondingly thin. The teeth are much worn.

Homo heidelbergensis thus seems to have been a creature still retaining strong reminiscences of his animal ancestry, but definitely across the border that separates the higher apes from Man ${ }^{1}$.

\section{The Piltdown Skull}

The appearance of Eoanthropus dawsoni, commonly and on the whole more accurately referred to as the "Piltdown Skull," complicates to no inconsiderable degree the problem of human development, and of the early peopling of Europe. This relic was found (in the rubbish thrown out from a gravel-pit) in 1912, five years after the Heidelberg jaw came to light, by the late Mr Charles Dawson, after whom it is named. Most unfortunately the skull had been dug out by careless workmen, and by them broken and thrown aside as a thing of no worth; the fragments were scattered and were only partially recovered.

The gravels which contained the skull were the deposit of the Sussex Ouse, and were thus stratified:
$E$. Surface clay $\quad \ldots \quad 30 \mathrm{~cm}$. thick.
$D$. Gravelly loam … 60, ,
C. Dark-brown gravel $\ldots 4 \quad 45, "$,
$B$. Clay $\quad \ldots \quad 20$, ,",
$A$. Wealden subsoil (Secondary period).

The skull was lying at the bottom of stratum $C$. This also contained fossils of Pliocene animals; but it does not follow that the human remains are also to be assigned to the Pliocene period. The case is similar to that of the Mauer jaw-bone; the gravels are a river deposit, and the bones may have been washed down from some earlier bed higher up the river, and carried down to their final resting-place at any time. Dr Keith, who is a strong advocate of the Pliocene age of the fossil, quotes ${ }^{2}$ some remarks made by Prof. Boyd Dawkins at the meeting of the Geological Society of London in 1912, where the skull was exhibited, with the following comment. He "agreed... 'that the deposit containing the human remains belonged to the Pleistocene age, and that the Pliocene mammalia in it-Mastodon

I For an anatomical description of the jaw, reference may be made to Keith, Antiquity of Man, chap. xiii.; Hrdlička, op. laud. A less technical description will be found in Duckworth, Prehistoric Man, p. I0. The first published description, which is also the fullest, is by O. Schötensack, Der Unterkiefer des Homo heidelbergensis aus den Sanden von Mauer bei Heidelberg, Leipzig, 1908; a good analysis of this monograph in L'Anthr. xx. [r.909], p. 8I .

${ }_{2}$ Antiquity of Man, p. 309. 
arvernensis and the rest-had been derived from a Pliocene stratum formerly existing in that area.' 'That opinion, coming from one who has the right to speak with authority, must evoke surprise. When he found the remains of the same species of Mastodon in the Doveholes Cave in Derbyshire in 1903 , unaccompanied by human remains, Prof. Boyd Dawkins unhesitatingly assigned the contents of that cave to the Pliocene period; but when the same remains are found in Sussex, accompanied by human remains, the deposit, in his opinion, should be referred to a much later date."

But surely there is all the difference in the world between an undisturbed cave deposit, in which the animals that have died there remain where they lay, and a stratum laid down, in the course of long centuries, by a stream, carrying material of all kinds and depositing it at lower stages of its course. In point of fact the Pliocene fauna were not the only ones found in the stratum; there were others (horse, beaver, deer) which represented more typically a Pleistocene fauna; and the Pliocene fossils were seen to bear traces of waterrolling, which were absent from the Pleistocene fossils and from the skull. As before, we date the deposit by its latest contents; the gravels were Pleistocene, not Pliocene, and the skull should be dated accordingly. In all cases a very large body of cumulative evidence is necessary before we can date gravels in which nothing but disconnected bones are found.

Several attempts have been made, by some of the foremost of our anatomists, to restore the original skull from the fragments preserved. But the results differ inter se to such an extent, that the bewildered layman is at a loss to know which to believe; and he finds an escape from the difficulty by believing in none of them. The problem of restoring Solomon's Temple from the data preserved in the Bible and Josephus seems to be child's play beside the difficulties of reconstruction presented by the Piltdown skull. At best, the mere fact that a dispute exists among those qualified to speak as to the proper restoration of the skull, deprives any restoration of scientific value as a basis for deductions.

One of the restorers submitted himself to an ingenious test of competence. An ordinary skull was taken, and after casts had been made of it, was cut up, and portions corresponding to the Piltdown fragments were submitted to him. From these he made a restoration, which, when compared with the casts, was found to be marvellously true. But even this triumph does not assure us of the authenticity of his restoration of the Piltdown specimen; for the test has a latent flaw. A normal skull was chosen for the experiment; it therefore conformed to a standard which the restorer was able subconsciously 


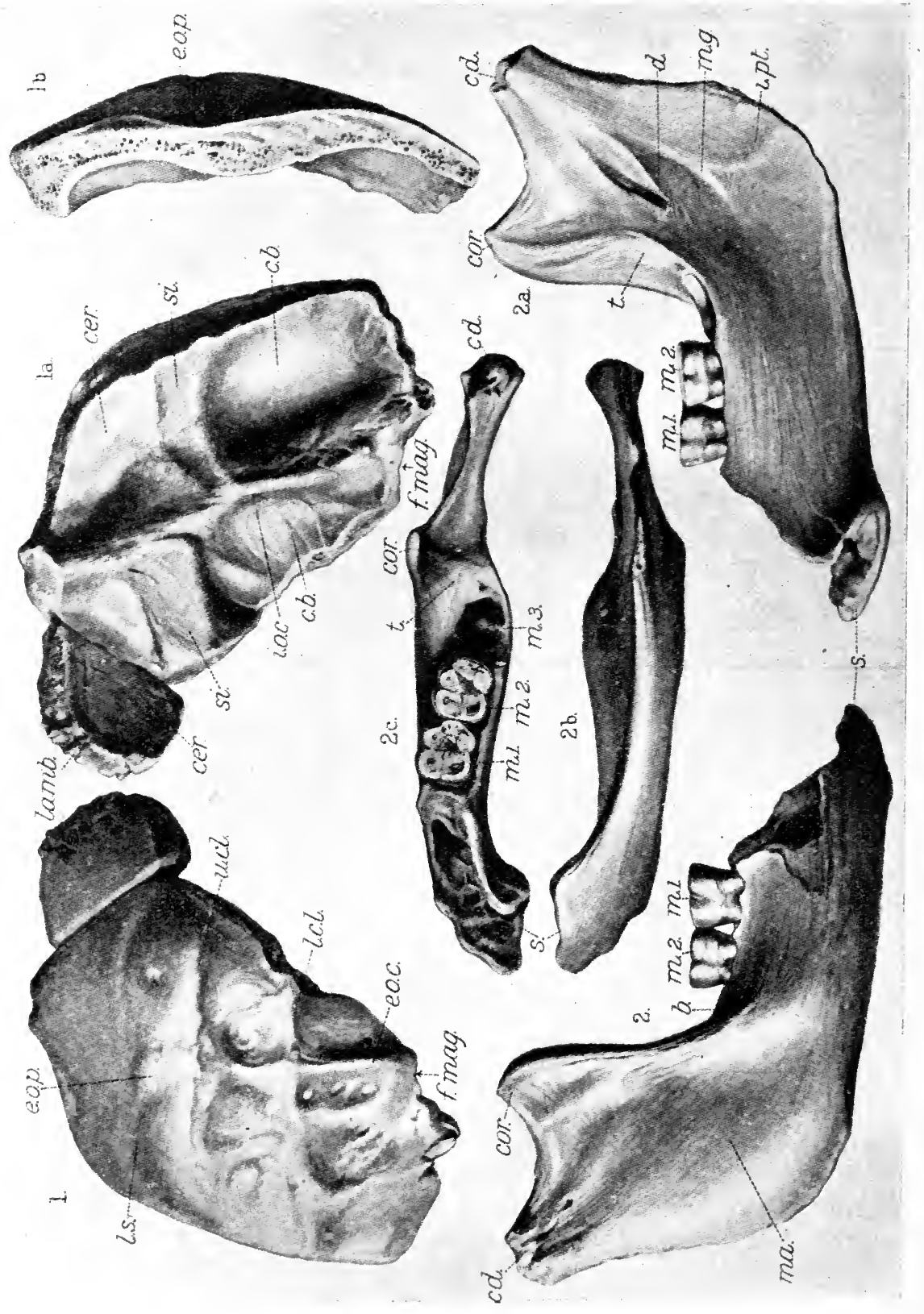

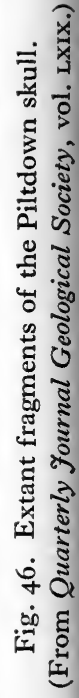


to assume as the basis of his work: but which might be misleading when applied to an abnormal specimen ${ }^{1}$.

The portions of the skull which still survive (Fig. 46), now preserved in South Kensington Museum, are fragments of the braincase, a canine tooth, and part of a lower jaw. We say intentionally $a$ lower jaw, because it is not proved that the jaw belongs to the skull. With regard to the skull itself, though the restorers differ in detail, they are all agreed that it is human, of unusual thickness ${ }^{2}$, and representing a person of an intellectual development which would be low among the lowest of any known modern people. The brain which the size and shape of the brain-case indicate is the "most primitive and most simian human brain so far recorded ${ }^{3}$."

The jawbone is also strongly simian in character, if anything more markedly so than is the jaw of Mauer; moreover, the teeth, of which two molars still remain in position, are much more ape-like than are those of the Heidelberg man. One canine tooth was found loose in the soil. This was a peculiarly savage-looking tusk, and must have overtopped the other teeth to an extent unparalleled in any other known human jaw.

To escape the difficulty which this strange combination of human and animal characters presents, it has been suggested that the skull and the jaw do not belong to one another; that the skull is human, but that the jaw belongs to a hitherto unknown species of chimpanzee ${ }^{4}$. This easy exit from the maze is open to the same objection as in the case of the Java Pithecanthropus; that whether the bones were buried where they lay, or were washed down by a river from somewhere else, it would be a strange coincidence if an unknown type of ape, and an unknown type of man (or rather woman, for, as in the Java case, the Piltdown specimen is considered to have been female) happened to become embedded in the same place, leaving behind bones which supplement, but do not duplicate one another, and which are sufficiently near in relative size to make it at all possible to regard them as belonging to one individual. Moreover, the identification of the canine tooth as an upper canine, shewing

1 Of the already extensive literature dealing with this skull, we may mention C. Dawson, A. Smith Woodward, and G. Elliot Smith, "On the discovery of a Palaeolithic human skull and mandible in a flint-bearing gravel overlying the Wealden (Hastings Beds) at Piltdown, Fletching (Sussex)"' (Q.尹̈.G.S.L. LxIx. [1913], pp. I 17 I 5 ); Keith and Hrdlička, publications already mentioned in this chapter. M. Boule, "La paléontologie humaine en Angleterre" (L'Anthr. Xxvi. [1915], p. I), gives an admirable summary of the whole complicated controversy.

2 The modern European skull is 5 or 6 millimètres thick; the average Middle Palaeolithic skull about 7 or $8 \mathrm{~mm}$.; the Piltdown skull i i or $12 \mathrm{~mm}$.

${ }^{3}$ G. Elliot Smith in Q.F.G.S.L. loc. laud. p. 147 .

"See especially G. S. Miller, "The jaw of the Piltdown skull" (Smithsonian Misc. Coll. LXv. [1915], No. 12). Also Boule, Les hommes fossiles, p. 166. 
that an upper jaw with ape-like teeth had lain there, weakens this otherwise attractive theory: for it suggests that more fragments of the postulated chimpanzee should have been forthcoming ${ }^{1}$.

\section{Implements found with the Piltdown Skull}

In a previous chapter we defined Man as the only tool-fashioner; therefore we naturally ask whether there were any remains associated with the bones which we have now considered to bring them into conformity with this definition. For the first two the answer must be negative; no tools of any kind were found with Pithecanthropus, or with the Mauer jaw. But some remarkable discoveries were made in connexion with the Piltdown skull.

There were in the stratum containing the skull certain eoliths, which were no more convincing than others of their kind ${ }^{2}$. In the stratum above there were a number of rude flakes, much more evidently bearing the marks of human workmanship. They are not unlike the flakes used in the Middle Palaeolithic, but are so rude that they may be assigned to any time. And there was a very singular implement, broken from the femur of some large animal, apparently a species of elephant (Fig. 47). This remarkable object is $42 \mathrm{~cm}$. long and from 9 to $10 \mathrm{~cm}$. broad. One end is artificially pointed to a chisel edge, at right angles to the plane of the flat sides, while the other is rounded. There is a notch at one side, as though there had been a perforation accidentally broken; and marks radiating from this notch have been interpreted, a little perilously perhaps, as indicating that at some time a thong had been tied to it.

Is it absolutely certain that this implement belongs to the archaeological level of the skull? It was not found in position, but in one of the gravel-diggers' spoil-heaps. One of the fragments of the skull was found in the same spoil-heap, and the incrustation on the surface of the instrument seems to indicate that it had come from the same level, being identical with the incrustation on the fragment of the skull. So far the evidence is in favour of the association.

The animal from whose bone the implement was made was an elephant of indeterminable species, but larger than the mammoth ${ }^{3}$;

1 It is not absolutely certain, however, that the jaw and the skull were in close association when embedded in the soil. Mr Dawson (loc.laud. p. I2I) says: "So far as I could judge, guiding myself by the position of a tree three or four yards away, the spot where the jaw was found was identical with that upon which the men were at work when the first portion of the cranium was found several years ago." This on the face of it is vague.

2 They are illustrated Q.F.G.S.L. LxIx. [1913], plate xvii.

3 Charles Dawson and A. Smith Woodward, "On a bone implement from Piltdown, Sussex" (Q.F.G.S.L. Lxxi. [1915], p. 144). 
and we are assured that the cuts upon it are such as can have been made only while the bone was fresh, so that an implement made out of a bone already fossil seems out of the question. Therefore the
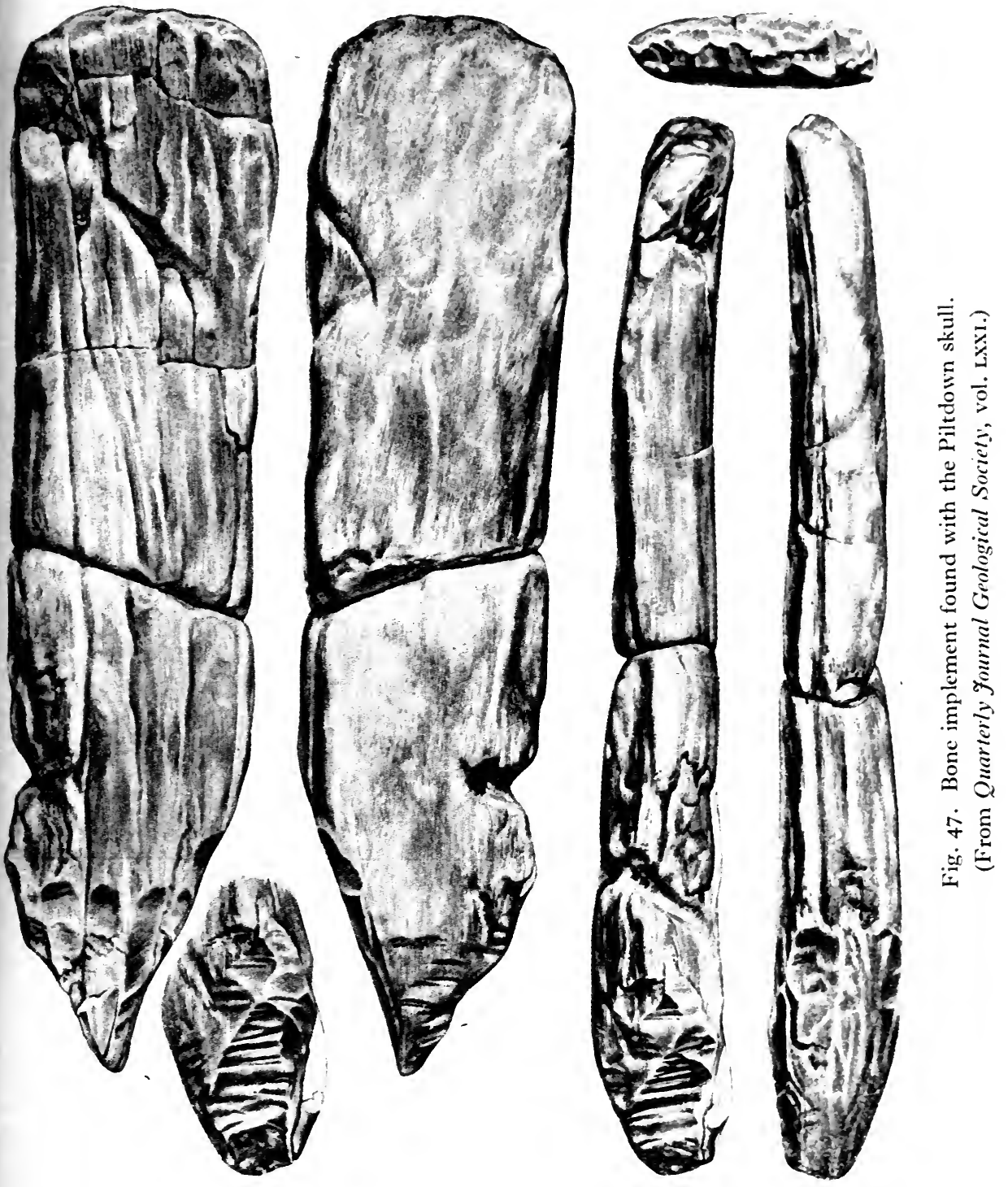

maker of the implement must have been contemporary with this problematical species of elephant. The point is of some importance; for the earliest generally admitted traces of industrially utilised bone 
previously found belong to the Middle Palaeolithic stage; and even the Middle Palaeolithic examples are more primitive than this, being indeed mere bones in their natural form, bearing marks indicating that they have been used as anvils. This would at first sight suggest a doubt as to whether the Piltdown skull be really so old as it has been supposed to be. But in the Middle Palaeolithic the oniy species of Elephant surviving in England was the mammoth, and this, we are assured, was not the elephant which yielded the material for the implement before us.

This difficulty is, however, to some extent relieved by the discoveries made in the important station at Taubach, near Weimar. These we must describe more fully in the following chapter; for the present we may say that Taubach lies a short distance southeast of Weimar, on the right bank of the river Ilm. In the year I $87 \mathrm{I}$ a bed of the bones of large animals was accidentally found here, and these were excavated at intervals during the following 20 years. The animals were of temperate species, including

\section{Hyaena, Rhinoceros mercki, Bison priscus, Elephas antiquus,}

Rangifer tarandus and other arctic animals being entirely absent. The molluscs found were also of temperate species. There was an undue proportion of the long bones of the larger animals, shewing that they had been slaughtered at a distance from the site, and cut up on the spot where they fell, only the most eatable parts being carried to the camp - for that Taubach was the site of an ancient human settlement was shewn by the numerous hearths scattered through the bone-heap, as well as by the charred condition of the bones themselves. There were also some instruments of flint, of which we shall speak later. Some of the bones had been scratched, as though they had been used, in their natural form, as crude makeshift tools; and the head of a rhinoceros-femur (Rhinoceros mercki), hollowed out as though to form a drinking-cup, came to light ${ }^{1}$, as well as a dagger made of the right ulna of a bear ${ }^{2}$.

The only human remains found at Taubach were two teeth, one an adult molar, the other a child's milk-tooth. On account of their markedly simian character, Dr Duckworth, writing before the

\footnotetext{
${ }^{1}$ H. Möller, "Über Elephas antiquus Falc. und Rhinoceros merki als Jagdtiere des alt-diluvialen Menschen in Thüringen, und über das erste Auftreten des Menschen in Europa" (Zeitschrift für Naturwissenschaften, LXXIII. [1900], p. 4I).

2 These, with the bones of animals shewing marks of fire or of scratches, as well as some rude flints, are figured by A. Lissauer, "Beiträge zur Kenntniss des paläolithischen Menschen in Deutschland und Süd-Frankreich" (V.B.A.G. [1902], p. 279). Obermaier (L'Anthr. xvi. [1905], p. 20) expresses his inability to accept their artificial nature.
} 
Piltdown discovery ${ }^{1}$, assigned them to the date-level of the Mauer jaw, or even of Pithecanthropus. The chronological relations of the Taubach settlement with the early Palaeolithic will be considered on a later page. The extreme scantiness of its human remains makes it impossible to interrogate it closely upon the vexed problems of human origins. We quote it here only as indicating a possible earlier date forthe use of bone implements than had generally been allowed.

The Piltdown skull itself cannot be made to tell us much as to the beginnings of the human occupation of Europe until we come to a definite decision on the following points:

I. The date of the gravels.

2. The mutual relation of the fragments of bone: do they really belong to each other; especially, does the jaw belong to the skull?

3. Assuming that the fragments belong to one skull, what was its original form, in general and in detail?

4. What is the alleged implement found with the skull, and what is its relation to the skull? To what species of elephant does it belong, and is it absolutely impossible that the bone should have been used as an implement in a fossil form?

5. Is the Piltdown type ancestral to modern man, to Middle Palaeolithic man, to both, or to neither?

Some of these questions are, and must remain, unanswerable. The unlucky accident that the gravels were dug without consideration for their priceless contents makes definite information with regard to the stratification of the remains no longer attainable. There does not seem to be any prospect of a final agreement as to the date of the gravels or the restoration of the skull; the indications are insufficient for the solution of both these problems.

In short, the conclusion of the whole matter is that the Piltdown skull, owing to the circumstances of its discovery, must be written off as one more of the many pieces of valuable scientific material wasted. It has no light to throw on problems in dispute, because it needs for itself all the light that can be shed from properly attested discoveries made in properly conducted excavations. We must be content to hold it in reserve, till a sufficient number of such discoveries shall have been made to enable us to put it in its proper evolutionary place.

Some time after the first discovery, Mr Dawson found in the same formation, and at a distance of about two miles from the place where the skull was lying, two small fragments and a molar tooth 
of a second skull. These display the like primitive features; and so far as they go, they confirm the evidence of the first group of fragments as to the existence in this region of an early type of Man ${ }^{1}$.

\section{Nomenclature of Early Human Remains}

We may permit ourselves here to make a few remarks on the nomenclature usually adopted for the three specimens with which we have just been occupied.

The generic name given to the Piltdown skull, Eoanthropus, is a misnomer if the jaw do not belong to the skull; and even if it do so belong, a person capable of making the elephant-bone tool had well passed beyond the "dawn" stage of humanity. Pithecanthropus, on the other hand, is a really useful word, if we bear in mind that we are not yet in the possession of sufficient knowledge to justify us in exalting it into the name of a genus. It should not be regarded as anything but a label, conrenient to describe such specimens of intermediate form, or apparently intermediate form, as may from time to time come to light. We may thus suitably speak of the Pithecanthropus of Java, of Nauer, of Piltdown. The word Homosimins is shorter, and in the threatened eclipse of Greek in our ultra-utilitarian generation will be more generally intelligible; but there is room for both terms. We can use Pithecanthropus in referring to actual specimens which may be fairly classed as to some extent "intermediate" between Simius and Homo; and Homosimius, as in this book, in referring to the theoretical but as yet unknown forerunner of the human species.

\section{Conclusions}

The skeletons from Nauer and Piltdown are isolated phenomena. They do not link human life in Europe to anything that has gone before. They cannot therefore be brought forward as evidence that the continent of Europe was the scene of the development of Man from Homosimius; for their owners may just as well have been immigrants from some other region.

We may assume these, the only "intermediate" beings that have as yet been found, to be genuine products of evolution; for apart from the exostosis in the Java femur they are admittedly not diseased or pathologically abnormal specimens. If the history of the origin of the human species is to be based on the evidence which they

1 A. Smith Woodward, "Fourth note on the Piltdown gravel, with evidence of a second skull of Eoanthropus dazwsoni" (Q.F.G.S.L. LxxiII. [1918], p. 1); G. Elliot Smith, "On the form of the frontal pole of an endocranial cast of Eoanthropus dar'soni" (ibid. p. 7). 
afford, we must conclude that the process of the development of Man from his progenitor must have been very gradual and irregular. Consider this table:

\begin{tabular}{l|cccl} 
SPECIMEN & LiMBS & SkULL & JAW & \multicolumn{1}{c}{ TeETH } \\
Java & Human & Simian & $\ldots$ & Homosimian \\
Mauer & $\ldots$ & $\ldots$ & Simian & Human \\
Piltdown & $\ldots$ & Human & Simian (?) & Homosimian
\end{tabular}

in which the words "Human" and "Simian" mean no more than that the feature so described tends to be on one side of the borderline or on the other. If we reject the Piltdown jaw, the process of evolution will be simplified, but will not be made regular. To use these three fragmentary specimens as a basis for far-reaching theories would be, to say the least, injudicious; but they seem to be pointing to the conclusion that, if so we may express it, Nature was trying in various ways to "humanise" one branch of her Primates, the three specimens which we possess being approximations to the ideal, bearing a cousinly but not an ancestral relation to one another. No conclusions can therefore be drawn as to the relative age of these three specimens, from the stage of physical human evolution to which they have attained.

All that we are at present entitled to say, is that just about the transition of Tertiary to Quaternary times there appears a creature in Java which may be roughly described as an ape with strong human tendencies; and that at some time in the Early Quaternary there were living in two places in Europe, between five and six hundred miles apart as the crow flies, beings which may be described as men with strong simian reminiscences. There are anatomical and embryological facts from which a theory of human origin may reasonably be deduced; but this is as yet the only evidence which archaeology has brought to light, corroborative, in any degree, of such deductions.

One of the European Pithecanthropi seems to have been a toolfashioner. But we unconditionally reject the flint chips called eoliths as having any bearing on the problem of early man in Europe, for the reasons summarised on pp. 175-6, ante: to which we are now in a position to add one more-Eolithists themselves do not agree upon even the most elementary details of the study of these objects.

\section{The Wooden Age}

Indeed, there is no real necessity to suppose that the earliest men, those of the Mauer and Piltdown level, made their tools of flint at all. It is much more probable that there was what we may call a Wooden Age at the very beginning of culture, when rude 
tools were made of wood, rubbed into shape with hard, rough, or sharp stones, or with shells. True, this theory has been severely criticised. Hoernes, commenting on a suggestion to this effect made by the cousins Sarasin, describes it as ein Product laienhafter Phantasie $^{1}$; and he calls on us to imagine the force necessary to break off a branch from a tree, and the futility of endeavouring to trim it without tools. Naturally every suggestion as to the origin of culture, like every suggestion as to the origin of Life, is unprovable hypothesis. But I cannot see that this hypothesis is so inconceivably absurd as to justify the use of such strong language. A heavy wooden club was assuredly the deadliest weapon in the hand even of the most advanced Palaeolithic man.

\section{Note Added in the Press}

Just as these sheets are receiving their final correction, the discovery (made so long ago as I889-90) of further fossil human bones in Java, is announced ${ }^{2}$. It is however too early yet to determine what, if any, bearing these discoveries may have, on the early populations of Europe on the one hand, or of Oceania on the other.

1 Moritz Hoernes, Urgeschichte der bildenden Kunst in Europa (Vienna, 1898), p. 3 .

See Nature, 6 Jan. 1921, p. 603. 


\section{CHAPTER VI}

\section{THE LOWER PALAEOLITHIC STAGES}

\section{The Place of the Lower Palaeolithic Culture in Human History}

We said in the last chapter that the Piltdown and the Mauer remains are isolated phenomena, which cannot be linked on to anything that has gone before. It is equally impossible to link Lower Palaeolithic Man to any predecessors in Europe. The scanty remains described in the preceding chapter are quite insufficient to afford us any basis for theories as to the origin of the men with whom we have now to deal. They may have evolved in Europe where we find them, out of earlier types; and it is not impossible that the Mauer and the Piltdown fragments may be specimens of those types. Or they may have entered the continent from some earlier home, as yet undetermined. For the present we are not in a position to say any more than this: Man appears in Europe, a fully developed human being, at the beginning of the stage of civilisation called the Lower Palaeolithic. Two very fragmentary specimens indicate that there was perhaps a previous chapter in the history of European humanity, but this is a chapter which we cannot yet read; perhaps we can never hope to do so.

Both in Asia and in Africa remains have been found, shewing a culture indistinguishable from that of the Lower Palaeolithic in Europe. In Syria ${ }^{1}$ and in India ${ }^{2}$, in Somaliland ${ }^{3}$, South Africa ${ }^{4}$, and even in Patagonia ${ }^{5}$, artefacts have come to light which might almost have been made by the same hands as those that formed the types on which the French archaeologists have founded their schemes of classification. But we must be cautious in drawing deductions from this most noteworthy fact. When we find a tool, weapon, ornament, custom, religious rite, or what-not, current in two widely different countries, there is absolutely no necessity to infer that there was a historical connexion between them. True, there are many reputable authorities who are assured in the conviction that such coincidences,

1 G. Zumoffen, S.J., La Phénicie avant les Phéniciens (Beirut, 1900).

2 V. Ball, "On the forms and geographical distribution of ancient stone implements in India" (Proc. Royal Irish Acad. ser. ii. vol I. [1878], p. 388).

${ }^{3} \mathrm{H}$. W. Seton-Karr, "Discovery of evidences of the Palaeolithic Stone Age in Somaliland (Tropical Africa)" (F.A.I. xxv. [1896], p. 27I).

4 J. P. Johnson, The Prehistoric Period in South Africa (London, 1910).

5 F. Outes, "La edad de la piedra en Patagonia" (Anal. del Museo Nac. de Buenos Ayres, XII. [1905]). 
as mere coincidences, never happen, but that they are always to be explained as the records of direct relations between the two centres -relations commercial or military, or else an actual migration from the one place to the other. Accordingly we are provided with maps of the ancient world, shewing lines of prehistoric communication radiating from some favoured centre, almost as complicated as the commercial maps of contemporary life with their steamer routes and telegraphs. The obvious answer to such fantasies is that even in our modern world, where intercommunication is rendered so swift and so easy, two people will often hit independently upon identical inventions or discoveries; as when Adams in England and Leverrier in France almost simultaneously discovered by calculation the unknown planet Neptune, each in ignorance of the work of the other. There is no reason to suppose that the inventor of the common safety-pin was inspired by the contemplation of a bronze-age or of an iron-age fibula, though these are identical with the safety-pin in principle and even in detail. I suppose that those who insist that all culture has flowed from one centre, be it India, Mesopotamia, Egypt, or even Atlantis, can trace some connexion between the spirals in the iron-work of my garden gate and those adorning the face of a Maori chieftain-probably via Mycenae. I confess my inability to follow threads so delicate.

For the present, and until future discovery shall shew us how to correlate the Palaeolithic of Europe with that of Asia and of Africaif this can ever be-it is better to treat them as entirely separate subjects, having no connexion one with another. We may indicate, as matters of mere theory, some possibilities of migration. We can also illustrate the essential unity of mankind by setting the works of one culture-centre in the light of those of another, as has been done by students of folk-lore and other branches of the psychical side of Anthropology in recent years, with illuminating results. But we can venture no further. Each region must be considered by itself, on its own merits. We cannot infer either a wide-spread Lower Palaeolithic culture, extending over almost the whole of the world at one and the same period of time, or an immigration from any one centre to the others, introducing the Lower Palaeolithic culture. A Lower Palaeolithic tool in one continent may for aught we know be 10,000 years older than a similar tool from another continent: the one may be the work of a man different in every respect from the maker of the other. The two have arrived at the same result because their needs were the same, their materials were the same, and the means by which they manipulated the materials to obtain their ends were the same. 


\section{Circumstances of Discovery of Lower Palaeolithic Remains}

The remains of the Lower Palaeolithic civilisation are as a rule found in the gravels accumulated by river action. It was natural that the earliest human communities should settle along the courses of the rivers. They supplied the colonists with water and with fish; they attracted beasts to drink, and these could be trapped-for as yet the chase and the wild fruits of the earth afforded the sole sustenance of Man; the arts of domestication of animals and of cultivating the ground were unknown. The rivers, further, were highways, opening tracks through the forest-clad continent, as a clue winds through a labyrinth; and though it is not likely that Lower Palaeolithic Man was in the habit of travelling very far from his base, such a guide as the river-courses afforded him would be useful to him in his hunting and warlike expeditions ${ }^{1}$.

\section{Scheme of Arrangement of Material in the present Book}

Fragmentary as our knowledge of Palaeolithic Man must inevitably be, it is yet so extensive that unless the details be set forth on a definitely arranged scheme, they would be found extremely confusing. It has already been said (p. 56) that the Palaeolithic period is divided into three subdivisions, which for want of a better word we propose to call Terms. These are the Lower Palaeolithic (the oldest), the Middle Palaeolithic, and the Upper Palaeolithic. This and the two following chapters are devoted each to one of these Terms.

Further, the first and third of these Terms are each subdivided into three parts, here called Stages; there is but one Stage in the Middle Palaeolithic Term. All these Stages are named after places in France which have yielded characteristic specimens of the industry of each in turn.

The Stages, again, it is sometimes necessary to subdivide further into Phases, named by some self-explanatory adjective, as Early, Middle, Late, Full, Transitional, etc.

In describing the remains belonging to each of the three Terms, we shall adopt the following order in arranging our material:

1. An enumeration of the Stages into which the Term is divided, with an explanation of the name of each.

1 It should however be clearly understood that the riverside flints do not necessarily imply a riverside settlement. Indeed, many of the flints found in river gravels show traces of attrition, due to water-rolling. This proves that they were not lying in the spot where their makers had left them, but that they had been carried down by a flood from some higher ground, which need not necessarily have been in or even near the ordinary river valley. Some cases of this will meet us later in the present chapter. 
2. An account of the known human remains associated with the archaeological remains of the Term under discussion. In these pages no attempt will be made to give a technical description of the bones; nothing is aimed at but what is sufficient to give an idea of the general physical structure of the men with whose handiworks we are concerned, and to indicate the bases on which they may be racially classified. References are given which will enable the student to find detailed anatomical descriptions, when such exist.

3. Particulars as to the fauna associated with the respective Stages, sufficient to afford a basis for conclusions as to the climate dominant over Europe in the time of each Stage.

4. A description of the characteristic implements in stone, bone, and other materials, with details as to their stratigraphical distribution among the Stages and their subordinate Phases.

5. A brief description of the chief sites in Europe (classified under the different regions into which for the purposes of this book we have divided the continent), which have yielded typical specimens of the culture of the different Stages; with notes on any peculiar local facies which their remains may present.

6. Under the general head of "Psychology," some attempt to recover from the available materials an idea as to the life of the ancient hunting communities, and their relation to the visible and invisible worlds around them. For the Upper Palaeolithic Term this subject is so extensive and important that a separate chapter has to be devoted to it.

In the last chapter of this volume (Chapter XI) we gather the threads together and present some attempt at a reconstruction of the history of Palaeolithic Europe.

\section{(1) Nomenclature of the Stages of Palaeolithic Givilisation}

In this book we continue, for the sake of avoiding confusion, the established nomenclature of the stages of Palaeolithic culture. It is often preferable to maintain a scientific terminology which for one reason or another is open to criticism, rather than to introduce complications by an over-production of synonyms. But the nomenclature is essentially objectionable. The principle followed is to select some place where typical specimens of the culture have been found, and to make an adjective out of its name. Thus, in the preceding chapter we have dealt with "Fagnian," "Mesvinian," and similar names. The stages of the Lower Palaeolithic "Term" are usually named as follows:

I. Pre-Chellean, sometimes called Strepyian, from Strépy in Belgium. 
2. Chellean, from the name of Chelles-sur-Marne, a place about eight miles from Paris.

3. Acheulean, from Saint-Acheul, near Amiens.

It would be absurd to object to such names on the chauvinistic ground that the places selected for distinction are mostly in France; though such an objection has sometimes been made. In Italy, for instance, attempts have been made to replace them with names derived from Italian localities, perugina for Chellean, vibratiana for the Middle Palaeolithic Mousterian, ventimigliese and faniese for the Upper Palaeolithic Solutrean and Magdalenian respectively; and the Belgian prehistorians have an even more complex system, based on Belgian place-names. If it be an honour to select the adjectives from the names of one country, it is an honour of which France is fully deserving; for the French stand at the head of prehistoric studies, beyond the possibility of competition. To a Frenchman, Gabriel de Mortillet, this classification, which first brought order out of chaos, is due ${ }^{1}$; and the nomenclature which he introduced has a prior claim over any other.

The real objection to the scheme of nomenclature is twofold. In the first place, the adjectives are not self-explanatory. To say that a flint is "Chellean" means nothing in itself. It certainly does not mean that an object which we may so describe was ever anywhere near Chelles-sur-Marne. And yet a self-explanatory term is not unattainable: thus, we might call the "Chellean" stage by some such name as "Lower Palaeolithic II," on the analogy of the nomenclature now generally used for the Cretan periods of civilisation. This would enable one coming fresh to the study to "orient" himself immediately. In the second place, the established nomenclature gives undue prominence to one site, the selection of which is more or less arbitrary. When we call a thing "Roman" we mean that it displays characteristics which evolved in Rome, or under Roman auspices, though the object itself may have been made in Britain. But no one supposes that Chelles-sur-Marne was the place of origin of the phase of civilisation which happens to be called after its name. The essentially unscientific nature of this nomenclature can best be exposed by putting a hypothetical case. Suppose that I should have the good fortune, in the course of a country excursion round my Dublin home, to light upon the remains of a strange civilisation in the lands of, let us say, a certain insignificant village which bears

1 It was first published in 1869 ; see $G$. de Mortillet, "Essai d'une classification des cavernes et desstations sous abris, fondée sur les produits del'industrie humaine" (Matériaux pour l'histoire de l'homme, ser. II. vol.v. p. 172). See also Préhist. introduction, chapter iv. Some modifications have been introduced by later investigators into the scheme as originally published. 
the name of Cloghran. Suppose, then, that traces of an identical facies of civilisation should subsequently be found over all Europe and the greater part of Asia. Would it not be absurd to continue to call the specific characters of this civilisation "Cloghranian," after an obscure place which it is no shame never to have heard of?

But while entering this protest, we follow the established terminology here, as the least evil of the possible alternative courses.

\section{(2) Human Remains of the Lower Palaeolithic Term}

Having regard to the circumstances of the Lower Palaeolithic deposits, it is clearly improbable that many bones should survive from the men of the Lower Palaeolithic Stages. The conditions of river-drift deposits, an alternation of droughts and spates, are the worst possible for the preservation of bones. The stronger and more massive bones of large mammals may survive the rough treatment and the corrosive action of such conditions; but there is very little reason to hope that the more delicate bones of Man should survive in adverse circumstances of the kind.

In point of fact, the record of Lower Palaeolithic human remains is of the scantiest; and even of those which have been assigned to this period with more or less confidence, the majority cannot be accepted without, at least, a considerable measure of reserve. In almost every case there are serious doubts as to their real antiquity. In all archaeological research, a healthy scepticism is one of the most desirable qualities for the investigator; it is better to reject even a genuine specimen to which some doubt attaches, than to accept a suspicious relic on the chance of its being genuine.

To be explicit, with four exceptions only, none of the human remains said to come from the river-drifts can fully substantiate their claim to date from the Lower Palaeolithic Term. Unfortunately even those four are so fragmentary that they can tell us little or nothing as to the physical characters of their original owners. Such as they are, however, we now proceed to give a brief description of them, and shall then give some notes on the more doubtful specimens, with the reasons for rejecting them, or, at least, of suspending judgment.

I. Bury St Edmunds. A fragment of a skull described by $\mathrm{Mr}$ Henry Prigg [afterwards Trigg] as having been found at a depth of 2.28 mètres below the surface in a deposit of brick earth; one of a series of such deposits, filling pockets in the surface of the underlying chalk at Westley, near Bury St Edmunds ${ }^{1}$. The fragment had all

1 Henry Prigg, "On a portion of a human skull of supposed Palaeolithic Age from near Bury St Edmunds” (F.A.I. XIV. [1885], p. 51). 
the appearance of having been gradually covered by the lacustrine deposit in which it was embedded; not of having been inserted at some later time. No other portion of the skeleton, or even of the skull, was forthcoming. The clay in some other.pits of the series contained molars of Elephas primigenius and implements of Acheulean type, i.e. of the third stage of the Lower Palaeolithic; and the skull is presumably to be dated to that stage of civilisation. It must not, however, be forgotten that no implements or other datable objects were found in the particular pit in which the skull was found; also that the skull was not found by Mr Prigg himself, but by one of the labourers. Nothing remains of the skull but the middle part of the frontal bone, from the bregma ${ }^{1}$ to a little more than halfway down the forehead, one-third of the left parietal bone (anterior portion), and a small fragment of the right parietal bone. A full description of the fragment has been given by Keith ${ }^{2}$, whose conclusion is that it "is such a mutilated document that one may well hesitate in forming any certain conclusion as to the type of person it represents." It is supposed to have belonged to a female ${ }^{3}$. So far as the existing relic goes, it appears to be entirely uncharacteristic, and approximates rather to the modern type of humanity, than to the Piltdown variety on the one hand, or to the well-established type of the Middle Palaeolithic on the other. But with the warning which the Piltdown skull affords, of the pitfalls awaiting the would-be restorer of a broken skull, it would be rash to base any conclusions upon this fact. Though the possibility that the fragment is later than the clay, in which it was found, is in the present case admittedly reduced to a minimum, it cannot be excluded altogether: nor can the further possibility of posthumous deformation. Keith has expressed a doubt as to whether the fragment could have carried the great brow-ridges which are a leading characteristic of Middle Palaeolithic man, in view of the remarkable thinness of the wall of the skull. It is probable that the brow-ridges of the Bury skull were not very prominent; but this seems to be generally the case in female subjects in the Middle Palaeolithic. Certainly the skull affords too slender a basis for the theory that there were already developed in Europe men of a modern type, who co-existed with the more brutal race or species of man characteristic of the Middle Palaeolithic. Our conclusion as to the

1 The bregma is the point on the summit of a skull where the sutures or jointlines between the frontal bone (the bone of the forehead and front part of the brain-case) and the two parietal bones (the side bones of the brain-case) meet.

2 A. Keith, "The Bury St Edmunds cranial fragment" (Fournal of Anatomy and Physiology, xLvir. [1913], p. 73); Antiquity of Man, p. 173 ff.

3 "An undersized, poorly-developed individual of middle age, probably of the female sex." Prigg, op. laud. 
Bury skull must be, that while it is scarcely questionable that it is genuinely old, and most probably Lower Palaeolithic, it is too imperfect to justify us in drawing any conclusions from it as to the physical characters of its owner, still less of the tribe to which he or she may have belonged. One of the labourers told Mr Prigg that, 30 years before, a complete human skeleton had been found in one of the pits, along with the tooth of an elephant; and $\mathrm{Mr}$ Worthington G. Smith refers to a similar discovery made at Ramridge End, Bedfordshire, in which the skeleton was likewise destroyed ${ }^{1}$.

II. Denise. A frontal bone, found in the year 1844 , embedded in tuff at Denise near Le Puy (Haute-Loire), and now preserved in the museum of Le Puy. Tuff is consolidated volcanic mud; and it is natural to infer that a bone embedded in such a material belonged to a person or animal overwhelmed by an eruption. As the same tuffs contain bones of Hippopotamus and of Hyaena spelaea, it is inferred that the eruption to which they are due took place at the time of the prevalence of a "warm" fauna in that part of Europe.

The discovery at Denise was among the first that raised the question of the high antiquity of Man, so that it naturally became, literally, a "bone" of much contention in the early controversies on this subject. The site of the discovery was examined personally by Lyell ${ }^{2}$, though with no very satisfactory result, 15 years after the bone was found. He tells us how he made the acquaintance of the labourer who had found the specimen, and how under this man's guidance he conducted special excavations on the alleged site of the discovery. But we must suspect some mystification, for Lyell could not find even a counterpart of the formation in which the bones are embedded in the museum! Beside the fragment of skull, Lyell records "some other parts of the skull[s?] including the upper jaw with teeth, both of an adult and [of a ?] young individual," as well as a radius, some lumbar vertebrae, and some metatarsal bones, all "embedded in light porous tuff, resembling in colour and mineral composition the ejectamenta of several of the latest eruptions of Denise."

To none of these last-named bones can any importance be attached. The zeal of collectors early did its deadly work at Denise, and the local dealers were quite competent to meet the demand which arose for human remains embedded in tuff (eked out and cemented with plaster of Paris). Only the first discovery, that of the frontal bone, can be taken seriously. Generally speaking, this

1 Worthington G. Smith, "A human skeleton of Palaeolithic Age" (Man, vI. [1906], No. 6).

${ }_{2}^{2}$ Antiquity of Man, 2nd edition, p. $195 \mathrm{ff}$. 
resembles the Bury fragment, though it represents a slightly different area of the skull. The frontal bone is almost perfect, but there is nothing left of the parietal bones. Like the Bury fragment, it seems to have belonged to a woman, and again, like that specimen, it does not display the marked characteristics of prominent brow-ridges and low sloping forehead which we find in the Middle Palaeolithic. But though a little more satisfying than the Bury fragment, the Denise skull is likewise too imperfect to bear much weight of theory ${ }^{1}$.

III. Taubach. We have already spoken, in the preceding chapter, of Taubach, near Weimar, and of the two human teeth there found, on account of certain analogies which this station presents to the circumstances under which the Piltdown skull was discovered. We must now return to it and describe it more fully. The stratification of the site is as follows:

$D$. Löss.

C. Later Tuff: Elephas primigenius, Rangifer tarandus. No human remains, or relics of human industry.

B. Older Tuff: Elephas antiquus, Rhinoceros mercki. Human tooth or teeth, rude flints, hearths, worked bones.

$A$. Glacial gravels.

It is evident that $A$ is a glacial deposit, and the fauna shews that $C$ is also glacial. $B$ is therefore interglacial, and its fauna bespeaks a genial climate. It is not so early as the time of the Mauer man, for the fauna is of a somewhat late facies; we are to think of the Riss-Würm interglaciation as the time to which the Taubach human remains are to be assigned.

It must not be forgotten, from the first, that there have been many frauds in connexion with this important site. As at Denise, the collector visited Taubach, and Nature has done her work! Prof. Klaatsch tells us ${ }^{2}$ of a quarryman whose acquaintance he made, and who complained bitterly to him that his wife had "dragged whole baskets-full of teeth" to Taubach and had received not more than ten marks the basket-full, though they had afterwards been purchased singly at a high price. After this, it behoves us to be on our guard about the archaeological and palaeontological yield of Taubach. Of the human teeth, only the child's can be accepted as certainly ancient. The other was found by one of the labourers, and though it also presents primitive features, it may have been imported by Prof. Klaatsch's friend or by one of his kind.

1 A description of the anatomical details of the Denise fragment will be found in Sauvage, "L'homme fossile de Denise" (Revue d'Anthrop. I. [1872], p. 289); Hamy, Précis de paléontologie humaine, p. 209. See also Keith, Antiquity of Man, p. 205; M. Boule, "L’âge des derniers, volcans de France" (La Géographie, xıII. [1906], p. 275).

2 Z.f.E. xxxv. [1903], p. 126. 
The teeth would seem to represent a stage of human development anterior to the fully-developed type of the two fragments just described $^{1}$. We have already seen that Duckworth compares them to those of the Java Pithecanthropus. According to Nehring, the chief simian characters presented by the child's tooth (a first molar) are the unusually oblique slope of the anterior side of the crown; and the division of the roots, not at the neck of the tooth as usual in modern specimens, but some distance below. Though a child's tooth, it is much worn. But we must not forget that both the Mauer and the Piltdown skulls shew that there is not a necessary correlation between the apparent degree of development of the teeth and of the skull in which they are set; in both cases the seeming incompatibility of teeth and skull has been one of the first subjects of remark. The other tooth (a left lower first molar) is of large size, with a highly complex upper facies, in this respect resembling a pithecoid tooth.

The artefacts found in the stratum containing the teeth are quite different from the classic types of the Lower Palaeolithic Term. They are much ruder, and bear a more general resemblance to those of the Middle Palaeolithic. The fauna, however, forbids us to bring the date of the Taubach settlement down so late; and the analogy of certain of the lower strata in the Mentone caves, to be described later, shews that there is no insuperable difficulty to finding flints with Middle Palaeolithic facies in Lower Palaeolithic deposits. In fact, the nature of the implements is only one, and that not necessarily the most important, of the criteria of the age of a deposit. Scattered among the communities who were manufacturing the classic forms of Lower Palaeolithic implements, there were others whose artefacts were of a different character.

Our knowledge is not as yet sufficiently far enough advanced to enable us to say whether the analogies which the Taubach and the Piltdown finds present are significant, or merely accidental. The present writer is inclined to believe that with future discoveries they will be found to be more closely akin than is at present generally admitted; in other words, that the Piltdown skull, so far from possessing the exceptional antiquity claimed for it, will ultimately be brought down to near the Taubach chronological level. The Piltdown man will then take his place at the head of the Lower Palaeolithic Term, and will no longer remain as an isolated phenomenon farther back in the obscurity of "the dawn of humanity";

1 These teeth have been described by Nehring, "Über einen fossilen Menschenzahn aus dem Diluvium von Taubach bei Weimar" (V.B.A.G. [1895], pp. 338-340; see also 425-433); R. R. Schmidt, Die diluviale Vorzeit Deutschlands (Stuttgart, I9I2), pp. 238-9, where further references to authorities will be found. 
he will then, it is to be hoped, be relieved of the unfortunate label Eoanthropus. The difficulty of dating the Taubach settlement is recognised by all prehistorians; those most conversant with the site and its remains call it early Acheulean. The Piltdown man may thus be a representative of the Pre-Chellean or Chellean people: and the Bury and Denise fragments, if these be genuinely palaeolithic, will then represent a later stage of Acheulean development, after millennia of the fruitfulness and ease of interglacial life; but with a new glaciation looming in the future, during whose rigours Man and his handiworks are to suffer a degeneration ${ }^{1}$.

IV. Ehringsdorf. Ehringsdorf is close to Taubach, and its deposits resemble those of that site, if, indeed, they are not to be considered as forming one with them. A lower jaw was found here in May 19I4, which has been described by G. Schwalbe ${ }^{2}$. An abstract of his account, accompanied by an illustration of the specimen, appears in the American Anthropologist ${ }^{3}$. The stratification of the site at Ehringsdorf is as follows:

$D$. Upper travertine, containing Rhinoceros tichorhinus as well as $R$. mercki.

C. Löss.

$B$. Lower travertine $e^{4}$ containing Elephas primigenius and Rhinoceros tichorhinus at bottom, E. antiquus and $R$. mercki at top.

$A$. Glacial gravel and sand.

This stratification evidently denotes a glaciation, responsible for $A$; a tundra period, the beginning of $B$, with its characteristic tundra animals, followed by a full interglaciation with the animals of a genial climate. Then follow steppe conditions, harbingers of a new glacial epoch, the coming of which is still more clearly foreshadowed by the fauna of stratum $D$. The jaw was found in stratum $B$, associated with Rhinoceros mercki; it therefore belonged to a man who

1 The following may be mentioned among the extensive literature of the Taubach settlement. Brief report of a paper by K. von Fritsch, "Ueber die bisher aus den Hänschen'schen Brüchen von Taubach bekannt gewordene diluviale Fauna" (Zeitschrift für Naturwissenschaften, LXI. [1888]); R. Virchow, "Ueber diluviale Funde bei Taubach" (V.B.A.G. [1877], p. 25); A. Götze, "Die paläolithische Fundstelle von Taubach bei Weimar" (V.B.A.G. [1892], p. 366); O. Schötensack, "Diluvial-Funde von Taubach, Weimar" (V.B.A.G. [1895], p. 92); S. Reinach, "La station de Taubach près de Weimar" (L'Anthr. viII. [1897], p. 53). R. R. Schmidt, op. laud., which has a bibliography that errs on the side of fulness, some of the items catalogued proving when consulted to be mere paragraphs adding nothing to the knowledge of the subject.

${ }^{2}$ G. Schwalbe, "Ueber einen bei Ehringsdorf in der Nähe von Taubach gefundenen Unterkiefer des Homo primigenius" (Anatomischer Anzeiger, XLVII. p. 337).

${ }^{3}$ G. G. MacCurdy, "Interglacial Man from Ehringsdorf near Weimar" (American Anthropologist, xvII. [1915], p. 189).

4 Travertine is a calcareous tufa, deposited by mineral springs. 
lived during the interglaciation. The stratification is practically identical with that at Taubach, except that the Löss and the upper bone-bearing strata appear to change places.

The jaw is very fragmentary, and appears to have suffered posthumous deformation. The ascending ramus on each side is lost, nothing remaining but the arch. The teeth are in fair condition, the incisors having apparently suffered damage. The molars are much worn. The complete absence of chin is noteworthy, as is the high degree of alveolar prognathism - the oblique projection upward and outward of the line of the chin and of the front teeth. In matters of anatomical detail, the specimen approximates to the Middle Palaeolithic type.

We may note here in passing a human tooth found associated with Acheulean tools at Neu-Essing in Lower Bavaria ${ }^{1}$.

The full significance of the four human fragments which have now been enumerated cannot be discussed until we have described those of later stages of the Palaeolithic period. For the present we proceed to notice, more briefly, certain other remains supposed to belong to Lower Palaeolithic Man. These cannot be altogether ignored, as much has been made of them from time to time; it is at least necessary to indicate the various reasons why they cannot safely be taken into consideration in endeavouring to reconstruct the anthropological history of Europe.

I. Moulin Quignon. A jaw-bone found by the diggers employed by Boucher de Perthes. Boucher was most anxious to discover bones of the people who had made the implements which he was the first to bring to notice; such a discovery would have been the best answer to the critics who had endeavoured to discredit his work. But unfortunately he adopted the expedient of offering a tempting reward for such a discovery, with the natural result that a jaw-bone, whence procured is unknown, was quickly forthcoming. On being cut across this bone was found to be clogged with soil quite different from that in which it had ostensibly been buried. The most reasonable inference is that the bone had previously been inserted in the place whence Boucher, guided by the labourer who thus earned the promised 200 francs, joyfully extracted it with his own hand. We have only to turn over the numerous plates in Boucher's book to see how cruelly he was defrauded by his workmen ${ }^{2}$.

II. Avenue de Clichy, Paris. A skeleton found in a gravel-pit here, most probably falls under the same condemnation, as a fraud.

1 Obermaier, El hombre fósil, p. 279.

2 Boucher's own account of the Moulin Quignon discovery will be found in Société impériale d'émulation d'Abbeville, $186_{\mathrm{I}-5}$, p. I. 
It was complete, in good condition, and stained red; whereas the bones of large animals, naturally more solid than human bones, were found in the same place, in bad condition, and unstained. We must again suspect the practice of the gentle art of "salting" on the part of labourers, stimulated by collectors ${ }^{1}$.

III. Dartford, Kent. The two preceding examples are to be rejected on the suspicion of bad faith attaching to them. The Dartford skull is disqualified by an uncertainty as to its stratification. There is at Dartford a gravel-pit which has yielded Acheulean implements. Had the skull been found in position, lying in this stratum, it might reasonably be admitted as at least establishing a good claim to being a relic of Acheulean man. But unfortunately it fell to the bottom of the pit in a landslip, so that it may equally well have come from a stratum overlying the implement-bearing bed. This is all the more probable in that the skull is entirely modern in all its characters ${ }^{2}$.

IV. L' Olmo, Italy. This skull was found in the year 1863 , in a lacustrine deposit of blue clay, in the course of railway excavations in the valley of the Arno, above Florence. The clay containing the skull was overlaid with stratified alluvium, ancient and modern; these are said to have been undisturbed.

The circumstances in which the skull was deposited are not, however, so satisfactorily recorded as we might have wished. They are described by Prof. Cocchi, the discoverer of the skull ${ }^{3}$; we may give an abstract of his account. It would seem that the railway works here having collapsed, owing to insufficient foundation, it was found necessary to dig deeper trenches. After describing these, Prof. Cocchi goes on to say "During a fine day, the I6th of June, I, with some

1 For some painful details on this unpleasant subject see Worthington Smith, Man, the Primeval Savage (London, 1894), p. 25 I ff. The details as to the Avenue de Clichy skeleton are here given on the authority of G. de Mortillet (Préhist. part 11. chap. iv.). A description of it will be found in E. Bertrand, "Crâne et ossements trouvés dans une carrière de l'avenue de Clichy" (B.S.A.P. ser. II. vol. III. [1868], p. 829); Hamy, Précis de paléontologie humaine, p. 2 10. Breuil (Les plus anciennes races connues, $\mathrm{p}$. 15 of reprint) appears to accept the authenticity of these bones, and an anonymous writer in Revue préhistorique, IV. [1909], p. 17, attaches no importance to the statements of G. de Mortillet. On the other hand, Obermaier (El hombre fósil, p. 272) protests against this skeleton being brought into evidence. When doubt exists to such an extent it is safest to reject the specimen, even though there may be a lingering chance of its genuineness.

2 See the description of the skull in Keith's Antiquity of Man, p. $165 \mathrm{ff}$. See also the same author's note (Report, Brit. Association, Portsmouth [1911] , p. 517), in which he says that the geological evidence is "altogether incomplete."

3 Prof. Cocchi's account is called " $L$ ' uomo fossile nell' Italia Centrale" (Memorie della Società Italiana di Scienze Naturali, II. [Milan, 1867], No. 7). I quote from the extracts appearing in G. Sergi, "Su l' uomo fossile dell' Olmo, provincia di Arezzo" (Rivista di Antropologia, xxı. [Rome, 1916-7]). I have to thank Dr Duckworth for a loan of a copy of this paper, which would otherwise have been inaccessible to me. See also E. T. Hamy, "Etude sur le crâne d'Olmo" (B.S.A.P. ser. 1I. vol. 111. [1868], p. I I2). 
others, was intent on the examination of the work, when the news came that in a part of the trench to the east, at a place where some props were for some reason wanting, a small fall of earth had taken place, in which a sub-spherical body resembling a human head had come out and had fallen to the bottom of the trench. It was indeed a human skull, which was quickly picked up and put in a place of safety." He goes on to say how notwithstanding the peculiarity of the site, the difficulty of the work, the interruption of rain-storms, and the necessity of repairing the damage immediately, every care was taken to search for more bones. A few fragments that had become separated from the skull, a fine lance- or arrow-head in brown flint, and some splinters of charcoal, were found. The place where the skull had lain was still, it is said, to be seen; this was ${ }_{5} 5$ mètres below the present surface of the soil. No less than eleven strata are distinguished by Prof. Cocchi at l' Olmo, down to and including the bed of clay in which the skull was lying. These, simplifying his descriptions, are as follows:

\section{RECENT}

$K$. Recent remains. Objects of fifteenth century.

7. Mediaeval remains. Animals' bones, coins.

I. Remains of the late Empire. Bones and coins.

$H$. Roman remains of all kinds.

$G$. Etruscan remains of all kinds.

$F$. Pre-Etruscan remains; bronze implements, possibly divisible into subordinate periods.

$E$. Ancient alluvium, I mètre thick. Fossils very rare. Human remains; obsidian implements, some flints.

\section{EPi-Pliocene}

D. Lehm or Löss. No human remains here. Contemporary with Upper Palaeolithic.

C. Gravel of rapid sedimentation. Bos primigenius, flint implements.

$B$. Minute ferruginous gravel and conglomerate. Fossils as in underlying clay. No human remains.

$A$. Lacustrine clay with layers of peat in upper part. Bones of Elephas antiquus, Cervus euryceros, Bison priscus. The l' Olmo skull and flint implement.

The elephant in stratum, $A$, of which only the point of a tusk had been found when Cocchi wrote, was at first identified as $E$. primigenius. Afterwards, however, a skeleton of $E$. antiquus was found, which makes it probable that the elephant characteristic of the bed was the earlier variety. This, however, is not a conclusive proof of a date contemporary with the deposits containing $E$. antiquus in Northern Europe; the more genial climate of Italy might enable the 
elephant to survive there longer than in the northern parts of the continent. The flint implement is too rude to offer any distinctive indication of date, though it is doubtless Palaeolithic: G. de Mortillet considered the skull to be Middle Palaeolithic, a verdict with which the writer in Revue préhistorique, quoted in footnote, p. 219, agrees, on account of its resemblance to the Avenue de Clichy skull, which would be more satisfactory if that specimen were certainly genuine.

On the other hand, the skull was not, actually, found in position, but, as at Dartford, had fallen down in a landslip. Thus, though a hollow where it might have lain was indicated, it is possible that it fell from higher up the pit. Presumably some of the blue clay would be adhering to it, however: but even if this were so, it would not necessarily prove that the skull was deposited contemporaneously with the blue clay. A burial at the time when stratum $B$ or stratum $C$ was in course of formation would account for its presence, and the fact that a flint weapon or implement had been deposited along with it makes this all the more likely. With the warning of the Castenedolo skeletons before us, it is perhaps well to keep an open mind as to the antiquity of the l' Olmo skull. It may be genuinely ancient, but we need corroboration, and there is reason to fear that this cannot now be forthcoming; once more we see good scientific material wasted. A sufficient number of sufficiently well authenticated discoveries of similar bones in the same stratum would go far to rehabilitate the l' Olmo skull, but as yet judgment must be suspended.

The skull has been described by different people, with strangely different verdicts. The cephalic index has been stated variously at from 72.5 to 85.3 -almost the extremes of normality! It has been described as closely resembling the Middle Palaeolithic people with their great brow-ridges, and as being entirely modern in type, with no brow-ridges at all ${ }^{1}$. Keith ${ }^{2}$ gives 74 as its cephalic index; $\mathrm{Sergi}^{3}$ estimates it at $72 \cdot 5$, and describes it as ovoid when viewed in norma verticali, almost ellipsoid. It is platycephalic (having a low headvault); and according to Keith is to all intents and purposes a modern skull, with no abnormal or simian features whatsoever. It resembles the Bury fragment, so far as that specimen goes. De Quatrefages and Haniy consider that it is a female skull, explaining thus its absence of brow-ridges ${ }^{4}$.

1 Mortillet, Préhist. part II. chap. vii.

2 Antiquity of Man, p. $106 \mathrm{ff}$.

3 Op. laud.

4 Another account of the l' Olmo skull by M. d'Acy will be found summarised in L'Anthr. I. 723. His conclusion is that the skull is Pre-Mousterian. See also de Mortillet (B.S.A.P. [1 868], p. 40); d'Acy, Les crânes de Cannstadt, de Néanderthal, et de l'Olmo, mémoire présenté au Congrès International tenu à Paris en I 886; Hamy, 
V. Galley Hill. We have dealt with specimens which are doubtful because there is reason to suspect fraud; others which are doubtful owing to uncertainty as to the stratification. We have now to mention one or two which are doubtful because, though the stratification has been examined with some care, there is an uncertainty as to the interpretation of the facts observed. One of the best illustrations of this form of difficulty is afforded by the skeleton of Galley Hill in Kent. This famous specimen was found sunk eight feet in gravel, at a place not far from Dartford. Unfortunately it fell a victim to the eager competition of collectors-and in their hurry to secure the prize no proper photographs of the interment were taken before its removal $^{1}$. We are assured that the stratification of the gravel above the skeleton was unbroken; but of this we cannot be sure, because the traces of the fosse of a grave might have been dug away before the skeleton was exposed in the gravel pit. At least, the corroboration of photographs is necessary to substantiate observations of the kind, by whomsoever made. The Galley Hill skeleton is one of the trump cards in the hands of those who hold that the modern type of man developed at an early stage of the history of humanity in Europe; the doubt that must always cling to it is therefore unfortunate. Its condition of fossilisation was less advanced than that of other bones deposited in the same stratum; and Duckworth has shewn reason for believing that it is merely an Anglo-Saxon interment ${ }^{2}$. The skeleton belonged to a man, entirely modern in type, and rather short in stature ${ }^{3}$ ( $\mathrm{I} \cdot 60$ mètres).

VI. Ipswich. The skeleton found at the end of I9II, embedded in the Red Crag at Ipswich, created much sensation at the time, but the discoverer has himself withdrawn it from the field of science, acknowledging the faultiness of the original observations. Nothing further need therefore be said of it ${ }^{4}$.

It is right to mention the foregoing six examples, because they have acquired a certain amount of notoriety, and it is well to warn

Précis de paléontologie humaine, p. $206 \mathrm{ff}$; de Quatrefages, Introduction $\dot{a}$ l'étude des races humaines, p. 6o; de Quatrefages and Hamy, Crania ethnica, p. $18 \mathrm{ff}$.

1 The story will be found in Keith, op. laud. p. $170 \mathrm{ff}$. No one should consider himself entitled to retain possession of a specimen so valuable; it should be deposited permanently in a museum immediately on its discovery.

2 "The Problem of the Galley Hill Skeleton," in Essays and Studies presented to William Ridgeway (Cambridge, 1913).

3 In addition to the authorities mentioned in the preceding footnotes, see H. Klaatsch, "Bericht über einen anthropologischen Streifzug nach London und auf das Plateau von Süd-England" (V.B.A.G. [1903], p. 875 ff. esp. p. $903 \mathrm{ff}$.); E. T. Newton, "On a human skull and limb bones found in the Palaeolithic Terrace Gravel at Galley Hill" (Q.F.G.S.L. LI. [1895], p. 505); A. Rutot, "A propos du squelette de Galley Hill" (M.S.A.B. 2 I Jan. I904).

${ }^{4}$ See Nature, 12 October 1916. 
the student that any conclusions based on the evidence which they afford must be taken with caution. There are a few other fragments that have been brought forward from time to time, but none of them are worth drawing from the obscurity into which they have fallen.

It will be obvious that we have not yet sufficient material to enable us to determine anything about the physical character of Lower Palaeolithic Man in Europe: and it may be doubted whether we can hope ever to be in possession of such material. Human bones, as we have already said, have but a poor chance of preservation in river-drift deposits.

\section{(3) Fauna of the Lower Palaeolithic Term}

The fauna associated -with the remains of the Lower Palaeolithic Term speak uniformly, over the whole continent of Europe, of a genial climate. In regions which were at any time dominated by ice, the Lower Palaeolithic men lived in an interglacial phase. A few illustrations, selected from various centres, will be sufficient to demonstrate this.

Let us take first the gravels of Chelles-sur-Marne, which has given its name to the second stage of the Lower Palaeolithic. These have been very carefully studied, and have yielded many remains of animals, and, what is more important, more or less complete skeletons, shewing that the animals were contemporary with the formation of the gravels, on a principle of palaeontological deduction already stated in these pages. With the animal bones were found numerous implements of forms typical of the Lower Palaeolithic. The animals included the following species:

Ursus spelaeus.

Hyaena spelaea.

Trogontherium cuvieri.
Hippopotamus amphibius.

Rhinoceros mercki.

Elephas antiquus.

Of these the last three are sufficient to prove a genial climate. In later Lower Palaeolithic strata we detect a gradual change, especially in such places as Abbeville or Saint-Acheul, on the Somme, where there are a number of strata, the records of successive stages of the history of the Lower Palaeolithic. As we proceed upwards through these strata, the hippopotamus first disappears, and we can see Elephas antiquus gradually giving place to E. primigenius, and Rhinoceros mercki to $R$. tichorhinus. The conquering animals, being covered with a coating of hair or wool, were better adapted to resist the deteriorating climate which heralded the coming glaciation ${ }^{1}$.

In the valley of the Thames the same combination of animals is

1 References to authorities on the Chelles station will be found on p. 254 . 
to be seen. With the earlier stages of the Lower Palaeolithic, which occupy the upper river-terraces, there appear Elephas antiquus and Rhinoceros mercki, giving place in the later stages to $E$. primigenius and $R$. tichorhinus ${ }^{1}$.

Coming down now to Northern Italy, we find the same animals in the lower strata of the caves of Mentone, associated with a large number of other species more or less characteristic of a warm climate $^{2}$.

Though the climate is thus uniform, it is reasonable to suppose that in southern Europe it would be still more genial than in the north of the continent. In some southern stations not only is Elephas antiquus contemporary with man, but some observers have thought to find even the still older elephant $E$. meridionalis associated with remains of human occupation.

In the gravel-pit of Tilloux (Charente), between Jarnac and Cognac, were found remains of an ancient human settlement, of the Lower Palaeolithic, associated with remains of animals, especially the tusks of elephants. Some of these belonged to E. antiquus; but others were so large that they were, at first at least, considered to belong to $E$. meridionalis. On this identification, however, doubt has been thrown. Déchelette says "il ne faut plus comprendre Tilloux parmi ces gisements"-i.e. among beds containing E. meridionalis, and informs us that Prof. Boule has restored the tusks "to a very archaic form of $E$. antiquus," rectifying their original ascription to E. meridionalis. For this statement he refers us to L'Anthr. vI. p. $502^{3}$ : but the statements as there contained do not seem to sanction so very definite a denial of the identification.

The Marqués de Cerralbo has reported the discovery of bones and tusks of Elephas meridionalis accompanying human artefacts of rude Lower Palaeolithic forms at Torralba, in the province of Soria, Spain ${ }^{4}$. These bones, however, have later been identified as representing rather an early form of $E$. antiquus, an elephant also found at Torralba ${ }^{5}$. The contemporaneity of man with Elephas meridionalis in southern Europe must therefore be held in suspense as "non-proven."

${ }^{1}$ For a full list of the fossil animals from the Thames valley, see W. Whitaker, "The Geology of London and of part of the Thames Valley" (Geological Survey, [r889], vol. I. p. 336).

2 See the section on Palaeontology in the monograph on the Grimaldi Caves published under the auspices of the Prince of Monaco.

${ }^{3}$ Manuel d'archéologie, I. 49.

${ }^{4}$ Marqués de Cerralbo, "Torralba, la plus ancienne station humaine de l'Europe?" (C.A.P.A. Geneva [1912], vol. I. p. 277).

${ }^{5}$ H. Obermaier, El hombre fósil (Madrid, 1916), p. I6o. 


\section{(4) Implements of the Lower Palaeolithic Term}

We now proceed to a consideration of the remains of human industry which have survived to us from the Lower Palaeolithic Term.

Within the limits of our knowledge there is no reason to compel us to doubt that the three stages, Pre-Chellean, Chellean, Acheulean, into which this Term has been divided, represent successive stages in the cultural development of one continuous population; gradually improving their methods of flint-chipping, and doubtless their other industries, of which no remains have survived. All the evidence available is in favour of one population, not of a series of immigrations, which would be the alternative theory. When, as at SaintAcheul, the remains of successive stages are represented in the stratification, the development is seen to be continuous: the unskilled Pre-Chellean gradually acquires the certainty of touch of the Chellean, and he in his turn the artistic finish which distinguishes the best work of the Acheulean.

The Pre-Chellean tools have all the crudity of the first attempts at any art. Indeed (it is scarcely unfair to say) we cannot be sure that the flint-chippers of the Pre-Chellean stage were fully aware of what they were about. They picked up chance pieces of flint or of other stones, broken by some accident into natural knives or scrapers, and they tried by touching up the edge to improve them as implements; or else, having these natural models, they tried to imitate them by breaking nodules into as close an approximation to their shape as they had the skill to obtain. But they had not as yet learnt thoroughly how to proceed; it is more than probable that they had no real knowledge of how to secure the results at which they were aiming. In a word, the technique of flint-chipping had yet to be discovered.

In consequence of this uncertainty of touch in Pre-Chellean tools, it is possible to make elaborate lists of types, the chief if not the only value of which would be to shew the uselessness, or worse, of such classifications. We can speak of Pre-Chellean flaked tools; but to group them as scrapers, knives, coups-de-poing, and so forth, is to venture further than we have any real right. It appears to have been actually the case, to judge from the results, that PreChellean man was at a stage of cultural development so primitive that when he chipped a flint he had to trust to luck whether his work would result in a scraper or a borer. If so, how can we undertake to supply names for these tools, which he probably used quite at haphazard? 


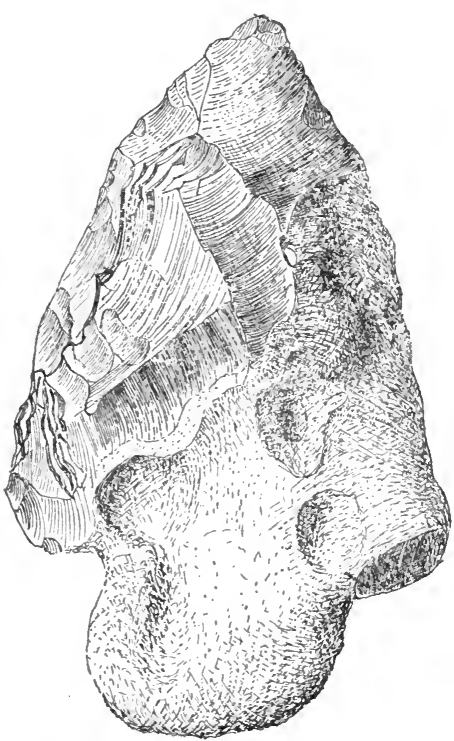

$a$

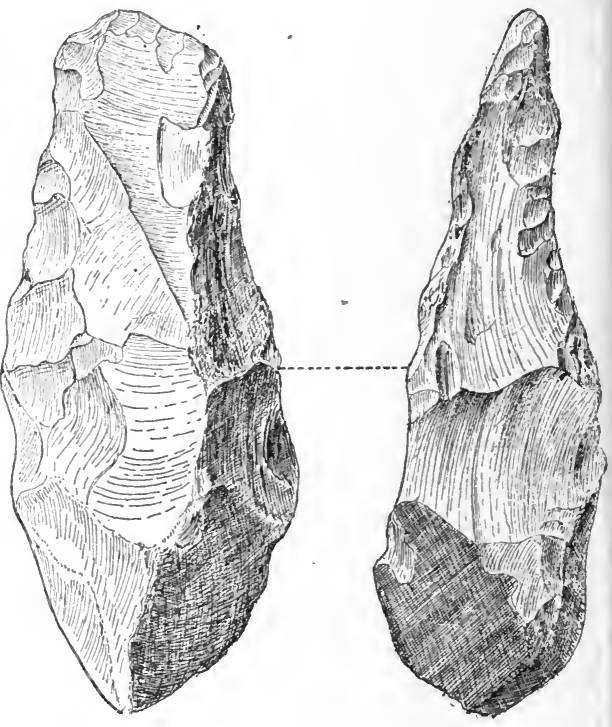

$b$

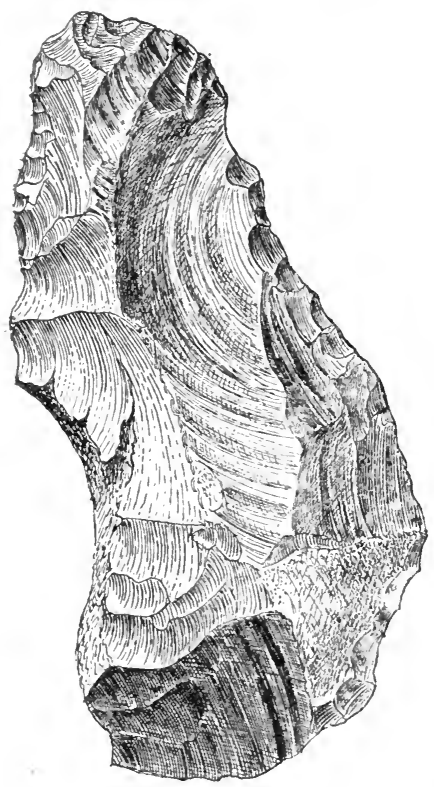

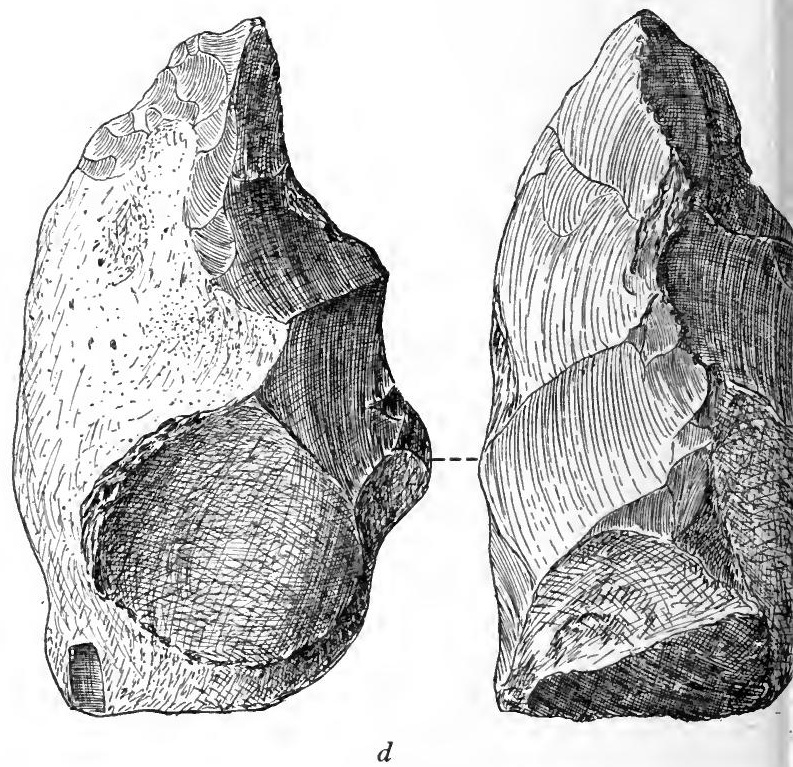

Fig. 48 (A). Pre-Chellean flint implements from Saint-Acheul.

(From L'Anthropologie, vol. xIx.) 

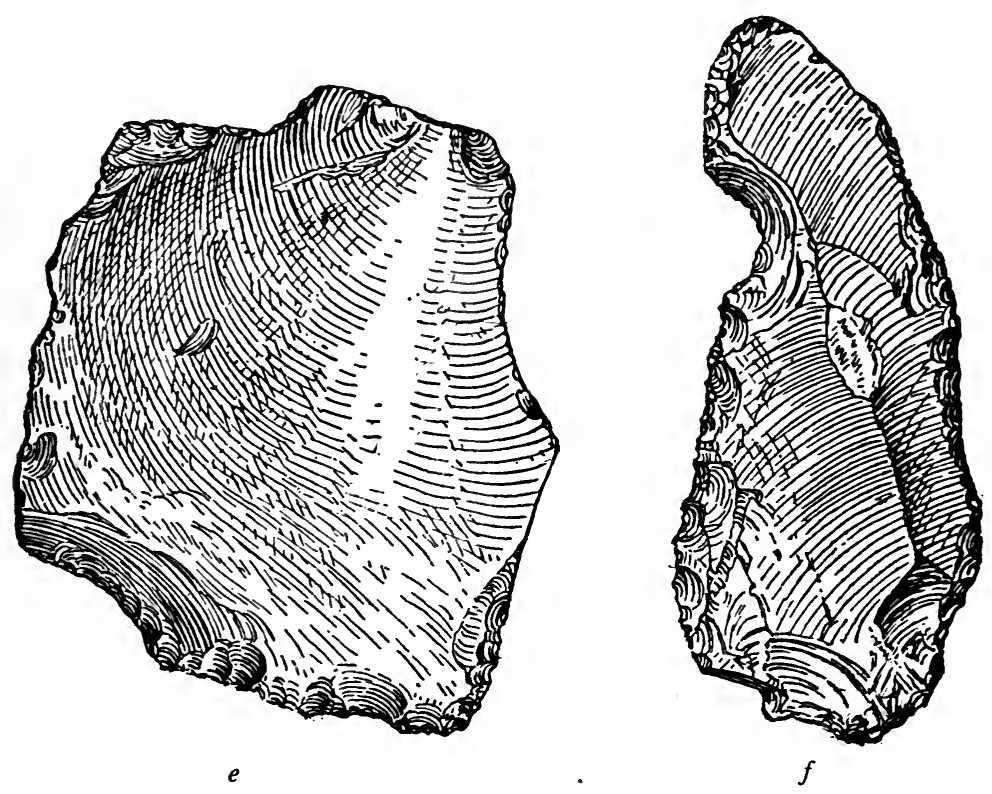

Fig. 48 (B). Pre-Chellean flint implements from Saint-Acheul.

(From L'Anthropologie, vol. x!x.)

One of the best series of Pre-Chellean tools that has been published is the collection formed by M. V. Commont in his admirable excavations at Saint-Acheul ${ }^{1}$. In the lower levels of the gravels at this famous site there were found a considerable number of shapeless flint chips, some of which are figured in Commont's report of his work. From these we borrow a few (Fig. 48). Of this selection, $a$ is a nodule which in its natural form accidentally happened to have the form of a barbed javelin-head. One edge and the point have been trimmed by coarse flaking; but Commont, in describing it, remarks that the tool is so thick that it is difficult to imagine what its use could have been. It is perhaps a little hazardous to call it a "primitive coup-de-poing," but after all the term means little, and will serve as well as any other. The second, $b$, is a tool pointed at one end, chisel-like at the other; it seems to have been grasped in the hand and the ends used for whatever purpose or purposes they were capable of serving. The side edges are blunt, and incapable of cutting. In $c$ we may perhaps identify a scraper or some sort of knife; it was grasped in the hand in the same manner as $b$. The next, $d$, may have been used as a coarse borer. There were also

1 An account of M. Commont's work, with references to the more important of his very numerous papers, will be found below, pp. $249 \mathrm{ff}$. 
numerous flakes, of which $e$ and $f$ are examples, apparently not detached with the intention of using them as implements; rather were they struck from the nodule in the process of shaping another tool, and according as they appeared adaptable for some practical purpose they were touched up along the edge. The conspicuous hollow in the edge of $f$ is not intentional, but was produced by rough use.

The specimen lettered $b$ in the above selection is unusual in that the entire calcareous surface of the original nodule is remored. As

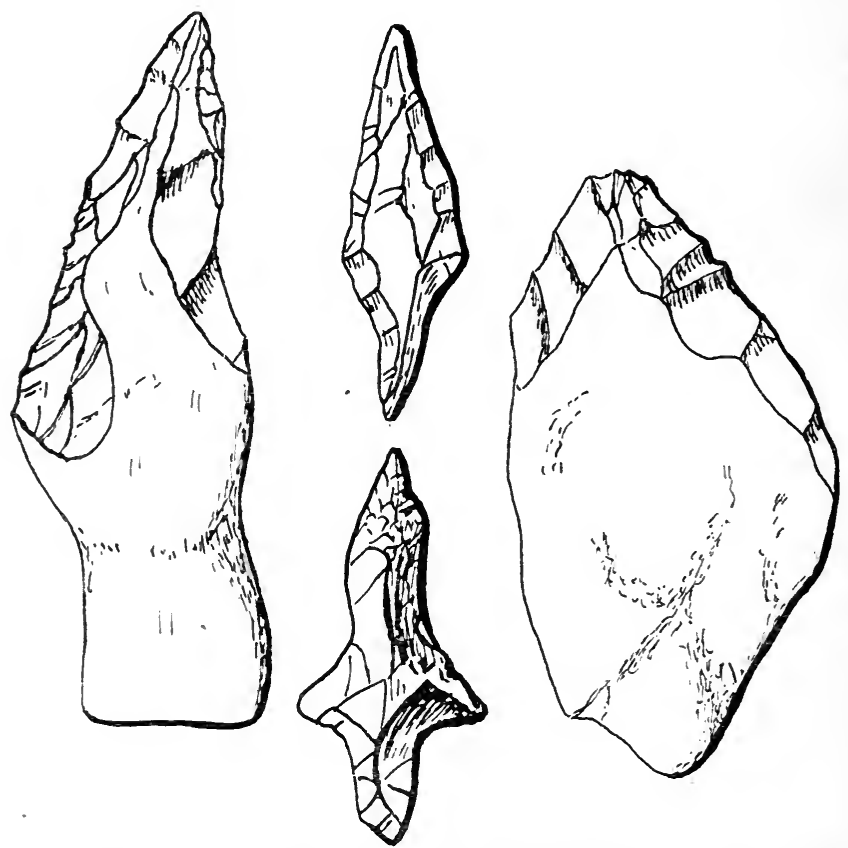

Fig. 49. Poignard, arrow-heads, and supposed primitive coup-de-poing, from Binche and Strépy.

a rule the calcareous skin of the flint is disturbed as little as possible in Pre-Chellean tools.

Underlying the Chellean in Belgium, at Spienne, Hélin, Mesvin, Strépy, and other places, flakes of flint are found which, like those in the lowest implement-bearing layer at Saint-Acheul, appear to be tentative attempts at flint-chipping on the part of early man. It must be said that some of the objects that have been produced from these strata as artefacts are not very convincing; indeed, they lie under the general suspicion inseparable from eoliths.

A remarkable series of objects has been found at Binche and Strépy, which it is difficult to know how to explain (Fig. 49). These 
have been called "daggers" or "poignards"; they consist of a bar of flint with a point roughly chipped at one end, so that they resemble a clumsy and badly pointed lead pencil. They are so extraordinary that not unnaturally Déchelette ${ }^{1}$ as well as some other authorities considered them forgeries. Certain arrow-heads from Binche would have a suspicious appearance if found on any site and in any stratum; these we need hardly hesitate about rejecting, thereby admitting the possibility that Binche has been the scene of the operations of forgers. But the investigations of Breuil and Schmidt ${ }^{2}$ forbid us to reject the poignards so easily; concretions which those competent authorities observed on certain specimens, covering the chipped part of the object, appear to indicate that they were genuinely ancient. But there is some doubt as to their stratigraphy, which does not seem to have been satisfactorily determined; and as the gravels said to have yielded them are now, apparently, all dug away, there is no immediate prospect of this vital question being settled. Schmidt considers the objects Neolithic, as also does Rademacher ${ }^{3}$.

The Pre-Chellean is the first stage in the history of humanity, at least in Europe, in which beyond the possibility of doubt we find flint worked artificially. Its implements are the oldest in which without any reserve we may recognise the essays of an intelligent being. Except the flints, no remains of Pre-Chellean industry are known.

Of the Chellean stage the most characteristic tool is the socalled coup-de-poing. This French name, the invention of Gabriel de Mortillet ${ }^{4}$, has been generally adapted in English (sometimes translated into "Hand-axe"); and we continue its use here in order to avoid the multiplication of technical terms. An attempt which has been made to substitute the name "boucher," in honour of Boucher de Perthes, has not met with general success, though the

1 Manuel, I. 65.

2 R. R. Schmidt, Die diluviale Vorzeit Deutschlands, p. 125 note.

3 C. Rademacher, "Frühneolithikum und belgischer "Chelléen", (Prähist. Zeitschrift, IV. [1912], p. 235).

4 M. Salomon Reinach (Alluvions, p. 93) objects to this name on the ground that it induces a prejudice against the theory that these tools were hafted. Unfortunately it is probably impossible to devise any name for them which, while giving some idea of what they are, does not prejudice the question in one direction or another. Thus "axe" or "chisel" almost inevitably suggests the by no means certain theory that they were hafted. Mr Worthington Smith describes (Man, the Primeval Savage, p. 222) an implement (coup-de-poing) from Bedford, "which had the butt end, when first found, wrapped round with herbaceous stems, probably rushes, as if for a protection for the hand." With this we may compare a Neolithic flake knife from the River Bann, in the North of Ireland, now preserved in the National Museum, Dublin, which retains its original handle-a wad of moss, wrapped round the butt end of the flake. See E. T. Stevens, Flint Chips (London, I870), p. 86. 
term is occasionally used. It is open to the objection that it means nothing-or rather, to the eve of one accustomed to English, it suggests a substantive derived from a non-existent verb "to bouch": at least, I am obliged to confess for my own part that I tried to work out the meaning of the word on such lines when I first happened to come across it! In any case a proper name looks ugly without its initial capital ${ }^{1}$. Other names occasionally used are langue de chat (a slang term used by the labourers in French gravel-pits where these tools come to light), and the German translation of coup-depoing, Faustkeil.

The coup-de-poing is a nodule of flint, so chipped as to be sharp and more or less pointed at the one end, blunt and rounded at the other. There are numerous subordinate varieties of shape, depending to some extent on the outline of the original nodule, or on the skill of the artificer; so far as the present writer can judge, these muances do not afford a basis for classification of what may be called technical importance. We have coups-de-poing of oval, lozenge, and triangular shape; and even greater refinements of classification have been sought. Capitan, for example?, has enumerated four different types, which he considers to have been as many different tools. These are (I) a more or less triangular form, the sharp point being the "working part" of the tool; (2) a similar form, but with a straight eige taking the place of the point; (3) a form in which the "working part" is an edge running along one side; and ( 4$)$ an oval tool approximating to the Acheulean type. A similar classification is applied in the same paper to coups-de-poing of the Acheulean stage. While it is clear from the drawings accompanying M. Capitan's paper (of which we give a selection here, shewing the appearance of a coup-de-poing (Fig. 50)) that these varieties of shape exist, it is not so evident- to the present writer, at least--that they are of such practical importance as to make it certain that the tools were intended to serve different purposes. It should however be noted that $\mathrm{M}$. d'Acy, possessor of a great collection of Palaeolithic remains ${ }^{3}$ (now happily

1 A writer in the fournal of the Anthropolngical Institute once suggested that the names "erans" and "prestwich" should be given to certain types of flint implements, in honour of the eminent bearers of those names. But there are other and more satisfactory wavs of bestowing upon them the honours which they deserve; and the names given to ancient implements should be such as to tell the reader something about those implements.

${ }^{2}$ L. Capitan, "Les divers instruments chelléens et acheuléens compris sous la dénomination unique de coup-de-poing" (L'Anthr. XII. [1901], p. I г ; C.A.P.A. Paris [1900], p. 55).

3 E. d'Acy, "Sur l'emmanchement des silex taillés du type généralement connu sous le nom de type de Saint-Acheul ou de Chelles" (B.S.A.P. ser. III. vol. x. [1887], pp. $15^{8}$ ff. 219 ff. esp. p. 163). 

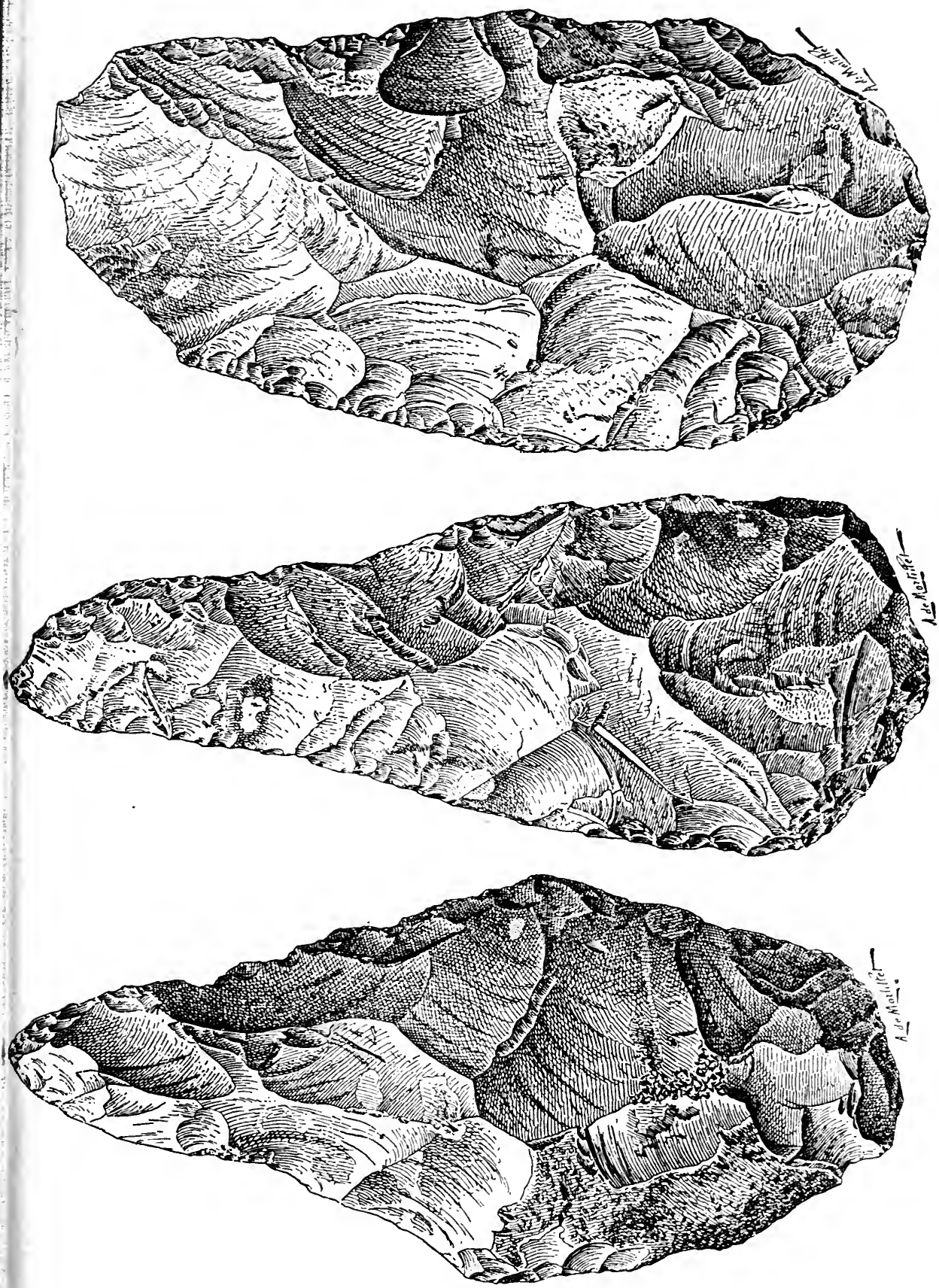
housed in the Museum of Saint-Germain), and M. Salomon Reinach ${ }^{1}$ have also expressed a belief in the variety of purposes as well as of types of coups-de-poing. On the other hand, M. Martial Imbert, during the discussion at the Prehistoric Congress on M. Capitan's paper, made the sensible remark that "certain instruments made in the same year in the north and in the south of France and intended for the same use may present different forms, this difference being nothing but the result of local difference in technique ${ }^{2}$." To this it may be added that the productions of different workmen in one and the same place, or even of one single workman in varying conditions of health, or of tractability of materials, will display a considerable amount of variety.

Though a coup-de-poing is thus to be treated as one and the same tool whatever its shape, the excavations of Commont afford reason to believe that there is a chronological importance in the diversities of shape, as we shall presently shew.

The length of a coup-de-poing is usually about ro-12 centimètres, but specimens have been found up to as many as $37 \mathrm{~cm}$. in length. G. de Mortillet has given ${ }^{3}$ a long list of specimens of coupsde-poing of different sizes and weights, great and small. The heaviest specimen in this catalogue weighs 2.04 kilogrammes. $\mathrm{Mr}$ Worthington Smith ${ }^{4}$ mentions an Indian example, in quartzite, weighing $2 \cdot 83$ kilogrammes; this must go near to being the record weight.

The blunt end of the tool is usually adapted for grasping in the hand-as is implied by the name which has been attached to it: Most frequently the calcareous skin of the nodule has not been chipped away, as though to avoid too great roughnesses that might hurt the palm; and, in some cases at least, the butt seems to have been chipped with the express purpose of accommodating the thumb on one side, the fingers on the other ${ }^{5}$. There is, however, a much less proportion of the calcareous coating left on Chellean tools than on Pre-Chellean. There is no reason to suppose that these tools were mounted in a wooden handle of any kind; many of them are so thick that the handle would have to be of an unmanageable size to avoid splitting.

The coup-de-poing is hardly to be called a weapon. Rather is

${ }^{3}$ Alluvions, p. 92.

2 I was myself much interested some time ago, when walking through a town in the heart of Ireland with an English friend, a stranger to the country, to note what a large number of variations in tools, carts, and other objects of common use he observed, from the corresponding objects to which he was accustomed at home.

${ }^{3}$ Préhist. part iI. chap. i.

4 Man, the Primeval Savage, p. 1 .

5 See Commont, in L'Anthr. xix. [1908], p. 547. 
it a tool, combining within itself the functions of axe, scraper, borer, knife, and saw. The weapons used by the owners of coups-de-poing were most likely either unworked stones thrown by the hand, or else massive wooden clubs.

Although the coup-de-poing thus served a variety of purposes, and was doubtless the most important implement of the Chellean stage, it is not to be supposed that it was the only tool in use at the time. The too dogmatic statement to this effect, made in the earlier days of prehistoric science, should no longer be repeated, in the light of present knowledge. In fact, the most serious objection to the subdivision of the Palaeolithic period, proposed by G. de Mortillet, is that it is too exclusively founded on the exceptional, "show," objects to be seen in museum cases, and neglects the more commonplace and less easily identifiable implements, which probably formed the majority of the tools at all periods.

Flakes, perhaps accidentally produced in the first instance, and afterwards worked more or less, with intention, come to light in most Chellean stations. Such amorphous implements can hardly be classified. But besides these, there are others, of well-defined form: a selection of such implements, from Saint-Acheul ${ }^{1}$, is given in Fig. 52. They include the following types:

I. Borers. These are varieties of the coup-de-poing, differing from the normal form in being smaller, and in having the point drawn out in a sort of narrow spike, instead of being a regular triangle with a rather wide base, as in the normal form. See Fig. $5 \mathrm{I} a$.

- 2. Scrapers. Flakes of different shapes, touched up along one or more edges, in order to make them serviceable, probably for dressing hides by scraping the inner surfaces clean. Scrapers present a large variety of shape, depending primarily on the shape of the flake from which the implement is made; specimens will be seen in Fig. $5^{\mathrm{I}}$, $b, c, d$.

3. Knives. These are flakes with one straight edge, sharpened by touching along one edge. The back is blunt, so as to make it more easily grasped. See Fig. $5^{\mathrm{I}}, e, f^{1}, f^{2}$; the last shews how the knife was held. Commont in his paper figures one knife which was evidently intended to be grasped with the left hand.

4. Pointed instruments. These were probably meant for boring holes, or for cutting wood or hide by scratching with the sharp point. There are a number of varieties; examples will be seen in Fig. $5^{\mathrm{I}}$, $g, h, k$.

When flint was not available, other stones were pressed into the service, though none was so useful or so easily worked as flint.

1 After Commont, L'Anthr. xix. [1908], p. 527 ff. 
Still, characteristic Chellean tools, especially coups-de-poing, are known in chert, sandstone, quartz, quartzite, and other stones.

There seems to be some reason to suppose that the use of personal ornament began in Chellean times. We may use the term, though such early ornament is doubtless to be regarded as having a magical rather than an aesthetic virtue. Be that as it may, in an interesting

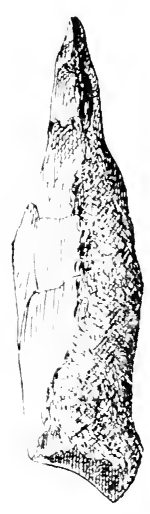

$a$

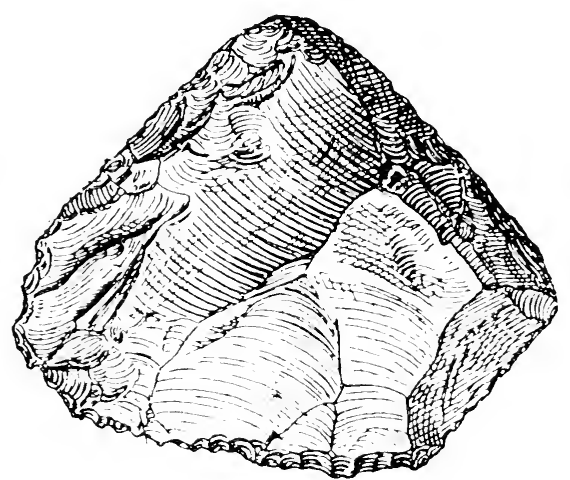

$b$
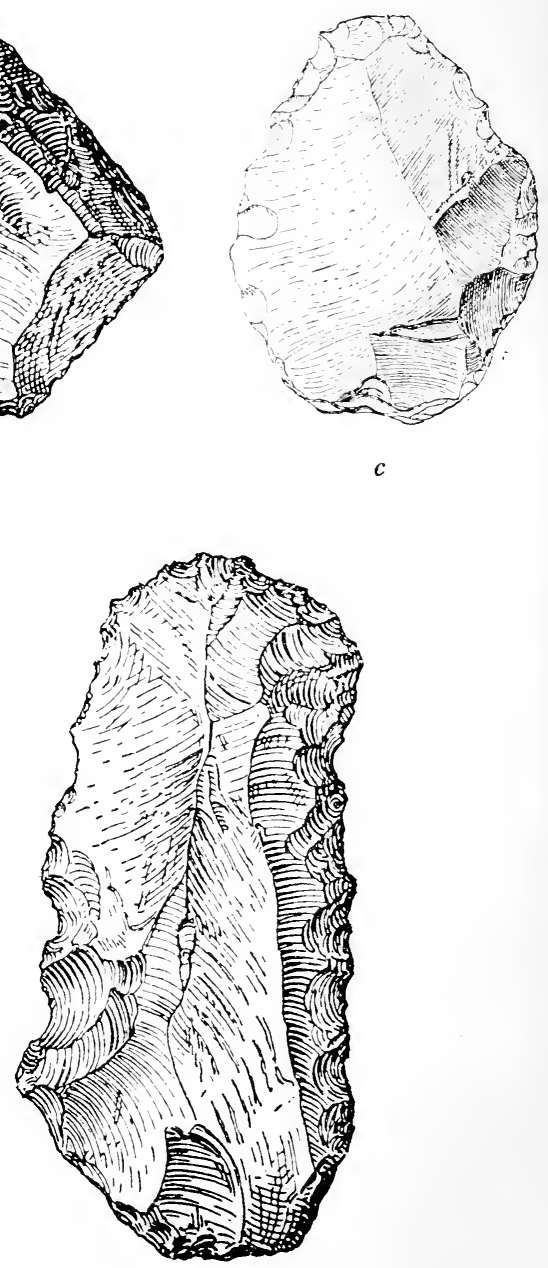

$e$

Fig. 51 (A). Miscellaneous Chellean inplements other than the coup-de-poing.

(From L'Anthropologie, vol. xIx.) 


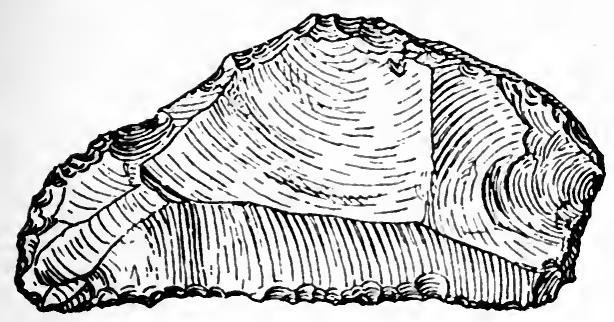

$f^{1}$
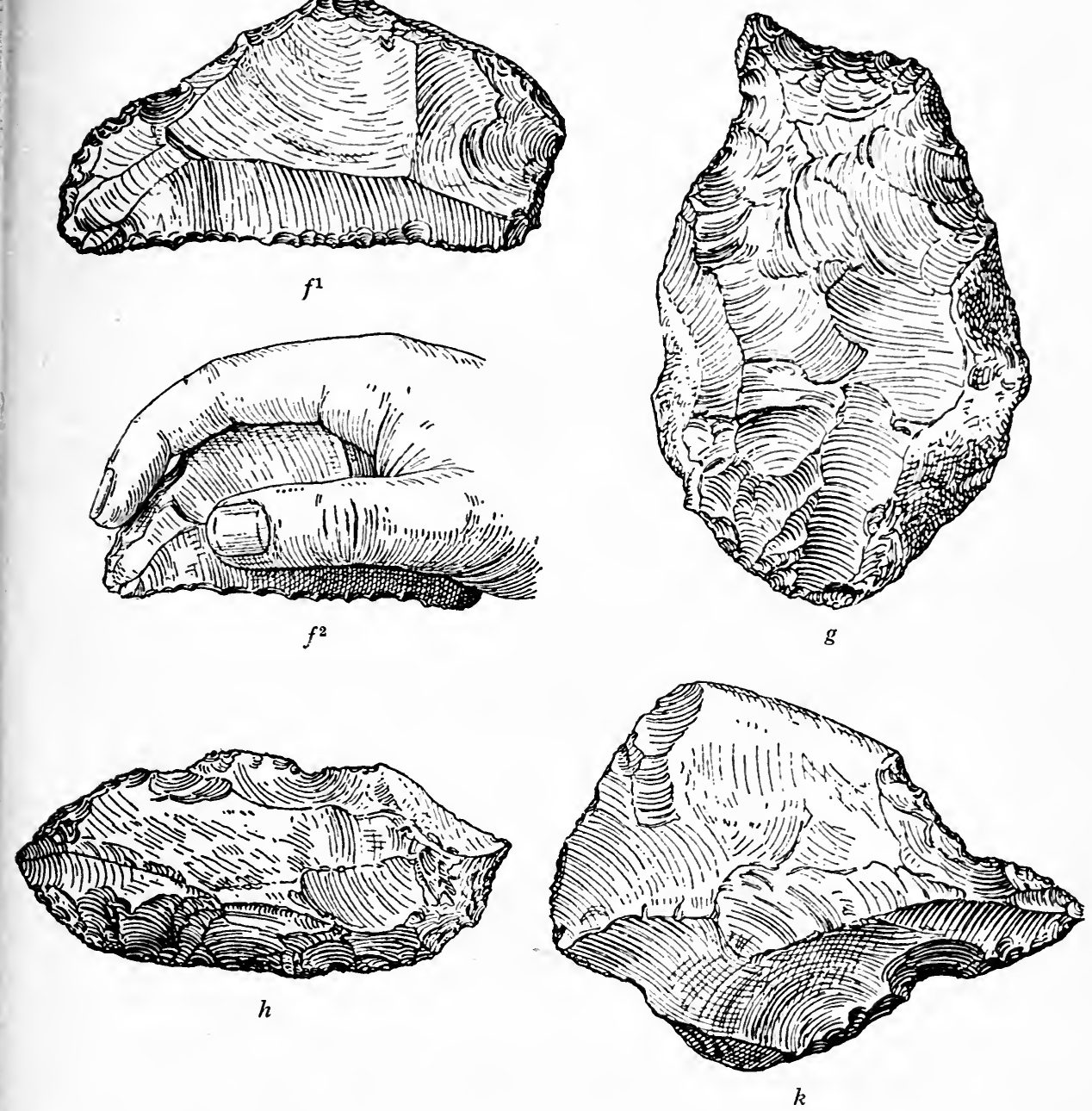

Fig. 5I (B). Miscellaneous Chellean implements other than the coup-de-po.n.

(From L'Anthropolngie, vol. xıx.)

paper $^{1}$ Dr Ballet of Paris describes a number of perforated flakes of flint, pebbles, and recent or fossil shells, found by himself in Chellean or Acheulean gravels. The perforations have all the appearance of having been made with intention (see Fig. 52), and it is hard to imagine any other purpose than that of suspension, either singly or with others as a collar. The idea was not improbably suggested by the finding of naturally perforated nodules of flint, which are p. 96).

1 "La parure aux époques paléolithiques anciennes" (B.S.P.F. xII. [1915], 
very common, and which might well awake the attention and wonderment of a primitive man.

The Acheulean stage derives its name from Saint-Acheul, the place to which we have already had occasion to refer more than once. It is, indeed, one of the classic sites for the study of Palaeolithic man, and has been so ever since 1853 , when Rigollot, one of Boucher de Perthes' chief opponents, was won over to his side by making similar discoveries for himself in the gravels of the river Somme.

Acheulean implements belong to the same general type as Chellean, but in detail they shew noteworthy points of difference. They are
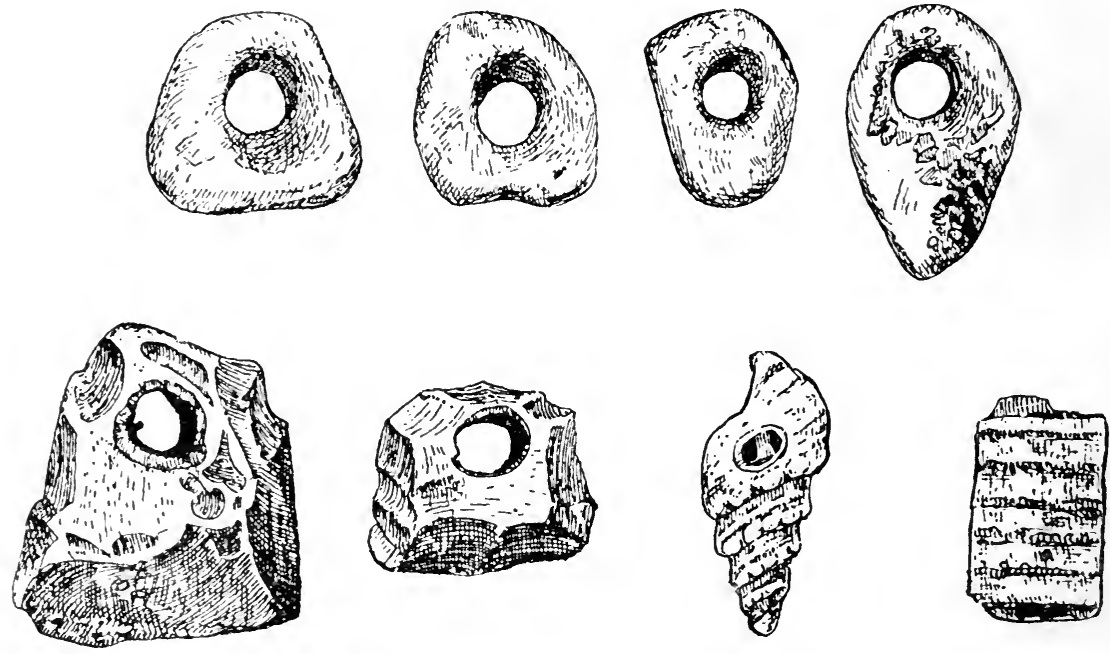

Fig. 52. Chellean ornaments made of pebbles or shells.

(From Bulletin de la Société préhistorique de France, vol. XII.)

on an average of rather a smaller size than are the Chellean coupsde-poing. They are also more skilfully and artistically made, and are brought to a more regular shape, the flakes being struck more judiciously from the nodule. The edges of the tool are consequently not irregular in their lines, as is almost always the case in Chellean tools, but are either straight or gracefully curved in screw fashion (Fig. 53). Acheulean coups-de-poing are amygdaloid (lozengeshaped), oval, or triangular.

Comparison between coups-de-poing found in different strata at Saint-Acheul indicates that the tool passed through certain transformations in shape as civilisation and technical proficiency advanced. The following is a synopsis of the varieties (Fig. 54). 

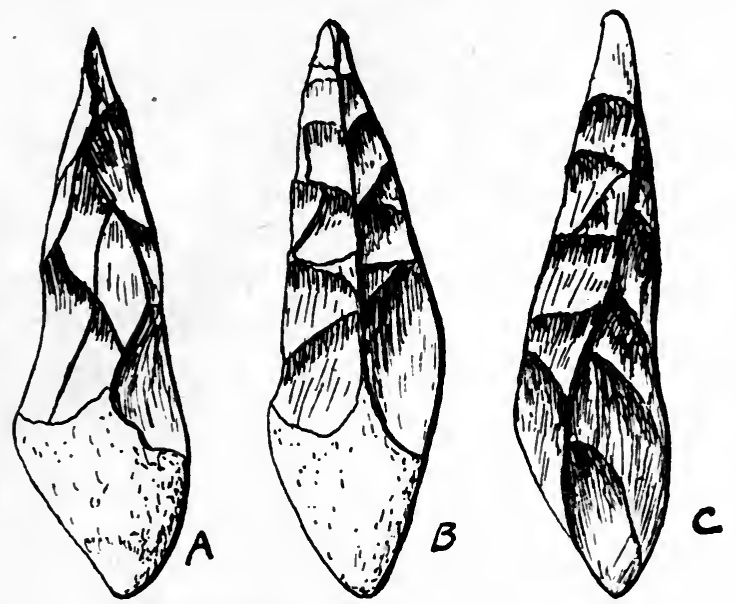

Fig. 53. Contrast between Chellean $(A)$ and Acheulean $(B, C)$ coups-de-poing.

Pre-Chellean. Rude tentative experiments.

Chellean. (a) Triangular with thick rounded butt; a portion of the calcareous incrustation left on the butt as a rule, for convenience in grasping (Fig. 54 a).

(b) Long pointed tools with concave sides. For this type M. Commont has adopted from his workmen the name ficron, primarily given by boatmen to the iron shoe of a barge-pole (Fig. $54 b)$.

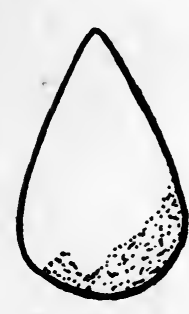

$a$

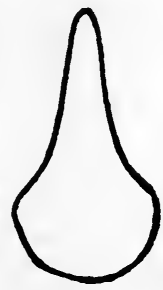

$b$

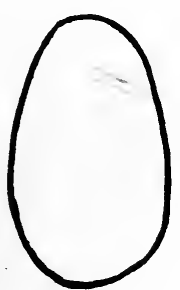

$c$

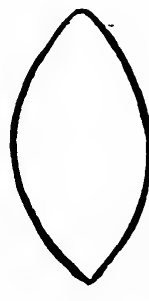

$d$

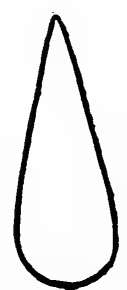

$e$

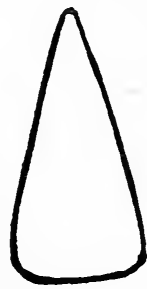

$f$

Fig. 54. Outlines of types of coups-de-poing.

End of Chellean. Triangular, resembling (a) above, formed with large coarse flaking.

Early Acheulean. Oval forms, the greatest thickness of the tool being towards the middle, not at the butt as in the Chellean. The ends may be rounded (Fig. $54 c$ ) or pointed (Fig. $54 d$ ). The latter form is sometimes called limande (literally "dab" or "flat-fish"). Later, triangular or oval tools with screw edges appear.

Late Acheulean. Long narrow triangular implements (Fig. $54 e$ ). 

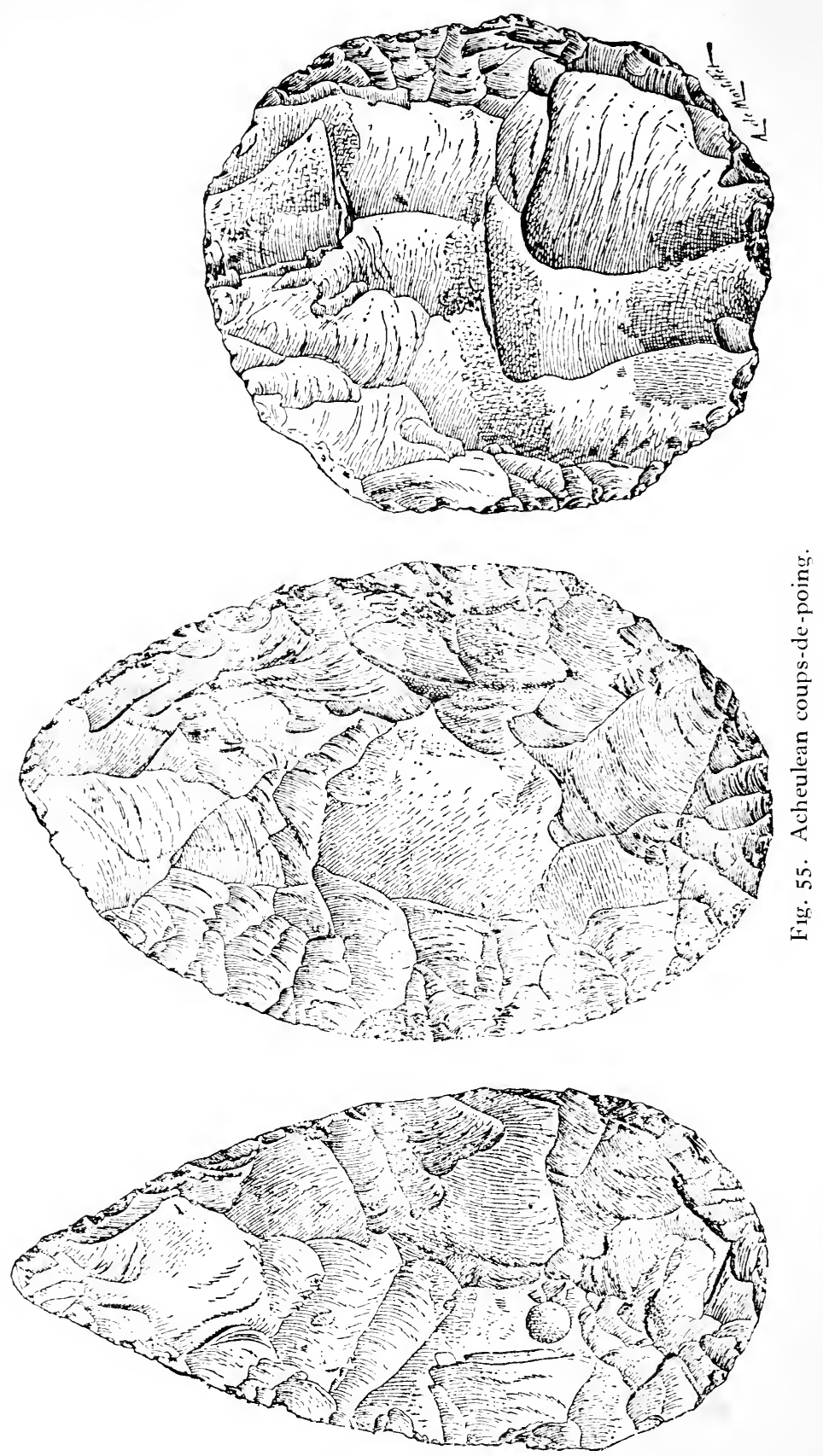
End of Acheulean, transition to Mousterian. The small type of La Micoque, triangular, often with secondary chipping along one side only. Also, large triangular forms, with straight base (Montières type, Fig. $54 f)^{1}$, which appear already in the end of the Chellean.

Along with the coups-de-poing we find many flint flakes in Acheulean deposits, as in Chellean, products of manufacture formed in making coups-de-poing, with secondary chipping adapting them to serve whatever purpose their accidental form suggested. Some, with long blunt edges, would have been useful for scraping and cleaning the hides of slaughtered beasts; others, with long sharp points, would serve as piercers for making thread-holes, so as to enable hides to be sewn together-the tendons of animals supplying the place of thread. It is, however, noteworthy that, except such accidental products of flint manufacture, which are hardly capable of classification, there are comparatively few varieties of tools found in Acheulean deposits; not so many, indeed, as appear to exist in Chellean strata. The reason probably is that the improvement in the manufacture of the coup-de-poing made it more and more the universal tool ${ }^{2}$.

Circular discs, trimmed like coups-de-poing and probably simple varieties of that tool, are found in some Acheulean stations: see No. 3 of Fig. 55. Implements resembling one-half of such discs are not infrequent. They are sometimes called "choppers" in English books; a good example, from Stoke Newington, is figured in Worthington Smith, Man, the Primeval Savage, p. 230.

Sometimes Acheulean coups-de-poing are seen to be old Chellean tools re-trimmed. This fact is betrayed by the disturbance of the old patination, as in the tool illustrated in Fig. 6, p. 51 ante.

The transition from Lower to Middle Palaeolithic is marked by the introduction of two important types of implements; the miniature coup-de-poing or scraper of La Micoque, and the Levallois scraper (Fig. 56).

The Acheulean station of La Micoque is situated in the valley of the river Vézère, of which we shall hear more in the following chapter ${ }^{3}$. The excavation of this settlement produced a number of

1 For another classification, differing to some extent in detail, see Th. Baudon, "Essai de classification des coups-de-poing Acheuléens" (C.P.F. Autun [1 907], 97).

2 For a classification of the minor implements of the Lower Palaeolithic Term see H. Obermaier, "Die Steingeräte des französischer Altpaläolithikums; eine kritische Studie über ihre Stratigraphie und Evolution" (Mittheil. d. prähist. Kommission der kais. Akad. der Wissensihaften Wiens, II. [1908]).

${ }^{3}$ L. Capitan, "La station acheuléenne de La Micoque" (R.E.A. vi. [1896], p. 406); G. Chauvet and E. Rivière, "Station quaternaire de La Micoque, Dordogne" (A.F.A.S. Saint-Etienne [1897], vol. II. p. 697); L. Capitan, "Nouvelles fouilles à La Micoque" (Revue préhistorique, II. [1907], p. 1). 

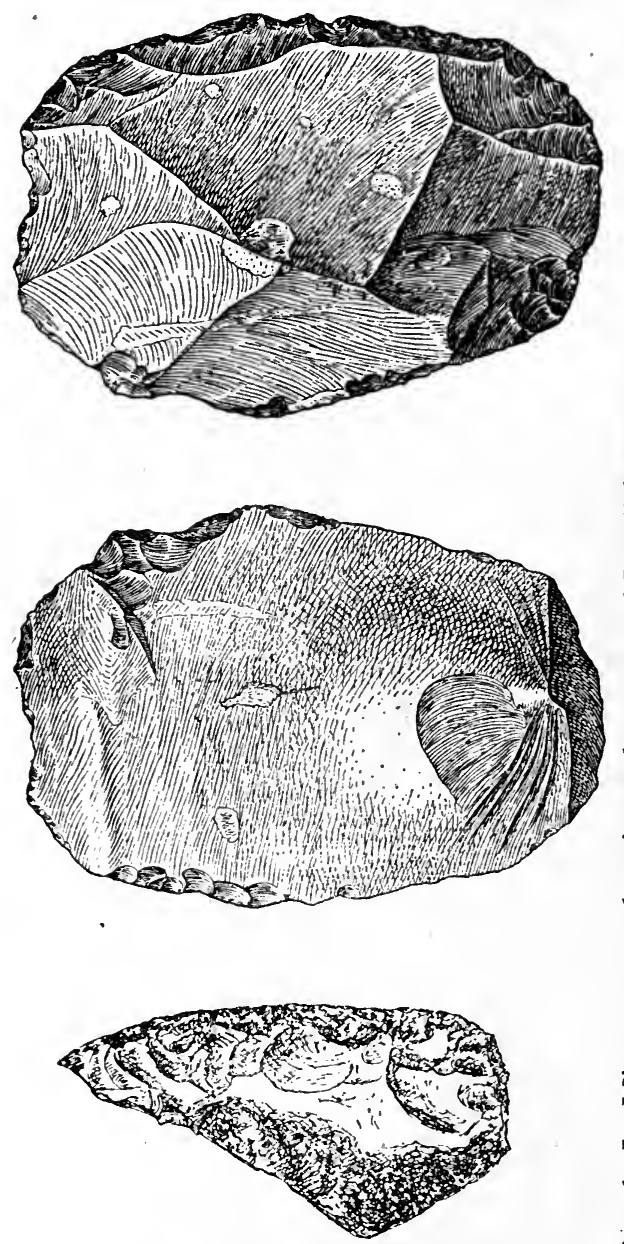

苛

ชั

4

สี

मे

莺. 연

을

들

岁 임

ฐ

व $\dddot{4}$

$\pi>$.

.

$\circ$ 중

它造

ठ ㄷㅇ

\&

茟

$\sum$ 证

ฐ

in

. $\sum$

祘

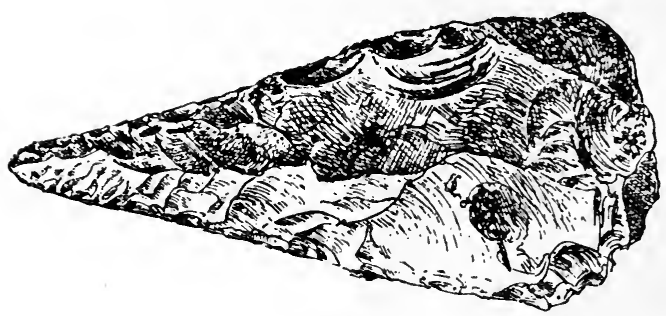

告 
Acheulean implements of the ordinary form; but the coups-de-poing were notably smaller than in the classical type (Fig. 56, No. I). An intermediate station between the full Acheulean and La Micoque is that of La Vignole ${ }^{1}$, also in the Vézère Valley, where there were abundant coups-de-poing, smaller than the ordinary Acheulean, but larger than those of La Micoque. At the latter site there was found in addition a kind of pointed scraper, about $5^{-7}$ centimètres in length, triangular in shape, and as a rule having secondary chipping along one side only (Fig. 56 , No. 2 ).

The Levallois scraper (Fig. 56, No. 3), so called from its frequency at Levallois-Perret near Paris, is especially characteristic of the Mousterian of Northern France, appearing first in the transition between Acheulean and the following Mousterian stage. This tool is a flake struck from the nodule with a skilfully directed blow, the result of which is that the face of the flake on the inner side is smooth and shews the bulb of percussion. On the outer side the edges are trimmed with chipping, so as to adapt the flake for the purpose of scraping the inner surfaces of hides. In making such a tool, the outer side was prepared before the flake was disengaged from the nodule; this is shewn by unfinished specimens which have been found in the sites of flint-factories.

\section{(5) The Lower Palaeolithic in the European Regions}

We now proceed to describe the nature of the Lower Palaeolithic discoveries that have been made in the different regions of Europe. By reference to the end of Chapter II, the reader will find a list of these, and will see which regions are omitted from the following enumeration, and the reasons for such omission. Only those regions are included in which important discoveries have been made.

\section{Region III. Italy and Sicily}

Typologically the Pre-Chellean, Chellean, and Acheulean stages are all represented in Italy, but without the clear stratification which makes their relative dating comparatively simple in France. Indeed, it is not absolutely certain that all the apparently Palaeolithic implements which have come to light from time to time in Italy are really to be assigned to so remote a date, however probable this may be. The Lower Palaeolithic people of Italy were certainly less progressive than were their brethren of north-western Europe; they never succeeded in attaining to the artistic perfection that we may see in the best Acheulean of France.

1 L. Capitan, "La station acheuléenne de la Vignole, vallée de la Vézère, Dordogne" (B.S.A.P. ser. Iv. vol. viII. p. $\mathrm{r}_{3} \mathrm{O}$ ). 
Very rude specimens of the coup-de-poing, comparable with the Pre-Chellean of Saint-Acheul and Strépy, have been found in the Upper Terraces of the Tiber in Perugia ${ }^{1}$. G. A. Colini ${ }^{2}$, following Bellucci ${ }^{3}$, classifies the coups-de-poing of Italy into two types, according as the greatest thickness of the implement is at the butt or nearer the middle of the tool. Of the first group there are two varieties, the one wedge-shaped with broad rounded top, the other triangular with pointed top; and as in the French and British examples, the butt is often left more or less unchipped, to facilitate grasping. Those of the second type are as a rule oval in shape, and are better made than the first: the typical Acheulean screw-edge appears in some cases. In both the main types the two sides have not always the same convexity; usually one side is markedly convex and the other more or less plane.

Besides these principal varieties, which may be the result of intention, Colini describes and figures in his very fully and admirably illustrated paper, quoted in the footnote, a number of individual specimens whose peculiarities are more probably the result of bungling on the part of the workman. Such are unsymmetrical specimens, with one edge concave, the other convex: or specimens with one side so hollowed that the axial plane of the tool is curved. In some specimens there is a certain amount of secondary chipping to be seen at the edges; and there is as great a variety of size in these implements to be seen in Italy as in France.

Colini's primary classification corresponds to the distinction between Chellean and Acheulean; but the stratification is by no means as clear as we could wish. There does not appear to be any evidence of the relative date of these types at present available in Italy, and we can only suppose by analogy that the instruments of Acheulean facies are later than are those of Chellean form.

With regard to the geographical distribution of these implements in Italy, they appear to occur most frequently in La Marche and gli Abruzzi ${ }^{4}$. The Vibrata Valley, in gli Abruzzi, has yielded a large number of the ruder forms, though without any clear stratification; for the beds in which they are found are comparatively recent

1 A. Mochi, "La succession des industries paléolithiques et les changements de la faune du Pleistocene en Italie" (C.A.P.A. Geneva [I912], vol. I. p. 255); see also Pompeo Castelfranco, "Age de la pierre en Italie" (Revue d'Anthrop. xvir. [1889], p. 573).

2 G. A. Colini, "Le scoperte archeologiche del dott. C. Rosa nella valle della Vibrata e la civiltà primitiva degli Abruzzi e delle Marche" (Bullettino di paletnologia italiana, xxxII. [1906], 125: continued for later periods in following volumes).

${ }_{3}$ Materiali paletn. della provincia dell' Umbria, p. I ff. plates i.-vi.

${ }_{4}^{4}$ Colini, op. lauil. p. I37. 
denudation deposits, and Chellean and Mousterian types are found within them in close association. We have just mentioned similar tools, with perhaps an even ruder facies, from Perugia. Umbria and Capri, also, have yielded rude coups-de-poing ${ }^{1}$, associated with the remains of such fauna as Rhinoceros mercki, Hippopotamus, and Elephas antiquus; with them were many scrapers, knives, borers, and
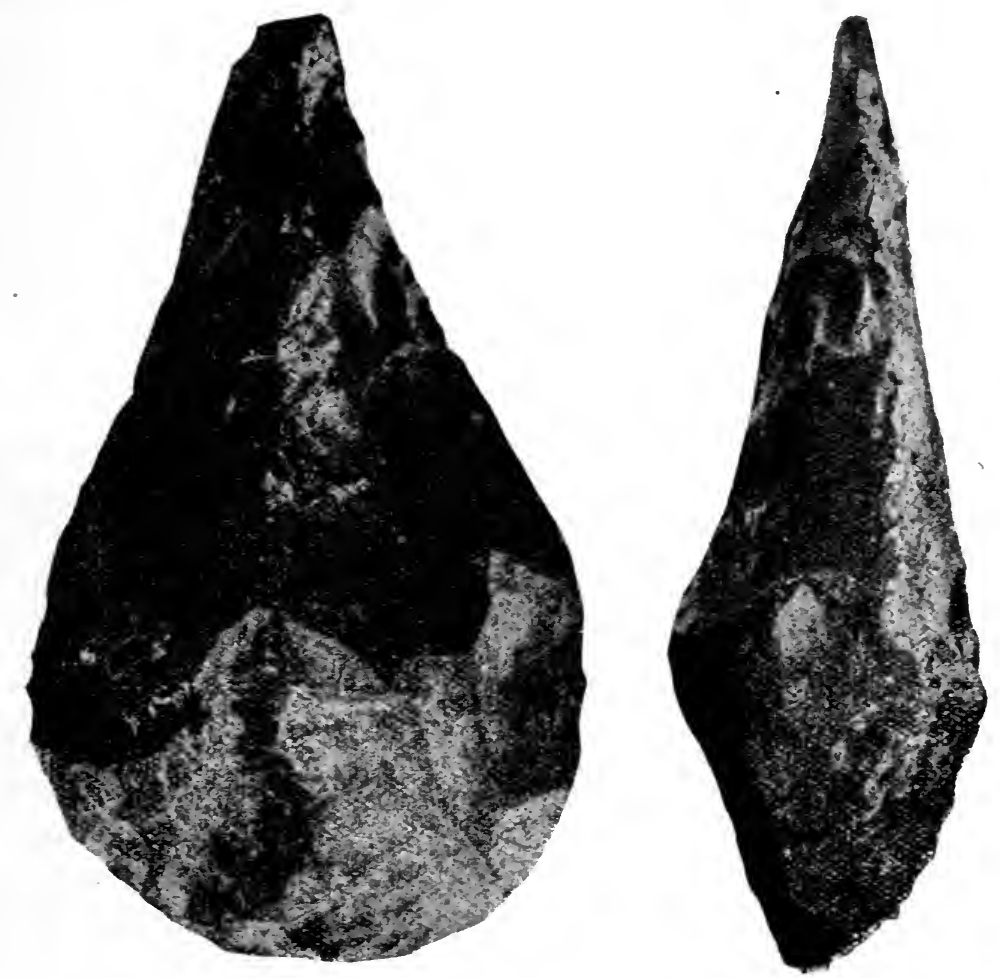

Fig. 57. Acheulean coup-de-poing from Venosa.

(From Bullettino di paletnologia italiana, vol. xxvrr.)

similar tools, such as are found in Chellean gravels in France associated with coups-de-poing. The material for these implements does not exist naturally on the island of Capri, but must have been carried into it artificially at a time when it was joined to the mainland ${ }^{2}$.

Better-made implements have been found at La Majella, near Chieti. They are comparable with the Acheulean in type, but their stratigraphy is uncertain ${ }^{3}$. The province of Emilia has also yielded

1 Colini, op. laud. p. I5 1 .

2 Mochi, op. laud. See also "Strumenti 'chelléens' dell' isola di Capri" (Bull. di paletn. ital. xxxvr1. [1912], p. 57).

3 Colini, p.r39; Mochi, op. laud. 
numerous implements of Lower Palaeolithic type. Others have been found at Viacupa in Siena ${ }^{1}$, and at Benevento ${ }^{2}$.

They are, however, rare in the north of the peninsula, and not very common in the south; the principal sources of supply in the latter part of the country are the Gargano peninsula and the neighbourhood of Venosa, in the province of Basilicata (Fig. 57) ${ }^{3}$. These are of the ruder types. In Sicily Lower Palaeolithic implements are extremely rare ${ }^{4}$.

\section{Region V. Liguria and Southern France}

This is one of the most important of the Palaeolithic regions of Europe. It includes the departments containing the river-system of the Garonne, with their wonderful archaeological wealth. It also includes the Mentone caves. These latter we describe in a later chapter, in order to be able to set forth their instructive stratification all at once.

The Lower Palaeolithic is, however, less fully represented in this region than are the later stages. It is intelligible that such parts of it as were covered and ground down by the glaciers of Auvergne should not possess any pre-glacial archaeological remains, just as is the case in Switzerland. It would appear, indeed, that during Chellean times the south of France was a dry and barren desert. P. Sarasin has made very ingenious comparisons between the flint nodules coming from strata corresponding to this stage and those found in the modern deserts of Egypt; they resemble one another in their dark patina, and in being covered with little depressions, the result of desquamation under a dry heat ${ }^{5}$.

There are accordingly comparatively few Lower Palaeolithic sites of importance in this region. We may mention one or two as examples. At Marignac (Gironde), described by F. Daleau ${ }^{6}$, there was a succession of strata which may thus be summarised:

$D$. Neolithic; vegetable soil and gravels, re-sorted. 0.50 mètre thick.

C. Mousterian with the characteristic "points" (see following chapter), worked on one side only. Fine sand, I mètre thick.

1 Bull. di paletn. ital. xxxvirr. [1912], p. 180.

2 Ibid. xxxv. [1910], p. 40.

3 A good specimen (Chellean) from Venosa is figured in Bull. di paletn. ital. XL. [1914], p. 185. See also ibid. xxxv. [1910], p. 40; xxxvIr. [1911] p. 146.

4 A very thorough account of the Palaeolithic remains in Italy, with many bibliographical references, will be found in the opening chapter of Modestov's Введеніе въ римскую псторію (St Petersburg, 1902) of which a French translation is available (Introduction à l'histoire romaine).

5 P. Sarasin, "Ueber Wüstenbildungen in der Chelléen-Interglaciale von Frankreich" (Verhandl. der naturforsch. Gesellsch. in Basel, xx. [1910], p. 255).

${ }^{6}$ F. Daleau, "Le gisement quaternaire de Marignac, commune de Tauriac, Gironde" (Actes de la Soc. linn. de Bordeaux, Lvin. [1903], p. $32 \mathrm{I}$ ). 
$B$. Acheulean, with small flakes and characteristic Acheulean implements, worked on both faces. Coarse sand with quartz pebbles, 3 mètres thick.

$A$. Chellean with coups-de-poing, worked roughly on both sides. Dark red sand, I mètre thick.

Tertiary gravels underlying.

Déchelette ${ }^{1}$ quotes from the Catalogue of the Museum of Périgueux coups-de-poing of Chellean type found in a sand-pit at Rodas, in the adjoining department of Dordogne; and others have been found in the much-discussed gravels of Tilloux between Jarnac and Cognac (Charente). To these latter we have already alluded, in connexion with the question of the species of elephant represented by the bones and tusks there found. Whatever the true answer to this question may be, there was certainly at Tilloux a very ancient settlement belonging to the Lower Palaeolithic. There were more shapely Acheulean types, mingled with the rude Chellean coups-de-poing, and Mousterian-like scrapers were found in the same gravels. The occupation of the site must therefore have continued over a very long time ${ }^{2}$. A scheme of the stratification, based on data supplied by Capitan $^{3}$, runs as follows:

$H$. Vegetable soil and sand, $0 \cdot 30$ to $0 \cdot 40$ mètre.

$G$. Sand and gravels coloured red with iron oxide, 0.80 mètre.

$F$. Moderately-sized gravel

$E$. Narrow bed of fine sand

$D$. Gravel of small stones

$C-F, 2 \cdot 20$ mètres.

C. Narrow bed of fine sand)

$\left.\begin{array}{l}B \text {. Gravels of moderately-sized stones } \\ A \text {. Narrow bed of fine sand }\end{array}\right\}-B, 0.90-1$ mètre.

Chalk underlying.

According to the results of enquiries made by Capitan among the workmen employed, the elephant tusks and Chellean tools all came exclusively from $A$, and the Acheulean implements from $C$. The overlying strata, up to the topmost, were as a rule completely sterile of implements, but Neolithic flints were found in $H$. Capitan says nothing of Mousterian implements in his report of his investigations. The stratification of Tilloux thus agrees in all respects with that revealed by the investigations of d'Ault du Mesnil and Commont in the Somme valley.

Gabriel de Mortillet has compiled a list of all the departments of France in which coups-de-poing, Chellean or Acheulean, have

1 Manuel d'archéologie, I. 87.

2 M. Boule, "La Ballastière de Tilloux près de Gensac-la-Pallue (Charente)" (L'Anthr. vi. [1895], p. 497).

${ }^{3}$ L. Capitan, "Une visite à la ballastière de Tilloux (Charente)" (R.E.A. v. [1895], p. 380). 
been discovered ${ }^{1}$. The list contains all the departments of the section of France under discussion, with the exception of the following, most of which are in the mountainous regions of Auvergne and the eastern Alps, and were therefore subject to glaciation:

$\begin{array}{lll}\text { Pyrénées Orientales } & \text { Var } & \text { Loire } \\ \text { Aude } & \text { Haute-Vienne } & \text { Isère } \\ \text { Hérault } & \text { Puy de Dôme } & \text { Haute-Savoie } \\ \text { Gard } & \text { Haute-Loire } & \text { Savoie } \\ \text { Bouches de Rhône } & \text { Lozère } & \text { Hautes-Alpes }\end{array}$

In his Musée préhistorique he figures specimens from the departments of Vienne (Leugny) and Corrèze (Chez Pouré) ${ }^{2}$.

\section{Region Vi. The Iberian Peninsula}

Recent archaeological activity has raised this region to one of foremost importance in Europe. Almost all the stages of Palaeolithic culture have been found to be represented, and the discoveries made within the past few years are an earnest of yet more surprising discoveries to be made in the near future.

The Pre-Chellean industry appears so far to be absent, though the very rude implements discovered at Torralba have been described as belonging to that stage. It would appear, however, that their rudeness and comparative formlessness are to be ascribed to the intractable nature of the materials in which they are made, rather than to the undeveloped skill of their makers.

The Torralba site, is, indeed, by far the most important Chellean site hitherto discovered in the peninsula. Its excavation is the work of the Marqués de Cerralbo ${ }^{3}$. It lies on the slope of the Sierra Ministra, at a height of I I I 2 mètres above the level of the sea. The place is situated on the borders of an ancient lake, now dry; and according to its discoverer, its fauna included Elephas meridionalis, Elephas antiquus, Rhinoceros etruscus, and Equus stenonis. The identification of the two latter animals depends on minute fragments or teeth only; that of the first-named on a series of magnificent tusks, some of them over 3 mètres in length. The bones of these animals were scattered, and not in connexion with one another; we evidently have to deal with the piles of kitchen débris left by the ancient human inhabitants.

The identification of Elephas meridionalis would evidently be of the most momentous importance if it could be sustained, as the

1 Préhist. part vi. chap. i.

2 G. and A. de Mortillet, Musée préhistorique (Paris, $\mathrm{x} 88 \mathrm{r}$ ), plate x.

3 Marqués de Cerralbo, "Torralba, la plus ancienne station humaine de l'Europe?" (C.A.P.A. Geneva [1912], vol. I. p. 277). 
early disappearance of that animal from Europe would necessitate our assigning a very early date to human remains found in association with it. The Marqués de Cerralbo has not suggested its identification without full realisation of its gravity. But later authorities who have examined the remains regard them rather as being those of Elephas antiquus, though of specimens of that animal unusually large ${ }^{1}$.

The industry associated with these animal bones consists of rude coups-de-poing, made of hard limestone, chalcedony, quartzite, and flint-the last-named material being exceptional. All these stones must have been carried to the station from a distance of several kilomètres, as they do not occur naturally in the locality. They are of the ordinary Chellean form, but so rudely shaped that, as has just been said, they were at first called Pre-Chellean.

Next in importance to the station of Torralba comes that of San Isidro, near Madrid. Here, in the gravels of the river Manzanares, was a stratum containing the remains of elephants, and Chellean implements (coups-de-poing) associated with them. The San Isidro gravels were a subject of much contention at one time, for they were used in an attempt to upset the Mortillet scheme of Palaeolithic evolution, or at least to shew that it was not applicable to Spain; the Baron de Baye in two communications to the Paris Société d'Anthropologie produced Chellean, Mousterian, and even Solutrean types from these gravels, found intermingled in one and the same stratum ${ }^{2}$. G. de Mortillet answered this argument by pointing out that the flints in question were discovered by workmen digging gravel, and that his opponent had only their word for the positions in which they were found. The Baron answered by asserting the absence of definite stratification in the gravels, an assertion which he substantiated by means of photographs. But more recent investigation of the gravels, or, rather, of the few remains of them which the diggers have left, has tended to shew that they were elaborately stratified, and that the Chellean remains were confined to one definite layer, above which was another containing excellent Acheulean coupsde-poing. It is now denied that there is any real evidence of the presence of Middle or Upper Palaeolithic at San Isidro at all ${ }^{3}$.

Other sites of less importance which have yielded Chellean implements are Puente Mocho, on the banks of the river Guadalimar, Posados in Cordoba, and La Janda in Cadiz 4

The Acheulean stage is more widely represented in Spain than

'1 See Obermaier, El Hombre Fósil, p. I6o.

${ }^{2}$ B.S.A.P. ser. Iv. vol. Iv. [1 893], pp. 274, 391.

3 Obermaier, El Hombre Fósil, p. $192 \mathrm{ff}$.

"See H. Breuil, "Stations chelléennes de la province de Cadix" (Comptes rendus des séances de l'Inst. franç. d'Anthropologie, vol. iI. p. 67). 
the Chellean, but the stations are of less importance. With the possible exception of the Acheulean stratum of San Isidro, just mentioned, and the Acheulean stratum in the cave of Castillo, there is no Acheulean station of significance comparable with the Chellean station of Torralba. The cave of Castillo is more fully described in Chapter IX of this book, in connexion with the wall-paintings which it contains; we need therefore say no more here than that there is an Acheulean layer, with coups-de-poing associated with bones of Cervus elaphus and Rhinoceros mercki underlying the great series of stratified débris covering its floor. Other sites, which have yielded Acheulean remains-chiefly coups-de-poing in quartz, found lying
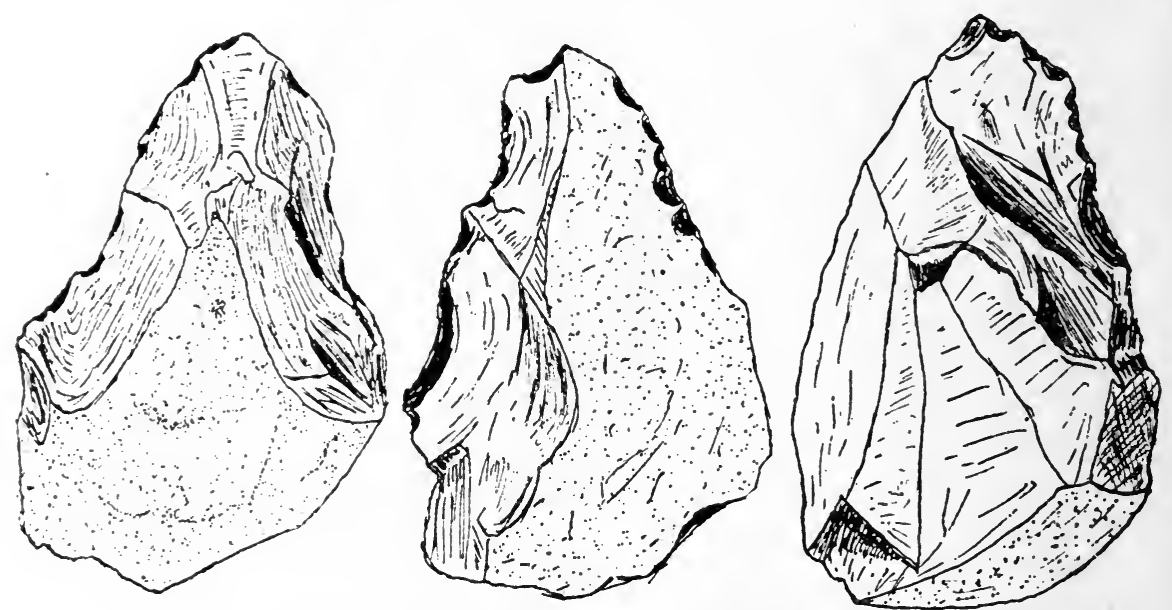

Fig. 58. Coups-de-poing from Casal do Monte.

(From Bulletin de la Société préhistorique française, vol. Ix.)

on the surface of the ground-are Astillero, near Santander; San Felice de Buelna, Santander; Panes, Asturias; Soto de las Regueras, Oviedo; and the cave of La Palomba, near the last-named site.

In Portugal both Chellean and Acheulean remains have been found, but in small quantities and of inferior workmanship. The cave of Furninha in the peninsula of Peniche, north of Lisbon, has yielded a Chellean coup-de-poing. The stratum containing this object also contained a small and unfortunately very indefinite fragment of a child's jaw, as well as bones of hedgehog, bat, several species of bear, badger, fox, wolf, Mustela and Hyaena; hardly a very instructive fauna. There were two strata underlying that containing these deposits, the upper of which contained some rude flakes; and four strata overlying it, which carried the history of the 
cave on to the Neolithic, to which the remains in the uppermost strata belonged ${ }^{1}$.

Some rude coups-de-poing, of small size, have been found at Casal do Monte near Lisbon ${ }^{2}$ (Fig. 58). In these, as in most of the Portuguese specimens of this type of instrument, there is a large proportion of the calcareous surface of the nodule left untrimmed; and one of the specimens here illustrated is an example of the type in which one edge is unchipped, the operation being confined to the other. It is rare to find Portuguese coups-de-poing chipped all over. The shapes of this implement favoured in Portugal are rounded or triangular. The Casal do Monte flints, by their rudeness, might be called Chellean, but their discoverer prefers to ascribe them to the Acheulean, on account of the presence of secondary chipping. Other Portuguese sources of coups-de-poing are Alcantara ${ }^{3}$ (probably Acheulean), and the gravels of Mealhada ${ }^{4}$ north of Coimbra.

\section{Region VII. Northern France and Belgium}

This is one of the richest regions in Lower Palaeolithic remains. The deposits of the valleys of the Marne and of the Somme, thanks to the care with which they have been investigated by devoted and competent workers, are of especial importance.

The Somme valley, the scene of the pioneer labours of Boucher de Perthes, has become classic in recent years by the long-continued work of Prof. V. Commont, especially at Saint-Acheul, Abbeville, and Montières. The stratified gravels on the river-terraces have yielded implements of all periods from the beginning to the end of the Palaeolithic period; nowhere in Europe can the evolution of industrial types be so completely studied. The following attempt to present a brief consecutive account of the course of development in the Somme basin is based upon M. Commont's numerous papers ${ }^{5}$.

1 Joaquim F. N. Delgado, "La grotte de Furninha à Peniche" (C.A.P.A. Lisbon [1880], p. 207).

" Joaquim Fontès, “Trois coups-de-poing acheuléens du Portugal" (B.S.P.F. Ix. [1 892], p. 522); Idem, Estacão paléolithica do Casal do Monte, Lisbon, 1910 (analysed L'Anthr. xxiv. [1913], p. 508).

3 A. A. da Fonseca Cardoso, "Nota sobre una estação chelleana no valle d'Alcantara" (Revista de sciencas naturaes e sociaes, Porto, I895); Idem, "Sur quelques types inédits de coups-de-poing du Portugal" (C.A.P.A. Geneva [1912], vol. I. p. 35 I).

" Joaquim Fontès, "Station paléolithique de Mealhada" (Communicaşões do serviço geologico de Portugal, xı. Lishon [1905]).

5 Chief among these are the following:

I. "Les hommes contemporaines du renne dans la Vallée de la Somme" (Mémoires de la Société des Antiquaires de Picardie, xxxvir. [1914], p. 207).

2. "Les industries de l'ancien Saint-Acheul" (L'Anthr. xIx. [1908], p. 527).

3. "Industrie des graviers inférieurs de la haute terrasse de Saint-Acheul" (A.F.A.S. Lille [1909], p. 774). 
The modern Somme takes its rise at Fonsomme, above SaintQuentin. It pursues a zig-zag course, running first south-eastward, as far as Ollezy, in a bed parallel with that of the Oise. It then turns almost northward, running in this new direction as far as Péronne; again south-eastward, almost parallel to its first direction, till it reaches Amiens; and thence pursues a straight course north-eastward to the sea. It receives numerous tributaries, the most important being the Ayre, which joins it at Amiens. There is reason to believe that this tributary was originally the main stream, prolonged in the Aisne, which in Tertiary times was captured from the Somme by the Oise.

At the beginning of the Quaternary period the Somme at Amiens flowed at a level which is now 70 mètres above the level of the sea, or 58 mètres above the level of the modern stream. The erosion of the bed was carried out in stages, each marked by a terrace traceable on one side or the other of the valley. The Somme terraces are not so clearly marked as are those of other, larger, rivers, being rather close together; they are also obscured by being covered with later alluvial deposits. But by careful study of the gravels, in pits sunk at various places along the river-course, especially in the neighbour-

4. "Les terrasses fluviatiles de la Vallée de la Somme" (Bulletin archéologique du Comité des traz'aux historiques et scientifiques [191 I], p. I73).

5. "Niveaux industriels et fauniques dans les couches quaternaires de SaintAcheul et de Montières" (A.F.A.S. Toulouse [1910], p. 236).

6. "Les gisements paléolithiques de Saint-Acheul; coupe de quaternaire dans la Vallée de la Somme. Géologie et préhistoire" (A.F.A.S. Clermont-Ferrand [1908], p. 454).

7. "L'industrie de l'âge du renne dans la Vallée de la Somme; fouilles à Belloysous-Somme" (Ibid. p. 634).

*8. "Note sur le quaternaire du Nord de la France, de la Vallée du Rhin, et de la Belgique" (Annales de la Société géologique du Nord, XLI.).

9. "Chronologie et stratigraphie des industries protohistoriques, néolithiques, et paléolithiques du Nord de la France" (C.A.P.A. Geneva [1912], vol. 1. p. 239).

I0. "L'industrie des graviers supérieurs à Saint-Acheul" (R.E.A. I907, p. 14).

I I. "Les découvertes récents à Saint-Acheul: l'acheuléen" (R.E.A. 1906, p. 228).

*I2. "Saint-Acheul et Montières" (Bulletin de la Société Géograph. du Nord, vi. [1909], p. 3).

*I3. "Note préliminaire sur les terrasses fluviatiles de la Vallée de la Somme; époque de l'apparition de l'homme quaternaire" (Annales de la Soc. géol. du Nord, XXXIX. [1890], p. 185).

* I 4. "Note sur les tufs et les tourbes de divers âges de la Vallée de la Somme" (Mém. de la Soc. géol. du Nord, xxxix. [1 890], p. 210).

*I5. "Les gisements paléolithiques d'Abbeville" (ibid. p. 249).

16. "Fouilles récentes exécutées dans la Vallée de la Somme" (Comptes-rendus Acad. des Sciences, CXLVIr. [r908], p. 1084).

17. "Evolution de l'industrie chelléenne dans les alluvions fluviatiles de la Vallée de la Somme" (Revue préhist. vi. [1911], p. 65).

18. "Niveau stratigraphique des industries représentées à Saint-Acheul et à Montières, Somme" (C.P.F. Autun [1907], p. I 15 ).

Also G. d'Ault du Mesnil, "Note sur le terrain quaternaire des environs d'Abbeville" (R.E.A. [1896], p. 284).

To articles marked with an asterisk I have been unable to obtain access, but have perused the analyses given in L'Anthropologie or elsewhere. 
hood of Amiens and of Abbeville, the existence of four terraces has been demonstrated. These terraces are named respectively the 56-mètres, 40-mètres, 30-mètres, and 10-mètres terraces, these being approximately their height above the present river. More shortly they may be named the first, second, third, and fourth terraces. In this book we number all river-terraces from top downwards, in the order of their formation. M. Commont, however, numbers them from bottom upwards.

The deposits upon these terraces fall into two series; the older gravels, which consist of flints washed out of the chalk in the process of erosion, carried down by the stream, and shewing indications of water-rolling; and the later alluvium, deposited on the terraces at later periods.

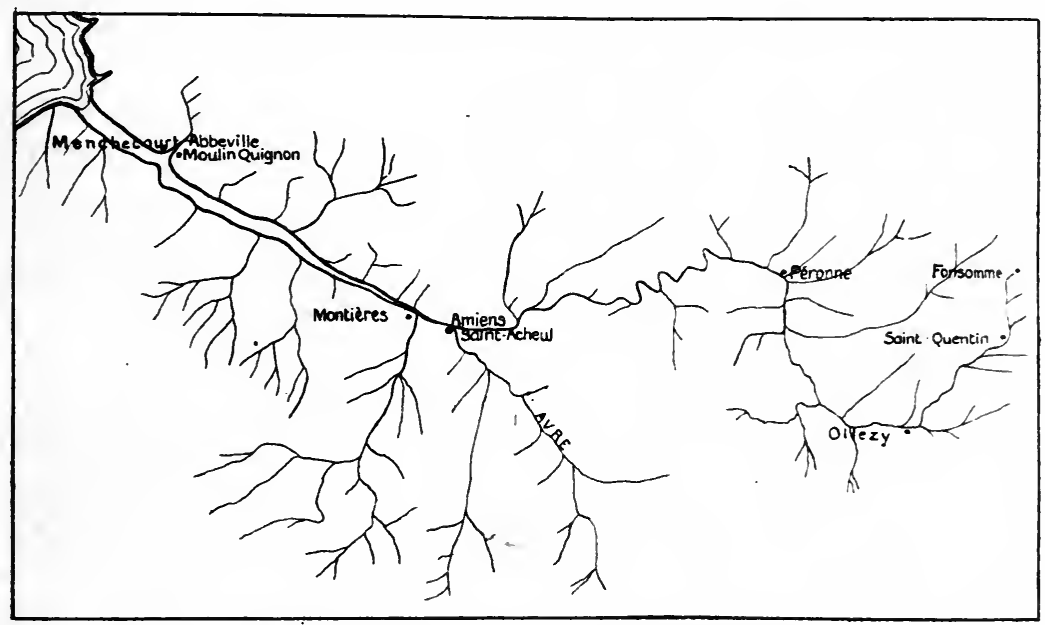

Fig. 59. Sketch-map of the Somme Valley.

The primary gravels on the first terrace are shewn by the animals, whose bones are interspersed among them, to be of Pliocene date. These gravels are absolutely destitute of any trace of human workmanship. There are certain chips of flint which some would call eoliths, but which M. Commont rightly regards as mere natural products ${ }^{1}$.

The second terrace, however, affords evidence for a very early occupation of the district. At Abbeville the terrace shews a fauna including the following animals: Machaerodus, Equus stenonis, Hippopotamus major, Rhinoceros etruscus, Elephas meridionalis-evidently representing a faunistic stage behind the usual time of the first

1 Terrasses fluviatiles de la Vallée de la Somme, p. I91, note 2. 
appearance of man on European sites. There are no remains of human workmanship associated with these bones at Abbeville. At Saint-Acheul this second terrace divided into two, the upper being 3 to Io mètres above the lower. The upper of these terraces is as sterile of objects of human workmanship as is the first terrace; but the lower shews some rude specimens of flint, of undoubted human workmanship. A selection of these has already been illustrated, Fig. 48 ante. This indicates that just at the end of the stage when the Pliocene mammalia were finally disappearing, man made his first appearance in the Somme valley. Probably if any human bones were to be found in the beds belonging to this stage, they would be comparable with the Mauer jaw. In point of fact, no human osseous remains of Palaeolithic date have come to light at any level in the Somme gravels. In these Pre-Chellean gravels, the first rude approximation to the coup-de-poing makes its appearance.

The third terrace, which marks the next step in the history of the river, displays fully developed coups-de-poing; it belongs to the middle phase of the Chellean stage. Many of the coups-de-poing found upon this terrace are of the ficron type.

The fourth terrace is still Chellean; its gravels display Chellean coups-de-poing, though of a better-made form than those of the third terrace. They are as a rule triangular (the "Montières" type of Commont).

When the river of the fourth terrace reached its base-level the land was still at a higher level than it is now; the English Channel was dry ground. The Strait of Dover did not exist, the rising ground which occupied its place being a water-shed between the riversystem of the North Sea (centring in the Rhine) and that of the English Channel, of which the Somme was a tributary. But after the formation of the gravels of which the fourth terrace is a relic, there befel a subsidence of the land. The sea invaded the present English Channel, and entered the Somme valley, reaching as far as Abbeville. At Menchecourt, near that town, the gravels with Chellean implements are overlaid with a marine deposit of chalky marl, containing sea-shells. This lowering of the river-bed, and consequent slackening of the river-course, resulted in the formation of alluvial deposits over the gravels. These deposits are, first, a streaky loam, grey in colour and sandy towards the base, and secondly, another bed of loam variegated with black dots of iron and manganese. A bed of gravel separates these loam-beds from the Chellean riverdeposits. They extend up the sides of the valley almost as far as the first terrace. The fourth terrace, having been wholly under water at the time of the deposition of these loam-beds, displays no imple- 
ments in these strata; but both at Saint-Acheul and at Abbeville implements belonging to the Acheulean stage are found in the upper levels in this stratum.

The depression was followed by an emergence, when the land once more rose, and the river began to deepen its channel, first through the Acheulean silt and the underlying fourth-terrace gravels, and then into the chalk base of its bed. The chalk was channelled to a depth of no less than 34 mètres below the present sea-level, as a boring near the existing river-mouth shews. The alluvia deposited by the river upon the terraces during this period of elevation are likewise stratified, and display the remains of later stages--first Mousterian, associated with Elephas primigenius and Rhinoceros tichorhinus, and then the stages of the Upper Palaeolithic, in order. On the fourth terrace, owing to the absence of the interposed Acheulean culture, the Mousterian is not infrequently found mixed with the Chellean by the river eroding the underlying strata of alluvium. This does not, however, take place in the upper terraces.

A bed of vegetable soil, representing all periods from the Neolithic onwards, covers the whole complicated series.

Such is the general Palaeolithic history of the river. For details as to the nature of the stratification in different pits, with elaborate sections and measurements, and many beautiful illustrations of implements, the reader is referred to M. Commont's papers, enumerated above. Although the general lines of the stratification are uniform throughout the course of the river, there are naturally here and there small local variations in the thickness and composition of the successive strata; but the following scheme fairly represents the system:

F. Vegetable soil; brick earth. Campignian onwards.

I. Loam; Magdalenian, Solutrean, Upper Aurignacian.

$H$. Later Löss alternating with beds of gravel; Middle Aurignacian.

$G$. Gravel; Mousterian. Some late coups-de-poing at the base.

$F$. Later Löss, base. Mousterian and late Acheulean. Well-made coups-de-poing.

$E$. Red loams (earlier Löss metamorphosed). Middle Acheulean. Oval pointed coups-de-poing.

$D$. Old Löss. Same industry as $E$.

C. Gravel. Elephas antiquus. Early Acheulean.

$B$. Fluviatile sand. Chellean.

$A$. Old river gravels. Early Chellean and Pre-Chellean.

The history of the river may thus be summarised:

I. Excavation of the bed in four stages to a depth of $5^{8}$ mètres. This entirely the work of the Pre-Chellean and Chellean stages.

2. Depression of the land, and invasion of the sea as far as Abbeville. Acheulean deposits. 
3. Re-elevation of the land. Excavation of the Acheulean deposits and further deepening of the rocky floor of the river bed. Mousterian deposits.

4. Deposition of the Upper Palaeolithic loams.

5 Re-depression of the land to its present level, involving the opening of the Strait of Dover.

Though properly belonging to the subject of later chapters of this book, it may be convenient here to mention that except for some vague scratches on the calcareous surfaces of certain flakes ${ }^{1}$ there was no trace of art in the Somme deposits. The Solutrean implements found, though the characteristic Solutrean touch was unmistakable, were very inferior in merit to those of Central and Southern France.

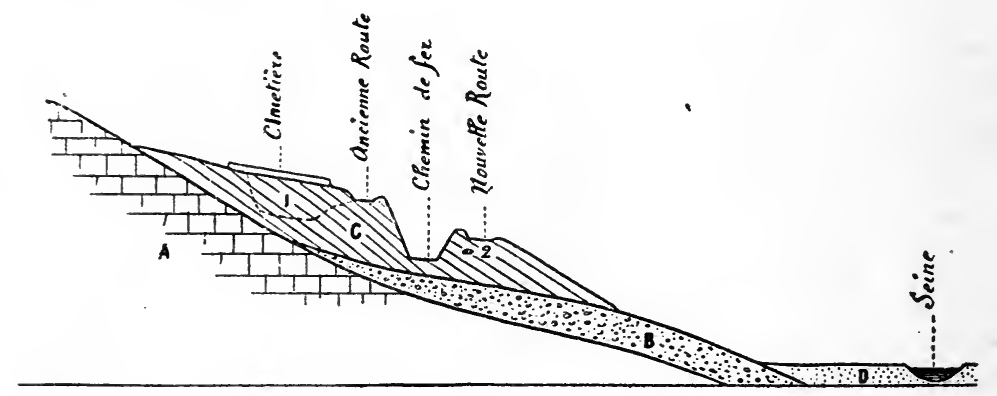

Fig. 6o. Section of the Chellean station of La Celle-sous-Moret.

(From Revue de l'école d'Anthropologie, vol. v)

The MARne valley is noteworthy for the presence of the type station of Chelles-sur-Marne, which has given its name to the Chellean period. The river alluvium at this site falls into two chief layers, each subdivided into minor alternations of sand and gravel. The upper layer is Mousterian, containing remains of Mammoth; the lower is the Chellean layer, with remains of Ursus, Hyaena, Trogontherium, Hippopotamus, and Rhinoceros mercki ${ }^{2}$.

Of the SEINE valley sites we may single out for reference that of La Celle-sous-Moret, an important station of the end of the Chellean stage. The accompanying section will shew the nature of the site.

1 Les hommes contemporains du renne, p. 569.

2 On the station at Chelles consult the bibliography contained in Reinach, Alluvions, p. 109, especially Chouquet, "Vestiges de l'industrie humaine dans le diluvium de la Vallée de la Marne" (Matériaux pour l'histoire de l'homme, xIII. [1878], p. 22). Sections of the Chelles alluvia will be found in Ameghino's account of the site, B.S.A.P. ser. III. vol. Iv. [188I], pp. $96,35 \mathrm{I}, 559^{-60}$, and also in G. and A. de Mortillet, Musée préhistorique (Paris, I881), plate ix. Reduced copies of these sections appear in the Manuel des recherches préhistoriques of the Société préhistorique de France, p. 140. 
$A$ is a Tertiary calcareous lacustrine deposit, in which the river Seine has cut its bed. The Quaternary gravels of the Seine are indicated by $B$, the more recent alluvium, in which the present bed of the river lies, being marked $D . C$ is a bed of tuff; in the quarry marked with the figure $I$, now partly covered with a cemetery, there were discovered impressions of vegetable forms and numerous land shells. These bear witness to a warmer, more equable, and moister climate than that which now dominates the region. Neolithic implements were found in the vegetable soil covering the tuff, and in its upper part there were some Mousterian implements (Middle Palaeolithic); but Lower Palaeolithic coups-de-poing were found at a deeper depth, especially at the spot marked $2^{1}$.

Of earlier finds in the basins of the Seine, Somme, and LoIRE a very long list will be found in Mortillet, Préhist., part vi. chap. I. It is hardly necessary to reproduce this; and it cannot be said that much would be gained from a detailed inventory of these discoveries. They all fall into the types already enumerated, and to be again illustrated when we describe the discoveries made in England. It will suffice to say that in de Mortillet's list of departments which have yielded coups-de-poing, every one lying in the region under discussion is represented except Morbihan, Sarthe, and the mountainous eastern departments which lie in the Alps and the Ardennes. In these latter districts, which came under the influence of the glaciations, we cannot expect to find pre- or interglacial remains.

In Belgium, Chellean and Acheulean implements have been found in various centres in the neighbourhood of Liège, Brussels, and Mons. They do not appear to occur in Holland.

\section{Region ViII. The German Plain}

The Lower Palaeolithic is very scantily represented in Germany. Though the Mauer jaw shews that in this region man appeared from a very early time, the Pre-Chellean and Chellean stages are as yet unrepresented among German palaeolithic sites. There are, however, a few places where remains of Acheulean culture have been discovered.

The oldest of these is in Lorraine ${ }^{2}$, at Sablon near Metz, on the Moselle. Here there was found an almond-shaped coup-de-poing

1 E. Collin, Reynier, and A. de Mortillet, "Découverte de silex taillées dans les iufs de La Celle-sous-Moret" (R.E.A. v. [1895], p. 3 I 8 ).

${ }^{2}$ As these words are being written Lorraine is passing back from German to French political control. But in the present work it is impossible to keep to the fluctuating limits of empires; we use the name "Germany" simply for convenience, as a name for the eighth of the regions into which in Chapter II we divided the map of Europe. 
at a depth of I mètre in the upper alluvial terrace of the river named. It measures $6 \cdot 1 \mathrm{~cm}$. in length and breadth, and is of a shape characteristic of the early Acheulean, with rather thick butt; both sides are carefully worked. It is, or was, preserved in the museum of Nancy ${ }^{1}$.

A gravel pit at Markkleeberg near Leipzig has yielded numerous flints, including some resembling Levallois scrapers. The general rudeness of the technique has led those who have studied these objects to ascribe them to the Lower Palaeolithic, and probably to early Acheulean; but the exact period to which they are to be assigned cannot be regarded as settled. There are no coups-de-poing or other distinctive implements among them. That they are to be ascribed to the last interglacial phase is suggested by the fact that the gravels in which they have been found embedded underlie the upper layer of boulder-clay, which is associated with the last extension of the Alpine glaciers ${ }^{2}$.

Of late Acheulean sites by far the most important in Germany is that of Achenheim, near Strassburg. The stratification of the implement-bearing soil may be set forth as in the following table:

L. Surface soil $\quad$... Neolithic:

Later Löss :

$K$. Löss turned to clay (Lösslehm).

F. Löss.

I. Löss turned to clay $\quad \ldots \quad$ Aurignacian.

$H$. Löss, containing at the bottom:

(a) Bed of rodents.

(b) Principal layer of bones.

(c) Mousterian settlement.

Older Löss :

$G$. Löss turned to clay.

$F$. Löss

... Acheulean near top of stratum.

$E$. Löss turned to clay

... Hearths with atypic flints.

D. Löss.

$C$. Löss turned to clay.

$B$. Löss

One flaked scraper.

A. Early quaternary sands.

Here we are concerned only with the deeper strata, those in the

${ }^{1}$ F. Barthélemy, "Outil acheuléen dans les alluvions de la Moselle" (A.F.A.S. Limoges [1890], vol. II. p. 596); Abbé Paulus, "Die prähist. Fundstätten in Lothringen" (Corr. [I90I], p. 74); Bleicher, "Sur le gisement des armes préhistoriques les plus anciens en Alsace et en Lorraine" (Bull. des séances de la Soc. de Nancy, II. 3, p. 25).

2 K. H. Jacob, "Paläolithische Funde aus Leipzigs Umgebung" (Praehistorische Zeitschrift, vol. III.). 
earlier Löss. The fauna whose bones were contained within it included the following:

$\begin{array}{lll}\text { Castor fiber } & \text { Sus scrofa } & \text { Equus caballus } \\ \text { Arctomys marmotta (?) } & \text { Rupicapra tragus } & \text { Rhinoceros mercki } \\ \text { Cervus giganteus } & \text { Bos primigenius } & \text { Elephas primigenius }\end{array}$

a thoroughly characteristic steppe fauna. The Acheulean implements included a shapely coup-de-poing found in stratum $F$, differing from the classical type in being formed not from a nodule or nucleus but from a flake struck off from a nodule; it is chipped on one side only, the other (that of the bulb of percussion) being only slightly "retouched." The edge has the screw shape characteristic of the late Acheulean. The underlying stratum contained rude and shapeless implements, evidently belonging to an older facies ${ }^{1}$.

Another coup-de-poing has been found at Rüderbach near Basel. It is probably late Acheulean, to judge from its appearance, but the stratigraphy of its site is uncertain ${ }^{2}$.

Next in importance to Achenheim come the sites of the Ilm valley-Weimar, Taubach, and Ehringsdorf. These have already been described to some extent, and we need only give here a few further particulars.

The flint industries of the lower travertine in the Ilm sites are difficult to classify, on account of their extreme rudeness. The ordinary types of the Lower Palaeolithic are absent. Instead we have formless flakes, mingled with a number of implements which seem better capable of seriation. The lower levels contain a number of scrapers made of thick, prismatic flakes, of which one edge is left thick and blunt in order to afford a convenient grasp for the hand, and the other edge is sharpened by secondary chipping which runs step-wise down the side of the tool, thus gradually reducing the thickness from one edge to the other. Slightly later, to judge by the stratification, are smaller flakes and points; the layer containing these are, at Ehringsdorf, separated from that containing the scrapers just described by a sterile bed some 2 mètres thick, whose only contribution to archaeology was a water-rolled fragment of flint with nothing characteristic about it. Later still are more elegant scrapers,

1 E. Schumacher, "Ueber das erste Auftreten des Menschen in Elsass" (Mitteil.d. Philomath. Gesellsch. in Elsass, 1898); F. Wiegers, "Die diluvialen Kulturstätten Norddeutschlands und ihre Beziehungen zum Alter des Löss" (Praehist. Zeitschrift, II. [1909], pp. 21, 35); P. Werner and R. R. Schmidt, "Die archäologischen Einschlüsse der Lössstation Achenheim (Elsass) und die paläolithischen Kulturen des Rheintallösses" (Praehist. Zeitschrift, 11. [1910], pp. 339-346).

2 R. R. Schmidt, Die Diluviale Vorzeit Deutschlands, p. 66, referring to Bleicher, "Sur le gisement des armes préhistoriques les plus anciennes en Alsace et en Lorraine" (Bull. des séances de la Soc. de Nancy, II. No. 3 [1890]). To this paper I have been unable to obtain access. 
flat and oval in outline, not unlike the miniature coups-de-poing of La Micoque, but always made from flakes, never from cores; with secondary chipping on both faces and with the edge carefully straightened by additional treatment of the same kind: and points, resembling those of the Mousterian stage, which are either symmetrical or asymmetrical-in the latter one of the edges forming the point is convex, in the other straight. Specimens of the Ilm valley implements will be found in Fig. $62^{1}$.
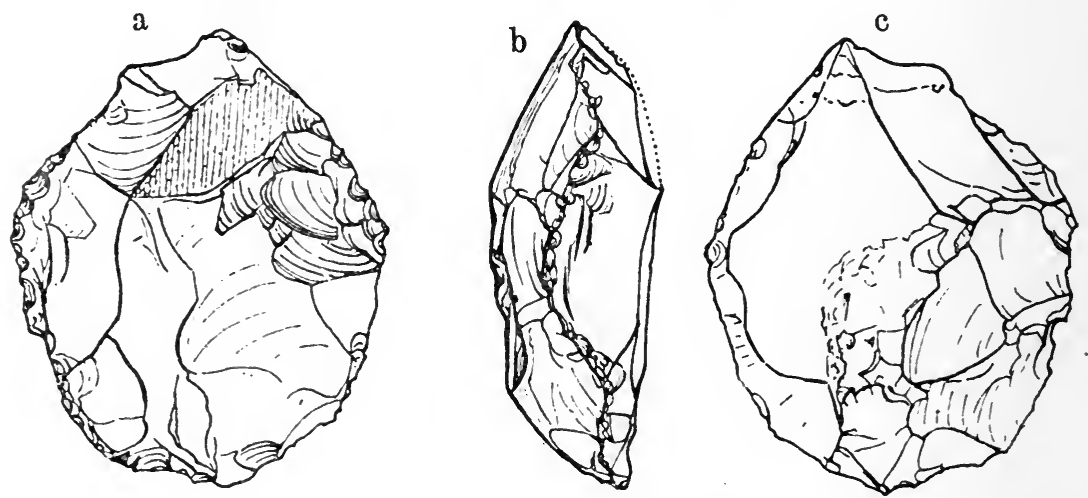

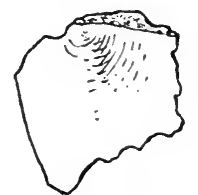

a

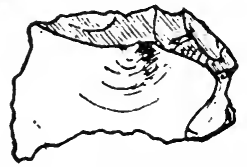

a
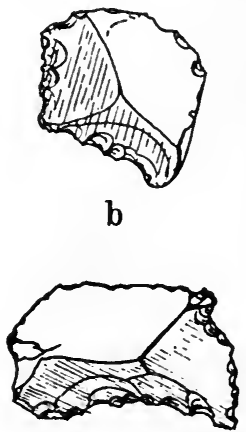

b

Fig. 6r. Specimens of the Ilm Valley implements.

(Upper row from Ehringsdorf, lower rows from Taubach.)

The last site in Germany to be enumerated in this section is Hundisburg, near Magdeburg, which, in a layer of deposit containing the bones of Elephas primigenius and Equus caballus, yielded certain very rude chipped flints, compared rather perilously by their

1 A full bibliography of the extensive literature on Taubach and the neighbouring sites will be found in R. R. Schmidt, op. laud. pp. 97, 98. To this the excellent account in Obermaier's Mensch der Vorzeit, p. 149 ff. should be added. 
discoverer to coups-de-poing and Levallois scrapers. Their genuinely artificial nature is by no means proved ${ }^{1}$.

\section{Region X. Austria Hungary and Western Russia}

Though this region yields much of importance for the study of the later stages, it is very poor in Lower Palaeolithic remains. Some coups-de-poing, five in number, resembling Acheulean forms, have been reported from Miskolcz in Hungary; they are in some kind of chert, not true flint, and are doubtless of local origin. But their antiquity has been questioned, on account of the nature and chronology of the alluvial bed in which they were lying; this there seems reason for believing to be a post-quaternary accumulation ${ }^{2}$. Many prehistorians deny altogether the existence of Lower Palaeolithic remains in Hungary ${ }^{3}$.

Near Ojców in Poland, at Smardzewitz, a number of Acheulean coups-de-poing have been found ${ }^{4}$ : and there is a distinct Acheulean facies in the flint implements from the lower stratum in the cave of Wiérzchow in the same neighbourhood, as well as in the Moravian caves of Čertova-díra and Šipka.

\section{Region XI. South Britain}

Although South Britain is a rich and promising field for Palaeolithic research, the work hitherto done in this region, both in quantity and in quality, comes far behind that to the credit of France. No English Commont has as yet arisen to systematise the study of the river-terraces; no English de Mortillet or Déchelette has come forward to co-ordinate the results of investigation. The pioneers in cave exploration did good work in their day, and as a catalogue of types of implements the great work of Sir John Evans must always occupy a prominent place. But there is still much leeway to make up. Prehistoric archaeology in Britain is, indeed, under an eclipse. Considering that the Imperial Government takes little or no practical

1 F. Wiegers, "Úber die paläolithischen Funde aus dem Interglazial von Hundisburg" (Z.f.E. xxxvir. [1905], p. 915); R. R. Schmidt, op. laud. pp. 99-100, where references to other literature will be found.

2 One of the five implements was found in a much-dug graveyard: see Földtani Közlöny, xxxvir. [1907], p. 206.

${ }^{3}$ See Otto Herman, "Der paläolithische Fund von Miskolcz" (M.A.G.W. xxIII. [1893], p. 77); Julius von Halaváts, "Zum paläolithischen Fund von Miskolcz" (ibid. p. 92); Aurel von Török, "Der paläolithische Fund aus Miskolcz und die Frage des diluvischen Menschen in Ungarn" (Ethnologische Mitteilungen aus Ungarn, anal. in L'Anthr. v. [1894], 78).

"Czarnowski, "Paleolit na zbaza gory Smardzewskiej" (Kosmos, Lemberg [1906], xxxı. p. I0); cf. Obermaier and Breuil, "Die Gudenushöhle in Niederösterreich" (M.A.G.W. xxxviII. [1908], p. 277). See also Czarnowski, Album przedhistoryczne (Warsaw, 1906). 
interest in promoting the anthropological study of the numerous native races under its control-though such study is of obvious administrative importance-no aid is to be looked for from that quarter. The subject is all but ignored at the Universities. The archaeological societies of the country expend most of their strength on the more easily studied and more popularly attractive mediaeval antiquities. Men of wealth, when not interested merely in sport, confine their endowments to severely utilitarian purposes. The subject thus becomes nothing better than a hobby for the leisure hours of men employed in other occupations, and of these the primary interest for the greater part is mere collecting. In consequence of this unsatisfactory state of matters, the monographer of the future will have to wade through many volumes with very little harvest, and will even then have to sift away an undue amount of chaff about eoliths, figure-stones, and other puerilities.

It is clear that this region is in reality a northward extension of the region of the North of France. In Chellean times the English Channel did not exist as an arm of the sea, and Britain was embedded in the heart of a northward prolongation of the continent. Thus we find Chellean and Acheulean tools of precisely similar facies to the corresponding tools of Northern France, in the drifts of the southeastern English rivers.

The Thames, the largest river and the centre of the most complex tributary system in England, is also the richest and most instructive for the Palaeolithic history of the country. Almost from its source to its estuary its gravels contain implements, and many of its tributaries are also of considerable archaeological importance.

The bed of the Thames probably began to be excavated in the plateau of south-eastern England in Late Tertiary times, by a torrent which, while following the same general course as the present river, was of a much greater size. The land was higher above the sealevel than at present, and the climate was continental rather than insular-colder and moister, thus giving a larger supply of water and a more complete saturation of the underlying chalk. The river was thus the centre of frequent floods, of a magnitude unexampled in modern times. The fall to the sea being greater, the rapidity of the torrent was also greater, and the area normally covered by the water was much broader than at present.

Such a river would have a much greater eroding and carrying power than the modern Thames, which flows at a depth of about 30 mètres below the level of the bed of its ancient predecessor. As in the Somme, the different stages in the erosion of the modern bed are marked by valley terraces covered with drift gravel, which in 
places attains a thickness of as much as 6 mètres. This gravel is for the greater part composed of flints, derived from the chalk through which the bed was cut. Fragments of other rocks, the beds of which are tapped by the main river or by one or other of its tributaries, are intermingled with the flint. Wide gravel-beds do not, however, occur along the entire length of the river. From Taplow onwards the bed lies in Tertiary deposits spread over the chalk, and here the gravels are much broader than in the upper reaches, where the bed is cut through the chalk itself. The gravels are on the whole more extensive on the north side of the river than on the south. They are by no means confined to the terraces, but appear likewise on the intermediate slopes. It is hardly necessary to say that the remaining fragments of the gravels are only a small proportion of the entire system as it originally existed; they have suffered much from denudation, and from the erosion of tributary streams. The tributaries shew terraced gravels similar to those in the main stream, though naturally on a smaller scale; but it is sometimes difficult to decide whether implements found in gravels close to the confluence of a tributary with the main stream are to be considered as belonging to the principal or to the subordinate system. This is especially the case at the mouth of the Lea, which has greatly eroded the original Thames gravels and intermingled with them its own deposits ${ }^{1}$.

Interspersed among the gravels are occasional beds of sand, which in some places completely occupy the place of the gravels. At certain places, especially in the lower reaches, are beds of brick earth or loam, which is a lacustrine deposit-records of a time when the river was by some agency blocked, and formed an extensive fresh-water pond or lake at its present estuary. Later still are the beds of silt or alluvium, which belong to a period when the river was reduced in bulk, owing to reduced rainfall, and in speed, by reason of the subsidence of the land; and when in consequence it bore its detritus in the form of silt rather than of gravel ${ }^{2}$.

The Thames gravels have been found to contain the bones of many extinct animals, and also of fresh-water molluscs. These latter afford a proof, if proof were needed, of their fluviatile origin. Among the animals the most noteworthy are Elephas antiquus, E. primigenius, and Rhinoceros. Among the molluscs the most interesting is Corbicula fluminalis, a small bivalve which no longer exists in Europe, though it has been found in modern times in rivers in Thibet and elsewhere

1 See Geologists' Association, Fubilee Volume, p. 83 ff.

2 For further particulars about the geology of the Thames valley see W. Whitaker, The Geology of London and of Part of the Thames Valley (Geological Survey Memoirs, I 889). 
in Asia, and in the Nile. This mollusc has been identified in fluviatile gravels at Wolvercote, Shacklewell (London), Grays Thurrock, and Erith. It has also been yielded by the Somme gravel.

The occupation of the region drained by the Thames began in the Pre-Chellean stage. Early Chellean tools, though much rarer than mid-Chellean and early Acheulean, have been reported in the Thames gravels from Oxford as well as from Farnham on the Wey. But in no case are these tools in their original positions. They have been carried down by floods, like any ordinary gravel stone, and shew marks of the rough treatment which this water-rolling has inflicted upon them. The same is true of the much more numerous late Chellean and early Acheulean flints which the gravels have yielded almost along the entire course of the river. There is a considerable variety of types represented by these implements, and they appear to follow out a line of evolution parallel to that which has been established by M. Commont in his researches on the Somme.

It will be evident from what has just been said that in attempting to date implements by their terrace we have to proceed with some caution. It may be taken for granted that the upper terraces are earlier than the lower. But the implements found in lower terraces may be derived implements, not innate implements. The implements may thus have fallen to a level later than that to which they properly belong. Thus the level at which an implement is found can as a rule give us only a minor, not a major, limit of date.

The oldest gravels are those of the original plateau, relics of which remain capping the hills along the course of the river. These contain no implements other than the more than doubtful eoliths. Such genuine implements as are found upon their surface are usually fresh, and shew no signs of water-rolling; they were dropped when newly made by Palaeolithic hunters, who had the misfortune to lose them in their wanderings over the plateau. Rolled tools are occasionally found on the plateau; this however merely means that waterworn implements have from time to time been picked up and carried to the place where they were found. Though, as has just been said, some caution is necessary in dating flints, by the terraces in which they are found, it is in general true that those from the upper terraces are on the whole ruder in construction than those from the lower levels ${ }^{1}$.

In Fig. 62 is given a sketch-map of the river and of its chief tributaries, with the names of places in which discoveries of Lower Palaeolithic remains have been made. Most of the particulars upon

1 See J. P. Johnston, "The Palaeolithic Period in the Thames Basin" (Essex Naturalist, xin. [1903-5], p. 97). 


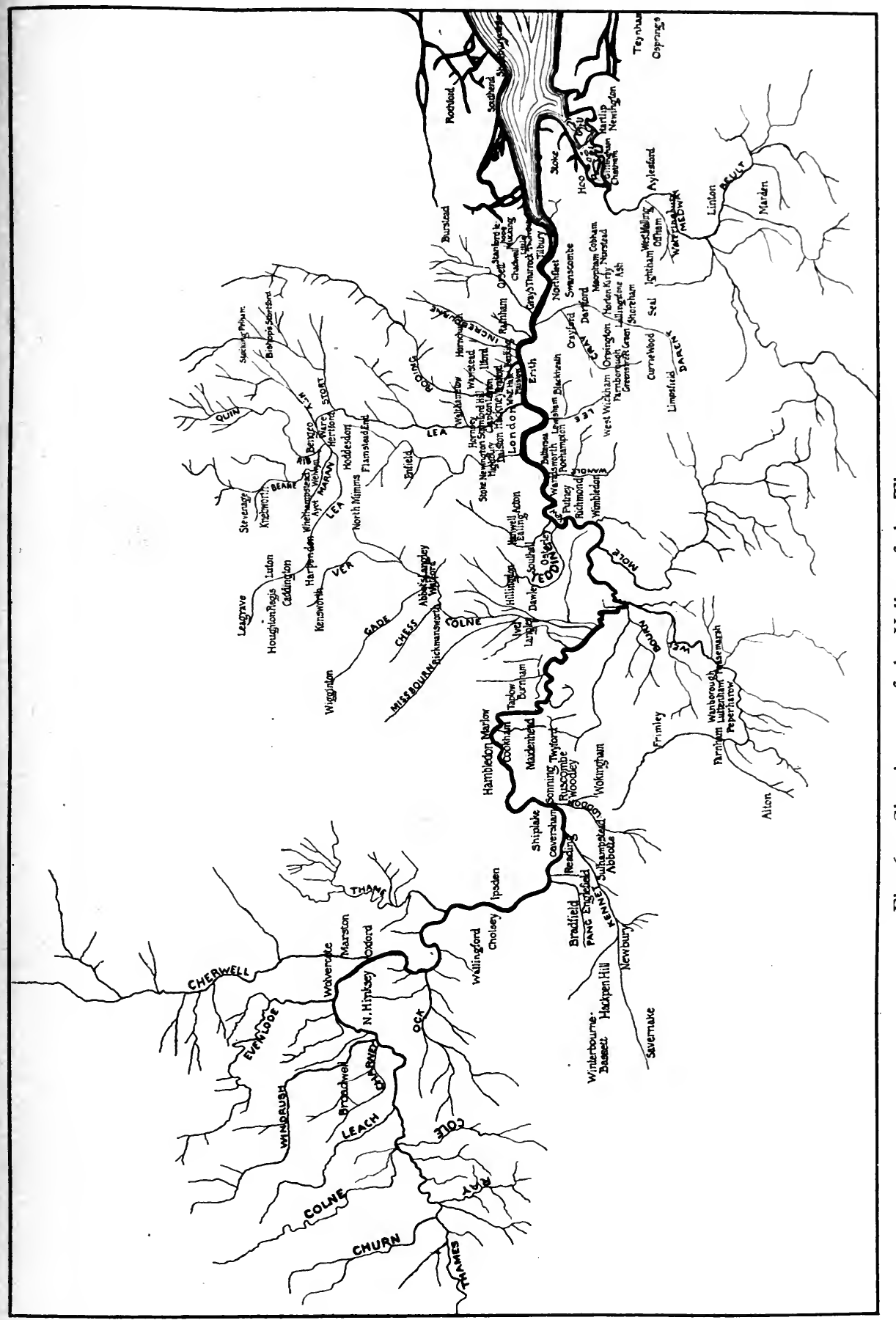


which this map has been based have been collected by the industry of Sir John Evans (Stone Implements, 2nd edition), and have been brought up to date by reference to the Victoria County History of the different counties through which the river passes. It would be a waste of tine and space to repeat details already so well set forth in books so easily accessible: accordingly, for particulars about sites not here singled out for special mention, the reader is referred to the works mentioned. A complete monograph on the Palaeolithic archaeology of the Thames Valley would fill a large volume.

The Thames rises in the Cotswold hills, in Gloucester; but there appears to be no trace of Palaeolithic man along its banks till it has left the county of its birth. The highest site that I can find recorded is Broadwell, on the Charney, a tributary which runs just within the borders of Oxfordshire.

Already at Oxford there are four well-marked terraces. The first is at a level of from 2I to 30 mètres above the river. This apparently contains no implements. The second terrace, at I2-I 5 mètres above the stream, presents the following section:

$D$. Finely laminated clay, 4.5 mètres thick.

C. Peat and sand, $5 \mathrm{~cm}$. thick.

$B$. Gravel and sand, with numerous Chellean implements.

A. Oxford Clay.

The other terraces are respectively at 6-9 mètres, and $I^{\cdot} 5-3$ mètres. They contain no implements ${ }^{1}$.

The archaeological importance of the river has hardly begun at Oxford. In the neighbourhood of Reading, however, the deposits yield a rich harvest.

The high-level gravels are found, not on the right side of the stream, where Reading stands, but on the left, at Caversham. Here at a place called Toot's Farm, there is a bed of gravel at a height of about 34.6 mètres above the stream. The stratification of this site is as follows:

$E$. Sandy soil, $30 \mathrm{~cm}$. thick.

$D$. Sandy gravel, with unrolled flints and pebbles, $\mathrm{I} \cdot 2$ mètres.

$C$. Fine shingly gravel, $15 \mathrm{~cm}$.

$B$. Hard compact gravel, $60 \mathrm{~cm}$.

$A$. Chalk.

Most of the implements come from the bottom of $D$. They are of the ficron type. There are, however, other types, and various degrees of excellence of manufacture; many of the implements are only

${ }^{1}$ Geologists' Association, Fubilee Volume [1910], p. 208. 
slightly trimmed. These upper gravel flints are but little waterrolled.

At Furze Platt, Caversham, there is a lower terrace, 22.4 mètres above the stream. The flints in this terrace are of inferior workmanship, and apparently much rolled. The same terrace appears at Grovelands, on the opposite side of the river (on the outskirts of Reading, in the angle formed by the junction of the Kennet with the Thames). Here the same type of flints appears, accompanied with bones of mammoth, horse, and deer. The terrace, still implementiferous, can be traced along the river to Woodley and Sonning.

The low-level gravels in which the present bed of the river is cut contain Neolithic implements ${ }^{1}$.

Occasionally re-worked implements are found in this section of the river gravels.

The valley of the Colne and its tributaries have yielded many implements, but none that need be especially commented upon here. The important site of Caddington, which stands on the watershed between the Ver and the Lea, will be noticed more particularly in connexion with the latter river. We therefore proceed on to the next tributary, the Wey. By far the most important site upon this river is Farnham.

The gravels of Farnham have been investigated by Messrs F. Lasham ${ }^{2}$ and, later, H. Bury ${ }^{3}$. Farnham stands on the left bank of the river, and the ground rises above the town to a plateau, 400 feet above the level of the stream. Upon this plateau a few flints have been found-all surface deposits, made after the formation of the gravels which cover it. On the right bank there are four well-marked terraces, the uppermost of which extends as a plateau over a wide area, and is itself channelled by other smaller rivers. This plateauterrace is at a level of $150-160$ feet above the stream. Here our doctors disagree; Mr Lasham tells us that the flints from this level are well-made Acheulean, as a rule much rolled; though one fine unrolled specimen was found under the gravel, on the top of the underlying greensand, having apparently been abandoned after being made. With these flints are mammoth and horse bones. Mr Bury, on the other hand, diagnoses the flints as Chellean. The majority

1 L1. Treacher, "On the occurrence of stone implements in the Thames valley between Reading and Maidenhead" (Brit. Association Report [1903], p. 670; Man, vol. IV. [1904], No. 10). See also R. A. Smith, "High-level finds in the Upper Thames Valley" (Proc. Prehist. Soc. E. Anglia, vol. II. [I 1 I 5], p. 99).

2 F. Lasham, "Palaeolithic Man in West Surrey" (Surrey Archaenlogical Collections, XI. [1893], p. 25).

3 H. Bury, "The gravel-beds of Farnham in relation to Palaeolithic Man" (Fournal Geologists' Association, xxiv. [1913], p. 178). See also ibid. xviII. [1904], p. 409. 
of the Farnham flints come from this terrace, though there are a fair number in the underlying terraces as well. According to Mr Bury the flints in the underlying terraces are distinctly later in facies than those in the first terrace. The second, whose gravels are overlaid with alluvium containing Neolithic implements, has flints of Acheulean types; those in the third terrace, which are also frequent, are still later, tending towards Mousterian; some Levallois scrapers have been reported from this level. The fourth terrace seems to contain few flint implements, all of them derived, and in consequence much rolled and abraded.

We now reach the London basin which, from the discovery of the Gray's Inn specimen, the first coup-de-poing to be recorded, has continuously yielded a series of valuable remains.

The river Lea is now the centre of our interest. On rising ground between the head-waters of the Lea and the Ver, the latter a tributary of the Colne, and not far from the Bedfordshire town of Luton, there stands the village of Caddington. There was here in Palaeolithic times a lake, or an assemblage of pools, on the borders of which a community of flint-workers established themselves. The remains of this settlement were discovered by Mr Worthington Smith, while investigating the sections revealed in the sides of pits dug for the extraction of brick-earth ${ }^{1}$. Of the numerous sections of which Mr Smith publishes drawings, we select that shewn in Fig. 63 as a specimen. Here $A$ is the surface vegetable soil. $B$ is a reddishbrown tenacious drift clay. $C, D, E$ are beds of sub-angular gravel, which have forced their way into the underlying strata. Palaeolithic flakes were found in these gravels. $F$ is boulder-clay. $G$ is another bed of gravel, also containing Palaeolithic implements and flakes. $H$ is stiff reddish-brown clay with similar implements and flakes. $I$ is another bed of gravel similar to $G$. $K$ is brick-earth. By some oversight $\mathrm{Mr}$ Smith has forgotten to explain $P$, but it is apparently brick-earth also, underlying the stratum $\mathcal{F}$.

Ff is what Mr Smith has called a Palaeolithic Floor-an ancient land-surface, having.the undisturbed remains of a Palaeolithic settlement still lying upon it. The stratum consists of a layer, of varying thickness, of sharp-edged artificial flakes; with heaps of flint nodules interspersed, some of which are of considerable size. That these nodules were artificially piled is proved by the lumps of chalk

1 A full account of the Caddington settlement will be found in chaps. iii.-xii. of Mr Smith's book, Man, the Primeval Savage. The short notice which is all we can find room for here is based upon this description. In "Notes on the Palaeolithic Floor near Caddington" (Archaeologia, LxvIr. [1916], p. 49) some further particulars are given (with many excellent illustrations), considerably extending the area occupied by the flint workers. 


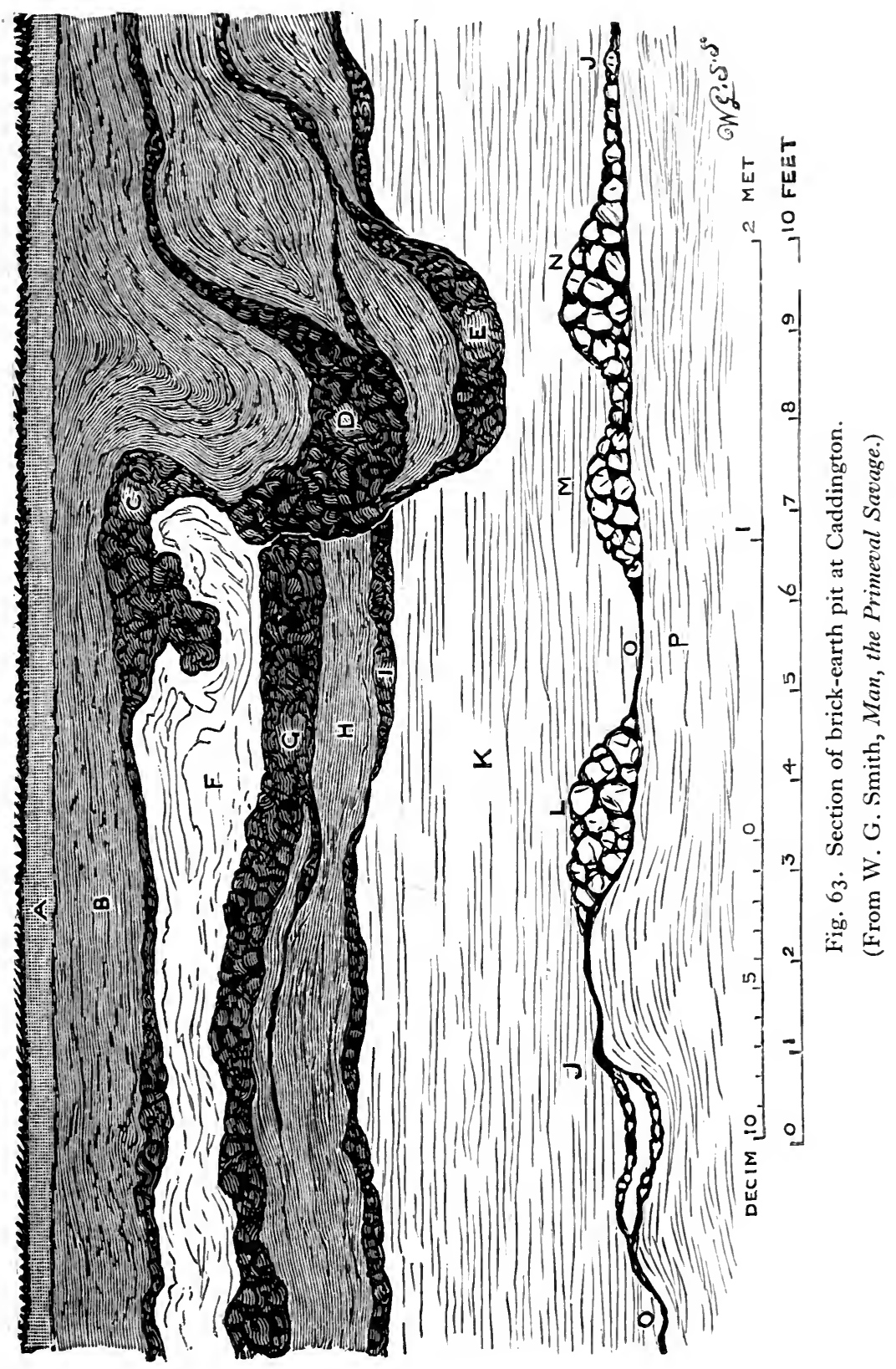


adhering to their sides, relics of the bed from which they have been dug; and that the flints were worked on the spot was proved by the fact that by a lavish expenditure of time and trouble Mr Smith was enabled to re-constitute, wholly or in part, many of the nodules which the action of the ancient flint-worker had reduced to flakes and tools.

The history told by such a section as this appears to be as follows. There was here originally a lake, which deposited the lower stratum of brick-earth. The lake became dried, temporarily, and during this time the flint-workers established themselves on its old bed. The waters, however, afterwards returned and drove out the flint-workers, depositing the upper layer of brick-earth alluvium over their handiworks. Afterwards the district was much disturbed by flood-bursts, which, rushing over the site, deposited the contorted strata overlying the brick-earth; the stratum $G$ must have been for a time an occupied settlement, for the flakes found within it are "capable of replacement," which would clearly not be the case if they had been deposited by the random action of a flood.

The flints found by Mr Smith, of which a long series is illustrated in his book, are uniformly Acheulean, though belonging to a number of different types, and of very different degrees of excellence. Interspersed among the coups-de-poing are borers, punches, and scrapers in considerable variety, as well as hammer-stones, flakes, and cores. Some of Mr Smith's replacements were not of flakes restored to the nodule, but fragments of implements which their ancient owners had broken by some mischance. Such fragments were often found at a considerable distance from one another, as though the man in whose hand the tool had broken had flung the pieces in opposite directions in a fit of temper. Some of these restored implements were unfinished, the accidental fracture having happened as the tool was being completed. Fig. 64 is shewn as one specimen of these restorations. It was a scraping implement, worked on one face only. Just as it was being finished, a misdirected blow of the hammer dislodged the flake marked $A$, thus spoiling the scraping edge, and the work on the tool was then abandoned. The restored nodule, shewn in the same figure, well illustrates the amount of labour which had already been expended in preparing the tool: the line drawn through the axis of the tool will help the reader to identify it among the mass of united flakes.

Passing down the Lea, along whose course there are various places where one or more palaeolithic implements have been found, we reach North London, where Mr Smith has demonstrated the existence of another "Floor." This lies on the top of the wide spread of river gravel, which in Palaeolithic times extended from west of 


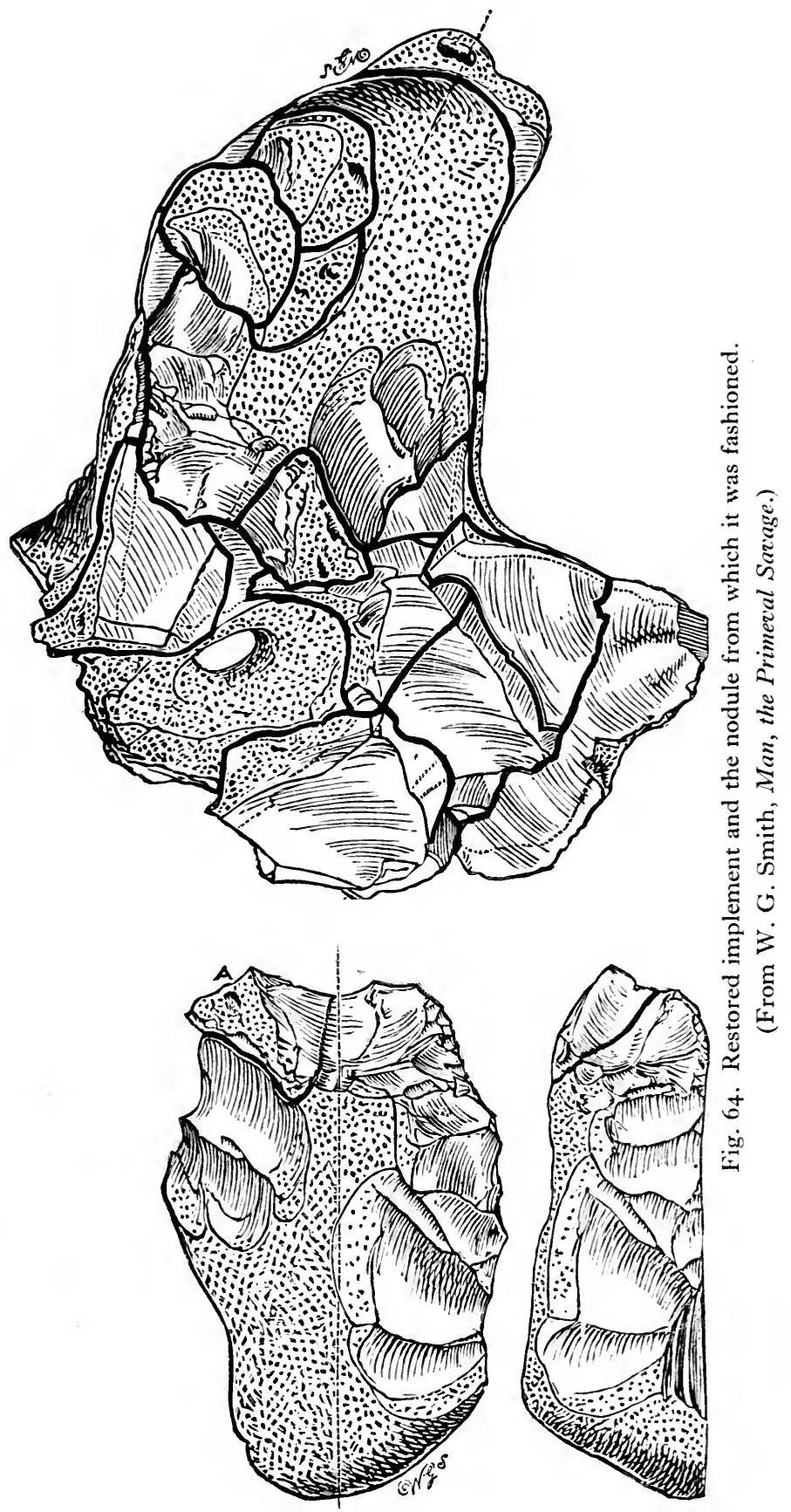


the Lea continuously to the bed of the Roding. In referring to the map of the Thames basin here given it must not be forgotten that it shews the modern contours (omitting recent canalisation). In Palaeolithic times these details, especially as regards the smaller tributary brooks, were often very different. The Palaeolithic Lea was a mile and a half wide at Homerton.

The North London Floor centres especially at Stoke Newington, where it lies at an average depth of four feet below the present groundlevel. At.a further depth of eight feet there is another implementbearing bed, in which, however, the flints are much water-rolled. This is therefore a bed of river deposit. In contrast, the implements found in the upper bed are fresh and sharp, just as their makers left them. The London floor could not be investigated so completely as that of Caddington. Most of the ground being occupied by buildings, no special excavations could be undertaken; the Floor could not be tapped except in the narrow trenches cut for foundations, or in drainage works and similar undertakings. The chance of collecting sets of flakes for reconstitution was thus reduced practically to nothing. Moreover, so soon as Mr Smith's researches became known, his preserves were invaded, and his market spoiled, by hordes of ignorant collectors and curio-mongers, offering competition prices for antiquities, with the usual results : general demoralisation, greed, forgery, and an appreciable resultant increment of the revenues of the local public houses ${ }^{1}$.

We come now to the section of the river below London, which has yielded the greatest harvest of Palaeolithic remains of any part of the river system. The researches of Prestwich and his followers have established the following successive stages in the history of this part of the Thames system².

I. In mid-Tertiary times (probably), before the cutting of the valley proper began, the land had become elevated above a sea that covered south-eastern England. The Weald was then a lofty snowcapped highland, the parent of rivers that flowed in a northward direction. These streams deposited gravels in their course, which gravels survive on the Kentish Plateau.

The Plateau gravels have been already referred to, in connexion with their eoliths. They now cap the various hills and uplands, the

1 A similar Floor at Ealing forms the main subject of $\mathrm{Mr}$ J. A. Brown's Palaeolithic Man in N.W. Middlesex (London, 1887 ).

2 References will be found in the excellent article by M. S. C. Hinton and A. S. Kennard, "The relative ages of the stone implements of the Lower Thames Valley" (Proc. Geologists' Assoczation, XIx. [1905-6], p. 76), on whose work the abstract here given is founded. See also R. A. Smith, "Plateau Deposits and Implements" (Proc. Prehist. Soc. E. Anglia, II. 392). 
modern valley system having been excavated through them. They occur at a wide range of heights; and it is claimed that eoliths from the lower spreads of Plateau gravels (e.g. those from 150 metres above Ordnance Datum) are superior in technique to those found at 200 mètres above O.D. This is what might $a$ priori be expected, for the lower gravels would presumably belong to rivers having a lower base-level and thus later than the upper gravels. But it is premature to decide whether one group of eoliths are or are not of superior workmanship to another group before the problem of their origin is finally solved. We have already seen the extraordinary variety of judgments passed by different observers on the relative merits of Reutelian and Mesvinian implements.

II. Following this Plateau period, there comes a later spread of gravels, sometimes called the Limpsfield gravels, which occupy heights of from 100 to I 70 mètres above Ordnance Datum. These gravels represent a stage when the existing river systems were just coming into existence. They are much eroded, and but few fragments remain of them. Some rough flakes, which it is possible to call scrapers, have been found in these gravels; they may be provisionally classed as Pre-Chellean. Other implements which have been figured from this site have all the appearance of being later: thus, a coup-de-poing from Bewley (Q.F.G.S.L. xLv. [1889], pl. x, Fig. 7) can hardly be other than Acheulean.

III. The first of the valley terraces, at a height of about $45 \cdot 6$ mètres above O.D.; with a subsidiary terrace at 30 mètres. At Dartford, at 45 mètres, there are gravels containing bones of Elephas primigenius and Rhinoceros, with some other animals of less importance; and molluscs, including Corbicula fluminalis. Very few implements, however, are contained in these upper gravels. The 30-mètre terrace, on the contrary, is very rich in Palaeolithic remains. At Wansunt, near Crayford, a channel, eroded after the deposition of its gravels, has proved very rich in late Acheulean and early Mousterian implements, having been the site of a factory ${ }^{1}$; and at Swanscombe still earlier remains have been found. The gravel-pits at the latter site have kept collectors supplied with materials for many years. They have recently been re-examined scientifically by Messrs Reginald Smith and Henry Dewey ${ }^{2}$. Sections were made which

1 R. H. Chandler and A. L. Leach, "On the Dartford Heath gravel and on a Palaeolithic implement factory" (Proc. Geol. Assoc. xxiII. [1912], p. 102). See also R. H. Chandler, "The Implements and Cores of Crayford" (Proceedings Prehist. Soc. East Anglia, II. 240).

2 R. A. Smith and H. Dewey, "Stratification at Swanscombe: Report on excavations made on behalf of the British Museum and H.M. Geological Survey" (Archaeologia, LxIv. [1912-3]; p. 177); Iidem, "The High Terrace of the Thames: 

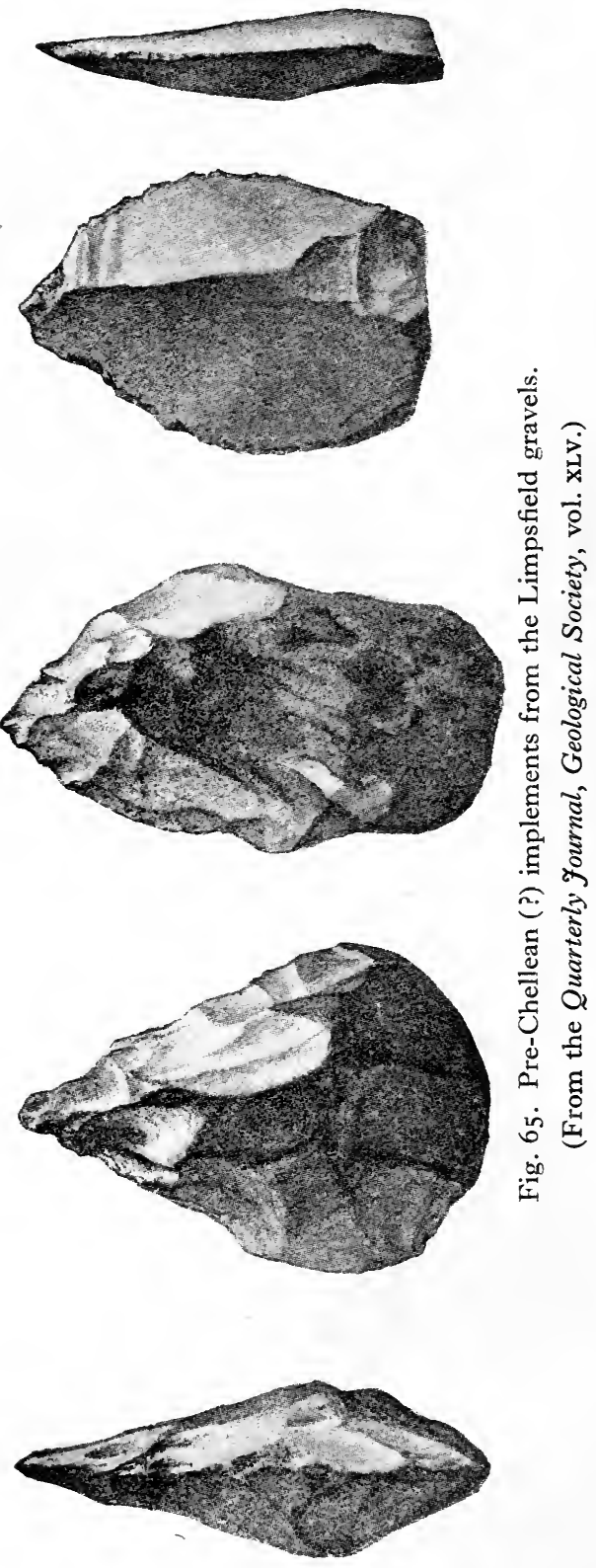
shewed three layers of gravel, with interspersed beds of loam. The lowest layer of gravel contained numerous crude flakes, apparently Pre-Chellean. The middle layer shewed Chellean ficrons and coupsde-poing of late facies, tending to Acheulean. The upper layer was practically sterile. No very satisfactory light was thrown by this investigation on the question whence came the fine Acheulean coupsde-poing which in past years this site has yielded; the authors indicate reasons for assigning them to the middle gravels. But the stratification has been shamelessly neglected by the hordes of collectors who have ravaged this important site, caring for nothing but the enrichment of their cabinets, and nothing can now be certain. Not improbably many of the Acheulean implements came from the I5-mètre terrace.

IV. The I5-metre terrace was formed before the close of the Acheulean period. It was the site of a workshop of Acheulean tools at Crayford, and of another at Grays Thurrock. These resembled the "Floors" at Caddington and Stoke Newington; the latter is on the same terrace. At Crayford, as at Caddington, the site is overlaid with a bed of brick-earth ${ }^{1}$.

V. The fifth stage was that of the ponding of the lower waters of the Thames, producing the brick-earth just mentioned. It contains Mousterian implements.

VI. The sixth stage is marked by the third terrace, 6 mètres lower.

VII. The next event in the history of the valley was an elevation of the land to a height of at least 27 mètres, and a consequent deepening of the bed of the river. This old bed has been found in deep borings, both in the main stream and in the tributaries; a list of these borings with their depths will be found in the paper by Hinton and Kennard already referred to.

VIII. Finally the land sank again to its present level, and the deepened bed was filled again with alluvium, through which the present channel is cut. These latter stages are described only briefly here, as they belong to a period later than that which is the subject of the present chapter.

The river next in importance is the OUSE. In the case of this river, a sketch-map of whose course is given in Fig. 66, the interest

Report on Excavation, etc." (ibid. Lxv. [1913-4], p. I87). References to earlier authorities will be found in the footnotes to these papers. See also Iidem, "The Palaeolithic sequence at Swanscombe, Kent" (Fourn. Geologists' Association, xxv. [1914], p. 90).

1 F. C. J. Spurrell, "On the discovery of the place where Palaeolithic inplements were made at Cravford" (Q.F.G.L.S. xxxvi. [1880], p. 544). See also R. H. Chandler, "The Pleistocene deposits of Crayford" (Proc. Geol. Assoc. xxv. [1914], p. 61).

M. E. A. I. 


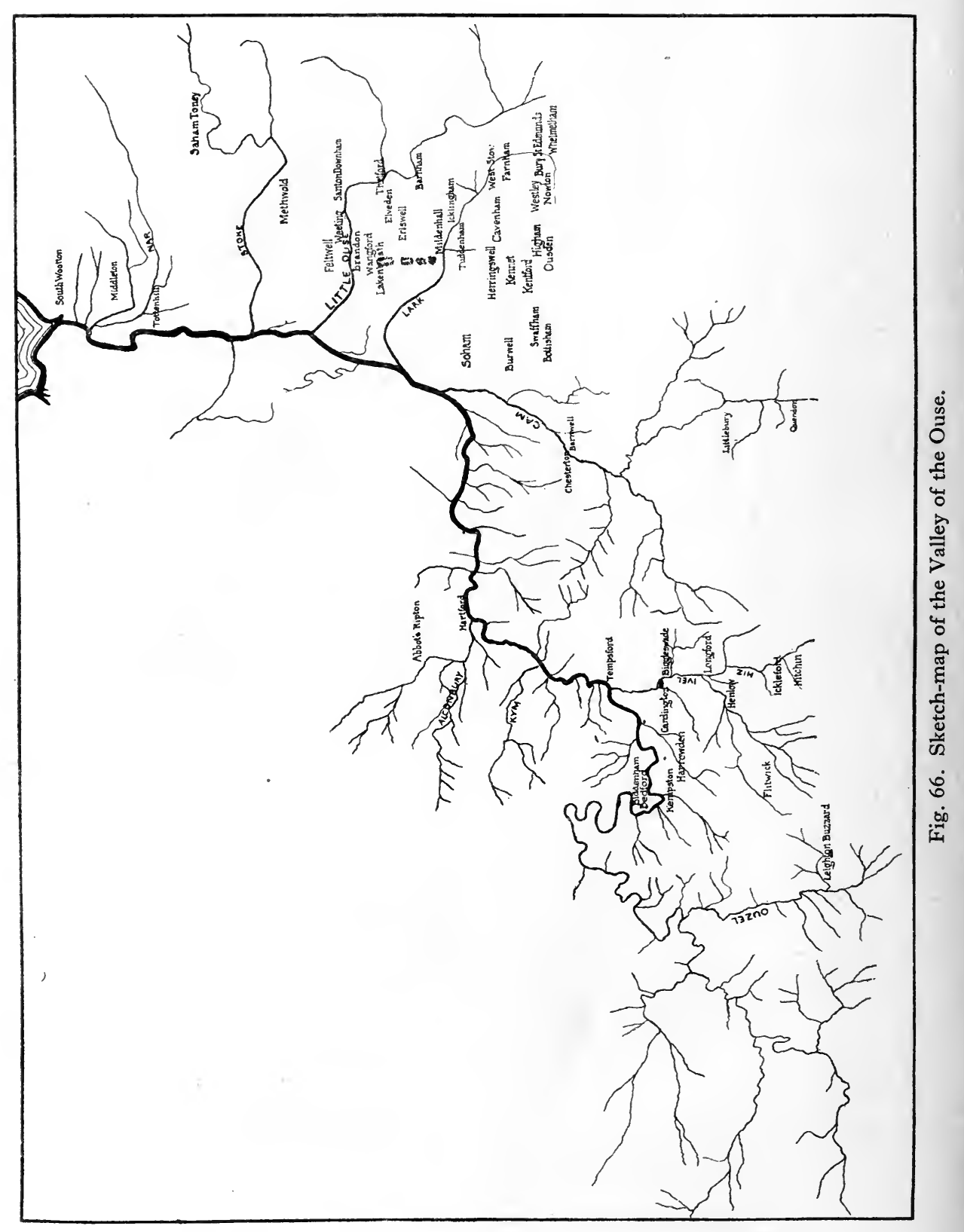


is concentrated on the subordinate tributaries rather than on the main stream. The latter flows for part of its course through the Fen district of East Anglia, which is almost bare of Palaeolithic remains. Indeed, Biddenham near Bedford is the only really important Palaeolithic site on the main river.

The tributaries which call for special notice are the Lark and the Little Ouse. The latter flows past Brandon and Thetford, both of them important sites. The Lark, however, is the more interesting of the two. Sir John Evans ${ }^{1}$ first pointed out the archaeological importance of this river, and offered an explanation of its geological phenomena. A more complete investigation (possibly open to future revision in some respects) is due to Dr Allen Sturge ${ }^{2}$.

Previous to the formation of the present Lark valley a river ran northward, passing through the neighbourhood of Mildenhall, and depositing gravels, some of which still remain in the form of a ridge, running, with three interruptions, from Mildenhall to Lakenheath. This ridge abuts on the Lark valley, which is here no less than 3 kilomètres wide - a striking contrast to the small stream that now flows through it. On the other side of the valley the gravels reappear. (The place of this ridge is indicated by hatching on the map, Fig. 66.) The cuttings which interrupt the course of the ridge are of different widths, the northernmost being the widest, and the southernmost the narrowest.

These gravels do not represent one stage only of the ancient river's history. At the south end they are 2 I mètres above Ordnance Datum, and 9 to 12 mètres above the surface of the modern river Lark, in what is known as the Warren Hill Pit. The remaining gravels are at about 30 mètres above Ordnance Datum.

The Warren Hill Pits contain oval implements with a sharp edge all round; an Acheulean type of rather early facies. The higher gravels are superposed river-bottom gravels, not terrace gravels, and they contain tools also Acheulean, but of the later long pointed triangular type.

The Warren Hill flints are not in their original position. They have lain elsewhere long enough to receive a patina, have then been water-rolled and chipped, and the chipped surfaces have once more become patinated, before they found their resting-place in the rivergravels at Mildenhall. Considering the extreme slowness with which patina forms, it will be seen that the Acheulean period must have been of enormous length.

1 Stone, p. 68I ff.

2 Proceedings Prehistoric Society of East Anglia, vol. I.; Victoria County History of Suffolk, vol. I. p. 235 ff. 
Erosion has completely destroyed the sides of this ancient river. On the western side the bank has been sunk to the level of the Fenland, 24 mètres below the average level of the ancient riverbottom, now the top of the gravel ridge. On the eastern side there is the deep and wide valley of a later river, now dry, 18 mètres below the level of the top of the ridge.

The next stage in the history of the district was the formation on the west side of the ridge of a fresh-water lake, which slowly deposited a sediment of brick-earth. Within this brick-earth Mousterian implements have been found. On the eastern plateau there were great floods from time to time. These were normally drained by the Lark, which now began to flow, and by three other streams which made the three cuttings in the gravel ridge. In some great rush of flood waters another bed of gravel was swept over the brickearth. This gravel contains Acheulean implements, which here, owing to the exceptional cause mentioned, overlie the later Mousterian.

The last stage of the history was the formation of the river on the eastern side parallel with the ridge. At first a small tributary of the Lark, this river gradually worked its way northwards, and captured in turn the three streams which had formed the interruptions in the gravel ridge. As the southernmost stream would naturally be the first to be thus deflected, its cutting is the smallest.

In making any chronological estimate of the antiquity and duration of the successive stages of the Palaeolithic Period in England, time must be allowed for these striking changes.

The third river system which calls for special mention is the ancient SolENT river, the greater part of which is now sunk in the sea. The existing fragments of the main stream are the Frome, and the Solent strait between the Isle of Wight and the mainland. The former tributaries of the Solent river have now become independent streams. (See the Sketch-map, Fig. 67.)

It has been shewn ${ }^{1}$ that in late Pliocene times this river received an important tributary fed by the upper waters of the Avon (above the site of Salisbury), the Nadder, and other rivers which meet at this point and joining the main stream at the mouth of what is now Southampton Water. The lower Avon was a separate river, flowing into the Solent River near its confluence with the Stour, but not reaching back to the site of Salisbury. The old course, at this stage of the history, is represented in Fig. 67 (a diagram on which, as on the other maps, the sites of Palaeolithic finds have been

1 Clement Reid, Geology of the Country round Ringwood (Geological Survey Memoirs, 1902).Idem," The Island of Ictis"(Archaeologia, LIX.part ii. [1905], p.281). 


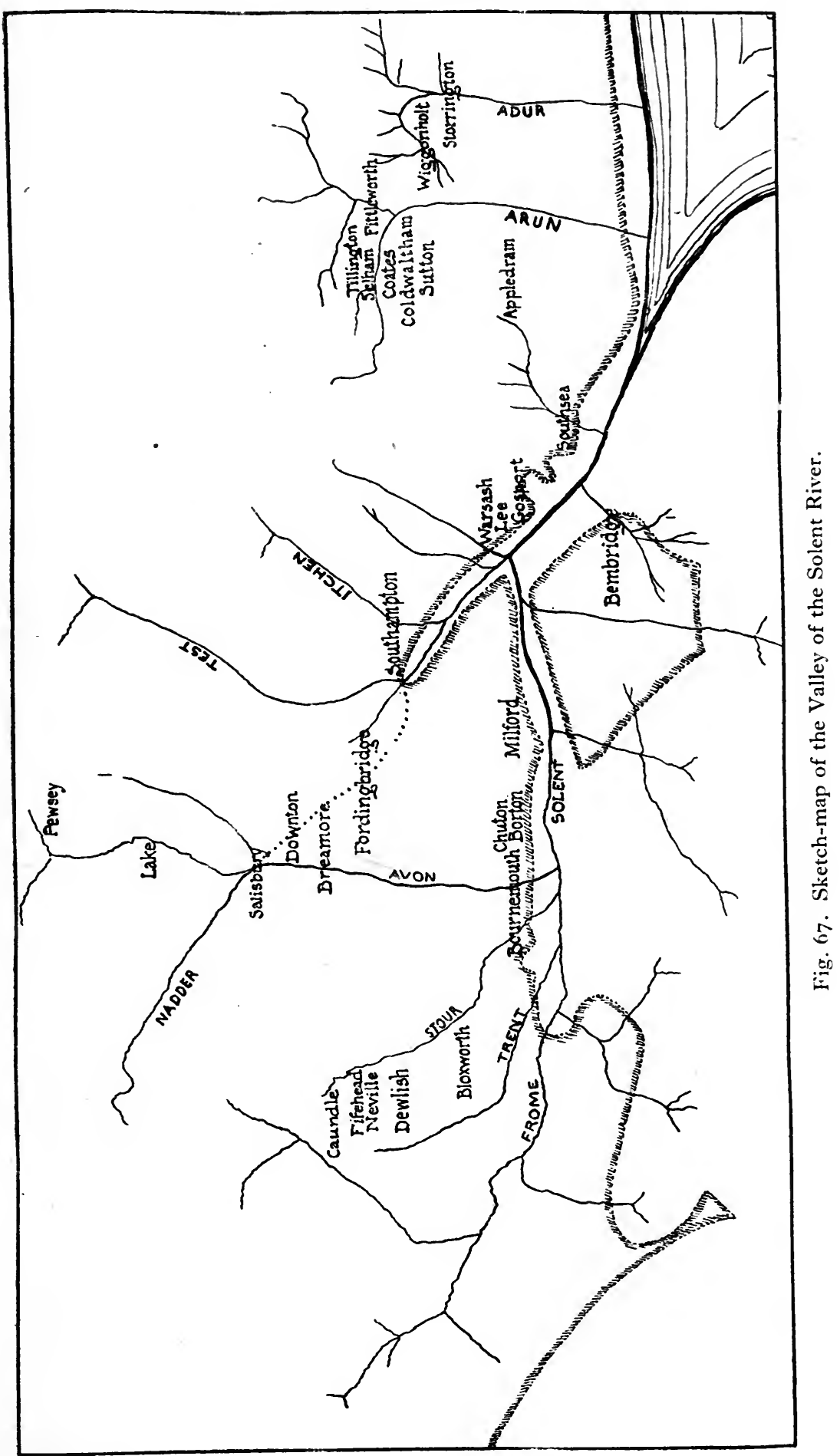


marked). Gradually, however, the lower Avon crept inland, and, at last reaching Salisbury, it tapped the Southampton Water tributary, deflecting it into the course shewn by firm lines in the figure. The greatly increased volume of water resulting from this change increased the erosive and carrying power of the Avon, in consequence of which we find along its banks a well-marked series of terrace gravels. Some of these contain implements. These terraces may be thus described:

High-level plateau I 20 mètres above Ordnance Datum.

First terrace (early glacial) $\quad \ldots \quad$ I05

Second terrace (mid-glacial) $\ldots . \quad 90$

Third terrace (Palaeolithic) ...

Valley-bed gravels (late glacial)

90,

75 ,

30 ,

Recent alluvium partly overlying the last-named.

Flints, of Acheulean types, have been found along the course of the river Avon, nearly all of them in the new bed below Salisbury. This city, with its environs, has proved a rich site, and a few "wanderers" have been found in the upper reaches of the river, and on higher levels.

Next to the Avon valley, must be named the trapezium of land intercepted between Southampton water, the Test, the Itchen, and the railway-line from Romsey to Eastley; as well as the high-level gravels on the eastern side of the Itchen. It is said that flints (ficrons, as well as ovate and triangular Acheulean implements) can be found in this region almost wherever one chooses to dig ${ }^{1}$.

The Frome, which, as has been said, is the last relic of the main stream, is unproductive. The gravels on the flat-topped hills round Wareham occasionally yield Palaeolithic implements, as do the plateaux of Bournemouth and the New Forest. These are presumably gravels deposited by the main stream ${ }^{2}$. Near the Trent, which has just escaped from servitude, is Dewlish, where Evans reports the discovery of a coup-de-poing.

The other implement-bearing sites do not call for such full description here. They all lie within a line drawn from the Wash to the Severn; outside that line the only places where Lower Palaeolithic implements have been certainly found are at Saltley, Warwickshire, where a quartzite coup-de-poing was found in the gravels of the river $\mathrm{Rea}^{3}$; at Walton in the same county, where a flake was found

1 W. Dale, "The Palaeolithic implements of the Southampton gravels" (Papers and proceedings of the Hampshire Field Club, 1II. [1894-7], p. 261). See also Clement Reid, The Geology of the Country around Southampton (Geological Survey Memoirs, 1902); Evans in Q.F.G.S.L. xx. pp. 188-9; and P.S.A. xxI. 37.

2 Clement Reid, The Geology of the Country around Dorchester (Geological Survey Memoirs, I 899).

3 Evans, Stone, p. 579. 
in the river Avon ${ }^{1}$ : and at Huntow, near Bridlington, Yorkshire ${ }^{2}$ where also a Palaeolithic implement has been picked up. What accidental cause brought these "wanderers" to the places where they were found it is impossible to guess ${ }^{3}$. Otherwise Palaeolithic flints have been found in a few places along the river Nene in Northamptonshire; at Hoxne ${ }^{4}$ and at Bungay on the Waveney; scattered through Norfolk, Suffolk, and Essex north of the Thames, and Kent and Surrey to the south of the Thames. They are found in diminishing quantities as we proceed westward in the southern counties, until we reach the Axe in Devonshire, the gravels of which have yielded a few flints. After this no more have been found.

The reason for the absence of Palaeoliths in the extreme southwest is probably the former greater elevation of the land. The existing land-surface was the ridge at the summit of a fairly lofty range of mountains, raised above the forest-belt. It thus was beyond the ordinary range of the Palaeolithic hunters, who confined their excursions to the regions where the animals which they chased were ordinarily to be found. The stations and hunting fields were thus on the lower ground, which is now sunk beneath the sea ${ }^{5}$.

The following is a list of sites and references supplementary to those in Evans, Stone, and to those in the Victoria County Histories. The compilation has cost no little time and trouble. Doubtless many references have been missed; it would probably be impossible to make the list complete unless the time at one's disposal was quite unlimited.

\section{CAMBridgeșhire}

Downham: S. B. J. Skertchly, The Genlogy of the Fenland (Geol. Survey Memoirs, I875), p. 203.

Furze Hill, near Hildersham: Proc. Geol. Association, xxvi. [191 5], p. I I.

Fenland, Archaeology and Geography of: British Archaeol. Association, N.S. v. [1809], p. 277.

\section{DEVONSHIRE}

Axe Valley, near Chard: Devon Association for Advancement of Science, Literature and Art, xxviII. [1896], 58.

Otterton, Palaeolithic flaked arrow-head (sic) found in a ploughed field: ibid. xxxIII. [1901], II6.

1 Victoria County History of Warwickshire.

${ }^{2}$ Evans, Stone, p. 572.

3 Certain palaeoliths in stone other than flints have been reported from riverdrifts in North Lancashire (Proceedings Prehistoric Soc. E. Anglia, II. 61). The photographs of these objects cannot be called convincing.

4 To the Hoxne site, which is of considerable chronological importance, we shall return in a later chapter.

5 Alex. Somervail, "On the probable cause of the seeming absence of Palaeolithic Man from Cornwall" (Transactions Royal Geological Society of Cornzvall, xII. [1896-1904], p. 169). 


\section{DORSETSHIRE}

Bishop's Caundle: Dorset Nat. Hist. and Antiq. Soc. XxxIr. [191 I], p. xxxvi.

Bloxworth: ibid. xxxiII. [1912], p. xiii.

Fiddleford: ibid. xxxII. [I9II], p. xxxvi.

Fifehead Neville: ibid. xxxII. [I9I I], p. xxxvi.

Holmbushes: ibid. xxxII. [I9II], p. Xxxvi.

\section{Essex}

Chadwell: Prehistoric Society East Anglia, 1. p. 117.

Dovercourt: ibid. pp. I 1 2, 360.

Grays Thurrock: Essex Naturalist, vol. vi.

Ilford: Proc. Geol. Association, xvI. p. 84; Essex Naturalist, vol. XII.

Leyton: Essex Naturalist, vol. XIII.

Mucking: Antiquary, xLviII. [1912], p. 57.

Orsett Heath: Antiquary, xLvIII. p. 57.

Stanford-le-Hope: Antiquary, xLviII. p. 57 ; Prehist. Soc. East Anglia, vol. I. p. 117.

\section{HAMPSHIRE}

Bembridge (Isle of Wight): Bristow, Geology of I.O.W. (Geol. Survey Memoirs, I 889), p. 222.

Isle of Wight, North-east Coast: British Association Report, Cambridge [1904], p. 7 I 5 .

Shirley: P.S.A. xxIII. p. 409.

\section{HERTFORDSHIRE}

Great Gaddesden: Transactions Herts. Nat. Hist. Society and Field Club, xIv. [1907-1 I] p. 1 .

Hemel Hempstead: ibid. xIv. [1907-I I], p. I.

Hitchin: ibid. x. [1897-1900], p. 14; xI. [1900-1902], p. 63.

Kensworth: ibid. XIV. [1907-I I], p. I.

Knebworth: Proc. Geol. Association, xxiII. [1912], p. 217.

Rickmansworth: Herts. Nat. Hist. Society and Field Club, x. [1897-1900], p. 14; XI. [1900-1902], p. 63; Archaeologia, LXVI. [1915], p. 195 .

Whipsnade Heath: same reference as Great Gaddesden.

\section{KENT}

Northfleet: F.A.I. xIIl. [1884], p. I 12 ; Archaeologia Cantiana, xv.

Rainham: British Association Report, Dover [1899], p. 753.

Swanscombe: $\mathcal{F}$.A.I. xxIx. [1899], p. 302.

Wateringbury: Topley, Geology of the Weald (Geol. Survey Memoirs, 1879), p. 178.

\section{$\times \quad$ London}

Wandsworth: Trans. Middlesex Nat. Hist. Soc. 1889.

\section{MIDDLESEX}

Hanwell: British Archaeol. Association, xIII. [1907], p. 123.

\section{NORFOLK}

See a bibliographical list of sites in this county in W. G. Clarke, "The distribution of Flint and Bronze Implements in Norfolk" (Transactions Norfolk and Norwich Naturalists' Society, viII. [1904-9], p. 393); Idem, "The classification of Norfolk Flint Implements," ibid. p. 3 I5.

Burston: F. J. Bennett, The Geology of the country around Diss, Eye, Bottesdale and Ixzorth (Geol. Survey Memoirs, I884), p. I9.

Cranwick: Prehist. Soc. East Anglia, vol. I. p. 454. 
Cringleford: H. B. Woodward, Geology of Country around Noruich (Geol. Survey Memoirs, $188 \mathrm{r}$ ), p. 145 .

Greshan: Prehist. Soc. East Anglia, vol. 1. pp. I 18,381 .

Runton: C. Reid, Geology of the Country around Cromer (Geol. Survey Memoirs, I882), p. I 20.

Rushford: Prehist. Soc. East Anglia, vol. I. p. 119.

Santon Downham: ibid. vol. I. p. 111 .

Tottenhill: ibid. vol. r. p. 118 .

Weeting: ibid. vol. I. p. I I 1 .

Wymondham: ibid. vol. 1. p. 237; Antiquary, xurv. [1908], p. 60.

Wells: H. B. Woodward, Geology of Country around Fakenham, Wells, and Holt (Geol. Survey Memoirs, r884).

\section{OXFORDSHIRE}

Wolvercote: British Association Report, Bradford [1900], p. 9 13.

\section{SUFFOLK}

Barnham: W. Whitaker and others, Geology of parts of Cambridge and Suffolk (Geol. Survey Memoirs, 1891), p. 80; Prehistoric Society East Anglia, I. 487.

Brettenham: Prehistoric Society East Anglia, I. I14.

Bungay: Antiquary, xL.Iv. [1908], p. 60; Man, vill. [1908], No. 19.

Chilton: Prehist. Soc. East Anglia, I. 109.

Clare: ibid. I. rog.

Corton: Antiquary, xurv. [1908], p. 60.

Culford: W. Whitaker, Geology of parts of Cambridge and Suffolk; Proc. Cambridge Philosophical Society, III. p. $285 ;$ F.A.I. vII. 162.

Great Cornard: Prehist. Soc. East Anglia, r. 109.

Great Waldingfield: Man, x. [1910], No. 20.

Hawkedon: ibid. x. [1910], No. 20.

Herringfleet: same reference as Corton.

Ipswich: British Association Report, Cambridge [1904], p. 725, York [1906], p. $693 ;$ F.A.I. xxxIv. [1904].

Normanton: same reference as Corton.

Stanstead: same reference as Great Waldingfield.

Thetford: Q.F.G.S.L. xxIII. p. 45.

\section{SURREY}

Mitcham: Science Gossip, N.S. vir. 69, 177, 221.

Sussex

Arun valley, various sites: $P . S . A . \mathrm{xx} . \mathrm{x} 97$.

Midhurst: P.S.A. xx. 207.

\section{WILTSHIRE}

Hackpen Hill : Q.F.G.S.L. L.xv. [1909], p. 166.

Savernake: ibid. LXV. [1909], p. 166; also Man, 1II. [1903], No. 29, vi. [1906], No. $26 ;$ F.A.I. xxxI. [190I], p. 3 10; P.S.A. xxIII. 453 .

Winterbourne Bassett: Q.F.G.S.L. LXv. [1909], p. 166.

\section{(6) Psychology of Lower Palaeolithic Man}

Of the mode of life, and, using the word in a very general sense, the psychology of Lower Palaeolithic Man we know next to nothing. $\mathrm{He}$ was probably in all respects lower, perhaps inconceivably so, than any savage tribe with which we can become acquainted in the 
[CH.

modern world. In fact, all that we can say about him, on the basis of the facts as yet discovered, may be stated in three propositions:

I. He was certainly a fully developed Man, capable of progress in such arts as he had evolved.

2. He lived on the product of the chase.

3. He dwelt in the open air, on the plateaux and not far from the rivers.

To these we may add the following as probabilities:

I. He was acquainted with the use of fire, and with means for its artificial production.

2. He built for himself huts of boughs, hides, etc.

3. He trapped the larger animals, as the weapons at his disposal were hardly adequate for the maintenance of a direct warfare with them.

Various efforts have been made to extend this very meagre list of secured facts. Thus, some have tried to shew that there was a cult of the axe in the Lower Palaeolithic Term; a theory based on the existence of very large and very small specimens in addition to the ordinary sizes, the last named being for use and the others for worship ${ }^{1}$. But both large and small alike shew traces of use; and the large and small specimens are not merely two categories, but two extremes to a continuous series of intermediate types. This theory, therefore, has nothing to recommend it $^{2}$.

When the aboriginal tribes of Tasmania were discovered, they were still at an early stage of their Stone Age. A description of these people may be quoted, as it gives us material for reasonably filling in the gaps which the perishable nature of materials other than stone necessarily leaves in our knowledge. I accordingly extract the following, from Cook's Second Voyage. It is a vague and superficial account, which is one reason why I have chosen it; a description too fully detailed might be misleading when applied to the men of the Lower Palaeolithic term.

There were several wigwams or huts, where we found some bags and nets made of grass, in which I imagine they carry their provisions and other necessities. In one of these was the stone they strike fire with, and tinder made of bark, but of what tree could not be distinguished. We found in one of their huts, one of their spears, which was made sharp at one end, I suppose, with a shell or stone...they seem to be quite ignorant of any sort of metal. The boughs of which their huts are made are either broken or split and tied together with grass in a circular form, the largest end

${ }^{1}$ A. Rutot, "Sur les traces de l'existence d'un culte de la hache pendant le Paléolithique inférieur" (C.P.F. Tours [1910], p. 152).

2 See the criticisms of M. A. Dubus, "Note sur les traces de l'existence d'un culte de la hache pendant le Paléolithique inférieur" (B.S.P.F. viII. [I9I I ], p. 677). 
stuck in the ground, and the smaller parts meeting in a point at the top, and covered with fern or bark, so poorly done that they will hardly keep out a shower of rain. In the middle is the fire-place surrounded with heaps of mussel, pearl, scallop, and crayfish shells, which I believe to be their chief food....They lie on the ground, on dried grass, round the fire; and I believe they have no settled place of habitation (as their houses seemed built only for a few days) but wander about in small parties in search of food, and are actuated by no other motive. We never found more than three or four huts in a place, capable of containing three or four persons only; and what is remarkable, we never saw the least marks of canoe or boat, and it is generally thought they have none, being altogether a very ignorant and wretched set of people, though natives of a country capable of producing every necessary of life $\mathrm{e}^{\mathbf{1}}$.

Even this short and very general description cannot be applied to the Lower Palaeolithic people without reserve. It would be easy for such small communities to maintain themselves in a country like Tasmania, which has no large formidable beasts, and in which nature produces the materials of food lavishly. But this would not be the case in Lower Palaeolithic Europe. There only a community of some considerable size would be able to exist, surrounded as they were by large and savage animals.

We may, if we like so to amuse ourselves, visualise the people who made the rude implements of Chelles, as roaming over the plains under their pleasant climate, surrounded by gigantic animals which they trapped or slaughtered with their heavy clubs, and on whose flesh they fed. But we have no authority to fill in the outlines thus summarily sketched ${ }^{2}$. We know nothing of their dress or ornaments (save a few perforated shells and stones); we know nothing whatever of their religion, their moral instincts, their language, customs, sepulture, tribal relationships, or social organization. To complete the picture would be to exchange the rôle of the truthseeking student for that of the novelist-one can hardly even say the historical novelist: and the most favourable verdict that could be passed on such work would be, c'est magnifique, mais ce n'est pas... la science!

1 Quoted from the edition in Kerr's Collection of Voyages and Travels, vol. xiv. p. Ir3.

${ }_{2} \mathrm{Mr}$ Worthington Smith, in Man, the Primeval Savage, chap. II. has essayed the task. The resulting picture is not pretty. 


\section{CHAPTER VII}

\section{THE MIDDLE PALAEOLITHIC STAGE}

\section{(1) Conditions of life in the Middle Palaeolithic Term}

Le Moustier is situated near to the village of Les Eyzies on the right bank of the Vézère, a tributary of the Garonne flowing through the department of La Dordogne. Here, some 200 mètres away from the river and about 24 mètres above its level, there is a little cave with a small flat table-land in front of it. The remains discovered in this cave have been accepted as typical of the stage now to be described, called from the name of the place in question the Mousterian stage. This single stage fills the whole of the Middle Palaeolithic Term.

Some authorities would group the Lower and the Middle Palaeolithic Terms together, under the single comprehensive name of Chelleo-Mousterian. It is, however, preferable to separate them, while acknowledging that (as in the case of all such divisions) it is impossible to assign a definite limit separating the one from the other. For Mousterian Man in Western Europe lived in very different conditions from those which his predecessor had enjoyed. The torrid temperature which Chellean Man had experienced, the still pleasanter and healthier moderately warm climate under which Acheulean Man had lived, had now given place to a climate which was cold and damp. The caves afforded a more substantial refuge from the weather than the flimsy huts in which we may imagine the men of the earlier stages as living; and so to the caves Man now began to resort in quest of a habitation. There was some overlap between the two kinds of dwelling; Mousterian implements have come to light in the upper strata of the river drifts or in associated brick-earths, and Chellean and Acheulean tools shew that Lower Palaeolithic Man on occasion used the caves as at least temporary refuges; the cave of Castillo in Spain affords an example of this. But such cases are exceptional; they prove nothing more than that the change, like most changes, was gradual. In the Mousterian stage, we are entitled to say, man definitely ceased to be a riverside-dweller, and became a cave dweller.

This had some consequences of importance. The cave life was certainly much less healthy than the old open-air existence, and even apart from the harder conditions that prevailed in the Middle Palaeolithic Term this might have been expected to influence injuriously 
the stamina of the people. True, as the accumulations of kitchen débris shew, the home was rather in the mouth than in the inner recesses of the cave; for it is usually in the mouth of the cave that the piles of refuse are to be found. But even here the lungs of the community would be affected by the choking smoke of the hearths. Driving rains would send the people to sleep in the damp interiors of the caves, with the result that they were not exempt from rheumatism and allied diseases. Thus at Krapina, an important station to be more fully described presently, several of the numerous human bones found shewed lesions of arthritis deformans ${ }^{1}$ and one of the jaws from the same site shewed the oldest known case of dental fistula ${ }^{2}$. The accumulation of piles of decaying refuse about the entrances to the habitations, however indifferent and hardened to them the people might have been, cannot have been healthy. The close confinement of a necessarily limited community, isolated from other similar groups, would probably lead to inbreeding with all its attendant physical disadvantages. These adverse influences, combined with an increasing difficulty of obtaining food, owing to the more rigorous climate and to the consequent restriction of animal life, must have had a degenerating effect upon the population. Signs of this degeneration are clearly visible, both in the physical constitution of the people and in their handiworks; and it culminated in their total disappearance.

\section{(2) Human remains of the Middle Palaeolithic Term}

When we reach the Mousterian stage we at last find ourselves tolerably well supplied with material for the study of the physical characters of the tool-makers. We now proceed to give a brief description of the principal human remains which have been discovered belonging to this stage.

I. Neandertal. It is natural to begin with the fragments from Neandertal, not because they offer the best specimen of Mousterian Man known, but because they were the first of their kind to attract scientific notice. The name has, in consequence, become indissolubly associated with this type of humanity. But for several reasons the Neandertal skeleton does not fulfil the ideal of a typical specimen. It is very imperfect: and it was not found associated with any datable objects, so that its period has to be determined by analogy with other

$1 \mathrm{~K}$. Gorjanović-Kramberger, "Anomalien und pathologische Erscheinungen am Skelett des Ur-Menschen aus Krapina" (Korrespondenzblatt d. deutsch. Gesellsch. f. Anthropologie, xxxIx. [1908], p. 108).

2 Prof. A. F. le Double, La Médecine et la Chirurgie dans les temps préhistoriques et protohistoriques, Tours, $191 \mathrm{I}$. 
skeletons, found later, which display the same characteristics. Like the Piltdown skull, the Neandertal skeleton has no light of its own to shed; it requires all the light available from other quarters for its own explanation. The tooth of a bear found in the cave with the skeleton,

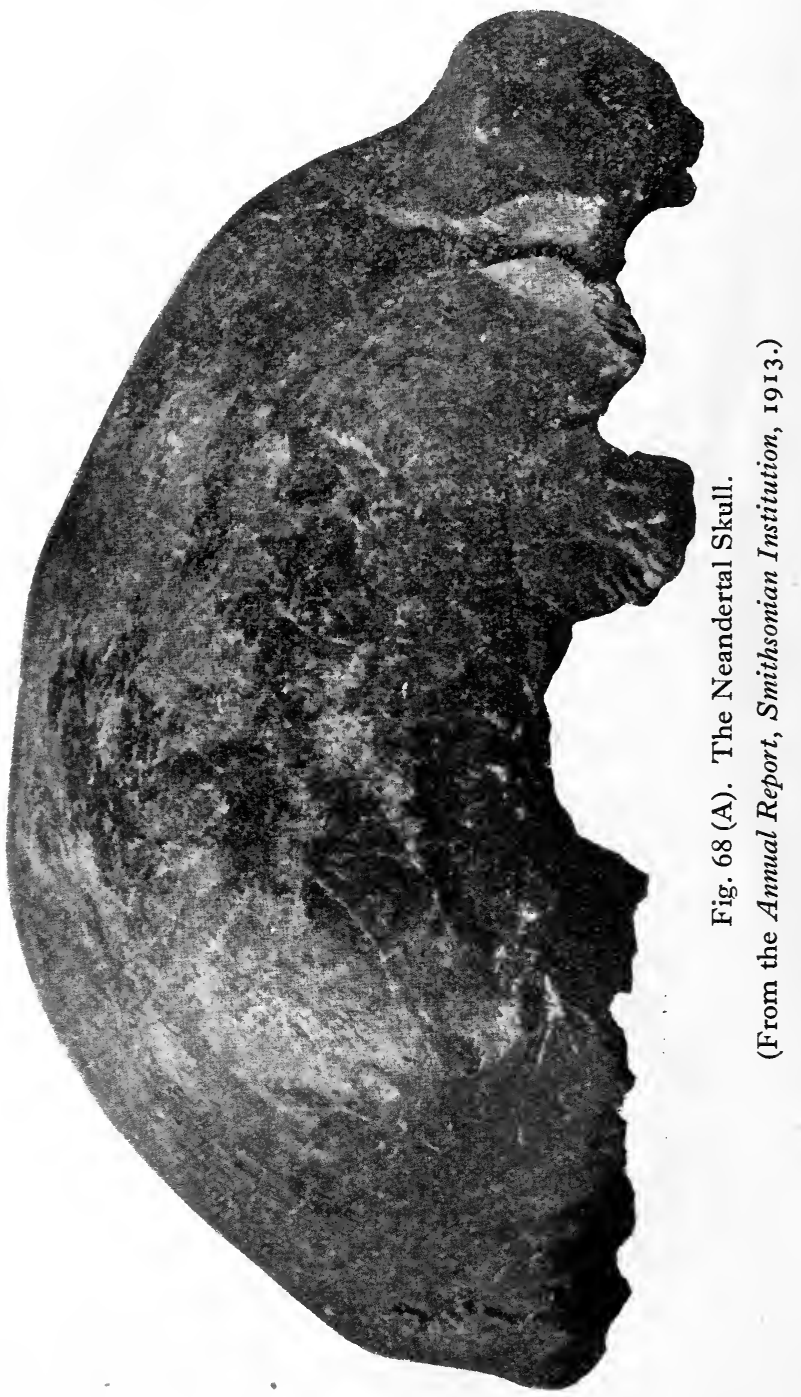

and some animal bones found in similar soil in an adjacent cave, and presumably though not certainly contemporary, offer the only direct evidence of date available.

The skeleton came to light in a little cave called Feldhofergrotte 
in the Neandertal, a valley lying half-way between Düsseldorf and Elberfeld, in the year 1856 . The cave was being quarried, and the bones were found embedded in its floor of solid mud, which was

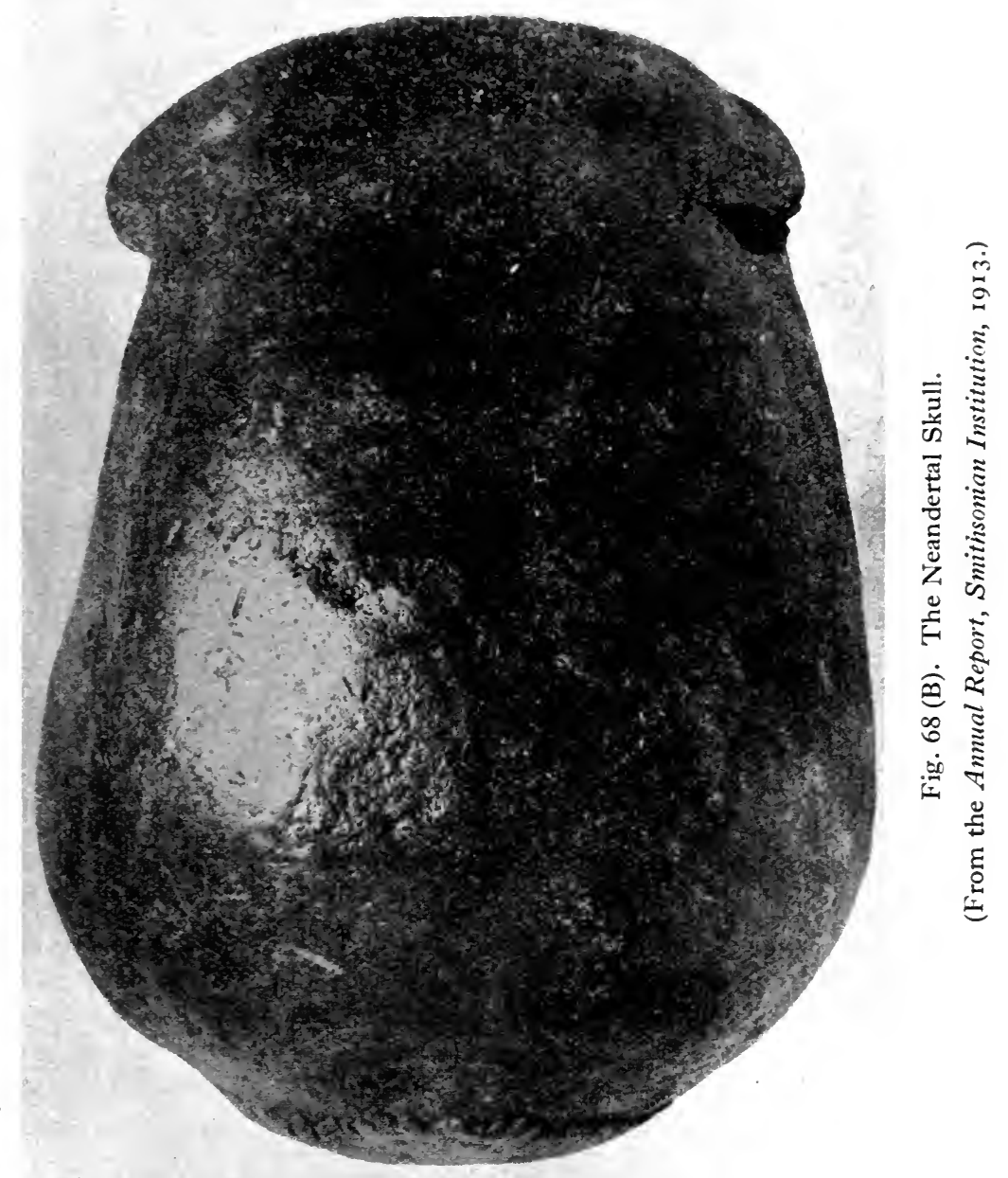

about 5 feet deep. The labourers who uncovered the bones took no special notice of them, and it was only the chance of a local physician, Dr Fuhlrott, coming on the scene that saved the fragments which have been preserved. Very likely the skeleton when uncovered was 
perfect, but nothing remains of it except the skull-cap, some of the long bones of the limbs, and one or two of the smaller bones. They are preserved in the provincial museum at Bonn.

The limb-bones of the skeleton are unusually thick, and shew by the great size of the muscular attachments that their owner had been a person of great strength. He had led a stormy life; the bones display marks of serious injuries which he received from time to time. Indeed one surgical authority has said that "the individual presents traces of traumatic lesions" (i.e. of injuries due to wounds), "of infantile rickets, and of arthritis deformans. Notwithstanding, he lived to an advanced age, which, according to Virchow, he could not have done had he not received attentive care from his fellowtribesmen ${ }^{1}$."

The skull, of which only the top remains, is remarkable for its great size and thickness, as well as for the extremely sloping forehead, low vault, and the enormous development of the bony ridges over the brows. According to Hrdlička ${ }^{2}$ the "sagittal suture [the line of junction between the frontal bone and the parietal bones] has evidently closed earlier than it does in the modern man, but this must have taken place after the brain had ceased to influence the cranial vault, for it resulted in no deformation. The coronal suture [that between the two parietal bones, running along the top of the head] is obliterated up to the temporal ridges, while the lambdoid [the triangular suture between the two parietal bones and the occipital bone at the back of the head] is still patent." This early closing of the sutures may perhaps indicate that as in many uncivilised races of the present day the growth in the intelligence of the individual ceased at a comparatively early age. The cephalic index is $73 \cdot \mathrm{I}$.

"The brain which filled the skull was lower and narrower and slightly more pointed than the human brain of to-day, approaching in these features more the anthropoid form. The right frontal lobe was slightly larger and longer than the left, and the whole right hemisphere was slightly longer than that of the opposite side. In the present man it is generally the left hemisphere which is the longer, but this exception in the Neandertal man is not necessarily of any special significance ${ }^{3}$ " (Fig. 68).

Not only was the skull clearly inferior in type to that of modern humanity; all the other bones which were rescued display signs of

${ }_{1}$ R. Lehmann-Nitsche, Beiträge zur prähistorischen Chirurgie nach Funden aus deutscher Vorzeit, Buenos Ayres, I898. (Analysed in L'Anthr.x. p. 689, from which the quotation is made).

2 Aleš Hrdlička, "The most ancient skeletal remains of Man" (Annual Report, Smithsonian Institution, I913), p. 5 I8.

${ }^{3}$ Hrdlička, op. laud. p. 520. 
a less advanced development ${ }^{1}$. The man of Neandertal throughout his whole body was more primitive than the man of to-day ${ }^{2}$.

II. Gibraltar. Though the Neandertal skeleton was the first of its type to attract attention, it was not actually the first discovered. That credit belongs to a skull found in the Forbes Quarry, Gibraltar, in 1848 , and now in the Museum of the Royal College of Surgeons, London. The exact circumstances of the discovery can no longer, at this distance of time, be recovered; and though in recent years the site has been carefully searched, no further light on the remains has been found, except that the discovery of Mousterian flints in a cave close to the site, if this could be confirmed (for the reason for this condition see the footnote), would be corroborative evidence for a Mousterian occupation of the region ${ }^{3}$.

The skull, which is smaller than most of the other skulls of the Neandertal type, seems to have belonged to a woman. Though the lower jaw is lost, the facial bones are well preserved, which can be said of only one other skull of its type; and the base of the skull remains in this and in no other specimen (Fig. 69). The leading characteristics of this skull are: its dolichocephaly (cephalic index 76.7); the very large nasal openings; the gigantic eye-sockets, which are great circular cavities, with an exceptionally wide space between them; the sloping forehead; the absence of the canine fossa-a depression between the nasal openings and the cheek-bones; and the flat and very simian skull-base. The brow-ridges are in this specimen less prominent than they are in other skulls of the type, which is possibly on account of the sex of the individual; perhaps for the same reason the brain of the skull was the smallest "Neandertal" brain as yet known. The jaw arches are horse-shoe shaped, not divergent as in modern man ${ }^{4}$.

III. La Naulette. The Trou de La Naulette is one of the numerous fissures in the rocky (carboniferous limestone) banks of the river Lesse, a tributary which flows into the Maas near Dinant. These

1 As enumerated by Hrdlička these bones are the femora, the humeri, the ulnae, the right radius, and parts of the left pelvic bone, of the right scapula, of the right clavicle, and of five ribs.

${ }_{2}^{2}$ On the Neandertal skeleton see Lyell, Antiquity of Man; Hamy, Précis de paléontologie humaine, p. 236; Obermaier, "Les restes humaines quaternaires dans l'Europe Centrale" (L'Anthr. xviı. [1906], p. 69), where a full bibliography will be found; Keith, Antiquity of Man, chaps. vi.-viii.

3 See W. L. H. Duckworth, "Cave Exploration at Gibraltar in September, 1910" (F.A.I. XLI. [1911] , p. 350); Idem, "Cave Exploration at Gibraltar in I91 I" (ibid. XLII. [1912], p. 515). The evidence, however, appears to be inconclusive, for the author says, in the second paper, that even the flints "of Mousterian form must, in my opinion, be attributed to a Neolithic culture."

- For further particulars regarding the Gibraltar skull see Keith, op. laud. p. 124; Hrdlička, op. laud. p. 512 ; P. Broca, "Remarques sur les ossements des cavernes de Gibraltar" (B.S.A.P. ser. II. vol. Iv. [1869], p. 154).

M. E.A. I. 
caves were explored in the sixties of the last century by the energetic Edouard Dupont, a fuller account of whose work will be given on a later page. The cave which at present concerns us is on the left

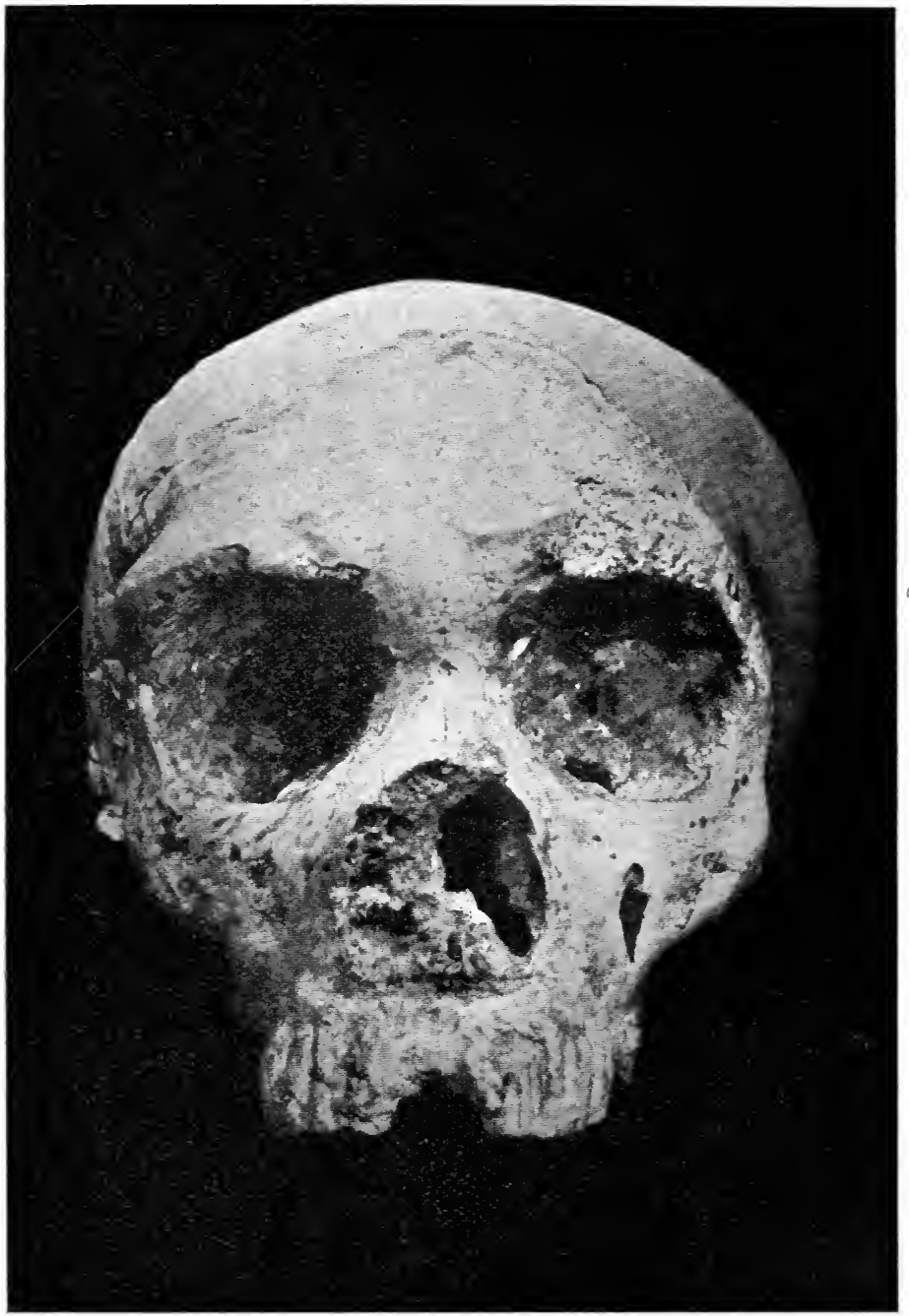

Fig. 69. The Gibraltar skull.

(From the Annual Report, Smithsonian Institution, 1913.)

bank of the Lesse, 25 mètres above the present level of the river, between Walsin and Chaleux. Its opening is not very broad, and it was further narrowed by great blocks fallen from the roof, through 
which the explorer had to cut a way before the excavation could be satisfactorily prosecuted. The length of the cave is over 60 mètres, its mean breadth 10 mètres.

At the entrance there was a thick deposit of yellow clay with fallen blocks of stone intermingled, and bones of horse and reindeer. This was 3 mètres thick at the entrance, but rapidly thinned out towards the interior of the cave, so that it disappeared at 4 mètres from the entrance. Behind this a great fall of stone from the roof had to be cleared away, consisting of about 300 square mètres of hard limestone, before the underlying strata could be examined. These were found to be as follows, in the interior of the cave:

7. Grey clay, surmounted by sandy clay, stratified; at its base third ossiferous level, including bones of sheep and other ruminants. 2.50-3 mètres.

I. Five more or less continuous beds of stalagmite alternating with grey stratified clay of variable thickness. I' $50-1 \cdot 75$ mètres.

$H$. Grey clay surmounted by stratified loam. Second ossiferous level, including Human bones, Elephas primigenius, Rhinoceros tichorhinus, Rupicapra tragus, Sus scrofa. 0.60-0.70 mètre.

$G$. Stalagmite, a continuous and generally the thickest bed.

$F$. Grey clay with great blocks of limestone, surmounted by stratified loam. First ossiferous level, including Hyaena and various animal bones gnawed by Hyaena. 0.50 mètre.

$E$. Stalagmite of varying thickness.

$D$. Yellowish clay containing large blocks of fallen stone. 0.80 mètre.

C. Clayey sand alternating with small discontinuous layers of sand and sandy clay. $I \cdot I 5$ mètres.

$B$. A series of strata of sand and gravel, total thickness $0 \cdot 70$ mètre.

$A$. Fine gravel. 0.60 mètre.

Cave floor underlying, covered with traces of red clay.

This stratification speaks of alternations of rise and fall of the river, in the course of which the alternating gravels and the stalagmite were deposited. Remembering the slow rate at which the latter material accumulates, the fact that there were no less than five layers of it above the human remains is very noteworthy. Nothing of the man of La Naulette was found except the lower jaw, a cubitus, and a canine tooth. But there were traces of his activity on the animal bones, some of which had been split to extract the marrow ${ }^{1}$ and one of which had been perforated (Fig. 70). On the other hand, there were no traces of hearths nor were there any flint implements in the layer containing the bones. Under the influence of water and

1 Marrow is a dainty appreciated by all savages, ancient and modern; it is also used as an animal fat to supply fuel for lamps. Bones split to obtain it are almost as good evidence as implements for proving the former existence of man on any site. 

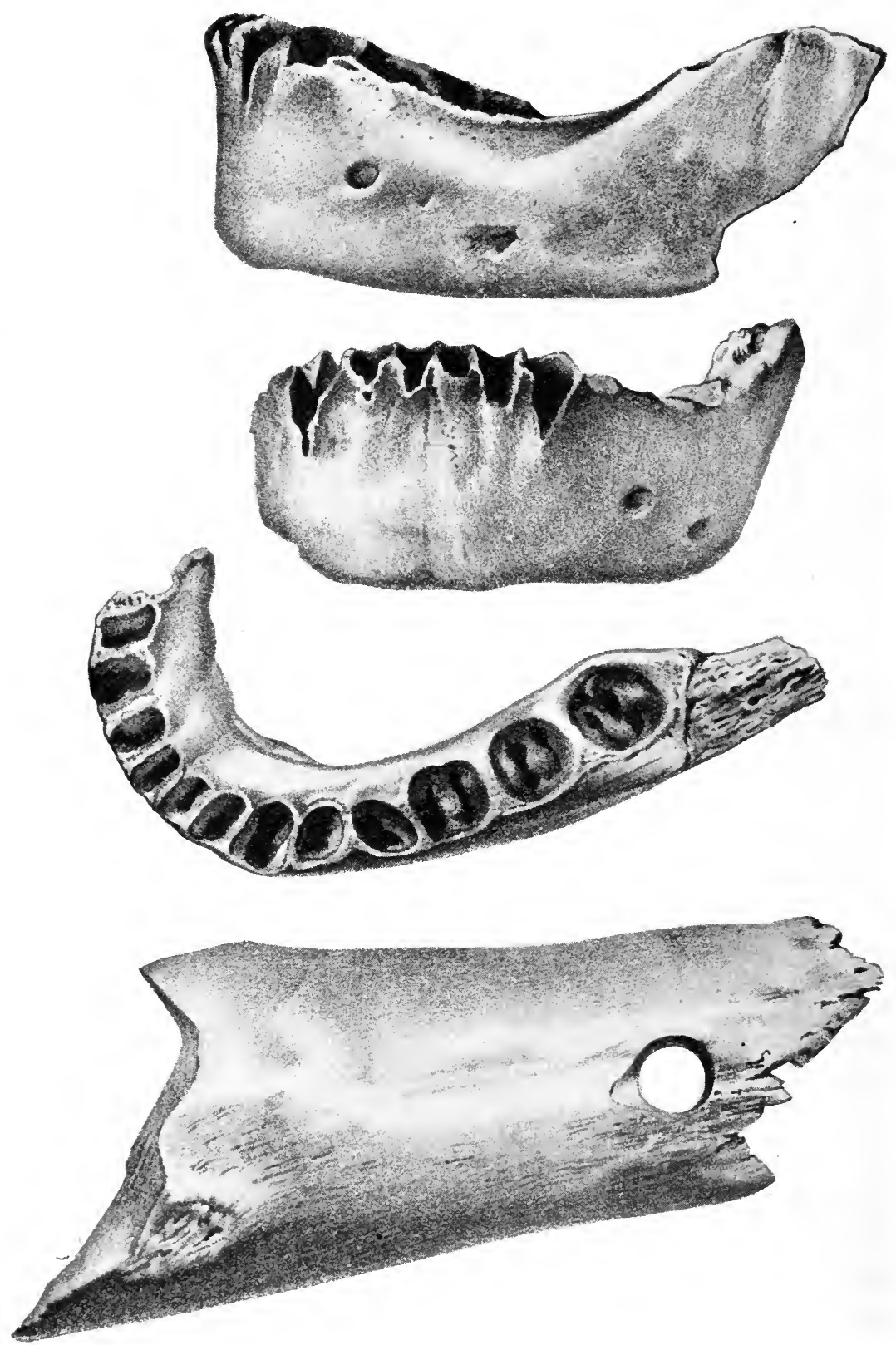

Fig. 70. Human jaw and perforated bone from Trou de La Naulette.

(From Bulletin de l'Académie de Bruxelles, vol. xxir.) 
carbonic acid the remaining bones must have corroded away; the skeletons even of modern foxes and badgers were seldom if ever found complete in these caves. It is to be noticed that the bones found with the human jaw-bone were for the greater part those belonging to the more edible parts of the animals; the vertebrae, ribs, pelvis and scapula bones were absent ${ }^{1}$.

Like the Gibraltar skull, this jaw is supposed to have belonged to a woman, whose age is estimated to have been about 30 years. It shews the following primitive characters-the thickness of the body of the bone in proportion to its height; the increase in the size of the molars from back to front; the presence of five roots in the wisdom-tooth; the small and receding chin, though the incisor teeth are not set obliquely; while on the other hand the branches of the jaw diverge clearly and have not the U-shape of the anthropoids. The structure of the symphysal region [the back of the chin-angle] is also entirely human, not anthropoid ${ }^{2}$.

IV. Spy. In, or rather in front of, a cave at Spy called Grotte de la Bèche-aux-Roches, about 8 miles eastward from Namur, Belgium, two skeletons of Neandertal type were found in the year 1886 by MM. Marcel de Puydt and Max Lohest. These were buried in the terrace in front of the cave mouth, at a depth of about 14 feet below the modern surface. The strata above were unbroken, and contained remains of later stages of the Palaeolithic period. The following is the scheme of the stratification:

$F$. Brown clay, mixed with great fallen stone blocks, sterile; 3 mètres thick.

$E$. Yellow tuff, very hard. Elephas primigenius. Flints of the end of Aurignacian, with transition to Solutrean, and perhaps a little Solutrean. $0.80-$ I mètre thick.

D. Red-coloured tuff, with numerous bones of Rangifer tarandus, Rhinoceros tichorhinus, Elephas primigenius. Ivory and bone implements, as well as Aurignacian flints of typical character (end of Middle Aurignacian). $0.05-0.30$ mètre thick.

$C$. Very hard breccia mixed with yellow clay; a layer of wood ash at the bottom. 0.15 mètre thick.

$B$. Brown earth veined with black towards the base, ranging from some centimètres to I mètre in thickness. Well worked typical flints of

1 For Dupont's account of his exploration of this cave (with an elaborate coloured section of the stratification) see "Etude sur les fouilles scientifiques exécutées pendant l'hiver de 1865-66 dans les cavernes des bords de la Lesse" (Bulletins de l'Académie royale des sciences, des lettres et des beaux-arts de Belgique, XXII. [1866], p. 31); Idem, "Etude sur cinq cavernes explorées dans la vallée de la Lesse et le ravin de Falmignoul pendant l'été de 1866 " (ibid. xxıI. [1867], p. 244).

"See P. Topinard, "Les caractères simiens de la mâchoire de La Naulette" (Revue d'Anthrop. xv. [1886], p. 384). 
the later Mousterian. Human skeletons in this layer, towards its top. Same fauna as in $D$.

$A$. Older Mousterian; numerous flakes much patinated, with unskilful secondary chipping; coups-de-poing ${ }^{\mathbf{1}}$.

In the layer containing the skeletons were some Mousterian tools, as well as a fragment of bone which appeared to have been artificially worked. There were a large number of bones of Elephas primigenius, Rhinoceros tichorhinus, and a very few of Rangifer tarandus, in the same stratum.

At the time of the discovery of these bones it was hotly disputed whether the owners of the skeletons had been buried intentionally or whether they had been accidentally overwhelmed in a landslide. The controversy is now dead; later discoveries have removed the natural hesitation, that was felt at the time, in believing that Palaeolithic man formally buried his dead. The skeletons of La Ferrassie, Le Moustier, and La Chapelle-aux-Saints have come to light, and have shewn clearly that Mousterian man, sometimes at least, gave the dead the rite of sepulture. The importance of this fact will appear later.

The skeletons lay at a distance of 2.50 mètres from one another. One was lying on its side, with the hand touching the lower jaw: the original position of the second skeleton could not be properly determined, as the bones had suffered some disturbance. The skull of the first of the skeletons resembled that of the Neandertal man; the second skull was, however, of a superior type. Indeed the jaw even of No. I was less primitive than that of any other jaw of the race yet found. The people of Spy thus appear to be of the Neandertal series, but to represent a family on the whole more advanced on the road of evolution than the majority of their kind, so far as we know them ${ }^{2}$.

The bodies had simply been covered with a little earth where they lay, not deposited in a formally dug grave. The same method of sepulture will meet us at La Ferrassie. The damaged condition of the second body is perhaps due to the operations of hyaenas, which may have taken advantage of the temporary absence of the representatives of the dead to root it up.

The leading characteristics of the two bodies may thus be briefly stated. Both are dolichocephalic. In No. I the brow-ridges are prominent-less so in No. 2. In both the forehead is receding,

${ }^{1} \mathrm{H}$. Breuil, "Remarques sur les divers niveaux archéologiques du gisement de Spy" (Revue anthropologique, xxir. [1912], p. 126); E. d'Acy, "Des sepultures dans les dépôts paléolithiques des grottes et des abris sous roche" (B.S.A.P. 1888).

2 See Julien Fraipont, "Les hommes de Spy" (C.A.P.A. Paris [1 889], p. 32x). 
straighter in No. I than in No. 2. In both the back of the head extends considerably. The parietal ridges of No. 2 are spherical to an exceptional degree. In both the frontal sinus is well marked, the orbits are very large and round, and the occipital region is flattened from above to below, the attachments for the neck muscles being very large. The upper jaw is powerful, with large teeth; there is no sub-nasal prognathism. The mental symphysis is straight in front, without projection. The molar teeth are of equal size; the canines are of moderate size and do not overtop the other teeth. The lower jaw of No. 2 was probably even more massive, but it is much injured ${ }^{1}$.

V. La Ferrassie. At La Ferrassie, Dordogne, there was a rockshelter which had been inhabited at different periods; each of these had left a layer of deposit. At the bottom was a stratum with Acheulean flints; over it was a stratum with Mousterian flints; and above this again were strata with implements of the later Palaeolithic stages. There were in all nine strata in this shelter. In addition, there were two minor sites at the same place; a small shelter with exclusively Mousterian remains, and the entry to a grotto whose soil contained remains of the Aurignacian stage, the first of the Upper Palaeolithic ${ }^{2}$.

The skeletons lay in the Mousterian stratum, overlaid with a sort of pavement of flat stones (supposed to have been intentionally laid down) which cuts the Mousterian stratum into two parts. There were four skeletons discovered, two of them belonging to children. No full account of the remains seems as yet to have been published, though one at least of the skeletons was in a good state of preservation. The bones of the head had been protected with a flat stone laid over it, and two other stones had been laid about the level of the arms; a great number of Mousterian flints were lying about. The body was not however buried in the strict sense of the word. Earth had been piled over it; the attitude of the skeleton suggested the attitude of sleep in which the subject had died. It lay on its back,

1 See De Puydt and Lohest, "Exploration de la grotte de Spy" (Annales de la Soc. géol. de Belgique, XIII. [1 886]); Idem, "L'homme contemporaine du mammouth à Spy" (Congrès de Namur, 1887); Fraipont and Lohest, "La race humaine de Neanderthal ou de Canstadt en Belgique" (Archives de Biologie, xvi. [1887], p. 587). A full suinmary of the foregoing paper by E. C[artailhac] in Matériaux pour l'histoire de l'homme, xxIr. [1 888], p. 17. Fraipont," "Les hommes de Spy" (C.A.P.A. Paris [1889], p. 321); R. Collignon, "Les fouilles de Spy" (Revue d'Anthropologie, XVI. [1887], p. 632); P. Topinard, "Os longs de Spy" (B.S.A.P. ser. II. vol. XI. [r888], p. 376); H. Klaatsch, "Occipitalia und Temporalia der Schädel von Spy verglichen mit denen von Krapina" (V.B.A.G. [1902], p. 392).

${ }^{2}$ L. Capitan and D. Peyrony, "Station préhistorique de La Ferrassie" (Revue anthropologique, xxII. [1912], p. 29); Iidem, "Deux squelettes humains au milieu de foyers de l'époque moustérienne" (B.S.A.P. ser. vi. vol. I. [1910], p. 48; Acad. des Inscriptions [1909], p. 797); Iidem, "Un nouveau squelette humain fossile" (Revue préhistorique, vi. [191 I], p. I29). 
the lower limbs both bent to the right, and left arm lying along the side, the right raised up and bent. Apparently the body had not been disturbed after death, but was simply covered where it lay. The character of the skeleton, so far as it has been described, appears to have been entirely in accordance with the other ordinary Mousterian subjects.

The excavation was carried out with great care, but the skull of the principal skeleton was unfortunately smashed ${ }^{1}$.

VI. Le Moustier. In a station at Le Moustier, the place which gives its name to the Mousterian culture, though not actually in the cave where the typical Mousterian culture was found, a dealer in antiquities resident in the neighbourhood found the skeleton of a youth of about $\mathrm{i} 6$ years of age. It is no part of our duty here to comment

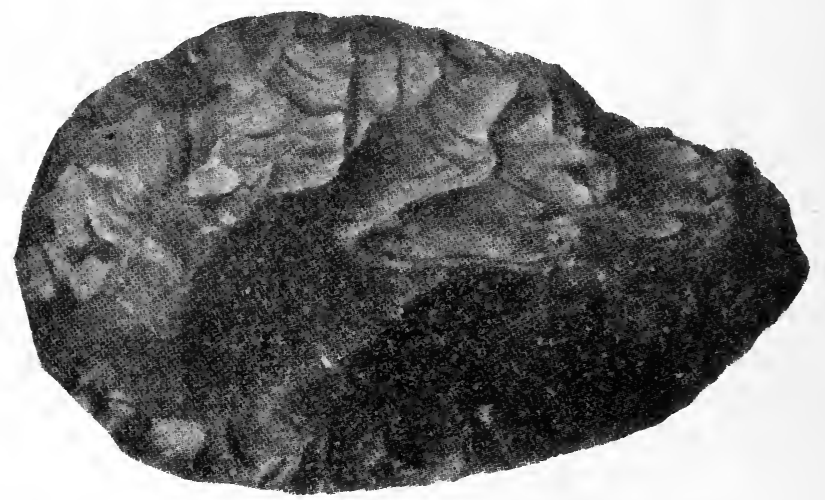

Fig. 71. Coup-de-poing found with the Le Moustier skeleton.

on the combination of commercial and political intrigues which would appear to have been associated with this discovery ${ }^{2}$; all that need be said is that the skeleton found a resting place in the Museum of Berlin, the dealer was made happy, and an extravagant pecuniary value was established for prehistoric skeletons which is likely to put a serious difficulty in the way of future research-parties not in the possession of unlimited funds.

The body had been undoubtedly buried with intention. The skeleton lay on its right side, with the right forearm under the head-in fact, the body was disposed in the attitude of sleep.

Close by the hand was a coup-de-poing $17 \mathrm{~cm}$. long (Fig. 71) which even in Acheulean surroundings would have been a good

1 L'Anthr. xxi. [1910], p. 372.

${ }^{2}$ On which see various articles in L'Anthr. vol. xxvi. 
specimen, but which in a Mousterian deposit was very remarkable; and a bed of flint chips formed a sort of pillow under the head. Numerous other flints presented the characters of early Mousterian implements, and there can be no doubt as to the stage to which to assign the interment. Bones of the wild ox, charred and split, apparently the relics of a funeral feast, were also found in the grave.

The body was that of a youth. Some parts of the skeleton fell into dust when it was uncovered, and could not be preserved. The

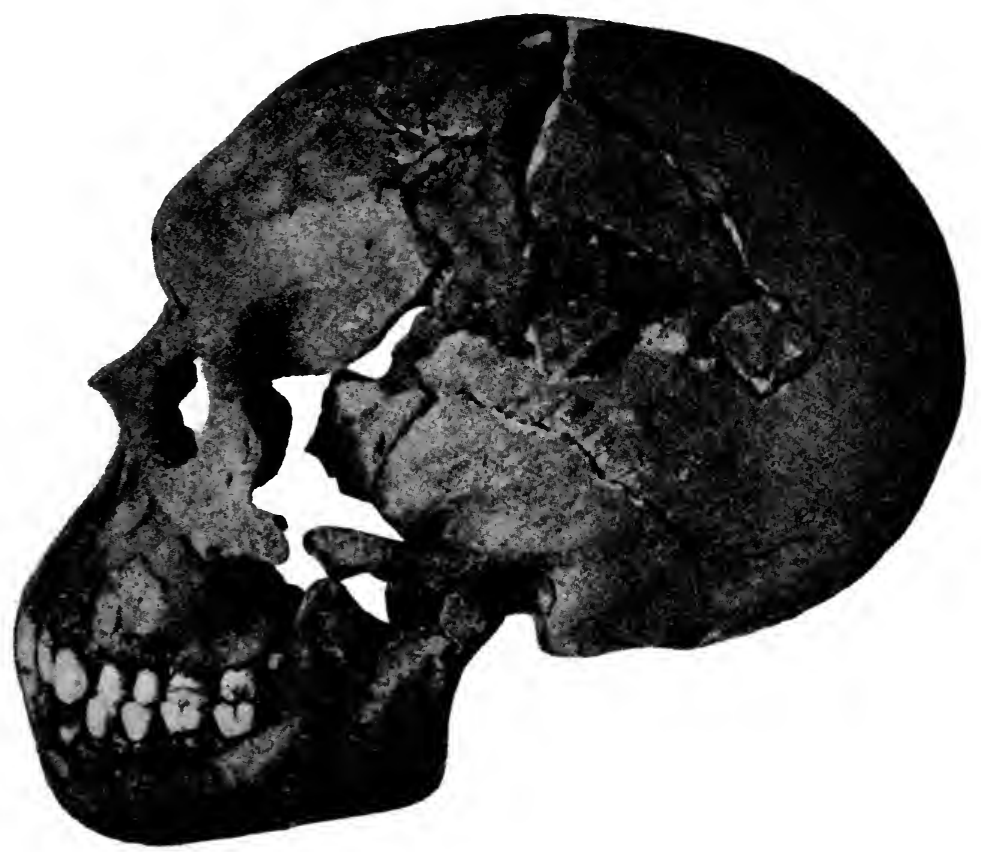

Fig. 72. The Le Moustier skull.

skull (Fig. 72) was almost complete, but in fragments, and with some lost parts which have been restored in the museum. The authenticity of the restoration has been questioned ${ }^{1}$. The epiphyses of the joints have not yet been closed, and the wisdom-teeth are not yet cut; the age of the subject was about 16 years. The characteristics of the race are less conspicuous, possibly owing to youth. The left femur measures 0.380 mètre, indicating a stature of from $\mathrm{r} \cdot 45 \mathrm{~m}$. to $\mathrm{I} \cdot 50 \mathrm{~m}$. (4 ft. 9 ins. to $4 \mathrm{ft}$. I I ins.). The diaphysis [shaft] of the femur is rounded, and almost of the same dimensions as that of the

1 L'Anthr. xx. [1909], p. 220. 
Neandertal skeleton; and as in that skeleton there is a disproportion between the diaphysis and the articular extremities, which are particularly large. The radius is very much curved; this is an anthropoid feature, also found at Neandertal and at Spy. The tibia is not platymeric. The glenoid cavity of the scapula is diverted backward as in the Neandertal skeleton. The radius is strongly curved, which is also a Neandertal character. The lower jaw is very massive; more so than in the Spy subjects. The greatest width of the symphysis is $0.016 \mathrm{~m}$. The left canine has not yet sprouted but remains still hidden by the milk tooth. The chin is receding. There is a genioglossal fossa, but no trace of the mental spine. The teeth are large, and the prognathism is very pronounced. The brow-ridge is well developed, but to a less extent than in the Neandertal specimen; it diminishes gradually from the median to the lateral part, which is different from the case in adult specimens; in these the browridge is equally accented in the lateral and in the median part. The configuration of the back of the skull also resembles that of the Neandertal skull ${ }^{1}$.

VII. La Chapelle-aux-Saints. The Le Moustier skeleton was not in a good state, and its restoration in the museum of Berlin has not commanded the acceptance of all the authorities who have examined it. Such cannot be said of the magnificent specimen found at about the same time in a cave close to the village of La Chapelle-auxSaints, department of Corrèze, and now one of the treasures of the Paris Museum of Natural History. It has been made, after a study extending over five years, the subject of a monumental monograph by Prof. Marcellin Boule, which it has now become a commonplace to describe as the most thorough and in every way the finest description of any human skeleton extant ${ }^{2}$.

The discovery was made by MM. les Abbés A. and J. Bouyssonie and L. Bardon. The cave in which the skeleton lay was one of a series; nothing was found in any of the others. A long passage, with very unequal walls, and a low roof-so low that it cannot have been used as a permanent habitation-had had a pit dug in the middle of its floor, in which the skeleton was deposited. There can be no

1 O. Hauser, "Découverte d'un squelette du type de Néandertal sous l'abri inférieur du Moustier" (L'Homme préhistorique, vir. [1909], p. I); H. Klaatsch, "Preuves que l'Homo mousteriensis Hauseri appartient au type de Neandertal" (ibid. p. Io); H. Klaatsch and O. Hauser, "Homo mousteriensis Hauseri: ein altdiluvialer Skelettfund im Departement Dordogne, und seine zugehörigkeit zum Neandertaltypus" (A.f.A. xxxv. [1909], p. 287); H. Klaatsch, "Die neueste Ergebnisse der Paläontologie des Menschen und ihre Bedeutung für das Abstammungsproblem" (Z.f.E. XL.I. [1909], p. 537).

2 Marcellin Boule, "L'homme fossile de La Chapelle-aux-Saints" (Annales de paléontologie, I9I I-I913, reprinted in a separate brochure). 
doubt of its having been an intentional interment ${ }^{1}$. The bones were very fragile, and broke easily when an attempt was made to remove them. The skeleton lay 3 mètres inward from the entrance, covered with a bed of deposit 30 to 40 centimètres thick, quite intact, containing bones, and chipped flints of Mousterian types. The fauna represented included

\section{Rangifer tarandus \\ Bison priscus \\ Equus caballus}

\section{Rhinoceros tichorhinus Capra ibex \\ Arctomys marmotta}

which it will be seen is a "cold" fauna. The pit in which the skeleton was laid measured $\mathrm{I} \cdot 45$ mètres in length, I mètre in breadth, and was 0.30 mètre deep. It had been excavated in the marly floor of the cave, for the reception of the body. The skeleton lay on its back, the head to the west, leaning against the border of the grave and wedged into position with stones. The right arm seems to have been bent in such a position as to bring the hand up to the head. The legs were folded up and turned to the right. Above the head were the remains of a food-deposit consisting of three or four large fragments of long bones and the metatarsal of a large cow. Round the body were many fragments of quartz, flint (some of them well chipped), ochre, and broken bones, but nothing very characteristic. None of the bones shewed any signs of working.

The flint implements in the cave, of which over 2000 were found, were uniformly Mousterian, though there were some Acheulean reminiscences, in the shape of tools chipped on both sides ${ }^{2}$.

The skeleton, on the whole, was in good condition. It was that of a man, probably 60 years of age. The nasal bones are lost, and there are a few other injuries. The bones are remarkably thick. The brain-case is flat, slightly more so than in the skulls of Neandertal or $\mathrm{Spy}^{3}$. The forehead is less sloping than that of the Neandertal specimen. The brow-ridges are very prominent, and are not interrupted in the middle by any notch over the base of the nose. The occipital region projects strongly backward; the angle of the inion is smaller than in the Neandertal and the Spy specimens. The muscles of the neck must have been very powerful. The face is long,

1 A. and J. Bouyssonie and L. Bardon, "Découverte d'un squelette moustérien à la Bouffia de La Chapelle-aux-Saints, Corrèze" (L'Anthr. XIx. [1908], p. 513. Bouffia is a local dialect word for cave or grotto). Brief notice by the same authors under almost the same title, Comptes-rendus de l'Acad. des Sciences, cxLVIr. [1908], p. 1414; Marcellin Boule, "L'homme fossile de La Chapelle-aux-Saints (Corrèze)" (ibid. p. 1349).

2 On the flint implements from the La Chapelle cave, see Bouyssonie and Bardon, "La station moustérienne de la 'Bouffia' Bonneval à La Chapelle-auxSaints" (L'Anthr. XxIv. [1913], p. 609).

S See the superposed outlines of these skulls, L'Anthr. xx. [1909], pp. 262-3. 
the head harmonic. The eye-sockets were large and round: the nose must have been broad and flat. As in the Gibraltar skull the canine fossa was absent. The teeth were arranged in a U-like arch. The cranial index is 75 , the facial index 57.89 , the orbital index 88.6 , the nasal index 55. The skull is thus considerably prognathous, a rather high mesoseme, and platyrrhine. The chin is retreating. The hands were short and broad. The fingers must have been more flexible, to judge from the articular surfaces of the joints, than either in the anthropoids or in modern man.

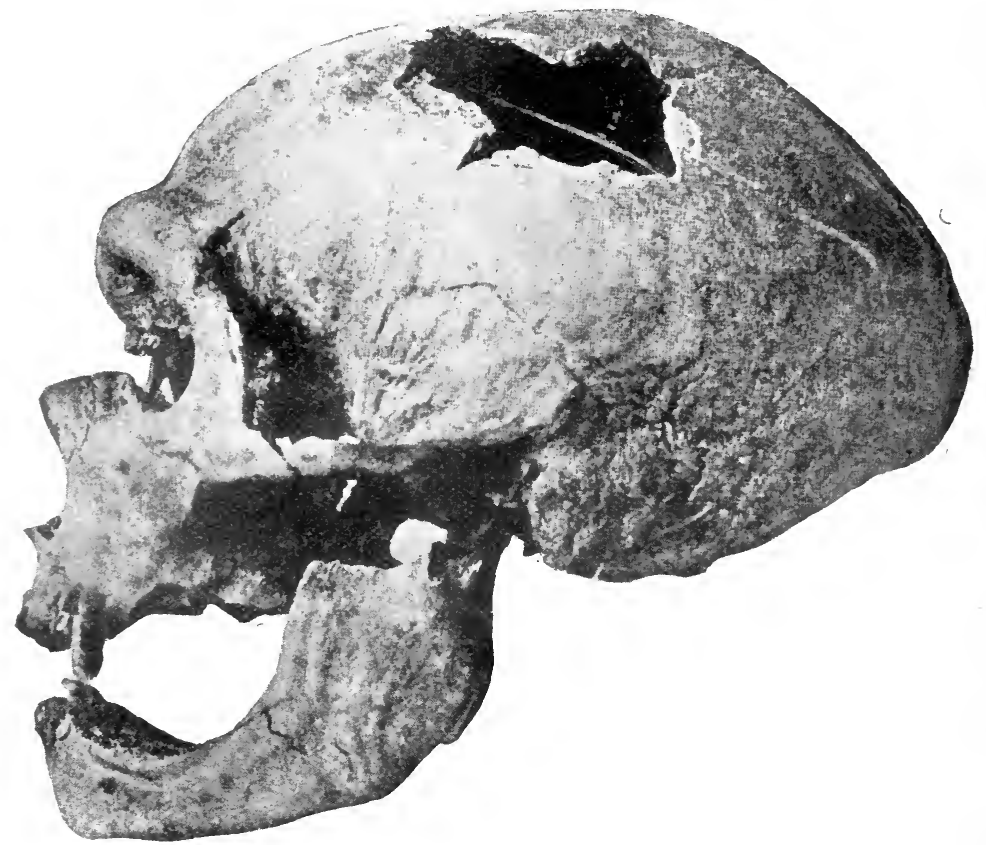

Fig. 73. The skull of La Chapelle-aux-Saints.

(From the Annual Report, Smithsonian Institution, 1913.)

Boule gives the following particulars of the cranial capacity of the La Chapelle skull, compared with others:

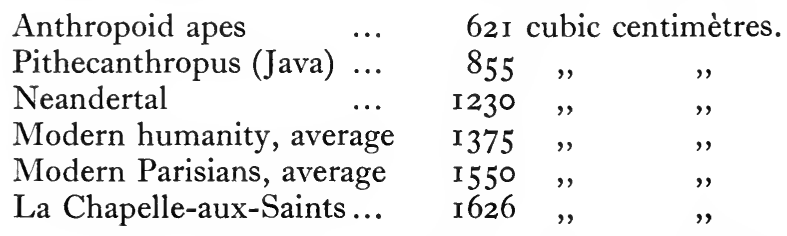

The cubic capacity of Beethoven's skull was $175^{\circ}$. Some doubt is cast by this table on the estimate for the imperfect Neandertal skull, 
due to Huxley. Virchow has estimated it as rather larger (1532), and the great capacity of the La Chapelle skull renders this figure more probable. It is not, however, to be inferred that the greater capacity of the La Chapelle man indicates a superiority of intellectual equipment. The greater height of the vault of the modern skull may be set against the apparent inferiority of actual capacity ${ }^{1}$.

With the collaboration of M. Raoul Anthony, Prof. Boule has also published a very elaborate study of the interior of the skull of this specimen, with deductions as to the brain and the mentality of its owner ${ }^{2}$. The brain is human, but still preserves many simian traits. It lacks the superior organization which characterises existing man. It is probable that the people of whom the La Chapelle man is a representative had a rudimentary language, but they cannot have possessed more than a rudimentary "psychism," superior to that of the anthropoid ape, but inferior to any human race known. It is likely that the people were right-handed.

VIII. La Quina (Charente). The station of La Quina, in the commune of Gardes, has been explored with admirable care and thoroughness by Dr Henri Martin of Paris, in a research extending over many years. The stratification of the site is clearly shewn in the section, Fig. 74, borrowed from one of Dr Martin's numerous communications on the subject of the site ${ }^{3}$. From this section it is clear that in Mousterian times there was here an overhanging rockshelter. The floor of this cave became covered with two beds of limestone blocks, ranging from about the size of a fist to the size of a head, those in the lower layer stained red with iron. These beds (numbered II, I2, on the section) contained no human remains of any kind. Above them there accumulated five layers of deposit with flints and other remains of human occupation; these are numbered I-5 in the section, that marked 5 being the lowest and therefore the earliest. The three lower layers are less rich in remains than the two upper, which Dr Martin calls the "Perfected Mousterian": these doubtless represent a later moment in the development of the Mousterian, though the whole series of the deposits certainly belong to this stage. A fall of the roof of the cave brought the sixth occupation to a sudden close. The whole of the layer (layer I) corresponding to this period of the history was covered with talus resulting from

1 M. Boule, "L'homme fossile de La Chapelle-aux-Saints (Corrèze)" (L'Anthr. XIx. [1908], $519 ; \mathrm{xx}$. [1909], 257). Among the illustrations of the latter paper is an interesting photograph of the La Chapelle skull combined with the Mauer jaw.

${ }_{2} \mathrm{M}$. Boule and Raoul Anthony, "L'encéphale de l'homme fossile de La Chapelle-aux-Saints" (L'Anthr. xxIr. [I9I I ], I29-195).

3 "Présentation d'un crâne humain trouvé avec le squelette à la base du Moustérien de La Quina (Charente)" (B.S.P.F. viIr. [I9II], p. 615). 
this catastrophe (layers 6 and ro in the section-the former consisting of smaller stones, the latter of large blocks). A soil formed over the talus, and it became the scene of a Mousterian occupation of a date later than the accident (stratum 7). The topmost layer, marked $\mathrm{I}_{3}$, is the stump of the natural rock, left behind after the collapse of the rock-roof which projected horizontally from it.

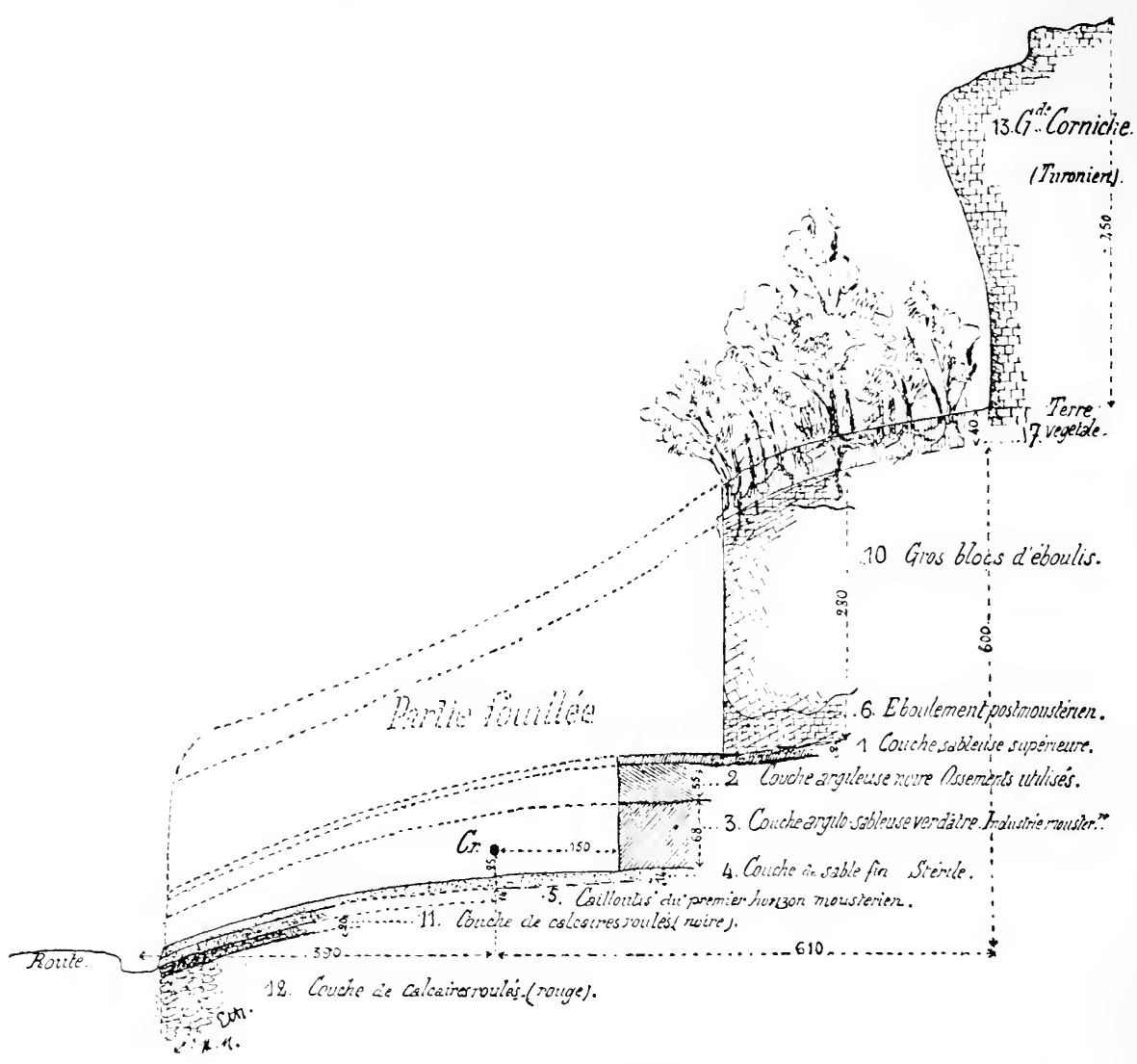

Fig. 74. Section of the strata at La Quina.

(From Bulletin de la Société préhistorique française, vol. viII.)

The numerous important relics of industry which this site yielded to its explorer will occupy a later page in this chapter; our present concern is with the human remains. Bones of no less than 16 or I7 individuals were found here, all but one, however, being represented by one or two bones only ${ }^{1}$.

${ }^{1}$ H. Martin, "Astragale humain du Moustérien moyen de La Quina, ses affinités" (B.S.P.F. vir. [1910], p. 391); Idem, "Position stratigraphique des osse- 
Of these by far the most important discovery was a complete skeleton, found in one of the earlier Mousterian layers. The position of its skull is indicated by the letters $C r$ in the section, Fig. 74, and the skull itself is shewn in Fig. 75.

The study of the La Quina skull has shewn that it presents in a marked degree the same characters as those of its contemporaries. The dolichocephaly is extreme, the index being as low as $68 \cdot 65$. The subject was young (about 25 years), and in all probability

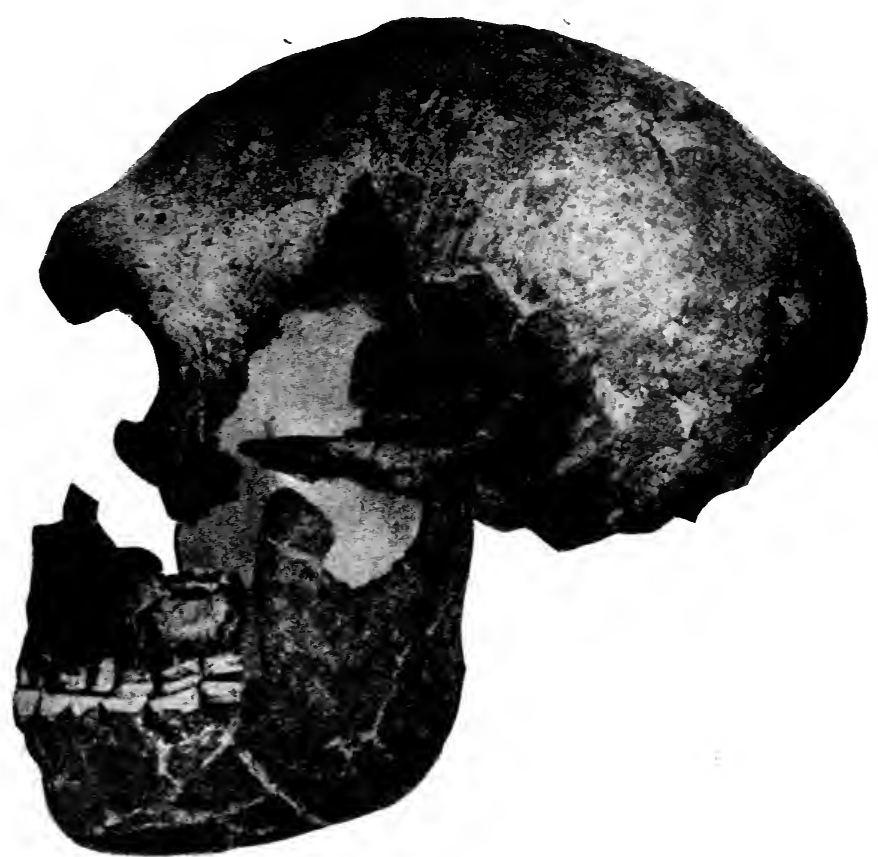

Fig. 75. The La Quina skull.

(From Comptes-rendus de l'Assoc. franf. pour l'Avancement des Sciences, 1912.)

female; the brow-ridges, however, are more prominent than in the Gibraltar specimen. They are slightly separated in the middle by a depression. The outline in norma verticali is ovoid. The forehead is extremely low-in fact it hardly exists, and the occiput is very prominent, with an extremely acute angle. The teeth are in good condition, but much worn; in two of them there was a groove scratched, it has been supposed, by the injudicious use of a tooth-

ments humains recueillis dans le Moustérien de La Quina de 1908 à 1912" (ibid. IX. [1912], p. 700); Idem, "Nouvelle série de débris humains disséminés trouvés en 1913 dans le gisement moustérien de La Quina" (ibid. x. [1913], p. 540). 
pick. There is otherwise no trace of disease or caries, though almost half the substance has been ground away by the mastication of rough food-material, probably containing grains of flint and other foreign bodies. The brain, as deduced from an examination of the interior of the skull, shews a marked inferiority to that of any modern race. It was in all dimensions smaller than that of the La Chapelle man, but otherwise was remarkably similar to it in all its proportions ${ }^{\mathbf{1}}$.

The skull and the other bones of this skeleton were in very bad condition when first unearthed, and the piecing together of the fragments of the skull proved to be an especially laborious operation. The face is much injured. The orbits appear to have been round and projected forward. 'The left branch of the lower jaw, which is the only complete portion of this part of the skull, is of large proportions, the ascending ramus being of almost simian breadth. The chin is retreating. In details the morphology of the skull resembles that of La Chapelle. The injuries which the bones had suffered were all post mortem, due probably to the pressure of the soil, or to other accidents which befell the body. Dr Martin does not in this case believe that we have to do with an interment; rather was the owner of the skeleton the victim of an accident, either of the fall of rubbish from the cave roof, or, more likely, of a flood which carried her off and drowned her.

IX. Pech de l'Asé (Dordogne). Here, in a layer of Mousterian débris about I mètre in thickness, covered over with later talus, M. D. Peyrony has found the skull of a child, about six years of age. There are signs of a chin on the lower jaw more accentuated than in most of the bones of the men of this stage 2 .

$\mathrm{X}$. Bau de l'Aubesier (Vaucluse). One tooth only, probably pertaining to a Mousterian man ${ }^{2}$.

XI. Malarnaud (Ariège). At Malarnaud there were two strata of accumulation, separated by a bed of stalagmite, in a cave. The deposits were in a chamber of the cave reached by descending a pit 12 mètres deep, at the end of a gallery 70 mètres long. The lower

1 The above particulars are selected and summarised from the very full description of the skull in H. Martin, "L'homme fossile moustérien de La Quina, deuxième note" (B.S.P.F. Ix. [1912], p. 389). Further details will be found in H. Martin, "Présentation d'un crâne humain trouvé avec le squelette à la base du Moustérien de La Quina (Charente)" (ibid. viII. [I9II], p. 645); Idem, "Reconstitution du type néanderthalien sur le crâne de l'homme fossile de La Quina" (ibid. x. [I9I3], p. 86); Idem, "A propos de la robusticité du maxillaire inférieure de l'homme néanderthalien" (ibid. x. [1913], p. 22I); R. Anthony, "L'encéphale de l'homme fossile de La Quina" (B.S.A.P. [1913], pp. Ir7-194); "Le crâne de l'homme fossile moustérien de La Quina" (A.F.A.S. Nîmes [I9I2], p. 538). See also H. Martin, "État des travaux dans le gisement de La Quina en I912" (C.P.F. Angoulême [1912], p. 282).

2 Obermaier, El Hombre Fósil, p. 268. 
of the two strata, which contained the jaw, had also remains of the following fauna:

Rangifer tarandus
Rhinoceros tichorhinus
Ursus spelaeus
Hyaena spelaea
Elephas primigenius

Felis spelaea

Felis pardus

Cervus giganteus

Canis lupus

which is Mousterian in character. The upper layer had Rangifer tarandus, but the other animals had disappeared, and in their place were Rupicapra tragus and Capra ibex, as well as Equus caballus.

There does not seem to have been any discovery of remains of industry made in this cave, which suggests that the jaw had belonged to some unfortunate who had been devoured by the wild beasts which made their den in the cave. Be that as it may, we can say that the jaw, which is in very good condition on the whole ${ }^{1}$, is thoroughly of the character established by the jaws found at Spy and at La Naulette. There is the same almost total absence of chin, and the same exaggerated width of the branches in proportion to their height. The subject was young, the wisdom teeth not having yet grown; and as a purely personal, not a racial anomaly, it may be noted that there were only two, not four, incisor teeth ${ }^{2}$.

XII. Le Petit Puymoyen (Charente). Two fragments of lower jaws of subjects aged about $\mathrm{I} 6$ and 25 , and a fragment of an upper jaw of a man aged about 6o, with some teeth. These resemble the La Naulette jaw in character, and add nothing new. There are some anomalies in the number of the roots in certain of the teeth of the second subject ${ }^{3}$.

XIII. Arcy-sur-Cure (Yonne). In the cave called Grotte des Fées, under a deposit dating from Neolithic and later times, was a series of Upper Palaeolithic beds with characteristic flint implements, and fauna; under this again was an earlier stratum, which contained Mousterian implements with Rhinoceros tichorhinus, Ursus spelaeus, and Elephas primigenius. In this stratum the Marquis de Vibraye found in 1859 a fragment of a lower jaw and an atlas, presumably

1 It has lost a few small splinters from the ascending ramus, and all the teeth except one molar.

2 F. Regnault, "La grotte de Malarnaud" (Revue des Pyrénées et de la France méridionale), to this article I have failed to obtain access; H. Filhol, "Note sur une mâchoire humaine trouvée dans la caverne de Malarnaud près de Montseron, Ariège" (Société philomathique de Paris, ser. vil1. vol. I. [1888-9], p. 69); Report in Revue d'Anthropologie, xvir. [1889], p. 25 I ; M. Boule, "La caverne de Malarnaud" (ibid.p. 83).

3 A. Favraud, "Découverte d'une mâchoire humaine dans une brèche quaternaire à industrie paléolithique" (Acad. des Sciences, cxlıv. [1907], p. 935); "La station moustérienne du Petit Puymoyen" (R.E.A. xvil. [1908], p. 46); A. Siffre, "Étude des dents humaines" (ibid. p. 66). 
belonging to the same individual; later an axis was found by M.l'Abbé Parat. The jaw represents a type intermediate between the Mousterian and the Upper Palaeolithic races; it presents characteristics similar to those of the La Naulette jaw, but in a less pronounced form. The front edge of the chin is vertical, and there are signs of a rudimentary chin. The subject was young, the wisdom teeth being still uncut ${ }^{1}$.

XIV. Saint-Brélade (Fersey). On the island of Jersey there is a cave called La Cotte, situated in the side of a fissure that cuts into a cliff in the Bay of Saint-Brélade. This cave was excavated at intervals between $188 \mathrm{I}$ and I $_{9}$ I $_{5}$, the last being a thorough undertaking (though impeded by the dangers arising from the rotten state of the rockroof), under the auspices of the Société Jersiaise. The antiquitybearing stratum in this cave yielded a very large number of flint implements, of markedly Mousterian character; there were also numerous animal bones, and remains of extensive hearths. The following were the principal animals represented (omitting some doubtful identifications and some less instructive species):

$\begin{array}{ll}\text { Elephas primigenius } & \text { Cervus elephus } \\ \text { Rhinoceros tichorhinus } & \text { Bos primigenius } \\ \text { Rangifer tarandus } & \text { Canis vulpes } \\ \text { Cervus giganteus } & \text { Myodes torquatus }\end{array}$

There can be no doubt that at the time of the formation of this stratum Jersey was connected with the mainland. There is no native flint in the island, and the source of supply which yielded the material to the Mousterian inhabitants of the cave is probably now sunk beneath the sea.

The damp of the cave was not suitable for the preservation of human bones, and very scanty remains of the inhabitants came to light. These were a much-decayed fragment, which might have been part of a tibia, and a series of teeth, $\mathrm{I}_{3}$ in number. These all belonged to one individual, and in their ensemble displayed many primitive features, recalling in many details the teeth of the Mauer $\mathrm{jaw}^{2}$.

1 Abbé Parat, "Les grottes de la Cure et de l'Yonne" (C.A.P.A. Paris [1900], p. 63); Hamy, Précis de paléontologie humaine, p. 235.

2 See R. R. Marett, "Pleistocene Man in Jersey" (Archaeologia, vol. LxIr. part 2 [I9II], p. 449); "Further observations on Prehistoric Man in Jersey" (ibid. LXIII. [I9I2], p. 203); “'The site, fauna, and industry of La Cotte de Saint-Brélade" (ibid. Lxvir. [1916], p. 75). Marett in British Association Report, Australia [1914], p. 527, Manchester [1915], p. 194. Ed. Toulmin-Nicolle and J. Sinel, "Report on the exploration of the Palaeolithic cave-dwelling known as 'La Cotte,' St Brélade, Jersey" (Man, x. [1910], No. I02); Iidem, "Rapport sur l'exploration de 'La Cotte' par la Société Jersiaise" (B.S.P.F. vII. [I9II], pp. 757, 765); R. R. Marett and G. F. B. de Gruchy, "Excavation of a cave containing Mousterian implements 
The nine teeth first discovered are described in Nature, 25 May I9II. It is there pointed out that the most remarkable thing about the Mauer teeth, according to Keith, is the large size of the roots as contrasted with the small size of the crowns. The Brélade teeth if anything exaggerate this disproportion, the roots being at least as large as in the Mauer teeth in proportion to the size of the crowns, if not larger.

XV. Bañolas (Gerona, Spain). A lower jaw of primitive type, discovered in 1887 embedded in hard travertine ${ }^{1}$.

XVI. Sipka (Moravia). A fragment of the lower jaw, apparently of a child, but of very large dimensions. The cave of Šipka is ro kilomètres east of Neutitschein, in the mountains of Kotouč. It is a large hollow, 55 mètres in length, in three divisions, of which only the first was accessible before excavation. From the third section a side gallery opens, which bears the name of the Dachsloch. The stratification of the cave can best be displayed in the table (p. 308), adapted from Obermaier ${ }^{2}$.

While the Šipka fragment is undoubtedly to be assigned to this stage, it may be questioned whether much can be learnt from itit is too imperfect. A very instructive controversy will be found recorded in M.A.G.W. vol. XII. pp. 37-42. When anatomists of the rank of Virchow and Schaafhausen, with the fragment under their eyes, dispute like Bret Harte's Stanislow amateurs on such apparently rudimentary questions as whether it is the jaw of a child or of an adult with retarded dentition, or whether it is pithecoid or not, it is surely rash to draw any other conclusion than that which we have already drawn in some other cases-that the object has no light of its own to offer, but needs all the light available from other sources for its own elucidation.

XVII. Ochos. Another Moravian cave, called by the name of the Schwedentisch cave, has yielded an imperfect jaw-bone ${ }^{3}$.

XVIII. Krapina. The discoveries at Krapina near Agram, Croatia, rank among the most important of Mousterian deposits.

near La Cotte de Saint-Brélade, Jersey" (Man, xir. [1912], No. 93); Nicolle and Sinel, "Report on the resumed excavation of La Cotte, Saint-Brélade, Jersey" (Man, xII. [I9I2], No. 88); E. N. Fallaize, "Recent excavation on a Palaeolithic site in Jersey" (Nature, 28 Oct. 1915, p. 238); A. Keith, "A description of teeth of Palaeolithic Man from Jersey" (Fournal of Anatomy and Physiology, XLvi. [1912], p. 12); I. Sinel, Prehistoric Times and Men of the Channel Islands (Jersey, 1914).

1 E. Hernández-Pacheco and H. Obermaier, "La mandibula neandertaloida de Bañolas" (Comision de investigaciones paléontológicas y prehistoricas, VI. [1915]).

${ }^{2} \mathrm{H}$. Obermaier, "Les restes humains quaternaires dans l'Europe centrale" (L'Anthr. xvi. [1905], p. 385). See K. J. Maška, Der diluviale Mensch in Mähren (Neutitschein, 1886) for an account of the excavation of the cave.

3 A. Rzehak, "Der Unterkiefer von Ochos" (Corr. xxxvi. [1905], p. 67). 


\begin{tabular}{|c|c|c|c|c|}
\hline & Outer gallery & Middle gallery & Inner gallery & Dachsloch \\
\hline$E$ & Modern deposits & Fallen rubbish & Absent & Absent \\
\hline$D$ & $\begin{array}{l}\text { Yellowish-brown } \\
\text { cavern loam, } \\
\text { with few archae- } \\
\text { ological remains. } \\
\text { Rangifer tarandus } \\
\text { Elephas primigenius } \\
\text { Rhinoceros ticho- } \\
\text { rhinus } \\
\text { A few hearths, } \\
\text { some flint chips }\end{array}$ & $\begin{array}{l}\text { As in outer gallery: } \\
\text { fauna here, } \\
\text { Myodes torquatus } \\
\text { Lagopus albus } \\
\text { Lagomys pusillus } \\
\text { Spermophilus rufes- } \\
\text { cens }\end{array}$ & $\begin{array}{l}\text { As in outer gal- } \\
\text { lery; fauna as } \\
\text { in middle. } \\
\text { Upper Palaeo- } \\
\text { lithic flints }\end{array}$ & Absent \\
\hline$C 2$. & $\begin{array}{l}\text { Grey stratum, with } \\
\text { Middle Palaeo- } \\
\text { lithic tools. } \\
\text { Elephas primigenius } \\
\text { Rhinoceros ticho- } \\
\text { rhinus } \\
\text { Equus caballus } \\
\text { No Rangifer taran- } \\
\text { dus. } \\
\text { Coarse formless } \\
\text { tools mostly in } \\
\text { quartzite }\end{array}$ & $\begin{array}{l}\text { Similar to outer gal- } \\
\text { lery }\end{array}$ & $\begin{array}{l}\text { Similar to outer } \\
\text { gallery }\end{array}$ & Absent \\
\hline$C_{1}$. & $\begin{array}{l}\text { Similar to } C_{2} \text {, but } \\
\text { without the least } \\
\text { trace of human } \\
\text { occupation. } \\
\text { Carnivora numer- } \\
\text { ous }\end{array}$ & $\begin{array}{l}\text { Similar to outer gal- } \\
\text { lery }\end{array}$ & $\begin{array}{l}\text { Similar to outer } \\
\text { gallery, but of } \\
\text { a more green- } \\
\text { ish colour }\end{array}$ & Absent \\
\hline$B$. & $\begin{array}{l}\text { Agreenish bed; the } \\
\text { principal archae- } \\
\text { ological stratum. } \\
\text { Arcto-alpine fauna } \\
\text { Myodes torquatus } \\
\text { Rangifer tarandus } \\
\text { Rupicapra tragus } \\
\text { Capra ibex } \\
\text { Arctomys marmotta } \\
\text { Rhinoceros ticho- } \\
\text { rhinus } \\
\text { Elephas primigenius } \\
\text { Ursus spelaeus } \\
\text { Bos primigenius } \\
\text { Equus caballus }\end{array}$ & $\begin{array}{l}\text { Similar to outer gal- } \\
\text { lery }\end{array}$ & $\begin{array}{l}\text { Similar to outer } \\
\text { gallery, with } \\
\text { brownish } \\
\text { layers. } \\
\text { The human } \\
\text { jawbone } \\
\text { found here } \\
\text { at the en- } \\
\text { trance to the } \\
\text { Dachsloch }\end{array}$ & $\begin{array}{l}\text { Lower } \\
\text { Palaeolithic } \\
\text { flints }\end{array}$ \\
\hline A. & $\begin{array}{l}\text { Grey and greenish } \\
\text { sand; no human } \\
\text { relics }\end{array}$ & $\begin{array}{l}\text { Similar to outer gal- } \\
\text { lery }\end{array}$ & $\begin{array}{l}\text { Sand and rub- } \\
\text { bish }\end{array}$ & $\begin{array}{l}\text { Sand and } \\
\text { rubbish }\end{array}$ \\
\hline
\end{tabular}

They were made in a large rock-shelter situated in the north-west of the village, on the bank of the river Krapinica (a tributary of the Drave), and about 25 mètres above its present level. The cave was 
excavated by the river when the latter was a much more important watercourse than it is now, and, subsequently, a fluviatile deposit filled it up to the roof. The total height of the cave was 8.50 mètres, and the deposit which it contained was stratified as set forth in the following scheme:

$E$. Decomposed deposit, broken fragments, etc., 6 mètres thick, containing human remains scattered through it.

$D$. Fluviatile deposit, the record of an inundation. Sand and clay.

C. Decomposed débris with flint implements and broken bones of large mammals.

$B$. Sand and alluvium.

$A$. River gravels.

Numerous remains of Castor fiber were found in the top of stratum $D$. At the top of $E$ was a bed of the remains of Ursus spelaeus, seemingly indicating that after the human occupation of the cave came to an end, these animals took possession of the shelter. Of the other animals whose remains were found, the only frequent species were Rhinoceros mercki (not tichorhinus) and Bos primigenius; a few, or even single, bones were found of Canis lupus, Ursus arctos, Equus caballus, Sus scrofa, Cervus elaphus, C. giganteus, C. capreolus, C. euryceros, Arctomys marmotta, Felis catus and species of Mus and Mustela.

A large number of human bones were found, all of them fragmentary. There were 10 or 12 more or less large fragments of skulls, 13 fragments of the brow-region of skulls, I00 fragments of other parts of skulls, and 144 teeth, as well as fragments of vertebrae, ribs, scapulae, clavicles, 5 humeri, 2 radii, 2 cubitus, and other small bones of hands and feet. It is calculated that at the very least I4 individuals were represented, but it was impossible to restore any considerable part of any one skeleton.

These bones displayed certain very marked peculiarities. It has been inferred from a study of the humeri and the clavicles that two different types of men were represented; thus the general uniformity which we have hitherto found to be dominant over Europe during the Middle Palaeolithic Term is for once broken. The skulls display the characteristic brow-ridges; but the foreheads are higher and better formed than is usually the case in Mousterian Man.

In another important point the Krapina skulls were peculiar. We have seen that Mousterian Man is as a rule dolichocephalic, sometimes excessively so. But some of the fragments of skulls are brachycephalic, as we are assured by qualified men who have examined them. In spite of the fragmentary state of all the specimens this is considered certain. 
It has been supposed that the very fragmentary condition of the bones was not altogether due to accident. One of them displayed artificial cuts, suggesting a deed of violence; and the fact that some of them were charred has suggested to the explorer to whom their discovery is due, Gorjanovic-Kramberger, that they are the remains of cannibal feasts. Whether this was so or not is a question belonging to the section in which we discuss the psychology of the people with whom we are concerned in this chapter.

The implements found at Krapina were in flint, quartz, chalcedony, opal, and jasper, all derived from the alluvial deposits of the Krapinica, and all definitely Mousterian in shape, though with Acheulean reminiscences which suggest an early date in the Mousterian stage for this important station. Gorjanovič-Kramberger has described an axe and a pricker in bone, in addition to the stone implements; but Obermaier ${ }^{1}$ doubts whether these are really artificial².

XIX. Marcilly-sur-Eure (Eure), A skeleton was found here in the course of railway-works, at a depth of 7 mètres, but was destroyed by the labourers; nothing was rescued except the vault of the skull. Fints of Acheulean and of Mousterian types were found in association with it. 'The skull partakes of the Neandertal characteristicsa thick wall, prominent brow-ridges, and a sloping forehead ${ }^{3}$.

XX. Bréchamps (Eure-et-Loir). A skeleton, found in a brickfield, associated with Mousterian flint implements. Nost unfortunately it was left unguarded overnight by the discoverers, and the bones were broken and dispersed by some unknown mischief-maker; only the crown of the head was preserved. This shewed dolichocephaly (index $75.5 \mathrm{I}$ ) and the characters of the corresponding part of the Neandertal skull ${ }^{4}$. Schwalbe ${ }^{5}$ refuses to accord a Neandertal character to either this or the Marcilly skull. The Denise skull, described ante p. 214 , is also claimed by him as a modern type.

XXI. Isturitz (Basses-Pyrénées). A jaw-bone found in a site rich

1 LiAnthr. xvi. [1905], p. 18.

" ()n the Krapina station see K. Gorjanovič-Kramberger, "Der paläolithische Mensch und seine Zeitgenossen aus den Diluvium von Krapina in Kroatien" (H.A.G.H. xxxil. [1902], p. 189; xxxiv. [1904], p. 187); also notes by the same author, ibid. xxix. [1899], p. (63); xxx. [1900], p. (203); xxxiv. [1904], p. (90). See also further notes by the same author Corr. Xxxi. 17; xxxvi. 88; Idem, "Der diluviale Nenseh ron Krapina in Kroatien" (Földtani Közlöny, xxxv. [1906], p. 307; a bibliography of the author's writings on the same subject, in German, Czech, and Magyár, will be found at p. 368 of the same volume). Obermaier, "La station paléolithique de Krapina" (L'Anthr. xvi. [1905], p. 14).

${ }^{3}$ G. de Nortillet, in L'homme, I. [1884], p. 48; L. Manouvrier, "Note sur les crànes humains quaternaires de Marcilly-sur-Eure et de Bréchamps" (R.E.A. vili. [1897], p. 302 ; B.S.A.P. ser. Iv. vol. vili. [1897], p. 564).

Manouvrier, op. laud.

5 Studien zur Vorgeschichte des Menschen, p. 153. 
in remains of Ursus spelaeus and Rhinoceros tichorhinus. The specimen is lost, but from a photograph Breuil ${ }^{1}$ infers that it displayed characters similar to those of Malarnaud.

Besides the above, there are a number of discoveries of alleged Middle Palaeolithic bones, such as the once famous Cannstatt skull, to which no importance can be attached in any discussion of the subject, owing to uncertainty as to their stratification. The omission of any specimen from the above list, which has been made so far as possible complete to the date of writing, is an indication that the specimen must be classed among the incert $a^{2}$.

What do all these skeletons and single bones teach us? This, that practically over all Europe there was a race of men displaying characters differentiating them from any other race, ancient or modern, of which we have any knowledge. These people were of moderate stature-as a rule a few inches above or below five feet; but the body was stout and very muscular. The skull was on the whole large; but the proportions of its parts differed widely from those to be seen in any modern type of skull. The facial part of the skull was exaggerated in comparison with the cerebral portion. In consequence we must assume that the general mentality of the people was of a low order. The speech-centres of the brain seem to have been imperfectly developed, though this is not quite certain; we may presume that they had a language, rudimentary perhaps, but far in advance of any method of communicating by sounds of which mere animals are capable. The skull was dolichocephalic, or at least a rather long mesaticephalic (with the exception of certain of the Krapina skulls); the forehead low and sloping backwards to an extreme extent; and the occiput prominent and forming a much more acute angle than in a modern skull.

The most striking feature of the skull is the superciliary torus, the great ridge which runs over the eye-sockets from side to side. This is a prominent feature in the skulls of anthropoid apes, such as the chimpanzee; but it is absent in all modern types of man. As a rule this ridge runs continuously from side to side without any interruption in the middle; in a few, such as the La Quina specimen, there is a slight notch or depression over the nose, reducing the ridge in the middle. The ridge is less prominent in female skulls than in male skulls.

1 L'Abbé $\mathrm{H}$. Breuil, "Les plus anciennes races humaines connues," Freibourg (Bulletin de la société freibourgeoise des sciences naturelles, vol. xvir. [1910], p. 18 of reprint).

2 Particulars about some of these doubtful specimens, with bibliographies, will be found in Obermaier's "Les restes humains quaternaires dans l'Europe centrale" (L'Anthr. xvi. [1905], p. 385, xvi1. p. 55). 
The orbits are large and round, sometimes, as in the Gibraltar skull, extraordinarily so. The nose was prominent and very broad. The cheek-bones were on the contrary not specially marked. The head was harmonic, a long face being associated with the long skull. The upper jaw was prominent and snout-like.

The lower jaw was massive, broad, but not proportionately high. The ascending ramus was broad. The chin was either absent or rudimentary, giving a weak look to the whole face. The muscles connected with the lower jaw were very powerful, and the teeth massive; a bite from a Mousterian man would be something to remember. Even the youthful boy of Šipka (to adopt one theory about the fragment which is all that is left of him) had a Gargantuan jaw with milk-teeth as large as the teeth of an ordinary modern adult. This strength of jaw and dentition explains the great brow-ridges, for some such strengthening of the upper bones of the face was necessary to withstand the shocks which the movement of the jaw in mastication inflicted upon them. Even in such minor details as the size and shape of the pulp-cavity of the teeth Mousterian man differed from any 'other kind of man; Keith ${ }^{1}$ distinguishes the Mousterian teeth with their large pulp-cavities as "taurodont," from the teeth with small cavities at the top of the roots, which characterise modern men, and to which he gives the name "cynodont"- on account of the superficial resemblance which the two kinds of teeth bear to those of bulls and dogs respectively. Throughout the whole body of Mousterian man the race had fully emancipated themselves from their animal ancestry; in every detail of their osteology they were men, though they were at a less advanced phase of development in most points than modern races. In the matter of the form of the teeth, however, Keith holds that modern man is nearer to the simian relatives of the race than Mousterian man was ${ }^{2}$.

The legs were very short in proportion to the body, but the bones are stout, and shew powerful muscular attachments. Some have inferred from the appearance of the joints that Mousterian man did not attain to such a perfection of bipedal walking as modern man has done: but Manouvrier ${ }^{3}$ has shewn that this is not a necessary inference from the indications. We need not suppose Mousterian man to have walked with a worse "slouch" than a modern tramp who has not had the advantage of military training.

1 Antiquity of Man, p. $147 \mathrm{ff}$. This is however questioned by Boule (L'Anthr. Xxix. [x918-9], p. 18r).

2 On the subject of the personal appearance of Mousterian Man, see W. J. Sollas, "On the cranial and facial characters of the Neandertal race" (Phil. Trans. Roy. Society, B i 99, p. 281).

${ }_{3}$ C.A.P.A. (Paris [r889], p. 354). 
In the size, shape, convolutions, and proportions of the different parts of the brain the Mousterian race was quite primitive, and much nearer to the ape than any modern race.

This type of man is entirely extinct. There are cases recorded of modern individuals presenting one or other of the different Mousterian traits, but none in which are found the whole series of traits as we find them uniformly recurring in Palaeolithic skeletons. Still, we must not forget that the total amount of the material available for study is small, and is as yet hardly sufficient to justify us in exalting Mousterian man to the level of an independent species. Palaeolithic ethnology is an imperfectly charted quagmire in which we must walk with caution.

So far as the material available permits us to judge, the indisputable Mousterian human remains give no support to the theory of a Pre-Mousterian development of modern types of man in Europe. This theory has become current in recent years, but it does not seem justified by the facts. We have already seen that much, if not all, of the osteological material, on whose positive evidence it to a large extent relies, is poisoned by uncertainties; we cannot build large structures of theory upon the Piltdown fragments, the Galley Hill and Dartford specimens, or the now discredited skeleton from Ipswich. If modern man had been fully evolved, in all his parts, at the beginning of the Chellean stage, he must have become swamped in the Mousterian stage by a new race or species, coming from no one knows where, and this race, notwithstanding its intellectual inferiority, must have dominated Europe through the whole long Mousterian stage and then disappeared, to give place in its turn to another "modern" race. Such a reconstruction of the course of events is very difficult to believe. What was the modern man doing while Mousterian man was having it all his own way in Europe? Into what hole did he creep? One might almost say that he had been playing a colossal game of leapfrog with his Mousterian cousin, for while the Mousterian's feet were planted firmly on Europe, the theoretically "modern" Acheulean seems to have been off the earth altogether!

If we reject the claim of the Galley Hill and other skeletons of "modern" type to a Palaeolithic antiquity, a reasonable course of development suggests itself. Mousterian man will appear to be the end of a chain of evolution, which if not running directly through the stages represented for us by the Java, Mauer, and Piltdown specimens, may at least be parallel with the lines on which those fragmentary relics lie: a chain which passing through the PreChellean, Chellean, and Acheulean stages, finally ends with the end 
of the Mousterian. There is certainly a break in the population of Europe when we come to the transition from Middle to Upper Palaeolithic. Mousterian man is certainly the end of the chain. And it is quite permissible to regard him as a product of degeneration, not a culmination of the evolution. The implements, at least, would suggest that the culmination of the evolution lay in the Acheulean stage. If this be so, it is not difficult to connect this degeneration with the climatic deterioration, and the consequent adoption of damp caves with their concomitant insanitary surroundings. The stock was, in fact, wearing itself out, and disappeared before the invaders who brought in the Upper Palaeolithic culture, almost as completely as native races in many South Sea Islands have degenerated or disappeared before the white colonists. But so long as the certainly authentic material available is so small that it could be packed easily into a moderately sized travelling trunk, we can theorise thus to any extent. We are as yet only at the beginning of knowledge.

The group of comparatively short-headed Mousterians found at Krapina is of especial interest. We have seen (p. I08) that in the modern world Central Asia is peopled with short-headed people; it is, indeed, the great reservoir of brachycephaly, if we may so express it, in the Old World. This may have been the case in Palaeolithic times, though we have no information whatever about the physical anthropology of Palaeolithic Asiatics. But if future discovery should shew that there was a brachycephalic strain in the Middle Palaeolithic populations of Central Asia, this brachycephalic community at Krapina, the most easterly group of Mousterians yet discovered, will be most easily explained as a result of interbreeding. Such a blend may perhaps account for other peculiar details of the Krapina bones, which display certain "modern" characteristics amid much which is extremely primitive. If this be the explanation, we have in the Krapina remains a record of an interesting moment in history-the first tentative record of Asiatics westward towards Europe. When the movement came to its full strength, it revolutionised the European world.

\section{(3) Fauna of the Middle Palaeolithic Term}

In the foregoing account of the circumstances in which the fossil remains of Mousterian man have been found, we have given some enumerations of associated fauna. The characteristic animals of the Lower Palaeolithic Term, which were weakening during the Acheulean, have now disappeared in the northern parts of the continent, partly or wholly, though they still linger in the southern 
peninsulas of Spain and Italy. Rhinoceros mercki has given place to $R$. tichorhinus, the woolly rhinoceros, whose coating of hair made it better capable of resisting cold than the rest of its kin. In the same way Elephas antiquus has yielded its domain to the woolly Mammoth, which still retains the misleading name Elephas primigenius given to it in the early days of palaeontology. The reindeer, Rangifer tarandus, now makes its first appearance in Central Europe, and with it come the Arctic fox (Canis lagopus), the glutton (Gulo borealis), and the first great invasion of small rodents.

These animals indicate that the Mousterian was essentially an Arctic period, and that it must have occupied the apex of a glaciation. There is not wanting contradictory evidence. however; notably a site at Villefranche-sur-Saône (Rhône) which presents, or appears to present, a Mousterian industry associated with "warm" fauna. This has led some prehistorians to deduce the existence of a "Warm Mousterian" as well as a "Cold Mousterian"; and the necessity for finding room for both these periods in the scheme of glaciations and interglaciations has given rise to much disputation. We cannot at this stage enter upon chronological questions, nor need we at present discuss the evidence for a "Warm Mousterian"; we shall consider this in the final chapter of the present volume, where the problem of chronology is considered. For the present we ask the reader to assume, when we speak of "Mousterian," that the Cold Mousterian is intended; unless reference to the hypothetical Warm Mousterian be specially indicated.

\section{(4) Implements of the Middle Palaeolithic Term}

We now turn to the implements of Mousterian Man. So far the evolution has proceeded thus: the Pre-Chellean people make rude attempts at flint-chipping, which develop into the coup-de-poing of the Chelleans. This is taken over and improved to the highest possible degree by the Acheuleans. The waste flakes chipped from the nodule in the process of manufacture are utilised by the Chelleans, and (so to speak) systematised by the late Acheuleans into the Levallois scraper. We are now to find the coup-de-poing diminishing in importance, and the Levallois scraper developing into the basis of a number of new tools. The germ of the Mousterian culture is thus latent in the Chellean, and the evidence for a continuous population throughout the Lower and the Middle Palaeolithic Terms is proportionately strengthened.

Though in some respects degenerate, the Mousterian period was not stagnant. The researches of M. Bourlon at the type station of 
Le Moustier ${ }^{1}$ has revealed distinct signs of an industrial evolution. There are here seven levels. Three of these are of minor importance; the remaining four shew the development of Mousterian culture. The persistence of the coup-de-poing to the end of the Mousterian stage is illustrated by this site. M. Bourlon, indeed, protests against any contemptuous judgment on the Mousterian flint-chipping as being in any way degenerate ${ }^{2}$; on the contrary, he sees in it a great advance on Acheulean technique. Certainly some of the implements which he and others have figured are of excellent workmanship; in some few cases they almost vie with the high achievements of the Solutrean artificers - a fact not without significance, as we shall see later. But taking them as a whole, they can scarcely be said to rival the neat finish of the Acheulean coups-de-poing. Bourlon himself admits that the chief characteristic of the Mousterian tool is an economy of labour ${ }^{3}$. Unlike the Acheulean coups-de-poing, neatly and carefully trimmed over the whole surface on both sides, Mousterian tools are distinguished from the tools of the preceding stages by the peculiarity that they are chipped on one side of the flake only: and so long as the edge or the point of his tool was such as served the purpose which he desired, the maker did not greatly care what the shape of the body of the tool might be, provided that it could be easily grasped. Projecting edges or points by which the hand might be injured were carefully trimmed away.

In making a Mousterian flake tool, the process followed was to form the outer surface of the tool, even down to the secondary chipping in some cases, before detaching the flake from the nodule. The detachment was accomplished by a skilful blow, after which the tool was complete except for a little touching-up and smoothing off of irregularities. This is shewn by cases (such as Fig. 76) in which it has proved possible to replace a flake tool upon the core from which it had been struck. The matrices of dislodged flakes may there be seen crossing the line of fracture ${ }^{4}$.

This figure is further instructive as shewing how the block of flint was prepared before striking the Levallois flake; experience had taught the manufacturer where the block should be made thicker, and which point should receive the blow. In consequence of this, not only the actual flake itself, but the core from which it has been

${ }^{1}$ M. Bourlon, "L'industrie des foyers supérieurs au Moustier" (Revue préhistorique, v. [1910], p. 157); Idem, "Industries des niveaux moyen et inférieur de la terrasse du grand abri au Moustier" (ibid. vi. [I9I I], p. 283).

${ }^{2}$ M. Bourlon, "L'industrie moustérienne au Moustier" (C.A.P.A. Monaco [1906], vol. I. p. 287, esp. pp. 289, 319).

${ }^{3}$ Op. laud. p. 290.

" On this technique of flint-chipping see V. Commont, "L'industrie moustérienne dans la région du nord de la France" (C.P.F. Beauvais [1909], p. I I5). 
struck, tends to assume a definite shape-a disc, more or less concavoconvex, something like a turtle-back. These cores have sometimes been erroneously taken for intentionally made implements.

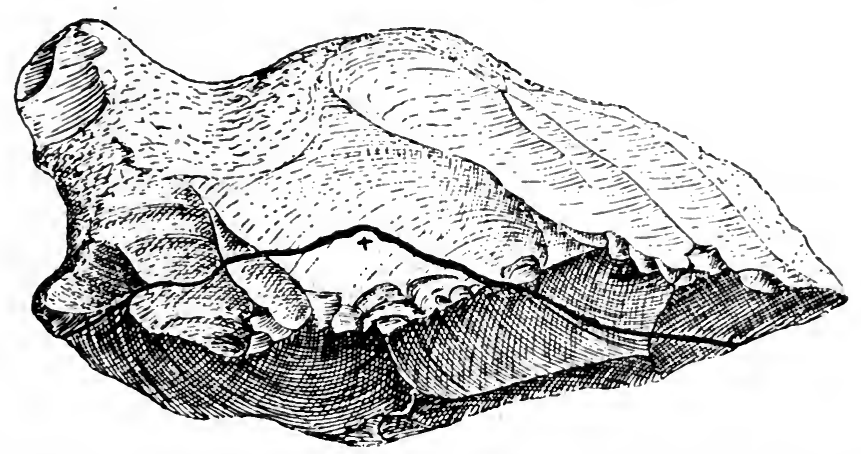

Fig. 76. Nodule shewing the completion of the external chipping of a flake tool before dislodging the flake. The point at which the dislodging blow was struck is indicated by a cross.

(From Congrès préhistorique de France, Comptes-rendus, 1909.)

The outer surface of a Mousterian tool is thus covered with the impressions or matrices of removed flakes, while its inner surface ${ }^{1}$ shews no disturbance except the bulb of percussion. Sometimes there is a chip crossing the bulb, as though to reduce its inconvenient thickness, or to roughen the tool and so to facilitate grasping; Fig. 77 is an example of this.

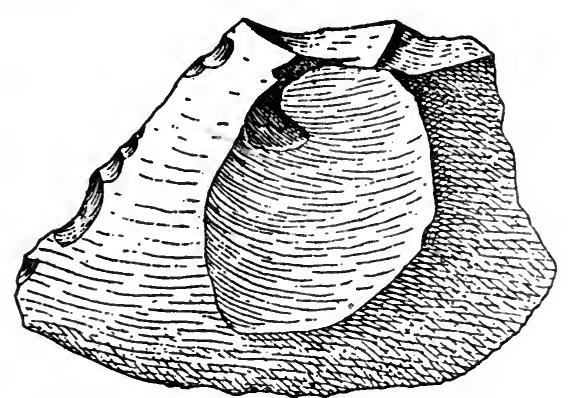

Fig. 77. Side-scraper with the bulb of percussion chipped.

(From G. and A. de Mortillet, Musée préhistorique.)

The new tools now introduced are all modifications of the Levallois scraper: though the practice just described of preparing the core was not continued. Their differences of form, which make them suitable to serve different purposes, arose, we can hardly doubt,

1 The words "outer" and "inner" are to be understood as referring to the position of the flake when in its bed on the nodule to which it belongs. 
quite accidentally. An artificer would find that some favourite flake was the best of those in his possession, for the purposes of a certain special class of work; just as (to take a homely parallel from contemporary civilisation) a man will have a favourite razor, which fulfils its duties more satisfactorily than its rivals. When the flint tool had outlived its term of usefulness - a term necessarily short in implements made of that brittle material-its disconsolate owner would try to provide a substitute as close to its pattern as possible. After many experiments he would succeed to a greater or less extent; and when he had acquired the knack of turning out the desired replicas, the new form of tool would thus become stereotyped and specialised. M. Bourlon, in the paper in C.A.P.A. already quoted, has illustrated a number of intermediate forms between "points" and "scrapers," saws and knives, which prove conclusively the essential unity of these different tools.

The Mousterian culture may be divided into four phases, which we may call early, middle, late, and final Mousterian.

The experimental process, just described, during which the different tools were approximating to their special forms, was the characteristic of the latest phase of the Acheulean and the early Mousterian. There is no sudden break, such as we shall find between the Middle and the Upper Palaeolithic, to justify us in deducing the invasion of Europe by a tribe of "Mousterians." The evidence of the flints corroborates the evidence, such as it is, of the bones, and renders it the more difficult to believe in the great antiquity claimed for certain skeletons of the "modern" type which have come to light here and there in Europe.

The coup-de-poing lingers into Mousterian times. We have already seen that a very fine specimen was found along with the buried youth of Le Moustier. Commont has found similar implements, some of them very well made, in Early Mousterian strata on the Somme ${ }^{1}$; and Bouyssonie and Bardon discovered several in the cave of La Chapelle-aux-Saints ${ }^{2}$. A good typical station of this early period is that at Combe Capelle ${ }^{3}$. Its industry includes coupsde-poing, associated with points, which now appear for the first time. These are more or less triangular flakes, with a sharp apical point. The base of the instrument is as the detaching blow left it, with the bulb of percussion on the inner surface. There is a certain amount

1 "Le Moustérien ancien à Saint-Acheul et Montières" (C.P.F. Angoulême [1912], p. 297).

2 A. and J. Bouyssonie and L. Bardon, "La station moustérienne de la 'Bouffia' Bonneval à La Chapelle-aux-Saints" (L'Anthr. xxiv. [1913], p. 609).

${ }^{3}$ H. Klaatsch and O. Hauser, "Homo aurignacensis Hauseri" (Prähist. Zsch. I. [1910], p. 273). 

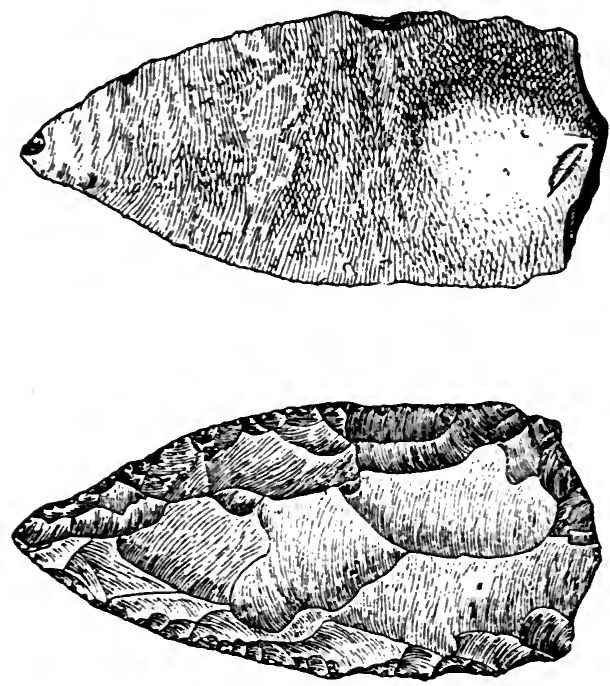

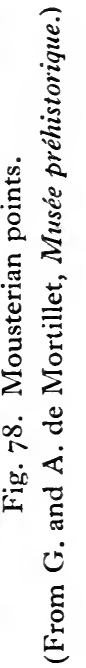

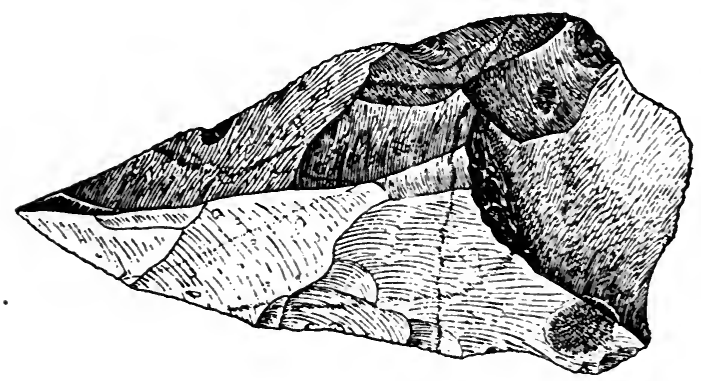


of secondary chipping to shape the tool near the point, but the maker paid little attention to the shape of the instrument except at the extremity (Fig. 78).

It is difficult to say what purpose was served by these instruments. They look at first sight like javelin- or spear-heads. It should however be noted that the spear - a weapon which the assailant holds firmly in his hand when attacking his victim-was in all probability not invented during the Stone Age. For if it had been, the advantage of tipping it with bronze would surely have been recognised at an early phase of the age of metal; whereas the evolution of the bronze spear-head was quite a late phenomenon in the Bronze Age, and grew, not from a stone-tipped spear, but from a bronze dagger. Therefore, if these points belong to any such weapon, they must have been used as javelin- or assegai-heads: the points of weapons cast with the hand. Such weapons, once thrown away, might never have been recovered, and for the sake of economy they would continue to be tipped with flint even after the introduction of metal.

It is however very far from certain that these objects were weapons at all. MII. Bouyssonie and Bardon have offered another explanation, in the report, already quoted, on their admirable work at La Chapelle-aux-Saints. 'They there suggest that these instruments were used for splitting bones in order to get at the marrow; on the ground that bones which have been so treated, discovered at that site, bear marks such as would have been made by such cutting instruments, and not by crushing instruments like hammers. Experiments with Mousterian points upon fresh bones produced similar marks; and some of the points were broken at the tip, as though they had snapped across in the course of using them for the purpose specified. Moreover, large numbers of these points were found in the heaps of kitchen débris, along with the split bones. If they had been weapons, theywould hardly have been thus flung into the middens; they would have been preserved in whatever place was the storehouse of the community.

Still, it is difficult to believe that the points would have been specially manufactured, in such great numbers, for this sole purpose.

The heavy mace or club would still be the chief weapon of the Mousterian warrior or hunter, and a cast stone would be the simplest medium for attacking his quarry at a distance. Piles of such ammunition have been found in several Mousterian caves - balls of sandstone, limestone, or quartz, in some cases trimmed so as to have a shape convenient for grasping in the hand, and not infrequently brought to a neat spherical form. They often display the marks of hammering, from which it has been inferred by some that they were rude pestles for grinding. But as agricultural processes were not as yet known, 
it would be difficult to guess what commodity was ground with them: paint-grinding would hardly need such large stores of pestles. No doubt they would be used on occasion as hammers, and would thus acquire the marks which they bear. Others have suggested other theories, such as that they were used in some game-that last refuge of the destitute archaeological theorizer. The simplest explanation surely is that they were stored up for the purpose of greeting any unwelcome human or animal intruder. It would be desirable to discourage a homeless Ursus spelaeus that might seek a refuge in a cave already tenanted by human occupants ${ }^{1}$.

The Middle Mousterian, illustrated by the middle strata at Le Moustier, shews the Mousterian industry at its best. The points continue in use, better made and more shapely than in the earlier phase. Other instruments, also incipient in the earlier phase, now reach their full perfection.

The most important of these is the side-scraper (in French racloir, in German Schaber), a flake with secondary chipping along one edge, making it fit to scrape the interior of hides in preparing garments. This was probably their principal use.

As the complete absence of anything that would do duty as a spindle-whorl shews, the art of manufacturing textiles was not practised at any time during the Palaeolithic period. Doubtless Chellean man troubled very little about ciothing; but the cold of the Mousterian stage must have made it essential that Middle Palaeolithic man should devise some shelter for his unprotected body, and for such a purpose the skin of a slaughtered beast would be of obvious utility. Flint scrapers are still used in Italy in preparing hides ${ }^{2}$; and the experiment described in the following words ${ }^{3}$ will explain the method of use of the scraper:

"I have made experiments with scrapers and find them more effectual for scraping purposes than if the sharp undressed edge of a flake were used. I procured the skin of a kid, which had been cured by strewing on the fleshy side a mixture of powdered alum and salt, which was allowed to remain for about two or three weeks, when the skin was washed and hung up to dry. It was dried when I got it, but so stiff and crumpled that no garment could have been made from it. I then scraped the one half of the skin on the fleshy side for a considerable time, leaving the other

'On these balls see H. Martin, "Présentation des sphéroïdes en calcaire" (B.S.P.F. v. [1908], p. 27): G. Chauvet, "Boules en pierre moustériennes" (C.P.F. Autun, [1907], p. 189).

2 The statement is made, I understand, in a paper in Archivio per l' antropologia el' etnologia, vol. xxIv, to which, however, I have not access. An elaborate study of the subject will be found in L. Pfeiffer, "Beitrag zur Kenntnis der steinzeitlichen Fellbearbeitung" (Z.f.E. xLII: [19ro], p. 839).

${ }^{3}$ By Mr W. J. Knowles, F.A.I. vol. Ix. [1879-80], p. 320.

M.E.A.I. 
portion in its natural state, and I found that the scraping had the effect of making it quite soft and pliable. The contrast between the scraped and unscraped portion was most striking."

The side-scraper (Fig. 79) is a more or less trapezoidal, rectangular, or triangular flake, which like the Levallois scraper is as a rule worked on one side only, and has the one edge prepared by secondary chipping along the whole or part of its length. The opposite edge is either left untouched; or it may be trimmed to take off roughnesses or dangerous projections or edges; or it also may be
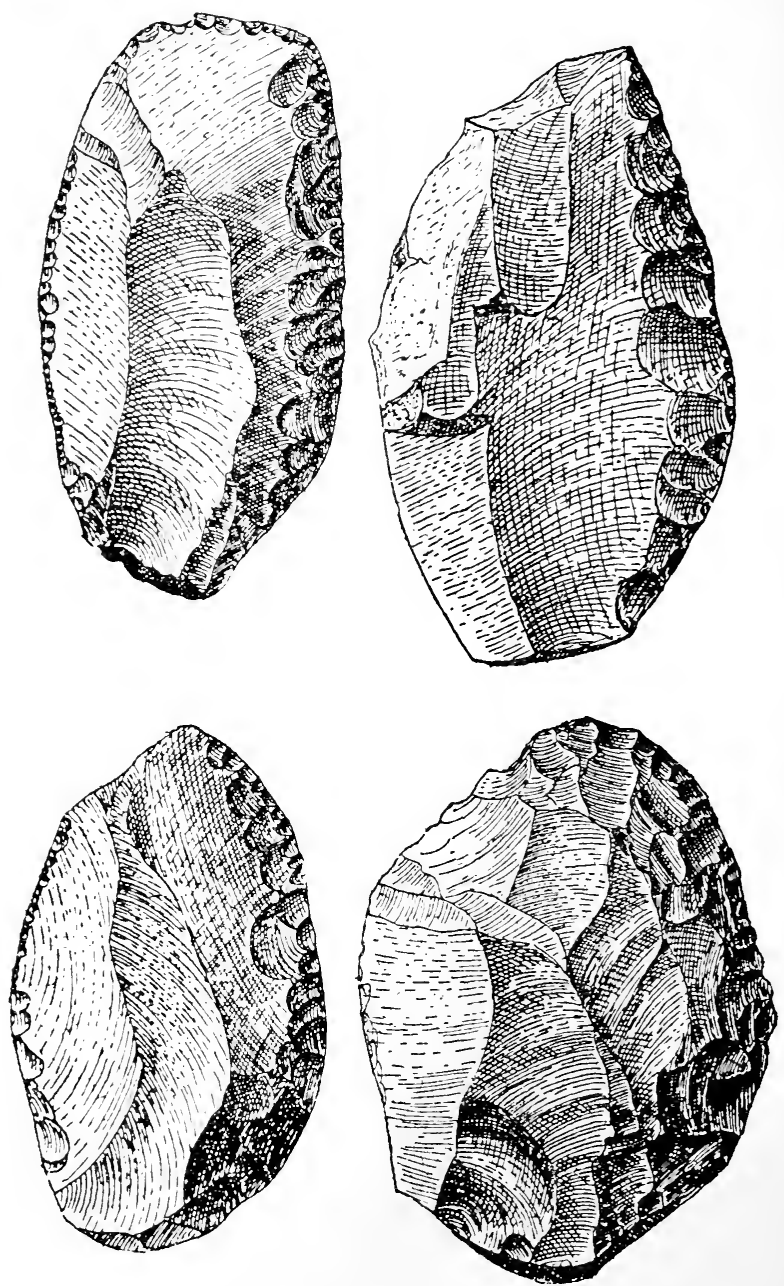

Fig. 79. Side-scrapers.

(Congrès préhistorique de France, Comptes-rendus, 1909.) 


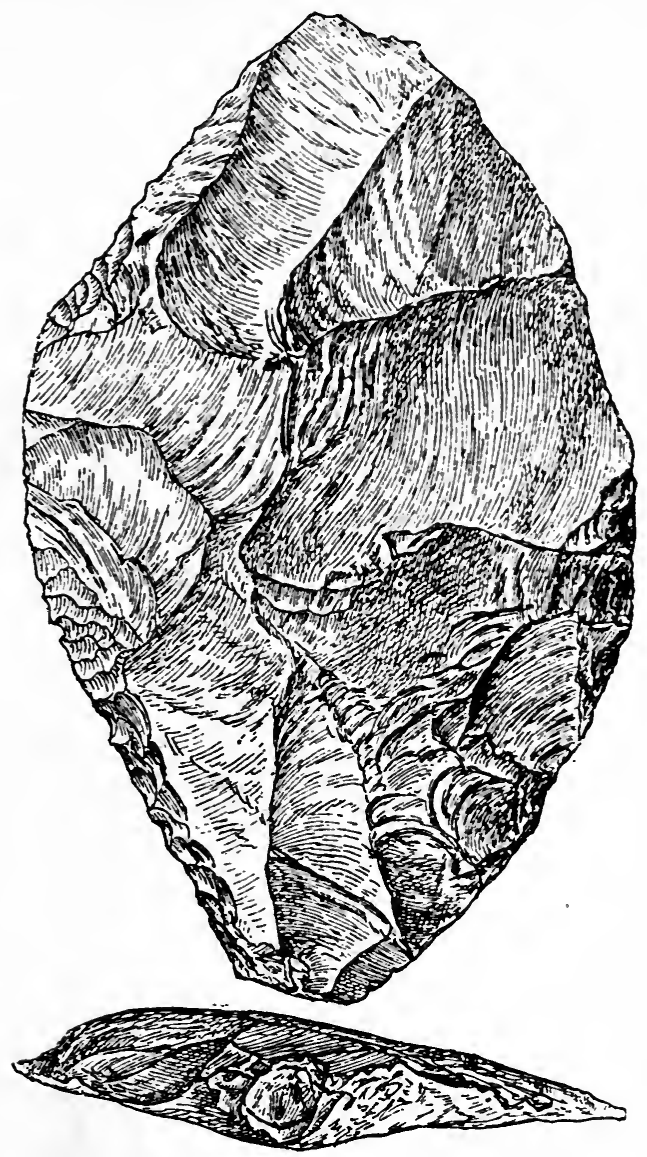

Fig. $79(a)$. Side-scrapers.

(Congrès préhistorique de France, Comptes-rendus, 1909.

trimmed in like manner to the working edge, making the instrument into a double scraper. The illustration will shew the different varieties better than a long description. The tool is called "side-scraper" to distinguish it from another variety of scraper, called in French grattoir, in German Kratzer, and in English end-scraper; as the last name implies, the distinguishing character of this form is the adaptation of the end of the flake as the scraping edge. This tool is of rather later introduction; for though it is found in Mousterian sites, it is more characteristic of the later stages.

Scrapers may be further classified to any extent, and elaborate schemes and terminology have been suggested from time to time. But these are of very doubtful utility. It stands to reason that no 

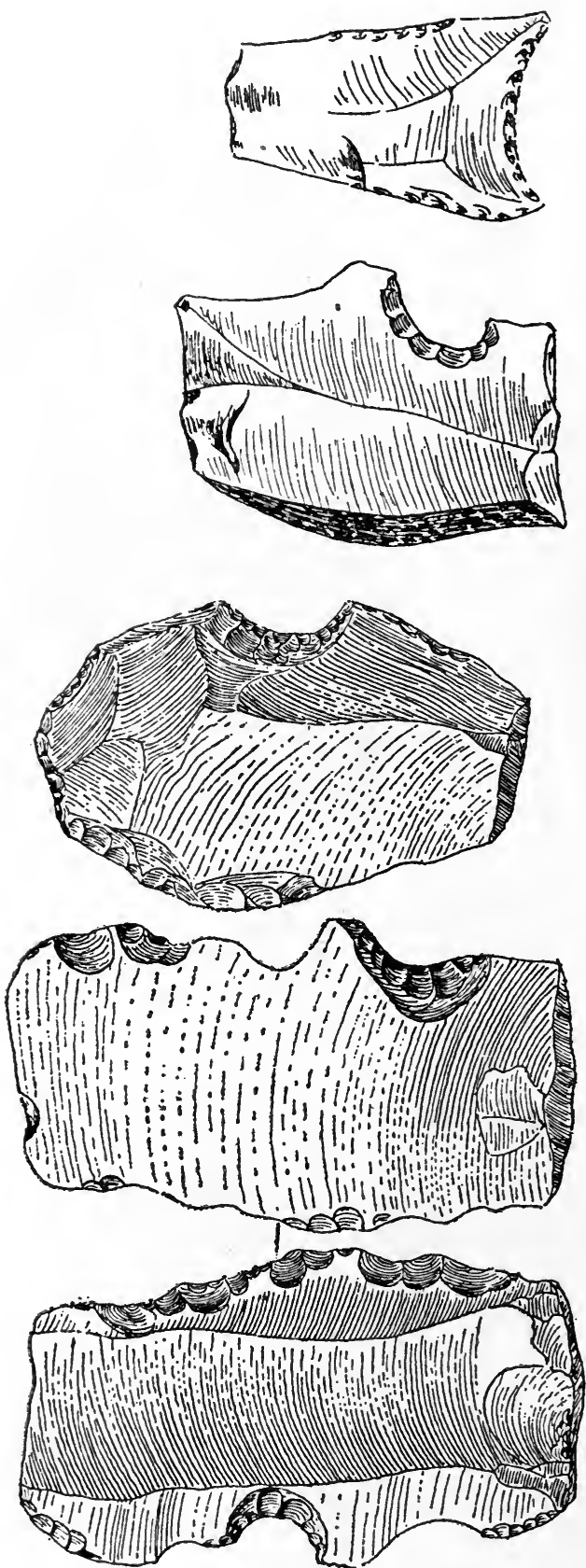

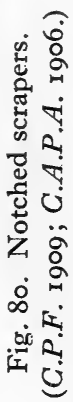


two flint implements can be absolutely identical; and a too complicated classification runs the risk of exalting merely individual peculiarities into criteria of type.
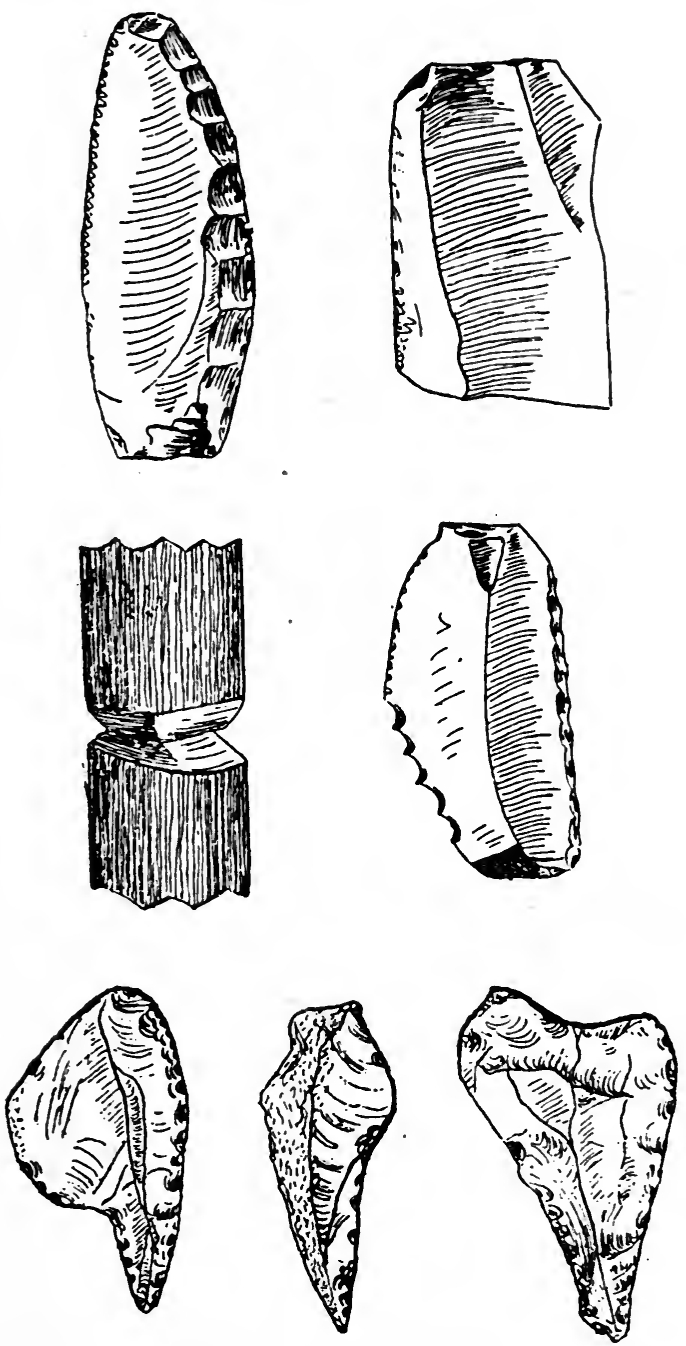

Fig. 81. Saws and borers.

(C.A.P.A. 1906.)

There is, however, an important tool which also appears in the Middle Mousterian and which certainly makes a class by itself; this is the notched scraper (Fig. 80).

This tool, as its name implies, is a scraper with a more or less 
semicircular notch formed in its edge, and touched with secondary chipping all round. It is adapted for scraping rounded surfaces; and if we might treat the points, above described, as assegai-points, the notched scrapers would be effective in preparing their shafts. They have also been explained as saws, with two teeth; and experiment has shewn that it is possible to cut a bone across with such a tool used as a saw. But this would not account for the careful chipping in the deepest part of the notch: and whether the objects to be made were assegai-shafts or not, it is most likely that the instrument was meant for scraping smooth a cylindrical staff of wood.

Of minor varieties of the Levallois scraper, the parent of all the Mousterian tools, must be mentioned saws and borers (Fig. 8I). The
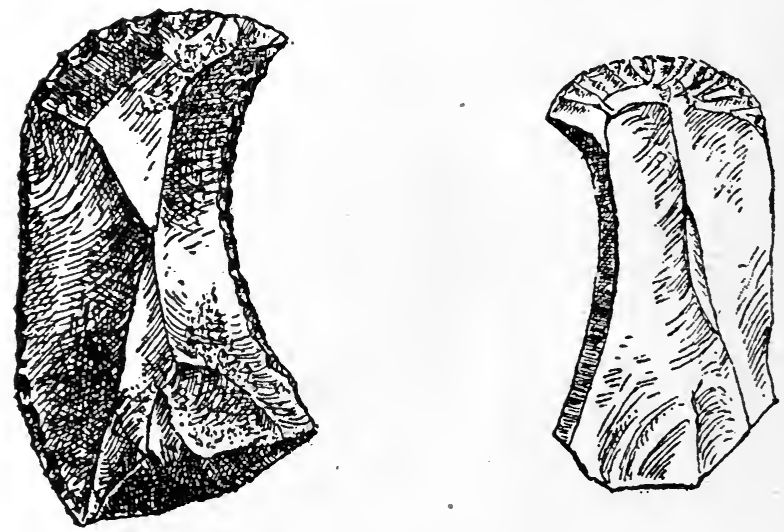

Fig. 82. The beaked scraper.

(From Bulletin de la Société d'Anthropologie de Paris, 1896.)

former of these resemble the side-scrapers, but the secondary chipping is deepened so as to divide the edge into a series of teeth. It is not altogether certain that these tools are to be treated as saws; they may be merely scrapers with rather deeper chipping. A piece of wood cut with one of these instruments is shewn in the figure. Borers are points made long and narrow, to serve the purpose which their name indicates.

There is a rare form of scraper consisting of a curved flake of flint, brought to a point like a parrot-beak, and on that account called the beaked scraper (grattoir a bec). Either the convex or the concave side of the beak, or both, may be adapted for scraping purposes. This instrument begins to appear in the Mousterian stage, and lasts in use till the Campignian (Fig. 82) ${ }^{1}$.

${ }^{1}$ L. Capitan and M. l'Abbé Brung, "Un nouveau type d'instrument, le grattoir à bec" (B.S.A.P. ser. Iv. vol. viı. [1896], p. 373). 
Ribbon-like flake knives begin to appear in the Mousterian deposits (Fig. 83), though these, again, are more characteristic of Upper Palaeolithic remains.

A less ordinary form of tool is the disc-scraper (disque-racloir) which is a circular disc, shaped like the ordinary side-scraper, with a scraping edge at one side and an untouched edge at the other for convenience in grasping. The special peculiarity of these instruments, however, consists in this, that the secondary chipping by which the edge is formed is on the inner or smooth side of the flake ${ }^{1}$.
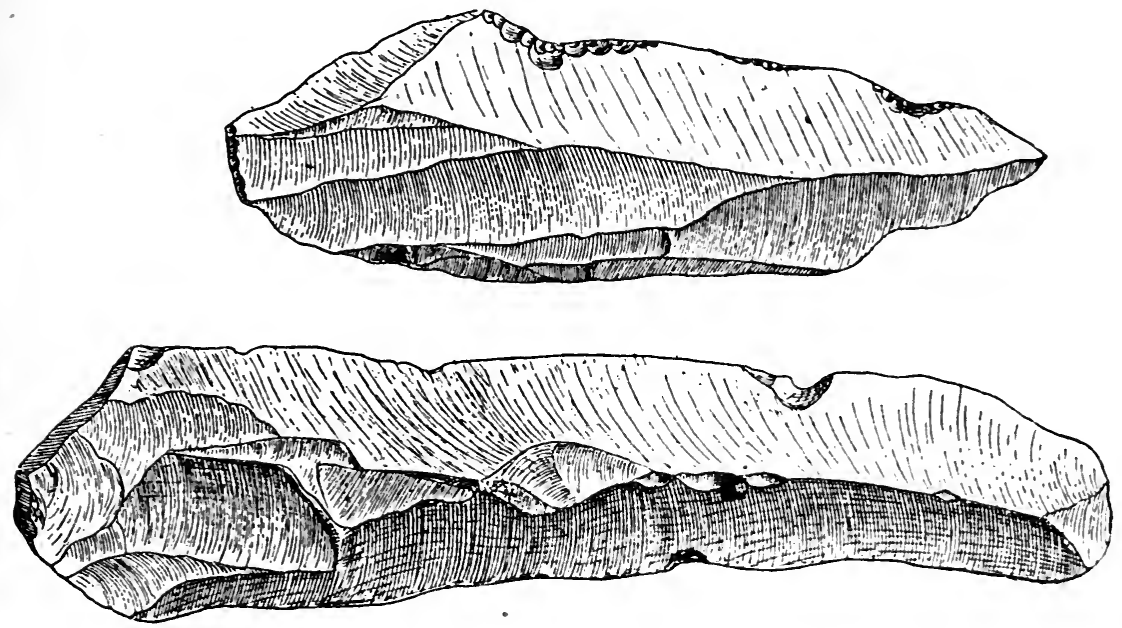

Fig. 83. Mousterian flake knives.

(C.P.F. 1910.)

In Lower and Middle Palaeolithic deposits at Catigny (Oise) two new forms of Mousterian tool have been found, to which their discoverer gave the names burins-ciseaux and ciseaux-engraverchisels and chisels ${ }^{2}$. The principle upon which these tools are constructed is the same-a small section of the edge of a flake is separated from the rest, either at the end of the flake or in its side, or else at an angle, by small and more or less semicircular chips on each side. In the engraver-chisel the cutting section is made in a thick edge of the flake, with the result that the cutting line of the section is either at right angles or oblique to the plane of the flake;

1 M. l'Abbé Blanquet, "Note sur la station paléolithique du Mont Roty et sur un type nouveau d'instrument en silex, le 'disque-racloir" (B.S.A.P. ser. III. vol. XI. [1888], p. 538); L. Capitan, "Nouveau type d'instrument moustérien, le disque racloir" (ibid. ser. IV. vol. II. [1891], p. 564).

${ }^{2}$ Albert Terrade, "Le 'burin-ciseau' de la station moustérienne de Catigny, Oise" (Mémoires, S.P.F. vol. II. [1912], p. 185). 
in the chisel the cutting section is made in a thin edge, so that its cutting line is parallel to the plane of the flake. The illustration (Fig. 84) will make this clear.

The Late Mousterian is well illustrated by the station at La Quina, which has already been mentioned in connexion with the human remains there found. Its leading characteristics are the following:
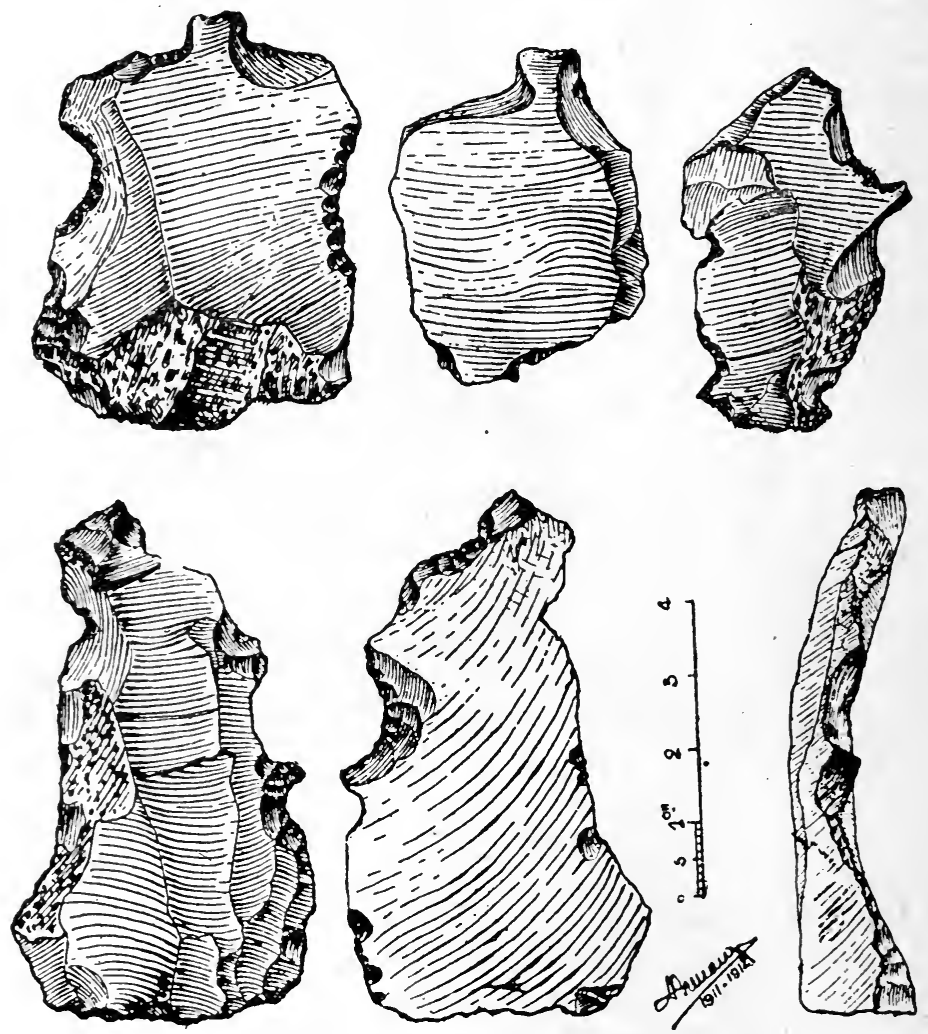

Fig. 84. Engraver-chisels and chisels.

(From Mémoires de la Société préhistorique française, vol. II.)

I. A recrudescence of the coup-de-poing; some very rude specimens were found in the latest Mousterian levels at Le Moustier ${ }^{1}$.

2. A preponderance of cutting instruments (the varieties of the side-scraper) over other tools, whereas in the earlier phases there is a preponderance of points.

3. The beginning of the industrial use of bone. With a few exceptions this is hardly to be traced in the Lower Palaeolithic. We

1 Bourlon, "L'industrie moustérienne au Moustier" (C.A.P.A. Monaco [1906], especially p. 317). 
have seen it at Taubach, and in the implement found with the Piltdown skull ${ }^{1}$. In the Middle Palaeolithic it is still rare; but it is definitely established, especially by the anvils of La Quina. Here there were found a large number of bones of animals, bearing scratches upon them. They were nearly all the lower epiphyses of the humeri of horses, or the first phalangeal bones of the feet of horses or of oxen: but though these were the chief bones used, they were by no means the only bones pressed into the service of men. Any bone that came to hand might be used on occasion. But the hard surface of the bones named made them especially suitable for rough work, and in consequence many of them were found bearing scratches which looked like random and meaningless marks, but which were seen to fall into a scheme when a large number of specimens were compared together.

The bones were not themselves shaped in any way, but were used in their natural form. They were not therefore brought to the shape of a tool, weapon, or ornament, but were used for the purpose of manufacturing some other object. The scratches might have been produced, as Dr Henri Martin puts it, actively or passively-that is to say, the bone might have been struck upon the object being formed (as a mallet) or the object might have been struck upon the bone (as an anvil). As the place on the bone where the scratches appear are not the natural points of striking, the inference seems sound that the bones were used as anvils. Moreover, in some cases they were so much ground away by the attrition that the spongy interior of the bone was exposed, which would clearly make it useless for giving blows, though it might retain sufficient substance and elasticity to continue to receive them (Fig. 85).

Dr Martin, in his very thorough and sumptuously illustrated monograph upon these objects ${ }^{2}$, has expressed it as the conclusion to which he has come that these bones were probably used for the purpose of making wooden pointed instruments, such as javelins, the wood being placed resting upon the bone and pared down with flint tools. The slipping of the flint against the bones would produce just such cuts as they display. Some long bones bearing cross-scratches upon them might have been used for producing secondary chipping on flint implements; when pressed transversely across the edge of a flint flake they would dislodge small scales of flint, and they would themselves receive such cross-scratches.

1 With the best will in the world I cannot believe that the broken splinters of bone from beneath the Red Crag of Suffolk (Prehist. Soc. E. Anglia, II. I 6 ff.) are artefacts.

${ }_{2}^{2}$ Recherches sur l'évolution du Moustérien dans le gisement de La Quina (Charente), Paris, 1907-1910. See also his communications in B.S.P.F. vols. III. IV. v. 
The La Quina discoveries were the first to be brought to scientific notice, but they were by no means the only ones that have been
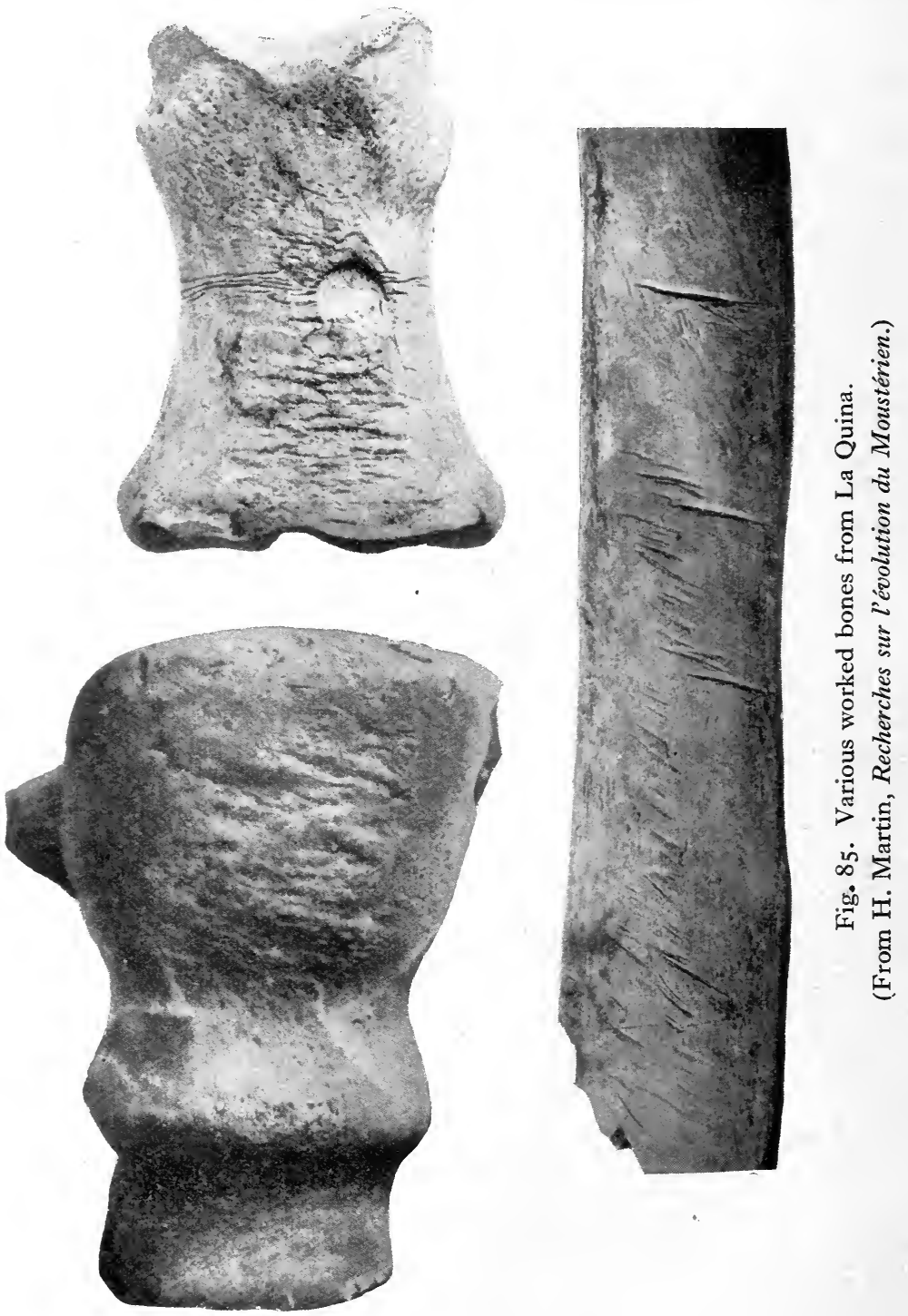

made. Pittard has found them in the Vallon des Rebières ${ }^{1}$, and Favraud at Le Puymoyen ${ }^{2}$; while Rutot has reported them from

1 E. Pittard, "Nouveaux instruments en os provenant d'une station moustérienne aux Rebières (Ourbières), Dordogne" (R.E.A. xVII. [1907], p. 429).

2 A. Favraud, "La station moustérienne du Petit-Puymoyen" (R.E.A. xviı. [1908], p. 46). 
Belgium from several caves, which, however, he ascribes to Upper Palaeolithic times ${ }^{1}$. Likewise Upper Palaeolithic, but of similar character to the La Quina bones, appear to be the examples found by Favraud at Le Pont-Neuf ${ }^{2}$.

The anvils were not the only bones bearing traces of human workmanship unearthed at La Quina. There were some fragments of ribs, and other splinters of bone, some pointed, with polished surfaces, evidently produced by friction. These had been used for some purpose which led to their being rubbed against other objects. A fragment of the scapula of a cow had some scratches upon it, apparently artificial, though for us meaningless ${ }^{3}$. A few small bones, as well as a canine tooth of a fox, had been perforated, doubtless to turn them into suspended amulets ${ }^{4}$.

There was another series of injured bones found at La Quina in considerable numbers. These were the first phalangeal bones

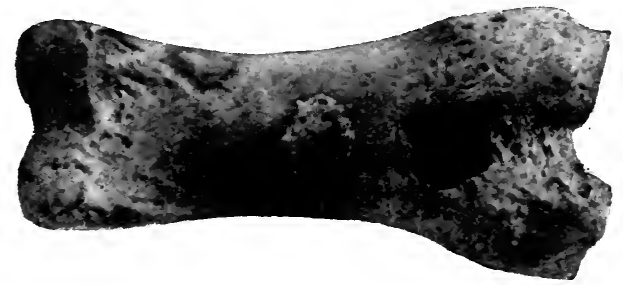

Fig. 86. The so-cailed reindeer-bone whistle.

(From H. Martin, Recherches sur l'évolution du Moustérien.)

of reindeer, bearing a more or less circular perforation at the upper end, just under the articulation, and on the posterior face (Fig. 86). Such bones, with similar perforations, not infrequently come to light in Palaeolithic deposits, and ever since the time of Lartet it has been the fashion to call them whistles; for Lartet ${ }^{5}$ observed, of a specimen which he discovered, that a sound could be produced from them by blowing across the hole; as one blows across the end of the shaft of a large key for a similar purpose. But in any case the sound produced would be too weak and too shrill: and Dr Martin has clearly shewn that the uniformity with which the hole occurs where

1 A. Rutot, "Sur la répartition des os utilisés en Belgique" (B.S.P.F. v. [1908], p. 280 ).

2 A. Favraud, "Station aurignacienne au Pont-Neuf, commune de la Couronne (Charente)" (R.E.A. xvir. [1907], p. 418). The similarly worked bones found by Bourlon and Givaux at Cro-Magnon (B.S.P.F. Iv. [1907], pp. 262, 264) are also Aurignacian. See also ibid. vir. [1910], p. 282.

${ }^{3}$ B.S.P.F. vir. [1910], p. 40.

B.S.P.F. v. [1908], p. 173 .

5 Reliquiae Aquitaniae [1865-75], plate V B, fig. 21. 
it does may be explained by the fact that it is just this point of the bone which is the weakest and the most liable to injury. He explains the holes as being due to the bite of some canine received during the lifetime of the animal, and draws the inference-possibly a little perilous - that the Mousterian hunter may have made use of some such auxiliary in the chase. It must be noticed that in some individual cases the perforation shews marks of artificiality ${ }^{1}$.

Other supposed traces of human industry upon bones, found at the same station, are perhaps less convincing. Such are the cups formed of the cotyloid cavity of the pelvis (i.e. the socket in which the head of the femur turns) and the similar cups made of the hollow articular surfaces of vertebrae. These might have become dislodged from the bones to which they belonged by mere accident.

One of the most interesting parts of Dr Martin's monograph, referred to in a previous footnote, is his reconstruction of the processes of the chase from the injuries which the bones of the animal victims have received. A phalangeal bone of a horse (figured above) shewed a depression, due to a severe blow received during life; this is explained as the blow of a stone cast either by a powerful hand or with the aid of a sling. Another bone, the first phalangeal bone of a young ox, had a splinter of flint still embedded in it. The animal had survived the wound, which had suppurated; there was an extensive ostitis around the spot where the flint adhered. Incidentally this proves the use of some kind of flint-tipped javelin, to which reference was made on a previous page. It is noteworthy that the La Quina station does not conform to the usual rule of shewing a large proportion of long bones and other edible portions of the larger animals. As a general principle, the midden-heaps of the caves indicate that these animals were usually cut up where they fell, and that the hunters bore only the useful parts to the habitation, thus sparing their parties the labour of carrying home the huge weight of a whole slaughtered bison or horse. Dr Martin would infer from this that some sort of domestication of animals was already practised by the inhabitants of La Quina; otherwise it would be difficult to account for so many beasts being slaughtered convenient to the shelter, making it possible to bring in the whole animal. But there are other possible explanations. The animals might, for instance, have been hunted and driven to precipitation (perhaps terrified by waving firebrands) down a neighbouring cliff. Many important stations are close to cliffs that would be suitable for such a nefarious hunting stratagem: the caves in the valleys of the Lesse or of the

${ }^{1}$ See B.S.P.F. Iv. [1907], p. $3^{8}$. 
Vézère, or the Rock of Solutré, are examples. Or the bodies might have been dragged to the station on sledges.

However captured, the first thing to be done with the dead animal was to flay it; and in a masterly enquiry, Dr Martin has followed out and reconstructed this important process, with the aid of the marks which the flaying knives of flint have left upon the bones in their passage. The process of evisceration followed, and the records of this also can be traced on the sternal bones and on the ribs. Then followed disarticulation, and scratches and cuts on the joints of the varicus limbs indicate the struggles of the Mousterian carver. The flesh was then scraped off, and the scraping and rubbing which this process produced can still be traced. Then the long bones were smashed with stones, to obtain the marrow; and finally many of them were thrown on the fire, for which the fat which they contained made them valuable as fuel, and there they were charred.

For a very full series of illustrations of Mousterian implements, the reader may be referred to V. Commont's paper, "Les hommes contemporains du renne dans la vallée de la Somme"."

The final phase of the Mousterian is illustrated by a very limited number of sites, chief among which is the settlement of l'abri Audi2 L'abri Audi is a rock-shelter situated on the right bank of the Beaune, a small tributary of the Vézère, not far from the village of Les Eyzies. It was excavated by Dr Lalanne ${ }^{3}$ and revealed the following stratigraphy:

$G$. Bed disturbed by previous excavations, $0.50-\mathrm{I}$ mètre.

$F$. Sterile bed, $0 \cdot 20$ mètre.

$E$. Limestone blocks and sand, with chipped flints, 0.60 mètre.

$D$. Bed of bones and some chipped flints.

$C$. Hearth, 4 mètres long, 0.80 mètre thick in the middle.

$B$. Sandy zone, 0.20 mètre.

$A$. Vegetable soil forming the primitive earth covering on the rock.

The fauna was unfortunately here insignificant. The industry is a peculiar facies of Mousterian, including small coups-de-poing, points, flakes, and side-scrapers; there is but little difference between the industry of the upper and the lower implement-bearing layers, except

1 Published in Mémoires de la Société des Antiquaires de Picardie, xxxvir. [1914], p. 207. In the fear that M. Commont's lamented death, announced as this volume nears its completion, may deprive the world of science of the monograph on his long labours which he had in preparation, may an admirer of his work venture to suggest that the collection into one volume of all his papers from the numerous journals among which they are scattered, would be one of the greatest boons that could be conferred on students of Prehistoric Europe?

2 By some spelt Abri Audit.

3 Gaston Lalanne, "L'abri des carrières dit 'Abri Audi,' station de la fin de l'époque moustérienne aux Eyzies (Dordogne)" (Actes de la soc. linnéenne de Bordeaux, LxII. [1909], p. 385). 
that those in the upper stratum are less perfect and fewer in number than those in the lower. The upper stratum yielded two prickers, one in bone, the other in ivory.

The typical Mousterian point is almost entirely absent at l'abri Audi; the coups-de-poing are all poor specimens, heart-shaped, of small size. The scrapers tend to become thick, foreshadowing the carinate scrapers of the Aurignacian. The curved flake point is a leading characteristic of this site; Breuil ${ }^{1}$ sees in it an anticipation of the Chattelperron knife, one of the leading types of the early Aurignacian.

\section{(5) The Niddle Palaeolithic in the European Regions}

The following particulars may now be given regarding the Middle Palaeolithic in the different European regions.

\section{Region III. Italy and Sicily}

Italy has yielded a considerable harvest of implements of Mousterian types, but, as in the case of those of the Lower Palaeolithic, the stratification leaves much to be desired, and the chronology cannot be said to be certainly fixed. The Lower and Middle Palaeolithic types are more closely associated in Italy than in France; the Lower Palaeolithic types seem to have persisted much more obstinately in the south than in the centre and north of the Continent.

The chief Mousterian implements in Italy, as in France, are points, side-scrapers, and flakes, the last-named with or without secondary chipping on the edges or the ends. There are also found discs, worked on one face only, as well as coups-de-poing or implements resembling them, also worked on one face only ${ }^{2}$. Such instruments appear, in limited numbers, in association with quasi-Acheulean coups-de-poing at la Majella.

The distribution of Mousterian implements in Italy is more uniform than that of the Lower Palaeolithic types. A long list of sites could be compiled with the aid of Colini's paper, referred to in the footnote. The Vibrata valley is here again a rich source of supply, as are the regions of le Marche and gli Abruzzi. In these, however, the stratification is uncertain. More satisfactory from this point of view appears to be the alluvial deposits of the river Santerno, near Imola, Emilia, which have yielded Levallois scrapers, points, and coups-de-poing worked on one side only. The Santerno de-

${ }^{1}$ H. Breuil, "Études de morphologie paléolithique: I. Le transition du Moustérien vers l'Aurignacien à l'abri Audi (Dordogne) et au Moustier" (R.E.A. XIX. [I909], p. 320).

"Colini, continuation of his paper quoted p. 242 ante (Bullettino, xxxil. p. I8I ff.). 
posits would thus appear to belong to an early phase of the Mousterian. Bones of Elephas antiquus and of Hippopotamus have been found in these gravels. This is not the fauna usually associated with remains of Mousterian culture; but it must be remembered that the climatological principles deduced for the colder countries north of the Alps do not necessarily apply to those of the warmer south. In point of fact, the association of Mousterian implements with a specifically cold fauna does not appear to occur in Italy.

A rather later facies is presented by the remains discovered at Traversetolo and Lesignano in Emilia. At Santa Maria dei Bagni, near the latter place, was a Mousterian deposit containing no coupsde-poing and no Levallois flakes; the industry consisted of points, scrapers, and one disc. No particulars as to the fauna are available in any account accessible to $\mathrm{me}^{1}$.

In a cave at Auresina near Trieste were found Mousterian flints along with bones of Felis spelaeus, Hyaena spelaea, Lupus spelaeus, Bos primigenius, and Cervus elaphus. There were also perforated bear-bones with fragments of flint sticking in them ${ }^{2}$.

Other Mousterian sites are the gravels near Rome; Scalea in Calabria-a late Mousterian facies, with "hot" fauna including Hippopotamus; la Grotta in the Rapido Valley, near Cassino (Campania); and certain caves in Sicily ${ }^{3}$. Here implements of Mousterian appearance are not uncommon; they are all rude, and their Palaeolithic date is by no means certain.

\section{Region V. Southern France and Liguria}

The greater number of the important Mousterian sites are concentrated in this region; to the most outstanding reference has already been made. G. de Mortillet, after an exhaustive survey of the stations known to him, concludes in effect that remains of this stage of civilisation are to be found in France wherever they are sought for, except in the glaciated mountain areas ${ }^{4}$. The best-known typical stations are situated just on the borderline between our regions V and VII. Combe Capelle, which with its triangular and heart-shaped coups-de-poing marks the transition between the Acheulean and the Mousterian, is in the department of Dordogne; so is Le Moustier, the numerous strata at which site enable us to trace the Middle Palaeolithic development. La Quina, the type station of

1 Mochi, Colini, opp. laud.

2 Bullettino di paletnologia ital. xxxiIr. [1907], p. 184 .

3 For the very meagre remains of the Palaeolithic period in Sicily see Ferd. Freiherr von Andrian, Prähistorische Studien aus Sicilien (printed as an appendix to $Z$.f.E. vol. x.).

4 Préhist. sect. vi. chap. ii. 
the late Mousterian, lies in the adjacent department of Charente, and l'abri Audi, where the Mousterian ends, is again in Dordogne. The whole history of the Mousterian period is concentrated in the deposits accumulated in the caves which tunnel the precipitous sides of the valley of the Vézère.

\section{Region Vi. The Iberian Peninsula}

The Mousterian stage is richly represented in Spain, and stations are found both in the open air and in caves-the latter more frequently. They occur in every province, as well as in Portugal. None of these sites is of sufficient importance to merit special notice, except perhaps the Mousterian strata in the great cave of Castillo. Here are found specimens of a peculiar local type of tool, made of quartzite, which resembles a coup-de-poing with a long edge in place of a point; the base is rounded, and the inner surface of the flake is unchipped after the usual fashion of Mousterian tools ${ }^{1}$.

\section{Region VII. Northern France}

That a larger number of Mousterian sites have not been found in this region is probably because they have not been looked for. Collectors have specialised in coups-de-poing, and have neglected the less obvious and less attractive implements of the Middle Palaeolithic. These have accordingly been cast aside as unprofitable by graveldiggers and other labourers. Commont ${ }^{2}$ records his conviction that the Mousterian industry is abundant in Northern France, contrary to the current opinion; it is borne out by his own magnificent work in the Mousterian deposits of the Somme.

There is nothing special to be added here regarding the Mousterian in this region.

\section{Region VIII. Germany}

In the remains of the Mousterian stage from Germany there are two distinct facies-a primitive, and a fully developed. The first of these is characterised by extremely rude tools; for the greater part mere rough flakes, chipped from the nodule, and formed into different varieties of scrapers by secondary chipping. The later Mousterian, which has some affinity with the industry of La Quina, shews much better-made scrapers, as well as flake knives and survivals of the coup-de-poing. Bone anvils, as at La Quina, are sometimes found.

\footnotetext{
$1 \mathrm{H}$. Breuil and H. Obermaier, "Institut de paléontologie humaine; travaux de l'année I913" (L'Anthr. Xxv. [1914], esp. p. 233).

2 Les hommes contemporains du renne dans la vallée de la Somme, p. $26 \dot{6}$.
} 
Of the Mousterian sites in Germany, the most important is the cave called Der Sirgenstein. This cave lies in the Achtal, between Schelklingen and Blaubeuren, about 30 kilomètres from the older moraines of the Rhine glacier. It consists of a passage running northwards for 12 mètres, after which it continues in a northeasterly direction for about 31 mètres; it then becomes too narrow for further exploration. At the place where the direction of the axis of the cave turns there is a domed chamber with two openings in the roof. The deposits on the floor, which extend for some distance inward from the entrance, were excavated with exemplary care by Schmidt ${ }^{1}$ in 1906 . The following stratification was determined:

$K$. Alluvium, $0.40-0.45$ mètre. Mediaeval and metal ages.

7. Late Magdalenian, with Lagomys pusillus, $0 \cdot 20$ mètre.

I. Early Magdalenian, with Myodes torquatus, 0.20 mètre.

$H$. Solutrean, 0.35 mètre.

$G$. Late Aurignacian, $0 \cdot 15$ mètre.

$F$. Fully-developed Aurignacian, $0.15-0.20$ mètre.

$E$. Early Aurignacian, $0.15-0.20$ mètre.

$D$. Interjected layer of rodents, especially Myodes obensis.

C. Late Mousterian, $0.08-0.10$ mètre.

$B$. Early Mousterian, 0.13 mètre.

$A$. Sterile Tertiary sands, 0.15 mètre.

There was thus no Lower Palaeolithic industry. The two Mousterian beds were well distinguished by their respective industries, though there was no appreciable difference in their fauna. Both beds contained remains of the following animals:

$\begin{array}{ll}\text { Canis lupus } & \text { Lepus variabilis } \\ \text { Canis lagopus } & \text { Rangifer tarandus } \\ \text { Ursus spelaeus } & \text { Bison priscus } \\ \text { Felis lynx (?) } & \text { Equus caballus } \\ \text { Myodes torquatus (rare) } & \text { Elephas primigenius }\end{array}$

Rhinoceros tichorhinus

The implements of the lower, primitive bed at der Sirgenstein included very rude flakes, more or less triangular, little if at all better made than the average eolith. There were also some scrapers of a rather better type, with secondary chipping; but all were poor. About 1000 flint implements of this primitive sort were collected from this layer. It contained a number of hearths, but no trace of wood ash; the fuel seems to have consisted to a great extent of bones, of which a large number of charred fragments came to light.

The upper Mousterian bed contained specimens of the characteristic Mousterian points as well as flake knives, borers and various

1 R. R. Schmidt, Der Sirgenstein und die diluvialen Kulturstätten Württembergs (Stuttgart, 1910); Idem, Die diluviale Vorzeit Deutschlands, p. $17 \mathrm{ff}$.

M.E.A.I. 

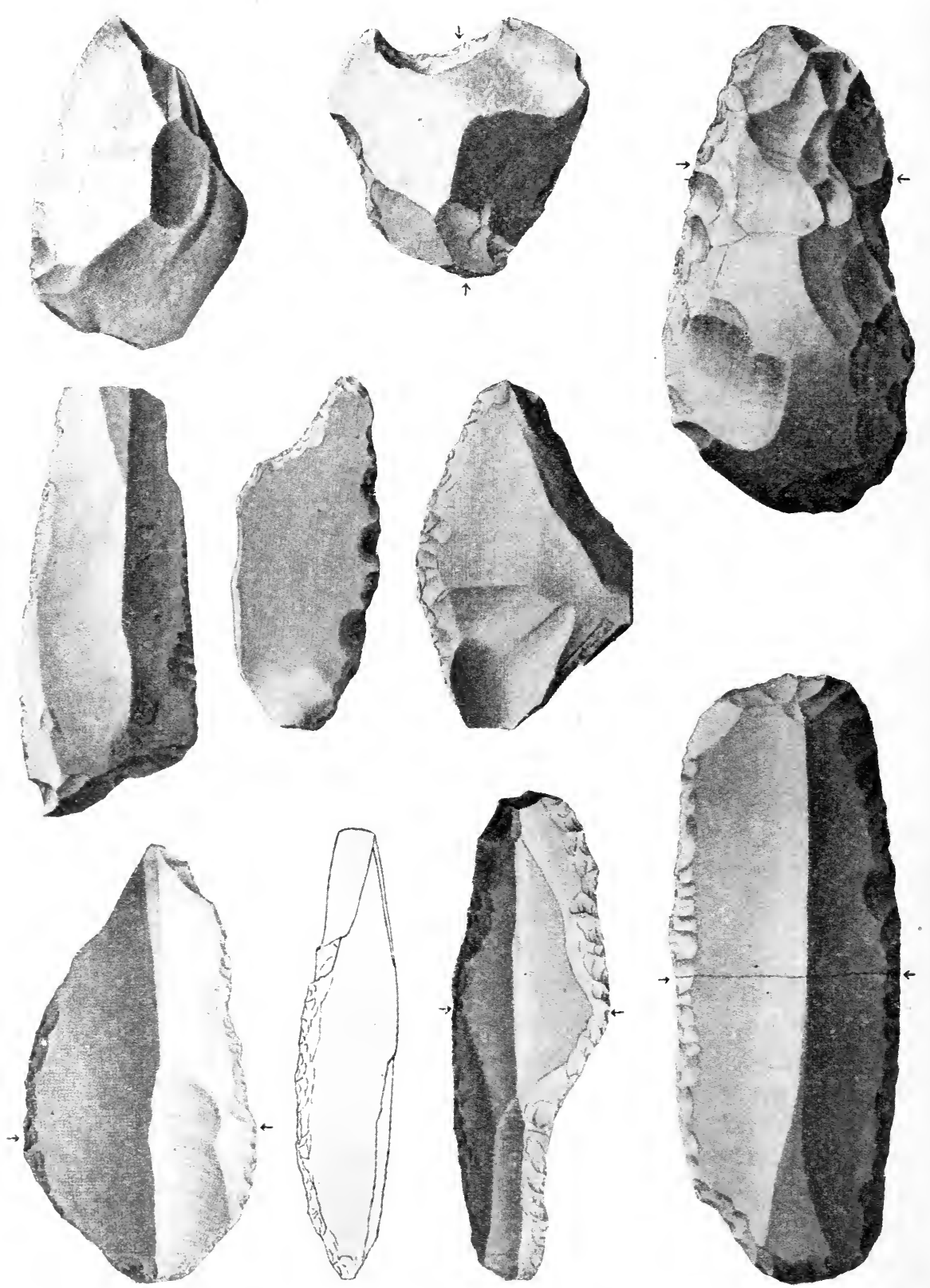

Fig. 87. Mousterian implements from der Sirgenstein.

(From Archiv für Anthropologie, vol xxxv.) 
types of scrapers. A number of splinters of bone were found, shewing marks of usage; they may have been employed in producing the secondary chipping. There was a quantity of ashes and burnt bones marking this bed; about 500 flints were recovered from it A selection of flints from this site is shewn in Fig. 87 .

Overlying the Mousterian beds at der Sirgenstein there was a thin bed, not extending over the whole area of the underlying deposits, without any trace of human industry, and containing the bones of the following animals-Canis lagopus, Mustela erminea, $M$. eversmanni, several species of Arvicola, Myodes torquatus, $\cdot M$. obensis, and Lepus variabilis.

The cave called Irpfelhöhle, in the Brenz valley, north-east of der Sirgenstein, contained a fauna similar to that of the Mousterian beds in that cave, with the addition of Hyaena, and a few implements comparable with those of the lower bed of der Sirgenstein.

At Achenheim a stratum of human culture was interpolated between the Lower and Upper Löss (see the scheme of stratification at Achenheim, ante, p. 256). This stratum contained the following fauna, which is similar to the Sirgenstein Mousterian fauna, but rather fuller:

$\begin{array}{ll}\text { Canis vulpes } & \text { Cervus elaphus } \\ \text { Ursus sp. }{ }^{1} & \text { Rangifer tarandus } \\ \text { Hyaena spelaea } & \text { Bison priscus } \\ \text { Spermophilus rufescens } & \text { Bos primigenius } \\ \text { Arctomys marmotta } & \text { Equus caballus } \\ \text { Arvicola amphibius } & \text { Rhinoceros tichorhinus } \\ \text { Cervus giganteus } & \text { Elephas primigenius }\end{array}$

and a number of flints. These were so very rude that seriation was impossible; their age could therefore not be exactly fixed. But on the whole it is most likely that they belong to the Early Mousterian. As at der Sirgenstein, a rodent layer overlies the Mousterian layer at Achenheim.

The Kartstein cave, near Eiserfey in the Eifel, told the same story. On the rock-floor of the cave was found a large rude coupde-poing, $14.5 \mathrm{~cm}$. long. This implement the excavator, C. Rademacher ${ }^{2}$, took to be Acheulean, not unnaturally; for it was separated by two fairly thick sterile layers from any other remains of human industry. There does not seem, however, to be any trace of specifically Acheulean fauna in the cave; and, having regard to the extreme rarity of Acheulean tools in Germany, it may perhaps be safer for the

1 This is the abbreviation commonly used by zoologists to denote "an uncertain species."

2 C. Rademacher, "Der Kartstein bei Eiserfey in der Eifel" (Prähist. Zeitsch. III. [I9II], p. 201). 
present to count this to very early Mousterian. The genuine Mousterian beds came above these sterile layers. They were two in number, separated by a sterile layer-the one corresponding to the lower bed at der Sirgenstein, the other to the upper. The lower bed at der Kartstein was, however, a little more advanced in culture than the lower Sirgenstein bed; it included definite Mousterian points in its remains. The upper layer included points, scrapers, borers, and flakes, in flint, quartz, and quartzite. The fauna did not differ from those of the corresponding layers of der Sirgenstein and Achenheim. Upper Palaeolithic beds overlay the Mousterian strata.

We may pass over with a bare mention das Buchenloch ${ }^{1}$ where also primitive Mousterian remains have come to light, but in insignificant quantities and in ill-stratified deposits. Nor need we say any more about die Räuberhöhle, near Regensburg, the stratification of which is imperfectly recorded; among the artefacts there found are a number of the late Mousterian facies ${ }^{2}$. Two caves near Rübeland in the Harz, Baumannshöhle and Hermannshöhle, proved on excavation to have been bear-dens: large quantities of bones of this animal were there found. A few Mousterian points were mingled with them; they shewed an advanced technique, and are certainly to be ascribed to the late Mousterian. There were also some fragments of bone (one of them perforated), a nodule of meteoric iron, and a piece of petrified wood, all bearing marks of polishing ${ }^{3}$.

\section{Region IX. The Alpine Region}

There is one Mousterian site only known to exist in this region; the cave of Wildkirchli. This will be described in Chapter XI, in connexion with the chronological problems on which it has a bearing.

\section{Region X. Austria, Hungary, and Western Russia}

The few sites in this region yielding Mousterian remains are of stratigraphical importance only. In the Löss at Tata, Hungary, some exceedingly rude flints have been found, supposed to be Mousterian.

1 R. Virchow, "Ueber die anthropologische Generalversammlung in Trier" (an analysis of communications by Herren Bracht and Niering) (V.B.A.G. [1883], p. 490); R. R. Schmidt, Dil. Vorz. Deutschlands, pp. 70, 77, where references to other literature will be found.

${ }^{2}$ R. R. Schmidt, op. laud.pp. 32-33, and other literature there noted.

${ }^{3}$ Wilhelm Blasius, "Spuren paläolithischer Menschen in den DiluvialAblagerungen der Rübeländer Höhlen" (Beiträge zur Anthrop. Braunschweigs, in Festschrift zur 29 Versammlung d. deutsch. anthrop. Gesellsch. 1898, pp. I-39); Idem, "Ueber die Vorgeschichte und Urgeschichte des Braunschweiger Landes" (Corr. [I898], p. 109); Idem, "Fortsetzung der Ausgrabungen in den neuen Teilen der Baumannshöhle" (13 Fahresbericht des Vereins $f$. Naturwissensch. [1904], p. 72); R. R. Schmidt, op. laud.pp. IOI-102, 225, and further literature there cited. 
To judge from the illustrations they might be anything, or (more probably) nothing ${ }^{1}$. The cave of Sipka, which contained an extensive Mousterian deposit, with a later settlement of the Reindeer Age overlying it, has been already described (ante, p. 307). The implements found throughout the strata were all rude atypic flakes of flint and quartzite, with the exception of a few scrapers. The caves of Čertova-díra, and Wiérzchow, which have yielded Mousterian remains, will be more fully described in the following chapter.

\section{Region XI. South Britain}

What was said above as to Northern France applies in equal measure to South Britain. The number of Mousterian sites known in this region is very small in comparison with the Lower Palaeolithic record: most probably because they have not been searched for with sufficient assiduity. Remains of both open-air and of cave stations have been found. The area covered by Mousterian stations does not exceed the limits of that containing Lower Palaeolithic sites.

We have already alluded to the Mousterian flints found in a brick-earth bed at Mildenhall. At Bungay on the Waveney river, between Norfolk and Suffolk, a flake resembling a rude Mousterian point came to light ${ }^{2}$ in a gravel-pit. At Ipswich, Mr J. Reid Moir reports a site of a manufactory of Mousterian flints, involved in the following stratification:

$D$. Alluvium, $\mathbf{I} \cdot \mathbf{2}$ mètres.

C. Sand, $60 \mathrm{~cm}$.

$B$. Stratified gravel, $2 \cdot 4$ mètres.

$A$. Loam, $60 \mathrm{~cm}$.

where a Solutrean implement was found some years ago in $B$, which also contained water-rolled Acheulean implements, while $A$ contained unrolled Mousterian flints and flakes, and numerous bones of Elephant, Reindeer, and Bos primigenius; there was also a coup-depoing $^{3}$. It is however in the Thames valley that the richest manufactory sites have been discovered. The Crayford site is perhaps the most instructive from the chronological point of view. The chalky boulder-clay was deposited on the north bank of the river; the first terrace was formed, containing Chellean and some Acheulean flints; there then took place a rise of the land to a height of some I2 mètres, and the old river channel at Wansunt near Crayford, the gravels of which contain late Acheulean and early Mousterian

1 T. Kormos in Fahrbuch d. kgl. ungarisch. geol. Reichsanstalt, Budapesth, xx. [I912], part I.

2 W. A. Dutt, "A new Palaeolithic site in the Waveney Valley" (Man, virI. [r908], p. 19).

3 J. Reid Moir, "An early Mousterian 'Floor' discovered at Ipswich" (Man, XVIII. [1918], No. 60). 
implements, was eroded. After a further elevation of about 27 mètres, the gravels of the second terrace were formed, and brick-earth to a depth of 9-12 mètres accumulated over them: this was laid down during a period of subsidence, when the mouth of the channel was wholly or partially blocked, and the waters of the river were in consequence ponded back. This brick-earth contains Mousterian, but no Acheulean implements. The cutting of the deep submerged valley of the river was the result of a still later emergence ${ }^{1}$. The industry of the Crayford brick-earth is typical Mousterian, with points; the fauna includes Felis leo, Canis lupus, Rhinoceros, Equus, and Bos primigenius $^{2}$. At the neighbouring station of Northfleet, in gravel, there is also a very important factory site, which has yielded many flakes, cores, and finished implements, including Levallois scrapers, and side-scrapers ${ }^{3}$.

A flake found in low-level gravel at Greatham, Sussex (in the Arun valley) is apparently Mousterian ${ }^{4}$.

The lower strata of certain of the British caves have yielded Mousterian implements. But there is no exclusively Mousterian cave in this region, and therefore it is more convenient, for stratigraphical reasons, to describe the caves in the following chapter.

\section{(6) The Psychology of Middle Palaeolithic Man}

At the end of the preceding chapter we stated three certainties, and three probabilities, as to the mode of life of Lower Palaeolithic Man, and indicated that to go beyond those narrow limits in attempts at reconstruction was perilous. We are in a slightly better case when we turn to Middle Palaeolithic Man. The following are the certainties:

I. Middle Palaeolithic Man dwelt in caves; the inhabitants of these formed communities which must have been organised on some social system.

2. In some respects he shews an advance, in others a retrogression, from the Acheulean level.

3. He possessed fire.

4. He had a religion.

5. Like his predecessor, he was a hunter.

${ }^{1}$ R. H. Chandler, "The Pleistocene deposits of Crayford" (Fournal Geol. Assn. XXv. [1914], p. 6r). See also references on pp. 270 ff. ante.

${ }^{2}$ R. Bruce Higgins and Reginald A. Smith, "Flint implements of Moustier type and associated mammalian remains from Crayford brick-earth" (Man, xIv. [1914], No. 4).

${ }^{3}$ Reginald A. Smith, "A Palaeolithic industry at Northfleet, Kent" (Archaeologia, LXII. part 2 [19II], p. 5I5); a beautiful series of photographs of Levallois scrapers and cores from this site will be found in $\mathcal{F}$. A.I. XLI. [I9I I], plates xlv.-lxiv.

P.S.A. xx. [1903-5], p. 207. 
There may be added the probability that the degeneration indicated in No. 2 of these propositions was partly induced by the deteriorated climate, partly by the unhealthy life in damp and smoky caves, partly, perhaps, by inbreeding caused by the limited numbers of which each cave community was composed.

The only one of these propositions which needs demonstration, after all the facts that have been set forth in the present chapter, is the fourth. We assert as a certainty, not as a probability merely, that Mousterian Man had a religion.

The inference is based upon the interments, of which several unquestionable examples are now known. In the free life of the Lower Palaeolithic stages, when Man roamed over the plains and beside the rivers, and found his food for the picking-up, there was little to direct his attention to the supernatural world. Yet we cannot infer that he had no conception of it; we are in complete ignorance on the subject. But in the harder life of the Mousterian stage, passed in gloomy and awe-inspiring caves, which resounded with the flutterings of bats and with the shrieks of owls, the thoughts of the people would inevitably become turned to the terrors of the Unseen. The cave-folk went to sleep as night fell, and awoke on the following day; but one by one they would fall into a different kind of sleep, from which they could not be aroused. Then the survivors would ask of one another the question of questions, which has passed down ever since from grave-side to grave-side through the generations-if a man die, shall he live again? As they sat round the fires, and discussed this momentous problem, one would tell of a dream that he had had, in which the dead had appeared. to him; another would relate how something, he knew not what, but which surely was not of the common things of nature, had startled him when he was wandering abroad in the gloom of the forest. With the weird dancing shadows cast by the fire on the rocky wall of their cave, with the wild noises of nocturnal nature all around them, small wonder that they found to their question an affirmative answer. Already even the lowly Mousterian Man, degenerate though he may have been, was conscious of something more than merely animal within him: already he had begun to look forward to a life beyond the grave-a life like that to which he was accustomed, for he could conceive of none other, where he would need food and clothing, and the instruments for procuring them. As his comrades passed, each in his turn, into the silent land, he laid beside their bodies such things as he imagined would minister to their necessities in the mysterious otherworld.

How far that otherworld was conceived of as being governed by beings more than human, we have no means of knowing. But it 
would seem psychologically scarcely possible for a community to imagine an entirely atheistic otherworld. The "gods" may be men, beasts, insects, monsters, what you will: but we may reasonably look upon Mousterian Man as being, within the inevitable limitations of our knowledge, the first seeker after God.

These are fair conclusions to draw from the existence of burial rites among the Mousterian people. If valuable objects are deposited with a corpse - weapons, ornaments, or what-not - it is common sense that the corpse must be in some way conscious of the gift, and capable of making use of it. Otherwise the practical and unsentimental savage will not waste these desirable goods. But it may be a question, whether of two instincts is uppermost with him in dealing with his dead-an altruistic desire for their welfare, or a selfish fear of the revenant. Probably both are operative, and in any case both presuppose a belief in the continued existence of the departed one.

Several facts may be adduced to prove the existence of a fear. The summary disposal of the body in the case of the La Ferrassie interment, in which the survivors did not venture to touch the body but simply heaped earth over it where it lay, is suggestive of some such feeling of awe: or else, possibly, of the existence of a hope that the wandering ghost might in time find its way back to the bodily habitation which it had tenanted, if the latter remained undisturbed in the spot where the spirit had left it. We shall meet in the next chapter with traces of similar ideas among the Upper Palaeolithic people; the victim of an accident (?), as at Laugerie Basse, or the victims of an act of violence, as at Cro-Magnon, are left where they fell, and no one dares to enter the cave to disturb the bodies. The most reasonable explanation of the common crouched attitude of the dead, with the knees drawn up, sometimes very tightly, under the chin, is a desire to hamper the movements of the dead, and to prevent it from coming back to disturb the living. It is probable that the body was actually bound with thongs in that position ${ }^{1}$.

But on the other hand certain precautions seem to have been taken, that would have been unnecessary if the purpose was merely to keep the ghost from "walking." The careful deposition of stones over the head of the body, to protect it, as at La Ferrassie; the protection of the nose by flakes of flint, as at Le Moustier; the deposition

${ }^{1}$ Another explanation sometimes given, that it is an attempt to imitate the attitude of a foetus in the womb, and so to typify the birth of the dead man into a ncw life, is much too far-fetched. Such typology is too abstract for nature-folk: their symbolism is always the degeneration of concrete practices, as when a human sacrifice is typified, which in former generations had been carried out in actuality. Moreover, the explanation involves a number of modern metaphors-" "the New Birth," "Mother Earth," and the like-which we have no right to assume to have been current among the Palaeolithic tribes. 
of the head on a sort of cushion of flint flakes; the presentation of food to the dead, and of flint implements, many of which are of exceptional excellence of workmanship-all of these things speak of personal affection for, and interest in the welfare of, the deceased. At La Chapelle a formal grave was dug, as at La Moustier and Spy. The La Chapelle interment was especially instructive. The cave in which this discovery was made was very small-it was impossible to stand upright within it; but there was a hearth just inside the entrance. This hearth, owing to its position, must have been lighted after the interment; and its existence in a cave which, on account of its inconvenience,cannot have been used as a permanent habitation, is certainly suggestive of burial rites of some elaboration, involving a funeral feast. There was a single detached rhinoceros-horn found inside the cave. This clearly cannot have been the remains either of feast or of food-offering; may it not have been a sort of amulet or, if we may use a not over-scientific term, a fetish? In the Aurignacian interment of Paviland an elephant's head, with tusks, was similarly deposited near the body.

At the entrance of the La Chapelle cave there was another small trench dug, containing bison bones, beneath which was a flint point; over them were heaped blocks of limestone. At La Ferrassie there was a similar trench, which contained a large cow bone. These seem to be buried food-offerings. All these indications point to a respect for the dead that went beyond mere fear.

To raise the question whether the Mousterian tribes practised cannibalism, after thus detecting in them instincts at least above the animals, may seem a descensus Averno; but we must not be deterred by such morbid fancies. The charred and split condition of some of the bones found at Krapina suggested to their excavator that the inhabitants of that station had practised cannibalism. There is no reason whatever that can be urged against this theory; it is, indeed, more than likely. The devouring of the bodies of enemies can very easily co-exist with no small degree of care for the bodies of fellow-tribesmen; and the evidence of a mixture of races at Krapina may perhaps accord with this-a raid on a rival settlement, belonging to an antagonistic race, and the ceremonial eating of prisoners of war. But after all it is pure theory, and cannot be anything else. No convincing proof of cannibalism could be found in the remains of an ancient settlement. The fleshy parts of both eater and eaten have disappeared. Man has not the teeth of a carnivorous animal, which make recognisable marks of gnawing on the bones of victims; indeed, he is not in the habit of gnawing bones. Long bones split for the extraction of marrow might be suggestive, but every 
other possibility must be eliminated before we proceed to make deductions from the condition of such bones. The same is true of charred bones; indeed, it is not usual to char the bones of flesh intended for the table, and charred bones such as are often found in ancient settlements have more probably been used for fuel. We must be content to leave the question of cannibalism non-proven; and so far as the present writer can see it must be left in this unsatisfactory state, unless by some wonderful chance a Palaeolithic representation of a cannibal feast should some day come to light painted upon a cave wall ${ }^{1}$.

1 See the sensible remarks of M. Marcel Baudouin appended to Rutot's paper, "Le cannibalisme à l'époque des cavernes en Belgique" (B.S.P.F. IV. [1907], p.3 I8). See also the description of the Cavern of Furninha and its contents, C.A.P.A. Lisbon, p. 207; H. Matiegka, "Anthropophagie in der prähistorischen Ansiedlung bei Knovize und in der prähistorischen Zeit überhaupt" (M.A.G.W. xxvi. [1896]. p. 129). Further references to authorities will be found in Déchelette, Manuel, I. I 10. 


\section{CHAPTER VIII}

\section{THE UPPER PALAEOLITHIC S'TAGES}

\section{$A$ breach of continuity}

WE have seen reason to believe that the development of man and of human industry proceeded in Europe upwards in an orderly course, from its first beginnings to a climax in the Acheulean stage: and that there followed a degeneration, produced ultimately by the setting-in of adverse climatic conditions. We now reach a sudden break in the evolution. An entirely new race, or rather group of races, comes on the scene, and so far as we-can determine, the place of Mousterian man knows him no more. The primitive type of humanity, which we have traced from Western France to Croatia, and whose instruments of flint are scattered over a yet wider area, now disappears, before a more highly civilised people, whose advent marks the beginning of the Upper Palaeolithic Stages.

It is not to be supposed that any of the varieties of humanity with which we are now to become acquainted can have developed out of the Mousterian race by ordinary evolutionary processes. Even if such a development were physically possible - which may or may not be the case-it would have required countless centuries, rather should we say countless millennia, for its accomplishment. The caves would have contained an enormous stratum of accumulation, with a long series of intermediate forms, both in bones and in products of industry, between the Mousterian and the first appearance of the fully-developed Upper Palaeolithic. But this is not the case. The Upper Palaeolithic strata overlie those of the Mousterian stage directly, shewing that the one stage was immediately succeeded by the other. There are, it is true, some apparently transitional forms, which we shall notice presently; but these are to be regarded as due to contamination of one type by the other, not as steps in a genealogical development.

The only possible explanation of the fact is that the Upper Palaeolithic civilisation was introduced into Europe by a new population, which entered the Continent from without, and carried on a relentless war of extermination against the aborigines. To shew that this interpretation of the facts is credible, we can unfortunately find in contemporary life parallels for such disappearances of communities, less extensive perhaps, but involving a not lesser accompaniment of horrors. If the Mousterians can rise in the Judgment to 
testify against the Upper Palaeolithic invaders, so can the almost extinguished Hereros against the Germans, many American tribes against the Spaniards and, in candour we must add, the quite extinguished Tasmanians against the English.

Just as the early colonists in Tasmania used to organise battues, in which the unfortunate aborigines were the game', so the incoming Upper Palaeolithic people "shot at sight" whenever a Mousterian man made his appearance, until the ancient race was almost wiped out.

It may be that after a while the deep-rooted racial antipathy which underlay this warfare was so far overcome as to allow of occasional union; and that a racial type, apparently presenting an intermediate form, of which we shall speak presently, was the result of such unions. This may pass as a working hypothesis, in the absence of real knowledge.

\section{(I) The Upper Palaeolithic Stages}

The history of the Upper Palaeolithic Term is much more difficult to understand than is that of the preceding Terms. It is no mere paradox to say that the reason for this is because we know more about it; for in archaeology, as in other sciences, every fresh addition to knowledge opens out new vistas of previously unsuspected problems. We may be certain that when more is known of the Lower Palaeolithic, its history will be found to be full of complexities of which we have as yet no conception. But for the present it is possible to regard Pre-Chellean, Chellean, Acheulean, Mousterian, as successive phases of the development of a single long-continued population. The three stages into which the Upper Palaeolithic Term is divided cannot be thus affiliated. They display profound differences both in the racial character of the human remains and in the associated implements and industries. In describing them, they must on this account be considered separately from one another.

These stages bear the following names:

Aurignacian, from the type station of Aurignac (Haute-Garonne).

Solutrean, from the station of Solutré, near Mâcon (Saône-etLoire).

Magdalenian, from the cave called La Madeleine, near Tursac (Dordogne).

\section{The Aurignacian Stage}

(2) Human remains

In accordance with the scheme followed in preceding chapters, we first describe the principal human remains which have been found in Aurignacian stations. 
Cro-Magnon (Dordogne). This site yielded five skeletons in the year 1868 . They were found in the course of removing earth from a cave, for the construction of a railway embankment; parts of four of them were preserved, belonging respectively to an old man, a woman, and two other men. The fifth skeleton was that of an unborn infant. These bodies had not been buried; they were lying on the top of the ancient débris in the cave in which they were found. It is not improbable that the people to whom the skeletons had belonged had been murdered and left where they lay.

It was formerly doubted whether a Palaeolithic antiquity was to be assigned to these skeletons; they represented a people which appeared to be too highly developed to belong to a stage of culture so remote and so lowly. The Cro-Magnon people would pass in a modern community without remark, which is certainly not true of their Middle Palaeolithic predecessors. But the progress of discovery, in both the physical and the cultural departments of the study of Palaeolithic man, has made these natural doubts needless; there can no longer be any question that the Aurignacian men belonged to a high type of mankind.

A full account of the finding of these remains is given in Lartet and Christy's monumental work ${ }^{1}$. When the bones were exposed, in the course of digging, the contractors, realising their importance, immediately stopped the work, and gave notice to M. Laganne, a geologist living in the neighbouring village of Les Eyzies $(O$ si sic omnes!). The excavation of the cave was completed by Lartet, and reports upon the bones by Pruner-Bey, Broca, and Quatrefages appear in the pages of his book. From these the following particulars are selected and compressed.

Round the skeletons were found a large number of shells perforated for suspension, or for sewing upon the surface of garments. Similar discoveries were made, as we shall presently see, in the Grimaldi caves. There were also a pendant of ivory, similarly perforated, some perforated teeth, fragments of antlers, and chipped flints. The débris underneath the skeletons contained traces of recurrent occupations of the cave, probably extending over a considerable time.

The following individuals were represented by the bones in the cave.

A. A healthy and vigorous old man, generally known to archaeologists and anthropologists as "The Old Man of Cro-Magnon." Pruner-Bey sought to find traces of the pathological condition known

1 Reliquiae Aquitaniae, pp. 62-125. The skulls are there figured in plates $C \mathrm{r}-6$, and some of the other bones in plates $C_{9}, \mathrm{ro}$. 
as rachitism in his bones; but Broca, a much higher authority, has shewn that the bones, though in some respects abnormal as compared with modern Europeans, were perfectly healthy. The only pathological phenomenon which they presented was a depression on one of the femora, which had driven the hard outer crust of the bone in upon the spongy interior, without fracturing the bone-the result doubtless of a severe blow received during life.

The sutures of the skull (except the lambdoid suture) had completely closed and were untraceable. The teeth had all disappeared, but Broca has shewn that this happened after death, as the sockets were open. There is no justification for Pruner-Bey's theory that their disappearance was due to caries: in fact, most of this writer's theories were rather unfortunate. Only the fang of one of the molars remained; this had become detached because the use of the tooth had gradually ground it away, down to the roots of the fangs. The skull is very dolichocephalic - the index being $73^{\circ} 76$; this is due to its extreme length, not to its narrowness, for it is broad and capacious. In fact, notwithstanding the length of the skull, the face is broad in proportion to its length, so that the head is dysharmonic. The cranial capacity reaches the respectable figure of 1590 cubic centimètres. The cheek-bones were very prominent, the orbits rectangular, with rounded angles, and long in proportion to the height - not the great circular cavities of the Middle Palaeolithic orbitsand the superciliary torus was absent. In its place there was a deep notch at the root of the nose, and the ridge of the nose was prominent and projected boldly forward. The chin also was not less prominent than in modern Europeans. From the length of the femur, Broca infers a stature of $5 \mathrm{ft}$. I I inches for this subject, though with the important reservation that scales of proportion between the length of the long bones and the stature, determined for one race or group of races, do not necessarily apply fully to another race. The lines of the muscular attachments are exceptionally strong, shewing that although there are not wanting signs of senility in the bones, their owner was still powerful. The tibiae were very platycnemic, and the ribs were extraordinarily thick.

Attempts have been made to realise, by means of restorations, the outward appearance of the people of the Palaeolithic Age, whose skulls have come down to us. A number of such restorations will be found figured in Dr Osborn's Men of the Old Stone Age; at pp. $275,300,301$ of that work will be found several views of a bust (a copy of which is to be seen in the Natural History Museum at South Kensington) modelled upon the skull of the Old Man of Cro-Magnon. The countenance looks like a composite of William 
Ewart Gladstone and Richard Wagner. Such restorations, it must be remarked, are of more than doubtful value. The slightest change in the soft parts of the cheek and nose makes profound differences in the whole appearance of the face; in fact, the same skull can carry many different faces. The modeller must choose one of them, and moreover must choose one phase of expression in the features depicted; and the tiro is apt to be misled into supposing that this is necessarily the real likeness of the owner of the skull. There is an independent restoration, founded upon the same skull, by Rutot: a picture of it is to be seen in G.' F. Scott Elliot's Prehistoric Man and his Story, p. 174; putting the two together, the most that I can find it in me to concede is that one can detect a vague suggestion of a family resemblance between them. Very similar criticisms may be passed upon restorations of extinct animals. They are very graphic to look at, and give some idea of the sort of creatures that the animals must have been. But as surface markings and colour must necessarily be guesswork, the idea cannot be more than vague. No one could deduce the stripes of a tiger or the spots of a leopard from their fossilised bones; but a restoration that did not represent those markings would give a very poor notion of the real animal.

B. A woman, probably aged between 35 and 40 years. The sutures of the skull were more closed than would be usual in civilised people of this age; but the closing of the sutures proceeds more rapidly among uncivilised peoples, and the teeth which remained (two molars) were less worn than they would have been had the subject lived to fifty ${ }^{1}$. The dolichocephaly of this woman was even more marked than that of her aged kinsman (index $71^{\cdot} 72$ ). Her facial structure displayed similar characters to his, though in a less marked degree, probably owing to the difference of sex. The back of the skull was damaged, and the cubic capacity could be only approximately estimated; the figure arrived at is $155^{\circ}$ cubic centimètres, which would give this woman a higher cranial capacity than the average modern male of Europe.

The skull displays the mark of an intentional act of violence (Fig. 88). On the left side of the forehead there is an opening in the bone, about $4 \mathrm{~cm}$. in length and $2 \mathrm{~cm}$. in breadth, tapering to a point at each end; just such a cut as would have been made by a violent blow from a small stone axe, or more probably a lance-head. The wound was certainly inflicted during life, and probably was the cause of death, which did not, however, take place immediately; there are marks of the natural process of bone-repair, which must have been

1 The subject must in any case have been within the age-limit of child-bearıng, whatever this may have been in the race to which she belonged. 
able to act for some ${ }_{5} 5$ or 20 days after the injury was received to advance as far as it has done ${ }^{1}$. The blow must have been given with great force, as the cut is clean and the bone is not splintered.

C. A man aged about 45 , the front parts of the sutures closed. (In all these skulls the closing of the sutures proceeded uniformly from front to back.) The skull is very imperfect, and adds little to the information yielded by the other two; the cranial index is 74.75 .

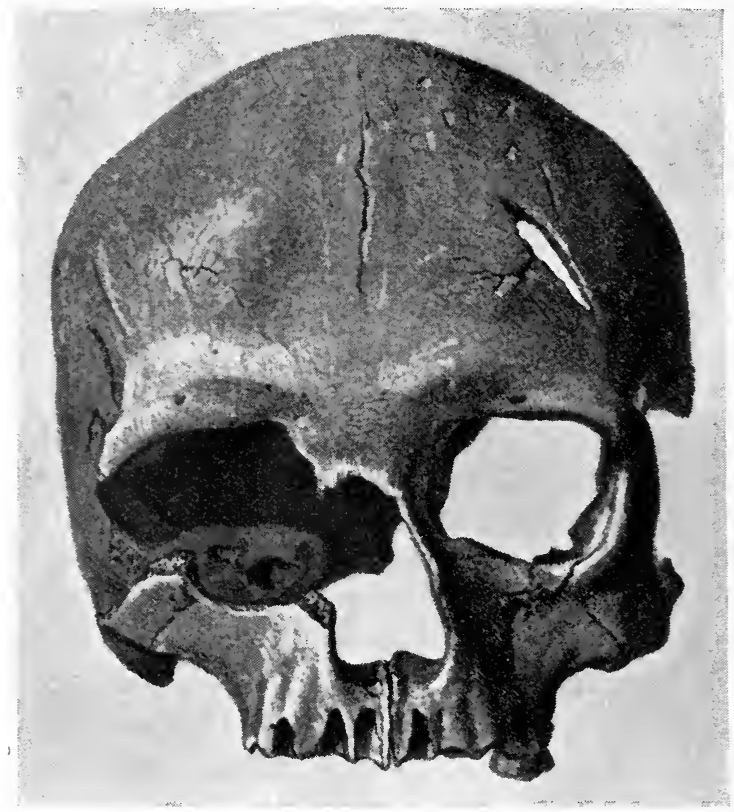

Fig. 88. Skull of the woman of Cro-Magnon.

D. Broken fragments of a very imperfect skull, belonging to an individual (probably a man) of fairly advanced age, but too imperfect to give us any particulars.

E. Fragments of the skull of a foetus, shewing that the woman (B) was with child when she was killed.

Mentone. In the caves known in the local patois as Baoussé Roussé (i.e. Balzi Rossi, the "Red Cliffs"), near Mentone 2 , there

1 Assuming that this process advanced at the same rate as in modern races.

${ }^{2}$ In one of the papers, unfortunately not uncommon in the volumes of learned societies, in which one prehistorian bludgeons another, I have found it recorded as a heinous crime to refer to these caves as "The Mentone Caves." The objection is weakened by the fact that in the paper in question (which I forbear to refer to more particularly) the eminent writer is evidently seeking in every possible direction for sticks with which to belabour his not less eminent colleague. No doubt Mentone is on the French side, and the caves are on the Italian side, of the frontier; but 
have been found some of the most important human remains of the Upper Palaeolithic Period.

We have already referred to these caves, and shall describe them more particularly in the concluding chapter of this volume. Meanwhile we may speak of the interments which they contain. There are nine caves in the series, four of which were found to contain important human remains ${ }^{1}$.

I. Grotte des Enfants. This is the first cave in the series, proceeding from west to east. There were nine different strata in the deposits of the floor of this cave. The two lowest strata were either Lower or Middle Palaeolithic, the upper seven were Upper Palaeolithic.

A. The oldest interment in the cave was immediately above the second stratum (counting from the bottom) at a depth of 8.50 mètres. It included two skeletons - that of an old woman, and that of a youth aged about 16 . Both of these were in the crouching attitude; the male skeleton slightly bent, but with the legs doubled under the thighs; the female tightly flexed. The youth was lying on his side, but the woman was face downward. The youth had upon his head a sort of crown, of four rows of perforated shells; the woman had two bracelets of similar shells ${ }^{2}$. There were some flakes of flint also deposited with the bodies. A flat stone supported on two others protected the heads; it will be remembered that a similar protection was found in the Middle Palaeolithic interments at La Ferrassie and at La Chapelleaux-Saints.

These two skeletons differed from the others found in the Mentone group in that they did not conform to the Cro-Magnon type. Indeed, they presented characters not yet found in any other set of Palaeolithic bones from Europe. They approximate in many respects to a negro type, though they are not pure negroes. As at Krapina we may here be on the track of a mixture of races.

It is said that the individuals to whom these skeletons belonged closely resembled one another; and the inference is copied from book to book that they may have been mother and son. One may perhaps venture to express a doubt as to whether a family resemblance so exclusive can be established between fleshless skeletons, differing

Mentone is the natural base from which to explore them, and to call them the "Mentone Caves" is the best way of indicating immediately their geographical position.

1 See M. Boule and R. Verneau, "Les grottes de Grimaldi" (L'Anthr. xvil. 257-320); also the very thorough description of the anthropology of the caves by the latter writer occupying fasc. i. of vol. II. of the monograph, Les Grottes de Grimaldi (Monaco, 1906).

2 These are well shewn in place in the magnificent photograph.(Les Grottes de Grimaldi, vol. II. plate II.). 
in sex and in age; and if not, whether such speculations, which it is impossible either to prove or to disprove, are worth printing.

The skulls are extremely dolichocephalic (the youth is $69 \cdot 27$, the woman $68 \cdot 58)$. The nose is flatter and broader than in the CroMagnon people, and the orbits are somewhat wider. The forehead is well formed, and there is an absence of the heavy superciliary torus of the Middle Palaeolithic people. The face is at least as broad in proportion to its length as in the old man of Cro-Magnon, so that the dysharmony of the head is extreme. The chin is well formed in the woman's skull, not so well in the youth's, though much better than in any Middle Palaeolithic skull. There is much more marked prognathism in these two specimens than in the normal Upper Palaeolithic type. The subjects were of medium height (woman I.59 mètre; youth, who was not fully grown, $\mathrm{I}^{\cdot} 5^{6}$ ).

Albert Gaudry, in an elaborate study ${ }^{1}$, has drawn attention to correspondences between the teeth of the youth and the dentition of the modern Australian. Dr Verneau's account of all the bones of these skeletons, with full measurements and very fine photographs, occupies pp. $125^{-1} 5^{8}$ of the monograph on the caves, vol. II.

So long as these two skeletons remain an isolated phenomenon, it is impossible to say what their history may be, and what is their racial relationship to the more ordinary Europeans of the Middle and Upper Palaeolithic. Their situation on the north coast of the Mediterranean Sea makes it natural for us to treat them as the record of an invasion of negroid people (how many we have no means of knowing) from Africa into Europe, at some time very early in the Upper Palaeolithic term. More than that we cannot yet say. It is the convenient custom to speak of the hypothetical race to which they belong as "the Grimaldi race," after the name of the property in which these caves are situated".

B. In the stratum next above there was the skeleton of an exceptionally tall man- $\mathrm{I} \cdot 89$ mètre in height-lying on his back, stretched at length, but with the forearms doubled up so that the hands were on the level of the neck. Upon his breast there was a sort of apron of shells, and there had also been a crown on the head, like that upon theyouth in the first interment. These shells had been strung together

1 Albert Gaudry, "Contribution à l'histoire des hommes fossiles" (L'Anthr. XIV. [1903], p. I).

2 Dr Keith (Antiquity of Man, p. 67) says, in opposition to the current theory: "I am of the opinion that it is a mistake to separate these two Grimaldi individuals... as types of a new race-a negroid race indigenous to Europe. To me these characters suggest that they are only an aberrant Cro-Magnon form, perhaps primitive, but nevertheless true members of the Cro-Magnon race. That race, in the proportion of its limbs and in certain features of its face, does not show negroid traits." 
and probably sewn upon some garment or ornament, presumably made of hides. The head rested upon a block of sandstone, and stones had been laid to cover the body. The skeleton was of the Cro-Magnon type. The skull was in bad condition, but was carefully reconstituted by Dr Verneau. It is of good capacity, and very dysharmonic ${ }^{1}$.

C. In the eighth stratum there was the grave of a woman of moderate stature (about $\mathrm{r} \cdot 50 \mathrm{~m}$.) but otherwise apparently of the Cro-Magnon type, and of advanced years. Such a disparity between the stature of the sexes is a common phenomenon among uncivilised or semi-civilised communities. It results from the hard life of drudgery to which the women are condemned, and early maturity and child-bearing. The bones were in very bad condition and satisfactory observations could hardly be made upon them ${ }^{2}$. This interment was of especial interest, for there was evidence (afforded by the presence of coprolites) that the body had been torn from its burialplace by hyaenas and then rescued and re-buried ${ }^{3}$. The skeleton was in consequence much injured; but it is important to note in passing that the sense of fear or of respect for the dead had so far advanced that the survivors had taken the trouble, and incurred the risk, of rescuing the body from the wild beasts for re-burial. A large number of trochus-shells had been strewed around the corpse on re-interment, but little or nothing remained of the original funeral deposits.

D. In the top stratum were the remains of two young children (from whom the cave has derived its name), aged about six and four years respectively. Their bodies were stretched at length, side by side, and lying on the backs. They had been clad in aprons of seashells, of which nearly a thousand were found lying above and below their waists. Racial characters can hardly be detected on the bones of children so young ${ }^{4}$. Jaws of two other young children were found just above the woman (C).

2. Grotte du Cavillon. This cave, the fourth in order, contained one sepulture. The body was that of a man lying on the left side, at a depth of 6.55 mètres in the deposit. The head lay to the north. and was raised a little higher than the rest of the body. A red ochreous powder covered the whole skeleton, tinging it red. The man had been buried with his ornaments; on the head was a fillet or headband, in the meshes of which small sea-shells (Nassa neritea) had been

${ }^{1}$ See the table of measurements in Verneau, op. laud.pp. $8_{5}, 86$.

${ }^{2}$ Verneau, op. laud. pp. $5^{1-55}$.

3 Chanoine L. de Villeneuve, "Historique et description" (Les Grottes de Grimaldi, vol. I. p. 64).

4 See R. Verneau, "Les fouilles du Prince de Monaco aux Baoussé-Roussé; un nouveau type humain" (L'Anthr. XiIr. [1902], p. 561). 
threaded. Near the temples there were 22 perforated canine teeth of deer. Across the brow was a bodkin made of a stag's bone; two flint flakes were leaning against the back of the head. The skeleton was in a crouching position, though not violently flexed; it is now preserved in the Museum of Natural History at Paris. The skull is in a bad state, but is certainly of Cro-Magnon type; the stature was tall (about $\mathrm{I} \cdot 75$ mètre).

3. Barma Grande. This is the fifth cave of the series. It was originally 28 mètres long, but the front portion has been quarried away. On the floor was a deep accumulation of débris, consisting of stones fallen from the roof and of remains of middens and other refuse. In digging out this material for fertilising purposes the discoveries of human remains were first made. This cave contained four interments.

A. The first of these was 8.40 mètres deep in the accumulation. The skeleton lay on its back in a pit lined with stones. The head was stained with red ochre, and near it were three large flint flakes. The skull is greatly injured, owing to its having been crushed by the weight of superincumbent stones, but it is certainly of Cro-Magnon type.

B. At a depth of 8 mètres: three persons, a tall man, a young woman, and a boy of about 15 years. The burial was at a depth of at least $7 * 90$ mètres below the surface of the accumulation in the cave. A pit had been dug and lined with red ochreous powder; in it the bodies were stretched at length, or only gently bent. On the man's head were canine teeth of deer, drilled for suspension, fish vertebrae, and small shells, also perforated, the whole being the ornaments of a sort of crown or cap. On the neck was a pectoral of the same materials; and a flint knife, $23 \mathrm{~cm}$. long, lay beside the body. The woman's head had been propped upon the thighbone of an ox; she had similar but simpler ornaments upon her. In her left hand was another flint knife, no less than $26 \mathrm{~cm}$. in length. The boy's skeleton had an elaborate crown of fish vertebrae and shells on the head, and a collar, consisting of two rows of fish vertebrae and one of Nassa-shells, divided into groups by deer's teeth (Fig. 89). On the foreheads of the skeletons were lying some remarkable ornaments of bone or reindeer horn, shaped like two eggs end to end. These have apparently been lost, like much, valuable material from this cave. It is said that there were seven in all and one had some fish vertebrae adhering to ${ }^{1}{ }^{1}$. The man was almost as tall as the

1 A. J. Evans, "On the prehistoric interments of the Balzi Rossi caves near Mentone and their relation to the Neolithic cave-burials of the Finalese" (F.A.I. XXII. [1892-3], p. 287 ff. esp. p. 299). 
Grotte des Enfants warrior; the woman was not fully developed, nor was the boy; both had a stature of about $\mathrm{I} \cdot 65$ mètre. All three presented a complete uniformity of type with the men of CroMagnon.

C. A little higher, and further toward the back of the cave: the skeleton of a man, lying on his back, with the legs crossed at the
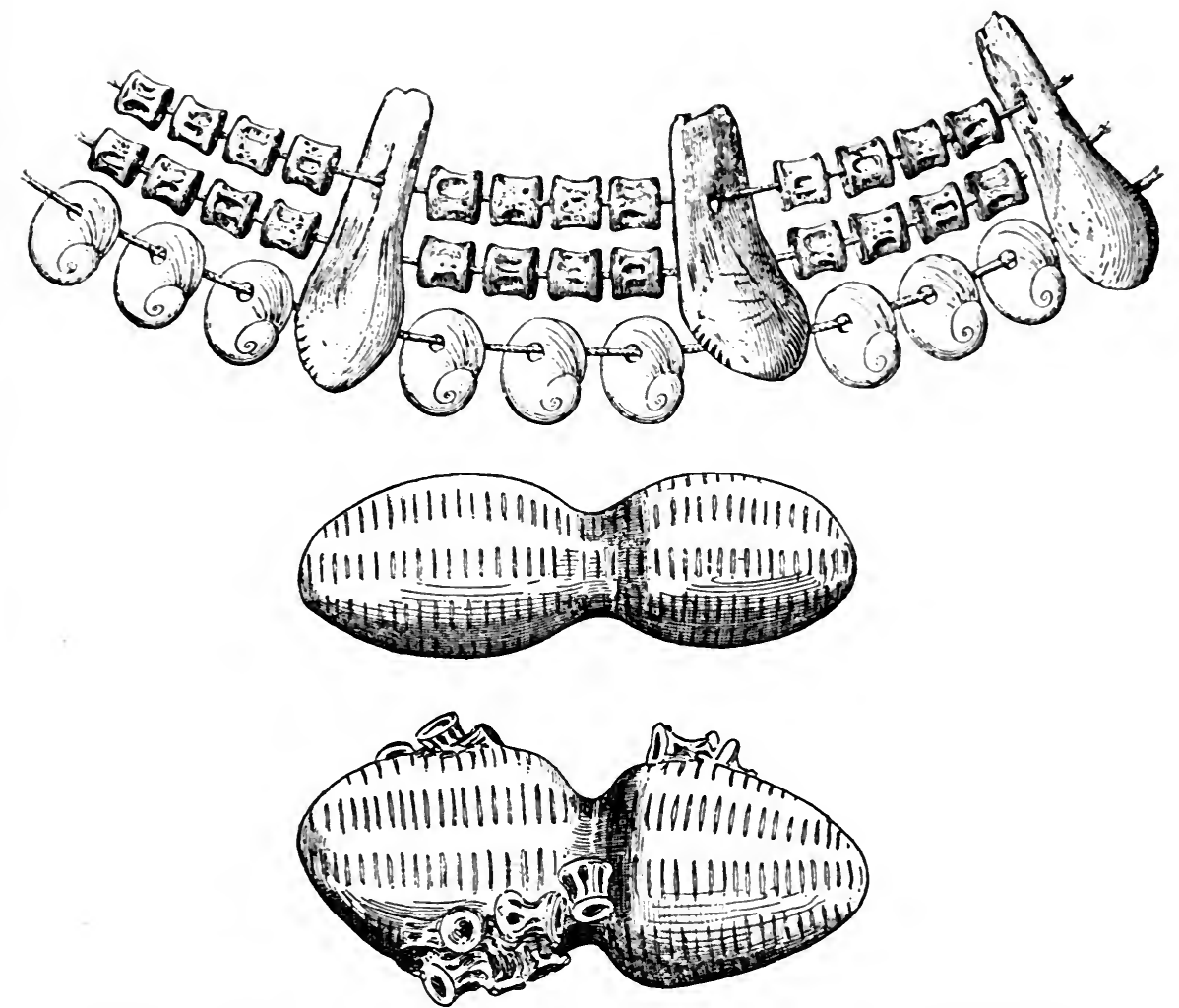

Fig. 89. Collar on the boy's skeleton from the Barma Grande, and egg-shaped ornaments from the interment.

(The collar from Les Grottes de Grimaldi; the ornaments from fournal Anthropological Institute, vol. xxiI.)

shins and the forearms bent, the left hand resting on the breast. There was a collar of Nassa shells, a large piece of gypsum near the left hand, Nassa shells on the head, canine teeth of deer and small pendants of ivory variously disposed on the body. The man was of about $\mathrm{I} \cdot 77$ mètre in stature, and his type was essentially that of Cro-Magnon. The cranial capacity of this subject was quite extraordinary: the figure cannot be stated with absolute exactness, as the 
skull had to be repaired, and there is room for a small margin of error, but it cannot have been less than 1880 , and probably was nearer $2000^{1}$.

D. A subject whose remains, unlike those of the other interments in the cave, had been burnt; a number of Nassa shells lay around it. Owing to the condition of the bones it could not be properly examined, but it appears to have been, like the others, of Cro-Magnon type.

4. Baousso da Torre. In this, the sixth cave, there were three interments.

A. At a depth of 3.90 mètres a man, stature $\mathrm{I} \cdot 80$ mètre, lying on the left side, not surrounded with stones. The body appeared to have been disturbed by hyaenas. There had been a shell crown, and a shell collar, as in other interments in the series, and apparently a girdle to which shell pendants had hung. It is stated that microscopic examination of the surrounding soil revealed traces of animal hairs, suggesting that the dead had been wrapped in a cloak of hides.

B. At the same level, a man, the skeleton lying on its face, with no grave goods.

C. Slightly higher, a man's skeleton, reddened with ochre. A collar of shells had apparently encircled the neck, and there had been similar ornaments on the arms and legs. These skeletons were in a bad state, but they were essentially of Cro-Magnon type.

Paviland. This example of a Cro-Magnon man is the most remote from the centre of distribution of that race as yet discovered. It was found so long ago as 1822 by Dean Buckland in exploring Paviland Cave, Glamorganshire, South Wales; but it is only within the present century that its true horizon has been determined. The body was intentionally buried, stained with ochre. The soil in the cave has yielded numerous implements, shewing that it was occupied for a long time as a habitation. Some ivory pendants and ornaments were buried with the body. The skeleton is very imperfect; indeed, there is nothing of importance remaining but the limb-bones of one side, the skull and the bones of the trunk not being forthcoming. The remaining bones are preserved in the University Museum of Oxford. Though the remains long bore the popular name "The Red Lady of Paviland," they are those of a tall man, of about the same stature as, and in racial character similar to, the old man of Cro-Magnon ${ }^{2}$.

The above are the most important discoveries hitherto made of remains of the Cro-Magnon type of humanity. There are besides a

1 Verneau, op.laud. p. 8I.

${ }^{2}$ W. J. Sollas, "Paviland Cave, an Aurignacian station in Wales" (F.A.I. XLIII. [1913], p. 325). 
number of fragments, which add little or nothing to our knowledge. Among a large number of interments found at Solutré, some appear to be Aurignacian; but the scanty note in C.A.P.A. Norwich [1868], p. 337 , tells us very little about them. We may also mention some fragments from La Rochette (Dordogne). In Spain, the cave of Camargo has yielded a few pieces of the top and side of a skull; and the cave of Castillo a child's jaw-bone. In Russian Poland (to employ the pre-war designation, which is still convenient until political settlements are finally made) a fragment of a skull was found in a cave near Ojców which seems to conform to the type. These fragments are of geographical importance only.

There is one skeleton which is certainly of Aurignacian date, but which does not conform to the Cro-Magnon type: namely the skeleton of Combe Capelle, near Montferrand (Périgord). This rich station yielded in 1909 a man's skeleton, buried, with flexed limbs. It had certainly been intentionally deposited where it was found, in a grave artificially made, and it was surrounded with flints of Aurignacian types. Except for an injury to the skull, the skeleton was on the whole in good condition. This skull has been studied by Gorjanović-Kramberger ${ }^{1}$ who pronounces it to be of a type superior to the Neandertal, and equal to the modern Australian. The supraorbital ridges are present in this skull, but are much reduced. The jaw has a feeble chin. The man was of low stature (a little over 5 feet), dolichocephalic, not dysharmonic, and with a comparatively small cranial capacity $(\mathrm{I} 440 \mathrm{~cm}$.). Klaatsch has made this skeleton the basis of an elaborate study, in which he seeks to determine the place in the stem of humanity occupied by the race to which its owner belonged ${ }^{2}$. He sustains the (prima facie not very probable) thesis that this skeleton, with which he couples the doubtful Galley Hill specimen, represents the pure Aurignacian race, and that the Cro-Magnon type is the result of a blend between the Aurignacian type and the Mousterian. With material so scanty at our disposal, it is possible to theorise in this way to any extent. But the peculiarities of the Combe Capelle man may be individual, not racial. While the dysharmonic heads of the Cro-Magnon people are suggestive of an origin in a racial blend, it is not likely that the blend took place in Europe. For we should want a long time for the blend to establish itself, and then to scatter over the Continent from Paviland to Mentone; and this must all take

1 "Homo aurignaciensis Hauseri" (Verhandlung der geologischen Reichsanstalt [1909], p. 302). See also Georg Wilke, "Die neue Skelettfund des Homo aurignaciensis Hauseri" (Manmus, I. [1900], p. 252); G. Kossinna, "Zum Homo aurignaciensis" (ibid. II. [1910], p. 169).

2 "Die Aurignac-Rasse und ihre Stellung im Stammbaum der Menschheit" (Z.f.E. XLII. [1910], p. 513). 
place within the limits of the Aurignacian stage. It is much more likely that the Cro-Magnon people, wherever and however they may have originated, developed and fixed their special characteristics in some extra-European centre, before they invaded our Continent; and that the Combe Capelle man is an individual example of reversion to one or other of the parent types. Another skeleton, found at the Hohlefels near Nürnberg, is also alleged to combine Mousterian and Aurignacian characters ${ }^{1}$. The stratification of this latter example is however doubtful.

\section{(3) Fauna}

The small Arctic rodents made a great invasion of Europe just at the end of the Middle Palaeolithic and the beginning of the Upper Palaeolithic. They then disappeared, as the climate improved. With them dwindle the reindeer, and its companions, the mammoth and Rhinoceros tichorhinus. During the Aurignacian stage the most prominent animal in Europe was the horse, which roamed the Continent in great herds-evidence of the steppe climate then dominant.

\section{(4) Phases of Industry and Implements}

The Aurignacian stage can be divided into three phases of industry, called the Lower, Middle, and Upper Aurignacian.

The Lower or Early Aurignacian, of which l'abri Audi, already described, is a type station, still contains Mousterian forms, sidescrapers, points, and even the obsolete coup-de-poing. We have already noticed that the existence of such intermediate stations is not to be regarded as evidence for a gradual evolution of Mousterian into Aurignacian. Such an evolution could not have taken place, unless the population had remained unchanged: but as we have seen, there is proof of profound changes in the population of the Continent. The sudden appearance of the pictorial art, which forms the chief subject of discussion in the following chapter, and of which there is not the slightest trace in the preceding stages, is in itself proof that we have to deal with a new people, having a wholly different mentality. Therefore the existence of a few intermediate stations, such as l'abri Audi, revealing an overlap of culture, means no more than this: that a Mousterian cave-dwelling was invaded and occupied by Aurignacians, who made use of the implements which they found there, and occasionally imitated them.

The Aurignacians had in addition to these inheritances a number of new tools of their own. First of these to be mentioned is the

${ }^{1}$ H. Klaatsch, "Die menschlichen Skelettreste von den paläolithischen Station Hohlefels bei Nürnberg und ihrer Stellung zu den bisher bekannten Diluvialformen" (Corr. XLIV. [1913], p. I10). 
Châtelperron knife, so called from the cave of Châtelperron (Allier), where large numbers of this kind of implement have been found,
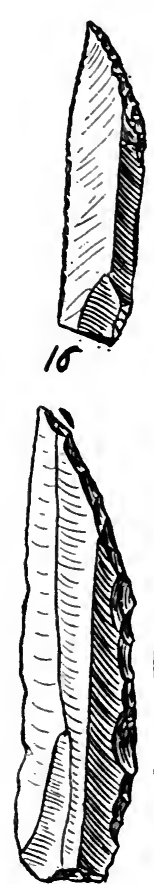

23

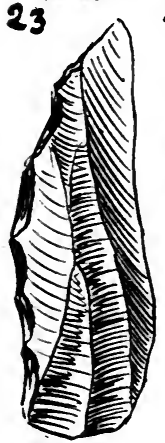

30
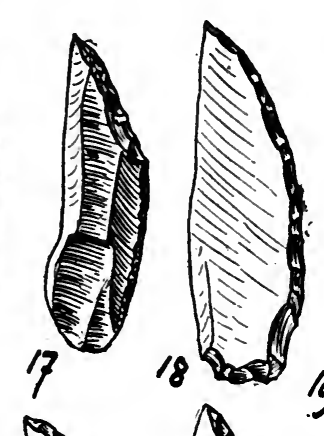
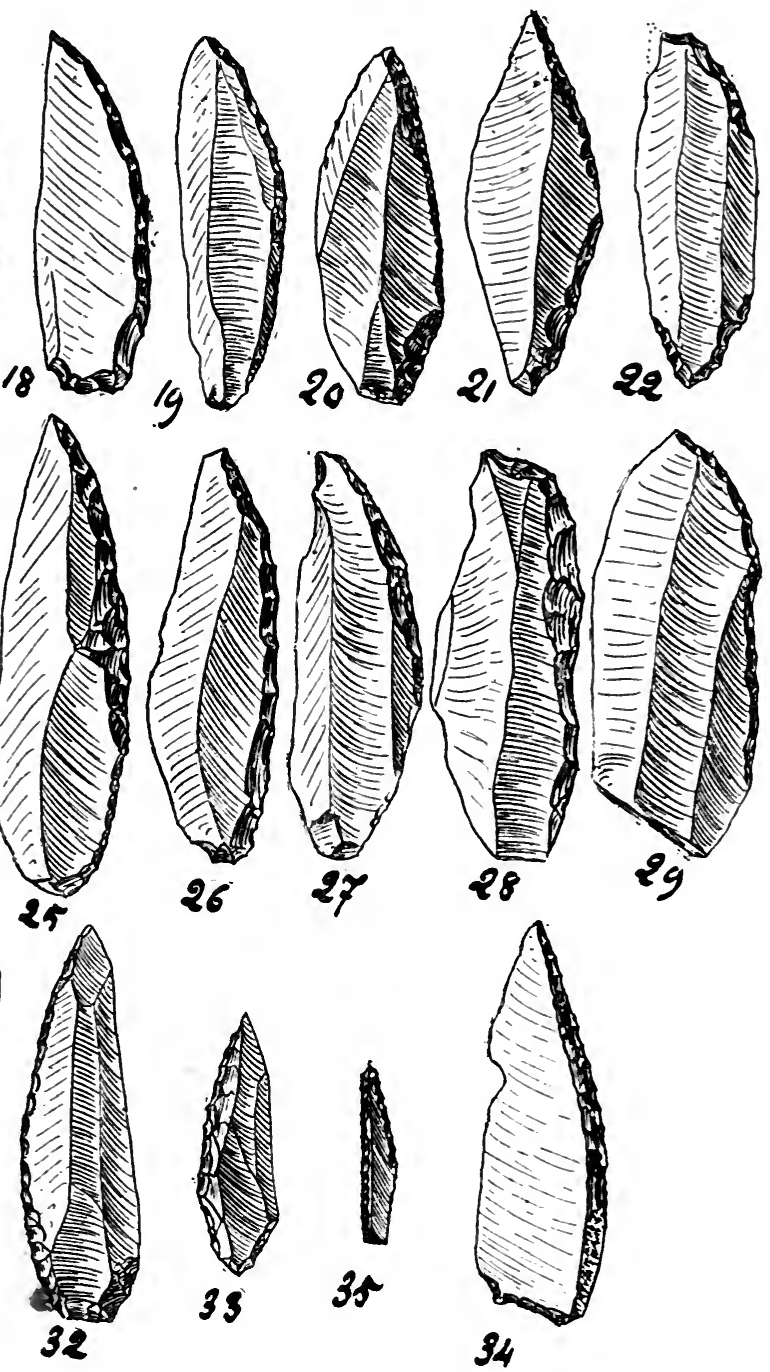

Fig. 90. Châtelperron knives.

(Drawn by M. l'Abbé Breuil; from Revue de l'École d'Anthropologie, vol. xxı.)

associated with coups-de-poing and other early types. This tool (Fig. 90) ${ }^{1}$ is a flake, of which one edge is trimmed away by vigorous

1 See H. Breuil, "Études de morphologie paléolithique: ii, l'industrie de la grotte de Châtelperron (Allier) et d'autres gisements similaires" (R.E.A. [I9II], p. 29). 
secondary chipping - it may be remarked, once for all, that the secondary chipping in the Aurignacian stage is coarser, and, if we may use the word, more "heroic" than in the other stages before or after. The opposite edge of the flake is left untouched, so that it remains straight and sharp. The chipped side makes a quasi-elliptical curve, while the unchipped side remains more or less straight; there

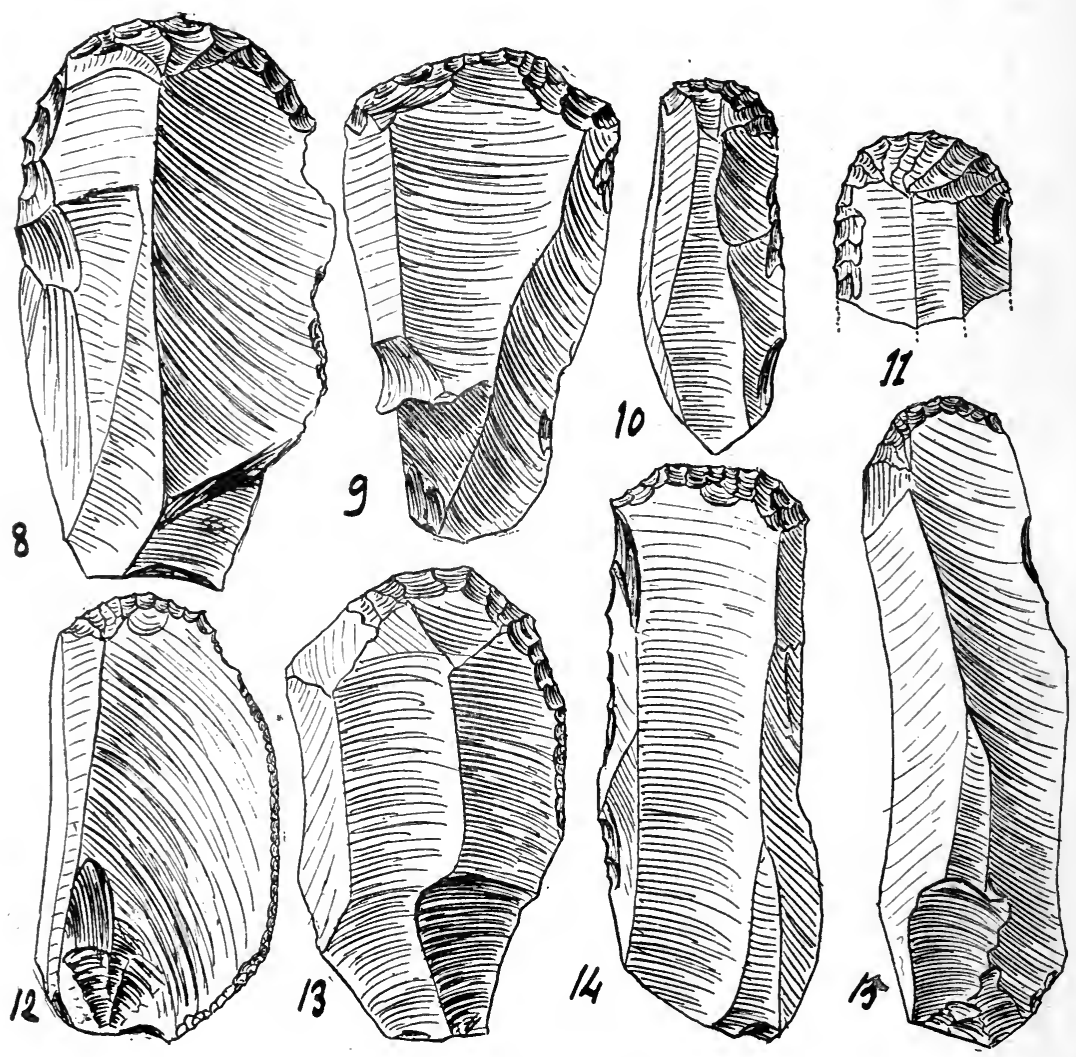

Fig. 91. End-scrapers.

(Drawn by M. l'Abbé Breuil; from Revue de l'École d'Anthropologie vol. xxı. ${ }^{1}$ )

is thus a sharp point at the tip of the blade, while the butt is usually rounded.

The end-scraper (Fig. 9I) now comes into prominence, taking to a large extent the place of the Mousterian side-scraper. As the name implies, this is a scraping tool in which the chipped edge is at the

${ }^{1}$ Figs. 90, 9I are from illustrations that have been kindly lent by the École d'Anthropologie. The reference numbers belong to the publication where they first appeared, not to their present context. 
end of the blade, and not along one side. Such tools may be single or double: in the former there is a scraping edge at one end only, in the latter at both.

Plain flake knives also make their appearance in Lower Aurignacian deposits. We have seen these tools beginning in the Mousterian stages but they are more characteristic of the Upper Palaeolithic.

Another tool which now becomes important is the engrarer. This is a flake knife, in which the chipping is so contrived as to give a small edge, more or less at right angles to the plane of the blade, instead of the sharp point which terminates flake knives upwards (Fig. 92). It is with this tool that Upper Palaeolithic man worked bone, horn, and ivory into implements, and engraved ornamental designs upon them. There are several varieties of engravers in use at different phases; the kinds figured in the accompanying illustration

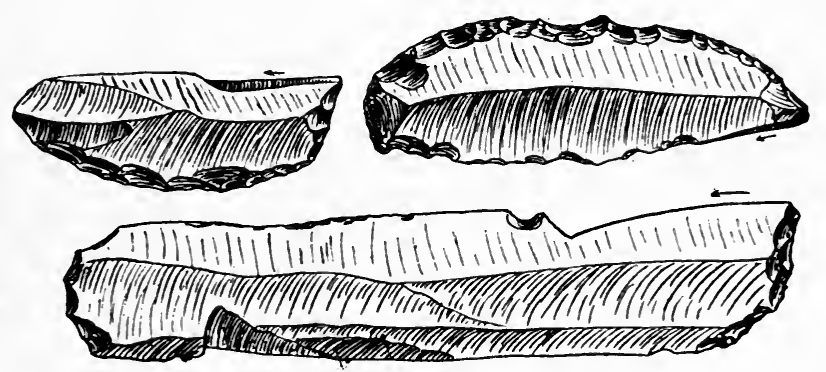

Fig. 92. Engravers.

(Drawn by M. l'Abbé Breuil; from C.A.P.A. Geneva, vol. I.)

with the engraving point in or near the middle of the end of the flake, or at one of the upper angles, are characteristic of the Lower Aurignacian.

The existence of this instrument prepares us for the great development of the industry in bone and horn. This is one of the most important distinguishing features of the Upper Palaeolithic Period. Where Lower and Middle Palaeolithic man used stone and perhaps wood, Upper Palaeolithic man used bone, and as time went on displayed an increasing expertness and ingenuity in adapting it to his ends. In the Lower Aurignacian the bone industry is still in a rudimentary condition; little is found except prickers and polishers. The first of these are flat or rounded slips of bone, pointed at one end; the second are similar flat slips, with a square end, and bearing traces of polishing.

Among the prickers there is one rather puzzling type of instrument, called the split-base point. This is a slip of bone, some I I or 
I $2 \mathrm{~cm}$. in length, which has a sharp point at one end and a broad butt at the other. The butt is usually, though not always, divided with a slit parallel to the greatest breadth of the object (Fig. 93). The use for which this instrument was intended has been much discussed. Some have supposed that it was a javelin or arrow-head, the slit being meant for the insertion of the shaft. But if this was the purpose it must be admitted that the shaft would have to be trimmed
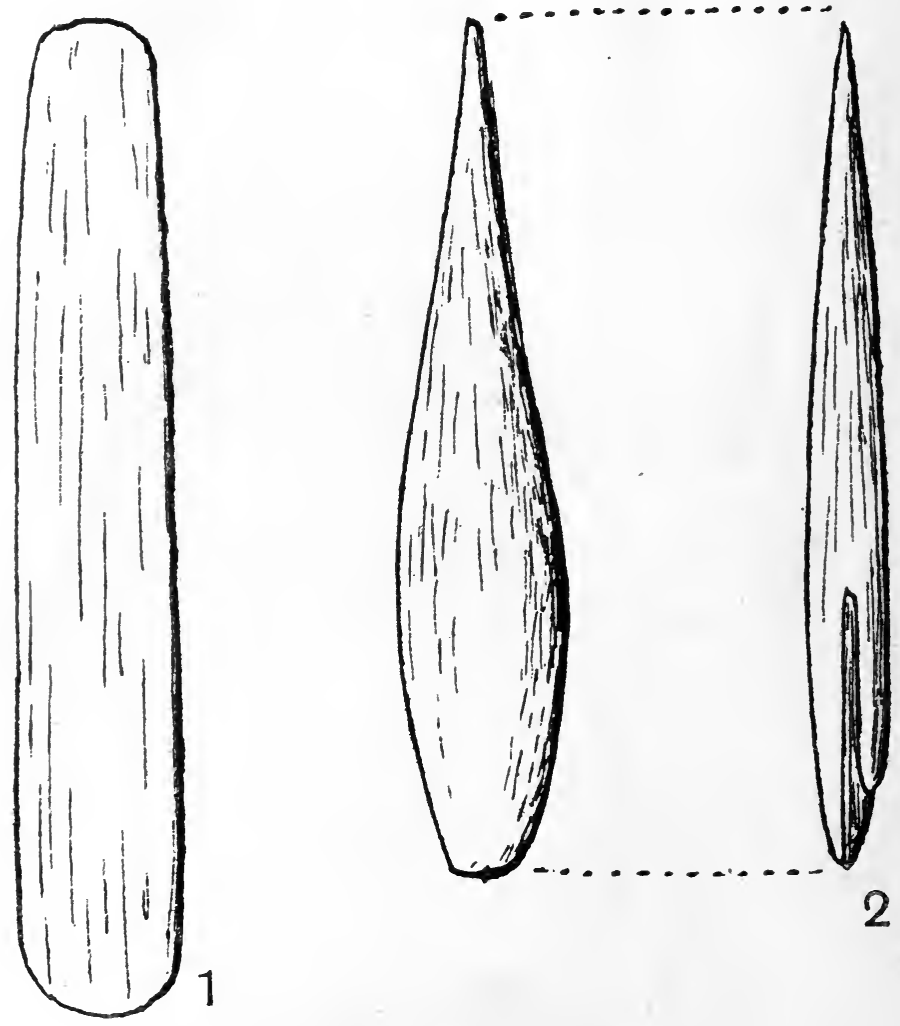

Fig. 93. Aurignacian bone implements.

to a very fine and fragile end to fit into the slit, and that the lips of the slit would also be very weak and would hardly be able to stand the strain of a blow. If this object were really a javelin head, the joint between the shaft and the head must have been very strongly and tightly bound with thongs of leather or of the tendons of animals, to counteract the strain on the weak spot of the weapon. Moreover the "javelin" theory does not account for the specimens which have no split in the butt. Another and a more probable suggestion is that 


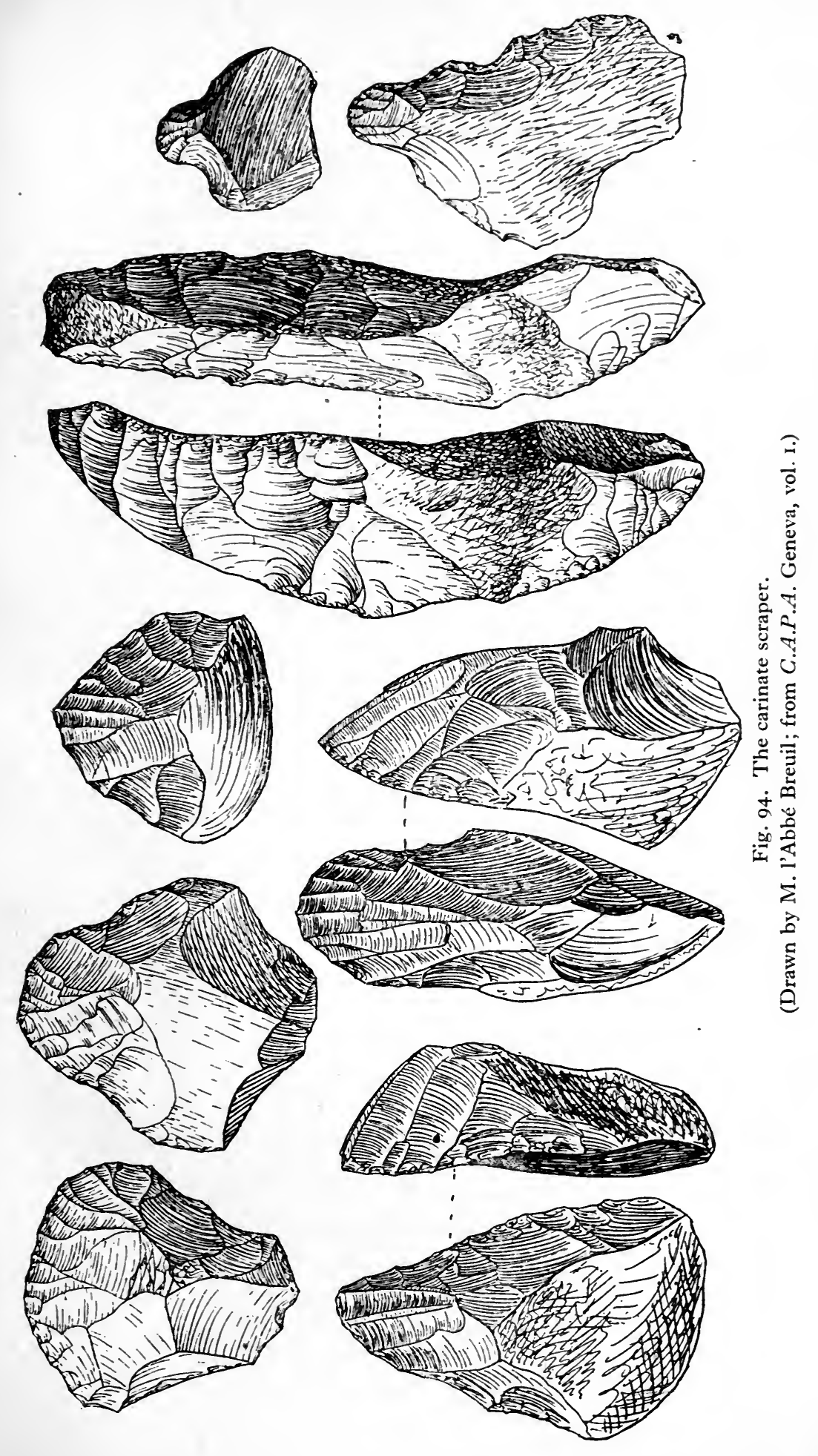


these instruments are the first attempts at bodkins - the sharp end being for pricking the holes in hides to be sewn together, and the rounded butt for pushing the thongs through; the split in the butt would clearly make it effective for this purpose. This would also account for the disappearance of the object after Aurignacian times, for when the much more convenient perforated needle was invented, this clumsy tool would naturally fall out of use.

In the Middle Aurignacian we find the carinate scraper developing. This implement is distinguished by its thickness, and by its general resemblance to an inverted boat. The base is flat, and the back rises to a greater or less height. The scraping edge is at the end of the tool, and has a chisel-edge shape. It is trimmed with long channelled flakings which are quite unmistakable (Fig. 94). There are a number
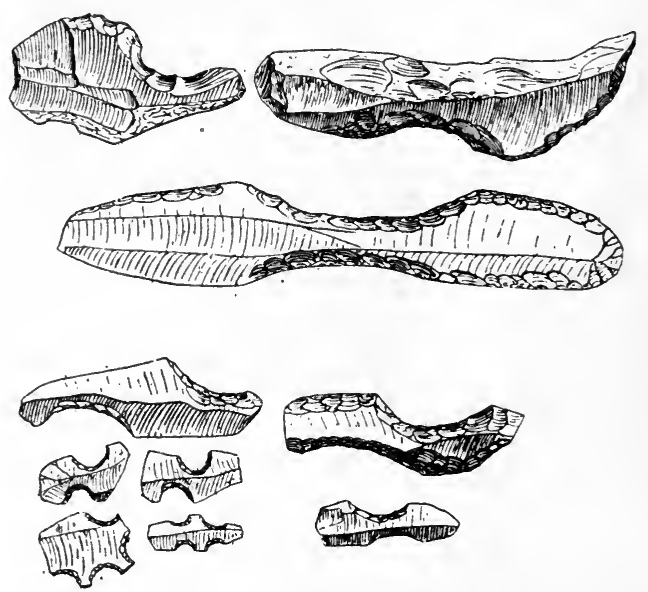

Fig. 95. Notched flakes.

(Drawn by M. l'Abbé Breuil; from C.A.P.A. Geneva, vol. I.)

of minor varieties, and modifications of this type, depending upon the thickness of the flake, the degree of flatness or convexity of the back, and the shape of the working edge, which is usually convexsometimes extremely so-but sometimes almost straight.

The notched flake begins to appear in the Lower Aurignacian, but it is there rare. This is a knife-like flake, with secondary chipping along both edges and over the top. The special peculiarity of the tool, however, is a concavity, formed in one or both of the edges. This concavity is shallow in proportion to its breadth. When there are two notches, one in each edge, they are usually so placed as to correspond, thus giving a wasp-waisted appearance to the tool, though sometimes they alternate with one another. On the other hand, there is sometimes a concavity in one side while the other is convex 
like the back of a Châtelperron knife, so that the whole flake has a bend sideways. Sometimes there is more than one notch in one edge. Various forms are shewn in Fig. 95. It is impossible to say with any certainty what purpose was served by these instruments.

Engravers are of various types. The simple engravers, with the cutting edge at the top of the flake, either in the middle or at one angle, already described as appearing in the lower phase, persist into the upper phases of the Aurignacian. There appears, however, in the middle phase a new form, called the burin busqué or curved engraver.
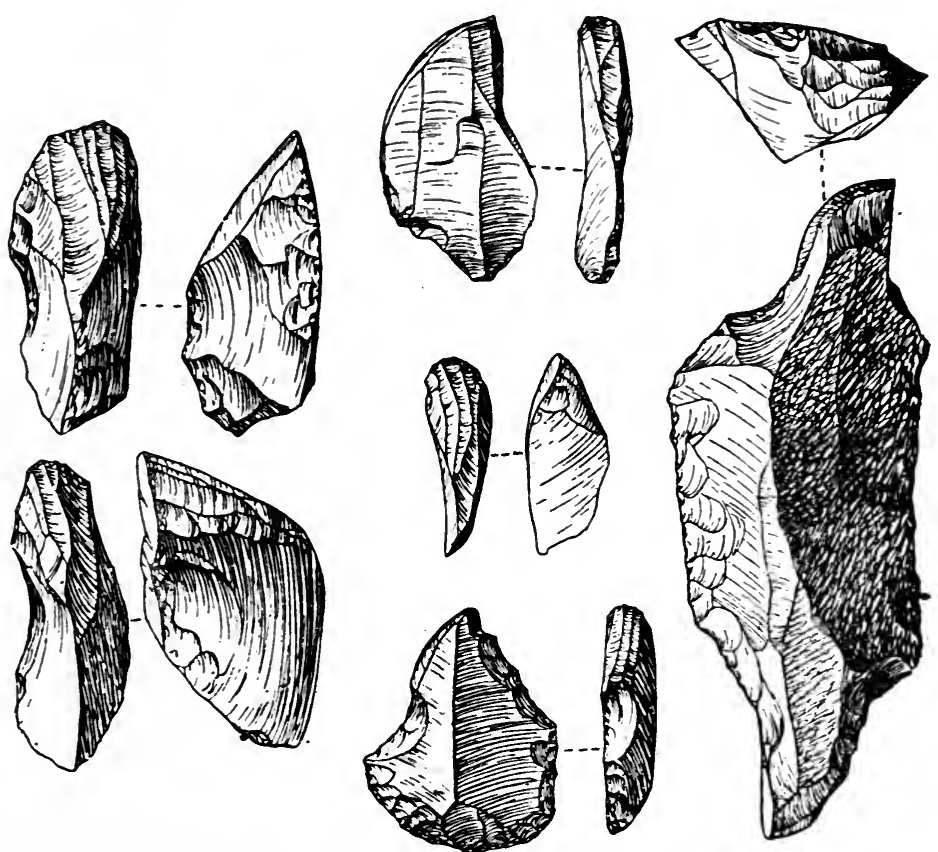

Fig. 96. The evolution of the curved engraver from the carinate scraper.

(Drawn by M. l'Abbé Breuil; from C.A.P.A. Geneva, vol. I.)

In this tool the engraving edge is bordered by two surfaces, the one strongly convex, the other slightly convex or straight. The convex face displays the caniculate flakings which characterise the carinate scraper, and indeed the latter tool is regarded as being the parent form from which the curved scraper was derived (Fig. 96). There is often a hollow chipped carefully at the base of the convex side of the engraving edge; it is supposed, for facility in grasping the tool or else to delimit the caniculate flakings. The butt of the tool is not infrequently treated with secondary chipping to make an end-scraper, 
the flake becoming thus a combination of two tools in one ${ }^{1}$. The curved engraver disappears from the upper stages of this Term.

The lateral or angle engraver, beginning in the Lower Aurignacian, persists through the succeeding stages. This implement is a flake, in which the working edge is formed in the upper angle of the lefthand edge. The angle-point is sometimes slightly beaked. In forming it, either the top or the edge may be treated with secondary chipping; and in the former case, the top of the flake may be made either convex or concave (Fig. 97).
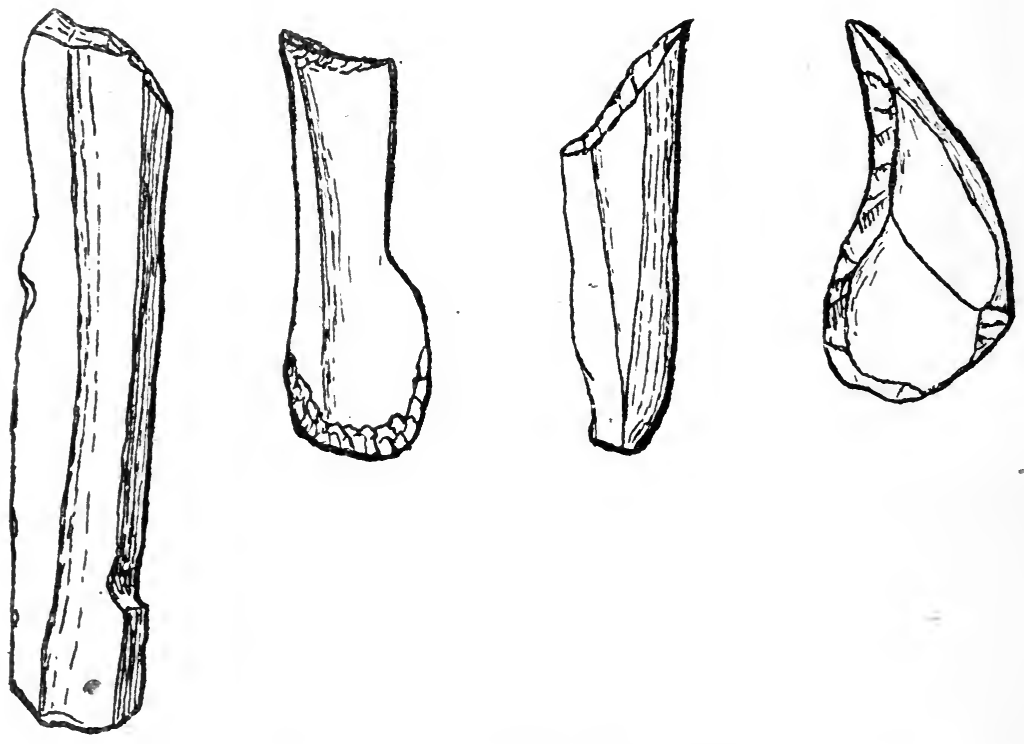

Fig. 97. Forms of the lateral engraver.

Bourlon has made an elaborate classification of engravers ${ }^{2}$, depending upon the form of their edge; the first of his classes is rectilinear, making incisions with an acute-angled section; the second polygonal, making rounded grooves. This classification, which Bourlon subdivides further into genera and types, corresponds roughly with the stratification of the deposits containing the objects; the older deposits have a larger proportion of the polygonal form, which become less frequent in the upper beds.

In this phase there develops a variety of the Chattelperron knife known as the Gravette point. This tool, like the Châtelperron knife,

1 See Bardon and Bouyssonie, "Le grattoir caréné et ses dérivés" (R.E.A. XVI. [1906], p. 40I).

${ }^{2}$ M. Bourlon, "Essai de classification des burins; leurs modes d'avivage" (Revue anthropologique, xx1. [1911], p. 267). 
is a flake having one edge treated with secondary chipping and the other left sharp and untouched. The chipped edge is generally worked back into the thickest part of the flake; and the two edges are as a rule parallel along the greater part of their length, though the chipped edge is sometimes slightly convex while the unchipped edge as a rule remains straight. The blade is finer than the Châtelperron blade, and drawn out to a sharper point at the tip; there is also very often a sharp point at the base ${ }^{1}$.
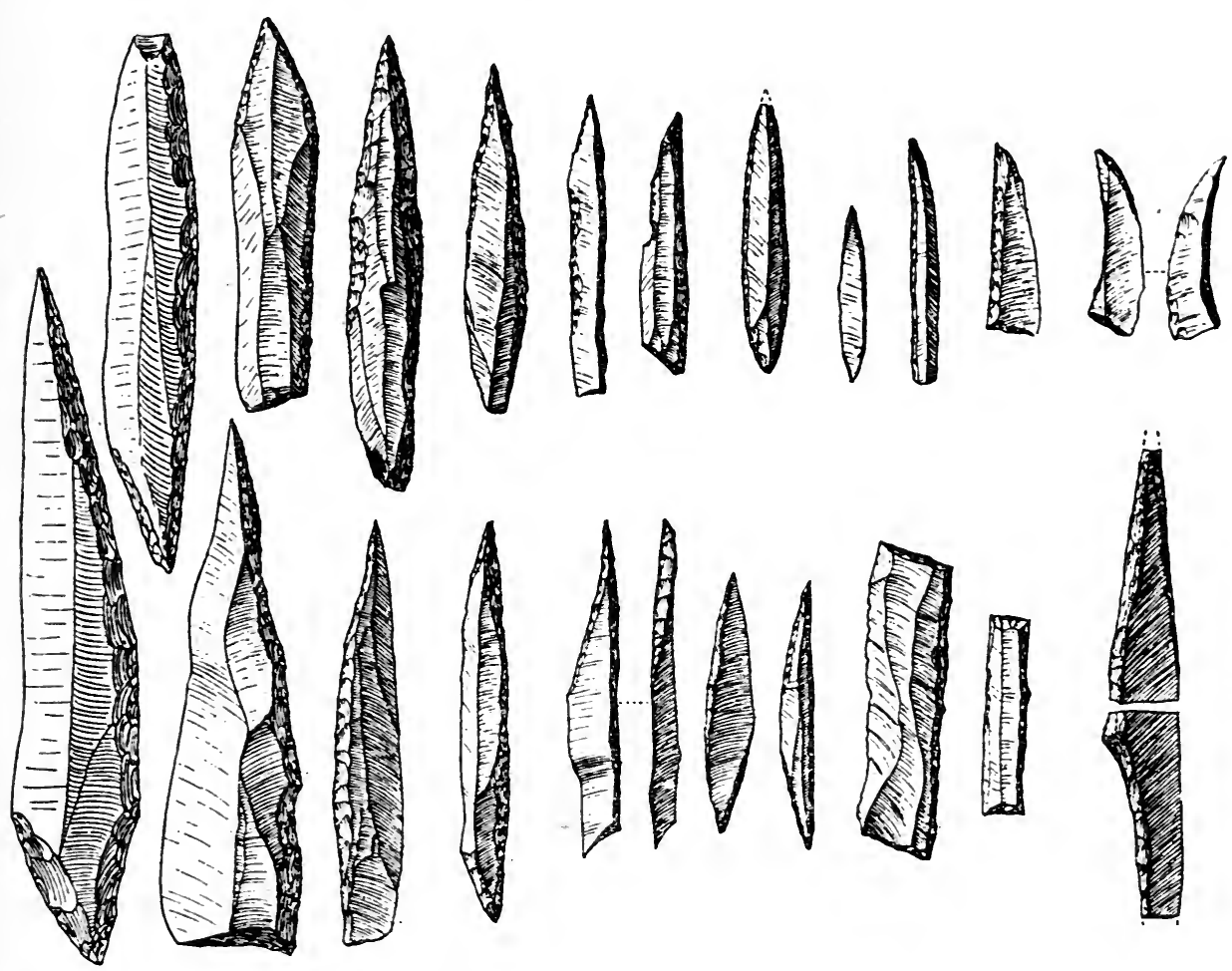

Fig. 98. Gravette points.

(Drawn by M. l'Abbé Breuil; from C.A.P.A. Geneva, vol. I.)

In some Gravette knives the chipped edge is not straight, but has a kind of hump. This seems to have suggested the device of providing the flake with a tang, which was introduced towards the end of the Aurignacian stage. This tang is isolated from the flake by chipping out a hollow at the base on one edge (making a pointe $\dot{a}$ cran) or on both edges (making a pointe $\dot{a}$ soie). This tang was

1 On the evolution of these points see D. Peyrony, "La pointe en silex dans les différents niveaux depuis le moustérien supérieur jusqu'au solutréen inférieur" (Revue préhistorique, Iv. [1909], p. 184). 
intended either for grasping in the fingers or for inserting in a bone or wooden handle.

A notable feature of the later Aurignacian, especially of the Gravette points, is the small size of some of the implements. Thus, in the careful researches in the Vallon des Rebières (Dordogne) conducted by M. Eugen Pittard, there was found a large number of very minute implements, flints of more ordinary sizes being exceptional. The site is Aurignacian, with a Mousterian bed underlying; these minute flakes were found in the Aurignacian bed, as well as in the Mousterian ${ }^{1}$. This form of implement is a curious anticipation of the "pygmy flint" industry characteristic of the Azilian stage.
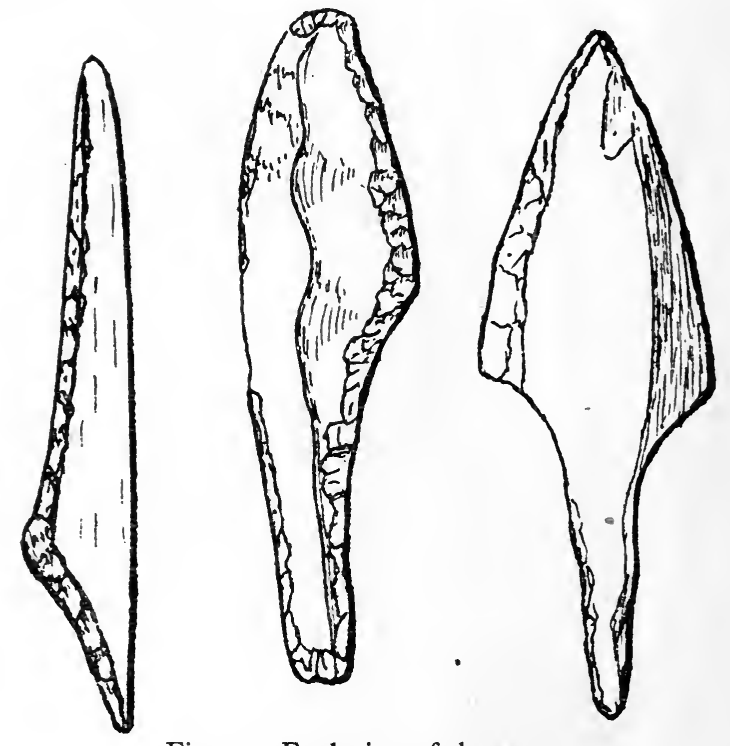

Fig. 99. Evolution of the tang.

Some minute Gravette points from Font-Robert (Corrèze) are shewn in Fig. 98 above.

No new implements are added to the industry in bone during the Middle and Upper phases of the Aurignacian, unless we are to ascribe to the latter the first appearance of needles with eyes. Some specimens of these from l'abri Blanchard at Sergeac, Dordogne, are by Breuil attributed to the Middle Aurignacian ${ }^{2}$. Pendants, and the so-called bâtons de commandement, also make their appearance. These however can more suitably be discussed on a later page.

1 See three papers in C.A.P.A. Geneva [1912], vol. 1. especially E. Pittard and Raoul Montandon, "Outillage microlithique de la station aurignacienne "DurandRuel,' vallon des Rebières, Dordogne," p. 479. See also E. Pittard, "Industrie microlithique moustiérienne"' (L'Anthr. xxIv. [I9I3], p. 635).

${ }^{2}$ C.A.P.A. Geneva [1912], vol. 1. p. 185 . 


\section{The Solutrean Stage}

Close to the village of Solutré near Mâcon (Saône-et-Loire), ther€ rises a prominent cliff, called the Rock of Solutré, in the shelter of which was established one of the most important Palaeolithic stations of all Europe.

The actual site is a field called Crot-du-Charnier, presumably in reference to the extraordinary mass of bones contained in the soil. Excavation began here in 1866 , and was continued at intervals for many years by Adrien Arcelin, l'Abbé Ducrost, and H. de Perry ${ }^{1}$.

The stratification of the site was perfectly clear, though its description in the paper referred to in the footnote requires careful reading to understand it. The soil attained a maximum depth of about 6.50 mètres above the rock, but owing to irregularities in the rock surface this varied considerably.

The earliest occupation is represented by two unimportant layers of ashes, containing very few implements. Their only contents were the bones of animals (horse, reindeer, hare) that had been used for food, and small flint knives of rude and simple manufacture. These layers probably belong to the first Aurignacian settlers who chose the site as a home.

Above these insignificant layers there extends a vast stratum of horse-bones. Arcelin, in the paper referred to (p. 309), reckons that there cannot be less than 100,000 animals represented. These bones are kitchen débris. There is as yet no domestication of the horse or of any other animal; the horses of Solutré were wild horses, hunted for food. With them were intermingled the bones of other animals in much smaller proportion-cave lion, hyaena, cave bear, hare, marmot, mammoth, and various species of deer and antelope, as well as reindeer. The last-named came next to the horse in frequency, though at a long distance.

Around this mass of bones were hearths, evidently representing the dwelling sites. These extended over a large area, and consisted of ashes mingled with the flat stones which had served as hearthstones. These hearths contained vast quantities of flints; in one of them, covering an area of 18 mètres by 9 mètres, l'Abbé Ducrost collected between 35,000 and 40,000 implements $^{2}$. These were of Aurignacian type, mingled with some survivals from earlier periods. With the flints were bone implements, also Aurignacian in type. The presence of waste cores of flint shews that we have here to deal with

1 See Adrien Arcelin, "Les nouvelles fouilles de Solutré" (L'Anthr. I. [1890], p. 295). In this article all the previous literature on the subject is summarised and superseded. Little more has been added since.

${ }^{2}$ Arcelin, op. laud. p. 311. 
a manufactory of flint implements. Arcelin mentions also a hammerstone, polished by grinding on two sides. 'This can hardly be right, as the technique of polishing stone had not been introduced in the Palaeolithic period; most likely the appearance of polishing had been produced by the use to which the tool was subjected. Flints similar to those in the hearths were found in the bone layer, shewing that the two were contemporaneous, and that the bone layer was the kitchen-midden refuse of the flint-chippers or of their descendants.

Above the bone layer was another, presenting notable contrasts. The people of this later settlement left behind hearths and graves. The hearths were oval or circular enclosures of rude slabs or stone, filled with ashes, and so close together that there was practically a continuous layer of ash over the whole area of the settlement. These people were still horse-eaters, but the reindeer was once more the principal diet; besides those animals, bones of fox, wolf, hyaena, bear, badger, marten, hare, mammoth, deer, ox, and several species of birds, were lying in the hearths. The domestic dog was entirely absent.

Besides these bones were found fossil shells, perforated for suspension in some cases; four figures of deer, more or less well engraved in limestone, deprived of their heads; an engraving of a quadruped in bone, similarly mutilated; and bone implements of the types presently to be described ${ }^{1}$. Pierced phalanges of reindeer, supposed to be whistles, also came to light; we have already referred to Dr Henri Martin's refutation of this theory, which applies to Solutré as well as to La Quina. Associated with certain of the hearths were burials. These hearth-burials were of especial interest, as indicating the usual primitive theory of another life, analogous in all respects to the present life. The dead were therefore interred in huts similar to those in which they had lived during life; we may perhaps compare the Tasmanian hut-burials ${ }^{2}$. These hearth-burials, according to Arcelin $^{3}$, varied in size and importance with the age of the individual interred within them.

Other sepulchres were found on the same site, which were not so evidently contemporary with the Solutrean settlement proper; they represent later intrusions. Besides tombs of all dates from Neolithic to Early Mediaeval, dated by their grave-goods, there were sepultures in the earth without associated hearths, and sepultures in cists of stone slabs. To these it is impossible to assign a date, and we therefore pass them over with this reference.

From what has been said above it will be seen that the climate

1 Bâtons de commandement, prickers, teeth pierced for suspension.

${ }^{2}$ H. I.ing Roth, The Tasmanians (Halifax, r899), p. I1 7 .

3 Op. laud. p. 307. 
of the Solutrean stage was less favourable than that of the Aurignacian. The horse had begun to give place to the returning reindeer; an indication that the steppe conditions were giving place to those of the tundras.

\section{(2) Human remains}

The human remains found which can with certainty be associated with the Solutrean are few in number, and are ill described. They are as follows:

Laugerie Haute (Dordogne). This is one of the most important and the richest Solutrean stations in existence: indeed, were it not for the presence of another station named Laugerie Basse, a short distance away, belonging to a different stage, Gabriel de Mortillet would have chosen this as the type station. To avoid confusion, he wisely preferred Solutré. A skeleton was discovered here in I906, or early in 1907, but, so far as I have been able to discover, no satisfactory particulars about it are as yet available ${ }^{1}$.

Predmost. This is a village about 3 kilomètres east of the town of Prerau in Moravia, situated on the Bečwa, a tributary of the March. In the neighbourhood of this village there rises an isolated rock, of Devonian formation, known as the Hradiško. Round it there are thick beds of gravel and fluviatile sand, overlying which is a bed of Löss, 20 mètres thick. This deposit was long known to contain large bones of animals, the beds of which were exploited by the country-people to furnish manure. Attention was first called to the site by $\mathrm{H}$. Wankel, and the work of scientific examination was followed up later by K. Maška and M. Križ̃ ${ }^{2}$.

The bones were for the greater part those of mammoths, which were hunted by the Solutrean inhabitants of the district: a rival theory, that the animals had been frozen by glacial cold, and that their dead bodies had been sought for the ivory at a later time ${ }^{3}$, is no longer admitted. Along with the abundant mammoth, there were found remains of steppe and tundra fauna, including the following species:

$\begin{array}{lll}\text { Canis lagopus } & \text { Cervus elaphus } & \text { Bison priscus } \\ \text { Gulo borealis } & \text { Alces latifrons } & \text { Bos primigenius } \\ \text { Hyaena spelaea } & \text { Rangifer tarandus } & \text { Equus caballus } \\ \text { Felis spelaea } & \text { Capra ibex } & \text { Rhinoceros tichorhinus } \\ \text { Myodes torquatus } & \text { Ovibos moschatus } & \text { Elephas primigenius }\end{array}$

1 For the discovery see B.S.P.F. Iv. [1907], pp. 46, 160.

2 See H. Wankel in Corr. xvir. [1886], p. I 46 ; Maška, Der diluviale Mensch in Mähren, I886; Idem, "Vorläufige Berichte über den Fund diluvialer Menschenskelette in Prodmost" (Corr. [1894], p. 137); Kṛ̛̌z, Beiträge zur Kenntniss des Quartars in Mähren (Steinitz, 1903); Hoernes, Der diluviale Mensch in Europa (Brunswick, 1903), esp. p. 140 ff.; M.A.G.W. xxiv. [1894], p. (127); L'Anthr. xII. p. 145 .

${ }_{3}$ M.A.G.W. xx. [1890] p. 1 ; xxIv. [1894] pp. 40, (129). 
Large numbers of flint implements, and also of those of ivory, bone, and reindeer-horn were found on the site; as well as a number of interments. In one group there were 14 bodies, evidently buried with intention, belonging to I I adults and three children. In anothergroup were remains of six other skeletons. One of the men was about $\mathrm{r} .77$ mètre in height, but the others were of moderate stature. The skulls, of which ro were found perfect, displayed the sloping Mousterian forehead and the conspicuous brow-ridges, but in a less marked degree than the full-blooded Mousterian ${ }^{1}$. The series has been examined by Hrdlička ${ }^{2}$ who expresses himself as much impressed with their importance; he believes that they will be found to occupy an intermediate place between the Middle and Upper Palaeolithic races. No thorough description of the series of bones appears to have been published.

Brünn. This important skull was found in the following circumstances. In digging a ditch in the town of Brünn, Moravia, a number of bones and teeth of elephant and rhinoceros were found, at a depth of over 13 feet. They were lying in Löss, which also contained many bones of Mammoth, Rhinoceros tichorhinus, Rangifer tarandus, Cervus giganteus, and, in smaller quantities, Ursus spelaeus and Felis spelaea. Scarcely any remains of human industry, and no human bones, had been reported from the bed till the skull came to light. This Löss overlies tertiary or quaternary clay or alluvial gravel. When the bones were found, the following objects were associated with them:

(a) A large mammoth tusk, $90 \mathrm{~cm}$. long and as thick as a man's arm.

(b) Over six hundred fragments of a tooth-shell (Dentalium badense) which had been cut and adapted for ornaments similar to shell ornaments found in the Mentone caves.

$(c)$. Fourteen smaller discs of red sandstone and quartzite, rhinocerosbone, and ivory, measuring from about $3 \mathrm{~cm}$. to about $6 \mathrm{~cm}$. in diameter, some of them perforated in the centre, others ornamented with notches in the margin, or with strokes on the surface running from the centre to the circumference.

(d) A smooth instrument made of the lower part of the horn of a stag.

(e) The ivory figure described in the following chapter(p.46r, Fig. I30).

The skeleton was coated with an ochreous substance (iron oxide with carbonate of lime and silica). The statuette $(e)$ shewed traces of the same colouring. The skull is markedly dolichocephalic (index $65^{\circ} 7$, but there may be some slight posthumous deformation). It displays a singular combination of Middle and Upper Palaeolithic

${ }^{1}$ K. J. Maška, "Nalež diluvialniho človeka v Predmosti" (anal. L'Anthr. vi. [1895], p. 194).

2 The Most Ancient Skeletal Remains of Man, p. 552. 
characters. The back of the head is of Upper Palaeolithic type, and its association with ochre-burial and with a sculptured figure likewise connects it with the Upper Palaeolithic. But the front of the head with its large brow-ridges is more reminiscent of the Middle Palaeolithic types of humanity. The forehead is, however, higher and less sloping than that of Middle Palaeolithic man ${ }^{1}$.

A second skull found at Brünn seems to be of the same type, but is too fragmentary to give much information.

Brüx. The roof and frontal portion of a skull, found with other bones in the year 1871 at Brüx in Bohemia, buried in the ancient alluvium of the Biela river $^{2}$. With it was associated a neolithic polished axe-head, which would prima facie raise doubts as to the antiquity of the skull. The association may have been accidental only; but an element of uncertainty must inevitably attach to this specimen.

Such as it is, it has been very thoroughly examined by Schwalbe ${ }^{3}$. The result of this investigation is to place it, at least morphologically, in an intermediate place between Neandertal man and the man of modern type. With it Schwalbe associated the Brün skull, just mentioned, and the too-accommodating Proteus of Galley Hill. We have already seen that the Galley Hill man has served as a proof of the pre-Mousterian existence of modern man in Europe. It has served Prof. Klaatsch as a makeweight to enable him to elevate the Combe Capelle man into a new racial type. Now we see it coming to Prof. Schwalbe's service in the same capacity. One has much sympathy with Aesop's satyr, who objected to the man who blew hot and cold with the same mouth! But seriously, there could be no better illustration of the uselessness of craniological deductions based on a small number of specimens.

The Brüx skull differs from the Neandertal type in the absence of the continuous brow-ridge, for which it substitutes a rather heavy pair of brow-arches; and in its shape, which involves a different distribution of the mass of the brain among its several parts. On the other hand it approximates to the Neandertal type in the small elevation of the cranial vault, and in a number of other measurements and proportions, which are enumerated at p. 147 of Prof. Schwalbe's monograph. His conclusion is that the Brüx skull is

1 See Georges Hervé, "Le squelette humain de Brünn" (R.E.A. III. [18y3], p. 20); Alex Makowski, "Der diluviale Mensch im Löss von Brünn" (M.A.G.W. xxII. [1892], p. 73, with good plates); Schaafhausen, in Niederrheinisches Gesellschaft, Bonn, II Jan. I892; Keith, Antiquity of Man, p. $6 \dot{9}$.

2 Felix Luschan, "Die Funde von Brüx" (M.A.G W. III. [1873], p. 25).

3 G. Schwalbe, "Das Schädelfragment von Brüx und verwandte Schädelformen" (Studien zur Vorgeschichte des Menschen, Stuttgart, 1906, pp. 83-182). 
comparable with the lowest contemporary races of modern man, such as the Australians. The skull is very dolichocephalic, the index being about 69 (an exact figure cannot be calculated, owing to the fragmentary state of the specimen). It does not shew the dysharmony of the Cro-Magnon type.

Neu-Essing, Bavaria. The skeleton of a man, interred in the cave known as die Klause, discovered by Obermaier ${ }^{1}$. No osteological particulars of this skeleton are as yet available, so far as I have been able to find.

In addition to the above, a number of bones and fragments have been found in Solutrean deposits, which, however, add nothing to our knowledge. Thus in the important Solutrean cave of Lacave (Lot) more fully described below, some bones came to light: and in the cave of Placard there were a number of cranial vaults, which had apparently been cut and trimmed to make drinking-cups. , To base ethnological deductions upon the last-named discovery would be doubly rash. For in the first place the material is in any case too fragmentary; and in the second, it is more than probable that the skulls so treated would have been those of enemies, who might have had totally different ethnological affinities from those of the people of whom we are in search. We cannot yet say any more than this: that the Solutreans of Eastern Europe seem to be intermediate between the Mousterians and the Aurignacians in some respects; and that as for the Solutreans of Western Europe, we know nothing whatever about their racial position.

\section{(3) Fauna}

Of the fauna during the Solutrean stage all that need be said is that it indicates a gradual return of Arctic conditions. The reindeer once more begins to assert itself as the principal animal of Central Europe, and the specifically steppe fauna of the Aurignacian stage again yields to that of the tundras.

\section{(4) Implements}

The carinate scraper disappears, but the Gravette points of the late Aurignacian continue into the flint industry of this stage: while other tools, such as end-scrapers, prickers, engravers, and borers, characteristic of every stage of the Upper Palaeolithic, are still in use. To these, however, the Solutrean flint-workers add a class of objects quite special to themselves.

These are javelin-heads of various forms. They are by far the

$$
1 \text { L'Anthr. xxv. [1914], p. } 260 .
$$


finest specimens of flint-flaking which the whole Palaeolithic period has to shew (Fig. 100). They are commonly spoken of as "willowleaf" and "laurel-leaf" points, and these names are so well established that they may be preserved, though as a rule it is well to avoid
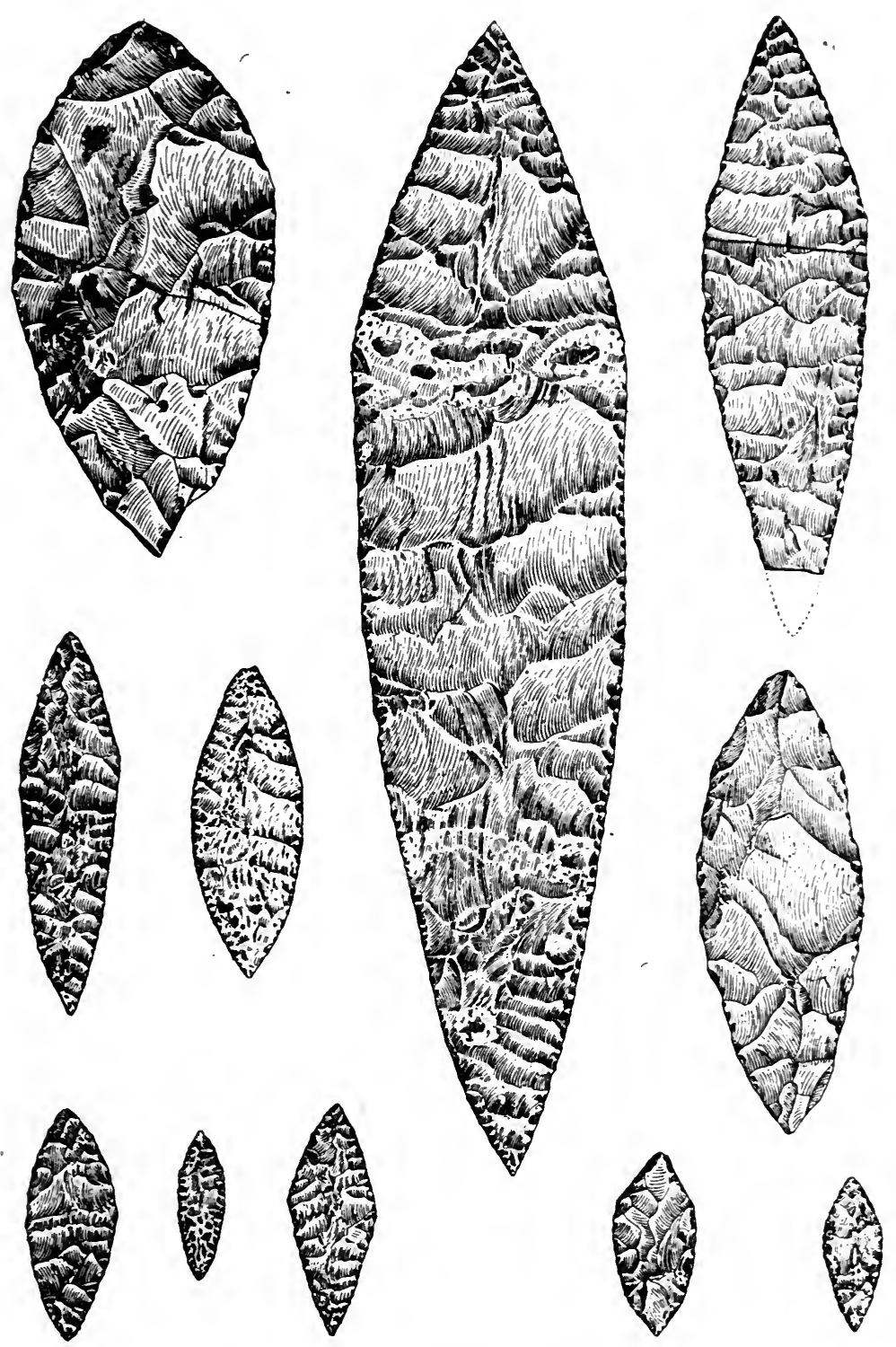

Fig. 100 (A). Solutrean javelin-heads.

(From G. and A. de Mortillet, Musée préhistorique.) 

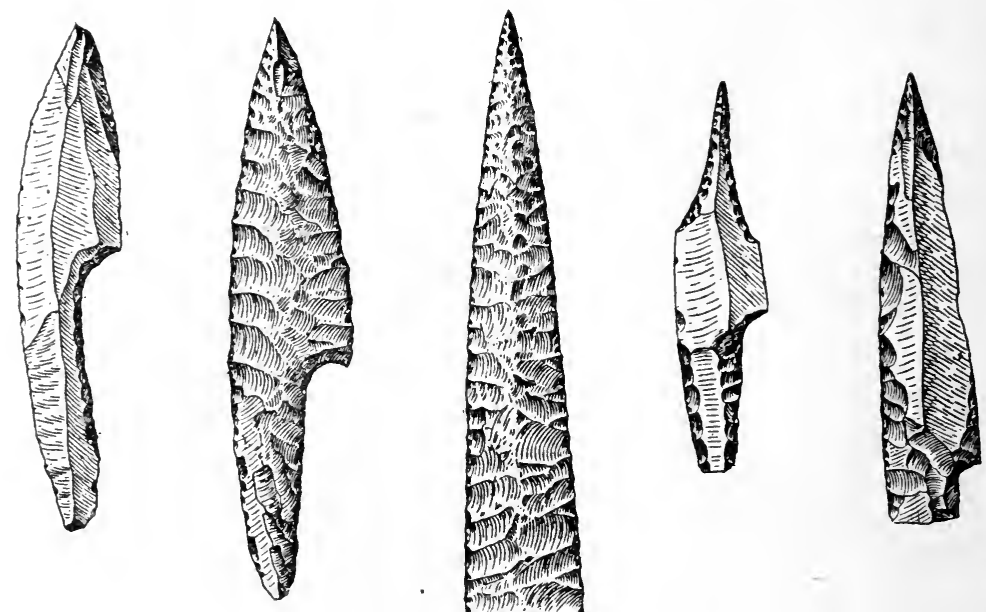

Fig. I00(B). Solutrean javelin-heads.

(From G. and A. de Mortillet, Musée préhistorique.)

such poetical terminology. They are lozenge-shaped, regular or irregular (i.e. consisting of two triangles base to base, equal and unequal respectively), oval (pointed at one end or at both) tanged ' (with lozenge or oval head), or triangular; the last-named form has a tang in line with one side of the triangle, so that the opposite basal angle makes a rudimentary barb. This form is usually spoken of by the French name pointe a cran. All these objects are most carefully brought to shape, and finished with a delicate chipping over the whole surface-a technique especially characteristic of the Solutrean style. This chipping is supposed to have been produced by pressure with a bone flaking-tool, rather than by striking with a hammer: a similar method is in use among aboriginal Americans and other flint-users. In the oldest Solutrean implements this form of chipping appears on one side of the flake only, or near the edge only; in the fully developed Solutrean it covers the whole surface of the flint on both sides. The pointe a cran is of late introduction in the style.

Among Solutrean deposits none is more remarkable than a collection of 40 specimens of javelin-heads of the irregular lozenge shape, found at Volgu in the department of Saône-et-Loire-the same which contains Solutré itself. The neatness and regularity of the chipping of these objects surpass anything found elsewhere in France; and the exceptional size of the points was also very noteworthy一the smallest being $24.50 \mathrm{~cm}$. long, and the largest $35 \mathrm{~cm}$. 

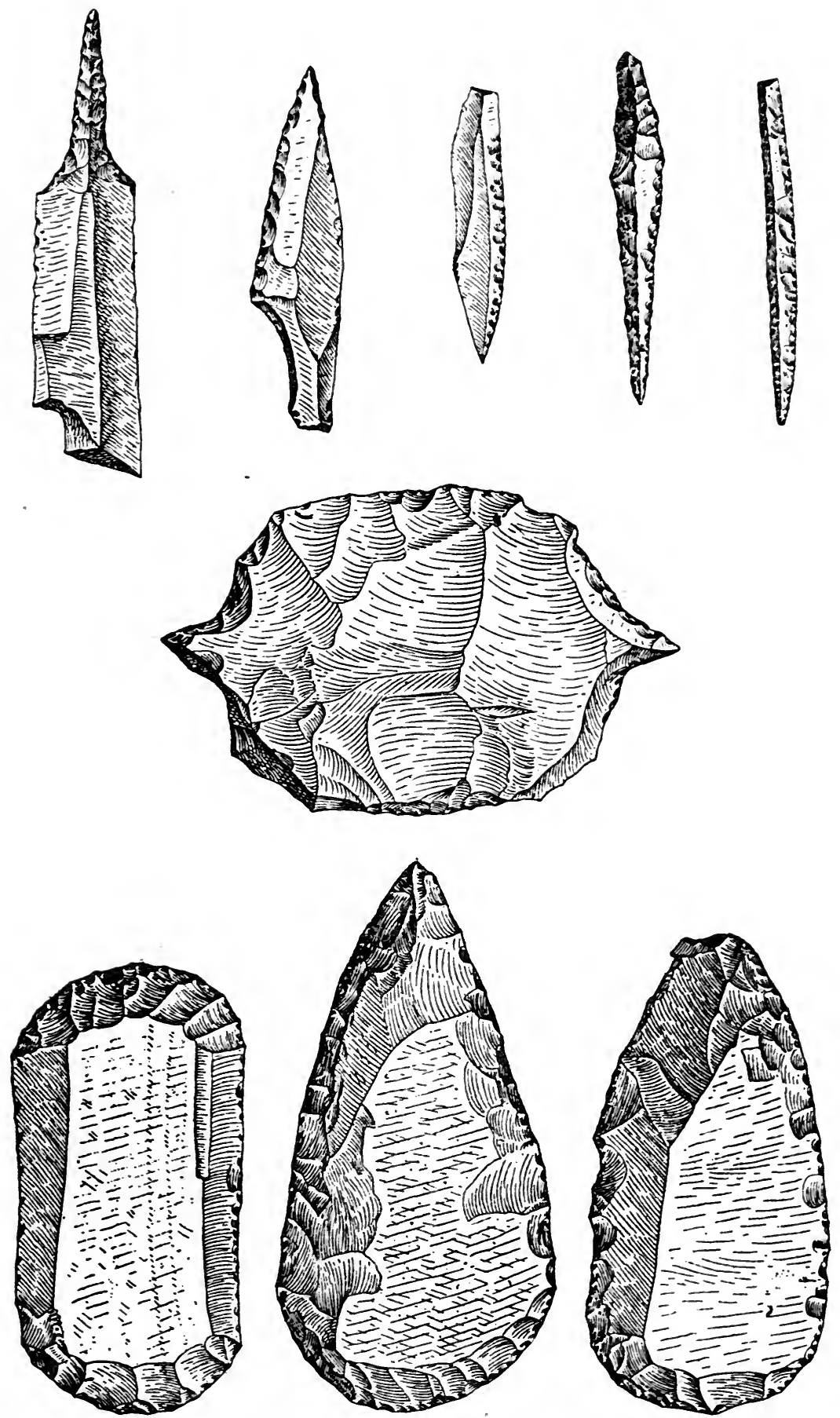

Fig. Ior. Solutrean scrapers and borers.

(From G. and A. de Mortillet, Musée préhistorique.) 
So delicate were they, that it is impossible to believe that they were meant for rough use as weapons; they would have snapped across like glass if subjected to any undue strain. A possible use for them will be suggested in the following chapter.

Hardly inferior in artistic merit are the scrapers, as well as the single and double borers, which Solutrean deposits have yielded (Fig. IOI).

In striking contrast with the excellence of the flint-working of the Solutrean stage, is the poverty of its working in bone. The Aurignacians did not advance very far in this art, it is true; but the Solutreans shew a distinct retrogression even from their modest standard. Bone prickers and polishers are all that the Solutreans attained to. And, as will be seen in the following chapter, the Solutreans also display a retrogression in pictorial art. These facts are of considerable ethnological importance.

\section{The Magdalenian Stage}

(2) Human remains

The following is an enumeration of the most important human remains that have been found associated with Magdalenian deposits.

Laugerie Basse. It was long believed that, as at Cro-Magnon (described above), we have here to deal with a case of violent death: that the skeleton belonged to a man who had been crushed beneath a sudden fall of rock, that had come down upon him from the roof of the cave while he slept. The spine was destroyed and other injuries were inflicted. But in a recent publication (Grottes $d u$ Grimaldi, vol. iI. fasc. ii. p 307) Cartailhac, who was present at the exhumation of the skeleton, has described this explanation as erroneous, and has pronounced the deposit to have been an interment.

The man had been decorated with shells strung on various parts of his body. He was of the same tall stature as the Old Man of Cro-Magnon, and, so far as we can judge from the much broken facial bones, he must have resembled the Cro-Magnon man in feature. He was, however, in the prime of life. The teeth were more perfectly preserved than in any of the Cro-Magnon specimens, but were much worn. The cranial index is estimated as 74.87 .

Three other skulls, or parts of skulls, were also found at Laugerie Basse, scattered amid the kitchen débris. How they got therewhether they were the remains of a cannibal feast, or were dragged by wild beasts, we have no means of knowing. There was one man, one woman, and one probably female child. The male skull was much injured and little could be made of it; the woman resembled 
the Cro-Magnon woman in appearance, but was of smaller build; her cranial index was $74 \cdot 86$. Of the imperfect and undeveloped bones of the child all that need be said is that the skull shewed an index of $72 \cdot 67^{1}$.

Chancelade (Dordogne). Here a skeleton was found lying upon the rock, and covered with several layers of Magdalenian débris. It was cramped closely into a crouching attitude-so much so, indeed, that those who examined it came to the conclusion that it must have been forcibly tied up in that distorted position before being placed in the grave. It is male, of superior type, cranial index 72 , jaw with well-developed chin, and in other details approximating to the Cro-Magnon model, except in stature. The Chancelade man was unusually short for an Upper Palaeolithic male, his stature being not more than $\mathrm{I}_{5} 5$ mètre-one of the smallest Palaeolithic men known. He was in fact a dwarf, whose growth had been arrested by some pathological cause ${ }^{2}$.

Grotte des Hoteaux, near Rousillon (Ain). This very important skeleton, discovered in 1895 by L'Abbé Tournier and Charles Guillon $^{3}$, was a storm-centre of dispute when it was first published It was among the earliest definite indications found of the practice of burial by Palaeolithic man: a fact till then zealously denied by one prominent school of investigators.

The deposit on the rocky floor of the grotto attained a depth of 2.35 mètres. It was divided into seven strata, ranging in depth from $5 \mathrm{~cm}$. to $64 \mathrm{~cm}$., with traces of occupation between each. A succession of occupations of the cave, interrupted by prolonged floods, is indicated. The lowest stratum contained Alpine erratics, which could not have been carried except by the great Rhone glacier-an indication of the post-glacial date of the entire settlement.

The skeleton lay in the lowest stratum. A glance at the illustration (Fig. I02) shews that it has been reconstructed - that is, deposited finally in the grave till after the flesh had disappeared or been removed; and that though an attempt has been made to replace the bones in their relative position, the vertebrae are misplaced, the position of the skull is distorted, and the right and left femora are interchanged. The exhumation of the skeleton took place in the presence of several witnesses, all of whom assure us that the strata above the bones were unbroken. The bones were lying on a bed of red ochre.

1 Rel. Aquit. pp. 255-265, 272.

2 L. Testut, "Recherches anthropologiques sur le squelette de Chancelade" (Bulletin de la Société d'anthr. de Lyon, viII; analysed in L'Anthr. 1. [1890], 716 ).

${ }^{3}$ See Préhist. part II. sect. 2, chap. viii; see also the lively discussion reported in B.S.A.P. ser. IV. vol. vi. [1895], pp. $388 \mathrm{ff} .419 \mathrm{ff}$. 


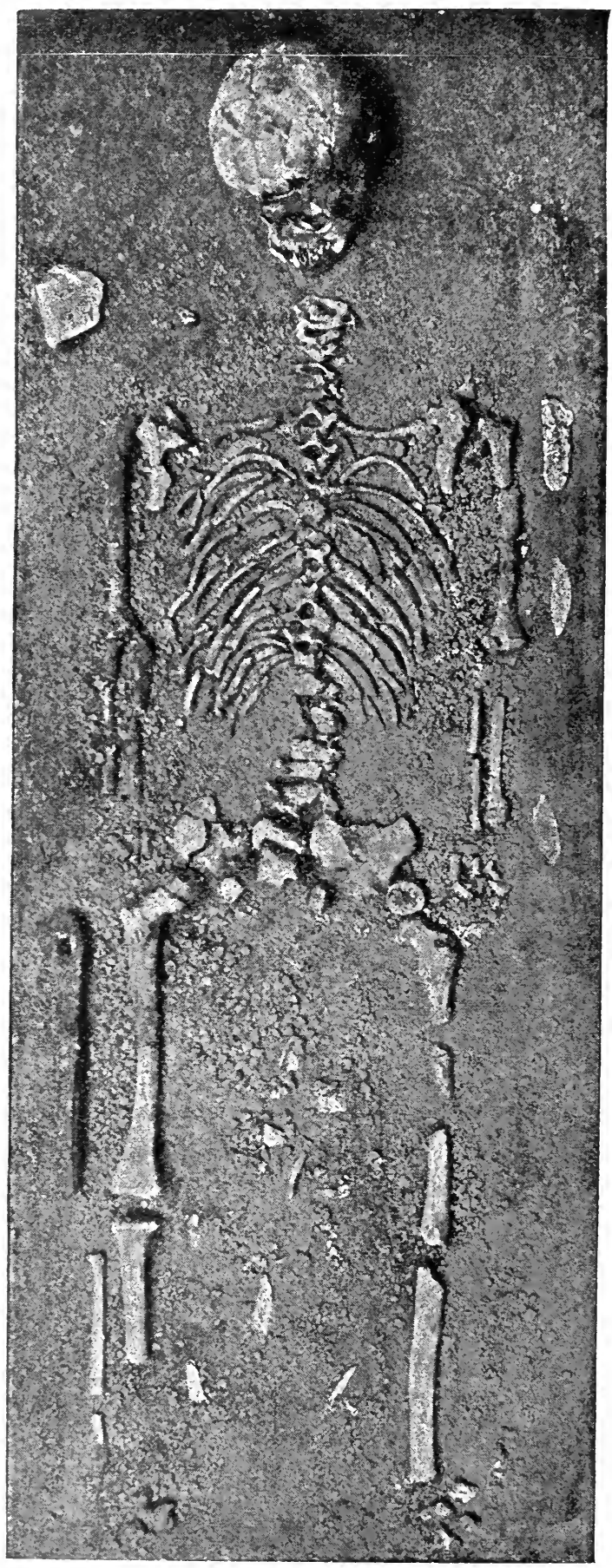

Fig. 102. The interment at Les Hoteaux.

(From L'Anthropologie, vol. vir.) 
This fact, that it was the bones only which were deposited in the grave, disposes of an objection made at the time, that the strata were too shallow to guard the body from hyaenas-which is perfectly true. There is indeed every reason to attach the greatest possible importance to the discovery at Les Hoteaux, as a convincing example of the practice of double sepulture-the temporary disposal of the body till the flesh has decayed, followed by a permanent burial of the bones.

The subject was a young man, aged from 16 to 18 years; he was not fully grown, and the stature was short, being not more than I.35 mètre. The cranial index was $77 \cdot 34$. The flints deposited with the body were of Magdalenian form, and the ornaments took the shape of perforated pecten shells and teeth. Bone pins and needles of Magdalenian type also came to light associated with the body, and there was one of the mysterious instruments commonly called battons de commandement, adorned with the figure of a stag engraved upon it, lying beside the right thigh. Of the animals whose bones were found in the cave Rangifer tarandus was the commonest; there were also Capra ibex, Cervus elaphus, C. alces, Ursus arctos, Arctomys marmotta, Sus scrofa, Castor fiber, Lepus timidus, Hyaena spelaea, Meles taxus, as well as several birds ${ }^{1}$.

Sorde (Landes). The cave, called after the name of the proprietor at the time of its excavation, M. Duruthy, is a rock shelter 8-9 mètres in length and now 2 mètres in depth; it was originally deeper, much of the roof having fallen. The deposits on the floor lay in a series of well-marked strata; the uppermost were Neolithic, and contained some skulls; but under a thick bed of ashes and other materials, containing Magdalenian implements, there were the remains of a Palaeolithic skeleton. It had been buried, and was girt with a girdle made of the canine teeth of lions and bears. The skeleton is described as being of Cro-Magnon type ${ }^{2}$.

Grotte de l'homme, Arcy-sur-Cure. Here there were found three

1 See Abbé Tournier and Charles Guillon, Les hommes préhistoriques dans l'Ain, Bourg, 1895. Analysed in $L^{\prime} A n t h r$. vi. [1895], 314 . It is a small point but worth a note, that the interment has been described in a way that suggests a misunderstanding of the stratification, in one of the most recent books on the subject of Palaeolithic man. The skeleton is there said to have been "buried at a depth of six feet beneath Magdalenian implements." It would be a hypercriticism to say that this means "beneath earth containing Magdalenian implements"; but the point is that this way of expressing the fact would suggest to a careless reader a grave six feet deep dug through all the overlying strata. In point of fact it would appear that the skeleton had been only lightly covered with earth, and that the overlying strata had accumulated after the interment.

${ }^{2}$ See B.S.A.P. Ix. [1874], p. 527; Lartet and Duparc, "Sur un sépulture des anciens troglodytes des Pyrénées" (C.A.P.A. Stockholm [1 874], I. p. 302 ; Matériaux pour l'hist. de l'homme, Ix. [1874], p. 101). 
skulls and some other bones, in a cave containing objects of Magdalenian type. There is no account of these skulls accessible to $\mathrm{me}^{1}$.

Lautsch, Moravia. From a cave known as the cave of Fürst Johann. A skull of Cro-Magnon type, but nothing to shew to which stage of the Upper Palaeolithic it is to be assigned ${ }^{2}$.

Obercassel, near Bonn. This discovery, made in 1914, is described by Verworn ${ }^{3}$. The abstract given us by Dr Osborn ${ }^{4}$ contains the main facts. There were two skeletons, buried in earth tinged red with ochre, and covered with slabs of basalt. Carved bone implements of Magdalenian type lay around, but no stone. The skeletons were (a) a young woman, cranial index 70 , stature 1.55 mètre; and (b) a middle-aged man, dolichocephalic (index 74 ) but very dysharmonic, stature $\mathrm{I} \cdot 60$ mètre, cranial capacity 1500 .

Cheddar, Somersetshire. The skeleton of a young man was found under stalagmite associated with Magdalenian flints and with a fragmentary bâton de commandement in Gough's Cavern, Cheddar. It has been described by Messrs Seligman and Parsons ${ }^{5}$. The skull is dolichocephalic (index 70.4); the stature was moderate. The result of the comparisons, which the authors of the paper cited draw, between this skeleton and the typical Upper Palaeolithic skeletons of the Continent is on the whole negative; the skeleton approximates rather to the types found in early Neolithic interments in England.

Of similar type are two other skeletons found in or near the Thames valley; they are too doubtful to be taken into consideration in attempting to formulate the principles of Upper Palaeolithic ethnology. These are the remains found in brick earth on the 20-feet terrace at Halling, Kent ${ }^{6}$, and the find made long ago in the alluvium of the submerged valley of the Thames at Tilbury. Both these skeletons are of modern type; and it is on the whole unlikely that they are so old as the Magdalenian stage. They may perhaps be Azilian.

Besides the above skulls and skeletons a number of small fragments, teeth, etc., which it is hardly necessary to enumerate here,

1 Abbé Parat, "Les grottes de la Cure et de l'Yonne: recherches préhistoriques" (C.A.P.A. Paris [1900], p. 63 ff. esp. p. 64).

2 J. Szombathy, "Un crâne de la race de Cro-Magnon trouvé en Moravie" (C.A.P.A. Paris [1900], p. 133). Obermaier (L'Anthr. Xvi. [1 905], pp. 407-8) speaks of five skeletons here above the animal deposits of the Reindeer Period, and presumably later in date.

${ }_{3}$ Die Naturuissenschaften, July 1914, p. 645.

${ }^{4}$ Men of the Old Stone Age, p. 380.

5 C. G. Seligman and F. G. Parsons, "The Cheddar Man; a skeleton of late Palaeolithic date" (F.A.I. XLIV. [1914], p. 24I). Reference to further literature will there be found.

${ }^{6}$ W. H. Cook, "On the discovery of a human skeleton in a brick earth deposit in the valley of the river Medway at Halling, Kent" (F.A.I. XLIv. [1914], p. 212). 
have been found in various places. They would all have their place in an exhaustive ethnological study of Upper Palaeolithic man, a work which still remains to be written. It must be observed that the ethnology of Upper Palaeolithic man has not been treated with anything like the thoroughness with which the men of the Mousterian stage have been studied. There is as yet no monograph worthy to set beside Boule's description of the man of La Chapelle-aux-Saints. In any case the material at our disposal is still quite insufficient to justify us in formulating any final principles with respect to Upper Palaeolithic ethnology. It is evidently by no means a simple subject; racial complications had already begun to make their appearance. Having regard to the rarity of Upper Palaeolithic skeletons, and the still greater rarity of specimens which may be accepted without qualms as absolutely genuine, it is hardly to be expected that we shall acquire much certain knowledge on this subject in the near future.

However, putting together the material which we have, and remembering the caution that has already been given as to the pitfalls awaiting the rash theoriser who has only a scanty amount of osteological material on which to found his speculations, we may in a paragraph indicate the course of history to which the available facts seem to be pointing. The Cro-Magnon people, a tall, well-developed, and big-brained race, entered Europe and brought with them into the Continent the Aurignacian civilisation. Then another racial group appears, developing, it would appear, in the eastern part of Central Europe. This race seems to hold a place intermediate between the Mousterians and the Aurignacians, not only in physique but also in culture. Like the Lower and Middle Palaeolithic people, they are skilful in flint-chipping, and indeed the resemblance between the Solutrean laurel-leaf javelin-heads and the well-made Acheulean coups-de-poing has often been noted. If we might suppose this race to have actually sprung from a blend of the two extreme types, it would almost seem that the grafting of the Aurignacian intellectual powers on the traditional Mousterian skull in this department, had raised the standard of flint-chipping. On the other hand, the Mousterian parent seems to have bequeathed to the Solutrean offspring the negative qualities of lack of art and of skill in bone-working. The Solutreans moved westward, and submerged the Aurignacians temporarily, driving them, perhaps, into Italy; where they were preserved, to reappear, after the Solutrean tyranny was overpast, as the Magdalenians. The Magdalenians seem essentially to have been similar in race to the Aurignacians, but to have lost the tall stature and the excessive cranial capacity-perhaps as a result of the deterioration of climate: and it seems possible to affiliate the Magdalenian culture 
to the Aurignacian. While this reconstruction appears to fit the facts as we have them, it must be freely admitted that many more discoveries must be made, and those already made must be more systematically described, before we can begin to solve the difficult questions involved in the study of Upper Palaeolithic ethnology.

\section{(3) Fauna}

A second invasion of small Arctic rodents heralded the Magdalenian stage, thus indicating a return of glacial conditions. The reindeer is the principal animal during this stage; but of its former companions the mammoth is attenuated in numbers, and the tichorine rhinoceros still more so. Man is a cave-dweller throughout the stage. The climate becomes less severe as the stage draws to a close,

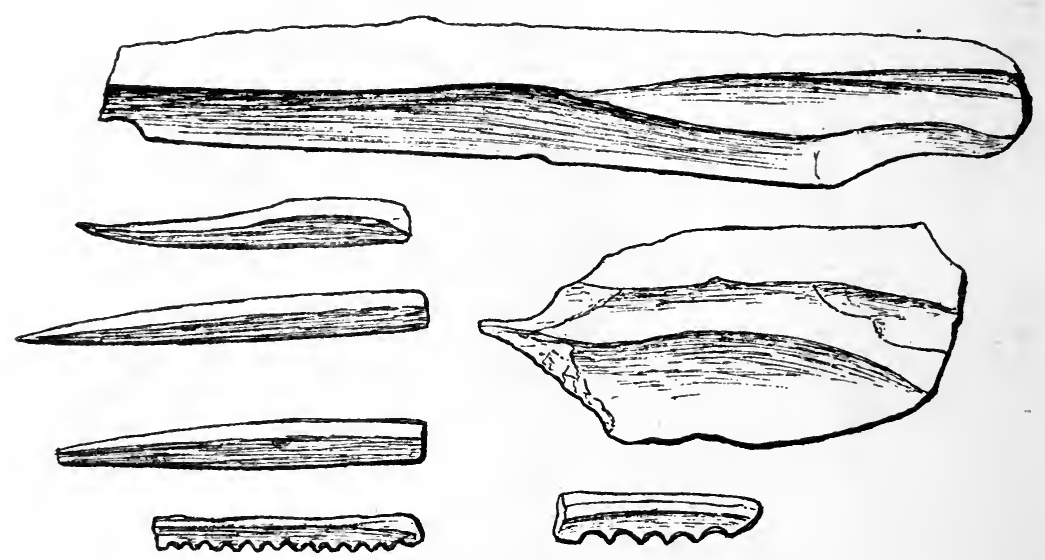

Fig. 103. Magdalenian flake tools.

and the conditions of the tundra once more give place to those of the steppes.

\section{(4) Implements}

The Magdalenian flint-workers had great skill in the art of detaching long ribbon-like flakes from the nodule with a single blow; some of these are as much as 20 to 25 centimètres long. They are frequently curved, so that the inner surface of the flake is concave. But on the whole the flint-workers of this stage cannot compare with their Solutrean predecessors. The majority of Magdalenian tools are simple flakes, struck from the nodule, and adapted as knives or scrapers with a minimum of secondary chipping. These flakes are sometimes wrought to a fine point, in which case they are to be considered as prickers or borers; sometimes the edge is denticulated, making a saw. 

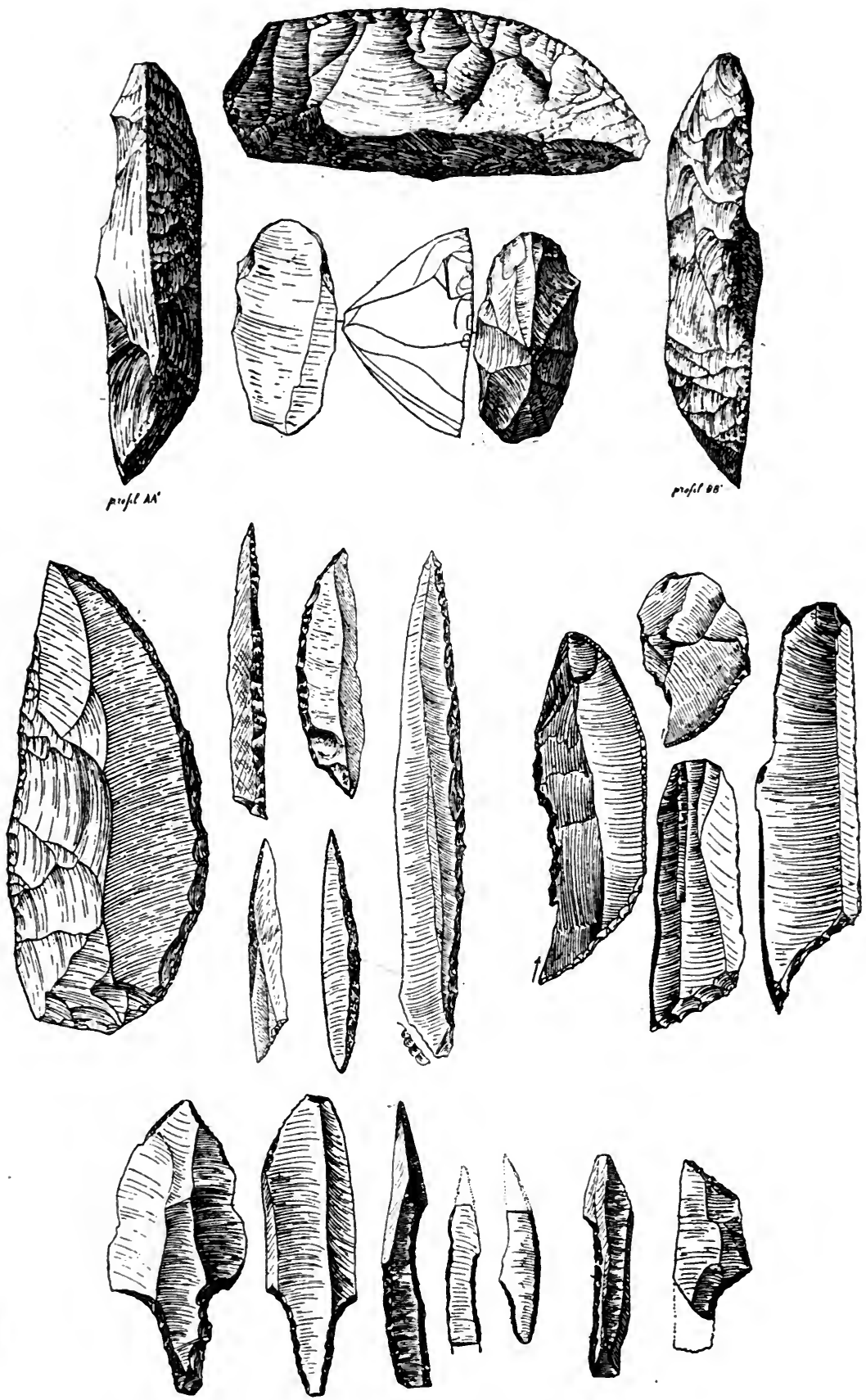

Fig. 104. Aurignacian types from late Magdalenian deposits. (Drawn by M. l'Abbé Breuil; from C.A.P.A. Geneva, vol. I.) 
The absence of secondary chipping has been indicated as a leading characteristic of Magdalenian scrapers by MM. Bourlon and Bouyssonie $^{1}$. Otherwise the Magdalenian forms resemble on the whole those of preceding stages of the Upper Palaeolithic Term. They are flakes, with convex, concave, rectilinear, or oblique ends, but without secondary chipping. There is an ogival form found in Aurignacian and Solutrean deposits which does not appear in Magdalenian sites. The Aurignacian keel-shaped scraper reappears as a plane (rabot) towards the end of the Magdalenian stage. There are also found throughout the Upper Palaeolithic deposits what are called core-like scrapers (grattoirs nucleiformes) which are simply accidental products of flint-chipping adapted for scraping purposes by a little trimming of the edge. Such instruments de fortune scarcely call for classification. Cores are frequently found in Magdalenian sites; they often display abrasions indicating that they have been used as hammers.

This recrudescence of the carinate scraper towards the end of the Magdalenian stage is only one example of a remarkable fact to which Breuil has drawn attention ${ }^{2}$, and which must be an indication of some historical fact at which we can as yet only guess. This is a general reappearance of Aurignacian forms towards the end of the Magdalenian stage. In late deposits of this stage not only carinate scrapers, but also Gravette points and tanged flakes make their appearance; and the curved engraver also comes to light with its curved point exaggerated into a parrot-beak.

Of greater interest and variety is the Magdalenian industry in bone, horn, and ivory, which adds a number of forms not met with in older depósits.

Assegais. These are sharp slender rods of bone or of ivory, with conical points, and adapted for fitting into a wooden shaft (Fig. 105). They may be rounded at the butt, pointed for fitting into a hole in the shaft; turnscrew-shaped, for fitting into a slit; or forked, to allow the uncut end of the butt being inserted into the bone. The surface of the butt is often roughened, by means of grooves, to increase the friction and to prevent the point from slipping off the shaft.

Darts. An object from Le Mas d'Azil looks more like a bone arrow- or dart-head than anything else ${ }^{3}$. A similar object was found at

${ }^{1}$ M. Bourlon and A. and J. Bouyssonie, "Grattoirs carénés, rabots, et grattoirs nucléiformes; essai de classification des grattoirs" (Revue anthropologique, xxII. [1912]).

${ }_{2}$ G.A.P.A. Geneva [1912], vol. I. p. 214 ff. See also L'Anthr. xx. [1909], p. 523 .

3 Figured L'Anthr. xIv. [1903], p. I90, fig. 6. 
Bruniquel $^{1}$. It is not absolutely certain that Magdalenian man as a whole possessed bows and arrows: the evidence of the Alpera rock paintings on this subject is inconclusive, as we shall see later. It is therefore better, for the present at least, to call these objects by the non-committal name "dart-heads."

Harpoons. These are barbed assegais, generally of reindeer-horn, more rarely of bone. The section of the shaft is cylindrical. The

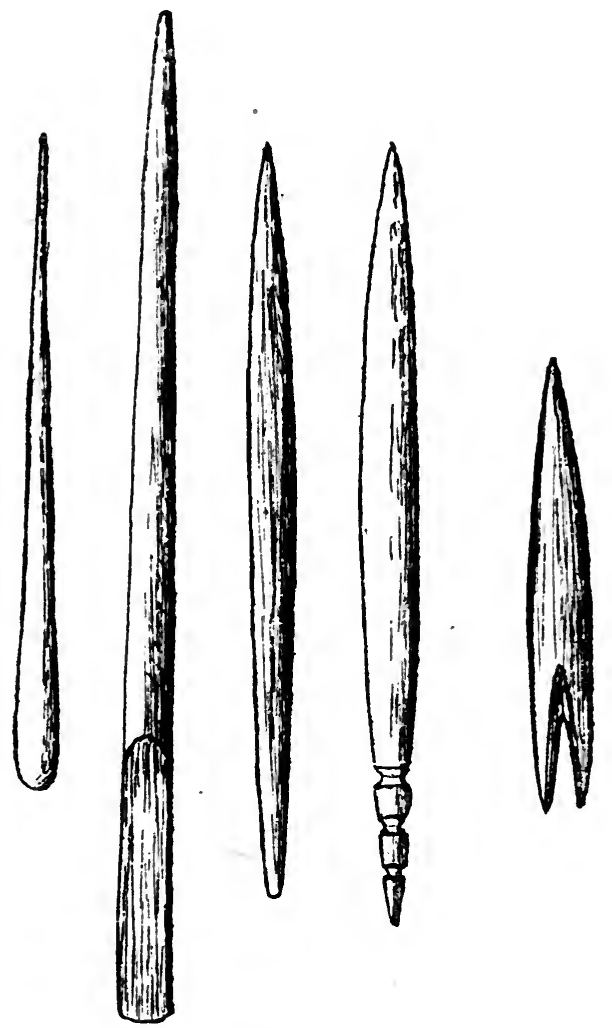

Fig. 105. Magdalenian assegais.

evolution of the harpoon has been studied by Breuil ${ }^{2}$. It begins in the earlier phases of the Magdalenian with a bone or reindeer-horn rod like an assegai or a polisher, having slight denticulation along one or both edges. After the middle of the Magdalenian stage, the one-sided harpoon develops, with one row of barbs; later still, there appears the double barbed harpoon. The number and shape of the

1 See E. Cartailhac, "Les stations de Bruniquel sur les bords de l'Aveyron" (L'Anthr. xIv. [1903], esp. p. 303).

${ }^{2}$ C.A.P.A. Geneva [1912], vol. 1. p. $210 \mathrm{ff}$. 
barbs are very variable, as also is their length, some being not more than 4 centimètres long, others as much as 40 . Near the butt is a collar or projection, sometimes a perforation-either for a thong securing the head of the harpoon in the shaft, or more probably for a cord which the owner held, thus keeping control over the weapon after he had cast it. It is not unlikely that these weapons were used for fish-spearing.

G. de Mortillet $^{1}$ propounded a theory that the wavy grooves with which the barbs of these harpoons are often decorated were intended for the reception of some poison ${ }^{2}$; and he gives an interesting list of
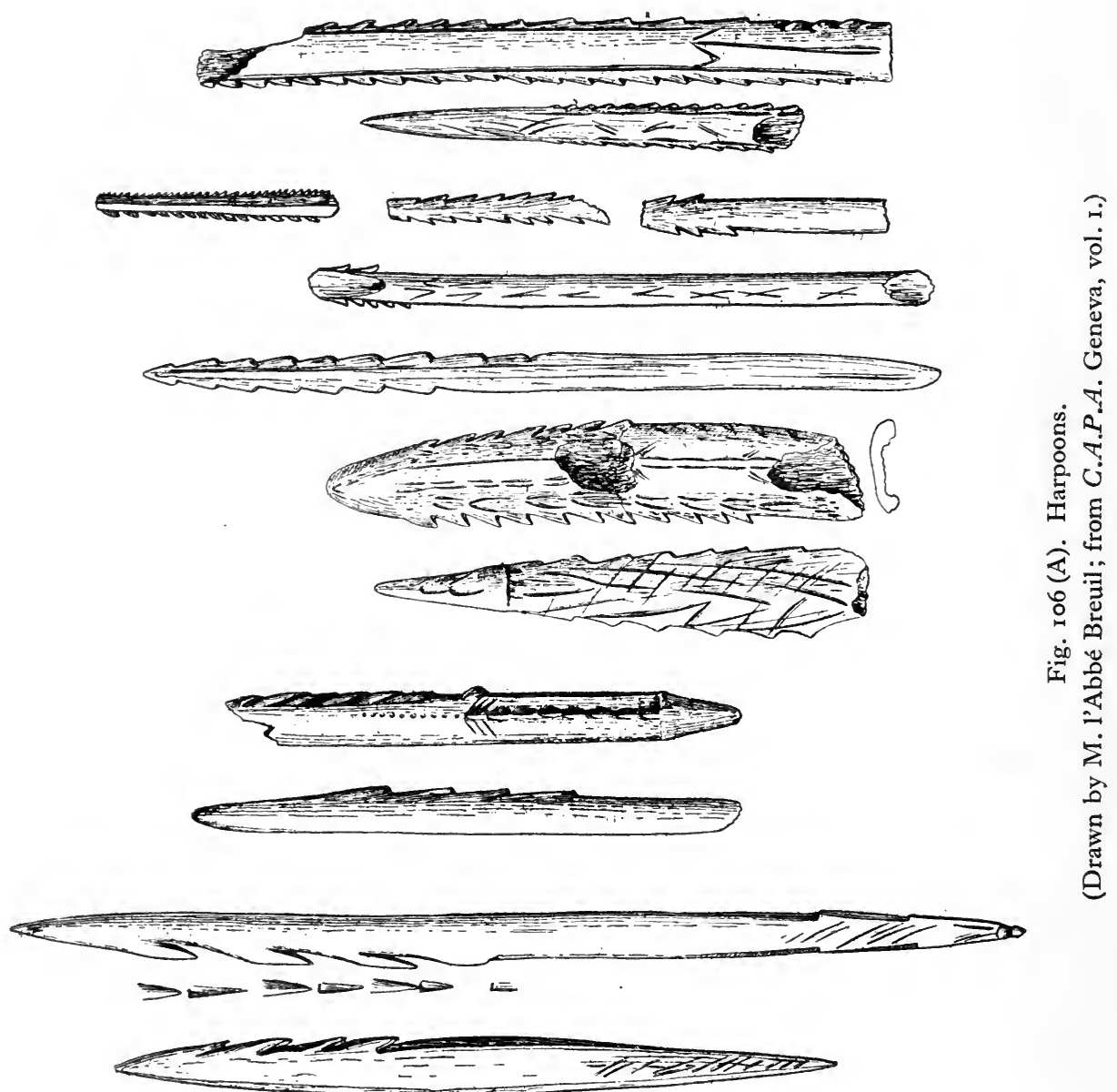

1 "Empoisonnement des armes" (R.E.A. r. [1891], p. 97).

2 In this theory he was anticipated by Lartet and Christy (Rel. Aquit. p. 70). 

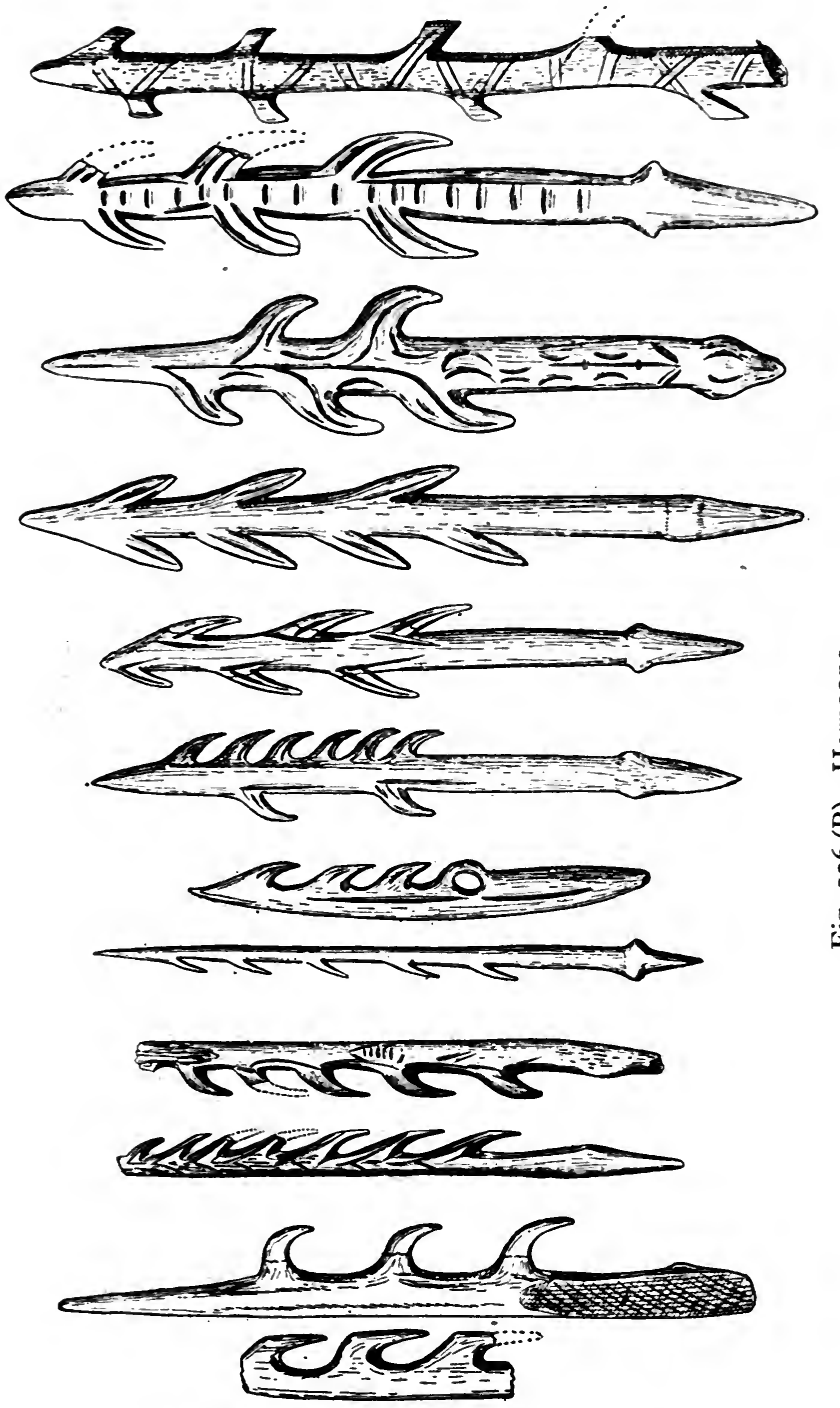

animal and vegetable poisons with which Magdalenian man might have been acquainted, and of which he might thus have made use. The grounds on which the theory is based amount to these, that the 
wavy lines as they stand are of little decorative value, are difficult to execute, and would not have been made at all except for some very special purpose; also that they are "too uniform in an industry whose leading character is variety and unexpectedness." There is no sentimental objection to supposing that Madgalenian man poisoned his weapons-it is certainly the sort of thing he would have done, had he thought of it - but this possibility is quite independent of the grooves on the harpoons. In the first place, it is hardly fair to deny
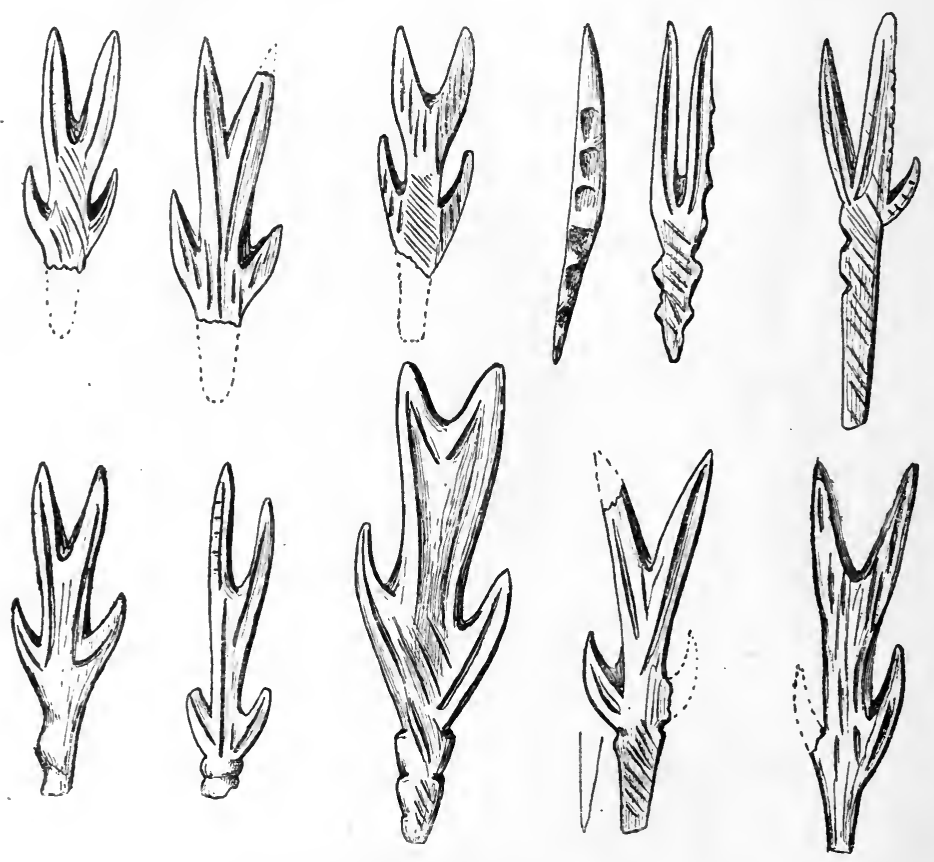

Fig. 107. Supposed fishing instruments.

(Drawn by M. l'Abbé Breuil; from L'Anthropologie, vol. xIx.)

an ornamental character to these. In the second, they would not increase the poison-bearing power of the weapon-a harpoon dipped in poison would be just as effective without the grooves as with them. In the third place, some of the ornamental grooves extend to the butt of the weapon, where they would have been outside the wound.

Akin to harpoons is a series of small instruments with double or triple points directed towards the upper end of the object, not, as in harpoons, toward the butt. These have been found at Bruniquel 
and some other sites ${ }^{1}$. It has been ingeniously suggested by M. l'Abbé Breuil, who has described them, that they were formed in the likeness of fishes, with the intention of calling in the aid of magic to securing the prey, or else of deceiving the fish by offering an artificial fish-like bait. The specimens here figured might also be interpreted as amulets in human form (as will be seen by inverting the page): but the existence of other specimens with trifid or even multiple points rules out this explanation.

"Bâtons de commandement." I retain this highly unsatisfactory term for want of a better. The objects so designated are the most puzzling of all the instruments bequeathed to us by Upper Palaeolithic man. They begin to appear in the Aurignacian stage, but are there rudely fashioned and usually without ornament. The Magdalenian examples are highly finished and are among the most elaborately decorated of Palaeolithic objects.

They are usually sections of reindeer-horn, cut from the stem at the root of one of the antlers, where a hole is perforated. Often one or more holes are added to this. The surface is almost always more or less elaborately ornamented with engraving. It is noteworthy that the perforation of the holes has generally been the last operation in the manufacture of the instrument, for very frequently it mutilates some of the decoration, which must therefore have been previously applied.

There is a wide range of theories, all equally unconvincing, to account for these objects. The current name is based upon an idea that they may have been sceptres or symbols of authority. This assumes a far greater knowledge of the organization of the Magdalenian communities than we possess. The very frequency of the instruments - for they appear in almost every Magdalenian caveis against a theory which would necessarily presuppose a limited number in use. Some have gone so far as to suppose that the number of the holes drilled through the "sceptre" varied with and indicated the rank of the man who wielded it. This is the sort of theory that makes us wish we could call a few Magdalenian men back to life, and watch their faces when they were told of it.

Another theory is that they were dress-fasteners ${ }^{2}$, for which they would surely have been too clumsy. The ingenious plate accompanying the paper cited in the footnote fails to inspire confidence.

It has also been suggested that they were used along with certain

1 M. l'Abbé Breuil, "Petits instruments magdaléniens à pointe bifide ou tridentée de Bruniquel et quelques autres gisements" (L'Anthr. xIx. [1908], 183). See also C.A.P.A. Geneva [1912], 1. pp. 212-214.

2 O. Schoetensack, "A quoi servaient les 'bâtons de commandement?"' (L'Anthr. XII. [1901], 140; C.A.P.A. Paris [1900], p. 123). 
forms of flints in the manufacture of baskets ${ }^{1}$. The author of this suggestion has illustrated many objects of similar appearance, used by various nature-folk for bending stiff twigs in the process of

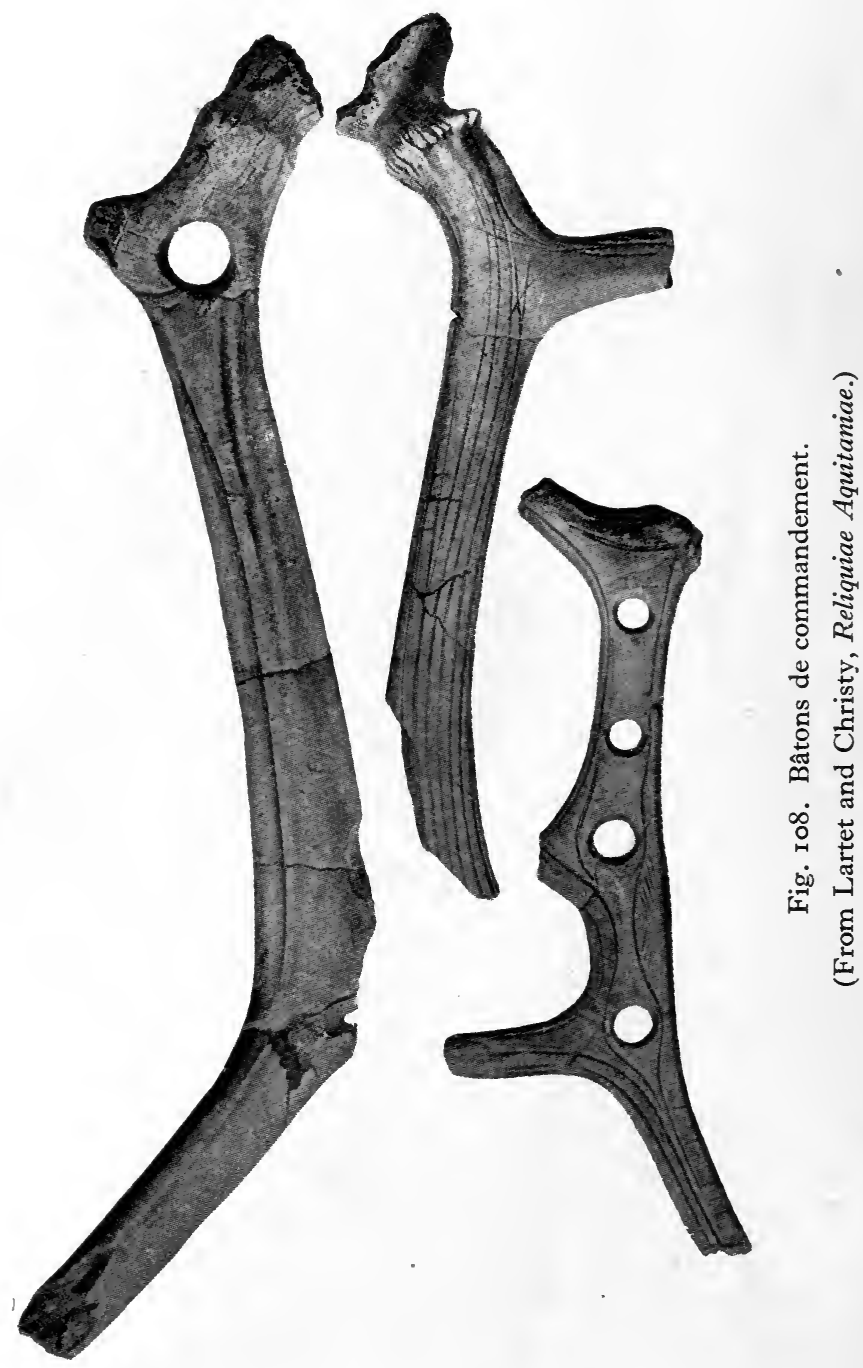

weaving basket-work. The suggestion is not without plausibility, but it hardly accounts for the elaborate decoration with figures of animals, etc., which the bâtons de commandement as a rule display.

${ }^{1}$ L. Pfeiffer, "Beitrag zur Kenntnis der steinzeitlichen Korbflechterei" (Z.f.E. XLII. [1910], p. 369). 
Again, they have been compared to a rod which the Laplanders are described as using for guiding reindeer harnessed to their sledges. The animal was controlled by a single rein which was tied to the end of the rod. The author of this suggestion ${ }^{1}$ has himself anticipated the most serious objection that can be urged against it, namely that it assumes the domestication of the reindeer in Palaeolithic times.

The same objection applies to the theory that they were the cheek-pieces of horse-bits ${ }^{2}$. There is no satisfactory proof of the domestication of the horse in Palaeolithic times. The evidence supposed to be yielded by teeth bearing lesions explained as due to the malady of crib-biting has been at least questioned by expert veterinary opinion $^{3}$.

Another and more promising suggestion is that they were shaftstraighteners. Very similar tools are used by the modern Eskimo for this purpose-the shaft being wetted, and then bound tightly to the straightener and left to dry and set. This would perhaps account for the frequency with which they are decorated with figures of animals - the shaft being pressed against the engraving in the process of being straightened, might have been supposed to absorb, so to speak, an affinity with the animal intended for the hunter's prey, and so might be the more ready to hit the mark when it came to be used.

They have also been called maces or clubs, for which they would assuredly be too weak, even without the hole or holes regularly drilled through them; still more so with the holes.

Another plausible theory is that they were instruments of sorcery ${ }^{4}$. But here again, we know far too little about Magdalenian life to criticise the theory favourably or adversely.

An apparently similar object was found in a Neolithic grave at the Rinnehügel in Livonia. It was supposed by Schoetensack, who described it, to be a fibula or dress-fastener-that being, as we have seen, his theory of the Palaeolithic specimens. It is clear, however, that this specimen is broken at both ends, and any explanation of its use must take account of its lost continuation ${ }^{5}$. In any case, this discovery of an example in a Neolithic site is unique.

1 A. Aymer, "Nouvelle hypothèse sur l'usage des bâtons de commandement" (A.F.A.S. Clermont-Ferrand [1908], p. 743).

"A. L. des Ormeaux, "Note sur l'usage des bâtons de bois de renne chez les populations primitives de l'Europe" (Revue d'ethnographie, vir. [1889], p. 39).

3 See the discussion, C.P.F. Nîmes [1911] pp. 73-77.

- S. Reinach, " $L$ 'art et la magie, à propos des peintures et des gravures de l'âge du renne" (L'Anthr. XIv. [1903], p. 257 ff. esp. pp. 264-5).

5 O. Schoetensack, "Ueber einen neolithischen Knochen-Schmuck vom Rinnehügel am Burtneck-See (Livland), der eine überraschende Aehnlichkeit hat mit dem durchlochten Zierstabe (Fibula palaeolithica) der Magdalénienne-Epoche" (Z.f.E. Xxxv. [1903], p. 378). 
Favelin-propulsors. These are bars of bone or of horn, with a hook at the end (Fig. I09). A javelin-shaft is held with the butt resting in the hook, and then by releasing the javelin and at the same time rapidly turning the shaft through a quarter of a circle, the missile is shot forward with additional force imparted to it by the extra leverage thus obtained. This instrument may be called the first machine of which we have any remains invented by man: it is still used by peoples so far removed from one another as the Australians, the Eskimo, and the South American Indians ${ }^{1}$. The Palaeolithic specimens are frequently decorated with sculptured figures of animals, perhaps for a magical purpose such as that which we have suggested in the "bâtons de commandement," viewed as a shaft-straightener. The javelin-shaft was pressed against the picture of the animal which it was desired to slay.

The companion machine to the propulsor is the boomerang. Two curved objects of bone figured by Girod and Massénat have been

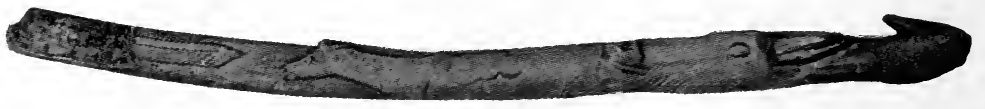

Fig. 'ro9. Javelin propulsor.

(From Lartet and Christy, Reliquiae Aquitaniae.)

supposed by Schoetensack ${ }^{2}$ to be boomerangs, who also refers to a bone object from La Madeleine figured by Lartet and Christy (Rel. Aquit. Plate B, Ix. 3) as bearing ornamentation which recalls the outline of a boomerang. The objects published by Girod and Massénat are however very small, and could only have been miniature models of boomerangs, made for some inexplicable purpose; and the wavy ornament on the La Madeleine bone might just as well be a rather conventionalised representation of a series of fishes. The evidence for the use of the boomerang in Upper Palaeolithic Europe is thus completely insecure.

Needles with pierced eyes first certainly appear in late Solutrean deposits, but again are commonest in the Magdalenian caves: there are some Aurignacian perforated rods of bone, but they are perhaps not needles. The Magdalenian needles are splinters of bone trimmed

1 See Pitt-Rivers, Evolution of Culture (Oxford, 1906), p. 132; Adrien de Mortillet, "Les propulseurs à crochet, modernes et préhistoriques" (R.E.A. I. [1891], p. 24I); Max Uhle, "Ueber die Wurfhölzer der Indianer Amerikas" (M.A.G.W. XvI1. [1887], p. I07); Otis T. Mason, "Throwing Sticks in the National Museum" (Smithsonian Report [1884], part 2, p. 279).

${ }^{2}$ Z.f.E. [I $\left.90 \mathrm{I}\right]$, p. I3I. 
to shape with notched scrapers (or perhaps between the fine teeth of the flint saws) and finished off by being polished on sandstone whetstones. A perforation is drilled though the butt with a fine-pointed flake of flint. The excellence of the finish of these needles is beyond all praise. The accompanying illustration (Fig. I IO) represents a group of objects from Bruniquel (Tarn-et-Garonne) now in the British Museum. No. 3 in the series is a piece of bone, from which a slip intended for working into a needle would be detached. No. 5 is a flake with saw-like teeth, which would be used to plane the shaft
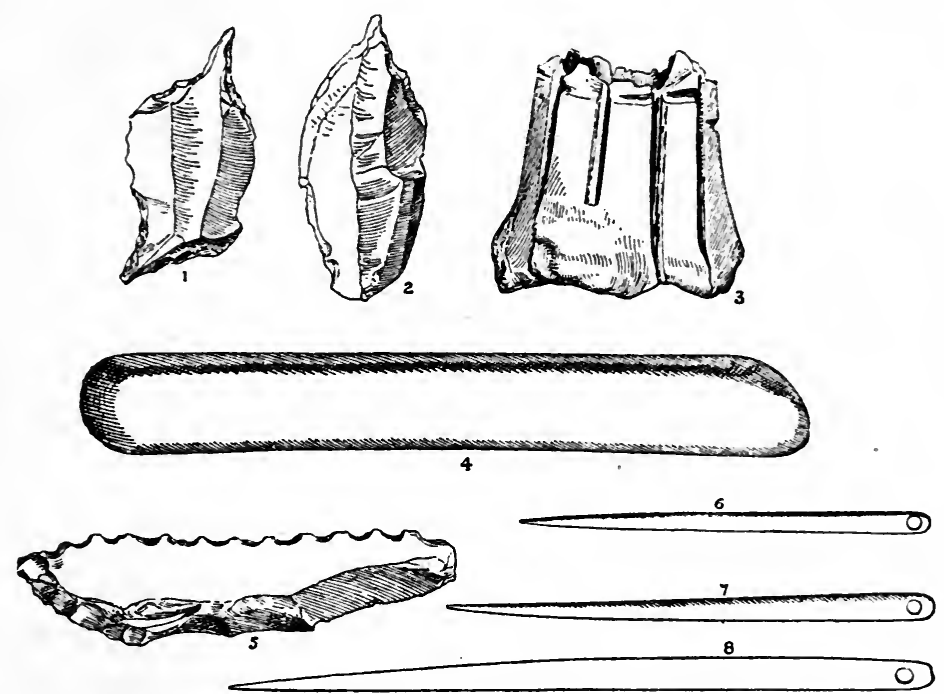

9

Fig. I 10. Needles and instruments for their manufacture.

(From British Museum Stone Age Guide.)

into a cylindrical form. No. 4 is a polisher of sandstone, on which the needle would be burnished and pointed. Nos. I, 2 are prickers of flint for perforating the eyes of the needles, and Nos. 6-9 are different types of the finished product. It should however be remarked that the manufacture of needles is not the sole purpose of these serrated flints, which are frequent in the rock-shelters of Bruniquel. Cartailhac has shewn that they are found in places where needles are absent, and vice versa; moreover it is obvious, as he points out, that if making needles had been the sole purpose of the flint saws, it would not have been necessary to notch the edge along 
its whole length. Doubtless their use for rubbing needles into shape was only an incident in their career of general utility ${ }^{1}$.

These needles would have been used for sewing hides together, not only for making garments, but also for making vessels for holding water and other liquids. In the absence of pottery, fluids had to be carried in bags of gut or of skin, as is still done in the East. In sewing, a flint piercer was probably used for drilling the hole in the hide, as the delicate needles would hardly have been strong enough to pierce it without snapping across.

Poignards. This name has been given to a supposed type of

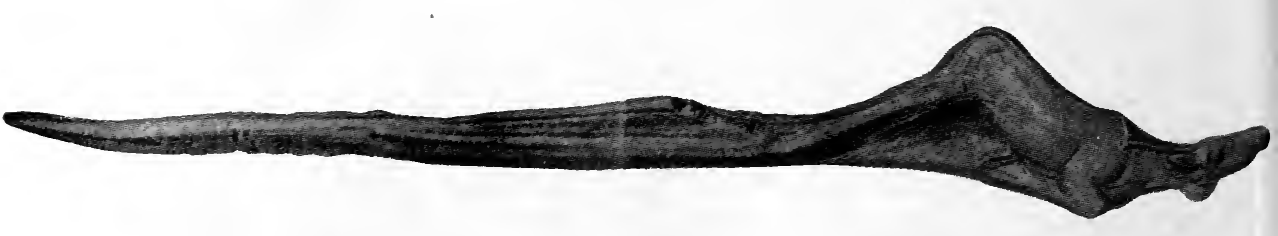

Fig. II I. Supposed poignard from Laugerie Basse.

(From Lartet and Christy, Reliquiae Aquitaniae.) i

object, represented by one perfect specimen and by a number of broken ones. The ascription is, however, certainly wrong.

The perfect specimen comes from Laugerie Basse (Fig. II I). It is in the form of an apparent blade of reindeer horn, with a sculptured figure of an animal forming a handle at one end. The broken specimens are similar animals, with the stump of a projection supposed to be the remains of a blade which has snapped off.

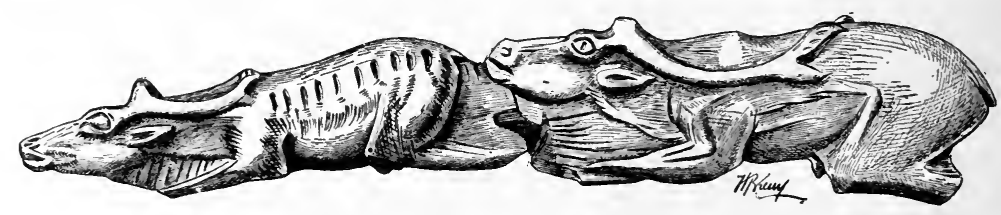

Fig. I12. Sculpture of two reindeer, wrongly supposed to have been two dagger-handles-from Bruniquel.

(Drawing by M. l'Abbé Breuil; from L'Anthropologie, vol. xvi.)

Quite apart from the obvious criticism that these delicate rods of horn would not be strong enough for the purpose suggested, but would break so soon as an attempt was made to use them as stiletti, M. l'Abbé Breuil has demonstrated that the explanation is inadmissible in the case of the two best-known of the fragmentary specimens-two from Bruniquel, now in the British Museum, in

1 See E. Cartailhac's excellent article, "Les stations de Bruniquel sur les bords de l'Aveyron" (L'Anthr. XIv. [1903], pp. I 28 ff. 295 ff. esp. pp. I33-r 35). 
which the stump of the "dagger blade" issues from the front of one of the animals, and from the hinder end of the other. In point of fact he has shewn that the fractures fit together, so that the two figures formed part of one sculpture, representing a male reindeer following its female (Fig. II2). There can therefore be no question of a dagger blade in this case. Also from Bruniquel is a figure of an elephant, with the trunk and the four legs brought curiously together (like a performing elephant balancing itself on an up-ended barrel). A more uncomfortable poignard-handle could scarcely be imagined, but the object has been restored as a poignard on the analogy of the Laugerie Basse specimen ${ }^{1}$. The little crooked tail on the back of the elephant shews that the figure so far from being the handle of anything, is really the head of a javelin propulsor: the tail forming the hook.

We are left therefore with the Laugerie Basse example. It will be seen that the animal figure at the end is curiously distorted. Lartet and Christy, who first published the object ${ }^{2}$, and after them G. de Mortillet ${ }^{3}$, comment upon the ingenuity of the adaptation of the animal figure to the hand. This comment has been copied from book to book, but I am not altogether sure that it is justified. Experiment with a cast in my possession, of the object, has convinced me that it is not comfortably adapted to the hand; at least, if it is to be explained thus it must be meant to fit a hand much smaller than mine. The upturned head of the animal presses awkwardly against the outer edge of the hand, so that only the middle, ring, and little fingers can find room upon the handle at all; and the blade is set at such an angle to the handle that when the object is thus grasped, it is impossible to give what would be an effective thrust with it, even supposing that the "blade" was strong enough to stand the strain of such a thrust. The peculiar attitude of the animal is simply to be explained as due to the shape of the "boss" of horn which the engraver had to work upon. Breuil, who first expressed doubt as to the object having been a poignard, supposes that it is unfinished, the apparent blade having been prepared for artistic treatment which was never completed. The cast shews (what G. de Mortillet seems to have missed, though it is indicated in Lartet and Christy's plate) that there is the beginning of a (phyllomorphic?) decoration near the point-a series of dots in two rows, suggestive of the leaves of a branch. This, so far as it goes, corroborates l'Abbé Breuil's con-

1 See for example E. A. Parkyn, Prehistoric Art [London, 1915], p. 28.

${ }^{2}$ Reliquiae Aquitaniae, plate B, XIx. 5, p. 447.

3 Préhist. part II, sect. I. chap. vi. 
clusions; and we may once for all remove "horn poignards" from the list of Palaeolithic objects ${ }^{1}$.

Drinking-cups. An interesting class of object is the group of drinking-cups, fashioned from the upper part of the vault of human skulls, found in the cave of Placard (Charente) ${ }^{2}$. In this cave there were three beds of Magdalenian, two of Solutrean, and one of Mousterian deposits, separated by sterile layers. There were several
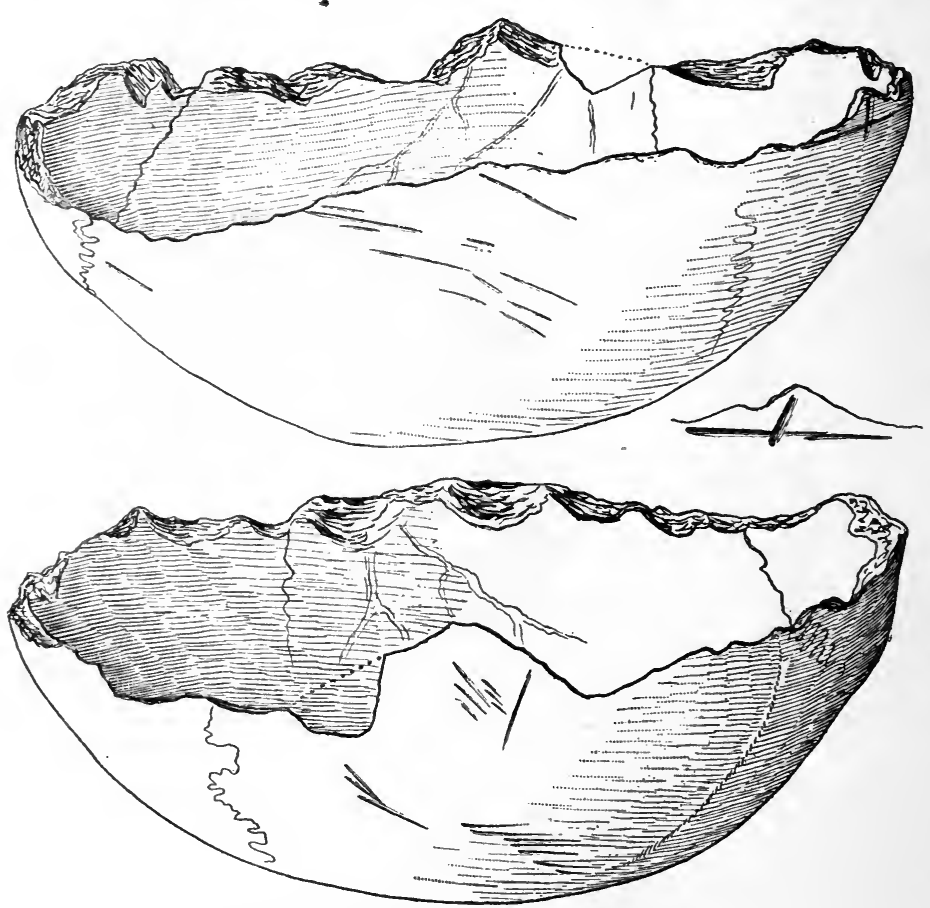

Fig. II3. Human skull made into a cup.

(The small figure in the middle shews the grooves made for trimming off a projecting angle.)

(Drawing by M. l'Abbé Breuil; from L'Anthropologie, vol. xx.)

fragments of skulls-two in the second Magdalenian, five in the first (lowest) Magdalenian, and two in the upper Solutrean layerson which there were scratches that seemed to indicate that the flesh had been scraped away; the base of the skull was then broken off, and the edges of the fracture made level (Fig. II3). The example here figured is the best of the series; the others are not quite so

1 See l'Abbé H. Breuil, "Prétendus manches de poignard sculptés de l'âge du renne" (L'Anthr. xvi. [1905], 629).

${ }^{2}$ Breuil and Obermaier, "Crânes paléolithiques façonnés en coupes" (L'Anthr. $\mathrm{xx}$. [1909], p. 523). 
convincing, in that (to judge by the excellent illustrations) they have suffered further fractures-due probably to subsequent injurywhich would diminish their power to hold liquid.

Among the minor objects of Magdalenian industry in bone may be mentioned polishers (pieces of ribs or other flat bones with one end slightly bevelled) and rods (baguettes) the purpose of which is not very obvious. These may be either circular or semicircular in section: a discovery, made at Isturitz, of a pair of semicircular examples placed face to face so as to form one circular rod, suggests that this was always the case, and that when such a rod was required of greater thickness than the available material permitted, it was made in two halves ${ }^{1}$. Occasionally other objects are found which seem to have

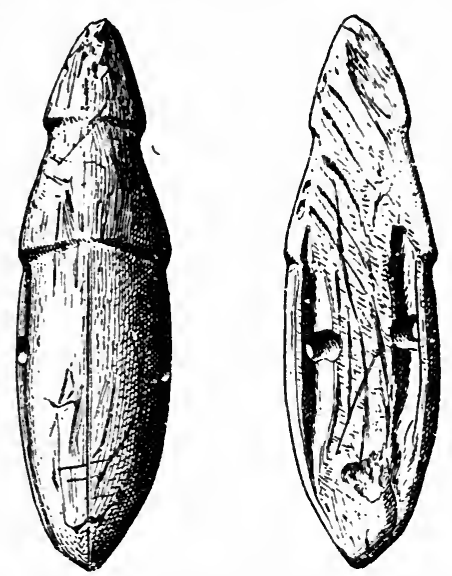

Fig. I 14. Wooden figure of a beetle, Arcy-sur-Cure.

(From Revue de l'École d'Anthropologie, vol. viI.)

been fashioned for other purposes, such as spoons or knives. But the types of instruments enumerated above include all those normally found in Magdalenian settlements.

If Magdalenian Man could work so well in bone and in horn, we cannot doubt that he had some skill in -carpentry. But wood is perishable, and practically no relics of his activities in this direction have survived. What is probably the only wooden object that has come down to us from Magdalenian times is the figure of a beetle ${ }^{2}$,

1 B.S.P.F. xIII. [1916], p. 301 .

2 This object was doubtless worn as an amulet. In Mannus, vol. vi. [1914], p. 32 , is a representation of what appears to be a figure of a ladybird beetle from Laugerie Basse (which the accompanying letterpress, with an excess of enthusiasm, describes as ausserordentlich realistisch), also intended for suspension. The material is not stated, and the author refers us to G. and A. de Mortillet, Musée préhistorique, pl. xxvii. fig. 239. I cannot find the figure either at the place indicated or elsewhere in my copy of the work quoted, which is of the first edition; presumably that used by the writer in Mannus is the second. 
found in one of the caves at Arcy-sur-Cure (Yonne), called Grotte du Trilobite (Fig. II4). A neighbouring cave, la Grotte des Fées, contained deposits of all stages from Chellean to Bronze Age; but the Grotte du Trilobite had been occupied only during the Solutrean (slightly) and Magdalenian stages. The wooden beetle was made of the wood of a conifer, and was $6 \mathrm{~cm}$. long. A hole was bored through it for suspension.

It has long been a problem to explain how Palaeolithic man was able to execute his works of art in the inmost recesses of complicated caverns, where the darkness is complete. Some have suggested that by an ingenious system of mirrors he shed the light of day upon his work $^{1}$; but those who indulge in such speculations do not tell us what material, of which to make a mirror of sufficient reflecting power, was at his disposal. We must, in any case, postulate a magnificent endowment of eyesight, and then must be content with supposing that he had some artificial illumination. Small stone cups, nodules of stone with a hollow rubbed in one side, are not uncommon in the caves. Some at least of these were lamps. One ${ }^{2}$, found in the cave of La Mouthe, had traces of ashes, which on chemical analysis proved to be "similar to the ashes produced by the burning of animal fat, such as tallow or lard, badly separated from its membraneous covering ${ }^{3}$." Similar cups may have been used for other purposes; for instance, some of them may have been used as anvils, i.e. the stones on which flint nodules were rested while being flaked; others may have been palettes or mortars for grinding the paints used by the Magdalenian artists.

It will naturally be asked, how no trace of smoke-blackening appears on the cave walls, though the delicate painting has survived. The answer is that the oxygen of the atmosphere has oxidised the carbon stains, and thus gradually, so to speak, eaten them away.

\section{Palaeolithic Pottery}

Attempts have been made to credit the Palaeolithic men of the Magdalenian stage, and even earlier, with a knowledge of the art of pottery-making. Certain supposed fragments found in the cave of Engis in Belgium are thus described": "The paste is a mixture of clay and sand, kneaded together; the two substances are identical with the clay and sand to be found in the various fissures of the second cave of Engis. The fragments are reddish outside, greyish

1 See for instance B.S.P.F. III. [1906], p. $208 \mathrm{ff}$.

2 Published by M. E. Rivière in B.S.A.P. ser. IV. vol. x. [1899], p. 558.

3 Berthelot, "Sur une lampe préhistorique trouvée dans la grotte de La Mouthe" (C.-R. Acad. des Sciences, cxxxill. [1901], p. 666).

1 Ernest Doudou, "Étude sur les cavernes d'Engis"' (L'Anthr. x. [1899], p. 522). 
inside, and in part become reduced to dust under the least pressure of the finger. They dissolve in water through and through, by reason of their imperfect baking." One vessel was found in whose clay "we could easily distinguish small flakes of flint similar to those which fill the archaeological and geological breccias of the neighbouring stations; from which we infer that the potters were the same as, or at least contemporary with, those who chipped the Mousterian flints of the caves of Engis." To this we can answer only, non sequitur. It is not easy to judge without having seen the fragments thus described, but the account as it stands would equally well describe accidentally formed concretions of clay such as are not infrequently to be found in the earth filling damp caverns. The writer quoted forgets that pottery is one of the most permanent of all human manufactures. If well-baked from the first it will continue impervious to decay almost indefinitely -it may be broken, even pulverised, but will remain recognisable. If ill-baked, it will be no worse after a lapse of time than it was at the beginning. If the supposed vessels became reduced to mud pies through and through when wetted, as seems to have been the case, they would have behaved in the same way in Palaeolithic times, and would have been of but little use for holding liquids. The writer of the article quoted asks how aged and sick people, and children, could have been supplied with drink if the cave-dwellers had no pottery. The answer is very simple; drinking-cups of hide, or of wood, even on occasion large shells, would supply the need. M. Rutot ${ }^{1}$ has given a long list of Belgian caves which, according to him, have yielded Palaeolithic pottery. But notwithstanding the scorn which he casts upon those who would determine the date of pottery from the details indicated in sketches, I am bound to say that I find it extremely difficult to believe that some of the sherds which he figures are older than the Roman period, while admitting that some few of them may be as old as the Neolithic. Certainly these Belgian discoveries can scarcely upset the conclusions to be legitimately drawn from the total absence of anything in the least suggestive of the use of pottery in the classical French caves. The same is true of a more recently published discovery in a dry valley at Ipswich, where the following succession of strata was found (the thicknesses are very variable):

$G$. Surface soil, $15 \mathrm{~cm}$.

$F$. Hill-wash, 2:40 mètres.

$E$. Bed with flints of Aurignacian type, $7 \cdot 5 \mathrm{~cm}$.

1 A. Rutot, "La poterie pendant l'époque troglodytique" (B.S.P.F. Iv. [1907], p. 523). See H. Muller's criticisms, ibid. v. [1908], p. I43, and Rutot's reply, ibid. p. 443 . See also a trenchant article by L'Abbé Parat, "Les grottes de la Cure et la poterie paléolithique" (A.F.A.S. Grenoble [1904], p. 1058). 
D. Loamy soil, unstratified, I mètre.

C. Peat, $23 \mathrm{~cm}$.

$B$. Bed with flints of Mousterian type, $10-15 \mathrm{~cm}$.

A. Sand.

In $G$ there were flint arrow-heads, probably of bronze-age date. The flints in $E$ resemble Aurignacian types, with carinate scrapers and end scrapers; while some of them might be regarded as tending towards Solutrean. The flints in $B$ contained Mousterian-like flints, rude points, side-scrapers, and coups-de-poing. But in $B$ there were a number of disconnected sherds (not whole vessels) of rude pottery, and there were also three human bones, belonging to as many individuals. These people, so far as the fragmentary condition of their remains permitted a judgment to be formed, were of modern type, and therefore not Mousterian; and of low stature, therefore not Aurignacian. Marks on some of them, explained as tooth-marks, once more revived the question of cannibalism; but man does not gnaw bones, neither will his teeth make such marks. The fauna was entirely holocene in character, excepting one bone, doubtfully identified as part of the tibia of a mammoth; and the flora, of which remains were to be found in the peat-bed $C$, was also exclusively of recent species, and indicated a modern climate, such as did not prevail during the Mousterian stage. The inference is inevitable that there is a faulty observation somewhere. It may be that the potsherds have in some way worked through the soft peat to the place where they were found. Or it may be that in spite of their Mousterian and Aurignacian facies, the flints are Neolithic. A button of coprolite, with a scratched ornament upon it-such as is not found in Mousterian strata-agrees with this; and the cautious judgment of the expert geologist whose opinion was invited is fully justified. He says "If one were to ask oneself the question as to whether one would be surprised if it were proved on other grounds that the floors were of Neolithic date, one must frankly confess the answer would be 'No ${ }^{1}$.'" The evidence for Palaeolithic pottery presented by this find is thus far too weak to bear any strain. Till Breuil, Obermaier, or some other of the eight or ten first-class excavators shall find a complete vessel (sound or broken), not mere disconnected sherds; in a Mousterian stratum, associated with Mousterian fauna and implements; where every possibility of a re-sortment of the soil is absolutely excluded; we must remain sceptical about the use of pottery by Palaeolithic people. If pottery was used in one site it would be used in many, if not in all; and the total absence of pottery from the numerous Upper Palaeolithic caves that have been carefully excavated is proof,

1 For an account of these discoveries see.7.A.I. XLvir. [1917], p. 367. 
so far as negative evidence can go, that it was unknown to the Upper Palaeolithic people. If so, it would a fortiori be unknown to their much less advanced predecessors.

We now proceed to give details regarding the Upper Palaeolithic in the different European regions.

\section{(5) The Upper Palaeolithic in the European Regions}

\section{Region III. Italy and Sicily}

In Italy the only Upper Palaeolithic stage represented is the Aurignacian; the Solutrean and Magdalenian are both absent. The Upper Palaeolithic art does not exist, and the industry is confined to poor flints and second-rate implements in bone and horn.

The fauna associated with the Italian Aurignacian is a steppe fauna, without Rangifer, Elephas primigenius, or Rhinoceros tichorhinus: the leading animals are Sus, Bos primigenius and Equus. The industry is on the whole of an early facies; the carinate scraper is uncommon, though an example has been reported from the cave of Pocala, near Trieste ${ }^{1}$, where also one of the wasp-waisted notched flakes has been found. Otherwise, however, Pocala has affinities with the transitional station of l'abri $\mathrm{Audi}^{2}$. The-engravers found in Italy are all of poor quality.

The other caves in this region which have yielded Aurignacian deposits add nothing special to our information. The industry in bone and horn is confined to prickers, polishers, and such simple instruments, with no ornament except occasional groups of straight lines.

Mochi has endeavoured to find a Magdalenian culture in the cave of Golino (Tuscany). It is probably late, and there is evident sign of the development of the microlithic industry which belongs to the end of the Upper Palaeolithic: but the bone industry so characteristic of the Magdalenian is absent, and some of the scrapers are distinctly Aurignacian in facies. There is an associated bed of small rodents: the date is therefore probably Magdalenian, that is, contemporary with the Magdalenian of the regions north of the Alps; but the Aurignacian limitations and reminiscences have persisted, just as we saw that the Chellean reminiscences persisted into the Mousterian horizon. The Palaeolithic men of Italy were in all stages less progressive than were their brethren further north.

1 Mochi, op. laud. ante, p. 242.

2 Mochi, in Archivio per l'anthrop. e la etnol. XL1. [I91 I], p. 3. 


\section{Region V. Southern France and Liguria}

Merely to enumerate the Upper Palaeolithic sites in this region would be an endless task, and for us in this place superfluous. Within our limits we cannot undertake to do more than to give a bird's-eye view of the distribution of the different Palaeolithic stages in Europe. We shall merely mention with a few occasionall words of description, the stations which are most instructive, on account of their stratification or their contents.

Of Lower Aurignacian sites we have already spoken of l'abri Audi. With it we may count La Grotte du Pape, Brassempouy (Landes); this site has acquired especial renown on account of the Aurignacian statuettes which it has yielded, to be more particularly described in the following chapter. It is a gallery about I I mètres in length, with subsidiary ramifications. The stratification of the deposits upon the floor is as follows:

$H$. Vegetable soil at and just within the entrance, ro $\mathrm{cm}$. deep.

$G$. Yellow loam, 2-2.5 mètres deep.

$F$. Yellowish earth, $\mathrm{I} \cdot 60$ mètre deep, full of limestone fragments. In upper part of the stratum pointes $\dot{a}$ cran, in the lower part laurel-leaf Solutrean javelin-heads. All through mammoth, Rhinoceros tichorhinus, horse, reindeer, stag, hyaena.

$E, D, C$. Three strata of yellow clay, mingled with some limestone fragments, to a total depth of $\mathrm{I}-2$ mètres. Bones of the same animals as in $F$, with in addition bison, wolf, fox, badger, hare, rat, and some birds; the reindeer rare, especially in the lower levels. The flints are Mousterian and Aurignacian; ivory prickers and the split-base point. In the upper levels canine teeth of stag and fox, perforated. Throughout the three layers, hearths of ashes, one of them (in stratum $E$ ) surrounded with a ring of stones. The statuettes were found in stratum $D$.

$B$. Impermeable yellowish or bluish clay, $25 \mathrm{~cm}$. thick.

$A$. Layer of stones $30 \mathrm{~cm}$. thick ${ }^{1}$.

Two other Lower Aurignacian stations we may pass over with a bare mention-La Ferrassie and Le Pont-Neuf. To these we have already alluded in connexion with bones there discovered.

Of the Middle Aurignacian, Cro-Magnon, La Ferrassie, Tarté (from which station a variety of the carinate scraper, with the flat base of rounded outline, is sometimes named the "Tarté scraper"), Aurignac, Les Cottés, may be enumerated. Reference to the authorities cited below ${ }^{2}$ will give the reader information as to the

1 Edouard Piette, "La station de Brassempouy et les statuettes humaines de la période glyptique" (L'Anthr. vi. [I 895], p. I29); Idem, "Fouilles à Brassempouy" (ibid. viII. [1897], p. I65; Ix. [1898], p. 531); Idem, and J. de Laporterie, "Les fouilles de Brassempouy en I 894" (B.S.A.P. ser. 1v. vol. v. p. 633).

2 Breuil, "La question aurignacienne" (Revue préhistorique, 1907); "L'aurignacien pré-solutréenne" (ibid. 1909); Bardon and Bouyssonie, "Station pré- 
discoveries made at these sites: we must be content here with a bare enumeration.

Important Upper Aurignacian sites are La Gravette and La FontRobert ${ }^{1}$.

For stratigraphical purposes few stations are more valuable than Le Ruth, well excavated by Peyrony ${ }^{2}$. Its stratification shews a transition from Upper Aurignacian to Solutrean, and from Solutrean to Magdalenian:

$K$. Fallen rubbish and vegetable earth.

F. Early Magdalenian; ordinary end-scrapers, various forms of engravers, flakes, assegai-points, needles, harpoons with one row of barbs. IO $\mathrm{cm}$.

I. Sterile bed, $70 \mathrm{~cm}$.

$H$. Upper Solutrean; laurel-leaf javelin heads, pointes à cran, endscrapers, numerous engravers, prickers, assegai-points in bone, perforated animal teeth, fragments of needles with eyes, bone fragments ornamented with groups of lines. A Solutrean flint industry overlapping with advancing Magdalenian bone industry. $70 \mathrm{~cm}$.

G. Middle Solutrean; laurel-leaf javelin heads, measuring from 7 to $20 \mathrm{~cm}$. in length; points with plane face, end-scrapers, engravers, prickers, very few bone implements. $60 \mathrm{~cm}$.

F. Lower Solutrean; points with plane face, some points with Solutrean chipping on both faces (incipient laurel-leaf points). End-scrapers, engravers rare; a few bone prickers. $10 \mathrm{~cm}$.

$E$. Sterile bed, $20 \mathrm{~cm}$.

$D$. Upper Aurignacian; single and double end-scrapers, carinate scrapers "snouted" (i.e. with very convex scraping edge), thick piercers, engravers of various types, flakes with or without secondary chipping, Gravette points, Châtelperron knives, assegai-heads in bone.

C. Sterile bed, $60 \mathrm{~cm}$.

$B$. Middle Aurignacian; large hearths, many ordinary scrapers, single or double, carinate scrapers, engravers, piercers, flakes with or without secondary chipping, Gravette points, Châtelperron knives, one formless and unfinished anticipation of the pointe $\dot{a}$ cran, bone assegai-points and prickers, perforated teeth. $75 \mathrm{~cm}$.

$A$. Fallen rubbish covering the rock floor.

In short, this well-stratified series of deposits shews us bone points increased, and flint points diminished, in proportion, in the

historique de la Coumbâ-del-Bouïtou" (R.E.A. xvir. [1907], p. 120); Capitan and Peyrony, "Les fouilles de la Ferrassie (Dordogne), contribution à l'étude de l'Aurignacien" (C.P.F. Autun [1907], p. I86).

1 Bardon and Bouyssonie, "Stations préhist. du château de Bassalir près Brive; la Grotte de la Font Robert" (Bull. de la soc.scient. de la Corrèze, Brive, 1908); Breuil, op. laud.

2 D. Peyrony, "Station du Ruth près Le Moustier (Dordogne); superposition du Solutréen à l'Aurignacien" (A.F.A.S. Clermont-Ferrand [1908], p. 689); "Station préhistorique du Ruth près Le Moustier, Dordogne" (R.E.A. xix. [1909], p. 156$)$. 
older Aurignacian, but the proportion becoming reversed in the later phase of the same stage; needles with eyes beginning to appear in the Upper Solutrean; the art of flint-chipping receiving a fresh stimulus as the Aurignacian draws to a close, and reaching its highest point in Middle and Upper Solutrean, while contrariwise there is a renascence of bone-working in the Upper Solutrean which attains its highest degree in the Magdalenian.

Important Solutrean stations are Laugerie Haute, already mentioned $^{1}$, and Lacave (Lot). At Lacave is a grotto opening out in the foot of a cliff on the brink of the Dordogne river; the stratification of the deposits is as follows ${ }^{2}$ :
$F$. Hearths, $30 \mathrm{~cm}$.
$E$. Fallen fragments, pébbles, etc., I mètre.
D. Hearths, $40 \mathrm{~cm}$.
$C$. Similar to $E, 2 \cdot 20$ mètres.
$B$. Hearths, $50 \mathrm{~cm}$.
$A$. Similar to $E$, I mètre.

indicating three periods of occupation. These were entirely Solutrean in character, so that the cave was valuable for illustrating the history of the development of this stage. In $A$ there were bones of horse, ibex, and reindeer, the latter represented by one bone artificially perforated; there were marks of a flint implement on the edges of the perforation. $B$ contained a mass of burnt bones of animals of indeterminable species, and a pointed instrument of reindeer-horn. In $C$ there were laurel-leaf javelin-heads and pointes $\dot{a}$ cran, as well as bones of ibex and reindeer. The small rodents began to appear in this stratum. $D$ contained many hearths, and Solutrean implements; needles and reindeer-horn implements ornamented with linear patterns but no animal engravings; a perforated schist pebble, and perforated teeth and shells. $E$ had no human relics. $F$ had some pointes a cran and implements in reindeer-horn, one of them engraved with the head of an antelopẹ.

Of Magdalenian sites in this region we may content ourselves with enumerating names like La Madeleine, Laugerie Basse, Bruniquel or Montastruc, Le Mas d'Azil, which are classic in Palaeolithic history ${ }^{3}$.

Auvergne, which was for the greater part covered with quaternary

${ }^{1}$ For the objects discovered at Laugerie Haute, with many illustrations, see $\mathrm{P}$. Girod, Les stations de l'âge du renne dans les vallées de la Vézère et de la Corrèze; stations solutréennes et aurignaciennes (Paris, 1906).

"Armand Viré, "Grotte préhistorique de Lacave (Lot); époque de Solutré" (L'Anthr. XVI. [1905], p. 4II).

"Cartailhac, "Les stations de Bruniquel" (L'Anthr. 1903); Peccadeau de l'Isle, "Notice sur des objets sculptés" (Revue archaeol. xvir. [1868], p. 213). For other places see bibliographies in Déchelette, Manuel, vol. I. p. $632 \mathrm{ff}$. 
glaciers, is poor in Palaeolithic remains of any stage; we may however make passing mention of the small cave called Le Rond, near SaintArcons-d'Allier (Haute-Loire) which has yielded Magdalenian implements. A peculiarity of this station is the large number of implements in basalt and other stones, the site not being near a flint-bearing region ${ }^{1}$.

\section{Region VI. The Iberian Peninsula}

The number of Upper Palaeolithic sites in the Iberian peninsula is very considerable; all three stages are represented. Their distribution over the area of this region is full of instruction, and has a bearing upon prehistoric problems, not confined to this region alone, but affecting all Europe. For this reason we postpone the details of description to the final chapter, in which problems upon which Spain throws especial light are discussed.

In the meanwhile we need say only that the Magdalenian stations are especially common, but are almost confined to the north of Spain; Solutrean stations are much less frequent, and are similarly limited in distribution; while Aurignacian stations, though not so common as Magdalenian, are scattered over the whole region. There is nothing calling for notice in the local facies of the Upper Palaeolithic.

\section{Region VII. Northern France}

Upper Palaeolithic stations in this region are uncommon, and important stations very rare. The only Aurignacian station which calls for mention is the Grotte du Trilobite at Arcy-sur-Cure(Yonne) ${ }^{2}$, which is one of the standard examples of the Upper Aurignacian. Its stratification is as follows:

$F$. Neolithic.

$E$. Magdalenian, with bâtons de commandement and other typical objects. Reindeer fauna.

$D$. Early Solutrean, with mammoth, cave bear, and hyaena. Laurelleaf javelin-heads, some of them with characteristic Solutrean chipping on both sides, others on only one.

C. Late Aurignacian. Mammoth, Rhinoceros tichorhinus, reindeer, horse. Curved prickers, flakes, Gravette points, one split-base point.

$B$. Middle Aurignacian. Reindeer rare; horse, mammoth, hyaena, Arctic hare, Rhinoceros tichorhinus. Carinate scrapers and Châtelperron knives.

$A$. Mousterian.

The Solutrean stage is almost confined to the southern region, but it is carried a step farther north by a station at Bellon, near

1 M. Boule and A. Vernière, "L'abri sous roche du Rond" (L'Anthr. x. p. $3^{8} 5$ ).

2 See Breuil, "La question aurignacienne" (Revue préhist. 1907). 
Vierzon (Cher), where all the stages between the Chellean and the Bronze Age are represented, except the Magdalenian ${ }^{1}$.

No Magdalenian station in this region calls for notice. The researches of Edouard Dupont in the Belgian caves is a subject belonging to a later chapter.

\section{Region ViII. The German Plain}

Most of the sites to be mentioned in the present section are in the southern and more mountainous parts of the German area; on which account it might be more accurate to describe them under the following section. But on the whole it is perhaps more convenient to describe them here.

The Aurignacian is better represented in Germany than are the preceding stages. At der Sirgenstein (see p. 337) there were three Aurignacian strata, representing the beginning, the middle, and the end of the stage respectively. The first (lowest) of these contained tools made of flint flakes, such as were comparatively rare in the underlying strata, with secondary chipping round the edges. The caniculate flaking does not yet appear. There are still reminiscences of the Mousterian technique, in the form of coarse bulbous flakes. Engravers are found, but are rare. Small points and various forms of scrapers, flake knives and a few borers of bone also appear. Three human teeth were found in this stratum - the only human remains from this important cave. They present no special peculiarities ${ }^{2}$.

The Middle Aurignacian stratum presents a rich mass of material: caniculate Aurignacian chipping now appears on scrapers. The carinate scraper, identical with the western type, is found, as well as the hollow scraper; this however is not so regularly worked as the western examples. There are also flake knives and engravers, but the latter are less common than in later strata. In bone we find polishers made of the ribs of bears and of horses, javelin-points, borers, as well as fragments of reindeer-horn with scratches upon them. The Aurignacian point, with or without the split base, is not found at der Sirgenstein. The bone implements are more highly polished than in the preceding stratum.

The Late Aurignacian shews a degeneration. There are numerous

1 Bourlon, "La station préhist. de Bellon près Vierzon (Cher)" (Mémoires de la soc. des antiquaires du Centre, Bourges, 1912).

2 A description of them will be found, with enlarged photographic illustrations, in Schmidt's Diluviale Vorzeit Deutschlands, p. 239 and plate xliv. A very full series of plates of implements from this cave is given in the same volume. See also A.f.A. xxxv. p. 66; and R. R. Schmidt, "Das Aurignacien in Deutschland" (Mannus, I. [1909], p. 97). 
engravers, including the curved type, which is unknown in the earlier strata. Flakes are thinner in section, as also are scrapers, the elaborate secondary chipping disappears, except in a few examples. A noteworthy characteristic of this stratum is the number of Mousterian tools re-worked; they were evidently dug for, through the intervening beds of deposit, and shaped into the tools in fashion in the later period. As usual, this manipulation is betrayed by the disturbance of the patination. Gravette points are found in this stratum. The bone implements resemble those of the Middle Aurignacian stratum; Schmidt figures a small ivory bead with two perforations, which he assigns doubtfully to this period.

The fauna found in these strata include the ordinary Canidae, Ursus spelaeus, Gulo borealis (late stratum only), Hyaena spelaea (ditto), Felis spelaea, catus, and lynx; F. pardus (doubtful, in early stratum only); Myodes torquatus and obensis (early stratum only), Equus, and the chief tundra animals.

Near Nördlingen, at the north end of the boundary between Württemberg and Swabia, there are two caves in a spur of the Jura known as the Greater and Lesser Ofnet. Both of these have yielded important archaeological material, though the excavations carried out within them have not been all as scientific as might be wished.

The stratification in the Greater Ofnet is as follows:

\begin{tabular}{llllcl} 
& & & \multicolumn{3}{c}{ Depth of stratum } \\
G. Metal age $\ldots$ & $\ldots$ & $\ldots$ & 0.32 mètre \\
F. Neolithic $\ldots$ & $\ldots$ & $\ldots$ & $0.53 \quad$, \\
E. Mesolithic & $\ldots$ & $\ldots$ & $\ldots$ & $0.25-0.50$ &, \\
D. Magdalenian & $\ldots$ & $\ldots$ & $0.15-0.20$ &, \\
C. Solutrean & $\ldots$ & $\ldots$ & $\ldots$ & 0.20 &, \\
B. Aurignacian ... & $\ldots$ & $\ldots$ & 0.20 &, \\
A. Dolomitic Sand & $\ldots$ & $\ldots$ & $0.65 \quad$,
\end{tabular}

The stratum $A$ contained no remains of human occupation. Towards its top there were evident traces of the use of the cave as a den by hyaenas. Above the gnawed bones left by these animals there was a layer of rodent bones, corresponding to the layer which at der Sirgenstein separates the Mousterian from the Aurignacian strata. These rodents had disappeared completely during the deposition of layer $B$; this contained at the bottom remains of an unimportant early Aurignacian occupation, which had left a few rude tools, scrapers and flakes, with the Châtelperron knife. In the upper part of the same stratum there were remains of a later facies of the Aurignacian culture, including engravers and a bone point with split base. 
The Lesser Ofnet cave shewed the following stratification:

Depth of stratum

$\begin{array}{llllll}\text { E. La Tène to Mediaeval } & \ldots & 0.30 & \text { mètre } \\ \text { D. Neolithic ... } & \ldots & \ldots & 0.55 & \text {, } \\ \text { C. Late Magdalenian or Azilian } & 0.25 & , \\ \text { B. Early Solutrean } & \ldots & \ldots & 0.26 & , \\ \text { A. Aurignacian... } & \ldots & \ldots & 0.20 & ,\end{array}$

in which the Aurignacian displayed specimens of every phase of that stage, indicating a continuous occupation. There was no trace of Mousterian occupation in either cave.

The fauna accompanying the Aurignacian remains in the Ofnet caves included the otter (early stratum only); Felis spelaea, Cervus elaphus, and Rangifer (late stratum only); and in both strata, Canis lagopus, Lrsus spelaens, Hyaena, Cercus megaceros, Rhinoceros tichorhinus and Elephas primigenius.

The Palaeolithic remains in the Ofnet caves were less important than the Mesolithic deposits, described on a later page.

Other sites where Aurignacian remains have been reported may he passed over with a bare mention. In some cases there is uncertainty in connexion with them, on account of faultily described stratification; in other cases they add nothing of importance to our knowledge of the subject. Such are die Räuberhöhle, der Kartstein, and das Buchenloch, to which reference has already been made in previous chapters; Kärlich (a Löss deposit, with a few indefinite, apparently early Aurignacian flints) ${ }^{1}$; Thiede (a site somewhat similar) ${ }^{2}$; and Westregeln in Brunswick ${ }^{3}$.

Iore important is the cave of Wildscheuer, near Steeden on the Lahn. The stratification of its deposits was as follows:

I)epth of stratum

$\begin{array}{lllll}\text { F. Neolithic to La Tène } & \ldots & 0.50 & \text { mètre } \\ \text { E. Early Magdalenian ... } & \ldots & 0.70 & , \\ \text { D. Late Aurignacian ... } & \ldots & 0.60 & \\ \text { C. Niddle Aurignacian } & \ldots & 0.60 & , \\ \text { B. Bed of rodents } \ldots & \ldots & 0.06 & , \\ \text { A. Sterile breccia } & \ldots & \ldots & \text { I.00 }\end{array}$

Here the rodent bed, as at der Sirgenstein and in the Greater Ofnet, underlies the Aurignacian. Of these animals, only Lepus variabilis

1 A. Günther, "Zur Entstehungs- und Besiedelungsgeschichte des Neuwieder Bechens" (Manmus, II. [1910], p. 33 ff. esp. p. 45).

$\because$ R. R. Schmidt, op. laud. p. 102 and literature enumerated there.

3 A. Nehring, "Die quartären Faunen von Thiede und Westregeln nebst spuren des vorgeschichtlichen Menschen" (A.f.A. x. 359; xı. I). Hoernes, Der diluciale Mensch in Europa (Brunswick, 1903), p. 48, where the sites of Thiede and Westregeln are described as Solutrean. 
survived into the period of human occupation. There was no Mousterian bed underlying the rodents. The rest of the fauna was similar to that of the other two places just mentioned; it was on the whole rather scantier as far as variety of species was concerned.

The industry of the Middle Aurignacian displayed the chief characteristic implements of the fully developed facies of that stageflake knives; some of large size, with marginal secondary chipping, carinate scrapers with caniculate flaking, bone prickers or borers. There was one flat slip of bone like a paper-knife, with a slight criss-cross ornament scratched upon it. There were also some personal ornaments, such as a bead of nephrite with a perforation drilled through it, other perforated fragments of stone and shell, pieces of fossil coral; an unworked piece of amber was found in this stratum, but is suspected to have fallen from the topmost layer, out of the side of the excavated shaft in which it was discovered. The Late Aurignacian displayed thinner flakes; the carinate scrapers and the caniculate "retouch" disappear, the Gravette points make their appearance, as well as curved engravers. In bone there were some prickers and polishers; the most remarkable was a section of the leg bone of a bird, with a chevron pattern cut upon it ${ }^{1}$.

The cave die Bockstein, near Langenau and in the region of the Jura which contains der Sirgenstein, was of some importance owing to its clear stratification. This separated, by a thick sterile bed, the early Aurignacian from later developments of the Upper Palaeolithic. The following was its scheme:

$D$. Neolithic and later accumulation, $0.40-0.60$ mètre.

C. Aurignacian and Late Magdalenian, $0 \cdot 20-0 \cdot 30$ mètre.

$B$. Sterile bed of loam, $\mathrm{I} \cdot 00-\mathrm{I} \cdot \mathrm{I} 0$ mètre.

$A$. Early Aurignacian, $0 \cdot 40-0 \cdot 60$ mètre.

The lowermost bed contained coarse scrapers, large flakes with irregular secondary chipping along the margins, a few thick scrapers anticipating the carinate type, and also one or two implements distinctly reminiscent of the coup-de-poing. There were also bone borers and polishers, anvils of bone, and a bear's canine tooth perforated. The upper bed had been disturbed by the mediaeval interment of a murderess in this unhallowed place, the discovery of whose skeleton made some excitement at first. Some intrusive Neolithic objects were accordingly found in this stratum. The Palaeolithic finds included the best and most varied series of engravers from Central Europe, flakes, bone prickers and smoothers: one of the latter with a deep groove running axially along its surface. cited.

1 On Wildscheuer see R. R. Schmidt, op. laud. pp. $84-5$, and literature there 
A reindeer-horn with a few scratched lines was the only ornamented object. This is an indication that the so-called "engravers" cannot have been used exclusively for the ornamentation of bone or for the carving of statuettes ${ }^{1}$.

The Aurignacian stratum at Achenheim contained Gravette flakes, and therefore belongs to the end of the stage; its fauna included the mammoth, reindeer, horse, and Rhinoceros tichorhinus. Other Late Aurignacian stations in the later Löss, with a similar fauna, are situated at Metternich and at Rhens, near Neuwied.

The Solutrean stage is but poorly represented in Germany. Der Sirgenstein contains a stratum shewing a very early facies of this stage, characterised by the disappearance of the caniculate flaking, the carinate scrapers, and the curved engravers, and on the other hand the persistence of the Gravette points and certain types of engraver. The Solutrean surface-flaking is foreshadowed, and appears in a tentative form on certain implements, but is still rude; the "laurel-leaf" is also still in a rudimentary phase. The bone implements from the Sirgenstein Solutrean do not differ from those of the underlying Late Aurignacian.

The associated fauna shews a great increase in the rodents, with however a diminution of Myodes obensis and the arrival of Lagomys pusillus.

The two Ofnet caves present a more fully developed Solutrean. It is associated with Canis lupus, C. vulpes, Ursus spelaeus, Lutra vulgaris, Hyaena spelaea, Bison priscus, Equus caballus, and Rhinoceros tichorhinus; no rodents and no reindeer. The industry is not comparable in excellence with the Solutrean of the west of Europe; the "laurel-leaves" lack the finish and symmetry of those of Central France, and the "retouching," though characteristically Solutrean, is by no means so skilful as in the French examples. The smaller Ofnet had a richer Solutrean deposit than the larger, but its technique was not more advanced. Only one really good "laurel-leaf" seems to have come from Germany; an excellent example, found embedded in brick-earth at Cannstatt in Württemberg. As there is no flint in the neighbourhood of this site, the probability is that the implement was imported ready made, and that it does not really belong to the region in which it is unique ${ }^{2}$.

The Magdalenian is much more fully represented in the German region. At der Sirgenstein there are two layers, an early and a late.

1 Bürger, "Der Bockstein" (23 Versam. d. deutsch. anthrop. Gesell. zu Ulm; Verein fïr Kunst u. Altertïmer in Ulm u. Oberschwaben, I-40); R. R. Schmidt, op. laud. p. 46, and further literature there enumerated.

2 R. R. Schmidt, op. laud. p. 48 . 
The former contained small flakes with or without "retouch," large scrapers, smaller scrapers, and, in ivory or reindeer-horn, small cylindrical rods. The upper stratum contained only a few small flakes and a limited variety of engravers. The Magdalenian strata at this site were very poor. The associated mammalian fauna included, with the larger tundra animals, a number of rodents, of which Myodes obensis was confined to the early stratum, and was there rare; $M$. torquatus on the other hand was rare in the early stratum and common in the later. The same is conspicuously true of Lagomys pusillus, which was, indeed, the characteristic animal of the second stratum.

At Niedernau, near Rottenburg on the Neckar, a small rockshelter was found to contain remains of a Magdalenian settlement, including flint borers of definitely Magdalenian form, a bone pricker with short ornamental strokes on one edge, a number of agate beads, and the shell of a Mediterranean mollusc (Pectunculus) perforated for suspension.

The Kastlhäng near Amberg in the Altmühltal contained the following stratified deposit:

$F$. Modern back to Neolithic, $0 \cdot 15-0 \cdot 20$ mètre.

E. Sterile, 0.02-0.03 mètre.

$D$. Rodent bed, a few implements, $0 \cdot$ IC $-0 \cdot 25$ mètre.

$C$. Magdalenian bed, $0 \cdot 10-0 \cdot 25$ mètre.

$B$. Yellow loam, remains of a bear's den, few implements, $0.10-0.15$ mètre.

$A$. Brown soil, bear's den, no sign of humanity.

The Magdalenian remains included a harpoon - a rare object in Eastern Europe-a perforated bone needle, some rods and polishers of bone and a small cylindrical rod of ivory, along with the usual flint flakes and engravers. The presence of ivory, and the occurrence of Elephas primigenius in the fauna (which was similar to that of the Lower Magdalenian stratum at der Sirgenstein), forbid us to assign these remains to the late Magdalenian, as does also their appearance beneath a rodent bed. On the other hand, the harpoon shews that it cannot be very early; the deposit must therefore lie somewhere in the Middle Magdalenian, and rather early in that phase ${ }^{1}$.

Wildscheuer has a similar Early Magdalenian bed (from which however the mammoth happens to be absent, though there are ivory objects among the artefacts); we may pass it over with a simple mention. Other sites of smaller account need not be here specified.

1 J. Frauenholz, H. Obermaier and M. Schlosser, "Die Kastlänghöhle, eine Rentierstation im bayrischen Altmühltale" (Beiträge zur Anthropologie und Urgeschichte Bayerns, xvIII. [IgII], p. II9). 
For the Middle Magdalenian one of the most important sites in Germany is die Schussenquelle near Schussenried. The mammoth has disappeared, but there is an abundance of reindeer. It is an open-air hunting station, specially characterised by the quantity of worked reindeer-horn. The flints are of less importance and of commonplace types. Among the artefacts in reindeer-horn are to be mentioned a harpoon with a single barb on one side, assegai-points with both forked and chisel-edge butts, a few bâtons de commandement, with however little or no ornament (a few scratches at most); and two fragments of reindeer-horn with efforts at art upon them, both extremely feeble. The first bears the headless fore-quarters of an unrecognisable animal; the second some scratches which with the aid of a sufficiently lively imagination can be interpreted as a fish or a seal, probably quite gratuitously ${ }^{1}$.

In der Höhlefels, near Hütten, a little to the south-west of der Sirgenstein, were found two Magdalenian strata of about 0.40 mètre thickness each, lying between two sterile beds of about the same thickness. The lower of the two belonged to the Middle Magdalenian, after the disappearance of Elephas primigenius. There were flint scrapers and flakes, but no bone or horn implements in this cave. The upper layer belonged to a very late phase of the Magdalenian. The microlithic technique - the use of extremely small flakes, which finds its climax in the pygmy flints of the Azilian stage-is here far advanced. The fauna clearly foreshadow the approaching departure of the reindeer, and the establishment of modern zoological conditions. The Magdalenian layers in the two Ofnet caves are completely analogous; the presence of the reindeer is there entirely doubtful. A stag's-horn chisel from the Greater Ofnet is the only object that needs to be specially mentioned.

In the Löss at Andernach on the Rhine a very important Magdalenian station was found. Analysis of the list of fauna shewed the reindeer still among the commonest animals-it came only second to the horse-so that the site cannot represent a very late phase of the Magdalenian. On the other hand Elephas and Rhinoceros have disappeared. The station may therefore be dated to a transition between the Middle and Late Magdalenian - a time of the decline from the full climax of that stage of culture ${ }^{2}$.

The objects found in the station included the usual flints appropriate to the stage. There were some single-row harpoons, and one

"See R. R. Schmidt, op. laud. p. 54 ff. and accompanying plates, where these objects are figured.

${ }^{2}$ Schaafhausen in Fahrbücher des Vereins von Altertumsfreunden in Rheinlande (Bonn, I888); A.f.A. [1881], p. 516; Corr. [1883], p. 121, [1884], p. 144. 
double-row. The flakes were tending toward the microlithic of the end of the Magdalenian, but there were some large flakes among them-some indeed of unusual size. A few perforated needles, a canine tooth of a horse perforated for suspension, were also characteristic. Most notable were the efforts at art, very feeble as is usual in Eastern Europe; a point from a reindeer-horn with a conventional floral (?) ornament on its butt, and a curious figure of a bird, made

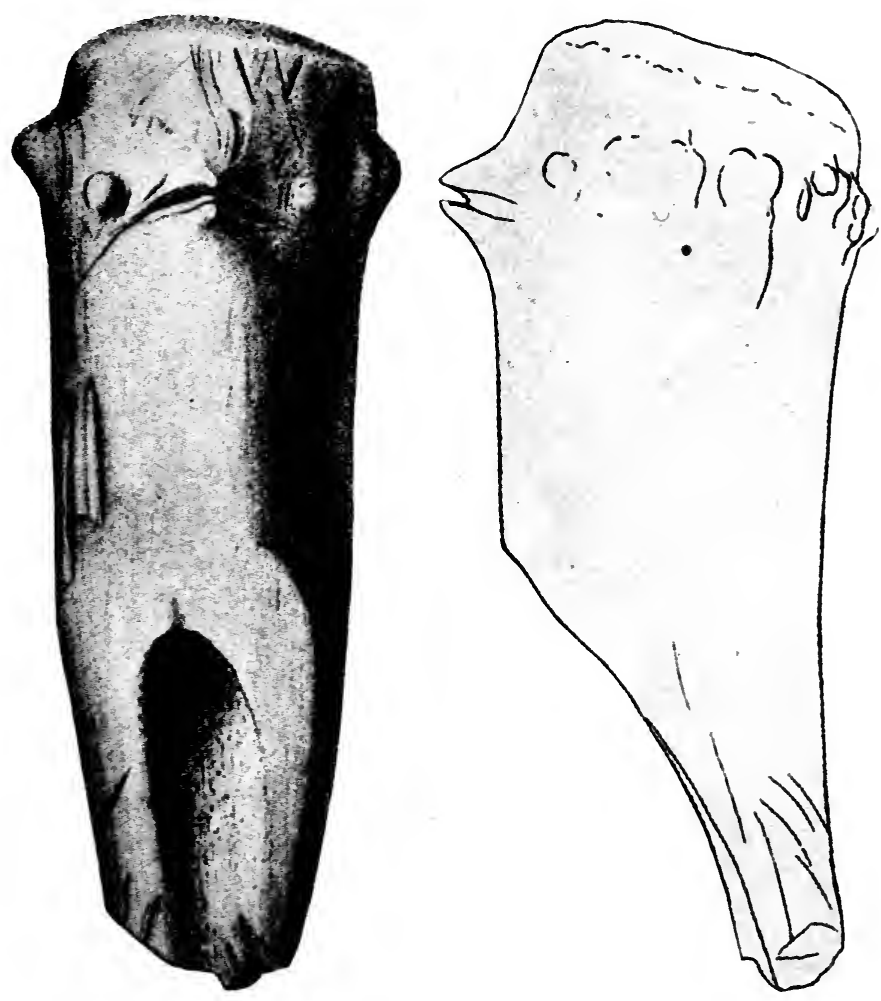

Fig. I 1 5. Figure of a bird in reindeer-horn, Andernach.

(From Correspondenzblatt, 1908.)

of a fragment of reindeer-horn by emphasising with scratches a natural resemblance which attracted the attention of its ancient owner (Fig. I I 5 ).

At Munzingen on der Tuniberg, near Freiburg, a station of reindeer hunters was found, situated in a stratum interjected between the older and the later Löss. The fauna being exclusively reindeer dated the settlement to the Magdalenian stage, though many of the flints had a Solutrean facies. Quantities of red ochreous stones were 
associated with the flints, which must have been collected from a site about a kilomètre away: it is supposed for paint, or perhaps to yield alum for dressing hides. Some bone and horn implements, among them the broken end of a bâton de commandement, were also found ${ }^{1}$.

But the most important Magdalenian station as yet discovered in this region is the cave of Propstfels near Beuron in Hohenzollern. The stratification of this cave was peculiar; the following is its scheme:-

$G$. Humus; Bronze Age and La Tène, I·oo mètre.

$F$. Sterile bed, 0.30 mètre.

$E$. Magdalenian, $0^{\circ} 17$ mètre.

$D$. Detritus, sterile, $0 \cdot 48$ mètre.

$C$. Magdalenian, 0.30 mètre.

$B$. Magdalenian, $0 \cdot 35$ mètre.

$A$. Sterile, I 40 mètres.

in which beds $B$ and $C$ were distinguished by their colour, $C$ being blackened with the ashes of numerous hearths. The peculiarity of the stratification consists in the unity of culture and fauna in the three archaeological beds. They cannot have been separated by long intervals; the period of abandonment, during which the sterile bed $D$ accumulated, must have been of short duration. Among the fauna the reindeer, which is evanescent, is the only Arctic animal left. This indicates a late phase in the Magdalenian, with which the industry of the cave accords. There was a large number of well-formed flake engravers of various types, and a distinct tendency towards the microlithic culture of the Azilian period. There was no sign of the Upper Palaeolithic art, and the industry in bone was but poorly represented. The cave, however, afforded the most complete typological series of Magdalenian flint implements that has yet come to light in this region ${ }^{2}$.

Mention should also be made of a small Magdalenian station at Unkelbach near Coblenz, containing typical Magdalenian implements in the later Löss ${ }^{3}$.

At Neu-Essing, Bavaria, Obermaier has excavated a series of caves having remains of all periods from Acheulean onwards except

1 G. Steinmann, "Die palaeolithische Rentierstation von Munzingen am Tuniberge" (Bericht der naturforsch. Gesellsch. in Freiburg i. B. xvi. [1906], p. 67); O. Schötensack, "Über die Gleichzeitigkeit der menschlichen Niederlassung im Löss bei Munzingen unweit Freiburg i. B. und der dem Magdalénien zugehörigen paläolithischen Schicht von Thaingen und Schweizersbild bei Schaffhausen" (A.f.A. xxIx. [1904], p. 69; xxxiv. [1907], p. I69).

${ }_{2}$ R. R. Schmidt, "Die späteiszeitlichen Kulturepochen in Deutschland und die neuen palaeolithischen Funde" (Corr. 1908).

3 Described by E. Stehn in Corr. XLIV. [1913], p. 56. 
Aurignacian. The Solutrean layer contained good laurel-leaf javelin heads: the Solutrean skeleton mentioned on a previous page (ante, p. 376) was sunk in a grave excavated into the underlying Mousterian layer. The Magdalenian strata contained the usual equipment, harpoons, assegais, bâtons de commandement, and discs of limestone bearing ornament in paint or engraving. A well-drawn engraved figure of a horse's head was the most notable of these ${ }^{1}$.

\section{Region IX. The Alpine Region}

In contrast to the poverty of the Alpine region in Lower and Middle Palaeolithic remains-a poverty fully accounted for by the action of the intervening glaciers-there are Upper Palaeolithic stations in the same region of considerable importance.

Of these the oldest, and in many ways the most interesting, is the cave of Kesslerloch, near Thayngen, a village some 8 kilomètres north-east of Schaffhausen and in the canton of the same name.

The remains of industry in this cave were first discovered in 1874 by $\mathrm{K}$. Merk, the schoolmaster of Thayngen, when on a botanical excursion with his pupils. He afterwards excavated part of the contents of the cave, finding no less than 12,000 flint implements, and numerous bones, worked and unworked. The excavation was resumed from time to time by Nuesch, Heierli, Rütimeyer, and other well-known Swiss archaeologists.

The mammalian fauna of the cave was found to include the following species:

$\begin{array}{ll}\text { Canis lupus } & \text { Spermophilus guttatus } \\ \text { Canis vulpes } & \text { Arctomys marmotta } \\ \text { Canis lagopus } & \text { Castor fiber } \\ \text { Ursus arctos } & \text { Myodes torquatus } \\ \text { Mustela martes } & \text { Cricetus vulgaris } \\ \text { Gulo borealis } & \text { Lepus timidus } \\ \text { Lutra vulgaris } & \text { Lepus variabilis } \\ \text { Felis leo } & \text { Sus scrofa } \\ \text { Felis lynx } & \text { Cervus elaphus } \\ \text { Felis manul } & \text { Cervus canadensis } \\ \text { Spermophilus rufescens } & \text { Cervus capreolus }\end{array}$

Rangifer tarandris

Rupicapra tragus

Capra ibex

Ovibos moschatus

Bison priscus

Bos primigenius

Equus caballus

Equus hemionus

Rhinoceros tichorhinus

Elephas primigenius

which is clearly a predominantly steppe and tundra fauna, the forest fauna being comparatively few in the number both of species and of individuals. The fauna thus agrees with the industry in assigning the occupation of the cave to the Magdalenian.

1 "Institut de Paléontologie humaine; fouilles en Bavière" (L'Anthr. xxv. [1914], p. 254). 
The following was the stratification of the deposits in the cave:

$G$. Vegetable soil.

$F$. Rubbish and detritus.

E. Grey stratum with remains of human industry.

$D$. Yellowish-red stratum with remains of human industry.

C. Yellowish-grey stratum ,

$B$. Yellow stratum

A. Yellow loam, sterile.

There is not however any important traceable difference between the fauna and the industry of different strata, though it may be noticed that harpoons are absent in the lower human strata, and the
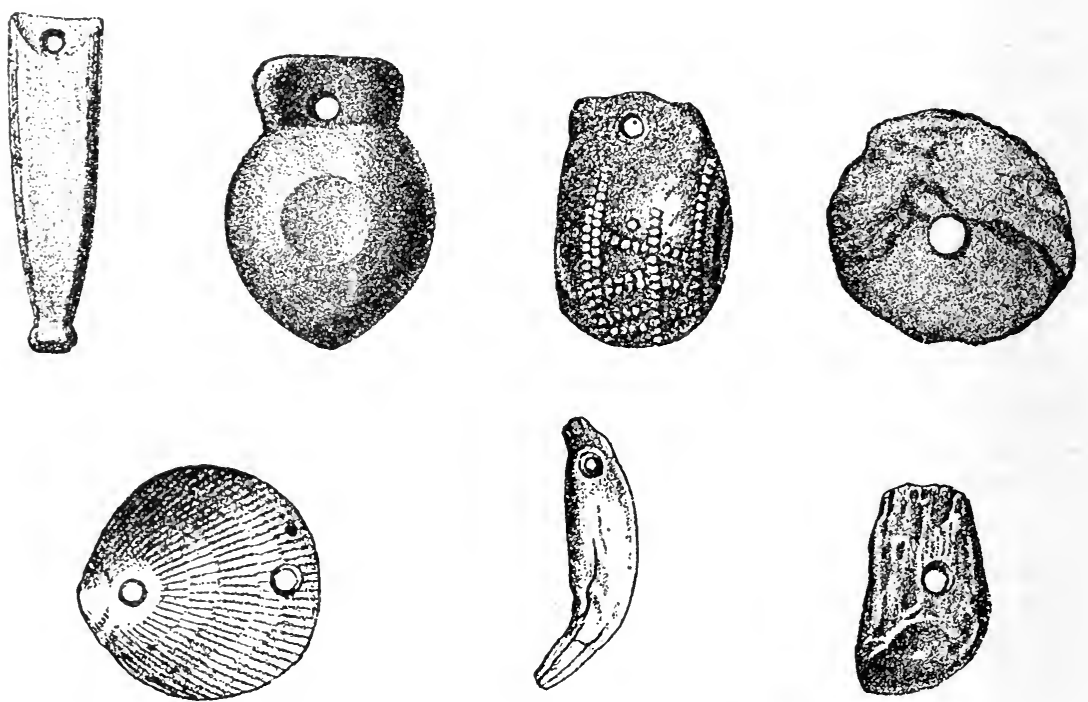

Fig. I 6 . Pendants from the Kesslerloch Cave.

flints have on the whole an earlier facies; while on the other hand the Mammoth is absent from the upper strata. The deposits are certainly post-glacial. But it must be said that the stratification of the cave was not satisfactorily observed in the earlier excavations, while in those of Heierli, where such observations were carefully made, not much of the débris remained to be examined, and it proved to be less rich in archaeological material than the parts of the cave which had previously been explored.

Throughout the cave there was no pottery and there were no polished stone implements. The flints included typical Magdalenian flakes, scrapers, knives, engravers, borers, all indistinguishable in type from the Magdalenian relics of western Europe. In like manner 
the objects in bone were thoroughly occidental-assegais, harpoons, eyed needles, bâtons de commandement. and the like.

Of special interest were the objects of personal ornament-marine and fossil shells, teeth of wolf or of bear, pendants in horn, bone, and lignite. One of the shells belonged to a species of oyster now found nowhere nearer to the site than the Red Sea or the Indian Ocean.

But the chief glory of the cave lay in its sculptured and engraved works of art, in bone or reindeer-horn. There were several pieces of ivory or bone decorated with lozenges or other linear decoration; and others bearing figures of animals, such as the musk ox (this identification is doubtful), the horse, the kiang or wild ass, and above all the world-famous browsing reindeer, which is generally regarded as the chef d'œuvre of Palaeolithic art (Fig. 20, ante, p. 76) ${ }^{1}$.

A human clavicle was the only ancient human bone found in the cave. A complete skeleton of a child (otherwise described as a dwarf) was found, but this was modern.

Next in importance and age to the Kesslerloch is the neighbouring station of das Schweitzersbild. This is an open-air station, situated at the foot of a great rock which gives it shelter, and in the neighbourhood of a good water-supply which made it attractive as a site for settlement to the early hunters. The stratification as determined by the excavator, Nuesch ${ }^{2}$, was as follows:

$F$. Humus, with Bronze Age remains; 0.40 mètre thick.

$E$. Neolithic bed, 0.40 mètre thick.

$D$. Breccia, with apparently Mesolithic remains. Small rodents, $0 \cdot 80-1$ mètre thick.

C. Yellow clay with Palaeolithic remains.

$B$. Stratum with but few traces of man; small rodents.

$A$. Alluvium, sterile.

1 There is a considerable literature on the Kesslerloch and its excavation; consult A. Bertrand, "Le renne de Thaïngen" (B.S.A.P. ser. II. vol. Ix. [1874], p. 466, reprinted in his Archéologie celtique et gauloise). K. Merk, "Der Höhlenfund im Kesslerloch bei Thayngen" (Mittheil. der Antiquar. Gesellschaft, Zürich, xIx. [1875], p. I: translation into English by J. E. Lee, London, Longmans, 1876). L. Rütimeyer, "Die Knochenhöhle von Thayngen bei Schaffhausen" (A.f.A. viIr. [1875], p. 123); Simonson, "Le Kesslerloch près de Thayngen" (B.S.A.B. 1905); J. Nuesch, "Das Kesslerloch, eine Höhle aus Paläolithischer Zeit" (Denkschriften d. schweiz. naturforsch. Gesell. Zürich, xxxix. [1904]); J. Heierli, "Das Kesslerloch bei Thaingen" (ibid. XLIII. [1917]); R. R. Schmidt, Diluviale Vorzeit Deutschlands, p. $7 \mathrm{r}$ ff.

2 J. Nuesch, "Das Schweitzersbild, eine Niederlassung aus palaeolithischer und neolithischer Zeit" (Mémoires de la soc. des sciences naturelles de Zurich, xxxv. [1896]); Idem, "Stratigraphie du Schweizersbild et l'âge des différents couches de cette station" (C.A.P.A. Monaco [1906], vol. I. p. 416); M. Boule, "La station quaternaire du Schweizersbild près de Schaffouse et les fouilles du Dr Nuesch" (Nouvelles archives des missions scientifiques et littéraires, Paris, 1893). 
The Palaeolithic remains were bounded above and below by the double layer of rodents which everywhere limit the Upper Palaeolithic strata; they are therefore Upper Palaeolithic. The fauna of $B$ is of a distinctly cold facies, including Canis lagopus, Gulo borealis, Myodes torquatus, Lepus variabilis, and Rangifer tarandus. That of $C$ shews the same animals (except Myodes) in reduced proportions, associated with steppe animals such as Equus caballus and E. hemionus, and some forest fauna as Sciurus vulgaris, Cervus elaphus, and Sus scrofa. The climate of $C$ is therefore an improvement on that of $B$

Its archaeological contents included more than 14,000 objects in flint, of Magdalenian type, with many waste flakes shewing that they had been manufactured on the spot; tools in bone and reindeerhorn (needles, harpoons, bâtons de commandement and similar Magdalenian objects); and objects of personal adornment, such as pierced fossil shells (ammonites and the like) many of which belonged to species found only at a considerable distance from the site-some of them from as far off as the Tertiary marine deposits of Mayence. These testify to wide-spread movements of peoples, with bartering of commodities, even at so remote a date as the Magdalenian Stage. There were also in this stratum a number of hearths, formed of blocks of schist set up in circular form. Ashes and stones were found in these enclosures.

The Mesolithic stratum (the attribution of which has been questioned) possesses little of interest.

There were a number of skeletons found at das Schweitzersbild, but though they were deposited in the Palaeolithic layer they do not properly belong there, and cannot be taken as representatives of the Magdalenian hunters. They were interments made by the Neolithic people, in graves dug through the underlying strata. There were the remains of $\mathrm{I}_{4}$ adults (including five dwarfs or pygmies; the rest were normal) and to children. Some of these graves may be even later than the Neolithic.

The exact dating of the Schweitzersbild Palaeolithic stratum is a matter of some difficulty. The two rodent-strata do not here agree with the usual position of these layers. These must mark glacial maxima; but ordinarily the first rodent bed marks the maximum after the Mousterian, the other the maximum early in the Magdalenian. The industry of the Magdalenian bed at das Schweitzersbild is however a late Magdalenian, and therefore should either overlie or be contemporary with the upper rodent layer. In other words, the rodents appear too late at das Schweitzersbild to fit in with the ordinary chronological scheme.

We must therefore infer that the lower rodent bed at this site is 
really the later rodent bed, and that the upper bed is the result of a re-sortment of the deposits. It does not extend over the whole of the excavated area, only over parts of it; and as we have seen that the Neolithic people dug graves, and perhaps other trenches as well in the underlying soil, it seems likely that this layer has been artificially produced by such operations.

Further late Magdalenian stations have been found in the neighbourhood of Villeneuve, Canton de Vaud (caves of Châtelard and Scex $)^{1}$ with, however, no very rich archaeological yield; and at Veyrier in the massif of the Salève, near Geneva.

The Veyrier station is of considerable importance. It yielded many late Magdalenian flints of the ordinary types, and a number of bone and horn implements, including bâtons de commandement with artistic designs engraved upon them (animal figures and, what is much rarer, phyllomorphic patterns $)^{2}$.

There are a number of minor Magdalenian stations in the Alpine region, in addition to those above described; but these need hardly be enumerated here ${ }^{3}$.

\section{Region X. Austria, Hungary, and Eastern Russia}

The distribution of the different Upper Palaeolithic stages through this region is rather complicated. The Aurignacian is rare at present, in Hungary, though with further research stations may come to light ${ }^{4}$. In the Balla cave near Miskolcz, Hungary, were found a number of Aurignacian implements, together with scrapers made of the teeth of the cave bear. Reindeer, wolf, bear, cow, boar, cave lion bones were associated with them. An upper stratum (post-Pliocene) contained the bones of a child, but no archaeological remains ${ }^{5}$. In Lower

1 L. de Saussure, "La grotte de Scé près Villeneuve, station suisse du renne" (Archives des sciences phys. et naturelles, Bibliothèque Universelle et Revue Suisse, xxxviII. Nouvelle Période [1870], p. 105).

2 A bibliography of the extensive literature on the caves of Veyrier will be found in Alfred Cartier, "La station magdalénienne de Veyrier (Haute-Savoie); historique des principales découvertes, $1833^{-1916 " ~(A r c h i v e s ~ s u i s s e s ~ d ' a n t h r o p o l o g i e ~}$ générale, II. [1916-7], p. 45). See also B. Reber, "La station paléolithique de Veyrier" (B.S.P.F. v. [1908], pp. $233,459,516)$. M. Raoul Montandon, after a careful study of the geological evidence, assigns the station to a time after the Bühl maximum. See his paper, "A propos de la station paléolithique de Veyrier; sa position chronologique" (Archives suisses, vol. I. [1914], p. 285).

3 For further details on the Palaeolithic archaeology of this region see A. Schenk, La Suisse préhistorique (Lausanne, 1912), pp. 1-172. Some of the conclusions which the author indicates are perhaps a little doubtful.

4 See T. Kormos, in Mittheilungen aus dem fahrbuche der kgl. ungarischen geolog. Reichsanstalt, xx. (Budapesth, 1912); Josef Bayer, "Ungarns Stellung im Eiszeitalter" (Földtani Közlöny, XLIII. [1913], p. 400), where its existence is denied. But contrast E. Hillebrand, "Recherches dans les grottes paléolithiques de la Hongrie" (C.A.P.A. Geneva [1912], vol. I. p. 355).

5 E. Hillebrand, "Resultäte der im Jahre $191 \mathrm{I}$ in der Ballahöhle vorgenommenen Grabungen" (Földtani Közlöny, xLII. [1912], p. 876). 
Austria, however, there are a number of Aurignacian sites, such as Thürnau, Trabersdorf, Nonndorf, Stillfried, Autendorf, Zeiselberg, and Elsern - the last-named is Mousterian, and there may be a Mousterian element in some of the others. These are Löss stations; there is no fauna associated with them ${ }^{1}$. To these must be added the important station of Willendorf. In Bohemia there are similar stations as at Jenerálka and Lubna; in Moravia there is Joslowitz and Brünn.

The only site of this list which calls for detailed notice is Willendorf ${ }^{2}$. This place is on the left bank of the Danube, 20 kilomètres from Krems. The Aurignacian station here was discovered in the Löss, which was being dug away in the course of railwayconstruction. The Löss is here $18 \cdot 20$ mètres thick, and rests upon white sand. The archaeological beds occur in its upper part only, between 2 and 3 mètres from the top; they are marked by brownish lines with particles of carbonised material scattered through them. Each bed measures about ro centimètres thick, on an average, though some are rather thicker. Hearths were found, surrounded with rings of stones. Flints and kitchen débris abounded, and were not absent from the beds of Löss intervening between the layers of occupation, which were in all eight in number.

The three lowest beds represented an early phase of Aurignacian, with very rude flints: among them were end-scrapers, points, and notched flakes, associated with bison, reindeer, and wolf bones. In the fourth stratum carinate scrapers began to appear, and points with the characteristic form of Aurignacian secondary chipping. There was here a deer-horn hollowed to serve as the handle of a tool. The fifth bed was rich in flint implements, including Gravette points and straight or curved borers; there were many scrapers, mostly end-scrapers, but some survivals of the Mousterian side-scraper form. The three following beds were likewise very rich in flint implements. There was a tendency toward Solutrean outlines in javelin-points, but the characteristic Solutrean chipping did not appear: there was nothing more than a marginal secondary chipping, of Aurignacian form. The horse was very common among the mammals; with it were associated mammoth, reindeer, lion, wolf. In the seventh bed there was a bone point, of the same type as the

1 See F. Kiessling and H. Obermaier, "Das Plateaulehmpaläolithikum des nordösterreichischen Waldviertels von Niederösterreich" (M.A.G.W. XLI. [I 9I I], p. I).

2 J. Szombathy, "Eine paläolithische Fundstätte im Löss bei Willendorf in Niederösterreich" (M.A.G.W. xIV. [I884],•p. (35)); Idem, "Die Aurignacienschichten im Löss von Willendorf" (Corr. [1909] p. 85). See also M.A.G.W. xxvi. [1896], p. (I 3 ). 
split-base point of western European stations. 'The ninth bed had piercers and scrapers similar to those in the lower strata, with in addition pointes $\dot{a}$ cran of Aurignacian type, a bone pin and rod of ivory as well as a rib-bone with indentations upon it. A statuette of oolitic limestone, which gives Willendorf an especial importance, and which will be more fully described in the following chapter, was found just under this bed.

At Krems itself there was a rich Lower Aurignacian station. There were here many flints, but very little bone; perforated shells, some of them of Mediterranean provenance, were found. The fauna was of steppe type, though the reindeer was also common ${ }^{1}$.

The Aurignacian is thus present in Austria, and absent from Hungary: on the other hand the Solutrean is represented in Hungary, as well as in Bohemia and Moravia, but is otherwise absent from Austria. Though there are many Upper Palaeolithic sites there, not a single laurel-leaf javelin-point has been found in that country. Of the Hungarian Solutrean sites we may mention especially Miskolcz ${ }^{2}$; and the cave of Szeleta, near Miskolcz, which has already been mentioned in connexion with the supposed coups-de-poing there discovered ${ }^{3}$.

There are several accounts of the stratification of the Szeleta cave ${ }^{4}$, and it is not easy to reconcile them with one another. But it is clear that under a stratum of recent accumulation, containing Neolithic flints and fragments of pottery, there is an underlying succession of beds, of red and dark grey clay, interspersed with fallen boulders, and containing bones of cave bear, cave lion, hyaena, horse, ox, deer, boar, and wolf, with some smaller animals. The human occupation was not continuous; the hearths are scattered here and there, as though the hunters used it as a temporary shelter when they found it free from the savage animals which were its normal inhabitants. The very numerous implements found consisted of shapeless fragments of stone, with or without secondary chipping, knives, scrapers, borers, and laurel-leaf javelin-points; all Solutrean. The material was for the greater part chalcedony or quartzite; there was one laurel-leaf point of obsidian, which probably came from Tokaj in

1 J. Stobl and H. Obermaier, "Die Aurignacienstation von Krems" (Fahrbuch für Altertumskunde, III. [1909] p. 129).

2 O. Herman, "Das Paläolithikum des Bökkgebirges in Ungarn" (M.A.G.W. xxxviII. [1908]).

${ }^{8}$ C.A.P.A. Stockholm [1874], vol. 1. p. 69. Römer, The Bone Caves of Ojców (tr. Lee, London, I884).

- See Ottokar Kadić, "Paläolithische Steingeräthe aus der Szeletahöhle bei Hámor in Ungarn" (Földtani Közlöny, xxxIx. [1909], p. 580); Eugen Hillebrand, "Bericht über die in der Szeletahöhle im Sommer des Jahres I 909 durchgeführten Ausgrabungen" (ibid. xL. [1910], p. 681); O. Herman, "Zum Solutréen von Miskolcz" (M.A.G.W. xxxvi. [1906], p. 1). 
Hungary. A similar object was found at Předmost, where obsidian does not occur locally, thus indicating intercourse with some region such as that named, where it can be procured. Some of the laurelleaves were of excellent workmanship. Another Solutrean station is in the Löss at Ondratitz in Moravia. It yielded flint implements in considerable numbers, and ochre, but no ivory or bone ${ }^{1}$.

It has been ingeniously suggested that some at least of the javelinheads found in this cave were not directly brought in by man, but were carried involuntarily by wounded animals.

The Magdalenian is represented in Hungary only by the rodentlayer, associated with a few atypic flints. In Austria there are some important sites, such as Aggsbach, and the Gudenus cave near Krems, the stratification of which is as follows:

$G$. Recent earth, stone, ashes, $7 \mathrm{~cm}$.

$F$. Hearths, worked bones, $28 \mathrm{~cm}$.

$E$. Cave earth sterile, $6 \mathrm{~cm}$.

$D$. Cave earth with bones, $26 \mathrm{~cm}$.

$C$. Cave earth, sterile, $28 \mathrm{~cm}$.

$B$. Sand, $65 \mathrm{~cm}$.

A. Cave earth with chalk, $22 \mathrm{~cm}$.

Stratum $F$ contained Magdalenian remains-worked bones, flints, needles, rude bâtons de commandement, assegai-heads. In lower strata were remains of a previous Mousterian occupation, with degenerate coups-de-poing ${ }^{2}$.

A cave near Lokve, in the Karstgebirge, Croatia, yielded many bear-bones, some of which had been broken for marrow, perforated, or otherwise artificially treated. No flints were found: the deposit was probably Magdalenian ${ }^{3}$.

Moravia has yielded also some important Magdalenian settlements, principally noteworthy as affording an extension eastward of the Magdalenian art, which otherwise is almost confined to the west of Europe. The excavations which have been thus productive are due to Dr Martin Křiž. At the cave of Kůlna, which is a great tunnel 85 mètres in length, 20 in breadth and 5 to 8 in height, he found stratified deposits representing a number of different periods, and containing the bones of animals belonging to different climatic conditions. The upper strata contained recent species: then followed steppe fauna, underlying which were those to which glacial condi-

${ }^{1}$ C. Maška and H. Obermaier, "La station solutréenne d'Ondratitz, Moravie" (L'Anthr. xxi1. p. 403).

${ }^{2}$ P. I.eopold Hacker, "Die Gudenushöhle, eine Renthierstation im nordösterreichischen Kremsthale" (M.A.G.W. xIv. [1884], p. 145); H. Obermaier and H. Breuil, "Die Gudenushöhle in Niederösterreich" (ibid. xxxvIII. [1908]).

3 Theodor Korrnos, "Die ersten Spuren des Urmenschen im Kroatischen Karstgebirge" (Földtani Közlöny, xLII. [1912], p. 98). 
tions were suitable. The layers containing the especially quaternary fauna also contained human artefacts of Magdalenian types, including bâtons de commandement of reindeer-horn, flints, worked bones, and the usual furniture of Magdalenian caves. There were also ribs of reindeer upon which recognisable attempts at drawing hoofs of horses were to be traced; otherwise the ornamentation on the bones consisted merely of groups of parallel grooves. At Kostelik, another cave, 14 kilomètres north-east of Brünn, 60 mètres long and 16 broad, there were similar discoveries made. The ornament upon the bones here consisted of figures of fishes, groups of lines, and one attempt at representing a face ${ }^{1}$.

A child's jaw-bone was found at the entrance of the Kostelik cave, but does not appear to have been contemporary with the Magdalenian remains.

Two important caves or group of caves must here be noticed. The first of these is Čertova-díra, in the Koutouč mountains, Moravia, not far from Šipka (ante, p. 307). This cave is 80 mètres in length, and is divided by a narrow part into two halls, with side ramifications. The deposits were stratified as follows:

$E$. Recent earth, $30-70 \mathrm{~cm}$., historic and late prehistoric objects.

$D$. Yellowish-brown cave earth, $30-50 \mathrm{~cm}$.; reindeer fauna. Objects in flint and bone.

$C$. Layer of small arctic rodents. No industry.

$B$. Greyish-brown or reddish earth, 20-50 $\mathrm{cm}$. Cave bear and associated fauna. Rude flints, Mousterian in character, atypic, except two scrapers, a point, and a flake. No bone implements.

$A$. Yellowish-green or reddish sand. No human remains.

This shewed that the cave had been inhabited twice, once in the Mousterian, and once in the reindeer period (probably either Solutrean or Magdalenian). The implements are throughout rude, made of flint, quartz, quartzite, or jasper ${ }^{2}$.

The series of caves at or near Ojców, in Russian Poland (using as before ante-bellum geographical nomenclature, faute de mieux) are famous for their palaeontological treasures, and also for their human remains. It is regrettable that the stratification of the deposits has not been very satisfactorily described, and that in some cases it is impossible to recover it. Several of the series of caves contain no trace of Palaeolithic Man; to these it is not necessary here to refer. Three caves however shewed evident signs of Palaeolithic occupation.

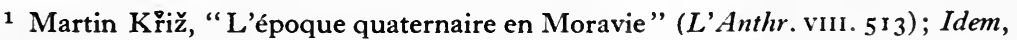
"Vorlege von geschnitzte und gezeichnete Funden aus diluvialen Schichten der Höhle Kůlna und Kostelik" (M.A.G.W.xix. [1889], p. (I I 4)); Idem, Kůlna a Kostelik, dvě jeskyně v útvaru dev'onského vápence na Moravě: bádáni a rozjimáni o pravěkém človéku (Brünn, 1891)

2 An account of this cave will be found in Maška, Der Diluviale Mensch in Mähren. 


$$
\text { li }
$$


These were (I) Feržmanowice, the largest cave of the Ojców series. The upper layers of its deposits were Neolithic, containing pottery, Neolithic flints, and recent fauna. The lower strata contained cave bear, reindeer, and implements including a Solutrean laurel-leaf javelin-head, and some bone prickers and needles. (2) Kozarnia, most of whose deposits were lost owing to the material in the cave being removed for agricultural top-dressing. The little that remained for scientific examination was chiefly Neolithic, but one or two flint flakes, and a perforated canine tooth of a cave bear, were probably Palaeolithic. (3) Wiérzchow, the Lower or Mammoth Cave (so called to distinguish it from the Upper Cave at the same place, the human remains in which were entirely Neolithic). Here a layer with Neolithic hearths, polished stone, pottery, and modern fauna covered a Palaeolithic deposit $\mathbf{2 \cdot 4 2}$ mètres thick, containing bones of reindeer, mammoth, rhinoceros, cave bear. The older deposit was stratified, but the stratification is not satisfactorily set forth: the upper layers were Magdalenian [sic Römer, read Solutrean?] in their affinities, the lower Mousterian. The most interesting contents of this cave were two ivory objects embedded in the upper layer. The first was a flat rod pointed at both ends: similar objects have been found elsewhere in eastern European caves in ivory or in bone (the rib of a mammoth) ${ }^{1}$, and in them Schmidt ${ }^{2}$ sees the prototypes of the Solutrean laurel-leaf. The second was a rod of ivory pointed at both ends, with a groove running round the middle. It has been suggested that this was an ornament intended to be passed through a perforation in the septum of some Palaeolithic dandy's nose, or through a similar perforation drilled in the lobe of an ear. It resembles the double-egg ornaments found in the Barma Grande (ante, p. 357) ${ }^{3}$.

We can hardly spare the space for fuller particulars as to Palaeolithic man in central Europe: but much information on the subject can be obtained in M. Hoernes, Der Diluviale Mensch in Europa (Brunswick, 1903), to which the reader is referred.

\section{Region XI. South Britain}

Both cave and open air stations, and isolated finds of implements, have been found in considerable numbers in south Britain, though there is not the overwhelming mass of material with which we have to deal in discussing the Lower Palaeolithic of this region.

1 Wildhaus in Germany, and Lautscherhöhle in Moravia, as well as the present example.

2 Diluviale Vorzeit Deutschlands, p. 85.

3 See C.A.P.A. Stockholm [1874], vol. I. p. 69; F. Römer, "Die Knochenhöhlen von Oiców in Polen" (Palaeontographica, xxıx. [1882-3], p. 195); English translation, The Bone Caves of Ojców, Poland (London, 1884). Hoernes, Der Diluviale Mensch in Europa (Brunswick, 1903). 
In recent years attempts have been made to put the pits at Cissbury, and the flint-mines known as "Grime's Graves" at Brandon, Suffolk, back into the Palaeolithic epoch. I must acknowledge myself unable to share these views; for me these sites, with their modern fauna, are Neolithic.

Of the caves that have produced remains of human occupation, the Oreston cave near Plymouth, Devonshire, was the first to be investigated. It was dug in 1816 , and bones of extinct animals were found within it, as well as one human humerus, which, however, was not preserved ${ }^{1}$.

The caves which were explored by Dean Buckland, in the twenties of the last century, concern us but little, as the discoveries made in them were exclusively of palaeontological importance. An exception must be made of the Paviland cave, already mentioned in connexion with its skeleton (ante, p. 358), for recent re-examination has proved it very rich in flint implements; these were Aurignacian types of all stages, as well as representatives of the end of the Mousterian and the beginning of the Solutrean. In accordance with the dating to which these flints testify, the horse was the animal most frequent in the cave. The deposit also contained some bone pins and polishers, a remarkable bone spatula, an ivory armlet cut from the hollow end of a mammoth tusk, and a very curious amulet, made of a globule of dentine which had formed during the life of a mammoth in the process of the repair of an injured tusk. Such an unusual object would have been a most powerful "mascot" for the ancient inhabitants of the cave ${ }^{2}$.

The next cave of importance is Kent's Cavern near Torquay. The exploration of this cave began in 1825 under the Rev. J. McEnery, and continued at intervals for many years under various directors. The stratification of the deposits is as follows:

$G$. Limestone fragments fallen from the roof.

$F$. Black mould, $7-30 \mathrm{~cm}$. thick.

E. Granular stalagmite, $2 \mathrm{~cm}-\mathrm{I} \cdot 5$ mètre thick.

$D$. Black band of charred wood, $0-10 \mathrm{~cm}$. thick.

C. Cave earth, O-I.2 mètre thick.

$B$. Crystalline stalagmite, $3-3 \cdot 65$ mètres thick.

$A$. Breccia.

The lowest layer, $A$, contained Chellean coups-de-poing, associated with bones of the cave bear. The enormously thick layer of stalagmite which has accumulated over them gives us an imposing

${ }^{1}$ Hamilton Snith, Natural History of the Human Species, p. 95.

2 W. J. Sollas, "Paviland Cave, an Aurignacian station in Wales" (F.A.I. XLIII. [1913], p. 325 ff.). 
idea of the antiquity of these implements. The layer $C$, which does not extend over the whole cave, contains Upper Palaeolithic implements, Magdalenian as a whole, but some of them with a distinct Solutrean facies; along with bone needles, assegais, hammer-stones,
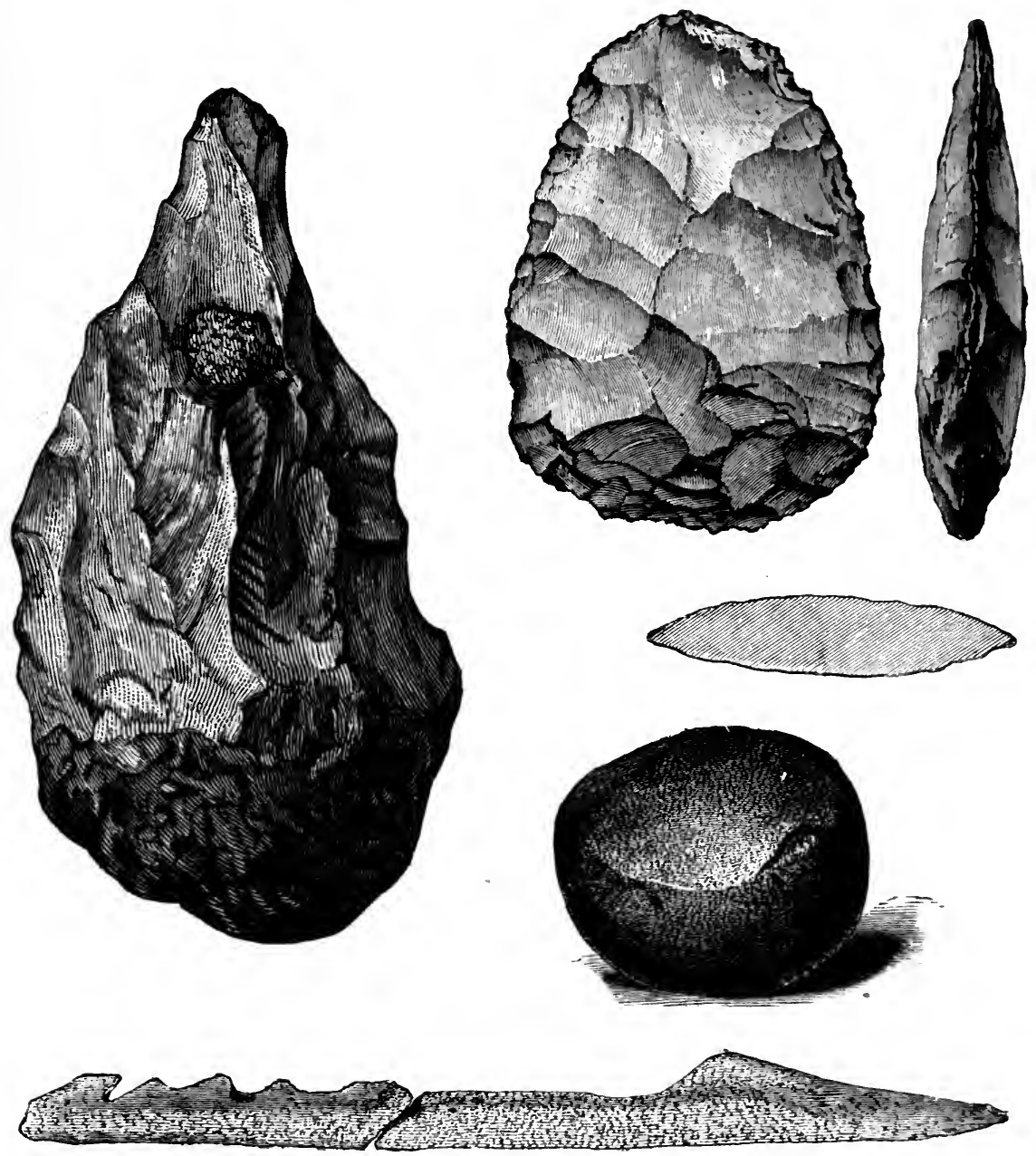

Fig. I 8 . Objects from Kent's Cavern.

(From W. Boyd Dawkins, Early Man in Britain.)

and a badger's tooth perforated (Fig. I 8 ), as well as the bone of a hare with several perforations cut in it. Whatever this was meant for, it can hardly have been a "whistle," as it is sometimes called, for it would scarcely emit a sound. A fragment of a human upper jaw was found embedded in the granular stalagmite $E$. It is described 
by Duckworth as closely resembling the corresponding part of the Spy skull No. ${ }^{1}$. Keith however ${ }^{2}$ does not agree that it shews any Mousterian features. Stratum $F$ contained Neolithic and later objects $^{3}$.

Another Devonshire cave is the cavern of Brixham. This contains three strata-gravel, overlaid with cave earth, and that in its turn covered with stalagmite. Some implements of Lower Palaeolithic type were found in the cave earth ${ }^{4}$.
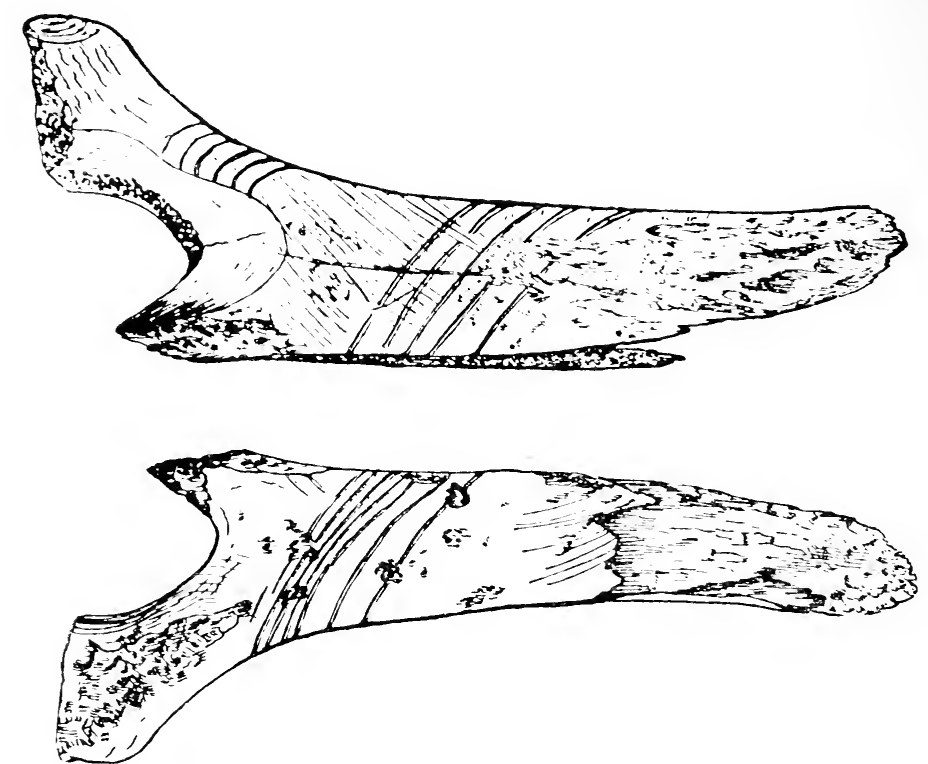

Fig. I19. Bâton de commandement from Gough's Cave, Cheddar.

(From Foumal of the Royal Anthropological Institute, vol. xuIv.)

In the neighbourhood of Wookey Hole, Somersetshire, there is a smaller cave commonly called the "hyaena den." It was filled with the débris left by hyaenas, alternating with remains of human habitation. The flints were for the greater part of Mousterian type, including small coups-de-poing, as well as flakes, scrapers, etc., of flint and chert. There were also some later (Upper Palaeolithic) types.

${ }^{1}$ Brit. Ass. Dundee [1912], p. 602.

2 Antiquity of Man, p. 98 .

"For reports of the successive investigations of Kent's Cavern see papers in Transactions of the Devonshire Association, vols. II. III. IV. XLv.; Proceedings Geol. Soc. vol. III.; Transactions Gerl. Soc. ser. II. vol. vi.; Boyd Dawkins, Cave Hunting, p. 324; Idem, Early Man in Britain, p. 194; Report, British Association, 1865-1880; Evans, Stone, p. $488 \mathrm{ff}$.

${ }^{4}$ See Phil. Trans. Royal Society, 1873, p. 471 ; Dawkins, Cave Hunting, p. 319. 
The large cave contains no Palaeolithic remains, though there are traces of later occupations ${ }^{1}$.

Gough's Cavern, Cheddar, also in Somerset, is a ramifying cave with the following stratification:

$D$. Recent deposit.

C. Stalagmite, $10-30 \mathrm{~cm}$. thick.

$B$. Cave earth $\mathrm{r}^{\cdot} 2 \mathrm{O}-\mathrm{r} \cdot 80$ mètres thick, with fallen block of limestone

$A$. Hard crystalline stalagmite.

In a fissure under the upper layer of stalagmite the skeleton referred to above (p. 384) was found. Magdalenian flints have been found through the cave earth deposit, as well as a fragment of a small bâton de commandement-a very rare object in Britain. This species bore as its only decoration groups of oblique stripes, possibly forming part of a twist that ran in screw-fashion down the shaft of the completed specimen ${ }^{2}$.

On the borders of Derbyshire and Nottinghamshire occur the four caves in the Cresswell Crags. Of these the most important from the anthropological point of view was Robin Hood's Cave, the stratification in which was as follows:

$D$. Breccia with a few bones and flints; $90 \mathrm{~cm}$. thick.

C. Cave earth with bones and implements, $90 \mathrm{~cm}$. $-\mathrm{r} \cdot 20$ mèt. thick.

$B$. Red sand, $60 \mathrm{~cm}$. - $\mathrm{r} \cdot 20$ mèt. thick.

$A$. Light coloured sand, $60 \mathrm{~cm}$. thick.

$A$ was sterile; $B$ contained remains of hyaenas and lions, and with them very rude atypic implements of quartzite; doubtless early Lower Palaeolithic. $C$ shewed man disputing with the hyaena for the possession of the cave; the implements were again of quartzite, Acheulean tending to Mousterian. In $D$ there were Aurignacian end-scrapers, fragments of Solutrean laurel-leaf points, and Gravette points, as well as needles and other implements of bone and reindeerhorn. The horse was the commonest animal in this stratum, which is clearly contemporary with the Paviland cave ${ }^{3}$.

At Langwith, Derbyshire, a cave was examined which was found to contain Magdalenian flints ${ }^{4}$. A human skull of entirely modern type was found in it, but no other bones. We seem to have here an example of - may we call it cephalotaphy? The rite of burial of the head alone is established, and seems to need a name. It will

1 For a picturesque account of this cave see Herbert E. Balch, F.S.A., Wookey Hole, its caves and cave-dwellers (Oxford, 1914). For the Hyaena-den see Q.F.G.S.L. xVIII. [1862], p. I1 5 ; xIx. [1863], p. 260; Dawkins, Cave Hunting, p. 295.

2 See "On the Cheddar cave," Brit. Association, Cambridge [1904], p. 569.

3 Proceedings, Geologists' Association, xxiIr. [1912], p. 145.

4 Derbyshire Archaeological Society, xxxv. p. 137.

M.E.A.I. 
meet us when we consider the Azilian stage in Chapter X; but it does not seem to have been practised in earlier stages. The Langwith skull must therefore, for the time being, be regarded as not earlier than Azilian, probably buried in previously existing deposit. It cannot, therefore, be safely treated as a document for the Upper Palaeolithic ethnology of south Britain.

A number of minor caves chiefly in Derbyshire, Somersetshire, and parts of Wales, have yielded Palaeolithic implements. These need not be here specified: they will be found mentioned with references in Evans, Stone, p. ${ }_{5} 16 \mathrm{ff}$. But mention must be made of a cave near that of Paviland, called Bacon's Hole, where Prof. Sollas and M. l'Abbé Breuil found painted on the wall " ten bright red bands approximately horizontal and slightly divergent, fan-like, arranged one upon the other in a vertical series about one yard high, each band being perhaps a foot in length and one to two inches in breadth ${ }^{1}$." These bands were covered with a layer of stalagmite, which makes it difficult to accept the statement, otherwise not inherently improbable, made by a local fisherman after public attention had been called to them, to the effect that he had made the marks himself in the process of cleaning a paint-brush. If the marks be genuine, they are the only trace of Palaeolithic parietal art yet found in Britain.

An Aurignacian floor has been reported from Heacham, Norfolk ${ }^{2}$, another (?) from Nettlebed, Oxford ${ }^{3}$, and another from Crayford, $K^{2} t^{4}$; a Magdalenian floor from Wangford Warren ${ }^{5}$, and another near Portcuthno, Cornwall ${ }^{6}$. A Solutrean fragment, said to have been found in Burnham, N.W. Suffolk, has been published ${ }^{7}$; it is clearly a broken specimen of a laurel-leaf point, not a pointe $\dot{a}$ cran, as described in the publication indicated. The specimen is so unusually good, that it is hard to believe that it really belonged where it was said to have been found; it might have been imported from southern France in ancient or modern times. Various sites in Norfolk have yielded engravers and other Magdalenian flake tools ${ }^{8}$.

1 Nature, 17 Oct. 1912.

2 Proceedings, Prehist. Soc. East Anglia, vol. I. p. 454.

3 Ibid. vol. II. p. 7 I.

${ }^{4}$ Ibid. p. 80.

5 Ibid. vol. 1. p. 378 .

Ibid. vol. II. [1915], pp. 41, I73.

Ibid. p. 300.

${ }^{8}$ An enumeration of these sites will be found in W. G. Clarke, "Norfolk implements of Palaeolithic cave types" (Prehist. Soc. E. Anglia, vol. I. p. 338). 
Region XVIII. South Russia [east of long. $30^{\circ} \mathrm{E}$.].

Russia possesses scarcely any traces of Palaeolithic Man. 'They are entirely absent in north Russia; and in south Russia they are confined to a few Magdalenian sites in Ukrainia. Among these sites the most important are as follows:

Gontzy, Lubna district, Pultova government: a site discovered by Theofilaktov and Kamensky in $1873^{1}$ in the valley of the river Udai. In the alluvia of the upper terrace were traces of human occupation, flint chips and two bone implements, mammoth and reindeer bones.

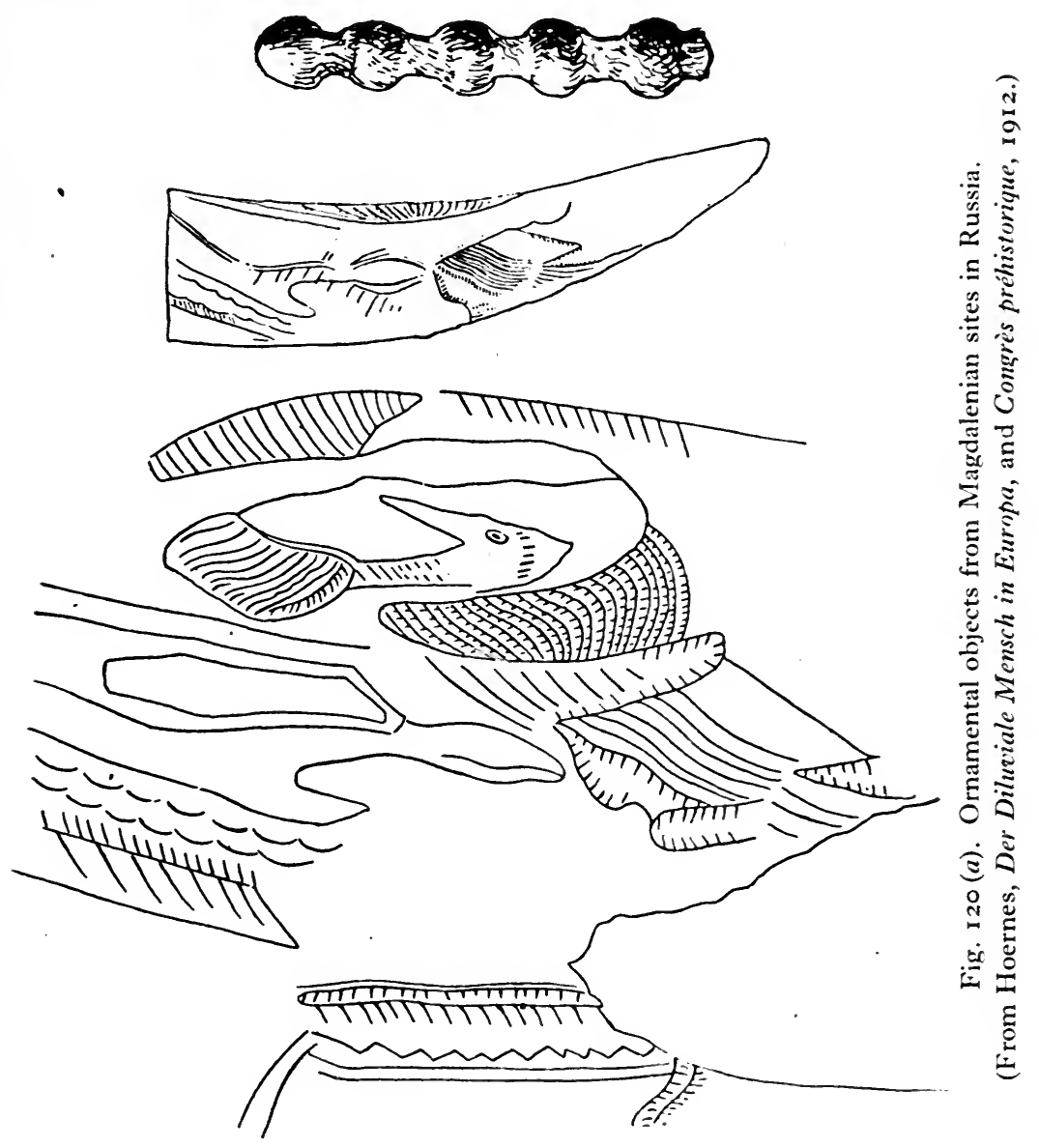

1 Travaux de la troisième session des Archéol. russes à Kiev, 1874; S. Nikitine, "Sur la constitution des dépôts quaternaires en Russie et leurs relations aux trouvailles resultant de l'activité au l'homme préhistorique" (C.A.P.A. Moscow, p. I). 

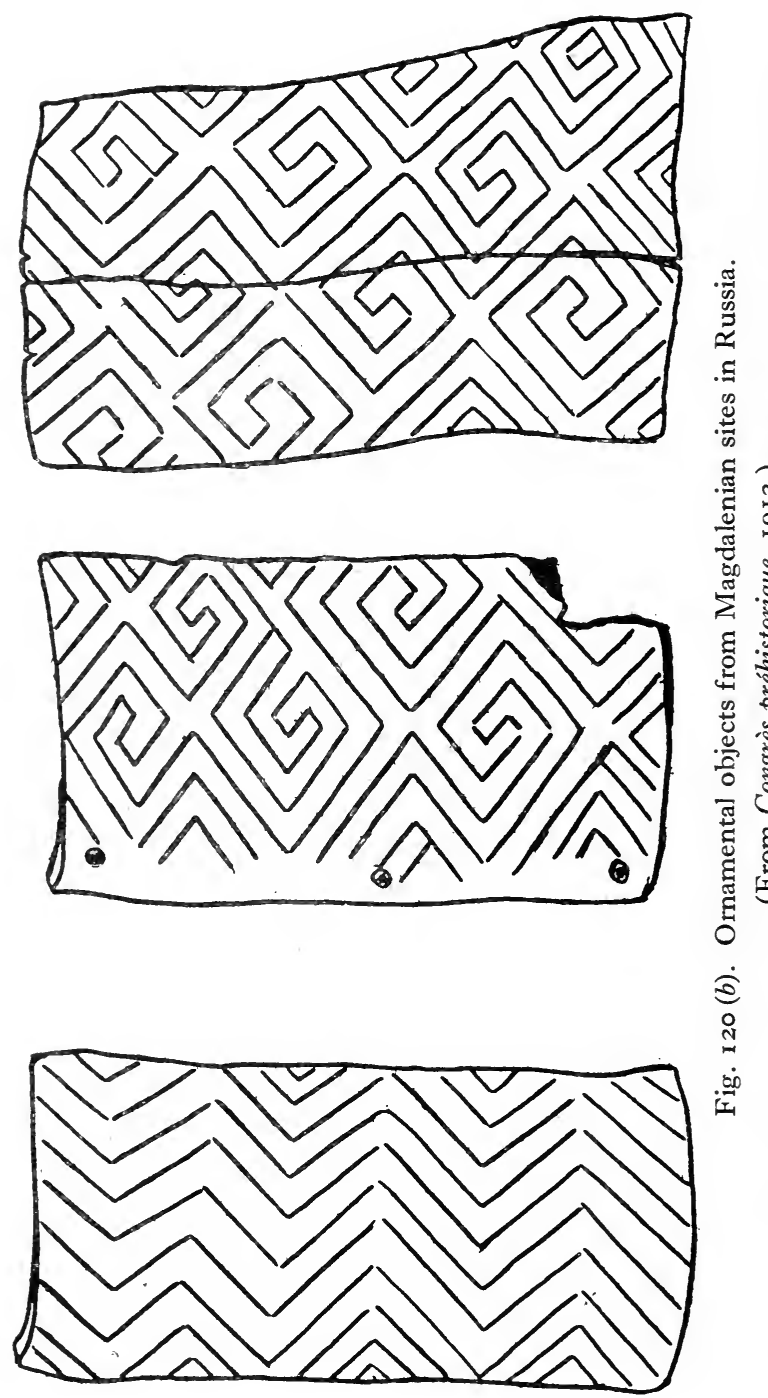

Kostenky, Voronetz government; a site on the banks of the Don. A station similar to Gontzy, in the upper river terrace. Flints, mammoth bones, some of them artificially broken. A Neolithic bed overlies $^{1}$.

Kiev. In the Street of Saint Cyril at Kiev were made some important discoveries, which extended eastward the known area of Upper Palaeolithic art. They were made in a bed of alluvium which

1 Nikitine, op. laud. 
lies along the right bank of the Dnieper, and included many mammoth bones, some of which had been cut or broken with intention, a considerable number of flint implements, fragments of charcoal and of wooden staves worked by man, as well as other objects. A fragment of a mammoth tusk with engraved ornament upon it (Fig. 120 a) was the most important find; it would be difficult however to guess what the design was intended to portray ${ }^{1}$.

Mezin, Tchernigov government. In a stratum underlying a bed of Löss 2.70 mètres thick; a layer of reddish clay, containing bones of mammoth, Rhinoceros tichorhinus, horse, bison, musk-ox, reindeer, bear, Arctic fox, wolf, glutton, and a few other animals; flint implements of Magdalenian forms (though with Solutrean reminiscences), end-scrapers, engravers, and prickers, as well as a few 'Tardenoisian " pygmies" (see post, p. 535); bone prickers and needles; ornamental ivory objects, including pendants, small rods with knobs worked upon them (Fig. I $20 a$ ), some objects which have perhaps a phallic significance, a number of plaques roughly cut into the form of a bird, and fragments of an ivory bracelet having cut upon it an astonishing anticipation of the Greek fret pattern (Fig. $120 b)^{2}$.

1 Luhor Niederle, "Ueber einen wichtigen diluvialen Fund in Russland" (M.A.G.W. Xxiv. [1894], p. (6); B.S.A.P. ser. Iv. vol. Ix. p. 120); Th. Volkov, "Magdalenske maisterstvo na Ukraini" (Bulletin de la société scientifique de Chevtchenko, xLV1.).

${ }_{2}$ Th. Volkov, "Nouvelles découvertes dans la station paléolithique de Mézine, Ukraine" (C.A.P.A. Geneva [1912], vol. I. p. 415). 


\section{CHAPTER IX}

\section{THE PSYCHOLOGY OF UPPER PALAEOLITHIC MAN}

\section{Contrast between this and the preceding stages}

WE were obliged, in speaking of the "psychology" of the men of the previous stages, to limit ourselves to a small number of detached propositions. The available materials did not allow us to venture farther. But when we turn to this aspect of the anthropology of the Upper Palaeolithic Term, we are in a much better position. We have a very remarkable and extensive series of documents, from which it is possible to draw important and far-reaching deductions as to the relation between the men of this Term and the visible and invisible worlds around them.

We must first set before the reader an account of this material, and therefore proceed at once to a summary of:

\section{THE HISTORY OF UPPER PALAEOLITHIC AR'T}

\section{$A$ new phenomenon}

The Upper Palaeolithic Art is a wholly new phenomenon in Europe. Except for some perforated stone and shell pendants, already described above (p. 236), there is no evidence whatever for an aesthetic sense in Lower or Middle Palaeolithic Man. [As we shall see later, the Upper Palaeolithic Art is not wholly aesthetic in its nature, but for the moment this way of expressing the facts may be allowed to stand for convenience.]

\section{Figure-stones}

True, Boucher de Perthes, and some of his followers after him, have produced certain curious flints which they claim to be evidence of the existence of such a sense, in a rudimentary form, in the men of the earlier Terms. These flints, which have received the name "figure-stones" (a translation of the French pierres-figures), are supposed to have been chipped in order to enhance a fancied resemblance to some natural object, which the original pebble displayed. We have probably all of us at one time or another picked up stones which if held at certain angles suggested a human face, or a duck's head, or what you will. The idea is that Palaeolithic man began his art career by attempting to improve'nature-knocking away a lump here, 
deepening a hollow slightly there, and, especially, inflicting a chip intended to represent an eye. As a rule there is only one such chip, and it is as often as not in the wrong place; we might have expected the primitive artist to have gone one step further, and furnished his handiwork with the orthodox two eyes. The curious will find a long series of illustrations of objects of this kind, some of them in colours, in the Gournal of the British Archaeological Association for March 1913. Everyone is free to make up his own mind about them, but the present writer is bound to confess that they leave him cold ${ }^{1}$.

For the following reasons the theory of "figure-stones" appears at least doubtful:

I. The resemblance alleged often requires a lively imagination; and sometimes cannot be seen at all, unless the stone be held at a certain angle. If, now, we try to conceive of the stone as it was before the postulated ancient artist took off the chips, we shall see that the resemblance must necessarily have been by so much the less obvious, even to the eye of a civilised man, accustomed to every possible variety of pictures and sculptures, including futurism and cubism. $A$ fortiori the resemblance would be invisible to a savage, to whom every form of pictorial art was ex hypothesi unknown. Such a person would be little above the level of an animal, which is to all appearance quite unable to recognise a likeness in a picture ${ }^{2}$.

2. The theory of the "figure-stones" assumes that because the primitive artist happened to detect a certain resemblance to something in a stone, he felt a desire to possess that stone. But this is an inversion of the natural course of events. The feeling of mere curiosity, which would impel a man to pick up and preserve a stone because it reminded him of a cat, or a coffin, or a cauliflower, or what-not, is essentially a mark of civilisation. All analogy would lead us to expect that the savage would, for a magical or religious purpose, first desire to possess the representation of the object, and would then set about acquiring it. If he were so fortunate as to find a stone which Nature had begun to shape into the form which he was seeking, he would unquestionably make use of it as the basis of his work-just as he would choose a nodule of the most convenient shape if he were intent on making a stone axe. But we have been told of whole sand-pits full of these objects, artificially chipped; a sort of Palaeolithic Art store-house or curiosity shop. Is it unduly

${ }^{1}$ See also C.A.P.A. Paris [1900], p. 52; Idem. Geneva [1912], vol. I. p. 515 . Revue préhistorique, 1909.

${ }_{2}$ I have seen Arabs puzzled by a photograph of objects familiar to them; and on one occasion an aged Irish peasant to whom I was trying to explain the process of photography was unable to see the image projected on the ground-glass of my camera; he could see nothing but the reflection of his own face. 
harsh to venture the comment that while no doubt the stones are there, the explanation lacks verisimilitude?

3. The Melanesians, according to Codrington ${ }^{1}$, are in the habit of burying stones which happen to resemble yams or other fruits of the earth beside the trees which yield these fruits, in the hope that the mana inherent in the stone will cause an increase of the crops. But this is entirely without analogy to the figure-stones according to the theory of their supporters, and we must be careful not to allow such a false though specious analogy to obscure the issue. We are shewn stones in which attempts have been made, so it is alleged, to increase their resemblance to gorillas, hippocampi, and other creatures, which it is difficult to imagine Palaeolithic or any other primitive people desiring to increase. Indeed, we may use the analogy very fairly in an opposite sense. A savage finding a stone in which he traced a picture of a gorilla would be more likely to try to destroy it, in the hope of diminishing the numbers of that formidable animal.

4. Gorillas, hippocampi, camels, dogs, and other animals have been traced in the "figure-stones" found in Europe; but such animals were almost or quite unknown to the early Europeans, because they did not exist in their surroundings. It is therefore impossible that the resemblances noted by modern collectors should strike the eye and the minds of Palaeolithic people 2 .

5. Nature frequently makes such resemblances without human interference at all ${ }^{3}$. The eye-chip, which is the most specious argument in favour of human intervention, is to be explained by the fact that the chip is almost always on a prominent and therefore specially vulnerable part of the stone. And that only one eye is figured, as a rule, seems (to me, at least) a fatal objection to the explanation suggested.

6 . These objects have generally been reported from Chellean gravels; more rarely, if ever, from Mousterian sites; never at all from Upper Palaeolithic. [One writer ${ }^{4}$ has gone so far as to describe Eolithic figure-stones in the shape of moccassins and cocked hats and sheep's heads-a selection of objects which affords a welcome illumination upon the clothing and the sense of humour of Eolithic man! As a rule, however, it is entertaining and not a little suggestive to see how bitterly the more prominent Eolithists resent the dis-

1 Codrington, The Melanesians, p. I 19.

2 See on this point the review by M. B[oule] of I. Dharvent's "Premiers essais de sculpture de l'homme préhistorique" (L'Anthr. XIII. [1902], p. 74I).

3 An amusing illustration of the possibilities of accidental mimicry in nature is afforded by the silhouette of a Polish Jew, outlined in the markings on the hide of a calf; published by von Luschan in Z.f.E. xxxIx. [I 907], p. 420.

4 Proceedings of the Suffolk Institute of Archaeology and Natural History, xıII. [1909], p. I I 3 . 
coveries of the Figure-stonians.] This distribution of the figurestones is another serious objection to them, and certainly takes from them all claim to lie at the basis of the imported Upper Palaeolithic Art. They should obviously have been commonest in Mousterian sites, had that been the case: and we might have expected that in the artistic atmosphere of the later stages inexpert amateurs would have on occasion amused themselves by producing such objects. It happens that a large number of figure-stones have been reported from England, but only two, or at most three, genuine specimens of Upper Palaeolithic Art.

With these words we may pass to the Upper Palaeolithic stage, simply repeating once more that there is no evidence for an aesthetic sense in Lower or Middle Palaeolithic man ${ }^{1}$.

\section{The scope of Upper Palaeolithic Art}

The manifestations of Upper Palaeolithic Art take the following forms :

I. Sculpture in the round, in horn, bone, and stone.

2. Relief sculpture on cave walls or on masses of stone or of stalactite.

3. Engraving on flat surfaces of horn, bone, or stone, or upon the walls of caverns.

4. Clay modelling.

5. Painting in single colours or in polychrome.

6. A combination of painting and engraving.

The objects represented are:

$A$. Human figures or parts thereof.

$B$. Figures of animals, birds, and fishes, or parts thereof.

C. Vegetable forms.

$D$. Geometrical patterns, and other symbols which cannot be identified.

$E$. Figures of artificial objects.

and while it will scarcely be possible to maintain the classification rigidly, we may adopt it as a basis on which to arrange the descriptions which now follow.

\section{The first discovery}

The first discovery of Upper Palaeolithic Art was made in 1834 , when an engraved figure was found in the cave of Chaffaud (Vienne). Naturally its significance was not understood at the time; not till 30 years later was it explained, and the existence of this ancient art

1 One exception alone may be admitted to modify the absoluteness of this statement. The well-made coups-de-poing of the Acheulean stage, with their screw borders, are certainly symmetrical and have a handsome appearance. But this does not necessarily prove an aesthetic sense, any more than the production of a wellmade and efficient axe or chisel would prove the possession of such a sense in a modern ironsmith. 
formally announced ${ }^{1}$. Later, mainly through the labours of Edouard Piette, sculpture in the round was added to engraving. The first discovery of mural paintings in the caves was made in 1879 , in the cavern of Altamira, North Spain. It is needless to recapitulate the history of this discovery, and of the struggles with which the early investigators had to contend against scepticism and indifference. The scepticism has now been completely vanquished, and dead controversies and futile arguments need not be disinterred ${ }^{2}$.

\section{Evolution of the technique}

It might appear at first sight surprising that sculpture in the round precedes engraving or painting on the flat in development. It seems so much easier to draw in two dimensions than to model in three dimensions. So it may be for us. But that is because we have discovered and use almost unconsciously the arts of perspective and skiography, by means of which we can suggest three dimensions to the eye with the actual use of only two. These arts, like all others, had to be acquired, or rather evolved; and in the study of Palaeolithic Art we can actually see their evolution. The artist began, crudely enough at first, by sculpture in the round. When he was limited by the size and shape of the block which he was carving, his sculpture would tend to degenerate into two reliefs, one on each side of the block, corresponding to one another. A solid bar of reindeer-horn would be suitable for sculpture in the round; a flat bone, or a section of the hard outer rind of a stag's horn, would scarcely be capable of treatment except in the second way. Thus the labour-saving device of cutting one side only would be suggested; and thus the sculpture degenerates into a low relief, the background being cut away. To make such a relief the outline would naturally be sketched first; and a lazy artist might be tempted to stop his work at this preliminary stage, which, as he could not fail to see, suggested the subject to be depicted sufficiently for all practical purposes.

There is no doubt that engraving thus in outline first began, in a rude and tentative way, before the end of the Aurignacian stage: for engraved figures have been found on cave walls, as at Pair-nonPair, buried in Aurignacian deposits, which must have accumulated before the engravings had been made. Engraving did not, however;

1 E. Lartet and H. Christy, "Sur des figures d'animaux gravées et sculptées, et autres produits d'art et d'industrie rapportables aux temps primordiaux de la période humaine" (Revue archéologique, N.S. vol. Ix. [1864], p. 233). It was in this paper that the discovery of contemporary representations of animals now extinct was first announced, as related in Chapter I. of this book.

2 A good account of the early discoveries will be found in Cartailhac and Breuil's sumptuous work, La caverne d'Altamira (Monaco, 1906). 
attain to the artistic excellence which it ultimately reached until it had finally superseded sculpture in the round, in the Magdalenian Stage ${ }^{1}$.

\section{THE AURIGNACIAN STAGE}

\section{SCUlpture in the Round}

\section{A. Human Figures}

The Aurignacian stage has left us certain examples of sculpture in stone, ivory, reindeer-horn, and bone. These all represent human figures-exclusively, in this stage, figures of women. They are invariably undraped, and the details of the body associated with the functions of motherhood are almost always exaggerated. The figures are usually represented as though pregnant, or at least corpulent, but to this rule there are exceptions. The breasts are prominent, and generally pendent; the external organs of sex are strongly marked, and the hips are also prominent. It has been sought to prove that these represent women racially akin to the Hottentots, on account of the prominence of the hips (which recalls the steatopygy which characterises Hottentot women) and of certain anatomical peculiarities of the organs of sex. Such deductions, however, are not justified. Though the sculptures are clever, they are by no means finished works of art, and least of all are they to be taken as ethnological documents ${ }^{2}$. We are no more entitled to draw conclusions from these figures as to the physical conformation of their makers, than we are entitled to make inferences as to the physical conformation of modern Europeans from the offensive drawings scrawled by street loafers upon blank walls. Someone once gravely took measurements of one or two of these statuettes, and calculated their cephalic, facial, and nasal indices for comparison with those of the indices of skulls. Perhaps in the whole chequered history of archaeological research a deeper depth of absurdity has rarely been plumbed.

The following are the most notable of the statuettes which the Aurignacian stage has bequeathed us:

I. From Le Mas d'Azil. The upper part of a female figure, sculptured from the incisor tooth of a horse (Fig. I2I). This statuette shews the face more clearly than any other as yet found. The forehead

1 See the important paper by M. l'Abbé Breuil, "L'évolution de l'art quaternaire" (Rezue archéologique, ser. IV. vol. xil1. [1909], p. 378). This supersedes all earlier papers on the same subject, such as Édouard Piette's "Notes pour servir à l'histoire de l'art primitive" (L'Anthr. v. [1894], p. 129), which offers a division of the development into periods, now obsolete, and therefore unnecessary to repeat.

"See Regnault, "Ia représentation de l'obésité dans l'art préhistorique" (B.S.A.P. ser. vi. vol. III. [1912], p. 35); Cartailhac, "Le soi-disant stéatopygie de quelques statuettes préhistoriques" (A.F.A.S. Cherbourg [1905], p. 732). 
is high and straight, the nose prominent, not flat. The upper jaw projects above the lower; the chin is weak and receding. The breasts are pendent. The arms are omitted, as it was impossible to model them in the narrow space which the limits of the tooth permitted.

2. From Brassempouy. The middle portion of a female figure in ivory. If completed in proportion this figure would have been about $20 \mathrm{~cm}$. in height. The breasts were pendent, as indications
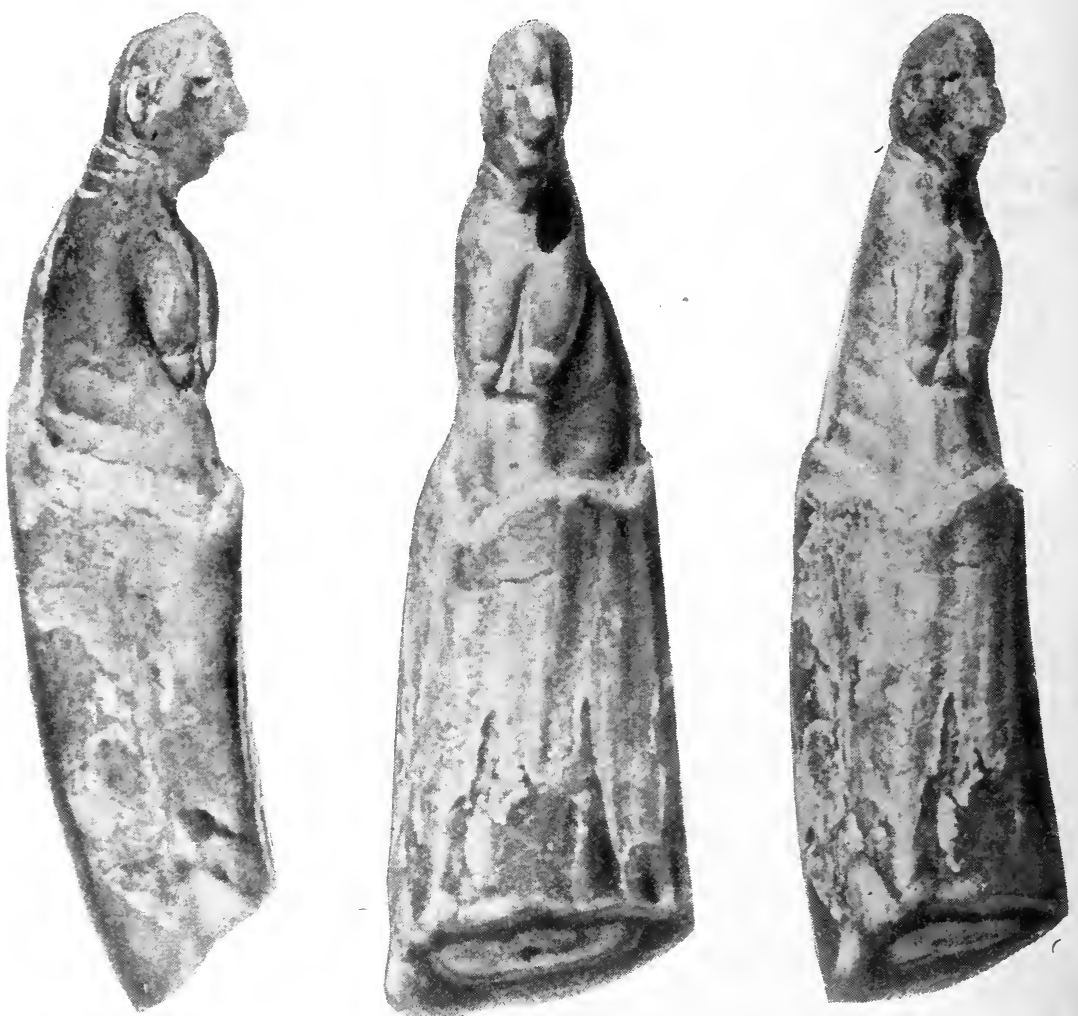

Fig. I21. Sculptured statuette from Le Mas d'Azil.

(From L'Anthropologie, vol. vi.)

at the top of the remaining fragment shew. The abdomen is prominent, and seems to be covered with hair. The right thigh, which remains, is very adipose.

3. From Brassempouy. A figure in ivory, $7 \mathrm{~cm}$. high, representing a woman. This figure has not the adiposity of most of the others. A band seems to be tied round the breasts. The groove down the spine is greatly exaggerated ${ }^{1}$.

1 An illustration of this figure will be found in L'Anthr. vi. [1895], pl. vii. fig. I. 
4. From Brassempouy. The head of a girl in ivory, $+\mathrm{cm}$. high. The features are represented as not unpleasing; the face is triangular and has the cat-like appearance not infrequently seen in broad-faced
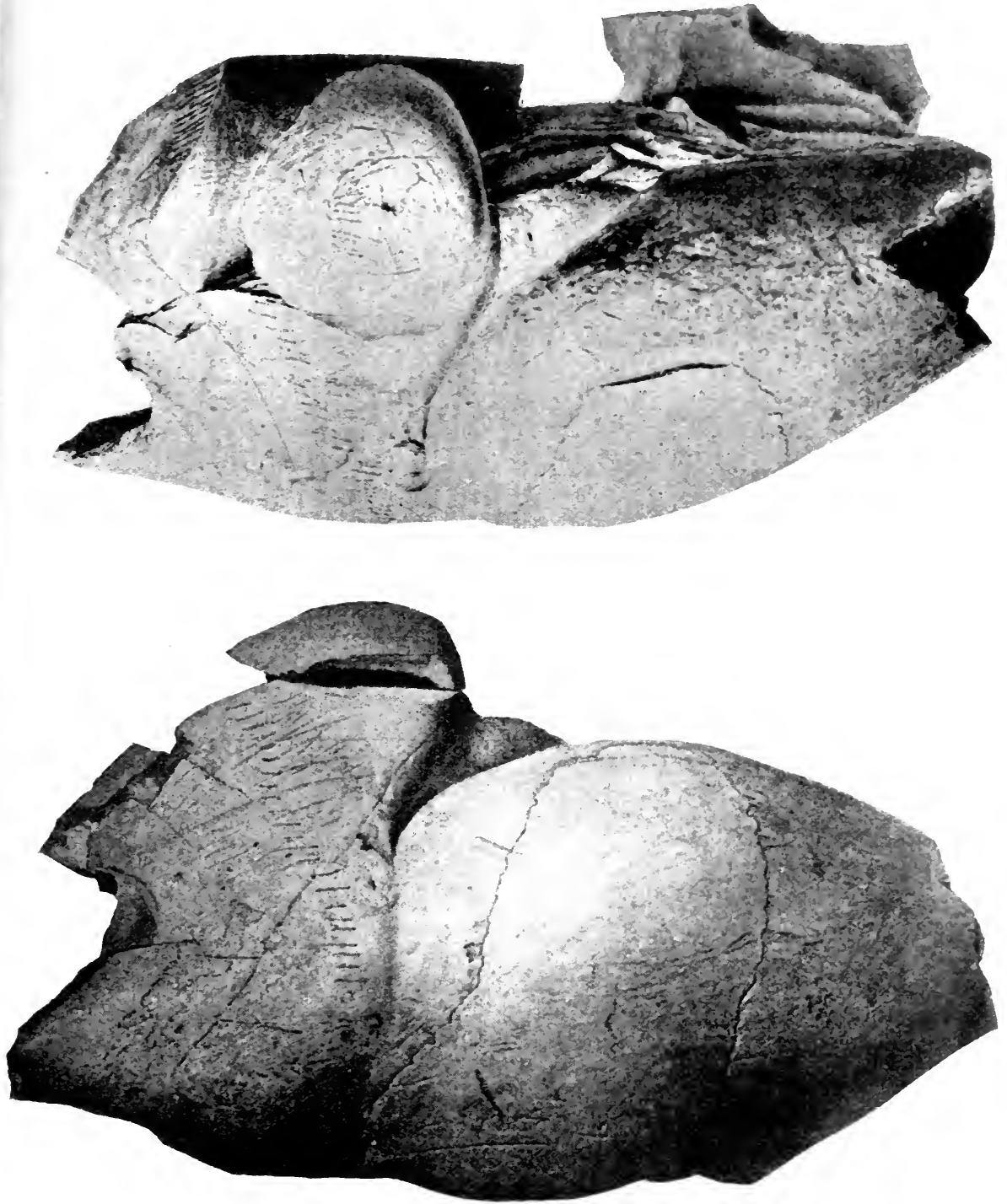

persons. The chin is conspicuously pointed (Fig. 123). The hair falls freely down the back; it appears to be braided and wavy at the lower end. We are hardly to think of a veil-like headdress.

5. From Mentone, probably the Barma Grande. This and the 
next two figures were obtained from the Grimaldi caves, before their final scientific excavation, through the medium of an excavator who for a time exploited them for commercial purposes. The history of their discovery and their stratigraphical position cannot therefore be recovered, as they were sold under the discreditable pledges of secrecy usual in such cases. Through Edouard Piette, their purchaser, they came ultimately into the possession of the Saint-Germain museum. Their authenticity has been attacked unjustifiably: and the later discovery of fragments of steatite (the material of which the figures
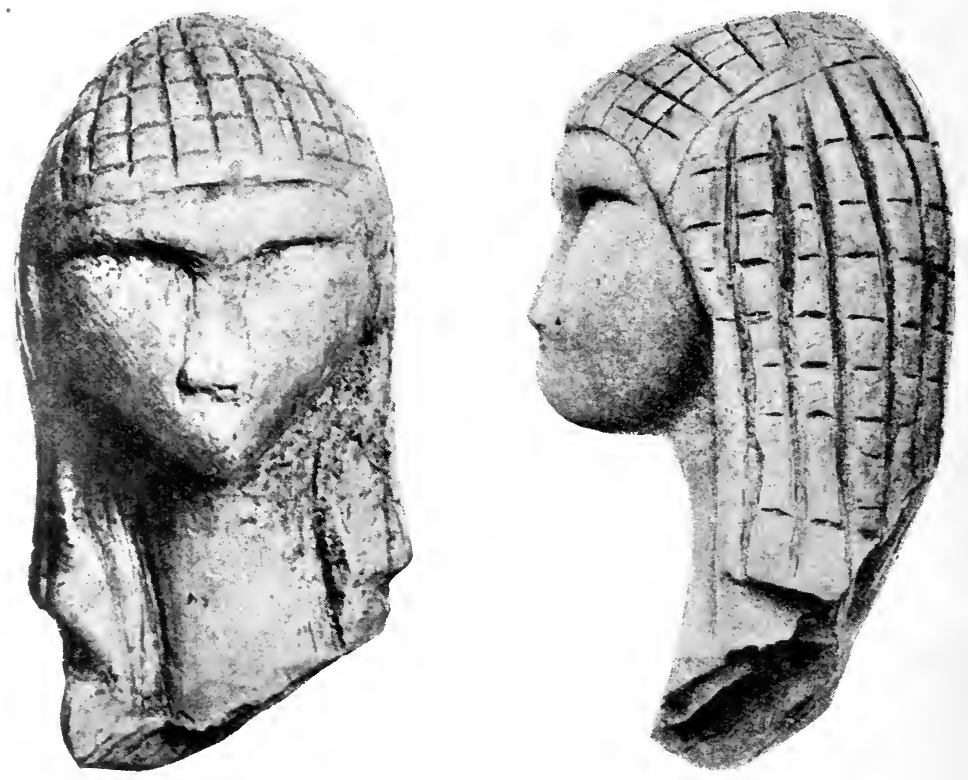

Fig. 123. Head of a girl from Brassempouy.

(From L'Anthropologie, vol. vi.)

are made) with scratches upon them (perhaps the beginning of other works of art, never carried out) within the cave, justifies their acceptance as authentic and as coming actually from this site ${ }^{1}$.

- The first statuette ${ }^{2}$ represents a woman, nearly $5 \mathrm{~cm}$. high. The arms are not represented, and the lower parts of the legs are also absent. The hair falls down the back. The breasts and the protuberance of the abdomen are enormously exaggerated ${ }^{3}$.

6. From Mentone. A figure similar to the last, with similar

1 See Les grottes de Grimaldi, vol. II. p. $267 \mathrm{ff}$.

2 Illustrated L'Anthr. vol. Ix. [1898] pl. i.-ii.

${ }^{3}$ See S. Reinach, "Statuette de femme nue découverte dans une des grottes de Menton" (L'Anthr. Ix. [1808], p. 26). For the attack on the authenticity of the object see G. de Mortillet in B.S.A.P. ser. IV. vol. Ix. [1898], p. 146. 
exaggerations. An engraving of it will be found in Edouard Piette's description ${ }^{1}$.

7. From Mentone. The head of a statuette wearing a crimped headdress (or curled negro-like hair) similar to the Brassempouy girl figured above?

8. From Laugerie Basse. Figure of a woman, in ivory, $8.5 \mathrm{~cm}$. in length. This figure differs in contour from the Brassempouy statuettes; the body is slender and well-shaped. The head is missing,

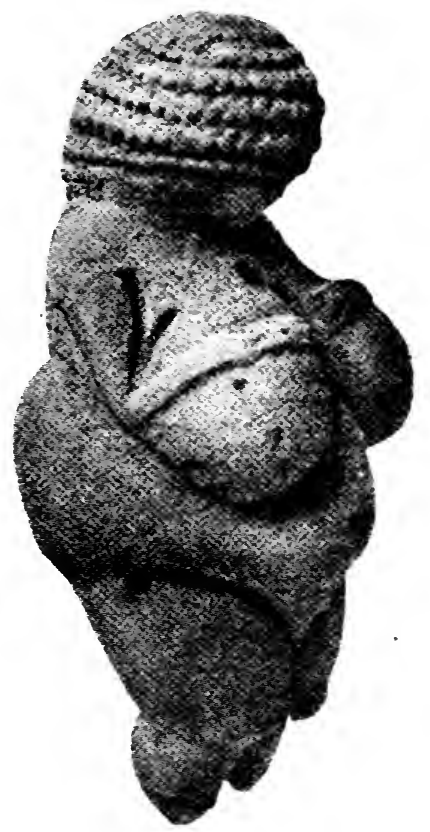

Fig. 124. The Willendorf statuette.

(From Corrcspondenzblatt [1909], p. 85.)

and there probably were never any arms. It is possible that this statuette is preferably to be called Solutrean ${ }^{3}$.

9. From Willendorf. The farthest east example of this type of Upper Palaeolithic Art as yet found. It lay, as has already been said, a short distance $(25 \mathrm{~cm}$.) under the ninth archaeological layer in the Löss at Willendorf (see p. 425 ). It is in oolitic limestone, and bears traces of red paint. The hair is braided, like that of the Brassempouy

1 "Gravure du Mas d'Azil et statuettes de Menton" (B.S.A.P. ser. v. vol. III. [1902], p. 77, fig. 4).

2 Piette, op.laud. fig. 3. Two other statuettes are described in the same paper, without illustration: the description, which seems slightly imaginative, calls for passing reference only.

${ }^{3}$ An illustration will be found in L'Anthr. vol. xvir. p. 10 . 
girl; the arms, which are much attenuated, rest on the upper surface of the greatly exaggerated breasts; a simple bracelet, denoted by strokes, decorates each forearm. The features of the face are not represented or even indicated; it is possible that these were originally painted on the surface of the stone. The breasts are not pendent. The fat of the haunches is emphasised, but the figure is not actually steatopygous. The abdomen is also prominent, and the sexual parts are carefully treated in detail. The thighs are short, and the lower part of the legs is absent (Fig. I24). Total height of the figure, I I cm.

\section{B. Other Subjects}

No other subjects are represented in sculpture in the round in the Aurignacian stage.

\section{SCUlpture in Relief}

Of these the most remarkable, if not the only Aurignacian series as yet discovered, are the five sculptures found at Laussel(Dordogne) ${ }^{1}$. This is a rock-shelter which was inhabited and abandoned six different times; traces of occupation in Acheulean, Mousterian, Middle and Upper Aurignacian, and Lower and Upper Solutrean times were revealed in the excavation of the deposits. In one of the shelters (which measured about 24 mètres by 18 ) were traces of a Magdalenian settlement as well, with the characteristic harpoons.

Laussel proved to be one of the richest stations known for UpperAurignacian remains. The stratum corresponding to this stage covered the whole floor-area of the settlement, though the other strata were interrupted here and there. There were many flint implements, some of them of great beauty. The sculptures belonged to this stratum, or perhaps to the bottom of the Lower Solutrean. They were as follows:

I. A flat block of limestone, measuring $47.5 \mathrm{~cm}$. in its maximum dimension, and bearing a sculpture in low relief, $23 \mathrm{~cm}$. in length. An illustration will be found in $L^{\prime}$ Anthr. XxII. [I9II], p. 259. It represents a scene either of coition or of parturition: more probably the former.

2. A woman, sculptured on a block of limestone. She is holding a bison-horn aloft in her right hand (Fig. 125). There are no features represented, but the head is turned in profile. The whole body is polished, except the head, which is however carefully carved; the figure was originally painted red. The horn

1 Gaston Lalanne, "Bas-reliefs à figuration humaine de l'abri sous roche de Laussel, Dordogne" (L'Anthr. XxIII. [1912], p. I29). 


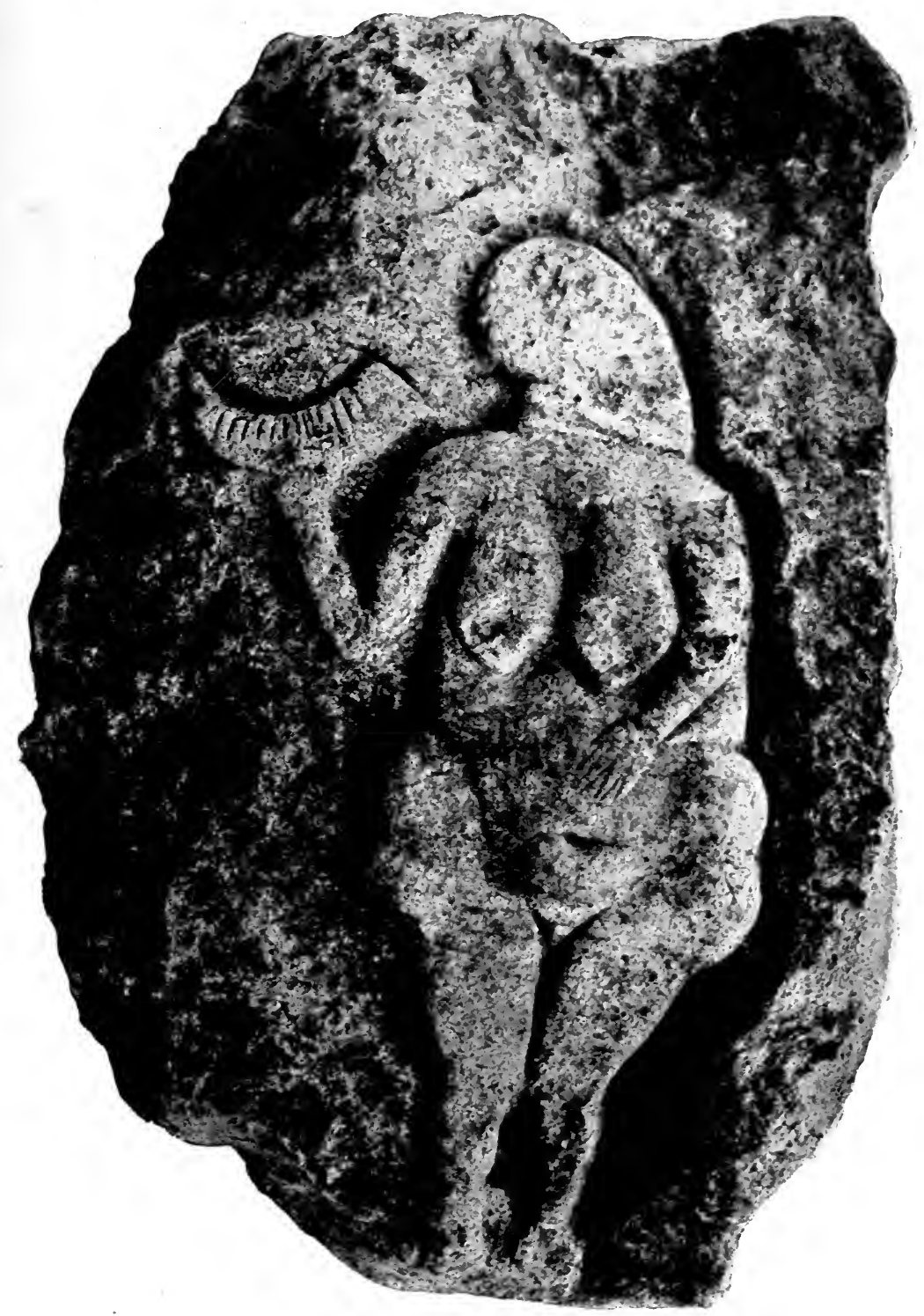

Fig. 125. Sculpture of a woman from Laussel.

(From L'Anthropologie, vol. xxIII.) 


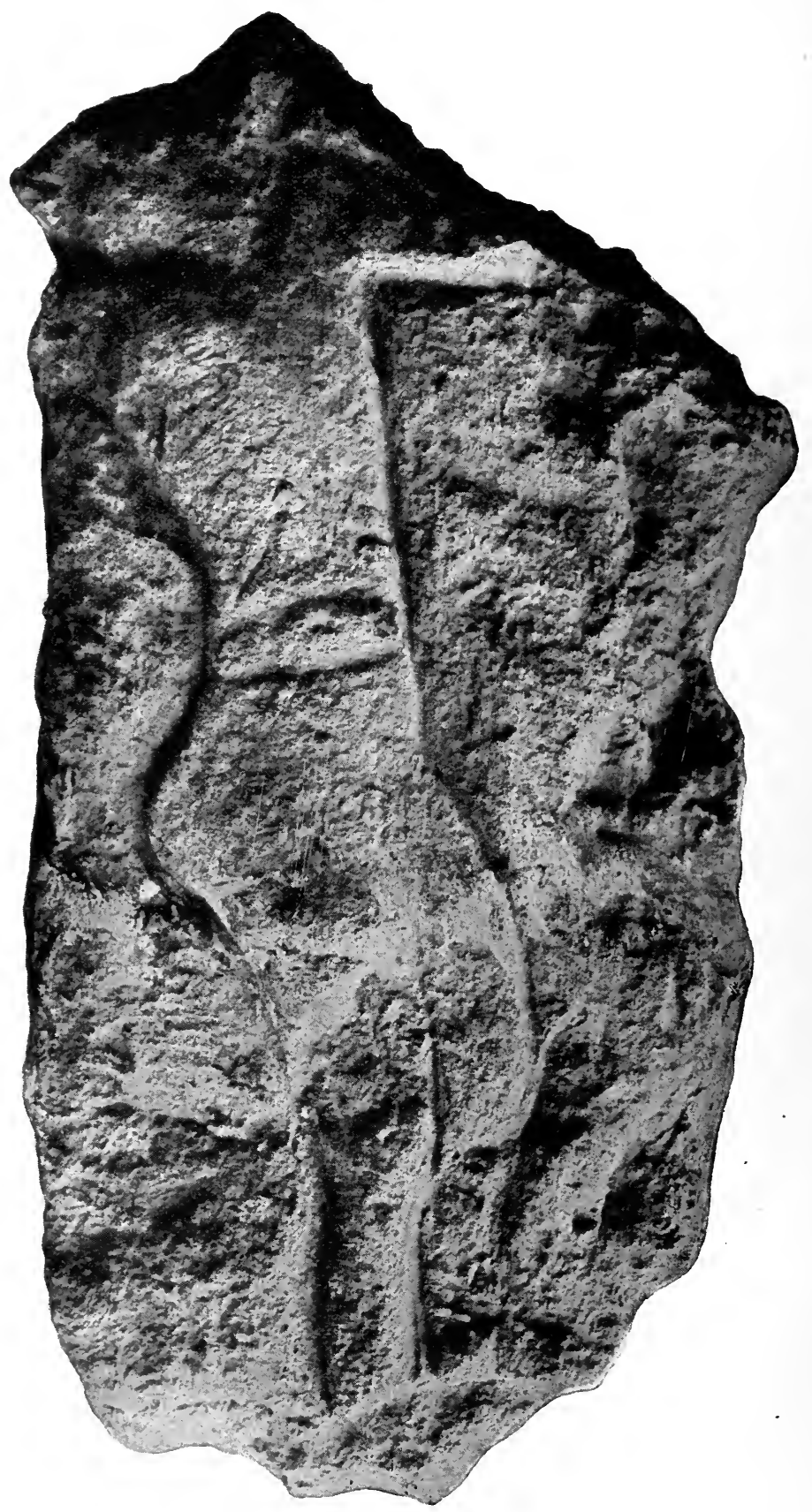

Fig. 126. Sculpture of a man, from Laussel. (From L'Anthropslogie, vol. xxiII.) 
which she is carrying has incisions upon it. Such incisions are frequent on bones found in Aurignacian deposits; they are often called "marques de chasse," as though they were records of the number of beasts killed in a hunt. The limestone block measures $\mathrm{I} \cdot 20$ mètre by $\mathrm{I} \cdot 57$ mètre; the figure was $47.5 \mathrm{~cm}$. high. There were no Solutrean deposits in its neighbourhood; it was certainly Aurignacian.

3. A similar figure of a woman, cut on a limestone block $43 \mathrm{~cm}$. by $39 \mathrm{~cm}$. by $33 \mathrm{~cm}$., found in the Aurignacian deposits not far from No. 2. This figure resembles No. 2, but is smaller and incomplete, the lower part of the figure being missing. The arms in this case lie along the side of the body. The hair is blocked into squares like the hair of the Willendorf figure. An illustration will be found in L'Anthr. XxiII. 143.

4. A man, cut on a block of limestone $47 \mathrm{~cm}$. by $25 \mathrm{~cm}$. by $13 \mathrm{~cm}$. The top of the head is lost as well as the lower part of the legs; the remaining part of the figure is $40 \mathrm{~cm}$. in length (Fig. 126). It is supposed that this figure is represented drawing a bow, as the left arm is extended; this however is doubtful; we might have expected to find some indication of the bowstring, had that been the intention of the sculptor. There is a girdle round the body of this man; the female figures have no covering.

5. A woman, similar to those already described, but not published, for the reason that it was secured by a museum, it is alleged, by tampering with the excavator's workmen, and is kept there in secret $^{1}$.

\section{ENGRAving}

\section{A, B. Figures of Men and of Animals}

In studying the engravings of the Aurignacian period, the first group that calls for our attention is the series on the wall of the cave of Pair-non-Pair (Gironde). Near the hamlet bearing this name a cave was discovered and excavated with admirable method and skill by $M$. François Daleau'.

The cavern was almost entirely filled with the deposit on the floor; this was carefully removed, stratum by stratum, by the explorer in person. The wealth of his harvest may be gauged by the fact that about 4 cubic mètres of flint and 3 cubic mètres of bone

1 See L'Anthr. xxIv. [1913], p. 734. The discredit attaching to the transaction is only partially evaded by the plea that the object was obtained, not directly from the workman, but from a dealer; Mannus, Iv. [1912], p. 459. On the Laussel sculptures see Gaston Lalanne, "Un atelier de sculpture de l'âge du renne" (Revue préhistorique, v. [1910], p. 33).

2 F. Daleau, "Les gravures sur rocher de la caverne de Pair-non-Pair" (Actes de la soc. archéologique de Bordeaux, 1897). 
remains were unearthed. These were stratified in three layers-the lowest Mousterian, $1 \cdot 50$ mètre deep, the next early Aurignacian, $30 \mathrm{~cm}$. deep, and the topmost later Aurignacian ${ }^{1}, 2 \cdot 30 \mathrm{~cm}$. deep.

When the contents of the cave were thus cleared out, figures of animals were seen to be scratched upon the walls. They were rudely drawn in outline, and for the greater part were hardly to be identified with any particular species, though horses, deer, and perhaps an elephant, were to be recognised. Faint traces of a red colour were detected on one of the figures.

The special importance of this cave lay in the fact that the engraved lines were completely covered with the matter which filled the cave. They must therefore have been later than the Mousterian and earlier than the later Aurignacian, for they were above the level of the first and concealed by the deposits of the second. They were
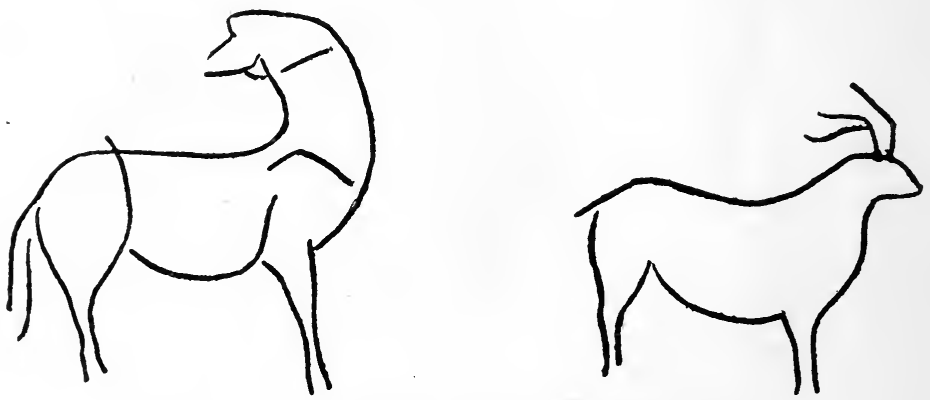

Fig. 127. Aurignacian engravings, Pair-non-Pair.

(From Revue de l'École d'Anthropologie, vol. xvi.)

therefore to be assigned to the earlier Aurignacian occupation. This affords a useful point of departure in dating the engraved figures ${ }^{2}$.

One of the animals, apparently a horse, is represented as turning its head; the others are all standing, head forward, and represented, as it were, "in elevation," to use the architectural technicality: that is, there is no attempt at perspective, the consequence of which is that only two legs are represented, those on the foreground hiding those in the background. They are outlined in deeply cut lines. On one of the figures traces of red colouring is to be detected (Fig. 127).

In the small cave of La Grèze, Dordogne, there are engraved a few figures of animals which shew a similar technique; the outlines

${ }^{1}$ A correction of the first estimate, which made the upper strata Solutrean and Magdalenian respectively.

2 See G. de Mortillet, "Grottes ornées de gravures et de peintures" (R.E.A. viII. [1898], p. 20). See also M. Boule's review of Daleau's paper (L'Anthr. IX. p. 66). 
are deeply cut and only two of the legs of each animal are shewn. These designs are much injured, with the exception of the figure of a bison, which was protected by being concealed under deposit containing Solutrean objects. The La Grèze engravings are thus proved to be contemporaneous with those of Pair-non-Pair, as we might have expected from their identity of type.

Some of the engravings in the caves of La Mouthe and Les Combarelles, both likewise in the department of Dordogne, shew similar technique. In both caves later additions have been made to the mural decoration, but among these the engraved outlines of the Aurignacian type are to be detected. The first-named of these caves, which is in the commune of Tayac, was supposed to be a simple grotto, which the proprietor of the land wished to make into a storechamber. In the course of levelling the soil for this purpose a passage was revealed, which though only about $45 \mathrm{~cm}$. and $60 \mathrm{~cm}$. broadso much was it encumbered with rubbish-was traced for a length of over 200 mètres. At a distance of about 90 mètres from the entrance there begins a series of engraved animals. The deposit on the floor, on being excavated, proved to be Palaeolithic, with a Neolithic stratum covering it; the latter fails just after passing the entrance of the cave, and after a while the Palaeolithic later also ceases, in accordance with the usual rule that the remains of occupation are for the greater part confined to the outer parts of the caves. Further in there were found the remains of bears and hyaenas, shewing that these animals had used the cave as a den. The engravings begin after this point is passed - the first illustration which we have come to of the remarkable and suggestive fact that in many cases the mural decoration of the caves is found in their inner resesses, though the remains of the life of the inhabitants are near the entrance. The drawings are for the greater part simple engravings, though some of them have been touched up with ochre ${ }^{1}$.

The cave of Les Combarelles is a straight gallery, some 230 mètres long, and about 2 mètres broad. At 120 mètres from the entrance, and therefore in total darkness, a series of animals engraved on the walls begins, and extends almost to the end of the cave. Some of these are only $10 \mathrm{~cm}$. in height, others as much as a mètre. They are sometimes single, sometimes superposed-that is, the figure of one animal formed over another and interfering with, if not almost completely effacing it, after the fashion of a palimpsest manuscript. More than a hundred figures of animals or heads of animals have been recognised-horses, buffaloes, remdeer, mammoth, ibex, wild

1 See a long article upon this cave by E. Rivière, B.S.A.P. ser. Iv. vol. vilı. [1897], pp. 302, 484, 497 . 
cat, bear, and some human faces. They are engraved, either in deep broad lines, or else in fine shaded lines. Occasionally the engraved line is accentuated with a line of black paint, but otherwise paint is not used in this cave. The figures are rather stiff, but on the whole better than those of La Mouthe; they are not without evidence of careful observation and accuracy of line ${ }^{1}$ (see Figs. I I, I4, ante).

Another cave to be classed in this series, also in the department of Dordogne, is that of Bernifal. It consists of three chambers, united by passages; these were partly blocked with Palaeolithic deposits, proving that the engravings on the walls were of earlier date. The second chamber is decorated with deeply engraved figures of animals, such as mammoths, horses, a bison, and some others, less easily identified. There are also a number of the so-called "tectiform" devices to be seen here: a description and an explanation of these remarkable designs will be given later ${ }^{2}$.

In the French cave of Marsoulas, and in the Spanish caves of Castillo and Altamira, are similar engraved animal figures, which are to be assigned to the same stage. These caves, however, contain more important later works of art, and therefore are noticed on a subsequent page, in the part of this study devoted to the period of these later works. On the other hand the cave of Hornos de la Peña appears to belong entirely to this type.

The Lower Aurignacian levels shew no trace of figure engraving upon portable objects of stone or bone; decoration of this kind is there confined to groups of lines or of notches or nicks which merely diversify the surface and represent nothing. One of the oldest specimens of Palaeolithic engraving as yet found is on a plate of schist from the Grotte du Trilobite at Arcy-sur-Cure (Yonne), referred to in the previous chapter as one of the few important Aurignacian stations in northern France. This engraving consists of a medley of animals, so much mixed up together that it is at first sight difficult to tell where one begins and the other ends. The technique is similar to that in the cave engravings. The superposition of designs, of which this is an early example, as we shall see, is not the least significant feature of Upper Palaeolithic Art: but we cannot consider its meaning until we have examined all the evidence. Among the animals represented is the two-horned rhinoceros, which is very rarely pictured in Upper Palaeolithic Art (Fig. 128).

We pass over as insignificant the Aurignacian engravings which

1 Capitan and Breuil, "Reproductions des dessins paléolithiques gravés sur les parois de la grotte de Combărelles" (Compte-rendu, Académie des Sciences, CXxxIIJ. [1901], p. 1038).

2 See Capitan, Breuil and Peyrony, "Les figures gravées à l'époque paléolithique sur le parois de la grotte de Bernifal, Dordogne" (R.E.A. xIII. [1903], p. 202). 
would fall under headings $\mathrm{C}, \mathrm{D}$, and $\mathrm{E}$ in the foregoing enumeration of classes of designs (ante, p. 44I). The only devices calling for mention are the wavy random groups of lines traced on the walls of the caves of Gargas, Altamira, and Hornos de la Peña-as though a person had made with his fingers or with a forked instrument a number of groups of parallel winding lines, without traceable meaning, in mud. It is possible that these wavy lines are an imitation of the claw-marks made by the cave bear.

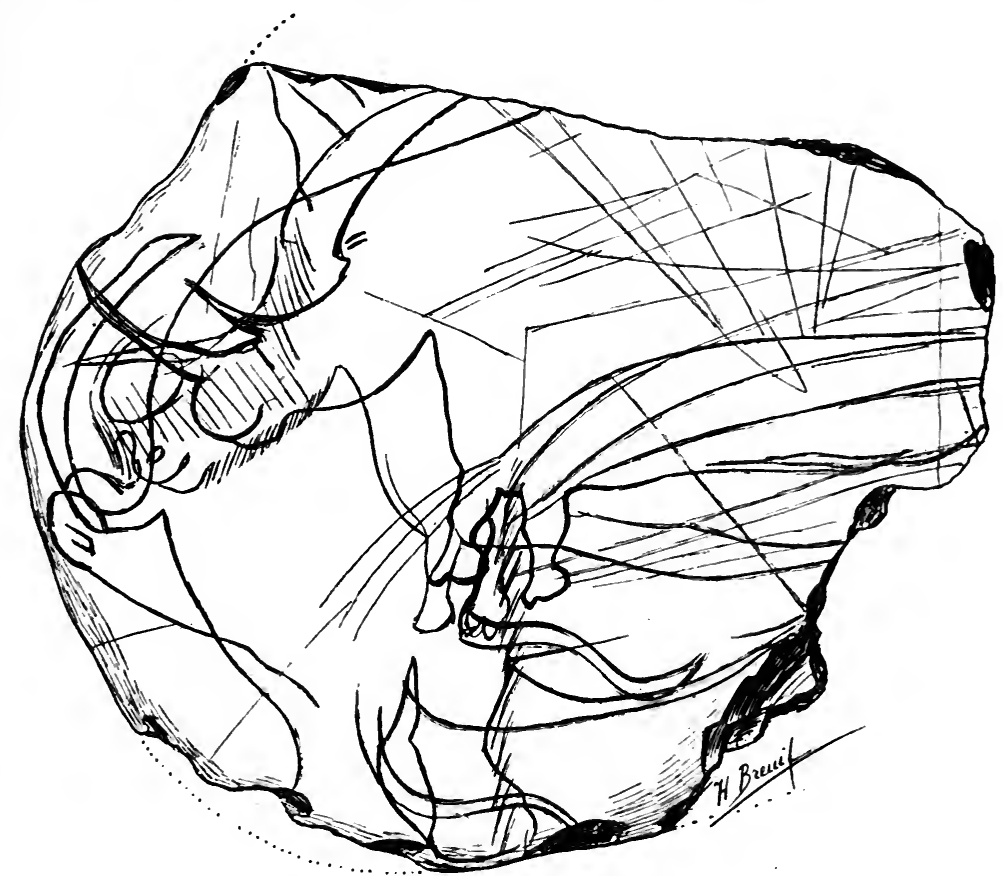

Fig. 128. Engraving from the Grotte du Trilobite.

(Drawn by M. l'Abbé Breuil; from Revue de l'École d'Anthropologie, vol. xvi.)

There is no known Aurignacian specimen of clay modelling: we therefore pass at once to

\section{Painting}

\section{A, B. Figures of Men and of Animals}

The oldest remains of painting are not human figures, but human hands, which are traced upon the walls of certain caves by the following method: a hand was pressed against the wall and colouring matter projected upon it, either with the other hand or by expulsion from the mouth of the artist. The process finished, the hand would be left silhouetted or rather stencilled upon the wall. The most remarkable series of such hands exists in the cave of Gargas, Hautes-Pyrénées. 
This very important cave first attracted notice by its rich palaeontological remains. Numerous skeletons of the cave bear, hyaena, and wolf were yielded by its deposits, as well as hearths assignable to the Aurignacian stage. Geologically, this cave, with its deep "oubliettes" or vertical pits, which make its exploration a matter requiring considerable caution, is of considerable interest ${ }^{1}$.

The Aurignacian hearths give us a date for the mural decorations on the cave walls. There is no evidence of any later occupation of the cave. The designs have been studied by Cartailhac and Breuil ${ }^{2}$. In many ways the Gargas designs are very remarkable from the point of view of technique and of the choice of subject. They consist of $(a)$ designs engraved upon the wall; $(b)$ designs traced with a finger-tip on the mud coating of the wall; and $(c)$ stencilled figures, in black and red colour.

The engraved lines portray an elephant, confused with horses and bovine animals. This is noteworthy partly as another example of the superposition of designs, and partly because the elephant is a comparatively rare figure in these Palaeolithic picture-galleries. The finger-tracings are as just described-meandering wavy lines, running apparently at random and without meaning over parts of the cave wall; there are one or two figures of animals to be traced among them (rhinoceros, cave bear, stag). Similar finger-tracings are to be seen in Hornos de la Peña and in Altamira.

The stencillings are for the greater part figures of hands, impressed in the manner described above. They were first discovered by Regnault, who also described the Aurignacian hearth ${ }^{3}$. Breuil gives the following table, shewing their number and distribution through the different parts of the cave:

\begin{tabular}{|c|c|c|c|c|}
\hline \multirow[b]{2}{*}{ In the entrance hall } & \multicolumn{2}{|c|}{ Right hands. } & \multicolumn{2}{|c|}{ Left hands. } \\
\hline & Black & Red & Black & $\operatorname{Red}$ \\
\hline Left wall as you enter & I & $\circ$ & 40 & 27 \\
\hline Right wall $\ldots$ & $5 *$ & 6 & IO & 3 \\
\hline Inner part of cave & 2 & $\circ$ & 26 & 18 \\
\hline
\end{tabular}

1 Plans and sections of the cave will be found in L'Anthr. III. [1 892], p. 32 ; xxI. [I9I0], p. I30. See also P. Garrigou and A. de Chasteigner, "Contemporanéité de l'homme avec le grand ours des cavernes et le renne dans la caverne de Gargas, Hautes-Pyrénées" (C.-R. Acad. des Sciences, Lxxı. [1870], p. 288); F. Regnault, "Foyers paléolithiques de la grotte de Gargas" (A.F.A.S. Bordeaux [1895], p. 781); "Foyers de l'époque quaternaire dans la grotte de Gargas" (A.F.A.S. Paris [I900], p. $76 \mathrm{r})$; Cartailhac and Breuil, "Les peintures et gravures murales des cavernes pyrénéennes" (L'Anthr. xxi. [1910], p. I 29).

${ }^{2}$ Op. laud. ante, also L'Anthr. Xvir. [1906], p. 624. See also papers and notes by Cartailhac and Regnault on the figures of hands in A.F.A.S. Lyon [1906], pp. 717, 720; Man, viI. [1907], No. 4 .

${ }^{3}$ F. Regnault, "Empreintes de mains humaines dans la grotte de Gargas, Hautes-Pyrénées" (B.S.A.P. ser. v. vol. vir. [1906], p. 331 ). 


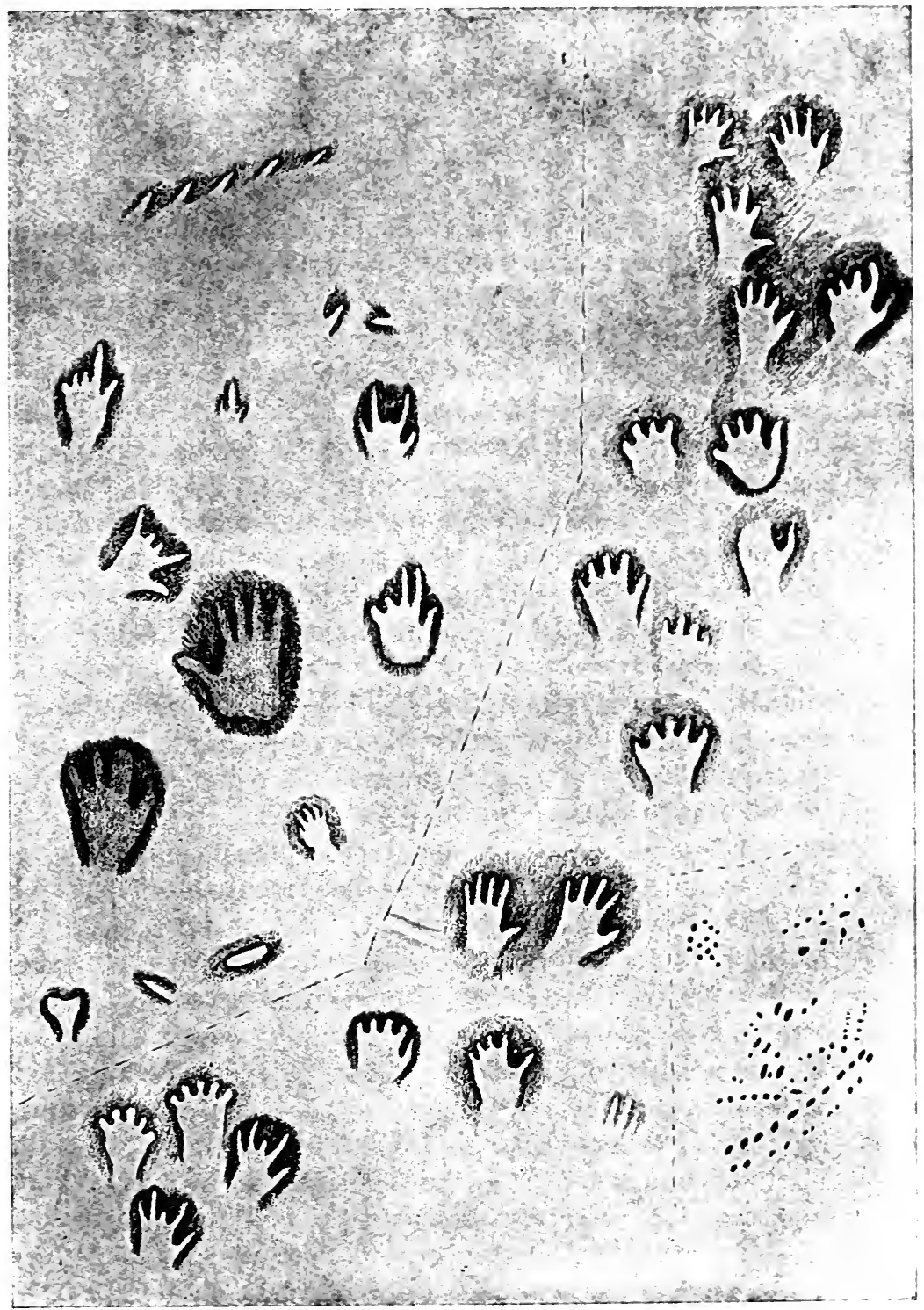

Fig. 129. Hands stencilied in the Cave of Gargas.

(Drawn by M. l'Abbé Breuil; from L'Anthropologie, vol. xxı.) 
There are also a few, too defaced to be certain about, omitted from the above table. Probably there were a larger number near the entrance, which have disappeared owing to the constantly damp condition of the cave.

For the present we are concerned with description only, not with theory, so we merely note the obvious preponderance of left hands over right, as a clear proof that right-handedness had already begun to characterise humanity. For it would be natural for a right-handed man, who for any reason wished to stencil his hand in the manner described, to press the left hand against the wall, leaving the dexterous member free to apply the paint. Similar figures of hands appear in the caves of Castillo, Altamira, and Font-de-Gaume.

A very curious feature of the Gargas hands is the mutilation of the fingers which they display. In many of them the fingers have almost disappeared. This has been explained as $(a)$ evidence for the prevalence of a mutilating disease, such as leprosy; $(b)$ evidence for a custom of finger-lopping, a form of mutilation found among naturefolk in several quarters of the modern world; and $(c)$ as merely the result of bending the fingers in the process of stencilling. The third hypothesis may be excluded, as the flexibility of a pianist's fingers would be needed in some cases, and in others the bending postulated is impossible ${ }^{1}$. The first is improbable. There are sufficient analogies for the second to make it the most likely explanation. It is to be noticed that the hands at Castillo and at Font-de-Gaume do not display these mutilations.

Besides the hands, there are a few examples of single fingers, stencilled in like manner. There is also the stencilling of what looks like the head of a humerus or of a tibia.

In addition to the figures of hands, the Gargas cave displays groups of red dots, irregularly distributed on the wall. Similar groups of dots, the meaning of which is unknown, appear at Castillo, and also in the cave of Bedeilhac, near Tarascon, Ariège. The latter cave contains several groups of red dots, in one case about 15 in number, arranged in an arc of a circle (L'Anthr. xxi. p. I49 f.).

Similar stencillings appear in the caves of Castillo and of Fontde-Gaume, described later. In these caves, which were occupied at times subsequent to the Aurignacian, there are later devices superposed to the hands, thus proving the superior antiquity of the latter. Undoubtedly these stencilled hands are among the earliest forms of parietal art which the Upper Palaeolithic has bequeathed, if they are not actually the earliest.

1 Though it will be remembered (ante p. 300) that the fingers of Mousterian man seem to have been more flexible than ours. 
But these hands and red dots do not exhaust the record of Aurignacian wall-painting. At Font-de-Gaume, La Mouthe, Les Combarelles, Bernifal, Castillo, Altamira, Pindal, there are figures of animals, outlined in black or in red, and resembling in every respect the animals represented by outline engraving.

\section{Combination of Painting and Engraving}

It is frequently to be observed that underlying the lines of painted figures such as those just described, there is a faintly traced engraved line, evidently drawn as a preliminary guide for the painter. This is not however what is meant by the heading of this section: it is the supplementing of the painted lines of a design by means of stippling or other embellishment in engraved lines. This technique also makes its appearance in the Aurignacian Stage. It is the end of a development which began in the effort to make the outlined animal figures more lifelike. The flat outline was supplemented at first by engraved strokes designed to represent surface markings, such as the coating of hair on a mammoth. This gradually improved, as the artists' touch became surer. It was noticed that the stippling gave an effect of relief to the figure; and thus the Aurignacian artists attained to the highest point of their development.

The dating of the paintings and engravings upon the cave walls rests upon a number of different indications, which have been combined in a masterly way by the insight of M. l'Abbé Breuil. By a delicate series of observations, he has succeeded in formulating a history of the development of Upper Palaeolithic Art, distributed not only over the principal stages into which the Upper Palaeolithic Term is divided, but also into the subordinate phases of each stage. We have already seen that the accumulation of a deposit containing datable antiquities against a wall decorated with engraving, or at the entrance to a cave-chamber thus adorned, necessarily gives a minor limit of date for the decorations. Further, the superposition of designs, of which we have already seen examples, gives us a means of ascertaining the relative date of different styles of technique. Again, as Breuil has demonstrated, the art of the cave walls (the "parietal" art) of any one phase is identical in type with the art of the smaller portable objects belonging to the same phase. The latter can be dated by the antiquities associated with them, in the deposits where they are found: and the deductions thus reached can be used as a basis for dating the parietal art.

Another, and a most ingenious, line of argument is drawn from the proportions of the numbers of different species of animals represented in different varieties of artistic technique. By first classifying 
the techniques, and then counting the animal figures in each class, Breuil was able to shew that there is a change of fauna in the art exactly corresponding to the change of fauna which actually took place as a result of the changing climate of the Upper Palaeolithic Term. Thus, when horses were the commonest animal, they were also the most frequently represented: the two-horned rhinoceros, which dropped out of the fauna of Europe early in the Upper Palaeolithic, is represented only in the earliest forms of technique, and so forth. The whole argument will be found set forth at length in Breuil's paper "L'Évolution de l'art pariétal des cavernes de l'âge du renne," C.A.P.A. Monaco, vol. I [igo6], p. 367.

As a result of these observations, the history of Aurignacian art can thus be summarised. It begins with rude finger-tracings in mud, covering the walls or floors of the caverns; the marks being mere idle meanders, winding and interlacing without recognisable order or meaning. They are sometimes, apparently, made not with the fingers but with some kind of forked instrument. Then, the hand impression begins to appear, either stencilled in the manner already described, or printed directly on the walls by dipping the palm in some colouring matter and pressing it against the surface of the rock. At about the same time dots and lines begin to appear timidly, as random and meaningless as the finger-tracings. Gradually these lines begin to take the shape of formal geometrical arrangements: and among the random finger-tracings figures of animals begin to be outlined. Such animal figures, outlined in mud, appear at Gargas and at Hornos de la Peña.

It will be observed that abstract geometrical ornament thus begins to evolve as soon as, if not actually before, a concrete pictorial art. This is of importance, for it is a canon of one school of art-historians that abstract devices do not originate of themselves, but that they are invariably the result of the copying and gradual stylisation of naturalistic forms. That this is very frequently the case needs no demonstration: it is a commonplace of art history. But there is a danger in making rules of the kind too absolute. The laws of the various departments of anthropology cannot possess the impersonal inevitableness of the laws of mathematics. The history of Aurignacian art as deduced from recent research shews clearly that abstract ornament can originate independently of any concrete representation of an actual object.

The engraved figures of animals take us a step further. They are an imitation of the finger-tracings, like them broad and deep, and cut in the rock surface. The animals are rudely outlined, "in elevation," and only two legs are shewn. About the same time 
similar imitations of the finger-tracings, in painted lines, begin to appear.

- The statuettes of women are to be assigned to the Late Aurignacian. They represent an altogether more advanced type of art; and they may well be imitations of figures modelled in clay, though none of the latter have survived from Aurignacian times. 'The parietal art, and the corresponding art on movable objects, also shew much
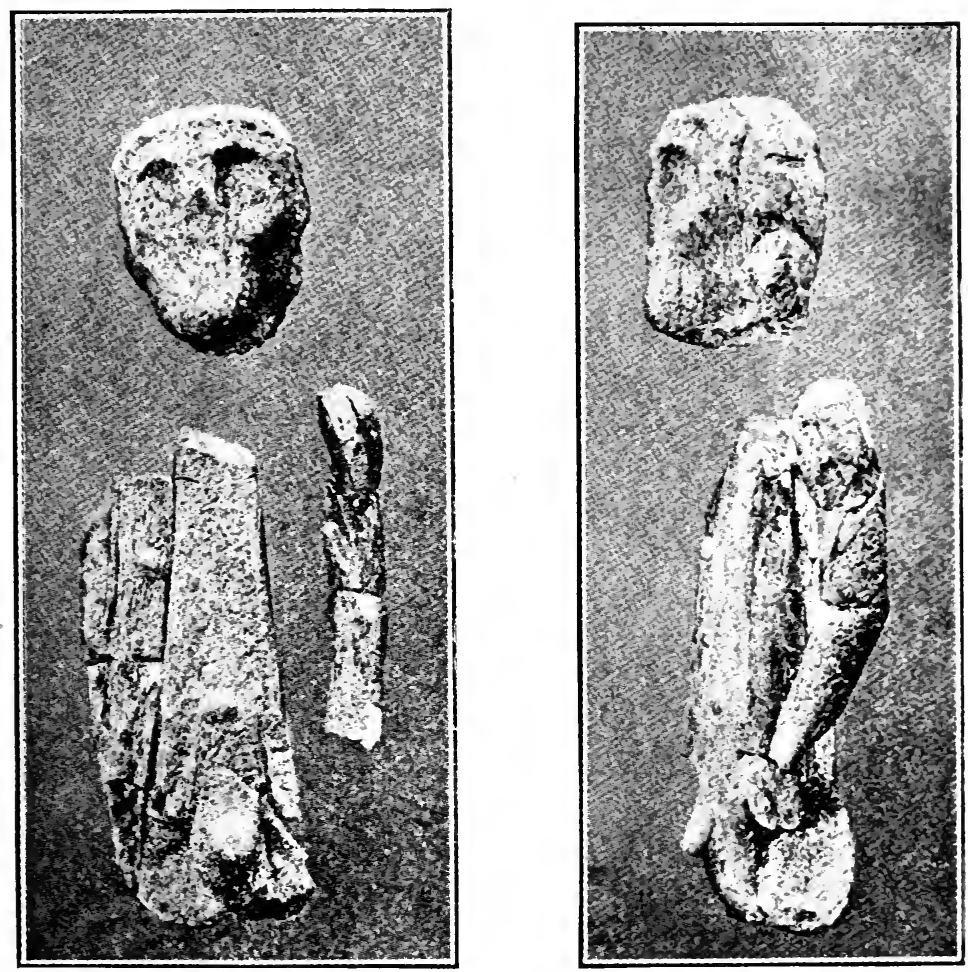

Fig. 130. Ivory statuette from Brünn.

improvement in the later phase. The lines are firmer and drawn with a surer touch; the outlines of the animals are more lifelike, and details of parts such as the hoofs and the head are truer to nature; and four legs are shewn, the animal being represented as walking. The outlines are filled in with other lines, or dots, painted or engraved, to represent hair or surface markings; and thus we at last reach the combination of painting and engraving which is the highest point attained by the Aurignacian people. 


\section{THE SOLUTREAN STAGE}

The art thus evolved now suffers a sudden and unexpected setback. Notwithstanding their skill in flint-chipping, the Solutrean people had only a moderate interest in pictorial art. They practised it, but made few contributions of importance to its development. Indeed, the only innovation which we find is the application of sculpture in the round to the representation of animals.

\section{SCUlPture}

\section{A, B. Human and Animal Figures}

Of human figures the most important is the ivory statuette found with the Brünn skeleton. This represents a male figure, without legs. If it had this deficiency from the first-a doubtful matter, owing to the imperfection of the figure and the disintegrated state of its surface - it might originally have been about $22 \mathrm{~cm}$. high. One arm is missing and the other is broken off (fig. I3O).

Of animal figures the most noteworthy is the statuette of a mammoth, found at Předmost. It is in ivory, measuring $116 \mathrm{~mm}$ long and $90 \mathrm{~mm}$. high. The animal is well outlined, and the hair and other surface features are shewn, but the style of art cannot be described in higher terms than merely tentative ${ }^{1}$ (fig. $13 \mathrm{I}$ ).

There is nothing known about Solutrean parietal art which enables us to distinguish it from Upper Aurignacian on the one hand and Lower Magdalenian on the other. We therefore pass at once to

\section{THE MAGDALENIAN STAGE}

\section{SculPture}

\section{B. Animal figures}

No sculptured human figures of Magdalenian date are known. There are however some figures of animals, or parts of animals, which are of quite extraordinary merit. These represent chiefly horses, oxen, or reindeer; and they are either cut out as separate pieces, or make a part of some larger object, such as a bâton de commandement. Not a few artists in more civilised surroundings might envy the skill of the nameless savage who wrought the

1 Obermaier, Breuil and Maška, "La statuette de mammouth de Předmost" (L'Anthr. XxiII. 273). 


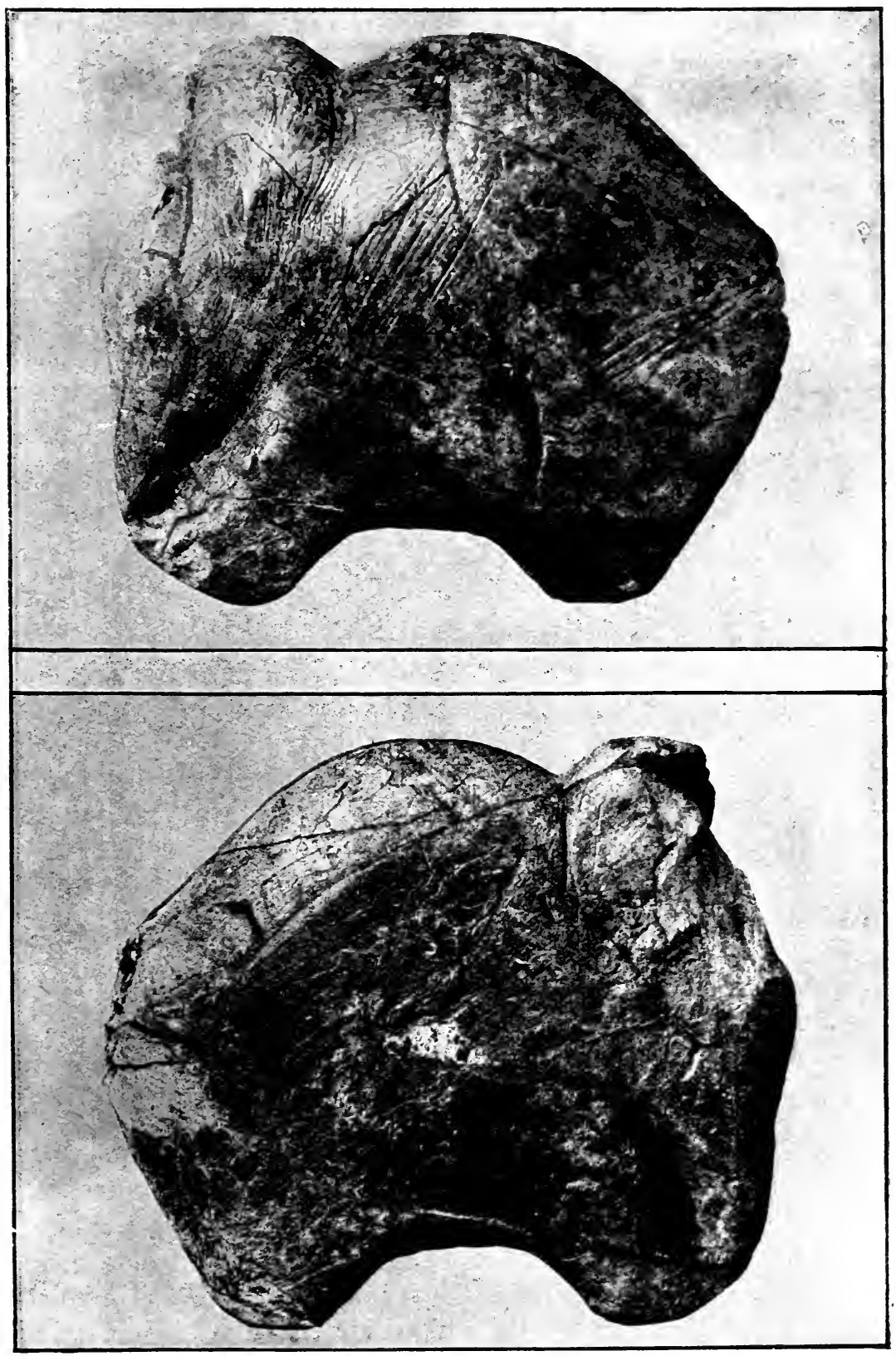

Fig. I31. Statuette of a mammoth from Předmost. (From L'Anthropologie, vol. xxirI.) 
Espélungues horse, or the superb study of a head of a neighing horse from Le Mas d'Azil (Fig. 132).
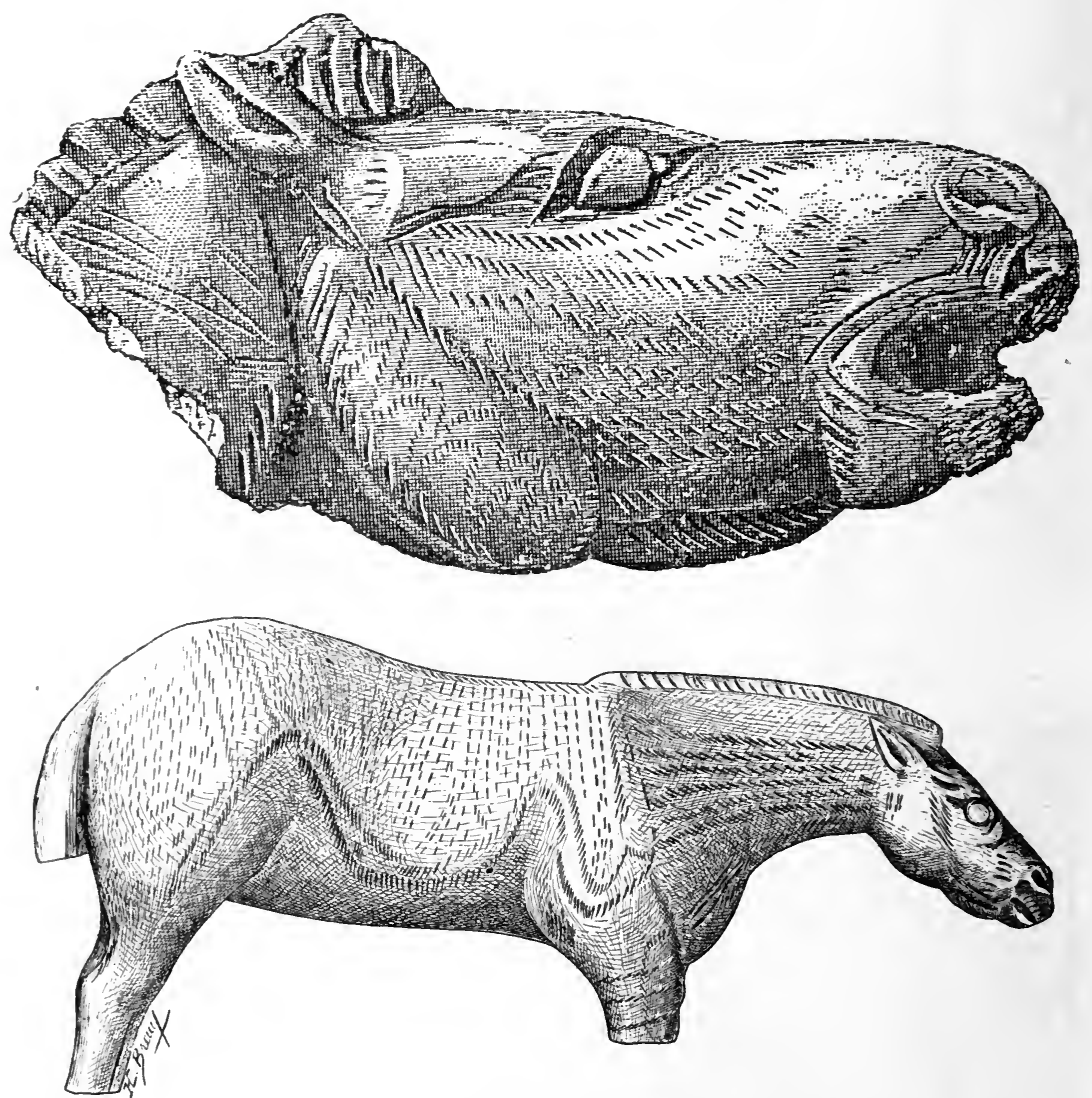

Fig. 132. Horse figures from Les Espélungues and Le Mas d'Azil.

(From L'Anthropologie, vols. v. xvir.)

\section{SCUlPtURE IN ReLiEF}

\section{B. Animal figures}

By far the most remarkable series of relief sculptures are those discovered in the rock-shelter at Cap-Blanc, near Laussel (the home of the Aurignacian human relief sculptures), the excavation of which also is due to Dr Lalanne ${ }^{1}$.

1 Gaston Lalanne and l'Abbé Breuil, "L'abri sculpté de Cap-Blanc à Laussel, Dordogne" (L'Anthr. xxII. [191 r], 385). 


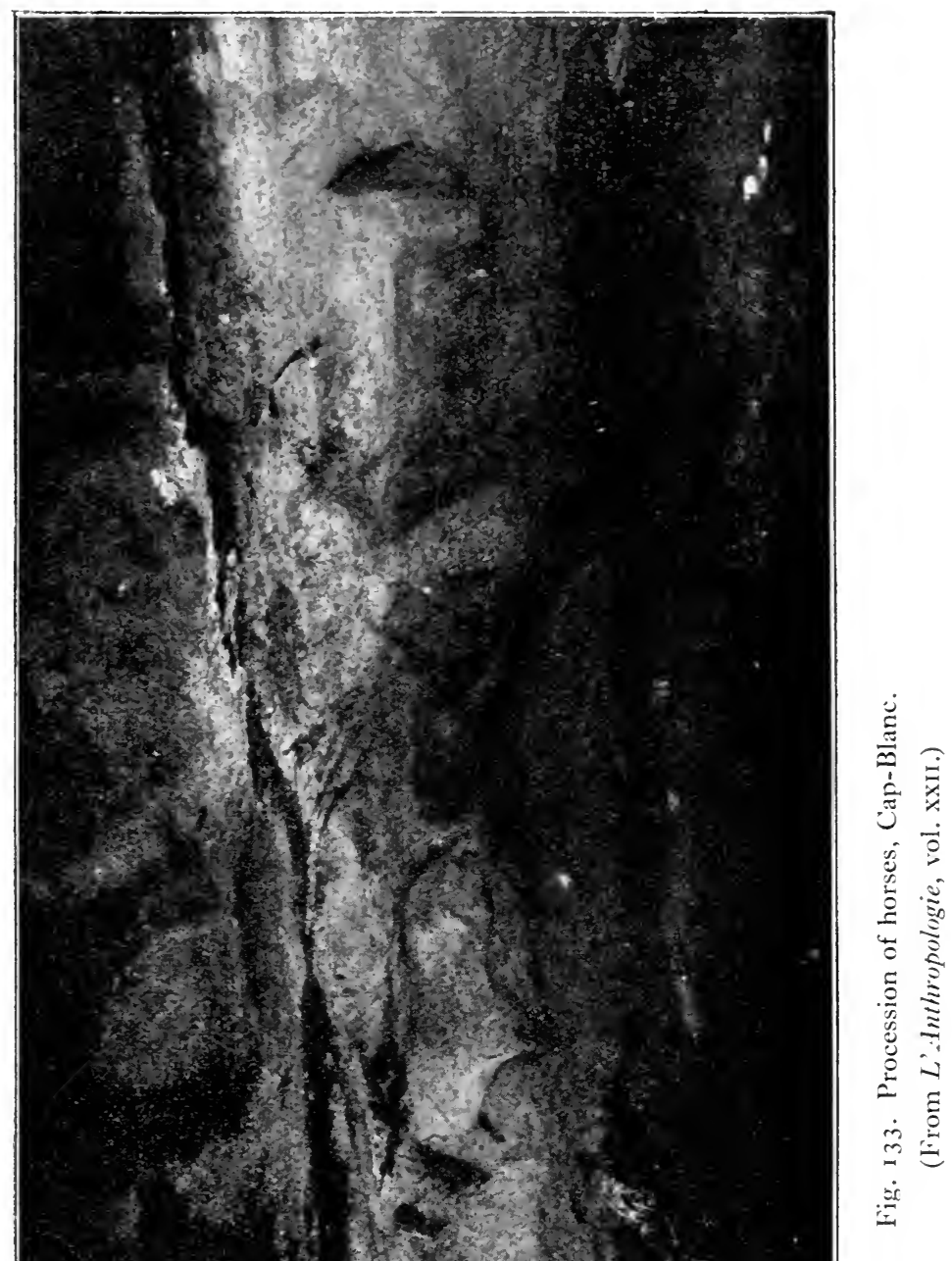


In the shelter of Cap Blanc there were two levels of occupation, early Magdalenian in date. There were no harpoons, but there were numerous prickers, needles, polishers in bone, assegais, rods with ornamentation, teeth and shells perforated for suspension: there were also some examples of objects with geometrical decoration sculptured upon them, and some few figures of animals. There was also a remarkable bâton de commandement, of which the short branch was cut into the shape of a human foot with four toes, the nails of which were well marked. The flints were more massive than those of the late Magdalenian, recalling the Aurignacian in type; they had nothing in common with the Solutrean forms. The animals whose bones were found were reindeer, horse, wolf, fox, lion, bear, deer, antelope -the first-named being the commonest.

This settlement was established in front of a rock-shelter measuring about 15 mètres long, and about 3.50 mètres high in the middle. On the right-hand side access was obtained to a circular hall, the floor of which had been carefully paved with flat stones. Round the wall of the outer shelter was sculptured an imposing procession of animals (horses and bisons) I I in number, all of considerable size and well executed. A pavement similar to that in the subsidiary chamber ran in front of these figures, forming a sort of footpath 2 mètres long and I mètre high.

\section{Engraving}

\section{A, B. Figures of Men and Animals}

The parietal art of the Magdalenian stage shews a gradual decline in the importance of the technique of engraving. The bold lines of the Aurignacian engravings give place to much finer lines, and the figures themselves are on the whole much reduced in dimensions. The actual drawing of the figures is however, as a rule, excellent. But as the stage advances, the lines become finer still, and the artists lose themselves in a "fussiness" of detail: the figures become stereotyped and lose their "life"; and sometimes the lines are such minute scratches that they are extremely difficult to follow. At last, as the Magdalenian stage draws to a close, the parietal engravings disappear altogether.

The great majority of the engravings on small objects represent animals, or parts of animals, mostly in profile. Reindeer are on the whole the commonest, but horses, mammoths, and bisons also appear. Other animals are less frequent; some of these have been already illustrated, in Chapter III : we may add to these figures representations (Fig. 134) of a serpent from the cave of Gourdan, and of a seal 

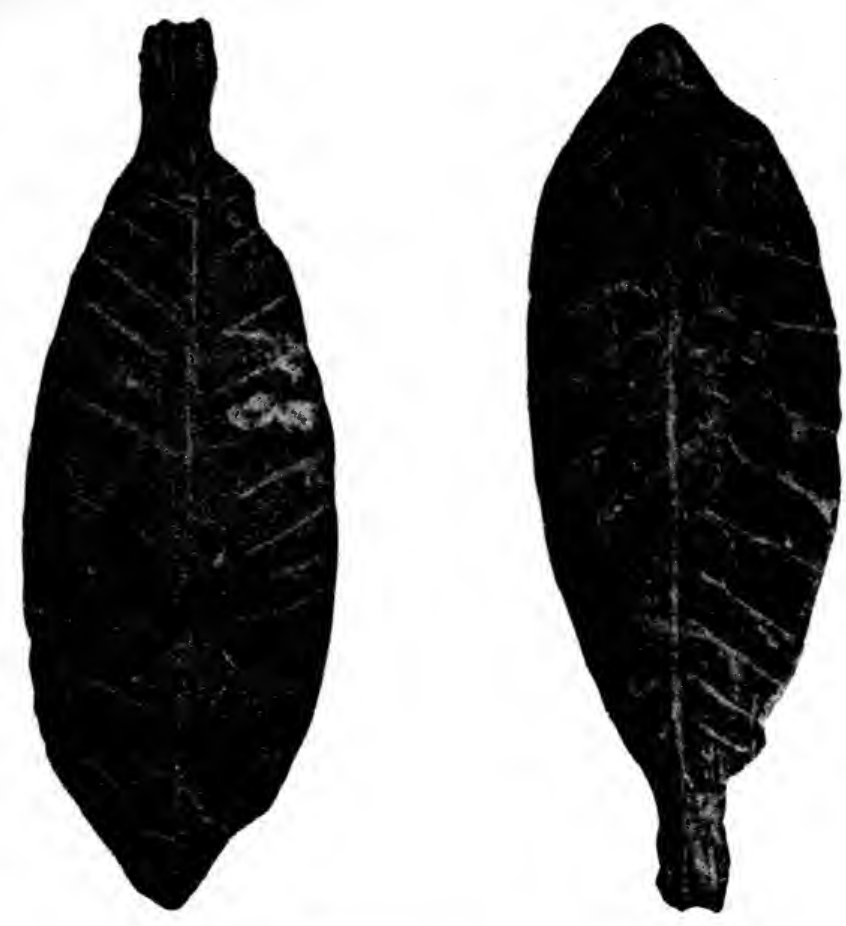

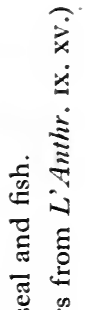
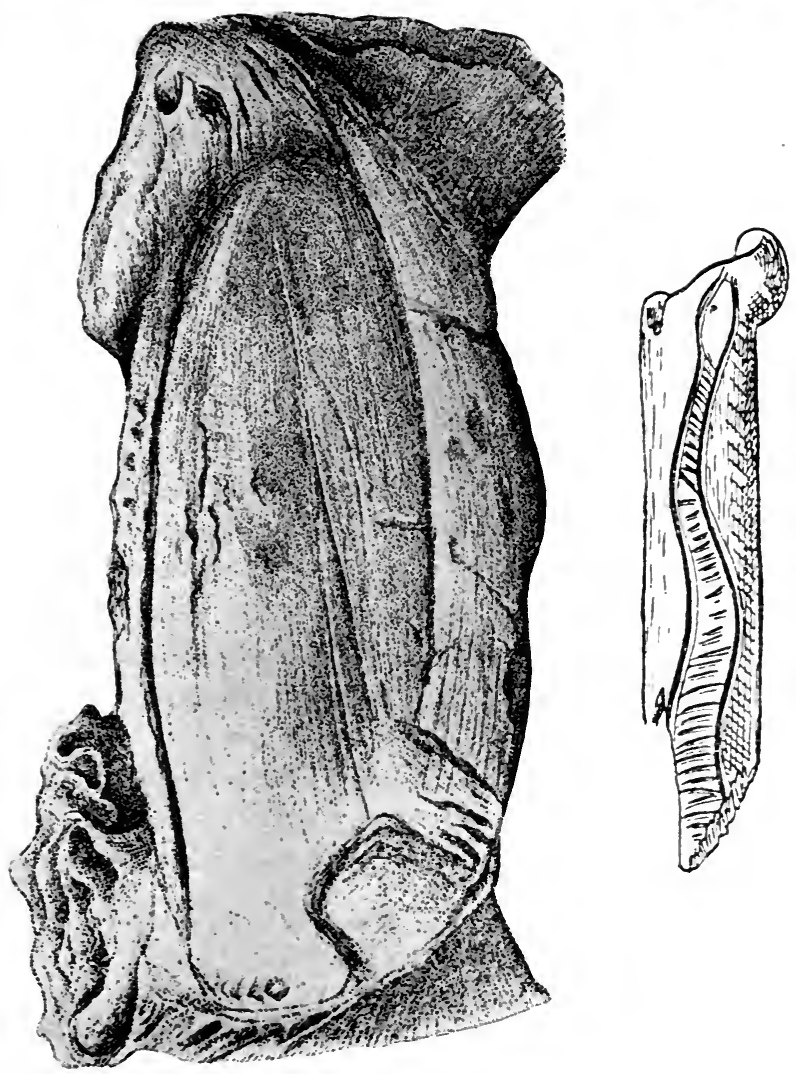

总

造

क्ष

(2)

$\stackrel{0}{3}$

运

मे के

in

站

E 
from Brassempouy, also a notable figure of a fish (probably a bream) in bone from the Grotte des Bœufs, Lespugne (Haute-Garonne). Human figures are comparatively rare, and they are always inferior in artistic merit to the drawings of animals. In an extremely interesting article, M. G. H. Luquet has called attention to the remarkable animal-like characteristics which some of the human figures represented in Palaeolithic Art display ${ }^{1}$; the dancing figure from Le Mas d'Azil (Fig. I35), is a good example. If held sideways it looks more like an animal than it looks like a human being when held upright. To account for this M. Luquet draws an analogy from the practice of children attempting to draw. They first draw men, then animals. Their animals are in reality horizontal men, drawn full face-sometimes even with legs on both sides of the body. The reason for this is that men have to be drawn full face in order to shew fully all their double attributes - two eyes, two arms, and so on. On the other hand, Magdalenian man began with animal figuration, because - to anticipate the theoretical part of our study - the magical purposes which his drawings were intended to serve required animal figures; and the details of an animal's body can best be shewn by drawing it side face. In consequence, in contrast to the efforts of children, the men represented are really upright animals, and are drawn side face. All the indications available go to prove that this theory is correct.

But it does not go the whole way in explaining the animal-like appearance of these human figures. Consider the dancing human figure just mentioned from Le Mas d'Azil. The animal-like form of the body may be explained by M. Luquet's theory; but not the snout-like head. The Palaeolithic artists could draw a human face, crudely perhaps, but more recognisably than this: this is quite certainly not a human head, but more closely resembles that of a dog or an ape. Some, indeed, have supposed that this and similar figures were really intended to represent apes; others, greatly daring, have seen in them the representation of a Homosimian "missing link." Much more reasonable is the suggestion that we are to understand this figure as the representation of a man, engaged in some kind of religious dance, and decorated with an animal mask, similar to the masks worn by those engaged in the $d u k-d u k$ and other savage ceremonies.

The Mas d'Azil figure is not isolated. There is a painting of a figure of identical type on the wall of the cave of Portel, Ariège ${ }^{2}$.

1 G. H. Luquet, "Sur les caractères des figures humaines dans l'art paléolithique" (L'Anthr. xxi. [I910], 409).

${ }^{2}$ Léon Jammes and René Jeannel, "Les peintures humaines de la grotte de Portel, Ariège" (A.F.A.S. Lille [1909], p. 8I I). 


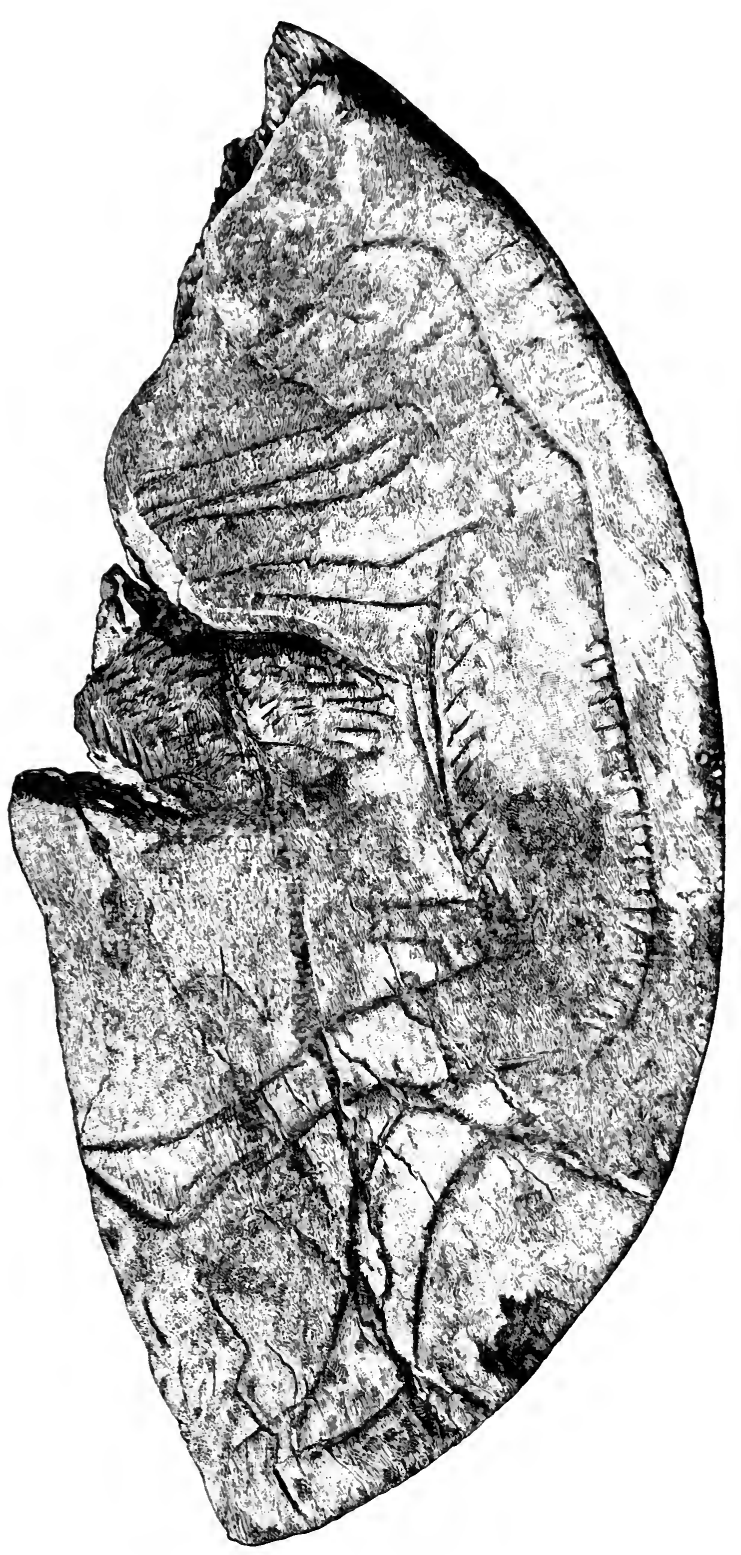

Fig. 135. Dancing figure from Le Mas d'Azil. (From L'Anthropologie, vol. xIv.) 
On a beautiful bâton de commandement made of stag's horn, found at l'abri Mège, Teyjat (Dordogne), among several engraved figures of animals, there appear three quasi-human figures, dancing, their legs bare, their bodies enveloped in coats covered with thick fur or
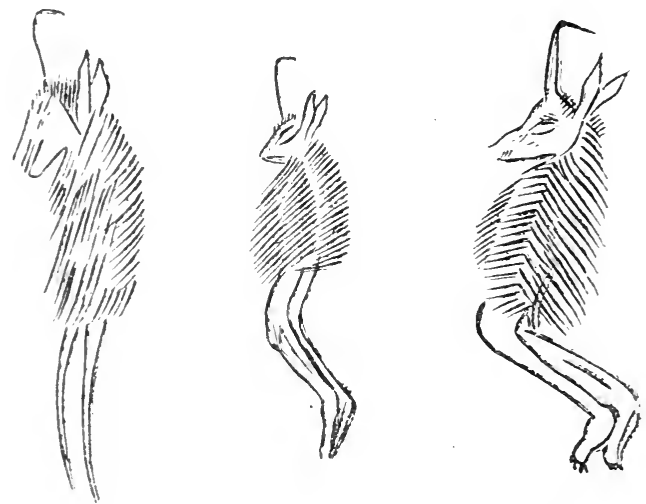

Fig. 136. Dancing figures from l'abri Mège.

(Drawn by M. l'Abbé Breuil; from Revue de l'École d'Anthropologie, vol. xIx.)

feathers, and their heads decorated with animal snouts and horns ${ }^{1}$. Similar figures appear in the cave of Altamira ${ }^{2}$, Les Combarelles ${ }^{3}$, Marsoulas ${ }^{4}$, and on a bâton de commandement from Gourdan ${ }^{5}$. The similarity between all these "diablotins," as our French colleagues

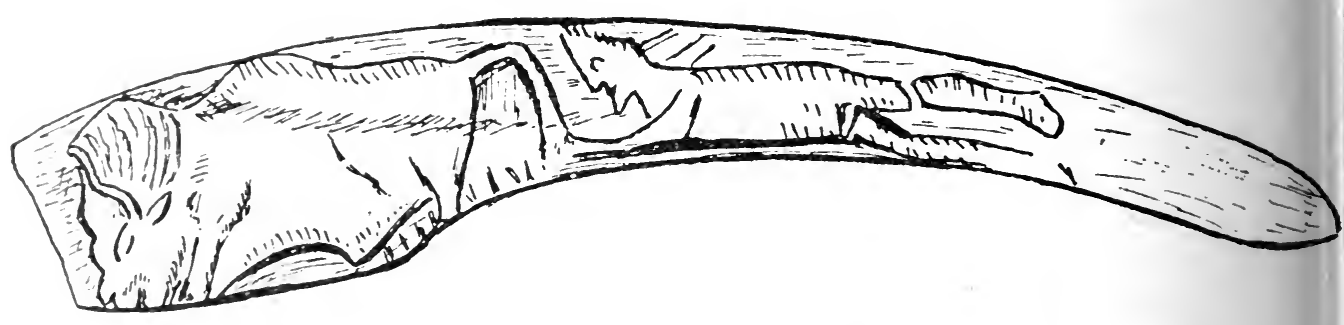

Fig. I37. Huntsman (?) from Laugerie Basse.

(From Girod and Massénat, Laugerie Basse.)

expressively call them, and the masked dancers of Melanesian rites is too striking to be entirely without significance.

${ }^{1}$ L. Capitan, H. Breuil, P. Bourrinet, and D. Petrony, "Observations sur un bâton de commandement orné de figures animales et de personnages semi-humains" (R.E.A. xIx. [1909], p. 62).

${ }^{2}$ Cartailhac and Breuil, La caverne d'Altamira, figs. 41-43.

3 Capitan, Breuil, and Peyrony, "Figures anthropomorphes ou humaines de la caverne des Combarelles" (C.A.P.A. Monaco [1906], vol. I. p. 408).

' Cartailhac and Breuil, L'Anthr. [1905], p. 437.

Revue préhistorique [1906], p. 6. 
Apart from these special cases, it is disappointing that the men represented in Palaeolithic engravings rarely if ever seem to be doing anything interesting. We should welcome a picture of a chief with his decorations and with his tribal marks tattooed upon him. But Palaeolithic man represented himself without clothing and without weapons; he has told us nothing as to how he cut the one or wielded the other. He is to be seen crawling flat on the ground behind an animal, in one well-known engraving from Laugerie Basse (Fig. 137). This may be a hunting stratagem; but it is equally possible that the attitude of the man is dictated by the shape of the space available for the figure, and that the picture has no story to tell. When animals and men are grouped, or animals together, it is the single figures that are of importance in the eye of the artist, not the ensemble. The beautiful engraving from Lorthet (Fig. I8, p. 75) has been supposed to represent a herd of deer crossing a fishful stream. But surely the artist, who displays such admirable powers of observation, would have in some way indicated the surface of the water, or the refractioneffects on the legs of the animals, had such been his intention: and the presence of a fish above the back of the foremost deer is fatal to the explanation suggested. The conclusion to which we must come is disappointing enough; that the artist having drawn a number of deer, had the happy thought that he could fit a number of fish into the blank spaces between their legs. He was less interested in making a pretty picture than in securing that his family should be supplied with venison and fish for their larder.

On the other hand, the artist was not oblivious to motion, and endeavoured to suggest it, as it were, cinematographically, by drawing an animal with its legs in the two extreme positions of walking, forward and backward-sometimes filling in the intermediate positions as well ${ }^{1}$. Thus we may find figures of animals with what we may call fans of legs in the mural decoration of the caves, as in the foremost of the two reindeer in Fig. 138. Similarly the graceful waving of the neck of a crane or some similar long-necked bird is represented on a pebble from Montastruc, now in the British Museum (same Fig.). A curious series of dots arranged in circles, associated with propulsors, and terminating in the figure of a wounded and dying bison (Fig. 139), painted on the wall of the cave of Niaux, may perhaps be intended to represent the whirling of a cast stone.

In connexion with the representation of motion, we must not omit to mention a stone disc found in the Chaffaud cave, with a most effective impressionistic sketch of two herds of wild horses in

1 See M. Faure, "La représentation du mouvement dans l'art magdalénien" (Revue anthropologique, xxiv. [1914], p. 201; A.F.A.S. Havre [1914], p. 40). 


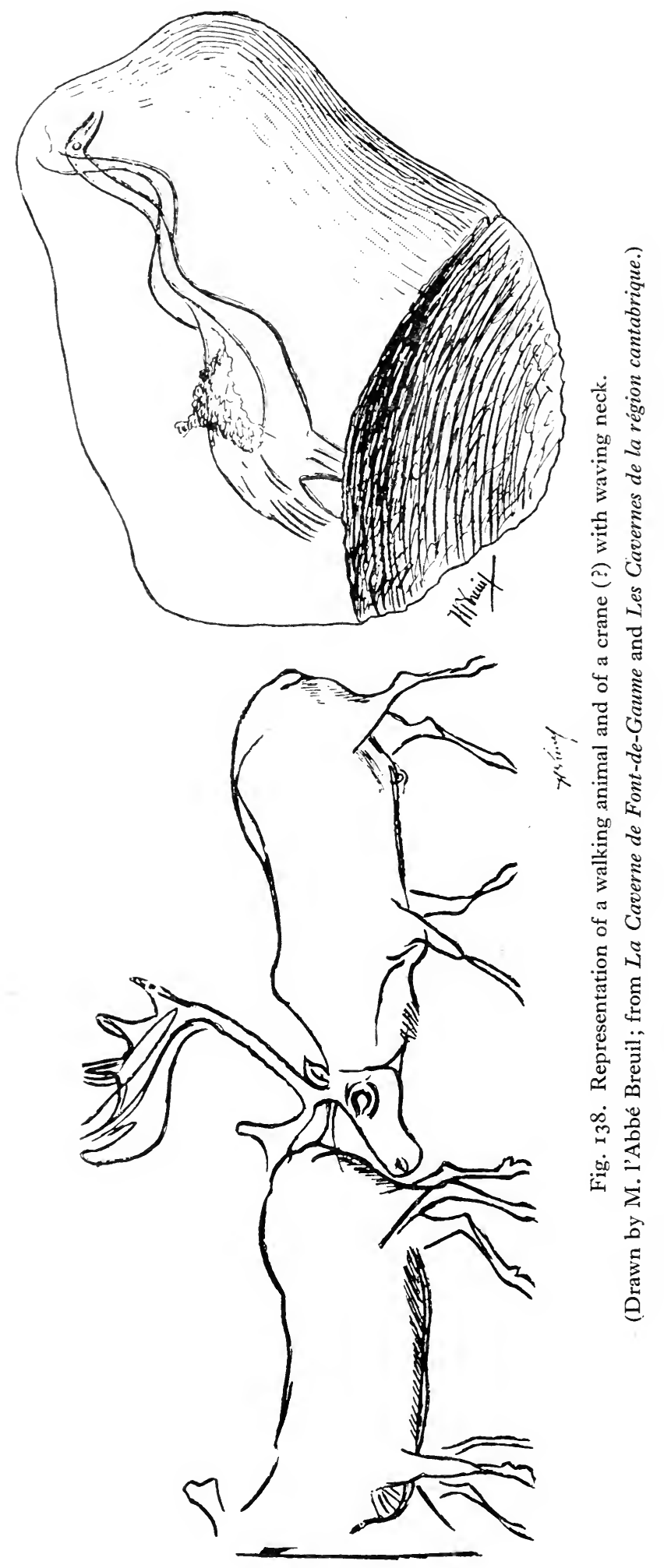


full charge; a good illustration to accompany a description of the piles of horse-bones in the Aurignacian midden-heaps at Solutré. The separation of the leader horse of the herd will not escape notice.

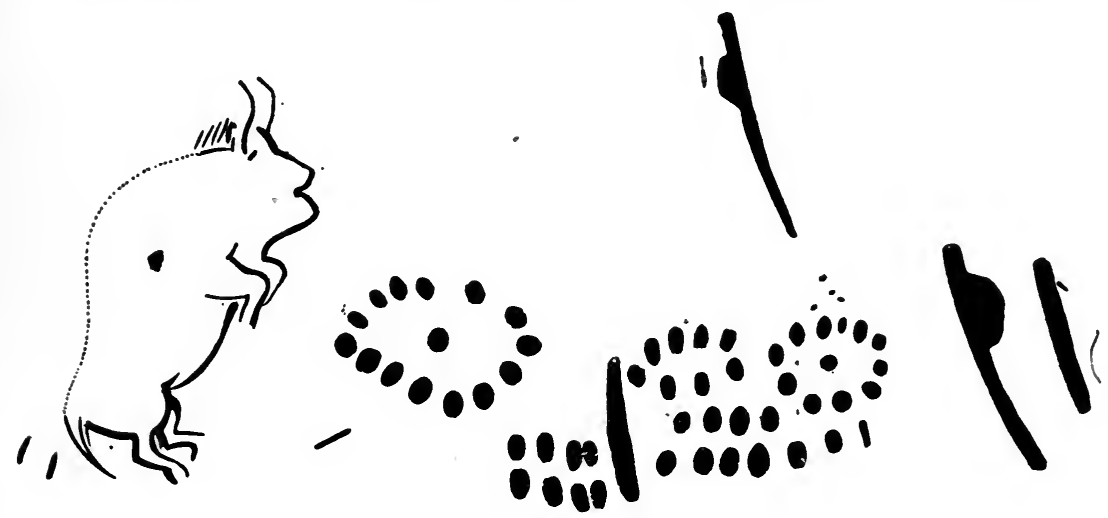

Fig. 139. Dying bison and cast stone.

(Drawn by M. l'Abbé Breuil; from L'Anthropologie, vol. xIx.)

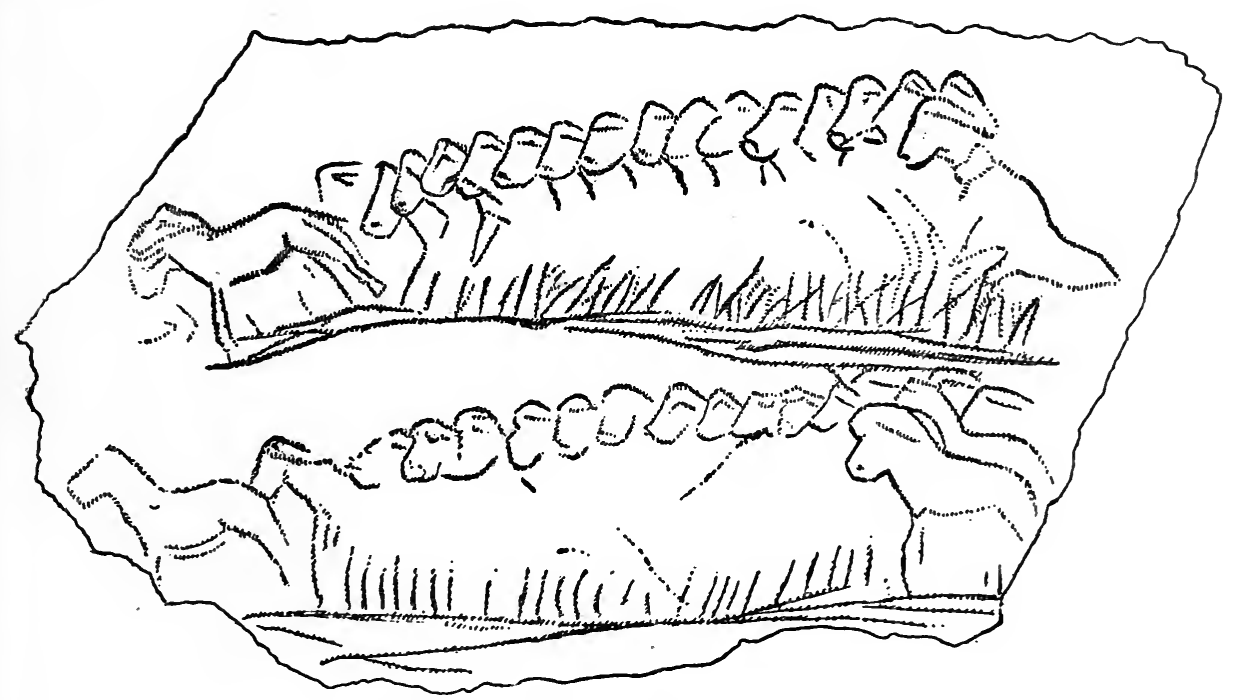

Fig. 140. Charging horses, Chaffaud.

(From L'Anthropologie, vol. xIv.)

The whole design is a remarkable anticipation of the art-conventions that would distinguish a modern sketch of such a scene.

Indeed, the contrast which the animal figures, with their truth to 
nature, present to the crude and helpless human figures, is wonderful. The drawings of extinct forms, such as the mammoth and certain varieties of horse, are of real zoological value. Perhaps the Thayngen reindeer (already illustrated, Fig. 20, p. 76) is the finest engraving of the Palaeolithic Age yet found. The well-known engraving from Saint-Marcel, representing the same animal galloping ${ }^{1}$, is almost equally excellent. It is engraved upon a plate of schist, which was carefully polished smooth before receiving the engraving ${ }^{2}$. The same rock-shelter yielded some other very remarkable works of art: such as a notable horse-head in bone, in which the relief of certain features, especially the lower lip and the eyes, is ingeniously expressed by a hollowing of the background ${ }^{3}$. Some of the engraved lines are filled in with red, possibly an indication that the whole object was so coloured; indeed, M. le Comte Bégouen, in describing a sculptured fragment from the cave of Enlène ${ }^{4}$, expresses it as his opinion that such traces are to be found on all sculptures which have not been washed.

As remote specimens of animal engraving, indicating the geographical limits of the art, may be mentioned the examples which England has yielded These are a representation of a horse-head, from Robin Hood's Cave (Cresswell Crags), and a similar but less definite example from Sherbourne. An engraved figure of a goat (?), standing with one leg raised, faintly inscribed on a pebble found at Nayland, Suffolk ${ }^{5}$, is perhaps a little doubtful; it seems somehow to lack the indefinable but unmistakable "feeling" of Magdalenian Art. We need say nothing of the "mammoth" from Saxmundham, Suffolk ${ }^{6}$.

An object from Brassempouy ${ }^{7}$ may possibly have a phallic significance. Such figures are not very common, but they are found occasionally. Thus a fragment of the butt of a bâton de commandement from Laugerie Basse ${ }^{8}$ is carved into two figures of phalli which seem to have undergone the operation of circumcision or some similar mutilation. Two remarkable carvings, representing the male and female generative organs respectively, from the Grotte du

1 See L'Anthr. XIII. [1902], p. I 59.

${ }^{2}$ L'Abbé Breuil, "Station de l'âge du renne de Saint-Marcel (Indre) d'après les fouilles de M. Benoist" (L'Anthr. XIII. [1902], p. 145).

${ }^{3}$ L'Anthr. XIII. p. I 5 I.

${ }^{4} L^{\prime}$ Anthr. XxiII. [1912], p. 287.

5 Miss N. Layard, "The Nayland figure-stone" (Proceedings of the Suffolk Institute of Archaeology and Natural History, xv. [1915], p. 3).

6 On which see Man, vol. xIx. [1919], No. 10, and subsequent correspondence.

7 L'Anthr. vi. [1895], p. 135 .

8 Girod and Massénat, Les stations de l'âge du renne; Laugerie Basse (Paris, 1900), plate i. 
Placard, have also been described and figured ${ }^{\mathbf{1}}$; and similar objects have been reported from the station of Mezin in the Ukraine ${ }^{2}$.

But to describe adequately the engraved zoology of the Upper
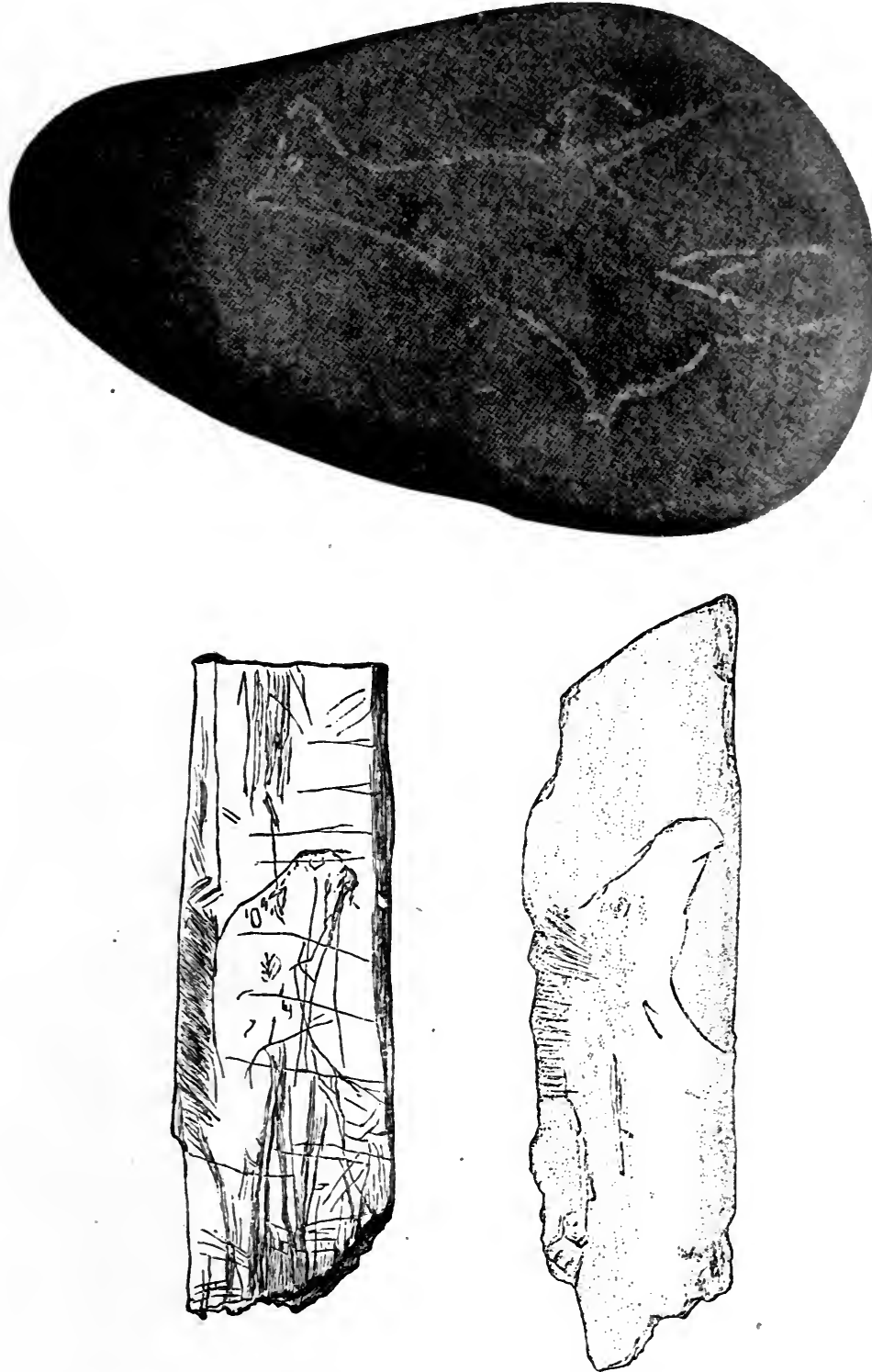



1 A. de Mortillet, "Deux curieuses pièces de la grotte du Placard, Charente" (B.S.P.F. III. [1900], p. 43I).

2 Th. Volkov, "Nouvelles découvertes dans la station paléolithique de Mézine, Ukraine" (C.A.P.A. Geneva [1912], vol. 1. p. 4r8). 
Palaeolithic Art would require a volume several times the size of this. We must be content with this small selection from the wealth of material already at the disposal of the student. Every year is bringing new discoveries and new surprises in this fruitful field.

\section{Vegetable Forms}

Vegetable forms are rare in comparison with animal figures, and it is evident that the artists were less interested in them. The execu-

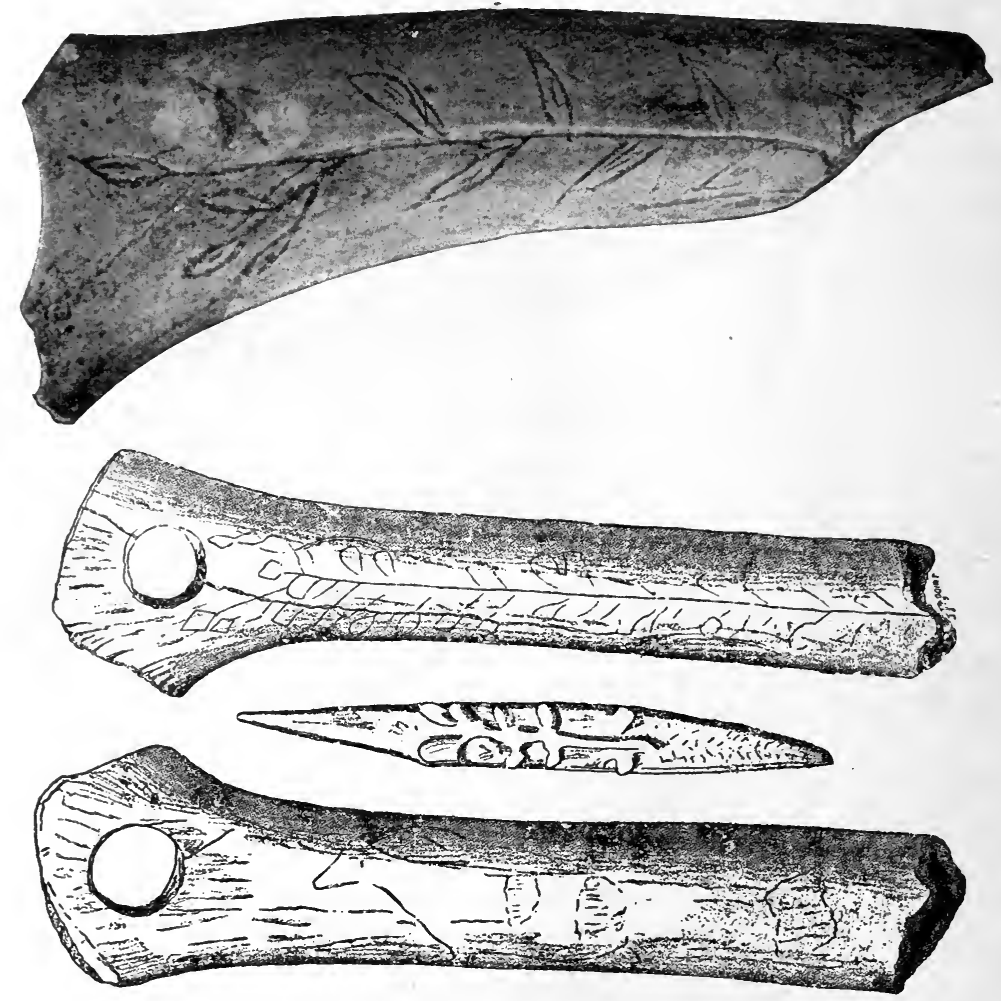

Fig. 142. Engraved vegetable forms.

(From L'Anthropologie, vol. XII.)

tion is as a rule perfunctory, and never sufficiently naturalistic to make it possible to recognise the species of plant indicated. There is sometimes evidence of the same exactness of observation as distinguished the animal figures; thus the fact that certain groups of plants have their leaves alternating with one another on the two sides of the stem is accurately rendered (as on a carved bone from the Grotte du Trilobite). But as a rule the vegetable forms are con- 
ventionalised to the last degree, and tend to become merely curvilinear geometrical patterns.

The pattern on a pendant from Saint-Marcel may represent a seed-pod (Fig. 162 below); and the spiral patterns from Lourdes and Les Espélungues d'Arudy may be founded on observation of the tendrils of a vine-like plant (see Déchelette, Manuel, vol. I. p. 230).

\section{Conventional and Geometrical Forms}

In addition to the figures derived from living forms, human, animal, or vegetable, there are a number of figures and patterns
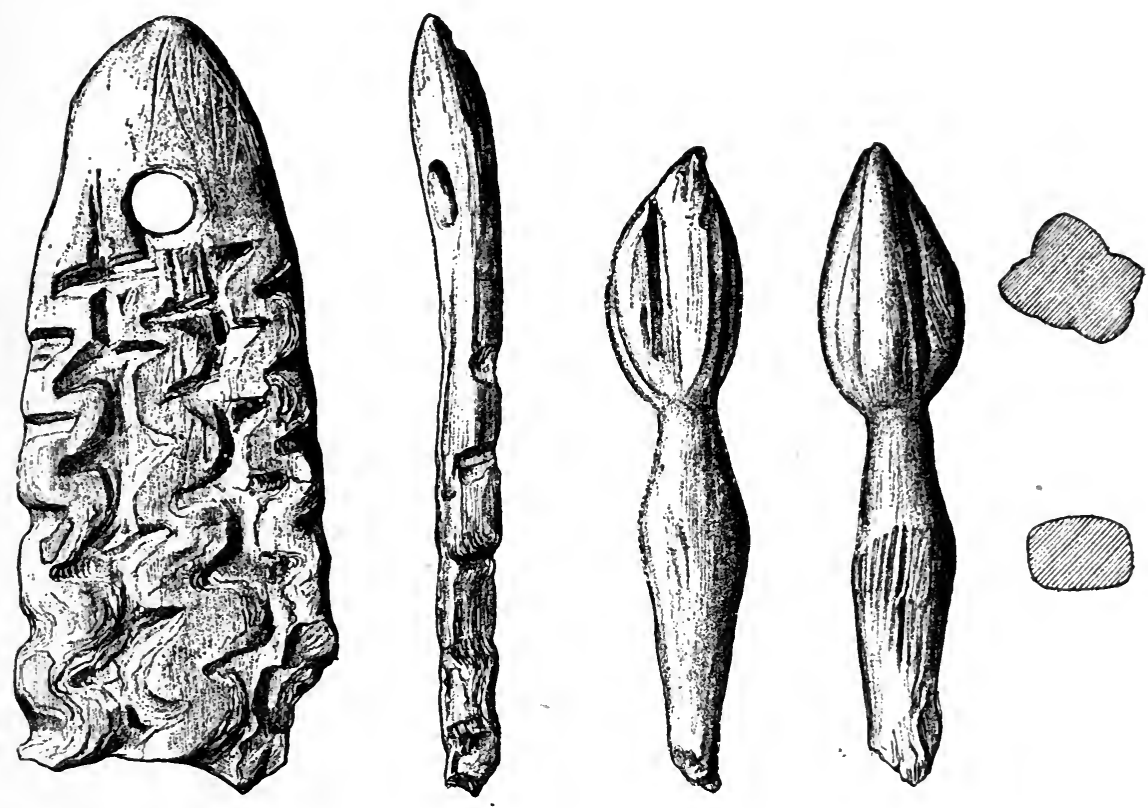

Fig. 143. Ivory objects from Brassempouy.

(From L'Anthropologie, vol. vi.)

which are purely conventional ornament and have no concrete meaning. Saint-Marcel has yielded a most remarkable double chisel of bone, with a basket-like pattern upon it which we should have dated, were it found apart from its surroundings, to the Bronze Age ${ }^{1}$. Zigzags and groups of lines, parallel or making frets with one another, are also not uncommon, and are found as far east as Russia. The wavy lines on an ivory pendant from Brassempouy can hardly be other than mere ornament; another ivory object from the same place

${ }^{1}$ See the figure, L'Anthr. vol. xiIr. p. 155, fig. 5. 

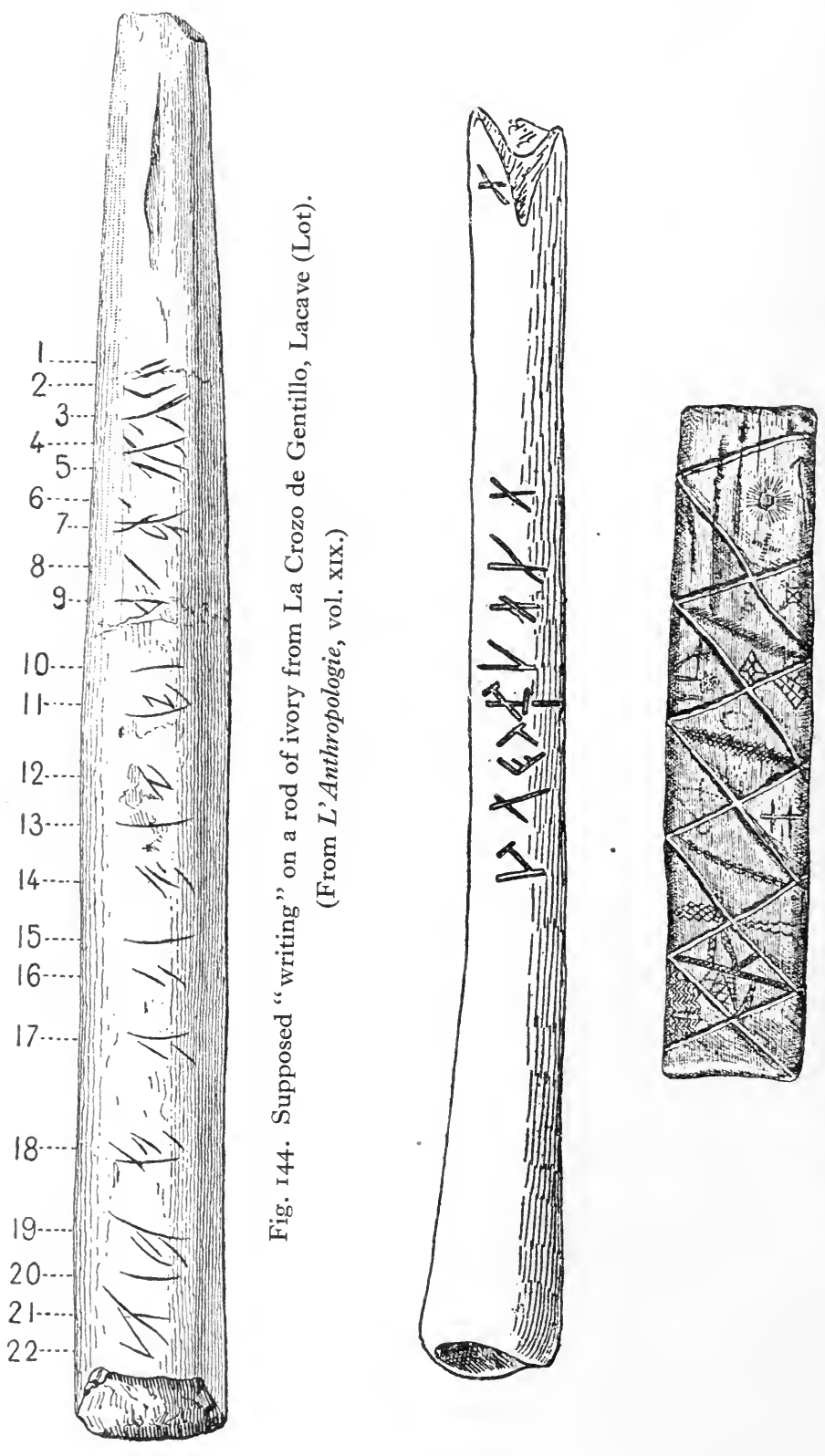

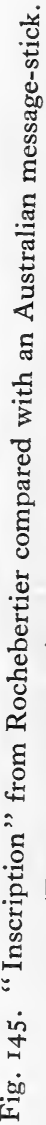


may possibly represent a flower (Fig. 143). The objects figured on a bone from Le Mas d'Azil may possibly represent some bean-like seeds; but what are we to make of the peculiar doubled mark on one end of the engraved bone from the same place (L'Anthr. xiv. p. 190, fig. 8), or the random patterns on similar objects (ibid. p. 189)?

Some of these marks or groups of marks have been claimed as proving the astonishing theory that Magdalenian man had evolved a form of writing by symbolic signs. But such a thesis cannot be sustained. The records of hunting expeditions and of similar events, found among American Indians and other nature-folk, which have been adduced in corroboration, tend rather to disprove than to support it. These records are essentially hieroglyphic: we see pictures of men, beasts, boats, arrows, camp-fires, and what-not, and we piece them together, supplying the conjunctions and other parts of speech, as we fill in the missing particles in an economically worded telegram. Only rarely do we find a symbol advanced a stage beyond a picture in these records, as when a number of strokes typifies the number of days occupied in the adventure. But the Magdalenian symbols are not pictures of anything. If they were writing, they must have had a picture-writing stage behind them, from which they were derived by a process of conventionalisation; but no trace of such a picture-writing has come to light in all the cave-exploration that has taken place. We must be content with regarding these symbols as mere ornament, possibly derived from the conventionalisation of plant motives in decoration.

There is, however, a certain resemblance between these Palaeolithic marks and the notches cut upon the Australian messagesticks (Fig. 145). The latter are not, however, writing in any sense of the term. These sticks are primarily the credentials of the messenger who bears them-the proof that he really represents the chieftain whose message he bears ${ }^{1}$. Secondarily the marks are mnemonics, designed to help the messenger to remember the details of the communication which he is to deliver by word of mouth. They bear the same relation to a written missive that a knot tied upon a handkerchief bears to a written memorandum of the engagement to be remembered. Whether or not the Palaeolithic bones bearing these marks are message sticks it is impossible to say; the explanation is plausible, but we cannot venture to say more. Groups of nicks are not infrequently cut in the edges of Magdalenian bone objects. They have been supposed to be tally-marks, reckoning up the victims of a hunter, or in some other way connected with numera-

1 Somewhat similar are the strings of shells and other odds and ends used for symbolic messages in Africa. See F.A.I. XvI. [1887], p. 295. 
tion. See M. Verworn, Die Anfänge des Zahlens, Corr. XLII. [I9I I], p. 53. But possibly they are mere ornament.

Sometimes there may be a magical meaning in the strokes. Piette figures an assegai-head from Brassempouy ${ }^{1}$ which has a simple linear pattern scratched on the place where it would be hidden if mounted
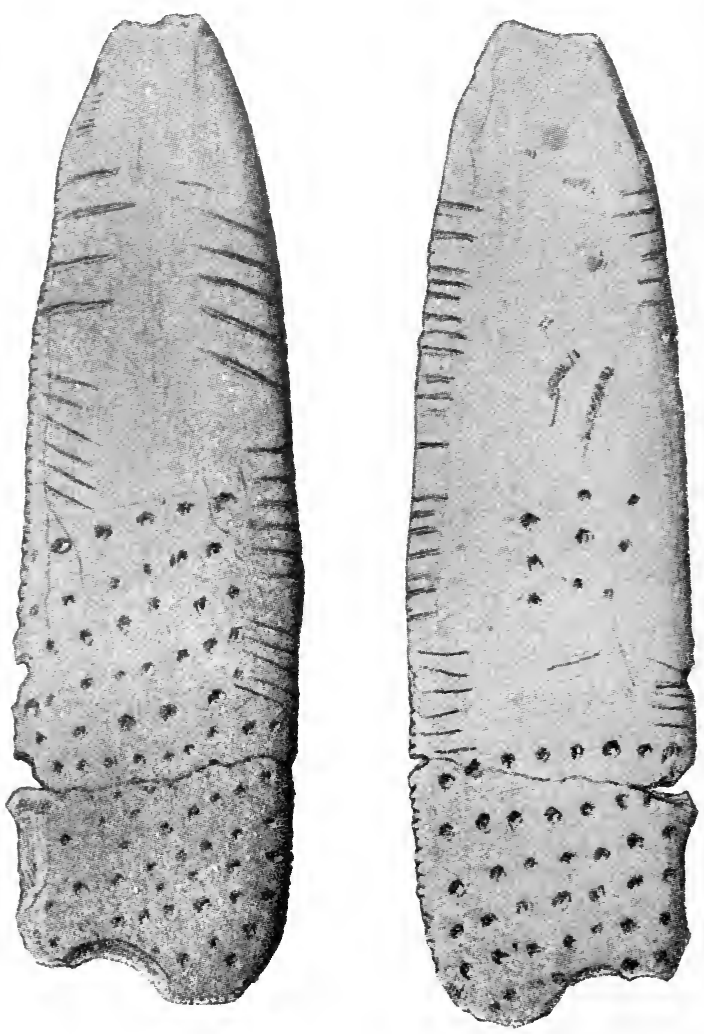

Fig. 146. Supposed "tally" or "hunting record."

(From Lartet and Christy, Reliquiae Aquitaniae.)

in a haft. He makes the not unreasonable suggestion that these lines possess a secret magical meaning, designed to render the weapon the more deadly, and that it was not for nothing that they were hidden. Only the owner of the weapon would be supposed to know about them. 


\section{E. Figures of Artificial Objects}

A pendant in bone from Saint-Marcel has on one side a drawing of a galloping deer, and on the other what looks like a wooden sledge, and may perhaps be an actual representation of such an object. Sledges might have been used for dragging the carcases of heavy animals from the place of slaughter to the encampment. But the chief representations of artificial objects in Magdalenian Art are the peculiar figures known as claviform, tectiform, and scutiform devices. These are much more frequently painted than engraved, and we therefore describe them in the section on painted patterns.
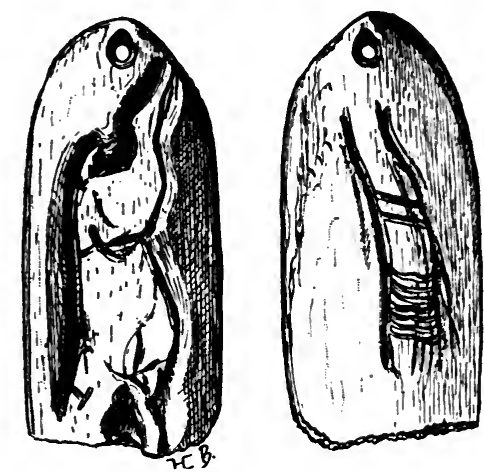

Fig. 147. Bone pendant, Saint-Marcel.

(Drawn by M. l'Abbé Breuil; from L'Anthropologie, vol. xv.)

\section{Clay Modelling}

There is as yet but one example of this technique known, but it is in many respects extremely remarkable.

The discovery was made by $M$. le Comte Bégouen at the cave known as Tuc d'Audoubert, in the department of Ariège ${ }^{1}$. This cave is difficult of access at all times, as a river, the Volp, rises within it and flows from its mouth. A boat is necessary to enter it, and sometimes in flood this is impossible. The cave is in three stages. The first of these is at the level of the water. The second is reached at a distance of about 150 mètres from the cave mouth, by climbing a cliff-surface about 2 mètres high. Here a gallery opens which enlarges into great halls ornamented with calcareous concretions of great scenic effectiveness. The walls at this level shew engravings,

1 Comte Bégouen, “Les statues d'argile de la caverne du Tuc d'Audoubert (Ariège)" (L'Anthr. xxIII. [1912], p. 657). See also Idem, "Une nouvelle grotte à gravures dans l'Ariège, la caverne du Tuc d'Audoubert"' (C.A.P.A. Geneva [1912], vol. I. p. 489). This article was written before the discovery of the statuettes.

M.E.A. 1 . 
and some traces of painting. In a corner of one of these halls there is a "chimney," at first vertical, then curving in screw-fashion upwards. This has to be climbed for a height of some 12 mètres by scrambling up the roughnesses of the rock surface. The summit of this "chimney" is decorated with engravings of bisons. At the top of the chimney we enter the third stage of the cave through a narrow passage, with a few animals engraved on the walls. The style of the engraving and the technique of the sculpture differ in the drawings of this uppermost stage from those in the lower stages; Comte Bégouen considers that they are older, ascribing them to the Aurignacian and those of the lower stage to the Magdalenian. The continuation of this passage was blocked by stalactite; but Comte Bégouen's party broke open a man-hole in the obstruction and found a passage decorated with a complication of meandering and interlacing lines; similar decoration has been found in the caves of Altamira, of Gargas, and of Hornos de la Peña, already described. The engravings of animals, however, came to an end. This passage led to parts of the cave which had been infested by cave bears, their claw-marks and bones were everywhere. Some of the skulls had been broken to extract the teeth for making ornaments ${ }^{1}$. On the hardbaked mud floor were distinct marks of the feet of the Palaeolithic people who had been the last men in the cave before the arrival of the Comte's party.

A little farther along this passage there was what we may fairly call the Inner Sanctuary. On the right of the passage there was a small hall at a lower level than the passage. Stepping downward into this, there were seen marked on the cave floor a number of curved lines, the meaning of which was not clear, and also a number of deep rounded depressions, which were identified as human heel-marks. No toe-marks were to be seen, from which it was ingeniously inferred that the cave was the scene of some kind of religious dance, in which only the heels were allowed to touch the ground.

Leaning up against a block of rock fallen from the roof of this chamber were two statuettes of bisons, modelled in clay. The illustrations, here reproduced, will be sufficient to shew what admirable works of art these are (Fig. I48). One of them is $6 \mathrm{r} \mathrm{cm}$., the other $63 \mathrm{~cm}$. in length.

Everything points to this cave being a Most Holy Place of the

1 They may have been collected as a medium of barter; the canine teeth of elks are used as currency by the aboriginal tribes of Idaho and Montana, according to Mr Henry Balfour, "Note on the use of 'elk' teeth for money in North America" (F.A.I. xix. [1 890 ], p. 54). 


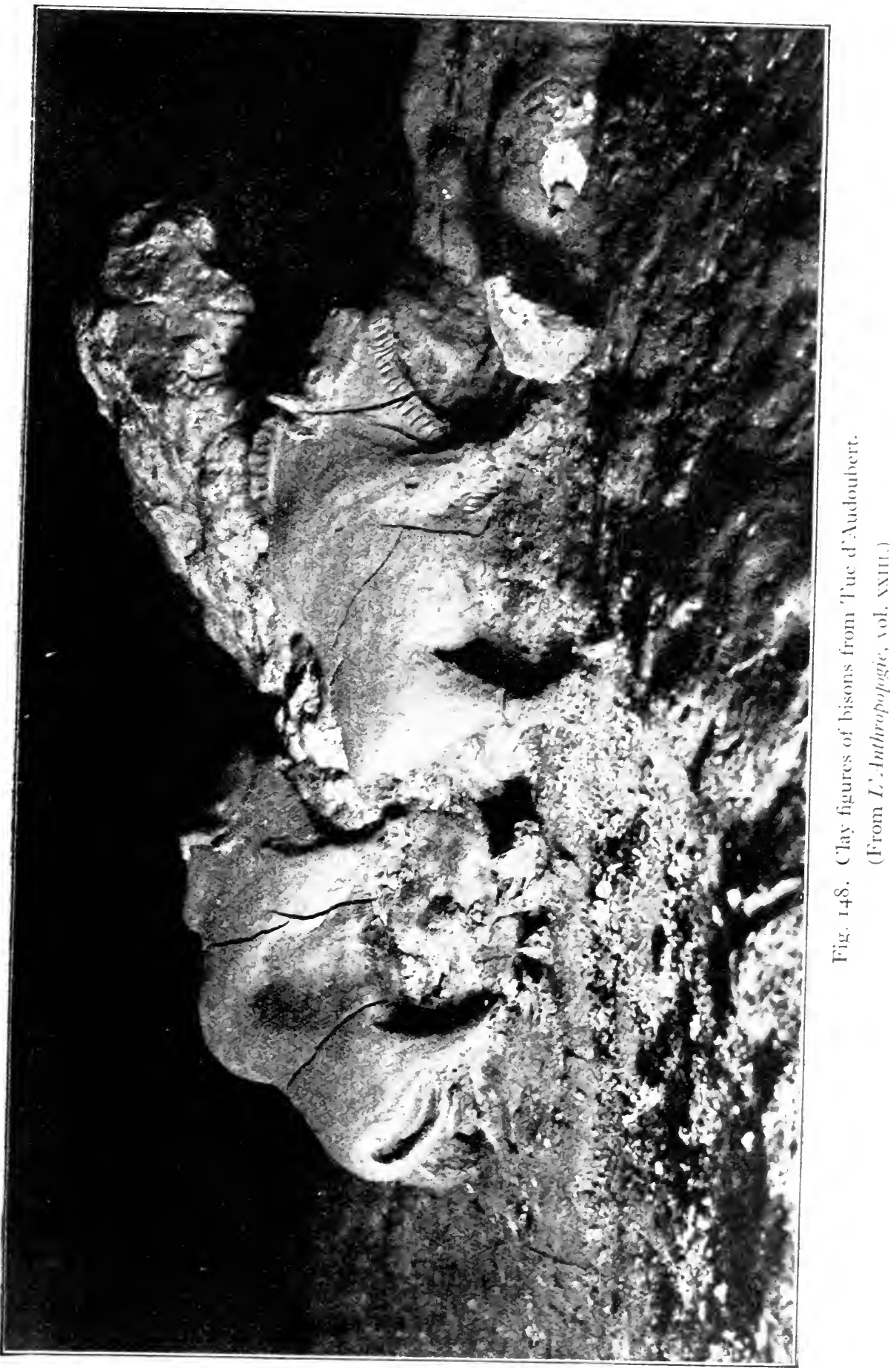


Upper Palaeolithic men. The difficulty of access shews that it cannot be a mere habitation. The evidence of dances in the innermost recesses of the cave, the figures sculptured in mysterious places only to be approached with great difficulty, all indicate that these people had already evolved a religion of no little complexity.

\section{Paintung}

In the Aurignacian stage painted figures were merely outlined or at most touched in with engraved or painted strokes. But at the beginning of the Magdalenian stage the whole surface of the figure is filled in with a uniform wash of red or black paint. Later in the stage, however, the artists attempted to improve upon these dull silhouettes. At first horns, hoofs, or eyes would be touched in with black on the figure of an animal otherwise red; and this polychrome treatment thus begun, was marvellously developed. The contours of the body, lights and shades, were caught and reproduced with astonishing skill. A whole spectrum of tints, produced by mixtures of colours in varying proportions, was invented and utilised; and by such processes as washing out, or sgraffito, the artist sought to emphasise salient details of his subjects.

Both in painting and in engraving it is to be noticed how often the artist adapted ingeniously natural irregularities in the surface of the wall to form part of the figure which he was drawing.

In some of the deposits in the caves paints have been found (iron oxide, red and yellow ochre, and oxide of manganese). These were the materials for the artist who decorated the caves, as well, no doubt, for the decoration of the persons of the cave-dwellers themselves. Tubes made of the long bones of birds or of reindeer were also found, containing paint; one, for instance, from the Grotte des Cottés (Vannes) still contained some red ochre ${ }^{1}$ (Fig. 149). The colours were pounded with round stones on flat plates of schist, which served as palettes; such plates, still bearing daubs of colour, have also been found. In l'abri des Roches (Indre) a bone pencil, with a point shaped like the end of a turnscrew, and smeared with red, was also found. This was probably one of the instruments with which the paint was applied to the surface to be decorated ${ }^{2}$.

1 In a communication entitled "Quelques réflexions relatives aux étuis en bois de cerf ou en os d'époque néolithique qui auraient servi, d'après certains auteurs, de flacons à ocre" (A.F.A.S. Dijon [1911], p. 621), M. Emile Schmit suggests that in some cases, at least, these bone tubes were merely the handles of small flint implements such as chisels. But when the ochre has actually been found in the tube, we need scarcely hesitate to accept the explanation adopted above.

${ }^{2}$ L'homme préhistorique, III. [1905], p. 267. 

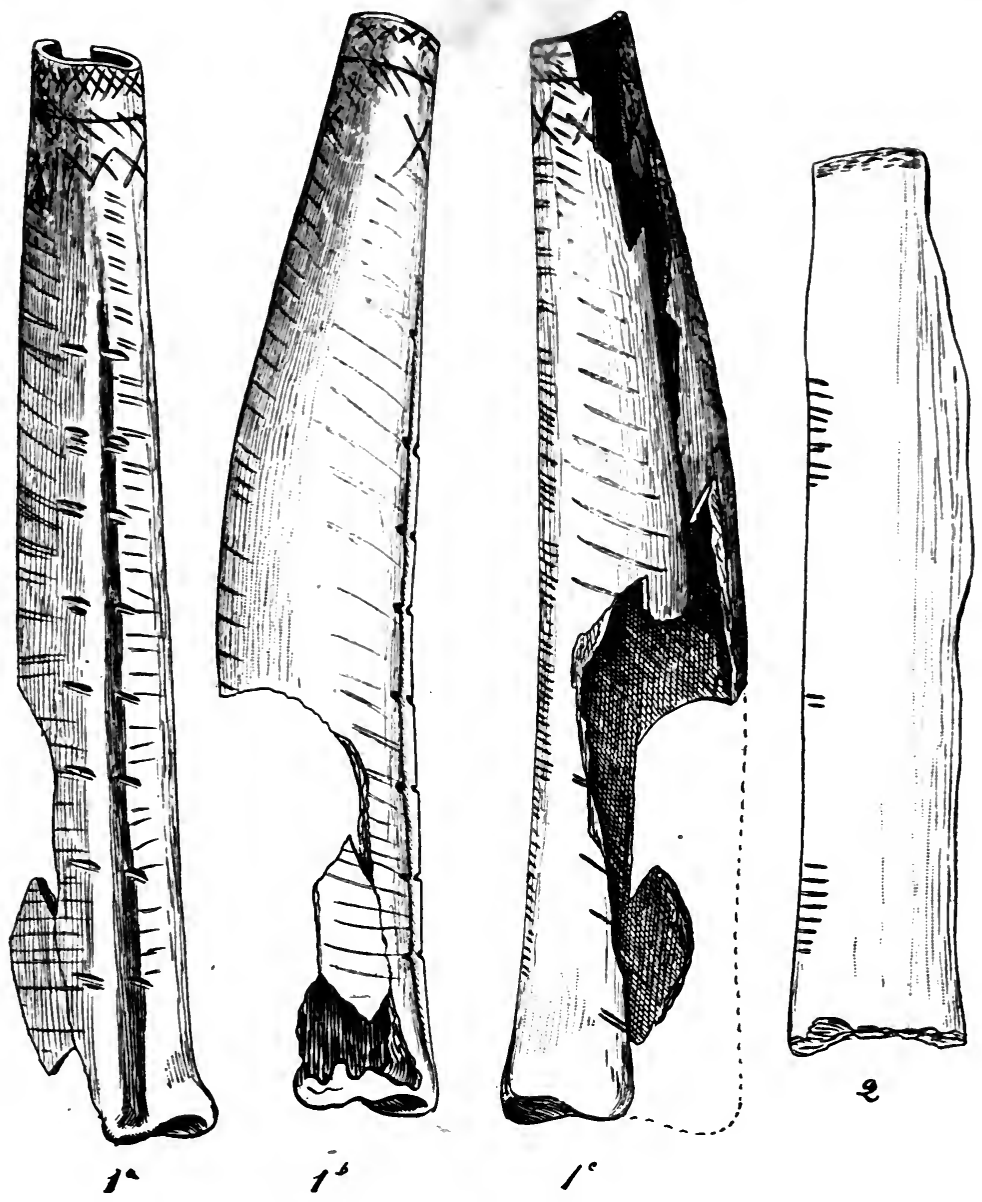

Fig. 149. Bone tube for paint.

(Drawn by M. l'Abbé Breuil; from Revue de l'École d'Anthropologie, vol. xvi.)

\section{A, B. Figures of Men and of Animals}

The best method of describing the material under this head is to give some particulars about the principal caves where painted subjects of the Magdalenian period have been found. No exhaustive enumeration is attempted; the number of sites already known is so large that such a catalogue would overstep the limits at our disposal.

Font-de-Gaume (Dordogne). This cave is to be reached by scrambling up a face of cliff-a process not without danger. It is a passage or gallery about 120 mètres long and 2 to 3 mètres broad, with a number of subsidiary passages opening out from it on both 
sides. In the middle there is an extremely narrow and difficult contraction of the passage, called by the poetical name of "the Rubicon"; whoever manages to squeeze through this will find the most important of the mural decorations in the cave inside it. The cave was at one time inhabited by the cave bear, which has left the scratches of its claws on the walls. The deposits on the floor of the cave contained a number of flints, including some with projecting angles worn and almost ground away. These were probably the tools with which the engravings were executed. Pieces of ochre were also found, which had been scraped into a crayon shape, and were doubtless the pencils of the artists.

The mural decorations do not begin till about 60 mètres from the entrance. It is possible that this may mean nothing more than that the weather has succeeded in influencing the wall of the cave as far as this, and has effaced any paintings that there may have been nearer the entrance. It is also possible that the paintings were intentionally placed in the more mysterious recesses of this and of the other caves: but this cannot be maintained with assurance. For all we may know, figures might have been painted on rock surfaces in the open air.

There are in all 198 figures on the walls of this cave, which has been described in an important monograph ${ }^{1}$. It has been shewn that these were not all executed at one time, but that there are clear indications of a development, the dating of which is assisted by the superposition of the designs.

The oldest designs are a number of hands, stencilled in black. These resemble the very remarkable series of hands in the cave of Gargas and like them they are assigned to the Aurignacian stage. Then follow a number of linear designs, also Aurignacian, rudely executed in red or black, representing heads of horses, mammoths, rhinoceros, bison. The paint is either red ochre, or the black of manganese oxide. Next come a series of black frescoes, comprising figures of large dimensions drawn with great vigour, and representing horses, bison, and reindeer. They are not merely outlined, as in the previous designs, but painted with a uniform wash over the whole surface. Contemporary with these are some engravings, nearly all representing horses. The so-called "tectiform" device, described on a later page, is frequent in association with this series of designs. Later still come the polychrome paintings, in which black, red, brown, and sometimes yellow are used in the one painting; shades are also produced by mixtures of these colours. They are distributed arbi-

1 L. Capitan, H. Breuil and D. Peyrony, La Caverne de Font-de-Gaume aux Eyzies, Dordogne (Monaco, 1910). 
trarily over the surface, not attempting, apparently, to reproduce the real colour or surface markings of the animals. The animals represented in this series are all bisons. Engraving is frequently combined with the painting. Last of all there come another series of outline representations, all representing mammoths. There is one representation of the cave lion and one human face in the series. One painting, representing a pair of reindeer, partly engraved and partly painted, ranks among the finest works of Palaeolithic Art known. A technical detail of interest is the utilisation of natural irregularities in the wall of the cave to form parts of the animals designed. Font-de-Gaume shews a good example of this in a horse partly adapted from a series of stalactites. The same technique has been noticed in the Altamira cave, and in another cave otherwise less important, at Comarque (Dordogne), where a finely drawn horsehead is fitted to a body more than six feet in length which consists entirely of irregularities in the wall slightly touched up ${ }^{1}$. This is the more remarkable in that it is impossible to see this great figure properly, as the cave is too narrow to allow the visitor to stand back far enough to take in the whole picture at a glance.

Marsoulas (Haute-Garonne). This cave was closed by a fall of rock at an early time-probably about the end of the Palaeolithic age-which has protected its valuable contents from interference till our own generation. The deposits on the floor were excavated from I88I onwards, revealing Solutrean remains overlaid with Magdalenian; but the wall decorations were not noticed seriously till $\mathrm{r} 88_{7}$. It appears that they have since suffered badly from the name-cutting and scribbling of totally unnecessary people ${ }^{2}$.

The decorations fall into three series, probably belonging to as many different stages of the development. of the art. There is first a series of paintings in black, with which seem to be associated a number of engravings in firm outline. Secondly there are some polychrome figures of animals, the outlines in black and the filling-in in red, or the heads in black and the body represented by red points (a peculiar technique characteristic of this cave). With these are associated tectiform and scutiform symbols. Allied with these paintings there are engravings in stippled lines with shading representing the hair and other surface markings of the animals indicated. Thirdly there are certain crescents and other inexplicable symbols in red. The combination of painting and engraving-the outline

1 L'Anthr. xxvi. [191 5], p. 5 IO.

2 See Cartailhac and Breuil, "Les peintures et gravures des cavernes pyrénéennes" (L'Anthr. xvi. [1905], p. 43I); F. Regnault, "La caverne de Marsoulas" (A.F.A.S. Cherbourg [1905], p. 644). 
engraved and the figure filled in with paint-is also found in this cave in one or two examples.

The animals represented are horses, deer, ibex, and, especially, bisons, of which there are over a hundred figures. Four of the bison figures are drawn in an extremely awkward place-on the roof of a narrow tunnel in the cave, where it is necessary to crawl. Even if this contraction be partly due to the accumulation of rubbish on the floor, the difficulty of executing a work of art in such a position must have been prodigious. One of these figures has been made by a process analogous to that called sgraffito, the rock surface having been blackened, and then the outlines of the animal scratched away. This gives an effect of relief to the drawing.

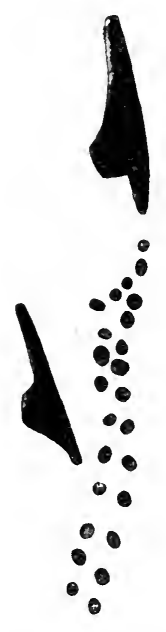

Fig. 150. Stone and throwingstick (?): Niaux.

(Drawn by M. l'Abbé Breuil; from L'Anthropologie, vol. xIx.)
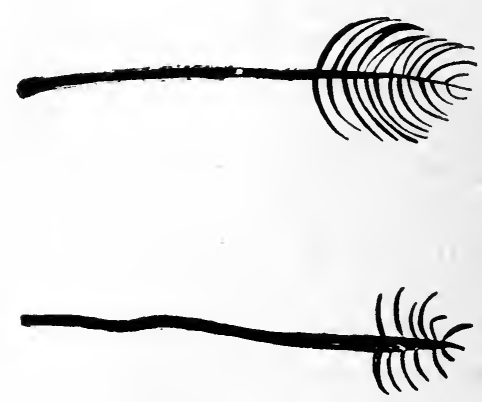

Fig. 15x. Arrows (?): Niaux.

(Drawn by M. l'Abbé Breuil; from L'Anthropologie, vol. xIx.)

Some extremely rude human faces contrast strangely with the excellence of the animal drawings. They look more like the first efforts of a child at drawing than anything else. It is to be. noticed that here as at Font-de-Gaume the later drawings sometimes are so placed as to interfere more or less with earlier ones.

Niaux (Ariège). This most remarkable cave, which is over $1400 \mathrm{~m}$. in length, has its walls covered with engravings and paintings, many of them of conspicuous merit. These paintings are entirely in black; the red and brown colours which appear in other caves are here absent. The subjects are, as usual, animals, with in addition certain other objects and marks. This cave was noteworthy for dis- 
playing designs traced in the clay covering the floor, protected by stalagmite; a wounded bison, bleeding from wounds in its side, is the most remarkable of these. There is also to be seen the footprint of one of the ancient artists, likewise protected by stalagmite. Other noteworthy designs in the cave of Niaux are a "claviform" sign with points, which is suggestive of a stone flying from a throwingstick (Fig. I 50 ); a series of what mav be representations of feathered arrows(Fig. 1 5I); and a bison with four circular marks upon it, possibly stone-wounds. The figure of a fish is also to be noted, on account of its rarity. A plan of the cave will be found in L'Anthr. xIx, p. I6: the paper containing it has also numerous illustrations of its art. The exploration of this cave is a matter of considerable difficulty, owing to deep pools which have to be swum, and narrow contractions which have to be passed. The designs continue to the end, shewing that the Palaeolithic artists penetrated to its furthest recesses $^{1}$.

Altamira. This cave in the province of Santander, Spain ${ }^{2}$, consists of a series of halls united by passages, having a total length of about 235 mètres. At the entry is a midden-heap of broken shells and bones. The deposits on the floor were in two layers, Solutrean and Magdalenian respectively. The reindeer, which rarely penetrated south of the Pyrenees, is not represented in the cave; the majority of the painted figures represent bisons. These are depicted in polychrome with amazing skill and truth to life, and are delicately and artistically shaded.

Covalanas. In a wild region near Biscay is a cave consisting of two long passages, in which are figured a horse, a cow, and two heifers, outlined in red. The line is sometimes firm, sometimes expressed by a series of dots close together. A similar technique is to be seen at Font-de-Gaume and at Castillo.

Castillo. This again is a large cave with numerous side passages and chambers, all of them containing wall-paintings and engravings, monochrome signs (tectiform, maniform, and the like), black and red horses, hinds, and bisons. The hands are represented as in the Gargas cave, and are older than the other figures, being in some cases covered by them. The deposits on the cave floor, which have been carefully excavated by Obermaier and Breuil, are well stratified and represent all stages from Mousterian to Neolithic ${ }^{3}$. The works

1 For a very striking description of the cave of Niaux, see the essay entitled "In a prehistoric sanctuary," in R. R. Marett's The Threshold of Religion (second edition). See also Cartailhac and Breuil, "Les peintures et gravures muraies des cavernes pyrénéennes, Niaux" (L'Anthr. xix. p. 15).

2 E. Cartailhac and H. Breuil, La Caverne d' Altamira.

3 See H. Obermaier and H. Breuil, "Fouilles de la grotte du Castillo (Espagne)" 
of Art in the cave are described by Breuil as "innumerable ${ }^{1}$." $\mathrm{He}$ classifies them thus: deep engravings with simple lines (horses, deer, goats, cows); striated engravings passing into graffiti of numerous deer, chamois, antelope, bison; paintings of hands, surrounded with red colour; red tectiform, scutiform, and rhomboidal forms, as well as dots and discs; drawings in line; more or less well modelled, red and black (bisons, horses, deer, goats); polychrome frescoes, not numerous, and later than the rest. Among these is an elephant; not apparently a mammoth, to judge from the shortness of the tusks and the want of hair.

The following are the principal facts which emerge as to the choice and treatment of subject by the Magdalenian painters, when the wall decorations of these and other caves are compared.

1. The paintings as a rule represent animals. Men are seldom if ever represented. The stencilling of hands is no longer practised, but hands and arms are painted at Castillo.

2. The animals shewn are as a rule those of service to man; savage carnivores, such as the large felines and bears, are sometimes represented, but not often.

3. As a rule the animal figure is not part of a picture, nor is it represented performing any action. Sometimes bisons are represented as in full charge; once an otter is shewn, catching a fish (on a fragment of horn from Laugerie Basse, Fig. 13, p. 70 ante) and sometimes a male animal is represented with its female, but such cases are the exception.

4. Not infrequently a part of an animal (especially the head) is made to do duty for the whole.

\section{Vegetable Forms}

There appear to be no painted devices which can be classed under this head: certainly none of importance.

\section{Conventional Forms}

Several caves have red dots, random strokes, zigzags and similar patterns here and there on the walls. There is nothing to add to what has been said under this head in the section on Engraving. Certain of the figures are evidently stylised from concrete forms (see

(C.A.P.A. Geneva [1 91 2], vol. I. p.361); Iidem, "Institut de paléontologie humaine; travaux exécutés en I912" (L'Anthr. xxiv. [1913], p. I). For these Spanish caves see also Hermilio Alcalde del Rio, Las pinturas y grabados de las cavernas preistoricas de la provincia de Santander (Santander, I906); Juan Cabré Aguilo, El arte rupestre en España (Madrid, 1915), and Alcalde del Rio, Abbé Breuil, and Père Siena, Les cavernes de la région cantabrique (Monaco, 1912).

${ }^{1}$ L'Anthr. XVII. [I 906], p. 625 ff. 
post, p. 53I); thus hands appear in a rake-like form-a horizontal stroke with a number of vertical strokelets rising from it; other similarly designed symbols, with the strokelets oblique, may represent harpoons. But most of the conventional patterns are quite unintelligible.

\section{E. Representations of Artificial Objects}

Under this head we must consider the so-called claviform, tectiform, and scutiform devices which are sometimes to be found.

Claviform devices (ante, Fig: 150) consist of upright bars, each

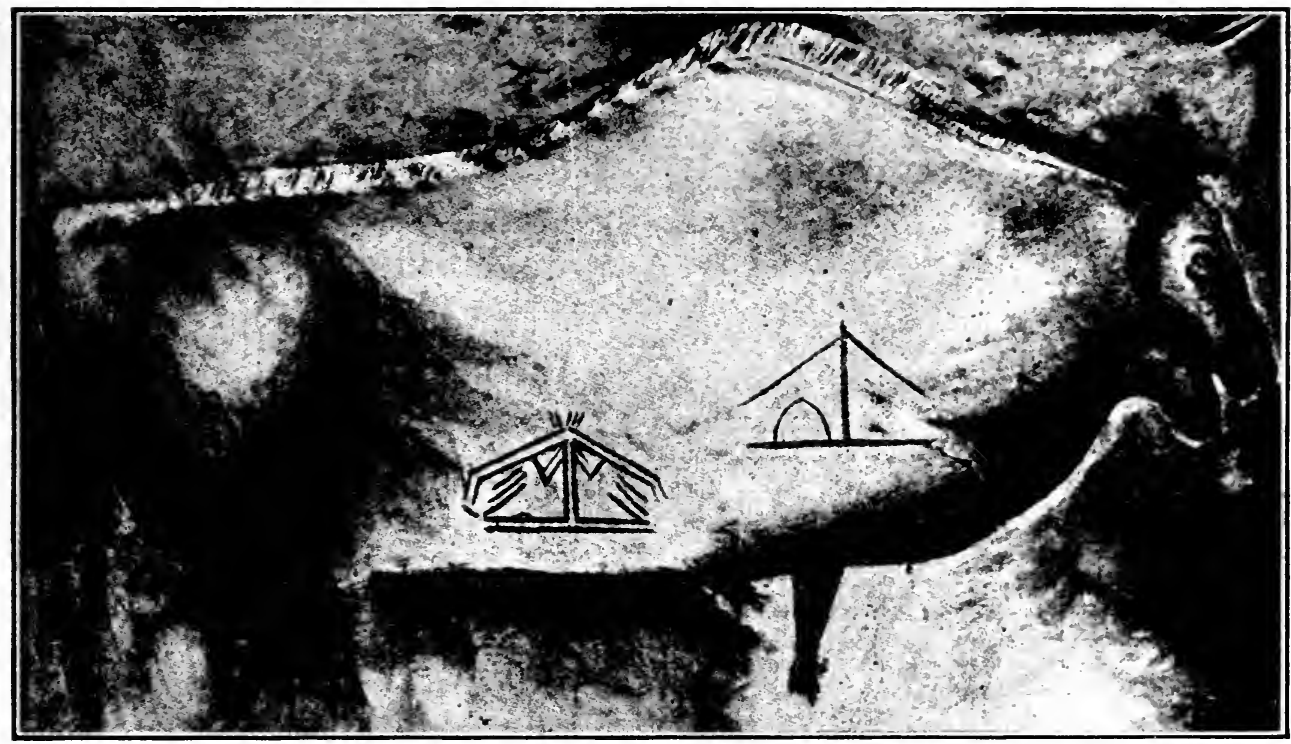

Fig. 152. Tectiform devices.

(Drawn by M. l'Abbé Breuil; from Revue de l'École d'Anthropologie, vol. xıx.)

with a small side projection. They have all the appearance of being representations of mounted stone axes, clubs, propulsors, or possibly. bâtons de commandement. It is probable that one or other of these comparisons is sound, and that it represents the actual intention of the artist.

Tectiform devices are essentially shaped like a more or less isosceles triangle, with a vertical line running from apex to base. There are many differences in detail of ornamental treatment, but this geometrical figure is the basis of all. They sometimes occur alone, but they are also painted over an animal figure, covering the middle of its body (Fig. I 52). 
They closely resemble huts, whence the name that has been given them. In the monograph on Font-de-Gaume, already cited, there will be found a number of illustrations of rude huts, tents, or wigwams, constructed by nature-folk in various parts of the world, all of which consist essentially of a sloping roof of some more or less flexible material, supported by a vertical pole set up in the middle of the floor of the structure.

The resemblance between such huts and the tectiform devices is striking, but not wholly convincing. Some questions arise when we consider the meaning suggested. Why should the hut be drawn over the animal figure? We are told that it is a magical attempt to secure an end aimed at; to get the animal into the hunter's power imprisoned

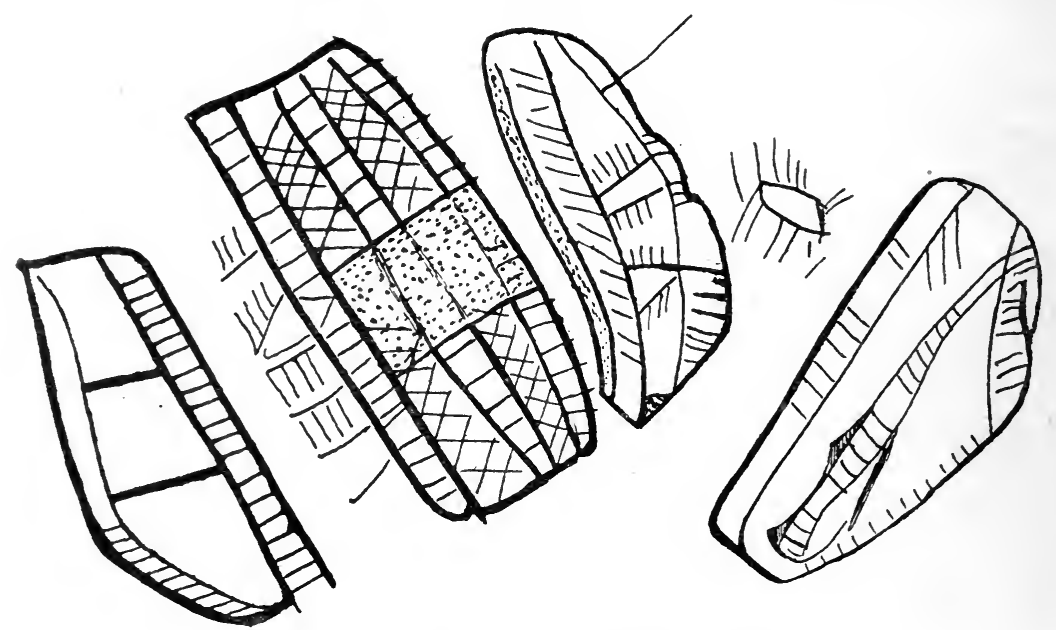

Fig. 153 . Scutiform and naviform devices.

(From La Caverne d'Altamira.)

in his hut. But the hunter would not want a living bison or mammoth in his hut; he wants the dead animal at his encampment, not necessarily within his hut. Moreover, he is a cave-dweller, and does not occupy such a hut as is supposed to be depicted in the paintings.

I have another suggestion to offer with regard to these devices; namely, that they are intended to represent traps. They are meant to suggest a pit with an impaling-pole in the middle, covered with branches and earth. The vertical post is usually, if not always, placed just on that part of the animal where such a post would strike it in actual use.

The scutiform and naviform symbols I would explain likewise as intended to represent nets. It may be reasonably objected that an 
artist who could draw such excellent animals might have been expected to be able to draw much better nets, if he had wished to do so. But did he wish to do so? In the strange ramifications of the savage mind, the idea of deceiving the victim by means which prosaic civilisation deems impossible, finds a prominent place. Hunting charms have been collected from many parts of the world in which the animal is appealed to as a reasoning being, and lied to, to persuade it to fall into the hunter's snare. Thus, to quote the first example that comes to hand, in the first book that I take down from my shelves, there is a Malay incantation in which the deer is addressed in these terms:

If you wish to wear bracelets and rings,

Stretch out your two fore-feet... ${ }^{1}$

the bracelets and rings being the noose and trap. The deer is supposed to be deceived into misunderstanding the nature of the ornaments promised. Likewise the wily Palaeolithic artist, when drawing a trap, took care not to make it too like the real thing, so as to keep the animal from guessing what it actually was.

If the reader will now turn back to the figure of the deer and salmon from Lorthet (Fig. I8, p. 75), he will see above the hindmost animal a couple of lozenges with a vertical bar crossing them. Piette, the discoverer of the object, took them for a hieroglyphic by means of which the artist or the owner made his signature. This is hardly likely, but no other theory has been suggested, so far as I know ${ }^{2}$. The objects presumably have a magical meaning, if we are to see magic in the rest of the design: and after what has now been said it is not difficult to see in these objects a simple kind of trap. A movable cross-bar of wood keeps the jaws of an elastic sided opening apart: an incautious bird or animal steps upon it, displaces the prop, and the jaws of the trap close on its leg. Similar traps are engraved on a cylindrical rod of bone in the collection of the Marquis de Vibraye ${ }^{3}$.

\section{THE SPANISH GROUP OF ROCK-PAINTINGS}

The caves of the north of Spain, such as Castillo and Altamira, are connected with the art-group to which the classical sites north of the Pyrenees belong. But there is another group in Spain quite independent of these, and representing an entirely different artaffinity. These are cave- and rock-paintings found in the eastern

1 W. W. Skeat, Malay Magic, p. I7I.

2 Except that the figures are meant for eyes. Georg Wilke, "Mythische Vorstellungen und symbolische Zeichen aus indogermanischer Urzeit" (Mannus, vi. [1914], p. 15). But the vertical stroke-which in the not very good reproduction of the engraving, illustrating the paper cited, is turned into a dot-does not resemble the pupil of an eye.

3 An illustration will be found in L'Anthr. xvil1. [1907], p. 33. 
and southern districts of the Peninsula. The following are the principal sites:

Roca del Moro, Cretas, Aragon. On a surface of rock that slopes outwards as a shelter, about Io mètres long and overhanging about 2.50 mètres, near the source of the Calapatà river. Flints of Magdalenian type were found in the floor deposits. The paintings are in dark red, which has sunk deep into the porous rock, and as it were, has become incorporated with it. A fine and scarcely visible engraved

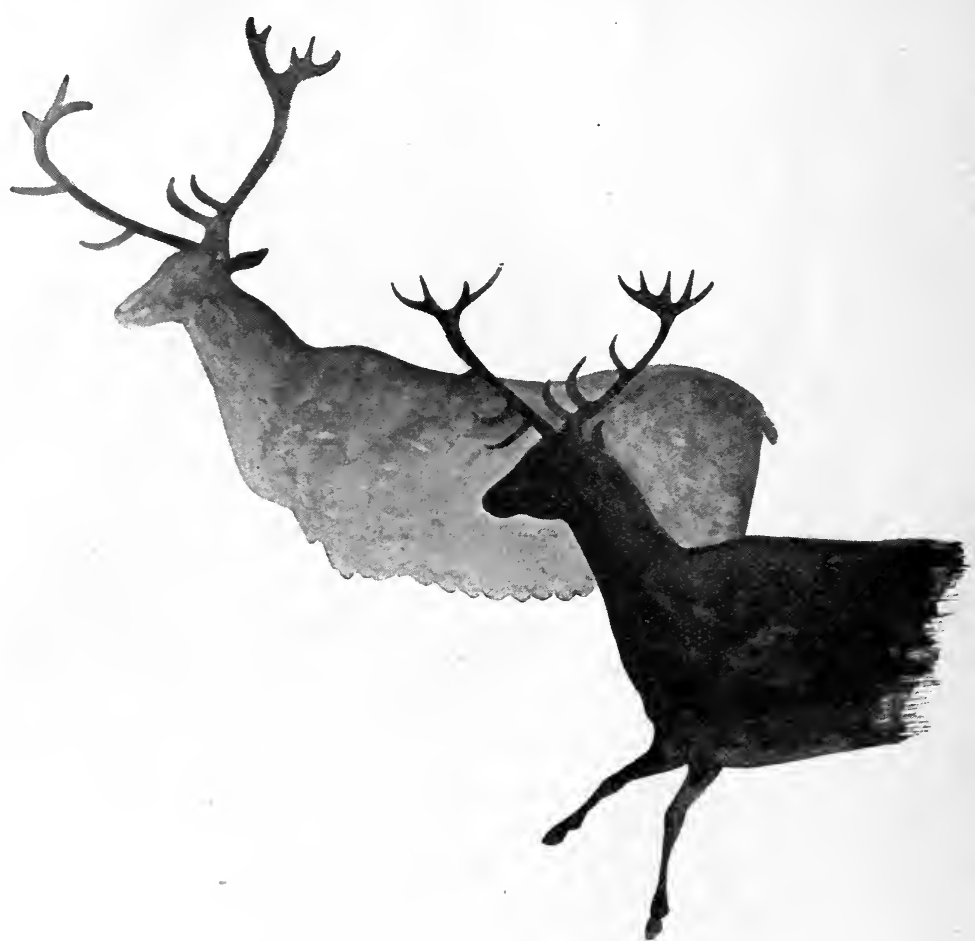

Fig. 154. Stags, Roca del Moro.

(Drawn by M. l'Abbé Breuil; from L'Anthropologie, vol. xx.)

line surrounds the margin of the figures, and by similar lines the eyes, nostrils, and other surface markings are indicated. The colour is a uniform wash over the surface.

Passing over some illegible traces at the right-hand end of the shelter, we notice a frieze of four animals - a stag rising from rest, two stags walking, and a cow; all painted with marvellous feeling for outline: the dimensions ranging about 0.30 mètre by 0.25 mètre. The body of the cow is shewn with colour as variegated as the cows in our own fields display. Next comes a small figure-it may be some 
sort of canine animal-imperfect at both ends and not clearly recognisable. This completes the series on Roca del Moro itself. But on a neighbouring rock some 200 mètres away L'Abbé Breuil noticed a beautiful picture of two stags, one black and the other red (Fig. I 54), and a pretty but much injured procession of ibexes: and Señor Juan Cabré Aguiló has afterwards discovered no less than ten rock-shelters in the neighbourhood with similar paintings ${ }^{1}$.

Cogul. In a similar rock-shelter on a hill-side at the village of Cogul, north of Lerida, are some other paintings of great importance. There are five groups, all very remarkable.

First comes a strange diagrammatical representation of a man

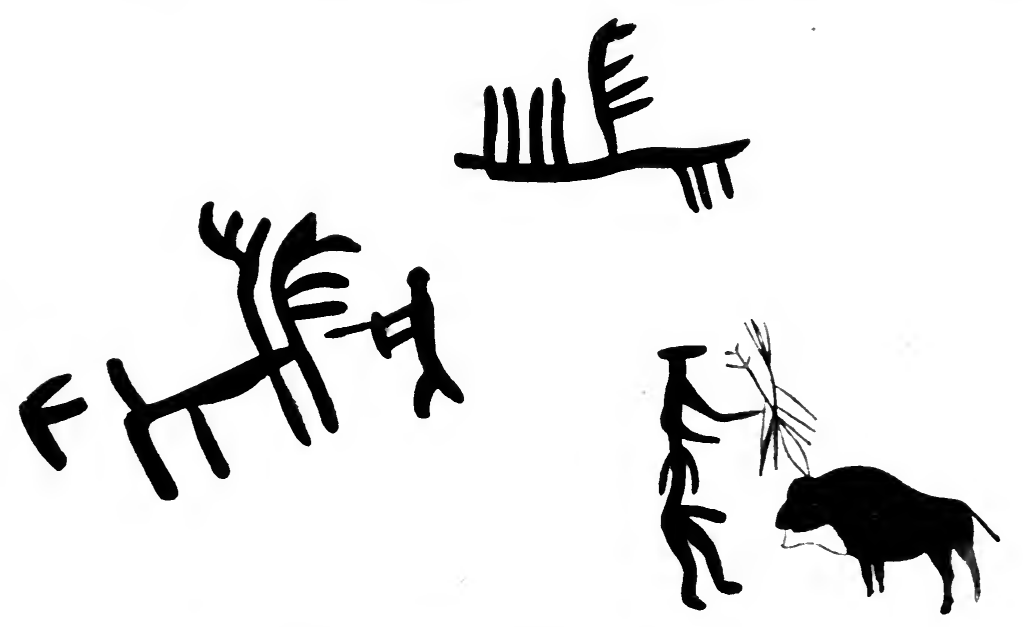

Fig. 155. Man killing stags, Cogul.

(Drawn by M. l'Abbé Breuil; from L'Anthropologie, vol. xx.)

killing stags (Fig. I55). We see at once that we are in a different art atmosphere. An action is being represented: while, on the other hand the drawing is so much conventionalised that it is hardly removed from a geometrical abstraction.

If we found the topmost figure alone, it would be impossible to say what it was intended for. It is really a dead stag, the four legs and one of the antlers turned upwards. This is shewn by the rest of the diagram, which depicts the hunter with his trappings, casting a javelin at another victim by means of his propulsor.

Also shewn in the above figure is a man attacking a bison with (apparently) an assegai. Thirdly comes a neat little group of animals-

1 L’Abbé H. Breuil and Juan Cabré Aguila, "Les peintures rupestres du bassin inférieur de l'Ėbre" (L'Anthr. xx. [1909], p. 1). 

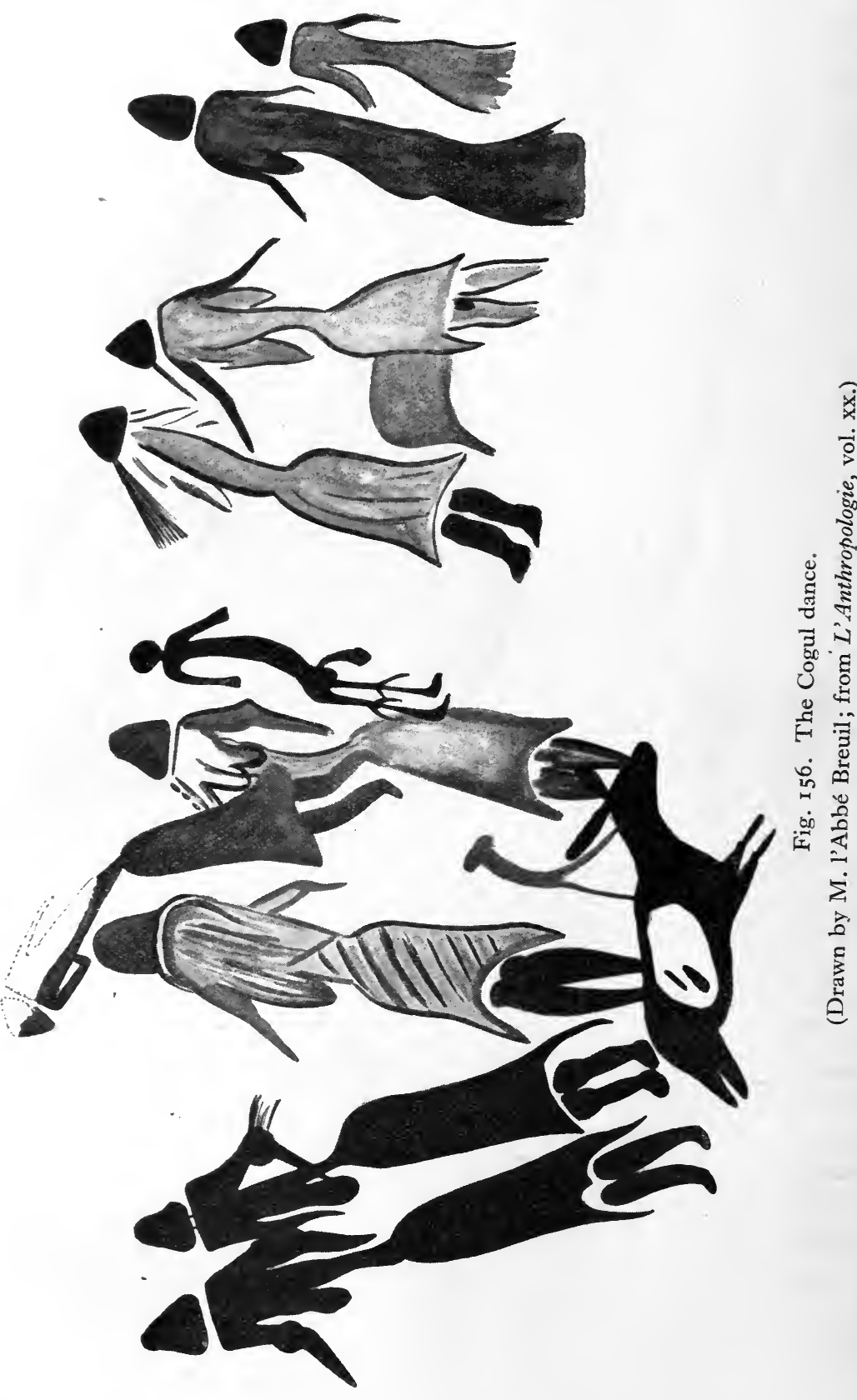



$$
1 . i^{3}
$$




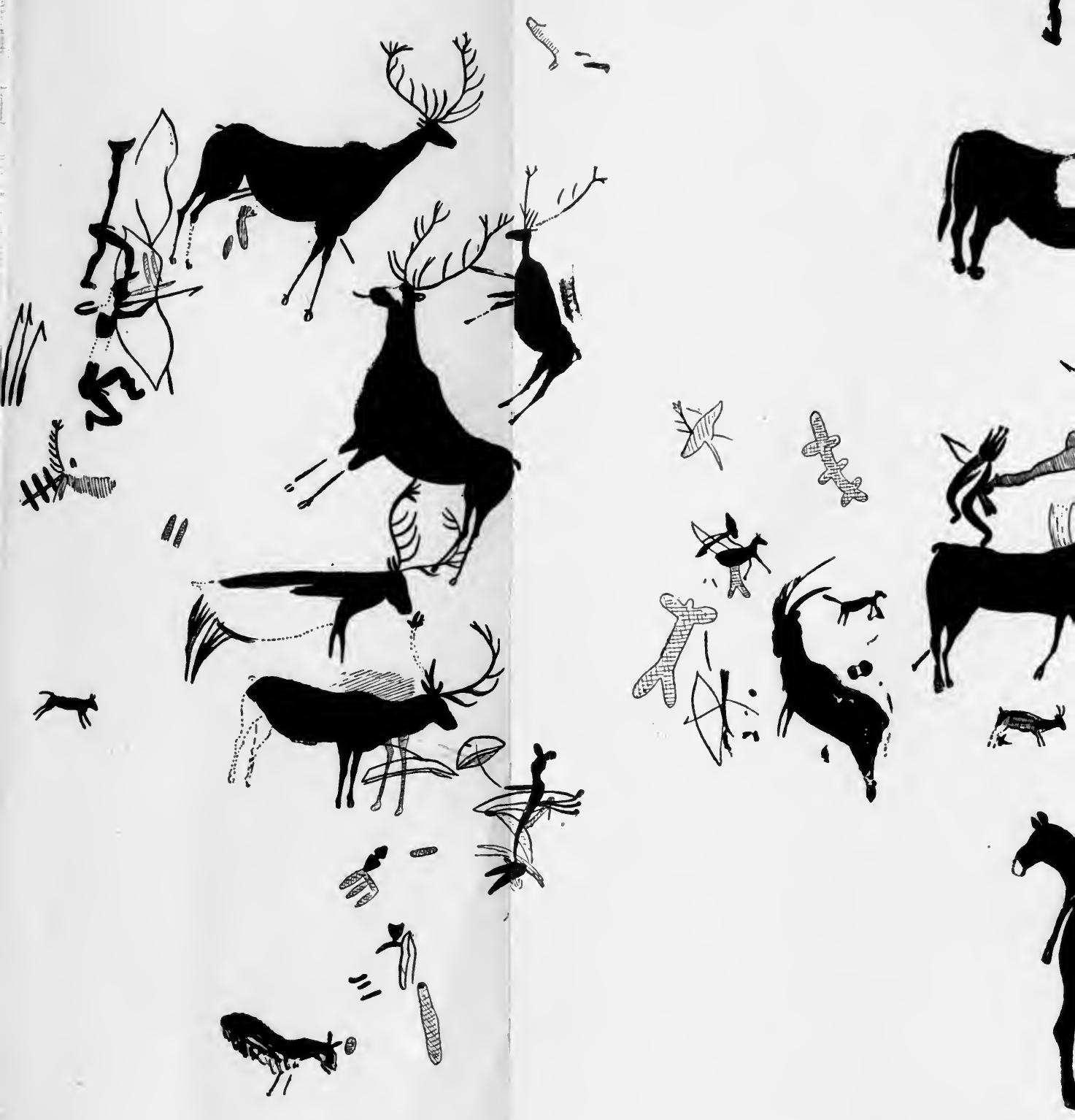




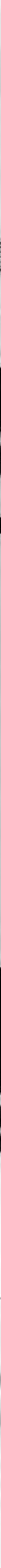




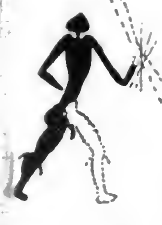

4
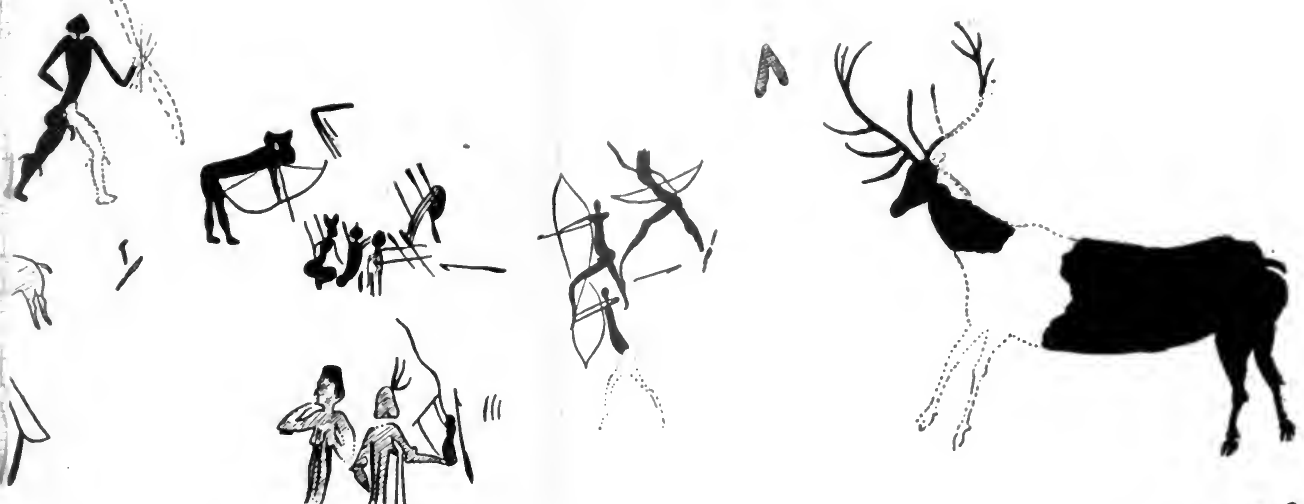

$y$

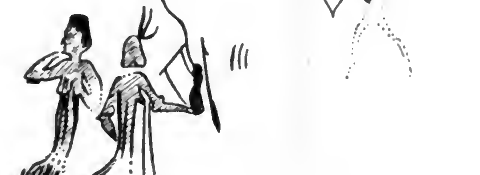

$\sqrt{3}$

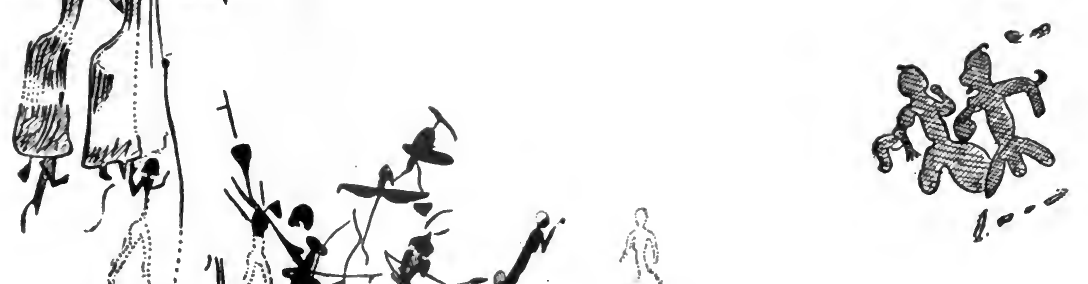

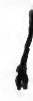
- 1 ,

17,0
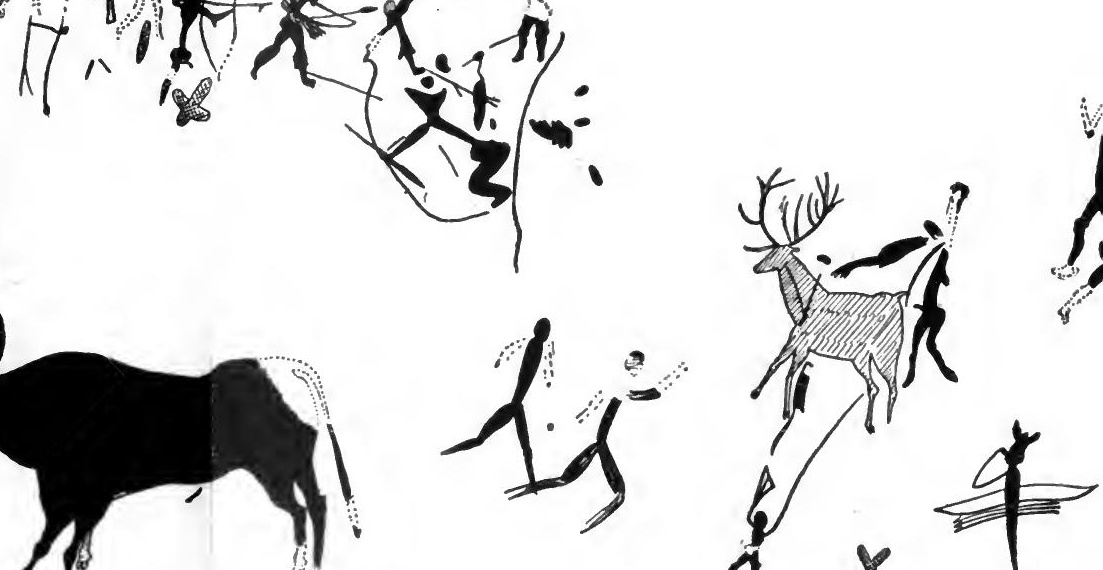

ra.

gie, vol. xx111 ) 


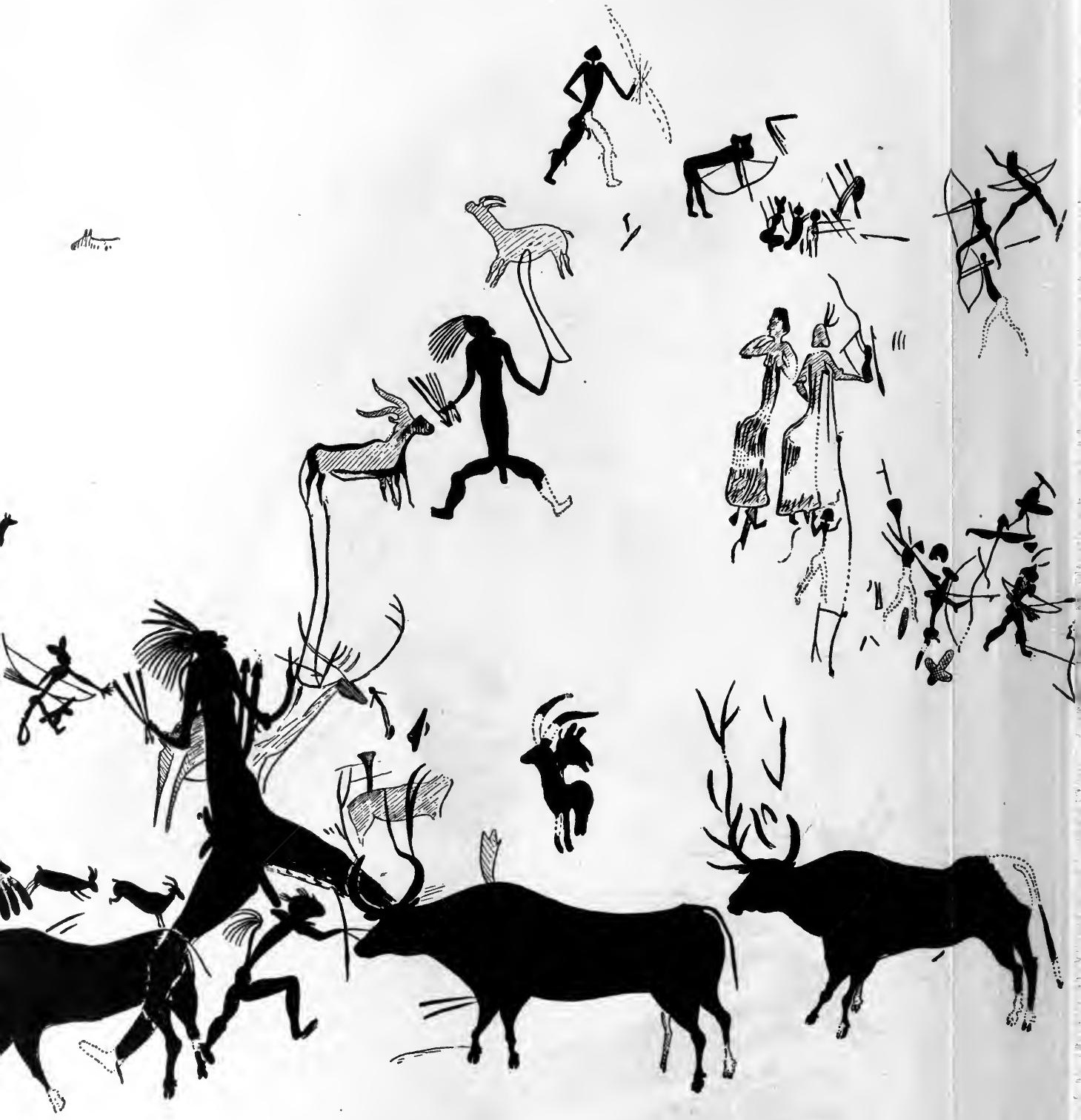

Fig. 157. The wall-painting at Alpera.

(Drawn by M. l'Abbé Breuil; from L'Anthropologie, vol. xxIII ) 


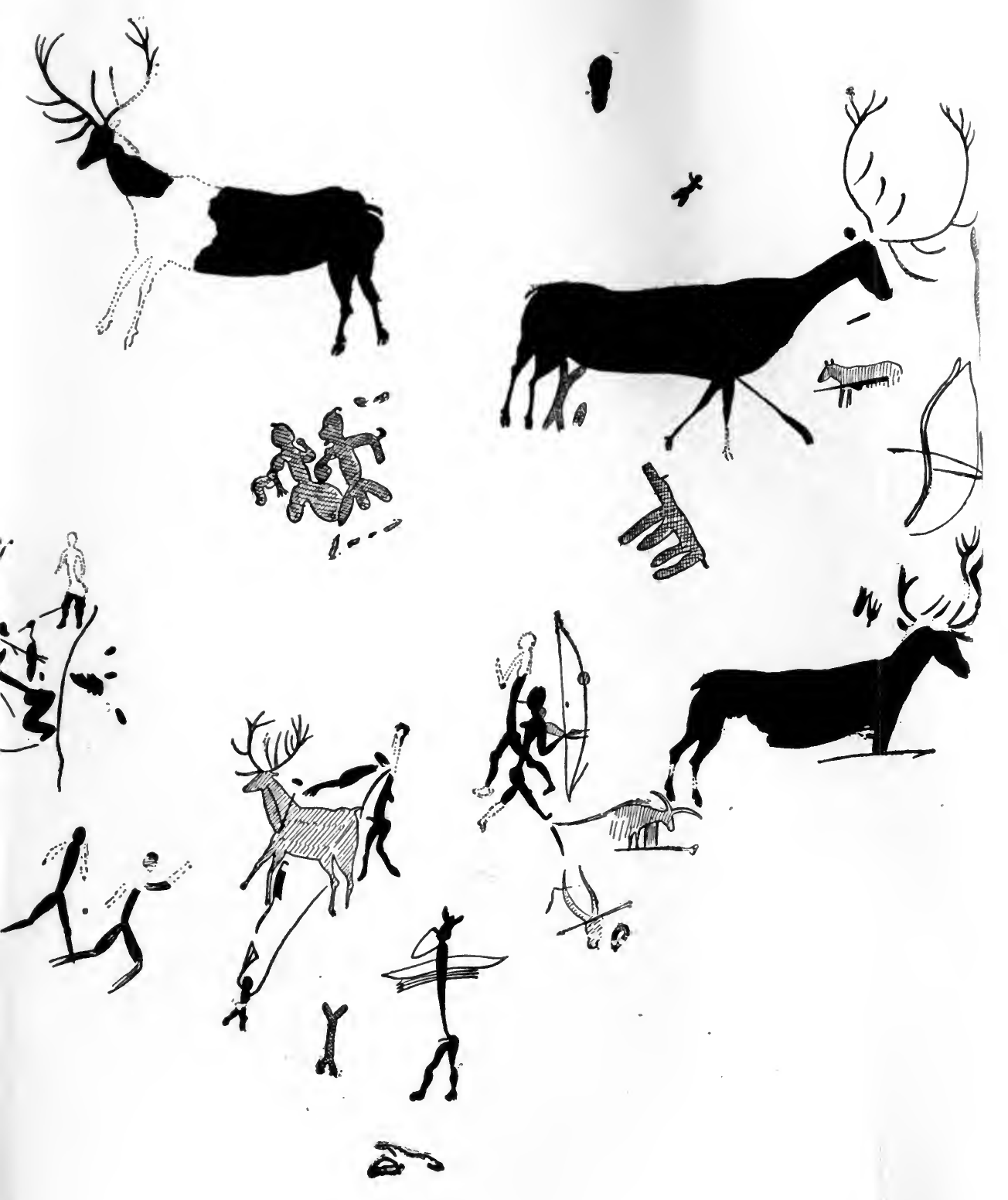



a stag, hinds, and at the bottom what seems to be a cow. This last is painted above another animal figure. Fourthly we see a group with further evidence of stratification; there are traces of very minute figures, of which three only remain - at the top a bull chasing a man (a reversal of the usual order of things), and in the middle a very small figure of another man. Superposed to this there comes a group of animals, chief of which are two excellent figures of ibexes, running or leaping. Below are two cows, of much inferior merit, one of them marked with zebra-like stripes on the body. Over these cow figures is painted another group-two women, attired in skirts. The last picture in the Cogul gallery is by far the most important. It represents a number of women similarly attired, dancing around what may either be a man or a male idol. The small size of the central figure in comparison with the women makes the latter the more probable. Here we have an actual representation of some ritual, probably connected with rites to secure fertility.

Alpera. The most extensive of these series of rock paintings is at Alpera, a railway-station between Madrid and Valencia, about half-way between Albacete and Alicante. The site of the paintings is a small farm called El Bosque. They are distributed over two rock-shelters, called respectively Cueva de la Vieja and Cueva del Queso. The former is the more important ${ }^{1}$.

The paintings in El Vieja cover a space 10.25 mètres long, on an overhanging rock. There are no archaeological deposits at its base, except some coarse flints which may be nothing more important than the lost teeth of a modern threshing-sledge. There are a few Roman and Ibero-Roman remains.

The figures comprise about 30 goats or antelopes, 26 stags, 5 cows, 2 horses, 3 deer, I moose, 5-7 wolves or other canines, and perhaps 3 birds. In one or two cases a cow has been changed to a stag by altering the horns; it would be interesting to know why this was done. There are besides over 60 human figures, of which I6 are drawing a bow on an animal or another man, six are walking (four to the right and two to the left), two are striking deer with weapons which are not sufficiently clearly expressed to be intelligible, one is striking another with a mace, and two are dancing. All the men are naked, but they have ornaments on the head or body. The head is bare in 13 , two have a headdress expressed by an oblong horizontal spot, seven have a triangular or semicircular headdress, which in two is developed into a sort of mitre; four have a horned headdress. There are also one or two women, depicted with a skirt as at Cogul.

1 See H. Breuil, Pascual Serrano Gomez, and Juan Cabré Aguilo, "Les abris del Bosque à Alpéra (Albacete)" (L'Anthr. xxiIr. [1912], p. 529).

M.E.A.I. 
The paintings in the Cueva del Queso cover a space 7.50 mètres long. They are much less perfect than the Vieja paintings, and include seven or eight human figures.

The authors quoted attempt-with considerable reserve-to interpret two of the Vieja groups as representing each a hunter going out attended by a dog. The drawing is however so bad in each case that no very far-reaching deduction can be based upon it.

Still, the Alpera paintings are of the highest importance, on account of the insight which they give into the life of their designers.

Albarracin. Breuil has reported further wall-paintings at Albarracin, and in the valley of Las Batuecas, Estremadura ${ }^{1}$. In the latter place there were found no less than eleven painted stations. Figures of bowmen were included among the paintings; with them were enigmatical signs, dots, radiating lines, etc. Other groups of the same type are reported in L'Anthr. Xxvi. [19I5], p. $3{ }^{\mathrm{I}} 3 \mathrm{ff}$.

These Spanish paintings differ in several important respects from the Magdalenian. The human figure, male and female, is freely introduced, and the men and women are shewn engaged in their pursuits-warfare, the chase, dancing. The technique is obviously quite different, and the tendency to stylisation is manifest. It is clear that we have to deal with the works of a different populationgroup.

The chronological relationship between these paintings and those of the Magdalenian type is not easy to fix. But as will appear in the following chapter, the subsequent Azilian civilisation has borrowed (or rather inherited) elements from both culture-groups. This would seem to indicate that they are approximately contemporary.

\section{CONCLUSIONS}

\section{Palaeolithic and Modern Savage Art}

It is usual, in describing Magdalenian works of Art, to compare them with those produced by Australians, Bushmen and other Africans, Eskimo, American Indians, and other nature-folk, many of whom are possessed in no mean degree of a native talent for drawing. The superficial analogies are striking, though as a rule the Magdalenian is easily superior to his modern rivals in actual technique. Both alike favour animals, just as a young child in Europe scribbling with a pencil will do, for the simple reason that the animal has a life which attracts it and renders it interesting to the artist. With the animals the modern peoples draw men in much greater frequency than do the Magdalenians; and this leads us to a very important

1 L'Anthr. xxir. p. II9. 
point of contrast between the ancient and the modern artists. The moderns are all in the habit of drawing rudely enough, but recognisably, scenes from their daily life-hunting, fishing, and battle scenes, and even half-humorous caricatures of the meeting of modern Europeans, in their ugly costumes, with the noble savage. But this historical or pictorial element is practically absent from the Palaeolithic Art-we may almost say entirely absent, if we exclude the Spanish group. Magdalenian Art all but begins and ends with the representation of isolated figures of animals.

It is not to be inferred that the comparison of Magdalenian and modern savage Art is on that account sterile of valuable results. One important principle results from the study of the modern Art, which is most probably applicable to the ancient. There is no pattern, however conventional it may appear to be, which is without its definite meaning. All the geometrical and other abstract patterns, decorating boomerangs and other objects used by the natives of Australia, have a definite message for the initiated ${ }^{1}$. Indeed, many of them are derived directly or indirectly from the graphic representations of animals or other natural forms ${ }^{2}$. This is probably equally true of many of the spirals and other seemingly abstract patterns with which implements and rock-surfaces are decorated in Magdalenian settlements ${ }^{3}$, though, as we have seen, the abstract patterns make their appearance quite as early as concrete figures.

There is nothing purposeless in the action of a savage. His most seemingly irrational acts are all directed to a definite end. If he wants the figure of a horse's head, it is because he believes that figure to be of importance in securing some practical purpose which he has in view. Mere aesthetics, "Art for Art's sake" and all the rest of it, make but a feeble appeal to him. It would no doubt

1 Brough Smyth, The Aborigines of Victoria (Melbourne, 1878), vol. I. p. 285.

${ }^{2}$ On this see Henry Balfour, The Evolution of Decorative Art (I.ondon, 1893); Alfred C. Haddon, Evolution in Art, as illustrated by the Life-histories of Designs (London, 1895); the same writer's The Decorative Art of British New Guinea, a Study in Papuan Ethnography (Dublin, Royal Irish Academy Cunningham Memoirs, I894).

${ }^{3}$ On the subject of the arts of nature-folk, especially with reference to its relation to Palaeolithic Art, see Cartailhac and Breuil, La Caverne d'Altamira (Monaco, 1912); I.. Robert, "Rapports de l'art glyptique avec d'autres arts anciens" (B.S.P.F. III. [1906], p. 253); Richard Andree, "Das Zeichnen bei den Naturvölkern" (M.A.G.W. xvII. [1887], p. 98: some remarkable drawings reproduced); $\mathrm{F}$. von Luschan, "Uber Buschmann-Malereien in den Drakensbergen" (Z.F.E. XL. [1908], p. 665, with excellent facsimiles); L. Frobenius, "Die bildende Kunst der Afrikaner" (M.A.G.W. xxvir. [1897], p. I); W. J. Hoffman, "The graphic art of the Eskimos" (Smithsonian Annual Report, 1895, p. 739); Theodor Koch-Grünberg, "Anfänge der Kunst im Urwald" (N.D.); "Australian cave-paintings" ( ournal Roy. Soc. N.S. Wales, xxvir. [1893], p. 353); H. Basedow, "Aboriginal rock carvings of great antiquity in South Australia" (F.A.I. xLIv. [1914], p. 195); M. H. Tongue and Henry Balfour, Bushman Paintings (Oxford, 1909). 
be unfair to deny that the savage sculptor or painter who succeeded in turning out a really artistic image would be conscious of, and would feel a genuine pride in, the attainments of his skill. But it is important to remember in studying the origins of this art, that unless the psychology of Upper Palaeolithic Man was very different indeed from that of the modern savage-which there is no real reason to believe-he would not have taken the trouble to acquire and to develop his wonderful artistic skill unless he had some ulterior purpose to serve. The very limitations of Upper Palaeolithic Artthe fact that it consists almost exclusively of endless repetitions of figures of animals-shew that it is not merely an art and nothing else, otherwise the artists would surely have sought fresh sources of inspiration sooner or later.

We may therefore now review the whole subject and see what may be inferred respecting Upper Palaeolithic psychology from the facts set forth in this and the preceding chapters.

\section{Upper Palaeolithic Mode of Life}

Upper Palaeolithic man, like his predecessors of earlier stages, was a hunter. He lived in caves when he could find them, though in some stations, as at Solutré and at Předmost, he dwelt, presumably in huts, in the open air. His natural mental gifts were much superior to those of the preceding inhabitants of Europe, and indeed, if we may judge by the capacity of his skull, he would compare very favourably with the average of modern Europeans.

\section{Upper Palaeolithic Religion}

That he possessed a religion may be inferred with certainty from $(a)$ the Aurignacian statuettes, $(b)$ the evidence for dances, $(c)$ the burial of the dead, and $(d)$ the paintings in the inner recesses of the caverns.

(a) Not every figure is necessarily an idol; but the prevalence in Aurignacian times of figures of women, with the maternal functions. emphasised, is most probably to be explained as due to belief in a goddess of fertility and birth. These figures call forcibly to mind similar figures found in Semitic Art, which display similar exaggerations, and which unquestionably possess the meaning suggested. Though no one would now venture to maintain, with the dogmatic assurance of the past generation of anthropologists, that Upper Palaeolithic man was destitute of a religion, some might find this explanation too recondite for such simple people as the Aurignacians, and might prefer to believe the apparently simpler theory, that these: 
figures are merely the expression of the not over-refined humour of the uncultured savage. But it may be questioned whether this is really less recondite, psychologically, than the former suggestion. It is noteworthy that these figures disappear in Magdalenian times, as 7 though some religious change had taken place - either the cult of the fertility-goddess had given place to some other rites designed for the same end, or a religious prohibition against the representation of human figures had been coming into force. It is certainly curious how rarely; on the whole, human figures are represented in Magdalenian art.

(b) The dancing "diablotins"; the footmarks in the cave of Tuc d'Audoubert; and the Cogul women; are all evidence for the practice of some kind of masked dance, like those performed in the duk-duk and similar ceremonies. The resemblance between the diablotins and the duk-duk performers cannot be without significance. We may be sure that the people of Tuc d'Audoubert did not climb into a cave chamber, difficult of access, to dance merely for amusement; the dance which has been recorded in the footprints on the floor ${ }^{1}$ must have had a very serious meaning indeed. These facts indicate the existence of a religion in which a highly developed ritual of dancing had already come into being.

In connexion with the marks in the Tuc d'Audoubert cave, which shew that the dancers struck the ground with their heels only, a modern analogy may be noticed in passing, for what it may be worth. In the Hausa Bori dances, the performers in which are possessed or "ridden" by certain Bori or spirits, one, who takes the part of a variously-named spirit responsible for giving leprosy, acts as though afflicted with that disease, and on entering makes the following speech: "You think me useless because I have no fingers nor toes. The hyaena says 'The footprint is confusing, is the man going this way or that way?' for if there is no foot the print is round ${ }^{2}$."

(c) The various interments that have been described enable us to formulate the following principles of Upper Palaeolithic burial.

I. Care was taken to dispose in a seemly way of the bodies of at least some of the tribesmen and women.

2. Burial, not cremation, was in almost all cases practised.

3. The dead were buried with weapons, ornaments, and implements that had been of use to them during life.

4. As a rule the body was outstretched, but sometimes it was closely crouched up into a cramped posture.

1 I suppose it would be impossible, by carefully mapping such footprints, to recover something of the steps of the dance?

2 A. J. N. Tremearne, The Ban of the Bori, p. 299. 
5. Sometimes when the body had been dragged from its place by wild beasts, an effort was made to recover it. In many cases it was carefully protected from injury by stones placed round and over it.

6. In some cases it is possible that there was a temporary burial, the body being deposited somewhere till the flesh had decayed from the bones; the flesh may perhaps have been artificially removed from the bones in certain cases by some such means as boiling. The bones were then taken up and laid in the grave; usually it would appear that an effort had been made to place them in their natural relative position.

7. When skulls are misused (as in making the drinking cups found at Placard) we are probably to see in them the skulls of an enemy tribe.

8. The bones when thus replaced in the grave (according to No. 6) were often painted red. Frequently the whole interment was made in a bed of ochre, which has coloured the bones.

The deposition of offerings with the dead is quite sufficient to indicate a belief in a life after death, in which the dead will have need of the gifts placed in his tomb. Women equally with men shared in its privileges.

The remarkable rite of painting the bones red should be especially noticed. It has also been found in the kurgans or Neolithic and Bronze-age tumuli of Russia ${ }^{1}$. The process followed is not always evident. Some have supposed that the body was coloured with ochre, and that when the flesh decayed the imperishable colouring matter attached itself to the bones. For my own part I should like to see the possibility of this verified by experiment-a pig could be used as the corpus vile-before accepting it.

The purpose of the rite is perfectly clear. Red is the colour of living health. The dead man was to live again in his own body, of which the bones were the framework. To paint it with the colour of life was the nearest thing to mummification that the Palaeolithic people knew; it was an attempt to make the body again serviceable for its owner's use. In this connexion it is instructive to recall a familiar incident in folk-tales, in which the hero having come to grief, the flesh of his body is restored from the bones, or even from a small splinter of bone, and then resuscitated ${ }^{2}$. In Irish hagiography even animals can be restored to life by miracle-working saints in

1 A. Spizyn, "Kurgane mit gefarbten Skelette" (K. Russ. Arch. Gesellschaft, XI. p. I). See also A. Hrdlička, "The painting of human bones among the [American] Indians" (Smithsonian Annual Report, 1904, p. 607).

${ }^{2}$ As in "La princesse Troïl" (F. M. Luzel, Contes populaires de BasseBretagne (Paris, 1887 , vol. I. p. 219 ff.). 
the same way ${ }^{1}$. In the tale Krośećka-Khavrošička, a Russian version of Grimm's Einäuglein, Zweiäuglein, und Dreiäuglein, the heroine collects, buries, and each morning waters the bones of her friendly cow, after it has been slaughtered by the cruel stepmother; from them an apple-tree grows, which is of course a re-birth, so to speak, of the cow, and through the apples the ultimate happiness of the persecuted girl is attained ${ }^{2}$.

(d) Already in 1877 Dr Heinrich Wankel ${ }^{3}$ speaking of the cave of Býćsskála in Moravia, where human remains were found along with bones of the cave bear", described it as "the great cave where once the reindeer man lived, whose antechamber was the scene of a cult of the dead where at a chieftain's grave human sacrifices were offered." This reconstruction goes rather beyond the evidence, especially as the Býćiskála deposits were almost all cleared out of the cave in the eighteenth century, without regard to their valuable osteological contents. But it well expresses the feelings which these ancient caverns naturally excite, even in one who lives in the sceptical atmosphere of modern science. Later, Dr Marett, in his essay on the cave of Niaux quoted above (p. 489), does not hesitate to call it a "sanctuary" and to treat of it as such. The existence of fine paintings at the farthest ends of these great and complicated caverns; the presence of the two splendid statuettes of bisons in the remotest recesses of Tuc d'Audoubert; are facts certainly suggestive of animal gods in their "chambers of imagery."

In this connexion a very interesting suggestion must be recorded, to the effect that the incomplete animals-heads, forequarters, etc.so frequently represented, are meant to indicate mysterious deities, or at least spirits, in animal form. Analogy is indicated with a modern Eskimo convention, in which half-figures of men represent spirits or shamanic influences, and imperfect figures of animals (e.g. reindeer without horns or hoofs) bear analogous meanings ${ }^{5}$. A painted incomplete figure might be explained as having been accidentally effaced. But when, as at Altamira, we find an engraved figure, otherwise well drawn but lacking a head, with no evidence of injury on the rock surface, it is to say the least legitimate to suppose that there

1 See the present writer's edition of the Latin and Irish Lives of Ciaran (London, 1921), p. 118 .

2 Brylinska and Smith, Russian Fairy Tales (London, 1919), p. 4. In Grimm's German version the friendly animal is a goat, and it is its entrails, not its bones, which are buried.

${ }^{3}$ H. Wankel, "Gleichzeitigkeit des Menschen mit dem Höhlenbären in Mähren” (M.A.G.W. vir. [1878], p. r).

${ }^{4}$ Here modern criticism has thrown doubt on the contemporaneity of the human bones with those of the bear in this cave; see Obermaier, L'Anthr. xvi. [1908], p. 406 .

5 Capitan and others in R.E.A. xIx. [1909], p. 68. 
must be some explanation of the fact more recondite than laziness on the part of the artist, or mere accident.

On the other hand, the presence of wounded animals, as at Niaux, tends to shew that the figures are not wholly to be regarded as representations of supernatural beings. We here touch other aspects of Palaeolithic psychology. It cannot be too often or too clearly stated that these pictures of animals had not, primarily, a merely aesthetic purpose, though we may admit that a skilful artist would have taken a pride in his work. In many cases the drawings and engravings are in the deepest recesses of the caves, where they cannot be reached without much trouble and even danger; and they can

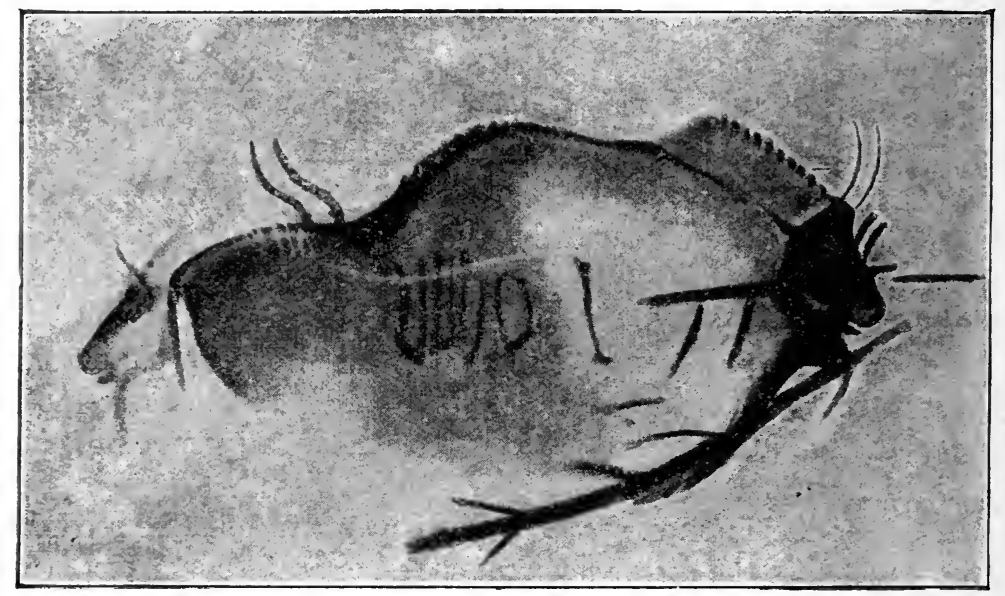

Fig. 158. Bison, Marsoulas.

(From L'Anthropologie, vol. xvi.)

scarcely be seen even with our modern devices of electric torchesmuch less with a smoky stone lamp burning animal fats. Not only must we admire the eyesight of the artists who made such beautiful drawings in the imperfect light at their disposal; we must also commend their powers of observation and memory, when we consider that it would obviously have been impossible, and undesirable, to introduce a bison or a reindeer into the cave to serve as artist's model $^{1}$. The obscurity of the situation of the drawings is one proof that they had not an aesthetic purpose. Another and an even more convincing proof is furnished by the superposition of the designs. The artist was interested only in the PROCESS of drawing. When the

1 We need not however assume that the artist drew altogether from memory, for he might have had one of the small bone engravings with him to serve as a guide. 
picture which was the result of the process had served its purpose, he took no further care of it, and often mutilated it by painting another picture over it. Thus we often find a thoroughly inartistic medley of almost meaningless lines, which when analysed resolve themselves into a number of well-designed animal figures one over another. A good example is the bison from Marsoulas (Fig. 158). This had the head of a second bison behind it, and the horns of a third above it. These are all that is left of earlier pictures, probably not inferior in merit, which were painted in the same place. Clearly this principle of the non-permanence of the efficacy of the drawings militates against our explaining them as representations of animal gods, just as strongly as against our taking them as mere works of art.

There are two other explanations possible, if we are thus to exclude religious iconography and aesthetics; namely totemism, and magic.

\section{Explanation of the Art. Totemism}

We have already explained what totemism is in our fourth chapter, to which we may refer the reader back (p. $125 \mathrm{ff}$.). A figure of the totem decorates the person, property, and graves of the tribesmen who possess it, just as the heraldic monsters which formed the coat of arms of the mediaeval knight decorated his shield, his castle, his plate, and his sepulchral monument. Conversely when we find a man spending much of his time drawing gazelles, let us say, it may not be because he thinks those animals fair to look upon, so much as because they occupy some mysterious position in his regard which invests them with a special import.

But there is a difficulty in the way of explaining the Palaeolithic cave paintings as totemistic, though it is not impossible that the occupants of the caves had already evolved the totemistic system of tribal classification. Adopting this view, it would be difficult to explain $(a)$ the wide area over which the different animals are found, and $(b)$ the co-existence of different kinds of animals in the one cave. Had we found nothing but reindeer in one geographical area-or perhaps reindeer and one or two other animals-bisons in another, cats, let us say, in a third, we should very fairly explain them as the totem-symbols of the tribes occupying those areas respectively. But there is no such distribution. Nor do we find many representations of animals not used by man (such as the lion). But these animals can be, and are, adopted as totems; and there is no reason in the totemistic theory why they should have been excluded from the Palaeolithic galleries.

M. l'Abbé Breuil, however, has pointed out one singular fact 
which, if it prove to be a rule, will go far to establish the totemistic theory, even in the face of these difficulties. This is, that the bones of animals depicted on the cave walls are often absent from the midden-heaps contained in the caves ${ }^{1}$. It will be remembered that the totem animal is never eaten by those to whom it belongs, though the totem of another tribe may be freely eaten. Emu men may eat cockatoos if they desire to do so, but must not eat emus; cockatoo men may eat emus freely, but must not eat cockatoos. So, if the caves containing many portraits of reindeer never have reindeer bones in their middens, the fact will go far to prove that the cave was inhabited by men with a reindeer totem. But what about the caves which have a large variety of the usual "table" animals depicted on the walls (such as Castillo)? The diet of the inhabitants must have been very much restricted.

\section{Magic}

The magical theory is on the whole preferable to the totemistic, at least in the present state of our knowledge. We may illustrate this fully by the Marsoulas bison, already shewn in Fig. 158. This has a number of signs marked upon its side to which we have not yet alluded. This painting may be taken as a text for a brief explanation of the theory underlying the practice of sympathetic magic. By juggling with a portrait of your enemy, or with a part of him-such as his severed nail-parings or a lock of his hair-even by winding spells round his name-you can produce upon his person all the ill effects your heart may desire. The following incident once came under my own notice. A peasant woman in Palestine had been presented with her photograph (which she had been at first unwilling to pose for, for she feared that the photographer intended to work magic upon it in order to compel her to become a Christian); this was snatched out of her hand and torn asunder by a jealous companion; whereupon the owner of the portrait burst into loud lamentations, not at its loss, but because she feared that as the head of her picture was torn off, so her own head was destined to come off before long. In such a belief we may see one possible explanation of the engravings and paintings; and we also see what the totemistic explanation leaves unelucidated, the reason for their neglect after they had been executed. The hunters of Marsoulas were going out to chase a bison. They took the precaution of first drawing on the wall of their cave a picture of the animal intended as a victim, and of filling the picture with javelins-for this is what the rods and strokes which cross the picture apparently are. Very likely the stay-at-home

1 La Caverne d' Altamira, p. 139. 
members of the community, or perhaps a hired medicine man, who may also have been the artist of the picture, were spending the whole time of the hunter's absence in performing unholy rites and chanting

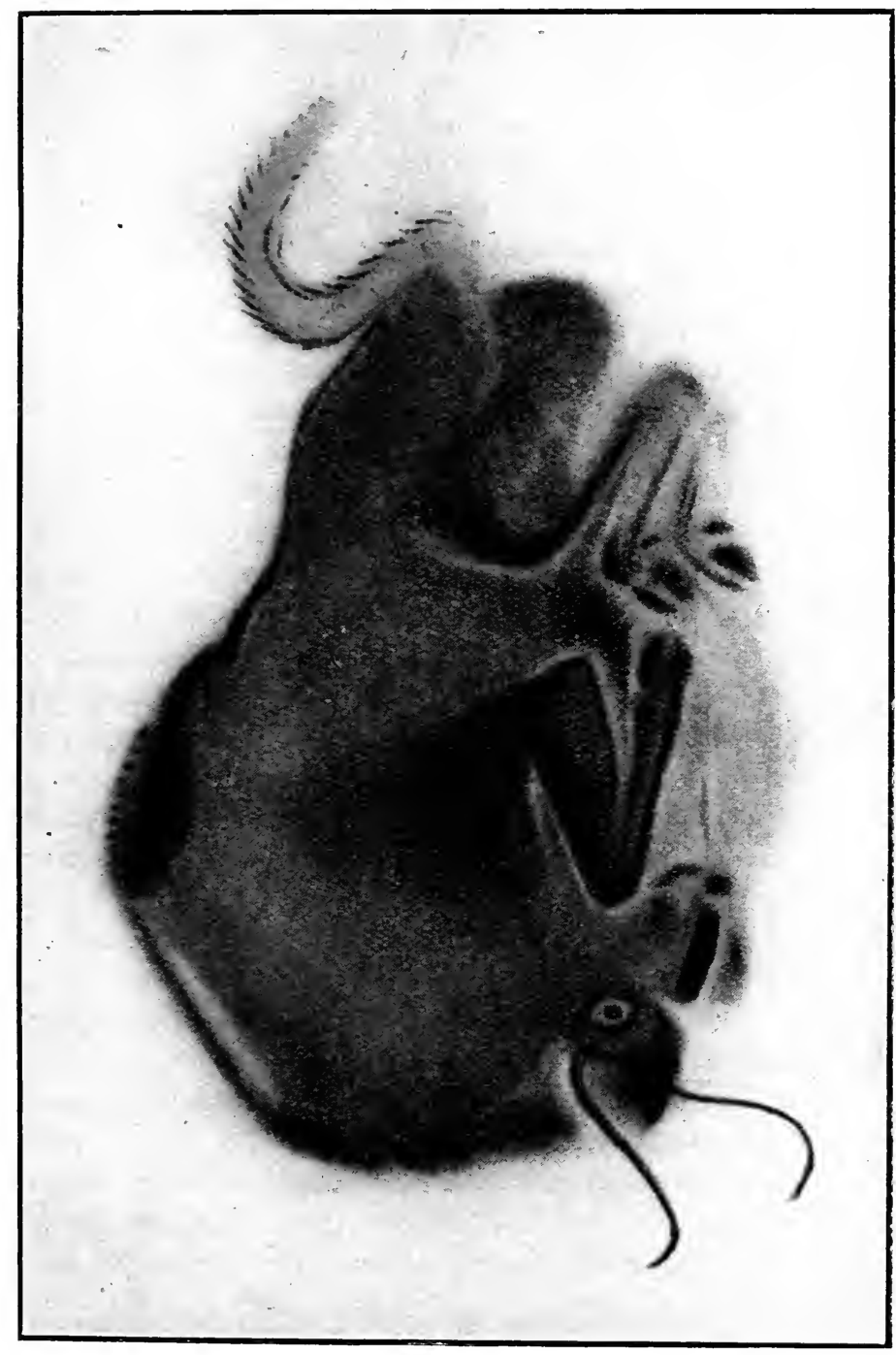

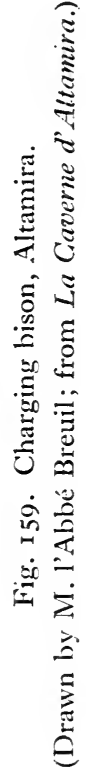

incantations in front of the picture. The two bisons whose remains we see underlying the figure have already been killed and eaten. Their pictures are no longer of any service. We can hardly blame the hunter for taking any advantage that he imagined this practice 
of the black art put in his power. One of the Altamira artists has recorded what appears to be his impression of the appearance of a charging bison ${ }^{1}$; and when we imagine his having to face this fearsome beast with the very inadequate weapons of the Palaeolithic period, we can sympathise with his casting about for means to enlist the services of the unknown powers of the supernatural world (Fig. I59) ${ }^{2}$.

M. Salomon Reinach, to whom this magical explanation of the Art of the Upper Palaeolithic Term is due ${ }^{3}$, has indicated two points which seem to support the theory. The first is that to which allusion has already been made, that the engravings are for the greater part in the secret recesses of the caves. This argument must be used with caution, for, as we have seen, the absence of designs from the more exposed parts of the cave is no proof that they were never to be found there. The second is the fact already noted that as a rule only the "useful" beasts are depicted. This rule has been broken by some discoveries made since M. Reinach's essay was written, as for instance the large felines at Les Combarelles and elsewhere. But these exceptions are rare, and the rule still holds that very nearly all the animals depicted are such as might be naturally chased by the hunter. He would not want to invoke cave lions and similar dangerous animals. But even if there were more of these large carnivores than there actually are, this would not disturb the explanation; for it would often be desired to kill a troublesome animal of the kind that had taken up its abode too near to the community for safety; and the hunter might profit by his incantations in this case as in the case of the food animals.

It is not impossible that a growing dread of similar arts being played upon a man by his enemies may have led to the development of a tabu against making human representations, which the rarity of such in Magdalenian deposits has already given us reason to suspect.

It would be absurd to describe as magical or totemistic every scratch that we find upon the surface of a wall. But when we find people who have acquired an extraordinary skill in art confining the exercise of their talents within one narrow groove; when we find them piling up reindeer after reindeer, bison after bison, till there

\footnotetext{
1 Though it is also possible to explain the painting in the contrary sense of a tison lying coiled up at rest.

${ }^{2}$ In Boyd Dawkins' Early Man in Britain, p. 214, allusion is made to an engraving figured in Reliquiae Aquitaniae, plate B ii. fig. 5, representing an impaled beast. Reference to the illustration indicated however shows that the explanation is not correct. There is a line passing through the animal, but it is merely a line of shading, or at most a fissure in the bone bearing the engraving.

3 "L'art et la magie, à propos des peintures et des gravures de l'âge du renne" (L'Anthr. xiv. [1903], p. 257 ff.).
} 
are hundreds of such figures spread with no apparent purpose over the cave walls; when we find these drawings made in the dark, where no one can see them, and when we find them recklessly mutilated after they have served their turn; we may be sure that some more recondite explanation than mere aesthetics must be sought for them, and that the artists did not spend so much time and energy in drawing animals merely because they thought them pretty.

\section{The Hand Devices}

But sympathetic magic is not the only superstition which we may trace in these paintings. On the bison of Marsoulas, of which we have been speaking, there is another figure which looks like a child's drawing of an open hand. We recall the cave of Gargas, already described, which displays a large number of hands upon its walls. Very remarkable analogies to this custom are to be found in other parts of the world. In Australia similarly stencilled hands are made on the walls of caves, for a purpose apparently unknown ${ }^{1}$. In this case the colouring matter is placed in the mouth and spat at the hand pressed on the cave wall. Similar figures are to be seen in Arizona $^{2}$ and they are to be seen everywhere in the peasant villages of Palestine, as I can assert from my own observation-in the latter the hand is dipped in some whitening substance and impressed on the walls of houses, round the doors, on store-chambers and cattle stalls, etc., and in a modified and conventionalised form tattooed on the faces of women. Now the hand, in one attitude or another, is constantly used as an amulet against the evil eye. This extraordinary superstition appears, like totemism, all over the world. Certain gestures with the hand, such as the Neapolitan mano cornuta, are supposed to avert this mysterious influence; and therefore a representation of a hand making such a gesture is worn as a permanent amulet to guard against the possibility of the eye falling on the wearer without his knowledge. We may see it worn thus by the cultured Neapolitan. We may see it sculptured over the lintel of every Jewish house in Jerusalem. We may see it, in fact, almost literally "here, there, and everywhere." Among the people who make use of it, the dread of "the eye" is an obsession that never quits their waking hours, and probably haunts their dreams. Conversely, when we find a people making use of the hand as a symbol, either represented naturalistically or indicated by a summary arrangement of

${ }^{1}$ R. H. Mathews, "The rock paintings and carvings of the Australian aborigines" (7.A.I. Xxv. [1895], p. 145, with three plates of facsimiles; xxviI. [1 898], p. 532, with two others). The identity of the figures of hands shown in these plates to those in the Gargas cave is very remarkable.

${ }_{2}$ Smithsonian Inst. Report, Bureau of Ethnology, $1894-5$, plate lv. 
strokes, in a place where there is no obvious reason in nature for its presence, then we may take it as at least an admissible conjecture that the tribe among whom we find the symbol have burdened themselves with this universal superstitious dread ${ }^{1}$.

Our study of the cave paintings, and of the sculptures and engravings of the Upper Palaeolithic, has led us therefore to the following conclusions, which are at least very probable:

I. Though the Upper Palaeolithic people possessed and cultivated a natural talent for Art, it was not the aesthetics of that Art in which they were primarily interested.

2. They drew figures of animals for magical purposes, with the intent of increasing the supply of useful animals, or of facilitating their capture. A totemistic interpretation of some of the animal figures is also admissible, though on the whole less probable.

3. Other devices (tectiform, scutiform symbols, etc.) were intended to represent the means of the capture of animals, and by thus suggesting the process of capture were supposed to produce its accomplishment.

4. Magical or religious rites were carried out in connexion with these figures in the darker recesses of caves. These rites involved dances, of which we have traces in the footmarks at Tuc d'Audoubert, and a representation at Cogul.

5. The people were perhaps afflicted with the superstition of the evil eye, and perhaps used the hand symbol to counteract its influence.

6. During the course of the Upper Palaeolithic Term a superstitious dread of representing human figures developed. This was either due to the fear of invoking superhuman beings (revenants or the like) as the animal figures were supposed to invoke animals: or else a precaution against the magical use of human figures as instruments of witchcraft, to injure another person without his knowledge. There are occasional breaches of the rule, but these are very few. Undesirable animals-bears, lions, and the like-were rarely represented, probably for a similar reason; a fear of attracting them.

7. The prohibition against human figures was less absolute in the earlier stages, and figures probably representing a female deity of fertility were then made. The tribes which executed the Spanish groups of paintings had no objection to human representations.

1 For an elaborate development of this way of explaining the hands at Gargas see Georg Wilke, "Mythische Vorstellungen und symbolische Zeichen aus indoeuropäischer Urzeit" (Mannus, vi. [19I4], p. I5). The apparently truncated fingers are in this paper considered as bent, the different combinations of bent fingers being regarded as different manual signs, each with its own peculiar apotropaic significance. 


\section{Hand Mutilation}

The hand symbols of Gargas introduce us to another phase of psychology. The extraordinary propensity which savages have for maiming and mutilating themselves seems to have been prevalent among the Upper Palaeolithic people. The hands from which the Gargas designs are stencilled had in many cases lost several joints of their fingers. To this practice also there are noteworthy analogies among contemporary savages. The Bushmen of South Africa had a custom of cutting off the little finger of the young men, and were also accustomed to shed finger-joints as a sign of mourning, sometimes continuing the process till there were hardly any remains of the fingers left at all. Similar mutilations were to be found among the ancient inhabitants of Panama, and the natives of Amsterdam Island and of New Caledonia ${ }^{1}$. Another form of mutilation, circumcision or some analogous operation, is apparently indicated by certain phallic figures to which allusion has already been made.

The practice of painting the body is suggested by the deposits of colouring matter among the offerings to the dead. That the painted decoration was made permanent by some process of tatu is at least probable, though naturally we cannot expect to have much definite information as to this. The weird conventionalised figure of (From Obermaier, El Hombre Fósil.) a woman from Předmost, engraved upon a piece of ivory (Fig. I6o), shews the various parts of the body emphasised in a way that suggests the application of tatu.

1 See Dr E. Magitot, "Essai sur les mutilations ethniques" (C.A.P.A. Lisbon [1880], pp. 549 ff., esp. p. 586). 


\section{Dress and Ornament}

This leads us to the subject of the decoration and clothing of the body, a subject which can also be considered under the comprehensive heading of this chapter.

The men of Alpera are all naked, as are the men represented in engravings from Le Mas d'Azil, Laugerie Basse, and elsewhere. So is the man round whom the women of Cogul are dancing, if this last be really a man, and not (as the present writer, with some others, is inclined to believe) a sort of idol $^{1}$. 'The man of Laussel has a narrow girdle round the waist of his otherwise uncovered body, designed, we may suspect, to do duty as a pocket when his hands should be inconveniently full. The women in the Spanish paintings, with the exception of one at Alpera, who is without clothing, are draped in a skirt which reaches from just above the waist to a little below the knee, leaving the upper part of the body bare. The Predmost figure, and the Aurignacian statuettes, are undraped; the same is true of the Semitic goddess-figures with which we have compared them, and for the same reason-that it was essential to the ritual use of these figures to emphasise the maternal functions.

In a community, or group of communities, in which dress was apparently of little moment, we might have expected the children to have been allowed to run about in their untrammelled skins. But the infants of Mentone wore elaborate aprons into which nearly a thousand shells were sewn; these shells remained clustered around the waists of the little skeletons. Lord Avebury quotes ${ }^{2}$ from D'Urville and from M'Gillivray statements to the effect that though certain tribes of Australia troubled very little indeed about clothes, yet they "did not think it decent that young children should go quite naked." Probably it was not so much decency as a dread of magic that inspired this feeling; but however that may be, the dress of the Mentone infants perhaps indicates a similar feeling among their tribesfolk.

It would however be quite unjustifiable to infer from these paintings and engravings that complete nakedness was universal, or even customary except on special occasions, in the Upper Palaeolithic Term. The climate throughout the whole Term would make this in any case improbable. The dancing "diablotins" testify to ceremonial costumes of some elaboration. The Mentone men were buried, possibly in wrappings of hides, and certainly in elaborate

1 The small size of the man as compared with the women-a reversion of the actual proportions-is in favour of this interpretation. There is a representation of a man carrying a small figure by the foot in the Queso group of paintings at Alpera.

2 Prehistoric Times, seventh edition, p. 448 . 
ornaments, presumably of leather, into which devices of shells had been sewn. These shells covered the heads and the breasts. In addition there were necklets, armlets, anklets, and girdles of shells, fish vertebrae, and teeth of animals. The shells thus used for ornament are not infrequently found in sites which are a long distance from any natural source of supply of their species, indicating either long journeys on the part of the huntsman who wore them, or else the existence of a system of barter by which they had been carried from hand to hand across the Continent.

The headdress of the statuettes of Willendorf and Brassempouy, with the curiously Egyptian-like crimping, has already been mentioned. This is the only indication of any special dressing of the hair or of the head which the statuettes indicate. But the Alpera painting has given us some material on this subject. A number of
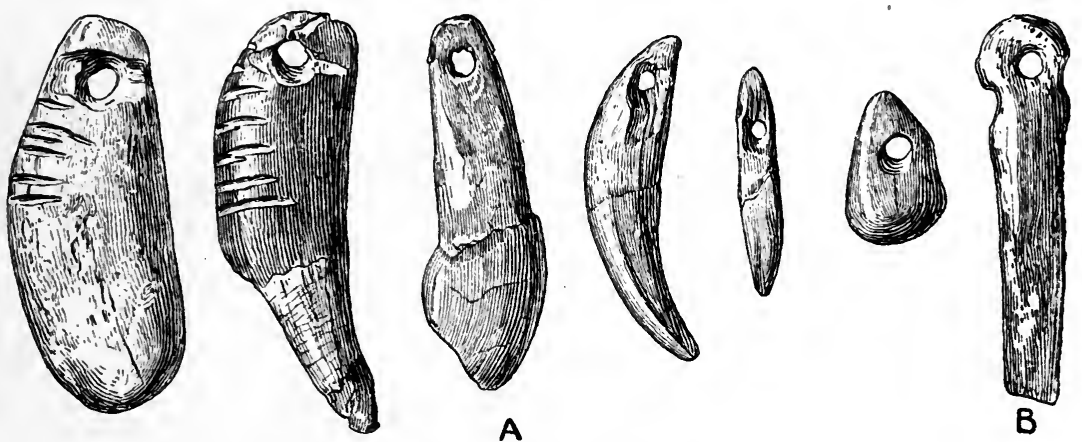

Fig. I6r. Ornamental teeth pendants from Lacave (Lot).

(From L'Anthropologie, vol. xvi.)

the men are there represented with wild plumed headdresses, closely resembling those of the American Redskin braves. Others wear hats, the make and material of which it is naturally impossible to deduce from the summary representation of them, but of which some are lofty and triangular, others flat, suggestive of a "Tam o' Shanter" cap. The difference of headdress may perhaps indicate a difference of function or of social rank. The women do not appear to wear any headdress, nor to dress their hair in any way (apart from the "crimping" on the statuettes). In most of the representations the women's hair is long and falls free.

Another frequent form of ornament is a plumed band surrounding the legs of the men, just below the knee. A similar band appears sometimes round the ankles. The women wear no such decoration.

Teeth were often used singly as suspended amulets. They were 
frequently ornamented with strokes, or with even more elaborate carving on both sides. Sometimes both teeth and shells used for ornaments were painted red. Besides bones, teeth, and shells, stones of bright colour and fossil shells are sometimes found in the caves, apparently used for similar decorative, or prophylactic purposes ${ }^{1}$.

\section{The Bull-roarer}

One very important and suggestive form of ornament is a flat oval pendant of bone, or sometimes stone ${ }^{2}$, perforated at one end.
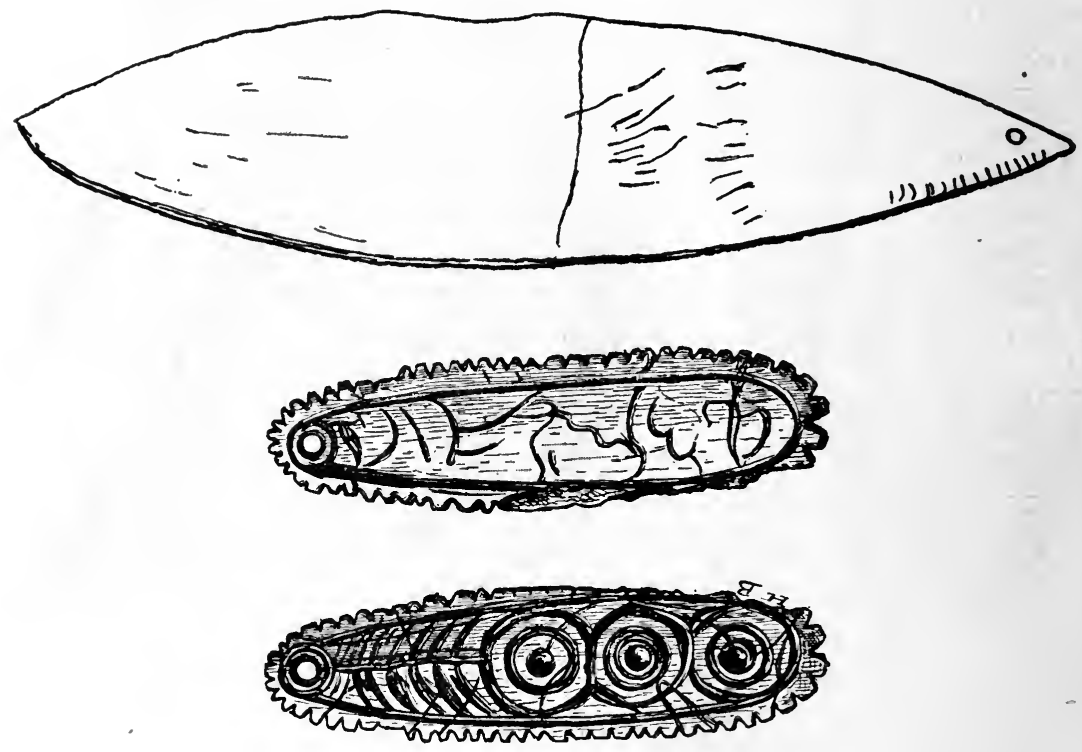

Fig. 162. Bull-roarer pendants.

(From L'Anthr. xv. and Girod and Massénat, Laugerie Basse.)

Specimens have been found at Laugerie Basse and at Laugerie Haute. This is identical in shape with that well-known magical instrument, the bull-roarer of which we have already given a short account (ante p. 140) ${ }^{3}$. Its wide-spread use makes it probable that it

${ }^{1}$ I cannot find the authority for G. de Mortillet's statement that in the Lower Cave of Wiérzchow in Poland imitation teeth of ivory were found; and I confess myself not altogether convinced by the alleged artificial shell from Laugerie Basse figured in Girod and Massénat, pl. lxxix. fig. 15. Both these imitations are quoted by Déchelette, Manuel, vol. I. p. 2 io.

${ }^{2}$ As in an example figured in B.S.P.F. IV. [1907], p. 215. For other examples see figs. 143,147 ante.

3 See essays on this instrument in Lang's Custom and Myth or Haddon's Study of Man, chap. x. 
originated at a very early period in human history; and it would not be surprising to find that it had been invented by the Magdalenians. Being made of wood, the original bull-roarers that might have been used by these people would naturally have decayed away: but miniature models of the mystic instrument might have been worn, and being of the less perishable material bone, they might have remained for our instruction. It is certainly tempting thus to explain the small bone pendants which exactly resemble bull-roarers.

It is above all things difficult to follow the workings of the savage mind even when he is alive and in the flesh before us. It is infinitely more difficult to reconstruct them when the skull that held his brain has been empty for several tens of thousands of years. But all analogy would lead us to infer that these personal ornaments were not mere decorations any more than were the cave paintings. There was a deeper meaning in both cases. The hunter wore the teeth of the wild beasts which he had slain ${ }^{1}$ in order to avert from himself some evil influence, perhaps the revenge of their indignant spirits; or to secure for himself some magical boon, perhaps the domination over the species to which they belonged, or a share in their enviable strength and agility; or to advertise his own prowess and so to render himself attractive to such women of his tribe as the social laws permitted him to associate with. These are some of the reasons for which nature-folk of modern times wear ornaments and amulets; and these we can hardly doubt were among the motives underlying the same practice as followed by the wild men of whom we have a vision in the paintings of Alpera.

1 Or which had died naturally. Probably the bears who died in the sacred cave of Tuc d'Audoubert were of a sacred character which would make their teeth "big medicine." Anyhow, the teeth had all been carefully extracted from the skulls. 


\section{CHAPTER X \\ THE MESOLITHIC PĖRIOD}

\section{The so-called Hiatus}

Whither Palaeolithic Man went, whence Neolithic Man came, by what steps Palaeolithic culture gave place to Neolithic, have long been fruitful themes of debate. There is unquestionably a chasm between the two. We leave the full Palaeolithic culture some time after the climax of the Magdalenian stage. The dolichocephalic Magdalenian hunters, decorating their caves with their marvellous art, afford us our last glimpse of it. On the other side of the gulf we see shepherds and tillers of the soil, round-heads and long-heads intermingled almost as completely as to-day, destitute of the skill in pictorial art, but polishing their stone tools, fabricating pottery and textiles, and surrounded by troops of domesticated animals. Looking back to the first side of the chasm, we see Europe still in a tundra condition, overrun, so far south as the Pyrenees, by troops of reindeer. Turning once more to the second side, we see the continent under the conditions of climate, fauna, and flora which it presents to a modern traveller, except for such comparatively insignificant modifications as have since been artificially produced by Man.

In the older days of prehistoric research, this chasm seemed to be unbridged. A hiatus, absolute and untenanted by any trace of humanity, appeared to lie between the Palaeolithic and the Neolithic periods. Europe was supposed to have completely lost its population, for some unknown reason, and to have been re-peopled at a later date by tribes wholly unconnected with the Palaeolithic inhabitants. It is now however recognised that though there is still a gap, it lies not in the orderly course of history but in our knowledge; and already some progress has been made towards filling it. The hiatus is no longer empty void; interesting transitional cultures have begun to appear, which help us partially to trace the history of the passage from the earlier to the later stone civilisations: and we may look with confidence to the discoveries of the future for further light.

\section{The Term "Mesolithic"}

The name "Mesolithic," by some given to this intervening period, and adopted as the heading of the present chapter, is perhaps the most convenient term that can be found. It has at least the advantage 
of brevity over "Epipalaeolithic" and "Protoneolithic," preferred by some authorities, though these may be more strictly scientific. The objection that has been made to the term "Mesolithic" is its appearance of assuming too readily that the stages thus named are actually transitional between the Palaeolithic and the Neolithic. But this objection seems a little hypercritical. Some convenient single word is wanted by which to denote the phases of civilisation intervening, in time if not in evolutionary sequence, between the full Magdalenian and the full Neolithic: and for this purpose the term "Mesolithic" is as appropriate as any other that can be found. We have already more than once laid down the principle that not much is gained by disturbing an existing nomenclature which is intelligible, and which adequately labels what we wish to describe. However the two other words quoted above are useful, if not indispensable, for the purposes of closer definition.

\section{The Domestication of Animals}

The key to the advance in civilisation which marks the Neolithic period is beyond all question the momentous discovery that certain animals can be domesticated. There is no reason to believe that Palaeolithic Man, down to the very latest moment of his existence, had any idea of this fact. The caves contain no pig, sheep, or goat bones; and the wild boar, bison, horse, and reindeer bones there found shew by various indications that they belonged to wild animals, slaughtered in the chase. In the first place, beasts of all ages are represented--both the very young and the very aged. Now a master of flocks would not slaughter very many of the young of his flocks, nor, on the other hand, would he allow his animals to attain an age past their best period of development. Again, animals of both sexes are found in the middens indiscriminately. Here again, a cattleowner would very early learn for obvious reasons to spare the females of his flocks. This want of selection is what we might expect to find in the midden-heaps of hunters who killed at sight whatever wild beast happened to have the misfortune to cross their path. In the third place, with domestic animals slaughtered at the homestead itself, all the bones of the beast, in something like their true proportions, ought to be found in the middens. This however is not the case as a rule, though, as we have seen,it has been noticed at La Quina. Most commonly there is an undue proportion of heads and legs. This means that when the hunters had killed their prey they cut it up for easier transport, and carried to the camp only those parts which were good for eating.

The great stratum of horse-bones at Solutré does not shew these 
peculiar features. The majority of the animals there represented are strong and vigorous (about seven years of age) and the whole carcase appears.'This has been supposed to prove that the Solutreans, or, more accurately, the Aurignacians of Solutré, kept horses for food, though not for burden purposes. The fallacy of this not unnatural deduction has been exposed by G. de Mortillet $^{1}$, who writes:

Whoever knows the habits of the horse understands that when he is taken alive and has no way to escape or to defend himself, he yields; he is morally annihilated, tamed, but for all that not domesticated. So soon as he can release himself he recovers his independence and escapes. The men of Solutré were well able to capture the horse alive, either with traps or with lasso, and to lead him to their dwellings for immediate slaughter, holding him fast. Had they released him for a single instant they would have lost their prey.

With regard to the absence of aged specimens in the midden-heaps, the same writer continues:

In the troops of wild horses it is always the most vigorous adults which protect the troop or cover the retreat. These then are the most exposed, and the most easily fall into the hands of the hunters. As a horse for kitchen purposes has acquired its full development at the end of two years, had it been domesticated they would have slaughtered it at that age, and would not have taken the trouble to have kept it for from two to four years longer.

Certain marks on the muzzles of Solutrean and Magdalenian engravings and sculptures of horses have been taken for representations of harness ${ }^{2}$. In some of these there is certainly a very cord-like appearance, especially on an example from Saint-Michel d'Arudy (Fig. 163). It may be that in this specimen, and in one or two others, the explanation given is at least partially accurate. But in others the explanation puts too severe a strain upon our imagination; and when we are asked to believe in the figure of a flayed horse thus harnessed, we feel it high time to call "Halt!" to our guide's Pegasus ${ }^{3}$. Even if we accept the theory in the case of the Saint-Michel d'Arudy example, it does not follow that the horse was necessarily domesticated. The figure might represent a horse tied up for slaughter after having been captured by the hunter and brought into the camp in the manner described in the extract given above from Gabriel de Mortillet. The cords would then be in some degree analogous to

1 Préhist. II. III. chap. $\mathrm{x}$.

2 See Ed. Piette, "Le chevêtre et la semi-domestication des animaux aux temps pléistocènes" (L'Anthr. XVII. [1906], p. 27). This paper contains a wealth of illustrations, though the explanation of some of the figures as harnessed horseheads is, to say the least, fanciful.

${ }^{3}$ See Piette, op. laud. p. 43. 
the "tectiform" devices, as these are explained in this book, and the sculpture would take its place with the rest of the works of art as a magical instrument: we might almost call it a materialised prayer. "This is the sort of thing we want" it says in effect, "a fine fat horse, ready tied up to be slaughtered."
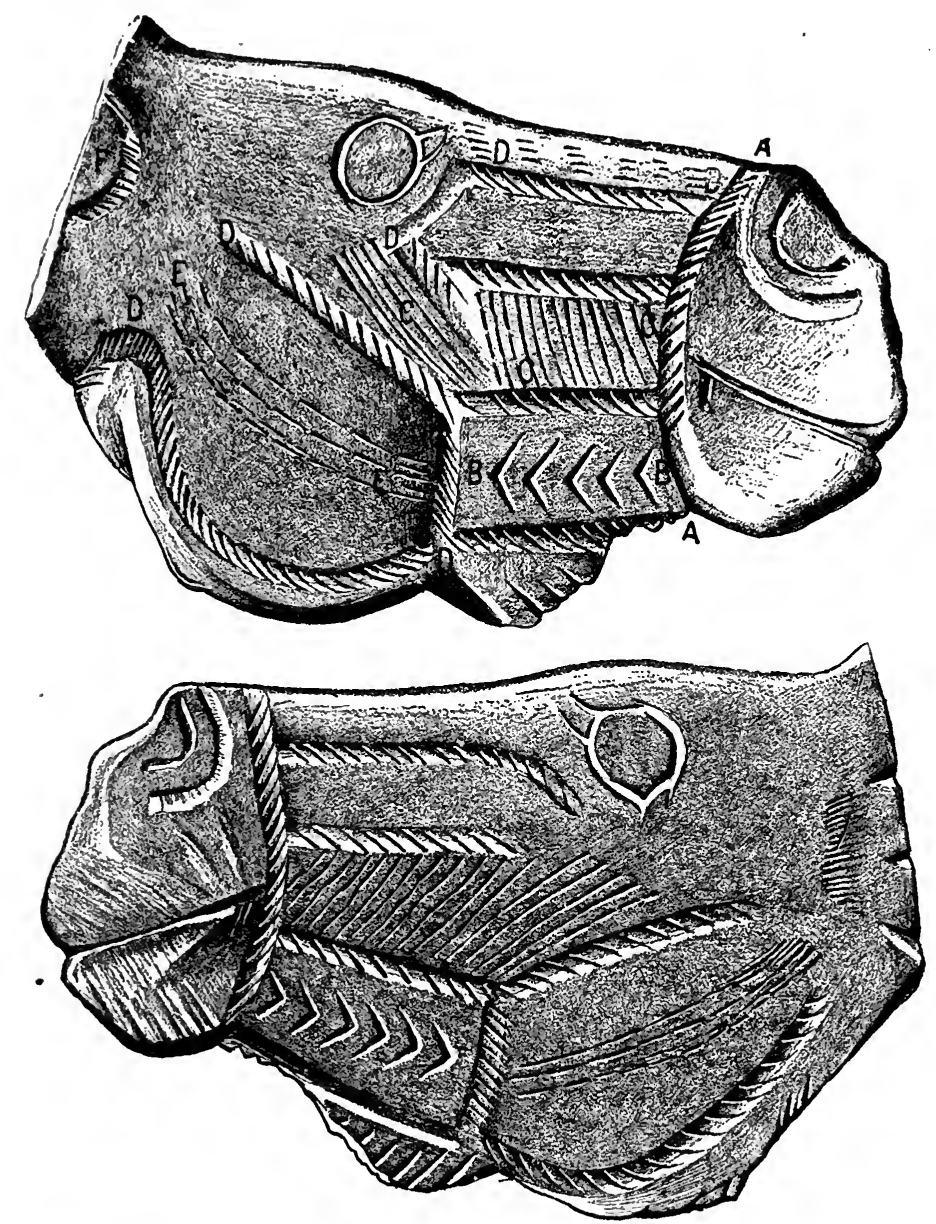

Fig. 163. Horse-head from Saint-Michel d'Arudy, with a supposed representation of harness.

(From L'Anthropologie, vol. xVII.)

The marks on other figures of horses which have been interpreted as representations of harness are evidently simple attempts to indicate hair, hollows, or other natural markings on the surface of the animals.

In the paper quoted, Piette figures some objects which he explains 
as portions of harness. But they do not in the least resemble any part of the "harness" shewn on the numerous engravings which he reproduces; and in point of fact, they are all clearly fragments of broken bâtons de commandement.

In short, the Palaeolithic European had no knowledge of the domestication of animals. He had to go out in all weathers, like Hiawatha, to seek his wild quarry. This is one explanation of the comparative sparsity of the population in Europe during Palaeolithic times. A community living on the chase alone requires a very wide area of territory to support them. Lord Avebury has collected calculations ${ }^{1}$, on the basis of statistics of existing hunting communities, their estimated populations, and the area of territory which they occupy, that a single hunter requires from to to 78 square miles for his sustenance, according to the nature of the country and its fauna.

The beginnings of the domestication of animals were probably quite simple and commonplace. To some extent I have seen the process re-enacted for myself, when encamped in the Judaean wilderness. Some wretched starving half-jackal cur crawls stealthily up to the refuse-heap and roots for bones, watching warily the while for the expected stone. The master of the encampment is however at the moment in a good humour. He has for once dined well, and in a fit of idle joviality he throws, not a stone, but another bone, to the visitor. The grateful beast, which has sprung aside with an anticipatory yelp, is taken by surprise at the unexpected favour, and creeps a little closer into the confidence of the encampment. At night some thief or enemy comes to surprise the camp, and the dog rouses the sleepers in time to defend themselves. Thus the use of a watch-dog is discovered, and the animal becomes permanently attached to the settlement. After a time he begins to accompany the man who is now his master on hunting expeditions, and there proves himself of further use. The domestication of the dog, the first conquest of the kind made by man over the animal kingdom, is thus easily explained by its habits and instincts. The absence of bones of the dog, or of bones gnawed by dogs, from Palaeolithic deposits is the strongest argument against the domestication of any animal by Palaeolithic man. Without the help of the dog to "round up" the wild herds, the subjugation of the other animals would probably have been impossible; indeed it is not at all unlikely that in the case of the other animals it was the dog which took the initiative, and that by his driving herds of wild cattle to his master's home, and keeping them there, he first suggested the practicability of taming them.

${ }^{1}$ Prehistoric Times, seventh edition, p. 585. 
The enormous advantage which the domestication of foodanimals would confer is obvious. Esau goes forth to fetch wild venison for his father; while he is away Jacob has gone out to the flocks, has killed and cooked a savoury dish, and has secured the blessing. The huntsman was never certain of finding food, and he had to spend his whole time in seeking it. The master of flocks needed only to go out and to select one of the animals which were always at his disposal. Life was thus relieved from the constant dread of famine, and, above all, time was saved and leisure gained, which could be occupied with experiments in one direction or another; some of these would no doubt be fruitful in results for the advancement of civilisation.

On the wide Asiatic steppes, where roamed herds of wild horses, cattle, goats, and sheep, the nomad huntsman, aided by his faithful $\mathrm{dog}$, gradually adopted a nomad pastoral life, and wandered from one watering-place to another with his flocks, which the dog had frightened into submission.

The further transition, from the pastoral to the agricultural life, would be comparatively easy. Plants (fruits, roots, and seeds) were doubtless important foods in Palaeolithic times, but they were used in their wild form; there is no reason to suppose that the idea of artificially cultivating them ever entered the head of Palaeolithic man. The possibility of tilling the soil was perhaps suggested to a pastoral people with progressive instincts who noticed that the seeds of some desirable plant, which they had thrown away beside one of their watering-places, had begun to germinate when they came back again to the same place. Further observations would be made as time went on; the effect of floods, and of the manuring of the land by cattle, would suggest empirical principles of land-improvement. The necessity of breaking up hard ground would lead to the invention of rudimentary ploughs, or rather digging-sticks; and thus by gradual steps the pastoral nomad would develop into the sedentary agriculturist. Doubtless these advances were not made without loss. There must have been many lives lost in discovering the nature of plants and animals. The blood of these unknown martyrs was the seed of civilisation.

\section{Further Evolution in Culture}

It goes without saying that our Neolithic agriculturist, once he had found out how to do all these things, would make his womankind do most of the hard labour of the fields. It should however be said in justice, that this was not mere laziness on his part, any more than it is among modern nature-folk where a similar division of labour 
among the sexes is to be noticed. The women work in the field, partly, no doubt, because they are the drudges of their lords, but partly for the important reason that it is supposed to be lucky that the fruitful half of the community should busy themselves in cultivating the fruits of the earth ${ }^{1}$. It is a form of sympathetic magic, of which so many manifestations and varieties are to be found the world over. The man, thus left free, can find time to make further discoveries. Idle twisting of a flock of wool, which a thorn-bush has torn from one of his sheep, would suggest to him the manufacture of thread, and would lead in time to the development of the textile industry. Sitting astride a log that had fallen into the river, in order to spear a desirable fish, he would suddenly find himself afloat, the $\log$ having slipped from its moorings and drifted into mid-stream. His frantic struggles to paddle himself back to shore were doubtless distressing at the time, but they revealed to him the possibilities of navigation.

Not only was the material civilisation thus evolving, but also what we may call the psychical civilisation. Around the man were unknown powers, of the existence of which he was consciouspowers supernatural and terrible, which had to be appeased. Methods of doing this had to be found out. In some way, certain of the people acquired a reputation for knowledge in such matters, and so gained a place apart. Castes of society thus became instituted, for better or for worse, and religion gradually became organised into a definite code of beliefs and practices out of the vague and formless imaginings in which it had begun.

The foregoing paragraphs are an attempt to construct in brief a general theory as to how the essential characters of Neolithic culture might have come into being. They form the first rough casting for a cantilever to be thrust backwards over the chasm between the Old Stone Age and the New, from the Neolithic side. They must be studied in greater detail in our second volume. For the present we pass over the question of where this development took place, and what was the progressive tribe to which Europe owes her knowledge of husbandry and of the allied crafts. Before we discuss this question we must transport ourselves back to the Palaeolithic edge of the gulf, and see whether there are any materials which enable us to narrow it on that side.

${ }^{1}$ See Frazer, The Golden Bough, third edition, vol. 1. p. 141, for modern illustrations of the same belief. 


\section{THE AZILIAN STAGE}

\section{Le Mas d'Azil}

The first and most obvious group of such materials consists of the remains of the peculiar culture known as the Azilian.

The Azilian stage derives its name from a great cave, or rather tunnel, called Le Mas d'Azil, in the Pyrenean department of Ariège. This name is preferable to Tourassian, an older term for the same stage of culture, derived from the name of a site discovered before the Mas d'Azil deposits, but inferior in richness and in clearness of stratification ${ }^{1}$. The tunnel of Le Mas d'Azil is about 400 mètres in length, and through it runs the river Arise ${ }^{2}$. On each side of the river there are deposits - one on the right bank in the middle of the tunnel, and one on the left bank at the entrance. The latter is the more important for our present purpose, and it is from this that the stage we are now to study takes its name.

The deposits have been studied by various explorers, chief among whom was Edouard Piette ${ }^{3}$. To him is due the determination of the stratification, and the important deductions which are drawn therefrom. The following is a summary of his full description of the strata observed by him ${ }^{4}$.

I. Depth 0.20 to 0.40 mètre. Black clay with bones of common animals, and nails, pottery, pins, etc., of Iron Age.

$H$. Depth 0.30 to $\mathrm{I} \cdot 20$ mètre. Black clay with bones of ordinary domestic animals, and Neolithic and Bronze Age remains.

$G$. Depth 0. Io to 0.60 mètre. Ashes, banded with white, red, and grey clay; many hearths, and traces of burnt bones. Snail-shells in large numbers. Flints of Magdalenian form, chisel-axes, and piercers; staghorn harpoons, perforated; nuts, acorns, and the seeds of various fruits; bones of horse, cow, stag, boar.

$F$. Depth 0.15 to 0.50 mètre. Reddish bed, coloured with iron oxide; ashes, bones of stag, chamois, Bos primigenius, horse, bear, boar, badger, wild cat, beaver, and several birds, fishes and frogs. No reindeer. Flints of Magdalenian type. Harpoons of stag-horn and other tools (prickers, polishers) of the same material. Two skeletons in this stratum, painted red.

$E$. Depth I.24 mètre. Alluvial bed of yellow silt, without antiquities.

$D$. Depth 0.30 mètre. Black layer of clay, with Magdalenian remains. Harpoons of reindeer-horn; numerous engraved works of art; no sculptures. Reindeer rare; stag common. Otherwise the fauna similar to stratum $F$. Magdalenian flints.

1 On the site of La Tourasse see Félix Regnault, "L'abri de La Tourasse à SaintMartory (Haute-Garonne)" (Revue des Pyrénées et de la France méridionale, MayJune, r892).

${ }^{2}$ A good plan of Le Mas d'Azil will be found in L'Anthr. Ir. p. 145 .

3 E. Piette, "Hiatus et lacune: vestiges de la période de transition dans la grotte du Mas d'Azil"' (B.S.A.P. ser. rv. vol. vi. [r895], p. 235).

${ }^{4}$ Which will be found in $L$ 'Anthr. vi. [1895], p. 276. 
C. Depth $\mathrm{I} 5^{\circ}$ mètre. Alluvial bed, similar to $E$.

$B$. Depth 0.83 mètre. Black layer, with ashes. Magdalenian flints, bone implements. Harpoons of reindeer-horn. Bones of reindeer, horse, ox.

$A$. Depth $1 \cdot 46$ mètre. Gravelly soil mixed with loam. A few bones, some charcoal. Traces of hearths, possibly Solutrean.

This stratification reveals the following history. The occupation of the cave began on the border-line between Magdalenian and Solutrean, and continued through Magdalenian times. Stratum $B$ tells of a fairly long-continued Magdalenian occupation, interrupted by a flood, which left the sterile bed of yellow alluvium, $C$. A second Magdalenian occupation followed at a later time, when the reindeer was giving place to the stag, though it was still extant in the neighbourhood. Then followed a second wash-out, which put an end to the second Magdalenian occupation, and then came the two beds whose antiquities were typical of the Azilian stage. They were followed by later strata, whose only importance for us at present is the limit of date which they afford. They begin with Neolithic, from which it follows that the interpolated Azilian strata- $F$ and $G$ represent a period of transition, or as we should perhaps be safer in saying, an intermediate period.

\section{Characteristics of Azilian Culture}

The characteristics of the Azilian culture, as illustrated by the remains found in these strata, are as follows.

The deposits testify to a damper climate than now exists in the region of the cave. The snail (Helix nemoralis), which is so common in the upper Azilian stratum, is rare or unknown, according to Piette $^{1}$, in the modern fauna of the district. Numerous remains of plants were found, shedding valuable light on the vegetable food of the Azilian people. Piette has given us a careful study of these ${ }^{2}$. Many of the seeds were opened as though to extract the kernelin some cases, perhaps, by man, in others probably by rats $^{3}$. The

1 L'Anthr. vir. [1896], p. 6.

2 E. Piette, "Les plantes cultivées de la période de transition au Mas d'Azil" (L'Anthr. viI. p. I). It should be added that many authorities believe, not without reason, that the stores of seeds, etc., found in these strata by Piette and described in this paper, were the hoards of modern rats, not ancient deposits.

${ }^{3}$ See L'Anthr. viI. p. 236. A suggestion is made by M.P. Briguel of Dunkerque (L'Anthr. xxir. p. 37I) that the perforated fruit-stones found by Piette at Le Mas d'Azil may have been whistles. This can take its place only as a theory which it is impossible either to prove or to disprove; its author is however able to show that to make whistles in the way suggested is quite practicable. But M. François Daleau wrote to the same journal (xxII. p. 736) to the effect that he had suggested to Piette that the perforations in the kernel-shells had been made by rats to get at the kernels; and that Piette, after comparing them with kernels which had been gnawed by modern rats, had expressed his agreement with him. 
fruits enumerated by Piette are oak-acorns, haws, sloes, hazel-nuts, chestnuts, cherries, prunes, walnuts; he also reports the discovery of a handful of barley-seeds in the lower Azilian stratum, suggesting that that cereal was already cultivated ${ }^{1}$.

Of the sloe, Piette says that it is doubtful if the Azilian people would habitually eat this bitter fruit, except under pressure of famine; and he infers that they made a drink of it, like the Italian vina di prugnola. Possibly; but in the absence of pottery, in what kind of receptacles did they store it?

The flints of the Azilian strata are Magdalenian in type. Pottery is still absent, and there is no trace of the domestication of animals. For these reasons the strata might be called still Palaeolithic. But the reindeer and other characteristic Palaeolithic animals, now extinct in the locality, have disappeared, and therefore in this important respect the stratum presents a facies later than the true Palaeolithic.

Other modifications, all indicating a decadence, are to be seen in the Azilian accumulations. The beautifully made, delicate needles, that excite our wonder as we turn over Magdalenian strata, have now disappeared. Bone prickers are given a rude point, and are no longer burnished or polished. The art of polishing stone has not yet been acquired.

Harpoons also occur in the Azilian strata. These weapons, which formerly had been made of reindeer-horn, must now be made of a substitute, which is found in the horns of stags. But this is not so satisfactory a material, on account of the difference in texture between the two kinds of horn. The horn of the reindeer is solid almost throughout, like a piece of wood, so that the harpoons can be made of a round section. The horn of the stag is hard on the outer surface only; the interior is of a soft and spongy texture, useless for implements. These have therefore to be made of the outer surface of the horn, and must in consequence be flat in section. The flat harpoon is one of the chief characteristics of the Azilian culture; it is fashioned with much less skill than is the harpoon of the Magdalenians. Over a thousand flat harpoons were found at Le Mas d'Azil.

Continuity with the Magdalenian culture is once more suggested by the existence of portions of two skeletons which were found buried in the Azilian strata, painted red. We have already noticed this burial custom; the bodies appear to have been deposited in some temporary place until the flesh decayed $^{2}$, the bones being then

1 Piette in his paper refers to sculptured representations of barley from Magdalenian stations, but these are more than doubtful. At least, the interpretation suggested is imaginative.

${ }^{2}$ Not artificially stripped of flesh as was at one time supposed. See Zaborowsky, Bull. et Mém. Soc. Anthrop. de Paris, ser. v. vol. vir. [1906], p. 4 I6. 
coloured and buried. Several of the smaller bones were not forthcoming, which suggests carelessness in the operation.

The shells found at Le Mas d'Azil were made the subject of an interesting and commendably thorough monograph by H. Fischer ${ }^{1}$, from the point of view of both zoology and anthropology. Most of
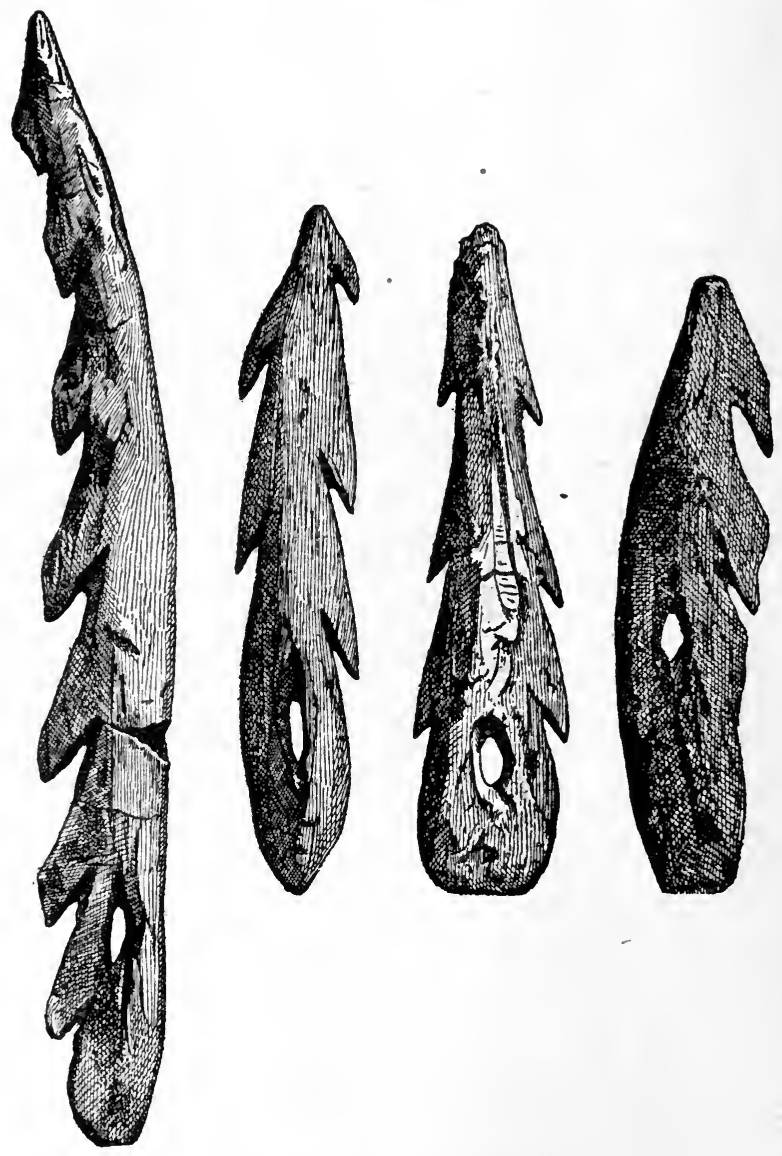

Fig. 164. Azilian harpoons.

(From L'Anthropologie, vol. vi.)

the shells are perforated for suspension as ornaments, either singly, or grouped in collars or similar decorations. The holes were made in different ways. Sometimes a saw-cut was made in the shell surface, by means of a flint flake, to reduce the shell-wall to per-

${ }^{1}$ H. Fischer, "Note sur les coquilles récoltées par M. E. Piette dans la grotte du Mas d'Azil"' (L'Anthr. viI. [1896], p. 633). Illustrations shewing the different forms of treatment of artificially worked shells will be found in this paper. 
forable dimensions, a flint needle being then thrust through the remainder. Sometimes the saw-cut was absent, the hole being drilled from the first; and sometimes the face of the shell was ground flat by being rubbed over a rough surface, the perforation being then drilled through the wall of the shell, thus reduced to a convenient thinness. Sometimes the perforations were simply broken roughly through with a blow. Certain shells were treated further, sections being cut out of them to make shaped amulets, or scratches being cut upon them for ornamental purposes. One pecten-shell had the head of a horned animal thus scratched upon its inner surface. With regard to the species of the shells represented, though many of them were of the kinds still to be found either in the Mediterranean or on the Oceanic coasts of France, others are no longer extant there: on the whole the shell-fauna of Le Mas d'Azil is more arctic than a modern collection of shells from the neighbouring seas would be. Certain species are not now to be found living further south than Bergen and the Shetland Islands, though single valves have been dredged up in the Mediterranean.

\section{The Coloured Pebbles}

The wonderful Magdalenian art has disappeared. In its place we find the most curious detail which the Azilian culture displays.

In stratum $F$ at Le Mas d'Azil were found a number of pebbles with marks painted upon them in red. One or two similar pebbles have been found in other places, but the great majority of the known examples come from the standard site.

These marks were painted in red peroxide of iron, mixed, apparently, with some resinous substance, ground upon scallop-shells or on flat stones which served as palettes, and smudged upon the pebbles with some sort of brush, or perhaps with the artist's finger ${ }^{1}$. They consist of the following types of patterns:

Vertical strokes, parallel, from one to eight in number.

Circular dots, in one, two or three rows. Often, though not always, surrounded with an oval frame following the outline of the pebble.

Crosses, with or without surrounding circles.

Zigzags.

Ladder-like patterns, consisting of a vertical line crossed by a number of horizontal lines.

Characters resembling the letter $E$.

A few groups of random lines, incapable of classification.

1 A very full description of them, accompanied with an album of coloured facsimiles, will be found in Ed. Piette, "Les galets coloriés du Mas d'Azil " ( $L$ 'Anthr. viI. [1896], p. 385). The descriptive part of this essay is excellent, the author's theorising is less happy. 
Some of the patterns of the first four groups are represented with jagged fringe-like edges.

It was first supposed that these signs are primitive numerical or alphabetical characters, and it was even suggested-whether seriously or in jest I know not-that the tunnel of Le Mas d'Azil may have been a Palaeolithic school. Others have supposed that the pebbles may have been the pieces used in a game like dominoes. Of such a theory all that need be said is that when an archaeologist is ashamed to confess his ignorance of the purpose of an object with which he has to deal, he usually suggests that it was meant for a game, or for an instrument of music; and his brother archaeologists accept the suggestion in the spirit in which it is offered.

More worthy of serious consideration is the parallel which has been sought to be drawn between these pebbles and the churinga of the native Australians-a sort of sacred totem-fetish, carefully preserved in sacred caves ${ }^{1}$. The resemblance is certainly very striking; but there is an important difference, which may be a fatal flaw in the identification suggested. The caves in which the churinga are preserved are very sacred places, where no unauthorised person dares to intrude, and which cannot be entered even by the elect except in very special circumstances and with very special precautions; whereas the deposits of Le Mas d'Azil shew that it was used as a common place of dwelling ${ }^{2}$.

The first real approximation to the true solution of the riddle of the pebbles of Le Mas d'Azil is given in a series of brilliant comparisons which have been drawn by Breuil ${ }^{3}$ and Obermaier ${ }^{4}$. The latter has shewn by means of a table the similarity, not to say identity, which subsists between the marks on the Azilian pebbles and those painted on the walls of certain caves in Spain. The latter, when arranged in series, prove to be stylistic human figures, which by continual conventionalisation have ultimately lost all resemblance to humanity. The comparisons amount to a demonstration that the enigmatical marks on the pebbles are really figures of men and women, reduced to their lowest terms. The accompanying diagrams shew this clearly.

A number of pebbles found in three brochs at Keiss, Caithness ${ }^{5}$,

${ }^{1}$ See the admirable article by A. B. Cook, "Les galets peints du Mas d'Azil" (I.'Anthr. XIV. [1905], p. 655), where this theory is persuasively set forth.

"Andrew Lang, "The problem of the painted pebbles, Mas d'Azil" (Man, vol. IV. [1904], No. 22), points out this objection to the churinga theory. He would see in them the pieces used in a game.

${ }^{3}$ H. Breuil, "L'âge des cavernes et roches ornées de France et d'Espagne" (Revue archéologique, ser. Iv. vol. xix. [1912], p. 193).

${ }^{4}$ El hombre fósil, p. $328 \mathrm{ff}$.

${ }_{5}^{5}$ Figured in Proc. Soc. Antiq. Scotland, vol. xxxv. [1900-1901], p. 146. 


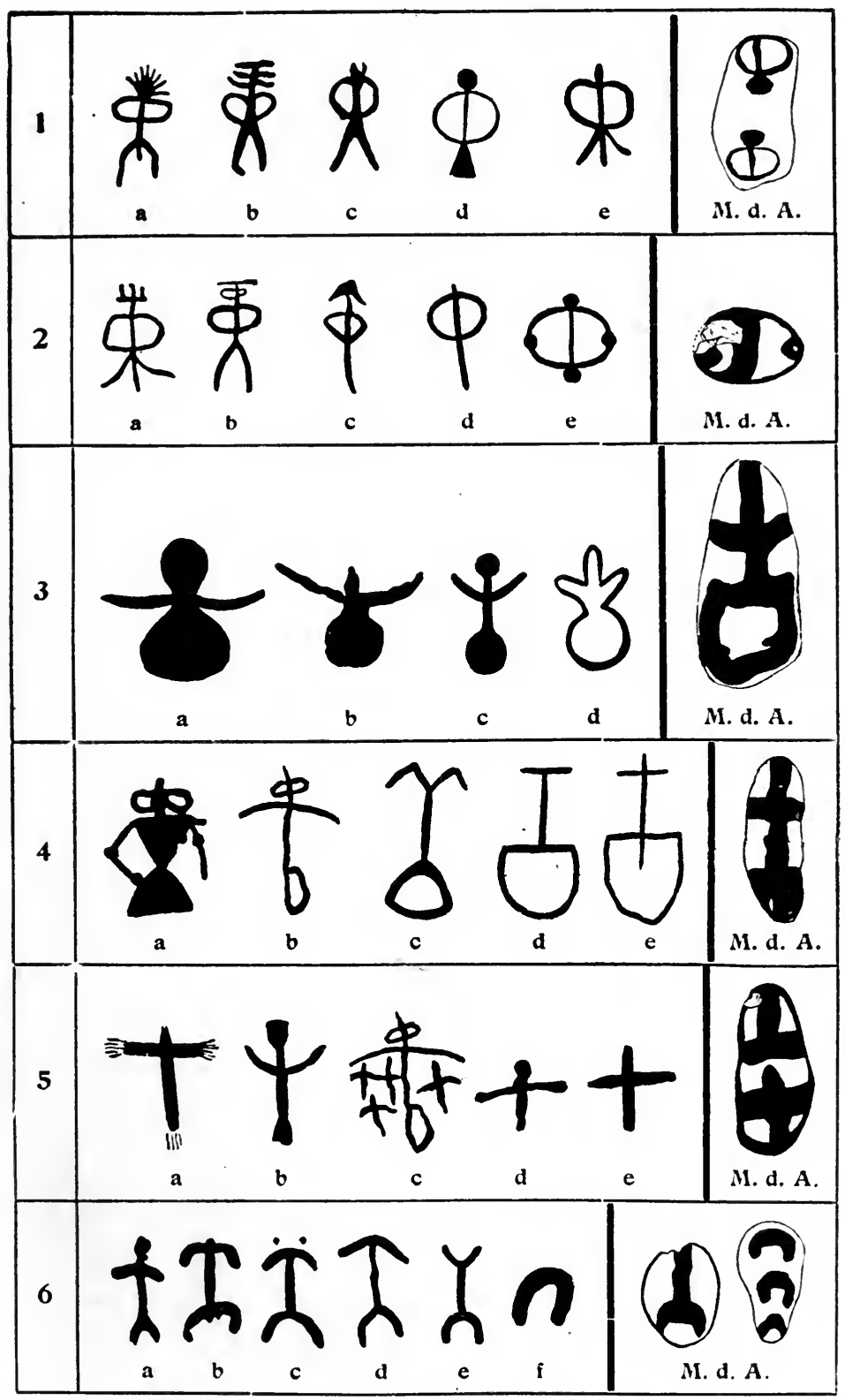

Fig. $165(a)$. Azilian painted pebbles compared with stylisation of human figures in caves.

(From Obermaier, El hombre fósil.) 


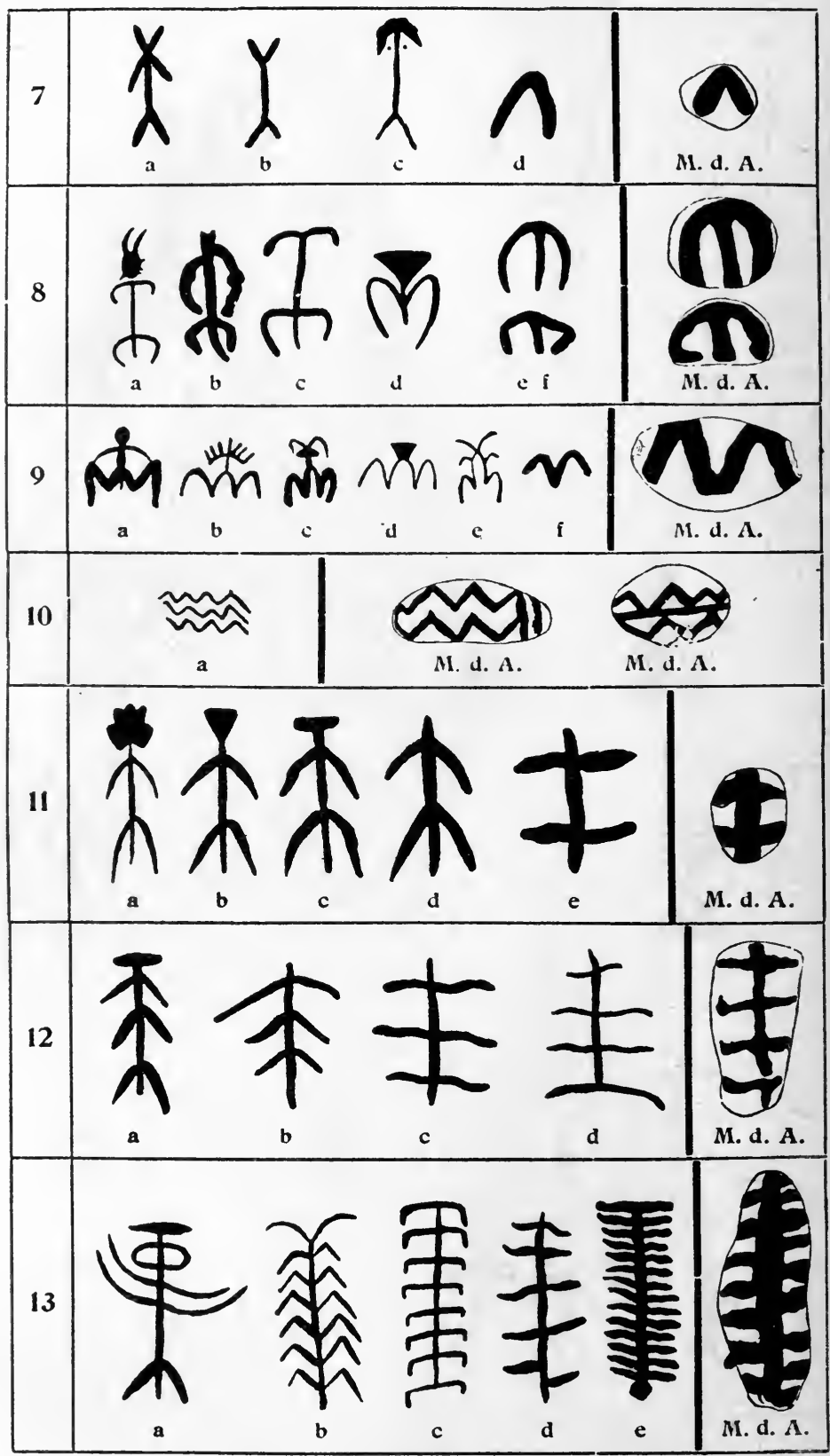

Fig. $165(b)$. Azilian painted pebbles compared with stylisation of human figures in caves.

(From Obermaier, El hombre fósil.) 
bear a close resemblance to the Azilian pebbles: but this can only be accidental. If they had been found together in one broch, it might have been inferred that the structure had happened to be built over an Azilian site: but being found in three (vide op. laud. p. 145) they must be treated as belonging intrinsically to the brochs, and therefore to be dated to the very late Iron Age time attested by the rest of the broch furniture.

In the absence of any exact information as to the nature and appearance of the Tasmanian stone, mentioned in an extract quoted by Sollas ${ }^{1}$ from Backhouse ${ }^{2}$, it would be perhaps rash to build too much upon the comparison which the description suggests. But it may well be that the painted pebbles are meant to be representations of dead or absent members of the community-most probably the former, for it is not likely that they would have been preserved after the return of the persons if they merely stood for absent friends. They are hardly churinga, either in the Tasmanian or in the Azilian case; for one of the most rigid rules about churinga is that no woman may see them. Perhaps we shall not greatly err if we suppose that these pebbles were what may be called "soulhouses," abodes for the spirits of deceased members of the community, and as such associated with a cult of the dead.

\section{The Degeneration of Palaeolithic Art}

How far these latter theories may be sound is for the future to decide. But the fact of the degeneration of concrete forms into the meaningless devices on the Azilian pebbles may be taken as established. Their relationship must be with the Spanish group of paintings, the highest efforts of which are to be seen at Alpera and at Cogul. The naturalistic figures of this type pass almost imperceptibly into the stylistic; the stylistic figures are almost if not entirely confined to the walls of the Spanish caves and rock-shelters; and the stylistic figures in their turn pass into the yet ruder figures of the pebbles. Indeed, the different stages of degeneration are sometimes to be seen side by side in the same group of wall-paintings.

As illustrative of the degeneration of the Spanish style of Art, we may compare a similar and parallel process through which the Magdalenian Art passed to its final disappearance. Breuil has published several series of figures collected from the walls of Magdalenian caves, which would be quite unintelligible separately, but which when

1 Ancient Hunters, first edition, p. 77.

2 "One day we noticed a woman arranging stones; they were flat, oval, about two inches wide, and marked in various directions with black and red lines. These we learned represented absent friends, and one larger than the rest a corpulent woman on Flinders Island, known as Mother Brown." 
placed together are seen to be successive degradations of animal figures or parts of animal figures ${ }^{1}$.

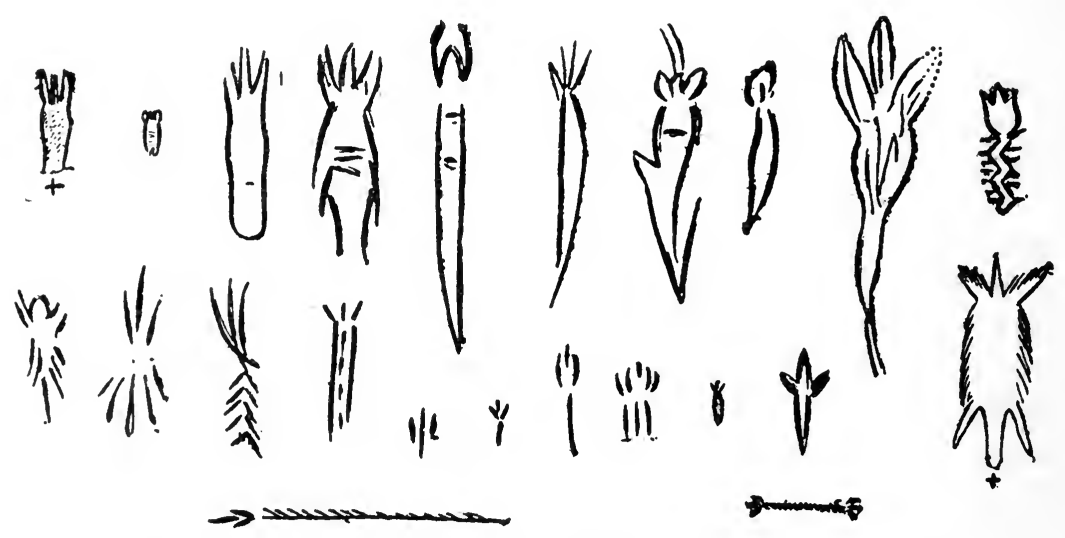

Fig. 166. Stylistic figures of horseheads from Magdalenian caves.

(Drawn by M. l'Abbé Breuil; from C.A.P.A. Monaco, vol. I.)

\section{Extent of Azilian Culture}

The Azilian culture has been found in Spain, especially in the north of the Peninsula, in Castillo, Valle, and other caves and openair stations: in France at Sorde (Landes), in a cave called l'abri Dufaure $^{2}$; here were found rude flints of Magdalenian type, a flat harpoon, and a fragment of stone with a badly-drawn horse-head scratched upon it. There were no painted pebbles at this site. Various other places in the departments of Hautes-Pyrénées and Ariège have also yielded Azilian remains; and even farther afield, in places where remains of earlier stages are unknown, such have come to light. Not only in France, but also in Great Britain have stations been found displaying some at least of the five characteristics of the Azilian civilisation-flat harpoons, modern local fauna, Magdalenian flints, and deteriorated bone implements. The fifth characteristic, the painted pebbles, are not so wide-spread, though they are by no means confined to Le Mas d'Azil. They have been found, for example, in the interesting group of Azilian stations at Le Vercors $(\text { Isère })^{3}$; the deposits of a community which made a living by trapping marmots for food and fur, as was indicated by the numerous bones of these animals shewing marks of knife-scratches. It is not easy to

${ }^{1} \mathrm{H}$. Breuil, "Exemples de figures dégénérées et stylisées à l'époque du renne" (C.A.P.A. Monaco [1906], vol. I. p. 394).

2 Breuil and Dubalen, "Fouilles d'un abri à Sordes" (R.E.A. XI. [1 90I], p. 25I):

${ }^{3} \mathrm{H}$. Muller, "Les stations aziliennes du Vercors; les chasseurs de marmottes" (A.F.A.S. Havre [1914], p. 642). 
know what to make of a flint, shaped something like a dagger, found in the course of constructing a railway from Beaune to Saint-Loupde-la-Salle. It was painted with vertical and horizontal lines in three colours, lilac, black, and yellow. The general aspect of the design resembled that of the Azilian pebbles, but polychrome decoration of such objects is otherwise unknown ${ }^{1}$. Pebbles with similar decoration (monochrome) have also been found in Birseck near Basle, and at Bobache (Drôme) ${ }^{2}$.

In England, as we have seen, Chellean man is practically confined to the southern counties. Magdalenian man is found as far north as Derbyshire. No remains of the Palaeolithic period to the end of the Magdalenian stage have been found in the north of England, or else in Scotland or in Ireland, some injudicious publications notwithstanding. But a cave near Settle, Yorkshire, has yielded an Azilian harpoon; a similar harpoon was found in the river Dee, and is now at Kirkcudbright: a third was found at Whitburn, Durham $^{3}$; two caves with Azilian deposits have been found at Oban; and five sites, including an important shore settlement with close Azilian analogies, have come to light in the island of Oronsay.

The Oban cave 4 was found by quarrymen in the end of 1894 . It was about 4.90 to $6 \cdot 10$ mètres in breadth, and 7.60 mètres in length. The implements consisted of hammer-stones and flint flakes, pins and awls of bone, flat harpoons of stag-horn, as well as certain bone objects which have been ingeniously explained as instruments for scooping limpets from their shells (Fig. I67). There was no pottery. The cave shewed signs of having been occupied by people who lived chiefly upon shellfish, though bones of animals and of birds were also found in the cave, the creatures to which they belonged having been used for food. The shells were as a rule of large size, shewing that they had been specially selected; in some cases patches of the same kind of shell lay together, evidently the remains of a feast after a single gathering of one kind of mollusc.

The great age of these deposits is indicated by the gravel covering them. It had evidently been washed in by the sea; yet the site of the

1 Cunisset-Carnot, "Sur un silex colorié" (A.F.A.S. Dijon [rg.1 I], p. 623).

2 F. Sarasin, "Les galets coloriés de la grotte de Birseck près Bâle" (C.A.P.A. Geneva [1912], vol. I. p. 566).

${ }^{3}$ R. Munro, Palaeolithic Man, p. 270. A few other, more doubtful, Azilian sites in Britain are enumerated in Proceedings Soc. Antiq. Scotland, xLviII. [191314], p. 55 .

${ }_{4}$ Joseph Anderson, "Notice of a cave recently discovered at Oban containing human remains and a refuse-heap of shells and bones of animals, and stone and bone implements" (Proc. Soc. Antiq. Scotland, xxix. [1894-5], p. 21 I); Idem, "Notes on the contents of a small cave or rock-shelter at Druimvargie, Oban; and of three shell-mounds in Oronsay" (ibid. xxxII. [1897-8], p. 298); R. Munro in P.S.A. xvI. [1896], p. 182 . 
cave is now about 9 mètres above the present level of the sea ${ }^{1}$. This shews that the beach must have been. nearly 9 mètres higher than it now is, when the people who left the remains lived in the cave. These deposits therefore belong to the time of the raised beach
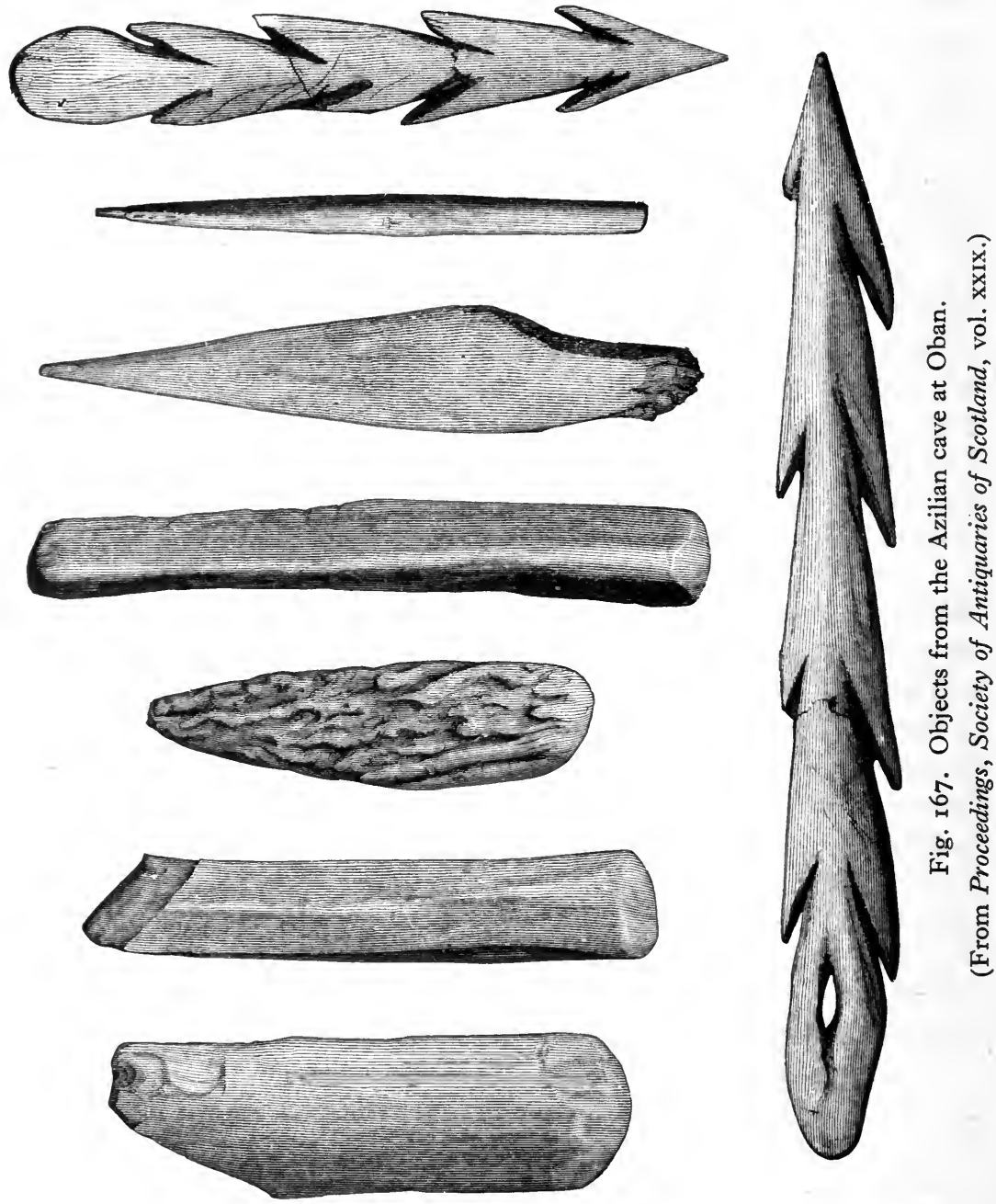

which in Scotland and the north of Ireland dates immediately after the final retreat of the ice-sheet. This corresponds, in time, with the Azilian stage, on the chronology adopted in the present work.

1 I understand that the cave, the oldest known human dwelling in Scotland, no longer exists, having been entirely quarried away after the deposits had been taken out of it. In a civilised country the oldest known human habitation would have been carefully preserved: but Britain is one of the last countries in Europe in which to look for such refinements of civilisation. 
The shell-mound on the raised beach at Oronsay, a full description of which has been published by its explorers ${ }^{1}$, testifies to an occupation of that island at a time when the land was some 8 mètres deeper in the sea than it is now. Flat harpoons were used, which connect this settlement with the Azilian culture; and limpet-gouges and flint chips, all very rude, also came to light. Even the holes in which the posts of the wooden huts had been fitted in the ground were discovered in the course of the exploration of the site. The general conclusions as to the degree of culture attained by the people who left this mound are as follows: Oronsay man was a hunter, a fisher, and a fowler. He did not, apparently, practise agriculture-at least, no corn-grinders were found. Fragments of red paint, and perforated shells, give a hint as to how he decorated his person. The pins and piercers of bone indicated that he was clothed in hides. No human remains were found, so that nothing is known as to his physical characteristics; some skulls from the Oban cave, which probably belong to people of the same race, were markedly dolichocephalic. That Oronsay man had some skill in navigation is indicated by the presence in the midden of shells of deep-sea varieties of crabs.

\section{Pygmy Flints}

In connexion with the Azilian culture must be described the objects commonly called "pygmy" or "Tardenoisian" flints-the latter name being derived from that of Fère-en-Tardenois (Aisne). These are minute splinters of flint, rarely measuring so much as an inch in length, and still more rarely exceeding that limit, chipped into geometrical shapes which may be classified generally into triangles, rhomboids, trapeziums, and segments of circles. Some have a sort of tang, as though for mounting them as arrow-heads on a shaft. These small implements are to be found in practically all the countries of Europe, as well as in Syria, India, and Egypt ${ }^{2}$. They probably served a variety of purposes. The present writer is bound to say that he has seen many alleged pygmy flints which he could not persuade himself to have been the product of human industry at all. Others are probably wastes, the refuse chips struck from a nodule in the process of shaping a tool: but this will not account for the care with which most of them have been brought to a definite geometrical form, and the majority of the "pygmy flints' that are

1 A. Henderson Bishop, "An Oronsay shell-mound: a Scottish pre-Neolithic site" (Proc. Soc. Antiquaries, Scot. XLvirr. [1913-4], p. 52).

2 A. de Mortillet, "Les petits silex taillés à contours géométriques" (R.E.A.vi. [1896], p. 377); J. Allen Brown, "On some small highly specialised forms of stone implements found in Asia, North Africa and Europe" (手.A.I. xvilr. [1889], p. 134); Edmond Vielle, "Pointes de flèches typiques de Fère-en-Tardenois" (B.S.A.P. 
acceptable as artefacts have certainly been intentionally made for some special purpose. Various guesses have been put forth as to what this purpose may have been: some have supposed, for example, that they were for surgical instruments, or for tatuing; or that they were arrowheads; or fish-hooks; or for adding to the effectiveness of wooden clubs; or else, observing that most of the finds of such
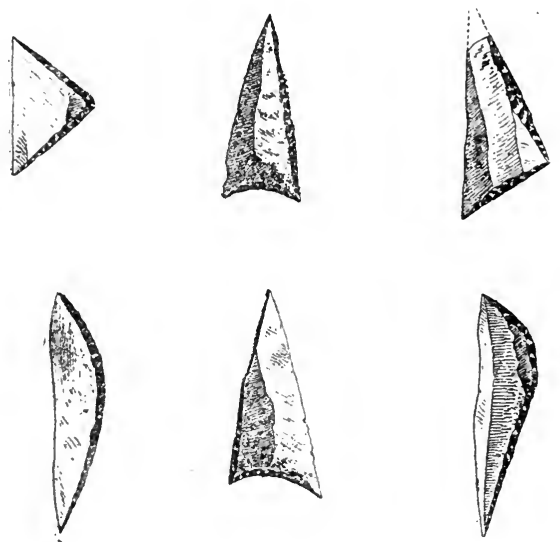

Fig. 168. Pygmy flints.

(From Revue de l'École d'Anthropologie, vol. vi.)

implements have been made in the neighbourhood of the sea or of rivers $^{1}$, that they were for harpoon-teeth. Some justification for the latter theory is afforded by actual specimens of bone harpoons with flint teeth which have been found in the peat-mosses of Denmark (Fig. I69).

Obviously the "pygmy" industry cannot represent the sole efforts

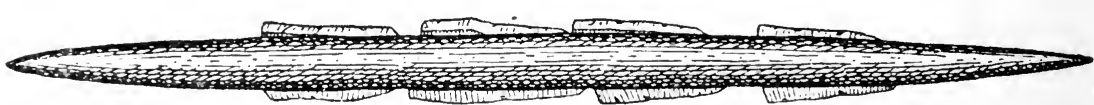

Fig. 169. Harpoon with flint teeth.

(From G. and A. de Mortillet, Musée préhistorique.)

at flint-chipping of any Stone Age community. For unless Tardenoisian man was the size of a squirrel, he would have needed flint implements of the ordinary size for ordinary purposes, using the "pygmies" for such special purposes as they were intended to serve.

ser. Iv. vol. I. [1 890], p. 959) ; L. Coutil, "Silex pygmées et micro-silex géométriques" (A.F.A.S.Havre [I91 I] ,p.434); Idem," "Tardenoisien... silex き̀ formes géométriques, silex pygmées, et micro-silex géométriques" (C.A.P.A. [1912], Geneva, vol. I. p. 3 or, where will be found a list of sites which have yielded these flints).

1 A. de Mortillet, op. laud. quoting Lewis Abbott in F.A.I. xxv. p. 137. 
The Tardenoisian phase of culture was shewn to have been closely associated with the Azilian by the discovery in the cave of Valle, Santander, of Tardenoisian "pygmies" along with Azilian flat harpoons and a painted pebble ${ }^{1}$. But though thus associated there is no indissoluble connexion between the two. Tardenoisian flints are found in sites which display nothing of the special Azilian facies, such as flat harpoons or painted pebbles. Indeed, the discovery of flints in all respects resembling Tardenoisian "pygmies" but associated with Roman remains has been reported from France ${ }^{2}$. On the other hand, there are Azilian stations-the typical station at Le Mas d'Azil is one of them-which do not present us with Tardenoisian flints in association with the specifically Azilian types. Thus, though the Tardenoisian and the Azilian are certainly, at least in part, contemporaneous, and are often closely associated together, they must be labelled with distinct names. On this account it is the custom to speak of Azilian, Tardenoisian, and Azilian-Tardenoisian sites, according as they display remains of the one culture, of the other, or of both. In Europe pygmy flints are found at least as far north as the Dee valley in Scotland ${ }^{3}$.

\section{THE CAPSIAN CULTURE}

\section{The Palaeolithic of North Africa}

The investigations of de Morgan, Capitan, and Boudy in North Africa $^{4}$ have thrown much light on the origin of the Tardenoisian culture in Europe. The Palaeolithic of Northern Africa lies per se outside the scope of this book; but in so far as it has a bearing on some European problems, it calls here for a few words of description.

The Acheulean and Mousterian stages appear in North Africa, generally speaking, similar to the corresponding stages in Europe and presumably contemporary with them. To the Mousterian succeeds the stage to which de Morgan has given the name Captian or Capsian, a name derived from that of the ancient Capsa, now Gafsa in Tunis ${ }^{5}$. The Capsian thus corresponds chronologically to the European Upper Palaeolithic, and culturally to the Aurignacian stage. The Solutrean and Magdalenian are absent from North Africa, as from Italy.

${ }^{1} \mathrm{H}$. Breuil and $\mathrm{H}$. Obermaier, "Travaux [de l'Institut de Paléontologie humaine] exécutés en I912" (L'Anthr. xxIv. [I9I3], p. I).

${ }^{2}$ Henri Quilgars, "L'industrie des silex à contours géométriques aux environs de Guérande, Loire-inférieure" (L'Anthr. x. [1899], p. 67I).

3 Miss H. L. Paterson, "Pigmy flints in the Dee Valley" (Brit. Assoc. Report, Dundee [1912], p. 605).

" "Les stations préhistoriques du Sud tunisien" (R.E.A. [I9IO-I9II]).

5 This name supersedes other terms which need not here be enumerated; they will be found in Coutil's paper in C.A.P.A., cited in a previous footnote. 


\section{Phases of the Capsian Industry in Africa and in Spain}

The Capsian is subdivided into two phases; the first of these (Lower Capsian) representing in time and in culture the Aurignacian of Europe, the other representing in time the Solutrean and Magdalenian, but differing from these in culture. Apparently the Lower Capsian cannot be so clearly subdivided chronologically as can the various facies of the European Aurignacian; the Chattelperron knives, which in Europe belong to an early phase of the Aurignacian, are found in association with Gravette flakes, which in Europe belong to a late phase. It is as though the Middle Aurignacian phase, which in Europe separates the Châtelperron from the Gravette culture, is suppressed, and the remaining early and late phases mingled together. The Upper Capsian shews bone needles, small bone beads, scrapers and other rude tools of flint, discs cut from the shells of ostrich-eggs, and the Aurignacian flakes of the Lower Capsian degenerating into flints of geometrical form. These, at first of normal size, dwindle into the Tardenoisian pygmies.

Thus the Tardenoisian culture in Europe is of North African origin; and there can be no question that it has entered Europe through Spain. The greater part of the Iberian peninsula shews only two stages in its Upper Palaeolithic; an Aurignacian, comparable with the European Aurignacian; and a Capsian, identical with the Upper Capsian of Africa.

This will explain why, in describing the UpperPalaeolithic remains of the different regions at the end of the preceding chapter, we passed over the Spanish Peninsula: for we had still to describe this new element in the Upper Palaeolithic of Spain, which is not found elsewhere in Europe. With the Capsian culture must undoubtedly be associated the peculiar art of the Spanish wall-paintings at Alpera, Cogul; and elsewhere, which have thus no direct connexion with the Upper Palaeolithic Art of the rest of Europe. It follows that there are two strong links uniting the Capsian with the Azilian culture. The Capsian Art is the parent from which the painted pebbles of Le Mas d'Azil have been derived; and the Capsian flint industry is the origin of the Azilian-Tardenoisian pygmies.

It is probably to the Capsian invaders that the credit of introducing the bow into Europe is due. This weapon appears frequently in the hands of the men in the Spanish rock-paintings; but so far as the evidence goes its use is confined to Spain, and the Spanish paintings can afford no proof of Palaeolithic archery north of the Pyrenees. We have seen already that the interpretation of the attitude of the Laussel man (ante, p. 450), as an archer is doubtful. 


\section{The Ofnet Azilian Deposits}

It is not, however, to be supposed that the Capsian immigrants are responsible for the entire "Epipalaeolithic" culture of central and southern Europe. On the contrary, that the ethnology of the Continent in Azilian times was not a little complex is shewn by the deposits which give their chief importance to the caves called Ofnet ${ }^{1}$.

The lower strata in these caves, up to the Magdalenian, have been described on previous pages. In the Greater Ofnet cave, the stratum immediately over the Magdalenian was as a rule only about five centimètres thick; but in two places it was deepened by pits sunk through the underlying layer to the top of the Solutrean layer next below. These pits were filled with a mass of red ochre, traces of which extended in a circle of $\mathrm{I}$ to 2 mètres round the deposits.

Of these pits, one was 0.76 mètre in diameter, and in it were no less than 27 skulls, closely packed side by side, contained in a fine earth permeated with powdered ochre. They were all placed nith the face turned towards the west; though as the mouth of the cave was not to the west, this was not the naturally obvious orientation in which to place them. All the skulls retained the jaw and one or more of the neck vertebrae adhered to them: a fact enough to shew that the heads must have been cut from the bodies and deposited where they were found while still covered with flesh. The vertebrae in some cases shewed the marks of the stone knives by which the decapitation had been effected; these marks were in all cases on the front surface of the vertebral column.

The second pit, which was I mètre distant from the first, contained a similar deposit, but comprising six skulls only.

It was noticed that the central skulls of each group were more broken and damaged than the outer skulls. This is interpreted as meaning that the skulls had not all been deposited at one time; but that the central skull was placed first, and the others added from time to time in concentric circles around it.

Not the least curious part of the deposits was the distribution of sexes and ages. There were skulls of five men, nine women, and 19 children; of the last, 12 were under five years of age, the remainder (apparently five boys and two girls) aged from 7 to 18 .

With the skulls were deposited flints and ornaments, the latter taking the form of perforated teeth of deer (about 200 or more) and perforated shells (about 4000). The women and children were more

1 R. R. Schmidt, "Die spätpaläolithischen Bestattungen der Ofnet” (Mannus, II. [1910], p. 56). 
richly decorated than the men. The deer's teeth had been strung as collars or crowns; these principally appeared on the women, being entirely absent from the men. The children were mostly decorated with shells; one of the youngest of the children had had a sort of coif covering the vault of the skull, into which several hundred shells had been sewn. These shells belonged to four species, one of them a local Tertiary fossil (Carinifex multiformis), two other river shells that might have come from the sands of the Rhine or the Danube

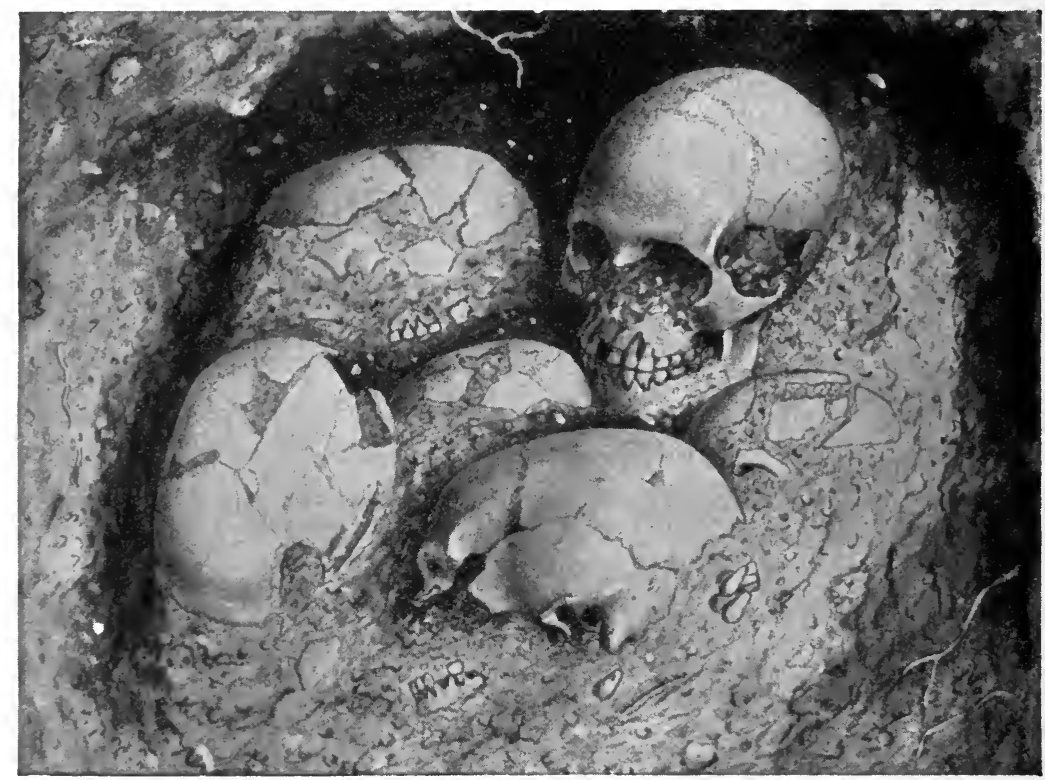

Fig. 170. One of the Ofnet skull burials.

(From L'Anthropologie, vol. xx.)

(Lithoglyphus naticoides and Neritina fluviatilis) and one that must have come from the Mediterranean (Columbella rustica).

On the following grounds the deposits are dated to the Azilian stage:

I. The fauna; except Gulo borealis the Arctic fauna has definitely disappeared, including the Reindeer. On the other hand there are remains of Felis leo, which did not survive in Europe into the full Neolithic.

2. The total absence of pottery or of the remains of domestic animals. The latter appeared freely in an overlying Neolithic stratum.

3. The industry, which included Tardenoisian "pygmy" flints. 
This stratum in the cave called Ofnet is the most easterly Azilian deposit as yet discovered in Europe.

The careful decoration of the remains forbids us to regard this deposit of skulls as the record of a deed of violence, which otherwise the treatment of the bodies and the undue preponderance of women and children would lead us to suppose. We are in the presence of a burial rite which on a previous page we have ventured to call cephalotaphy; the careful orientation of the faces of the heads indicated a deliberate intention, possibly based on a (solar?) cultus. The special honour given to the head of the deceased is not without precedent, ancient and modern. Thus, to mention but one example: the Anatomical Museum in Trinity College, Dublin, possesses a number of skulls taken by a military expedition from a native sanctuary at Jini, E. Africa. These were the skulls of persons who had been ceremonially eaten by the tribe. They were coloured red, and preserved with great reverence ${ }^{1}$. The preponderance of women and children, at first sight difficult to account for, is really a very simple matter. In a hunting community, these are the stay-at-home people; most of the adult males will meet their deaths in the hunting or the battle field, and their bodies will not be recovered. It is interesting that even the youngest children were made recipients of the burial honours.

It is impossible to give more than a summary here of the ethnological results of the examination of these skulls ${ }^{2}$. It must not be forgotten that after all, 33 skulls - of which 12 are too fragmentary for satisfactory measurement-are but a small proportion of the population to which the owners of the skulls belonged; and determination of racial character, with deductions as to movements and inter-relations of peoples, based on the evidence which they afford, are apt to have the instability of an inverted pyramid. With this word of warning, we may proceed to say that Schliz recognises two leading racial types, and a number of intermediate forms due probably to the mixture of those types, among the people represented in the Ofnet cave.

These types are brachycephalic and dolichocephalic respectively. There are also a number of mesaticephalic skulls, which do not differ in other details from the brachycephalic group, and are to be enumerated with them.

The pure short-headed type has a head, the outline of which as viewed from above (norma verticalis) consists of two segments of

1 I owe this information to my friend Prof. A. F. Dixon.

2 The fullest account is that contributed by M. Schliz to R. R. Schmidt's Diluviale Vorzeit Deutschlands, p. 24I ff. 
circles, the one forming the back of the head, the other the front. There are slight brow-ridges, above which the broad forehead curves rapidly into the top of the head, and then passes over the summit and down the back in an almost regular quasi-circular curve. The face shews a short straight nose, low, almost rectangular and horizontal orbital openings, a low upper jaw, a lower jaw low on the whole but higher in front than behind, with wide ascending rami, chin weak and undeveloped. The cheek-bones are not very prominent. This type of skull, to which nine of the subjects belonged (four brachycephalic and five mesaticephalic), is compared with the early Neolithic type called the Type of Grenelle, from a place near Paris where a typical specimen long ago came to light.

The pure long-headed race, as determined by Schliz, is represented by one specimen only, the skull of a man of about 25 years of age. The outline viewed from above is elliptical. There are strong brow-ridges, above which the forehead slopes regularly and without any abrupt angle to the top of the head: from this the curve runs in a regular quasi-elliptical curve round the back of the skull. The forehead is broad, the orbits low, angled, and obliquely set, the upper jaw high, the lower jaw small, but with well-developed chin. The owner of this skull seems to have belonged to the Solutrean Brünn type.

The blends are of two kinds, the one brachycephalic (and mesaticephalic), the other dolichocephalic. The former (four brachycephalic, three mesaticephalic) is characterised by a pear-shaped head as viewed from above - the rounded back of the pure type, but with a depression on each side just in front of the parietal eminences (the prominent parts above the ears) from which the side lines run straight to join the rounded forehead. The face resembles that of the pure brachycephalic type, as does the side view (norma lateralis), except that the forehead is higher, and does not curve with an abrupt angle to the top. These skulls are comparable with those found in the oldest Neolithic lake-dwellings of Central Europe, in which are generally seen the beginnings in the Continent of the "Alpine Race."

The dolichocephalic blend has an elliptical outline with flat sides and somewhat flattened forehead curve. The side view shews prominent brow-ridges, with a broad hollow at the root of the nose, a forehead curving rapidly to the top of the head, after which the curve is quite regular over the top and down the back. The face resembles that of the brachycephalic people. This type conforms to the type called after the Belgian cave of Engis, where a well-known specimen was found.

While admitting that the osteological material from the Ofnet 
caves, though the fullest series yet discovered, is scanty, it may still be claimed that it brings us a step nearer to the solution of the problem of the origin of the European Neolithic and modern races. It shews us that even these are capable of analysis into component races. The Alpine race is not a pure race, but a blend, having in it an old Palaeolithic element, and a brachycephalic element, the exact origin of which is still to seek.

\section{Other similar deposits}

M. l'Abbé Breuil, analysing R. R. Schmidt's report on the Ofnet excavation ${ }^{1}$, compares with this remarkable deposit the find at Placard, of which he found a description among the papers of M. de Maret. There were here three strata:

C. Magdalenian; containing part of maxilla and calvaria of a woman's skull ${ }^{2}$ surrounded with shells.

$B$. Magdalenian; four skulls side by side, one femur and one humerus with them.

$A$. Upper Solutrean; a portion of a skull.

$\mathrm{He}$ also compares the deposits in the Grotte des Hommes at Arcy-sur-Cure ${ }^{3}$, where there were three skulls placed on flat stones at the highest point of the floor. In the depressions were several piles of long bones, the chief of which, being laid on a sloping floor, was held up by a row of stones. There was no pottery, and one flint flake. But reference to Parat's paper, cited below, makes it clear that it would be unsafe to quote this as a case of cephalotaphy. The osteological finds in this cave are very unsatisfactorily recorded: the competition of collectors, and the intervention of a guide who broke up and sold the bones piecemeal to tourists, made all scientific examination in the remains impossible.

\section{The Tagus Midden-heaps}

In close affinity to the Tardenoisian culture are the contents of the series of midden-heaps and other evidences of early settlements along the borders of the river Tagus in Portugal, which have been explored with success by F. de Paula e Oliveira ${ }^{4}$. In these excavations there were found no less than 600 skeletons, the greater number

${ }^{1}$ L'Anthr. xx. [1909], p. 207. But see further p. 523 in the same volume, where it is shown that some of the skulls in this cave were not buried with honour, but misused (see ante, p. 400).

${ }^{2}$ Described by Hany in C.A.P.A. Paris [1899], p. 433 ff. This article also contains a description and illustrations of the Malarnaud jaw and some other remains enumerated above.

3 Abbé Parat, "La Grotte des Hommes à Saint-More" (Bulletin de la société des sciences d' Yonne, XLIX. [1896], part 2, p. 47).

${ }_{4}$ Communicą̧ãoes da commissão dos trabalhos geologicos, vol. II. p. I. 
of them belonging to women and children: the disproportion is accounted for in the same way here as in the Ofnet. These skeletons were almost all in a crouching position, lying on their backs; a posture explained by the explorer as the position into which the body would naturally fall if it were seized by the hands and feet, and cast unceremoniously into a pit of small size. On the other hand, though the bodies were thus treated with scant courtesy, the interests of the souls in the other world were not wholly neglected, as is shewn by the flints deposited with them in considerable numbers.

There were no polished tools of stone, and in the earlier parts of the deposits no pottery. There was no trace of any domestic animal, not even of the dog. The undue proportion of bones from the more edible parts of the animals, whose remains were found, shewed that they had been killed at a distance from the settlement, and cut up on the spot. A considerable number of pygmy flints were found.

The majority of the people were dolichocephalic, bearing some resemblance to the Cro-AIagnon race (cranial index averages about 73.3 ). But there was a brachycephalic strain mingled with them, and also traces of a hypobrachycephalic group were found, probably the result of mixture. 'The brachycephalic races associated with the Neolithic culture had therefore made some way into the region where the remains came to light ${ }^{1}$.

It is suggestive that it is in this period of overlap that we meet for the first time with brachycephalic people in Europe-if we except the single anomalous group at Krapina in the extreme east of the Continent. The short-headedness of the new race or races which now appear suggests that it is to Asia we must look for the secret of the beginning of European Neolithic culture; short-headedness being characteristic of the Central Asiatic peoples.

\section{The Belgian Caves}

We can follow the immigration with the help of the extensive researches made by Edouard Dupont in the caves of Belgium. This energetic explorer excavated some 60 caves, on which he reported in various volumes of the Mémoires publiés par l'Académie royale des Sciences, dies Lettres, et des Beaux-arts de Belgique, and in the Bulletins of the same body during the sixties of the last century; and afterwards in his volume, Les temps préhistoriques en Belgique. While many of the caves were insignificant, a few were of great importance. We

\footnotetext{
1 For a very thorough study of the bones from these Portuguese middens see (jeorges I Iervé, "Populations mésolithiques et néolithiques de l'Espagne et du Portugal" (R.E.A. Ix. [1899], p. 265).
} 
have already had occasion to refer to one, the Trou de La Naulette, in connexion with the Middle Palaeolithic jaw-bone which it yielded.

Some of the caves were full Magdalenian. Thus the Trou Magrite at Pont-à-Lesse, on the river Lesse, displayed the following stratification:

$C$. Clay mingled with fallen blocks.

$B$. Sandy clay, with bones, $2 \cdot 50$ mètres thick.

$A$. Rolled pebbles, I mètre thick.

There were bones of many animals, including mammoth, Rhinoceros tichorhinus (numerous), horse (ditto), stag, bear, hyaena, cave lion, reindeer. The last-named was especially abundant in stratum $C$, the other extinct animals were commoner in $B$. Thus we see the persistence of the reindeer after the disappearance of the other tundra species. That the reindeer should last longer in this comparatively northerly region than in the southern parts of the Continent is only what we might expect. There were many flint implements,
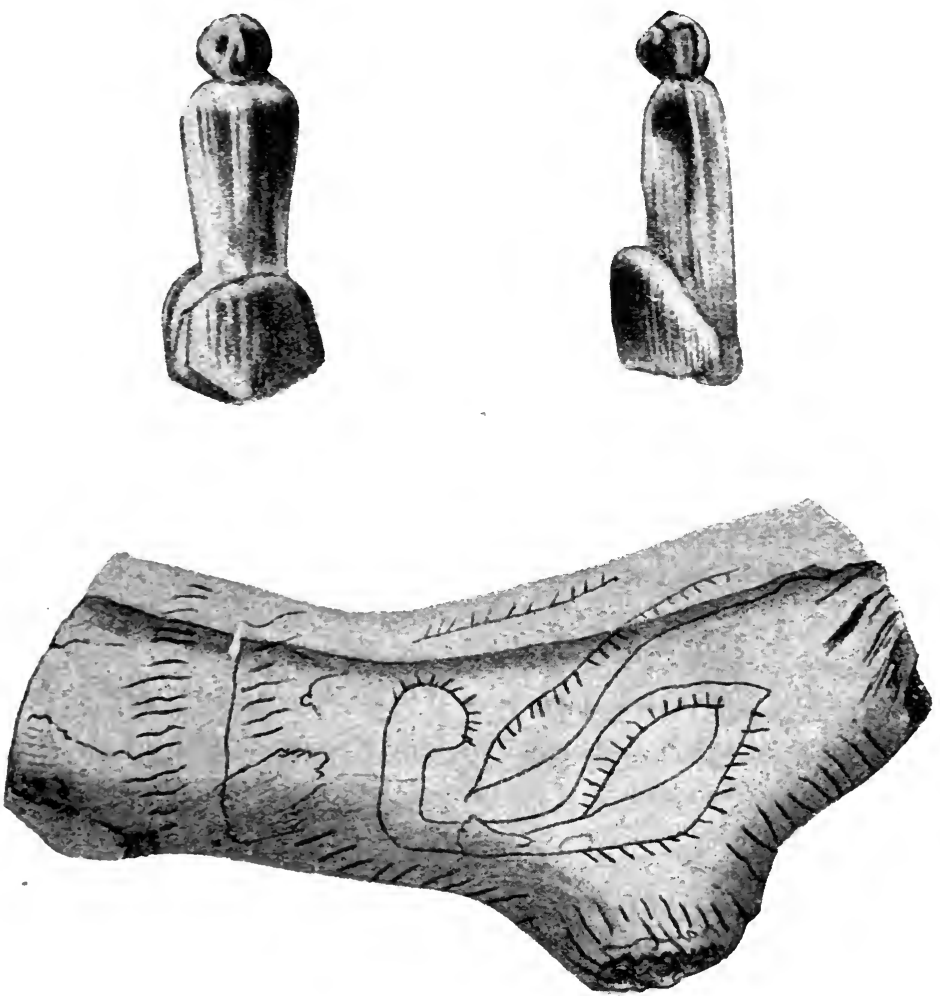

Fig. I7 I (a). Ornamented reindeer-horn objects from Belgian caves.

(From Bulletin de l'Académie de Bruxelles, vol. xxıv.)

M. E. A. 1 . 


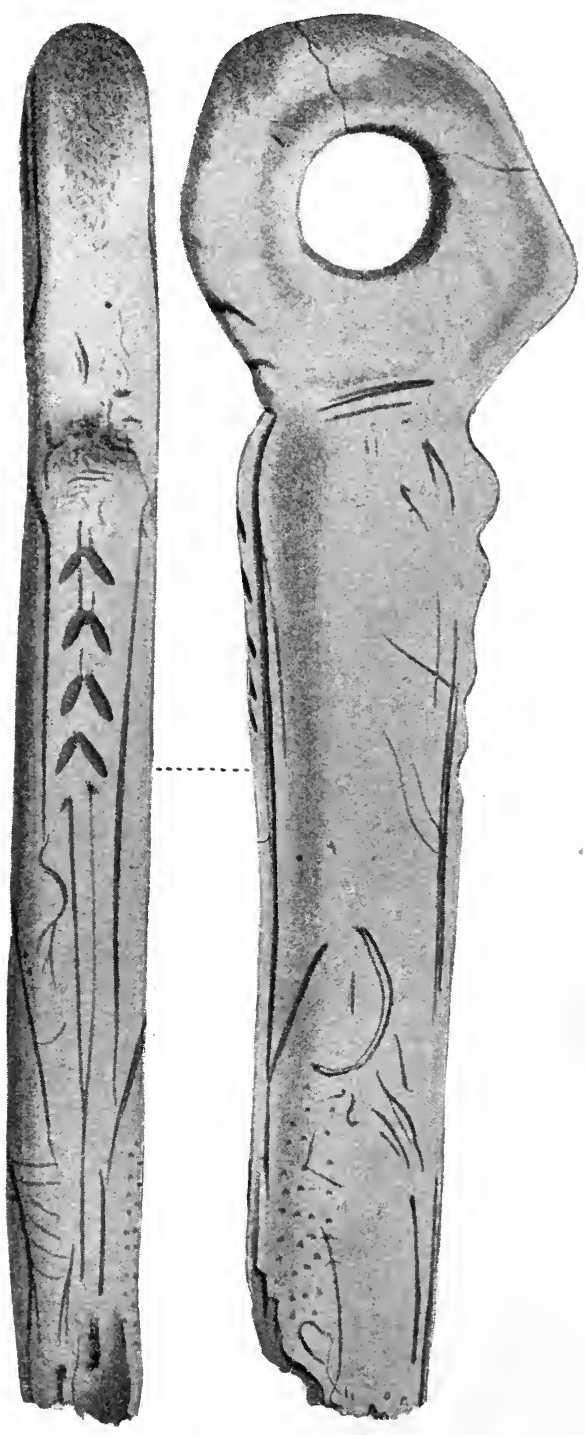

Fig. I7I (b). Ornamental reindeer-horn objects from Belgian caves.

(From Bulletin de l'Académie de Bruxelles, vol. xxiv.)

and bones broken for marrow; two pieces of reindeer-horn, one of them cut into a very rude, almost amorphous, statuette, and the other bearing an indefinite engraving (shewing a curious resemblance to the engraved mammoth-bone from Kiev) linked this cave to the Magdalenian art-centres. In the cave of Goyet, province of Namur, two fragments of bâtons de commandement were found-one of them 
plain, the other with an indefinite ornament on the edge. Magdalenian flakes and bones of the characteristic reindeer fauna accompanied them ${ }^{1}$.

But at Furfooz, on the same river Lesse, where seven caves were examined, and at Chaleux, the deposits told a different tale. The stratification in the Furfooz caves conformed to a general scheme, though in some caves certain of the strata were absent, and in others were of abnormal thickness. This scheme is as follows:

$F$. Re-sorted layers with objects from historic times (Roman, Frankish, Mediaeval).

$E$. Yellow clay containing numerous angular fragments of limestone. Bones of animals; man, reindeer, glutton, eland, bear, chamois, ibex, beaver.

D. Stalagmite.

C. Sandy clay without bones.

$B$. Pebbles with scanty bones (cave bear, horse).

$A$. Gravels with traces of peat. Beaver bones. No sign of human occupation.

The human remains were all in the stratum $E$. The reindeer is still to be found, but it is getting rare. The human artefacts include flint knives, and other implements of Magdalenian type, associated, however,with coarse pottery; this shews that we have passed out of the full Palaeolithic. Of the Furfooz caves, one called Trou Reuviau, contained some fragments of human bones; another, Trou Rosette, had also some bones and an imperfect skull (cranial index 86. I) and another cave, nameless, but which Dupont has labelled Trou de Frontal, contained a remarkable ossuary of bones, representing about I4 skeletons. The bones were not in their natural relative position, so that they must have been deposited loose, after the decay of the flesh. Only two skulls were sufficiently sound for examination; they yielded cephalic indices of $8 \mathrm{I} \cdot 3$ and $8 \mathrm{I} \cdot \mathrm{I}$ respectively. The local facies of Magdalenian art, such as it was, has here disappeared. Besides the pottery were found poor flints, and small bone needles, as well as perforated shells and pendants of jet ${ }^{2}$.

The cave at Chaleux, called in the local patois Trou qu'on broye (Cave where flax is worked), had richer deposits. The elephant and

1 Dupont, "Découverte d'objets gravés et sculptés dans le Trou Magrite à Pont-à-Lesse" (Bulletin, xxiv. [1867, part 2], p. I 29); "Sur deux fragments d'objets appelés bâtons de commandement découverts dans la caverne de Goyet, province de Namur" (Bulletin, xxvir. [1869, part I], p. 274).

2 Dupont, "Étude sur l'ethnographie de l'homme de l'âge du renne dans les cavernes de la vallée de la Lesse" (Mémoires, XIx. [I867], p. I). A description of the bones by Pruner-Bey is included. P. J. van Benenden and Dupont, "Sur les ossements humains du Trou du Frontal" (Bulletin, XIx. [1865], p. 15); Dupont, "Notice sur les fouilles scientifiques exécutées dans les cavernes de Furfooz, province de Namur" (Bulletin, Xx. [1865, part 2], p. 244). 
reindeer are still lingering, but are yielding to the modern fauna. Ornaments made of perforated shells, a dog-fish vertebra likewise perforated, and some fluorine crystals, one of them perforated, were found in the principal human layer (there was evidence of three successive occupations in the deposits of this cave, but only one was of importance). No less than 30,000 flint implements were found in this cave-cores, knives, flakes, saws, scrapers, and piercers. Fluorine and flint are alike foreign to the locality, so that these materials must have been imported from a distance. The cave also yielded fragments of wood with scratches upon them, plates of bone elliptical in form, perforated in the middle, and rude pottery ${ }^{1}$.

\section{The Brachycephalic Immigrants}

These brachycephalic Furfooz people may represent the advanceguard of the Asiatic immigration ${ }^{2}$. But we must be as cautious in our interpretation of the phenomena as in the case of the Capsian influence. It is not to be supposed that a destroying Asiatic army suddenly burst into Europe, bringing with it the blessings of Neolithic culture, but submerging in its flood the old Palaeolithic peoples in their degenerate Azilian stage-as when the Aurignacians swept down upon and all but rooted out the Mousterian people. Rather are we to see what in modern phraseology is known as "peaceful penetration." The nomad Asiatic herdsman gradually enlarged his beat, as he sought for pasture and watering-places for his cattle and his flocks. It is evident that at the time he must have been in the pastoral stage of development rather than the agricultural, for in the latter stage he would have been anchored to the fields which he cultivated and would be less likely to wander. But step by step he worked his way into Europe, along the Alps and to the north of them. Gradually he elbowed out the dolichocephalic races. To some parts of the Continent he never penetrated; thus, England did not receive a brachycephalic strain in her population till the beginning of the Bronze Age, and Ireland never at all till the coming of the AngloNormans. But elsewhere over the Continent, excepting in the southern peninsulas, we find traces of the intruders.

'This infusion of new blood was an unmixed advantage to the Europeans, who seem to have been degenerating, if we may judge by the degeneration of their implements. The brachycephalic people

${ }^{1}$ P. J. van Benenden, Nicholas Hauzeur and Dupont, "Sur les fouilles de (haleux" (Bulletin, xx. [1865, part 2], p. 54); Dupont, "Étude sur les cavernes des bords de la Lesse et de la Meuse explorées jusqu'au mois d'octobre i 865 " (ibid. p. 824$)$.

2 Similar skulls were found at Grenelle in France, but their archaeological level is not so certainly established. 
came among them, to some extent mixed with them, and taught them the business of shepherds and cattle-tenders. Thus an improvement entered into their mode of life which had a strengthening influence on the race. Though at first they yielded place to the immigrants, in time they reasserted themselves; so that the fertile plains of Europe are now peopled almost exclusively by populations which are predominantly dolichocephalic, while the brachycephalic people have been squeezed back into the mountainous regions.

But we have not yet finished with the complication of influences which play upon Europe during the Mesolithic period--the formative period of the modern world. The "Epipalaeolithic" Azilian overlaps with a culture independent of any of those which we have now considered, namely the "Protoneolithic" Campignian.

\section{THE CAMPIGNIAN STAGE}

\section{Le Campigny}

This stage derives its name from Le Campigny, a hill near the town of Blangy-sur-Bresle(Seine-Inférieure). Here a hut site was discovered, the excavation of which was carried out in the early seventies of the nineteenth century ${ }^{1}$.

The site was in the form of a pit, funnel-shaped, 4.30 mètres across at the top and $\mathrm{r} \cdot 20$ mètres deep, hollowed in the gravels with which the underlying marly chalk is covered. At the bottom of the pit was a bed of ashes, the remains of a hearth, oval in shape, $2.10 \mathrm{~m}$. long, between 1.70 and $\mathrm{r} .80 \mathrm{~m}$. broad, and $0.45 \mathrm{~m}$. thick. The remainder of the pit was filled with yellow loam, and over all was spread a thin layer of vegetable soil.

In the vegetable soil over the whole hill are found the remains of a fully developed Neolithic industry, including polished stone implements. This stage of civilisation therefore is later than the hut-site. The loam with which the hut-site was filled contained many fragments of flint with some worked flints of a different type from those contained in the vegetable soil. The hearth contained a large number of implements of types similar to thosefound in the loam.

No polished tools whatever were found in the loam or in the hearth. The flints were mined in a site on the opposite side of the river Bresle, about a mile away from the settlement. At the spot indicated were found a number of the characteristic stone picks and implements of deer-horn.

1 E. and H. de Morgan, Notice sur Le Campigny, station de l'âge de la pierre polie sise à Blangy-sur-Bresle (Amiens, 1872); Philippe Salmon, d'Ault de Mesnil, and Capitan, "Le Campignien" (R.E.A. vir. [1898], p. 368); L. Capitan, " Passage du paléolithique au néolithique: étude, à ce point de vue, des industries du Campigny, etc." (C.A.P.A. Paris [1900], p. 206; L'Anthr. xII. [1901], p. 354). 


\section{Campignian Implements}

The implements found at Le Campigny included the following types, in addition to a number of chance flakes, with or without traces of usage, incapable of classification:
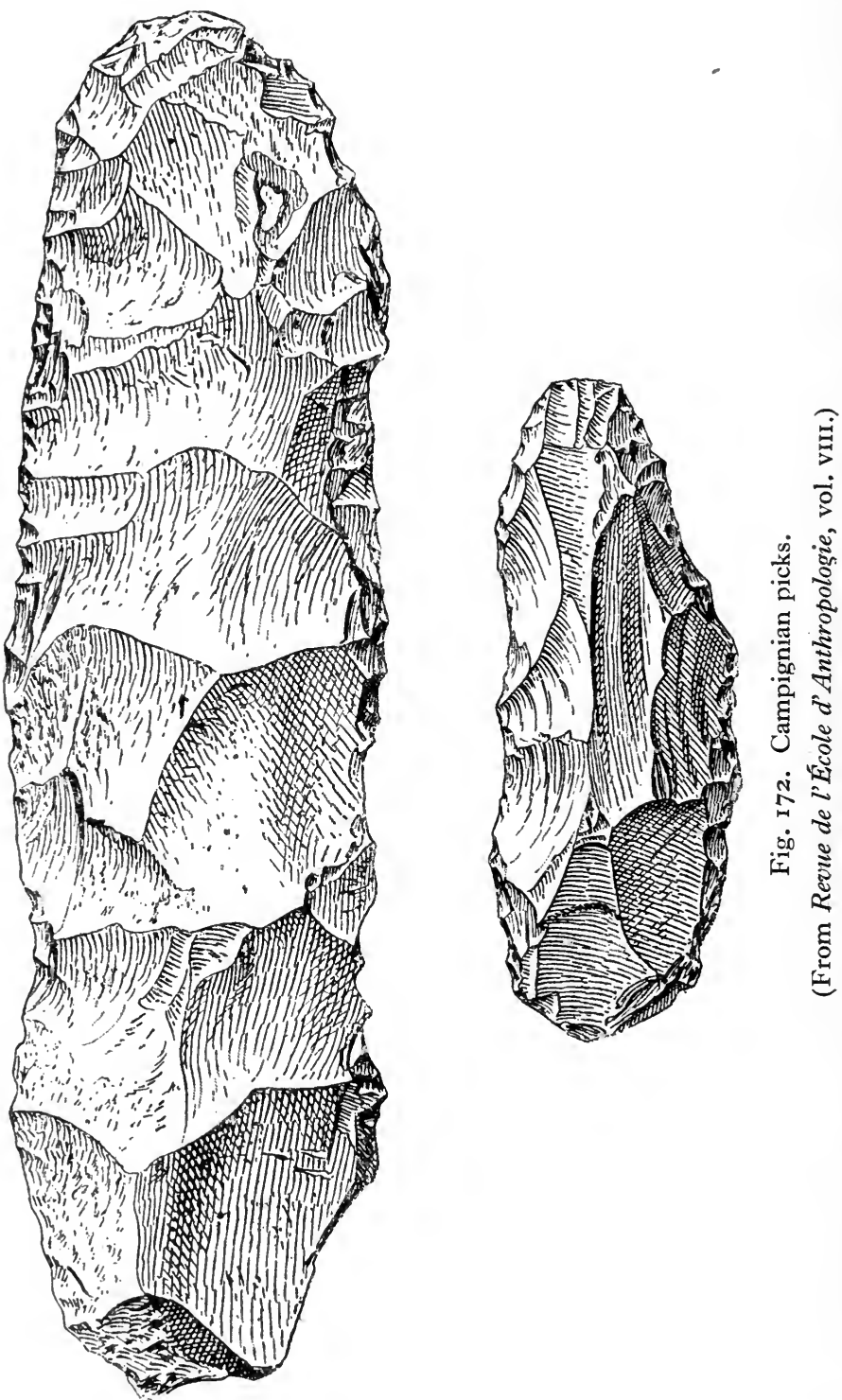

Flake knives, resembling generally those of Magdalenian sites.

Picks. This is a new tool, which does not appear in Palaeolithic 
sites, nor is it found in the fully developed Neolithic (Fig. 172). It is a bar of flint, roughly chipped to shape, about 8-15 centimètres in length, and with a blunt point at both ends. Some of them have a sort of chisel point at one of the ends.
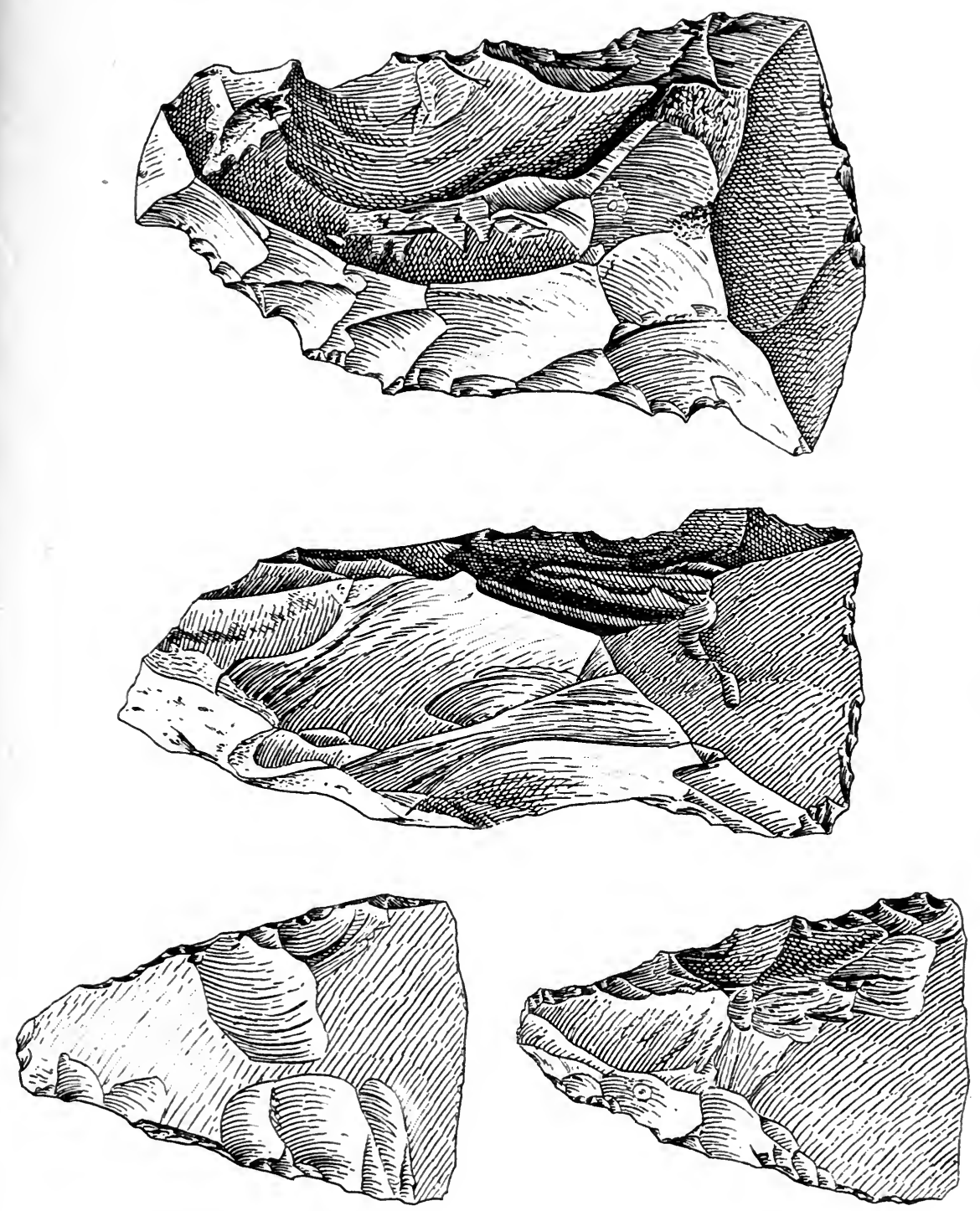

Scrapers and saws. These do not differ to any appreciable extent from the similar tools of the Upper Palaeolithic.

Engravers, borers, and prickers, resembling the Magdalenian types.

Chisels or choppers. These are nodules of flint so chipped as 
to have a straight edge, resembling that of a turnscrew (with two bevelled sides). This tool is often called the "kitchen-midden axe" on account of its frequent occurrence in the midden-heaps of Denmark (Fig. I73). A rare form has the chisel-edge at both ends.

The Campignian sites, therefore, add to the tool-box of the Palaeolithic artificer the pick and the kitchen-midden axe. But in addition to these there was in the typical site a large quantity of pottery. This, it is to be noted, was by no means the rude ware that we might expect in the first efforts after a new art. The vessels were all broken, and it was found impossible to reconstruct any of them; but the curvature of the sherds shewed that they had been of large size; they were provided with handles, and were ornamented with linear patterns-frets, chequers, and zigzags.

The following conclusions as to the culture of Campigny are indicated by the authors of the paper in the subject in R.E.A.:

I. That polishing stone was unknown, and that the sites are older than the full Neolithic period.

2. That two new implements are introduced, in addition to the Palaeolithic types.

3. That pottery was invented before the art of polishing stone; and that the pottery of the typical site, though coarse, is not primitive, but is often well formed and ornamented.

4. That mill-stones found on the site shew that agriculture had been invented, and that therefore the introduction of these preceded the polishing of stone.

5. That the fauna and flora indicated by animal and vegetable remains prove that these were identical with the modern flora and fauna, and therefore that the climate was as in modern times ${ }^{1}$.

\section{Campignian Sites in Germany, Ireland, and Italy}

Among the important Campignian sites may be mentioned a large factory of the characteristic chisel-axe at La Coudraie (SeineInférieure $)^{2}$ and an important site at Calbe an der Milde, Altmark ${ }^{3}$. Here were found the characteristic Campignian axe and pick, as well as flake knives and scrapers of Magdalenian types.

${ }^{1}$ On the Campignian culture see further Adrien de Mortillet, "Campigny et le Campignien" (B.S.A.P. ser. Iv. vol. x. [1899], p. 36); Kupka, "Das Campignien im nordeuropäischen Glazialgebiet," with many illustrations of implements (Z.f.E. xxxix. [1907], p. 192).

"G. Romain, "L'atelier de tranchets de La Coudraie près Montivilliers" (R.E.A. vi. [1896], p. I49).

${ }^{3}$ Kupka, "Ueber einen Fundort der älteren Steinzeit bei Calbe a. Milde". (Z.f.E. xxxviIr. [1906], p. 744). 
Mr J. Allen Brown ${ }^{1}$ has described flint implements from East Dean, Sussex, as well as from Acton (middle terrace gravels of the Thames) and Shrub Hill, Norfolk, occupying an intermediate position between Palaeolithic and Neolithic. Some of these have a certain affinity with Campignian types, but they have a more definitely Neolithic facies than the true Campignian types. Prof. Boyd Dawkins, however, has traversed Mr Brown's conclusions ${ }^{2}$.

The Campignian is the oldest culture which appears in Ireland. At Larne there is a raised beach, which has yielded Campignian picks in large numbers. There are a few other Campignian sites in northwest Ireland, as at Kilroot and Portrush. The whole island is encircled with shore sites, but the majority of these belong to a much later period.

The Larne site is of some importance for Chronology. The Azilian of Oronsay, and the Campignian of Larne, both appear on the 25 -feet raised beach, and therefore are presumably contemporary. The population of the remoter parts of Scotland and Ireland must have proceeded slowly, and the wandering Azilian community must have led a sort of gypsy existence for many generations before it finally settled on the coast of the former country at about the same time that another community, connected with the later Campignian culture, found their way to the north of the latter. This indicates that during the Mesolithic period the population of Europe was sparse, and consisted of small communities, half nomadic, and maintaining but little mutual intercourse: also that although as a whole the Epipalaeolithic is presumably older than the Protoneolithic, the two overlap.

The Campignian culture also appears in southern Europe. Chiselaxes from Breonio, Italy, are figured in Bullettino di Paletnologia italiäna, XxviII. [1902], p. I75, and a pick from Rivole, Verona, ibid. pp. I6I-I64.

\section{Danish Shell-heaps}

But the most important Campignian sites are undoubtedly the

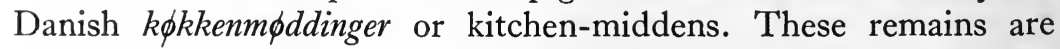
usually spoken of by this Danish name (but less frequently in Denmark than elsewhere); though it undergoes some adaptation to the languages in which it is used, by the substitution of a plural in $s$ for its own plural in $e r$. The term is misleading: it involves wholly inappropriate modern ideas, and obscures the fact that the dwelling places were in the middle of the heaps which rose around them.

1 "On the continuity of the Palaeolithic and Neolithic Periods" (F.A.I. xxiI. [1893], p. 66).

2 "On the relation of the Palaeolithic to the Neolithic Period" (F.A.I. xxilI. [1894], p. 242). 


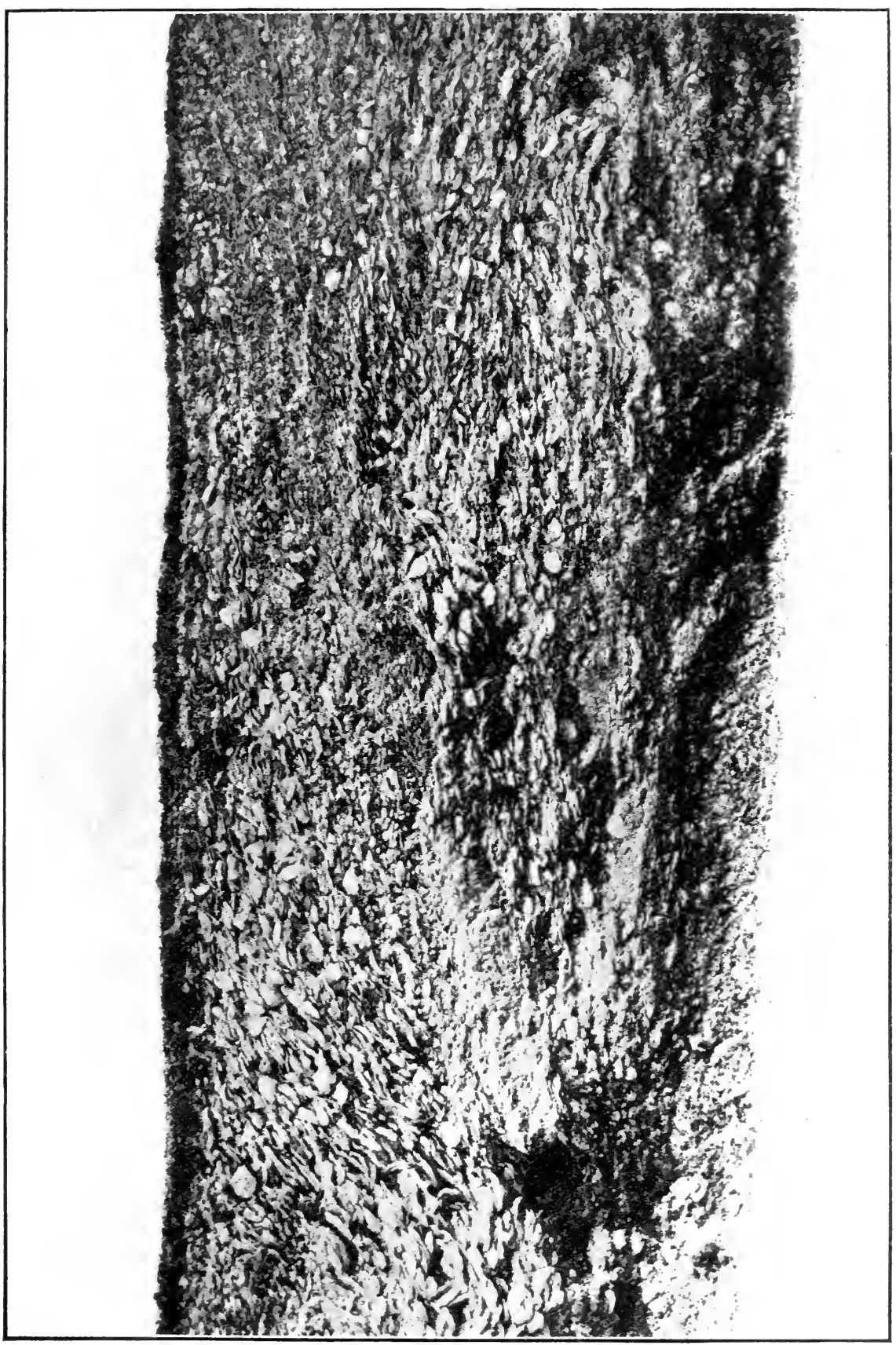

苟 
"Shell-heaps" would in an English setting be a better name for them, and would be a more accurate description; and it is preferred by most Danish archaeologists, who call these remains affaldsdynger (refuse-heaps) or skaldynger (shell-heaps). The popularisation of the

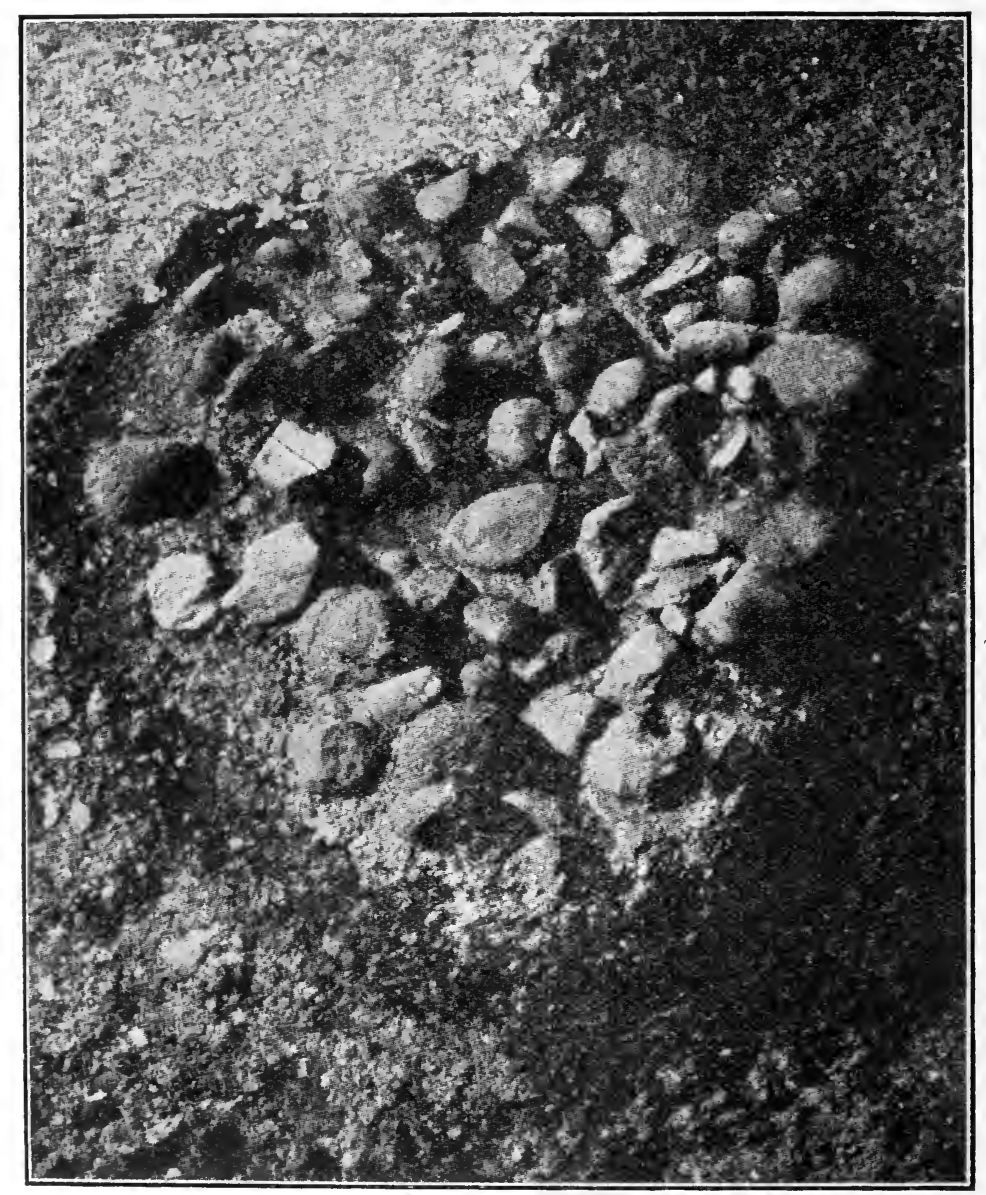

Fig. I76. Hearth found in the shell-heap of Ertebølle.

(From Madsen, Affaldsdynger.)

former name (in the form kjökkenmöddings with the plural in $s$, and sometimes without the marks of modification in the $o$ 's), is probably due to Lubbock's Prehistoric Times, which first introduced these remarkable remains to English readers ${ }^{1}$.

${ }^{1}$ It is fortunate that this book has not taught people its practice of speaking of "löess," or of calling one of the most eminent of French archaeologists "M. Delechette"! 
The Danish shell-heaps are piles of oyster and other shells, along with broken bones of animals and of fish, mingled with flint flakes and tools, horn axes, some bone combs, and coarse sherds of pottery. In the heaps are also buried the remains of hearths, consisting of stones covered with bones and charcoal. No polished stone objects have been found in any of the older piles, a fact which proves their early date; on the other hand the presence of pottery as well as the absence of extinct species of animals forbids our assigning them to the Palaeolithic. The Campignian chisel axe and pick are common tools and indicate the true relationship of these remains.

These shell-heaps are found chiefly on the shores of the Limfjord and the Kattegat. None have been found on the North Sea coast, for the simple reason that they have all been washed away, the sea having made great encroachments on the western shores of Denmark. They were formerly rather nearer the edge of the sea than they are now, the elevation of the land having increased since their formation. Certain examples belong to later times, when the ordinary domestic animals had been tamed.

The width of these mounds or banks ranges from 45 to 60 mètres, and their length is sometimes as much as $25^{\circ-}-300$ mètres. There are often hollows or depressions in the top, which are supposed to indicate the positions of huts or of tents standing in the middle of the accumulation of the remains of feasts. A thin layer of earth has accumulated over the surface of the mounds in most cases, but underneath, as Lubbock says, the mass consists exclusively of shells, bones, and artefacts of one kind or another. Only one of the Danish heaps is not on the sea-coast: but this exception is apparent rather than real. It is at Fannerup, which; although now some ten miles from the sea, lies on the shore of what was once a long inlet, from which the sea has receded. There may have been inland stations which have been destroyed, by being dug away for fertilising purposes; but the inhabitants of Denmark of the Campignian stage seem to have depended so completely for their sustenance on the produce of the sea that they are hardly likely to have settled far away from its shores.

Besides the flint axes, and the shells and bones, other objects have come to light in these mounds. Such are combs of bone, with short handles and long teeth, ranging from about $6 \mathrm{~cm}$. to about $10 \mathrm{~cm}$. in length; needles, pins, and bodkins, made of pointed bone; as well as pottery, which is always of the roughest possible description, and is scarce and fragmentary.

Towards the close of the last century a number of these shellheaps were examined by a commission nominated by the Danish 
government, the final memoir being published in $1900^{1}$. The chief deductions from the investigation may be briefly stated. The shellheaps represent the huts of a 'long-shore population, living a poverty-

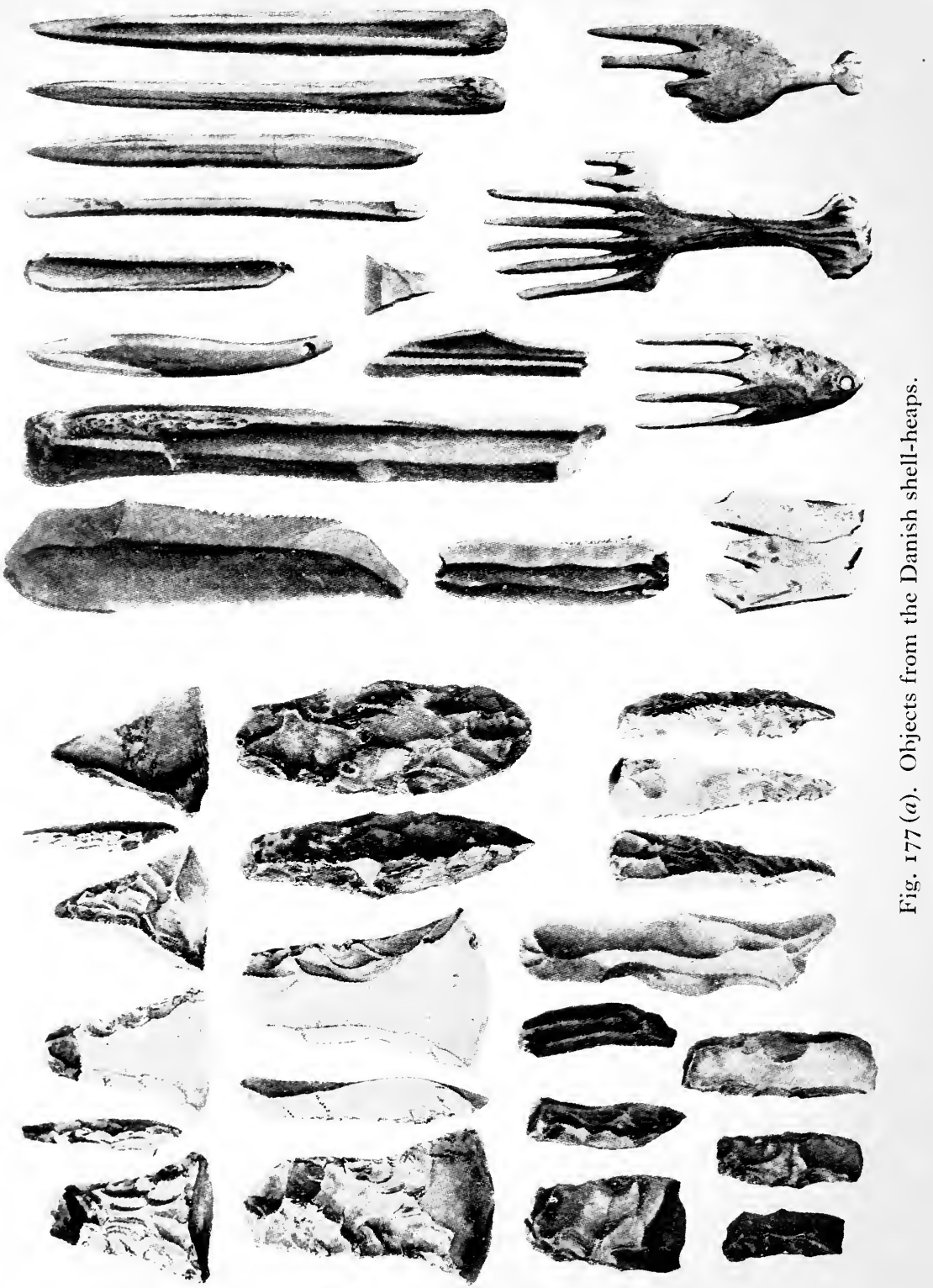

1 A. P. Madsen, Sophus Mïller and others, Affaldsdynger fra Stenaldere $i$ Danmark (Copenhagen, igoo). 

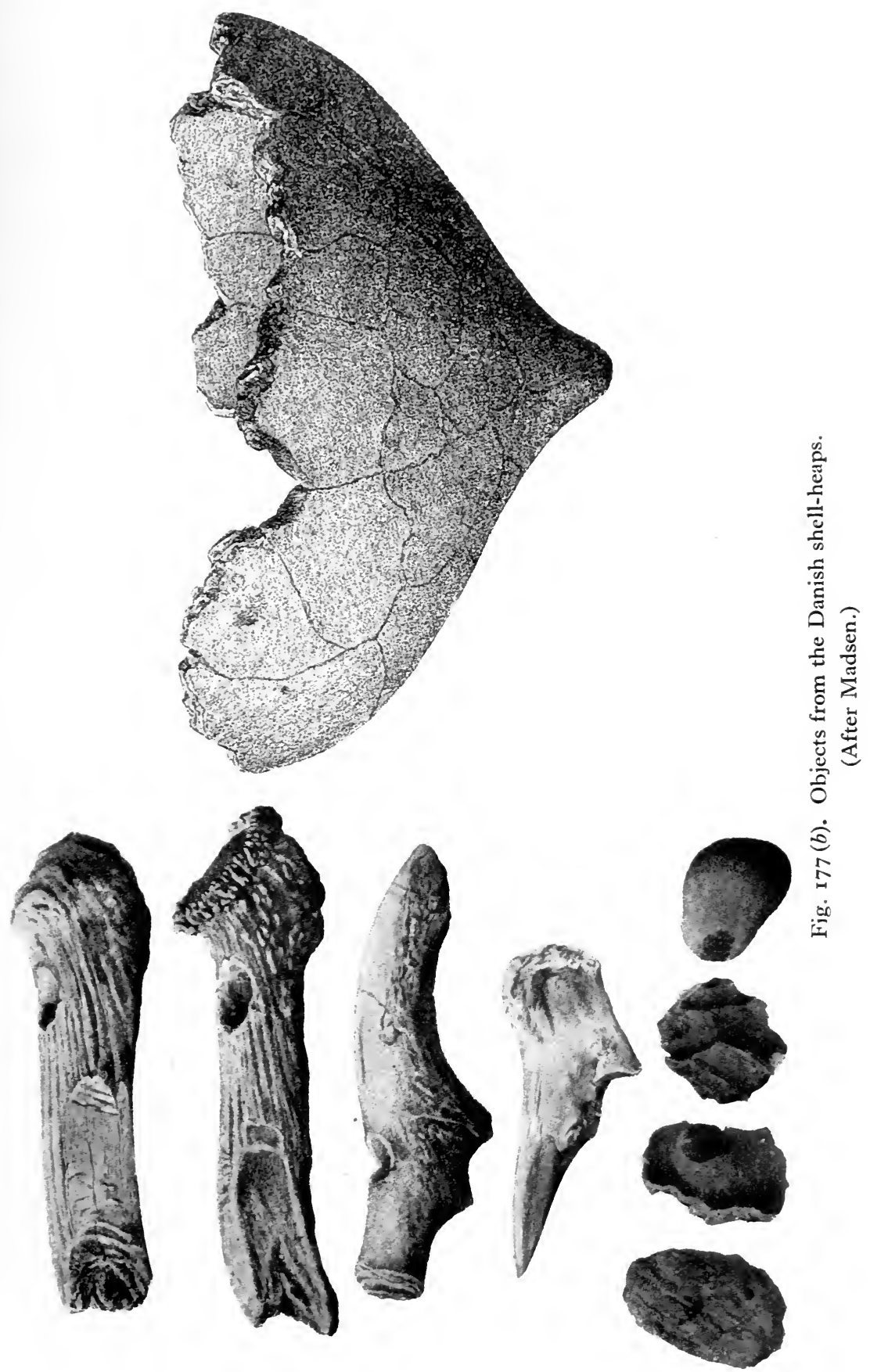
stricken existence, and depending for their living chiefly on fishing. They also trapped animals; and the bones and shells, with the broken pottery, were thrown out and formed heaps which gradually increased in size. The chief birds and land animals which they used were the swan, duck, gull, boar, roebuck, and deer. The reindeer was entirely absent. The general ensemble of the fauna shewed that the climate was appreciably warmer than in modern times.

The presence of the swan was a fact of great importance. For it definitely settled the question of the shell-heaps representing a stage in the development of culture. It would otherwise have been quite possible and legitimate to hold that the heaps had been piled by summer migrants, who lived inland during the winter, but sought the sea as modern civilised people do, for a summer variety, where for a while they lived a "simple life." But the swan is a winter bird in Denmark, and therefore those who used it as food on the seacoast of that country must have done so during the winter months. Moreover, the bones of animals were found at all stages of development, even of those which reach certain stages only at certain seasons of the year.

The fact that the bones of deep-sea fishes were found in the shellheaps proves that the shore-dwellers were capable of venturing in some kind of boat out on the sea for the purpose of capturing them.

The softer bones of some of the animals were gnawed, and many parts of them were regularly missing. The director of the exploration very neatly proved that this was the result of the attentions of dogs, by giving similar bones to modern dogs, which left them in precisely the same condition as their Campignian ancestors had left the bones which their masters had thrown to them. This proved the important fact that the dog had become attached to the home of man at the time when the shell-heaps were being formed: but the dog was the only domestic animal of which the shell-heaps afforded any evidence.

\section{Maglemose}

The Shell-heap culture is a late phase of a stage of civilisation, whose earlier phases are only beginning to be discovered. The shoreline on which the shell-heaps lie, the fauna, the large size of the oysters and other molluscs in the heaps, the presence of oysters, testifying to a greater saltness of the Baltic, and therefore to a more open connexion between that sea and the ocean than exists under present conditions, all indicate that the shell-heaps belong to the Littorina period. But an older culture, with fauna linking it to the time of the Ancylus Lake, meets us at Mallerup, in the island of 
Seeland. Close to this village there is a large peat-moss called Maglemose, in which a very remarkable lake-dwelling was found early in the present century ${ }^{1}$.

The stratification of the site is given thus by Dr Sernander ${ }^{2}$ :

Vegetable soil.

Peat, $35 \mathrm{~cm}$.

Pine trunks.

Peat, $35 \mathrm{~cm}$.

Trunks of birch and other leaf-bearing trees.

$\left.\begin{array}{l}\text { Peat, } 35 \mathrm{~cm} \text {. } \\ \text { Brown mud, ro cm. }\end{array}\right\}$ the archaeological beds.

Alluvium with molluscs, $20 \mathrm{~cm}$.

Peat, $80 \mathrm{~cm}$.

Glacial fresh-water alluvium, $10 \mathrm{~cm}$.

Moraine.

There are botanical differences in the composition of the different layers of peat, which have climatological importance, but need not be specified here.

The human settlement must have begun when the site was occupied by a large lake, and continued during its conversion to a peat moss. The dimensions of the occupied area were 35 mètres north to south, 30 mètres east to west. Another site, of similar character but of smaller size, was found in the same Moss, at some distance away.

There are no traces of buildings associated with the remains. It was certainly not one of the two ordinary types of lake-dwelling; neither a village built on a natural or artificial island, for there is no such island; nor a structure of piles, for there is no trace of the feet of piles, though a considerable quantity of wood has otherwise been preserved by the peat. Even if piles had decayed away, the holes in which they had been set would here have been traceable: for they would have penetrated into the light-coloured bed of alluvium with molluscs, which underlies the archaeological strata; and these holes, filled with the darker-coloured matter from the stratum next above, would have been conspicuous. As there is no trace of anything of the kind, we must conclude that there were no piles.

1 G. F. L. Sarauw, "En Stenalders Boplads i Maglemose ved Mallerup" (Aarbфger for nordisk Oldkyndighed og Historie, ser. II. vol. XviII. [1903], p. 148). A German translation of the first part of this monograph, with numerous additions, appears in Prähistorische Zeitschrift, III. [1911], p. 52; the second half did not appear before the war, and (if it has been published since) has not yet come into my hands.

2 "Om Ancylustidens Människa och Tallperioden i södra Skandinavien” (Geologiska Förening $i$ Stockholm Förhandlingar, xxx. [1908], p. 390), cited in the German translation quoted in the previous footnote. 
An occupation of the surface of an ice-covered lake, apart from its improbability, is not to be thought of; for just as animals in their winter state were found in the Danish shell-heaps, so young animals in their summer condition were found at Maglemose. There is no theory that will fit the facts except one; namely that the inhabitants dwelt on a floating raft. The timbers of such a raft could hardly survive decay. They would rot when stranded on the surface of the peat. In the lake-dwellings of the ordinary pile type, the platforms of the pile-structures are rarely preserved; only the feet of the piles themselves, stuck in the peat, resist corrosion.
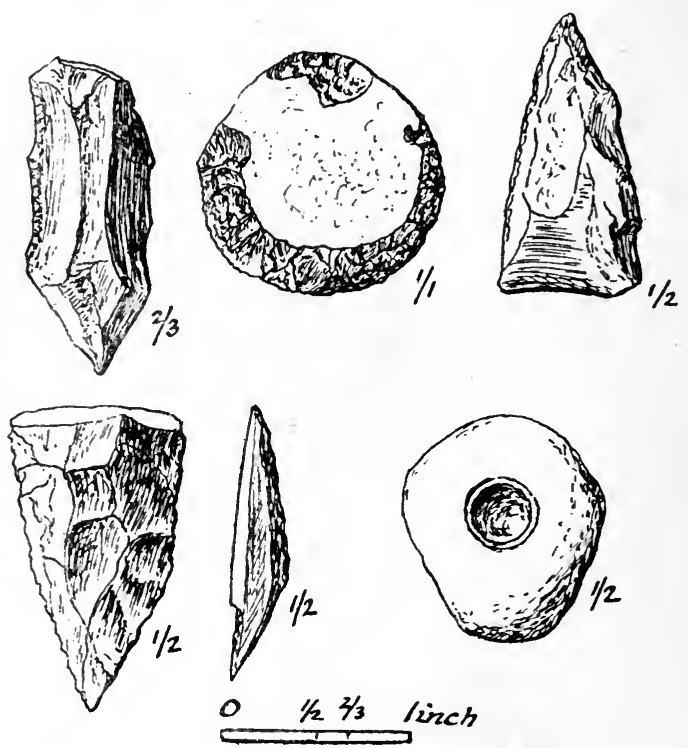

Fig. 178. Stone objects from Maglemose.

(From Aarbфger for nordisk Oldkyndighed, 1903.)

The only human remains found at Maglemose were the femur and a finger-joint of an adult, and the lower jaw of a child. The ends of the femur were broken off, and the remaining part had suffered injury - cuts and scratches-how and when inflicted there was no evidence to shew. The only domestic animal was the dog. The fauna included elk, stag, boar; the reindeer was missing.

The objects found at Maglemose consisted entirely of stone, bone and horn. There was no pottery. The stone implements included flint flakes, scrapers, Campignian chisel axes (rare; only two were found) and a few small points having more affinity to Tardenoisian pygmy flints than to any other forms. A lump of pyrites may have 
been used as a strike-a-light, and a block of grey sandstone with a circular depression on each face is explained as a hammer-stone.

In bone and horn there was a variety of interesting objects, such as axes and hammers of horn, perforated for receiving the wooden handie; chisels, made by cutting an oblique bevel at one end of rods
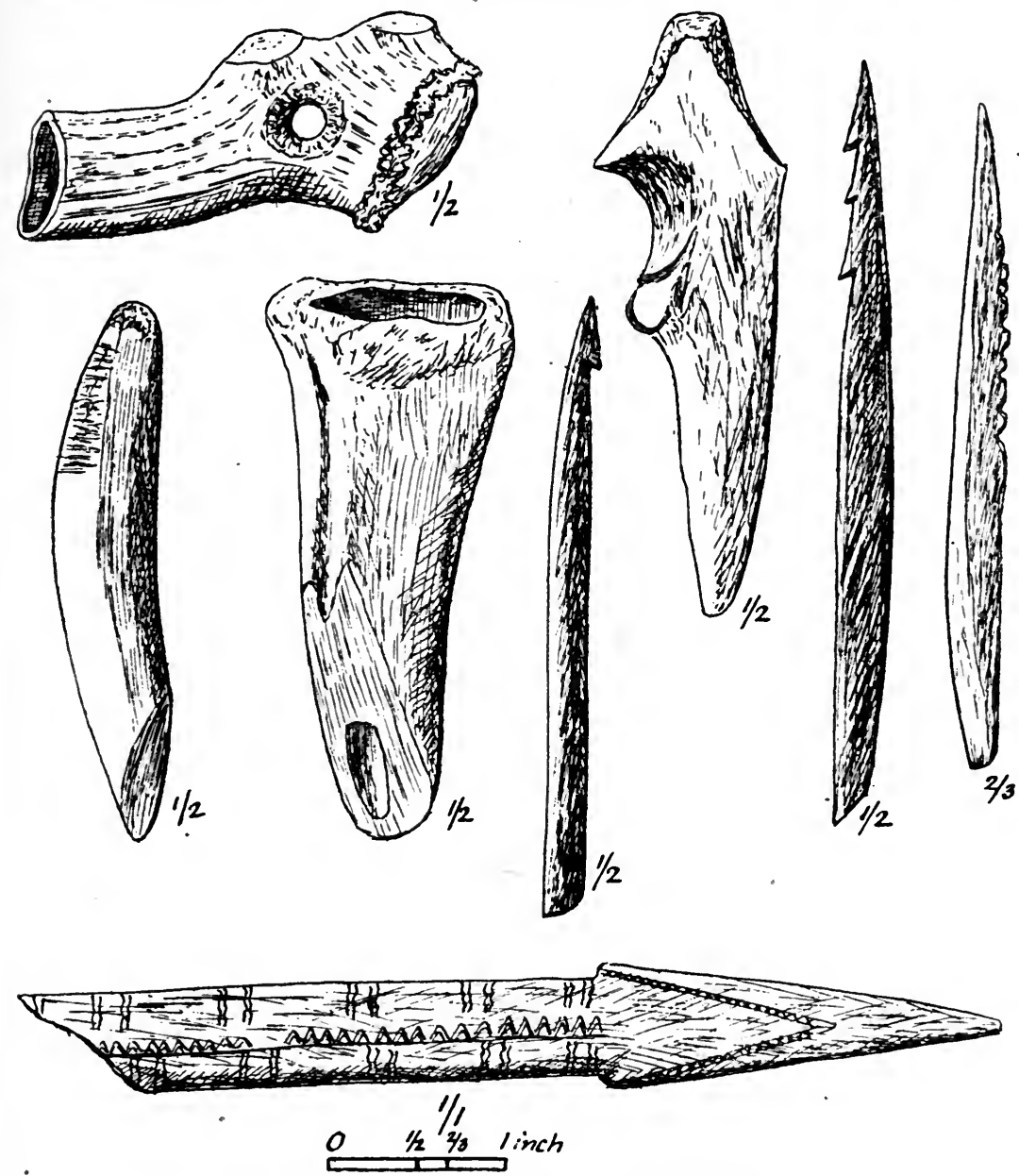

Fig. 179. Bone and horn objects from Maglemose.

(From Aarbфger for nordisk Oldkyndighed, 1903.)

of one or other of these materials; knives, polishers, daggers, boartusk knives, and harpoons of various forms, made of rib-bones with teeth notched in one side. A spear-like weapon of bone was ornamented with zigzag lines. Fishing-hooks of bone and horn, and curved instruments explained as netting-needles (for weaving fishingnets) likewise came to light. 


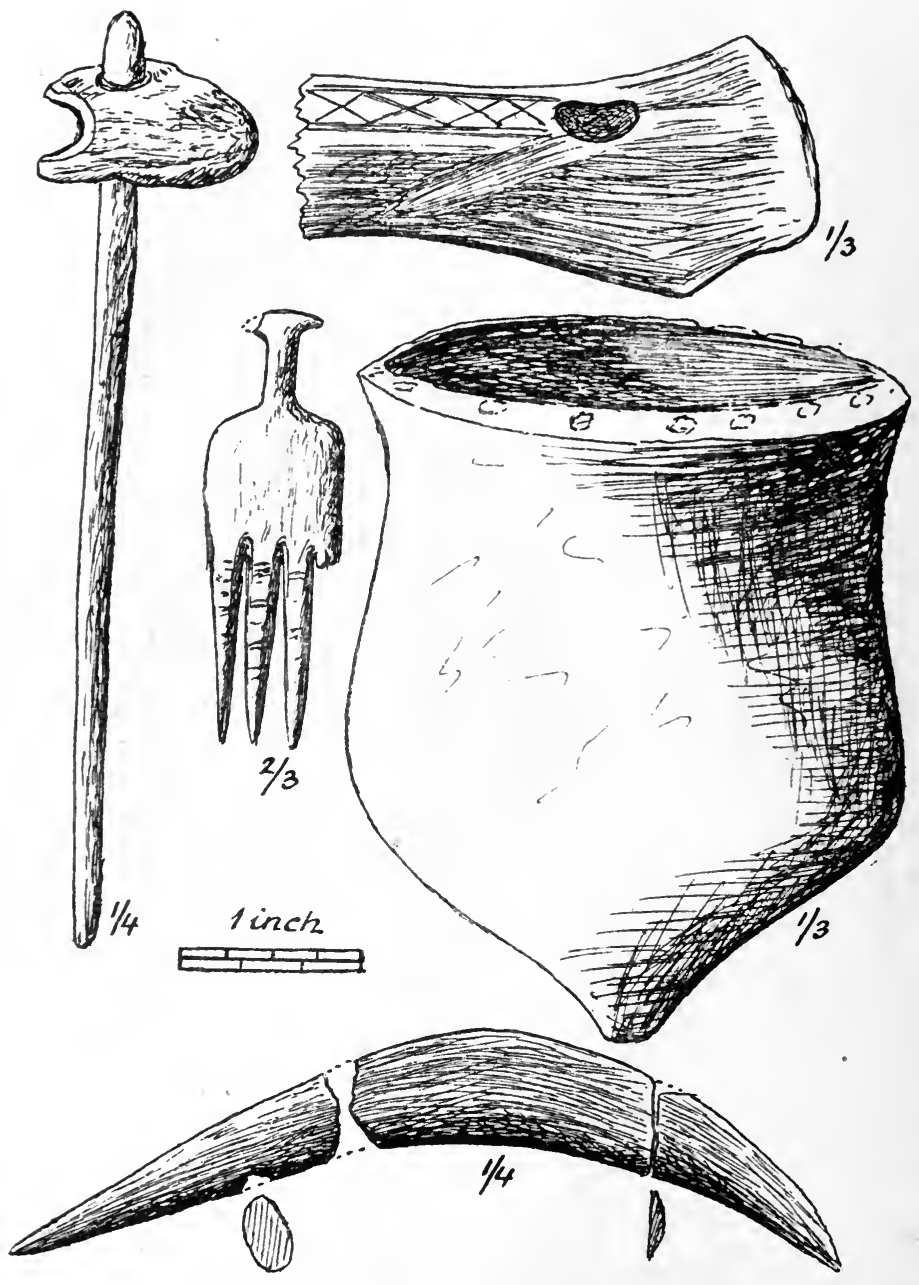

Fig. I80. Objects from Viby.

(From Aarbøger for nordisk Oldkyndighed, 1906.) 
Viby

Some time between the Maglemose period and that of the shellheaps-between full Ancylus and full Littorina-may perhaps be dated the settlement found in estuarine mud at Viby, near Aarhus, a year or two after the discovery at Maglemose ${ }^{1}$. The flints found here included chisel-axes, scrapers, and flakes in several varieties: other objects were horn axes, like those at Maglemose - of these, one was ornamented crudely with a simple linear pattern; another retained its wooden handle, and was also interesting as it had evidently broken at its perforation, and been re-perforated to serve as an adze: daggers, combs, knives of boar-tusks, as well as pottery. But by far the most interesting objects from Viby were the end of a wooden bow, and a series of boomerangs in the same material. This seems to be the first tangible evidence of the early use of the boomerang in Europe. The culture at Viby evidently lies on an evolutionary stage between that at Maglemose and that of the Shell-heaps.

\section{Campignian in Norway and Sweden}

Crossing into Norway and Sweden, we find there early traces of the same culture-group. At the Soldattorp near Limhamn, S.W. Sweden, on the strand called Järavallen, were found the remains of a very early Stone Age settlement ${ }^{2}$. Among an enormous accumulation of flints there appeared Campignian chisel-axes and picks, the former of a very rude and primitive kind, and clearly belonging to an early stage of the development of this type of tool. Associated with these objects were specimens of rude pottery, resembling that found in the Shell-heaps.

The Campignian chisel-axe has also been found in several sites in Norway ${ }^{3}$.

But most important for the early history of the Campignian culture is the site of Nostvet on the Kristiania fjord, about ${ }_{15}$ kilomètres south of the capital. It must be remembered, in appreciating the significance of this site, that Norway is very poor in flint, and indeed, there is reason to believe that all the flint used for making implements was imported from Denmark. The ancient inhabitants

1 Thoman Thomsen and A. Jessen, "Brabrand-fundet fra den ældre Stenaldre" (Aarbpger for nordisk Oldkyndighed og Historie, ser. II. vol. XXI. [1905], p. I).

2 Knut Kjellmark, "Ofversikt af Sveriges Stenåldersboplatser" (Y'mer, xxıv. [1904] p. 187).

3 An enumeration of these will be found in W. C. Brøgger, "Strandliniens Beliggenhed under Stenalderen" (Norges geologiske Undersфgelse, No. 4I, Kristiania, 1905, pp. 52-61). 

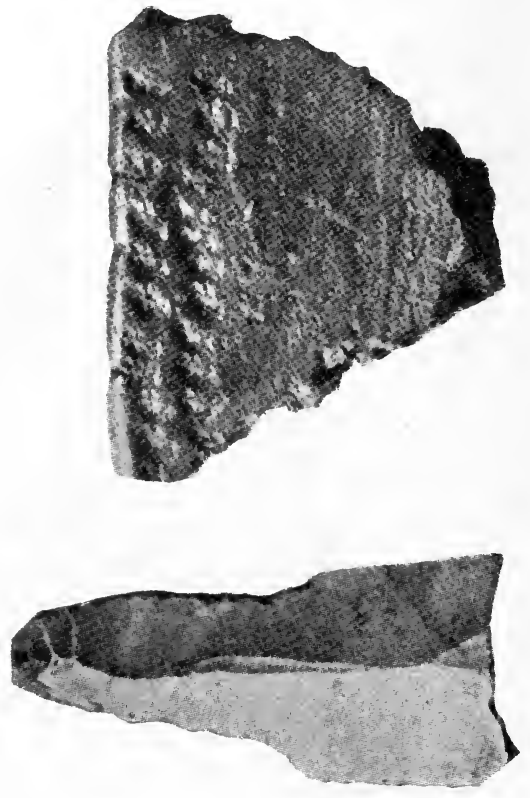

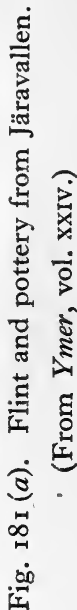
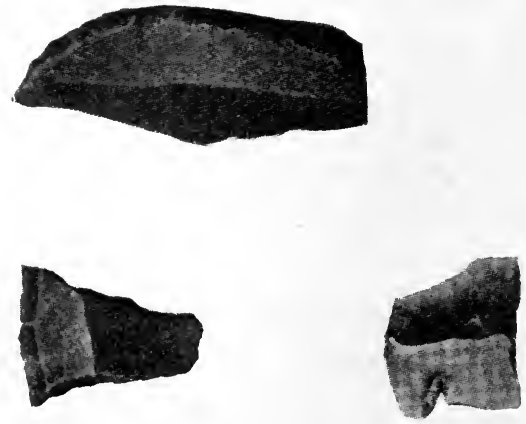


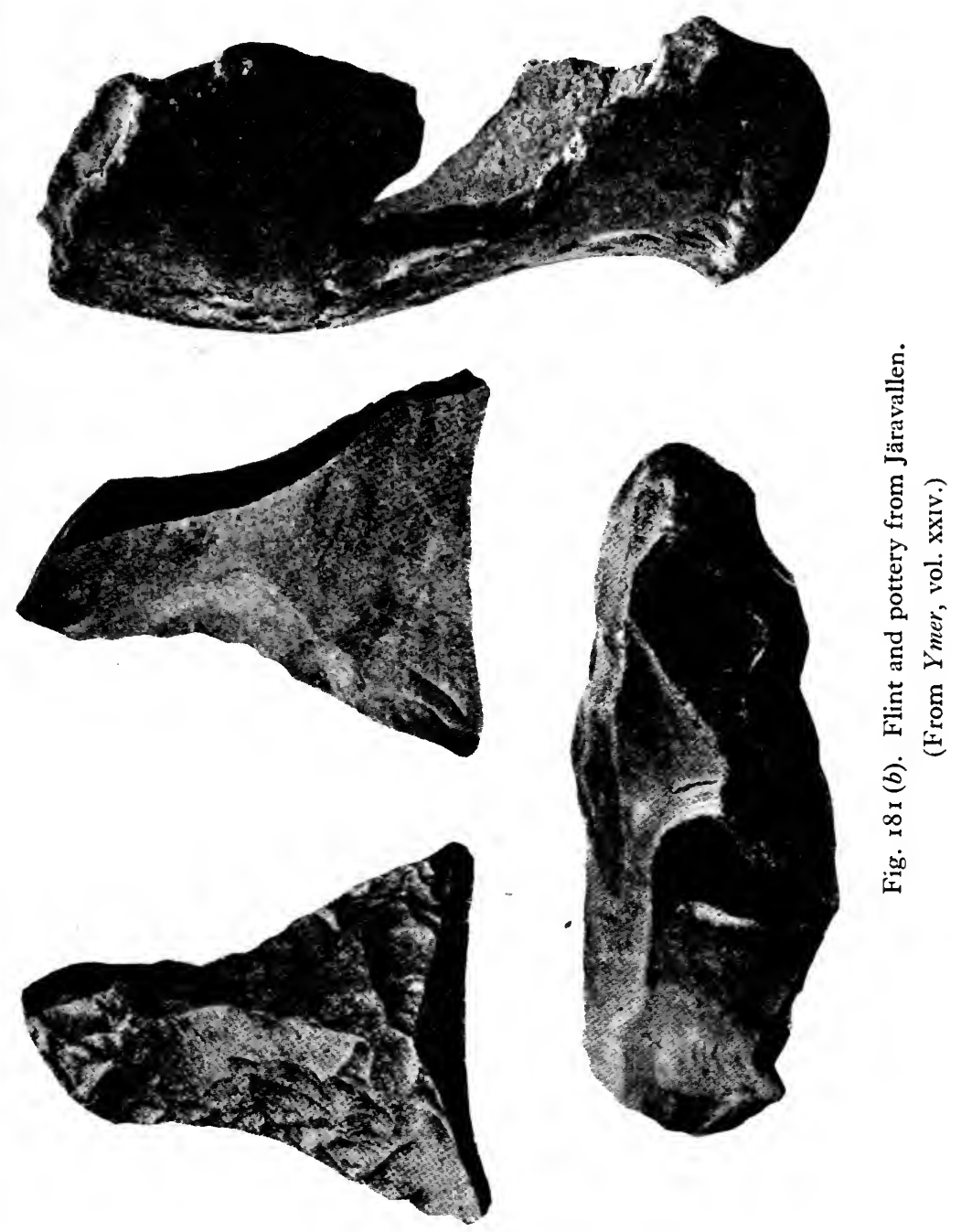

had as a rule to make shift with other stones, and they used hard igneous rocks of different varieties. Of such materials were made the large picks of Campignian facies found at the site named. These are just such implements as would be produced by workers in stone deprived of flint, and obliged to manufacture axe-heads of this unsatisfactory material; and it is highly probable that in such makeshift tools we are to see the inception of the Campignian pick ${ }^{\mathbf{1}}$.

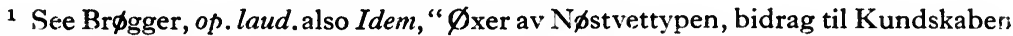
omı ældre norsk stenalder" (Norges geol. Undersфg. No. 42). 
$[\mathrm{CH}$.

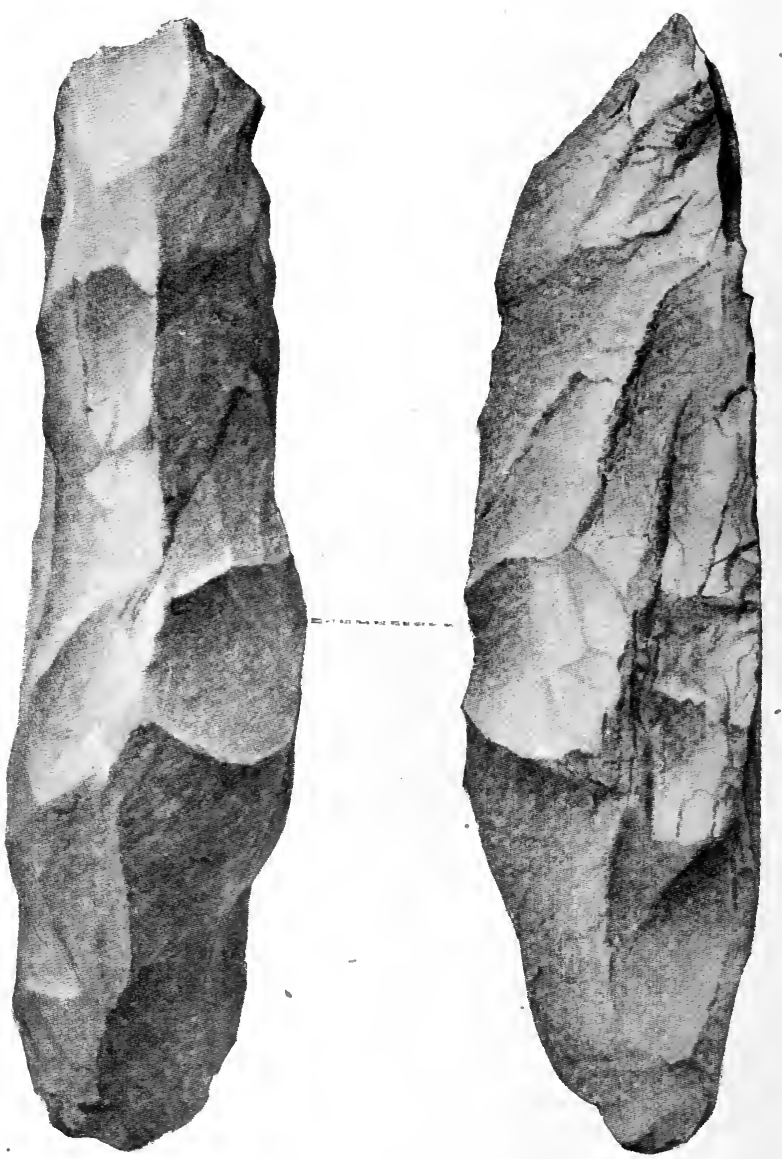

Fig. 182. Nфstvet axes.

(From Brфgger, Strandliniens Beliggenhed.)

\section{Origin of Campignian Culture}

These Scandinavian sites, in fact, appear to lead us back to the beginning of the Campignian culture, and they suggest that the south of the Baltic basin was the centre of its distribution. The region was settled by a colony, at some time before the Ancylus Maximum, when southern Scandinavia was accessible from the mainland of Europe by a land-bridge running northward from Jutland. They there developed the Campignian pick (at N $\phi$ stvet or some allied site) and the chisel axe, which we see incipient at Järavallen. The Maglemose and Viby sites represent later stages, leading on to the local culmination of the Campignian culture in the Shell- 
heaps. The Campignian culture was probably taken up and carried westward by the invading Asiatics; and by different channels it reached Italy in the south and Ireland in the north.

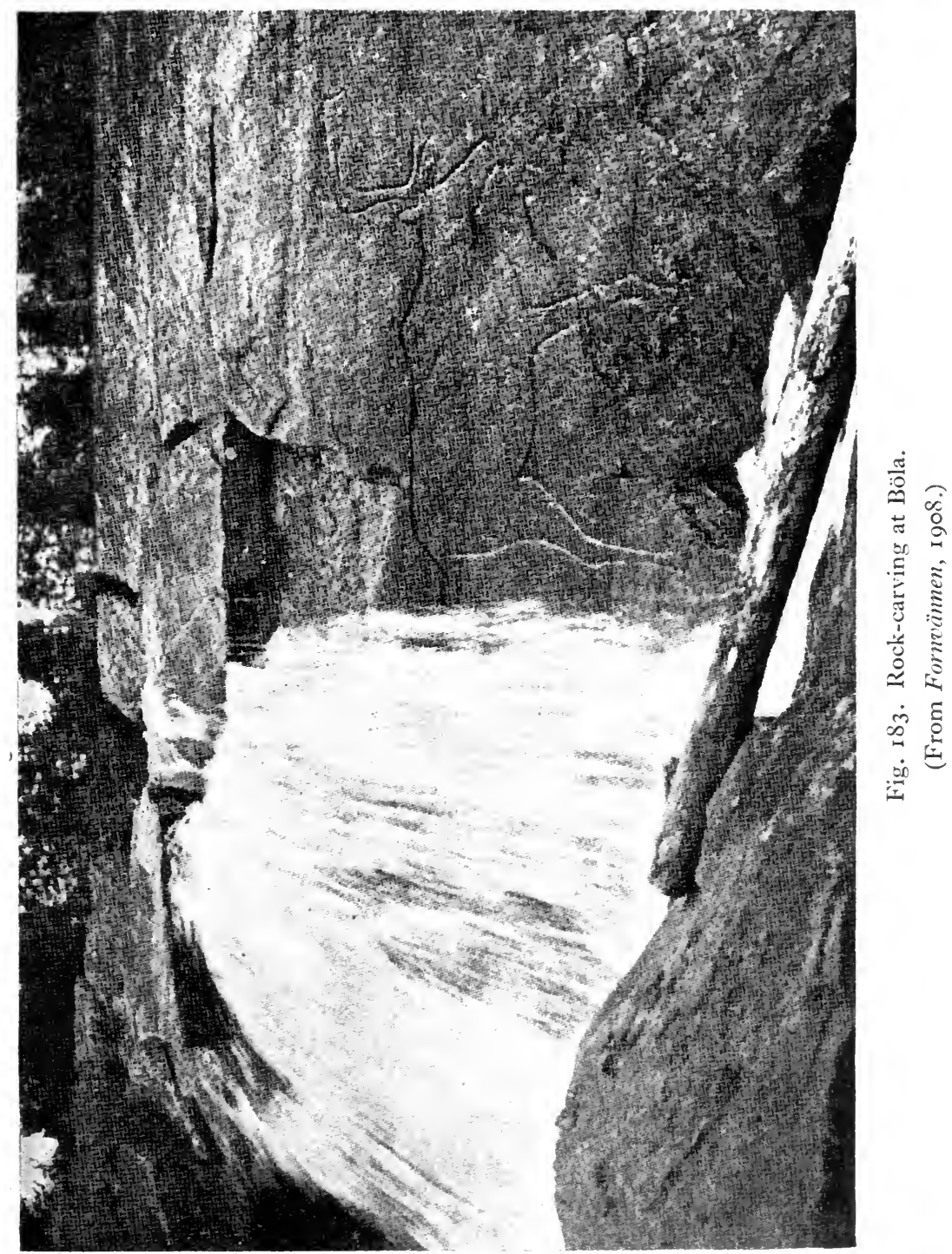

Whence came the colony which we suppose thus to have developed the Campignian culture, and so inaugurated the Neolithic of Europe? In seeking to answer this question we are in a difficulty, owing to 
the extreme scantiness of the osteological material. One or two human skeletons were found in the excavation of the Shell-heaps; I can find no particulars as to their physical character. Nor have I found any description of the skeleton found in a midden at Viste, near Stavanger, which appears to be contemporary with the Danish Shell-heaps ${ }^{1}$. Kossinna ${ }^{2}$, recalling that all the German protoNeolithic skulls are round, infers that the Ancylus people of the Baltic were also brachycephalic, though admittedly with very little tangible evidence to support him. But whatever may have been the physical origin of the colony, there can be no question of what its cultural origin was. The harpoons, the Tardenoisian flints at Maglemose, link it with the Azilian civilisation.

\section{Magdalenian Art in Norway}

And it has roots going back yet further. For although in the sites which we have described in the foregoing paragraphs there is no evidence for any special appreciation of Art, there are elsewhere clear traces of an Art-tradition. Norway and Sweden are well known for their Bronze Age rock-scribings, representing ships and other devices. But there are a number of older scribings, representing different subjects, and displaying a different technique. Especially are these older sculptures found round about the fjord of Trondhjem. There are here a number of rock-scribings which unmistakably carry on the Magdalenian tradition. At Hell, near Trondhjem; at Bardal near Stenkjar; and at Böla on the lake called the Snaasen-vand, there are representations of reindeer which might have come out of the Pyrenean caves. The last-named, which is picturesquely situated beside a waterfall, is illustrated here ${ }^{3}$.

${ }^{1}$ A. W. Br’pgger, "En kjökkenmödding fra ældre Stenalder i Norge" (Ymer, xxviII. [1908], p. I22).

2 G. Kossinna, "Der (Trsprung der Urfinnen und der Urindogermanen und ihre Ausbreitung nach dem Osten" (Mannus, I. [1901], p. I7 ff. esp. p. 34).

3 For these and other carvings see G. Hallström, "Nordskandinaviska Hällristningar" (Fornvännen [1907], p. I60; [1908], p. 49); Idem, "Hällristningar i norra Skandinavien" (Ymer, xxvir. [1907], p. 2II). 


\section{CHAPTER XI}

\section{THE PALAEOLITHIC PERIOD AS A WHOLE}

\section{Retrospect}

WE have now reached the threshold of the modern world, and we may pause at this convenient halting-place to take a backward glance over the ground which we have traversed.

We have considered, as it were piecemeal, the remains which the Palaeolithic period has left us. We have now to see whether the fragments are sufficiently coherent to be fitted together into a single picture, like the tesserae of a mosaic pavement.

\section{The Beginning of Human Life in Europe}

The beginning of the human history of our Continent is hidden in a mist impenetrable. We know not what startling and revolutionary discoveries the future may hold in store for us; but in the meanwhile we are constrained to say that the researches carried out, up to the present, have given us no reason to believe that Man is autochthonous in Europe. He attained to Manhood elsewhere, and entered Europe after reaching his full development. If any of the readers of this book do not share the hesitancy expressed in its pages regarding eoliths, and other supposed evidences for Tertiary man or fore-man, they are entitled to maintain their opinions. The author can only reiterate his conviction, formed after reading a fairly large proportion of the extensive literature on the subject, and after examining a goodly number of actual specimens of eoliths, that a European Homosimius is still unknown. The Mauer jaw and the enigmatical Piltdown fragments are those of beings already human, and are not convincing proofs of a European origin for humanity.

\section{The Origin of the European People}

But if man entered the Continent from elsewhere, when and whence did he come? The first query can for the moment be answered in general terms. There is no evidence for Tertiary man in the Continent; this gives us a major limit of date. There is plenty of evidence for late Glacial man in the Continent; this gives us a minor limit. Therefore man arrived in the course of some early phase, probably an interglaciation, of the Ice Age. 
The second query cannot be answered, even vaguely: it is more than likely that it will never be possible to answer it. A Pithecanthropus has been found in Java; but who can say in what other corners of the world similar remains may not be buried, awaiting the spade of an explorer? It may be the merest chance that Java, has witnessed the first discovery of the kind: and in any case, the relation of the Java remains to Homo is still disputed.

\section{The Australian Theory}

Dr Schötensack, in an extremely interesting paper $^{1}$, has marshalled arguments in favour of Australia as having been the scene of the first development of humanity, and the centre of the dispersion of the human species. The theory is a sort of converse of that maintained by Prof. Sollas in his book Ancient Hunters, to the effect that the modern Australian aborigines are in some way the representatives of the Palaeolithic hunters of Europe.

The heads of Prof. Schötensack's arguments are as follows:

I. Australia was connected with the mass of Asia by means of landbridges running through the West India Islands at different times during the Tertiary period. A "Pithecanthropoid" group of Primates could therefore find their way to Australia overland.

2. The only mammalian animals native to Australia are the dingo and the marsupials. The latter are stupid and easily subdued. Much larger species of marsupials lived in Australia during the Tertiary period than at present, so that the slaughter of such creatures, which was not a matter of difficulty, afforded an abundant supply of flesh-meat, and so helped to develop the carnivorous tendencies which distinguish Man among the Primates.

3. The special physical and mental characteristics of Man, more particularly the adoption of the erect posture, could not have developed in a forest-land, with its arboreal life and savage animals. But the wide open spaces of Australia were well adapted to be the scene of such a development.

4. The modern Australians are difficult to place in the stem of human races; they seem to have certain characters in common with some of the races of the Old World, and certain other characters in common with others, widely separated. This suggests that they may represent a common parent race, of whom certain characters were transmitted to one group of descendants, others to another.

1 5. Culturally the Australians recall the Palaeolithic Europeans. The stone implements by means of which they cut steps in tree-trunks, to facilitate ascent, resemble Lower Palaeolithic coups-de-poing; they possess propulsors and boomerangs; and they tame the dingo, so far as that animal is capable of domestication. On the other hand they do not possess bows and arrows.

${ }^{1}$ Otto Schötensack, "Die Bedeutung Australiens für die Heranbildung des Menschen aus einer niederen Form" (Z.f.E. xxxIII. [1901], p. 127). 
6. Circumcision and analogous painful operations, practised over a large part of the world, are more likely to have spread from one centre than to have developed independently in several centres. These operations are much in use among the Australians, and some Magdalenian engravings afford evidence for their use in Palaeolithic Europe.

7. The Tasmanians, who did not possess the propulsor or the boomerang, represent an earlier stage in the development of humanity, these people having become isolated from their brethren by the formation of Bass Strait.

8. The frequent lightning-flashes of Australia, and the consequent bush fires, would cook naturally the flesh of animals caught in the conflagrations, and would thus teach the utility of fire.

These arguments are impressive, on which account we have thought them worth setting forth at length; but they are not wholly satisfactory. One serious objection lies in their ignoring of the stratification of culture in Europe. We are told that certain stone implements resemble coups-de-poing, while certain other instruments, such as the propulsor and the boomerang, are common to Australia and to Europe. Passing over the doubt as to the European use of the boomerang in Upper Palaeolithic times, we must notice that these latter objects belong to an entirely different horizon of culture, and to people presenting entirely different racial features, from the corresponding associates of the coups-de-poing: so that if Australia be the common centre of origin for all these instruments of culture, there must have been a succession of immigrations from that region. Geologically this is unlikely, for the land-bridges probably broke down before the Upper Palaeolithic Stage began in Europe; and ethnologically it is impossible, for the men of the Lower Palaeolithic and of the Upper Palaeolithic are quite incompatible racially, and must have entered Europe from a different centre of dispersion. Moreover, no evidence for Tertiary Man has come to light in Australia any more than elsewhere. No importance can be attached to the alleged footmarks in sandstone at Warnambool ${ }^{1}$.

\section{The Lower Palaeolithic Communities and their Relation to the Ice Age}

In reconstructing the remote pre-history of Europe, we do not begin to find ground under our feet till we reach the Chellean communities. But when these appear on the scene the beginnings are well over, and fully organised human societies, probably small in actual numbers, but wide-spread in area of distribution, are

1 W. Branco, "Ueber die fraglichen fossilen menschlichen Fussspuren im Sandsteine von Warnambool, Victoria, und andere angebliche Spuren des fossilen Menschen in Australien" (Z.f.E. XxxviI. [1905], p. 162). 
scattered over the Continent. This people has already made considerable progress in the art of flint-chipping; and perhaps in other arts as well, which in the nature of things would not leave us any tangible traces. We can picture them gradually improving themselves in these industries, preparing hides for clothing, carrying on a ceaseless warfare with the formidable beasts among which they found themselves, and developing a religion of a sort, which looked forward to a life beyond the grave.

The Chellean stage in Europe was distinguished by fauna of a tropical or sub-tropical character. The climate must therefore have been appreciably more genial than that of modern times. It follows that Chellean man lived at the maximum of an interglaciation. Which one of the series of interglaciations recognised and named by geologists we cannot at the moment discuss; let us call it temporarily the Chellean Interglaciation.

The imposing phenomena of river erosion, which we have already briefly described in speaking of the remains of the Thames and the Somme valleys; the remarkable changes that have taken place in the basin of the river Lark; the great thickness of stalagmite which separates the Chellean from the Magdalenian deposits in Kent's Cavern; the general ensemble of geological evidence-all these indicate an antiquity which even if its length could be expressed in numbers of years or of centuries would be beyond our limited powers of comprehension. Evolution, like a railway-train leaving a station, moves at first slowly - almost imperceptibly - and gains momentum as it advances. The first steps are the slowest and the most painful; and the advance in culture which we can follow through the Lower and the Middle Palaeolithic Terms, moderate though it be, required many thousands of years for its accomplishment.

As the Chellean Stage passes into the Acheulean, and this in its turn into the Mousterian, we become conscious of a deterioration in the climate. We are ascending the icy slope of an oncoming glaciation, the summit of which is reached with the full Mousterian. As before, we may temporarily name this the Mousterian Glaciation.

\section{Palaeolithic Man outside Europe}

So far, except for our preliminary glance round the world for a possible place of origin for European Man, we have ignored the neighbouring continents. But there were men there also, though as yet practically nothing is known about them. Their existence is proved by implements which have come to light both in Asia and in Africa, and which are strikingly analogous to the European types. Nothing has as yet been reported from America that has stood the 
test of criticism; and with the possible exception of a skull from Talgai in Queensland ${ }^{1}$, nothing is known about possible contemporaries of our most ancient Europeans in the islands of the Southern Seas. But we have seen as in a flash traces that make us think of a tribe of short-headed invaders from Central Asia, in the cave of Krapina-the only short-headed Palaeolithic people as yet found in Europe. Of Palaeolithic human remains in Asia we know nothing; the Java Pithecanthropus hardly counts. From Africa only two skeletons or parts of skeletons have been reported. The first is an almost complete skeleton found at Oldoway, in what used to be German East Africa. This skeleton, to judge from photographs, is of Aurignacian type, not Mousterian ${ }^{2}$. A skull from Boskop, Transvaal, is not as yet satisfactorily published; the negative fact that it, also, is not Neandertaloid is all that is as yet known about $\mathrm{it}^{3}$.

At the time of which we are now speaking, the Europeans were not of necessity in the van of civilisation, as they are in modern times-at least, in the opinion of Europeans. There is, indeed, every reason to believe that if anything they were rather backward. The insignificance of the material at our disposal makes it impossible for us to say whether the Mousterian type of humanity was confined to Europe; but it would only be natural that the Europeans of the time, under the rigorous life of a glaciation, would be less highly developed than their contemporaries who lived under more genial conditions. Somewhere in the world there were such contemporaries, who had made much greater advances in material culture, and who were awaiting the day when they were destined to sweep over Europe and to submerge its inhabitants.

\section{The Aurignacian Invaders}

Whether these intruders were the fruit of an entirely separate evolution, with an immediate pre-human ancestry different from that of the Mousterians; or whether they were an offshoot from the same cradle of the human race as that from which the Lower Palaeolithic

1 Nature, 9 September 1915, p. 53. But since the above was written a monograph on this skull has been published (S. A. Smith, "The fossil human skull found at Talgai, Queensland," Philosophical Transactions of the Royal Society, vol. $208 \mathrm{~B}$ [1918], p. 351). The conclusions there indicated are that the skull belonged to an immature boy of the Australian type, and had nothing in common with the Lower or Middle Palaeolithic people of Europe.

${ }^{2}$ L'Anthr. xxvi. [1915], p. 492.

3 L'Anthr. loc. laud. Small photographs will be found in Nature, 5 August 1915, p. 615, compared with the Neandertal skull. It hardly needs the trenchant criticisms contained in a later letter (ibid. 30 Sept. 1915, p. II 4) to emphasise the dissimilarity of the skulls, which is obvious even in the minute illustrations. Some further particulars, with a good illustration of the Boskop skull, will be found in Boule's Les hommes fossiles, a copy of which has reached me just in time to insert this note in the proof-sheets. 
men of Europe came, having developed differences in their different environment, during the long millennia of the Chellean interglaciation-these are questions which we have no means of answering. All that we can say is that they appear suddenly out of the Unknown at the beginning of the Aurignacian stage, and introduce the Upper Palaeolithic culture into Europe.

Why? Whence? When?-These are the three questions which press for solution when we consider the Aurignacian immigration. That it was actually an immigration and not a local development has been maintained in this book, for reasons already given. The theory is not altogether free from difficulties, which have been well stated by Dr Laloy, in the review of an essay by Giuffrida-Ruggeri ${ }^{1}$. The thesis there maintained was to the effect that "the first importers of civilisation into Europe were a band of Somalis, who immigrated in the interval of two interglacial periods." Laloy, commenting on this ${ }^{2}$, says :

Rude tribes do not change their habitation, simply because among them the population increases very slowly. Infant mortality, and that of male adults, are very high. A fortiori the same must have been true in the prehistoric periods, where man was still worse armed for the struggle than is the modern savage. Thus it is altogether improbable that the ancient Somalis were ever sufficiently numerous to be able to swarm into Europe; all the more in that great spaces of Africa, still very thinly peopled, were open before them. The problem of the populations of the earth is extremely complex, and its solution is not a matter of imagination or of sentiment.

With this we may agree, though with some reservations. The fact of a superposition of races at the time of the change from Mousterian to Aurignacian is a stubborn reality, and the theory of an immigration, to whatever cause it may have been due, is the only one that will account for it satisfactorily, however improbable it may appear to be on the quite legitimate grounds stated by Dr Laloy. And again, are we entitled to assume that at the time of which we are speaking. Africa was necessarily "very thinly peopled"? We know practically nothing about the "pre-history" of that continent.

\section{The Probable African Origin and Affinities of the Aurignacians}

Indeed it is to Africa that we naturally look in seeking for a place of origin for the Upper Palaeolithic peoples. Most of the important Upper Palaeolithic remains come from the southern parts of Europe. The long heads of the Upper Palaeolithic people are suggestive of African analogies, and, on the other hand, of a contrast at least with

\footnotetext{
1 "Dal paleolitica al neolitica" (Rivista di scienze biologiche, vol. II.).

${ }^{2}$ L'Anthr. XI. [1900], p. 750.
} 
the Central Asiatics. Other African analogies are obvious; the feeling for art displayed by the Bushmen, which recalls the Upper Palaeolithic arts; the strange custom of finger-lopping, practised by the Bushmen, and testified to by the hands in the cave of Gargas. But the tall Aurignacians were not dwarfish Bushmen: we may not regard them as the ancestors or the descendants either of Bushmen or of negro tribes. The physical peculiarities of the statuettes of the Aurignacian caves resemble to some degree physical peculiarities of the Hottentots, as we have already noticed; but we have also warned the reader against laying too much stress on these coincidences, which may be due to other causes.

The relationship between the Aurignacians and the Bushmen, if these points of contact shew a true relationship, is cultural, not racial. A few negroes or negro half-castes find their way into Europe with the migration, and two skeletons of these people have been found in the cave of Mentone-if we may assume the truth of this disputed theory about these much-discussed remains.

Our knowledge of the early peopling of Asia and of Africa is practically nil, so that while there is endless room for theorising, there is as yet no adequate control for testing our theories. The best-argued hypothesis is necessarily shadowy and tentative. But it may be claimed that a central African source for the Aurignacian people is a working hypothesis which seems to fit the facts as at present known. The Aurignacians evidently entered Europe from the south, and even those who prefer to assign an Asiatic origin to them are constrained to lead them through the regions on the north coast of Africa, to account for the absence of their handiwork in eastern Europe ${ }^{1}$.

Let us then assume as a working hypothesis-which, it may be freely admitted, is little better than a guess - that the cradle of the Aurignacian people, as such, was somewhere between the head-waters of the Nile and of the Congo. We say and emphasise as such, in order to admit the possibility that they were not autochthonous there, any more than were the Mousterians in Europe. It may well be that they were compelled by Negro pressure to leave this central African home and to scatter; and that four streams, one of them cultural and the other three racial, diverged from the centre indicated.

The cultural stream was carried southwards by the Bushmen, a people of alien race. There is reason to believe that the Bushmen are a southern migration from central $\mathrm{Africa}^{2}$ : and their Art resembles

1 See for instance H. F. Osborn, Men of the Old Stone Age, pp. 261-2.

2 See the very interesting map of the wanderings of the South African tribes at the end of G. W. Stow's The Native Races of South Africa (London, 1905).

M.E.A.I. 
that of the Aurignacians more closely than any other of the arts of nature-folk. The two-horned rhinoceros engraved on a plate of schist from the Grotte du Trilobite (ante, p. 455) bears a striking resemblance to a figure of the same animal at Wolmaransstad, assigned by Johnson ${ }^{1}$ to the Upper Palaeolithic; and the pocking technique which some of the Bushmen cave-sculptures display recalls in some degree
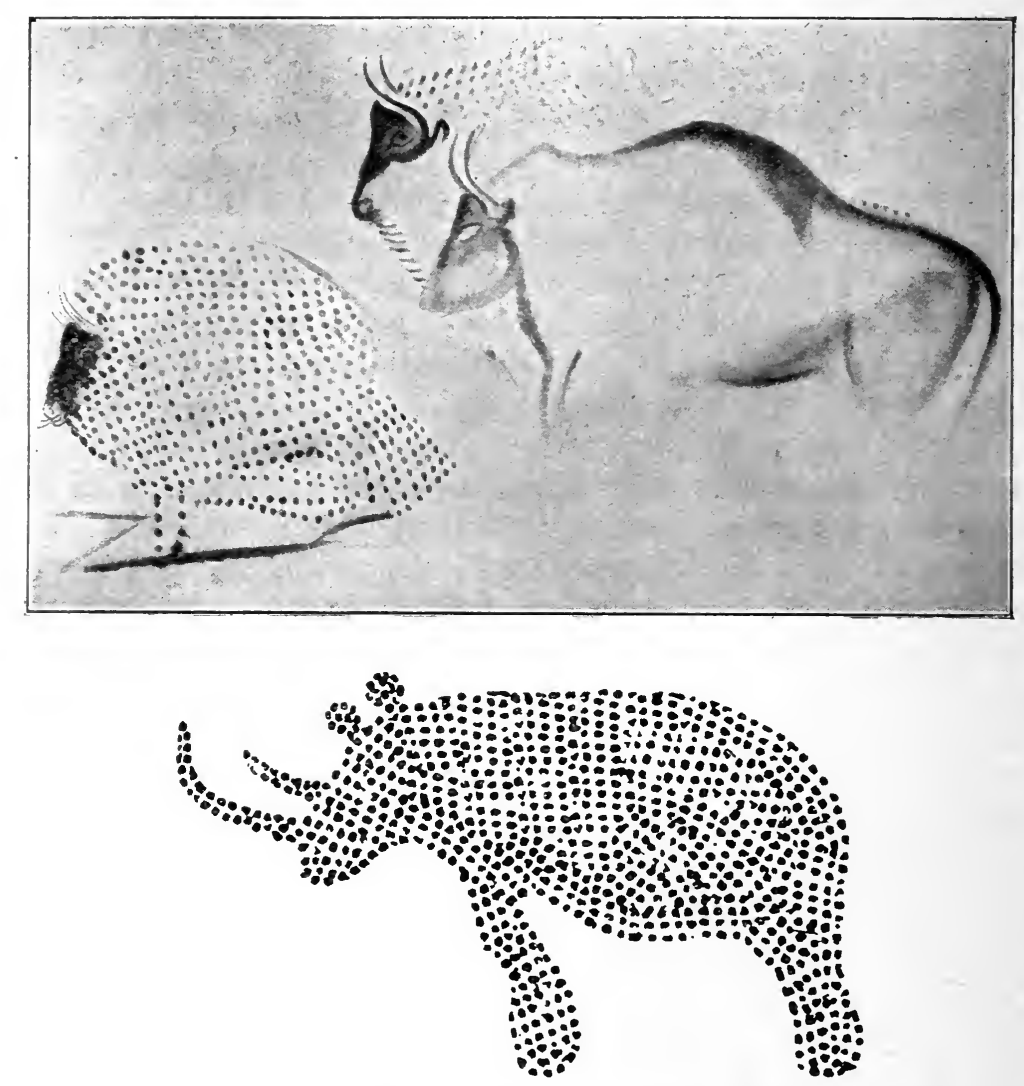

Fig. 184. Upper Palaeolithic and Bushman animal figures compared.

(From L'Anthropologie, vol. xvi. and J. P. Johnson, The Prehistoric Period in South Africa.)

the dotted figures, such as the well-known bison of Marsoulas (Fig. I84). This last comparison is however less significant than it would be if the dotting technique were found in Aurignacian Art.

The three racial streams we suggest to have flowed from the African centre indicated, along the following courses. The first

${ }^{1}$ J. P. Johnson, The Prehistoric Period in South Africa (London, 1910), p. 55. 
skirted the Sahara, and, crossing into Spain, founded the Aurignacian civilisation of Europe - a branch carried the same culture along the north African coast, which (probably under later central African influences) developed the Capsian variety. The second passed down the Nile, to found the civilisation of Egypt. The third traversed the mountain-passes of Abyssinia and crossed the strait of Bab-elMandeb, to become the parent of the various Semitic civilisations which radiated from Arabia.

These theories may appear rather daring. But there are one or two indications which are not without significance. For instance, it is well known that there are linguistic affinities of a very singular nature uniting the Egyptians and the Semites. Their languages coincide in grammar only, the vocabularies being as remote as they well can be. The pronouns and certain numerals, usually the most primitive parts of a language, are nearly identical, as is the construction of the verbal system, the use of $t$ as a feminine suffix, the use of $m$ as a participial prefix. There are other analogies no less striking, which need not be enumerated here ${ }^{1}$; but they point to a descent of Egyptian and Semitic from a common parent, the divergence taking place while the civilisation was still low and the vocabulary correspondingly meagre, but when the principles of linguistic construction had already evolved. The very close kinship between the Semitic languages proper, both in construction and in vocabulary, shews that all the Semitic tribes must owe their origin to one small community which retained its isolation long enough after its divergence from the Egyptian stem to develop fully, and to stereotype its language. As Barton points out ${ }^{2}$, the Hamitic languages so-called-the Egyptian, Berber, and allied tongues-have much less unity than the Semitic, and must therefore have been formed by people more widely scattered. It follows that it is more probable that the Semitic family was an offshoot from the African stem than that the Africans were early offshoots from an Arabian stem. The Abyssinians speak a Semitic language, it is true, but these are to be treated as a later colony returned to Africa from Arabia.

It may be that the curious resemblance to an Egyptian wig presented by the headdress of the women of Brassempouy and of Willendorf may after all not be a mere accident; and that there may be a closer connexion than mere external resemblance between the Aurignacian statuettes and the Semitic "cakes to portray the queen of heaven"-in other words, terra-cotta plaques with a relief of a nude goddess of fertility-against which the prophet Jeremiah in-

\footnotetext{
1 A full list will be found in G. A. Barton, A Sketch of Semitic Origins, p. 9.
}

2 Op.laud. p. 12. 
veighed, hundreds of generations later ${ }^{1}$. These may be late recrudescences of a long-latent tradition.

The osteology of the members of the three branches which we suggest to have hived off thus from a centre in the heart of Africa is not identical. But this is quite intelligible. We cannot tell what transformations, due to mixture or other causes, the three groups may not have undergone during their migrations. They doubtless found aborigines before them in both Egypt and Arabia, whose influence may have modified them both physically and culturally. Certainly the Aurignacians, with their dysharmonic heads, look as though they were the result of a blend, not a pure race.

In the foregoing paragraphs answers have been suggested to the questions Whence and Why. The Aurignacians may have come from central Africa, compelled to do so by some movement of the peoples of that continent: a movement the nature and history of which is beyond our ken. The question When still remains to be considered; but it can be more easily answered when we have examined the course of history which followed the settlement of the Aurignacians in Europe.

\section{The Relation between the People of the Upper.Palaeolithic Stages}

One of the most difficult problems of the Upper Palaeolithic Term is the relation of the Solutreans to the Aurignacians which preceded them, and to the Magdalenians which followed them. The Solutrean stage is, as it were, a wedge, driven between the closely related Aurignacian and Magdalenian cultures: and as Solutrean strata overlie Aurignacian and underlie Magdalenian, wherever these happen to be found together, the Solutrean stage is a real chronological interpolation. Yet it differs from them in almost every respect. The Solutrean people were the best flint-workers which the whole Palaeolithic period produced; and their tools shew distinct affinities with those of the Lower and Middle Palaeolithic, both in form and in technique. The Aurignacians and Magdalenians were, comparatively speaking, only moderately skilful in flint chipping. On the other hand, the Aurignacians and Magdalenians were accomplished workers in bone and in horn, and were skilful in pictorial art: in both these industries the Solutreans were comparatively feeble. It is not surprising that some authorities have maintained the stratigraphically impossible theory that the true sequence of the later Palaeolithic stages was Mousterian, Solutrean, Aurignacian, Magdalenian.

That the Solutrean culture is associated with a people of different

1 Illustrations of some of these objects will be found in the present writer ${ }^{\circ}$. Excavation of Gezer, vol. III. plate ccxxi. 
racial affinities from the Aurignacian is indicated by the bones from Předmost and Brünn.

\section{A Reconstruction of History}

The following course of events seems to be suggested by the observations recorded in the foregoing pages. Down to the end of the Middle Palaeolithic Term the whole of Europe was peopled by the race called Mousterian, mingled in the east with a round-headed stock. There is no evidence that can stand criticism for a race more nearly resembling the modern type of humanity as existing in the Continent along with or previous to them.

A race from Africa, probably from Central Africa, and possibly having a cousinly relationship with the Proto-Egyptians and with the Proto-Semites, entered Europe in the south-west. They were superior in physique and in mental and cultural equipment to the Mousterians, but they were probably a mixed multitude to some extent: there was with them a strain of semi-negro (?) blood, of which we find traces at Mentone; and aberrant individuals such as the man of Combe Capelle.

The newcomers began a relentless war of extermination against the Mousterian aborigines, and cleared them out of France and of Spain, occupying their caves and their hunting-grounds.

But as they penetrated farther into the Continent, they became less malignant in their treatment of their predecessors. In the eastern part of the Continent they so far forgot their race-prejudices as to intermarry with them. Thus arose the mongrel Predmost tribe, which, according to Hrdlička, occupies an intermediate place between the Mousterian and the Aurignacian. As a direct evolution from Mousterian to Aurignacian is out of the question, the only available explanation for intermediate types is intermarriage.

This composite people developed a composite culture. The Mousterian parent had no interest or skill in art, so the half-breed progeny to some extent lost the artistic skill which should have been their inheritance. Flint-chipping had been the chief art of the Mousterians, and the composite race carried this industry to its fullest development. Anticipations of the Solutrean touch have been detected in some Mousterian implements, and there is a close kinship between the Solutrean laurel-leaf javelin-point and the better-made coup-de-poing of the Acheuleans. There may be a connecting link in the bone javelin head which has been found in some caves in eastern Europe (ante, p. 428). As the bone point is confined to eastern Europe, this analogy strengthens the evidence for the eastern origin of the Solutrean culture. 
Some circumstances drove the Solutreans back from central and eastern Europe along the way by which their ancestors had come. They crowded back on the Aurignacians and for a time kept them suppressed. What was happening to the Aurignacians while the Solutreans were occupying their territory we do not know; they may have taken refuge in Italy or in some other place where Solutrean culture is not conspicuous or wholly absent. But after a time they re-asserted themselves, and once more, as the Magdalenians, they held the fort in Europe until the Palaeolithic Period came to an end, and new tribes with new ideas entered the Continent.

It is clear that just as the climate deteriorated from Chellean through Acheulean to Mousterian, so the climate deteriorated from Aurignacian through Solutrean to Magdalenian. The Aurignacians lived in a steppe climate, when herds of wild horses roamed over their lands. The horse gave place to the reindeer as the Upper Palaeolithic Term advanced, and the Magdalenian people lived under Arctic conditions. It is reasonable to connect the Solutrean invasion of western Europe with this deterioration of climate. It would be natural for hunters who lived under the shadow of the Alps to seek fresh scenes, when their old hunting-grounds were invaded more and more cruelly by the bitter climate of the tundras.

\section{The Chronological Tables}

Before going further we must endeavour to anchor the history, traced so far, to firmer chronological moorings. It is impossible to assign dates, in years, centuries, or millennia B.c. to the movements which we have been describing. Dates have, it is true, been suggested by various writers, but they are hopelessly untrustworthy: and even if they were absolutely certain, they are incomprehensible, for we cannot really conceive the significance of lapses of years reckoned in rows of five or six figures. We must make use of larger units, and we therefore for convenience adopt the phases of the Ice Age as our chronometer. For the same reason we make use of the Penck nomenclature for these episodes.

It will be remembered that the succession of climatic phases, from glaciation to glaciation, was as follows:

IN GLACIATED REGIONS

Icè

Intermediate

Full interglaciation

Intermediate

Ice
IN SURROUNDING REGIONS

Tundra

Steppe

Forest

Steppe

Tundra 
and when we compare this sequence with the Lower Palaeolithic it answers exactly. The Chellean corresponds to a forest period; the Acheulean to the beginning of a steppe; and the Mousterian to the development of the steppe into a tundra.

But in the Upper Palaeolithic there is a difference. There is nothing in its course to correspond with the forest stage. Steppe succeeds to tundra and is succeeded immediately by a return of tundra conditions. The Chelleans were the only men who ever saw a " tropical" Europe.

We infer from this that the genial phase in which Aurignacian man entered Europe was not a true interglaciation, but was one of the minor metastadia, as we may call them-the intervals between the three minor stadia which have been shewn to have followed the Würm glaciation. The oscillations of climate during the stadia and metastadia, in the direction both of heat and of cold, were more moderate than those during the preceding glaciations and interglaciations. If Magdalenian Europe was not so cold as Mousterian Europe, on the other hand Aurignacian Europe was not so genial as Chellean Europe.

From this we infer that Mousterian man belongs to the Würm, the last of the great glaciations. Magdalenian man belongs to the next cold phase, namely the Bühl stadium.

All the evidence, rightly interpreted, agrees with this chronology. It is an important principle that if any pre-glacial station once existed in a glaciated region, it would have been cleared out of existence by the scour of the glaciers; therefore if there are any Magdalenian stations within the area of the Würm glaciers, they must be of a later time. Now such stations actually exist, at Kesslerloch, Veyrier, Schüssenried, and one or two other places. It follows that the Magdalenian stage is later than the Würm glaciation.

Germany and Poland afford analogous evidence. The stations at Rübeland (Harz), Taubach, and Wiérzchow Cave lie within the outer limits of the great Rissian moraines, and outside the more recent Würmian moraines. These stations are therefore later than the Rissian ice-extension and earlier or contemporary with the Würm glaciation.

Contrariwise, with the exception of a single station, there are no Mousterian or pre-Mousterian stations within the Würm area. This exception is more apparent than real. It is the cave of Wildkirchli, the loftiest Mousterian station known in Europe-in the canton of Appenzell, in the massif of the Säntisgebirge, and on the eastern slope of the Ebenalp, at a height of 1500 mètres above sea-level. 
The site was excavated in $1904-6$ by $\mathrm{E}$. Bächler ${ }^{1}$; it yielded the remains of an industry in quartz and quartzite, certainly Mousterian; though rude and atypic. No objects in bone were found, nor yet hearths. The fauna included the following mammals-Canis lupus, Cuon alpinus, Ursus spelaeus, Mustela martes, Meles taxus, Lutra vulgaris, Felis spelaea, F. pardus, Arctomys marmotta, Cervus elephus, Capra ibex, Rupicapra tragus - unfortunately rather indefinite in character. It is not, as Penck would urge ${ }^{2}$, a definitely interglacial fauna; this has been disposed of by Obermaier ${ }^{3}$. Even the cave lion is met with in Aurignacian and Solutrean sites, in associations which do not denote a warm climate. Remarkable is the total absence of the reindeer, with its associates, the Mammoth and Tichorhine Rhinoceros. The facies of the Wildkirchli fauna is distinctly modern.

The situation of the cave, high up on the slopes of a mountain that towered above the surface of the Würmian ice, is such that the evidence of its contents is hardly conclusive. Old Rissian or RissWürm deposits might have lain undisturbed in a cave excavated in a nunatak at a safe height above the level of the ice-river. But in such a case we should have expected to find an older fauna. While there is room for some latitude in interpreting the evidence, the greatest probability is in favour of the occupation dating to some time after the maximum of the Würm glaciation: probably to the time when there was a sudden rise in the snow-line during the Laufen oscillation.

More satisfactory evidence of the same kind comes from the Pyrenean glacial centre. At Bouichéta (Ariège) on the slope of the Soudours mountain, there is a cave containing Mousterian flints and remains of the cave bear. This site was covered by the latest glaciers, and the deposits would have been disturbed if not destroyed had they accumulated before the passage of the ice. They must therefore belong to some time after the last glacial visitation of the region. This fixes their date to the period of retreat of the glaciation corresponding to the Alpine Würm.

The theory here maintained, that the Mousterian is to be assigned to the Würm glaciation, and the Upper Palaeolithic to the subsequent metastadium and the Bühl stadium, is associated with the names of Boule, Obermaier and Schmidt ${ }^{4}$. There is a rival theory, formulated

1 Emile Bächler, "Die prähistorische Kulturstätte in der Wildkirchli-ebenalphöhle (Säntisgebirge)" (Verh. der schweizerischen naturforschenden Gesellschaft in St Gallen, i $906-7)$.

${ }^{2}$ Die Alpen im Eiszeitalter, vol. III. p. I $174 \mathrm{ff}$.

3 H. Obermaier, "Les formations glaciaires des Alpes et l'homme paléolithique" (L'Anthr. xx. [1909], 497).

" M. Boule, "Essai de paléontologie stratigraphique de 1'homme" (Revue d'Anthropologie, xviIr. [1889], pp. I 29, 272, 385, 647); H. Obermaier, "Beiträge zur 
by Penck, and adopted in England by Geikie ${ }^{1}$. This would put the different stages of civilisation a step backwards; making the Mousterian contemporary with the Riss glaciation, and the Magdalenian with or immediately after the Würm. In such a case the Chellean and Acheulean phases must be pre-Riss. Now applying the principle already stated, there should be no Chellean or Acheulean remains extant in the regions which were covered by the Riss glaciers. We do not in any case expect Chellean remains in the Würm glacial area. But the Riss glaciers were more extensive than the Würm: there is a margin between the limits of the Würm and of the Riss glacial areas which should be equally sterile, if the Chellean was pre-Riss.

This, however, is not the case. At least two discoveries of Acheulean coups-de-poing have been made within the limits of the Riss glaciers. The first of these was at Challes-de-Bohan, near Hautecour (Ain) ${ }^{2}$; the second in the Jura ${ }^{3}$. Not only were these within the Rissian area, but they were contained in deposits which overlay the deposits of the Riss glacier. These implements must therefore be post-Rissian, in which case the Mousterian must also be post-Rissian ${ }^{4}$.

The reason for assigning a Riss antiquity to the Mousterian stage is the supposed necessity for finding a place for the Warm Mousterian, for which otherwise there would not be room. This warm Mousterian is a curious phase, which requires a few words of comment.

The association of Mousterian implements with a cold fauna is the regular rule; but there are a few places where it is found associated with a fauna of distinctly warm facies. These places demand to be noticed separately.

Kenntnis des Quartärs in den Pyrenäen" (A.f.A. xxxII. [1906], p. 299, xxxıII. [1907], p. 244); Idem, "Les formations glaciaires des Alpes et l'homme paléolithique" (L'Anthr. xx. p. 497); Idem, "Das geolog. Alter des Menschengeschlechts" (Mitth. geol. gesellsch. Wien, 1. [1908], p. 290); R. R. Schmidt, Diluviale Vorzeit Deutschlands, p. $259 \mathrm{ff}$.

1 E. Penck, "Die alpinen Eiszeitbildungen und der prähistorische Mensch" (A.f.A. xxIx. [1904], p. 78); Geikie, The Antiquity of Man in Europe, p. 246 ff. With some modifications in detail Penck's scheme has also been adopted by F. Wiegers, "Die geologische Grundlagen für die Chronologie des Diluvialmenschen" (Monatsbericht der Deutsch. Geol. Gesellschaft, 1912, p. 578) and Bayer (C.A.P.A. Geneva [1912], vol. 1. p. 156).

2 Ch. Tardy, "L'homme quaternaire dans la vallée de l'Ain" (Mém. de la Soc. des sciences natur. de Saône-et-Loire, vi. p. 4); A. Arcelin, "I a vallée inférieure de la Saône à l'époque quaternaire"' (ibid. I 904).

3 M. Boule, "Observations sur un silex taillé du Jura et sur la chronologie de M. Penck' (L'Anthr. xix. [1908], p. I).

4 It must be noted that MM. Mayet and Pissot (Abri-sous-roche préhistorique de La Colombière, Paris, 1915, p. 13) have thrown doubt on the Challes-de-Bohan piece; but while admitting that the documentation of the discovery is not as satisfactory as could be desired, the doubts, so far as one can judge, do not appear altogether necessary. 


\section{Villefranche}

The site on which the greatest stress has been laid is Villefranchesur-Saône. The gravels here are situated on the right bank of the Saône, between Villefranche and the bridge of Beauregard. The industry is characteristically Mousterian; but the artefacts are associated with fauna usually found with Chellean implements-Rhinoceros mercki, Elephas antiquus, Hyaena spelaea ${ }^{1}$. G. de Mortillet tried to evade the evidence by asserting that the fauna was coldRhinoceros tichorhinus, Elephas primigenius, Rangifer tarandus ${ }^{2}$. D'Acy, quoting Gaudry and Boule, was equally positive that it was warm $^{3}$; and there can be no doubt that he was right, and that Rhinoceros mercki was actually found in the gravels.

But-it did not belong there. The bones of the Rhinoceros were much fossilised, and shewed clear evidence of water-rolling. They were in the gravels by accident only. The true fauna of the gravels were mammoth, reindeer, bison, whose bones were not fossilised and were not displaced ${ }^{4}$. Thus the fauna of these gravels is a cold fauna, and the intrusive rhinoceros bones, which have been washed into them from elsewhere, belong to a much older period, and have no bearing upon the climate of Mousterian Europe.

\section{Montières}

The other three sites are however of greater importance, and are not so easily disposed of: indeed, they raise problems to which no ${ }^{\circ}$ certain answer can as yet be given. The first of these is the cave of Krapina, where as we have already seen (p. 309) Mousterian remains are asscciated with Rhinoceros mercki. The second is at Montièreslès-Amiens on the Somme, where the indefatigable Commont made the very remarkable discovery of a stratum containing Hippopotamus, Rhinoceros mercki and other warm fauna, associated with what are certainly Mousterian flints ${ }^{5}$.

\section{The Mentone Caves}

The third is the series of caves on the sea coast between Mentone and Ventimiglia, called the Grimaldi caves: and we may pause here to give a description of the nature of the deposits in these caves, to

1 Ch. Deperet, "Sur la découverte de silex taillés dans les alluvions quaternaires à Rhinoceros mercki de la vallée de la Saône à Villefranche" (C.-R. Acad. des sciences, CXV. [1 892], p. 328); l'Abbé Béroud, "Âge de la terrasse quaternaire de Villefranche-sur-Saône" (A.F.A.S. Lyon [1906], p. 587).

2 B.S.A.P. IV. VI. [1895], p. 57.

3 Ibid. p. 80.

"H. Obermaier, "Das geologische Alter des Menschengeschlechts" (Mitth. geolog. Gesellsch. Wien, I. [1908], p. 290).

$5 \mathrm{~V}$. Commont, "Moustérien à faune chaude dans la vallée de la Somme à Montières-lès-Amiens"' (C.A.P.A. Geneva [1912], vol. 1. p. 291). 
which reference has already been made in connexion with the human remains found within them.

They are, or were, nine in number. The seven most important, in order from west to east, are named as follows: Grotte des Enfants, Abri Lorenzi, Grotte de Florestan, Grotte du Cavillon, Barma Grande, Baousso da Torre, Grotte du Prince. The excavation of these caverns has been carried out at different times and by different persons, with very various qualifications: some of the work that has been done has been of a deplorable character. Fortunately, under the auspices of the Prince of Monaco, in the early years of the present century, a thoroughly competent body of investigators examined what their predecessors had left, and were able to excavate one till then almost untouched cave (the Grotte du Prince) completely; so that a goodly quantity of scientific material was thus rescued. The interest that has been taken in the caves is well shewn by the extensive bibliography which will be found at p. 321 of the second volume of the great monograph, Les Grottes de Grimaldi, where the most recent work is described and illustrated ${ }^{1}$.

In the Grotte des Enfants there were ro layers of accumulation, which had attained a total height of over Io mètres. This accumulation was principally due to human agency, not, like the pile of débris in the Grotte du Prince, to the action of water or other natural causes. The cave had originally been a hyaena den, and there followed a slight Mousterian occupation, if we may judge by the implements; which though in sandstone and limestone, not in flint, were evidently Mousterian in facies. They were however accompanied by Rhinoceros mercki, a distinctively warm animal. The "Negroids" were interred in this Mousterian layer: but as their grave was dug from above, this does not necessarily date them to the Mousterian Stage. The overlying strata were all Aurignacian, and yielded a long series of characteristic implements, associated with what was on the whole a steppe fauna.

Abri Lorenzi was merely a small rock-shelter of minor importance. The explorers found Mousterian and Aurignacian implements within it.

The Grotte de Florestan had been completely emptied out before the epoch of scientific excavation, so that its ancient contents, if any, were lost. A polished axe-head was found in the rubbish outside this cave, and gave occasion for an erroneous theory, energetically maintained by those who would deny the existence of sepulture

1 This bibliography includes no less than 76 items, and yet is incomplete. No reference is made to the articles by Reinach, G. de Mortillet, and Piette on the statuettes found in the caves. 
among the Palaeolithic peoples, that the deposits in the cave were Neolithic. If anything was wanted to disprove such a contention, it would be the existence of remains of the reindeer in the topmost strata of some of the caves.

The Grotte du Cavillon was originally filled with deposit to a depth of 14 mètres, stratified, like that in the Grotte des Enfants, in a series of successive habitation-floors. The fauna and industry were identical in facies and in evolutionary sequence with that of the Grotte des Enfants: Mousterian implements of sandstone and limestone below, associated with Rhinoceros mercki, and a succession of Aurignacian layers above.

It is impossible to describe satisfactorily the deposits in the Barma Grande, notwithstanding the richness of its contents, as it was excavated over-hastily, and the stratification was not satisfactorily determined. But on the whole it seems to have conformed to the scheme of the Grotte des Enfants and of the Grotte du Cavillon. To Rhinoceros mercki this cave added an elephant, probably E. antiquu ${ }^{1}$.

If little can be said about the Barma Grande, less can be said about Baousso da Torre, which has been entirely destroyed by quarrying operations.

The Grotte du Prince, however, must remain as the representative cave of the series, owing to the care with which it was excavated and the results described and illustrated. The history revealed was as follows:

The cave, which is over 20 mètres in height, was originally made by the action of the sea, and at one time the sea filled it to a depth of about I I mètres - that is, the level of the land was at a point 22.70 mètres lower in the sea than it is now. This is shewn by the presence of marks, left on the walls of the cave up to this level, by marine boring mollusca.

The land then rose, but still stood at a depth of some I I mètres below its present level. At this time the waves still invaded the cave, and left a stratum of marine deposit on the floor.

There was then a considerable rise of the land, to a height unknown above its present level. This left room between the mouth of the cave and the margin of the sea for the movements of large animals such as Rhinoceros (mercki) and Elephant (E. antiquus); bones of both of these animals were found in the lower human stratum of the cave. This is an occupation-floor spread just above the marine deposit, and (like the corresponding lower strata in the other caves) containing Mousterian implements, in sandstone and limestone.

1 For the Barma Grande see C.A.P.A. Monaco [1906], vol. 1. p. 72. 
The cave was then abandoned for a while. Over the occupationfloor was spread, by the action of water, a bed of silt, mingled with coprolites and other traces of the presence of hyaenas.

Another occupation-floor, or group of occupation-floors, follows, testifying to a protracted use of the cave by man. The fauna is still "warm," and the implements still Mousterian.

There is then another sterile layer, with many traces of hyaena, followed by a third occupation-floor, of slightly later facies, but still of the same character as the preceding.

Then follows a thick sterile bed, of clay, stalagmite, and fallen blocks, with no trace of man; above which is a series of occupationfloors with Aurignacian flints, associated with Rhinoceros tichorhinus and reindeer, as well as other animals indicating a colder climate. Stalagmite and a modern deposit overlie the whole series, which filled the cave up to its roof.

\section{Significance of these Sites}

These phenomena may be explained in several ways, but there is no evidence to shew which is the true explanation; it is one of the problems for the future to settle. The Mousterian industry may prove to be after all an importation into Europe, like the Aurignacian which succeeded it: and the sudden appearance of implements of Mousterian type amid the conditions of a Chellean or an Acheulean world may tell of the first appearance of the incomers who brought this Mousterian culture into the Continent. Again if the Grimaldi caves were an isolated case, we might legitimately explain their warm fauna as being due to their southern situation; but this explanation will not suit the Montières case. As Rhinoceros mercki does not appear to have survived the Würm glaciation, the "Warm Mousterian" must be regarded as an early phase, in the Riss-Würm interglaciation, not a late phase in the Achen oscillation. With this would agree its association with Acheulean remains at Montières.

In the present state of knowledge, the one lesson that can be drawn from the Grimaldi deposits is a warning that the stages of civilisation, into which the Palaeolithic Period has for convenience been divided, are not to be regarded as watertight compartments. They enshrine a real history, and a real development: but there are long periods of overlap between successive stages, and a community in one region may be making Chellean tools while another more progressive - or more degenerate, if you will-are feeling their way toward a Mousterian culture. We have already indicated the same conclusion in speaking of the remains at Taubach: and much the same remark, again, applies to the deposits at Montières. The 
evidence that the Mousterian was not succeeded by a later great glaciation, but that it fell in the last of the series, is too overwhelming to be upset by the remains of a few isolated communities who for all we know may have lived in very exceptional conditions.

\section{Hoxne}

The results of the excavations at the brick-earths of Hoxne, Suffolk, may here be alluded to. The early investigations, beginning with those of John Frere mentioned above (p. 7), have been superseded by the work of the committee appointed by the British Association for the Advancement of Science, and published in the report of the Association for $1896^{1}$. The stratification revealed by the excavation enshrined the following history:

I. An ice-sheet, which deposited the great stratum of chalky boulderclay that overlies East Anglia.

2. At some time (length unknown) after the deposition of the boulderclay, an emergence of the land to a height sufficient for the excavation of a small river-channel, to a depth exceeding that of recent river-channels in the same neighbourhood.

3. A subsidence, producing a damming of the river waters and the formation of a lake, which stood until 6 mètres of lacustrine silt were deposited.

4. The drying of the waters of the lake, by silting or by emergence of land, and the growth of a thicket or forest of alders on the site, marked by a stratum of lignite.

5. Return of lacustrine conditions; the organic matter in the silt of this new lake testifies to an Arctic climate. Another 6 mètres of silt deposited.

6. Floods deposited gravels over the lake alluvium; the gravels contained Acheulean coups-de-poing.

7. Sand, perhaps aeolian in origin, spread over the gravel.

At the river Lark, and in the Thames valley, the lacustrine conditions are associated with the Mousterian stage. There were no Mousterian implements at Hoxne, but at the Lark we find a Mousterian lacustrine deposit, overlaid by flood gravels containing Acheulean implements, as here. The lakes $3-5$ may therefore be reasonably equated to the Mousterian stage. There are evidently no glacial conditions following the time of the lakes, though a great glaciation, that which deposited the boulder-clay, took place some time before. The climatic conditions of the first lake were mild; they were succeeded by a time of moorland, on which the alder-forest grew; and then followed arctic conditions, during which the second lake was formed. While not forgetting that a correlation between the glaciations of

1 "The relation of Palaeolithic Man to the Glacial Epoch" (British Association Report, Liverpool [1896], p. 400). 
the Alps and those of other centres is a matter of probability rather than of certainty, we may reasonably associate this last glaciation with the Würm ice, and the floods which deposited the implementiferous gravels with the melting of the ice. The glaciation which deposited the boulder-clay would then be correlated with the Riss glaciation.

\section{Conclusions as to Palaeolithic Chronology}

Thus we may take it as the most reasonable and probable hypothesis that the glaciation which we provisionally called the Mousterian glaciation is to be correlated with the Würm glaciation of Penck; and it follows that the interglaciation which for the moment we called by the name of Chellean is the same as Penck's Riss-Würm. We have now to ask whether there is evidence forthcoming for assigning any remains of man in Europe to a period older than the Riss-Würm interglaciation.

The only evidence yet available is uncertain and ambiguous. Apart from the Mauer and Piltdown osseous fragments, there is nothing except an obiter dictum of Commont's, to the effect that at Saint-Acheul and at Abbeville he had found Chellean implements, with other fragments of flint, splintered by the action of ice ${ }^{1}$. Evidently this suggests the hitherto unsuspected existence of a cold phase of the Chellean. Commont seems to date this to the end of the Chellean phase, which would involve a revision of all the chronology hitherto formulated: Obermaier ${ }^{2}$ provisionally dates this theoretical cold Chellean to the Riss glaciation, prefixing the preChellean in the Mindel-Riss.

Having now decided to follow the authorities who place the Mousterian stage on the Würm glaciation, we have now to consider more closely the chronology of the later stages. We are limited by the climate of the Magdalenian, which is the first definitely cold stage following the Mousterian. This must therefore be assigned to the Bühl stadium. The Achen oscillation must accordingly have witnessed the Aurignacian immigration, and the development of the Solutrean culture.

In eastern Europe, the chief remains of the Aurignacian and the Solutrean stages are buried in the great beds of Löss which cover vast areas of that part of the Continent. These Löss-beds are in two main layers, an older and a later. It may however be questioned whether this stratification has much light to throw on the chronological problem before us, for the simple reason that the dating of

1 C.A.P.A. Geneva [1912], vol. I. p. 253.

${ }^{2}$ El hombre fósil, p. 256. 
the Löss-beds is itself a very difficult problem, and needs all the light that can be thrown upon it. We need the evidence of the implements to date the Löss, and can hardly use the Löss to date the implements. We may notwithstanding recall the stratification at Achenheim, given above (p. 256), where we see a number of Löss beds, the succession of which may be simplified thus:

Later Löss with Aurignacian deposits.

Intercalated bed with rodents, testifying to arctic conditions, Mousterian deposits.

Older Löss with Acheulean deposits.

indicating that the older Löss is pre-Würm, the later Löss postWürm. This stratification therefore falls into line with the scheme based on other evidence.

It was probably some time before the maximum of the Bühl stadium that the Capsian invasion took place. The Capsians held the Iberian Peninsula against Magdalenian invasion, and therefore we find the characteristics of Magdalenian Art only in the northern parts of Spain. The Asiatic brachycephalic people did not, however, make their appearance in Europe till after the Magdalenian stage was well over-some time, probably, in the Bühl-Gschnitz metastadium. The Magdalenian and the Capsian cultures unite to produce the composite Azilian, which we may date approximately to the Gschnitz.

\section{Mesolithic Chronology}

The pressure of the Asiatic tribes must have driven the earlier Europeans into regions previously uninhabited; regions which were indeed now becoming available for occupation for the first time owing to the retreat of the ice. The close connexion between the Azilian culture and that of Maglemose shews that the two must be approximately contemporary. The Maglemose culture is dated by its associated fauna and flora to the time of the Ancylus lake. There is no trace of man in Scandinavia contemporary with the Yoldia Sea, which is of about the same period as the later Upper Palaeolithic: Man must therefore have appeared in the Baltic basin some time between the close of the Yoldia period and the damming up of the Ancylus lake. The mollusca found in the Danish Shell-heaps indicate a salter sea than the modern Baltic, with a more open connexion with the ocean; this condition can have prevailed only in the Littorina period, to which these remains are to be assigned. The Littorina period corresponds to the $25-\mathrm{ft}$. raised beach in Scotland and Ireland: in Scotland we find an Azilian culture, in Ireland a Campignian culture, on the 25 - $\mathrm{ft}$. beach. The latter is comparable with the culture of the Shell-heaps. 
After the Daun stadium began the full Neolithic, with which we are not concerned in this volume. In the Alpine region Neolithic objects overlie the Daun deposits.

\section{Supposed Glacial Striae on Neolithic Flints}

Such, then, is the course of events and of cultural development as indicated by the remains. But a passing mention must here be made of recently-published discoveries which, if the interpretation put upon them by their authors is to be admitted, would throw everything hitherto gained as to Palaeolithic history into the meltingpot. This is the presence of striae, resembling the marks left on rock-surfaces by the passage of ice, upon Neolithic flint implements. They have been published from Ireland ${ }^{1}$, from various sites in Dorsetshire ${ }^{2}$, and above all from Suffolk ${ }^{3}$, where a large number of different types of striations have been enumerated, and as many glaciations succeeding the Neolithic Period are deduced.

It is certainly very difficult to know what to make of these striations. On the one hand, flint is so hard that it is not easy to imagine any agency other than ice which could have made them. On the other hand, what are we to say of one glaciation, let alone five or six, which passed over the country and left no traces whatever except scratches on artificial implements? How did the ice choose on zohich side to make the scratches? for we are told, in the East Anglian Society's Proceedings, that the scratches are almost always on the bulbar side of the flake. How could such an ice-flow produce criss-cross scratches on a small flake? These are some of the questions which present themselves when we examine the illustrations: and we feel constrained to conclude that almost any theory of the origin of these markings is better than the glacial theory! They might even have been made artificially, as ownership marks, or, more probably, to roughen them and so to facilitate firm grasping.

\section{A Chronological Table of Palaeolithic History}

We may now set forth in the following form the course of developments during the Palaeolithic Period, using, for convenience as before, the Penck terminology.

\section{GÜNZ GLACIATION \\ GÜNZ-MINDEL INTERGLACIATION \\ MINDEL GLACIATION}

No certain traces of humanity in any of these phases.

1 British Association Report, Ipswich [1895], p. 825.

2 Proceedings, Bournemouth Natural Science Society, vol. II. [1908-1910], plate iv. In the accompanying text these implements are described as Palaeolithic, but they have all the appearance of being Neolithic.

${ }^{3}$ Prehistoric Society of East Anglia, I. [1914], p. 43.

M.E.A.I. 


\section{MINDEL-RISS INTERGLACIATION}

Man probably appeared in Europe in this phase. Pre-Chellean (?). Limpsfield gravels (?).

Second Terrace in Somme and Thames valleys.

\section{RISS GLACIATION}

Chellean flints fractured by ice, found at Saint-Acheul (?).

\section{RISS-WÜRM INTERGLACIATION}

Steppe period. Early Chellean.

Third terrace in Somme valley.

Forest period. Full Chellean with tropical animals.

Third terrace in Thames valley.

Fourth terrace in Somme valley.

Anticipation of Mousterian at Montières and at Mentone may perhaps have begun about this period.

Steppe period. Acheulean begins to develop out of Chellean. Older Löss beds.

Valley terrace gravels in Thames.

Acheulean passing into Mousterian.

Mousterian culture.

\section{WÜRM GLACIATION}

Subsidence with ponding of waters in Thames and Somme.

In the Laufen oscillation, probably, occupation of Wildkirchli Cave. Emergence with cutting of deep beds of Thames and Somme.

\section{ACHEN OSCILLATION}

Steppe period. The Aurignacian invasion.

Eastward movement of the Aurignacians and development of Solutrean culture. The later Löss beds deposited.

Tundra period. Return westward of the Solutreans.

In Scandinavia, the Yoldia period.

\section{BÜHL STADIUM}

The Magdalenian stage.

Invasion of the Iberian Peninsula by the Capsians.

\section{BÜHL-GSCHNITZ METASTADIUM}

Beginning of Asiatic invasion.

Growth of the Azilian culture.

Movement northward of the first settlers on the Baltic. Beginning of the Ancylus period.

\section{GSCHNITZ STADIUM}

The Azilian-Tardenoisian stage.

Development of the Campignian culture.

Maglemose. 


\section{DAUN STADIUM}

The Danish Shell-heaps on the shore of the Littorina Sea.

Spread westward and southward of the Campignian industry.

First appearance of man in Scotland (Azilian) and Ireland (Campignian).

Gradual development of Neolithic culture, which follows the Daun stadium.

\section{Theories as to the Modern Representatives of European Palaeolithic Man}

There is one thing more to consider before we close. What has become of the peoples with whose handiworks we have been concerned in the foregoing volume?

They have been sought in various parts of the world. Certain physical and cultural coincidences have been considered sufficient to equate the Mousterians to the Australians, and to warrant the conclusion that when driven out of Europe they found refuge in the southern Continent. But assuming the truth and the significance of the alleged facts, they may more reasonably be explained on the hypothesis of descent from a common ancestor: the relation between the European Mousterians and the Australians being cousinly. We have already seen that the facts are interpreted by others quite differently, namely, that the Australians represent the ancestors from whom the Mousterians passed into Europe.

Again, the Aurignacians have been sought in the modern Bushmen. Here again, there certainly seems to be a cultural connexion, but there is no osteological reason for believing in a physical connexion.

A rival theory about the Aurignacians seeks them in the modern people of Perigueux and the surrounding region; these display the dysharmony of head which we have seen to be a characteristic of the Aurignacians. But they have not the long limbs and the tall stature: and the dysharmony seems to have disappeared toward the end of the Upper Palaeolithic Period, as it does not so conspicuously characterise late Upper Palaeolithic skulls ${ }^{1}$.

Lastly the Magdalenians have been sought in the Eskimo of Greenland, on the strength of the dysharmony of Eskimo skulls, of the alleged similarity between Eskimo and Magdalenian Art (which are however as different as primitive arts well can be), and of the use of implements such as bâtons de commandement, which certainly resemble Eskimo shaft-straighteners of reindeer-horn. The Magdalenians are supposed, on this theory, to have "followed the reindeer" when it retreated to its Arctic home after the disappearance of the ice of the Central European glaciations. But why should the

1 For this identification see Ripley, The Races of Europe, p. $16_{5} \mathrm{ff}$. 
Magdalenians have inconvenienced themselves in such a way? The reindeer is naturally an Arctic animal; man is not: and Magdalenian man would have been very foolish, to say the least, if he had left the rapidly improving climate of Europe, where deer and horses were multiplying for his use, in order to hamper himself with the economically inferior reindeer. Those who speak of the Magdalenians "following the reindeer" seem to picture a sudden emigration of that animal, in great droves, so soon as the climate began to improve, with their hunters tamely marching in their train: it makes one think of Sam Weller's superannuated post-boys riding off into the Unknown on moribund donkeys. What really happened must have been of quite a different character. The disappearance of the reindeer was gradual, and occupied a long time. Man is adaptable, the reindeer is not: man could thrive in warmer climates, where the reindeer would languish. That man stayed where he was, so long as his human enemies allowed him to do so, is the only reasonable theory on which to base a history of the population of any region.

We conclude that Palaeolithic man remained in Europe, and formed the substratum of the population in the succeeding stages of the history of the Continent; but that changes of the conditions of his environment and of his civilisation, the intermingling of new blood, and other causes, have modified his physical character so profoundly that it is now impossible to isolate him among the modern occupants of the Continent. 


\section{INDEX}

Abbeville, 8, 223, 249, 25 I ff.

Abbott, W. J. L., 156, 168

Abruzzi, 242

Achen oscillation, 32

Achenheim, 256, 339, 414

Acheulean stage, and implements, 56, 211,236

Acy, E. d', 221 , 230, 294, 586

Aegean, 56

Aesthetic development of Man, 96

Affaldsdynger, 556

Africa, North, palaeolithic in, 537

African origin of Aurignacians, probable, 576

Ages of civilisation, $9 \mathrm{ff}$.

Agglutinating languages, I 5

Aggsbach, 426

Agriculture, effect upon communal life of its development, I 3 I

Albarracin, 498

Alcalde del Rio, H., 490

Aldovrandi of Bologna, 4

Alcantara, 249

Alluvium, 29

Alpera, 76, 389, 497, 512, 513, 51 5, 531, 538

Alpine ice-centre, 27

Alpine race, characteristics of, I 12 ; origin of, 542

Alpine archaeological region, 56; Middle Palaeolithic in, 340

Alpine glaciation, 27

Altamira, Cave of, $73,80,442,454 \mathrm{ff}$., $458 \mathrm{f} ., 470,489,493,507$

Amber, 53

Ameghino, F., 254

American Indians, methods of flintchipping among, 168

Amiens, $250 \mathrm{f}$.

Amulets, 33I

Ancylus lake, 43, 560

Ancylus maximum, 43

Andernach, $416 \mathrm{f}$.

Anderson, J., 533

Andree, R., 499

Andrian, Freiherr von, 335

Anhistoric defined, I 5

Animalism, human revolt against, 95

Animals, domestication of, 517, 520; language of, 113

Animals most useful for chronological purposes, 9i $\mathrm{f}$.

Animism, 136

Anthony, R., 301, 304

Anthropolatry, alleged, in the dog, 96

Anthropological prolegomena, $93 \mathrm{ff}$.

Antiquity of Man, demonstration of, 7 8

Anvils, bone, 329
Apes and men, differences between, $94 \mathrm{f}$.

Aral Sea, 55

Arcelin, A., 37 I

Archaean rocks, 24

Archaeolithic culture and industry, I 52, I 62

Archaeological research, methods of, I $4 \mathrm{ff}$.; purpose of, I, I 5

Archaeology contrasted with history, I ; definition of, I

Arcy-sur-Cure, 305, 383, 401 f., 409 , $454 \mathrm{f} ., 543,578$

Area required for support of a hunter, 520

Arno river, 219

Arrangement of material in this book, scheme of, 209

Arrow-heads, alleged, from Binche, $228 \mathrm{f}$.

Art, Palaeolithic, 413, 417, 419, 421 ff., $434 \mathrm{ff}$., $438 \mathrm{ff}$.; compared with modern savage art, 498

Artificial deformation of skulls, 107

Artificiality of a flint implement, tests of, 146

Arun river, 342

Asia, influence of, 3 I 4 ; invaders from, 544.

Assegai-heads, 320, 388

Astillero, 248

Atkinson, J. J., 144

Audi, l'abri, 333, 334, 336, 360, 405

Ault du Mesnil, G. d', 245, 250, 549

Auresina, 335

Aurignac, 406

Aurignacian invasion of Europe, 575

Aurignacian stage, $56,348 \mathrm{ff}$.; art of, its development, 459; fauna of, 360 ; implements of, reappearance in Magdalenian, 388 ; phases of, 360

Australia, supposed connexions between early Europeans and, 572, 595

Australians, 396

Austria, 57; Lower Palaeolithic in, 259; Middle, 340; Upper, 423

Autendorf, 424

Avebury, Lord, I 2, I 4, 512, 520, 556

Avenue de Clichy, skeleton from, 218 , 221

Avon river, Warwickshire, 279

Avon river, Wiltshire, 276

Axe river, 279

Axeheads, stone, interpreted as thunderbolts, 3

Aymer, A., 395

Ayre river, 250

Azilian culture, characteristics of, 524; extent of, 532 ; origin of, 538

Azilian stage, $523 \mathrm{ff}$.

Azoic period, 24 
Bächler, E., 584

Backhouse, $53 \mathrm{I}$

Bacon's Hole, 434

Bagford, J., 7

Baguettes, 40 I

Balch, H. E., 433

Balfour, H., 482, 499

Balkan peninsula, 56

Balkash lake, 55

Balla cave, 423

Ballet, Dr., 235

Baltic glaciation, $27,35 \mathrm{ff}$.

Baltic sea, land-oscillations round, 43

Bann river, 229

Bañolas, jaw from, 307

Baousso da Torre, 358 ; see also Mentone caves

Bardon, L., 298, 3 I $8,320,368,406 \mathrm{f}$.

Barma Grande, 356; see also Mentone caves

Barton, G. A., 579

Bâtons de commandement, 383

Batuecas, Las, 498

Bau de l'Aubesier, tooth from, 304

Baudon, Th., 239

Baudouin, M., 3, 346

Baumannshöhle, 340

Baye, Baron de, 247

Bayer, J., 423

Beaches, raised, 4I, $43 \mathrm{f}$.

Beachy Head, eoliths from, 156

Beaked scraper, 326

Bédeilhac, cave of, $45^{8}$

Beetle, wooden figure of a, $40 \mathrm{I} \mathrm{f}$.

Bégouen, Comte de, 474, $48 \mathrm{r}$

Belgium, 56; caves of, 544; Lower Palaeolithic in, 255

Bell, A. M., I 54

Bellucci, 242

Beloid skulls, r 08

Renendeil, P. J. van, 547, .548

Benevento, 244

Bengawan river, 177

Bennett, E. F. J., I 56

Berkshire, eoliths from, 156

Bernifal, 454, 459

Béroud, Abbé, 586

Berthelot, 402

Bertrand, A., 421

Bertrand, E., 219

Bewley, $27 \mathrm{I}$

Biddenham, 275

Binche, arrow-heads from, 228

Birds of Palaeolithic period, 84

Birseck, 533

Bishop, A. H., 535

Blackmore, H. P., I 56

Blanckenhorn, M., I77, I 83

Blanquet, Abbé, 327

Blasius, W., 340

Bleicher, 256, 257

Plinckenberg, C., 3

Blood-kinship of Man with Chimpanzee, 93

Bobache, 533

Bockstein, 4I 3
Böla, rock-carving at, 569,570

Boncelles, I 63

Bone, industrial use of, in Palaeolithic times, $200 \mathrm{ff}$., $328,363,380,388$

Bones, scratched, $156 \mathrm{f}$.

Bonnemère, L., 3

Boomerangs, 396, 565

Borers, 326; Chellean, 233; Solutrean, 376

Bori, the, of the Hausa, 501

Boskop skull, 575

Boucher, a term for the coup-de-poing, 229

Boucher de Perthes, 8, I52, 2 I 8,229 , 249,438

Boudy, 537

Boué, Ami, 7

Bouichéta, 584

Boulder-clay, 27

Boule, M., I 5 I, I 54, I70, I76, I99, 21 5, 224, 245, 298, 299, 300, 305, 312, 353. $409,421,440,452,575,584,586$

Bourgeois, Abbé, I 50, I 53, I $56 \mathrm{f}$.

Bourlon, M., 189, 315, 318, 328, 331, $368,388,410$

Bournemouth, 278

Bouyssonie, Abbés A. and J., 298, 299, $3 \mathrm{I} 8,320,368,388,406 \mathrm{f}$.

Bow, use of the, 389, 45 I , 497, 539

Bracht, E., I 88

Brachycephalic skulls, $105 \mathrm{f}$.; invaders, 548

Branco, W., 573

Brandon, 275, 430

Brassempouy, 406, 444 ff., 468, 474, $477,480,5 \mathrm{I} 3$

Breccia of Hötting, 33

Bréchamps skeleton, 3 Io

Breonio, 554

Breuil, Abbé, 63 ff., I 64 ff., 219, 229, $247,259,294,311,334,336,361 \mathrm{ff}$., 370,389 ff., 406 ff., $426,434,442$, 443,454 ff., 459, 462, 473, 48I ff., $485,487,489,495,497,499,505,528$, $531,532,537,543$

Briguel, P., 57

Britain, South, Lower Palaeolithic in, 259 ff.; Middle, 34I ; Upper, 429

Brixham cave, 432

Broadwell, 264

Broca, P., ro6, 289, 349

Bronze Age, I I

Brown, J. A., I 53, 270, 535, 536, 554

Brøgger, A. W., 570

Brøgger, W. C., 148, 565, 567

Brückner, E., $29 \mathrm{ft}$.

Brünn, 427; skeleton from, 374 ; statuette from, 46r, 462

Brüx, skull, 375

Brung, Abbé, 326

Bruniquel, 79, 86, $397 \mathrm{ff}$., 408; see also Montastruc

Brylinska, A., 503

Buchenloch, 340, 412

Buckland, Dean, 358, 430

Bühl stadium, 32 
Bürger, 414

Bulb of Percussion, 146

Bullen, Rev. R. A., I 56, 173

Bull-roarer, 140, 514

Bungay, 34I

Burial, Palaeolithic, 294, 296, 344, 501

Burin busqué, 367

Burin-ciseau, 327

Bury, H., 265, 266

Bury St Edmunds, skull, 212, 217

Bushmen, 51 I , 576, 598

Bł́čískála cave, $5 \circ 3$

Cabré Aguiló, Juan, 490, 495, 497

Cacciamali, C. B., 184

Cacholong, 5o

Caddington, 265 ff., 273

Caesar, Gaius Iulius, 127

Cainozoic period, 25

Calaveras skull, 1 57, I 83

Calbe an der Milde, $55^{2}$

Camargo, 359

Cambridgeshire, Palaeolithic sites in,

279
Campignian culture, its origin, $568 ;$ in Norway and Swedęn, 565

Campignian stage, $549 \mathrm{ff}$.

Campigny, Le, 549

Canidae, 65

Cannstatt, 4I4; skull from, 3 I I

Cantalian industry, 161

Cap-Blanc, $464 \mathrm{f}$.

Capitan, L., 22, 50, 162, 163, 230, 232, $239,241,245,295,326,327,407$, $454,456,485,503,537,549$

Capri, 243

Capsa, 537

Capsian culture, 537; origin of, 579; compared with Aurignacian, 538

Carinate scraper, 365 f., 376,388

Carnivora, $64 \mathrm{f}$.

Cartailhac, E., 3, 295, 389, 397 f., 408, $442,443,487,489,499$

Cartier, A., 423

Casal do Monte, 249

Caspian sea, 55

Castelfranco, P., 242

Castenedolo skeletons, 183

Castillo cave, 248, 336, 359, 454, 458, $459,489,493,506,532$

Catastrophal hypothesis in geology, 7

Cave-dwelling, effects of, 284

Caversham, 264, 265

Caves, 284; formation of, 46 ; stratification of deposits in, $47 \mathrm{f}$.

Cave-sanctuaries, 503

Cavillon, Grotte du, 355 ; see also Mentone caves

Celle-sous-Moret, La, 254

Cels, M., 166

Centres of culture, supposed, 208 .

Cephalic index, 105

Cephalotaphy, 433, 54 I

Cerralbo, Marqués de, 224, 246

Čertova-díra, cave, 259, 341, 427

Chaffaud, 44I, 47 I
Chaleux cave, 547

Challes-de-Bohan, 585

Chamaeprosopic defined, 112

Chamberlin and Salisbury, 23

Chancelade, $38 \mathrm{I}$

Chandler, R. H., 271, 273, 342

Chapelle-aux-Saints, La, skeleton, $298 \mathrm{ff}$., $318,320,345,353$

Characters of Mousterian man, physical, 31 I ff.

Charms, axe-heads and arrow-heads used as, 4

Charney river, 264

Chase, processes of, reconstructed from injuries on bones, 332

Chasteigner, A. de, 456

Châtelperron knives, 334, 361

Chauvet, G., 239, 321

Cheddar, 433 ; skeleton, 384

Cheiroptera, 64

Chellean stage, 56, 211 ; implements of, $229 \mathrm{ff}$.

Chelles-sur-Marne, 211,254 ; fauna of, 223

Chert, 52; Chellean tools in, 234

Cheshire, eoliths from, ${ }_{5} 6$

Chez Pouré, 246

Chimpanzee, blood-kinship of man with, 93

Chisels, 327 ; Campignian, 55 I

Chloromelanite, 52

Choppers, 239

Choquet, 254

Christy, H., 81, 84, 349, 399, 442

Chronology, 12, 60; animals most useful for, 91 ; methods of determining, I9 f.; Mesolithic, 592; Palaeolithic, 591 ; of the periods of the Old Stone Age in Europe, $582 \mathrm{ff}$.; table of, 593

Churinga, 528, 531

Circumstances of discovery of Lower Palaeolithic remains, 209

Ciseau, 327

Cissbury, 430

Clarke, W. G., 1 58, 280

Classification of Human Communities, $98 \mathrm{ff}$; t table of, 143; of Mammalia, 61 ; use and abuse of, $17 \mathrm{f}$.

Classificatory relationship, $123 \mathrm{ff}$.

Claviform devices, $49 \mathrm{I}$

Clift, J. G. N., I 77

Climate of Europe before the Ice Age, 62

Climatic classification of animals, 87

Clubs, 320

Cocchi, 219,220

Codrington, $44^{\circ}$

Cogels, P., 3

Cogul, 495 ff., 501, $512,531,538$

Colini, G. A., 242 f., 334 f.

Collecting antiquities, use and abuse of, I4, 2 I f.

Collignon, R., 295

Collin, E., 50, 255

Colne river, 265

Colonisation, effects of, $347 \mathrm{f}$. 
Coloration as a race-criterion, $108 \mathrm{ff}$.

Combarelles cave, Les, 68, 70, 79, 453, 459, 470, 508

Combe Capelle, skeleton, 3 8 8, 335, 359

Commont, V., 164, 227, 232, 233, 237, 245,249 ff., 262,3 r6, 333, 336, 586 , 591

Communism, primitive, 130

Communities, classification of human, $98 \mathrm{ff}$. ; organisation of, I 21

Conclusions as to early human remains, 204 ; eoliths, 175 ; palaeolithic art, 5 io

Contrast of magic and religion, I 38

Cook, A. B., 528

Coral, 4I3

Corbicula fluminalis, 261, 27 I

Cosmogony, speculations as to, 140

Costume, Upper Palaeolithic, 5 I 3

Cottés, Les, 406, 484

Coudraie, La, 552

Coumbâ-del-Bouïtou, La, 407

Coups-de-poing, 229 ff., 236 ff., 296, 328 ; Italian, 242 ff.; Mousterian, 316 , 3 I 8 ; types of, 237

Cousinship, varieties of, 125

Coutil, L., 536, 538

Covalanas, 489

Cranial index, 105

Crayford, 271, 273, 341, 434

Cresswell Crags, 433, 474

Cretas, 494

Crete, 56

Criteria of race, 105

Criticism of archaeological deductions, 18

Cro-Magnon, 344, $349 \mathrm{ff}$., 406; race of, its development, $3^{8} 5$

Cromer, I 56,170

Crot-du-Charnier, 37 I

Cultural classification of humanity, I 8 ; bases of, 120

Cunisset-Carnot, 533

Cynodont teeth, 3 I 2

Czarnowski, 259

Daggers, alleged pre-Chellean, 229

Dale, W., 278

Daleau, F., 244, 45 I ff., 524

Dances, $482,496 \mathrm{f}$.

Dancing figures, 63, I 54, 468 ff., 497 , 501

Darenth, I 54

Darmsden, I 56

Dartford, 219, 22 I, 27 I, 31 3

Darts, 388

Dating of ancient deposits ; see Chrono$\log y$

Daun stadium, 32

Dawkins, W. Boyd, I 54, I 96, I 97, 43 I f., 508,554

Dawson, C., 196, 199, 200, 203

Déchelette, J., I 52, I 53, I 57, I67, I9 I, $224,229,245,346,408,477,514$

Deckenschotter, 29

Dee, river, Azilian harpoons from, 533; pygmy flints from, 537
Deformation of skulls, artificial, 107

Degeneration of Mousterian Man, 284 of Palaeolithic Art, $53 \mathrm{I}$

Delgado, J. F. N., I6r, 249

Delvaux, M., 166, I 88

Deniker, J., I06, I 12

Denise skull, 21 4, 2 I 5, 217,310

Denmark, 9,57 ; peat-mosses in, ro

Departmental gods, I4I

Deperet, C., 586

Derived implements, 46, 262

Descent of Man, 93

Descriptive relationship, $123 \mathrm{ff}$.

Desnoyers, J., I 57

Development of Man, 204; of Upper Palaeolithic Man, 385; see also Evolution

Devonshire, Palaeolithic sites in, 279

Dewey, H., 27 I

Dewlish, I 57, 278 ; elephant-trap at, 18.5 !

Dharvent, I., 440

Diablotins, 470

Differences between Man and ape, 94

Discs, Acheulean, 239

Disc-scrapers, 327

Discussion of eoliths, $164 \mathrm{ff}$.

Diseases in ancient bones, $285,286,349$, $35^{\circ}$

Disposal of archaeological material, 2 I

Disque-racloir, 327

Divisions of the Stone Age, 12

Dixon, A. F., 54I

Dog, domestication of the $498,520,560$

Dolichocephalic skulls, 105 , 106

Domestication of animals, effect upon communal life of, 130

Dorsetshire, eoliths from, 156; Palaeolithic sites in, 280

Double, A. F. le, 285

Double patination, $5 \mathrm{I}$

Doudou, E., 402

Douglas, Rev. J., 5

Dover, Strait of, 252, 254

Dress, Palaeolithic, 497, 5 I 2

Drinking-cups, skulls made into, 376 , 400

Droop, J. P., 22

Duan, 165

Dubalen, 532

Dubois, E., 177, I 80,183

Dubus, A., 282

Duckworth, W. L. H., 178, 180, 196, 202, 216, 219, 222, 289, 432

Ducrost, Abbé, 37 I

Dufaure, l'abri, 532

Duk-duk, 468, 470, $50 \mathrm{I}$

Duparc, 383

Dupont, E., 290, 293, 409, 544, 547, 548

Dürntenian interglaciation, 36

Duruthy, M., cave of, 383

D'Urville, 512

Dutt, W. A., 34I

Dysharmonic heads, 107

Eagle-beak implements; see Rostrocarinate 
Earth, formation of the, $23 \mathrm{ff}$.

East Dean, 554

Eckhard, Io

Effects, of Ice Age upon European mammals, 57 ; of a blow upon flint, I46; of fire upon flint, 145

Egypt, eoliths in, I9I

Egyptians, a suggested origin of, 579

Ehringsdorf, $257 \mathrm{f}$.; jaw from, $217 \mathrm{f}$.

Eighteenth century, archaeology in, 5

Elders, Councils of, I 33

Elephants, chronology of, 92; prehistoric, 224, 246

Elephant-trap at Dewlish, $185 \mathrm{f}$.

Elf-shot cattle, 4

Elliot, G. F. Scott, $35^{1}$

Ellipsoid skulls, I 08

Elsern, 424

Emilia, 243

Endogamy, 127

End-scrapers, 323, 362, 376

Enfants, Grotte des, 353; see also Mentone caves

Engis, 8, 402, 542

Engraver-chisels, 327

Engravers, $363,367,376$

Enlène, 474

Environment, modifying influence of, upon racial characters, 107, I I0

Eoanthropus dawsoni, I92, $196 \mathrm{ff}$; the name, 204, 217

Eocene, 25

Eocene eoliths, $163 \mathrm{ff}$.

Eolithic period, definition of, 13

Eoliths, 145, $148 \mathrm{ff}$.; bibliography of, 177 ; conclusions as to, 175 ; definition and origin of, 148, 149; discussion of, 164 ; Quaternary, 187 ; in Thames valley, 262; use of, 173 ; found with Piltdown skull, 200

Epipalaeolithic, $5^{17}$

Erith, 262

Erosion, river, 44

Eskimo, r 07, 395 f., 595

Espélungues d'Arudy, Les, 464, 477

Essex, eoliths from, 156; Palaeolithic sites in, 280

Evans, Sir A. J., 356

Evans, Sir J., 3, 4, 146, I 52, I 54, 259, $264,275,278,432,434$

Evil eye, 509

Evolution in the animal kingdom, 59; of Culture, I 15 ; religious and political, relation between, 142 ; of man as indicated by intermediate forms, 204; of Palaeolithic art, 442, 459

Excavation, methods and purpose of, I $5 \mathrm{ff}$.

Exogamy, 127

Exteens, M., 17 I

Eye-shape as a race criterion, II I

Eyzies, Les, 284, 333

Face-shape as a race criterion, I I I

Facial angle, Ir2

Fagnian industry, 163
Fallaize, E. N., 307

Family, meaning of the word, 122

Faniese, 2 I I

Farnham, 262, $265 \mathrm{f}$.

Fauna of Lower Palaeolithic, 223: of Middle, 314; of Aurignacian, 360; of Solutrean, 376 ; of Magdalenian, 386; see also Animals, and Chap. III.

Faure, 47I

Faustkeil, 230

Favraud, A., 305, $330 \mathrm{f}$

Favreau, P., 92

Feldhofergrotte, 286

Felidae, 70

Fen district, 275

Fère-en-Tardenoise, 535

Ferrassie, La, 295, 344, 345, 353, 406

Ferraz de Macedo, 184

Fetichism, 137

Fibrolite, 52

Ficrons, 237, 252, 264

Figure-stones, $438 \mathrm{ff}$.

Filhol, H., 305

Fire, discovery and use of, I 19,163

Fischer, H., 526

Fisher, Rev. O., 186

Fishing implements, supposed, $392 \mathrm{f}$.

Flake knives of flint, $327,363,386$

Flakes, Chellean, 233; Acheulean, 239

Flint, effects upon, of a blow, 146; of heat, 145; industrial use of, I45: nature of, $49 \mathrm{ff}$.

Floors, Palaeolithic, 266, 270, 273

Fonseca Cardoso, A. A. da, 249

Fonsomme, $25^{\circ}$

Font-de-Gaume, 82, 84, 458, 459, $485 \mathrm{ff}$.

Fontès, J., 249

Font-Robert, 370, 407

Forchhammer, 10

Forestian interglaciations, 36

Forests, submarine, 40, 43

Formation of caves, $46 \mathrm{f}$.; of the earth, $23 \mathrm{ff}$.

Fouju, 50

Fraipont, J., 294, 295

France, 56; Lower Palaeolithic in, $244 \mathrm{ff}$. $249 \mathrm{ff}$; Middle, 335, 336; Upper, $406 \mathrm{ff} ., 400 \mathrm{ff}$.

Frauenholz, J., 4I 5

Frazer, Sir J. G., 126

Frere, J., 7, 590

Fritsch, K. von, 217

Frobenius, L., 499

Frome river, 276,278

Frontal, Trou de, 547

Fuhlrott, Dr, 286

Furfooz, 547, 548

Furninha, 248

Gafsa, 537

Galley Hill skeleton, 222, 313, 359, 375

Gargano, 244

Gargas, 455,482 , 5 I I

Garonne river, 244, 284

Garrigou, P., 456 
Gaudry, A., 354, 586

Geikie, J., 36, 40, $5^{8} 5$

Geis, 136

Geognosy, $49 \mathrm{f}$.

Geography, archaeological, of Europe, $54 \mathrm{ff}$.

Geological history of the earth, 23; table of, 37

Geological prolegomena, $23 \mathrm{ff}$.

Geotechnics, 37 ff.

Germany, 56; Lower Palaeolithic in, 25.5; Niddle, 336 ; Upper, 4 ro

Ghilain, M., I70

Giants, beliefs regarding, 5

Gibraltar skull, 289, 290

Gillet, $\mathrm{M} .$, r $>0$

Girod, P., 71, 396, 408, 5 I 4

Giuffrida-Ruggie: i, 576

Givaux, $33 \mathrm{I}$

Givenchy, P. de, 172

Glabella, 105

Glaciation, European centres of, $27 \mathrm{ff}$.

(ilaciers, $26 \mathrm{ff}$.

Gods, departmental, I 4 I ; development of belief in, I $40 \mathrm{ff}$.

Götze, A., 217

(jolino, 405

Gomme, Sir G. L., I3 I

(iontzy, +35

Gorjanovic-Kramberger, K., 285, 310, 359

(jough's cavern, 433

Gourdan cave, $65,77,85,466,470$

Govet cave, $54^{5}$

(ilanite, 53

(irattoir, 323 ; à bec, 3.26 ; nucléiforme, 388

(iravette, La, 407

Gravette points, 368,376

(iray's Inn, London, 7, 266 .

(irays 'Thurrock, 1 56, 262, 273

Greatham, $3+2$

(ireece, 56

Grenelle, skull-type of, 541,548

(irew, E. S., 156

Grize, La, 452

Grimaldi caves; see Mentone

Grimaldi race, 354

(irime's graves, 430

(irist, C. J., 156,173

(irotta, la, 335

Crotte du 'T'rilobite; see Arev-sur-Cure

(iroup-marriage, 127

(irovelands, 265

Gruchy, G. F. B. de, 306

(ischnitz stadium, 32

(judenus cave, 426

(;ïnther, A., 412

(jünz glaciation, $30,3 \mathrm{I}$

(jünz-Minclel interglaciation, 31

(ivillon, C., $3 \delta_{1}, 3 \delta_{3}$

Haberlandt, A., 5

I Iabitation, classification of humanity by, 120

Hacker, P. I., 426
Haddon, A. C., 499, 5 I 5

Hafting of coup-de-poing, $229 \mathrm{f}$.

Hair, dressing of, $445 \mathrm{ff}$., $45 \mathrm{I}$

Hair-texture as a race criterion, I I I

Halaváts, J. von, 259

Halling, skeleton from, 384

Hallström, G., 570

Hampshire, eoliths from, I 56 ; Palaeolithic sites in, 280

Hamy, E. 'T., 21 5, $219,221,222,289$, 306,543

Hand-axe, 229

Hands, figures of, $455 \mathrm{ff}$., 509, 5 I I

Harlé, E., 77, 91

Harness, supposed representations of, in Palaeolithic art, $518 \mathrm{ff}$.

Harpoons, 389 ff. ; Azilian, 525, 526

Harrison, B., I 54

Hauser, O., 208, 318

Hauzeur, N., $54^{8}$

Havre, submarine station at, $4 \mathbf{I}$

Haward, F. N., I67

Heacham, 434

Headdress, Upper Palaeolithic, 5 I 3

Head form, 105

Hearth-burials, 372

Hearths at Penzance, 185,186

Heat, effects of, upon flint, 145

Heidelberg jaw, $192 \mathrm{ff}$.; see also Mauer

Heierli, J., 4I9, 42I

Hélin, pre-Chellean from, 228

Hell, rock-carvings at, 570

Henotheism, I 42

Herman, O., 259, 425

Hermannshöhle, 340

Hernándes-Pacheco, E., 307

Hertfordshire, Palaeolithic sites in, 280

Hervé, G., 375, 544

Hesiod, 9

Hiatus between Palaeolithic and Neolithic, 516

Hides of animals, preparation of, $32 \mathrm{I}$

Higgins, R. B., 342

Hilber, V., 77

Hillebrand, E., 423, 425

Hinton, M. S. C., 270

Historic defined, 15

History and archaeology, I

History of archaeological research, $2 \mathrm{ff}$.

Hoernes, M., Io, I I, 1 4, 94, 206, 373, 412,429

Hötting breccia, 33

Hohlefels, 360

Holland, 56, 255

Holmes, W. H., I 68

Holocene, 26

Homerton, 270

Homo heidelbergensis, $192 \mathrm{ff}$.

Homosimius, 94, 98, 204

Horn, industrial use of, 363

Hornblende, 53

Hornos de la Peña, 63, 64, 454 ff., 482

Horse, supposed domestication of, 518

Hoteaux, Les, skeleton, 38I ff.

Houssay, F., I 63

Hoxne, 7, 279, 590 
Hrdlička, A., 178, 1 80, 1 82, 1 83, 196, $199,288,289,374,502,581$

Human classification, table of, 143

Human figures in Palaeolithic art, peculiarities of, 468

Human remains of Lower Palaeolithic, 212 ; of Middle, 285 ; of Aurignacian, 348 ; of Solutrean, 373 ; of Magdalenian, 380

Hundisburg, 258

Hungary, Lower Palaeolithic in, 259; Middle, 340; Upper, 423

Hunter, area required for his sustenance, 520

Huntow, 279

Huntsman, supposed representation of a, $470 \mathrm{f}$.

Hut-burials, 372

Huxley, T. H., 30r

Hyaenidae, 68

Iberian Peninsula, 56; Lower Palaeolithic in, 246; Middle, 336 ; Upper, $409,537 \mathrm{f}$.

Ice Age, $26 \mathrm{ff}$.; effect of, upon European mammals, $87 \mathrm{ff}$.

Iceland, 57

Icenian industry, 153,158

Idols, 50o

Ilm valley, 202, $257 \mathrm{f}$.

Imbert, M., 232

Imola, 334

Implements found with Piltdown skull, $200 \mathrm{ff}$.; of Lower Palaeolithic, $225 \mathrm{ff}$.; of Middle, 3 I 5 ; of Aurignacian, 360 ; of Solutrean, 376 ; of Magdalenian, 386

Incomplete figures in Palaeolithic art, possible meaning of, 503

Index, cephalic, 105; cranial, I05; facial, I I I ; nasal, I I I ; orbital, I I I

Indo-European languages, I 16

Industrial use of flint, 145

Inflexional languages, 116

Innate implements, 46, 262

Innsbrück, 38

Insectivora, 64

Instruments of culture, classification of mankind by, 120

Interments, Upper Palaeolithic, 50I

Ipswich, $158,176,222,341,403$

Ireland, 4,57 ; eoliths from, ${ }_{5} 6$

Iron Age, 11

Iroquois, relationship among, 124

Irpfelhöhle, 339

Isolating language, 114

Issel, 184

Isturitz, 401 ; jaw from, 310

Italy, 56; I.ower Palaeolithic in, 24I; Middle, 334; Upper, 405

Itchen river, 278

Jacob, K. H., 256

Jade, 52

Jadeite, 52

Jammes, L., 468
Janda, La, 247

Järavallen, $565 \mathrm{ff}$.

Java, 177, 206

Javelin-heads, $320,376 \mathrm{ff}$.

Javelin-propulsors, 396

Jeannel, R., 468

Jenerálka, 424

Jeržmanowice, 429

Jessen, A., 565

Jini, E. Africa, 54I

Johnson, J. P., 262, 578

Joslowitz, 424

Jousset de Bellesme, ${ }_{46} 6$

Jussieu, B. de, 5

Kadić, O., 425

Kärlich, 412

Kamensky, 439

Kartstein, 339, 4r 2

Kastlhäng, 4I 5

Keiss, painted pebbles from, 528

Keith, A., 94, 103, 180, 183, 196, 199, $213,215,219,221,222,289,307$ 312, 354, 375, 432 [now Sir A. Keith]

Kempston, 51

Kendall, Rev. H. G. O., ${ }_{5}^{8}$

Kennard, A. S., 270

Kennet river, 265

Kent, Palaeolithic sites in, 280

Kent's cavern, 47, $43^{\circ}$

Kentian industry, $153 \mathrm{ff}$.

Kesslerloch, 76, 419

Kiessling, F., 424

Kiev, 436,546

Kilroot, 554

Kingship, evolution of, 132

Kinship, 121 ; definition and expression of, 122

Kjellmark, K., 565

Klaatsch, H., 94, I48, I 52, I $_{54}, 1_{62}$, I 69, I7 I , I 89, 2 I 5, 222, 295, 298, 3 I 8 , $359,360,375$

Knives, Chellean, 233 ; flake, 327

Knowles, W. J., I 56, 32 I

Koch-Grünberg, T., 499

Køkkenmøddinger; see Shell-heaps

Kola peninsula, 43

Kormos, T., 34r, 423, 426

Kossinna, G., 359, 570

Kostelík, 427

Koștenky, 436

Kozarnia cave, 429

Krapina, 285, 307 ff., 3 1 4, 345, 353, 544

Kratzer, 323

Krause, E., I 50, 169

Krems, 425

Kứǐz, M., 373, 426, 427

Kroeber, A. L., 124

Kůlna cave, 426

Kupka, H., 552

Kurgans, 502

Lacave, $376,408,478,513$

Lake-dwellings, $56 \mathrm{I}$; of Switzerland, I I

Lakenheath, 275

Lalanne, G., 333, 448, 451, 464 
Laloy, L., 576

Lamps, stone, 402

Land-bridges, $38 \mathrm{f}$.

Land-oscillation, $37 \mathrm{ff}$.

Lang, A., I 26, I 44, 51 5, 528

Language, nature of, I 12 ; origin of, I $_{3} 3$, I $6 \mathrm{ff}$.

Languages, groups of, I I 4

Langue de chat, 230

Langwith, 433

Lankester, Sir E. R., I 58, I60, I6I

Laplanders, 395

Laporterie, J. de, 406

Lark river, 275, 276, 590

Larkby, J. R., I 54, I67

Larne, 554

Lartet, E., 81 , 84, 33 I , 349, 383, 399, 442

Lasham, F., 265

Laufen oscillation, 32

Laugerie Basse, 70, 7 I, 344, 380, 398 f. $408,447,47$ I , 474, 5 I 2, 5 I 4

Laugerie Haute, 69, 373, 408, 5 I 4

Laussel, 448 ff., 464

Lautsch, cave of, 384,429

Laville, A., I64

Lea river, $26 \mathrm{I}, 26_{5} \mathrm{ff}$.

Leach, A. L., 27 I

Lee, J. E., 42 I

Lehmann-Nitsche, 286

Leland, J., 7

Leptoprosopic, I 12

Leptorhine, I I I

Lesignano, 335

Lespugne, 468

Lesse river, 290

Letourneau, C., 96

Leugny, 246

Levallois scraper, $239 \mathrm{ff}$.

Life, appearance of, 24; origin and nature of, 58

Lighting of caverns, 402

Liguria, 56; Palaeolithic in; see France

Limandes, 237

Limitations of archaeological knowledge, I 8

Linguistic palaeontology, fallacy of, I I 8

Lisch, F., Io

Lissauer, A., 202

List of pleistocene mammalia, 62

Littorina minimum, 43

Littorina sea, 43,560

Löss, $33 \mathrm{f}$.

Lohest, M., 293, 295

Loire valley, 255

Lokve, 426

Lomas, J., I 56

London, coup-de-poing from Gray's Inn in, 7 ; Palaeolithic sites in, 280

Lorraine, 255

Lorthet, 75, 47 1, 493

Lourde, 85

Lower Palaeolithic, $207 \mathrm{ff}$.

Lubbock, Sir J.; see Avebury, Lord

Lubna, 424

Lucretius, 9

Luquet, G. H., 468
Luschan, F. von, 375, 440, 499

Luzel, F. M., 502

Lyell, Sir C., Io, 214,289

MacCurdy, G. G., I 56, 177, 217

Maces, 320

McEnery, Rev. J., 430

M'Gillivray, 5 I 2

McLennan, J. F., I 24

Madeleine, La, 8I, 396, 408

Madsen, A. P., 535 ff.

Mafflian eoliths, 187

Magdalenian, 56, 348, 380 ff.

Magdalenian people, origin of, 385

Magdalenian art, development of, $464 \mathrm{ff}$.

Magic, I36, 480, 493, 506, 519, 522; contrasted with religion, 138,143

Magitot, E., 5 I I

Maglemose, $560 \mathrm{ff}$., 568

Magrite, Trou, 545

Mahoudeau, 163

Mahudel, N., 5, ro

Majella, La, 243, 334

Makowski, A., 375

Malarnaud jaw, 304

Mallerup, 560

Mammalia, classification of, 6r ; Pleistocene, list of, $62 \mathrm{ff}$.

Man, development of, 204

Mana, I35 ff.

Manzanares river, 247

Marbodaeus Gallus, 3

March, C., I 86

Marche, La, 242

Marcilly-sur-Eure, skeleton, 3 ro

Maret, de, 543

Marett, R. R., I 40, I4I, 306, 489, 503

Marignac, 244

Markkleeberg, 256

Marne valley, 254

Marques de chasse, $45 \mathrm{I}$; see also Tallymarks

Marriage by capture, I29; by exchange, I 29; regulation of, $127 \mathrm{ff}$.

Marrow, 291, 320

Marsoulas, 454, 470, 487, $505 \mathrm{f}$

Martin, H., 30I ff., 321 , 329, 33 I ff., 372

Martin, P. A. B., I 56

Mas d'Azil, Le, 78, 85, 388, 408, 443, $464,468,479,5$ 12, 523 ff., 532, 537

Mascots, 137

Maška, K., 373, 374, 426, 427, 462

Mason, O.'T., I 68, 396

Massénat, E., 71, 396, 514

Material, archaeological, disposal of, 21 ; method of obtaining, I 5 ; treatment of, 17

Materials of culture, classification of humanity by, 120

Mathews, R. H., 509

Matiegka, H., 346

Matres, I42

Matriarchate, 129

Matrilinear succession, I 29

Matrilocal marriage, 129

Matter, origin of, 23 
Mauer jaw, I 92 ff., 204, 255, 59 I

Mayet, L., 162, I77, $5^{8} 5$

Mealhada, 249

Mecklenburgian glaciation, 36

Medicine-man, 133, 134

Mediterranean race, characteristics of, 112

Medway river, 154

Megaseme, I I I

Mège, l'abri, 470

Melanochrous peoples, 109

Menchecourt, 252

Mentone caves, $77,244,512,586$; fauna of, 223 ; skeletons of, $352 \mathrm{ff}$.

Mercati, M., 4

Merk, K., 419, 42 I

Mesaticephalic, I05, 106

Mesocephalic, 105, I06

Mesolithic defined, 12, 516; period, $516 \mathrm{ff}$.

Mesoprocopic, II 12

Mesorhine, I I I

Mesoseme, I I I

Mesozoic period, 25

Message-sticks, 479

Mesvin, pre-Chellean from, 228

Mesvinian eoliths, I 87

Metternich, 4I 4

Mezin, 437, 475

Michaelis, A., I 4

Micoque, La, coups-de-poing of, 239, 240,258

Microseme, I I I

Middle Palaeolithic defined, 209: fauna of, 3 I 4 ; implements of, $315 \mathrm{ff}$.

Middlesex, Palaeolithic sites in, 280

Mildenhall, 275,34I

Miller, G. S., I 99

Milne-Edwards, 84

Mindel glaciation, 30,31

Mindel-Riss interglaciation, $3 \mathbf{I}$

Miocene, 25 ; eoliths, I6 I

Miskolcz, 259, 423, 425

Mochi, A., 242, 243, 335, 405

Mode of life, classification of humanity by, 120; in Upper Palaeolithic, 500

Modern representatives of European Palaeolithic man, $595 \mathrm{f}$.

Modestov, B., 244

Mörnsheim, cave at, 60

Mötefindt, H., Io

Moir, J. P., I 7 I

Moir, J. R., I 56, I 58, I 60, I67, 34I

Möller, 202

Monogamy, 127

Monoglacia! hypothesis, 35

Monotheism, 142

Mons, I66, 176

Montandon, R., 370, 423

Montastruc, 408, $47 \mathrm{I}$; see also Bruniquel

Montières, 249, 586; coup-de-poing of 239,252

Moraines, 28, 35

Morgan, E. and H. de, 549

Morgan, J., 537

Morgan, L. H., I 23, I 24, 126
Mortillet, A. de, $147,185,255,396,475$, $535,536,552$

Mortillet, G. de, 41, 147, 1 53, I 57, 165 . $184,211,219,221,229,232,233$, $245,246,247,254,255,373,390$, $399,401,446,452,514,518,586$

Motion, representation of, in Palaeolithic art, $47 \mathrm{I}$.

Mousterian culture, phases of, $3 \times 8$

Mousterian Man, disappearance of, 347 ; evolution of, 313 ; physical characters of, $311 \mathrm{ff}$.

Mousterian stage, $284 \mathrm{ff}$.

Moustier, Le, 284, $316,335,344$; skeleton from, $296 \mathrm{ff}$.

Mouthe, La, 402, 453, 454, 459

Müller, Sophus, $9,10,55^{8}$

Muller, H., 402, 532

Munck, de, 170

Munro, R., r4, 95, 183, 533

Munzingen, 417

Mustelidae, 68

Mutilation of hands, 458, 5 I I ; of Upper Palaeolithic art, 504

Mya period, 43, 44

Nadder river, 276

Narverød, 148

Naulette, La, jaw from, 289 ff., 545

Naviform devices, $492 \mathrm{f}$.

Navigation, origin of, 522,560

Nayland, 474

Neandertal skeleton, $285 \mathrm{ff}$.

Needles, 396 ff., 525

Negroids, 353

Nehring, A., 92, 216,412

Nene river, 279

Neolithic, definition of, 12

Neolithic flints, glacial striae upon, 593

Nephrite, 52

Nets, representation of, 493

Nettlebed, 434

Neu Essing, 418; tooth from, 218; skeleton, 376

Newton, E. T., 222

Neyrinckx, 188

Niaux, 488, 504

Nicholson, 92

Niederle, L., 437

Niedernau, 4 I 5

Nikitine, S., 435

Nilsson, 10

Nineteenth century, discoveries during, 7

Nördlingen, 4I I

Nomenclature of stages of Palaeolithic civilisation, 210; of early human remains, 204

Nordic race, characteristics of, I I 2

Norfolk, eoliths from, 156; Palaeolithic sites in, 280

Norfolkian interglaciation, 36

Northern ice-centre, $35 \mathrm{ff}$.

Norway and Sweden, Campignian in, 565 ; Magdalenian art in, 570

Nose-shape a race criterion, I I I

Nostvet, $56_{5}, 568$ 
Notched scrapers, $324,325,366$

Nudity, Palaeolithic, 5 I 2

Nuesch, J., 419, 421

Nunataks, 27, 584

Nuttall, G. H. F., 93

Nyerup, Rasmus, 9

Oban, Azilian caves at, 533, 534

Obercassel, 384

Ober Laibach, 77

Obermaier, H., 34, 164, 177, 202, 218, $219,224,239,247,258,259,289,304$, 307,3 I0, 3 II , 336, 376, 400, 4I 5, 4I 8 , $424 \mathrm{ff} ., 462,489,503,528$ ff., 584 , 586,591

Obsidian, 52

Obtaining of archaeological material, 15

Occiput, I05

Ochos jaw, 307

Ofnet, caves, 4II f., 4I4, 539

Ojców, 259, 359, 427

Oldoway skeleton, 575

Oligocene, 25 ; eoliths, 163

Ollezy, $25^{\circ}$

Olmo, L', skull from, $219 \mathrm{ff}$.

Ondratitz, 426

Ooid skulls, I08

Oreston cave, $43 \circ$

Organisation of human communities, I2I

Origin of European peoples, $57 \mathrm{I} \mathrm{ff}$.

Ormeaux, A. L. des, 395

Ornaments, Chellean personal, $234 \mathrm{ff}$; Aurignacian, 356

Oronsay, Azilian settlements on, 533, 535,554

Osborn, H.F., 92, 94, I83, 350, 384, 554

Oscillation of land, $37 \mathrm{ff}$.

Ota (or Otta), 161, 162, 165

Ouse river, 273

Ouse, Little, 275

Ouse, Sussex, 196

Oxford, 262, 263

Oxfordshire, Palaeolithic sites in, 28I

Painted bones, 502

Painting, technique of, 484 ; of body, 5 II

Pair-non-Pair, $45 \mathrm{I} f$.

Palaeolithic defined, 12; Age, divisions of, 56; Man, modern European representatives of, 595

Palaeontological prolegomena, $58 \mathrm{ff}$.

Palaeontology, importance of, to the archaeologist, 59

Palaeozoic period, 25

Palomba, La, 248

Panes, 248

Parat, Abbé, 306, 384, 403, 543

Parsons, F. G., 384

Paterson, Miss H. L., 537

Patina of flint, 5० f.; double, 5 I, 239

Patriarchate, 129

Patrilinear succession, 129

Patrilocal marriage, 129

Paula e Oliviera, F. de, 543

Paulus, Abbé, 256

Paviland, $345,358,43 \circ$
Peat, 44, 49; submarine, 40

Peat-mosses of Denmark, stratification of, 10

Pebbles, coloured, from Le Mas d'Azil, $527 \mathrm{ff}$; from other places, 532; with polychrome decoration, 533

Peccadeau de l'Isle, 407

Pech de l'Azé, jaw from, 304

Pencenedl, 132

Penck, A., 26, 29 ff., 584, 585, 59I

Pendants, 420

Pentagonoid skulls, 108

Penzance hearths, 185, r 86

Périgueux, 245

Péronne, 250

Perry, H. de, 37 I

Perugia, 242, 243

Perugina, 2 I I

Petit Puymoyen, Le, 305, 330

Petrie, George, 174

Petrie, W. M. F., 22

Peyrony, D., 295, 304, 369, 407, 454, 485

Pfeiffer, L., 32 I, 393

Phallic objects, 474

Phases defined, 209; of Mousterian culture, 3 I 8

Photography, use and abuse of, 16

Physical characters of Mousterian Man, 3 I I ff.

Physical classification; see Racial classification

Picks, Campignian, $55^{\circ}$

Piercers, Acheulean, 239

Piette, E., 64, 406, 442, 447, 480, 5 r8, $523 \mathrm{ff}$.

Piltdown skull, r 96 ff., 204, 216, 329, 591 ; implements found with, $200 \mathrm{ff}$.; problems surrounding, 203

Pindal, 83, 459

Pinnipedia, 71

Pissot, J., 585

Pithecanthropus, use of the word, 204

Pithecanthropus erectus, $177 \mathrm{ff}$.; femur of, I 78 ; place of, in human evolution, I 82 ; skull of, 180 ; teeth of, 182

Pittard, E., 330, 370

Pitt-Rivers, 396

Placard, 66, 376, 400, 475, 502, 543

Planes, 388

Plateau of Kent, I 54, I71, 172, $270 \mathrm{ff}$.

Platyrrhine, II I

Pleistocene, 26

Pliny, 3, 4

Pliocene, 25 ; conditions of life in, 62

Pocala, 405

Poignards, alleged, from Strépy, 228; supposed horn, $398 \mathrm{ff}$. .

Pointe à cran, 378

Pointed instruments, Chellean, 233

Points, Mousterian, $318 \mathrm{ff}$.

Poisoned weapons, $390 \mathrm{ff}$.

Polishers, Mousterian bone, 401 .

Political evolution, I30; relation between and religious evolution, 142

Polonian glaciation, 36 
Polyandry, 127

Polygamy, 127

Polyglacial hypothesis, 35

Polygyny, 127

Polysynthetic languages, I I 5

Pontlevoy, I 50

Pont-Neuf, Le, 33 I, 406

Popular notions regarding antiquities, 2, 3

Porphyry, 53

Portcuthno, 434

Portel, 468

Portrush, 554

Portugal, Lower Palaeolithic in, 248; Middle, 336

Posados, 247

Pottery, 12, 402 ff., 552, 553

Prah sands, 186

Prarond, E., 8

Pre-archaeolithic culture, 152

Pre-Chellean 56, 210 ; implements of, $225 \mathrm{ff}$; of River Somme, 252; of Thames valley, 262

Předmost. $373,426,462 \mathrm{ff}$., 500, $5 \mathrm{II}$, 512,581

Pre-eolithic culture, 142

Prehistoric defined, 15

Pre-history and archaeology, 2

Prestian industry, $154,{ }_{5} 6$

Prestwich, Sir J., 1 54, I 55, I 7 I , 270

Prickers, 376

Prigg, H., 2 I $2 \mathrm{ff}$.

Primary period, 25

Primates, 62 ; genealogy of, 94

Propstfels, 418

Propulsors, 396

Prognathism, I I 2, 218

Protoneolithic, $5 \mathrm{I} 7$

Pruner-Bey, 349, 350, 547

Pseudo-eoliths, 170

Psychology of Lower Palaeolithic Man 281 ; of Middle, 342 ; of Upper, 438

Puente Mocho, 247

Purpose of archaeological research, I, 15 ; of Magdalenian art, 505

Puy Courny, Le, I61, I67, 174

Puydt, M. de, 293, 295

Pygmy flints, 370,535

Pygmy skeletons, 422

Pyrenean ice-centre, 27, 34

Quartz and quartzite, Chellean tools in, 234

Quaternary period, 25 ; eoliths, 187

Quatrefages, A. de, $221,222,349$

Quilgars, H., 537

Quina, La, 301 ff:, $328 \mathrm{ff}$., 334, 517

Rabots, 388

Race, criteria of, ro5; definition of, 99, 100

Race and species in human classification, I03

Racial classification of humanity, $99 \mathrm{ff}$.

Racloirs, 32 I

Rademacher, C., 229, 339
Räuberhöhle, 340, 4 I 2

Ragazzoni, I 83

Raised beaches, $4 \mathrm{I}, 554$; of Britain, 43

Rames, J. B., I6I

Ramridge End, 214

Raymonden, 86

Rea river, 278

Reading, $264 \mathrm{f}$.

Reber, B., 423

Reconstruction of flint nodules, 268

Regions and zones, archaeological, in Europe, $54 \mathrm{ff}$.

Regnault, F., 305, 443, 456, 487, 523

Reid, C., r86, 276, 278, 28 I

Reinach, S., 3, 14, 151, 161, 165, 175, $217,229,232,254,395,446,508$

Reinhardt, L., I 74, I87, I 88

Religion, 136 ; of Middle Palaeolithic Man, 343 ff.; Primitive, difficulty of studying, I34; Upper Palaeolithic, 500

Religious classification of humanity, 134 ff.; development, in Man, 96; and political evolution, relation between, 142

Remaniement, 48

Repository of archaeological material, 22

Requisites of archaeological research, I 4

Re-sortment of soil, 172

Restorations of Palaeolithic Man, 350; of flint nodules, 268

Retouch, meaning of, 148,169

Reutelian eoliths, 187

Reuviau, Trou, 547

Revolt of man against animal existence, 95

Re-worked flints, 51, 239

Reynier, 50, 255

Rhens, 4 I4

Ribiero, C., I6r

Richthoven, F. von, 34

Rigollot, 236

Rinnehügel, 395

Ripley, W. Z., I 12, 595

Riss glaciation, 30, 3 I

Riss-Würm interglaciation, $3 \mathbf{I}$

River erosion, 44

Rivière, 239, 402, 453

Rivole, 554

Robert, L., 499

Robin Hood's cave, 433, 474

Rochbertier, 478

Roches, l'abri des, 484

Rochette, La, 359

Rock scribings in Norway, 570

Rodas, 245

Rodentia, 7 I ; Alpine, invasion of Europe bv, $90,9 \mathrm{I}$

Roding river, 270

Rods, Magdalenian bone, $40 \mathrm{I}$

Römer, F., 425, 429

Romain, G., 41, 552

Rond, Le, 409

Rosette, Trou, 547

Rostro-carinate implements, $5^{8} \mathrm{ff}$., 176 
Roth, H. Ling, 372

Rübeland caves, 340

Rüderbach, 257

Rütimeyer, L., 419, 421

Russia, 55, 57; glaciation of, 35 ; Palaeolithic in, 259, 435

Ruth, Le, 407

Rutot, A., 50, 149, I 52, I 54, I 57, I62, I63, I 70, I 77, I 87, I 89, 222, 282, 330, $331,346,351,403$

Rzehak, A., 307

Sablon, 255

Sadika marriage, 129

Saint-Acheul, 2 I I , 223, 226 ff., 233, 236, 249,253

Saint-Brélade, teeth from, 306

Saint-Marcel, 474, 477, 48I

Saint-Martory, $9 \mathrm{I}$

Saint-Michel d'Arudy, 7 I, 5 I 8

Saint-Prest, I 56, I 57

Saint Wolfgang, cave of, 60

Salisbury, 276

Saltley, 278

San Felice de Buelna, 248

San Isidro, 247,248

Sandstone, 50, 53; Chellean tools in, 234

Santa Maria dei Bagni, 335

Santerno river, 334

Sarasin, F., 177, 206, 533

Sarasin, P., 206, 244

Sarauw, G. F. L., 56 I

Sauer, A., 192

Saussure, S. de, 423

Sauvage, 215

Saws, 325, 326

Saxmundham, 474

Saxonian glaciation, 36

Scalea, 335

Scandinavia, 57 ; glaciation of, 35 ; landoscillations in, $4 \mathrm{I} \mathrm{ff}$.

Scandinavian race, characteristics of, I 12

Scanian oscillation, 36

Schaafhausen, 307, 375, 4I 6

Schaber, 32 I

Scharff, R. F., 92

Schenk, A., 423

Schliemann, H., 13

Schliz, M., 54I f.

Schlosser, M., 60, 41 5

Schmerling, P. C., 7,8

Schmidt, R. R., I 4, 216, $217,229,257$, $258,259,337,340,410 \mathrm{ff}$., $418 \mathrm{ff}$., $539,541,584$

Schmit, E., 484

Schötensack, O., I 96, 2 I 7, 393, 395, 41 8, 572

Schumacher, E., 257

Schwalbe, G., 182, 217, 310, 375

Schwankungen, 32

Schweinfurth, G., I9I

Schweizersbild, das, 8I , 42 I

Scott, Sir W., 5

Scrapers, Chellean, 233; from La Vignole, $24 \mathrm{I}$; Solutrean, 380
Sculpture, Aurignacian, 443

Secondary chipping, I 49, 388

Secondary period, 25

Seeds found in Le Mas d'Azil, 524

Seine valley, 254

Selenka, L., I 77, I 83

Seligman, C. G., 384

Sellers, G. E., I 68

Selsey Bill, I6r

Semites, suggested origin of, 579

Semitic languages, I 16

Sepulture, 343, 38 I

Sergeac, 370

Sergi, G., 108, 1 12, 183, 219

Sernander, 561

Serrano Gomez, P., 497

Settle, Yorkshire, 533

Sevenoaks, I 54

Shacklewell, 262

Shaft-straighteners, 395

Shell-heaps, Danish, 554

Shell ornaments, $5^{\mathrm{I}} 3$

Shells, artificial use of, 526

Sherbourne, 474

Sheringham, 170

Shrub Hill, 554

Shrubsole, O. A., I 56

Sicily, 56, 244; see also Italy

Side-scrapers, $321 \mathrm{ff}$.

Siena, Père, 490

Siffre, A., 305

Simonson, 421

Sinel, J., 306, 307

Šipka, 259, 307, 31 2, 341 , 427

Sirgenstein, der, 337 ff., 410, 412, 414

Skaldynger, 556

Skeat, W. W., 493

Skull-shape, 108

Skulls made into drinking-cups, 376 , 400

Sledge, representation of a, 481

Sloes, use of, 525

Smardzewitz, 259

Smith, G. Elliot, I 99, 204

Smith, H., 430

Smith, R. A., 265, 270, 271, 342

Smith, S. A., 575

Smith, Worthington G., 51, 177, 214 , $219,229,232,239,266$ ff., 283

Smyth, Brough, 499

Snodland, I 54

Snow-line, estimated height of, 31,32

Social classification of humanity, 12 I

Soldattorp, $5^{6} 5$

Solent river, 276

Sollas, W. J., 50, I6 1 , 175, 31 2, 358, 430, 434,531

Solutré, 37 I

Solutrean stage, 56, 348, $371 \mathrm{ff}$.

Solutrean people, art of, 462 ; origin of, 385 ; relation of, to Aurignacians, 580

Somervail, A., 279

Somme river, 8,262 ; history of, $252 \mathrm{ff}$.; terraces of, 45, 250; valley, 223 , $249 \mathrm{ff}$., 318

Sonning, 265 
Sorcery, 395

Sorde, 383,532

Soto de las Regueras, 248

Spain, see Iberian peninsula

Spanish group of rock-paintings, $493 \mathrm{ff}$.

Spear-heads, 320

Species and race in human classification, $103 \mathrm{ff}$.

Sphenoid skulls, 108

Spienne, pre-Chellean from, 228

Spirits, development of belief in, $138 \mathrm{f}$.

Spizyn, A., 502

Split-base points, 363,364

Spurrell, F. C. J., 168, 273

Spy skeletons, $293 \mathrm{ff}$.

Stages defined, 209

Stalagmite, $47 \mathrm{f}$.

Stature as a race criterion, 110

Steenstrup, Io

Stefanescu, G., 83

Stehn, E., 418

Steinmann, G., 418

Steppes, $33 \mathrm{ff}$.

Stevens, E. T., 4, 229

Stillfried, 424

Stobl, J., 425

Stoke Newington, 270, 273

Stolyhwo, K., 103

Stone Age, I I ; divisions of, 12

Stones for throwing, 320

Stour river, 276

Stow, G. W., 577

Stratification, importance of recording, I6; of cave deposits, $47 \mathrm{ff}$.; method of setting out, 48

Strépy, 2 10; pre-Chellean of, 228

Strepyian stage, 2 10

Striae, glacial, on Neolithic flints, 593

Sturge, W. A., 50, 275

Submarine forests, 40,43

Suetonius, 3

Suffolk, alleged bone implements from, 329; eoliths from, I56; Palaeolithic sites in, 28 I

Surrey, eoliths from, I56; Palaeolithic sites in, 281

Sussex, eoliths from, I56; Palaeolithic sites in, $28 \mathrm{I}$

Sutton, B., I 50

Swanscombe, 27 I

Switzerland, lake-dwellings of, I I

Syenite, 53

Szeleta cave, 425

Szombathy, J., 384, 424

Table of human classification, 143

Tabu, I 35

Tagus midden-heaps, 545

Tally-marks, $479 \mathrm{f}$.

Tang, evolution of, 369

Tapes period, 43

Taplow, 26I

Tardenoisian flints, 535

Tardy, C., 585

Tarté, 406 ; scraper of, 406

Tasmania, 12
Tasmanians, $171,173,282,372,531$

Tata, 340

Tatu, 5 I I

Taubach, 6o, 202, 2 I 5, 257 f., 329

Technique of flint chipping, 168

Tectiform devices, $49 \mathrm{I} \mathrm{f}$.

Teeth, animal's, connected for use, 482 ; used as amulets, 5 I 3

Terms defined 209

Terraces of rivers, how formed, $44 \cdot \mathrm{ff}$.; of Somme, 45, $25 \mathrm{I}$; of Thames, 45

Terrade, A., 327

Terrassenschotter, 29

Tertiary man, problem of, 145

Tertiary period, 25

Test of artificiality of a flint implement, 146

Test of humanity, 94

Test river, 278

Testut, L.., 38 I

Tetraprothomo argentinus, 183

Teutonic race, characters of, 112

Textiles, invention of, 522

Teyjat, 67, 470

Thames estuary, 270; history of, 260; terraces of, 45 ; valley of, $223,260 \mathrm{ff}$.

Thayngen, 76, 419, 474

Thenay flints, $150,153,163$

Theofilaktov, 435

Thetford, 275

Thiede, 4I 2

Thomsen, C. J., 9, 10

Thomsen, T., 565

Three ages, principle of, $9 \mathrm{ff}$

Thürnau, 424

Thunderbolts, stone axe-heads interpreted as, $3 \mathrm{ff}$.

Tilbury skeleton, 384

Tilloux graveis, 224, 245

Török, A. von, 259

Tokaj, 425

Tomes, 182

Tongue, M. H., 499

Tool-fashioning as a test of humanity, 97

Topinard, P., I I 2, I 85, 293

Torralba, 224, 246

Totemism, 125 f., 505

Toulmin-Nicolle, E., 306, 307

Tourassian stage, 523

Tournier, Abbé, 381,383

Trabersdorf, 424

Trade, 513

Trap for elephants at Dewlish, I85, I 86

Traps, representations of, 493

Traversetolo, 335

Treacher, L1., 265

Treatment of archaeological material, 17

Tremearne, A. J. N., 501

Trent river, 278

Trilobite, Grotte du, 403, 476; see also Arcy sur Cure

Trinil, I 77

Tubes for paint, 484

Tuc d'Audoubert, 48I ff., 5 I 5

Tuff, 2 I 4

Tundras, $33 \mathrm{f}$. 
Tuniberg, 417

Turbarian glaciations, 36

Tylor, Sir E. B., I7I

Types of coups-de-poing, 237

Tyrolian interglaciation, 36

Uhle, M., 396

Umbria, 243

Ungulata, 74

Unkelbach, 4 18

Upper Palaeolithic defined, 209; stages of, 348 ; in European regions, 405

Ural Mountains, glaciation of, 35

Ursidae, 67

Ventimigliese, 2 I I

Ver river, 265

Vercors, Le, 532

Verneau, R., 77, $353 \mathrm{ff}$.

Vernière, A., 409

Verworn, M., I62, $163,174,177,384$, 480

Veyrier, 423

Vézère river, 239, 24I, 333

Viacupa, 244

Vibrata valley, 242, 334

Vibratiana, 2I I

Viby, 564 f., 568

Vieille, E., 535

Vignette, La, $5 \circ$

Vignole, La, 24r

Villefranche-sur-Saône, 31 5, 586

Villeneuve, 423

Villeneuve, Chanoine L. de, 355

Virchow, R., 180, 217, 287, 301, 307, $34^{\circ}$

Viré, A., 408

Viste skeleton, 570

Volgu, 378

Volkov, Th., 437, 475

Wales, eoliths from, 156 ; ancient customs in, 123,132

Walton-on-the-Naze, sculptured shell from, 185

Wanderings of peoples, evidences of, 52

Wangford Warren, 434

Wankel, H., 373, 503

Wansunt, 271, 34r

Wareham, 278

Warm Mousterian, 315, 585

Warnambool, footmarks at, 573
Warren, S. H., 167

Warren Hill, 275

Waveney river, 279, 34I

Weimar, 257

Werner, P., 257

Westley; see Bury St Edmunds

Wey river, 262, 267

Whistles, 33I, 372

Whitaker, W., 224, 26r, 28r

Whitburn, 533

White, A. D., 14

Wiegers, F., 92, 177, 257, 259

Wiérzchow, 259, 340, 34I, 428 f., 514

Wildhaus, 429

Wildkirchli, 340, 583

Wildscheuer, 412, 415

Wilke, G., 359, 493, 510

Willendorf, 424 f., $447,45^{6}, 5^{1} 3$

Wilson, T., 168

Wiltshire, eoliths from, 156 ; Palaeolithic sites in, $28 \mathbf{r}$

Winchester, dedicatory inscription at, 142

Wolmaransstad, 578

Wolvercote, 262

Women working in fields, reason for, $520 \mathrm{f}$.

Wood, industrial use of, $40 \mathrm{r}$

Wooden Age, 205

Wood-Jones, F., 95

Woodley, 265

Woodward, A. S., 199, 200, 204

Woodward, H. B., 28I

Wookey Hole, 432

Worsaae, J. J. A., I0, II

Wounded animals, representations of, 504

Writing, supposed Magdalenian, 479

Wright, W. B., 3 I, 36, 40

Würm glaciation, 30 , $3 \mathrm{I}$

Xanthochrous peoples, ro9

Yoldia minimum, 43

Yoldia sea, 43

Zaborowsky, 525

Zeiselberg, 424

Zittel, von, 92

Zones and regions, archaeological, in Europe, $54 \mathrm{ff}$.

Zygomatic arches, 112 






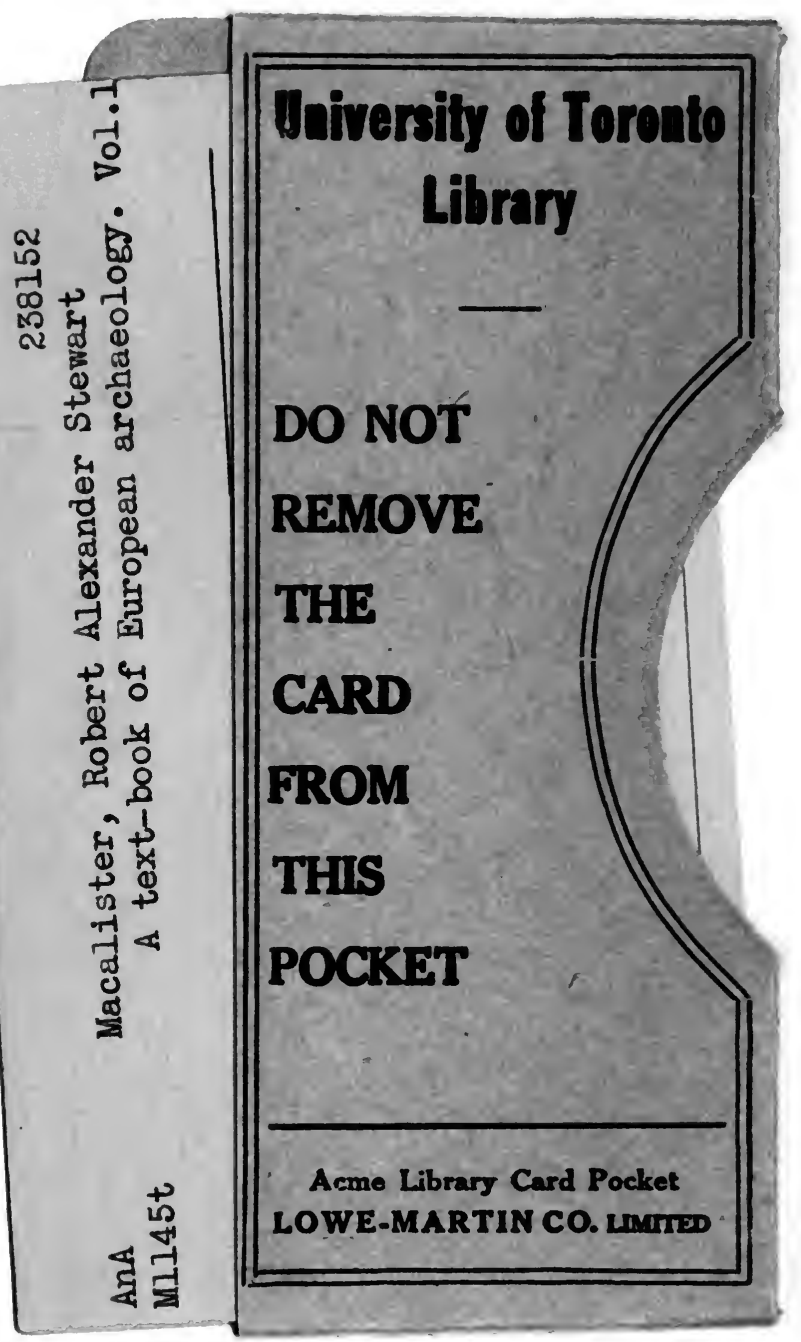


